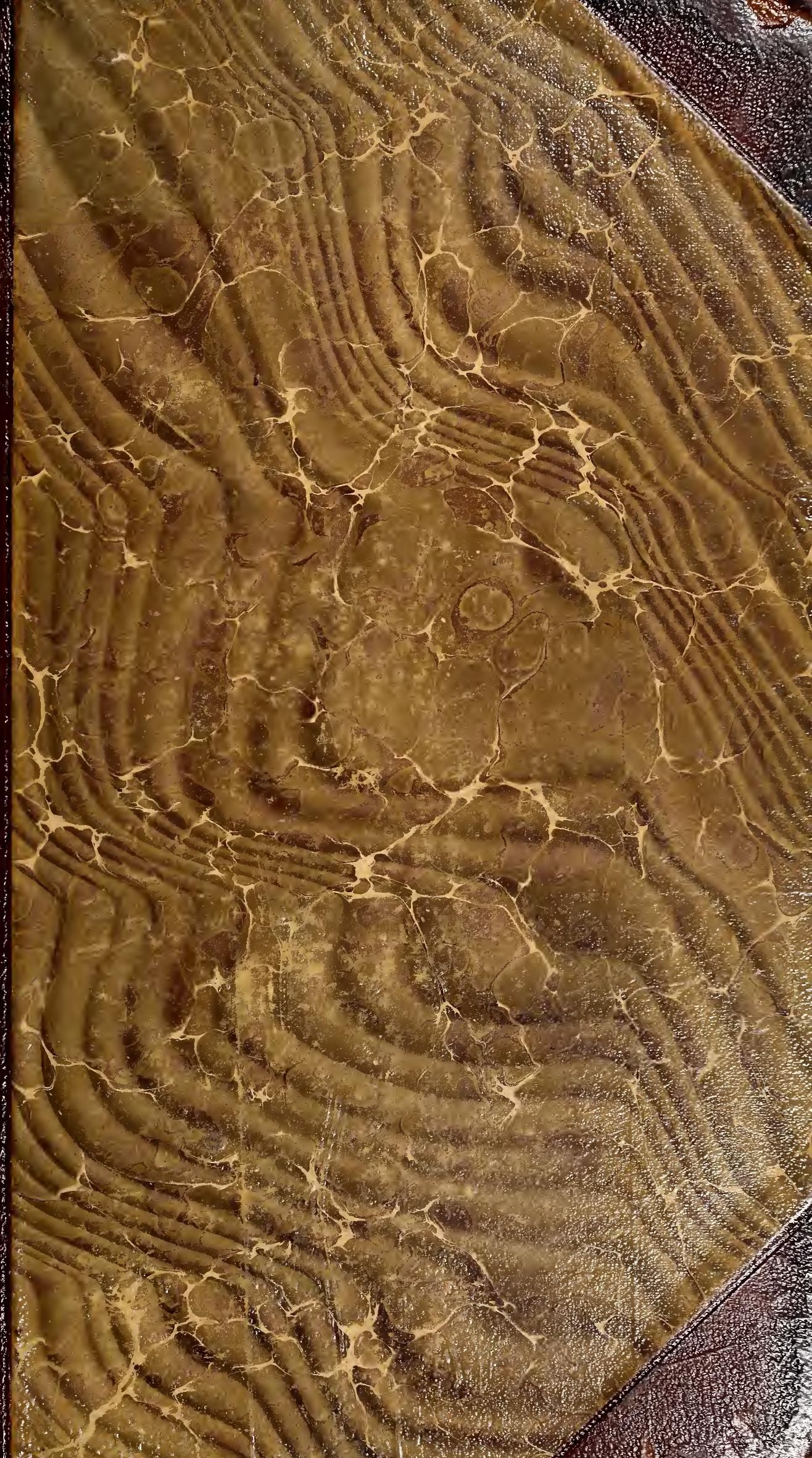







\title{
DER
}

\section{GOLDSCHMIEDE MERKZEICHEN}

\author{
2000 STEMPEL
}

AUF ÄLTEREN GOLDSCHMIEDEARBEITEN

IN FACSIMILE HERAUSGEGEBEN UND ERKLÄRT

VON

\section{MARC ROSENBERG}

A. O. PROFESSOR

AN DER TECHNISCHEN HOCHSCHULE KARLSRUHE
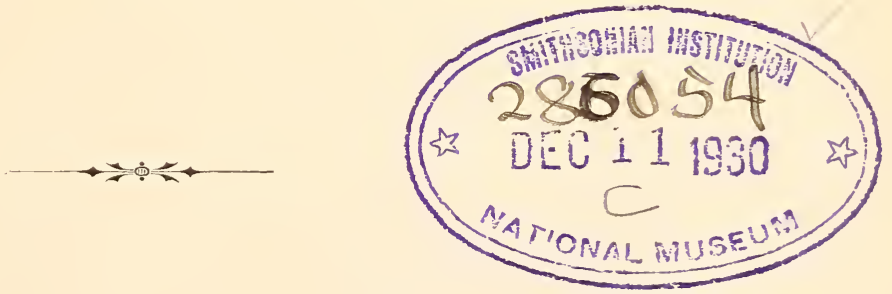

FRANKFUR'T AM MAIN

VERLAG VON HEINRICH KELLER 


$$
6
$$




\section{Vorwort.}

Das Buch, welches ich hiermit der Oeffentlichkeit übergebe, enthält eine Auswahl von 2000 Marken, aus einem Materiale von Io000. Wenn es ungeachtet dieser Einschränkung, welche aus ökonomischen Gründen nicht zu umgehen war, auf einen gewissen Grad von Brauchbarkeit Anspruch erhebt, so liegt das in der Natur des Materials, welches gewisse Ausscheidungen sehr gut zuliess. Indem ich alle Marken unterdrückte, welche nicht wenigstens auf eine bestimmte Stadt zurückgeführt werden konnten, viele Stempel wegliess, welche schon in anderen Büchern im Zusammenhang gegeben waren, und bei den langen Reihen von Jahresbuchstaken nur einzelne als Typen auswählte, gewann ich den Raum, um innerhalb der gegebenen Grenzen eine Uebersicht über die alte und neue Goldschmiedestempelung von ganz Europz, unter besonderer Berücksichtigung Deutschlands, zu geben.

$\mathrm{Da}$ es mir bei Wiedergabe der Marken neben der Treue auch ganz besonders auf Deutlichkeit ankam, habe ich dieselben meistens nicht mit den Zufälligkeiten aufgenommen, welche sie auf den einzelnen Stücken zeigen, sondern habe sie als Typus behandelt und in doppelter Grösse, mit schematischer Wiedergabe von Licht und Schatten, reproduzieren lassen.

Die mannigfachen Schwierigkeiten, die sich einer Arbeit, wie die vorliegende, entgegen zu stellen pflegen, liessen sich stets leicht überwinden, wo ich auf das Entgegenkommen Anderer angewiesen war; Personen und Behörden, welche ich um Oeffnung ihrer Kabinette oder der ihnen unterstellten Sammlungen, um Mittheilung von Akten und Büchern oder Zusendung derselben, sowie um Auskunft ersuchte, haben sich alle mit der grössten Liebenswürdigkeit dazu bereit finden lassen. Viele sogar haben meinen Studien eine ganz besondere Theilnahme entgegen gebracht und dieselben in wirksamster Weise unterstuitzt. Vor Allen Seine Königliche Hoheit der Grossherzog von Baden, Höchstwelcher mir nicht nur seine hervorragende Privatsammlung geöffnet, sondern mir auch durch wirksame Fürsprache manchen anderen Schatz erschlossen hat. Dem Grossherzoglichen Staatsminister Seiner Excellenz Hęrrn 
Dr. Ludwig Turban gebührt mein Dank für die Empfehlungen an die Regierungen befreundeter Staaten, welche die öffentlichen Kabinette zu meiner Verfügung stellen liessen. Bei der Drucklegung des Buches haben mich durch ihre Sachkenntniss und Erfahrung vier Herren besonders unterstützt: Herr Professor Dr. Julius Lessing in Berlin durch Berathung bei der Anordnung des Textes, Seine Hochwürden Herr Geistlicher Rath Dr. Friedr. Schneider und besonders Herr C. Wallau in Mainz durch aufopfernden Beistand bei dem Suchen nach einer passenden typographischen Form für das complizierte Material, sowie endlich Herr Direktor Dr. A. Pabst in Cöln, der mir manchen werthvollen Wink gegeben und ausserdem sämmtliche Correcturen mit mir gelesen hat. Ich erwähne diesen letzteren Umstand als einen merkwürdigen Fall ausdauernden freundschaftlichen Beistandes, aber keineswegs um meinem Freunde etwas von meiner Verantwortlichkeit aufzubürden.

Wer mir sonst in irgend einer Weise bei dieser Arbeit gefällig gewesen ist, findet sich an geeigneter Stelle im Texte genannt. Es erübrigt mir nur noch, allen Sammlern und Sammlungsvorständen, welche Zeit und Mühe nicht gespart haben, ihre Vitrinen zu öfnen und mir die Untersuchung jedes einzelnen Stückes zu gestatten, Dank zu sagen, sowie allen denjenigen Herren, welche als Leiter der grossen Alterthümerausstellungen der letzten Jahre fungirten, und mir trotz ihrer grossen Verantwortlichkeit immer und überall Gelegenheit zu den eingehendsten Studien geboten haben. Ohne die Benützung all' dieser Ausstellungen, wie: Karlsruhe I88I, Amsterdam und Zürich I883, Pest I884, Nürnberg und Petersburg I885, Augsburg I886, Wien I887 und I889, Brüssel I 888, hätte ich meine Arbeiten in den acht Jahren, in welchen ich ihnen meine Musse gewidmet habe, nicht so weit fördern können, dass eine Veröffentlichung möglich gewesen wäre.

Wohl sehe ich auch jetzt noch viele Lücken und Ungleichheiten, die sich bei fortgesetzten Studien beseitigen liessen. Da ich mit meiner Arbeit aber einem praktischen Bedürfniss entgegen zu kommen glaubte, dachte ich nicht länger zögern $z u$ dürfen, als sich mir durch die Energie und Opferwilligkeit meines Herrn Verlegers die Möglichkeit zur Veröffentlichung darbot, nachdem ich auf einige vergebliche Anfragen bei mehreren unserer bedeutendsten Verleger die Hoffnung schon ganz aufgegeben hatte, das Buch jemals an die Oeffentlichkeit zu bringen.

Karlsruhe, I 5 . October 1889. 


\section{Inhaltsverzeichniss.}

Vorwort

Nummer
Deutschland

Reichsstempel

Aachen

Ansbach

Augsburg

Frühe Arbeiten

Beschauzeichen

Gestempelte Arbeiten

Baden-Baden

Berlin.

Biberach

Braunschweig

Breslau

Brieg .

Cassel

Celle

Cöln

Colmar

Dannenberg.

Danzig

Darmstadt

Dresden .

Dringenberg

Elberfeld

Elbing

Emden

Erfurt

Frankfurt a. M

Frankfurt a. d. O.
Seite

S. $\mathrm{I}-383$

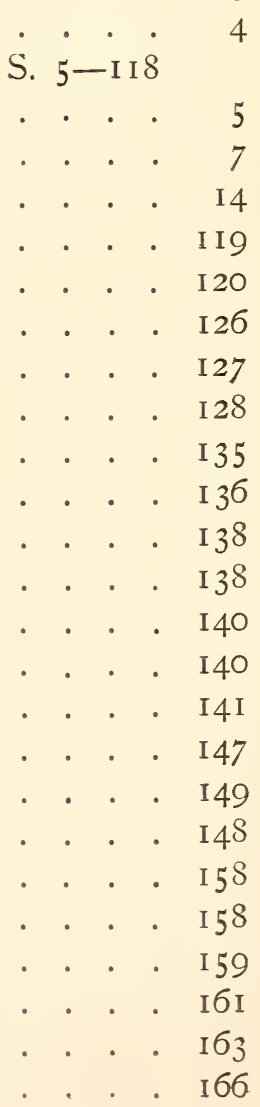


Nummer $\quad 697-702$ $703-707$ 708

$709-710$ 7 I I -7I 2 $713-737$ $738-746$ $747-748$ $749-766$ $767-778$ $779-838$ $839-848$ $849-854$ $855-860$ $86 \mathrm{I}-864$ $865-869$ $870-873$

$874-906$ $907-927$ 928-98 I $982-987$ 988-IOI I IOI 2

$1013-1057$ $1058-1070$ $107 \mathrm{I}-1087$ I088-I I04 I IO5-I I I I

I I 12

I I 3 -I I I 7

I $20-$ I I 69 III 8 -I II

I 70 - I 175 II 76 - I I77 I 78 -I I 81 I I 82 - I 399 II $82-$ II 84 II $85-I 209$ I $210-1399$ I 400 - I 401 I 402

I4O3-I4IO

I 4 I I-I I I 9 I $420-1442$
Freiberg i. S.

Freiburg i. B.

167

I68

Freising

Geislingen

Gengenbach

(Schwäb.-)Gmünd

Gotha

Halberstadt

(Schwäb.-)Hall

Halle a. d. S.

Hamburg

Hanau .

Heidelberg .

Heilbronn

Ingolstadt

Karlsruhe

Kaufbeuern

Königsberg i. Pr.

Konstanz

Leipzig .

Ludwigsburg

Lübeck .

Lüchow

Lüneburg .

Magdeburg

Mainz

Mannheim .

Memmingen

Minden .

I 70

170 170 I 7 I 73 I74 I 74 I 76 I 78 I 84 I 86 187 I 88 I 89 190 I9I I94 197 207 208 210 2 I I 2 I 8 220 222 223

Mülhausen i. E. . . . . . . . . . 225

München . . . . . . . . . . 226

Münster i. W. . . . . . . . . . 226

Neustadt a. d. H. . . . . . . . . 234

Nördlingen . . . . . . . . . 235

Norden . . . . . . . . . . . . 235

Nürnberg . . . . . . . S. 236-324

Frühe Arbeiten . . . . . . . . . . 236

Beschauzeichen etc. . . . . . . . 239

Arbeiten mit Meisterstempel . . . . 242

Oettingen . . . . . . . . . . . 325

Passau . . . . . . . . . . . 326

Pforzheim . . . . . . . . . . . 327

Preussen . . . . . . . . . . . . 328

Regensburg . . . . . . . . . 330 
Nummer I443-I444 Reutlingen.

I 446

Scharmbeck

I 447 - I 448

Schwabach

Schweinfurt

I 449-I 454

Speier

I 455 - I 460

Stettin

Strassburg

I $46 \mathrm{I}-\mathrm{I} 528$

I 529 -I 573

Beschauzeichen etc.

S. $338-354$

I 574

I 575 - I6I 3

Arbeiten mit Meisterstempel

338

Straubing

I $614-1629$

I630-I 631

I $632-1634$

I $635-165$ I

1652

Stuttgart

355

Torgau .

Tübingen

361

Tuttlingen .

Ueberlingen

Uelzen

364

I $653-\mathrm{I} 703$

Ulm .

368

I $704-$ I $7 \mathrm{c} 6$

Villingen 368

I707-I709

Warburg

375

I $710-1712$

I 7 I 3

Warendorf .

Weimar .

Wertheim

Winsen a. L.

I $720-1721$

Wismar .

Wittenberg

I 724 -I 726

Worms .

Würzburg .

Zeitz .

I 729-I730

Zweibrücken

Zwickau

I $735-26 \mathrm{co}$

Ausland

I 735 - I 764

I $735-1742$

I 743 -I 745

I $746-1750$

I 75 I - I 754

I755-I757

I758-I763

I 764

Belgien .

S. $385-522$

386-393

Moderne Stempelung . . . . . . 386

Antwerpen . . . . . . . . . . . 387

Audenarde. . . . . . . . . . . 387

Brügge . . . . . . . . . . 388

Brüssel . . . . . . . . . . . 389

Dendermonde . . . . . . . . . 390

Gent . . . . . . . . . . 390

Lokeren . . . . . . . . . . . 391

Mons . . . . . . . . . . . . . 391

Oignies . . . . . . . . . . . 393

Tamise . . . . . . . . . . . . . 393

I765-I8I I Dänemark . . . . . . . S. 394-400 
VIII

Nummer I765-I808 I 809-I 8 I I I $812-2007$ I $812-2007$ $2008-2079$ 2008-2062 2063-2073 2074-2079 2080-2 100 2080-2092 2093

2094-2100 $2101-2239$ $2 \mathrm{IOI}-2 \mathrm{II} 8$ 2II9-2I 39 2I $40-2$ I 44 $2145-2147$ $2 \mathrm{I} 48-2 \mathrm{I} 5 \mathrm{I}$ $2152-216 \mathrm{I}$ $2162-2164$ $2165-2180$ 2I 8 I-2 192 2193-2224 $2225-2226$ 2227-2239 $2240--2384$ $2240-2255$ 2256-226I $2262-2266$ $2267-2268$ 2269-2273 2274-2278 2279-2283 2284-2287 2288-229I 2292-2296 2297-2303 2304-2307 2308-23I I 231 $2-2353$ 2354-2384 2354-2369 $2370-2374$
Inhaltsverzeichniss

Kopenhagen .

Odense .

Frankreich

S. $40 \mathrm{I}-4 \mathrm{I} 7$

Paris 402

Grossbrittannien .

S. $418-424$

London

Edinburgh 423

Dublin 424

Italien

S. $425-428$

Neapel 426

Padua 427

Rom 428

Niederlande

S. $429-45 \mathrm{I}$

Moderne Stempelung . . . . . . 429

Amsterdam . . . . . . . . . 43

Breda . . . . . . . . . . 434

Dokkunı . . . . . . . . . . 435

Der Haag . . . . . . . . . . . . 436

Haarlem . . . . . . . . . . . 437

Herzogenbusch . . . . . . . . . 438

Leeuwarden . . . . . . . . . 439

Rotterdam . . . . . . . . . 442

Utrecht . . . . . . . . . . . 444

Vlissingen . . . . . . . . . . . . 449

Zwolle . . . . . . . . . . . 450

Oesterreich-Ungarn . . . . S. $452-476$

Moderne Stempelung . . . . . . 453

Steuerstempel . . . . . . . . 454

Brünn . . . . . . . . . . 455

Eger . . . . . . . . . . 456

Graz . . . . . . . . . . 456

Klagenfurt . . . . . . . . . . 457

Laibach . . . . . . . . . 458

Lemberg . . . . . . . . . . . 459

$\operatorname{Lin} z$. . . . . . . . . . . 459

Prag. . . . . . . . . . . . . 460

Salzburg . . . . . . . . . . 46 I

Triest . . . . . . . . . . 462

Troppau . . . . . . . . . . 462

Wien . . . . . . . . . . 463

Ungarn . . . . . . . S. $468-476$

Budapest . . . . . . . . . . 468

Hermannstadt . . . . . . . . 470 


\section{Nummer 2375}

$2376-2384$

$2385-2443$

$2385-2406$

$2407-2443$

2444-2485

2444-2453

2454-2465

2466-2485

$2486-2600$

2486-2489

2490-2494

2495-2526

$2527-2538$

2539-2540

$254 \mathrm{I}-2542$

$2543-2545$

2546-2548

$2549-255^{8}$

$2559-2565$

$2566-2569$

$2570-257 \mathrm{I}$

$2572-2594$

2595-2600
Mediasch

Seite

Schemnitz

Russland

Verschiedene Städte

Riga

Schweden und Norwegen

Kristianstadt • • • • . • • • • • 493

Stockholm . . . . . . . . . . 495

Bergen

Schweiz .

Moderne Stempelung .

Baden

Basel

Bern

Biel

Chur

Einsiedeln

Luzern

Neuchâtel .

Rappersweil

Schaffhausen

Winterthur

Zürich

Zug .

S. $49 \mathrm{I}-498$

S. $499-522$

\section{Register.}

I. Markenregister

a) Register der Monogramme

b) Register der figürlichen Marken

525

c) Zahlen

II. Verzeichniss der Goldschmiedenamen

III. Verzeichniss der Besitzer

558 568

Druckfehler und Berichtigungen . 



\section{DEUTSCHLAND.}

Die Städte Deutschlands, von welchen Beschauzeichen und Meistermarken mitgetheilt werden, folgen einander nach dem Alphabet.

In diese Reihenfolge sind auch die Namen der einzelnen Bundesstaaten aufgenommen, so dass die Preussische Silbersteuer z. B. bei P. (Preussen) zu suchen ist.

Die Stempelung dagegen, welche das ganze Land umfasst, wird dem Verzeichniss der Städte vorangestellt (Reichsstempel). 


\section{Reichsstempel.}

Gesetz vom I6. Juli i 884 und Bestimmung des Bundesrathes vom 7. Januar I 886: Angabe des Feingehalts in Tausendtheilen und Firma oder Schutzmarke des Geschäfts, ferner

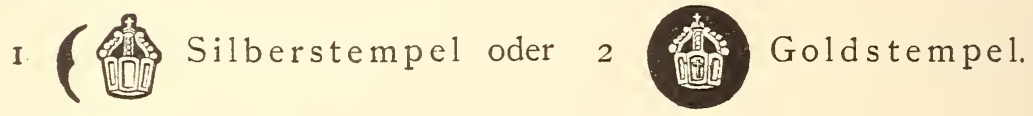




\section{AACHEN.}

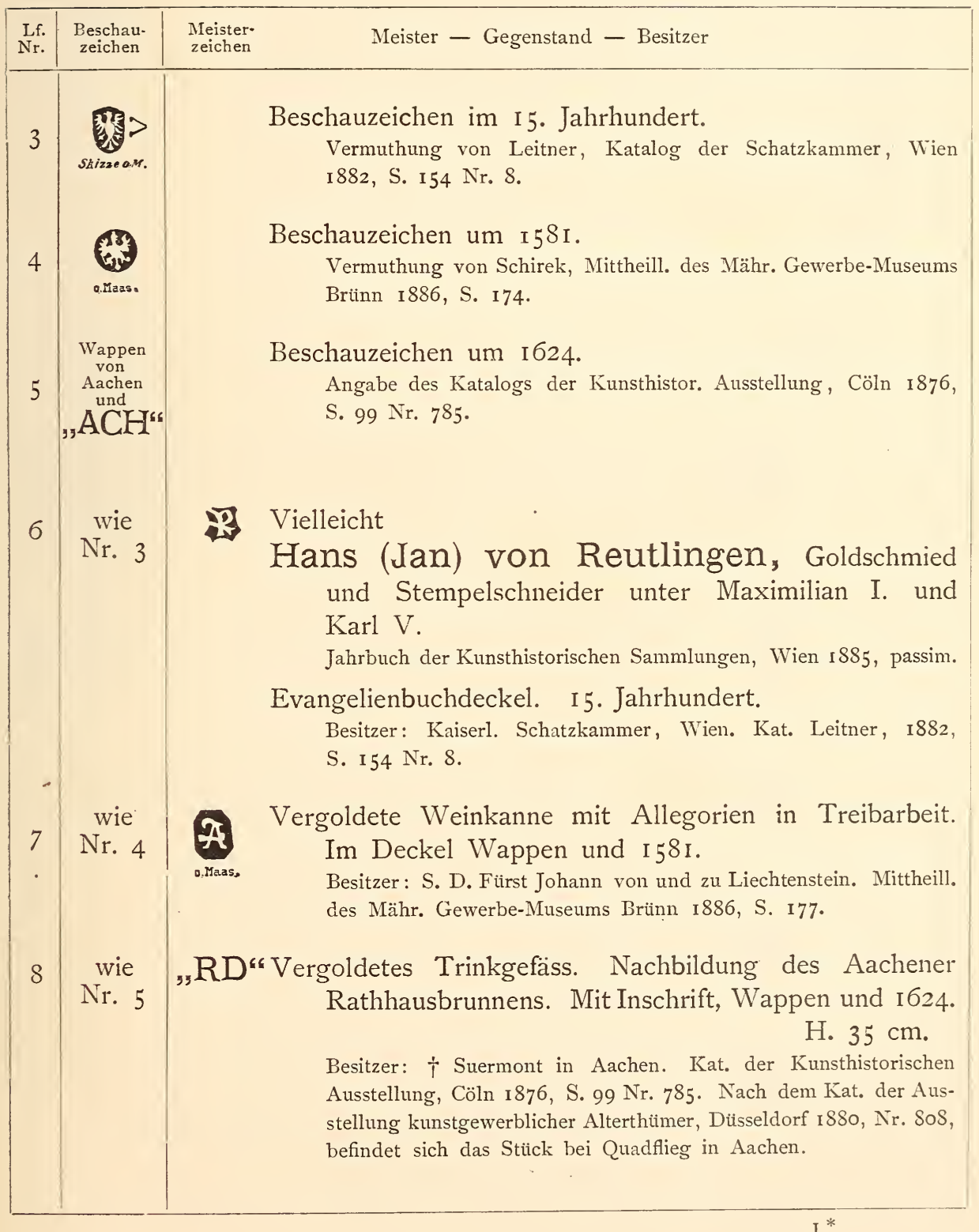




\section{ANSBACH.}

\begin{tabular}{|c|c|c|c|}
\hline $\begin{array}{l}\text { Lf. } \\
\text { Nr. }\end{array}$ & $\begin{array}{l}\text { Beschau- } \\
\text { zeichen }\end{array}$ & $\begin{array}{l}\text { Meister- } \\
\text { zeichen }\end{array}$ & Meister - Gegenstand - Besitzer \\
\hline 9 & & & Beschauzeichen. I6.- I7. Jahrhundert. \\
\hline IO & & & Beschauzeichen. I7. \\
\hline I I & & & Beschauzeichen. I7.-I 8 . \\
\hline $\mathrm{I} 2$ & & & Beschauzeichen. I8. \\
\hline I 3 & 10 & & Beschauzeichen. I8. \\
\hline I4 & & & $\begin{array}{l}\text { Einfuhrstempel auf den Beständen des »Ansbacher } \\
\text { Silbers» in der Königl. Silberkammer zu München. }\end{array}$ \\
\hline I 5 & $\begin{array}{l}\text { wie } \\
\text { Nr. } 9\end{array}$ & & $\begin{array}{l}\text { Vergoldeter Becher mit halbkugelförmiger Cuppa. (Hälfte } \\
\text { eines Doppelbechers.) Ornamentation durch Punkte. } \\
\begin{array}{l}\text { H. I } 3,6 \mathrm{~cm} .\end{array}\end{array}$ \\
\hline I6 & $\begin{array}{l}\text { wie } \\
\mathrm{Nr} \text {. IO }\end{array}$ & & $\begin{array}{l}\text { Theilvergoldete sechseckige Hostienbüchse mit getrie- } \\
\text { benen Blumen. Mit Initialen und I680. H. I9 cm. } \\
\text { Besitzer: Johanneskirche, Ansbach. }\end{array}$ \\
\hline I7 & $\begin{array}{l}\text { wie } \\
\mathrm{Nr} \text {. II }\end{array}$ & $B$ & $\begin{array}{l}\text { Vergoldeter Kelch mit Patene und Hostienbüchse. Auf } \\
\text { dem Kelch eine Stifterinschrift von I706. } \\
\text { Besitzer: Gumbertuskirche, Ansbach. }\end{array}$ \\
\hline I 8 & $\begin{array}{l}\text { wie } \\
\text { Nr. } 12\end{array}$ & 周 & $\begin{array}{l}\text { Vergoldeter Pokal (Kelch) mit Wappen und Namen } \\
\begin{array}{l}\text { des Stifters. }+1729 . \\
\text { Besitzer: Gumbertuskirche, Ansbach. }\end{array}\end{array}$ \\
\hline I9 & $\begin{array}{l}\text { wie } \\
\text { Nr. I3 }\end{array}$ & $M * M$ & $\begin{array}{l}\text { a) Weisssilberne Schelle, von einem Klingelbeutel, mit } \\
\text { Namen und I } 742 . \\
\begin{array}{ll}\text { b) Vergoldeter Kelch mit Stifterinschrift und I } 742 . \\
\text { Besitzer: Johanneskirche, Ansbach. } & \text { H. } 24 \mathrm{~cm} .\end{array}\end{array}$ \\
\hline
\end{tabular}




\section{AUGSBURG.}

Bei keiner Stadt, deren Stempelung ich zu untersuchen Gelegenheit hatte, herrscht eine so grosse Verschiedenheit in der Form des Beschauzeichens wie bei Augsburg. Da diese Verschiedenheit aber nur in Variationen zu dem einzigen Thema, dem Pinienzapfen, besteht, so schafft sie tausend minime Abweichungen, deren Beobachtung, Fixirung und Datirung nicht immer vollständig gelingen will.

Bestimmte, durch ein Zunftgesetz vorgeschriebene, leicht erkennbare Unterscheidungsmerkmale bei dem Beschauzeichen kommen in Augsburg erst seit I735 etwa vor, bis dahin sind die Veränderungen bedingt durch die allgemeine Stilwandlung, welche sich auch in der Auffassung eines Pinienzapfens nicht verleugnet, und durch das Können, wie durch die künstlerische Individualität der einzelnen Meister, welche den Stempel zu schneiden hatten. Diesen Verhältnissen Rechnung tragend und die Datirung einzelner erhaltener Arbeiten durch Inschrift und Meisterbezeichnung zur Richtschnur nehmend, habe ich versucht eine Chronologie der Augsburger Beschauzeichen zusammenzustellen. Eine absolute Richtigkeit war mit dem mir vorliegenden Material nicht zu erreichen, und manche Fehler wären nur mit verhältnissmässig grossem Zeitaufwand zu berichtigen gewesen. Ich gebe daher das Verzeichniss, wie es sich mir auf den ersten Wurf ergab, und hoffe es bei fortgesetzten Studien berichtigen zu können.

Eine geregelte Stempelung hat in Augsburg erst sehr spät (vergl. S. 7) begonnen, wir müssen daher vor den Beschauzeichen diejenigen Stücke aufzählen, deren Anfertigung vor Einführung eines solchen fällt.

\begin{tabular}{|c|c|c|}
\hline $\begin{array}{l}\text { Lf. } \\
\text { Nr. }\end{array}$ & $\begin{array}{l}\text { Beschau- } \\
\text { zeichen }\end{array}$ & Meister - Gegenstand - Besitzer \\
\hline 20 & & $\begin{array}{l}\text { CONRAD' DE LINDOVVE FECIT ME P' } \\
\text { QVO ORATE (nicht facsimilirt). } \\
\text { Verfertigerinschrift auf einem Ostensorium, welches } \\
\text { der 2. Hälfte des 14. Jahrhunderts zugeschrieben } \\
\text { wird. } \\
\text { Besitzer: Kreuzkirche, Augsburg. Butsch, Allgemeine Zei- } \\
\text { tung I887, Nr. 152. So lange weitere Nachrichten über } \\
\text { den Meister fehlen, sei das Stück den Augsburger Arbeiten } \\
\text { angereiht. Es ist dasselbe, welches 1494 von Georg Seld um- } \\
\text { geändert worden ist. Vergl. S. } 7 \text { Nr. 25. }\end{array}$ \\
\hline
\end{tabular}




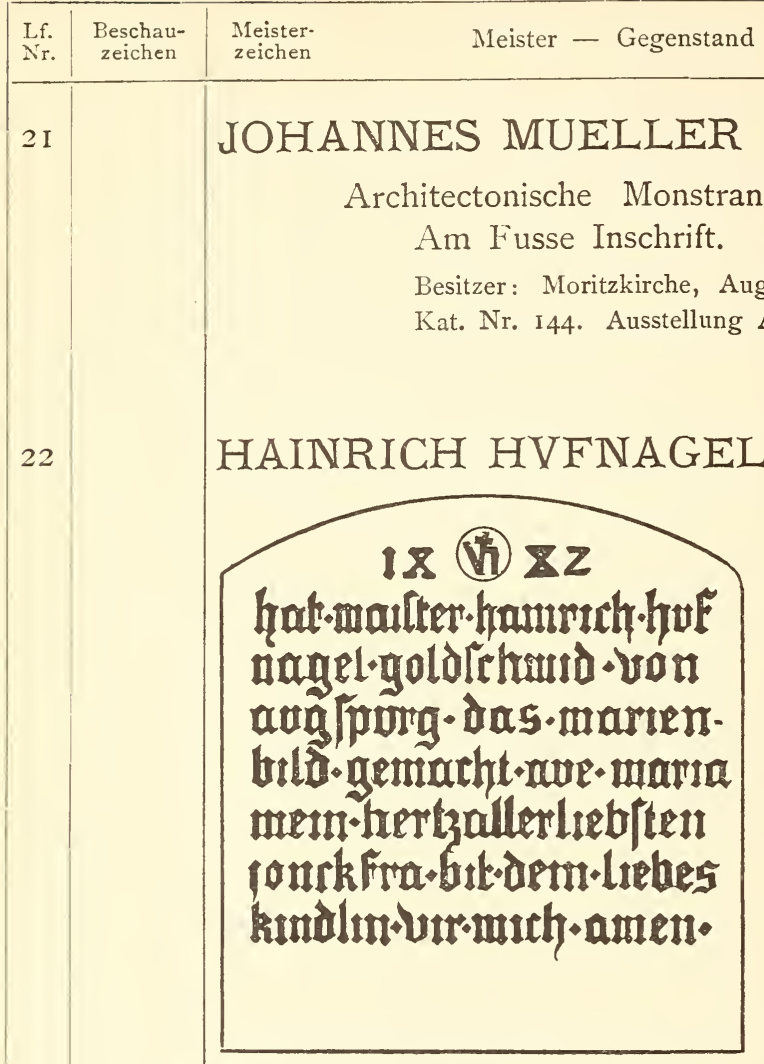

Getriebene Meisterbezeichnung auf einer silbergetriebenen Marienfigur, theilvergoldet, auf Postament mit Stifterinschrift von $\mathrm{I} 482$.

H. 85 resp. $63 \mathrm{~cm}$. Besitzer: Königl. Museum, Berlin. Abtheilung der Bildwerke der christlichen Epoche Nr. 587. Ausstellung München 1876, Kat. Nr. 224. Photographie des KunstgewerbeMuseums Berlin Nr. I72.

Ostensorium in Kreuzform mit Gravirungen.

Besitzer: Bischöfliches Domkapitel, Augsburg. Ausstellung Augsburg 1886, Kat. Nr. 1302. Berlepsch in der Allgemeinen Zeitung I886, Nr. 167.

\section{MANUS GEORGII SELD AURIFABRI AU-} GUSTAE FECIT HOC OPUS 1492 (nicht facsimilirt).

Dreitheiliger Silberaltar mit vielen Figuren und Inschriften.

H. ca. $48 \mathrm{~cm}$.

Besitzer: Fideicommiss weiland S. M. König Ludwig I. von Bayern. Meisterwerke Schwäbischer Kunst Taf. XVII. Berlepsch in der Allgemeinen Zeitung 1886, Nr. I68. 


\begin{tabular}{|c|c|c|}
\hline $\begin{array}{l}\text { Lf. } \\
\text { Nr. }\end{array}$ & $\begin{array}{l}\text { Beschau- } \\
\text { zeichen }\end{array}$ & Meister - Gegenstand - Besitzer \\
\hline 25 & & $\begin{array}{l}\text { OPIFEX GEORG SELD (nicht facsimilirt). } \\
\text { Inschrift auf den I } 494 \text { gemachten Ergänzungstheilen zu } \\
\text { dem Ostensorium des Conrad von Lindau. Vergl. } \\
\text { S. } 5 \text { Nr. 20, } \\
\text { Besitzer: Kreuzkirche, Augsburg. Butsch in der Allgem. Zei- } \\
\text { tung I887, Nr. 152. }\end{array}$ \\
\hline 26 & & 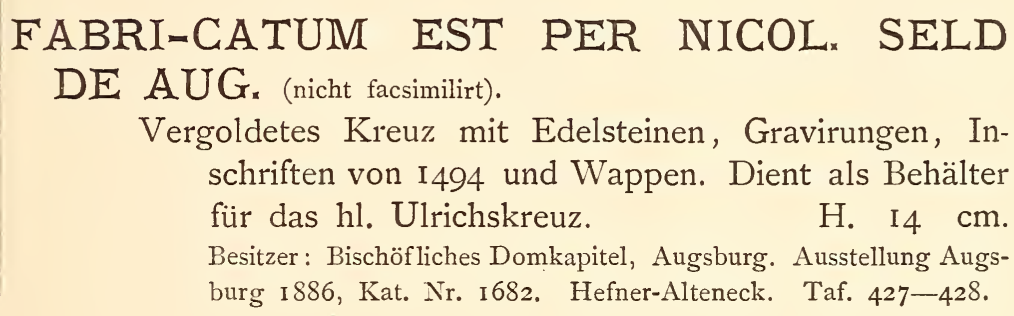 \\
\hline \multicolumn{3}{|c|}{$\begin{array}{l}\text { Die hier oben verzeichneten Arbeiten reichen nahezu bis an den Beginn } \\
\text { des I6. Jahrhunderts, und damals gerade wurde die Stempelung obligato- } \\
\text { risch. Die Goldschmiede-Ordnung von I } 529 \text { sagt darüber: Die Silberarbeiten, } \\
\text { die der Ordnung entsprechend gefunden werden, »söllen sy, die gescha W - } \\
\text { maister, mit der stat piren vnnd der maister vnnder vnns, so so̊lchs } \\
\text { selbs gemacht hete mit seinem zaichen bezaichnen. } \\
\text { Trotzdem vermag ich gestempelte Augsburger Arbeiten nicht früher als } \\
\text { am Schlusse des I6. Jahrhunderts nachzuweisen. Es beginnt daher die } \\
\text { chronologische Zusammenstellung der Beschauzeichen erst mit einem Zeichen } \\
\text { von etwa I } 575 \text {. Nicht undenkbar ist es, dass die I } 529 \text { festgestellte Form } \\
\text { desselben ein halbes Jahrhundert lang ohne Variationen streng eingehalten } \\
\text { worden ist, und erst am Schlusse des Jahrhunderts beginnt verschiedene } \\
\text { Gestaltungen anzunehmen. In diesem Falle wäre unsere Nr. } 27 \text { der Typus } \\
\text { für den grössten Theil des I6. Jahrhunderts. }\end{array}$} \\
\hline 27 & & Beschauzeichen, Ende I6. Jahrhundert. \\
\hline 29 & \% & Beschauzeichen, I6. bis I7. Jahrhundert. \\
\hline
\end{tabular}




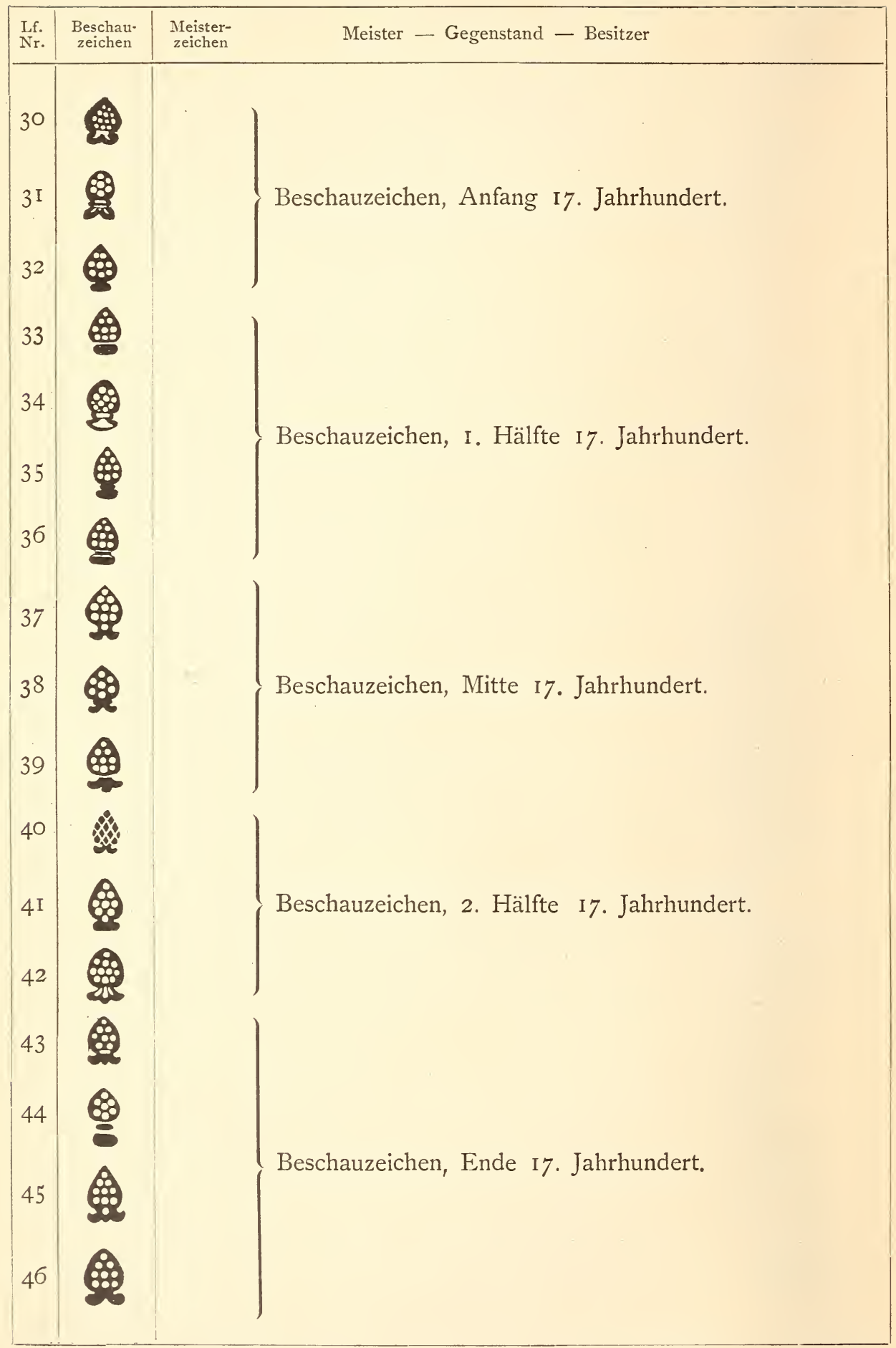




\begin{tabular}{|c|c|c|c|}
\hline $\begin{array}{l}\text { Lf. } \\
\text { Nr. }\end{array}$ & $\begin{array}{l}\text { Beschau- } \\
\text { zeichen }\end{array}$ & $\begin{array}{l}\text { Meister- } \\
\text { zeichen }\end{array}$ & Meister - Gegenstand - Besitzer \\
\hline 47 & 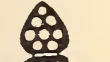 & & \\
\hline 48 & 20 & & Beschauzeichen, Ende I7. Jahrhundert. \\
\hline 49 & & & \\
\hline 50 & & & \\
\hline $5 \mathrm{I}$ & 急 & & \\
\hline 52 & 808 & & \\
\hline 53 & & & \\
\hline 54 & & & \\
\hline 55 & & & \\
\hline 56 & g & & Beschauzeichen, I7. bis I8. Jahrhundert. \\
\hline 57 & & & \\
\hline 58 & $\frac{88}{17}$ & & \\
\hline 59 & 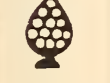 & & \\
\hline 60 & 6 & & \\
\hline $6 \mathrm{I}$ & $\frac{98}{\omega}$ & & \\
\hline 62 & 8 & & \\
\hline
\end{tabular}




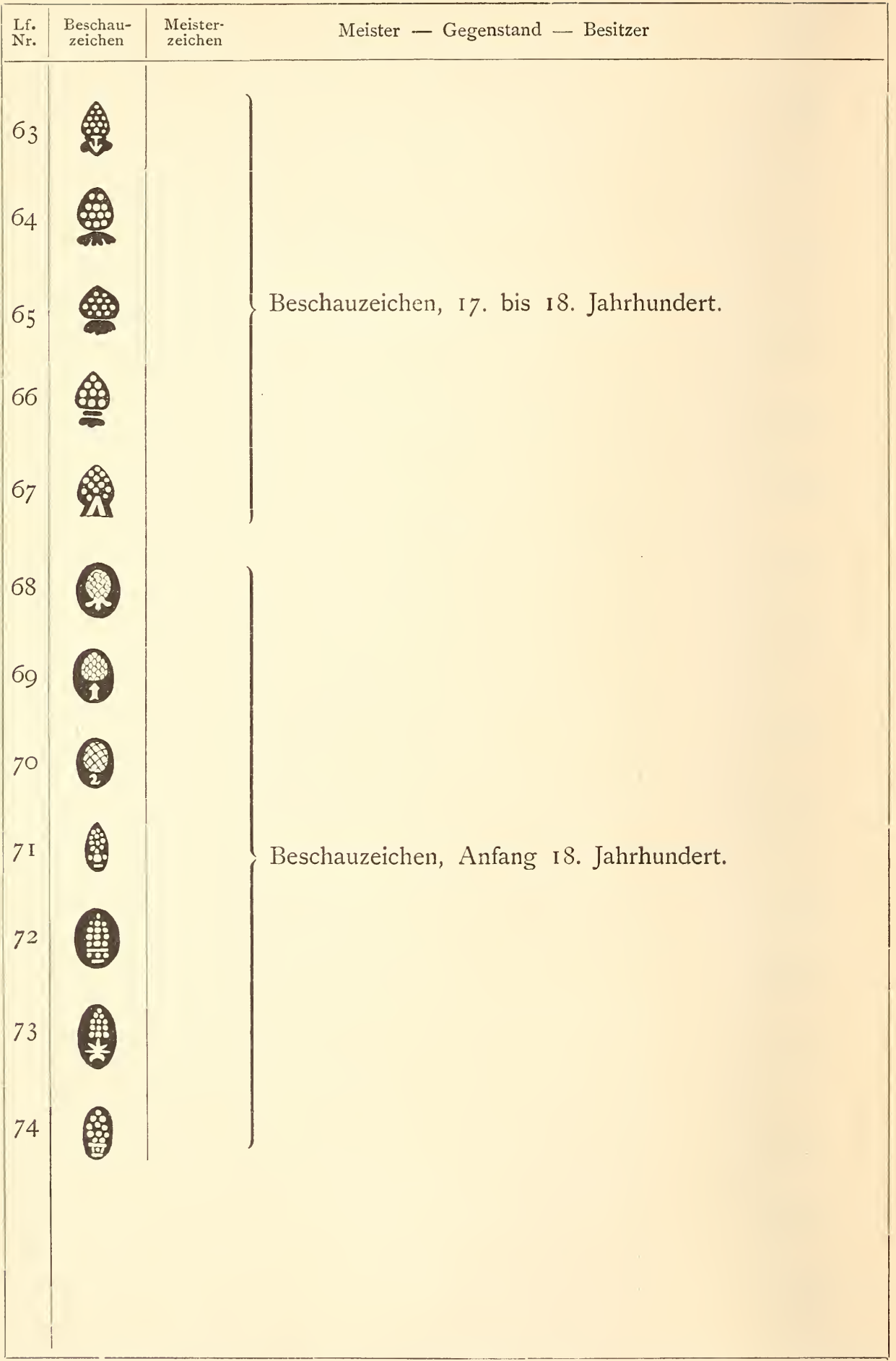




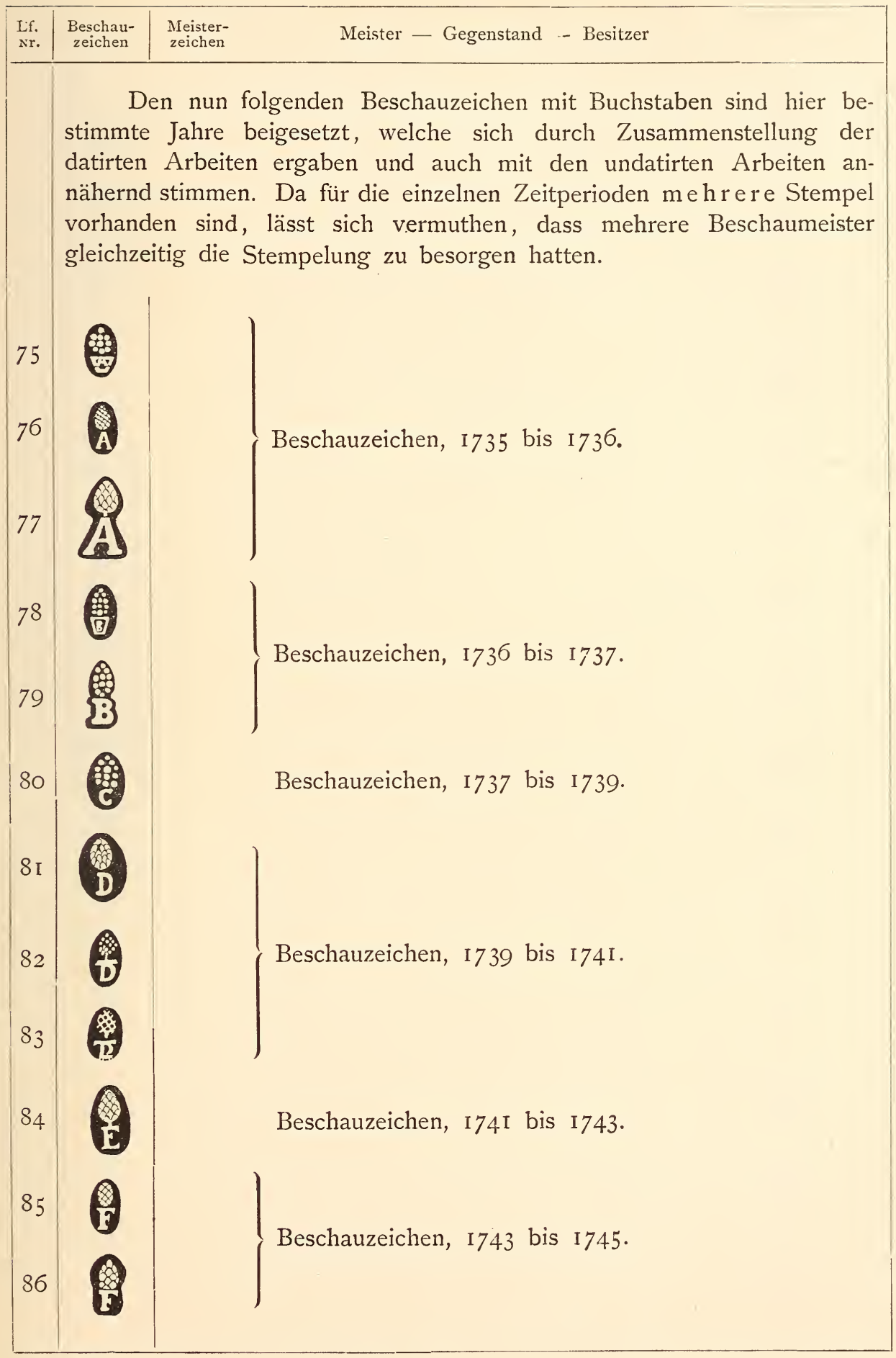




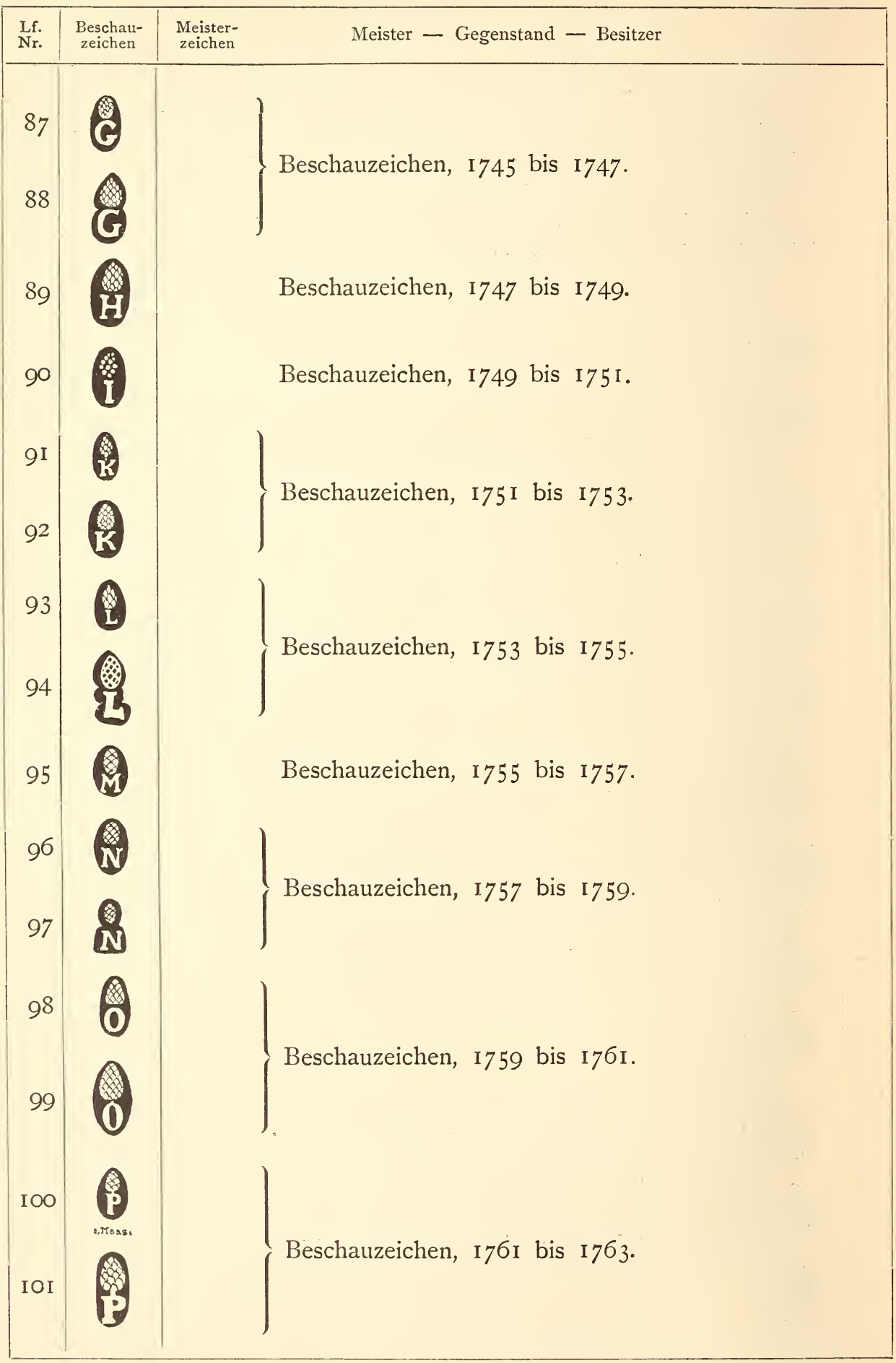




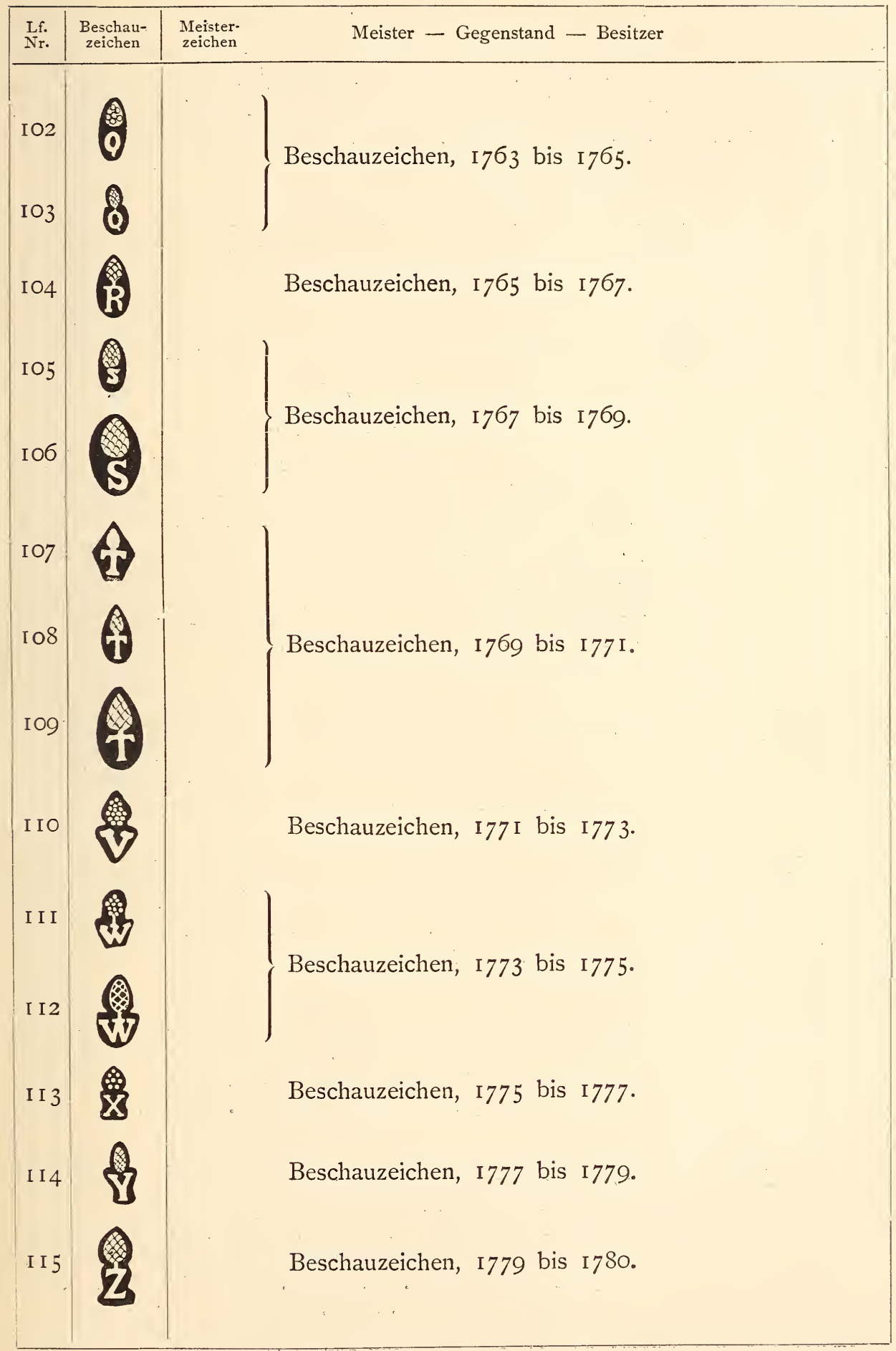


Die meisten Angaben über die Augsburger Goldschmiede und ihre Namen entnehme ich den in Augsburg im Maximilians-Museum aufbewahrten Wappentafeln. Manche Notiz schöpfe ich aus den einschlägigen Acten des Augsburger Stadtarchivs, von welchen ich aber nur einen kleinen Theil eingesehen habe. Ich unterlasse meist die Quellenangabe für die aus diesem Material gewonnenen Informationen.

\begin{tabular}{|c|c|c|}
\hline $\begin{array}{l}\text { Lf. } \\
\text { Nr. }\end{array}$ & $\begin{array}{l}\text { Beschau- } \\
\text { zeichen }\end{array}$ & Meister - Gegenstand - Besitzer \\
\hline I I6 & & $\begin{array}{l}\text { 4t Dieses Zeichen stimmt nach der Augsburger Gold- } \\
\text { schmiede-Sterbetafel mit der Hausmarke von } \\
\text { Elias Grosz, } \dagger \mathrm{I} 572 \text {, und } \\
\text { Cornelius Grosz, } \dagger \text { I } 575 \text {. } \\
\text { Wegen des relativ frühen Sterbejahres wage ich keinem } \\
\text { der obigen Meister die folgenden Stücke mit Bestimmtheit zu- } \\
\text { zuschreiben. Das Erscheinen der Marke an dem später (I6I2 } \\
\text { bis I6I7?) entstandenen Pommerschen Kunstschrank stellt alles } \\
\text { in Frage, so lange nicht nachgewiesen werden kann, dass die } \\
\text { betreffenden Theile an demselben vor I } 572 \text { resp. vor I } 575 \text { ge- } \\
\text { macht worden sind. Vergl. Nr. I } 6 \text { d. }\end{array}$ \\
\hline & $\begin{array}{c}\text { wie } \\
\text { Nr. } 27\end{array}$ & $\begin{array}{l}\text { a) Pokal, mit Medaillonsköpfen und Blumenfestons. } \\
\text { H. } 62 \mathrm{~cm} \text {. } \\
\text { Besitzer: Königl. Schatzkammer, München. Katalog Schauss } \\
\text { I879, K. 4. Abgeb. bei Schauss, Schatzkammer. }\end{array}$ \\
\hline & wie 27 & $\begin{array}{l}\text { b) Vergoldete Fassung an einem »Trinkhorn in Ge- } \\
\text { stalt eines Basilisken aus Schildpatt. « Mit Wappen. } \\
\text { Besitzer: Kaiserl. Schatzkammer, Wien. Katalog Leitner I882, } \\
\text { S. 104 Nr. 63. }\end{array}$ \\
\hline & wie 27 & $\begin{array}{l}\text { c) Silbernes Gehäuse einer Standuhr mit Emailarbeiten } \\
\text { von Dav. Altenstetter. } \\
\text { Besitzer: Kaiserl. Schatzkammer, Wien. Katalog Leitner 1882, } \\
\text { S. } 24 \text { Nr. } 38 \text {. Vergl. unten S. } 28 \text { Nr. 149/50 e. }\end{array}$ \\
\hline & wie 30 & $\begin{array}{l}\text { d) Arbeitstheile an dem Pommerschen Kunstschranke } \\
\text { (I6I2-I617 ?). } \\
\text { Besitzer: Kunstgewerbe-Museum, Berlin. Vergleiche meine } \\
\text { frühere Zuschreibung dieser Theile an Gross in der Allgem. } \\
\text { Zeitung I884, Nr. 60. Vergl. auch weiter unten S. } 25 \\
\text { Nr. I40 u-y und S. } 28 \text { Nr. 149/50 f. }\end{array}$ \\
\hline
\end{tabular}




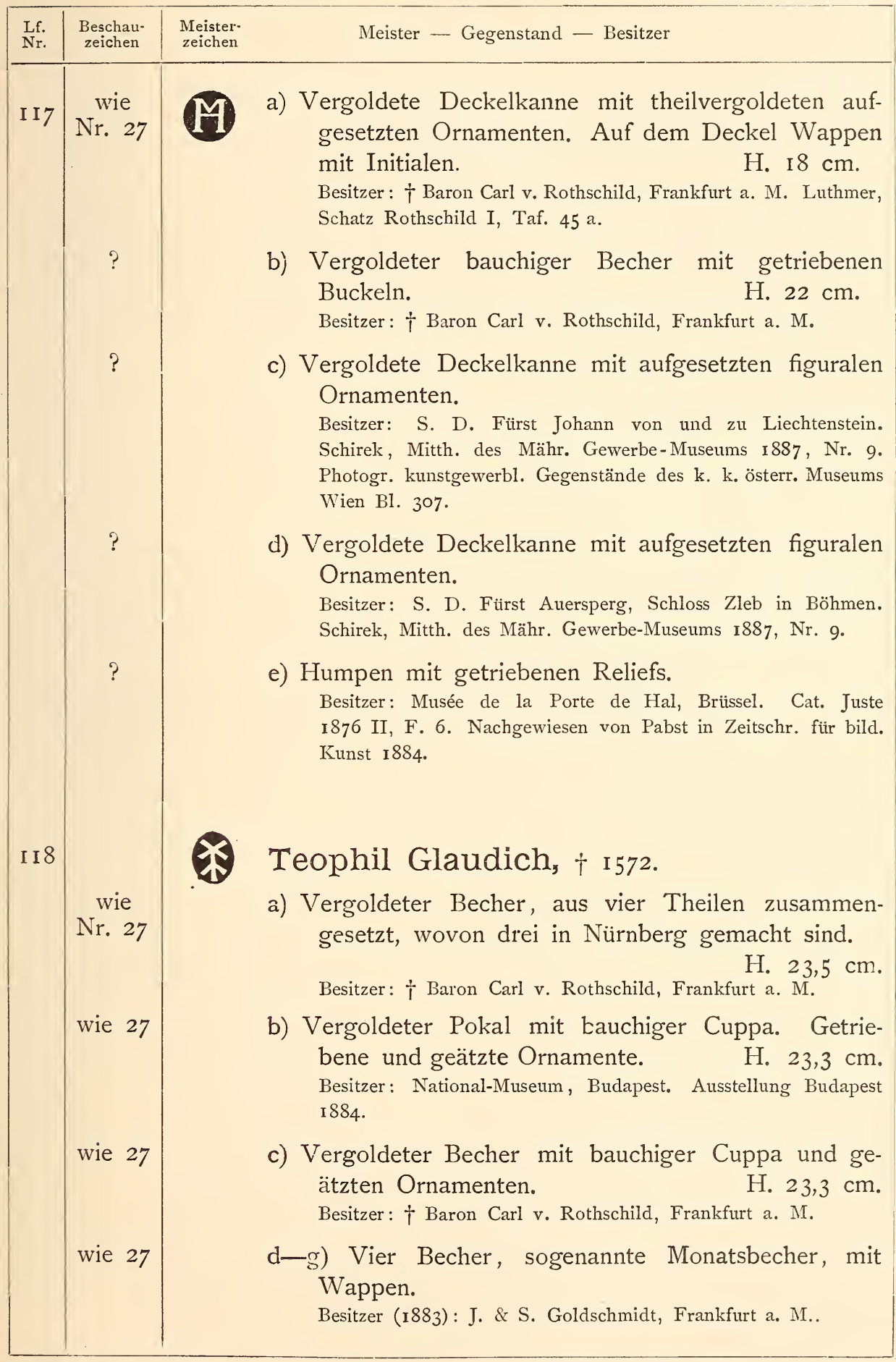




\begin{tabular}{|c|c|c|c|}
\hline $\begin{array}{l}\text { Lf. } \\
\text { Nr. }\end{array}$ & $\begin{array}{l}\text { Beschaur } \\
\text { zeichen }\end{array}$ & $\begin{array}{l}\text { Meister- } \\
\text { zeichen }\end{array}$ & Meister - Gegenstand - Besitzer \\
\hline I I 8 & $\begin{array}{c}\text { wie } \\
\text { Nr. } 27\end{array}$ & \multicolumn{2}{|c|}{$\begin{array}{l}\text { Vielleicht auch: } \\
\qquad \begin{array}{l}\mathrm{h}-\mathrm{n}) \text { Sechs Monatsbecher. } \\
\text { Besitzer: Gg. Agath, Breslau. }\end{array}\end{array}$} \\
\hline I I9 & $\begin{array}{c}\text { wie } \\
\text { Nr. } 27\end{array}$ & & $\begin{array}{l}\text { Pokal mit sackartiger Cuppa, an welcher niellirte Orna- } \\
\text { mente. Griff, ein Baumstamm mit Holzhauer. } \\
\text { H. } 28,7 \mathrm{~cm} . \\
\text { Besitzer: } \dagger \text { Baron Carl v. Rothschild, Frankfurt a. M. }\end{array}$ \\
\hline I 20 & $\begin{array}{c}\text { wie } \\
\text { Nr. } 27\end{array}$ & & 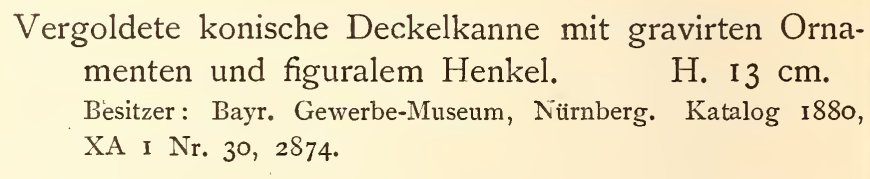 \\
\hline I $2 \mathrm{I}$ & $\begin{array}{c}\text { wie } \\
\mathrm{Nr} .27\end{array}$ & & $\begin{array}{l}\text { a) Vergoldeter getriebener Doppelpokal mit ciselirtem } \\
\text { Griff. H. } 66 \mathrm{~cm} \text {. } \\
\text { Besitzer: Grünes Gewölbe, Dresden. Katalog Erbstein I884, } \\
\text { S. } 97 \text { Nr. } 252 \text {. }\end{array}$ \\
\hline & wie 27 & & $\begin{array}{l}\text { b u. c) Vergoldete Taufkanne und Schüssel, in deren } \\
\text { Mitte eine Medaille eingelassen. Aussen Seethiere, } \\
\text { Ornamente, Figuren. } \\
\text { Dm. 53,2 cm. }\end{array}$ \\
\hline & ? & & $\begin{array}{l}\text { Die Kanne mit figürlichem Henkel, am Ausguss } \\
\text { Maskaron. } \\
\text { Besitzer: Herzogl. Hofkapelle, Gotha. Ausstellung München } \\
\text { I876, Kat. Nr. 286. Abb. Taf. } 68 \text {. } \\
\text { d) Riesenpokal mit Treibarbeit, Aetzung und Email. } \\
\text { Sogen. Landschadenbund-Becher. } \\
\text { Besitzer: Landhaus in Graz. Abgeb. in Renaissance in Oester- } \\
\text { reich, Leipzig I884, und photographirt von Wlha in Wien. } \\
\text { Ohne das vorstehende Stück selbst gesehen zu haben oder im } \\
\text { Besitze eines Facsimile der Marken zu sein, habe ich es den- } \\
\text { noch hier angeschlossen, weil mir die Kunstweise desselben } \\
\text { unserem Meister verwandt scheint und die Angabe »Meister- } \\
\text { punze HS oder SH " die Möglichkeit nahe legt, dass wir wirk- } \\
\text { lich die gleiche Marke vor uns haben. }\end{array}$ \\
\hline I 22 & $\begin{array}{l}\text { wie } \\
\text { Nr. } 27\end{array}$ & & 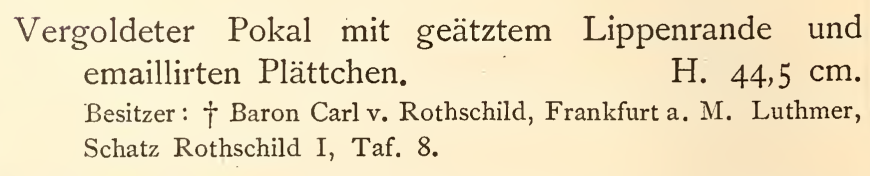 \\
\hline
\end{tabular}




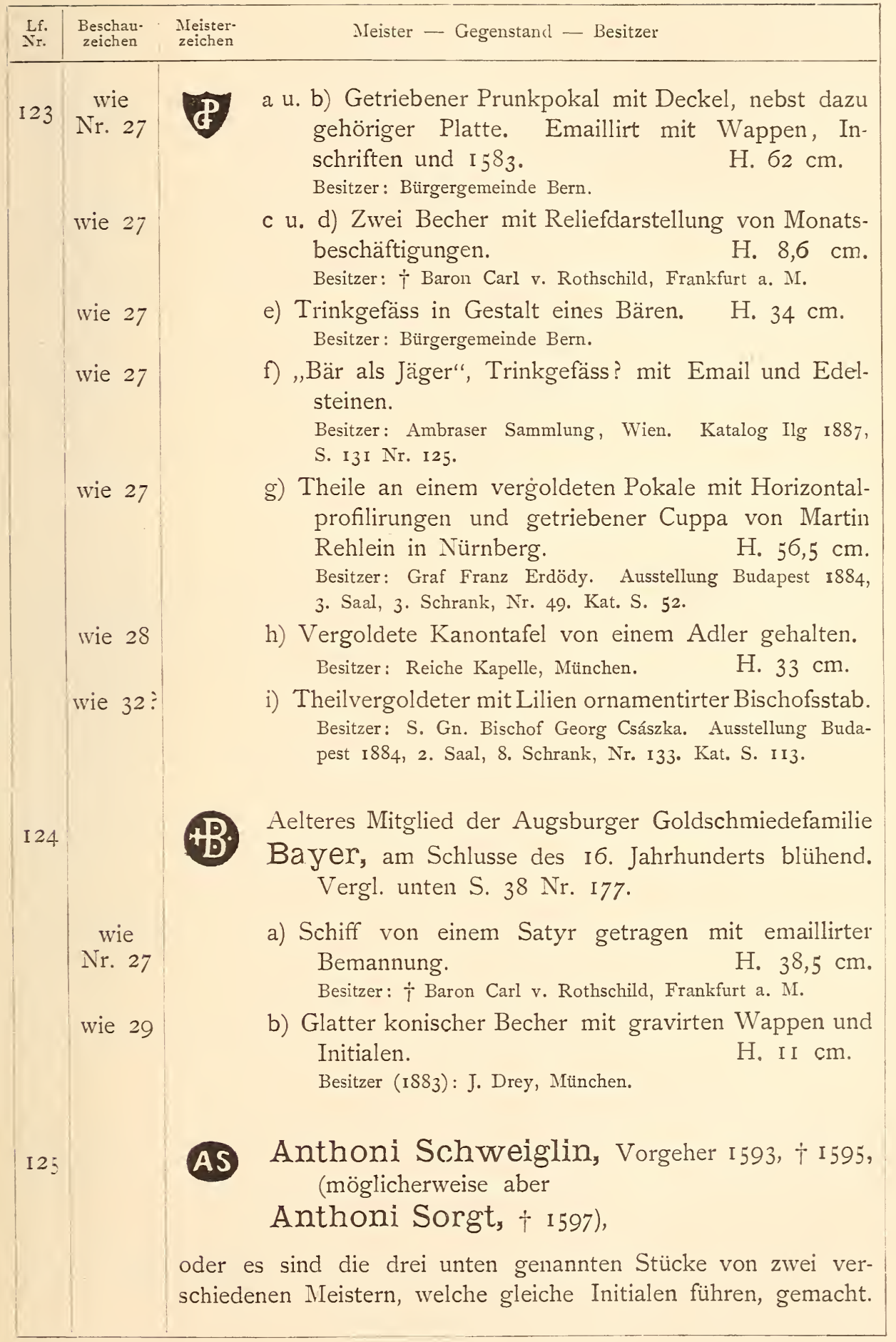




\begin{tabular}{|c|c|c|}
\hline $\begin{array}{l}\text { Lf. } \\
\text { Nr. }\end{array}$ & $\begin{array}{l}\text { Beschau- } \\
\text { zeichen }\end{array}$ & Meister - Gegenstand - Besitzer \\
\hline I 25 & & $\begin{array}{l}\text { Der ältere von ihnen scheint seine Buchstaben in einem mehr } \\
\text { rundlichen Schilde zu führen, der jüngere in einem ausge- } \\
\text { sprochenen Oval. }\end{array}$ \\
\hline & $\begin{array}{l}\text { wie } \\
\text { Nr. } 27\end{array}$ & $\begin{array}{l}\text { a u. b) Kanne und Schale, emaillirt und mit Türkisen } \\
\text { besetzt. } \\
\text { Besitzer: Königl. Schatzkammer, München. Katalog Schauss } \\
\text { 1879, G. } 59 \text {. }\end{array}$ \\
\hline - & wie 39 & $\begin{array}{l}\text { c) Theilvergoldeter Kugelbecher, getrieben mit Land- } \\
\text { schaften. Anscheinend Mitte des I7. Jahr- } \\
\text { hunderts. } \\
\text { Besitzer: S. D. Fürst von Hohenzollern-Sigmaringen. Aus- } \\
\text { stellung Augsburg i } 886 \text {. }\end{array}$ \\
\hline I 26 & & $\begin{array}{l}\text { Ulrich Schönmacher, Vorgeher I } 568 \text {, † I } 585 \text {, } \\
\text { wenn nicht die Beschauzeichen, die sich neben } \\
\text { diesem Stempel gewöhnlich finden, auf eine etwas spätere Zeit } \\
\text { deuten. }\end{array}$ \\
\hline & $\begin{array}{l}\text { wie } \\
\text { Nr. } 46\end{array}$ & $\begin{array}{l}\text { a) Fassung eines Elfenbeinbechers. } \\
\text { Besitzer: National-Museum, München. }\end{array}$ \\
\hline & wie 39 & $\begin{array}{l}\text { b) Vergoldetes viereckiges Köfferchen, auf vier Vo- } \\
\text { iutenfüssen. } \\
\text { Besitzer: J. \& H. Jeidels, Frankfurt a. M. }\end{array}$ \\
\hline & wie 37 & $\begin{array}{l}\text { c) Vergoldeter konischer Becher mit geschweisstem } \\
\text { Grund. } \\
\text { Besitzer (1883): L. Paar, Karlsruhe. }\end{array}$ \\
\hline & wie 39 & $\begin{array}{l}\text { d) Theilvergoldetes, ovales, getriebenes Plättchen. } \\
\text { Ausstellung Budapest I } 884 \text {. }\end{array}$ \\
\hline & wie $59 ?$ & $\begin{array}{l}\text { Vielleicht von demselben Meister: } \\
\begin{array}{ll}\text { e) Weisssilberne durchbrochene Schale auf drei ge- } \\
\text { gossenen Füsschen. } & \text { H. } 3,5 \mathrm{~cm} .\end{array} \\
\text { Besitzer (1883): Gebr. Heilbronner, München. }\end{array}$ \\
\hline & ? & $\begin{array}{l}\text { f) Löffel mit einem in Maskaron endigenden Stiele. } \\
\text { Besitzer: Alterthums-Museum, Kopenhagen. Nyrop, Dansk } \\
\text { Guldsmedekunst I885, S. 45. }\end{array}$ \\
\hline
\end{tabular}




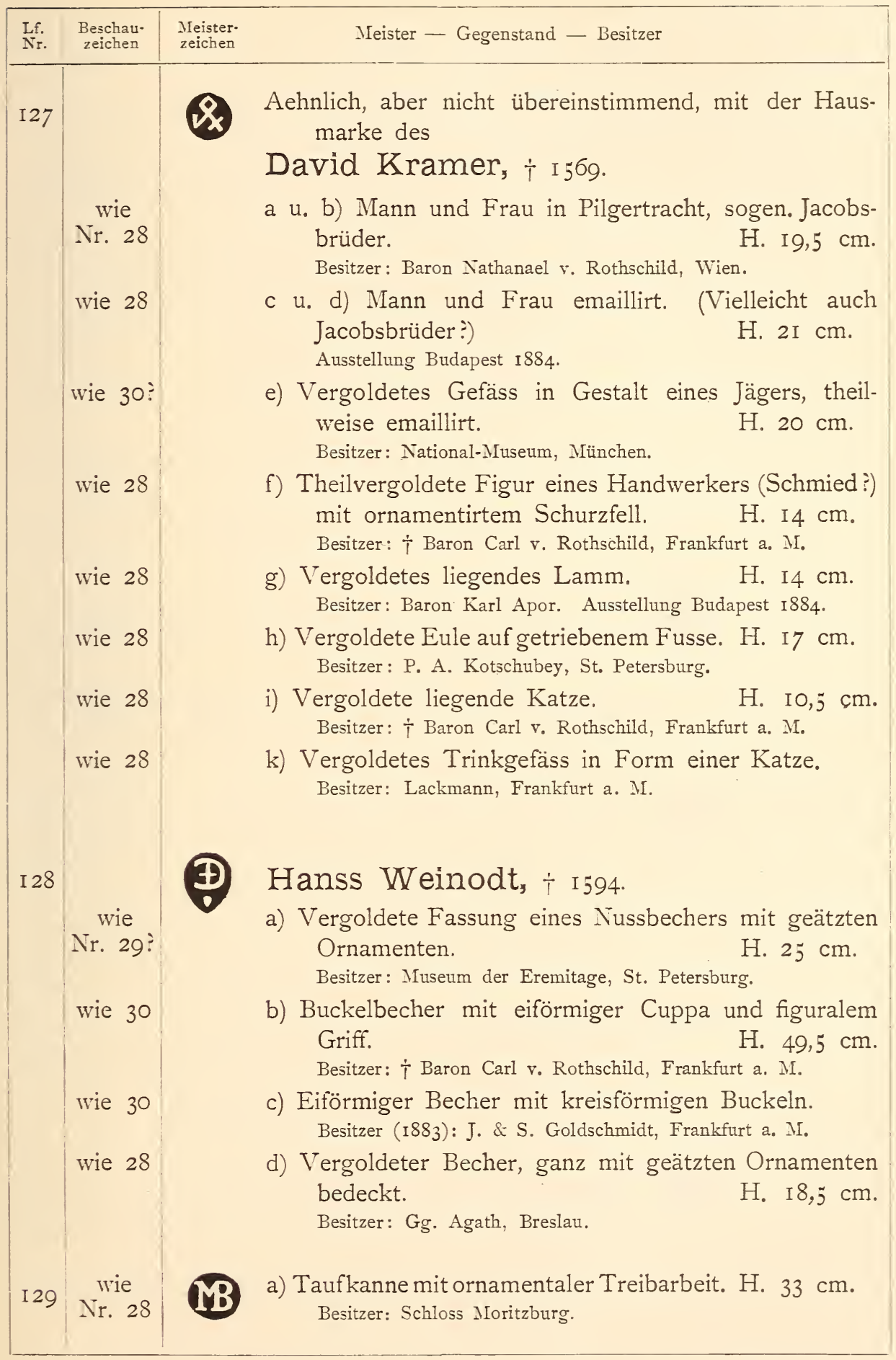




\begin{tabular}{|c|c|c|}
\hline $\begin{array}{l}\text { Lf. } \\
\text { Nr. }\end{array}$ & $\begin{array}{c}\text { chau- } \\
\text { chen }\end{array}$ & Meister - Gegenstand - Besitzer \\
\hline \multirow[t]{5}{*}{ I 29} & ? & $\begin{array}{l}\text { b) Löffel im Reisetisch des Kurfürsten August I. } \\
\text { Besitzer: Historisches Museum, Dresden. }\end{array}$ \\
\hline & $\begin{array}{c}\text { wie } \\
\text { Nr. } 28\end{array}$ & $\begin{array}{l}\text { c) Ovale Platte mit ornament. Treibarbeit. Dm. } 53,5 \mathrm{~cm} \text {. } \\
\text { Besitzer: Patriarchen - Schatzkammer, Moskau. Katalog der } \\
\text { Sammlung, Taf. XIII Nr. } 72 .\end{array}$ \\
\hline & & $\begin{array}{l}\text { Die beiden folgenden Stücke sind vielleicht von einem } \\
\text { jüngeren Meister, der die gleichen Initialen geführt hat. }\end{array}$ \\
\hline & wie 32 ? & $\begin{array}{l}\text { d) Sechseckige Büchse mit Achatplatten, die vergoldete } \\
\text { Silberfassung mit Reliefemail. } \\
\text { Besitzer: Königl. Schatzkammer, München. Katalog Schauss } \\
\text { I879, D. 37. }\end{array}$ \\
\hline & ? & $\begin{array}{l}\text { e) Tasse von Achat in getriebener, silbervergoldeter } \\
\text { Fassung. } \\
\text { H. } 4 \mathrm{~cm} \text {. } \\
\text { Besitzer: Königl. Schatzkammer, München. Katalog Schauss } \\
\text { I879, G. 9. }\end{array}$ \\
\hline \multirow[t]{2}{*}{ I 30} & $\begin{array}{l}\text { wie } \\
\text { Nr. } 30\end{array}$ & $\begin{array}{l}\text { I. a) Vergoldetes hohes Schälchen mit zwei Henkeln. } \\
\text { Besitzer: Baron von Walterskirchen, Wien. Ausstellung } \\
\text { Augsburg I } 886 .\end{array}$ \\
\hline & wie 44 & $\begin{array}{l}\text { b) Vergoldetes Schälchen. } \\
\text { Besitzer (I883): A. S. Drey, München. }\end{array}$ \\
\hline \multirow[t]{3}{*}{ I 3 I } & $\begin{array}{l}\text { wie } \\
\text { Nr. } 27\end{array}$ & $\begin{array}{l}\text { (2) a) Vergoldete Deckelkanne mit drei, durch Säulen } \\
\text { getrennten, getriebenen biblischen Darstellungen. } \\
\text { Bezeichet I609. } \\
\text { B. I6,8 cm. } \\
\text { Besitzer: } \dagger \text { Baron Carl v. Rothschild, Frankfurt a. M. }\end{array}$ \\
\hline & wie 34 ? & $\begin{array}{l}\text { b) Vergoldeter Mühlenbecher, die bauchige Cuppa mit } \\
\text { Rhomben und Punkten. } \quad \text { H. } 20 \mathrm{~cm} \text {. } \\
\text { Besitzer: Königl. Museum, Cassel. Katalog Lenz I 88I, Nr. } 22 .\end{array}$ \\
\hline & wie $28 ?$ & $\begin{array}{l}\text { Vielleicht mit derselben Marke versehen ist: } \\
\begin{array}{l}\text { c) Hälfte eines Doppelbechers, getrieben mit Linien- } \\
\text { ornament und Früchten. } \\
\text { Besitzer (1885): Jacobsohn, St. Petersburg. }\end{array}\end{array}$ \\
\hline 132 & $\begin{array}{c}\text { wie } \\
\text { Nr. } 30\end{array}$ & $\begin{array}{l}\text { B. Bernhard Vesenmaier, thätig I } 593 \text { bis I6ог. } \\
\text { a) Sanduhr in silbernem Gestelle, mit Wappen und } \\
\text { Initialen. } \\
\text { Besitzer: Königl. Schatzkammer, München. Katalog Schauss } \\
\text { IS79, M. 4I. }\end{array}$ \\
\hline
\end{tabular}




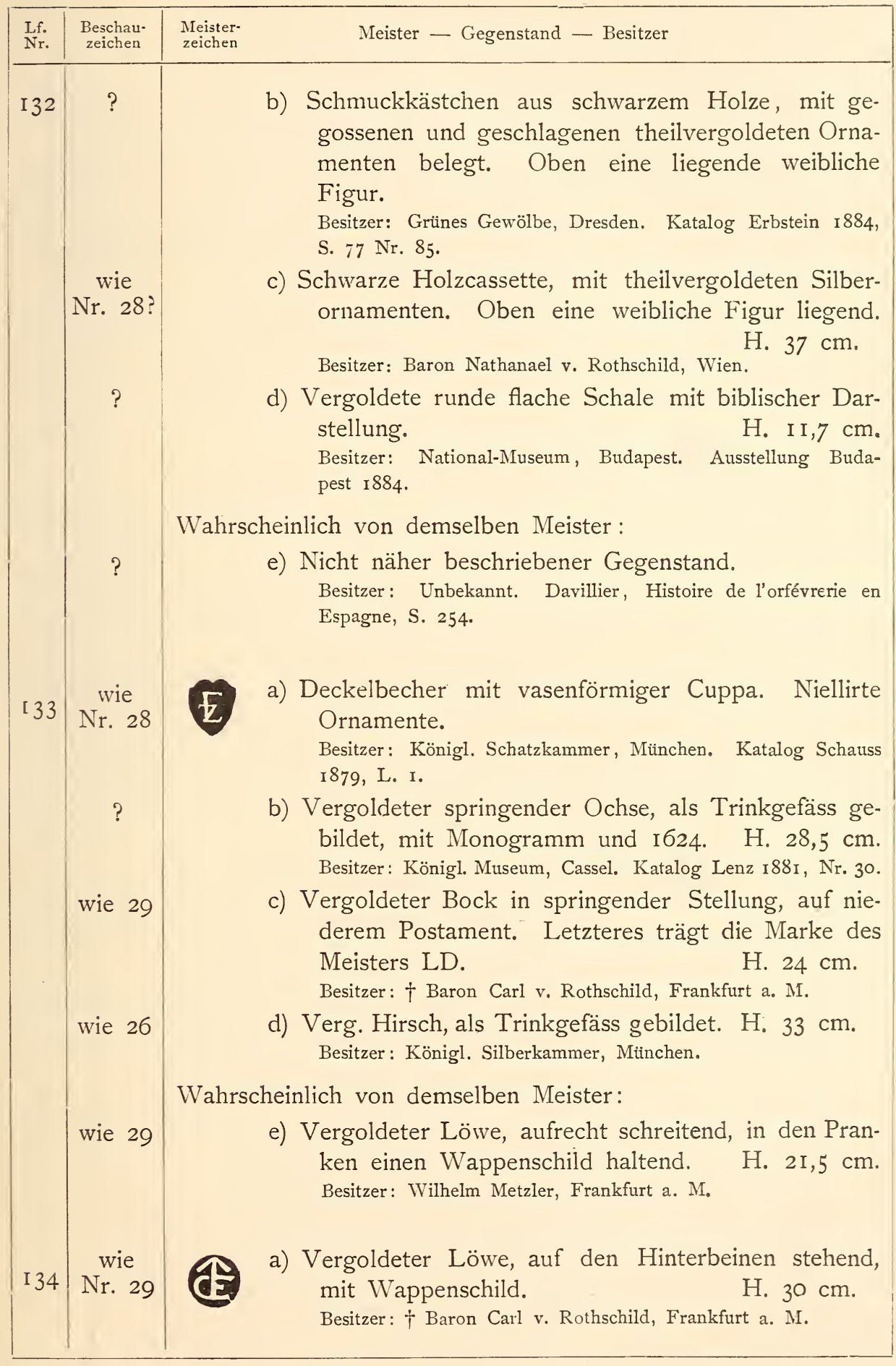




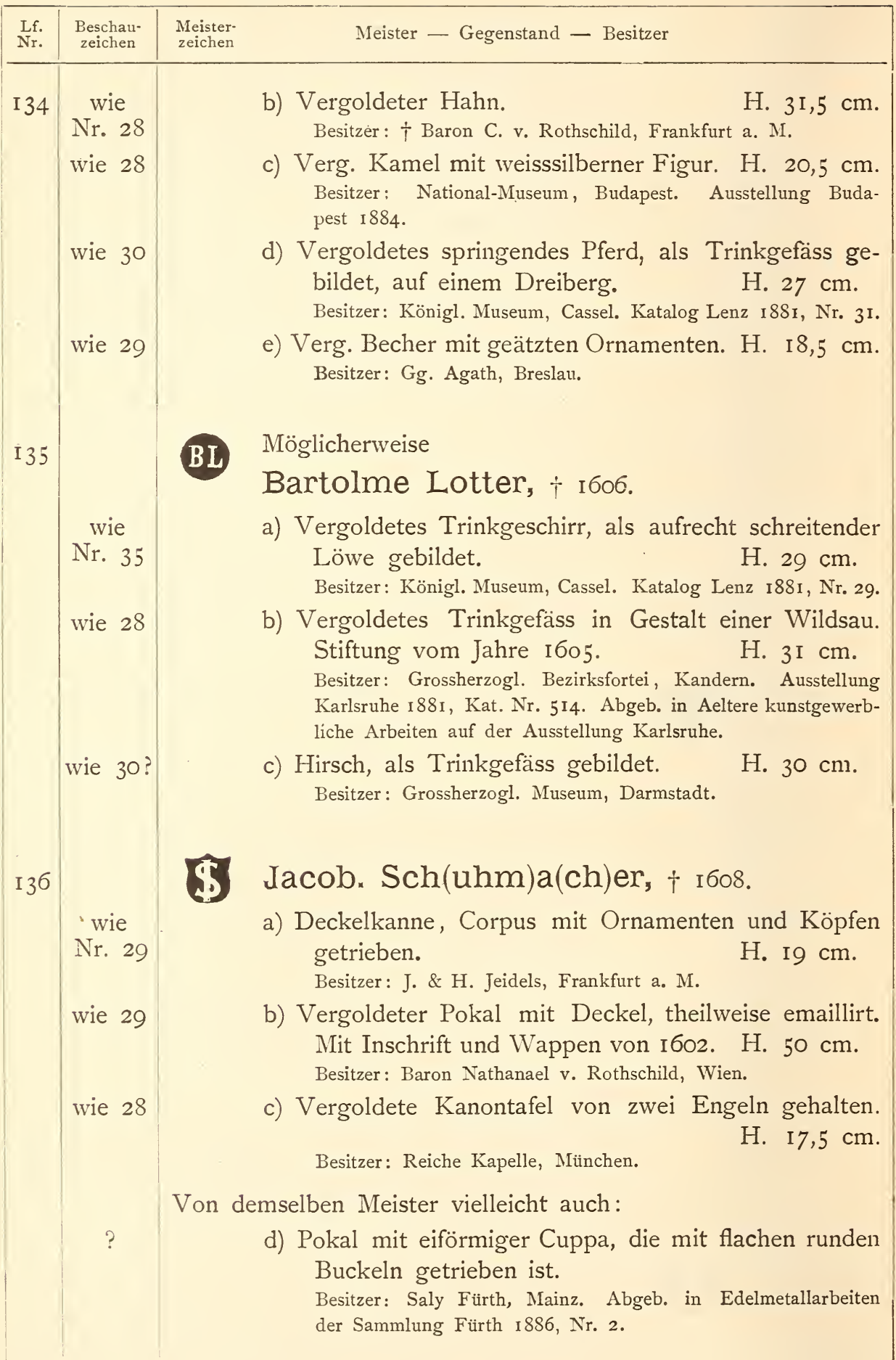




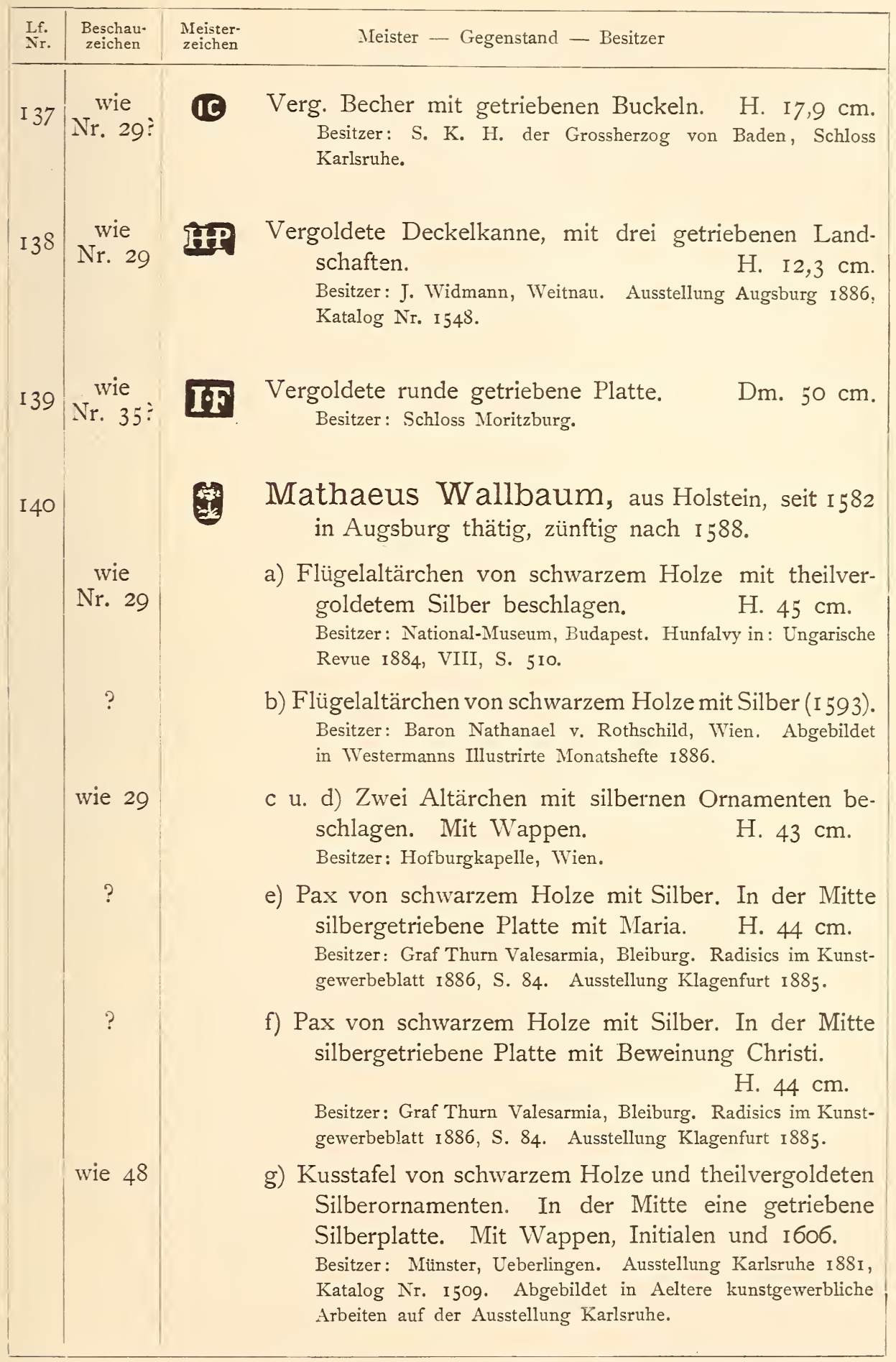




\begin{tabular}{|c|c|c|}
\hline $\begin{array}{l}\text { Lf. } \\
\text { Nr. }\end{array}$ & $\begin{array}{c}\text { Beschau- } \\
\text { zeichen }\end{array}$ & Meister - Gegenstand - Besitzer \\
\hline 140 & $\begin{array}{c}\text { wie } \\
\text { Nr. } 92\end{array}$ & $\begin{array}{l}\text { h) Kusstafel auf silbernem Fusse mit Wachsbossirung } \\
\text { in Holz- und Silberrahmen. H. ca. } 40 \mathrm{~cm} \text {. } \\
\text { Besitzer: S. D. Carl Egon Fürst von Fürstenberg, Donau- } \\
\text { eschingen. Ausstellung Augsburg I886, Katalog Nr. 1607. } \\
\text { Meisterwerke Schwäbischer Kunst, Taf. XXIII. }\end{array}$ \\
\hline & wie 29 & $\begin{array}{l}\text { i) Kusstafel von schwarzem Holze mit Silbermontirung. } \\
\text { In der Mitte ein ovales silbergetriebenes Medaillon } \\
\text { mit Maria und Kind. H. } 48 \mathrm{~cm} \text {. } \\
\text { Besitzer: S. D. Carl Egon Fürst von Fürstenberg, Donau- } \\
\text { eschingen. Ausstellung Augsburg I } 886 \text {, Katalog Nr. I607. } \\
\text { Meisterwerke Schwäbischer Kunst, Taf. XXIII. }\end{array}$ \\
\hline & wie 30 & $\begin{array}{l}\text { k u. 1) Zwei kleine Pacificalien mit getriebenen Mittel- } \\
\text { stücken. } \\
\text { Besitzer: Hof burgkapelle, Wien. }\end{array}$ \\
\hline & wie 30 & $\begin{array}{l}\text { m) Reliquientafel von schwarzem Holze mit silbernen } \\
\text { Ornamenten beschlagen. } \\
\text { Besitzer: Hofburgkapelle, Wien. }\end{array}$ \\
\hline & wie $3 \mathrm{I}$ & $\begin{array}{l}\text { n) Vergoldetes Reliquiar mit vielen Emails im Lencker- } \\
\text { schen Charakter, Smaragden und Perlen, Oben } \\
\text { im Halbbogen schliessend. } \\
\text { Besitzer: Reiche Kapelle, München. Stockbauer, Die Reiche } \\
\text { Kapelle II, xxx. }\end{array}$ \\
\hline & wie 28 & $\begin{array}{l}\text { o) Längliche Cassette mit weisssilbernen Ornamenten. } \\
\text { Basis lang 4I cm. } \\
\text { Besitzer: Herzogl. Museum, Gotha. }\end{array}$ \\
\hline & wie 33 & $\begin{array}{l}\text { p u. q) Zwei Schmuckkästen von schwarzem Holze und } \\
\text { Weisssilber. Basis lang } 37 \mathrm{~cm} \text {. } \\
\text { Besitzer: Historisches Museum, Dresden. }\end{array}$ \\
\hline & wie 29 & $\begin{array}{l}\text { r) Schreibzeugcassette von schwarzem Holze mit ein- } \\
\text { gesetzten getriebenen Silberplatten. Auf dem } \\
\text { Deckel eine weibliche Figur mit einem Knaben. } \\
\text { Besitzer: Königl. Schatzkammer, München. Katalog Schauss } \\
\text { 1879, M. 22. Abgebildet bei Schauss, Schatzkammer. }\end{array}$ \\
\hline & ? & $\begin{array}{l}\text { s) Relief, oben im Halbkreis geschlossen, Marter des } \\
\text { Heiligen Laurentius. } \\
\begin{array}{ll}\text { Besitzer: } † \text { Haron Carl v. Rothschild, Frankfurt a. M. } & \end{array}\end{array}$ \\
\hline & $?$ & 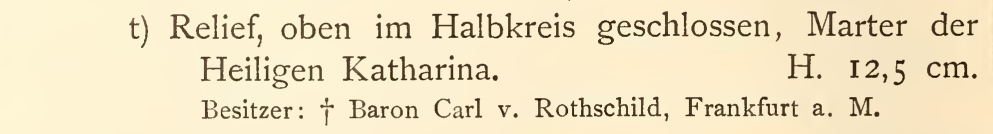 \\
\hline
\end{tabular}




\begin{tabular}{|c|c|c|c|}
\hline $\begin{array}{l}\text { Lff. } \\
\text { Nr. }\end{array}$ & $\begin{array}{l}\text { Beschau- } \\
\text { zeichen }\end{array}$ & $\begin{array}{l}\text { Meister- } \\
\text { zeichen }\end{array}$ & Meister - Gegenstand - Besitzer \\
\hline \multirow[t]{9}{*}{ I 40} & $\begin{array}{c}\text { wie } \\
\text { Nr. } 29\end{array}$ & & $\begin{array}{l}\text { u bis } \mathrm{x} \text { ) Vier weisssilberne Füsse in Gestalt von Greifen, } \\
\text { welche den Pommerschen Kunstschrank tragen. } \\
\text { Besitzer: Kunstgewerbe-Museum, Berlin. Lessing im Jahrbuch } \\
\text { der Kunstsammlungen, Berlin I } 884 \text {. Vergl.oben S. I4 Nr. II6. }\end{array}$ \\
\hline & fehlt & fehlt & $\begin{array}{l}\text { y) Pegasusgruppe auf dem Pommerschen Kunstschranke. } \\
\text { Beglaubigt durch die Werktafel. } \\
\text { Besitzer: Kunstgewerbe-Museum, Berlin. Lessing a. a. O. }\end{array}$ \\
\hline & $\begin{array}{l}\text { wahrscl } \\
\text { ohne I }\end{array}$ & $\begin{array}{l}\text { einlich } \\
\text { Iarken }\end{array}$ & $\begin{array}{l}\text { z) Hausaltärchen von schwarzem Holze und Silber. Mit } \\
\text { getriebenen und gegossenen Darstellungen. } \\
\text { Besitzer (I860): Gebr. Löwenstein, Frankfurt a. M. Abgebildet } \\
\text { in "The Vienna Museum «. Auction Christie, London } 1860 .\end{array}$ \\
\hline &, & , & $\begin{array}{l}\text { aa) Altaraufsatz von schwarzem Holze mit Silberorna- } \\
\text { menten. } \\
\text { Besitzer: Pfarre Spital am Pyhrn. Abgebildet in Kunst- } \\
\text { gewerbliche Gegenstände der culturhistorischen Ausstellung zu } \\
\text { Steyr } 1884 \text {, Heft III. }\end{array}$ \\
\hline & ," & ", & $\begin{array}{l}\text { bb) Altar mit Silberornamenten. } \\
\text { Besitzer: Städtisches Museum, Mailand. }\end{array}$ \\
\hline & " & , & $\begin{array}{l}\text { cc) Relief mit Auferstehung Christi. } \\
\text { Besitzer: Cesare Pace. Metallausstellung Rom } 1887 \text {. }\end{array}$ \\
\hline & , & Wahrsc & $\begin{array}{l}\text { dd) Kusstafel von schwarzem Holze mit Silbermon- } \\
\text { tirung. In der Mitte ein ovales silbergetriebenes } \\
\text { Medaillon mit Pietà. } \\
\text { Besitzer: S. D. Carl Egon Fürst von Fürstenberg, Donau- } \\
\text { eschingen. Ausstellung Augsburg 1886, Kat. Nr. I607. Ber- } \\
\text { lepsch in der Allgem. Zeitung 1886, Nr. 174. Meisterwerke } \\
\text { Schwäbischer Kunst, Taf. XXIII. } \\
\text { heinlich von ihm: }\end{array}$ \\
\hline & ohne & Iarken & $\begin{array}{l}\text { ee) Altar von schwarzem Holze mit Silber. In der } \\
\text { Mitte eine silbergetriebene Darstellung mit Maria. } \\
\text { H. } 37 \mathrm{~cm} \text {. } \\
\text { Besitzer: Hof burgkapelle, Wien. Kirchl. Ausstellung Wien } \\
\text { 1886, Nr. 749. Folnesics in Mittheilungen des Oesterreichischen } \\
\text { Museums } 1887, \text { S. } 362 .\end{array}$ \\
\hline & ohne II & arken & 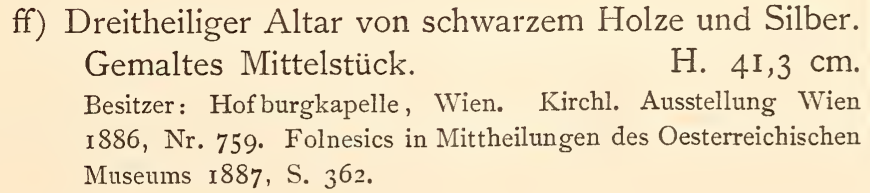 \\
\hline
\end{tabular}




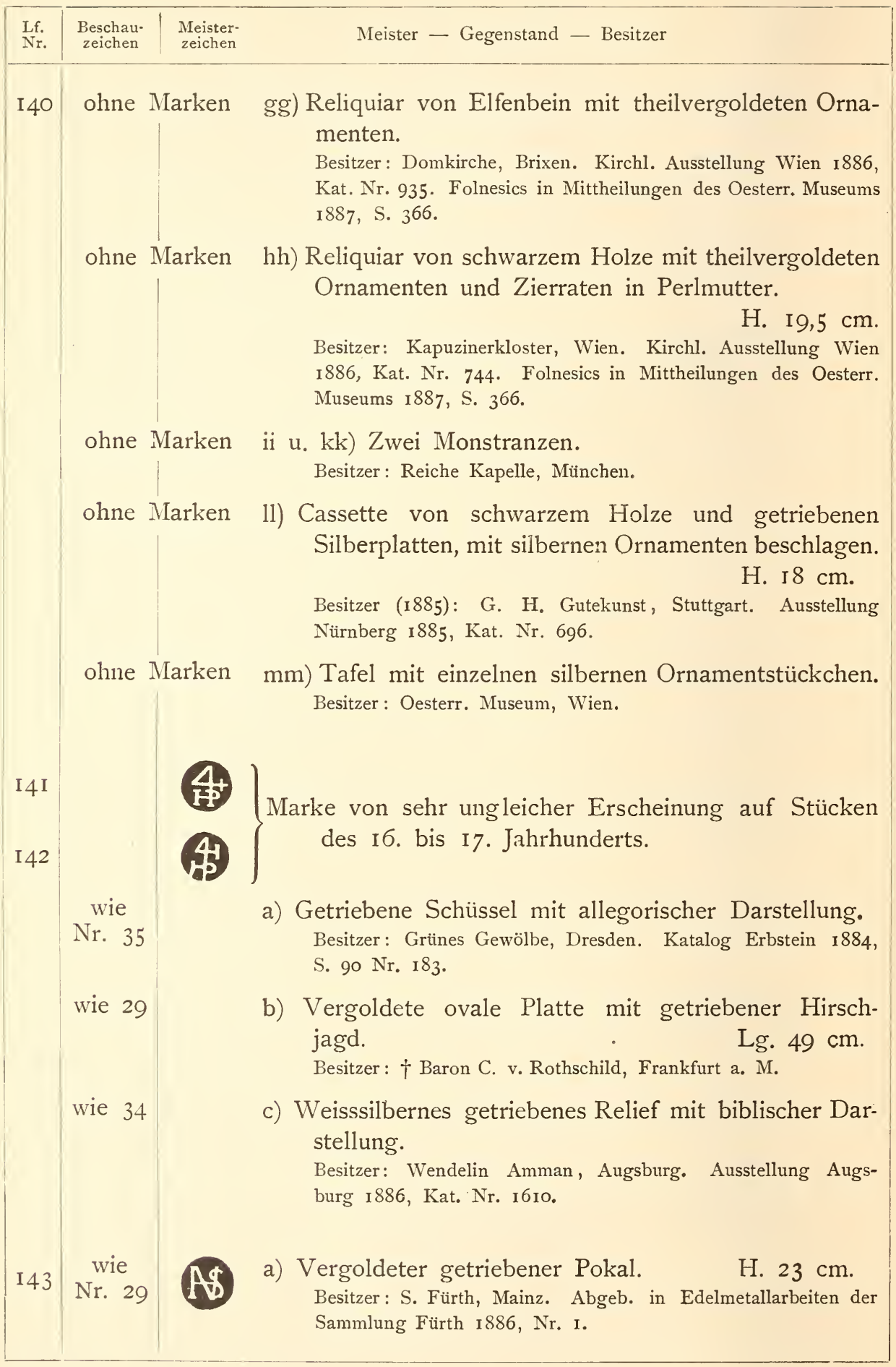




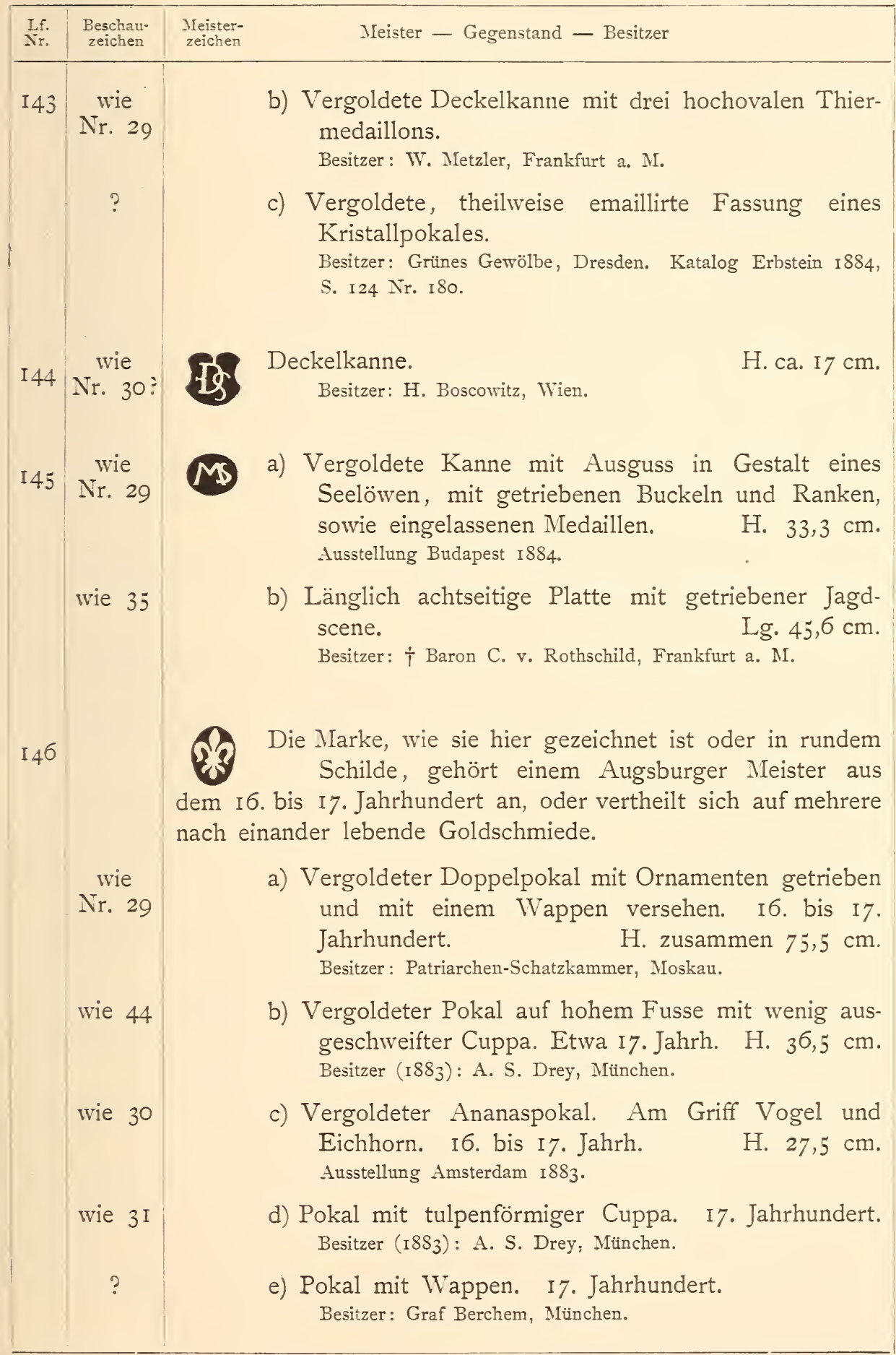




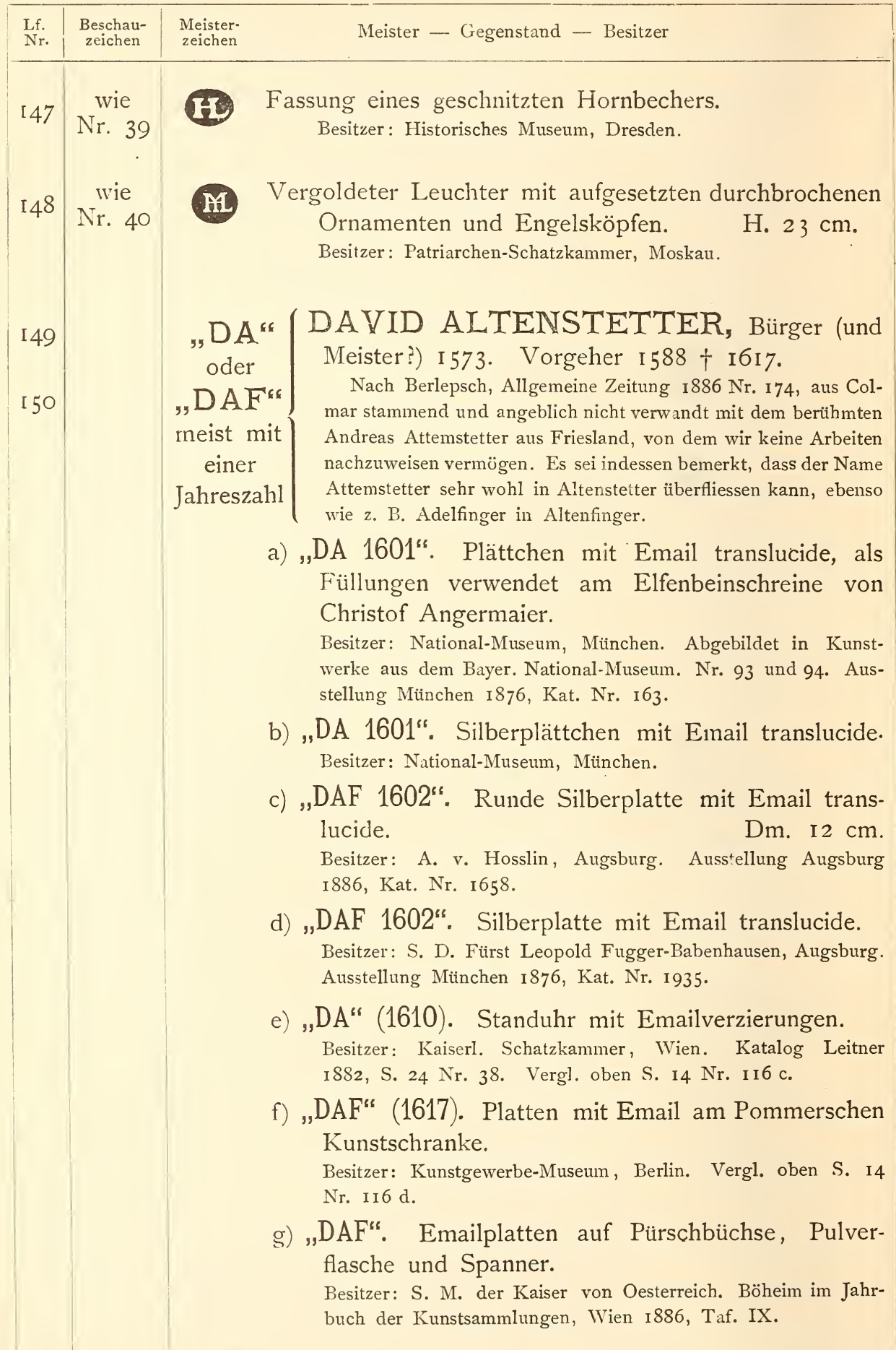




\begin{tabular}{|c|c|c|}
\hline $\begin{array}{l}\text { Lf. } \\
\text { Nr. }\end{array}$ & $\begin{array}{l}\text { Beschau- } \\
\text { zeichen }\end{array}$ & Meister - Gegenstand - Besitzer \\
\hline $\begin{array}{l}\text { I } 49 \\
\text { I } 50\end{array}$ & & $\begin{array}{l}\text { Ihm zugeschrieben: } \\
\text { h) Kleine Dose mit Email translucide. } \\
\text { Besitzer: von Stettensches Töchterinstitut, Augsburg. Aus- } \\
\text { stellung Augsburg I886, Kat. Nr. I659. } \\
\text { i) Oesterreichische Kaiserkrone mit Inschrift von I602. } \\
\text { Besitzer: Kaiserl. Schatzkammer, Wien. Katalog Leitner I882, } \\
\text { S. I24 Nr. I. Abgeb. in Leitner, Schatzkammer des Oester- } \\
\text { reichischen Kaiserhauses. } \\
\text { k) Forchtensteiner Esterhazy-Pokal. } \\
\text { Ausstellung Budapest I884. Abgebildet in Chefs-d'oeuvres de } \\
\text { l'orfèvrerie hongroise. Ilg in der Frankfurter Zeitung 29. April } \\
\text { I884. Böheim im Jahrbuch der Kunstsammlungen, Wien I886. } \\
\text { 1) Emailarbeit an einem Elfenbeinpokal, dessen Fassung } \\
\text { von dem Augsburger Goldschmied SM (ver- } \\
\text { schlungen) herrührt. } \\
\text { Besitzer: Schloss Moritzburg. } \\
\text { m u. n) Zwei hochgetriebene Reliefplatten. } \\
\text { Besitzer: Herzogl. Museum, Gotha. }\end{array}$ \\
\hline
\end{tabular}

"GS ${ }^{\star \xi}$ könnte nach Berlepsch in der Allgem. Zeitung I886, $\mathrm{Nr}$. I75 das Zeichen sein von

Georg Siebenbürger, Vorgeher I589, Beschaumeister 1603 .

Vergoldeter Zunftpokal der Ulmer Goldschläger mit anhängenden Denkmünzen (?). Bezeichnet I600. Besitzer: Gewerbe-Museum, Ulm. Ausstellung Augsburg I886, Kat. Nr. 1485 .

Marke von sehr ungleicher Erscheinung auf Stücken des I6. bis I7. Jahrhunderts. Vielleicht zwei verschiedenen Meistern angehörend.

wie

Nr. 44

wie 28

wie 28

a) Vergoldete springende Antilope.

H. $2 \mathrm{I}, 5 \mathrm{~cm}$. Besitzer: $\dagger$ Baron C. v. Rothschild, Frankfurt a. M.

b) Vergoldeter Storch auf flachem Untersatze, mit Wappen.

H. $30,5 \mathrm{~cm}$. Besitzer: $†$ Baron C. v. Rothschild, Frankfurt a. M.

c) Vergoldeter Hahn.

H. $23 \mathrm{~cm}$.

Besitzer: † Baron C. v. Rothschild, Frankfurt a. M. 


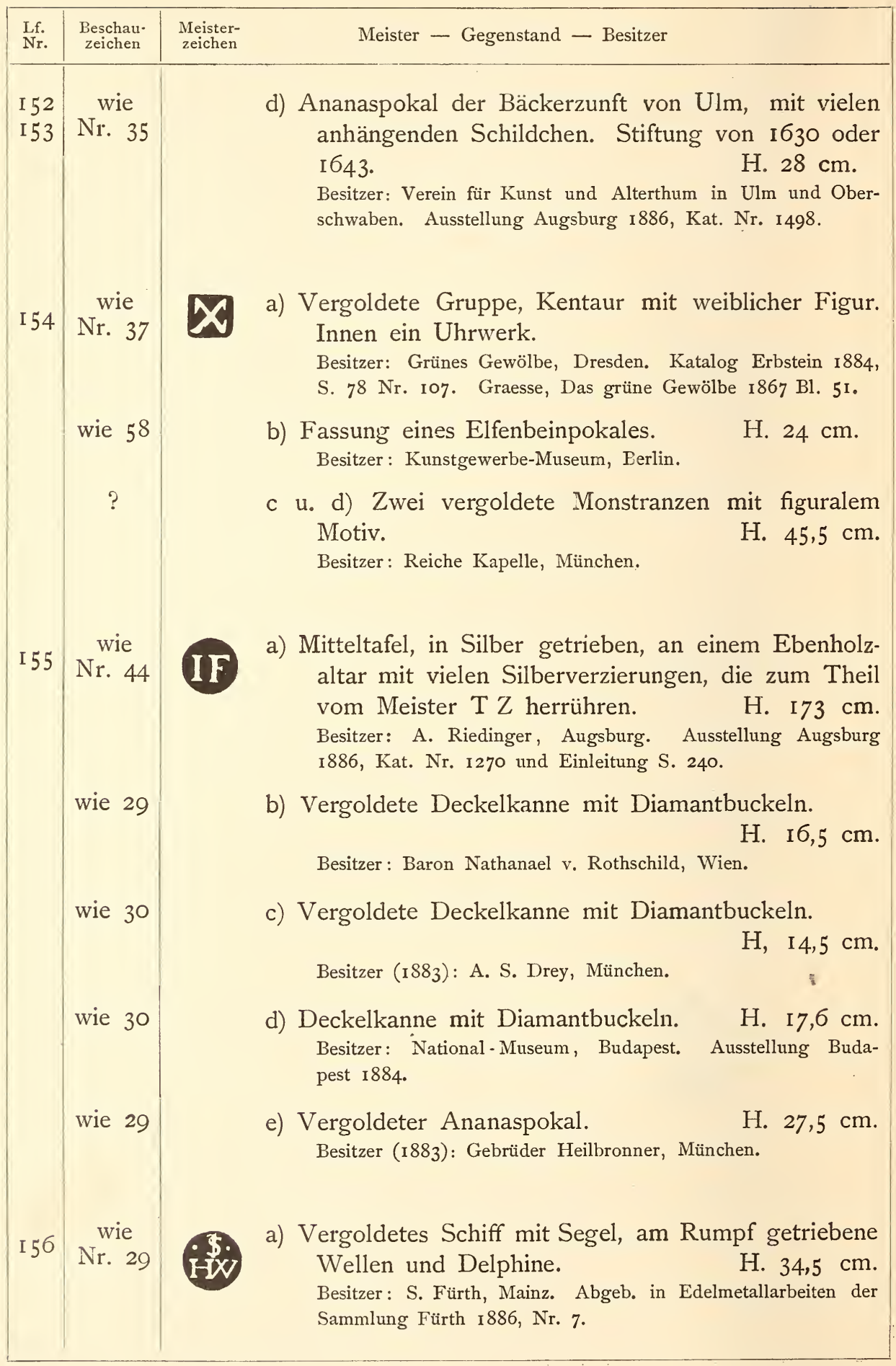




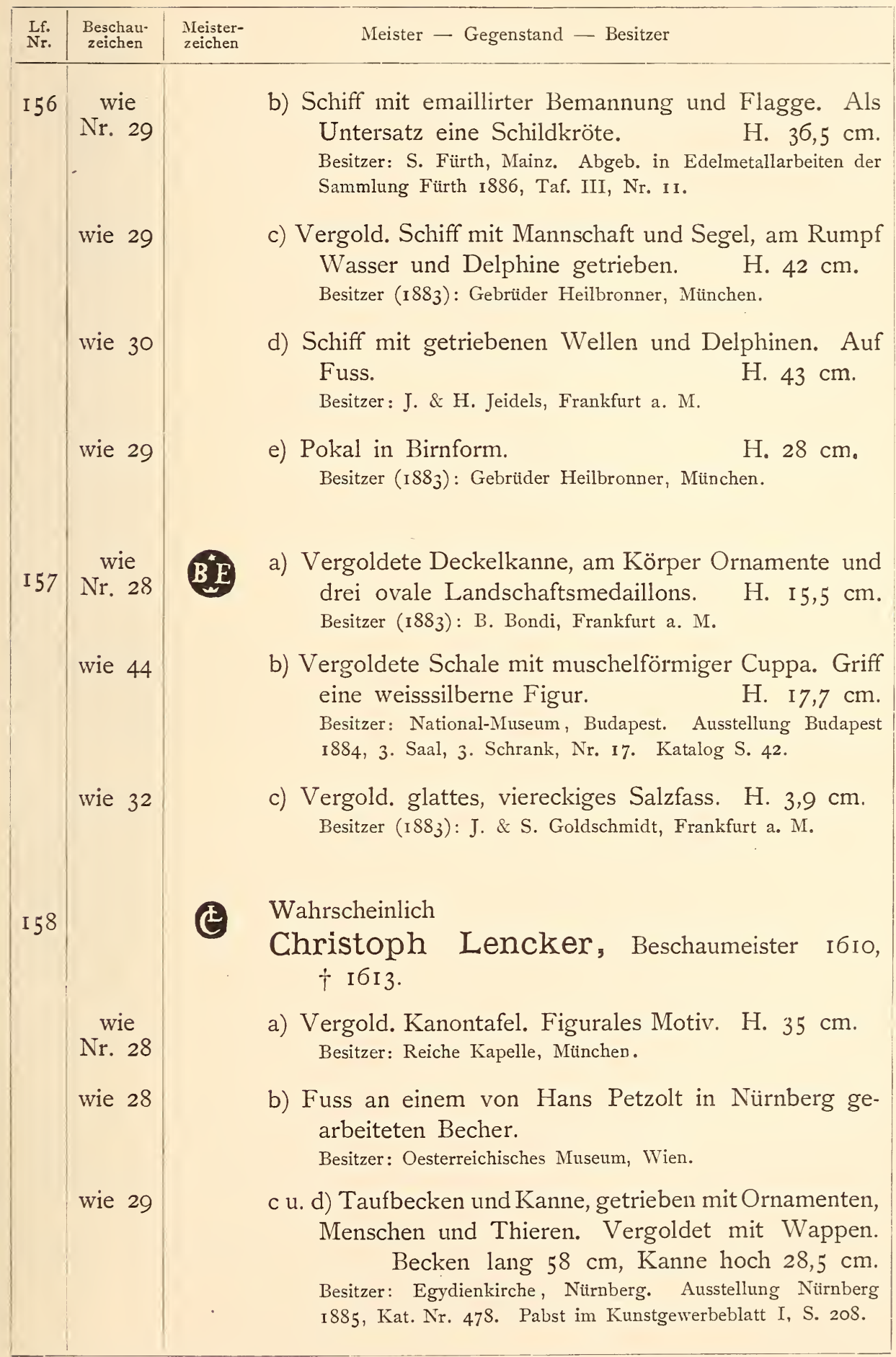




\begin{tabular}{|c|c|c|}
\hline $\begin{array}{l}\text { Lf. } \\
\text { Nr. }\end{array}$ & $\begin{array}{l}\text { Beschau- } \\
\text { zeichen }\end{array}$ & Meister - Gegenstand - Besitzer \\
\hline \multirow[t]{5}{*}{158} & $\begin{array}{c}\text { wie } \\
\text { Nr. } 29\end{array}$ & $\begin{array}{l}\text { e) Fassung eines Nautilus, Griff figural, als Fuss eine } \\
\text { Schildkröte, auf dem Deckel Figur. Mit Email. } \\
\text { H. } 78 \mathrm{~cm} .\end{array}$ \\
\hline & wie 29 & $\begin{array}{l}\text { f) Vergoldete Prunkschüssel, am Rande aufgelegte } \\
\text { emaillirte Ornamente, in der Mitte getriebene } \\
\text { mythologische Darstellung. } \\
\text { Besitzer: Kaiserl. Schatzkammer, Wien. Katalog Leitner r882, } \\
\text { S. Ior Nr. 51. }\end{array}$ \\
\hline & $?$ & $\begin{array}{l}\mathrm{g} \text { bis } \mathrm{k}) \text { Vier Silberplatten mit Scenen aus der Passion } \\
\text { von dem ehemaligen Altar der Schlosskirche in } \\
\text { Rügenwalde. } \\
\text { Besitzer: Marienkirche, Rügenwalde. Lessing im Jahrbuch der } \\
\text { Kunstsammlungen, Berlin I885, S. } 60 \text { ff. Vergl. unten S. } 33 \\
\text { Nr. I60. }\end{array}$ \\
\hline & & Vermuthlich von demselben Meister: \\
\hline & $?$ & $\begin{array}{l}\text { 1 u. m) Kanne und Becken, beide ganz vergoldet und } \\
\text { mit biblischen Scenen getrieben. } \\
\text { Besitzer: } \dagger \text { Baron Lionel v. Rothschild, London. South } \\
\text { Kensingston-Museum, Loan Exhibition 1862, S. } 568 \text {. }\end{array}$ \\
\hline \multirow[t]{4}{*}{ I 59} & & $\begin{array}{l}83 \text { Die Identifizirung dieser Marke mit dem Namen eines } \\
\text { Augsburger Goldschmiedes bietet Schwierigkeiten. } \\
\text { Sie stimmt sowohl mit dem Wappenbilde der Gaab (vgl. } \\
\text { Padua) und Kolb, welche aber für die hier verzeichneten } \\
\text { Arbeiten etwas zu jung sind, als auch mit dem Wappen von } \\
\text { Christoph und Johannes Lencker. Wenn ich mich für einen } \\
\text { dieser Meister entscheiden soll, wähle ich am liebsten }\end{array}$ \\
\hline & & $\begin{array}{l}\text { Johannes Lencker, geboren I573 (I } 570 \text { ?) } \\
\qquad 1637 .\end{array}$ \\
\hline & $\begin{array}{l}\text { wie } \\
\text { Nr. } 30\end{array}$ & $\begin{array}{l}\text { a) Trinkgeschirr in Gestalt eines Schiffes, aus ver- } \\
\text { steinertem Palmenholz, Griff figural. Mit Wappen. } \\
\text { Besitzer: Königl. Schatzkammer, München. Katalog Schauss } \\
\text { 1879, E. 25. Abgebildet bei Schauss, Schatzkammer. }\end{array}$ \\
\hline & wie 35 & $\begin{array}{l}\text { b u. c) Zwei Marschallstäbe mit allegorischen Figuren, } \\
\text { Wappen und Inschrift. } \\
\text { Besitzer: Königl. Silberkammer, München. }\end{array}$ \\
\hline
\end{tabular}




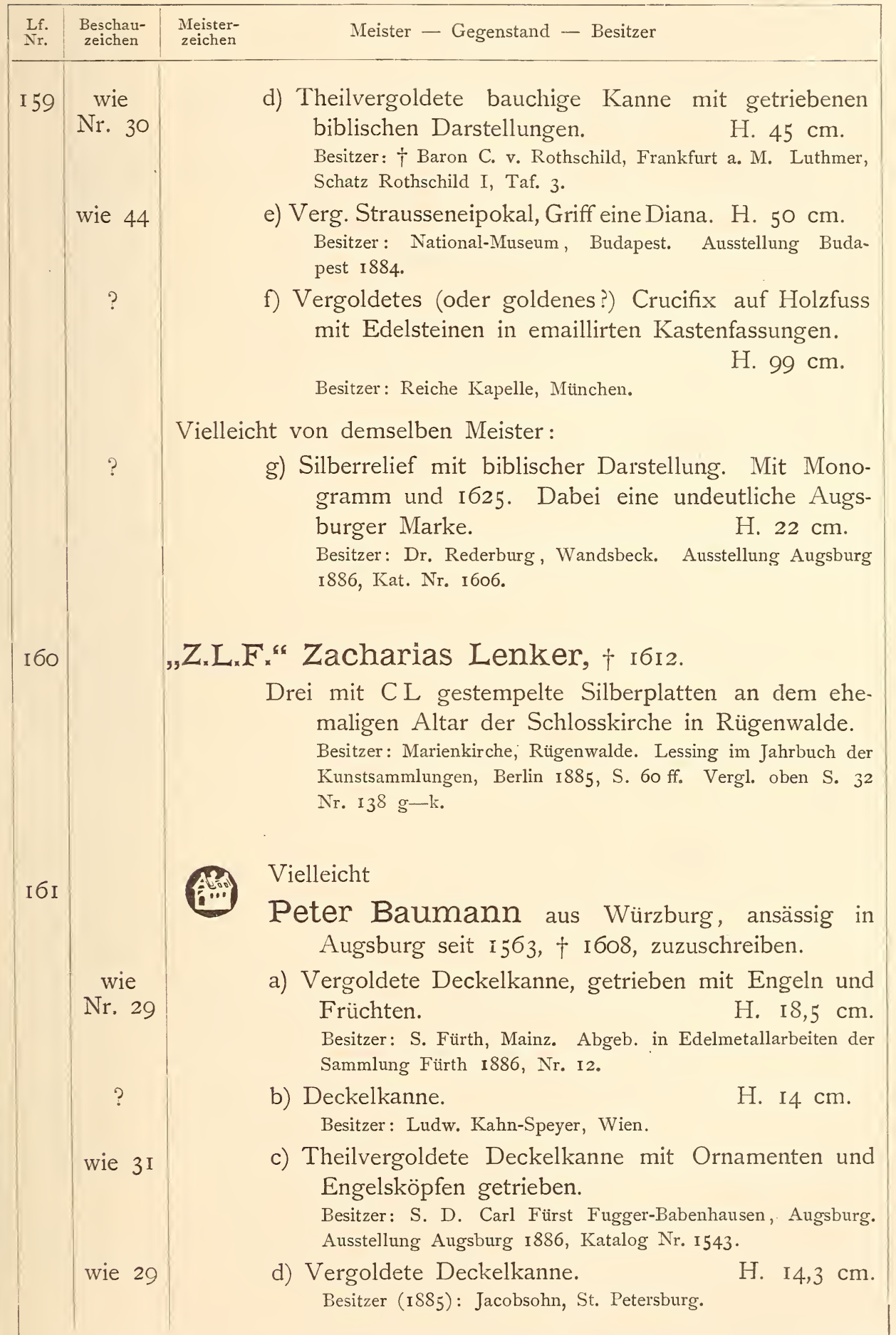




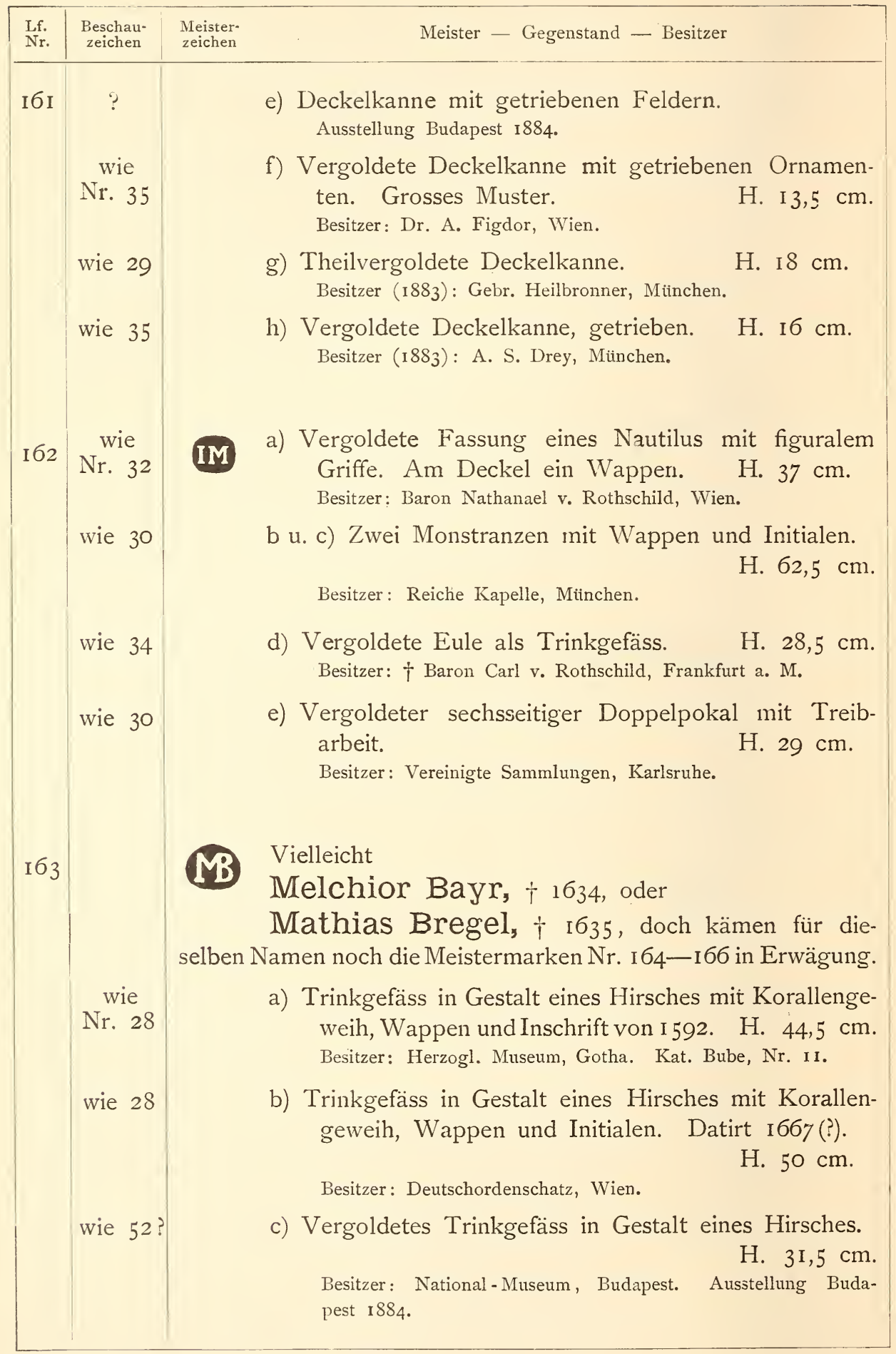




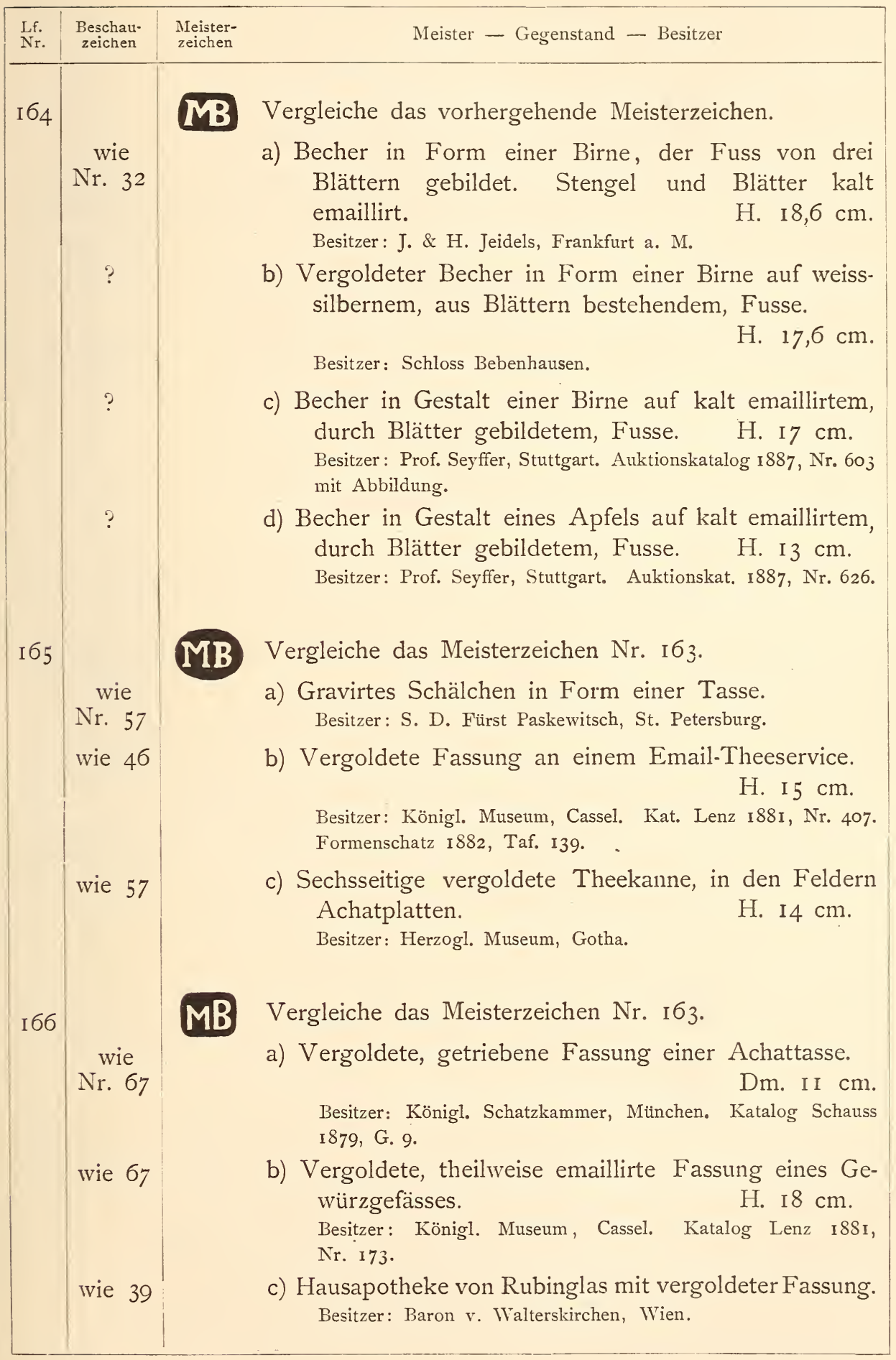




\begin{tabular}{|c|c|c|c|}
\hline $\begin{array}{l}\text { Lf. } \\
\text { Nr. }\end{array}$ & $\begin{array}{l}\text { Beschau- } \\
\text { zeichenn }\end{array}$ & $\begin{array}{l}\text { eister- } \\
\text { ichen }\end{array}$ & Meister - Gegenstand - Besitzer \\
\hline І67 & & B & $\begin{array}{l}\text { Vielleicht } \\
\text { Bartolme Koch, Vorgeher ıбо5. }\end{array}$ \\
\hline & $\begin{array}{l}\text { wie } \\
\text { Nr. } 30\end{array}$ & & $\begin{array}{l}\text { a u. b) Zwei vergoldete getriebene Becher der Augs- } \\
\text { burger Goldschmiedezunft, mit Wappen, Inschriften } \\
\text { und I607. } \\
\text { B. I } 5 \mathrm{~cm} \text {. } \\
\text { Besitzer: E. Thewalt, Cöln. Katalog der kunsthistorischen } \\
\text { Ausstellung Cöln I876, Nr. } 744 \text { und } 745 \text {. }\end{array}$ \\
\hline & wie 35 & & $\begin{array}{l}\text { c) Vergoldeter Kelch mit weisssilbernen aufgesetzten } \\
\text { Ornamenten, Inschrift und I613. H. 22,5 cm. } \\
\text { Besitzer: Ursulakirche, Solothurn. Ausstellung Zürich i } 883 \text {, } \\
\text { Katalog Nr. } \text { 14, S. 225. }\end{array}$ \\
\hline & $?$ & & $\begin{array}{l}\text { d) Vergold. Ciborium auf hohem Fusse. H. } 29 \mathrm{~cm} \text {. } \\
\text { Besitzer: Museumsverein, Aachen. }\end{array}$ \\
\hline I68 & & & $\begin{array}{l}\text { Hans Andreas Anthoni, Vorgeher I634, } \\
\qquad \sigma_{1} \sigma_{50} \text {. }\end{array}$ \\
\hline & $\begin{array}{l}\text { wie } \\
\text { Nr. } 30\end{array}$ & & $\begin{array}{l}\text { a) Weisssilbernes Crucifix auf schwarzem Holzposta- } \\
\text { mente. } \\
\text { Besitzer: Reiche Kapelle, München. }\end{array}$ \\
\hline & wie 35 & & $\begin{array}{l}\text { b) Theilvergoldetes Crucifix, mit einem Uhrwerk im } \\
\text { Fusse. } \\
\text { Besitzer (1884): G. v. Aaken, Baden-Baden. }\end{array}$ \\
\hline & wie 57 & & $\begin{array}{l}\text { c) Vergoldete flache Henkelschale mit getriebenen } \\
\text { Figuren. } \\
\text { Besitzer: J. Dreyfus-Jeidels, Frankfurt a. M. }\end{array}$ \\
\hline 169 & & & $\begin{array}{l}\text { Marke von etwas ungleicher Erscheinung auf Stücken } \\
\text { aus dem Anfang oder der Mitte des } 17 \text {. Jahrh. }\end{array}$ \\
\hline & $\begin{array}{l}\text { wie } \\
\text { Nr. } 30\end{array}$ & & $\begin{array}{l}\text { a) Vergold. Fassung einer Elfenbeinkanne. H. I } 8,5 \mathrm{~cm} \text {. } \\
\text { Besitzer: S. D. Fürst Nicolaus Esterhazy. Ausstellung Budapest } \\
\text { I884 5. Saal I. Schrank, Katalog S. 2. }\end{array}$ \\
\hline & wie 58 & & $\begin{array}{l}\text { b) Vergold. Fassung einer Elfenbeinkanne. H. } 22 \mathrm{~cm} \text {. } \\
\text { Besitzer: Museum der Eremitage, St. Petersburg. }\end{array}$ \\
\hline & $?$ & & $\begin{array}{l}\text { c) Salzfass, zu einem Service gehörig. } \\
\text { Besitzer: } † \text { Baron Carl v. Rothschild, Frankfurt a. M. }\end{array}$ \\
\hline
\end{tabular}




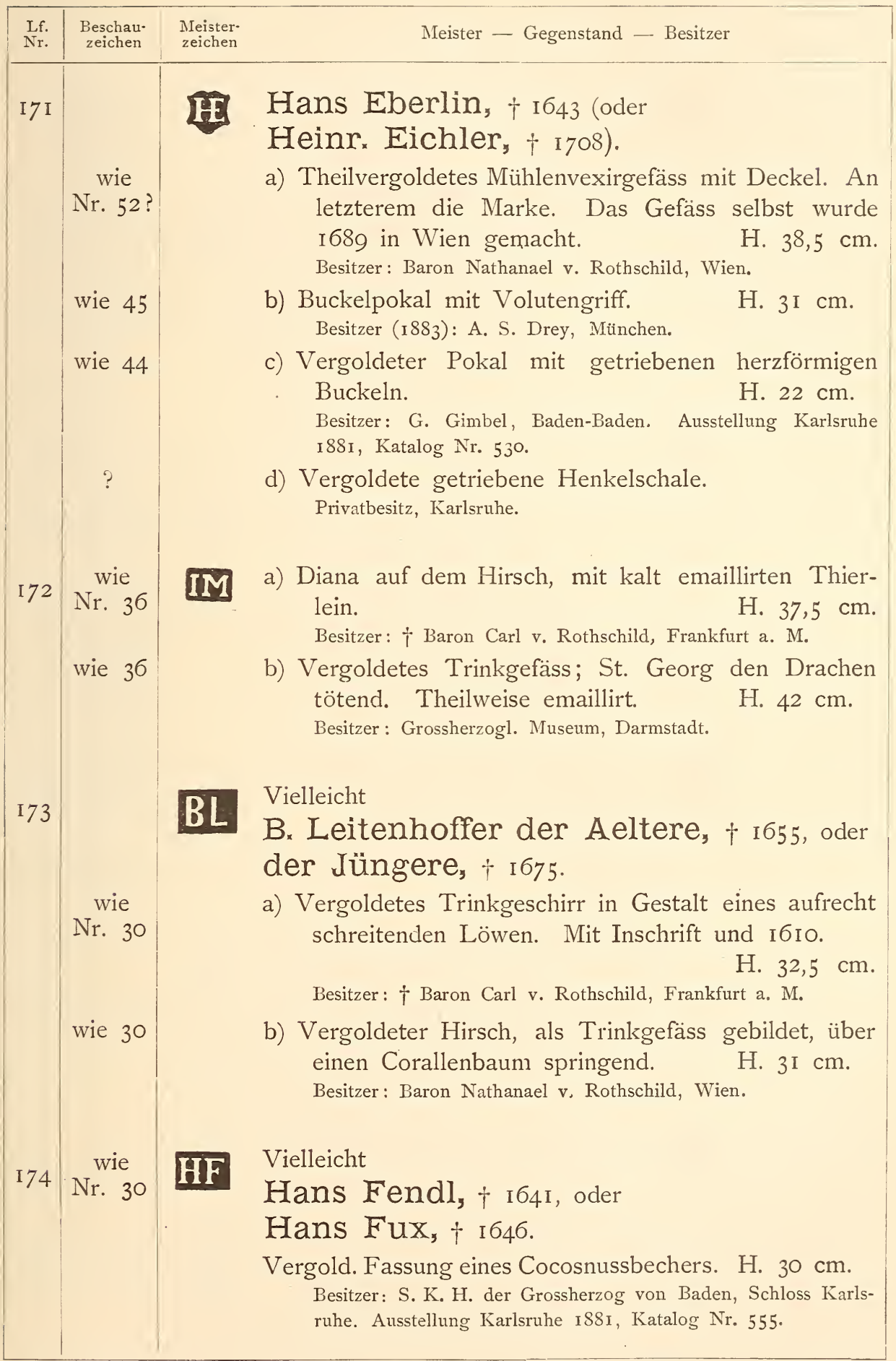




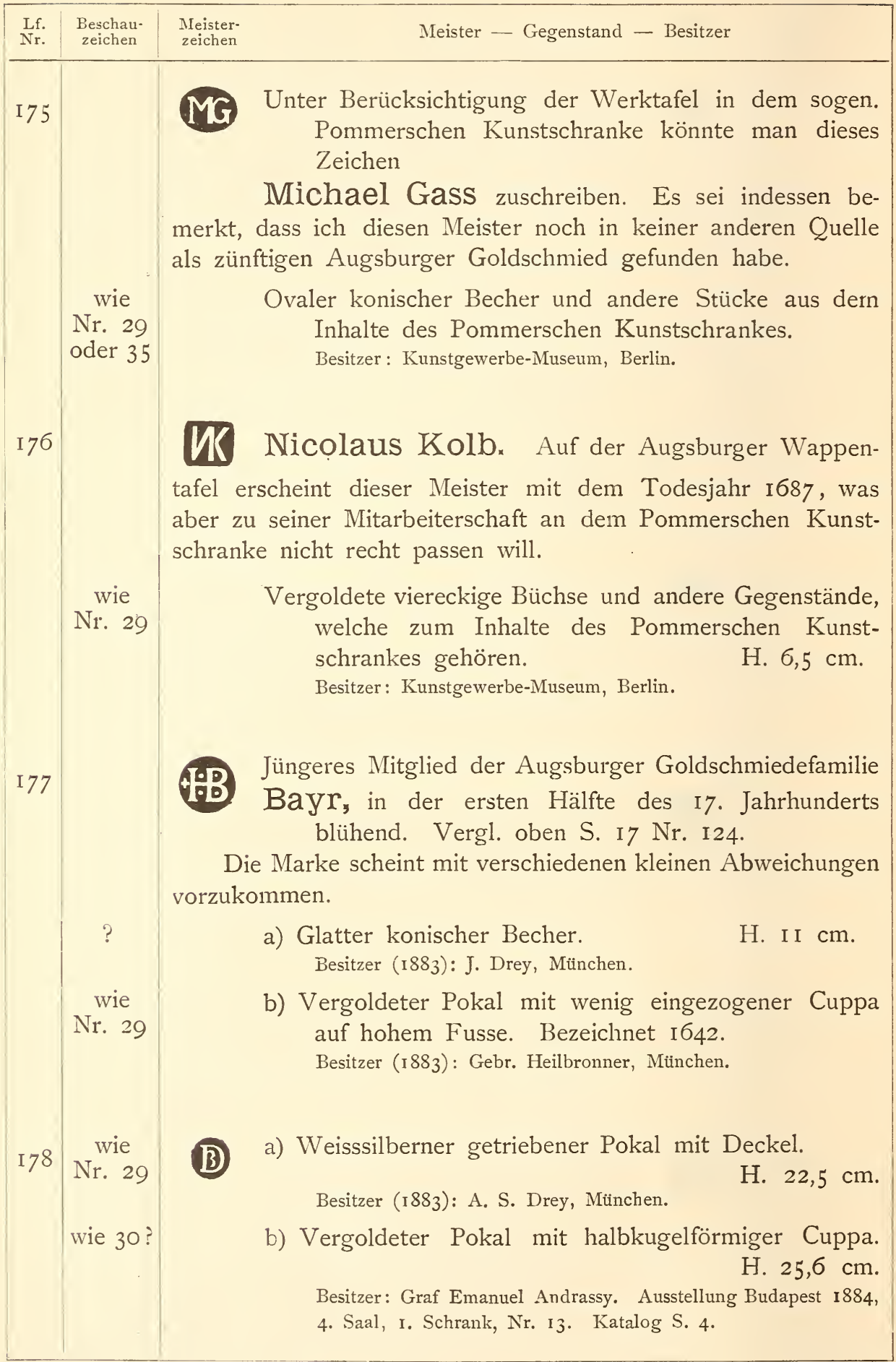




\begin{tabular}{|c|c|c|c|}
\hline $\begin{array}{l}\text { Lf. } \\
\text { Nr. }\end{array}$ & $\begin{array}{l}\text { Beschau. } \\
\text { zeichen }\end{array}$ & $\begin{array}{l}\text { Meister- } \\
\text { zeichen }\end{array}$ & Meister - Gegenstand - Besitzer \\
\hline $17 \mathrm{~S}$ & $\begin{array}{c}\text { wie } \\
\text { Nr. } 29\end{array}$ & & $\begin{array}{l}\text { c) Vergoldeter Pokal, mit wenig eingezogener Cuppa, } \\
\text { auf hohem Fusse. } \\
\text { Besitzer }\left(\mathrm{IS}_{3}\right) \text { : A. S. Drey, München. }\end{array}$ \\
\hline I79 & $\begin{array}{c}\text { wie } \\
\text { Nr. } 29\end{array}$ & & $\begin{array}{l}\text { Christof Bantzer, } \uparrow \text { I653. } \\
\begin{array}{ll}\text { a) Vergoldeter schlanker Pokal. Cuppa getrieben, Griff } \\
\text { geätzt. } & \text { H. } 26,5 \mathrm{~cm} . \\
\text { Besitzer: National-Nuseum, Budapest. } & \text { Ausstellung Buda- } \\
\text { pest I884. } & \text { H. } 30,5 \mathrm{~cm} . \\
\text { b) Vergoldeter Buckelpokal. } & \end{array}\end{array}$ \\
\hline I 80 & $\begin{array}{l}\text { wie } \\
\text { Nr. } 29\end{array}$ & & $\begin{array}{l}\text { a) Vergoldete flache Schale mit figürlicher Dar- } \\
\text { stellung. } \\
\text { Besitzer: S. D. Först Paskewitsch, St. Petersburg. } \\
\text { b) Getriebene Platte mit acht Vertiefungen. H. IO cm. } \\
\text { Besitzer: Patriarchen-Schatzkammer, Moskau. }\end{array}$ \\
\hline & wie 29 & & $\begin{array}{l}\text { c) Vergoldete Bechertheile, zu einem Leuchter zu- } \\
\text { sammengesetzt. } \\
\text { Besitzer: Patriarchen-Schatzkammer, Moskau. }\end{array}$ \\
\hline & wie 35 & & $\begin{array}{l}\text { d) Vergoldete ovale Schüssel, mit Ornamenten ge- } \\
\text { trieben. } \\
\text { Besitzer: Kaiserl. Schatzkammer, Wien. Katalog Leitner } \\
\text { 1882, S. } 102 \mathrm{Nr} .58 \text {. }\end{array}$ \\
\hline I 8 I & $\begin{array}{l}\text { wie } \\
\text { Nr. 3I } \\
\quad ?\end{array}$ & & $\begin{array}{l}\text { Abraham Riederer, Vorgeher I6oI. } \\
\text { a bis e) Fünf tiefe Teller mit russischer Inschrift. } \\
\text { Besitzer: Patriarchen-Schatzkammer, Moskau. Katalog der } \\
\text { Sammlung, Taf. XI Nr. 6r. } \\
\text { f) Vergoldete Kanne mit gravirten Ornamenten, Wappen } \\
\text { und Inschrift. } \\
\text { Besitzer: } † \text { E. Felix, Leipzig. Eye \& Börner, Katalog der } \\
\text { Sammlung Felix r88o, Nr. I48. }\end{array}$ \\
\hline $\mathrm{I} 82$ & $\begin{array}{l}\text { wie } \\
\text { Nr. 3I }\end{array}$ & & $\begin{array}{ll}\text { a) Vergoldeter Pokal mit getriebenen Zügen und } \\
\text { Buckeln. Inschrift von I630. } & \text { H. 25,8 cm. } \\
\text { Besitzer: Bürgergemeinde Bern. } & \end{array}$ \\
\hline
\end{tabular}




\begin{tabular}{|c|c|c|c|}
\hline $\begin{array}{l}\text { Lf. } \\
\text { Nr. }\end{array}$ & $\begin{array}{l}\text { Beschau- } \\
\text { zeichen }\end{array}$ & $\begin{array}{l}\text { ster- } \\
\text { shen }\end{array}$ & Meister — Gegenstand - Besitzer \\
\hline I 82 & $\begin{array}{c}\text { wie } \\
\text { Nr. } 46\end{array}$ & & $\begin{array}{l}\text { b) Vergoldete Deckelkanne mit getriebenen Engeln. } \\
\text { H. I6 cm. } \\
\text { Besitzer: Bayr. Gewerbe-Museum, Nürnberg. Katalog I88o, } \\
\text { XA I Nr. 43, 286. Galvanopl. Reproduktion. }\end{array}$ \\
\hline I 83 & $\begin{array}{l}\text { wie } \\
\text { Nr. 3I }\end{array}$ & & $\begin{array}{l}\text { a) Trinkgefäss in Gestalt eines Himmelsglobus vom } \\
\text { heiligen Christophorus getragen. Die Kugel weiss- } \\
\text { silbern mit Christuskind als Bekrönung. Im Fusse } \\
\text { eine Rollmechanik. } \\
\text { Besitzer: Grïnes Gewölbe, Dresden. Katalog Ërbstein I884, } \\
\text { S. 102 Nr. 290. }\end{array}$ \\
\hline & wie 35 & & $\begin{array}{l}\text { b) Trinkgefäss in Gestalt einer Weltkugel von Her- } \\
\text { kules getragen. Als Bekrönung ein Adler. Im } \\
\text { Fusse eine Rollmechanik. } \\
\text { Besitzer: Grünes Gewölbe, Dresden. Katalog Erbstein I884, } \\
\text { S. I03 Nr. 294. }\end{array}$ \\
\hline
\end{tabular}

wie

Nr. 3 I

wie

Nr. 30

wie 32

wie 42
HB Hans Kolb, $\dagger 1640$.

\author{
Vergoldete Deckelkanne mit getriebenen Ornamenten. \\ Ausstellung Augsburg I886.
}

Marke eines Goldschmiedes aus der Familie

Grill, der um die erste Hälfte des I7. Jahrh. thätig war.

a) Vergoldeter Pokal auf hohem Fusse mit wenig ausgeschweifter Cuppa, daran landschaftliche Medaillons getrieben.

H. $36 \mathrm{~cm}$.

Besitzer: H. Boscowitz, Wien.

b) Ovale getriebene Platte. In der Mitte Landschaft, Rand mit Früchten und Ranken. Lg. $25,5 \mathrm{~cm}$. Besitzer: Karl Kah, Baden-Baden. Ausstellung Karlsruhe I88I, Katalog Nr. 1682.

c) Vergoldete Schale auf hohem Fusse mit getriebenen Grottesken.

H. $15 \mathrm{~cm}$.

Besitzer: Patriarchen-Schatzkammer, Moskau. Kat. der Sammlung S. 44 Nr. II4 und II5 und Taf. XIV Nr. 78.

d) Theilvergoldeter Becher mit grossen getriebenen Blumen.

H. Io $\mathrm{cm}$.

Besitzer (I882): N. M. Oppenheim, Frankfurt a. M. 


\begin{tabular}{|c|c|c|c|}
\hline $\begin{array}{l}\text { Lf. } \\
\text { Nir. }\end{array}$ & $\begin{array}{l}\text { Beschau- } \\
\text { zeichen }\end{array}$ & $\begin{array}{l}\text { Mreister- } \\
\text { zeichen }\end{array}$ & Meister - Gegenstand - Besitzer \\
\hline I 8 & $\begin{array}{c}\text { wie } \\
\text { Nr. } 29\end{array}$ & & $\begin{array}{l}\text { e u. f) Drei theilvergoldete konische Becher mit ge- } \\
\text { schweisstem Grunde. } \\
\text { Besitzer: Patriarchen-Schatzkammer, Moskau. }\end{array}$ \\
\hline & ivie $3 j$ & & $\begin{array}{l}\text { g) Vergoldete Deckelkanne, schlank mit engem Hals. } \\
\text { Besitzer: Grünes Gewölbe, Dresden. Katalog Erbstein I887, } \\
\text { S. го2 Nr. 29I. Graesse, Das Grüne Gewölbe I877, B1. 24. }\end{array}$ \\
\hline I86 & $\begin{array}{c}\text { wie } \\
\operatorname{Nr} .3 \text { I }\end{array}$ & & $\begin{array}{l}\text { a) Vergoldetes Ciborium, die Cuppa von Achat, die } \\
\text { Fassung mit Perlen und Steinen besetzt. Be- } \\
\text { zeichnet I620: } \\
\text { Besitzer: Hofkirchenfonds-Administration, Neuburg a. D. Aus- } \\
\text { stellung Augsburg I886, Katalog Nr. }{ }_{357} \text {. }\end{array}$ \\
\hline & wie 46 & & $\begin{array}{l}\text { b) Tergold. Kelch mit Emailmedaillons und aufgelegtem } \\
\text { Silberfiligran. Bezeichnet I69 I } \quad \text { H. } 29 \mathrm{~cm} \text {. } \\
\text { Besitzer: Johanneskirche, Erding. Ausstellung Augsburg i886, } \\
\text { Katalog Nr. I379. }\end{array}$ \\
\hline I 87 & $\begin{array}{l}\text { wie } \\
\text { Nr. } 32\end{array}$ & & $\begin{array}{l}\text { a) Vergoldetes kleines Deckelkännchen mit geschweiss- } \\
\text { tem Grunde. } \\
\text { Besitzer }\left(\mathrm{I}^{8} 8_{3}\right) \text { : A. S. Drey, München. } 9 \mathrm{~cm} .\end{array}$ \\
\hline & wie 45 & & $\begin{array}{l}\text { b) Niedere theilvergoldete Deckelkanne mit getriebenen } \\
\text { grossen Blumen. } \mathrm{H} \text {. I } 5 \mathrm{~cm} \text {. } \\
\text { Besitzer: National-Museum, Budapest. Ausstellung Buda- } \\
\text { pest I } 884 \text {. }\end{array}$ \\
\hline & wie 32 & & 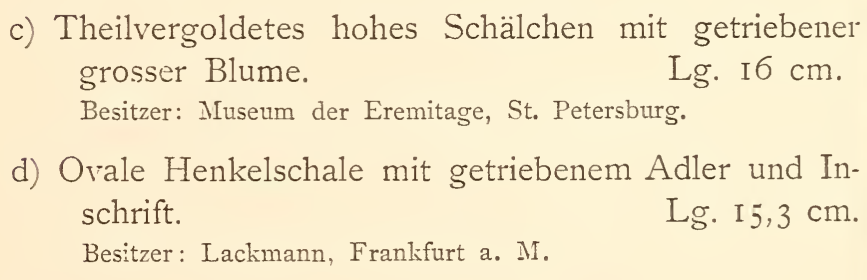 \\
\hline I 88 & $\begin{array}{l}\text { wrie } \\
\text { Nr. } 35 \\
\text { wie } 40\end{array}$ & AH. & 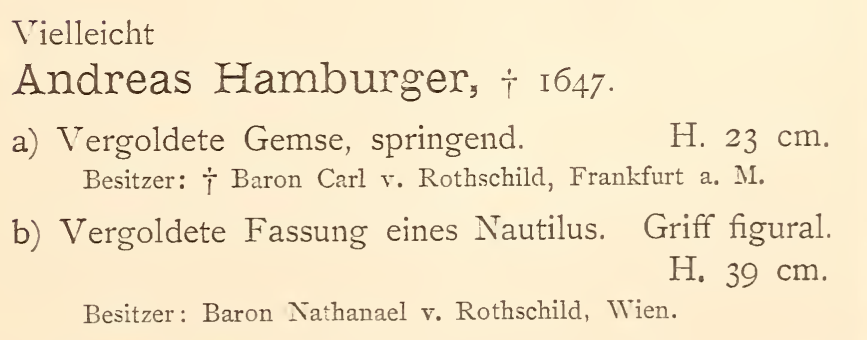 \\
\hline
\end{tabular}




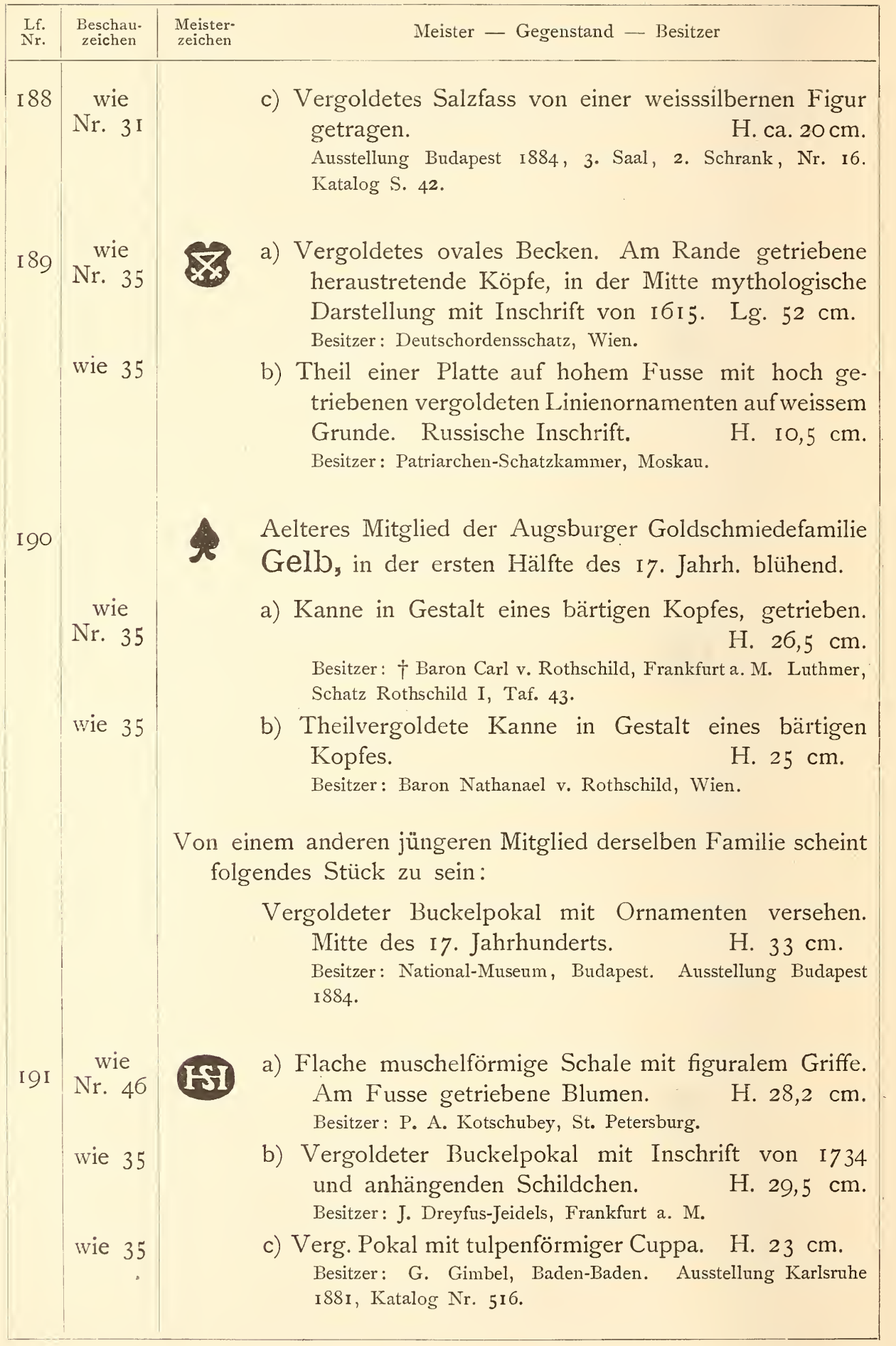




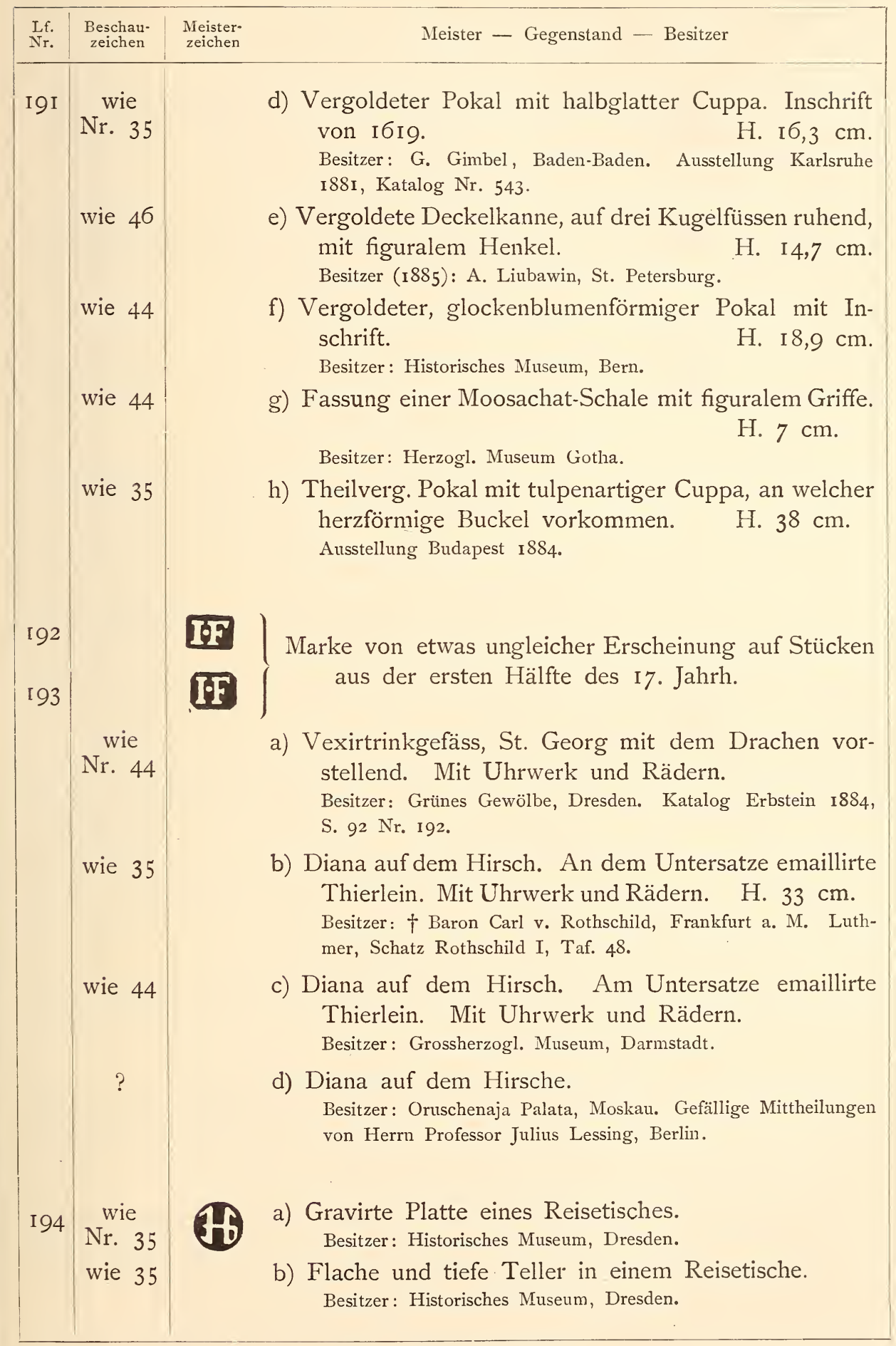




\begin{tabular}{|c|c|c|c|}
\hline $\begin{array}{l}\text { Lf. } \\
\text { Nr. }\end{array}$ & $\begin{array}{l}\text { Beschau- } \\
\text { zeichen }\end{array}$ & & Meister - Gegenstand - Besitzer \\
\hline I95 & $\begin{array}{l}\text { wie } \\
\text { Nr. } 35\end{array}$ & $\sqrt{4}$ & $\begin{array}{l}\text { Theilvergoldete Deckelkanne mit geschweisstem Grund. } \\
\begin{array}{ll}\text { Besitzer (1884): Ratzersdorfer, Wien. } & \text { 1 }, 5 \mathrm{~cm} .\end{array}\end{array}$ \\
\hline 196 & $\begin{array}{c}\text { wie } \\
\text { Nr. } 35\end{array}$ & 26 & $\begin{array}{l}\text { Vier Reliquiare in Gestalt von Laternen, vergoldet, } \\
\text { emaillirt und mit Wappen versehen. H. je } 50 \mathrm{~cm} \text {. } \\
\text { Besitzer: Reiche Kapelle, München. }\end{array}$ \\
\hline I97 & $\begin{array}{c}\text { wie } \\
\text { Nr. } 44\end{array}$ & 7 & $\begin{array}{l}\text { a) Vergoldeter konischer Becher mit Inschrift von } \\
\text { I634. } \\
\text { Besitzer (1883): L. Paar, Karlsruhe. }\end{array}$ \\
\hline & wie 35 & & $\begin{array}{l}\text { b) Deckelkanne mit Ranken und Fruchtgehängen. } \\
\text { Besitzer: E. Oppenheim, Frankfurt a. M. Ausstellung Frank- } \\
\text { furt a. M. 1875, Katalog Nr. I724, Abbild. Taf. 82. } \\
\text { c) Vergoldetes Kännchen mit Ornamenten, Früchten } \\
\text { und Thieren. } \\
\text { Besitzer: Englische Fräulein, Mainz. Gefällige Mittheilung des } \\
\text { Herrn O. Cornill, Frankfurt a. M. }\end{array}$ \\
\hline I98 & $\begin{array}{c}\text { wie } \\
\text { Nr. } 35\end{array}$ & DI & $\begin{array}{l}\text { Vielleicht } \\
\text { Lucas Neisser, } \dagger \text { I } \sigma_{5}(2) \text { ? } \\
\text { a) Vergoldete ovale Platte mit getriebenen Orna- } \\
\text { menten. } \\
\text { Besitzer (1883): A. S. Drey, München. Wohl identisch mit e). }\end{array}$ \\
\hline & wie 44 & & $\begin{array}{l}\text { b) Vergoldete Deckelkanne mit getriebenen Orna- } \\
\text { menten. } \\
\text { Ausstellung Budapest } 1884 .\end{array}$ \\
\hline & wie 46 & & $\begin{array}{l}\text { c) Vergoldete ovale Platte mit allegorischer Dar- } \\
\text { stellung. } \\
\text { Ausstellung Budapest I884. } 55 \mathrm{~cm} \text {. }\end{array}$ \\
\hline & wie 37 & & 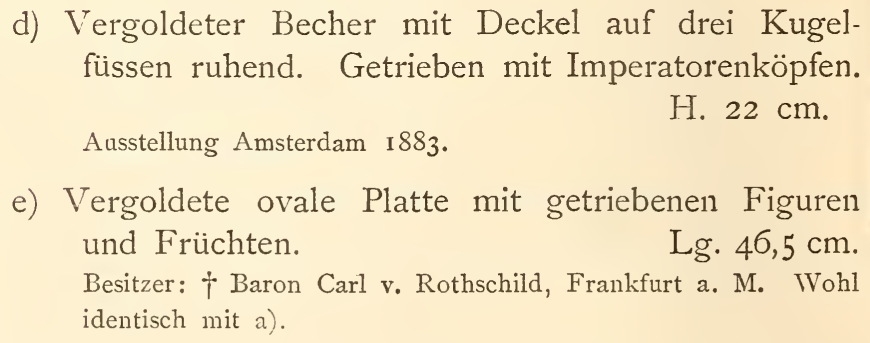 \\
\hline
\end{tabular}




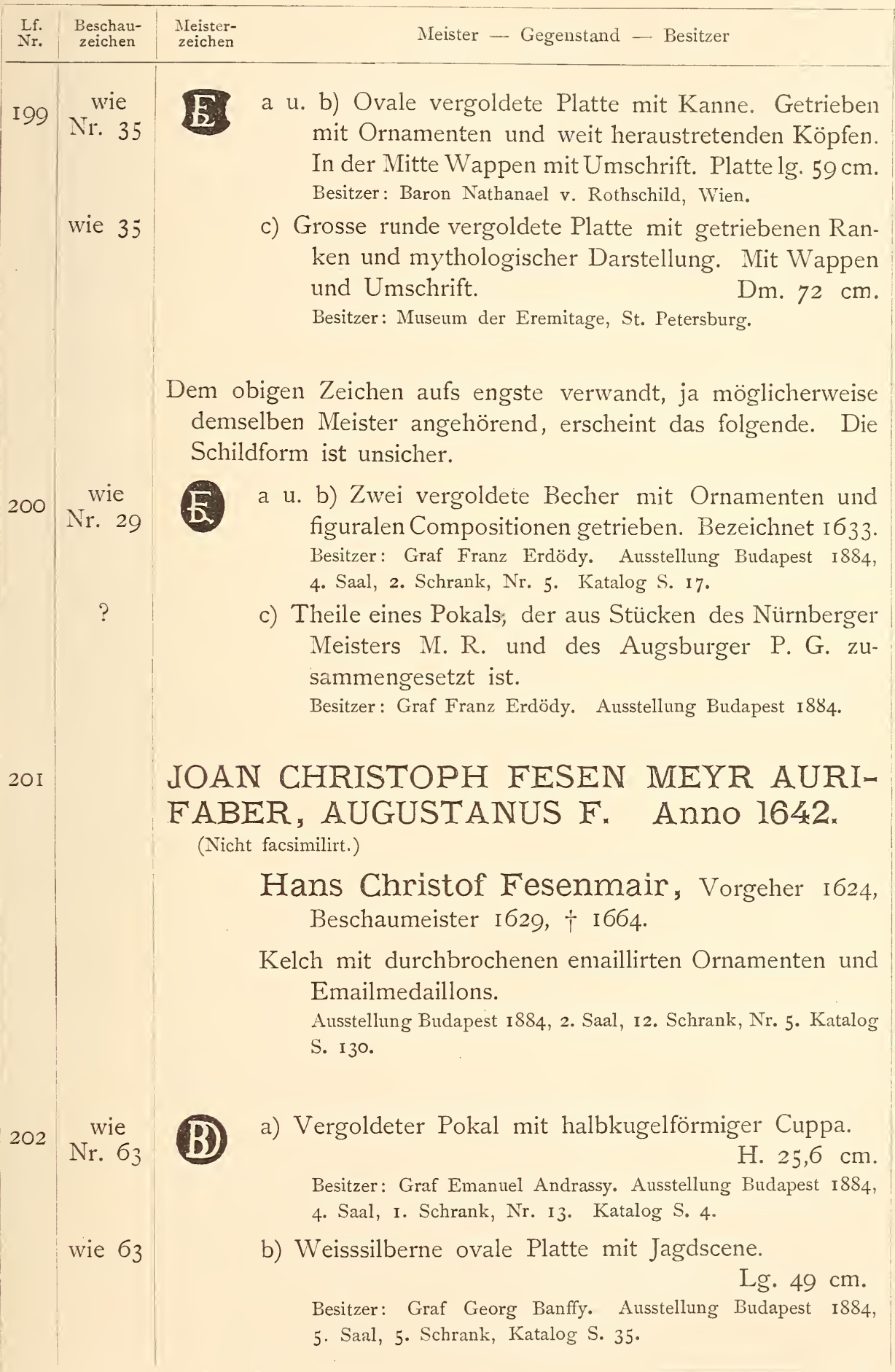




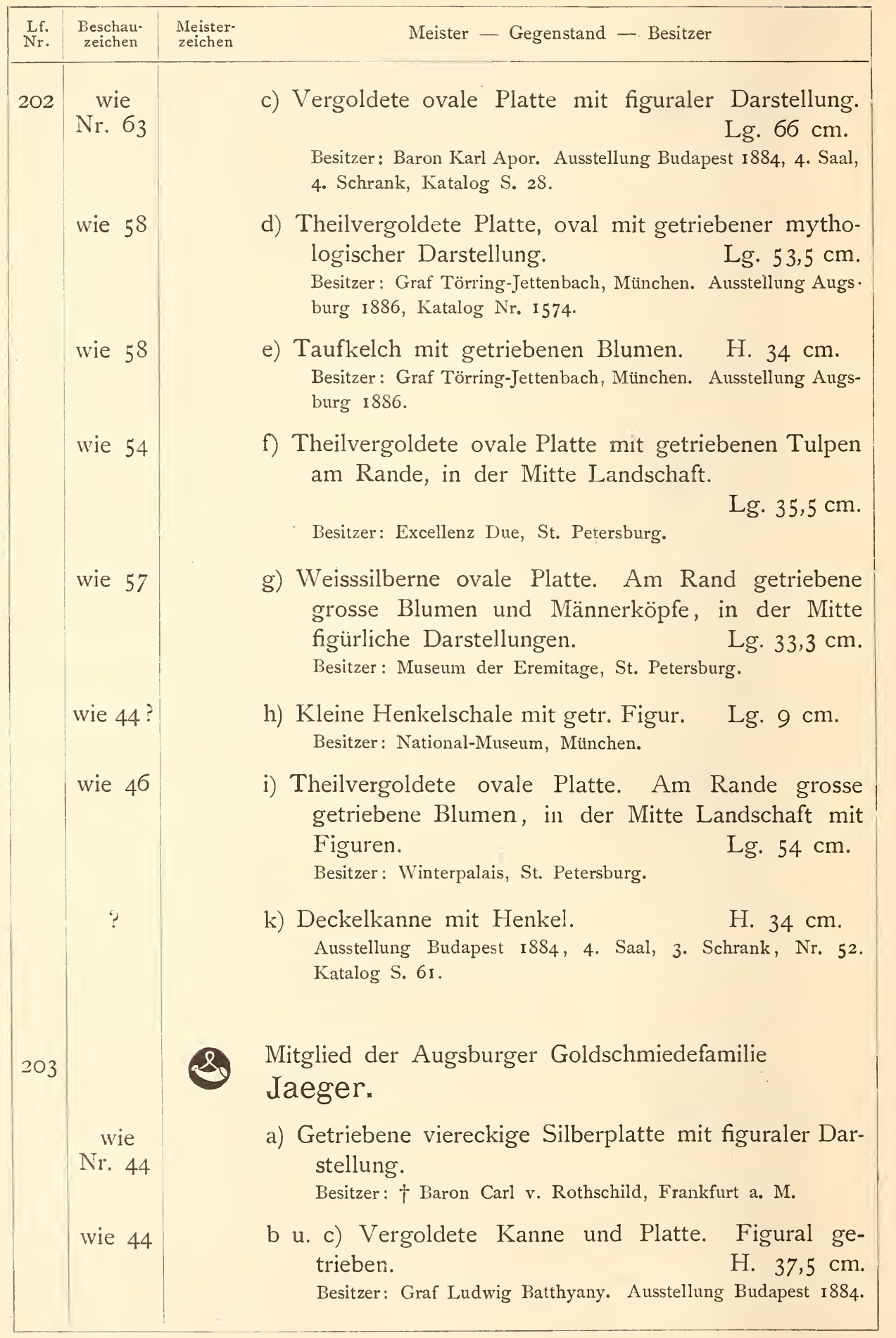




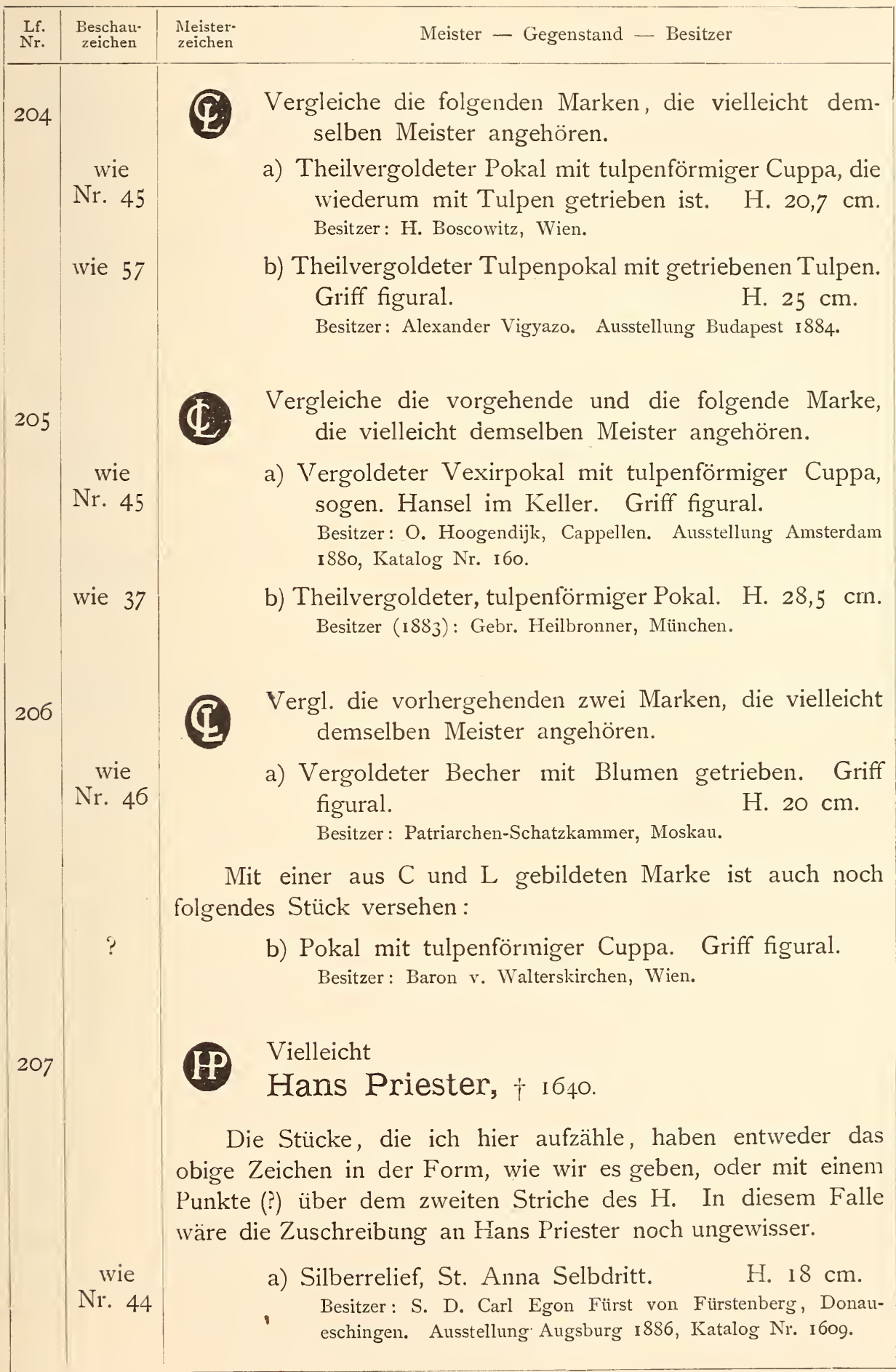




\begin{tabular}{|c|c|c|c|}
\hline $\begin{array}{l}\text { Lf. } \\
\text { Nr. }\end{array}$ & $\begin{array}{l}\text { Beschau- } \\
\text { zeichen }\end{array}$ & $\begin{array}{l}\text { eister- } \\
\text { ichen }\end{array}$ & Meister — Gegenstand - Besitzer \\
\hline 207 & $\begin{array}{l}\text { wie } \\
\text { Nr. } 37\end{array}$ & & $\begin{array}{l}\text { b) Erdkugel von einem Manne getragen, theilweise } \\
\text { vergoldet. Mit Wappen, Inschrift und } 1604 \text {. } \\
\text { Besitzer: Schloss Bebenhausen. Biermann, Ausstellung Gmünd, } \\
\text { Blatt } 3 \text { und } 4 \text {. }\end{array}$ \\
\hline 208 & $\begin{array}{l}\text { wie } \\
\text { Nr. } 37\end{array}$ & & $\begin{array}{l}\text { Vergoldeter Pokal mit Balustergriff. Am Corpus ein } \\
\text { Wappen. } \\
\text { H. } 23,5 \mathrm{~cm} . \\
\text { Besitzer: Patriarchen-Schatzkammer, Moskau. }\end{array}$ \\
\hline 209 & $\begin{array}{l}\text { wie } \\
\text { Nr. } 37\end{array}$ & & $\begin{array}{ll}\text { a) Getriebenes Schälchen. } & \text { Lg. I7 cm. } \\
\text { Besitzer: H. Boscowitz, Wien. } & \end{array}$ \\
\hline & wie 40 & & $\begin{array}{l}\text { b) Vergoldetes hohes Schälchen mit getriebenen } \\
\text { Buckeln. } \\
\text { Besitzer: Baron R. v. Walterskirchen, Wien. }\end{array}$ \\
\hline & ? & & $\begin{array}{l}\text { c) Vergoldete Schale mit leicht herausgetriebenen herz- } \\
\text { förmigen Buckeln. } \\
\text { Privatbesitz, Karlsruhe. }\end{array}$ \\
\hline 210 & $\begin{array}{l}\text { wie } \\
\text { Nr. } 44\end{array}$ & & $\begin{array}{l}\text { Fassung eines Elfenbeinpokals. } \\
\text { Besitzer: Museum der Eremitage, St. Petersburg. } 28 \mathrm{~cm} \text {. }\end{array}$ \\
\hline 2I I & $\begin{array}{l}\text { wie } \\
\text { Nr. } 44\end{array}$ & & $\begin{array}{l}\text { Vergoldeter Tulpenpokal. Griff mit drei Voluten. } \\
\text { H. } 44 \mathrm{~cm} . \\
\text { Besitzer: P. A. Kotschubey, St. Petersburg. }\end{array}$ \\
\hline $2 \mathrm{I} 2$ & $\begin{array}{l}\text { wie } \\
\text { Nr. } 5^{8}\end{array}$ & H & $\begin{array}{l}\text { a) Theilvergoldete getriebene Platte. Lg. } 49 \mathrm{~cm} \text {. } \\
\text { Besitzer: Graf Törring-Jettenbach, München. Ausstellung } \\
\text { Augsburg I886, Katalog Nr. 1573. }\end{array}$ \\
\hline & wie 46 & & $\begin{array}{l}\text { b) Vergold. Pokal mit figuralem Griff. H. } 38,5 \mathrm{~cm} \text {. } \\
\text { Besitzer: Alexander Vigyazo. Ausstellung Budapest } 1884 .\end{array}$ \\
\hline & wie 45 & & $\begin{array}{l}\text { c) Becher in Form einer flachen Muschel. H. } 30,2 \mathrm{~cm} \text {. } \\
\text { Besitzer: J. \& H. Jeidels, Frankfurt a. M. }\end{array}$ \\
\hline & ? & & $\begin{array}{l}\text { d) Ananasbecher. Griff Baumstamm mit Holzhauer. } \\
\text { H. } 30 \mathrm{~cm} \text {. } \\
\text { Besitzer: Prof. Seyffer, Stuttgart. Auctionskatalog } 1887 \\
\text { Nr. 605. }\end{array}$ \\
\hline & ? & & $\begin{array}{l}\text { e) Verg. Buckelpokal mit Balustergriff. H. } 64,5 \mathrm{~cm} \text {. } \\
\text { Winterpalais, St. Petersburg. }\end{array}$ \\
\hline & ? & & $\begin{array}{l}\text { f) Fuss an einem Buckelpokal von Nürnberger Arbeit. } \\
\text { Besitzer: Patriarchen-Schatzkammer, Moskau. }\end{array}$ \\
\hline
\end{tabular}




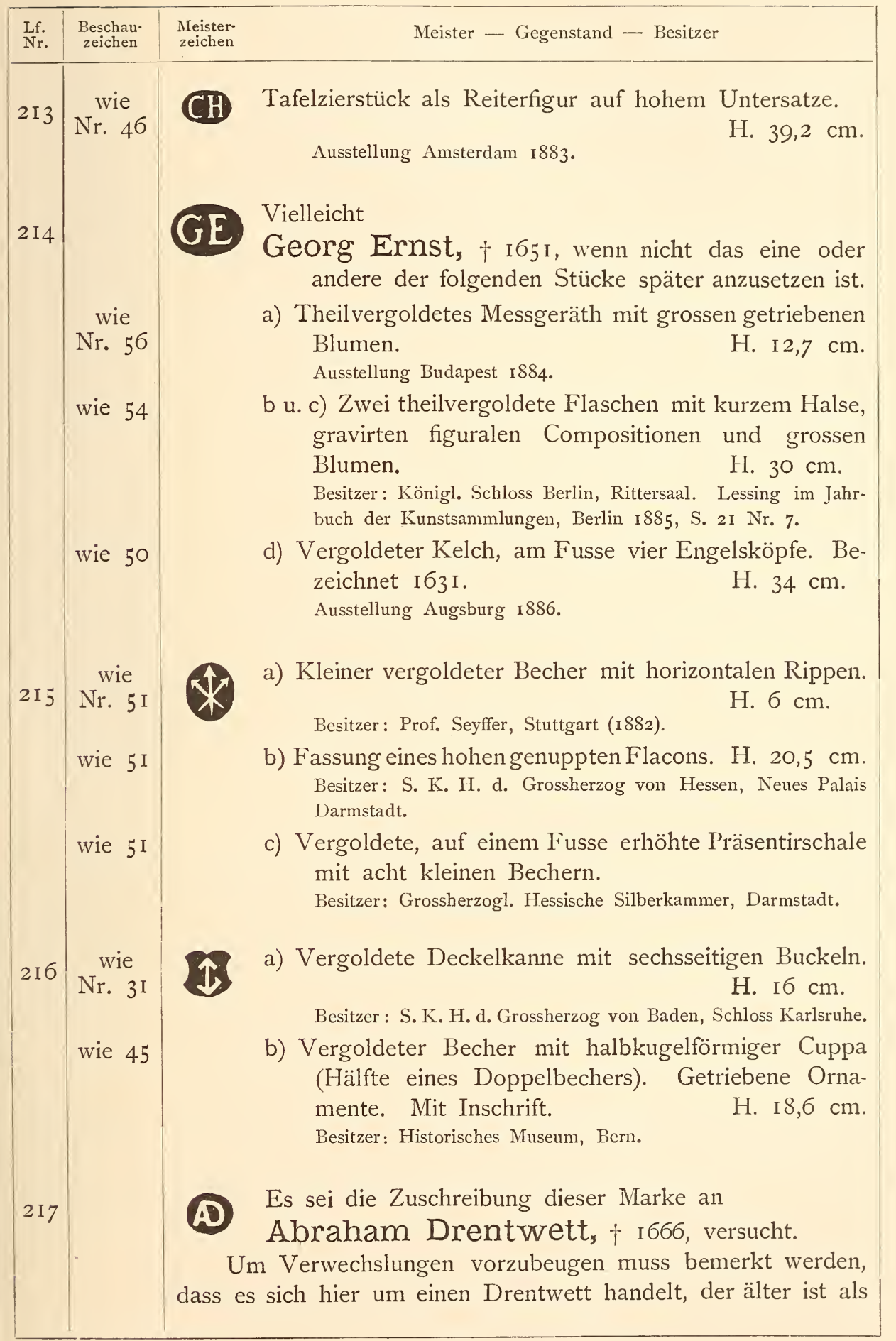




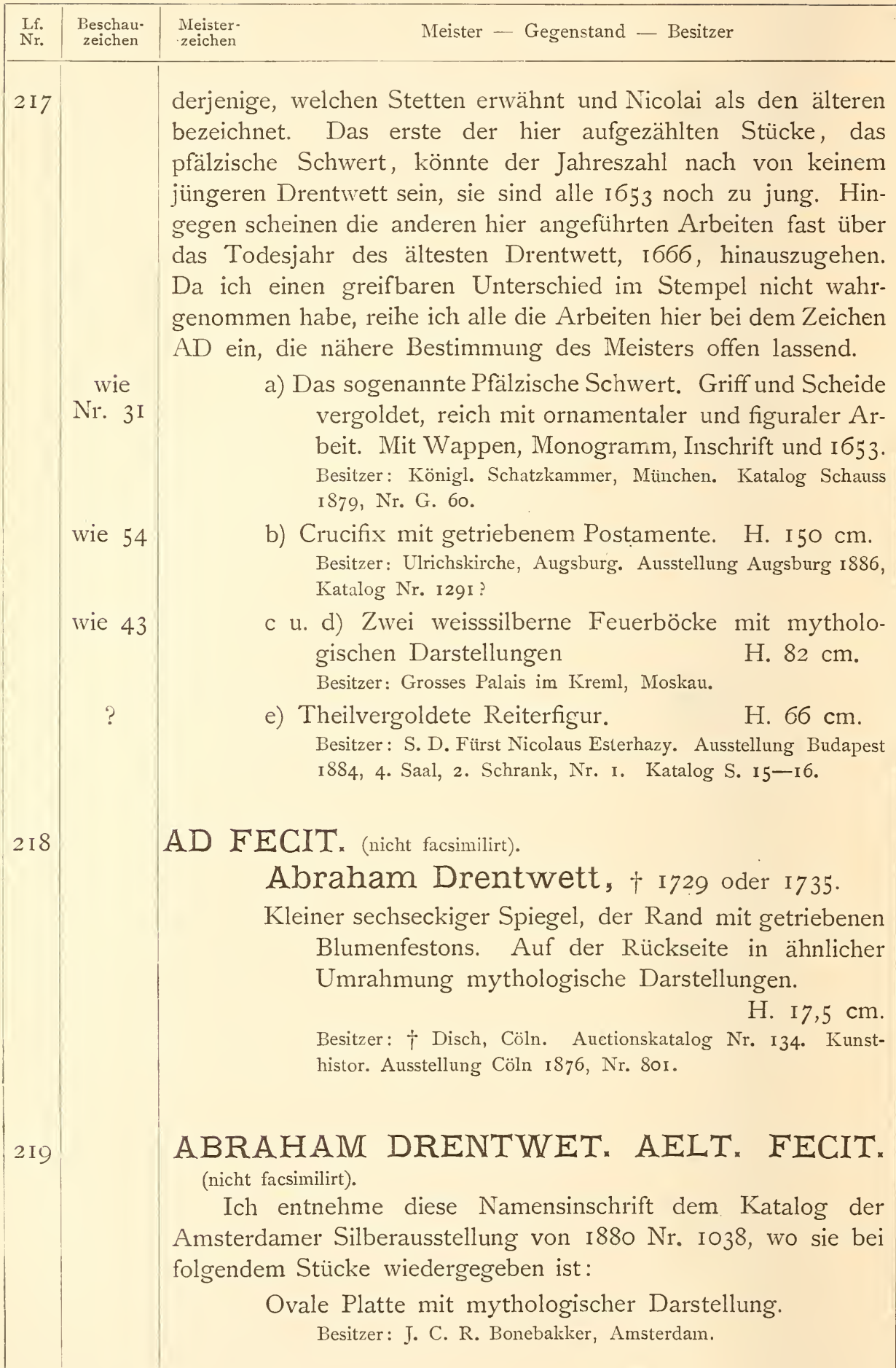




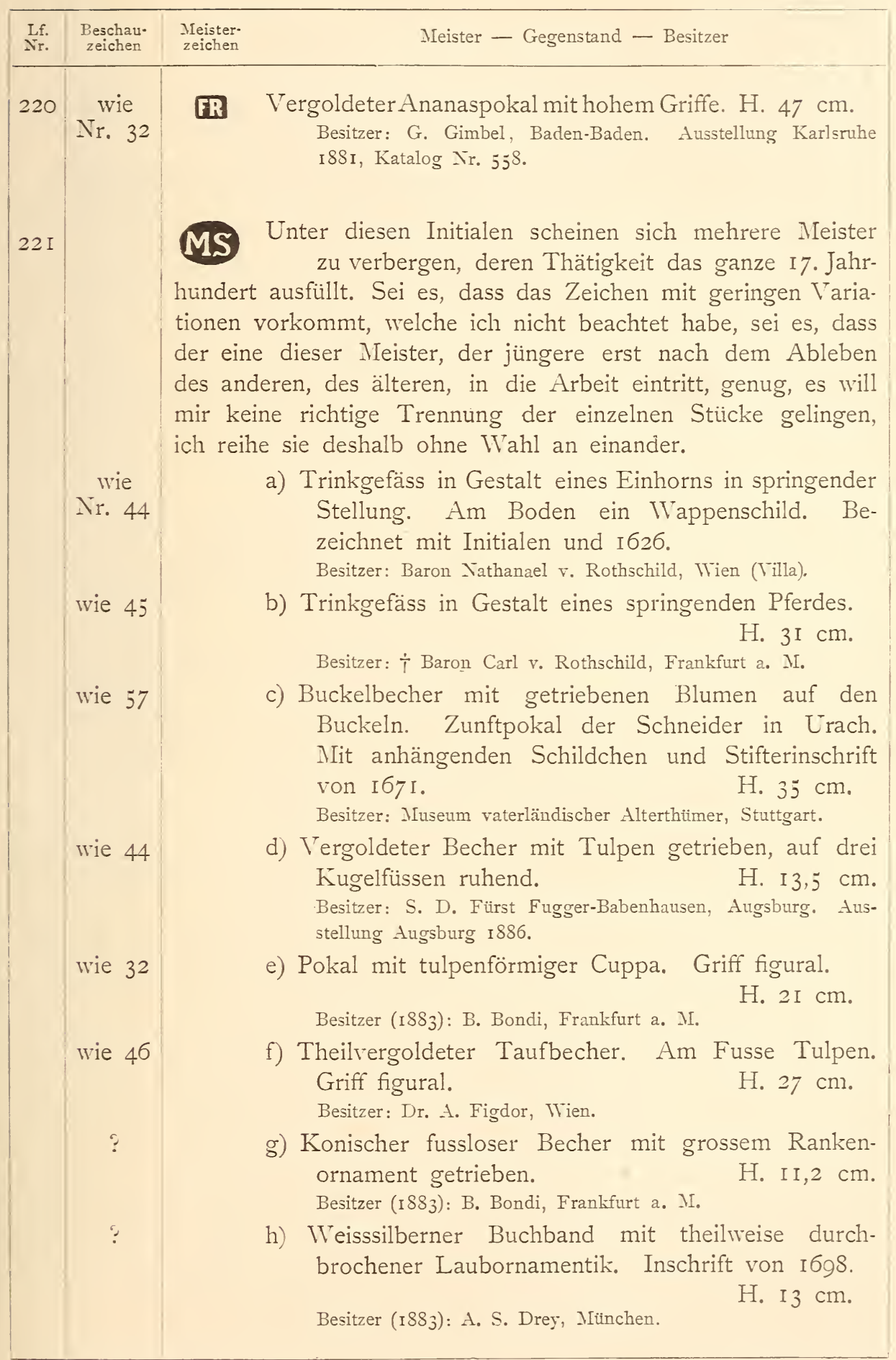




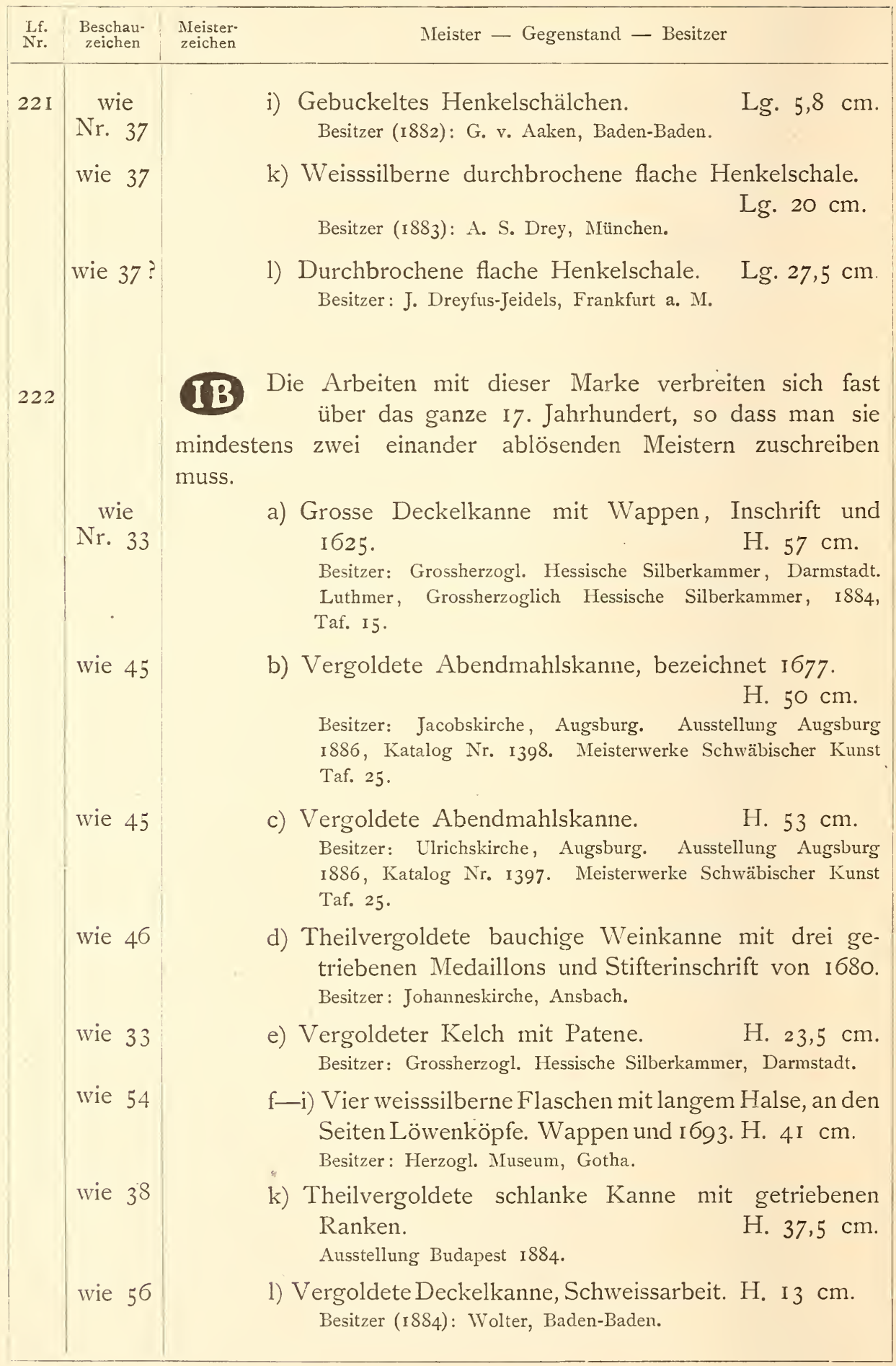




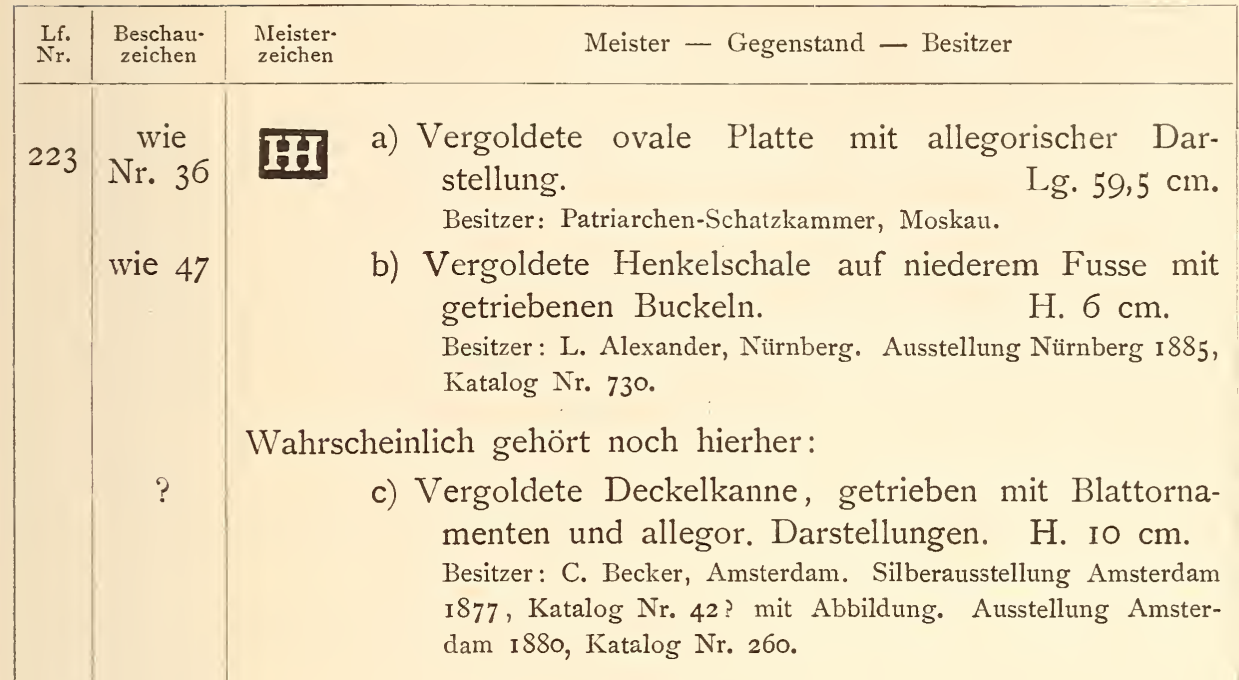

Bi Vielleicht

Heinr. Rott, † 1685.

wie

Nr. 38

wie 58

wie 36

wie 36

wie 37

wie 57

225 Nr. 42 a) Pokal mit Balustergriff.

Ausstellung Budapest I884.

H. $28 \mathrm{~cm}$.

b) Vergoldeter Ananaspokal. Griff ein Baumstamm, Bekrönung weisssilberner Doppeladler. H. $33 \mathrm{~cm}$. Besitzer: Kaiserl. Silberkammer, St. Petersburg.

c) Vergoldeter Buckelpokal mit getriebenen Zügen. Figuraler Griff in Weisssilber.

H. $27,6 \mathrm{~cm}$.

Besitzer: Patriarchen-Schatzkammer, Moskau.

d) Vergoldeter Buckelpokal mit weisssilbernem figuralem Griffe.

H. $20,5 \mathrm{~cm}$.

Besitzer: Patriarchen-Schatzkammer, Moskau.

e) Deckel auf einem Nürnberger Buckelpokale von I65I.

Besitzer: Patriarchen-Schatzkammer, Moskau.

f) Vergoldeter Deckel auf einem Nürnberger Buckelpokale.

Besitzer: Patriarchen-Schatzkammer, Moskau.

a) Weisssilberne ovale Platte mit biblischer Darstellung getrieben.

Lg. $95 \mathrm{~cm}$.

Besitzer: Dom, Augsburg. Ausstellung München I876, Katalog Nr. 2091. Ausstellung Augsburg 1886, Katalog Nr. 1613. 


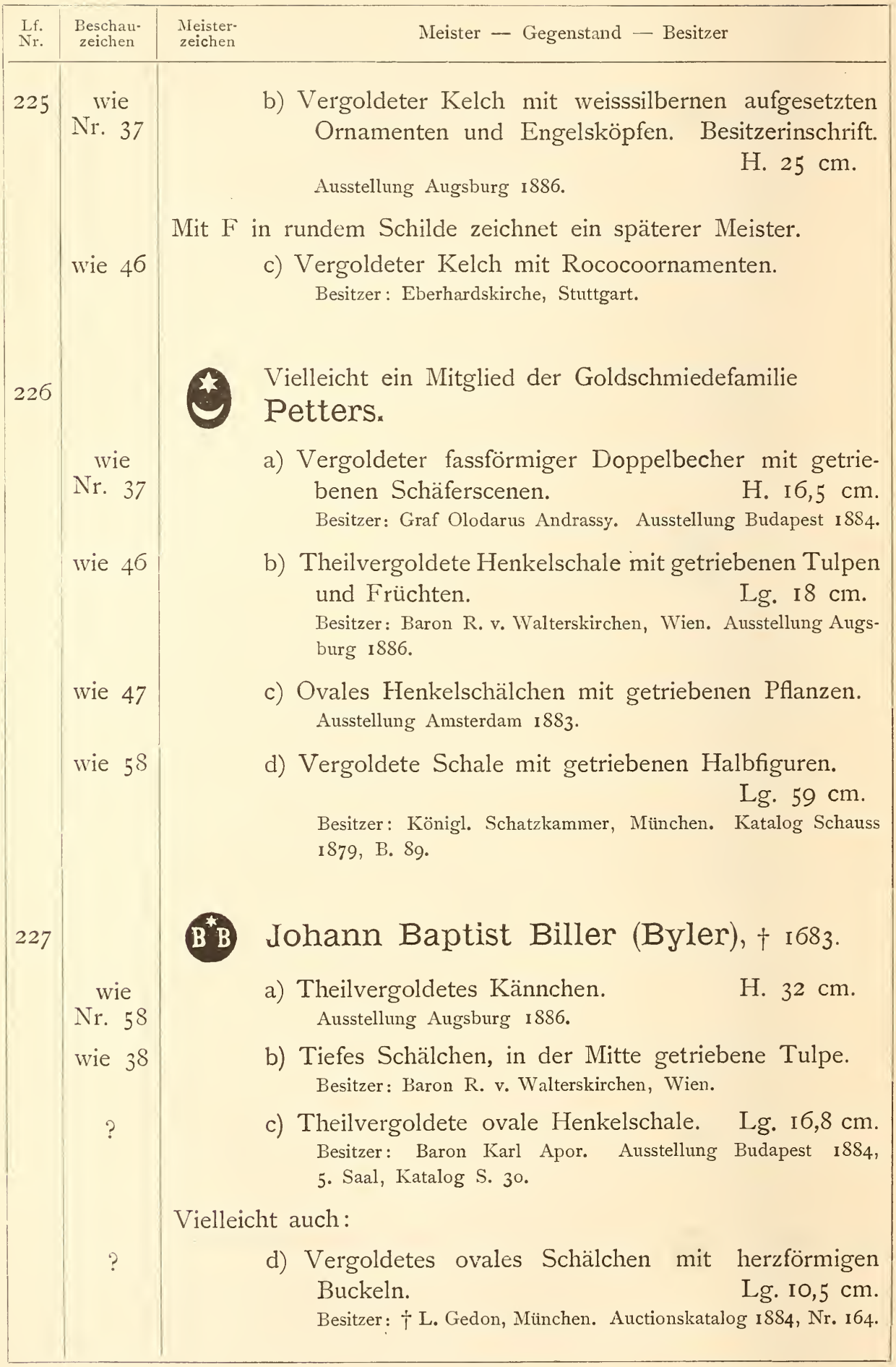




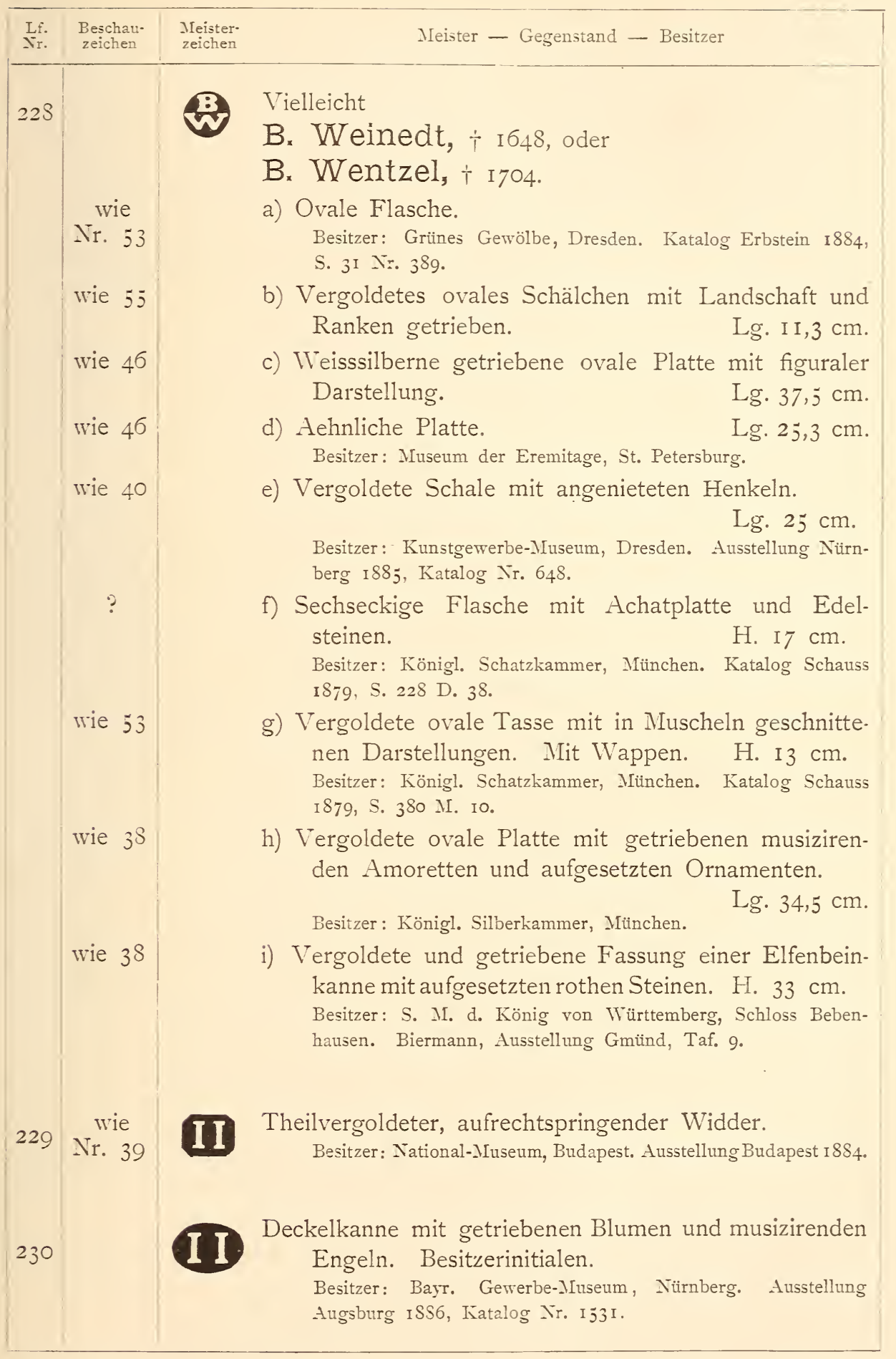




\begin{tabular}{|c|c|c|c|}
\hline $\begin{array}{l}\text { Lf. } \\
\text { Nr. }\end{array}$ & $\begin{array}{l}\text { Beschau- } \\
\text { zeichen }\end{array}$ & $\begin{array}{l}\text { Meister- } \\
\text { zeichen }\end{array}$ & Meister - Gegenstand - Besitzer \\
\hline $23 \mathrm{I}$ & & 28 & $\begin{array}{l}\text { Vielleicht } \\
\text { Jacob Jäger }{ }_{5} \uparrow 1673 .\end{array}$ \\
\hline & $\begin{array}{l}\text { wie } \\
\text { Nr. } 39\end{array}$ & & $\begin{array}{l}\text { a) Vergoldeter Buckelpokal mit figuralem Griffe. } \\
\text { Besitzer: } \uparrow \text { Baron Carl v. Rothschild, Frankfurt a. M. }\end{array}$ \\
\hline & wie 46 & & $\begin{array}{l}\text { b) Weisssilberne ovale Platte mit Hirschjagd getrieben, } \\
\text { am Rande Blattornamente. } \\
\text { Besitzer: Königl. Silberkammer, München. }\end{array}$ \\
\hline & wie 39 & & $\begin{array}{l}\text { c) Becher auf Kugelfüssen mit getriebener Jagddar- } \\
\text { stellung, Inschrift, Wappen und } 1659 . \text { H. } 27,5 \mathrm{~cm} \text {. } \\
\text { Besitzer: S. K. H. d. Grossherzog von Hessen, Neues Palais, } \\
\text { Darmstadt. Schïrmann \& Luthmer, Grossherzogl. Hessische } \\
\text { Silberkammer, Darmstadt I } 884 \text {, Taf. } 23 \text {. }\end{array}$ \\
\hline & wie $\sigma_{3}$ & & 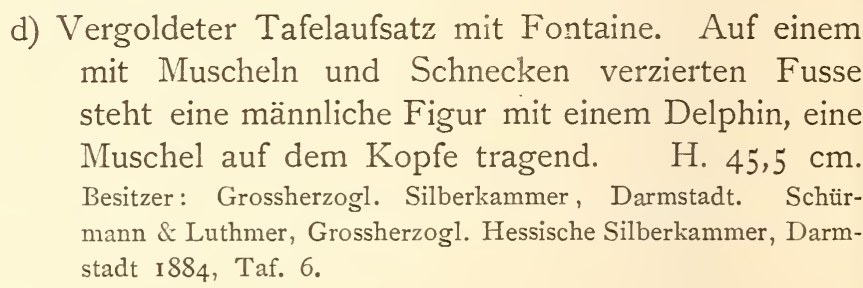 \\
\hline
\end{tabular}

(AT) Wahrscheinlich

Andreas Wickhert, $\uparrow$ 166r oder Andreas Wichhert, $†$ i674.

Möglicherweise aber auch

\section{Abraham Winterstein, $\dagger$ г66r.}

wie

Nr. 58

wie 58

wie 40 a) Fassung einer Elfenbeinkanne.

H. $30 \mathrm{~cm}$.

Besitzer: Königl. Museum, Cassel. Katalog Lenz I88I, Nr. 283. Photographirt.

b) Vergoldete Fassung einer Elfenbeinkanne. Auf dem Deckel Kinderfries.

H. $33 \mathrm{~cm}$.

Besitzer: S. K. H. d. Grossherzog von Baden, Schloss Karlsruhe. Ausstellung Karlsruhe r88r, Katalog Nr. 607. Abgeb. in Aeltere kunstgewerbliche Arbeiten auf der Ausstellung Karlsruhe.

c) Vergoldete Fassung einer Elfenbeinkanne mit gravirten Weinranken.

H. $33 \mathrm{~cm}$. 


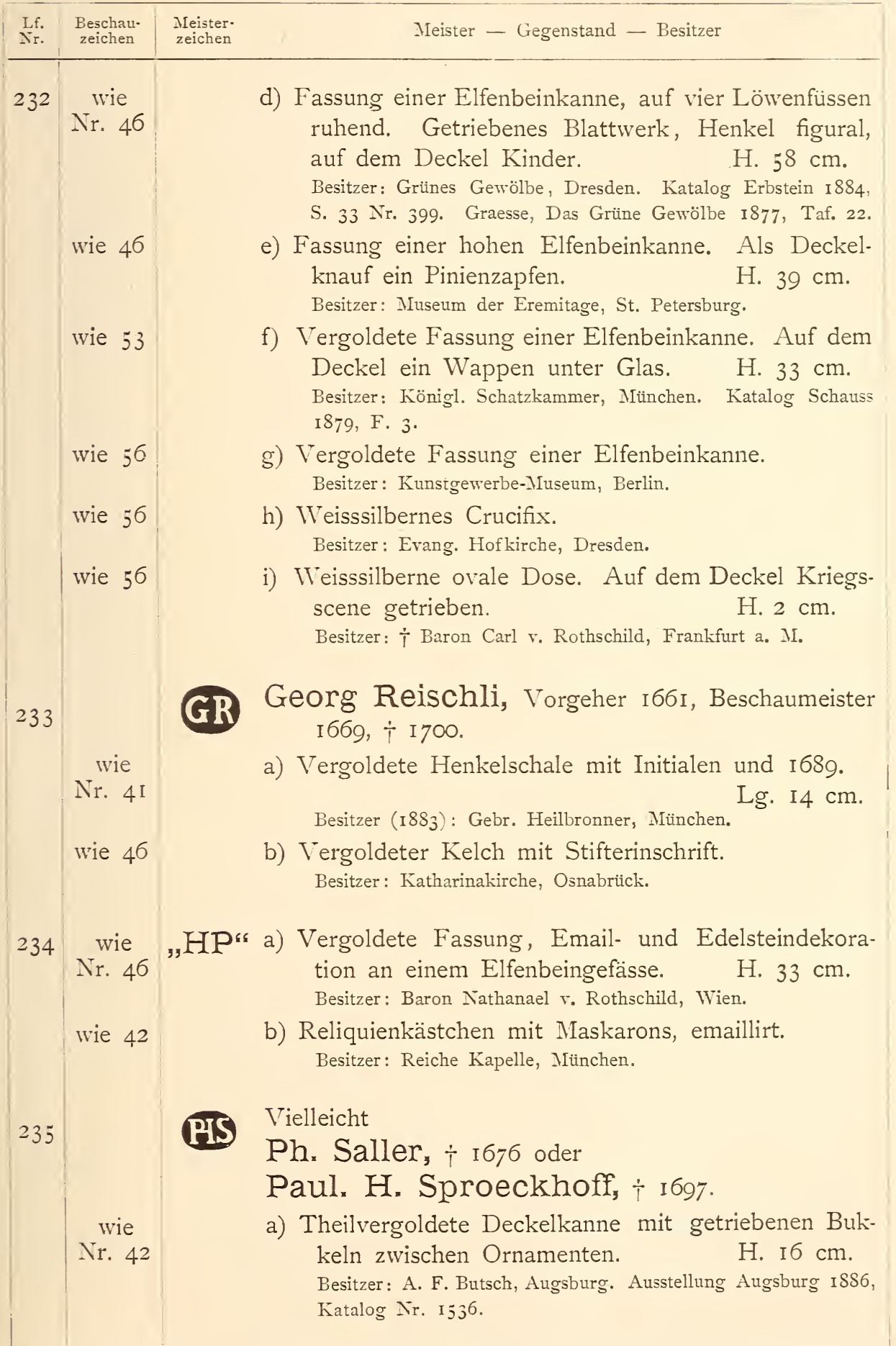




\begin{tabular}{|c|c|c|c|}
\hline $\begin{array}{l}\text { Lff. } \\
\text { Nr. }\end{array}$ & $\begin{array}{l}\text { Beschau- } \\
\text { zeichen }\end{array}$ & $\begin{array}{l}\text { ster- } \\
\text { hen }\end{array}$ & Meister - Gegenstand - Besitzer \\
\hline 235 & ? & & $\begin{array}{l}\text { b) Becher in Gestalt eines Fasses. } \\
\text { Besitzer: Prof. Seyffer, Stuttgart (I882). }\end{array}$ \\
\hline 236 & $\begin{array}{l}\text { wie } \\
\text { Nr. } 44 \\
\text { wie } 45\end{array}$ & & 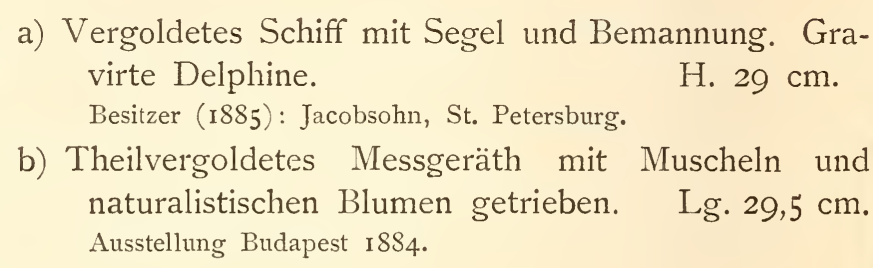 \\
\hline 237 & $\begin{array}{c}\text { wie } \\
\text { Nr. } 45\end{array}$ & IF & 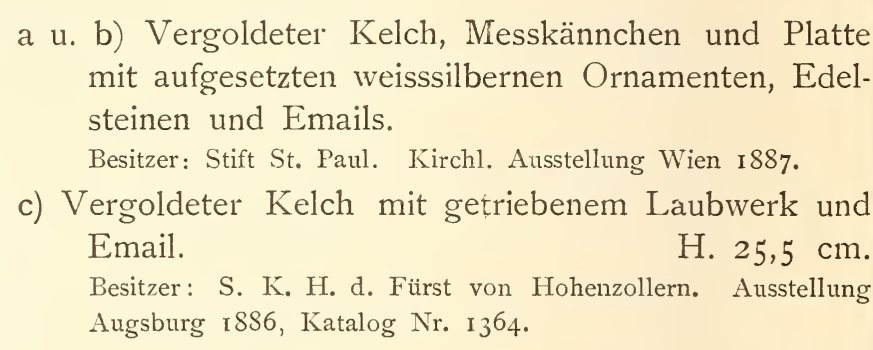 \\
\hline 238 & $\begin{array}{l}\text { wie } \\
\text { Nr. } 47\end{array}$ & (1) & $\begin{array}{l}\text { a) Vergoldeter Kelch mit getriebenen Früchten und } \\
\text { Medaillons. } \\
\begin{array}{l}\text { Besitzer: Wengenkirche, Ulm. } \\
\text { H. } 27 \mathrm{~cm} .\end{array}\end{array}$ \\
\hline & wie 42 & & $\begin{array}{l}\text { b) Weisssilberne Hängelampe mit aufgesetzten grossen } \\
\text { getriebenen Blumen und Ranken. } \quad \text { H. I } 20 \mathrm{~cm} \text {. } \\
\text { Besitzer: Kath. Pfarrkirche, Baden-Baden. }\end{array}$ \\
\hline & wie 49 & & $\begin{array}{l}\text { c) Vergoldetes Messgeräth, am Rande der Platte vier } \\
\text { Medaillons figural getrieben. } \\
\text { Besitzer: Wengenkirche, Ulm. }\end{array}$ \\
\hline & wie 59 & & 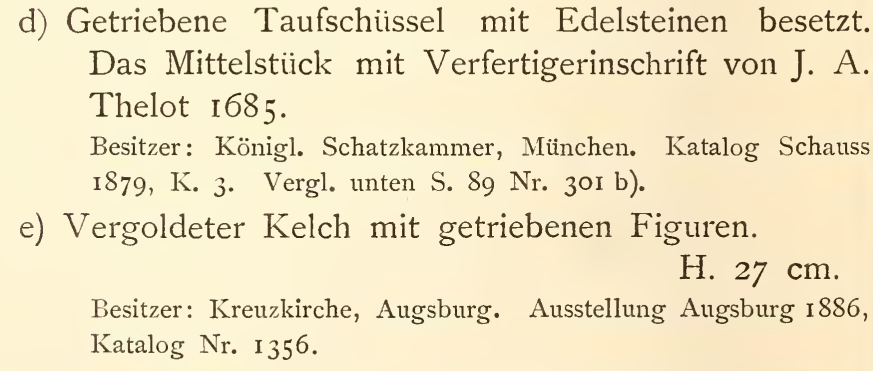 \\
\hline & wie 60 & & $\begin{array}{l}\text { f) Theilvergoldete evale Platte mit getriebenen Vögeln, } \\
\text { grossen Blumen und Medaillons. Lg. } 63 \mathrm{~cm} \text {. } \\
\text { Besitzer: Winterpalais, St. Petersburg. }\end{array}$ \\
\hline
\end{tabular}




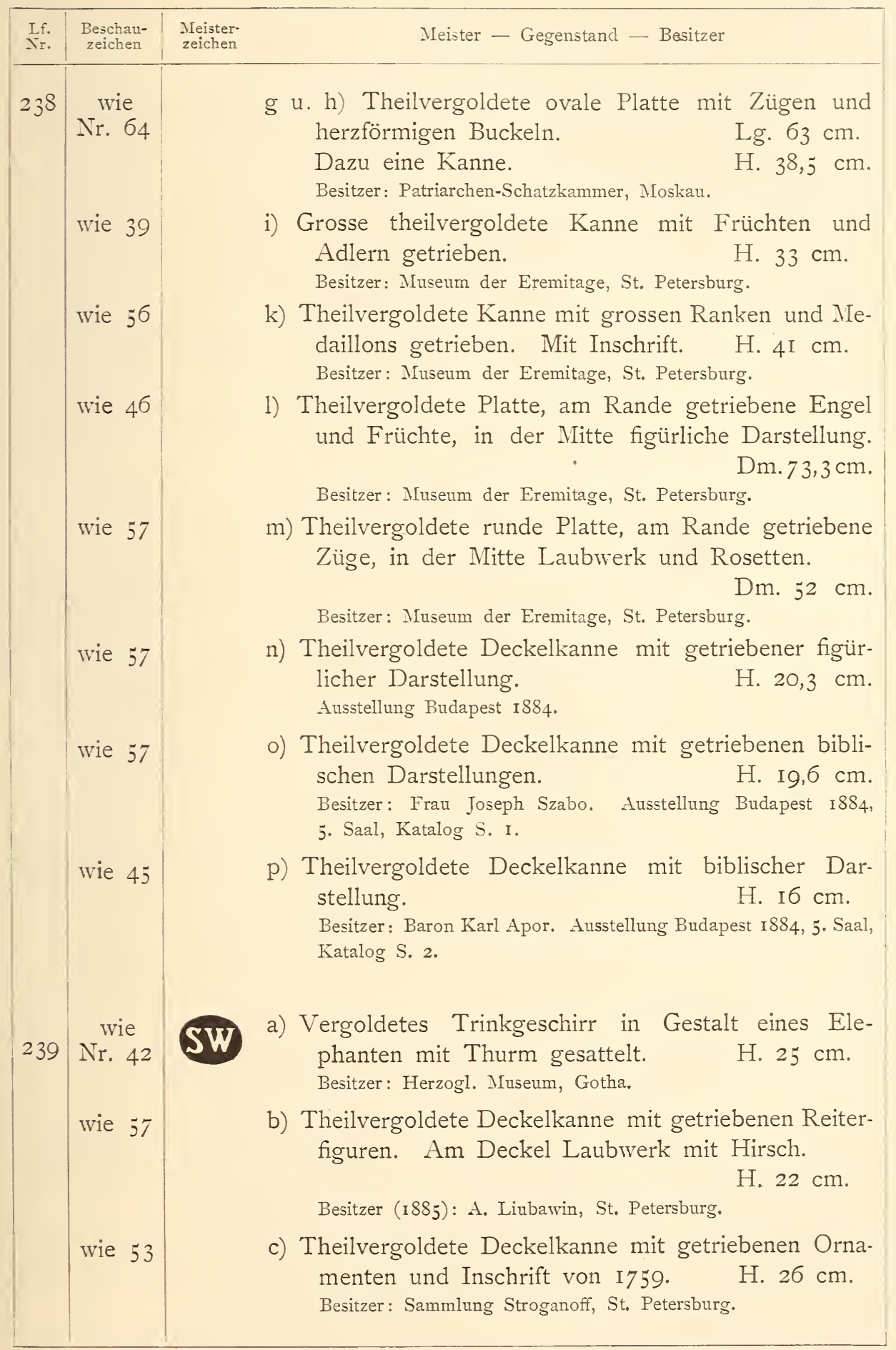




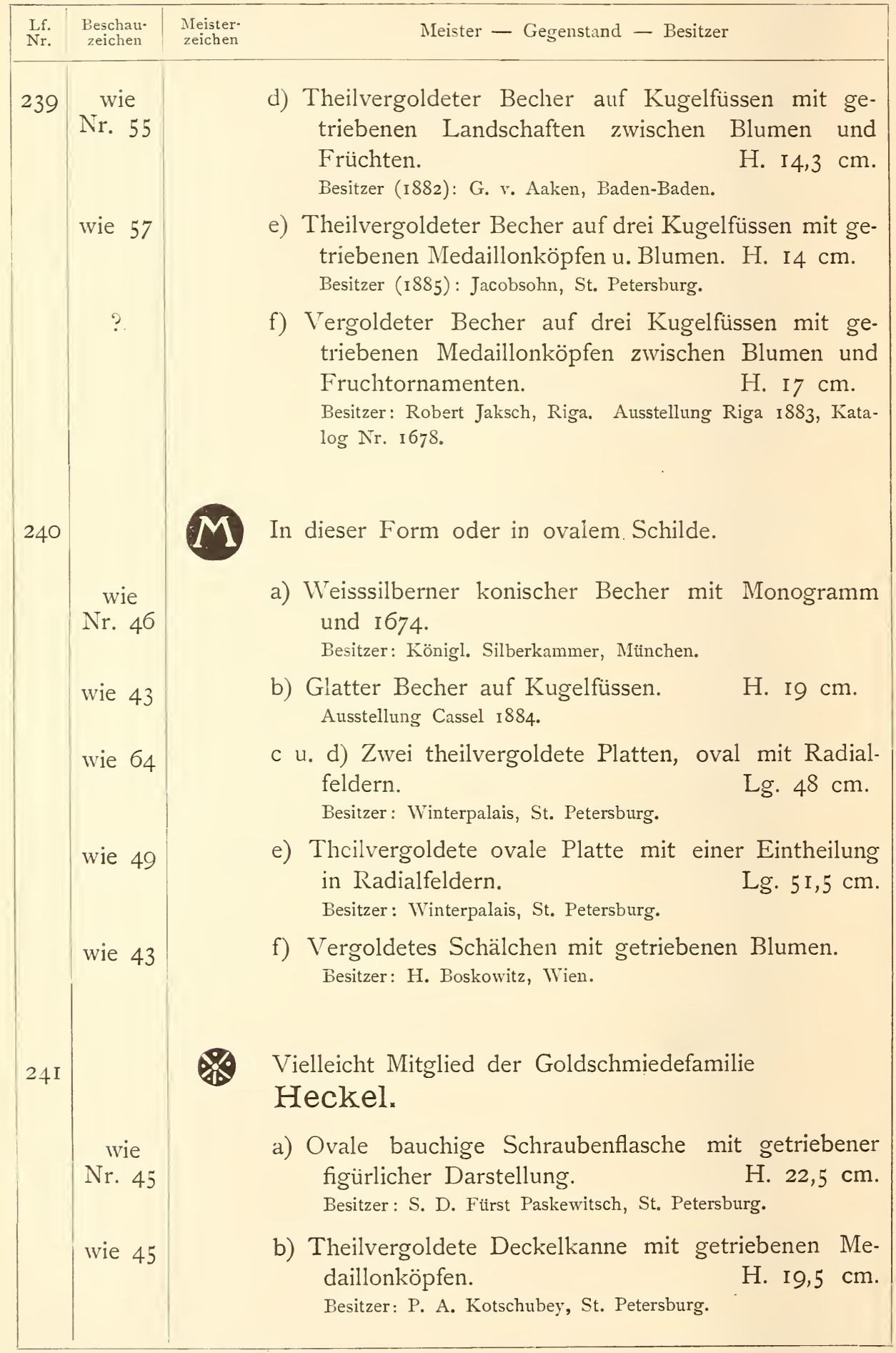




\begin{tabular}{|c|c|c|c|}
\hline $\begin{array}{l}\text { If. } \\
\text { Nr. }\end{array}$ & $\begin{array}{l}\text { Beschau- } \\
\text { zeichen }\end{array}$ & $\begin{array}{l}\text { Meister- } \\
\text { zeichen }\end{array}$ & Meister - Gegenstand - Besitzer \\
\hline $24 \mathrm{I}$ & $\begin{array}{c}\text { wie } \\
\text { Nr. } 58 \\
\text { wie 5T }\end{array}$ & & 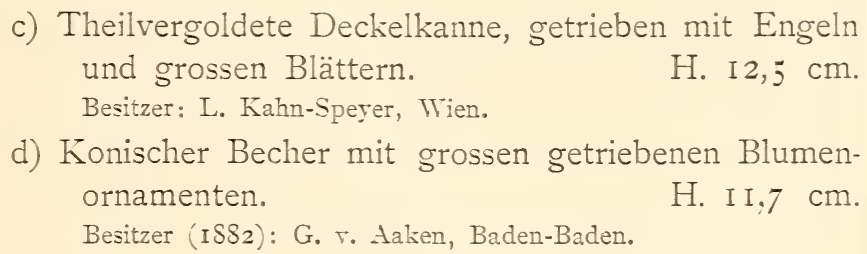 \\
\hline 242 & $\begin{array}{c}\text { wie } \\
\text { Nr. js }\end{array}$ & & $\begin{array}{l}\text { a-c) Theilvergoldetes Reiseservice, bestehend aus einem } \\
\text { Becher mit gravirten Medaillons, Bouillon und Be- } \\
\text { steck. Ein dazu gehöriges Salzfass ist von an- } \\
\text { derem Meister. } \\
\text { Besitzer: † Baron Carl v. Rothschild, Frankfurt a. M. } \\
\text { d) Theilverg. Becher auf Kugelfüssen, am Corpus getrie- } \\
\text { bene Putten zwischen grossen Blumen. H. } 22 \mathrm{~cm} \text {. } \\
\text { Besitzer: Excellenz Due, St. Petersburg. } \\
\text { e) Theilvergoldete ovale Platte mit figuraler Dar- } \\
\text { stellung. } \\
\text { Besitzer: Winterpalais, St. Petersburg. } \\
\text { f) Theilvergoldete Abendmahlskanne mit grossen Blät- } \\
\text { tern decorirt. } \\
\text { Besitzer: Kreuzlirche, Augsburg. Ausstellung Augsburg ISs6, } \\
\text { Katalog Mr. I39g. }\end{array}$ \\
\hline
\end{tabular}

243 Nr. 45 Sm

a) Theilvergoldete Kassette, länglich achtseitig, mit getriebenen figürlichen Darstellungen. $H .22,5 \mathrm{~cm}$. Besitzer: $\uparrow$ Baron Carl v. Rothschild, Frankfurt a. M.

wie 46

b) Kassette mit grossen getriebenen Blumen.

Besitzer: Grünes Gewölbe, Dresden.

wie 43

c) Vergoldete Kassette mit weisssilbernen aufgesetzten Ornamenten und Diamanten. Inschrift. H. I2 cm. Besitzer: Mruseum der Eremitage, St. Petersburg.

wie 46

d) Vergoldete Flasche mit Kette und Schraube.

Besitzer: Königl. Schatzkammer, München. Katalog Schauss IS $79, \mathrm{G} .50$.

wie 60

e) Theilverg. Deckelkanne. Am Corpus getriebene Figuren und Tulpen mit eingelassenen Münzen von I626. Besitzer ( $\mathrm{ISS}_{3}$ ): J. J. Boasberg, Amsterdam.

wie $j 4$

f) Theilvergoldete Deckelkanne mit figürlichen Darstellungen.

H. $22 \mathrm{~cm}$.

Besitzer: Excellenz Due, St. Petersburg. 


\begin{tabular}{|c|c|c|c|}
\hline $\begin{array}{l}\text { Lf. } \\
\text { Nr. }\end{array}$ & $\begin{array}{l}\text { Beschau- } \\
\text { zeichen }\end{array}$ & $\begin{array}{l}\text { Meister- } \\
\text { zeichen }\end{array}$ & Meister - Gegenstand - Besitzer \\
\hline 243 & $\begin{array}{c}\text { wie } \\
\text { Nr. } 60\end{array}$ & & $\begin{array}{l}\text { g) Theilvergoldete Deckelkanne mit getriebenen Putten } \\
\text { und Blumen. } \\
\text { Besitzer }\left(\mathrm{IS8} 8_{3}\right) \text { : Gebr. Bourgois, Cöln. }\end{array}$ \\
\hline 244 & $\begin{array}{c}\text { wie } \\
\text { Nr. } 48\end{array}$ & & $\begin{array}{l}\text { a) Hostienbüchse in Gestalt der Bundeslade. } \\
\text { Besitzer: Jacobskirche, Augsburg. Ausstellung Augsburg I886, } \\
\text { Katalog Nr. I404. Meisterwerke Schwäbischer Kunst Taf. 22. }\end{array}$ \\
\hline & wie 56 & & $\begin{array}{l}\text { b) Eiförmiger Ananaspokal. } \\
\text { Besitzer: Consul Becker, Frankfurt a. M. Ausstellung Cassel } \\
\text { I884, Katalog Nr. 53I. }\end{array}$ \\
\hline & wie 67 & & $\begin{array}{l}\text { c) Vergoldete runde Platte mit mehrfachen Reihen } \\
\text { von Zügen. } \\
\text { Dm. } 63,5 \mathrm{~cm} \text {. } \\
\begin{array}{l}\text { d) Dazu eine Kanne mit Mascaron als Ausguss und } \\
\text { Henkel in Form einer Klaue. } \\
\text { Besitzer: Herzogl. Museum, Gotha. }\end{array}\end{array}$ \\
\hline
\end{tabular}

a) Vergoldete Hostienbüchse in Gestalt der Bundeslade.

H. $2 \mathrm{I}, 5 \mathrm{~cm}$. Besitzer: Kreuzkirche, Augsburg. Ausstellung Augsburg 1886, Katalog Nr. 1405.

wie 56

b) Vergoldeter Schwenkkessel.

Besitzer: Grünes Gewölbe, Dresden. Katalog Erbstein I884, S. $75, \mathrm{Nr} .62$.

wie 38

c u. d) Zwei vergoldete Trinkschalen mit je einer weisssilbernen Figur als Griff.

H. $19,5 \mathrm{~cm}$. Besitzer: Königl. Museum, Cassel. Katalog Lenz I88I, Nr. $54 / 55$.

wie $4 \mathrm{I}$

e) Vergoldete Schale, getrieben auf hohem figuralem Fusse.

H. $20,5 \mathrm{~cm}$.

Besitzer: S. Fürth, Mainz.

f) Theilvergoldete Henkelschale mit getriebenen Blumen. Lg. $20,5 \mathrm{~cm}$. Besitzer: Museum der Eremitage, St. Petersburg.

wie 54

g) Theilvergoldetes Henkelschälchen.

Lg. $12,7 \mathrm{~cm}$. Ausstellung Budapest I884.

a) Kugelbecher mit drei getriebenen Medaillons und späterer? Stifterinschrift von I743. H. 21 cm. Besitzer: Museum vaterländischer Alterthümer, Stuttgart. 


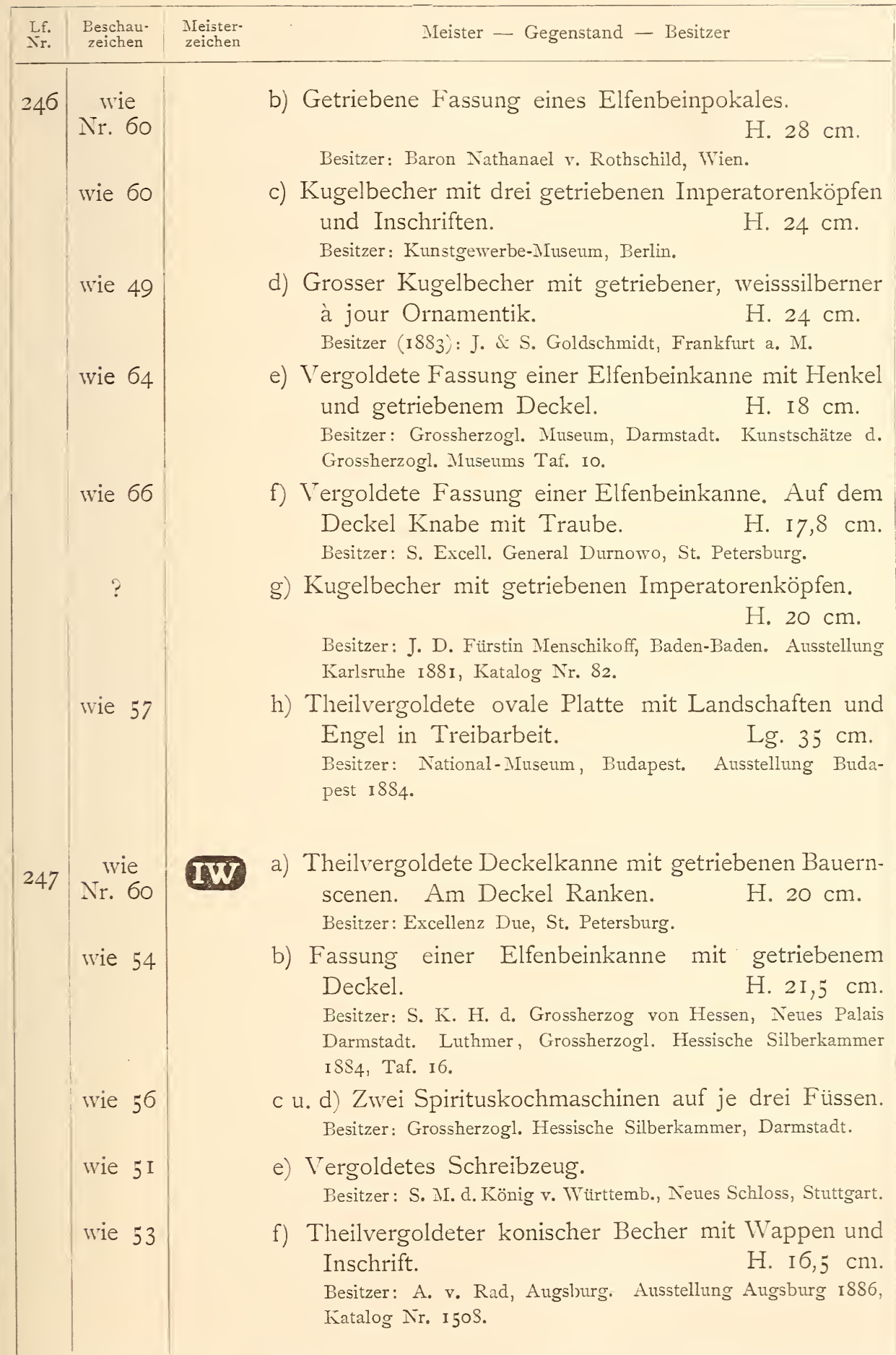




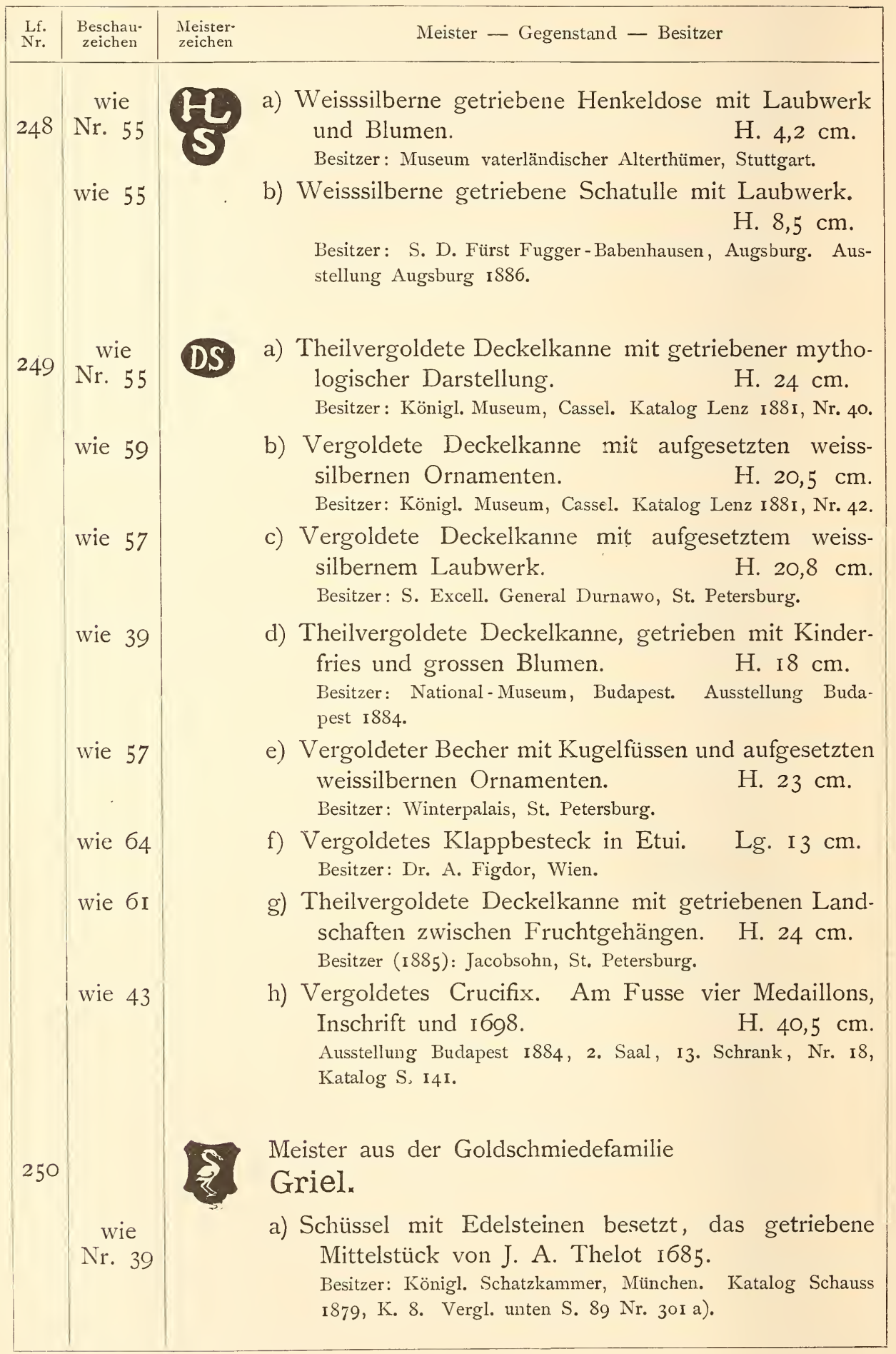




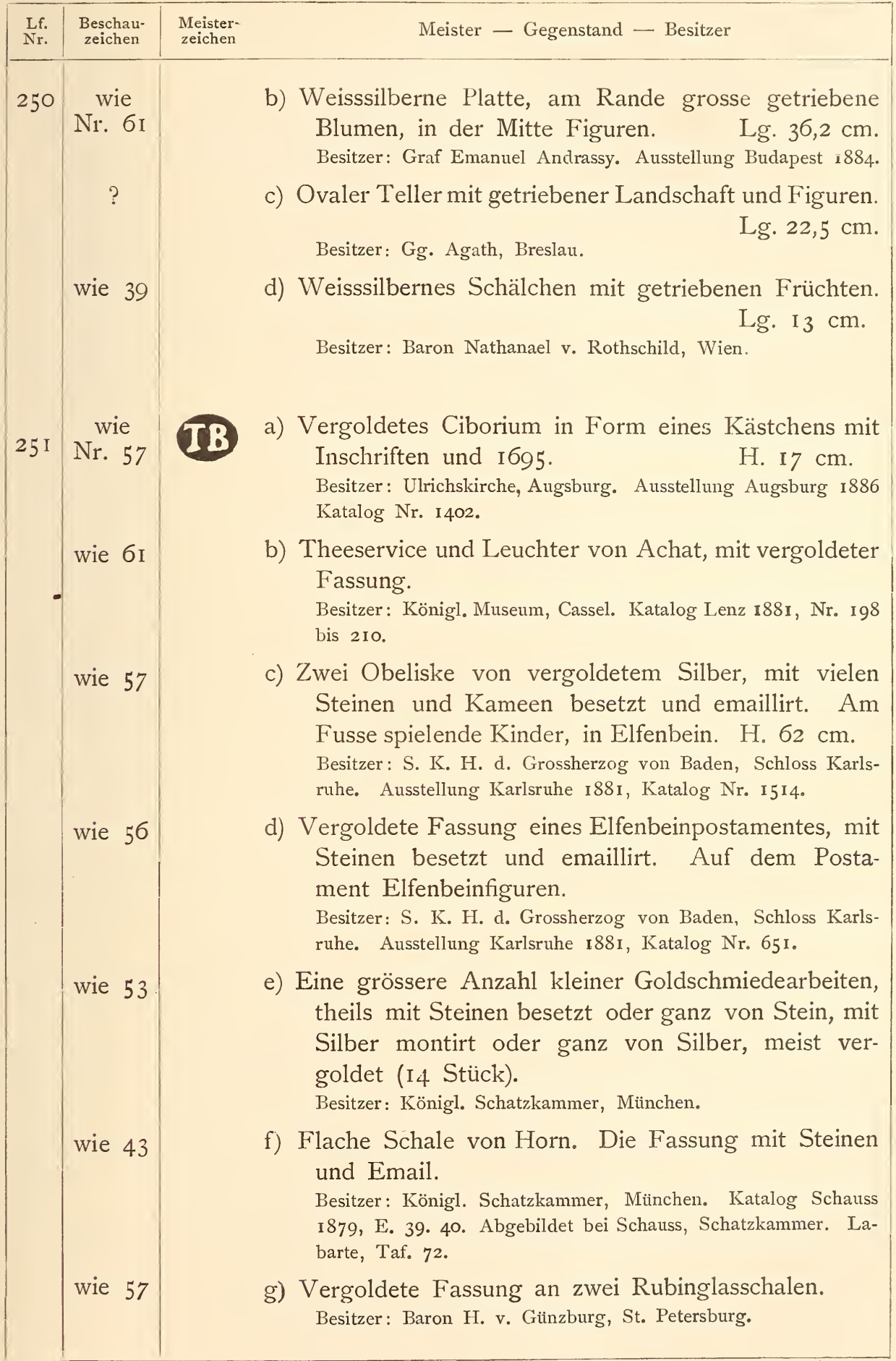




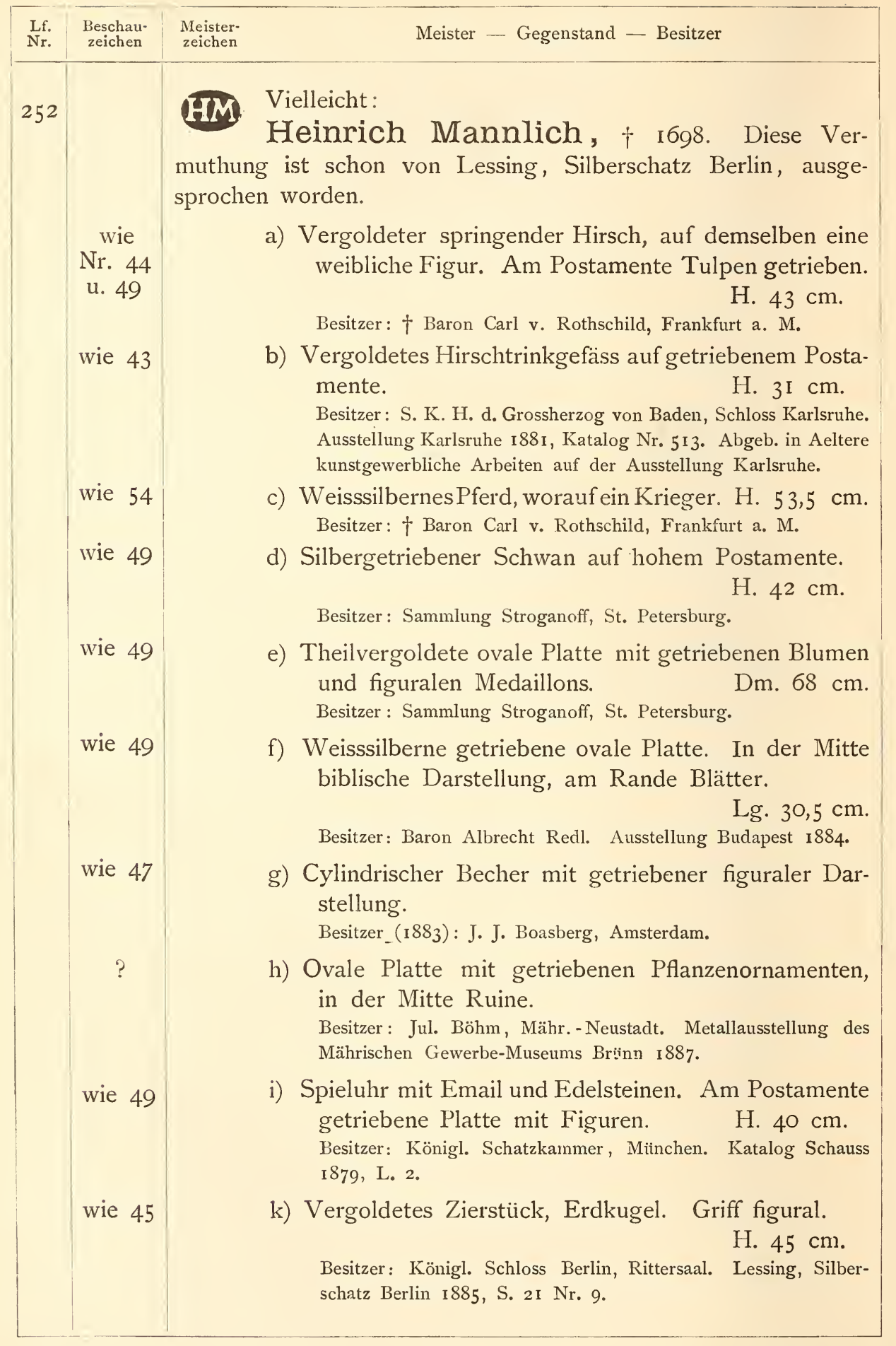




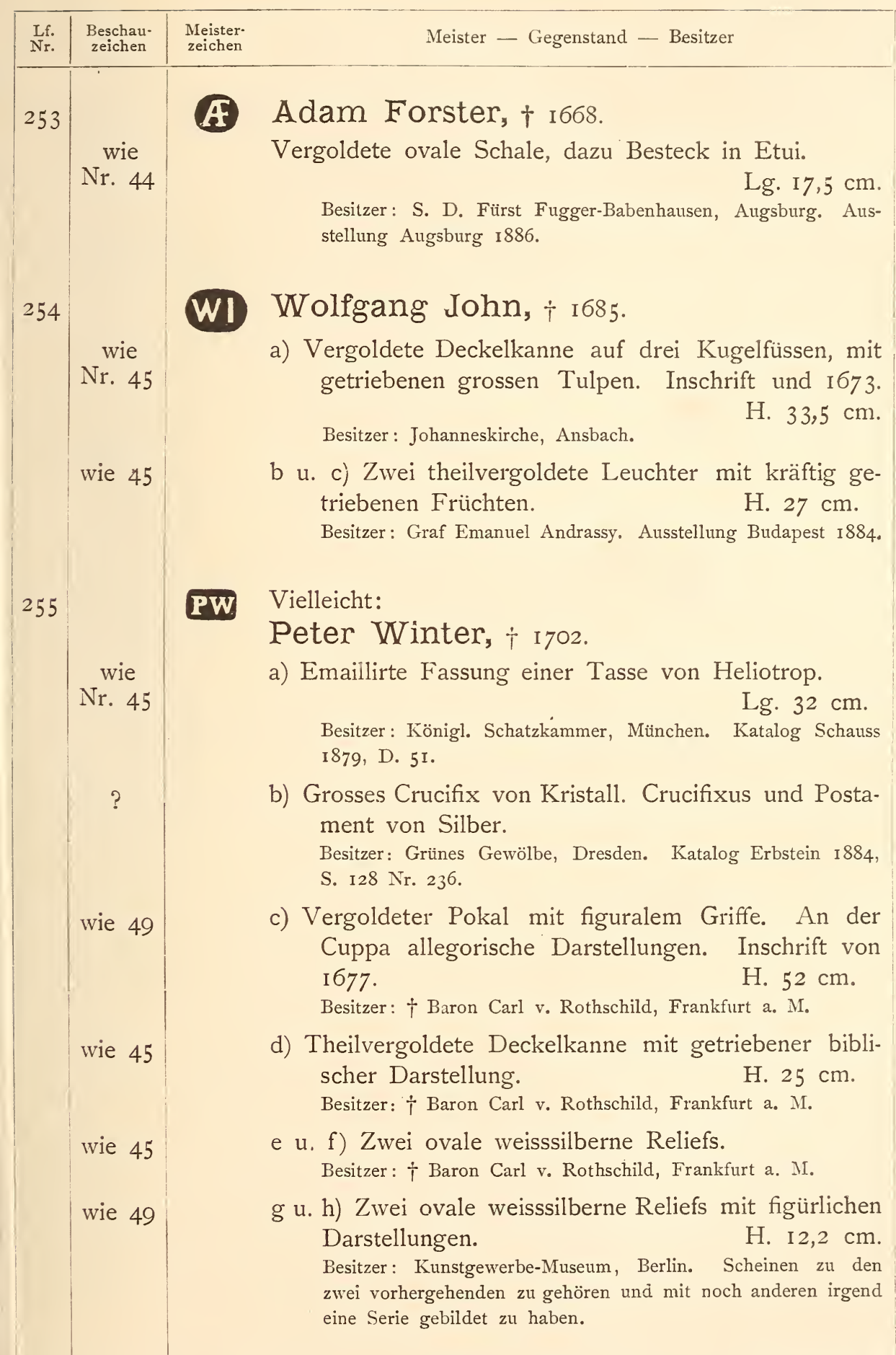




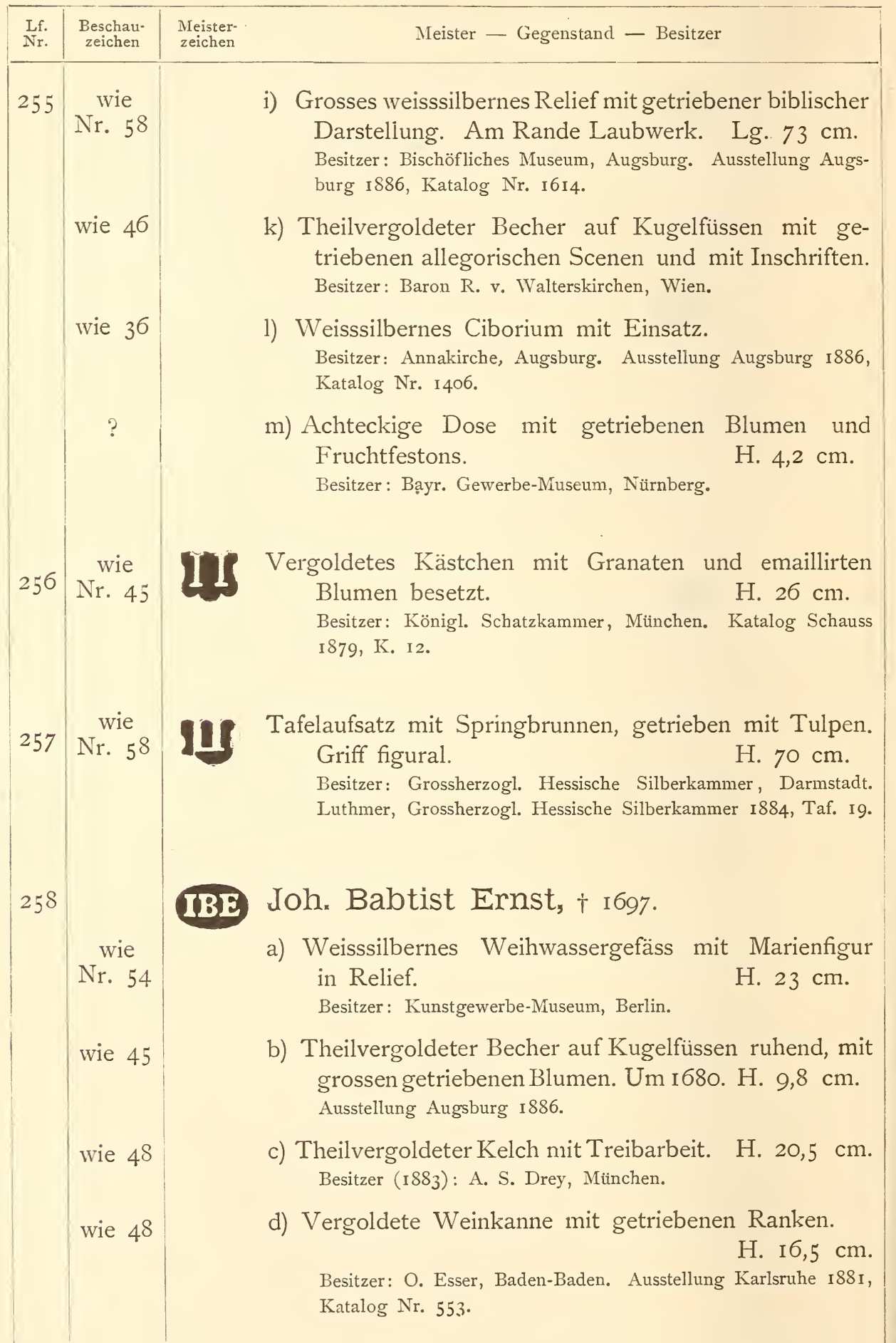




\begin{tabular}{|c|c|c|}
\hline $\begin{array}{l}\text { Lf. } \\
\text { Nr. }\end{array}$ & $\begin{array}{l}\text { Beschau- } \\
\text { zeichen }\end{array}$ & Meister - Gegenstand - Besitzer \\
\hline 259 & & $\begin{array}{l}\text { D4. Der Tradition und der zienlich allgemein herrschenden } \\
\text { Annahme zufolge setze ich zu dieser Marke den } \\
\text { Namen von } \\
\text { Johann Heinrich Mannlich, Vorgeher I698, } \\
\dagger \text { I } 78 \text {, } \\
\text { bemerke aber, dass das Zeichen fast vollkommen dem Hand- } \\
\text { gemal von } \\
\text { Hans Manhart, † I640, } \\
\text { entspricht, einem Meister, der aber zu früh verstorben ist, um alle } \\
\text { hier verzeichneten Stücke vertreten zu können. }\end{array}$ \\
\hline & $\begin{array}{l}\text { wie } \\
\text { Nr. } 60\end{array}$ & $\begin{array}{l}\text { a) Vergoldete Fassung eines Hornbechers mit Halb- } \\
\text { edelsteinen besetzt. } \\
\text { Besitzer: Historisches Museum, Dresden. } 62 \mathrm{~cm} \text {. }\end{array}$ \\
\hline & wie 45 & $\begin{array}{l}\text { b) Deckelkanne mit figürlicher Treibarbeit. H. IO,3 cm. } \\
\text { Ausstellung Cassel I } 884 \text {, Katalog Nr. I } 234 \text { ? }\end{array}$ \\
\hline & wie 55 & $\begin{array}{l}\text { c) Vergoldete Deckelkanne mit figürlicher Treib- } \\
\text { arbeit. } \\
\text { Besitzer: Excellenz Due, St. Petersburg. }\end{array}$ \\
\hline & wie 46 & $\begin{array}{l}\text { d) Schüssel mit getriebener Medaille und beigesetzten } \\
\text { Inschriften. } \\
\text { Ausstellung Amsterdam I } 883 .\end{array}$ \\
\hline & wie 49 & $\begin{array}{l}\text { e) Vergoldeter Deckelpokal auf drei Kugelfüssen ruhend, } \\
\text { ganz mit Granaten bedeckt. } \\
\text { Besitzer: Grünes Gewölbe, Dresden. Katalog Erbstein } 1884 \text {, } \\
\text { S. } 109 \text { Nr. } 8 \text {. }\end{array}$ \\
\hline & ? & $\begin{array}{l}\text { f) Emaillirte und mit Edelsteinen besetzte Fassung } \\
\text { eines Elfenbeinkruges. } \\
\text { Besitzer: Grünes Gewölbe, Dresden. Katalog Erbstein I884, } \\
\text { S. I5 Nr. 29. }\end{array}$ \\
\hline & ? & $\begin{array}{l}\text { g) Vergoldete, mit Blumen getriebene Fassung eines } \\
\text { Elfenbeinpokals. } \\
\text { Besitzer: Grünes Gewölbe, Dresden. Katalog Erbstein 1884, } \\
\text { S. } 15 \text { Nr. 30. Graesse, Das Grïne Gewölbe 1877, Taf. 26.j }\end{array}$ \\
\hline & wie 47 & $\begin{array}{l}\text { h) Fassung einer Elfenbeinkanne. } \quad \text { H. } 25 \mathrm{~cm} \text {. } \\
\text { Besitzer: Baron Nathanael v. Rothschild, Wien. }\end{array}$ \\
\hline & wie 65 & $\begin{array}{l}\text { i) Theilvergoldete getriebene Platte, in der Mitte } \\
\text { Säulenhalle. } \\
\text { Besitzer: S. D. Prinz Heinrich Reuss, Wien. }\end{array}$ \\
\hline
\end{tabular}




\begin{tabular}{|c|c|c|c|}
\hline $\begin{array}{c}\text { Lf. } \\
\text { Nr. }\end{array}$ & $\begin{array}{c}\text { Beschau- } \\
\text { zeichen }\end{array}$ & $\begin{array}{c}\text { Meister. } \\
\text { zeichen }\end{array}$ & Meister - Gegenstand - Besitzer \\
\hline 259 & $?$ & k) Vergoldetes Schmuckkästchen, emaillirt und mit \\
& Steinen besetzt. \\
Besitzer: Grünes Gewölbe, Dresden. Katalog Erbstein I884, \\
S. II8 Nr. I64. \\
Nr. 52
\end{tabular}

Vergoldete Fassung einer Elfenbeinkanne. H. $30,5 \mathrm{~cm}$. Besitzer: Kunstgewerbe-Museum, Berlin.

Vergoldete Deckelkanne mit Fuchsjagd. H. I4 cm. Besitzer: National-Museum, Budapest. Ausstellung Budapest 1884 .

Mit einer anscheinend gleichen Marke, es fehlt hauptsächlich der senkrechte Strich in der Mitte des M, ist auch folgendes Stück versehen:

Deckelkanne mit figuralem Henkel. Corpus vergoldet mit aufgesetzter weisssilberner Ornamentik.

H. $16,5 \mathrm{~cm}$. Besitzer: S. D. Fürst Auersberg, Zleb. Roula, Böhmens kunstgewerbliche Denkmäler Taf. 6 . 


\begin{tabular}{|c|c|c|c|}
\hline $\begin{array}{l}\text { Lf. } \\
\text { Nr. }\end{array}$ & $\begin{array}{l}\text { Beschau- } \\
\text { zeichen }\end{array}$ & $\begin{array}{l}\text { Meister- } \\
\text { zeichen }\end{array}$ & Meister - Gegenstand - Besitzer \\
\hline 监 & $\begin{array}{l}\text { wie } \\
\text { Nr. } 46\end{array}$ & & 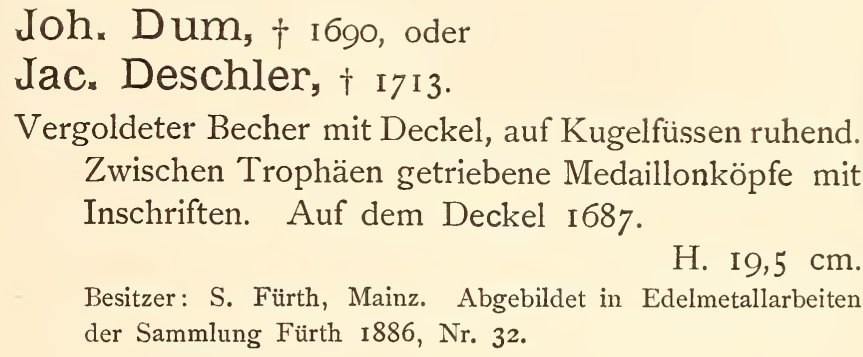 \\
\hline 263 & $\begin{array}{c}\text { wie } \\
\text { Nr. } 46 \\
\text { wie } 6 \text { I }\end{array}$ & HIS & 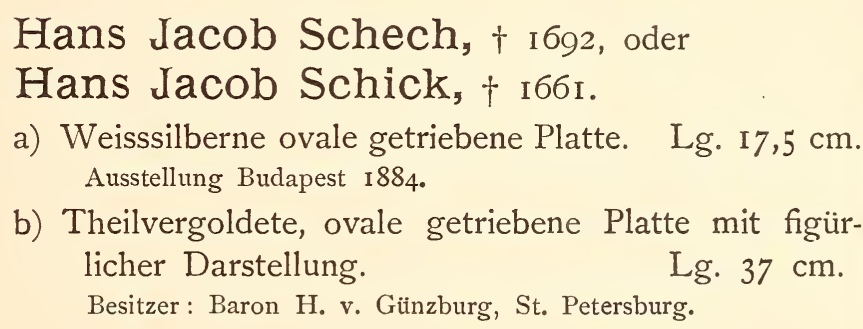 \\
\hline
\end{tabular}

Diese Marke gehört sicherlich einem Augsburger Goldschmiede Namens

Abraham Waremberger an, und zwar wahrscheinlich demjenigen unter den verschiedenen dieses Namens, welcher I704 gestorben ist.

wie

Nr. 65

wie 65

wie 46

wie 67

wie 67

a) Theilvergoldete ovale Platte, getrieben. In der Mitte musicirende Frauen, am Rande die vier Jahreszeiten.

Lg. $73 \mathrm{~cm}$.

Besitzer: Winterpalais, St. Petersburg.

b) Ovale Platte, getrieben mit Medaillonköpfen und Früchten.

Besitzer: Winterpalais, St. Petersburg.

c) Weisssilberne runde Platte, getrieben mit Früchten, Medaillonköpfen und Inschrift.

Dm. $31,5 \mathrm{~cm}$.

Besitzer: P. A. Kotschubey, St. Petersburg.

d) Theilvergoldete runde Platte, getrieben mit Imperatorenköpfen und Laubwerk. Dm. $3 \mathrm{I} \mathrm{cm}$. Besitzer: P. A. Kotschubey, St. Petersburg.

e) Leichtvergoldete runde Platte, getrieben mit Blumen und Früchten.

Dm. $28 \mathrm{~cm}$.

Besitzer: Baron Nathanael v. Rothschild, Wien. 


\begin{tabular}{|c|c|c|}
\hline $\begin{array}{l}\text { Lf. } \\
\text { Nr. }\end{array}$ & $\begin{array}{l}\text { Beschau- } \\
\text { zeichen }\end{array}$ & Meister - Gegenstand - Besitzer \\
\hline 265 & & $\begin{array}{l}\text { PID Philipp Jacob Drentwett, und zwar wahr- } \\
\text { scheinlich derjenige unter den sechs Meistern } \\
\text { gleichen Namens, welcher I } 7 \text { I } 2 \text { gestorben ist. }\end{array}$ \\
\hline & $\begin{array}{l}\text { wie } \\
\text { Nr. } 57\end{array}$ & $\begin{array}{l}\text { a) Scherzbecher (sogen. Hansel im Keller) mit figura- } \\
\text { lem Griffe und muschelförmiger Cuppa, darin ein } \\
\text { Fass, in welchem das Figürchen. } \quad \text { H. } 47 \mathrm{~cm} \text {. } \\
\text { Besitzer: } \uparrow \text { Baron Carl v. Rothschild, Frankfurt a. M. }\end{array}$ \\
\hline & ? & $\begin{array}{l}\text { b) Theilvergoldeter Becher in Gestalt eines aufrecht- } \\
\text { schreitenden Greifes mit Ellenmass, Wappen und } \\
\text { Inschriften von I I IO. } \\
\text { Besitzer: Weberzunft, Basel. Goldschmiedearbeiten der Zünfte } \\
\text { in Basel Taf. 20. }\end{array}$ \\
\hline & wie 47 & $\begin{array}{l}\text { c) Theilvergoldeter Becher auf Kugelfüssen ruhend, mit } \\
\text { drei getriebenen Imperatorenköpfen. H. I6,5 cm. } \\
\text { Besitzer: S. Nagel, Gudensberg. Ausstellung Cassel I884, } \\
\text { Katalog Nr. I746. }\end{array}$ \\
\hline & wie 56 & $\begin{array}{l}\text { d u. e) Zwei kleine getriebene Deckelbecher mit Gem- } \\
\text { men verziert. } \\
\text { Besitzer: Schloss Bebenhausen. Abgebildet in Biermann, Aus- } \\
\text { stellung Gmünd. }\end{array}$ \\
\hline & ? & $\begin{array}{l}\text { f u. g) Zwei Becher mit Kugelfüssen und getriebenen } \\
\text { Medaillonköpfen. } \\
\text { Ausstellung Budapest I884. }\end{array}$ \\
\hline & wie 48 & $\begin{array}{l}\text { h) Theilvergoldeter Becher auf Kugelfüssen ruhend, } \\
\text { getrieben mit grossen Blumen. } \\
\text { Besitzer (I885): Jacobsohn, st. Petersburg. }\end{array}$ \\
\hline
\end{tabular}

PK Philip Küsel, Beschaumeister I685, $\dagger$ เ 700 .

wie

Nr. 48

wie 57

wie 57 a) Grosse Deckelkanne mit getriebenen Kaisermedaillons, Wappen, Inschrift und $1678 . \quad$ H. $23 \mathrm{~cm}$. Besitzer: S. H. d. Fürst von Hohenzollern. Ausstellung Augsburg 1886, Katalog Nr. $155^{\circ}$.

b u. c) Zwei vergoldete grosse Kannen mit getriebenen Zügen und leichten Henkeln.

H. $3 \mathrm{I} \mathrm{cm}$.

Besitzer: Museum der Eremitage, St. Petersburg.

- d) Vergoldete runde Platte, in der Mitte Rosette von getriebenem Laubwerke gebildet. Dm. $64 \mathrm{~cm}$. Besitzer: Kaiserl. Silberkammer, St. Petersburg. 


\begin{tabular}{|c|c|c|}
\hline $\begin{array}{l}\text { Lf. } \\
\text { Nr. }\end{array}$ & $\begin{array}{l}\text { Beschau- } \\
\text { zeichen }\end{array}$ & Meister - Gegenstand - Besitzer \\
\hline 266 & ? & $\begin{array}{l}\text { e) Silberbeschlagenes Kabinet. } \\
\text { Besitzer: Ambraser Sammlung, Wien. Gefällige Mittheilung } \\
\text { von Herrn Dr. Albert Ilg. }\end{array}$ \\
\hline 267 & $\begin{array}{c}\text { wie } \\
\text { Nr. } 49\end{array}$ & $\begin{array}{l}\text { Vergoldeter konischer Becher mit grossen getriebenen } \\
\text { Blumen und Blättern. Inschrift von I677. } \\
\text { Besitzer: Kunstgewerbe-Museum, St. Petersburg. }\end{array}$ \\
\hline 268 & & Christian Schliesser ${ }^{\dagger} \dagger$ I 7 I 2. \\
\hline & $\begin{array}{l}\text { wie } \\
\text { Nr. } 55 ?\end{array}$ & $\begin{array}{l}\text { a) Becher auf Kugelfüssen mit getriebenen Impera- } \\
\text { torenköpfen und Inschrift von I708 (Schlosser- } \\
\text { zunftbecher). } \\
\text { Besitzer: Germanisches National-Museum, Nürnberg. }\end{array}$ \\
\hline & wie 49 & $\begin{array}{r}\text { b) Konischer Becher mit geschweisstem Grunde. ( } 677 .) \\
\text { H. IO,8 cm. } \\
\text { Besitzer: Museum vaterländischer Alterthümer, Stuttgart. }\end{array}$ \\
\hline & ? & $\begin{array}{l}\text { c) Vergoldeter konischer Becher mit Wappen, In- } \\
\text { schrift und I677. Gegenstück des vorhergehenden. } \\
\text { H. I I cm. }\end{array}$ \\
\hline 269 & & $\begin{array}{l}\text { A.B Albrecht Biller. Der eine ist gestorben I720, } \\
\text { der andere, geb. I720, } \dagger \text { I } 777 \text {. Die Arbeiten, } \\
\text { welche ich hier verzeichne, und die mit zwei verschiedenen } \\
\text { Stempeln gezeichnet sind, scheinen kaum nach I702 ent- } \\
\text { standen zu sein. }\end{array}$ \\
\hline & $\begin{array}{c}\text { wie } \\
\text { Nr. 6I }\end{array}$ & $\begin{array}{l}\text { a) Becher in Form eines Narrenkopfes mit kalter } \\
\text { Email. H. I 7,5 cm. } \\
\text { Besitzer: S. K. H. d. Grossherzog von Hessen, Neues Palais Darm- } \\
\text { stadt. Luthmer, Grossherzogl. Hess. Silberkammer I 884, Tat. 7. }\end{array}$ \\
\hline & wie 60 & $\begin{array}{l}\text { b) Silbergetriebene Platte an einer Uhr. Mit Namens- } \\
\text { schilden. } \\
\text { Besitzer: Grossherzogl. Museum, Darmstadt. }\end{array}$ \\
\hline & wie 57 & $\begin{array}{l}\text { c u. d) Zwei weisssilberne ovale Reliefs mit Darstel- } \\
\text { lungen aus dem neuen Testamente. Lg. } 85 \mathrm{~cm} \text {. } \\
\text { Besitzer: Ulrichskirche, Augsburg. Ausstellung Augsburg i } 886 \text {, } \\
\text { Katalog Nr. I6r2. }\end{array}$ \\
\hline
\end{tabular}




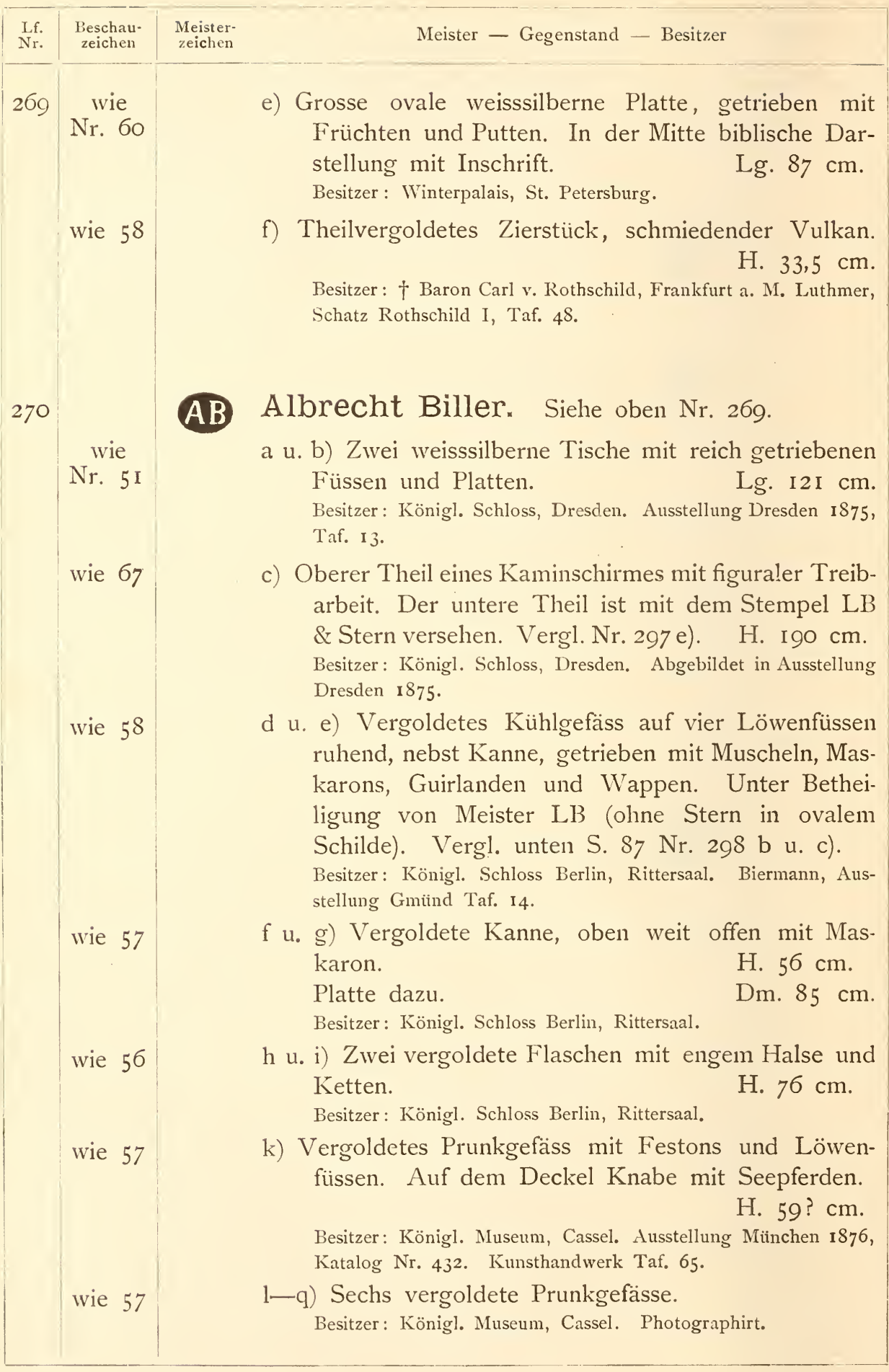




\begin{tabular}{|c|c|c|c|}
\hline $\begin{array}{l}\text { Lf. } \\
\text { Nr. }\end{array}$ & $\begin{array}{l}\text { Beschau- } \\
\text { zeichen }\end{array}$ & $\begin{array}{l}\text { Meister- } \\
\text { zeichen }\end{array}$ & Meister - Gegenstand - Besitzer \\
\hline $27 I$ & $\begin{array}{c}\text { wie } \\
\text { Nr. } 27\end{array}$ & & $\begin{array}{l}\text { a) Getriebener Becher auf drei Kugelfüssen ruhend. } \\
\text { H. I } 7 \mathrm{~cm} \text {. } \\
\text { Besitzer: Frhr. L. Riedesel, Eisenbach. Ausstellung Cassel } \\
\text { 1884, Katalog Nr. 1716. }\end{array}$ \\
\hline & wie 53 & & $\begin{array}{l}\text { b) Vergoldete Deckelkanne mit getriebenen Impera- } \\
\text { torenköpfen und Zügen. } \\
\begin{array}{l}\text { Besitzer: Baron Nathanael v. Rothschild, Wien. } \\
\text { H. }\end{array}\end{array}$ \\
\hline & wie 67 & & $\begin{array}{l}\text { c) Weisssilbernes ovales Plättchen mit getriebenem Laub- } \\
\text { werk und Wappen. } \\
\text { Besitzer: Kunstgewerbe-Museum, Berlin. }\end{array}$ \\
\hline & wie 57 & & $\begin{array}{l}\text { d) Theilvergoldeter Becher auf Kugelfüssen mit ge- } \\
\text { triebenen Imperatorenköpfen. } \\
\text { Besitzer (1884): H. Ratzersdorfer, Wien. }\end{array}$ \\
\hline & & Viellei & ht gehört auch hierher: \\
\hline & wie 68? & & $\begin{array}{l}\text { e) Vergoldetes und gravirtes Reiseservice in Etui. } \\
\text { Besitzer: Gg. Agath, Breslau. }\end{array}$ \\
\hline 272 & $\begin{array}{l}\text { wie } \\
\text { Nr. } 53\end{array}$ & $u$ & 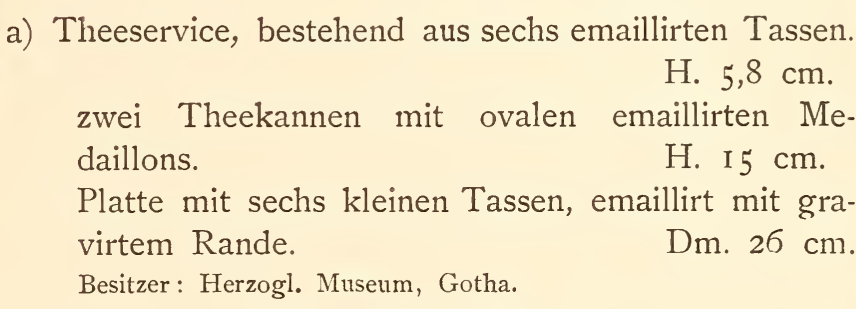 \\
\hline & ? & & $\begin{array}{l}\text { b) Vergoldete Zuckerdose, auf dem Deckel Frauen- } \\
\text { bildniss. } \\
\text { Besitzer: S. H. d. Herzog von Anhalt. Ausstellung München } \\
\text { 1876, Katalog Nr. 2062. }\end{array}$ \\
\hline & wie 57 & & $\begin{array}{l}\text { c) Emaillirte Untertasse mit vergoldeter Fassung. } \\
\text { Dm. I I cm. } \\
\text { Besitzer: Excellenz Due, St. Petersburg. }\end{array}$ \\
\hline 273 & & & $\begin{array}{l}\text { Vielleicht } \\
\text { V. Hueter, ein Name, der im I7. und I8. Jahr- } \\
\text { mehrmals vorkommt. }\end{array}$ \\
\hline & $\begin{array}{c}\text { wie } \\
\text { Nr. } 53\end{array}$ & & $\begin{array}{l}\text { a) Vergoldeter birnförmiger Becher mit Inschrift von } \\
\text { I68I. } \\
\text { Ausstellung Budapest I884. }\end{array}$ \\
\hline
\end{tabular}




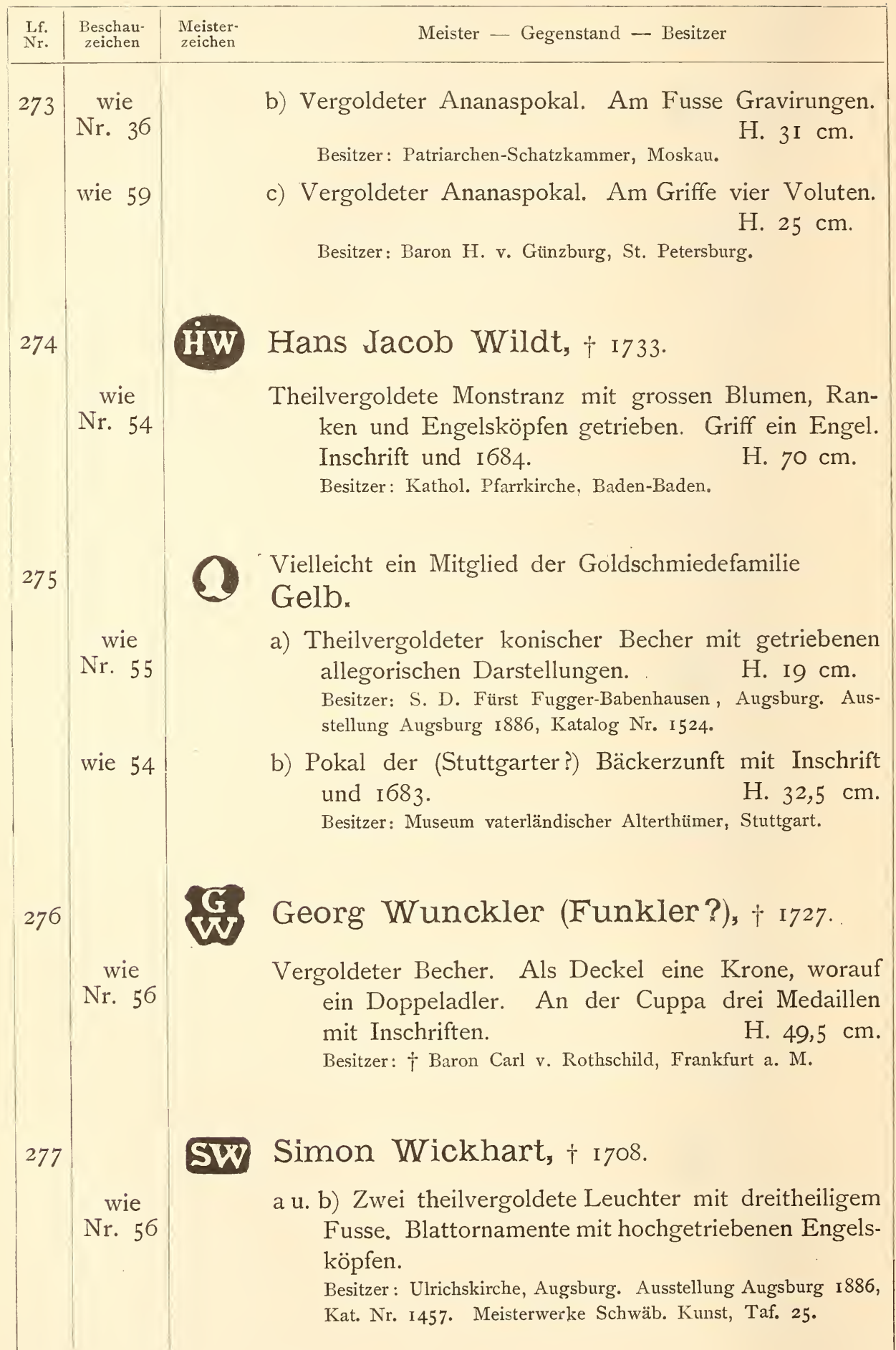




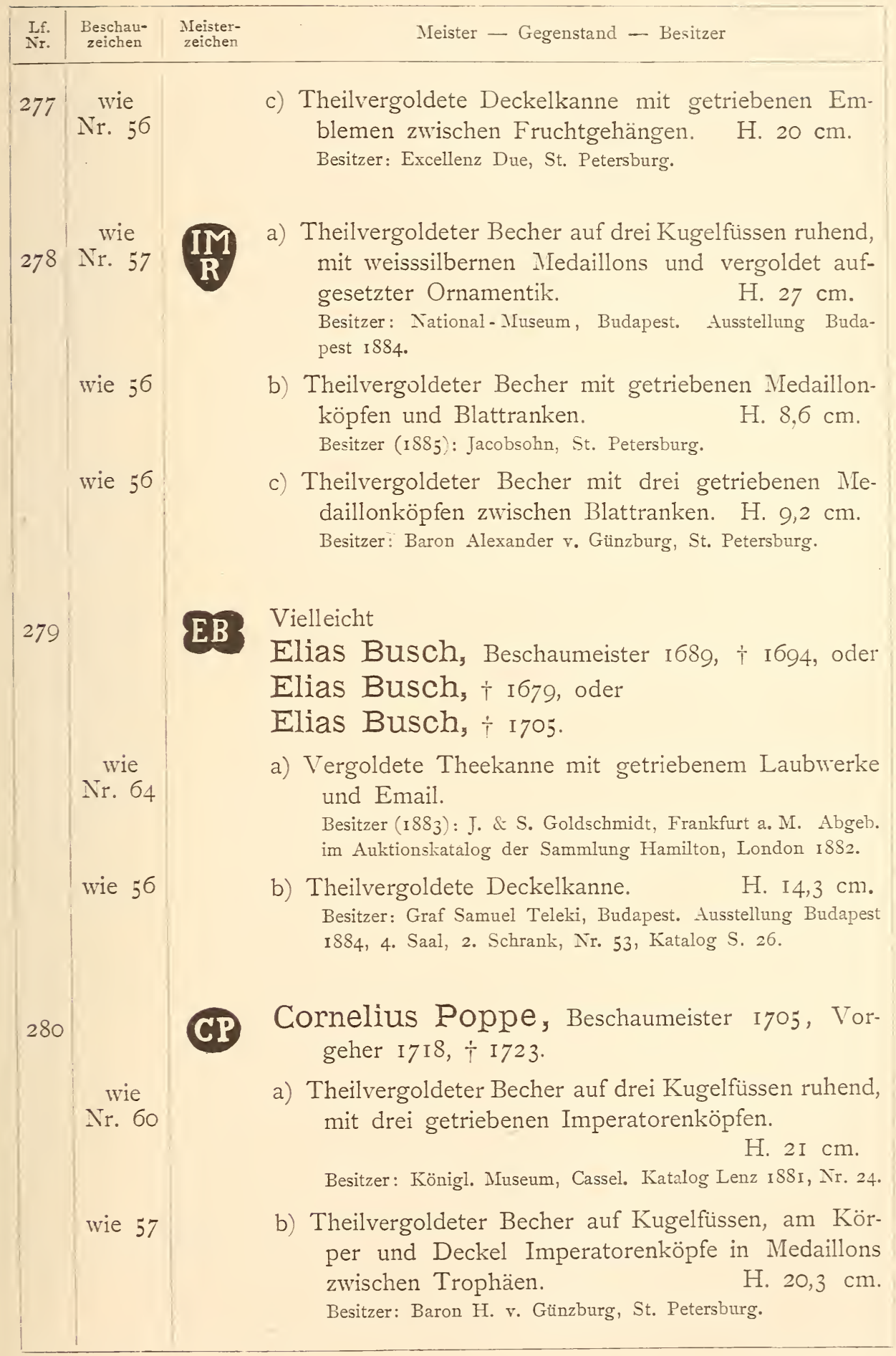




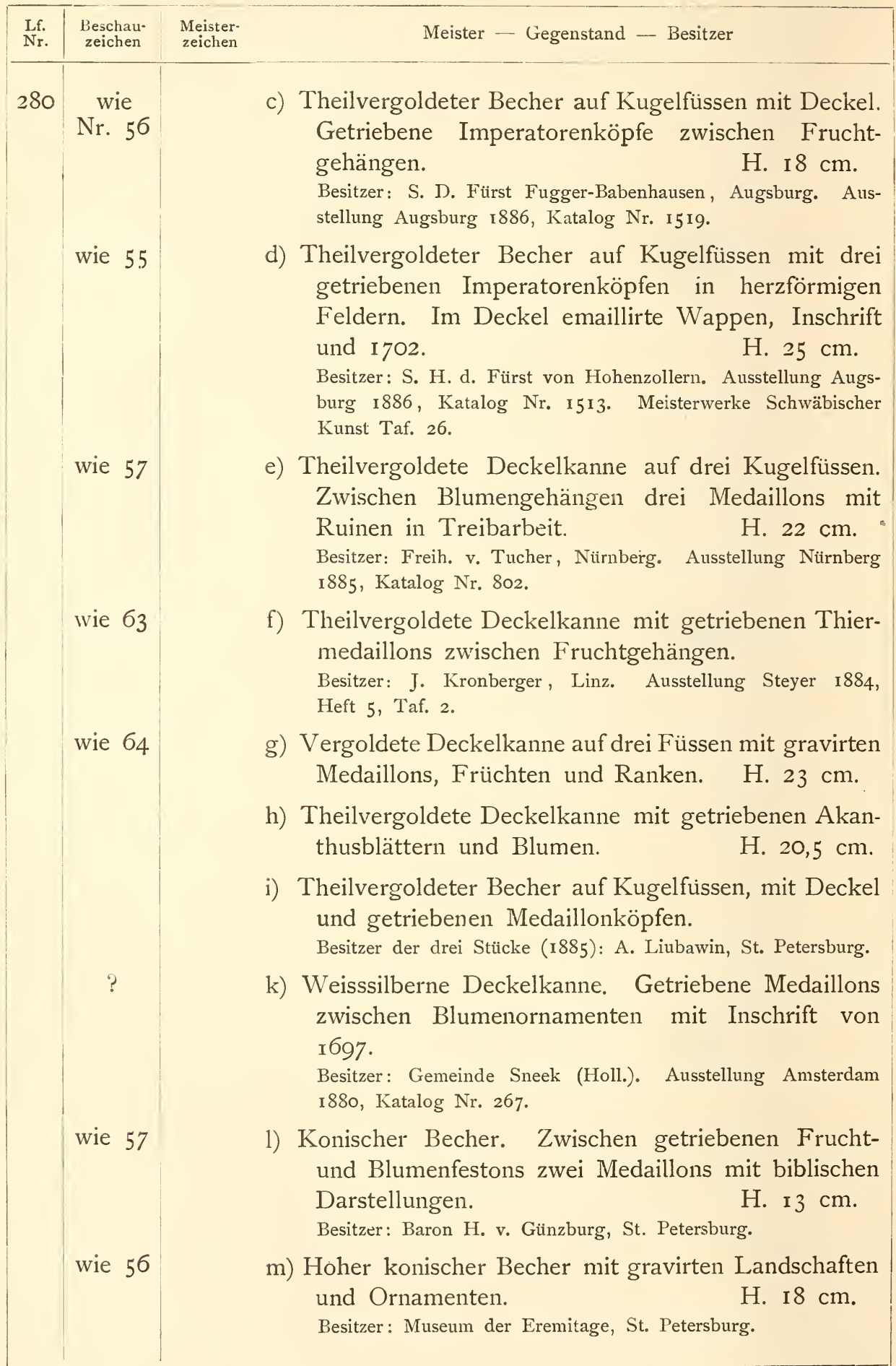




\begin{tabular}{|c|c|c|c|}
\hline$\underset{\text { Nr. }}{\text { Lf. }}$ & $\begin{array}{l}\text { Beschau- } \\
\text { zeichen }\end{array}$ & $\begin{array}{l}\text { Meister- } \\
\text { zeichen }\end{array}$ & Meister - Gegenstand - Besitzer \\
\hline 280 & $\begin{array}{l}\text { wie } \\
\text { Nr. } 56\end{array}$ & & $\begin{array}{l}\text { n u. o) Zwei gleiche Becher mit Kugelfüssen und Deckel, } \\
\text { theilvergoldet, mit getriebenen Ranken und Wappen, } \\
\text { sowie gravirter Inschrift von I697. H. I9 cm. } \\
\text { Besitzer: Schloss Bebenhausen. Ausstellung Stuttgart I88I, } \\
\text { Katalog Nr. I21. Ausstellung München 1876, Katalog } \\
\text { Nr. 30I. }\end{array}$ \\
\hline & & & $\begin{array}{l}\text { p) Grosse Deckelkanne mit Gravirungen. } \\
\text { Besitzer (I883): J. \& S. Goldschmidt, Frankfurt a. M. }\end{array}$ \\
\hline & wie 64 & & 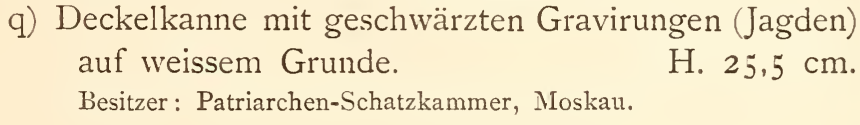 \\
\hline
\end{tabular}

GB Die mit dieser Marke bezeichneten Arbeiten sind entweder

Gottlieb Bauer, $\uparrow$ i 735 , oder

Gabriel Besmann, † I735, zuzuschreiben, oder auf einen dieser Meister und auf

Georg Berthold, † ı686, zu vertheilen.

wie

Nr. 57

wie 64

wie 6I

wie 6I

wie 64

a) Deckelkanne mit allegor. Darstellung. H. I9 cm. Besitzer: Patriarchen-Schatzkammer, Moskau.

b) Theilvergoldete Deckelkanne, getrieben mit Laubwerk und figuraler Darstellung. H, $19,5 \mathrm{~cm}$. Besitzer (1885): A. Liubawin, St. Petersburg.

c) Deckelkanne mit Löwenjagd getrieben. Besitzer (1883): J. \& S. Goldschmidt, Frankfurt a. MI.

d) Theilvergoldete Deckelkanne. Zwischen getriebenen Fruchtgehängen drei weisssilberne Medaillons mit Inschrift.

H. $I 7,5 \mathrm{~cm}$.

Besitzer: Schloss Bebenhausen.

e) Vergoldete Monstranz von einem Engel getragen. Besitzer: Georgskirche, Augsburg. Ausstellung Augsburg I886, Katalog Nr. I335.

f) Vergoldetes Messgeräth, bezeichnet I69I.

Besitzer: Johanneskirche, Erding. Ausstellung Augsburg I886, Katalog Nr. 1380. 


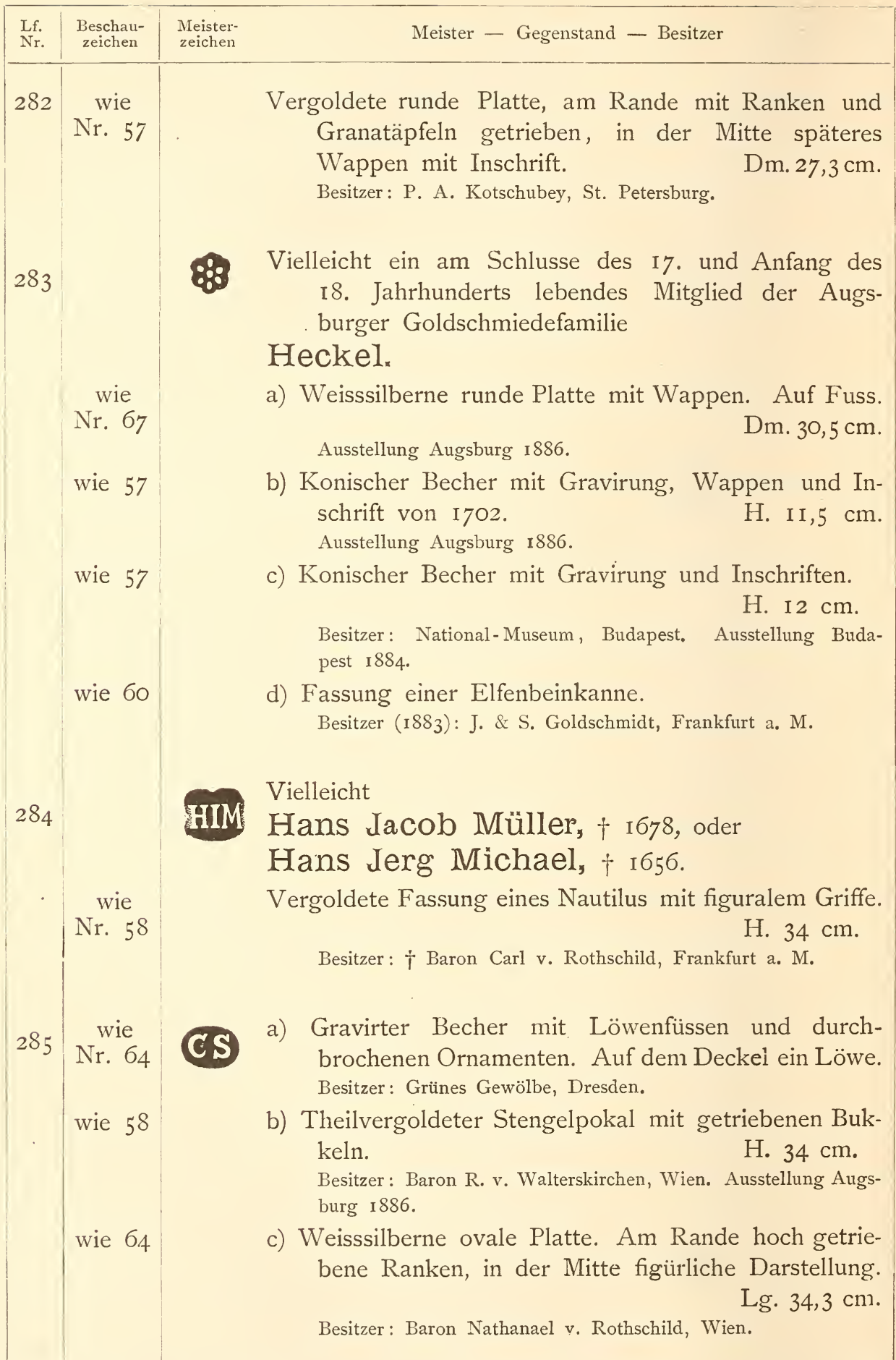




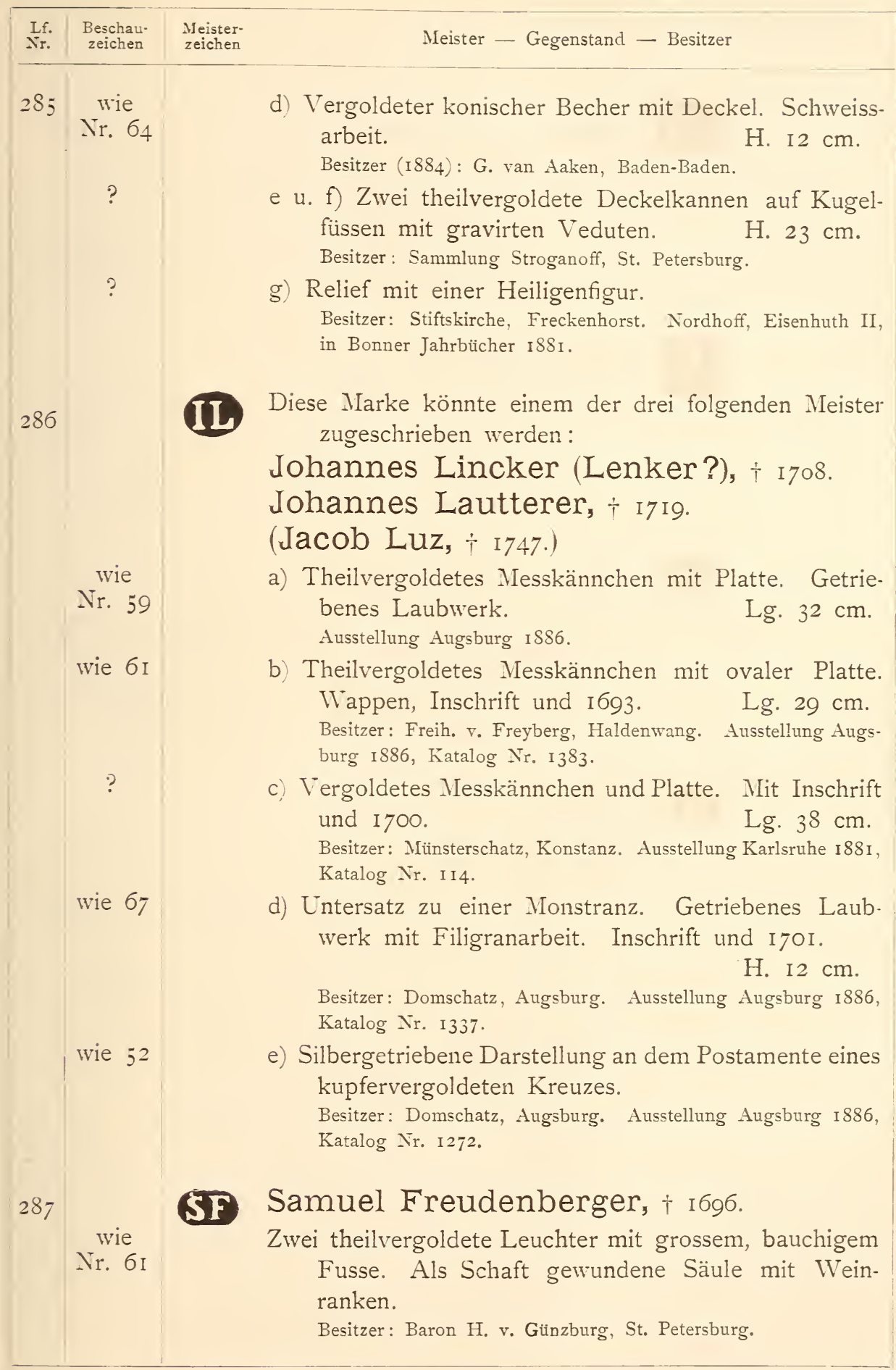




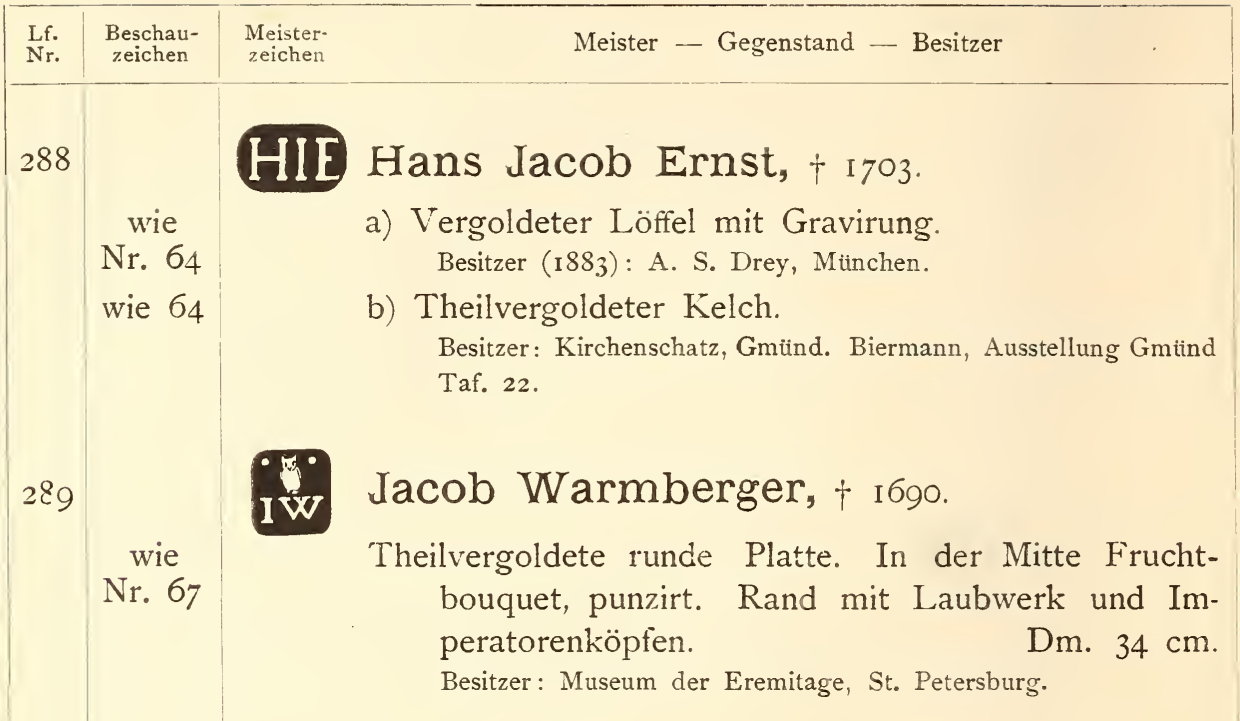

ICS Joh. Conrad Schnell, + i 704.

Becher auf Kugelfüssen mit Deckel. Gravirte Wappen, Landschaften und Engel in Ranken. Inschrift von I699.

H. $27,8 \mathrm{~cm}$.

Besitzer: Schloss Bebenhausen. Herald. Ausstellung Berlin I882, Katalog Nr. I72I.

(S1) Vielleicht

Seb. Mylius, $\uparrow$ I 722 , oder

Joh. Seb. Milius, $\uparrow$ ז 727 .

wie

Nr. 55

wie 38

wie 47

a u. b) Zwei weisssilkerne Thronsessel mit getriebenen Kinderköpfen.

Besitzer: Königl. Schloss Berlin, Rittersaal. Ausstellung München 1876, Katalog Nr. 167 .

c) Vergoldete Reiterfigur, Gustav Adolf von Schweden. Mit Wappen.

H. $43 \mathrm{~cm}$.

Besitzer: $†$ Baron Carl v. Rothschild, Frankfurt a. M.

d) Reiterfigur, Gustav Adolf von Schweden. Mit Inschrift.

H. $44,5 \mathrm{~cm}$.

Besitzer: Compagnie der Schwarzen Häupter, Riga. Cult.hist. Ausstellung Riga I883, Katalog S. 156 Nr. I 593.

e) Vergoldete emaillirte Fassung eines Elfenbeinpokales.

H. $59 \mathrm{~cm}$.

Besitzer: Schloss Moritzburg. Ausstellung München I876, Katalog Nr. 248. Obernetter, Ausstellung München Taf. Io6. 


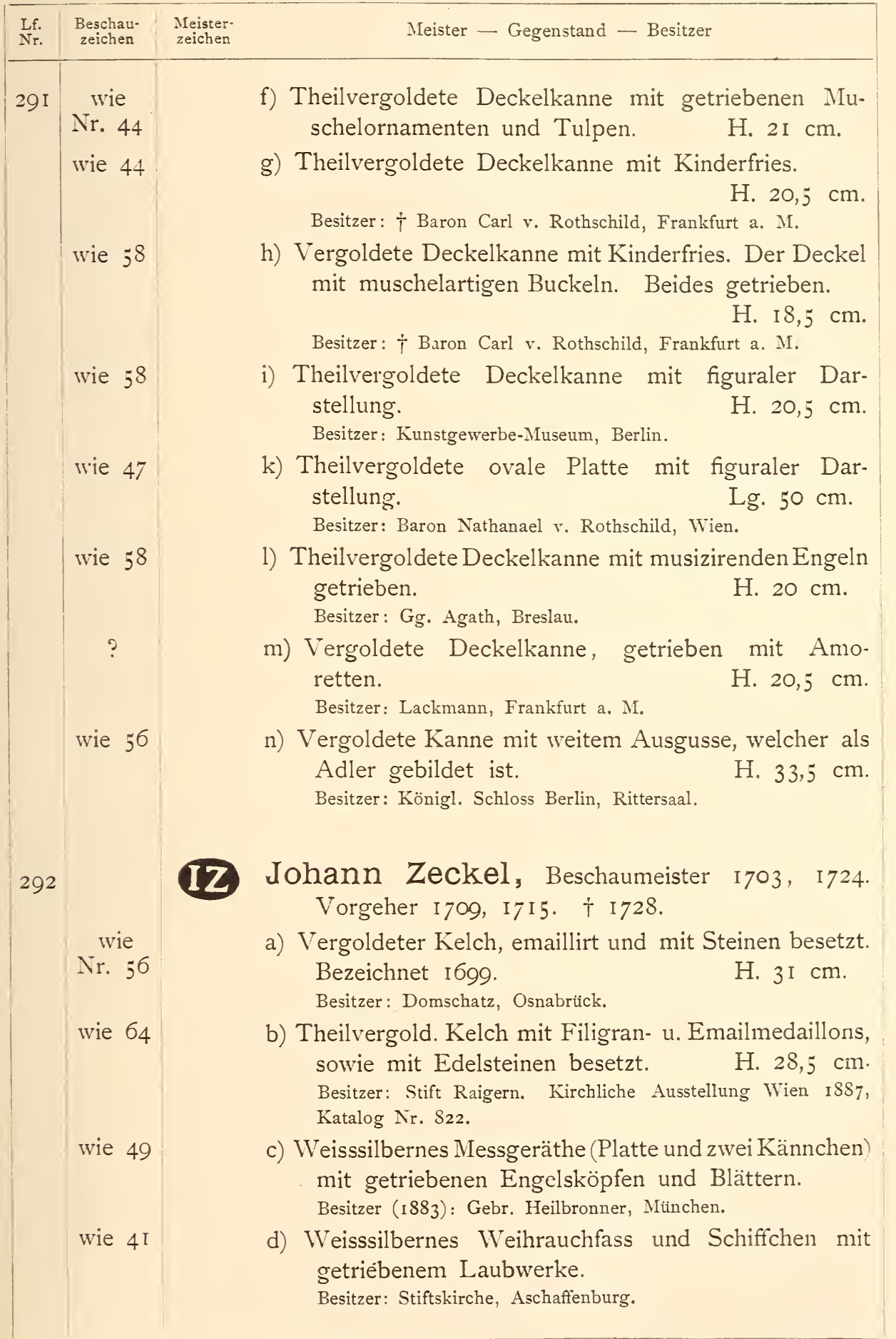




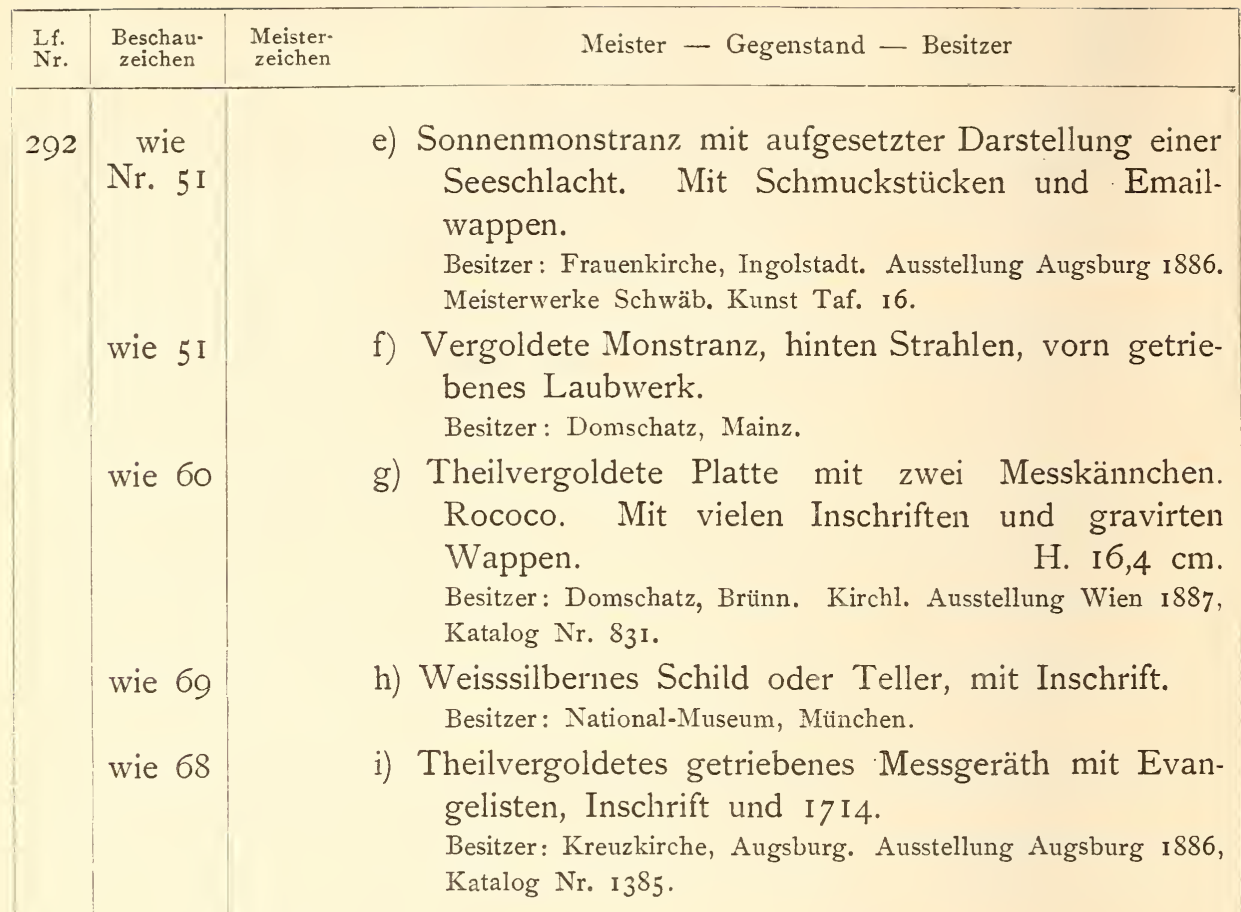

Für die Initialen LB kommen aus der Familie Biller drei Namen in Betracht:

\section{Laurentius Biller, $+\mathrm{I} 720$, \\ Lorenz Biller, + I726,}

Ludwig (Johann Ludwig?) Biller, † I732.

Da es mir leider nicht gelungen ist, die in folgendem aufgezählten Arbeiten jedem einzelnen dieser Meister mit Sicherheit zuzuschreiben, lasse ich die aus L B gebildeten Marken in willkürlicher Reihe hier folgen.

Nach der Feststellung von Lessing

CB Ludwig Biller der Aeltere, geb. I656 (oder I676), † I732.

wie

Nr. 45

wie 54

a) Weisssilberne grosse ovale Platte mit getriebener mythologischer Darstellung.

Besitzer: Kunstgewerbe-Museum, Berlin.

Lg. $2 \mathrm{I}, 5 \mathrm{~cm}$.

b) Erdglobus, gravirt von „Christoph Schmidt Augustae i696". Als Bekrönung ein Adler. Griff figural, Nach I 7OI.

H. $8 \mathrm{I} \mathrm{cm}$.

Besitzer: Königl. Schloss Berlin, Rittersaal. Lessing im Jahrbuch der Kunstsammlungen Berlin I885, S. 21. 


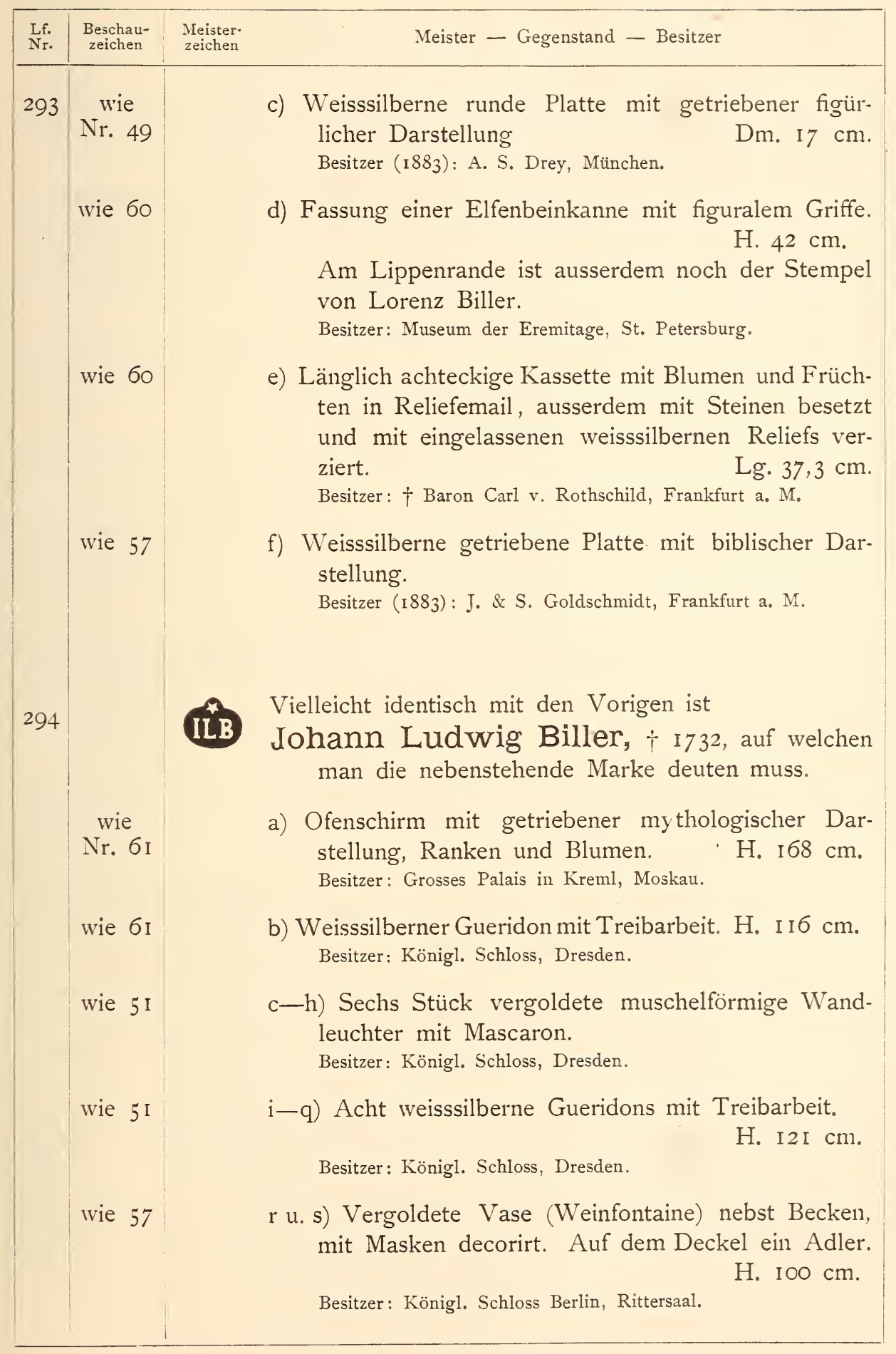




\begin{tabular}{|c|c|c|}
\hline Lff. & & Meister - Gegenstand - Besitzer \\
\hline \multirow[t]{9}{*}{295} & & $\begin{array}{l}\text { ILB Vielleicht ist es möglich, unter den mit ILB bezeichne- } \\
\text { ten Arbeiten den Theil, an welchem die Marke etwas } \\
\text { anders erscheint als bei Nr. 294, für } \\
\text { Johann Ludwig Biller den Jüngeren, } \\
\text { Vorgeher I708, Beschaumeister I74I, † I746, auszuscheiden. }\end{array}$ \\
\hline & $\begin{array}{c}\text { wie } \\
\text { Nr. } 43\end{array}$ & $\begin{array}{l}\text { a) Vergoldetes rundes Servirbrett mit getriebenen, viel- } \\
\text { leicht gepressten Ornamenten. } \\
\text { Besitzer: Königl. Silberkammer, Dresden. }\end{array}$ \\
\hline & wie 56 & $\begin{array}{l}\text { bu. c) Kanne und Becken mit gestanzten Ornamenten. } \\
\text { Bezeichnet I733. } \\
\text { Besitzer: Königl. Silberkammer, Dresden. }\end{array}$ \\
\hline & wie 65 & $\begin{array}{l}\text { d) Weisssilberne Theekanne mit Henkel und Ausguss. } \\
\text { Besitzer }\left(\mathrm{r} 88_{3}\right) \text { : J. J. Boasberg: Amsterdam. }\end{array}$ \\
\hline & wie 69 & $\begin{array}{l}\text { e) Weisssilberne runde Platte, gravirte Ornamente mit } \\
\text { aufgesetzten Frauenköpfen. } \\
\text { Dm. } 58,5 \mathrm{~cm} .\end{array}$ \\
\hline & wie 69 & $\begin{array}{ll}\text { f) Dazu eine Kanne. } & \text { H. } 3 \mathrm{I}, 3 \mathrm{~cm} . \\
\text { Besitzer: Herzogl. Museum, Gotha. } & \end{array}$ \\
\hline & wie 68 & $\begin{array}{l}\text { g) Vergoldete runde Schüssel mit eingezogenem Rande. } \\
\text { Dm. } 66 \mathrm{~cm} .\end{array}$ \\
\hline & wie 68 & $\begin{array}{l}\text { h) Dazu Kanne mit breitem Ausguss. H. } 32 \mathrm{~cm} \text {. } \\
\text { Besitzer: Herzogl. Museum, Gotha. }\end{array}$ \\
\hline & wie 68 & $\begin{array}{l}\text { i u. k) Zwei vergoldete Deckelbecher mit je drei Füssen. } \\
\text { Besitzer: Grünes Gewölbe, Dresden. Katalog Erbstein } 1884 \text {, } \\
\text { S. } 75 \text { Nr. } 66 \text { und } 67 \text {. }\end{array}$ \\
\hline 296 & & $\begin{array}{l}\text { IOHANN LUDWIG BILLER, FECIT IN } \\
\text { AUGSPURG GOLD . . . . (nicht facsimilirt). } \\
\text { Goldener Spiegelrahmen, Theil einer ganzen Gold- } \\
\text { toilette. Mit Initialen. } \\
\text { Besitzer: Oruschenaja Palata, Moskau. Maskell, Russian art } \\
\text { I884, S. } 253 .\end{array}$ \\
\hline 297 & $\begin{array}{l}\text { wie } \\
\text { Nr. } 56\end{array}$ & $\begin{array}{l}\text { a) Becher auf Kugelfüssen mit Gravirungen und In- } \\
\text { schriften von I694. } \\
\begin{array}{ll}\text { Besitzer: Herzogl. Museum, Gotha. } & \text { H I,5 cm. }\end{array}\end{array}$ \\
\hline & wie 56 & $\begin{array}{l}\text { b) Becher auf Kugelfüssen, mit Gravirung, Inschriften } \\
\text { und I688. H. } 32,5 \mathrm{~cm} \text {. } \\
\text { Besitzer: Herzogl. Museum Gotha. Ausstellung Frankfurt a. M. } \\
\text { 1875, Katalog Nr. 1618. }\end{array}$ \\
\hline
\end{tabular}




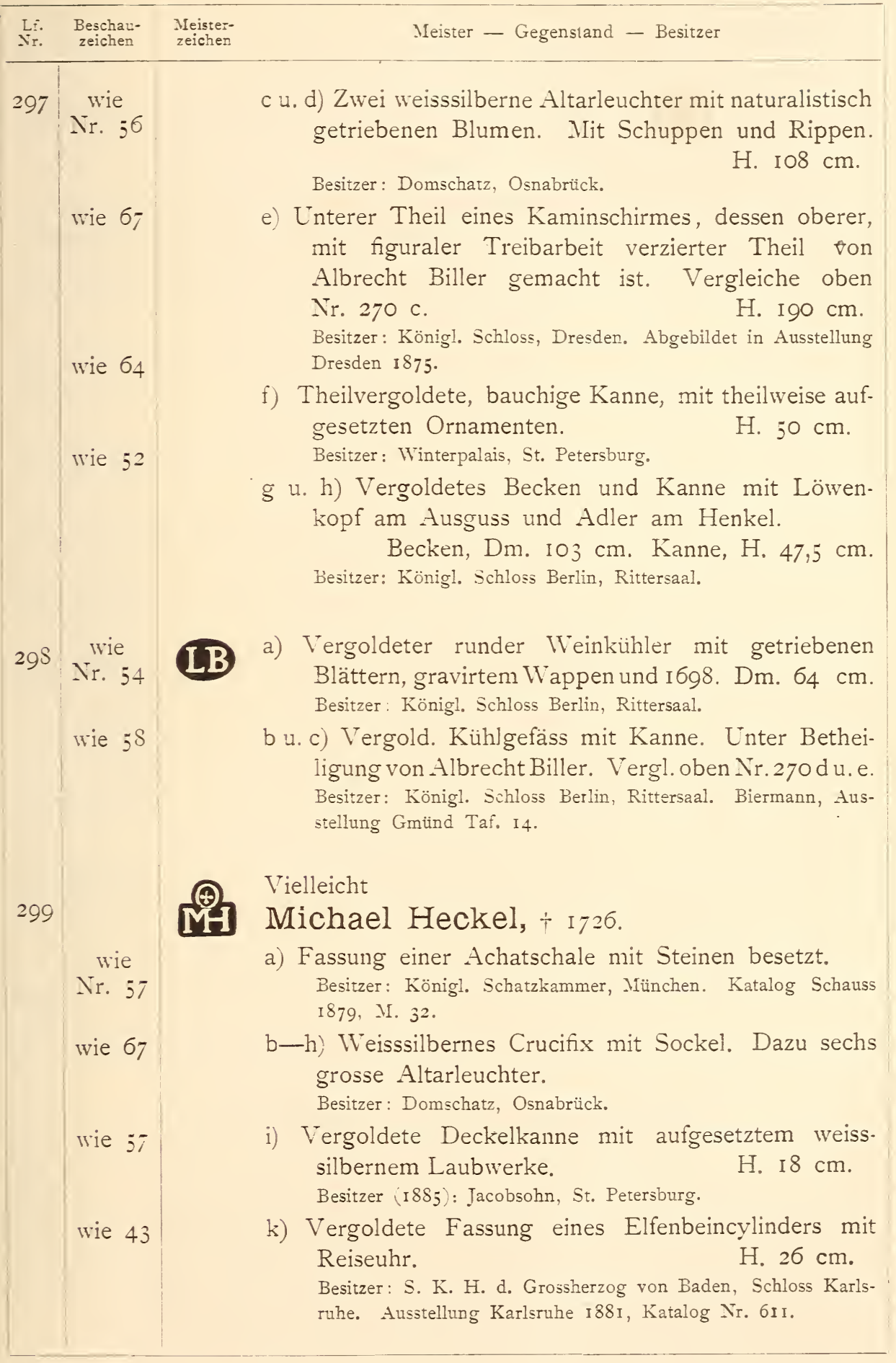




\begin{tabular}{|c|c|c|c|}
\hline $\begin{array}{l}\text { Lf. } \\
\text { Nr. }\end{array}$ & $\begin{array}{l}\text { Beschau- } \\
\text { zeichen }\end{array}$ & $\begin{array}{l}\text { Meister- } \\
\text { zeichen }\end{array}$ & Meister - Gegenstand - Besitzer \\
\hline 300 & $\begin{array}{l}\text { wie } \\
\text { Nr. } 49\end{array}$ & $\tau$ & $\begin{array}{l}\text { a u. b) Zwei theilvergoldete ovale Platten mit figuraler } \\
\text { Darstellung. } \\
\text { Besitzer: Winterpalais, St. Petersburg. } 67 \text { u. } 73 \mathrm{~cm} \text {. }\end{array}$ \\
\hline & wie 39 & & $\begin{array}{l}\text { c) Theilvergoldetes Messkännchen nebst Platte, mit ge- } \\
\text { triebenen grossen Blumen, Engeln und Ranken. } \\
\text { Platte, lg. } 32 \mathrm{~cm} \text {. Kännchen, H. I } 3 \mathrm{~cm} \text {. } \\
\text { Besitzer: Kirchenpflege, Rheinau. Ausstellung Zürich I } 883 \text {, } \\
\text { Katalog S. } 218 \text { Nr. } 4 .\end{array}$ \\
\hline & wie 46 & & $\begin{array}{l}\text { d) Theilvergoldete sechsseitige Theebüchse mit ge- } \\
\text { triebenen Medaillonköpfen. } \\
\text { Besitzer }(1884) \text { H. H. Ratzersdorfer, Wien. }\end{array}$ \\
\hline & wie 65 & & $\begin{array}{l}\text { e) Deckelkanne mit Henkel, getriebene Köpfe und In- } \\
\text { schrift. } \\
\text { Besitzer: Schloss Bebenhausen. }\end{array}$ \\
\hline & $?$ & & $\begin{array}{l}\text { f) Salzfass auf drei Kugelfüssen mit getriebenen Blumen- } \\
\text { ornamenten. } \\
\text { Besitzer: Bayr. Gewerbe-Museum, Nürnberg. Katalog I880, } \\
\text { XAI, Nr. 63, So7. }\end{array}$ \\
\hline & wie 6 I & & $\begin{array}{l}g-m \text { ) Sechs silbergetriebene Platten als Wandleuchter, } \\
\text { mit Landschaften, Früchten und Blättern. } \\
\text { Besitzer: Grossherzogl. Silberkammer, Darmstadt. Luthmer, } \\
\text { Grossherzogl. Hessische Silberkammer I884, Taf. 2I. }\end{array}$ \\
\hline & wie 65 & & $\begin{array}{l}\text { n) Vergoldeter Pokal mit dünnem, gewundenem, weiss- } \\
\text { silbernem Griffe. } \\
\text { Besitzer (1885): A. Liubawin, St. Petersburg. } 26 \mathrm{~cm} \text {. }\end{array}$ \\
\hline & wie 49 & & $\begin{array}{l}\text { o) Becher mit muschelförmiger Cuppa und aufgesetzten } \\
\text { Ornamenten. Mit getriebenen Wappen und In- } \\
\text { schriften. H. } 42 \mathrm{~cm} \text {. } \\
\text { Besitzer: } \dagger \text { Baron Carl v. Rothschild, Frankfurt a. M. } \\
\text { D) Weisssilberne ovale Platte mit getriebenem Bouquet }\end{array}$ \\
\hline & Wie 00 : & & $\begin{array}{l}\text { p) Weisssilberne ovale Platte mit getriebenem Bouquet } \\
\text { und Ranken. } \\
\text { Lg. I8,2 cm. } \\
\text { Besitzer: Museum vaterländischer Alterthümer, Stuttgart. }\end{array}$ \\
\hline
\end{tabular}

\section{JOHANN ANDREAS THELOT, geb I654, $\dagger$ I 734.}

Wir nehmen bei diesem Meister, wie übrigens auch bei den meisten anderen, nur diejenigen Stücke auf, von welchen wir sicher sind, dass sie noch vorhanden, oder deren Signirung wir kennen. Wo wir ein Facsimile derselben nicht beibringen, setzen wir den Wortlaut in fetter Schrift. Der Anker, Thelot's amtliche Meistermarke, sieht auf den Abdrücken oft sehr ver- 


\begin{tabular}{|l|l|l|}
\hline $\begin{array}{l}\text { Lf. } \\
\text { Nr. }\end{array}$ & $\begin{array}{l}\text { Beschau } \\
\text { zeichen }\end{array}$ & $\begin{array}{l}\text { Meister. } \\
\text { zeichen }\end{array}$ \\
\hline & $\begin{array}{l}\text { schieden aus, so dass man nicht bestimmt sagen kann, ob der } \\
\text { Meister mehrere Stempel geführt hat oder ob Abnützung und } \\
\text { undeutliche Stempelung an dieser Verschiedenheit schuld sind. } \\
\text { Es bleibe auch nicht unerwähnt, dass es ausser Thelot noch an- } \\
\text { dere Meister in Augsburg gegeben hat, welche einen Anker im } \\
\text { Wappen führten, aber es ist schwer einen von ihnen als Ver- } \\
\text { fertiger einzelner der weiter unten verzeichneten Arbeiten zu } \\
\text { erweisen. }\end{array}$
\end{tabular}

301

wie 43

wie

Nr. 39

ein

Anker

wie

Nr. 3 I4

ein

Anker

ein

Anker

\section{THELOT 1685 (nicht facsimilirt).}

a) Taufschüssel mit Edelsteinen, Arbeit des Augsburger Meisters Grill. Vergl. oben S. 64 Nr. 250 a. In der Mitte eine Treibarbeit von Thelot mit den nebenstehenden Signaturen.

Besitzer: Königl. Schatzkammer, München. Katalog Schauss I 879 , K. 8.

b) Taufschüssel mit Edelsteinen, gestempelt mit dem Zeichen des Augsburger Goldschmiedes I M. Vergl. oben S. 58 Nr. 238 d. Das Mittelstück getrieben mit obiger Meistersignatur.

Besitzer: Königl. Schatzkammer, München. Katalog Schauss I879, K. 3. Abgebildet bei Schauss, Schatzkammer.

c) Viereckiges weisssilbernes Relief, Taufe Christi, mit Inschrift.

Besitzer: $\uparrow$ Baron Carl v. Rothschild, Frankfurt a. M.

d) Viereckiges weisssilbernes Relief mit Verkündigung. H. $39 \mathrm{~cm}$.

Besitzer: $†$ Baron Carl v. Rothschild, Frankfurt a. M.

I. A. THELOT 1687 (nicht facsimilirt).

e) Vergoldete Platte mit figuraler Treibarbeit.

Besitzer: Gräfin v. Rezende, Porto. Ausstellung Lissabon I 882, Nr. 343 (und 342 ?).

303

J. A. THELOT 1689 (laut urkundlichem Nachweise?).

f) Pokal mit mythologischen Scenen getrieben. Angeblich sein Meisterstück. Es kommen indessen, wie aus diesem Verzeichnisse ersichtlich. frühere Ar- 


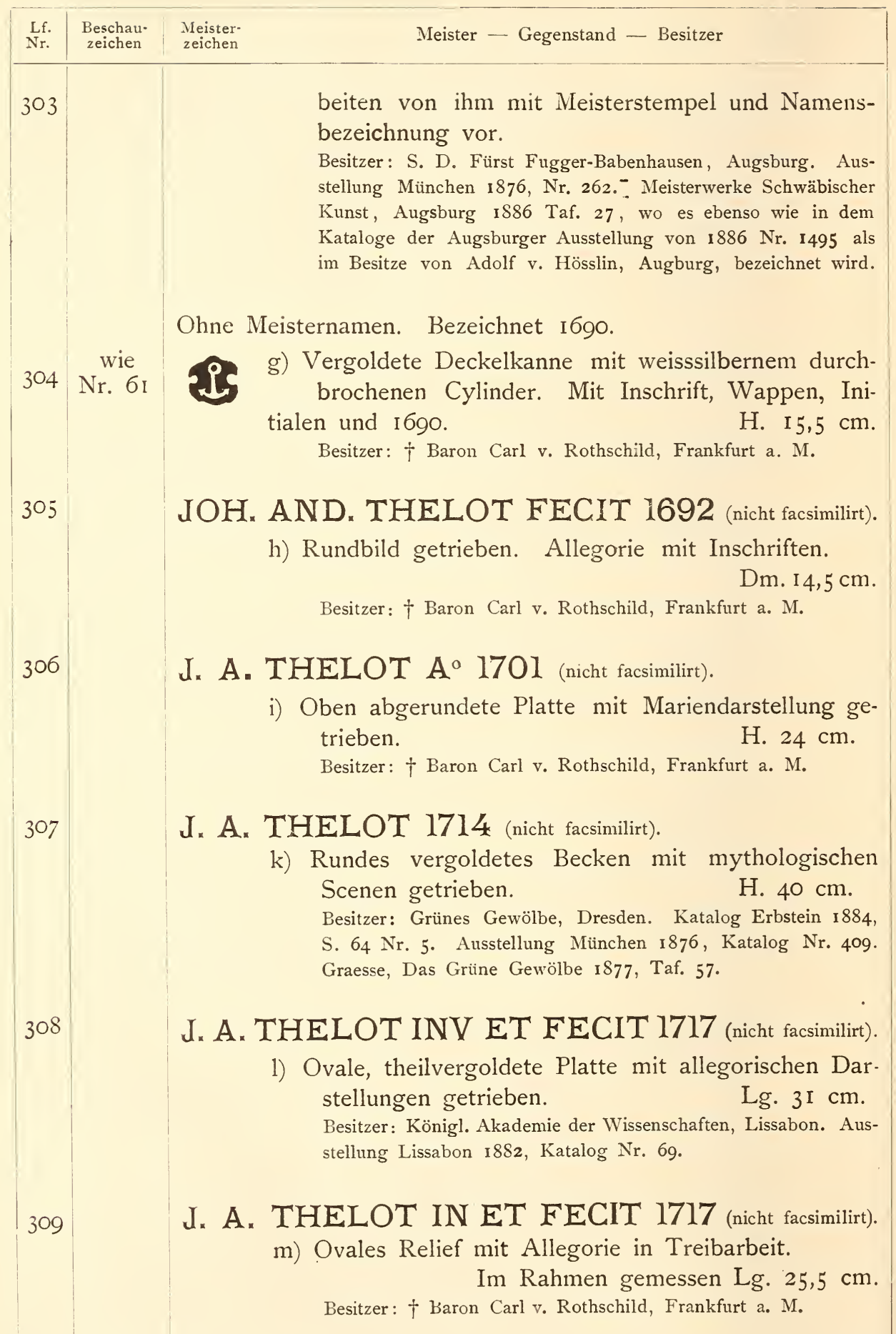




\begin{tabular}{|c|c|c|}
\hline $\begin{array}{l}\text { Lf. } \\
\text { Nr. }\end{array}$ & $\begin{array}{l}\text { Beschau- } \\
\text { zeichen }\end{array}$ & Meister - Gegenstand - Besitzer \\
\hline 310 & & $\begin{array}{l}\text { J. A. THELOT } 1722 \text { (nicht facsimilirt). } \\
\begin{array}{l}\text { n) Platte mit getriebenem Mittelstücke und kleinen } \\
\text { Reliefs am Rande (Jagdscenen). } \\
\text { Besitzer: Königl. Schatzkammer, München. Kat. Schauss I879, } \\
\text { K. 23. Abgebildet ist diese Platte oder eines der zwei zuge- } \\
\text { hörigen Stücke bei Schauss, Schatzkammer. }\end{array}\end{array}$ \\
\hline
\end{tabular}

J. A. THELOT FECIT (1724) (nicht facsimilirt).

o) Rundes getriebenes Goldplättchen mit Inschrift. Als Pathenpfennig verwendet.

Besitzer: Fanny v. Fröhlich, Augsburg. Ausstellung Augsburg, Katalog Nr. I6I7.

J. A. THELOT 1730 (nicht facsimilirt).

p) Silberrelief, Jagdstück.

Besitzer: A. v. Rad, Augsburg. Ausstellung Augsburg I886, Katalog Nr. 1627 .

J. A* THELL(?)OT 1730 (nicht facsimilirt).
q) Silberrelief, Jagdstück.
H. $16 \mathrm{~cm}$.

Besitzer: S. D. Fürst v. Fugger-Babenhausen, Augsburg. Ausstellung München 1876́, Katalog Nr. 1993.

3 I4 $\underset{\text { Nr. } 69}{\text { wie }} \int$ J. A. THELOT (nicht facsimilirt).

r) Weisssilberner Kalender mit einem vergoldeten Mittelrelief in Treibarbeit.

H. $26,5 \mathrm{~cm}$. Besitzer: Verein für Kunst und Alterthum in Ulm und Oberschwaben, Ulm. Ausstellung Augsburg 1886, Katalog Nr. I655. Abgebildet in Zeitschrift des Bayrischen Kunstgewerbevereins, München 1887,6 .

3 I5 Nr.6I $\$$ J. A: THELOT (?) (nicht facsimilirt).

s) Gebetbuch mit getriebenen Platten. Bez. ${ }_{168}$ (oder I696).

Besitzer: Ulrichskirche, Augsburg. Ausstellung Augsburg 1886, Katalog Nr. I635 oder 1636. Wahrscheinlich zwei Stiicke. 


\begin{tabular}{|c|c|c|}
\hline $\begin{array}{l}\text { Lf. } \\
\text { Nr. }\end{array}$ & $\begin{array}{l}\text { Beschau- } \\
\text { zeichen }\end{array}$ & Meister - Gegenstand - Besitzer \\
\hline 316 & $\begin{array}{c}\text { wie } \\
\text { Nr. 6I }\end{array}$ & 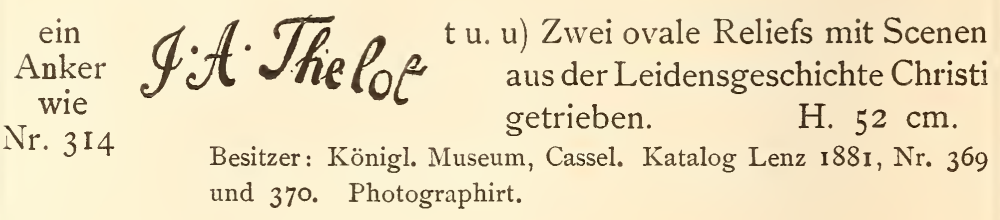 \\
\hline 3 I 7 & $\begin{array}{c}\text { wie } \\
\text { Nr. 6I }\end{array}$ & 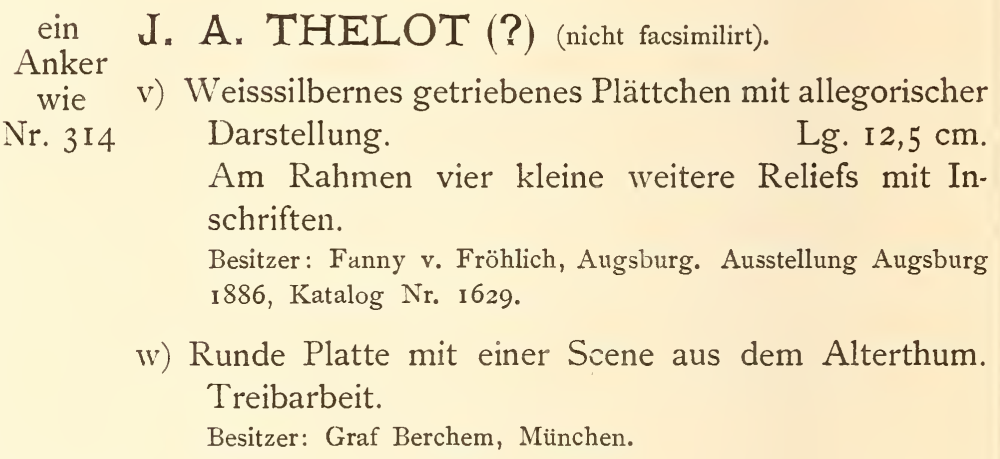 \\
\hline
\end{tabular}

$J_{*}$ A. THELOT (nicht facsimilirt).

$\mathrm{x})$ Platte, mit dem Zeichen des Augsburger Meisters ICD, mit getriebenem Mittelstücke und kleineren Reliefs am Rande.

Lg. $34 \mathrm{~cm}$.

Besitzer: Königl. Schatzkammer, München. Katalog Schauss I879, K. 23 .

y u. z) Zwei Silberreliefs mit mythologischen Darstellungen.

Besitzer: Ed. Landauer, Augsburg. Ausstellung Augsburg 1886, Katalog Nr. 1626.

aa) Platte, mit dem Zeichen des Augsburger Goldschmiedes ICD, mit getriebenem Mittelstücke und kleineren Reliefs am Rande. $\quad$ Lg. $34 \mathrm{~cm}$. Besitzer: Königl. Schatzkammer, München. Katalog Schauss 1879, K. 23. Abgebildet bei Schauss, Schatzkammer.

bb) Vergoldetes Schild mit dem Zeichen des Augsburger Meisters SGK. In der Mitte weisssilbernes getriebenes Relief mit antiken Darstellungen.

H. $34 \mathrm{~cm}$.

Besitzer: Königl. Schatzkammer, München. Katalog Schauss I879. K. 9. 


\begin{tabular}{|c|c|c|}
\hline $\begin{array}{l}\text { Lf. } \\
\text { Nr. }\end{array}$ & $\begin{array}{l}\text { Beschau- } \\
\text { zeichen }\end{array}$ & Meister - Gegenstand - Besitzer \\
\hline 318 & & $\begin{array}{r}\text { cc) Platte mit mythologischer Scene, getrieben. } \\
\text { H. ca. I } 7 \mathrm{~cm} . \\
\text { Besitzer: } † \text { Baron Carl v. Rothschild, Frankfurt a. M. } \\
\text { dd) Ovales Relief mit Allegorie getrieben, in Rahmen. } \\
\text { Lg. } 25,5 \mathrm{~cm} . \\
\text { Besitzer: } \rightarrow \text { Baron Carl v. Rothschild, Frankfurt a. M. }\end{array}$ \\
\hline 319 & & $\begin{array}{l}\text { J. A. THELLOT (nicht facsimilirt). } \\
\begin{array}{l}\text { ee) Getriebene Platte. } \\
\text { Besitzer: Jitta, Amsterdam. Kunsthistorische Ausstellung Cöln } \\
\text { I } 876, \text { Katalog Nr. } 7 \text { I3. }\end{array}\end{array}$ \\
\hline 320 & & $\begin{array}{l}\text { THELOT FECIT (nicht facsimilirt). } \\
\text { ff) Crucifix. Am schwarzen Holze weisssilberne durch- } \\
\text { brochene Ornamente. Am Postamente getriebene } \\
\text { Platte mit Kreuzabnahme. Daran die obige Be- } \\
\text { zeichnung. } \\
\text { Besitzer: National-Museum, München. }\end{array}$ \\
\hline $32 \mathrm{I}$ & & $\begin{array}{l}\text { J. A. THELOT INV ET (?) EEC* (nicht facsimilirt). } \\
\text { gg) Rundes weisssilbernes Relief mit figuraler Treib- } \\
\text { arbeit. } \\
\text { Besitzer: } \uparrow \text { Baron Carl v. Rothschild, Frankfurt a. M. }\end{array}$ \\
\hline 322 & & $\begin{array}{l}\text { J. A. THELOT INY ET FE* (nicht facsimilirt). } \\
\text { hh) Rundbild, figurale Treibarbeit. } \quad \text { Dm. I } 3 \mathrm{~cm} . \\
\text { Besitzer: } \dagger \text { Baron Carl v. Rothschild, Frankfurt a. M. }\end{array}$ \\
\hline 323 & & $\begin{array}{l}\text { I. A. DELOH * } \\
\text { ii) Rundes weisssilbernes Relief mit Allegorien. } \\
\text { Dm. I } 3,2 \mathrm{~cm} \text {. } \\
\text { Besitzer: } \dagger \text { Baron Carl v. Rothschild, Frankfurt a. M. }\end{array}$ \\
\hline 324 & $\begin{array}{c}\text { wie } \\
\text { Nr. } 47\end{array}$ & $\begin{array}{l}\text { kk) Wenig nach oben erweiterter Becher mit getrie- } \\
\text { bener Monatsdarstellung. (Stück einer Serie?) } \\
\text { H. } 9,5 \mathrm{~cm} \text {. } \\
\text { Besitzer: S. H. d. Fürst von Hohenzollern. Ausstellung Augs- } \\
\text { burg i } 886 .\end{array}$ \\
\hline
\end{tabular}




\begin{tabular}{|c|c|c|c|}
\hline $\begin{array}{l}\text { Lf. } \\
\text { Nr. }\end{array}$ & $\begin{array}{l}\text { Beschau- } \\
\text { zeichen }\end{array}$ & $\begin{array}{l}\text { Meister- } \\
\text { zeichen }\end{array}$ & Meister - Gegenstand - Besitzer \\
\hline 324 & $\begin{array}{l}\text { wie } \\
\text { Nr. } 49\end{array}$ & & $\begin{array}{l}\text { 11) Theilvergoldeter Deckelpokal mit mythologischen } \\
\text { Scenen getrieben. H. } 40 \mathrm{~cm} \text {. } \\
\text { Besitzer : Baron Nathanaei v. Rothschild, Wien. }\end{array}$ \\
\hline & wie 60 & & $\begin{array}{l}\text { mm) Fussloser Becher mit Fries. } \\
\text { Besitzer: National-Museum, Budapest. A Ausstellung Buda- } \\
\text { pest I } 884 \text {. }\end{array}$ \\
\hline & wie 46 & & $\begin{array}{l}\text { nn) Nach oben erweiterter Deckelbecher mit figuraler } \\
\text { Treibarbeit am Corpus. } \\
\text { Besitzer: } \uparrow \text { Haron Carl v. Rothschild, Frankfurt a. M. }\end{array}$ \\
\hline
\end{tabular}

325 Nr. 54

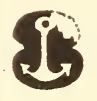

oo) Weite vergoldete sechsseitige Schraubenflasche mit Monatsdarstellungen.

H. $2 \mathrm{I} \mathrm{cm}$.

Ausstellung Budapest 1884 .

326 Nr. 64 Y

pp) Sechsseitige theilvergoldete Platte. Innen figural, aussen mit Ranken und Adlern getrieben.

Lg. $26 \mathrm{~cm}$.

Besitzer: Baron Nathanael v. Rothschild, Wien.

wie 70 wie qq u. rr) Zwei weisssilberne Kännchen. H. ca. I $8 \mathrm{~cm}$. Nr. 3I 5 Besitzer: A. v. Rad, Augsburg. Ausstellung Augsburg 1886, Katalog Nr. 1605 .

wie 69 wie 3 I4 ss) Kanne mit gravirten und getriebenen Darstellungen. H. $19,3 \mathrm{~cm}$.

Besitzer: $†$ Baron Carl v. Rothschild, Frankfurt a. M. Luthmer, Schatz Rothschild I, Taf. 40.

tt) Schraubenflasche mit getriebenen figuralen Darstellungen.

H. I8 $\mathrm{cm}$.

Besitzer: S. D. Fürst Fugger-Babenhausen, Augsburg. Ausstellung München 1876, Katalog Nr. 1930.

uu) Getriebene Kanne, „Scenen aus der Mythologie, Arabesken und Hirsche".

H. I $8 \mathrm{~cm}$.

Besitzer: S. D. Fürst Fugger-Babenhausen, Augsburg. Ausstellung München I876, Katalog Mr. 2033.

Auf der Scheide vom I7. zum I8. Jahrhundert lebendes Mitglied der Goldschmiedefamilie

\section{Drentwett.}

Wahrscheinlich ein Abraham D., deren es drei oder vier damals neben und nach einander gab. 


\begin{tabular}{|c|c|c|}
\hline $\begin{array}{l}\text { Lff. } \\
\text { Nr. }\end{array}$ & $\begin{array}{l}\text { Beschau- } \\
\text { zeichen }\end{array}$ & Meister - Gegenstand - Besitzer \\
\hline 327 & $\begin{array}{c}\text { wie } \\
\text { Nr. } 56\end{array}$ & $\begin{array}{l}\text { a u. b) Zwei Spiegelrahmen mit grossen getriebenen } \\
\text { Ranken und vorgesetzten Figuren und Thieren. } \\
\text { Breit } 157 \mathrm{~cm} . \\
\text { Besitzer: Grosses Palais im Kreml, Moskau. }\end{array}$ \\
\hline & wie 49 & $\begin{array}{l}\text { c) Bauchiges Ciborium mit getriebenen Blumenguir- } \\
\text { landen, Griff ein knieender Engel. H. } 4 \mathrm{I} \mathrm{cm} \text {. } \\
\text { Besitzer: Ulrichskirche, Augsburg. Ausstellung Augsburg I886, } \\
\text { Katalog Nr. }{ }^{4003 .}\end{array}$ \\
\hline & wie 55 & $\begin{array}{l}\text { d u. f) Drei weisssilberne Figuren mit vergoldeten Ge- } \\
\text { wändern und Attributen. } \\
\text { Besitzer: Königl. Museum, Cassel. Kat. Lenz I88 } 28,5 \mathrm{~cm} \text {. Nr. } 52 .\end{array}$ \\
\hline & ? & $\begin{array}{l}\text { g u. h) Zwei theilvergoldete Figuren. H. } 44 \mathrm{~cm} \text {. } \\
\mathrm{i} \text { u. k) und zwei Vasen mit getriebenen vergoldeten } \\
\text { Blättern, Halbedelsteinen und Email geziert. } \\
\text { Besitzer: Reiche Kapelle, München. }\end{array}$ \\
\hline & wie $6 ;$ & $\begin{array}{l}\text { 1-q) Sechs Stück kleine weisssilberne Figuren mit ver- } \\
\text { goldeten Gewändern, je zwei auf gleichen Posta- } \\
\text { menten. } \\
\text { B. I } 7-19 \mathrm{~cm} . \\
\text { Besitzer: } \uparrow \text { Baron Carl v. Rothschild, Frankfurt a. M. }\end{array}$ \\
\hline & wie $5 \mathrm{I}$ & $\begin{array}{l}\text { r) Vergoldete grosse Prunkvase. } \\
\text { Besitzer: Grünes Gewölbe, Dresden. Katalog Erbstein I } 884 \text {, } \\
\text { S. } 86 \text { Nr. I22. Graesse, Das Grüne Gewölbe I } 877 \text {, Taf. } 68 .\end{array}$ \\
\hline & ? & $\begin{array}{ll}\text { s) Grosse Kunstuhr. } & \text { H. ca. } 50 \mathrm{~cm} \text {. } \\
\text { Besitzer: Deutschordensschatz, Wien. } & \end{array}$ \\
\hline 328 & & $\begin{array}{l}\text { Peter Rams, } \uparrow \text { I737, oder } \\
\text { Peter Rox, } † \text { I } 742 \text {. Vergl. ubrigens die folgende } \\
\text { Marke. }\end{array}$ \\
\hline & $\begin{array}{l}\text { wie } \\
\text { Nr. } 56\end{array}$ & $\begin{array}{l}\text { a-c) Drei weisssilberne ovale Platten mit figürlichen } \\
\text { Darstellungen. Rand mit Blumen. Lg. } 30 \mathrm{~cm} \text {. } \\
\text { Besitzer: National-Museum, Budapest. Ausstellung Buda- } \\
\text { pest } 1884 \text {. }\end{array}$ \\
\hline & wie 5 I & $\begin{array}{l}\text { d) Vergoldetes ovales Schälchen. In der Mitte Land- } \\
\text { schaft, am Rande Laubwerk. } \mathrm{Lg} \text {. I I, } 3 \mathrm{~cm} \text {. } \\
\text { Besitzer: Museum der Eremitage, St. Petersburg. }\end{array}$ \\
\hline & wie 70 & $\begin{array}{l}\text { e) Vergoldeter zweiarmiger Wandleuchter. Reflector mit } \\
\text { Spiegel und getriebenen Ornamenten. H. I03 cm. } \\
\text { Besitzer: Königl. Schloss, Dresden. }\end{array}$ \\
\hline
\end{tabular}




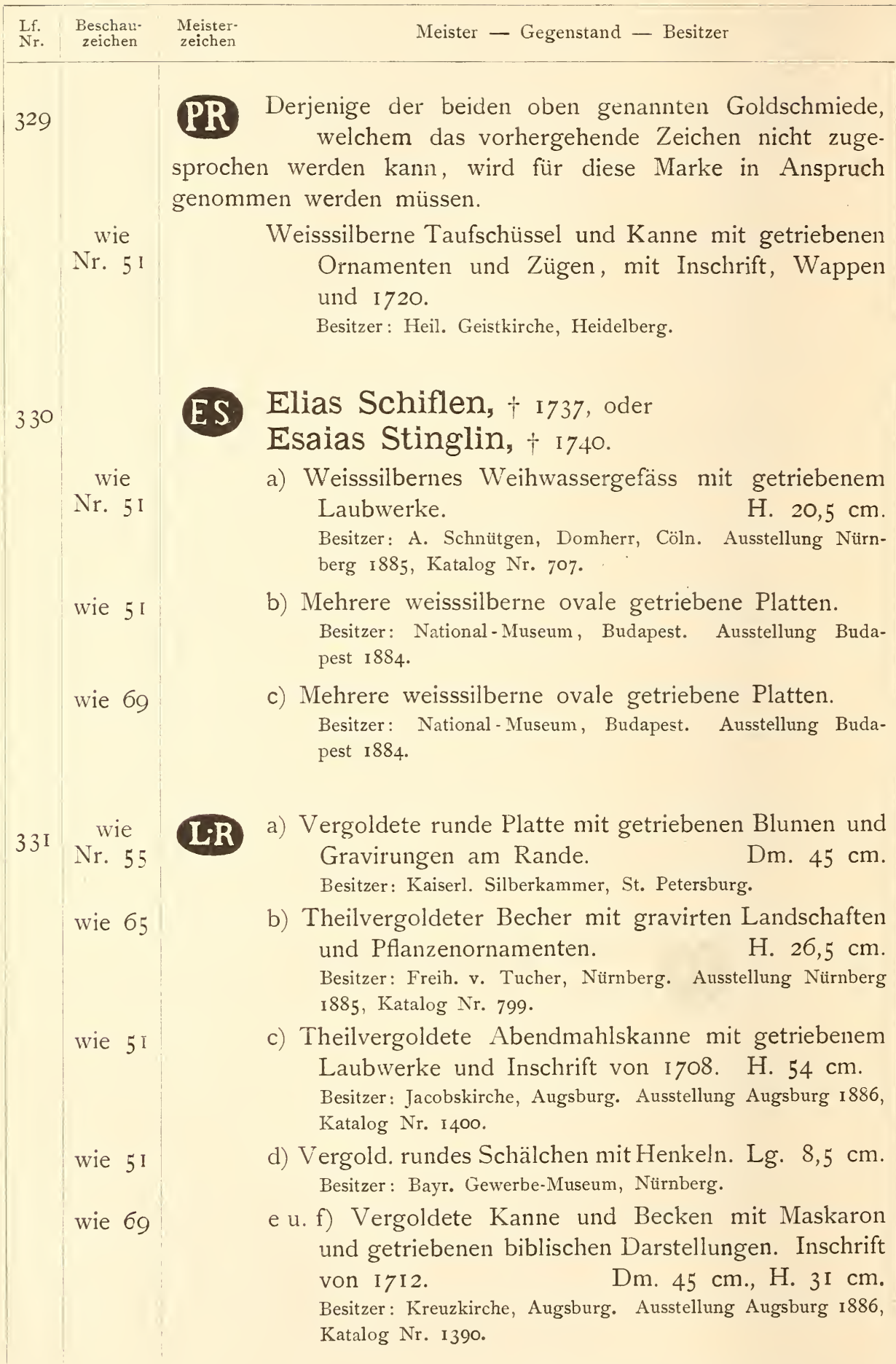




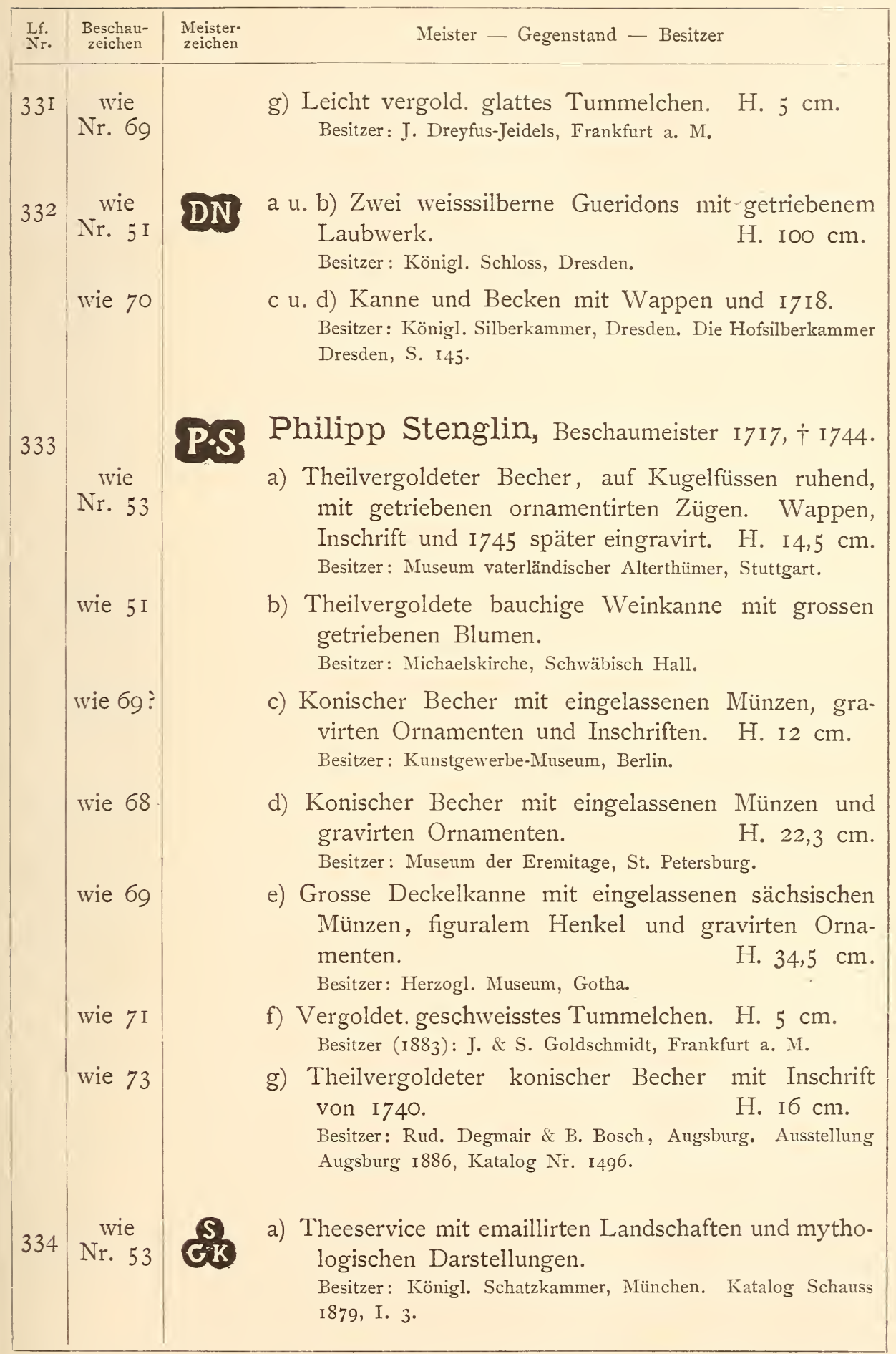




\begin{tabular}{|c|c|c|c|}
\hline $\begin{array}{l}\text { Lf. } \\
\text { Nr. }\end{array}$ & $\begin{array}{l}\text { Beschau- } \\
\text { zeichen }\end{array}$ & $\begin{array}{l}\text { Meister- } \\
\text { zeichen }\end{array}$ & Meister - Gegenstand - Besitzer \\
\hline 334 & $\begin{array}{l}\text { wie } \\
\text { Nr. } 69\end{array}$ & & $\begin{array}{l}\text { b) Trinkgefäss in Gestalt eines Fasanen, bemalt, mit } \\
\text { Inschrift und I } 7 \mathrm{I} 6 . \\
\text { Besitzer: Herzogl. Museum, Gotha. Katalog Bube I869, Nr. } 30 .\end{array}$ \\
\hline 335 & $\begin{array}{l}\text { wie } \\
\text { Nr. } 54\end{array}$ & ISA & $\begin{array}{l}\text { Joh. Sigmund Aberell, Beschaumeister I699 } \\
\text { und I II3, † I } 733 \text {. } \\
\begin{array}{l}\text { a) Vergold. glatter Becher in Römerform. H. } 8,3 \mathrm{~cm} \text {. } \\
\text { Besitzer: Herzogl. Museum, Gotha. }\end{array}\end{array}$ \\
\hline & wie 69 & & $\begin{array}{l}\text { b) Vergoldetes ornamentirtes Tummelchen. } \\
\text { Besitzer: Baron R. v. Walterskirchen, Wien. }\end{array}$ \\
\hline & wie 69 & & $\begin{array}{l}\text { c) Weisssilberner Leuchter. H. } 20 \mathrm{~cm} \text {. } \\
\text { Besitzer: Grossherzogl. Silberkammer, Darmstadt. }\end{array}$ \\
\hline
\end{tabular}

wie

Nr. 54

wie 56

wie 39

wie 69

u. 74

-

wie

Nr. 56

wie

Nr. 68

\section{IC}

Joh. Cristoph Träffler $†$ † 1722 .

a) Vergoldete Gurde (Flasche) mit gravirten Bauernscenen.

H. $19 \mathrm{~cm}$.

Besitzer: $\uparrow$ Baron Carl v. Rothschild, Frankfurt a. M.

b-d) Drei Stück vergoldete niedere Becherchen (Tummelchen) mit gravirten Blätterranken. H. $5 \mathrm{~cm}$.

Besitzer: S. Fürth, Mainz. Abgebildet in Edelmetallarbeiten der Sammlung Fürth I886, Nr. 31.

e) Vergoldeter Becher, auf Kugelfüssen ruhend, mit gravirten Landschaften.

H. $9,6 \mathrm{~cm}$.

Besitzer: National-Museum, Budapest. Ausstellung Budapest 1884 .

f) Mehrere weisssilberne, zum Theil auch vergoldete Deckelbecher mit Zügen.

H. $20-22 \mathrm{~cm}$. Besitzer: Herzogl. Museum, Gotha.

Die beiden folgenden Marken sind wahrscheinlich identisch. CI Löffel und Gabel mit geätzten Ornamenten. Löffel, Lg. I7 $\mathrm{cm}$. Besitzer: Ed. Goldschmidt, Frankfurt a. M.

Zwei vergoldete Zuckerdosen mit getriebenen Zügen. Auf dem Deckel einer jeden ein Reitergefecht in Email. $\mathrm{Zu}$ einem Service gehörig. H. 6,4 cm. Besitzer: Museum der Eremitage, St. Petersburg. 


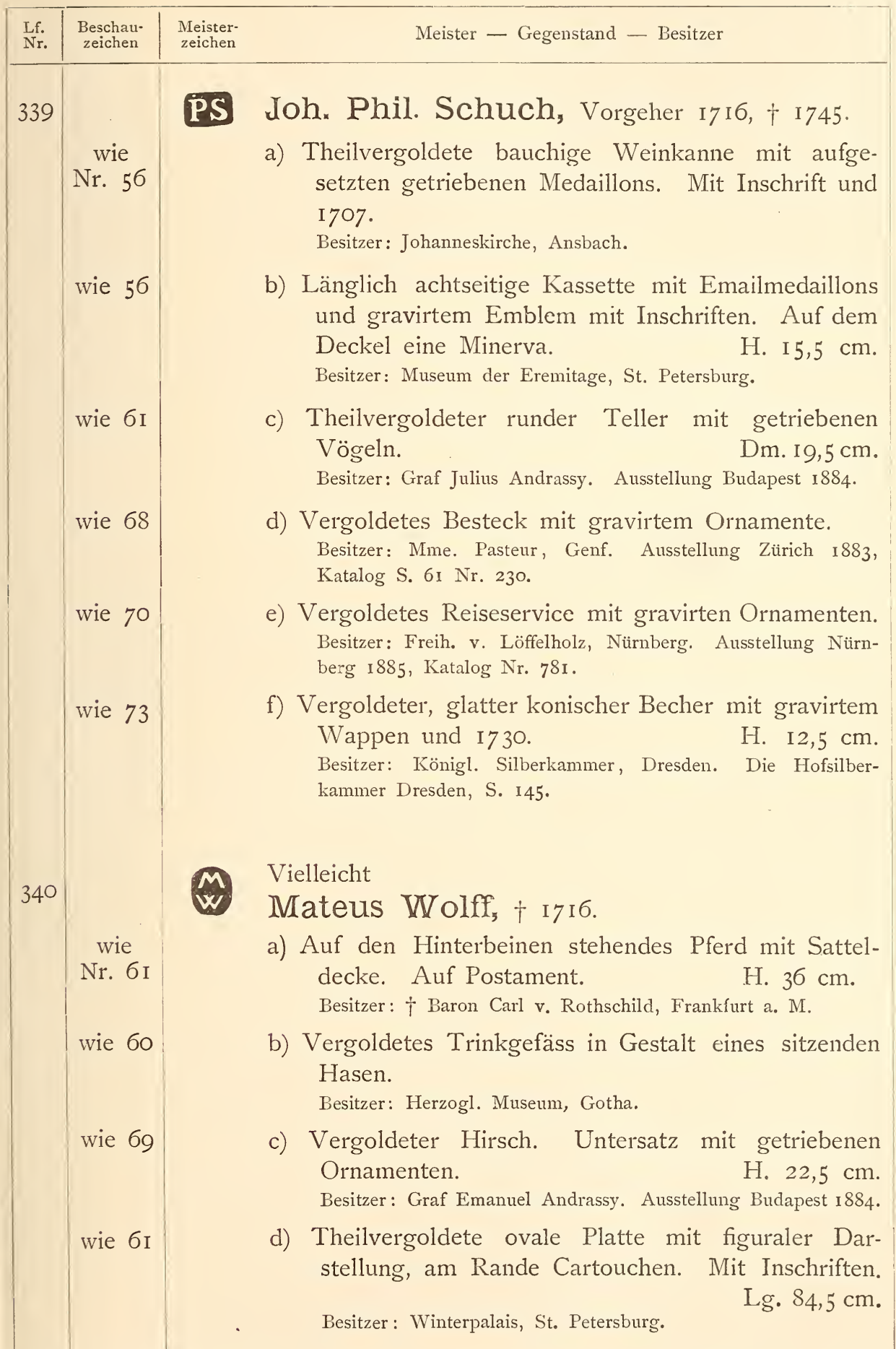




\begin{tabular}{|c|c|c|c|}
\hline $\begin{array}{l}\text { Lff. } \\
\text { Nr. }\end{array}$ & $\begin{array}{l}\text { Beschau- } \\
\text { zeichen }\end{array}$ & & Meister - Gegenstand - Besitzer \\
\hline \multirow[t]{4}{*}{340} & ? & & $\begin{array}{l}\text { e) Ovale weisssilberne Platte mit figuraler Darstellung. } \\
\text { Am Rande getriebene Portraitmedaillons mit In- } \\
\text { schriften. } \\
\text { Besitzer: Winterpalais, St. Petersburg. }\end{array}$ \\
\hline & $\begin{array}{l}\text { wie } \\
\text { Nr. 6I }\end{array}$ & & $\begin{array}{l}\text { f) Weisssilberne getriebene ovale Platte; Kinder, Blu- } \\
\text { men und Früchte. } \\
\text { Ausstellung Budapest i } 884 .\end{array}$ \\
\hline & wie $6 \mathrm{I}$ & & $\begin{array}{l}\text { g) Theilvergoldete getriebene Kanne. H. } 43 \mathrm{~cm} \text {. } \\
\text { Besitzer: } † \text { Baron Carl v. Rothschild, Frankfurt a. M. }\end{array}$ \\
\hline & wie 57 & & $\begin{array}{l}\text { h) Vergoldeter Weihwasserkessel, getrieben und mit } \\
\text { einer Mariendarstellung gravirt. } \quad \text { H. I7,9 cm. } \\
\text { Besitzer: Baron Karl Apor. Ausstellung Budapest I884, } \\
\text { 2. Saal, 13. Schrank, Nr. 59. Katalog S. 145. }\end{array}$ \\
\hline \multirow[t]{6}{*}{$34 \mathrm{I}$} & & 1 & $\begin{array}{l}\text { Möglicherweise } \\
\text { Michael Mayr, Vorgeher I695, Beschaumeister } \\
\text { ı699, † I7I4. }\end{array}$ \\
\hline & $\begin{array}{l}\text { wie } \\
\text { Nr. } 66\end{array}$ & & $\begin{array}{l}\text { a) Monstranz von Gold und Silber mit Emailverzierung, } \\
\text { Perlen und Edelsteinen besetzt. H. } 53,5 \mathrm{~cm} \text {. } \\
\text { Besitzer: Stadtpfarrei, Augsburg. Ausstellung Augsburg I886, } \\
\text { Katalog Nr. I331. }\end{array}$ \\
\hline & wie 57 & & $\begin{array}{l}\text { b) Vergoldetes Ziergefäss mit muschelförmiger Cuppa. } \\
\text { Füsse figural gebildet. } \\
\text { Besitzer: } † \text { Haron Carl v. Rothschild, Frankfurt a. M. }\end{array}$ \\
\hline & wie 57 & & $\begin{array}{l}\text { c) Vergoldetes Messgeräth mit Emailmedaillons und } \\
\text { Steinen besetzt. Bezeichnet I 705. Platte, Lg. } 33 \mathrm{~cm} \text {. } \\
\text { Besitzer: Kirche und Schulpflege, Schwäb. Gmünd. Ausstellung } \\
\text { Augsburg I886, Katalog Nr. I375. Biermann, Ausstellung } \\
\text { Gmünd, Taf. 14. }\end{array}$ \\
\hline & ? & & $\begin{array}{l}\text { d) Weisssilberne Hängelampe. } \\
\text { Besitzer: Domschatz, Gran. }\end{array}$ \\
\hline & wie 64 & & 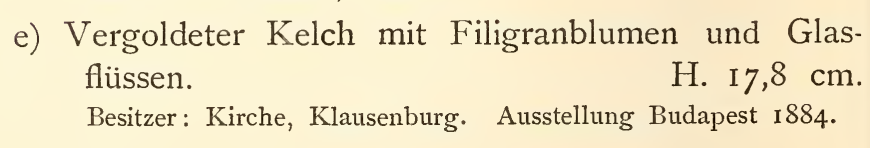 \\
\hline \multirow[t]{2}{*}{342} & & & $\begin{array}{l}\text { Meister des beginnenden I8. Jahrhunderts aus der } \\
\quad \text { Goldschmiedefamilie } \\
\text { Pfeffenhauser }\end{array}$ \\
\hline & $\begin{array}{l}\text { wie } \\
\text { Nr. } 60\end{array}$ & & $\begin{array}{l}\text { a) Weisssilbernes ovales Plättchen. Lg. I7,5 cm. } \\
\text { Besitzer: Grossherzogl. Silberkammer, Darmstadt. }\end{array}$ \\
\hline
\end{tabular}




\begin{tabular}{|c|c|c|c|}
\hline $\begin{array}{l}\text { Lf. } \\
\text { Nr. }\end{array}$ & $\begin{array}{l}\text { Beschau- } \\
\text { zeichen }\end{array}$ & $\begin{array}{l}\text { Meister- } \\
\text { zeichen }\end{array}$ & Meister - Gegenstand - Besitzer \\
\hline 342 & $\begin{array}{l}\text { wie } \\
\text { Nr. } 74\end{array}$ & & $\begin{array}{l}\text { b u. c) Weisssilberne Kanne und Becken mit Ini- } \\
\text { tialen. } \\
\text { Besitzer : Königl. Silberkammer, Dresden. }\end{array}$ \\
\hline & wie 7 I & & $\begin{array}{l}\text { d) Weisssilberne ovale Platte mit eingezogenem Rande } \\
\text { und schwachen Henkeln. } \\
\text { Besitzer: Staatssecretär Polowzow, St. Petersburg. } 49 \mathrm{~cm} \text {. }\end{array}$ \\
\hline 343 & $\begin{array}{l}\text { wie } \\
\text { Nr. } 64\end{array}$ & & $\begin{array}{l}\text { Nicolaus Ostertag, Beschaumeister I72I, † I74I. } \\
\text { Zwei theilvergoldete grosse Vasen mit Reliefs, die } \\
\text { Welttheile darstellend. } \quad \text { H. } 62 \mathrm{~cm} \text {. } \\
\text { Besitzer: } \dagger \text { Baron Carl v. Rothschild, Frankfurt a. M. Auf } \\
\text { die Ausstellung Karlsruhe I88I, Katalog Nr. I665, gesandt } \\
\text { durch die kath. Stadtkirche Karlsruhe. Abgebildet in Aeltere } \\
\text { kunstgewerbliche Arbeiten auf der Ausstellung Karlsruhe r88I. }\end{array}$ \\
\hline 344 & $\begin{array}{l}\text { wie } \\
\text { Nr. } 67\end{array}$ & & $\begin{array}{l}\text { Johx Jac, Kraus, † I74I. } \\
\text { Vergoldeter Kelch mit Inschrift von I7OI. H. } 25 \mathrm{~cm} \text {. } \\
\quad \text { Besitzer: Katharinenkirche, Schwäb. Hall. }\end{array}$ \\
\hline 345 & $\begin{array}{l}\text { wie } \\
\text { Nr. } 67\end{array}$ & $\eta$ & $\begin{array}{l}\text { Weisssilberne ovale getriebene Platte. In der Mitte } \\
\text { eine Figur, am Rande Laubwerk. Lg. I7,7 cm. } \\
\text { Besitzer: Kunstgewerbe-Museum, Berlin. }\end{array}$ \\
\hline 346 & & IB & $\begin{array}{l}\text { Johannes Biller }{ }_{3} \dagger \text { I } 745 . \text { Verwechselung mit } \\
\text { Hans Biller nicht ausgeschlossen. }\end{array}$ \\
\hline & $\begin{array}{l}\text { wie } \\
\text { Nr. } 69\end{array}$ & & $\begin{array}{l}\text { a u. b) Zwei weisssilberne, dreieckig abgekantete Gueri- } \\
\text { dons mit Treibarbeit. } \\
\text { Besitzer: Königl. Schloss, Dresden. }\end{array}$ \\
\hline & wie 69 & & $\begin{array}{l}\text { c) Weisssilberne Vase, als Samowar gebildet. An den } \\
\text { Henkeln weibliche Köpfe. } \\
\text { Besitzer: Winterpalais, St. Petersburg. }\end{array}$ \\
\hline & wie 68 & & $\begin{array}{l}\text { d) Vergoldete Platte mit gravirtem Wappen und I } 7 \text { I } 8 . \\
\text { Lg. } 56 \mathrm{~cm} \text {. } \\
\text { Besitzer: Königl. Silberkammer, Dresden. }\end{array}$ \\
\hline & ? & & $\begin{array}{l}\text { e) Vergoldete Terrine, bezeichnet I7I8. } \\
\text { Besitzer: Königl. Silberkammer, Dresden. }\end{array}$ \\
\hline
\end{tabular}




\begin{tabular}{|c|c|c|}
\hline $\begin{array}{l}\text { Lf. } \\
\text { Nr. }\end{array}$ & & Meister - Gegenstand - Besitzer \\
\hline 346 & $\begin{array}{l}\text { wie } \\
\text { Nr. } 72\end{array}$ & $\begin{array}{l}\text { f) Vergoldete runde, mehrfach eingezogene, Platte mit } \\
\text { getriebener biblischerDarstellung. Inschrift von I } 720 \text {. } \\
\text { Besitzer: Ulrichskirche, Augsburg. Ausstellung Augsburg } 1886 .\end{array}$ \\
\hline & wie 68 & $\begin{array}{l}\text { g) Bauchige Kanne mit Gravirung. } \\
\text { Ausstellung Augsburg I } 886 .\end{array}$ \\
\hline & $?$ & $\begin{array}{l}\text { h) Weisssilbernes ovales Relief; Abundantia. Lg. } 24 \mathrm{~cm} \text {. } \\
\text { Besitzer: } † \text { Baron Carl v. Rothschild, Frankfurt a. M. }\end{array}$ \\
\hline 347 & & $\begin{array}{l}10.5 \text { Eine Notiz in „Die Hof-Silberkammer und die Hof- } \\
\text { Kellerei zu Dresden“, Dresden I } 880 \text {, S. I43, I44, } \\
\text { I46 und I } 93 \text { aufnehmend, mache ich den Versuch für neben- } \\
\text { stehendes Monogramm den Namen } \\
\text { Daniel Schlesinger vorzuschlagen, den ich } \\
\text { aber in den benützten Augsburger Quellen nicht gefunden habe. }\end{array}$ \\
\hline & $\begin{array}{l}\text { wie } \\
\text { Nr. } 68\end{array}$ & $\begin{array}{l}\text { a-d) Rosenwasserkanne und Becken. Auch zwei weitere } \\
\text { Stücke. } \\
\text { Besitzer: Grünes Gewölbe, Dresden. }\end{array}$ \\
\hline & wie 68 & $\begin{array}{l}\text { e) Weisssilberner runder Teller. Dm. } 29 \mathrm{~cm} \text {. } \\
\text { Besitzer: Grossherzogl. Silberkammer, Darmstadt. }\end{array}$ \\
\hline & wie 68 & $\begin{array}{l}\text { f) Grosse Deckelkanne, gegossen u. ciselirt. H. } 29 \mathrm{~cm} \text {. } \\
\text { Besitzer: Grossherzogl. Silberkammer, Darmstadt. }\end{array}$ \\
\hline & wie 70 & $\begin{array}{l}\text { g) Vergoldetes Servirbrett, auf Fuss, mit gravirtem } \\
\text { Wappen und I7 I8. } \\
\text { Besitzer: Königl. Silberkammer, Dresden. }\end{array}$ \\
\hline & wie 70 & $\begin{array}{l}\text { h) Rundes Servirbrett mit gravirten Ornamenten und } \\
\text { Medaillonköpfen. } \\
\text { Besitzer: Königl. Silberkammer, Dresden. }\end{array}$ \\
\hline & wie 69 & $\begin{array}{l}\text { i) Vergoldete Confectschale auf Fuss. } \text { H. } 8,5 \mathrm{~cm} \text {. } \\
\text { Besitzer: Königl. Silberkammer, München. }\end{array}$ \\
\hline & wie 74 & $\begin{array}{l}\text { k) Vergoldete Fassung einer Porzellankanne. } \\
\text { Besitzer: S. K. H. d. Grossherzog von Baden, Schloss Karls- } \\
\text { ruhe. Ausstellung Karlsruhe I88I, Katalog Nr. I340. }\end{array}$ \\
\hline & wie 74 & $\begin{array}{l}\text { 1) Vergoldete runde Platte mit getriebener mytho- } \\
\text { logischer Darstellung und aufgesetzten Medaillons. } \\
\text { Dm. } 55 \mathrm{~cm} .\end{array}$ \\
\hline & wie 74 & $\begin{array}{ll}\text { m) Dazu eine Kanne. } & \text { H. } 28 \mathrm{~cm} . \\
\text { Besitzer: Herzogl. Museum, Gotha. } & \end{array}$ \\
\hline
\end{tabular}




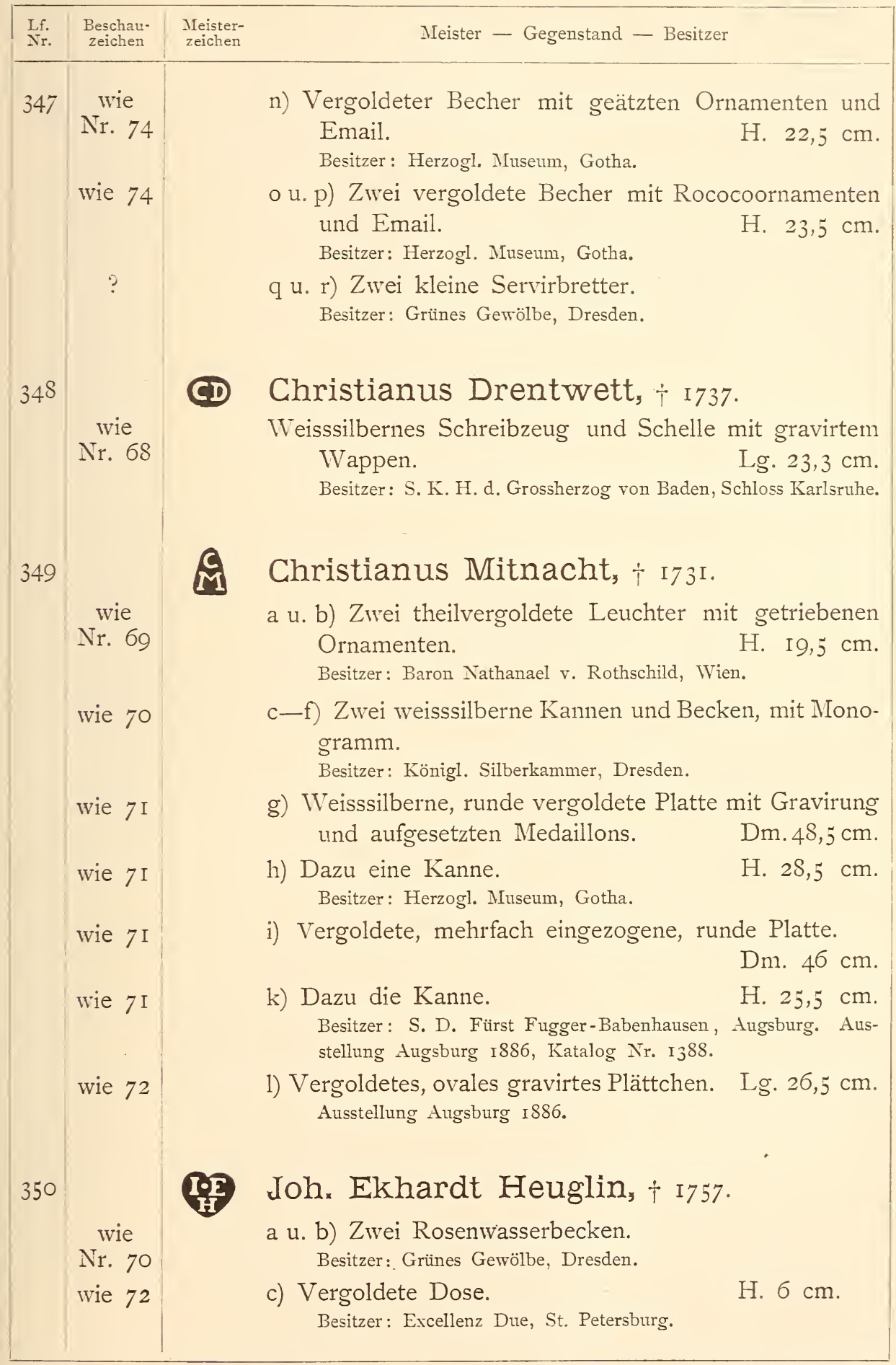




\begin{tabular}{|c|c|c|c|}
\hline $\begin{array}{l}\text { Lff. } \\
\mathrm{Nr}_{\mathrm{r}}\end{array}$ & $\begin{array}{l}\text { Beschau- } \\
\text { zeichen }\end{array}$ & $\begin{array}{l}\text { Meister- } \\
\text { zeichen }\end{array}$ & Meister - Gegenstand - Besitzer \\
\hline 350 & $\begin{array}{l}\text { wie } \\
\text { Nr. } 69\end{array}$ & & $\begin{array}{l}\text { d) Circa } 25 \text { diverse Gegenstände wie Becken, Kannen, } \\
\text { Schalen, Tassen, Toilettenstücke etc. } \\
\text { Besitzer: Königl. Silberkammer, München. Katalog Schauss } \\
\text { I879, G. } 43 \text { bis G. } 54 \text {. }\end{array}$ \\
\hline $35 \mathrm{I}$ & & EA & Elias Adam $†$ i 745. \\
\hline & $\begin{array}{l}\text { wie } \\
\text { Nr. } 59 \text { ? }\end{array}$ & & $\begin{array}{l}\text { a) Vergoldete Fassung eines Trinkgeschirres von Rhino- } \\
\text { ceroshorn, in Schiffsform geschnitzt. Mit figuralem } \\
\text { Griffe. } \\
\text { Besitzer: Königl. Schatzkammer, München. Katalog Schauss } \\
\text { I879, E. I3. Abgeb. bei Schauss, Schatzkammer. }\end{array}$ \\
\hline & wie 53 & & $\begin{array}{l}\text { b) Kleiner silberner Becher, aussen vergoldet. } \\
\text { Besitzer (1883): J. \& S. Goldschmidt, Frankfurt a. M. }\end{array}$ \\
\hline & wie 5 I & & $\begin{array}{l}\text { c u. d) Zwei vergoldete Dosen, getrieben mit Land- } \\
\text { schaft und Ornamenten. } \\
\text { Besitzer: Museum der Eremitage, St. Petersburg. }\end{array}$ \\
\hline & wie $5 \mathrm{I}$ & & $\begin{array}{l}\text { e) Weisssilbernes getriebenes Gefäss, mit figuralem } \\
\text { Griffe. Auf dem Deckel ein Steinbock. H. } 2 \mathrm{I}, 3 \mathrm{~cm} \text {. } \\
\text { Besitzer: S. K. H. d. Grossherzog von Baden, Schloss Karlsruhe. }\end{array}$ \\
\hline & wie 5 I & & $\begin{array}{l}\text { f) Vergoldeter Becher in Gestalt einer Nonne mit Buch } \\
\text { und Kerze. } \\
\text { Besitzer: G. Gimbel, Baden-Baden. Ausstellung Karlsruhe I } 88 \mathrm{r} \text {, } \\
\text { Katalog Nr. SI. }\end{array}$ \\
\hline & ? & & $\begin{array}{l}\text { g) Kirchliches Geräth in Form einer Schale. } \\
\text { Besitzer: Winterpalais, St. Petersburg. Silberausstellung St. Pe- } \\
\text { tersburg 1885, Katalog Nr. } 35 \text {. }\end{array}$ \\
\hline & wie 69 & & $\begin{array}{l}\text { h) Vergoldete Fassung einer von Bellekin gravirten } \\
\text { Muschel. Von einem Amor getragen. H. } 28 \mathrm{~cm} \text {. } \\
\text { Besitzer: Johannes Paul, Hamburg. Auctionskatalog } 1882 \\
\text { Nr. 723. }\end{array}$ \\
\hline & wie 69 & & $\begin{array}{l}\text { i) Vergold. konischer Becher mit Email. H. 9,9 cm. } \\
\text { Besitzer: S. K. H. d. Grossherzog von Baden, Schloss Karlsruhe. }\end{array}$ \\
\hline & wie 69 & & $\begin{array}{l}\text { k) Ovale Dose mit gepunzten Ornamenten. Lg. } 4,5 \mathrm{~cm} \text {. } \\
\text { Besitzer: Prof. Seyffer, Stuttgart (1882.) }\end{array}$ \\
\hline & wie 69 & & $\begin{array}{l}\text { 1-r) Vergoldete Schale, auf Fuss, mit sechs von J. J. } \\
\text { Priester emaillirten Becherchen. } \\
\text { Besitzer: Herzogl. Museum, Gotha. }\end{array}$ \\
\hline
\end{tabular}




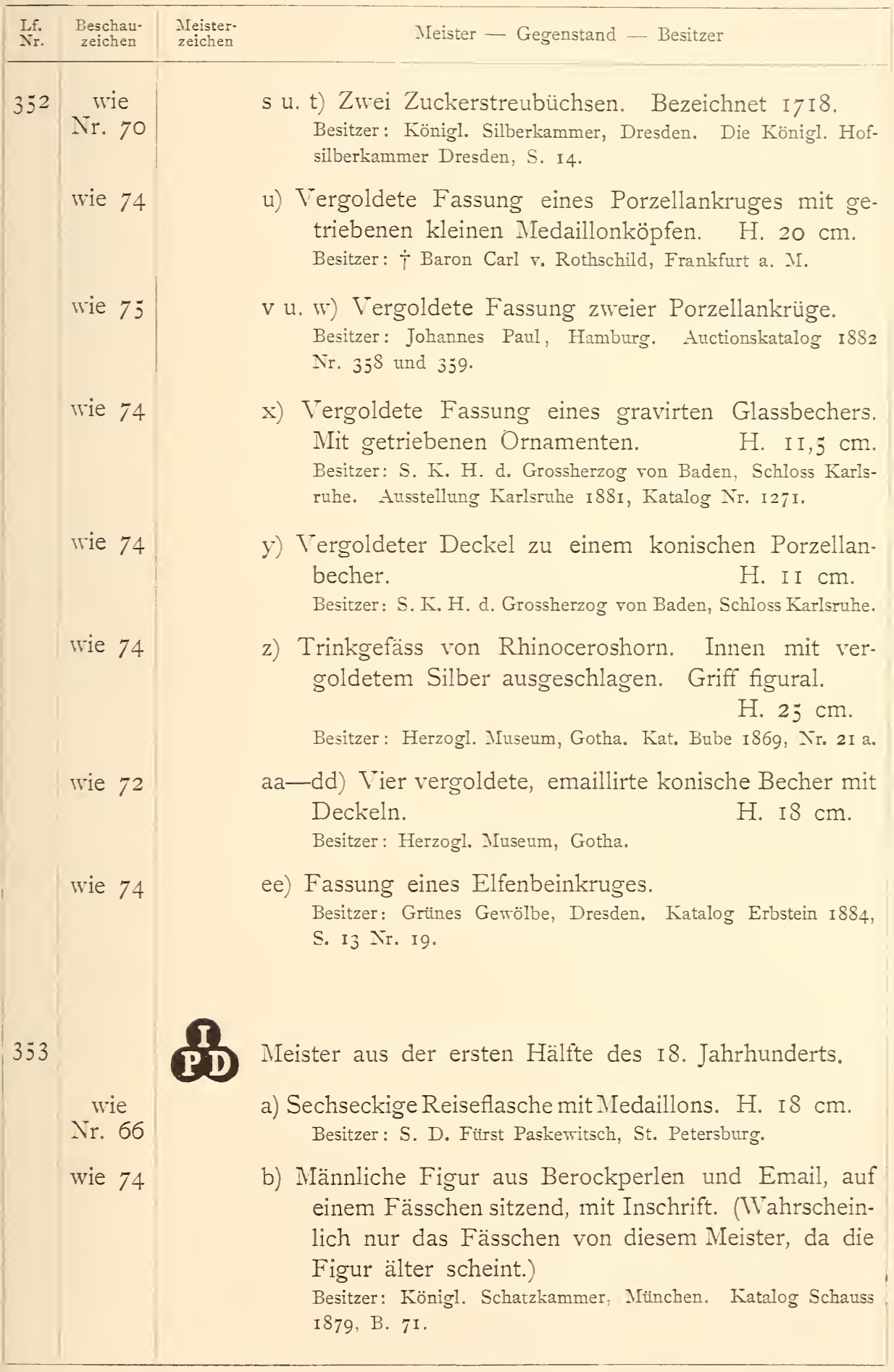




\begin{tabular}{|c|c|c|c|}
\hline $\begin{array}{l}\text { Lf. } \\
\text { Nr. }\end{array}$ & $\begin{array}{l}\text { Beschau- } \\
\text { zeichen }\end{array}$ & $\begin{array}{l}\text { Meister- } \\
\text { zeichen }\end{array}$ & Meister - Gegenstand - Besitzer \\
\hline 353 & $\begin{array}{l}\text { wie } \\
\text { Nr. } 72\end{array}$ & & $\begin{array}{l}\text { c) Silberne Montirung eines Tisches, mit grüner Mar- } \\
\text { morplatte, auf drei Füssen mit drei getriebenen } \\
\text { identischen Büsten. } \\
\text { Besitzer: Grosses Palais im Kreml, Moskau. }\end{array}$ \\
\hline & wie 78 ? & & $\begin{array}{l}\text { d u. e) Vergoldete Platte und Kanne mit getriebenen } \\
\text { Rococoornamenten und biblischen Darstellungen. } \\
\text { Dm. 44,5 resp. H. } 37 \text { cm. } \\
\text { Besitzer: Barfüsserkirche, Augsburg. Ausstellung Augsburg I886, } \\
\text { Kat. Nr. 1391. Meisterwerke Schwäb. Kunst, Taf. 22. }\end{array}$ \\
\hline & wie 73 & & $\begin{array}{l}\text { f) Vergoldete Terrine mit Deckel. Griffe als weib- } \\
\text { liche Figuren gebildet. Wappen und I730. } \\
\text { Besitzer: Königl. Silberkammer, Dresden. }\end{array}$ \\
\hline & wie 69 & & $\begin{array}{l}\text { g u. h) Zwei weisssilberne Altarleuchter. H. } 39 \mathrm{~cm} \text {. } \\
\text { Besitzer: Reiche Kapelle, München. }\end{array}$ \\
\hline & ? & & $\begin{array}{l}\text { i) Theilvergoldeter Kugelbecher mit getriebenen Land- } \\
\text { schaften in Medaillons. H. I6,5 cm. } \\
\text { Besitzer (1885): A. Liubawin, St. Petersburg. }\end{array}$ \\
\hline & wie 67 & & $\begin{array}{l}\text { k) Weisssilberner Becher auf drei Kugelfüssen ruhend. } \\
\text { Zwischen Blätterranken drei Medaillonköpfe ge- } \\
\text { trieben. } \\
\text { B. I3 } 3 \mathrm{~cm} \text {. }\end{array}$ \\
\hline & wie 77 & & $\begin{array}{l}\text { 1) Weisssilberner Leuchter, säulenartiger Schaft mit } \\
\text { Fruchtfestons. } \\
\text { Besitzer: Kaiserl. Silberkammer, St. Petersburg. }\end{array}$ \\
\hline & wie 89 & & $\begin{array}{l}\text { m) Getriebener Crucifixus auf einem Holzkreuze, mit } \\
\text { silberbeschlagenen Enden. } \\
\text { Besitzer: Eberhardskirche, Stuttgart. }\end{array}$ \\
\hline & wie 92 & & $\begin{array}{l}\text { n) Vergoldeter getriebener Pokal mit Wappen, In- } \\
\text { schrift und I753. } \\
\text { Besitzer: Graf Töring-Jettenbach, München. Ausstellung Augs- } \\
\text { burg 1886, Katalog Nr. 1505. Meisterwerke Schwäb. Kunst, } \\
\text { Taf. 26. }\end{array}$ \\
\hline
\end{tabular}

Nach der Feststellung von Lessing ist dies die Marke von Johannes Engelbrecht, † I748.

a-c) Zwei ovale Schwenkkessel und ein vergoldeter Teller von I7 8 .

Besitzer : Königl. Silberkammer, Dresden. Die Hofsilberkammer Dresden, S. 145 . 


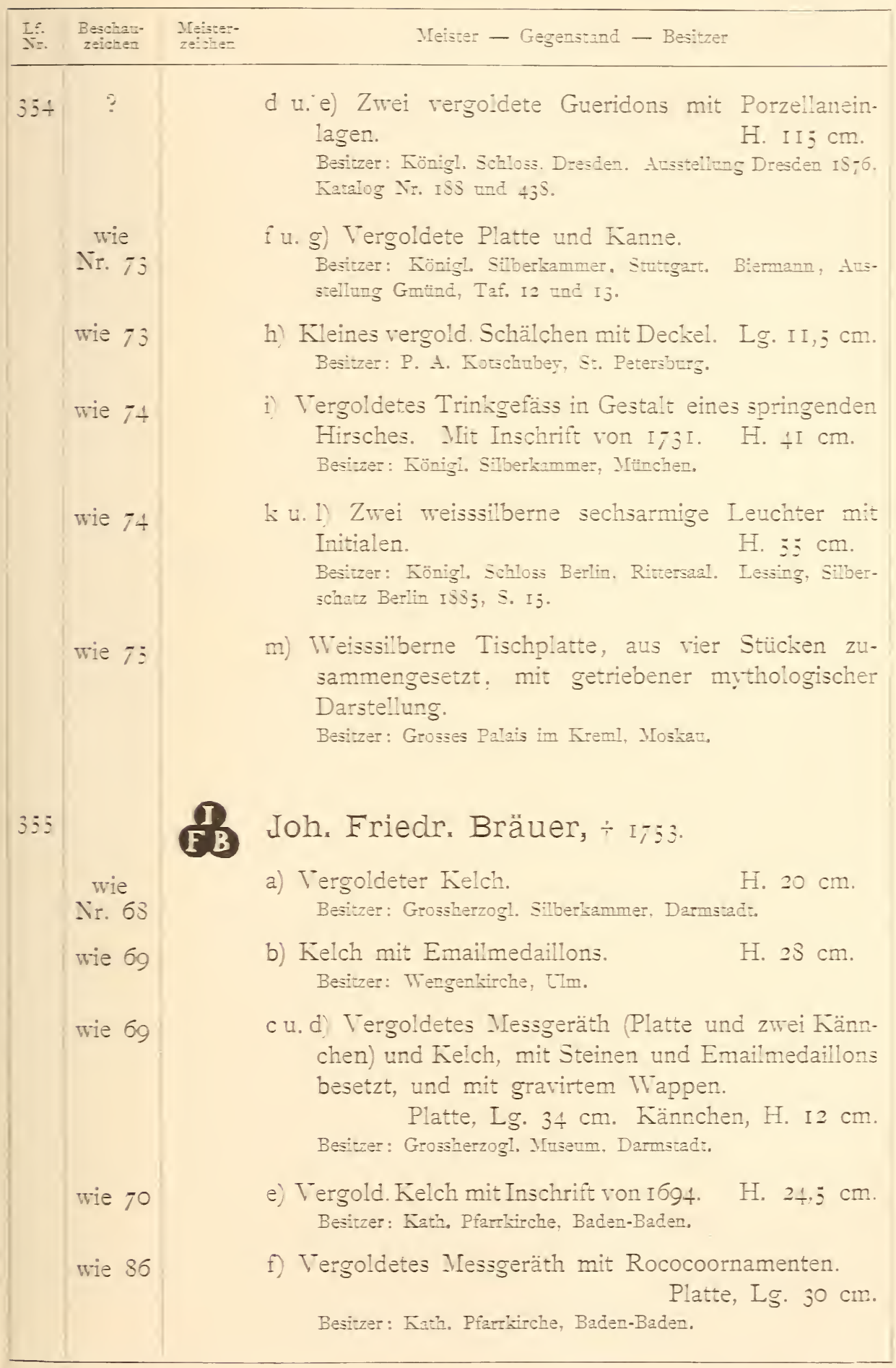




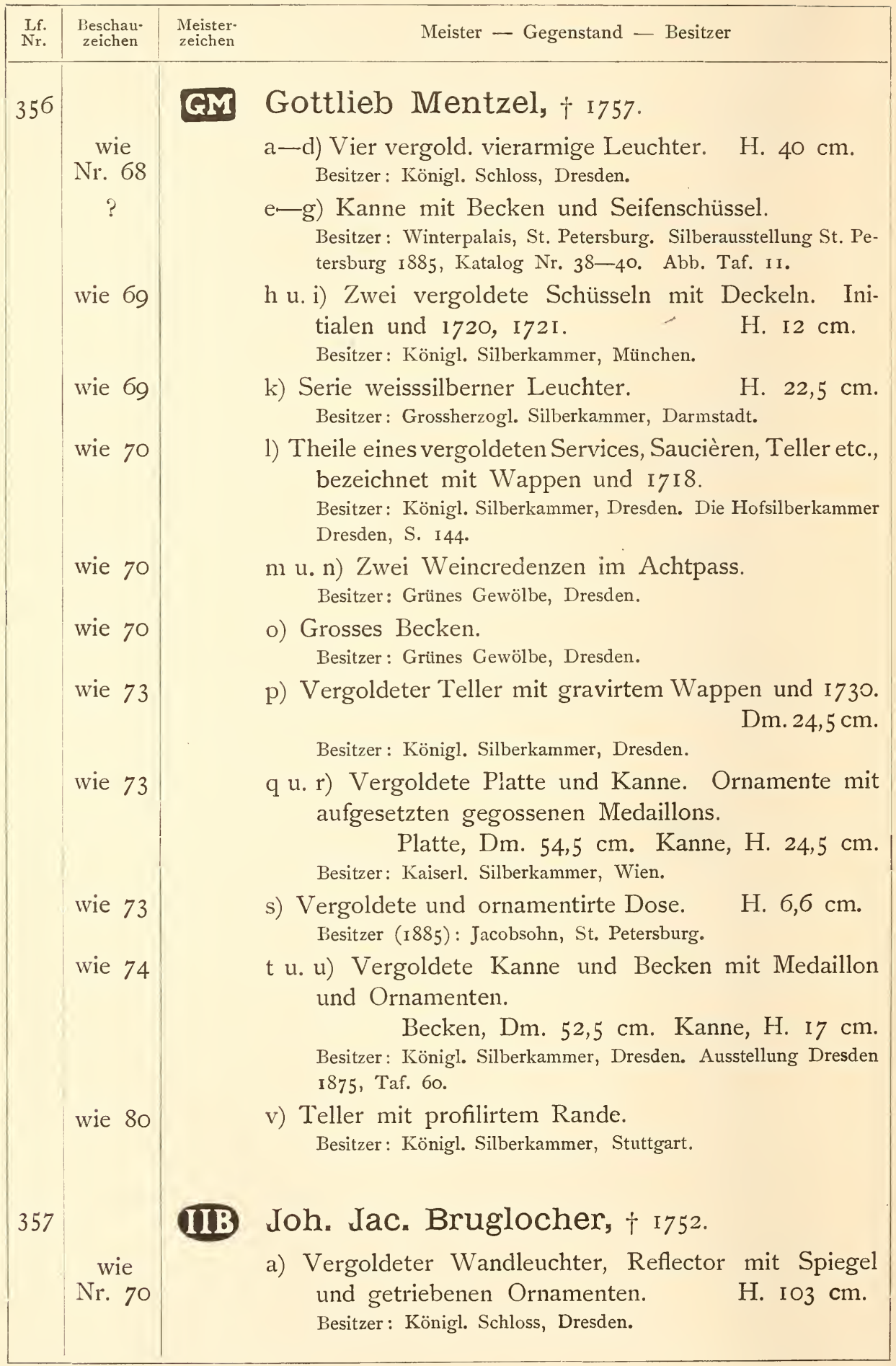




\begin{tabular}{|c|c|c|c|}
\hline $\begin{array}{l}\text { Lf. } \\
\text { Nr. }\end{array}$ & $\begin{array}{l}\text { Beschau- } \\
\text { zeichen }\end{array}$ & $\begin{array}{l}\text { ister- } \\
\text { chen }\end{array}$ & Meister - Gegenstand - Besitzer \\
\hline 357 & wie 72 & & $\begin{array}{l}\text { b) Grosse weisssilberne Fontaine mit ovalem Becken. } \\
\text { H. } 35 \mathrm{~cm} .\end{array}$ \\
\hline & wie 72 & & $\begin{array}{l}\text { c) Hoher weisssilberner Weinkühler. } \\
\text { Besitzer: Herzogl. Museum, Gotha. }\end{array}$ \\
\hline & wie 74 & & $\begin{array}{l}\text { d) Vergoldete Terrine mit Initialen. } \\
\text { Besitzer: Königl. Schloss Berlin, Rittersaal. }\end{array}$ \\
\hline & wie 74 & & $\begin{array}{l}\text { e) Weisssilberne Jardinière. } \\
\text { Besitzer: Kaiserl. Silberkammer, St. Petersburg. }\end{array}$ \\
\hline & wie 74 & & f) Hoher ovaler Weinkühler. \\
\hline & wie 74 & & $\begin{array}{l}\text { g u. h) Zwei Weinkühler auf Füssen. } \\
\text { Besitzer: Herzogl. Museum, Gotha. }\end{array}$ \\
\hline & wie $8_{3}$ & & $\begin{array}{l}\text { i) Vergoldete Rococokanne. } \\
\text { Besitzer : Königl. Silberkammer, München. }\end{array}$ \\
\hline 358 & & & $\begin{array}{l}\text { Franz Thaddaeus Lanz, Vorgeher I727, Be- } \\
\text { schaumeister I } 732 \text { und } 1748, \dagger 1773 \text {. }\end{array}$ \\
\hline & $\begin{array}{l}\text { wie } \\
\text { Nr. 71 }\end{array}$ & & $\begin{array}{l}\text { a) Vergoldeter Kelch. } \\
\text { Besitzer: Kirche, Niederbühl (Baden). }\end{array}$ \\
\hline & ? & & $\begin{array}{l}\text { b) Vergoldeter getriebener Kelch mit aufgesetzten Sil- } \\
\text { berornamenten, Rubinen und Emails. Bezeichnet } \\
\text { I } 750 \text { H. } 28,5 \mathrm{~cm} \text {. } \\
\text { Besitzer: Kath. Pfarrkirche, Salem. Ausstellung Karlsruhe } \\
\text { 1881, Katalog Nr. I15. }\end{array}$ \\
\hline & wie $73:$ & & $\begin{array}{l}\text { c) Vergoldeter getriebener Kelch mit aufgesetzten Me- } \\
\text { daillons. } \\
\text { Besitzer: Eberhardskirche, Stuttgart. }\end{array}$ \\
\hline & wie 75 & & $\begin{array}{l}\text { d) Vergoldetes Besteck. } \\
\text { Besitzer: I. Excellenz Freifrau v. Freydorf, Karlsruhe. }\end{array}$ \\
\hline & wie 80 & & $\begin{array}{l}\text { e) Vergoldeter Kelch, mit ächten Steinen besetzt und } \\
\text { mit Inschrift versehen. } \\
\text { Besitzer: Kath. Kirche, Kaisheim. Ausstellung Augsburg I } 886 \text {, } \\
\text { Katalog Nr. I37I. }\end{array}$ \\
\hline & wie 80 & & $\begin{array}{l}\text { f) Weisssilberne getriebene Tabernakelthüre mit bibli- } \\
\text { scher Darstellung. } \\
\text { Besitzer: Universität, Freiburg. Ausstellung Karlsruhe is81, } \\
\text { Katalog Nr. 1696. }\end{array}$ \\
\hline & wie 82 & & $\begin{array}{l}\text { g) Ovale, mehrfach eingezogene Platte mit Mess- } \\
\text { kännchen. } \\
\text { Ausstellung Augsburg i } 886 .\end{array}$ \\
\hline
\end{tabular}




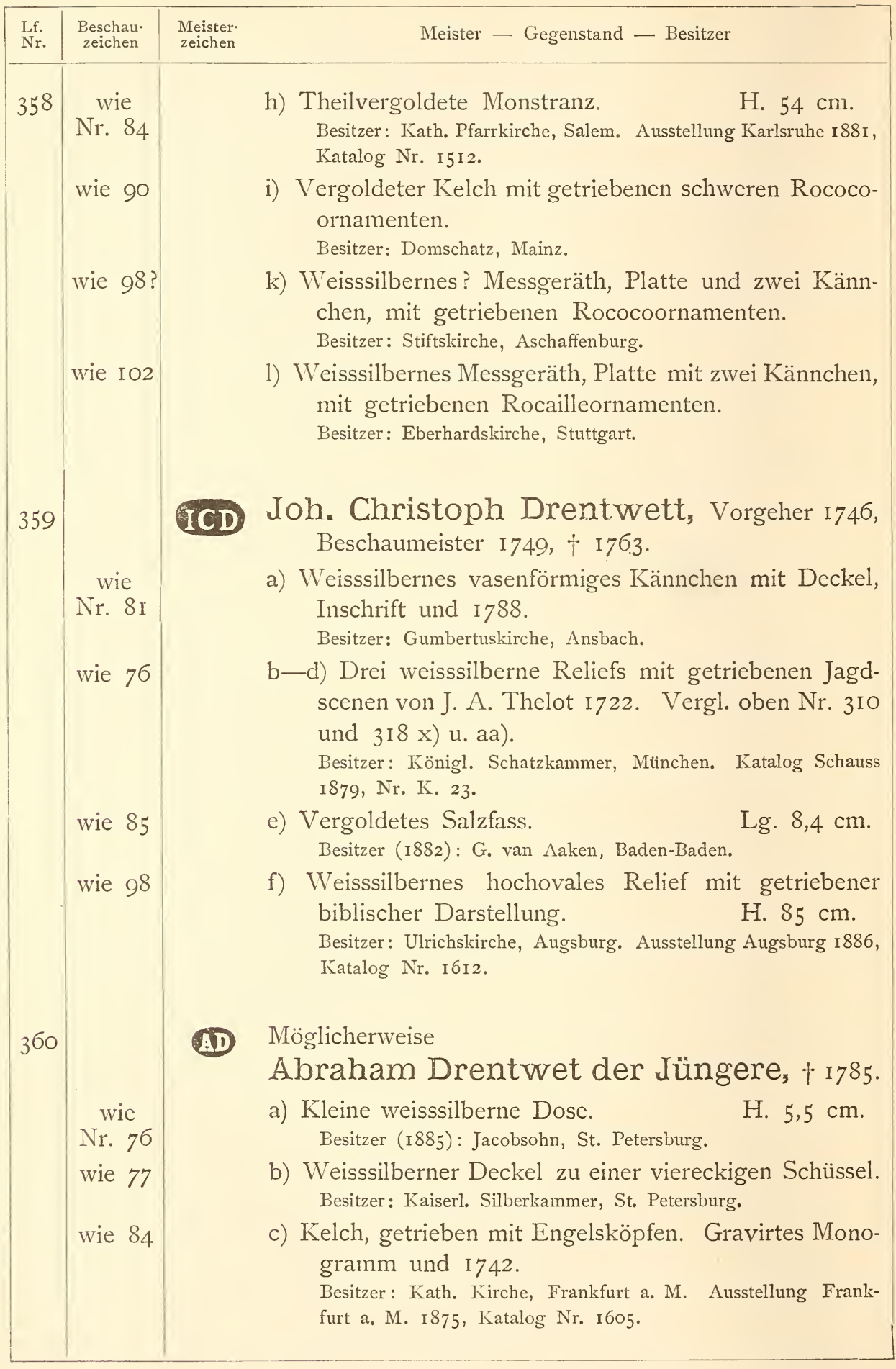




\begin{tabular}{|c|c|c|c|}
\hline $\begin{array}{l}\text { Lf. } \\
\text { Nr. }\end{array}$ & $\begin{array}{l}\text { Beschau- } \\
\text { zeichen }\end{array}$ & $\begin{array}{l}\text { Meister- } \\
\text { zeichen }\end{array}$ & Meister - Gegenstand - Besitzer \\
\hline 360 & $\begin{array}{l}\text { wie } \\
\mathrm{Nr} .85\end{array}$ & & $\begin{array}{l}\text { d) Theilvergold. Kelch, Rococo, mit Inschrift von I } 785 \text {. } \\
\text { Besitzer: Kath. Pfarrkirche, Baden-Baden. }\end{array}$ \\
\hline & wie 86 & & $\begin{array}{l}\text { e u. f) Platte und Schale, theilweise mit getriebenen } \\
\text { Zügen und Rococogravirungen. } \\
\text { Besitzer: Graf v. Stauffenberg, Jettingen. Ausstellung Augs- } \\
\text { burg 1886, Katalog Nr. 1594. }\end{array}$ \\
\hline & wie 92 & & $\begin{array}{l}\text { g u. h) Theilvergoldeter Kelch mit getriebenen Rococo- } \\
\text { motiven, dazu Patene und Hostienbüchse. } \\
\text { Ausstellung Augsburg } 1886 \text {. }\end{array}$ \\
\hline & wie 92 & & $\begin{array}{l}\text { i) Teller mit gravirtem Monogramme. } \\
\text { Besitzer: Königl. Silberkammer, München. }\end{array}$ \\
\hline & wie 96 ? & & k) Ovale Schale und \\
\hline & & & $\begin{array}{l}\text { 1) Teller mit profilirtem Rande. } \\
\text { Besitzer: Königl. Silberkammer, Stuttgart. }\end{array}$ \\
\hline & wie I09 & & $\begin{array}{l}\text { m) Vergoldete flache Schale auf Rococofuss, mit Ini- } \\
\text { tialen. } \\
\text { H. } 8,5 \mathrm{~cm} \text {. } \\
\text { Besitzer: Königl. Silberkammer, München. }\end{array}$ \\
\hline
\end{tabular}

Salomon Dreyer, Beschaumeister i761, $\uparrow$ i 762 .

wie

Nr. 82

wie 82

wie 90

wie 82 ?

362

wie

Nr. 84

wie 84

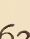

a) Theilvergoldete bauchige Weinkanne mit Inschrift von I740.

H. $40,5 \mathrm{~cm}$.

Besitzer: Johanneskirche, Ansbach.

b) Schifftrinkgefäss, bemannt und bewehrt. Inschrift von I744.

H. $39,5 \mathrm{~cm}$.

Besitzer: J. \& H. Jeidels, Frankfurt a. M.

c) Weisssilberne Wärmeschüssel mit Rococogriff, Wappen, Initialen und $175 \mathrm{I}$.

Besitzer: Königl. Silberkammer, München.

d) Vergoldete Toilette.

Besitzer: S. D. Fürst Reuss j. L., Schloss Orterstein bei Gera.

Gefällige Mittheilung von Herrn Director Dr. A. Pabst, Cöln.

Joh: Jacob Schoap, $\uparrow$ i 766, oder Joh, Jacob Schoap, † I774.

a u. b) Zwei weisssilberne Reliefs mit Holzunterlage, Engel als Lichthalter darstellend.

Besitzer: Domschatz, Osnabrïck.

c) Weisssilberne getriebene Marienfigur. H. $77 \mathrm{~cm}$.

Besitzer: Kath. Pfarrkirche, Baden-Baden. 


\begin{tabular}{|c|c|c|c|}
\hline $\begin{array}{l}\text { Lf. } \\
\text { Nr. }\end{array}$ & $\begin{array}{l}\text { Beschau- } \\
\text { zeichen }\end{array}$ & $\begin{array}{l}\text { Meister- } \\
\text { zeichen }\end{array}$ & Meister - Gegenstand - Besitzer \\
\hline 362 & $\begin{array}{c}\text { wie } \\
\text { Nr. } 87\end{array}$ & & $\begin{array}{ll}\text { d) Vergoldeter Kelch mit getriebenen } & \text { Rococoorna- } \\
\text { menten und Inschrift von I 744. } & \text { H. } 25 \mathrm{~cm} \text {. } \\
\text { Besitzer: Evangel. Kirche, Wertheim. } & \end{array}$ \\
\hline & wie 98 ? & & $\begin{array}{l}\text { e) Grosse vergoldete Monstranz, mit Steinen und Perlen } \\
\text { besetzt. } \\
\text { Besitzer: Hofkirche, Neuburg a. D. Ausstellung Augsburg } \\
\text { I } 886 \text {, Katalog Nr. I332. } \\
\text { f) Kelch mit Emailmedaillons. } \\
\text { Besitzer: Kirche, Niederbühl (Baden). }\end{array}$ \\
\hline
\end{tabular}

wie

Nr. 85

wie 89

wie 90

wie 90

wie 9I

wie 9I

wie 92

wie 94

wie 98

wie

Nr. 85
Jacob Mald, $\uparrow$ I $76_{3}$

a) Setzbecher, einzelnes Stück.

Privatbesitz in Bühl (Ortenau).

b u. c) Zwei konische Becher. H. $9 \mathrm{~cm}$.

Besitzer: Grossherzogl. Silberkammer, Darmstadt.

d) Vergoldeter geschweifter Becher mit Rocailleornament, Wappen, Monogramm und I749.

Besitzer (1882): J. \& S. Goldschmidt, Frankfurt a. M.

e) Theilvergoldeter konischer Becher. H. I3,5 cm. Besitzer: Kirche, Bodenheim. Gefällige Mittheilung des Herm Dompräbendat Dr. F. Schneider, Mainz.

f) Theile eines vergoldeten Reisebestecks. Rococo. Besitzer (I882): J. \& S. Goldschmidt, Frankfurt a. M.

g) Vergoldeter konischer Becher. H. IO $\mathrm{cm}$. Besitzer: G. Gimbel, Baden-Baden.

h) Vergoldeter konischer Becher mit Inschrift und Wappen.

H. $18 \mathrm{~cm}$.

Besitzer: S. H. d. Fürst von Hohenzollern. Ausstellung Augsburg 1886.

i u. k) Zwei vergoldete konische Becher mit Rococoornamenten.

H. $9,5 \mathrm{~cm}$.

Besitzer: Baron R.v. Walterskirchen, Wien. Ausstellung Augsburg 1886.

1) Konischer Becher.

Besitzer: Prof. Seyffer, Stuttgart (1882).

H. II,8 cm. 


\begin{tabular}{|c|c|c|c|}
\hline $\begin{array}{l}\text { Lf. } \\
\text { Nr. }\end{array}$ & $\begin{array}{l}\text { Beschau- } \\
\text { zeichen }\end{array}$ & $\begin{array}{l}\text { Meister- } \\
\text { zeichen }\end{array}$ & Meister - Gegenstand - Besitzer \\
\hline 364 & $\begin{array}{l}\text { wie } \\
\text { Nr. } 98\end{array}$ & & $\begin{array}{l}\text { b) Kleiner Becher mit hochgetriebenen Medaillons. } \\
\text { Besitzer: Prof. Seyffer, Stuttgart (1882). } \\
\text { c) Weisssilberner dreieckiger Rococoleuchter mit Wap- } \\
\text { pen, Monogramm und I } 764 \text {. } \\
\text { Besitzer: Königl. Silberkammer, München. }\end{array}$ \\
\hline 365 & $\begin{array}{l}\text { wie } \\
\text { Nr. } 84\end{array}$ & $C X$ & 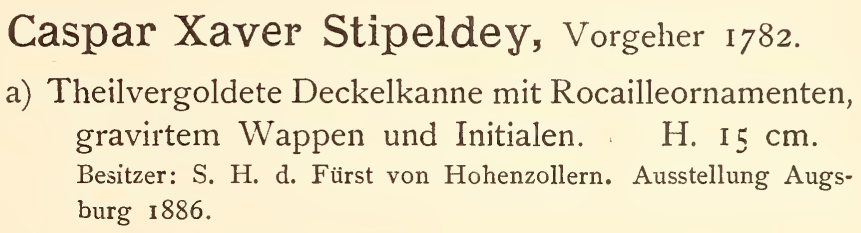 \\
\hline & wie 89 & & $\begin{array}{l}\text { b) Vergoldete Deckelkanne mit gravirtem Wappen, } \\
\text { Initialen und I796. Arbeit von I750 etwa. } \\
\text { Besitzer: S. H. d. Fürst von Hohenzollern. Ausstellung Augs- } \\
\text { burg I } 886 \text {. }\end{array}$ \\
\hline & wie 87 & & $\begin{array}{l}\text { c) Vergoldeter getriebener Kelch. } \quad \text { H. } 23 \mathrm{~cm} \text {. } \\
\text { Besitzer: Kath. Pfarrkirche, Baden-Baden. }\end{array}$ \\
\hline & wie 89 & & $\begin{array}{l}\text { d) Vergoldeter getriebener Kelch. } \\
\text { Besitzer: Kath. Pfarrkirche, Baden-Baden. }\end{array}$ \\
\hline & wie 89 & & $\begin{array}{l}\text { e) Theilvergoldeter konischer Becher mit Deckel, gra- } \\
\text { virtem Wappen und Monogramm. H. I } 3,3 \mathrm{~cm} \text {. } \\
\text { Besitzer: S. K. H. d. Grossherzog von Baden, Schloss Karlsruhe. } \\
\text { f) Vergoldete Dose mit weisssilbernen Ornamenten. } \\
\text { Besitzer: Kath. Pfarrkirche, Baden-Baden. }\end{array}$ \\
\hline 366 & $\begin{array}{l}\text { wie } \\
\mathrm{Nr} \cdot 78\end{array}$ & & $\begin{array}{l}\text { Bernhard Heinrich Weye (Weyse?), } \\
+ \text { I782. } \\
\text { a u. b) Vergoldete runde Platte nebst Kanne mit getrie- } \\
\text { benen Rococoornamenten und biblischen Dar- } \\
\text { stellungen. Platte, Dm. 44,5 cm. Kanne, H. } 37 \mathrm{~cm} \text {. } \\
\text { Besitzer: Barfüsserkirche, Augsburg. Ausstellung Augsburg I } 886 \text {, } \\
\text { Katalog Nr. 139. Meisterwerke Schwäbischer Kunst, Taf. 22. } \\
\text { c) Schreibzeug mit Glocke und Lichthalter. } \\
\text { Besitzer: Königl. Schatzkammer, München. Katalog Schauss } \\
\text { I879, G. 42. }\end{array}$ \\
\hline
\end{tabular}


I 44 Deutschland - Augsburg (Weye - Drentwet - Biller $\dagger$ I 777)

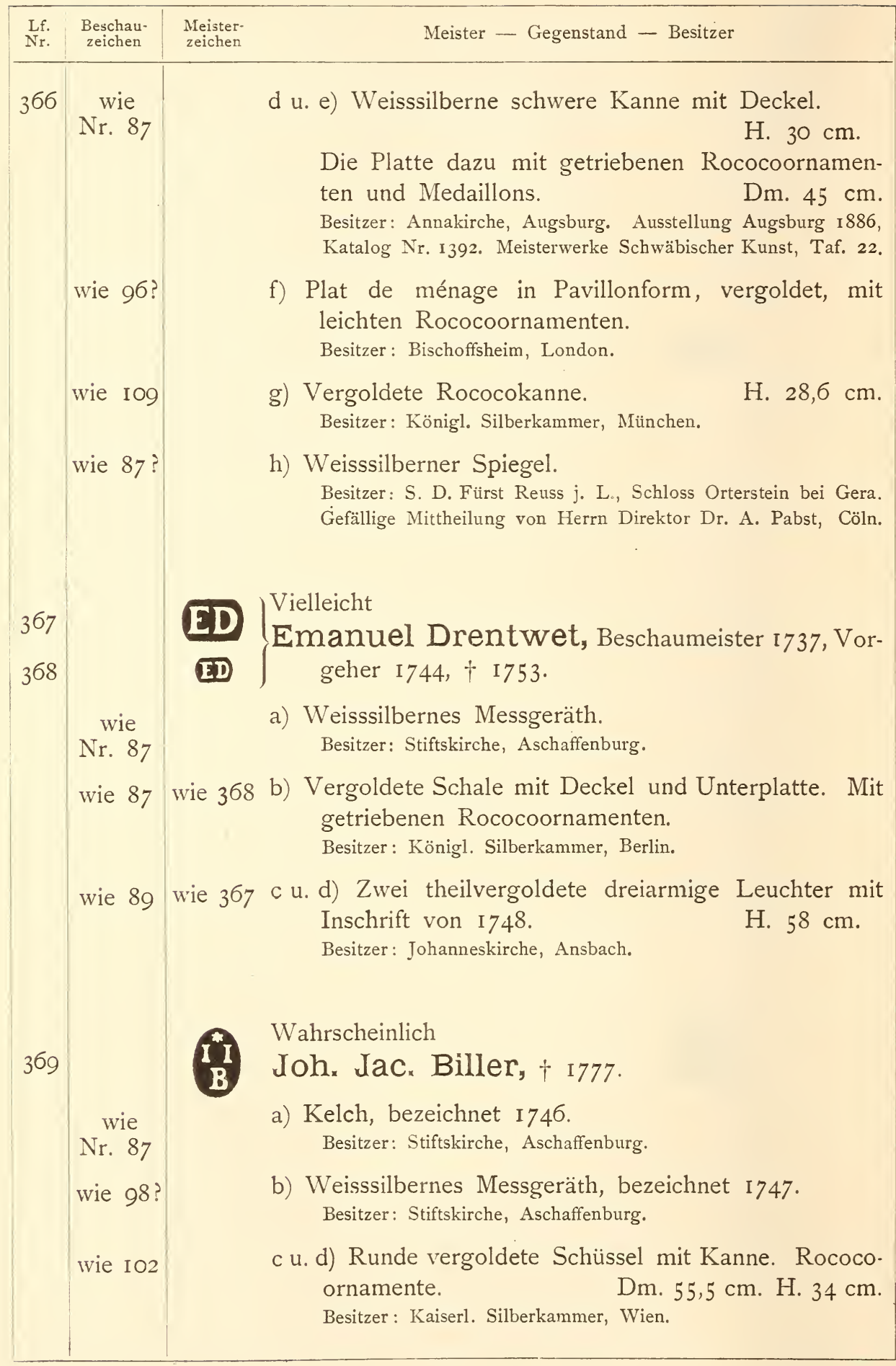




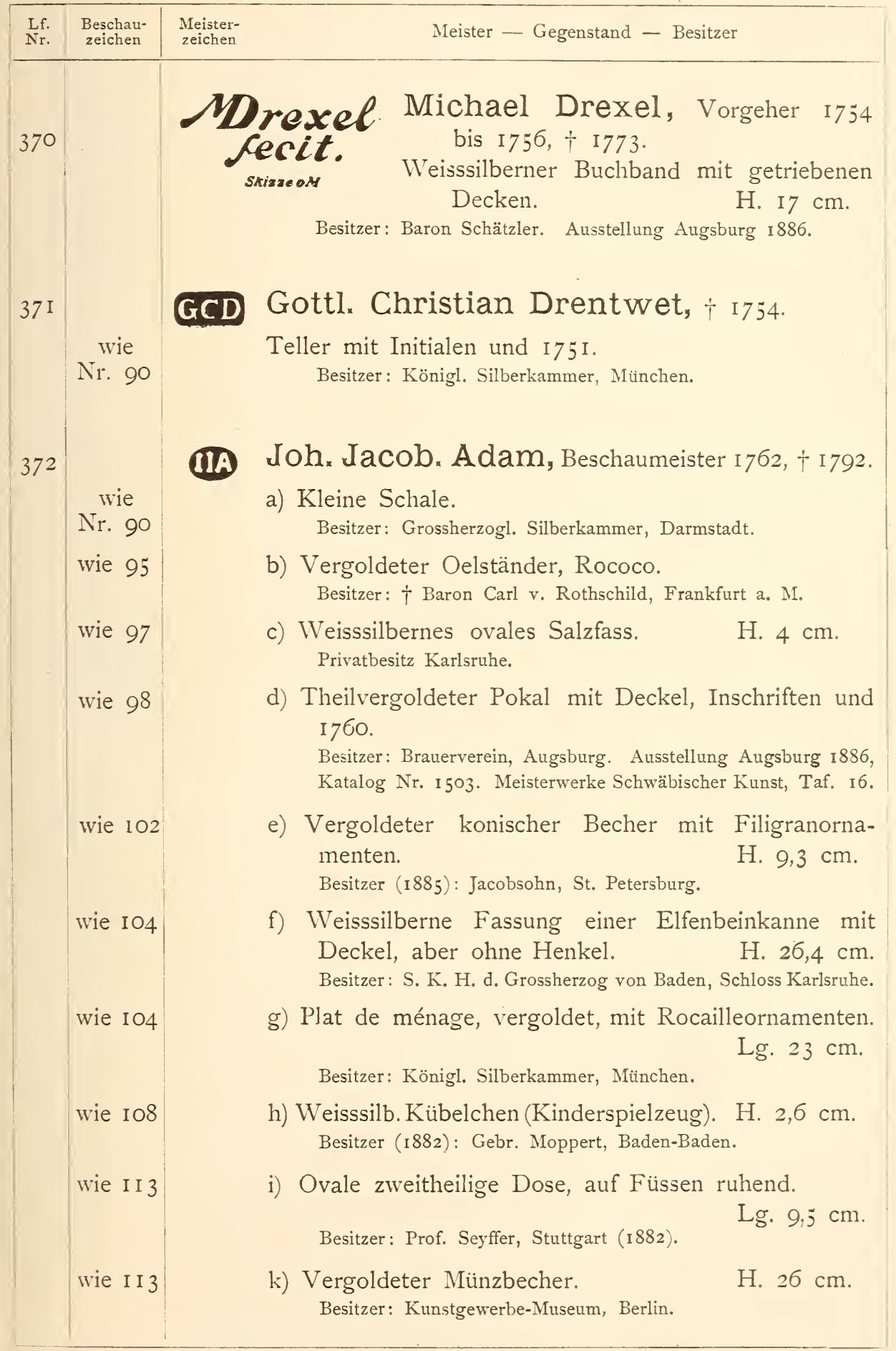




\begin{tabular}{|c|c|c|c|}
\hline $\begin{array}{l}\text { Lf. } \\
\text { Nr. }\end{array}$ & $\begin{array}{l}\text { Beschau- } \\
\text { zeichen }\end{array}$ & $\begin{array}{l}\text { Meister- } \\
\text { zeichen }\end{array}$ & Meister - Gegenstand - Besitzer \\
\hline 373 & & CD & Christianus Drentwett, Vorgeher I784. \\
\hline & ? & & $\begin{array}{l}\text { a) Weisssilberner Rococoleuchter. } \\
\text { Besitzer: Reiche Kapelle, München. }\end{array}$ \\
\hline & $\begin{array}{l}\text { wie } \\
\text { Nr. } 90\end{array}$ & & $\begin{array}{l}\text { b u. c) Waschbecken nebst Kanne. } \\
\text { Besitzer: Grossherzogl. Silberkammer, Darmstadt. }\end{array}$ \\
\hline & wie 90 & & $\begin{array}{l}\text { d) Mehrere silberne Leuchter. } \\
\text { Besitzer: Grossherzogl. Silberkammer, Darmstadt. }\end{array}$ \\
\hline & wie 105 & & $\begin{array}{l}\text { e) Verschiedene kleine Becher auf einer älteren Schale. } \\
\text { Besitzer: Königl. Museum, Cassel. Katalog Lenz 188I, Nr. I3. }\end{array}$ \\
\hline & wie Io8? & & $\begin{array}{l}\text { f) Vergoldete glatte Confectschale. } \\
\text { Besitzer: Königl. Silberkammer, Stuttgart. }\end{array}$ \\
\hline & wie I IO & & $\begin{array}{l}\text { g) Weisssilberner glatter Potagelöffel. } \\
\text { Besitzer: Königl. Silberkammer, Nünchen. }\end{array}$ \\
\hline & wie I I I & & $\begin{array}{l}\text { h u. i) Zwei vergoldete Deckelpokale. Rococo mit } \\
\text { Weinranken. } \\
\text { H. 3I,5 cm. } \\
\text { Besitzer: Handelsverein, Augsburg. Ausstellung Augsburg I } 886 \text {, } \\
\text { Katalog Nr. } 1494 .\end{array}$ \\
\hline & wie I I I & & $\begin{array}{l}\text { k) Vergoldeter Ananaspokal, Griff und Bekrönung } \\
\text { weiss. } \\
\text { Hesitzer: Handelsverein, Augsburg. Ausstellung Augsburg I } 886 \text {, } \\
\text { Katalog Nr. } 147 \mathrm{I} \text {. }\end{array}$ \\
\hline & wie I I4 & & 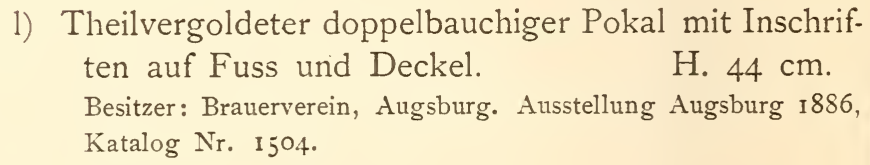 \\
\hline
\end{tabular}

(G Georg Ignatius Bauer, Beschaumeister I764, Vorgeher I77I, † I 790 .

wie

Nr. 94

wie 97 a) Vergoldeter Kelch mit getriebenen Rococoornamenten. H. $27,5 \mathrm{~cm}$.

Besitzer: Katharinenkirche, Weinheim.

b) Vergoldete hohe Deckelkanne mit figürlicher Darstellung und Rococoornamenten.

Besitzer: $\uparrow$ Baron Carl v. Rothschild, Frankfurt a. M. 


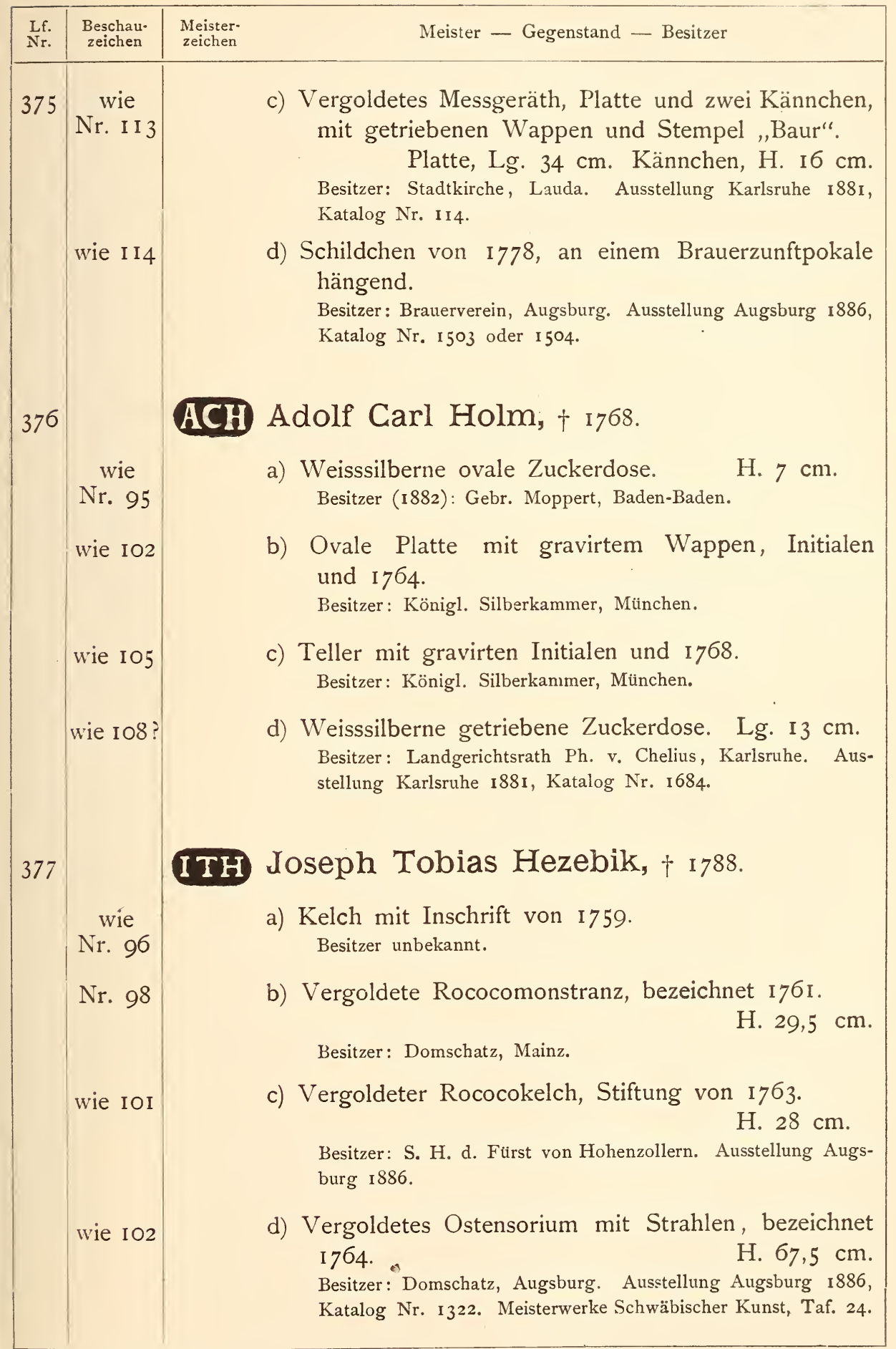




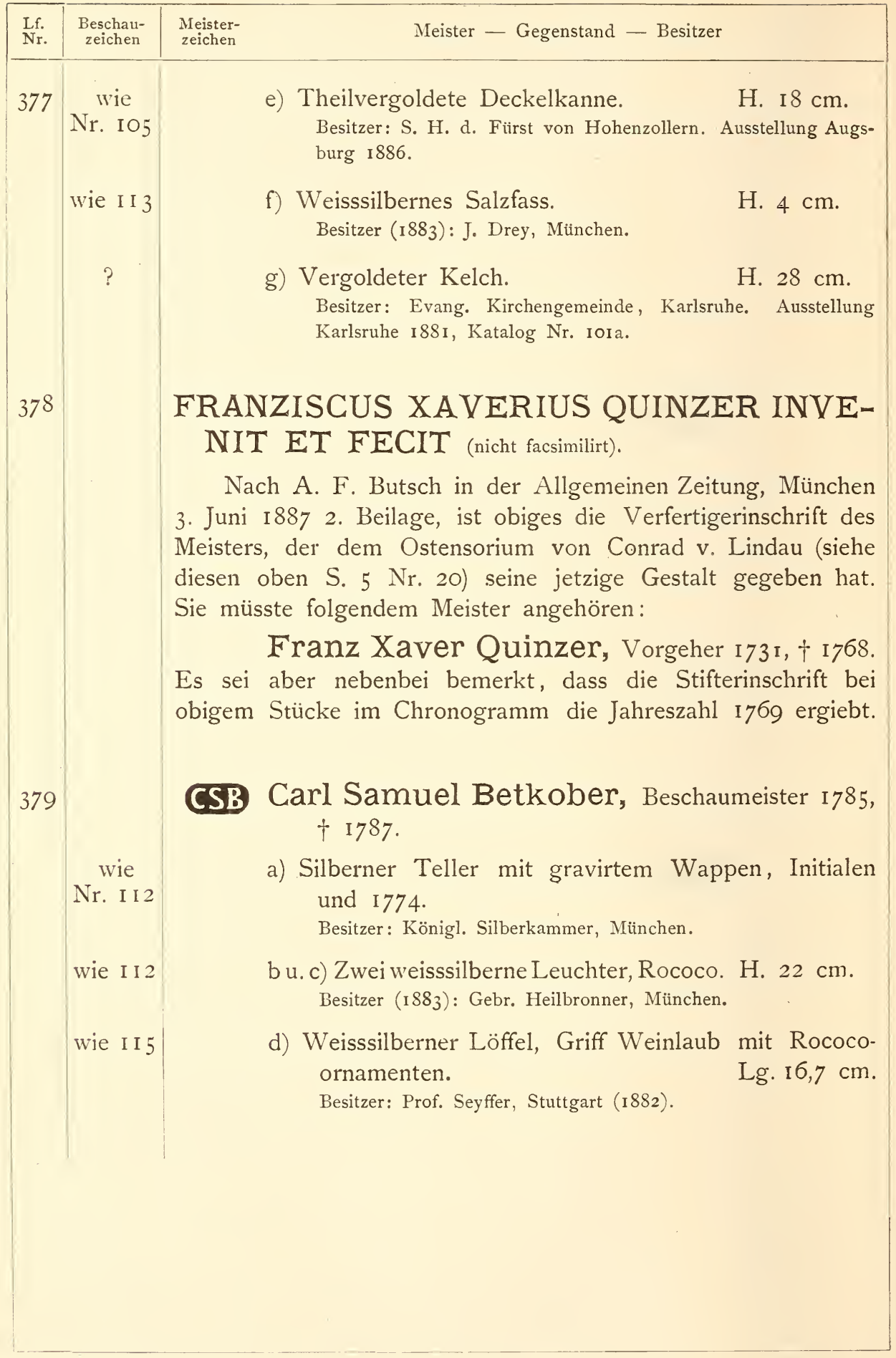




\section{BADEN - BADEN.}

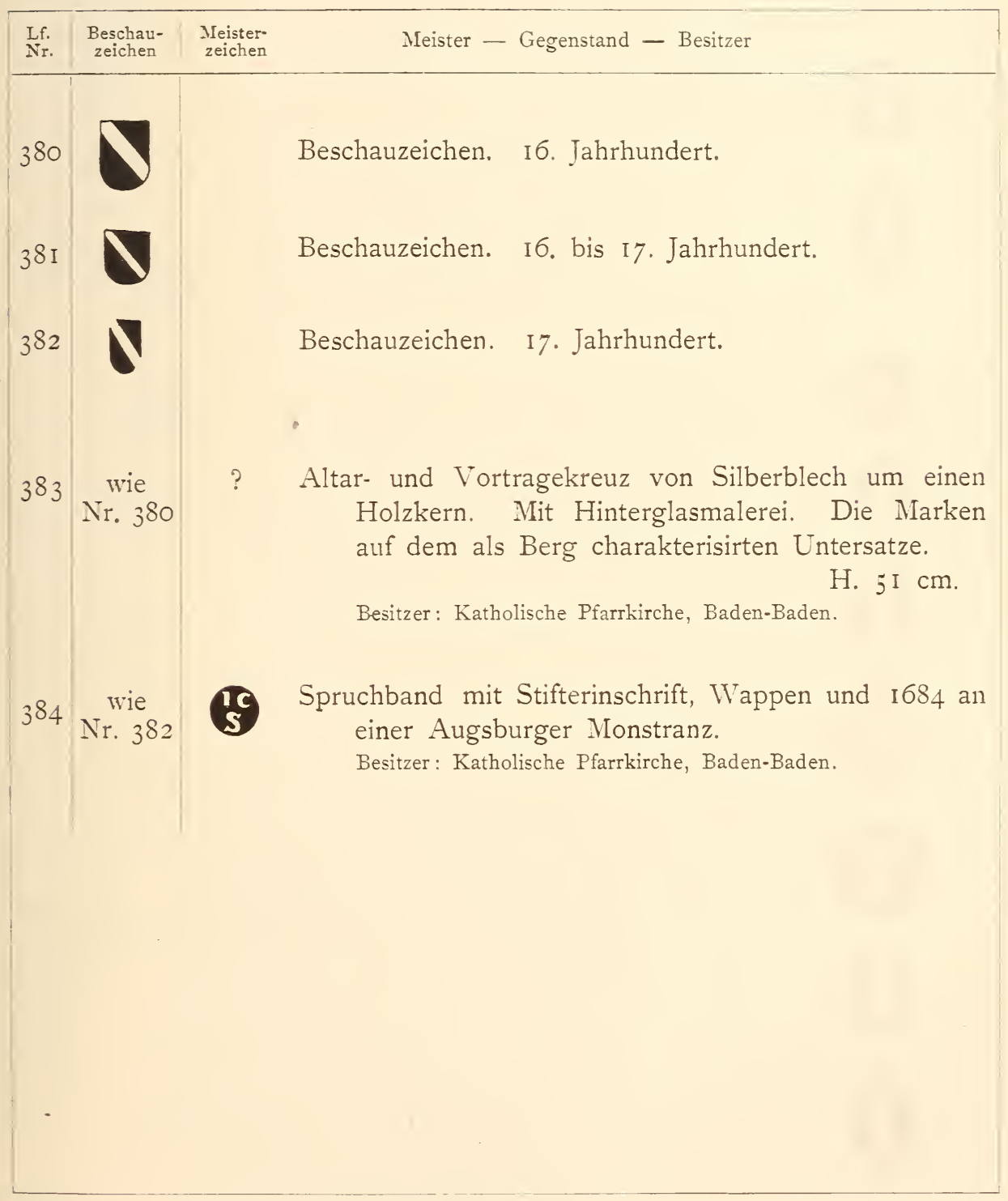




\section{BERLIN.}

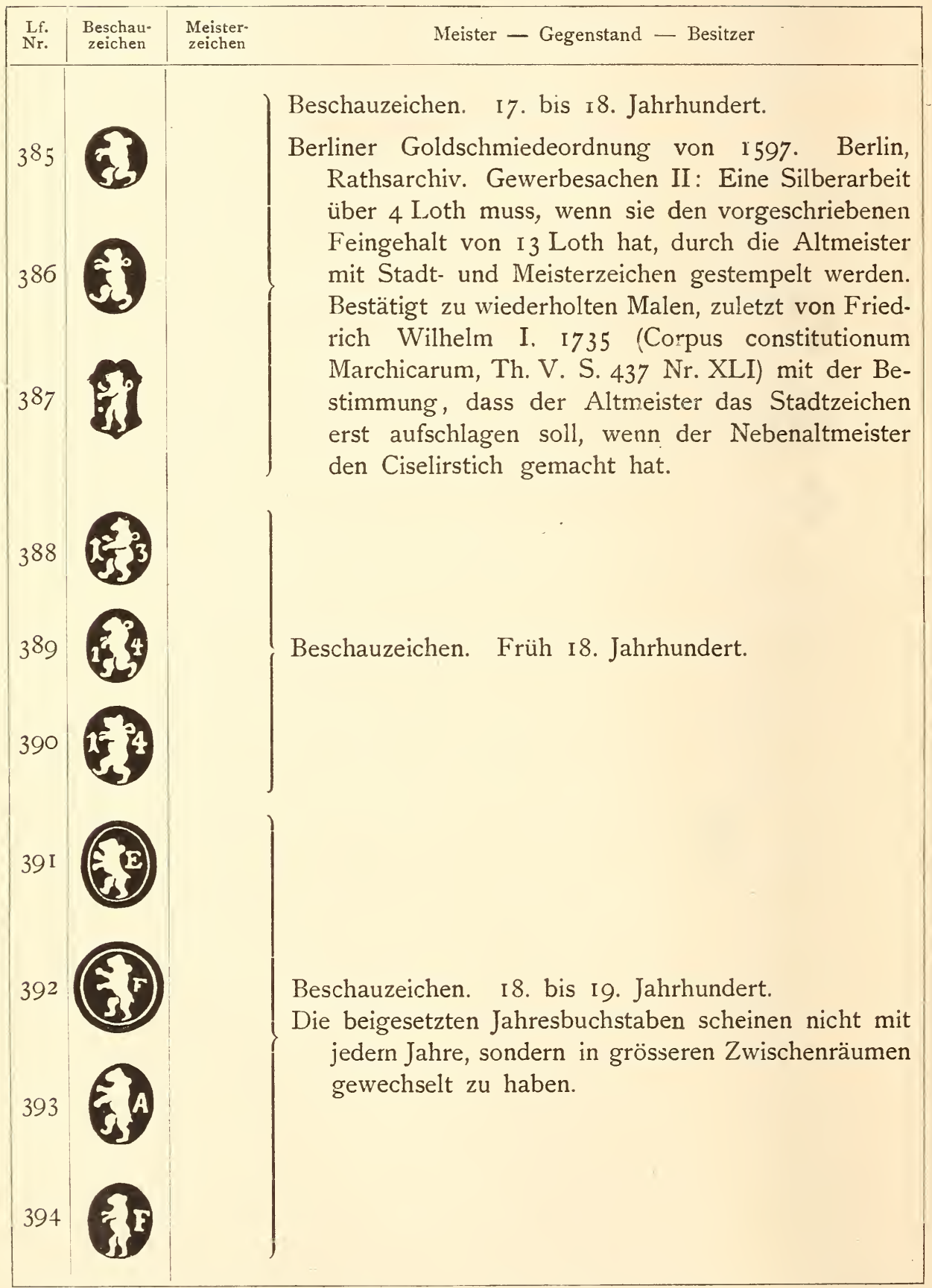




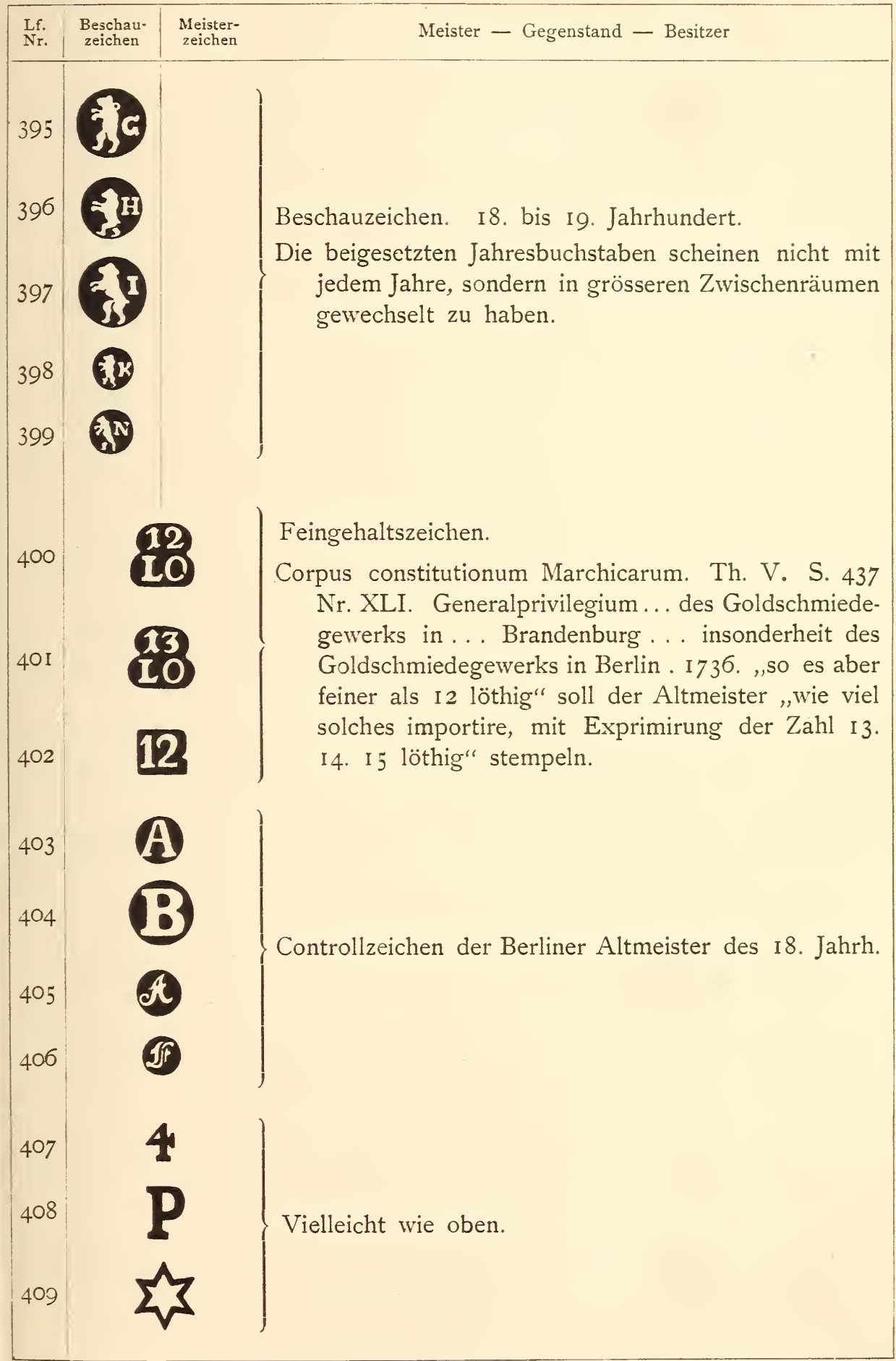




\begin{tabular}{|c|c|c|c|}
\hline $\begin{array}{l}\text { Lf. } \\
\text { Nr. }\end{array}$ & $\begin{array}{l}\text { Beschau- } \\
\text { zeichen }\end{array}$ & $\begin{array}{l}\text { Meister- } \\
\text { zeichen }\end{array}$ & Meister - Gegenstand - Besitzer \\
\hline 410 & & & $\begin{array}{l}\text { Daniel Manlich, geb. I625, I } 650 \text { nach Berlin, } \\
\text { I676 Hofgoldschmied, † I } 701 \text {. } \\
\text { Nicolai, Nachrichten von Berliner Künstlern S. } 53 \text {. }\end{array}$ \\
\hline & $?$ & & $\begin{array}{l}\text { a) Weisssilb. Münzkanne mit zwei Henkeln. H. } 57 \mathrm{~cm} \text {. } \\
\text { Besitzer: Königl. Schloss Berlin, Rittersaal. }\end{array}$ \\
\hline & wie & & b u. c) Zwei vergoldete zweihenkelige Münzkannen, nach \\
\hline & Nr. 385 & & $\begin{array}{ll}\text { I } 692 . & \text { H. } 39 \mathrm{~cm} . \\
\text { Besitzer: Königl. Schloss Berlin, Rittersaal. } & \end{array}$ \\
\hline & wie 385 & & $\begin{array}{l}\text { d) Vergoldete Münzkanne nach I679. H. } 3 \text { I cm. } \\
\text { Besitzer: Königl. Museum, Cassel. Katalog Lenz I88 Nr. } 38 .\end{array}$ \\
\hline & wie 385 & & $\begin{array}{l}\text { e u. f) Zwei theilvergoldete Münzkannen, eine nach } \\
\begin{array}{ll}\text { I } 678 \text {. } & \text { H. } 22,5 \mathrm{~cm} \text {. } \\
\text { Besitzer: Königl. Schloss Berlin, Rittersaal. }\end{array}\end{array}$ \\
\hline & $\begin{array}{l}\text { wie } 385 \\
\text { u. } 386\end{array}$ & & $\begin{array}{l}\text { g u. h) Zwei konische Münzbecher. } \\
\text { Besitzer: Königl. Schloss Berlin, Rittersaal. }\end{array}$ \\
\hline & wie 385 & & $\begin{array}{l}\text { i) Vergoldeter konischer Becher mit Gravirungen. } \\
\text { H. } 20,5 \mathrm{~cm} \text {. } \\
\text { Besitzer (1885): A. Liubawin, St. Petersburg. }\end{array}$ \\
\hline & wie 385 & & $\begin{array}{l}\text { k) Vergoldete Hostienbüchse mit Maleremail auf dem } \\
\text { Deckel. } \\
\text { Hesitzer (1885): Jacobsohn, St. Petersburg. }\end{array}$ \\
\hline & wie 385 & & $\begin{array}{l}\text { 1) Silberfassung einer Elfenbeinflasche mit Schrauben- } \\
\text { deckel. } \\
\text { Besitzer: Gg. Agath, Breslau. }\end{array}$ \\
\hline 4 I I & $\begin{array}{l}\text { wie } \\
\text { Nr. } 386\end{array}$ & & $\begin{array}{l}\text { Nautilus, von einem sitzenden Faun gehalten. } \\
\text { H. } 30 \mathrm{~cm} \text {. } \\
\text { Besitzer: Grünes Gewölbe, Dresden. Katalog Erbstein } \\
\text { 1884, S. } 58 \text { Nr. 189. Gruner, Das Grüne Gewölbe 1862, } \\
\text { Taf. 5. Graesse, Das Grüne Gewölbe I877, Taf. 9. }\end{array}$ \\
\hline 412 & $\begin{array}{c}\text { wie } \\
\text { Nr. } 385\end{array}$ & & $\begin{array}{l}\text { Zwei theilvergold. Flaschen mit Wappen. H. ca. } 37 \mathrm{~cm} \text {. } \\
\text { Besitzer: Königl. Schloss Berlin, Rittersaal. }\end{array}$ \\
\hline $4 \mathrm{I} 3$ & $\begin{array}{c}\text { wie } \\
\text { Nr. } 385\end{array}$ & & $\begin{array}{l}\text { Konischer Münzbecher des Amtes der Kleinböttcher } \\
\text { in Hamburg. Mit Inschrift. } \\
\text { Besitzer: Museum für Kunst und Gewerbe, Hamburg. }\end{array}$ \\
\hline
\end{tabular}




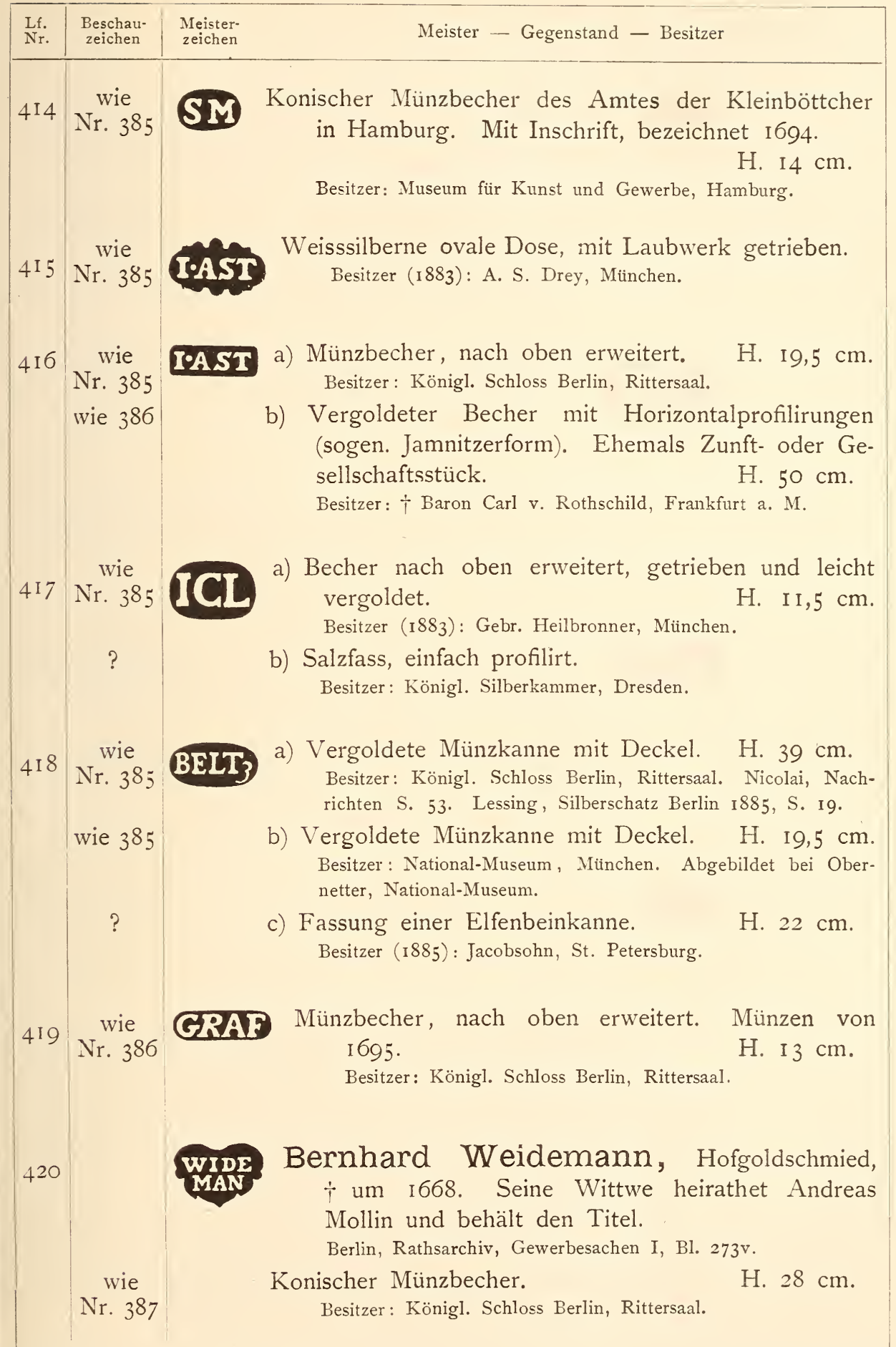




\begin{tabular}{|c|c|c|}
\hline $\begin{array}{l}\text { Lf. } \\
\text { Nr. }\end{array}$ & $\begin{array}{l}\text { Beschau- } \\
\text { zeichen }\end{array}$ & Meister - Gegenstand - Besitzer \\
\hline $42 \mathrm{I}$ & & $\begin{array}{l}\text { OM Otto Männlich, Hofgoldschmied, Sohn und Nach- } \\
\text { folger seines Vaters Daniel, welcher I } 70 \text { I starb. } \\
\text { Nicolai, Nachrichten, S. } 98 \text {. }\end{array}$ \\
\hline & $\begin{array}{l}\text { wie } \\
\text { Nr. } 388\end{array}$ & a) Runde vergoldete Platte. Dm. $60 \mathrm{~cm}$. \\
\hline & & $\begin{array}{l}\text { b) Mehrere einfach profilirte Salzfässer. } \\
\text { Besitzer: Königl. Silberkammer, Dresden. }\end{array}$ \\
\hline 422 & & $\begin{array}{l}\text { LIEBSR Christian Lieberkühn, Hofgoldschmied. } \\
\text { MVIN } \\
\text { Mitte des I8. Jahrhunderts. } \\
\text { Nicolai, Nachrichten, S. 129. }\end{array}$ \\
\hline & $\begin{array}{c}\text { wie } \\
\text { Nr. } 386\end{array}$ & a) Weisssilberner Leuchter. $\quad$ H. I4,5 cm. \\
\hline & wie 388 & $\begin{array}{l}\text { b) Weisssilberne zweihenkelige Schüssel auf vier Füssen. } \\
\text { Besitzer : Königl. Silberkammer, Berlin. }\end{array}$ \\
\hline 423 & $\begin{array}{c}\text { wie } \\
\text { Nr. } 390\end{array}$ & $\begin{array}{l}\text { IIEBER c) Weisssilberne Münzkanne mit zwei Henkeln und } \\
\text { Hahn. } \\
\text { Besitzer: Königl. Schloss Berlin, Rittersaal. }\end{array}$ \\
\hline & wie 389 & $\begin{array}{l}\text { d u. e) Zwei weisssilberne gehenkelte Münzkannen mit } \\
\text { Hahn. } \\
\text { Besitzer: Königl. Schloss Berlin, Rittersaal. } 52 \mathrm{~cm} \text {. }\end{array}$ \\
\hline 424 & $\begin{array}{l}\text { wie } \\
\text { Nr. } 396\end{array}$ & $\begin{array}{l}\text { CV Milchkanne mit Drahtverzierung. } \\
\text { Besitzer: Oberstaatsanwalt Bartels, : Cassel. } \\
\text { 1884, Katalog Nr. } 1729.5 \mathrm{~cm} . \\
\text { Ausstellung Cassel }\end{array}$ \\
\hline & & $\begin{array}{l}\text { Johann Christian Müller, Goldschmied und } \\
\text { Juwelier in Berlin, feierte I } 757 \text { seine silberne Hochzeit. Bei } \\
\text { diesem Anlass widmete ihm der Königliche Leibarzt J. C. W. } \\
\text { Möhsen eine kleine Schrift unter dem Titel: „Versuch einer } \\
\text { historischen Nachricht von der künstlichen Gold- und Silber- } \\
\text { arbeit in den ältesten Zeiten". Berlin I } 757 \text {. } \\
\text { Unter seinem Namen sammele ich alle die Stücke, welche } \\
\text { mit einem Stempel Müller oder Müllers versehen sind, obgleich } \\
\text { es wahrscheinlich mehrere Goldschmiede dieses Namens da- } \\
\text { mals in Berlin gab. }\end{array}$ \\
\hline
\end{tabular}




\begin{tabular}{|c|c|c|c|}
\hline $\begin{array}{l}\text { Lf. } \\
\text { Nr. }\end{array}$ & $\begin{array}{l}\text { Beschau- } \\
\text { zeichen }\end{array}$ & $\begin{array}{l}\text { Meister- } \\
\text { zeichen }\end{array}$ & Meister - Gegenstand - Besitzer \\
\hline 425 & $\begin{array}{l}\text { wie } \\
\mathrm{Nr} .388\end{array}$ & & $\begin{array}{l}\text { Zwei weisssilberne Leuchter. } \mathrm{H} .26 \mathrm{~cm} \text {. } \\
\text { Besitzer: E. A. Balaschow, St. Petersburg. Silberausstellung } \\
\text { St. Petersburg 1885, Katalog Nr. } 140 \text { und 141. }\end{array}$ \\
\hline 426 & $\begin{array}{c}\text { wie } \\
\text { Nr. } 393 \\
\text { wie } 393 \\
\text { aber mit } \\
\text { Jahres- } \\
\text { buch- } \\
\text { stabe B }\end{array}$ & & $\begin{array}{l}\text { a) Vergoldeter Münzbecher. H. 9,5 cm. } \\
\text { Besitzer (1885): Jacobsohn, St. Petersburg. } \\
\begin{array}{ll}\text { b) Weisssilberner, nach oben erweiterter Becher, mit } \\
\text { eingelassenen Münzen. } & \text { H. } 9,7 \mathrm{~cm} \text {. } \\
\text { Besitzer (1885): Jacobsohn, St. Petersburg. } & \end{array}\end{array}$ \\
\hline 427 & $\begin{array}{c}\text { wie } \\
\mathrm{Nr} .392\end{array}$ & & $\begin{array}{l}\text { Mit dem Zeichen P Nr. } 408 . \\
\text { Weisssilberne Terrine mit Deckel, Einsatz und Unter- } \\
\text { satz. } \\
\text { Besitzer: Staatssecretär Polowzow, St. Petersburg. }\end{array}$ \\
\hline 428 & $\begin{array}{c}\text { wie } \\
\mathrm{Nr} .394 \\
?\end{array}$ & & $\begin{array}{l}\text { a) Weisssilberner Speisewärmer. } \\
\text { Besitzer: Königl. Silberkammer, Berlin. } \\
\text { b) Weisssilberner Altarleuchter mit Inschrift von } 1745 \text {. } \\
\text { Besitzer: Nicolaikirche, Lüneburg. }\end{array}$ \\
\hline 429 & $\begin{array}{c}\text { wie } \\
\text { Nr. } 43 \mathrm{I}\end{array}$ & & $\begin{array}{l}\text { a) Mit dem Feingehaltstempel Nr. 4OI und dem Con- } \\
\text { trollstempel Nr. 403. } \\
\text { Vergoldete Schüssel. Rococo. } \\
\text { Besitzer: Königl. Silberkammer, Berlin. }\end{array}$ \\
\hline & wie 43 I & & 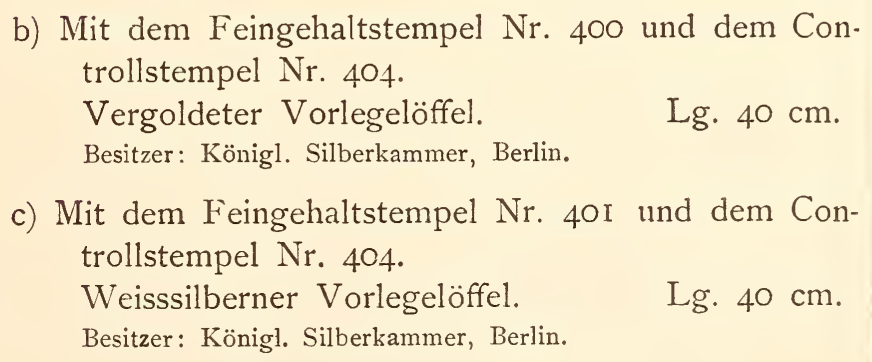 \\
\hline 430 & $\begin{array}{l}\text { wie } \\
\text { Nr. } 433\end{array}$ & & $\begin{array}{l}\text { Vergoldete Dose mit Gravirung. } \\
\text { Besitzer: Königl. Silberkammer, Berlin. }\end{array}$ \\
\hline
\end{tabular}




\begin{tabular}{|c|c|c|}
\hline $\begin{array}{l}\text { Lf. } \\
\text { Nr. }\end{array}$ & $\begin{array}{l}\text { Beschau- } \\
\text { zeichen }\end{array}$ & Meister - Gegenstand — Besitzer \\
\hline \multicolumn{3}{|c|}{$\begin{array}{l}\text { Hier bei Berlin muss ich eine Marke anschliessen, deren Erklärung } \\
\text { mir noch nicht gelungen ist, und auf die ich weiter unten bei Preussen } \\
\text { wieder zurückkommen werde. Es ist ein Adlerstempel, der in verschiedenen } \\
\text { Variationen vorkommt. Ich glaube die folgenden beiden Typen zu erkennen. }\end{array}$} \\
\hline 431 & & $\begin{array}{l}\text { „K“" Vergoldete Deckelkanne, mit Linearornamentik, Frucht- } \\
\text { gehängen und Maskarons getrieben. } \\
\text { Besitzer: Kunstgewerbe-Museum, Berlin. }\end{array}$ \\
\hline 432 & $\begin{array}{l}\text { Adler } \\
\text { wie } \\
\text { Nr. } 433\end{array}$ & $\begin{array}{l}\text { „MÜLLER“ Schüssel und zwei Vorlegelöffel wie Nr. } 433 . \\
\text { wie } \\
\text { Nr. } 429 \quad \text { identisch Königl. Schatzkammer, Berlin. Diese Stücke sind } \\
\text { Nie } 429 \text { a-c). }\end{array}$ \\
\hline 433 & & 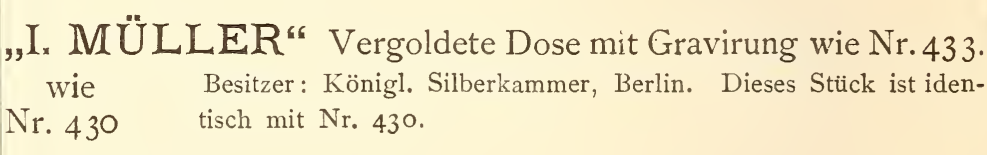 \\
\hline
\end{tabular}

\section{BIBERACH}

(wahrscheinlich Biberach in Württemberg).

\begin{tabular}{|c|c|c|c|}
\hline $\begin{array}{c}\text { Lf. } \\
\text { Nr. }\end{array}$ & $\begin{array}{c}\text { Beschau- } \\
\text { zeichen }\end{array}$ & $\begin{array}{c}\text { Meister- } \\
\text { zeichen }\end{array}$ & Meister - Gegenstand - Besitzer \\
\hline 434 & Beschauzeichen. I8. bis 19. Jahrhundert. \\
435 & $\begin{array}{c}\text { wie } \\
\text { Nr. } 434\end{array}$ & ZIEHER Neuer Fuss, an einem weisssilbernen gothischen Re- \\
liquar. \\
Besitzer: Wengenkirche, Ulm.
\end{tabular}




\section{BRAUNSCHWEIG.}

\begin{tabular}{|c|c|c|c|}
\hline $\begin{array}{l}\text { Lf. } \\
\text { Nr. }\end{array}$ & $\begin{array}{c}\text { Beschau- } \\
\text { zeichen }\end{array}$ & $\begin{array}{l}\text { Meister- } \\
\text { zeichen }\end{array}$ & Meister - Gegenstand - Besitzer \\
\hline 436 & & & $\begin{array}{l}\text { Beschauzeichen um I } 595 \text {. } \\
\text { Sick, Notice sur les ouvrages en or et en argent dans le nord. } \\
\text { Kopenhagen } 1884, \mathrm{Nr} .50 \text {. }\end{array}$ \\
\hline 437 & & & Beschauzeichen. I7. Jahrhundert. \\
\hline 438 & & & Beschauzeichen. I9. Jahrhundert. \\
\hline 439 & $\begin{array}{c}\text { wie } \\
\text { Nr. } 436\end{array}$ & $\begin{array}{l}\text { IHB } \\
\text { skitrs on. }\end{array}$ & $\begin{array}{l}\text { Vergoldetes Trinkgefäss in Gestalt einer Reiterfigur. } \\
\text { Besitzer: Sammlung Rosenborg, Kopenhagen. Sick, Notice etc. } \\
\text { Kopenhagen I884, Nr. } 50 \text { theilt diese Marke mit. Ich vermuthe, } \\
\text { dass er sie copirt hat von dem verg. Trinkgefäss, das er S. I8 } \\
\text { bis } 19 \text { erwähnt. Es ist eine Arbeit von I } 595 \text { bis I } 596 \text { und stellt } \\
\text { Christian IV. beim Ringelrennen dar. Vielleicht geht die } \\
\text { Marke auf Heinrich Beust, der nach Nyrop, Dansk guld- } \\
\text { smedekunst, ein von Christian IV. beschäftigter Goldschmied } \\
\text { ist. Es scheint mir diese Vermuthung mehr für sich zu haben, } \\
\text { als die von mir früher im Kunstgewerbeblatt i886 S. I72 } \\
\text { ausgesprochene. }\end{array}$ \\
\hline 440 & $\begin{array}{c}\text { wie } \\
\text { Nr. } 437\end{array}$ & $\begin{array}{l}\text { SB } \\
\text { Wahrs }\end{array}$ & 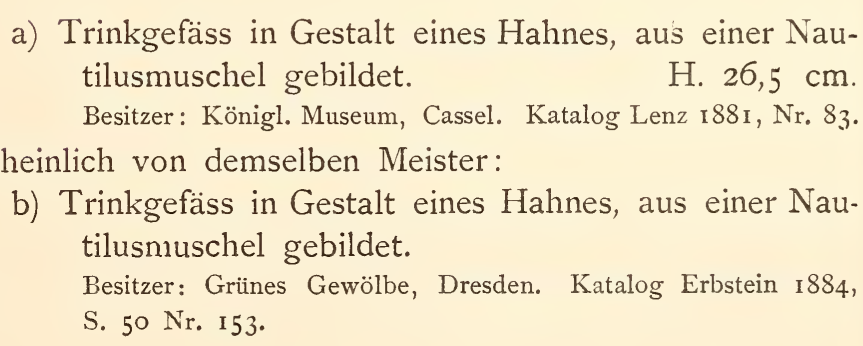 \\
\hline $44 \mathrm{I}$ & $\begin{array}{c}\text { wie } \\
\text { Nr. } 437\end{array}$ & B B & $\begin{array}{l}\text { Vergoldeter getriebener Pokalmit Deckel. H. } 3 \mathrm{I}, 3 \mathrm{~cm} \text {. } \\
\text { Besitzer: National-Museum, Budapest. Ausstellung Buda- } \\
\text { pest i } 884 \text {. }\end{array}$ \\
\hline
\end{tabular}




\section{BRESLAU.}

Die Möglichkeit über Breslau an dieser Stelle einige genauere Angaben zu machen verdanke ich Herrn Professor Dr. Markgraf, der die Güte gehabt hat eine Reihe wichtiger Excerpte durch Herrn A. Jahn für mich machen zu lassen, und dieselben mit den Originalen zu vergieichen.

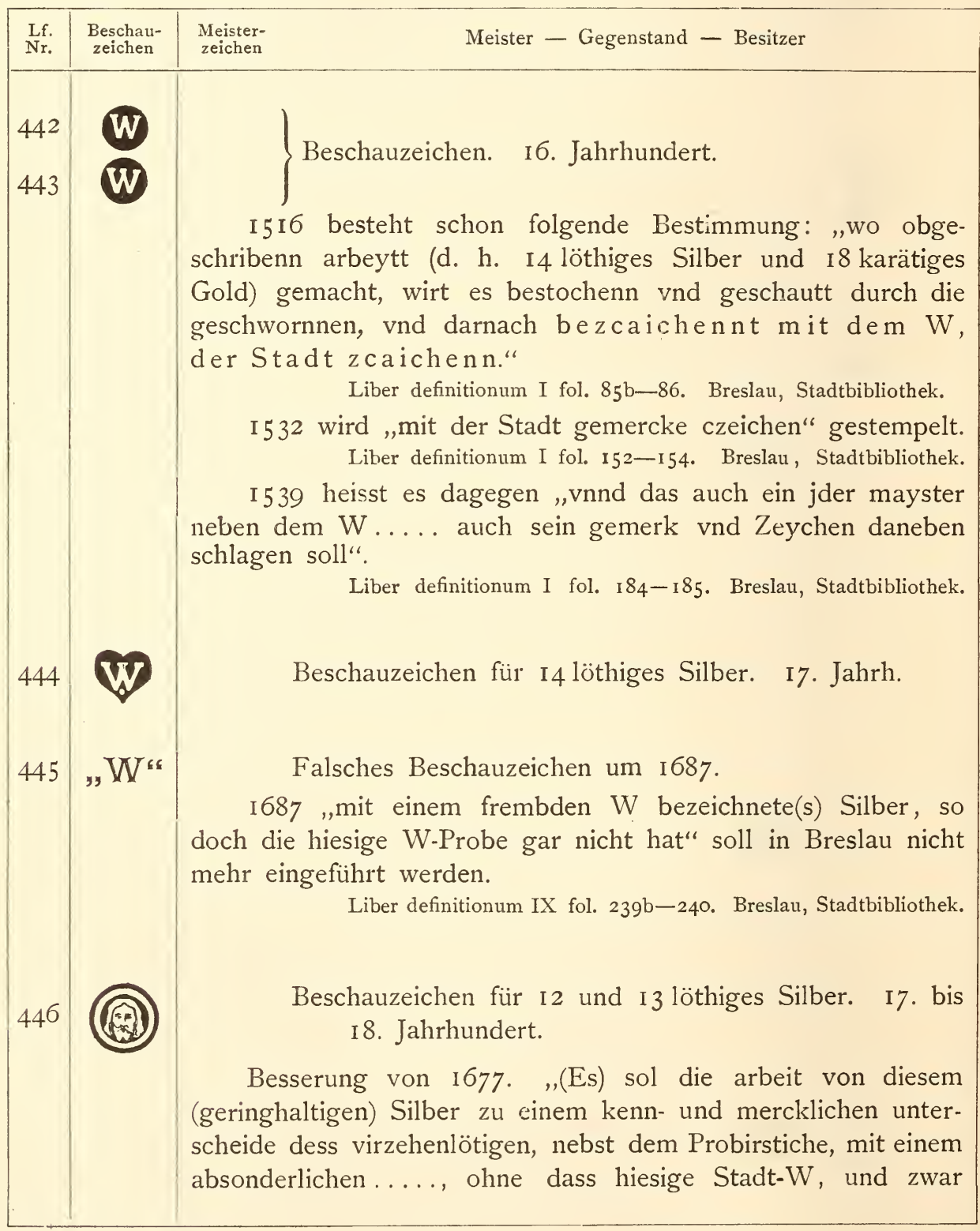




\begin{tabular}{|c|c|c|}
\hline $\begin{array}{l}\text { Lf. } \\
\text { Nir. }\end{array}$ & $\begin{array}{l}\text { Beschau- } \\
\text { zeichen }\end{array}$ & Meister - Gegenstand - Besitzer \\
\hline 446 & & $\begin{array}{l}\text { olne unterscheid, ob selbte gleich mehr alss zwölflötig, auf } \\
\text { einerley art und weise gezeichnet werden." } \\
\text { Liber definitionum IX fol. 45-46b. Breslau, Stadtbibliothek. } \\
\text { Nach den mir vorliegenden Abschriften scheint das Wort } \\
\text { zwischen ,absonderlichen" und „ohne" nicht lesbar zu sein. Viel- } \\
\text { leicht ist "Zeichen" zu setzen. Dieses Zeichen für geringhaltige } \\
\text { Waare von I2 und I } 3 \text { Loth bestand in dem Johanneskopf, der } \\
\text { zugleich mit dieser neuen Bestimmung oder wenigstens bald } \\
\text { nach derselben für die Stempelung verwendet worden ist. } \\
\text { I687 ist er schon seit einiger Zeit in Gebrauch. Es wird aus- } \\
\text { drücklich gestattet ",nebenst dem I4 löthigen Silber, als Bress- } \\
\text { lauischen Ordinar-Proba, auch auf Begehren und Bestellen } \\
\text { I3 löthiges, wie nicht weniger zum Verkauf I löthiges Silber, } \\
\text { unter rem bisherigen Zeichen des Johanneshaubts } \\
\text { (zu) verfertigen". } \\
\text { Liber definitionum IX fol. 239. Breslau, Stadtbibliothek. }\end{array}$ \\
\hline $\begin{array}{l}447 \\
448\end{array}$ & $A$ & $\begin{array}{l}\text { Jahresbuchstaben oder Beschaumeisterzeichen. } \\
\text { I 7. Jahrhundert. }\end{array}$ \\
\hline $\begin{array}{l}449 \\
450\end{array}$ & & $\begin{array}{l}\text { Jahresbuchstaben oder Beschaumeisterzeichen. } \\
\text { I 7. bis i } 8 \text {. Jahrhundert. }\end{array}$ \\
\hline 452 & & \\
\hline 453 & 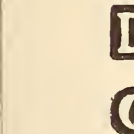 & $\begin{array}{l}\text { Jahresbuchstaben oder Beschaumeisterzeichen. } \\
\text { I8. Jahrhundert. }\end{array}$ \\
\hline 455 & $\begin{array}{c}\text { wie } \\
\text { Nr. } 442\end{array}$ & $\begin{array}{l}\text { Nivilede Deckelkanne. Flächen getrieben. H. } 13,8 \mathrm{~cm} \text {. } \\
\text { Besitzer: S. Fürth, Mainz. Edelmetallarbeiten der Sammlung } \\
\text { Fürth } 1886 \text {, Fig. 16. }\end{array}$ \\
\hline $45^{6}$ & $\begin{array}{c}\text { wie } \\
\mathrm{Nr} .442\end{array}$ & $\begin{array}{l}\text { MS Vergoldeter (?) glockenförmiger Becher mit Inschrift } \\
\text { und I } 583 \text {. } \\
\text { Besitzer: Kunstgewerbe-Museum, Berlin. }\end{array}$ \\
\hline
\end{tabular}




\begin{tabular}{|c|c|c|c|}
\hline $\begin{array}{l}\text { Lf. } \\
\text { Nr. }\end{array}$ & $\begin{array}{l}\text { Beschau- } \\
\text { zeichen }\end{array}$ & $\begin{array}{l}\text { Meister- } \\
\text { zeichen }\end{array}$ & Meister - Gegenstand - Besitzer \\
\hline 457 & & & $\begin{array}{l}\text { Vielleicht } \\
\text { Hans Schonow, erwähnt I 544, I 579-1600, oder } \\
\text { Hans Strich, erwähnt I 579, I 589-1600. }\end{array}$ \\
\hline & $\begin{array}{c}\text { wie } \\
\text { Nr. } 443\end{array}$ & & $\begin{array}{l}\text { Vergoldete Fassung eines Muschelbechers. Am Lippen- } \\
\text { rande geätztes Ornament. } \\
\text { Besitzer: } \dagger^{\top} \text { Haron Carl v. Rothschild, Frankfurt a. M. } 30 \mathrm{~cm} \text {. }\end{array}$ \\
\hline 458 & & & Georg Hoffmann, erwähnt I589-1600. \\
\hline & $\begin{array}{c}\text { wie } \\
\text { Nr. } 443\end{array}$ & & $\begin{array}{l}\text { Vergoldeter Becher. Cuppa eiförmig, mit Punkten in } \\
\text { Rauten dekorirt. } \\
\text { Besitzer (1885): Jacobsohn, St. Petersburg. }\end{array}$ \\
\hline 459 & & 2 & Daniel Mohner, erwähnt I589-i6oo. \\
\hline & $\begin{array}{c}\text { wie } \\
\text { Nr. } 443\end{array}$ & & $\begin{array}{l}\text { Theilvergoldete Kanne mit Rippen (Pfeifen) am Corpus, } \\
\text { ferner Wappen und Besitzerinitialen. H. I } 8 \mathrm{~cm} \text {. } \\
\text { Besitzer: } \dagger \text { Baron Carl v. Rothschild, Frankfurt a. M. }\end{array}$ \\
\hline 460 & & FN & Fabian Nitsche, erwähnt ı6oo. \\
\hline & $\begin{array}{c}\text { wie } \\
\text { Nr. } 442\end{array}$ & & $\begin{array}{l}\text { Deckel auf einem mit } N \text { gestempelten Pokale von } \\
23 \mathrm{~cm} \text {. Höhe. Im Deckel Wappen von I6I } 8 \text { ? } \\
\text { Besitzer: Dr. A. Figdor, Wien. }\end{array}$ \\
\hline $46 \mathrm{I}$ & & (6) & Caspar Pfister, erwähnt i60o-i6i7. \\
\hline & $\begin{array}{c}\text { wie } \\
\text { Nr. } 443\end{array}$ & & $\begin{array}{l}\text { Weisssilberner konischer Becher mit figuralen Gra- } \\
\text { virungen, Wappen, Initialen und I6 } 3 . \text { H. } 8,5 \mathrm{~cm} \text {. } \\
\text { Besitzer (1883): J. Drey, München. }\end{array}$ \\
\hline 462 & & (11) & $\begin{array}{l}\text { Matheus Jachmann (oder Jachner?), er- } \\
\text { wähnt ıбoo und I6ı } 7 \text {. }\end{array}$ \\
\hline & $\begin{array}{c}\text { wie } \\
\text { Nr. } 443\end{array}$ & & $\begin{array}{l}\text { Theilvergoldete achtseitige Kanne. } \\
\text { Besitzer: Oesterr. Museum, Wien. }\end{array}$ \\
\hline
\end{tabular}




\begin{tabular}{|lc|cc}
\hline Lf. & $\begin{array}{c}\text { Beschau- } \\
\text { zeichen }\end{array}$ & $\begin{array}{c}\text { Meister- } \\
\text { zeichen }\end{array}$ & Meister - Gegenstand - Besitzer \\
Nr.
\end{tabular}

463

wie

Nr. 442

wie 442 ?

464

wie

Nr. 443

wie 443

?

wie

Nr. 443

466

wie

Nr. 443

467

wie

Nr. 443

\section{(16) Hans Volgnadt, erwähnt $1600-1617$.}

a) Deckelkanne, getrieben mit Lederwerk und Thieren. Besitzer: C. Thewalt, Cöln.

b) Theilvergoldete Deckelkanne mit Treibarbeit.

H. I $8 \mathrm{~cm}$.

Besitzer: Georg Agath, Breslau.

(5) Fridrich Schönaw, erwähnt $1600-1617$.
a) Fassung eines Nussbechers.
H. $33 \mathrm{~cm}$.

Besitzer: Herzogl. MIuseum Gotha.

Vielleicht auch:

b) Vergoldeter Spitzbecher mit Diamantbuckeln, Inschrift und Iб I6.

H. $24,5 \mathrm{~cm}$.

Besitzer: Museum der Eremitage, St. Petersburg.

c) Theilvergoldeter cylindrischer Becher mit geätzten Ornamenten.

H. $9 \mathrm{~cm}$.

Besitzer: $\uparrow$ Lorenz Gedon, München. Auktionskatalog I884, Nr. 143.

Löffel mit Bernsteinheft.

Besitzer: Königl. Schatzkammer, München. Katalog Schauss I879, I. 30.

Fridrich Viecke, erwähnt i6 7 .

Niedrige Deckelkanne mit Lederwerkornament getrieben. Besitzerinitialen.

H. $15 \mathrm{~cm}$.

Besitzer: P. A. Kotschubey, St. Petersburg.

(H) Hans Jachmann, erwähnt I6I7 und I640.
a) Hohe Henkelschale.
H. $5,8 \mathrm{~cm}$. Besitzer (I883): A. S. Drey, München.

Vielleicht auch:

b) Vergoldeter und emaillirter Büttenmann. ,The rim (of the hat) is engraved with hunting scenes. I $5^{\text {th }}(?)$ century. Marks, II. and I. H. (:) Height, $\mathrm{IO}^{\mathrm{x} / 4}$ in."

Besitzer: $\uparrow$ Baron Lionel vo Rothschild, London. South Kensington Museum, Loan Exhibition I862, S. 5 I I Nr. 6, I79. 


\begin{tabular}{|c|c|c|c|}
\hline $\begin{array}{l}\text { Lf. } \\
\text { Nr. }\end{array}$ & $\begin{array}{l}\text { Beschau- } \\
\text { zeichen }\end{array}$ & $\begin{array}{l}\text { Meister- } \\
\text { zeichen }\end{array}$ & Meister - Gegenstand - Besitzer \\
\hline 468 & & & $\begin{array}{l}\text { Hans Boxhammer, oder } \\
\text { Hans Boy, erwähnt I640. }\end{array}$ \\
\hline & $\begin{array}{c}\text { wie } \\
\mathrm{Nr} .443\end{array}$ & & $\begin{array}{l}\text { Achtseitige Kanne mit figuralen Gravirungen in den } \\
\text { glatten Feldern. } \\
\text { Besitzer: Baron Albr. Redl. Ausstellung Budapest } 6884 \text {. } \\
\text { 4. Saal, 2. Schrank Nr. 35. Katalog S. 23. }\end{array}$ \\
\hline 469 & & C & $\begin{array}{l}\text { Vielleicht } \\
\text { Christof Hönsch, erwähnt I746-1793. }\end{array}$ \\
\hline & $\begin{array}{c}\text { wie } \\
\text { Nr. } 446\end{array}$ & & $\begin{array}{l}\text { Theilvergoldeter konischer Becher mit flachgetriebenem } \\
\text { Ornamente. } \\
\text { Besitzer: H. I0, } 3 \mathrm{~cm} \text {. Freih. v. Tucher, Nürnberg. Ausstellung Nürn- } \\
\text { berg 1885, Katalog Nr. Sor. }\end{array}$ \\
\hline 470 & $\begin{array}{c}\text { wie } \\
\mathrm{Nr} \cdot 446\end{array}$ & A & $\begin{array}{ll}\text { a) Konischer Münzbecher. } & \text { H. } 24,5 \mathrm{~cm} . \\
\text { Besitzer: Winterpalais, St. Petersburg. } & \end{array}$ \\
\hline & wie 446 & & $\begin{array}{l}\text { b u. c) Fassung zweier Nussbecher. H. } 23 \mathrm{~cm} \text {. } \\
\text { Besitzer: Museum der Eremitage, St. Petersburg. }\end{array}$ \\
\hline & wie 446 & & d) Theilvergoldete Kanne. \\
\hline & wie 446 & & 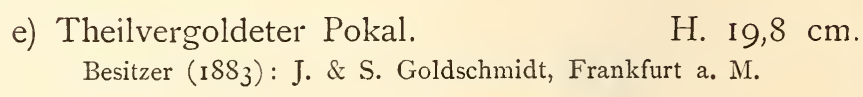 \\
\hline
\end{tabular}

a) Theilvergoldeter Pokal mit Horizontalprofilirungen und weit über den Lippenrand vortretendem Deckel. Dekoration in Flachrelief. H. $39 \mathrm{~cm}$. Besitzer: Baron Nathanael v. Rothschild, Wien (Villa).

b) Theilvergoldete Kanne. Der Cylinder mit figuraler Treibarbeit auf Futter aufgesetzt. Wappen, Initialen und Inschriften.

H. $22,3 \mathrm{~cm}$.

Besitzer: P. A. Kotschubey, St. Petersburg.

Thomas Beyl, erwähnt I758, wenn die folgenden Arbeiten nicht zu früh für ihn sind. 


\begin{tabular}{|c|c|c|c|}
\hline $\begin{array}{l}\text { Lf. } \\
\text { Nr. }\end{array}$ & $\begin{array}{l}\text { Beschau- } \\
\text { zeichen }\end{array}$ & & Meister - Gegenstand - Besitzer \\
\hline 472 & $\begin{array}{c}\text { wie } \\
\text { Nr. } 444\end{array}$ & & $\begin{array}{l}\text { a) Mit dem Jahresbuchstaben C Nr. } 452 . \\
\text { Löffel. } \\
\text { Besitzer: Excellenz Due, St. Petersburg. } 2 \text { I cm. } \\
\text { b) Schale, getrieben mit Kinderfiguren. } \\
\text { Besitzer (1882): J. \& S. Goldschmidt, Frankfurt a. M. }\end{array}$ \\
\hline 473 & $\begin{array}{c}\text { wie } \\
\text { Nr. } 446\end{array}$ & & 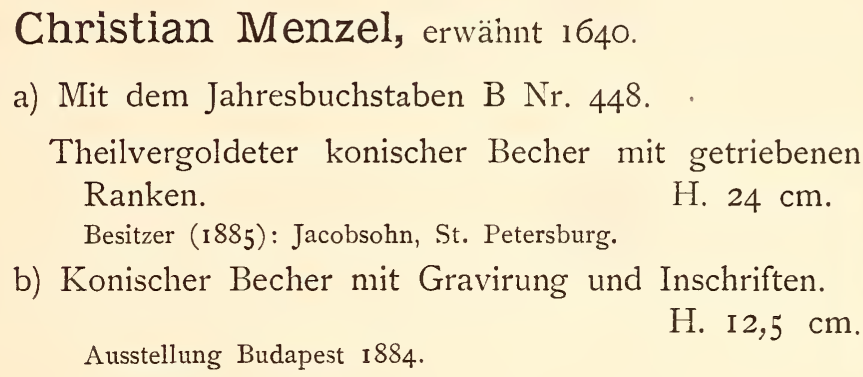 \\
\hline 474 & $\begin{array}{c}\text { wie } \\
\text { Nr. } 446\end{array}$ & & $\begin{array}{l}\text { Mit dem Jahresbuchstaben A Nr. } 447 . \\
\text { Eiförmiger Pokal mit Griff u. Deckel. } \\
\text { Besitzer: J. \& H. Jeidels, Frankfurt a. M. }\end{array}$ \\
\hline 475 & $\begin{array}{c}\text { wie } \\
\text { Nr. } 446\end{array}$ & GK & $\begin{array}{l}\text { Mit dem Jahresbuchstaben B Nr. } 448 . \\
\text { Vergoldeter Löffel. Griff sechsseitig mit Maskarons. } \\
\text { Lg. } 2 \text { r, } 3 \mathrm{~cm} .\end{array}$ \\
\hline 476 & $\begin{array}{c}\text { wie } \\
\text { Nr. } 446\end{array}$ & Viellei & $\begin{array}{l}\text { a u. b) Mit dem Jahresbuchstaben B Nr. } 448 \text {. } \\
\text { Weisssilberne Taufschüssel mit zugehöriger Kanne. } \\
\text { Schüssel, Dm. } 29 \mathrm{~cm} \text {. Kanne, H. } 25,5 \mathrm{~cm} \text {. } \\
\text { Besitzer (1883): Gebr. Heilbronner, München. } \\
\text { ht auch: }\end{array}$ \\
\hline & wie 446 & & $\begin{array}{l}\text { c) Mit dem Jahresbuchstaben B Nr. } 448 . \\
\text { Konischer Becher. } \\
\text { Besitzer: P. A. Kotschubey, St. Petersburg. }\end{array}$ \\
\hline 477 & $\begin{array}{c}\text { wie } \\
\text { Nr. } 446\end{array}$ & & $\begin{array}{l}\text { Mit dem Jahresbuchstaben B Nr. } 45 \mathrm{I} \text {. } \\
\text { Weisssilberner Buchdeckel mit durchbrochenem Laub- } \\
\text { werke. } \\
\text { H. I } 4,5 \mathrm{~cm} \text {. } \\
\text { Besitzer: Baron Horace von Günzburg, St. Petersburg. }\end{array}$ \\
\hline
\end{tabular}




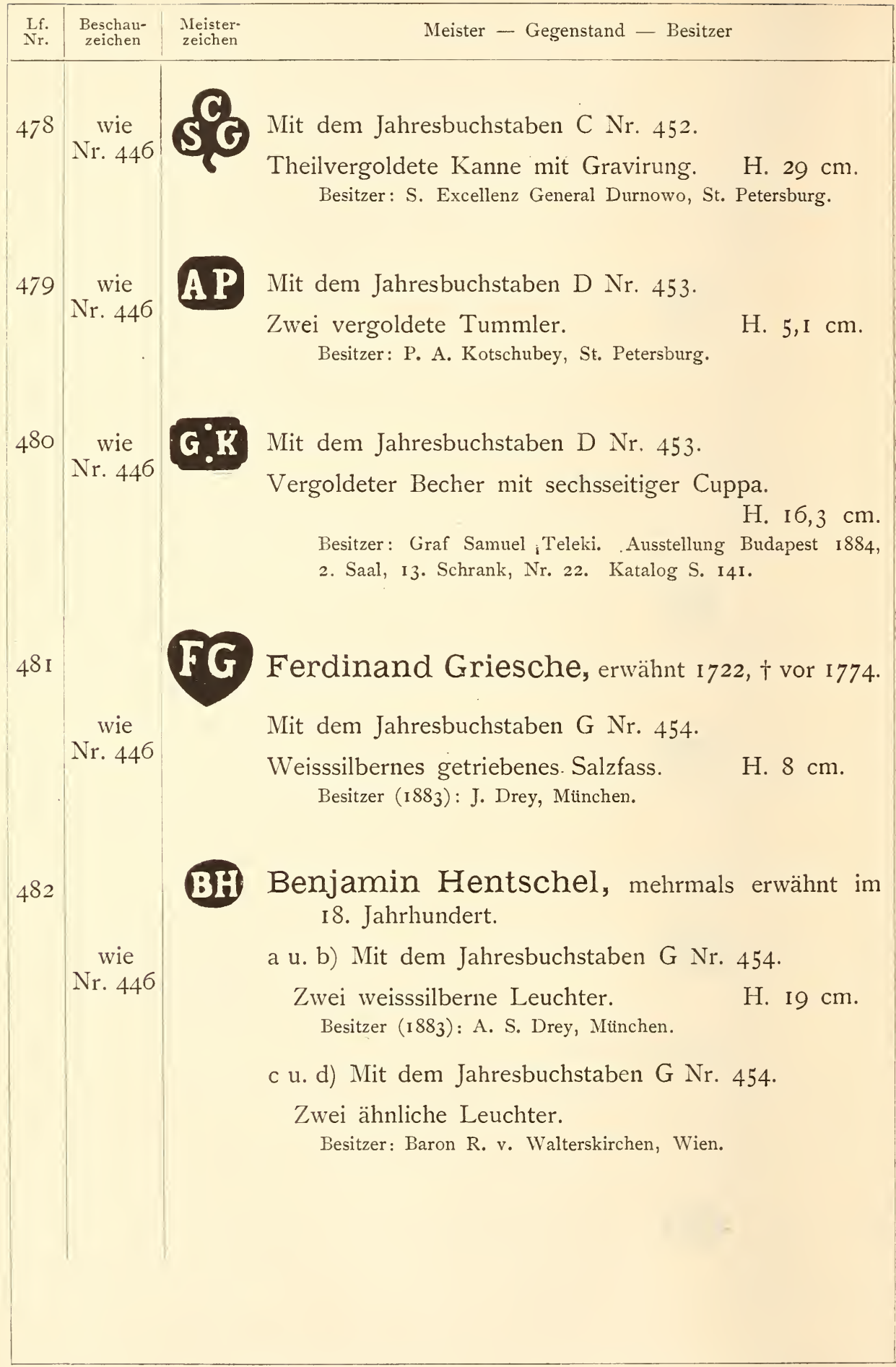




\section{BRIEG.}

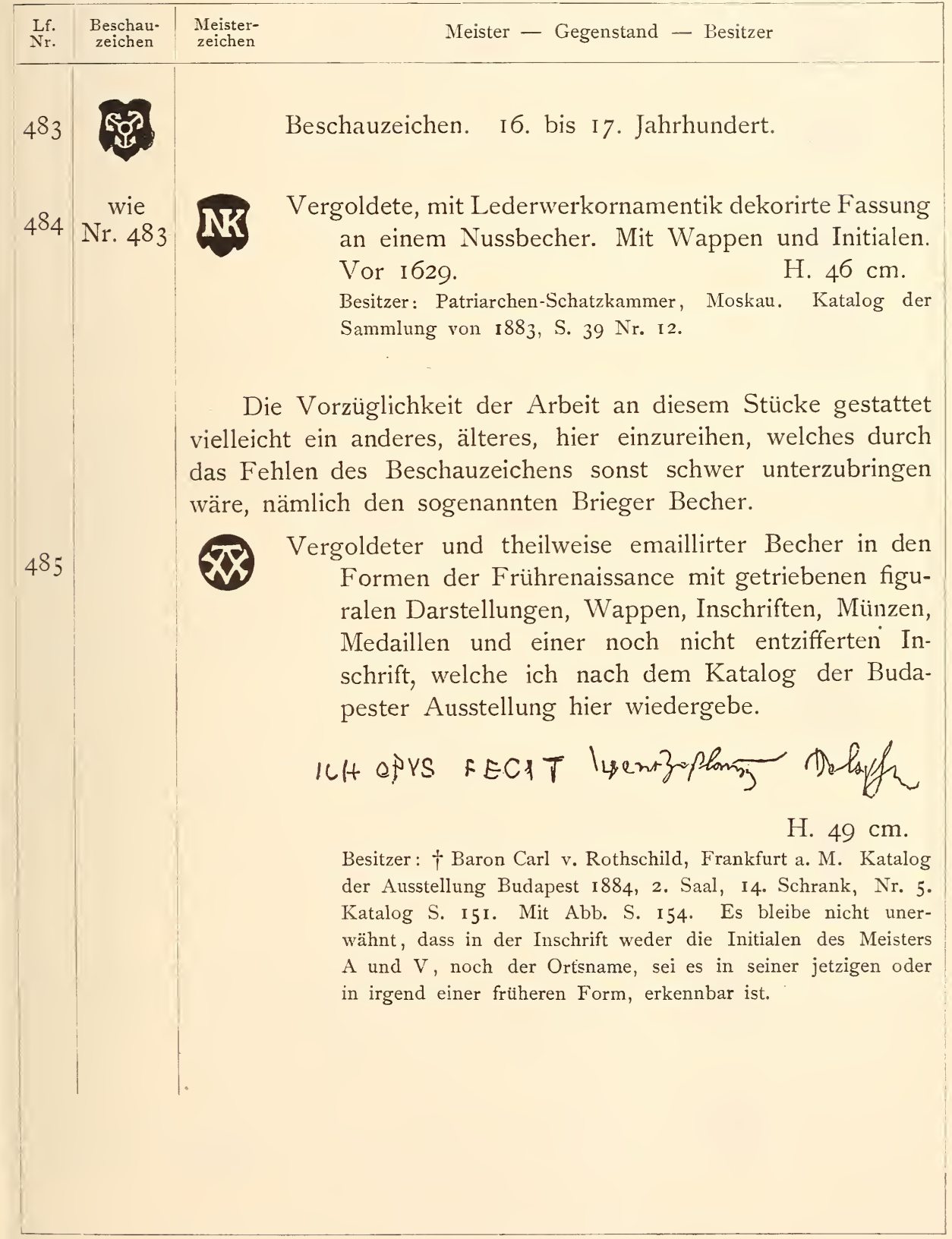




\section{CASSEL.}

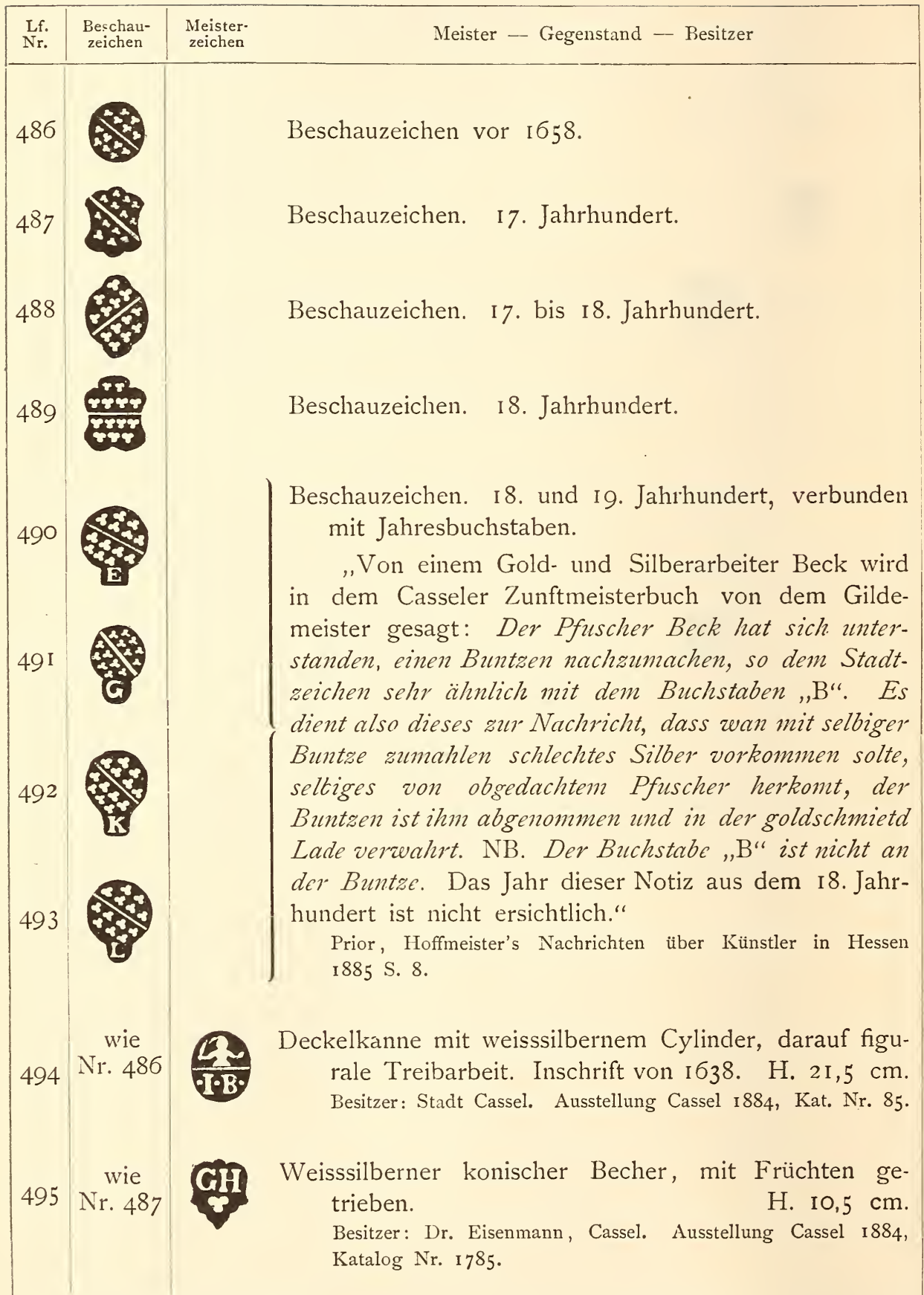




\begin{tabular}{|c|c|c|}
\hline $\begin{array}{l}\text { Lf. } \\
\text { Nr. }\end{array}$ & $\begin{array}{l}\text { Beschau- } \\
\text { zeichen }\end{array}$ & Meister - Gegenstand - Besitzer \\
\hline 496 & & $\begin{array}{l}\text { Georg Schmidt, I7O3-I735. } \\
\text { Angabe des Katalogs der Hessischen Landesausstellung, Cassel } \\
\text { I } 884 \text {, S. II3. }\end{array}$ \\
\hline & $\begin{array}{c}\text { wie } \\
\text { Nr. } 478\end{array}$ & $\begin{array}{l}\text { a) Runde Henkelschale. Dm. I } 3 \mathrm{~cm} \text {. } \\
\text { Besitzer: Bayerisches Gewerbe-Museum, Nürnberg. }\end{array}$ \\
\hline & wie 488 & $\begin{array}{l}\text { b) Konischer Becher mit Deckel. H. } 23 \mathrm{~cm} \text {. } \\
\text { Besitzer: Stadt Hersfeld. Ausstellung Cassel I } 884 \text {, Katalog } \\
\text { Nr. I03. }\end{array}$ \\
\hline & Ivie $488 ?$ & $\begin{array}{l}\text { c) Weisssilbernes Theekännchen. } \\
\text { Besitzer: J. Hoffmeister, Cassel. Ausstellung Cassel I } 884 \text {, Kata- } \\
\log \text { Nr. I } 756 \text {. }\end{array}$ \\
\hline 497 & $\begin{array}{c}\text { wie } \\
\text { Nr. } 489\end{array}$ & $\begin{array}{l}\text { Fassung einer geschnitzten Elfenbeinkanne. H. } 20 \mathrm{~cm} \text {. } \\
\text { Besitzer: Königl. Museum, Cassel. Kat. Lenz I88I, Nr. } 279 \text {. }\end{array}$ \\
\hline 498 & $\begin{array}{c}\text { wie } \\
\operatorname{Nr} .490\end{array}$ & $\begin{array}{l}\text { WEIGIL Zwei weisssilberne Kännchen mit Fries am Halse. } \\
\text { H. } 20 \mathrm{~cm} . \\
\text { Besitzer: Frau Knetsch, Cassel. Ausstellung Cassel } 1884 \text {, Kat. } \\
\text { Nr. I693/94. }\end{array}$ \\
\hline 499 & $\begin{array}{c}\text { wie } \\
\text { Nr. } 49 \text { I }\end{array}$ & $\begin{array}{l}\text { LI Vergoldete flache, runde Schale auf Fuss. } \\
\text { Besitzer: Königl. Museum, Cassel. }\end{array}$ \\
\hline 500 & $\begin{array}{c}\text { wie } \\
\mathrm{Nr} .492\end{array}$ & $\begin{array}{l}\text { J. Beauclair (Baucair), um I780. } \\
\text { Angabe von Lenz, Führer durch die Sammlung Cassel I } 88 \text { I. } \\
\text { a u. b) Vergoldete Fassung an zwei mit Kinderfries } \\
\text { geschnitzten Elfenbeinkannen. } \quad \text { H. } 22 \mathrm{~cm} \text {. } \\
\text { Besitzer: Königl. Museum Cassel. Katalog Lenz I88I, Nr. } 282 \\
\text { und } 284 \text {. }\end{array}$ \\
\hline & ? & $\begin{array}{l}\text { c) „Spülkumpchen“. } \\
\text { Besitzer: Dr. R. Harnier, Cassel. Ausstellung Cassel i } 884 \text {, } \\
\text { Katalog Nr. I753. }\end{array}$ \\
\hline $5 O I$ & $\begin{array}{c}\text { wie } \\
\text { Nr. } 493\end{array}$ & 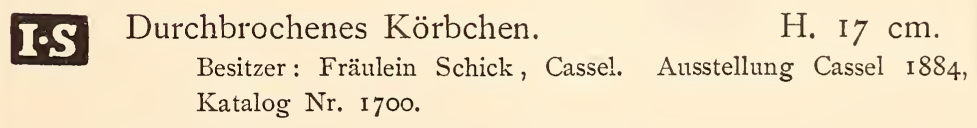 \\
\hline
\end{tabular}




\section{CELLE.}

\begin{tabular}{|c|c|cc|}
\hline $\begin{array}{c}\text { Lf. } \\
\text { Nr. }\end{array}$ & $\begin{array}{c}\text { Beschau- } \\
\text { zeichen }\end{array}$ & $\begin{array}{c}\text { Meister- } \\
\text { zeichen }\end{array}$ & Meister - Gegenstand - Besitzer \\
\hline 502 & Löwe & $\begin{array}{r}\text { Stempelt betrügerischer Weise mit dem Löwen. Siehe } \\
\text { Lüneburg. }\end{array}$ \\
\hline
\end{tabular}

\section{CÖLN.}

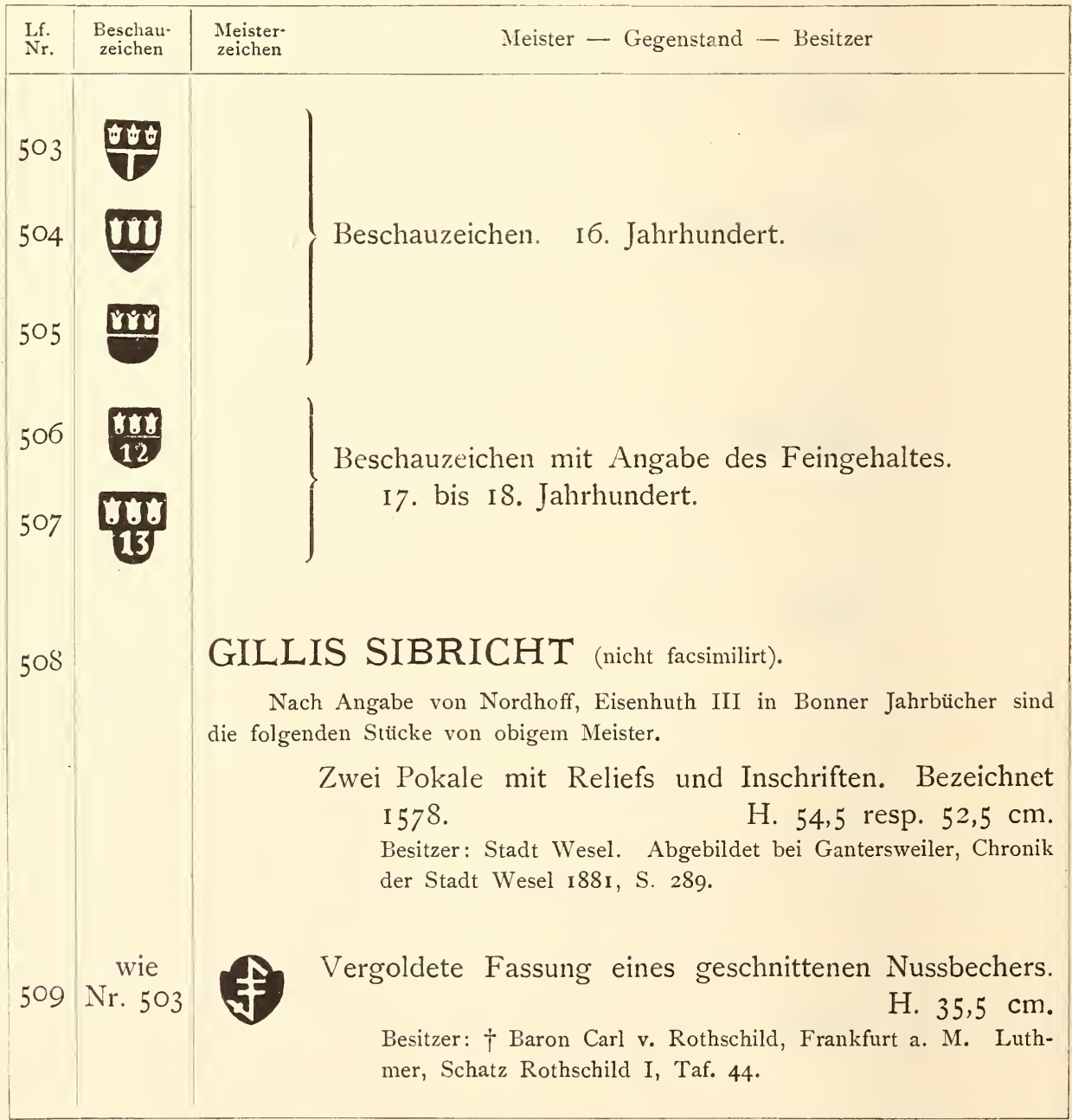




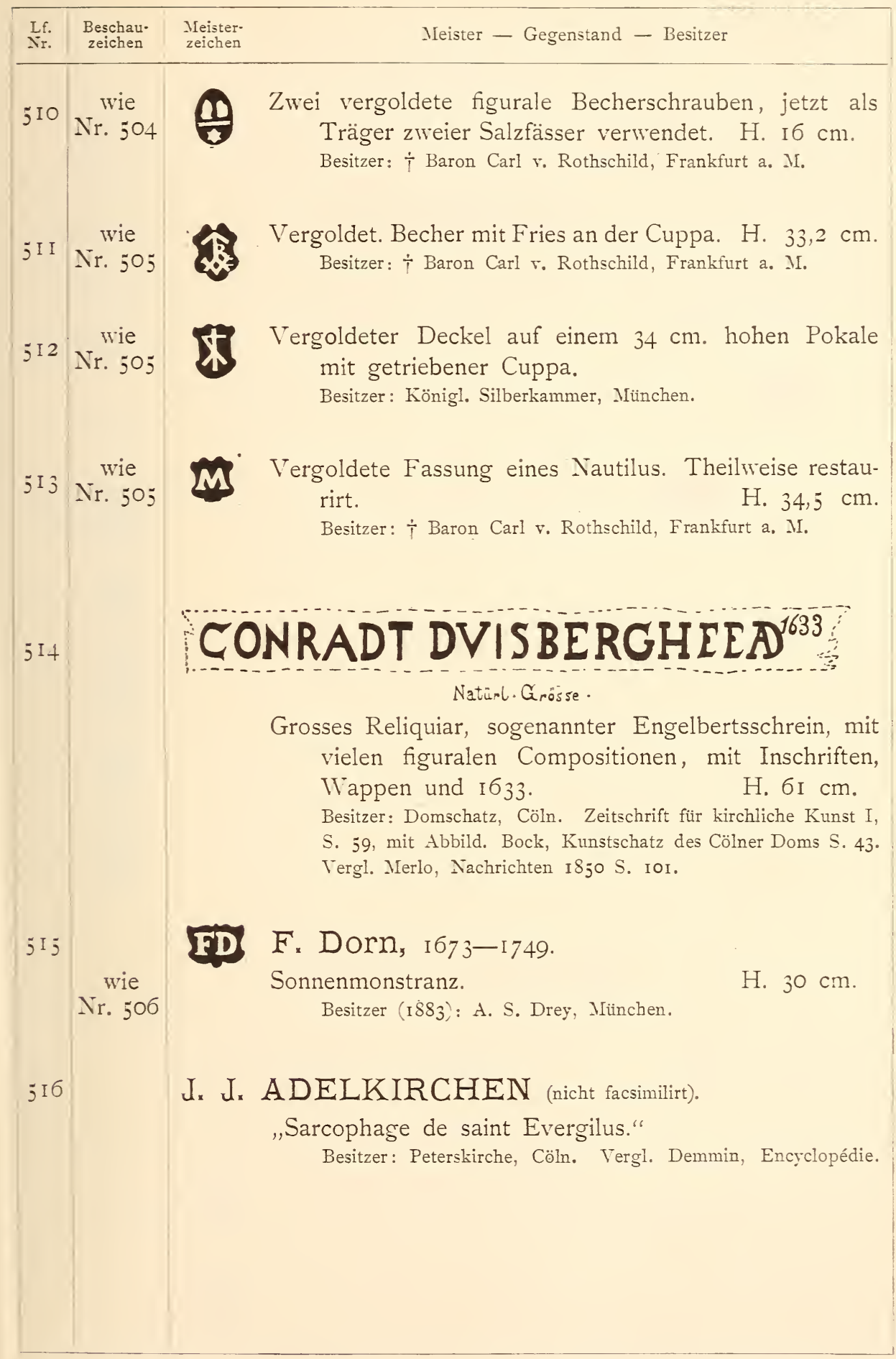




\section{COLMAR?}

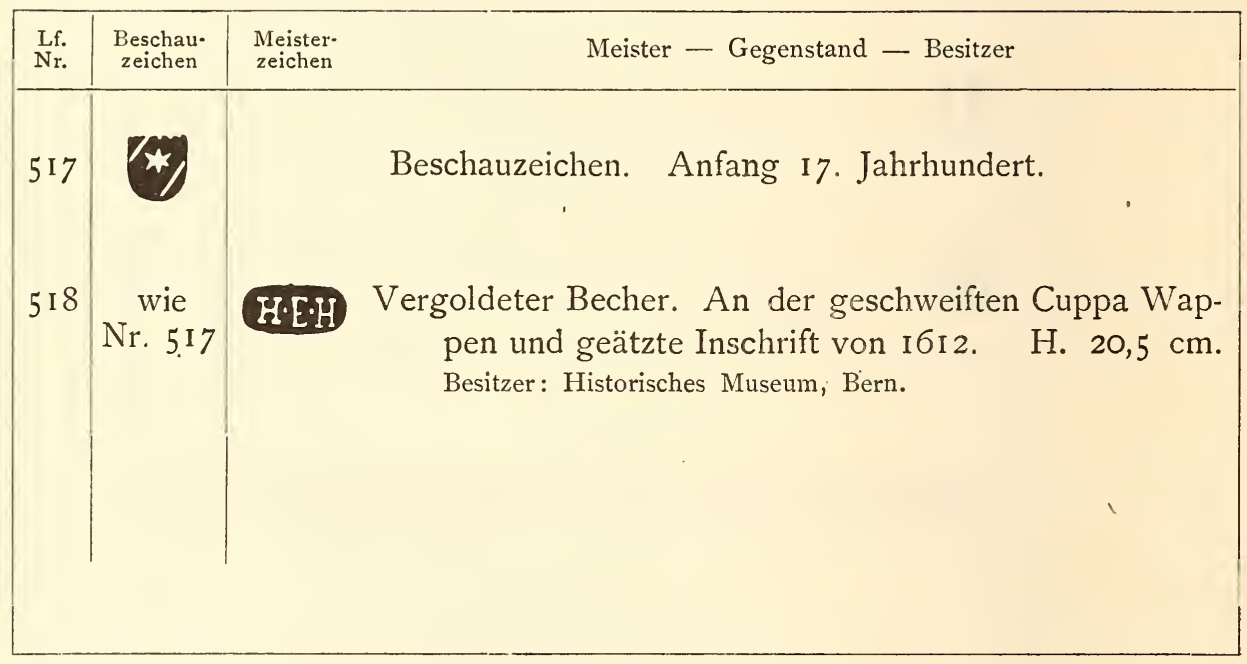

\section{DANNENBERG.}

\begin{tabular}{|c|c|cc|}
\hline $\begin{array}{c}\text { Lf. } \\
\text { Nr. }\end{array}$ & $\begin{array}{c}\text { Beschau- } \\
\text { zeichen }\end{array}$ & $\begin{array}{c}\text { Meister. } \\
\text { zeichen }\end{array}$ & Meister - Gegenstand - Besitzer \\
\hline 519 & Löwe & $\begin{array}{c}\text { Stempelt betrügerischer Weise mit dem. Löwen. Siehe } \\
\text { Lüneburg. }\end{array}$ \\
& \\
\hline
\end{tabular}




\section{DANZIG.}

Beschau- und Meisterzeichen schon seit dem I 5. Jahrhundert obligatorisch. Die Danziger Goldschmiedeordnung von I4I8, erweitert I45 I, verlangt: ,Jeder Goldschmied soll ... auf seine Arbeit sein Zeichen, sofern die Arbeit gross genug zum Einzeichnen ist, neben dem der Stadt schlagen." (Theodor Hirsch, Danzigs Handels- und Gewerbegeschichte unter der Herrschaft des deutschen Ordens [Jablonowskische Preisschrift VI]. Leipzig r858 S. 3 14.) Das älteste Beschauzeichen, das ich nachzuweisen vermag, geht kaum bis ins I6. Jahrhundert zurück.

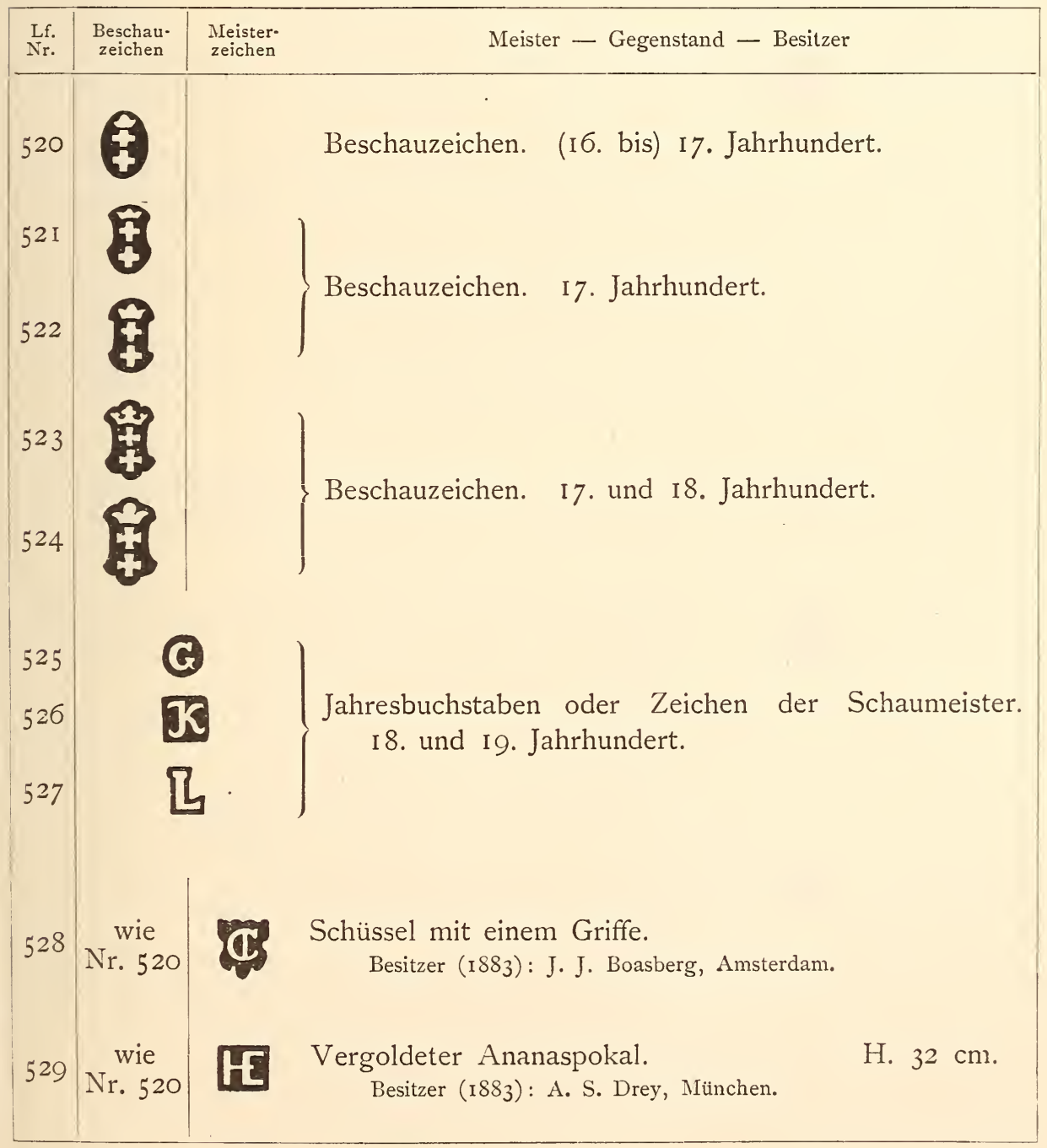




\begin{tabular}{|c|c|c|c|}
\hline $\begin{array}{l}\text { Lf. } \\
\text { Nr. }\end{array}$ & $\begin{array}{l}\text { Beschau- } \\
\text { zeichen }\end{array}$ & zeichen & Meister - Gegenstand - Besitzer \\
\hline 530 & $\begin{array}{c}\text { wie } \\
\text { Nr. } 520\end{array}$ & & $\begin{array}{l}\text { Buckelpokal. } \\
\quad \text { Besitzer: Winterpalais St. Petersburg. }\end{array}$ \\
\hline $53 \mathrm{I}$ & $\begin{array}{c}\text { wie } \\
\text { Nr. } 52 \mathrm{I}\end{array}$ & & $\begin{array}{l}\text { a) Vergoldeter konischer Becher (Kluftbecher), mit } \\
\text { Ornamenten getrieben. } \\
\text { Besitzer (I88I): Gebr. Moppert, Baden-Baden. I7 cm. Ausstellung } \\
\text { Karlsruhe I88I, Katalog Nr. I692. }\end{array}$ \\
\hline & wie $52 \mathrm{I}$ & & $\begin{array}{l}\text { b) Konischer Becher. H. } 20 \mathrm{~cm} . \\
\text { Besitzer: S. D. Fürst Paskewitsch, St. Petersburg. }\end{array}$ \\
\hline 532 & $\begin{array}{c}\text { wie } \\
\text { Nr. } 522\end{array}$ & & $\begin{array}{l}\text { a) Fassung einer geschnitzten Elfenbeinkanne. } \\
\begin{array}{ll}\text { Besitzer: Herzogl. Museum, Gotha. } & \text { H. } 23 \mathrm{~cm} \text {. }\end{array}\end{array}$ \\
\hline & wie 522 & & $\begin{array}{l}\text { b) Theilvergoldeter Becher mit getriebenen figuralen } \\
\text { Darstellungen. } \\
\text { Besitzer: Excellenz Due, St. Petersburg. }\end{array}$ \\
\hline & ? & & $\begin{array}{l}\text { c) Tischplatte von getriebenem und vergoldetem Silber } \\
\text { mit Elfenbeinreliefs. } \\
\text { Besitzer: Kunstgewerbe-Museum Berlin. Nagler, Monogram. } \\
\text { misten II S. 621. Kugler, Beschreibung der Kunstkammer, } \\
\text { Berlin 1838, Nr. } 317 \text {. }\end{array}$ \\
\hline 533 & $\begin{array}{c}\text { wie } \\
\text { Nr. } 522\end{array}$ & & $\begin{array}{l}\text { Vergoldete Kanne mit Gravirungen in drei Feldern. } \\
\text { Besitzer (I883): J. \& S. Goldschmidt, Frankfurt a. M. }\end{array}$ \\
\hline 534 & $\begin{array}{c}\text { wie } \\
\text { Nr. } 522\end{array}$ & ${ }^{P}$ & $\begin{array}{l}\text { a) Vergoldete Kanne. Am Körper Köpfe und Früchte } \\
\text { getrieben. Wappen und Inschrift. H. I8 cm. } \\
\text { Besitzer: P. A. Kotschubey, St. Petersburg. }\end{array}$ \\
\hline & wie 522 & & $\begin{array}{l}\text { b) Theilvergoldete ovale Platte. Mitte figural, Rand } \\
\text { mit Ornamenten getrieben. } \\
\text { Besitzer: Winterpalais, St. Petersburg. }\end{array}$ \\
\hline 535 & $\begin{array}{c}\text { wie } \\
\text { Nr. } 522\end{array}$ & PR & $\begin{array}{l}\text { a) Konischer Becher mit Ranken getrieben. H. I } 5 \mathrm{~cm} \text {. } \\
\text { Besitzer (1882): Gebr. Moppert, Baden-Baden. }\end{array}$ \\
\hline & wie 522 & & $\begin{array}{l}\text { b) Theilvergoldeter Kelch. An der Cuppa geflügelte } \\
\text { Engelsköpfe in durchbrochener Arbeit. H. 38,5 cm. } \\
\text { Besitzer: } \dagger \text { Baron Carl v. Rothschild, Frankfurt a. M. } \\
\text { c) Deckelkanne mit Blumengravirungen. } \\
\text { Besitzer (I883): J. \& S. Goldschmidt, Frankfurt a. M. }\end{array}$ \\
\hline
\end{tabular}




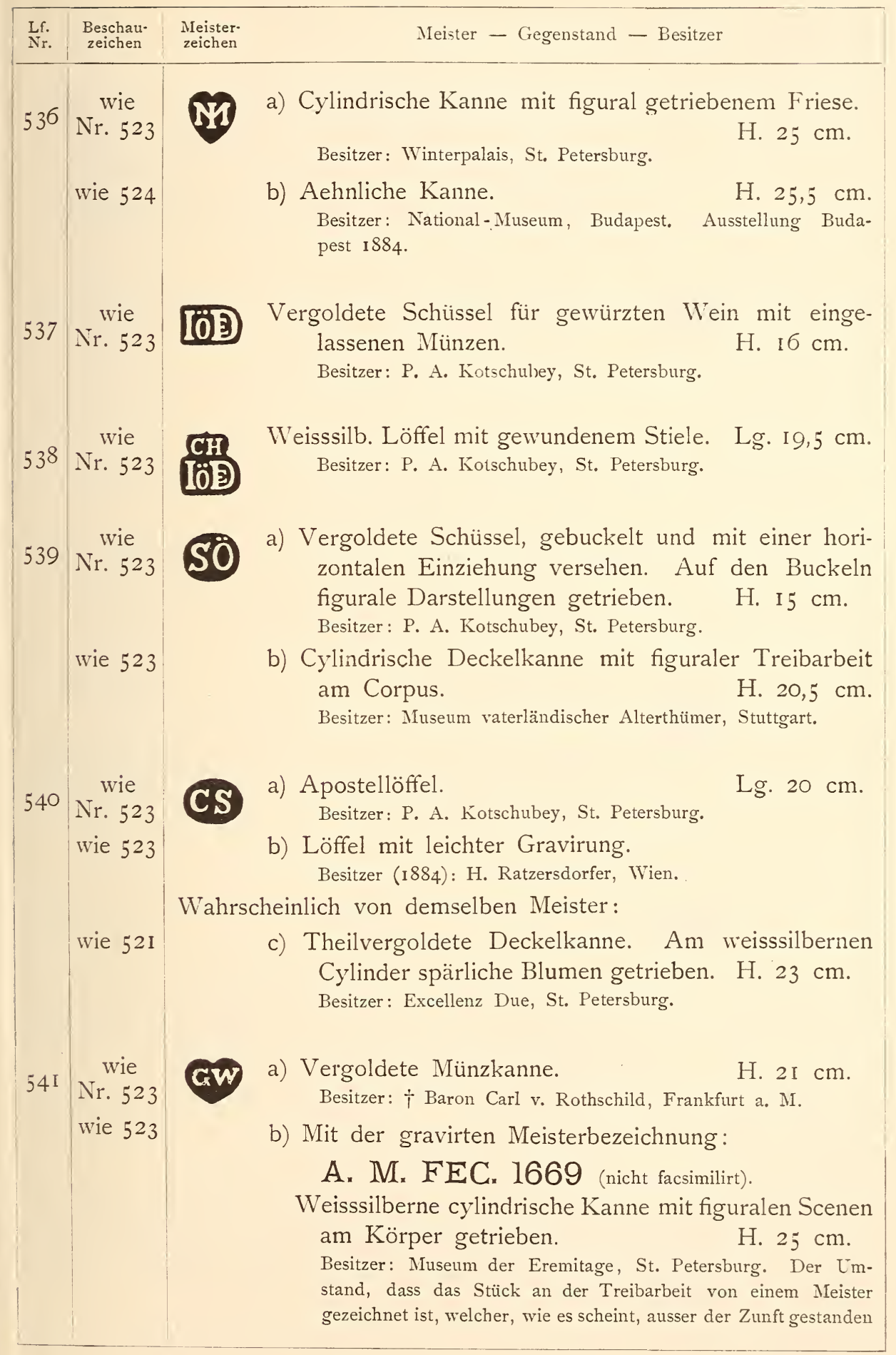




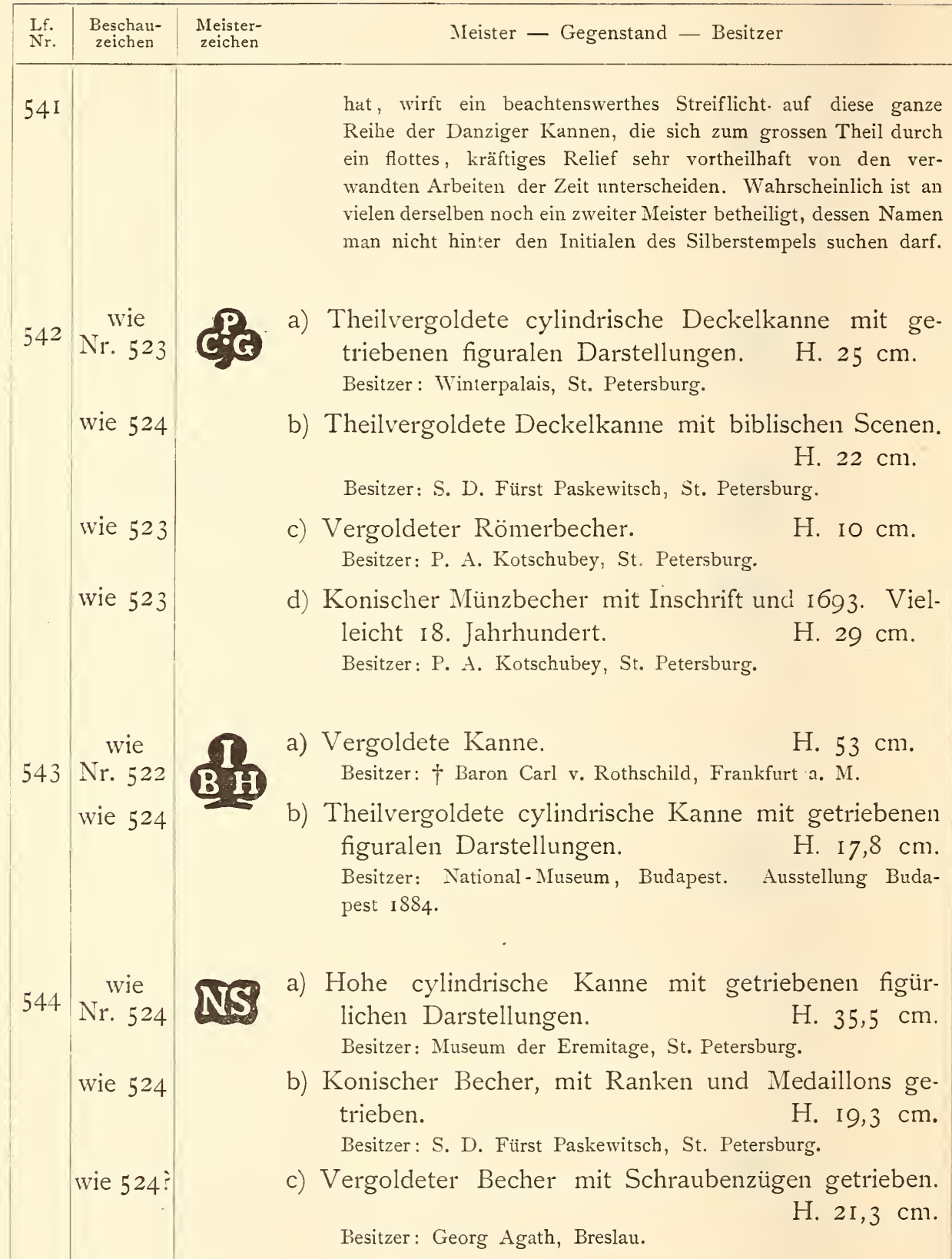

$\mathrm{Ob}$ die folgenden zwei aus $\mathrm{N}$ und $\mathrm{S}$ gebildeten Marken demselben Meister, wie die obigen Stücke, angehören, oder einem anderen Goldschmiede mit gleichen Initialen, bleibe dahingestellt. 


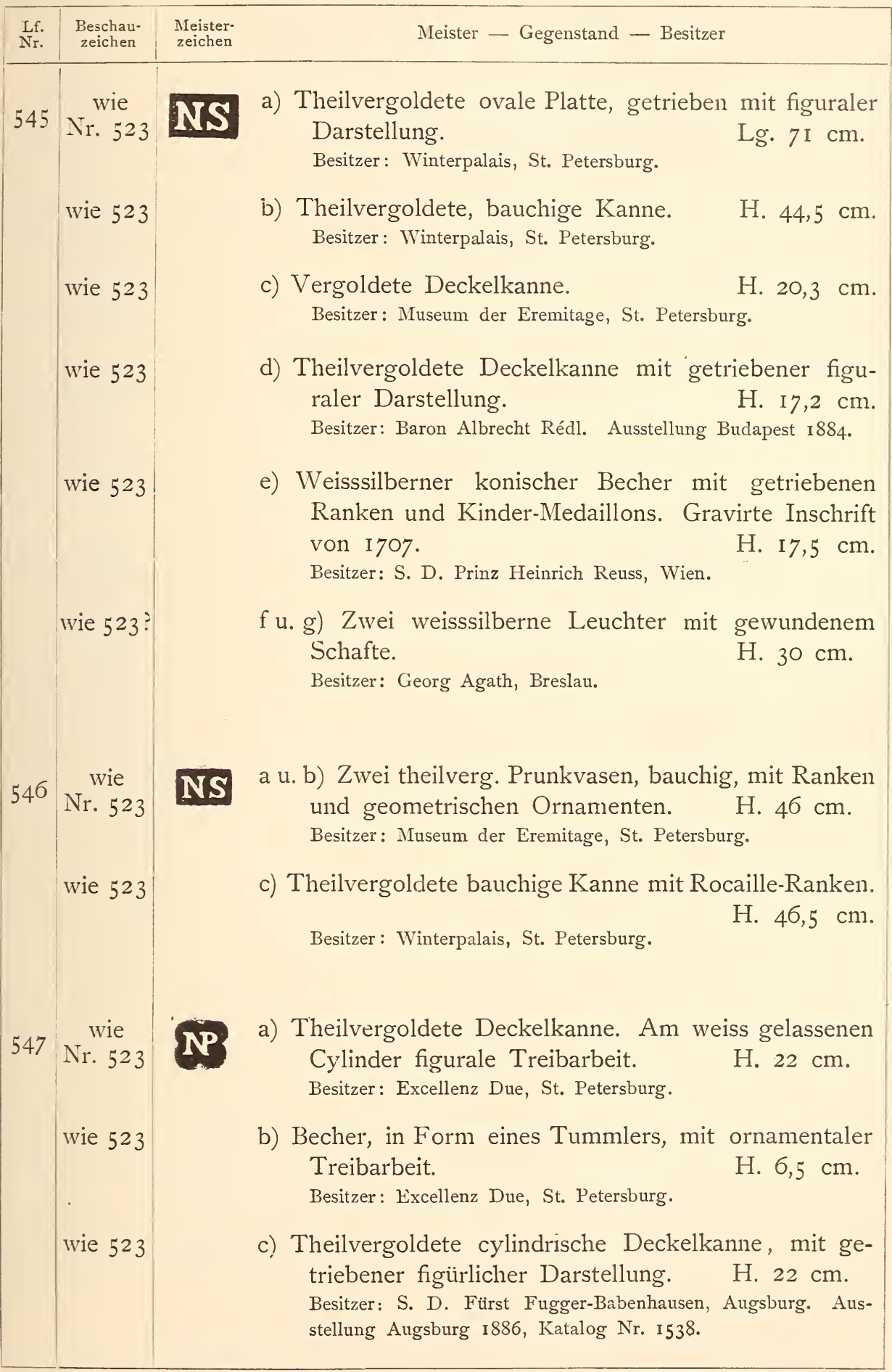




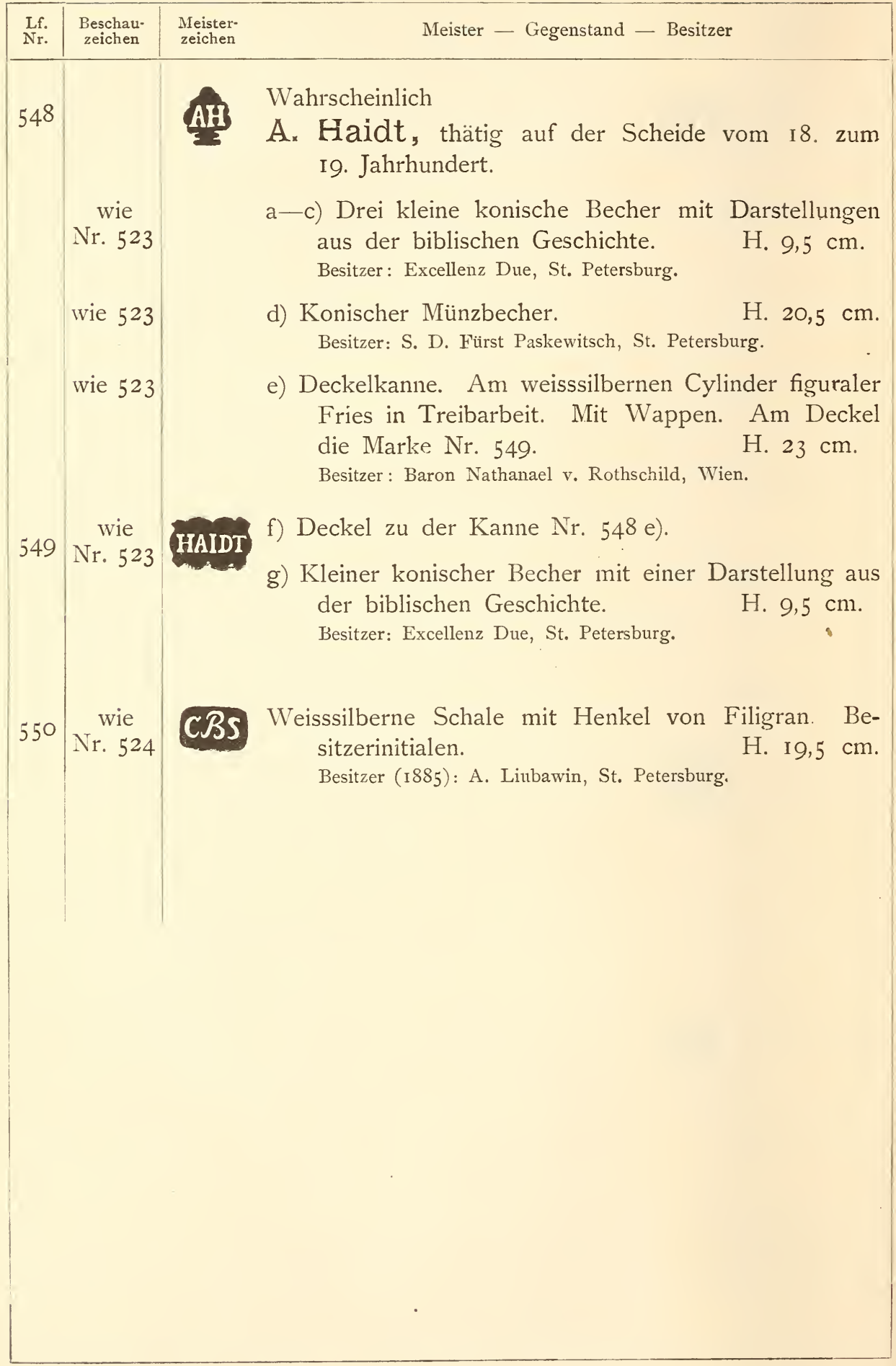




\section{DARMSTADT.}

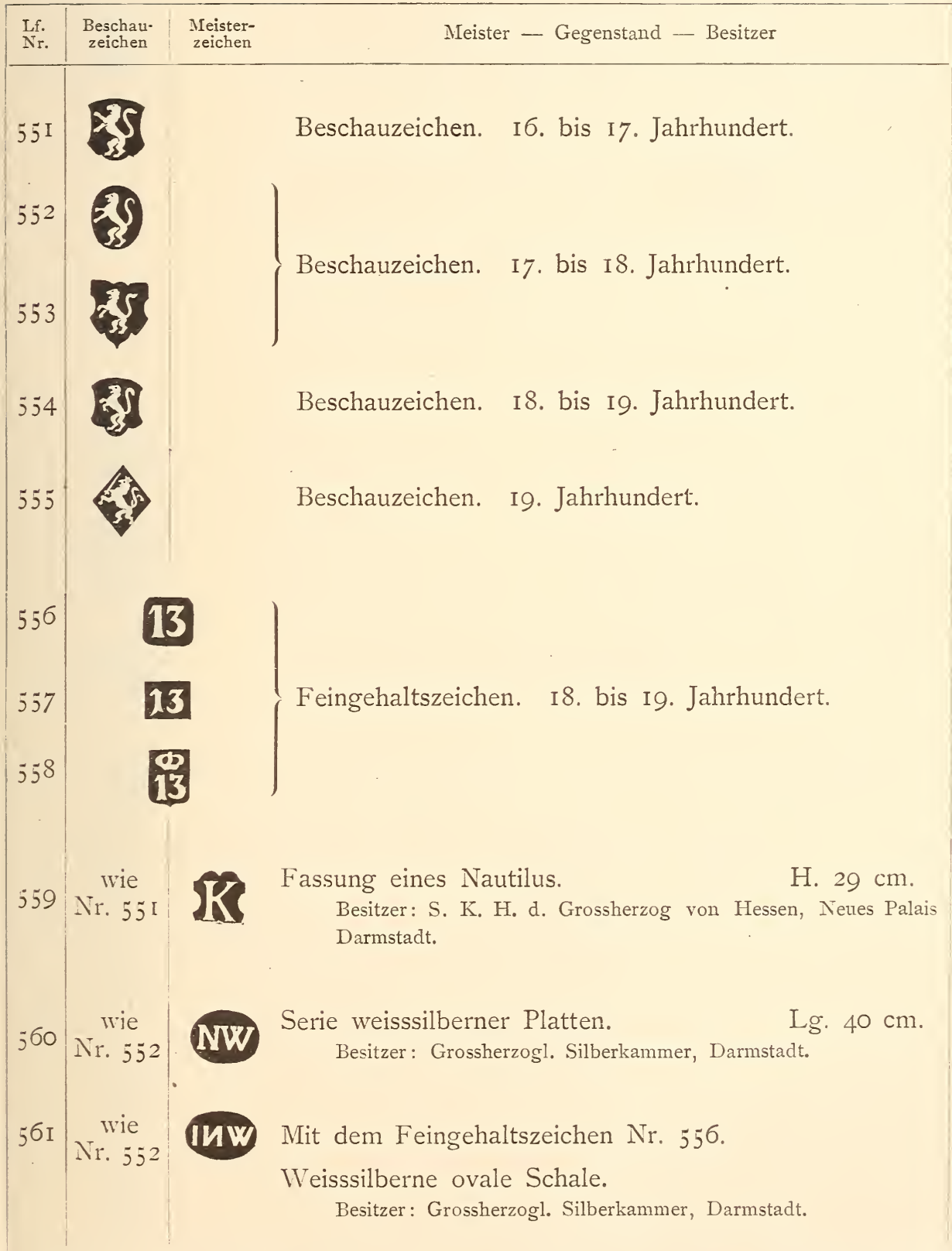




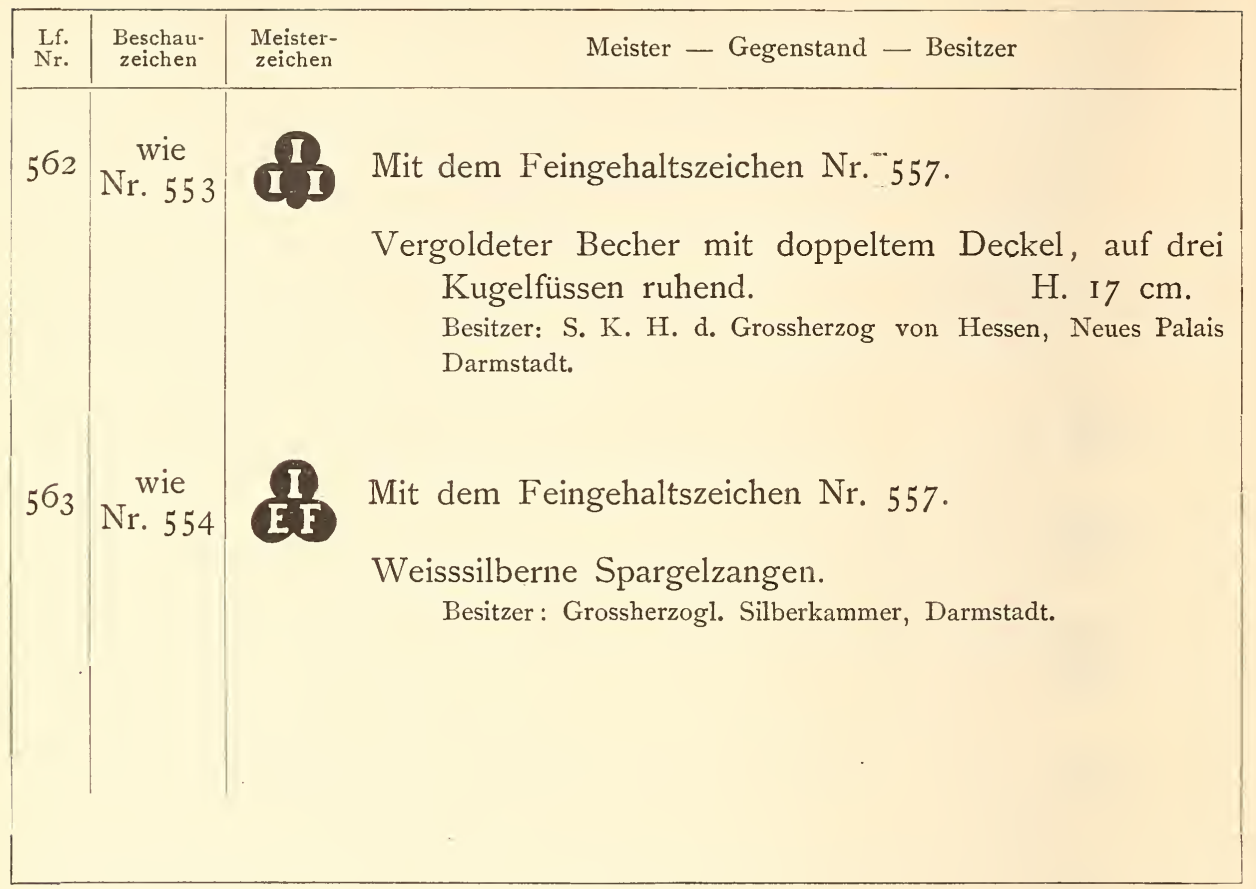

\section{DRINGENBERG.}

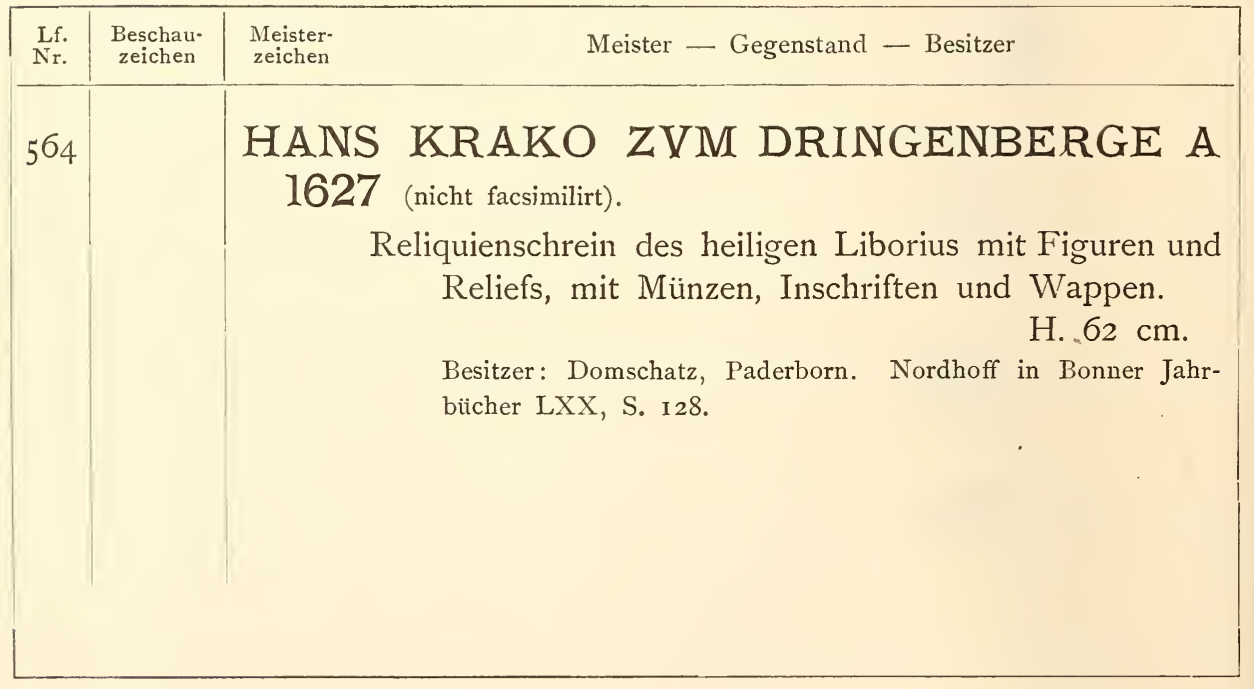




\section{DRESDEN *}

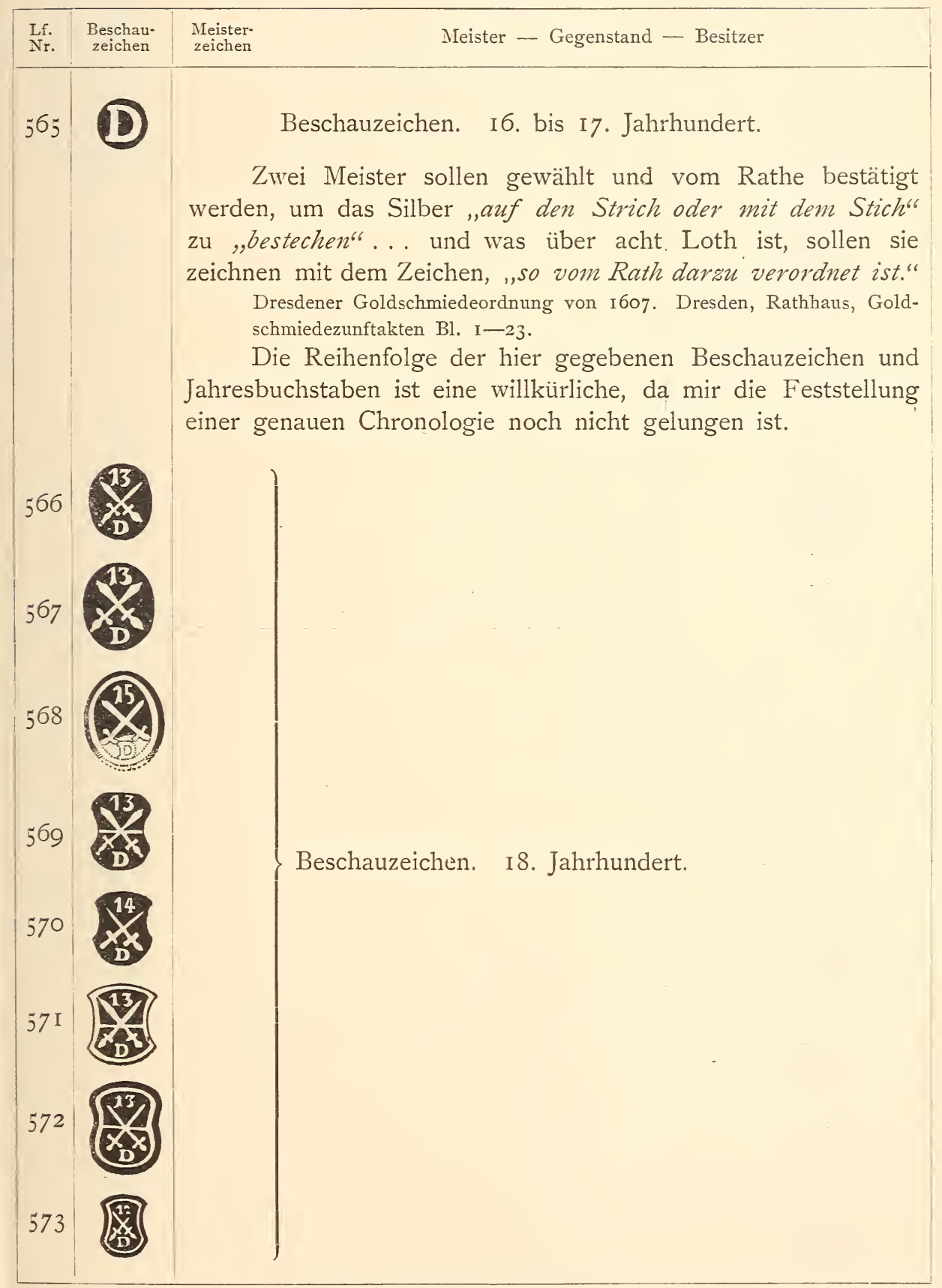




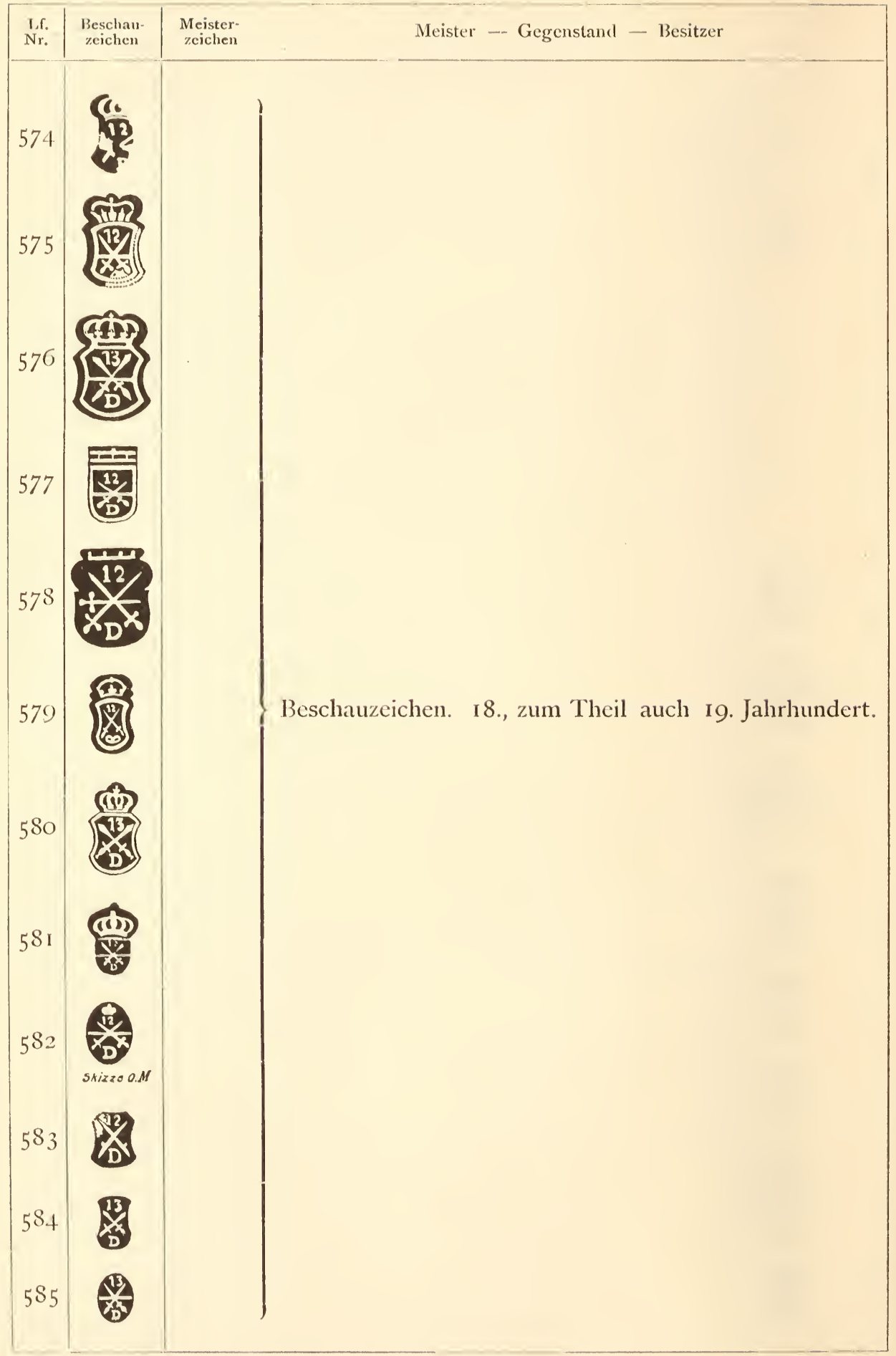




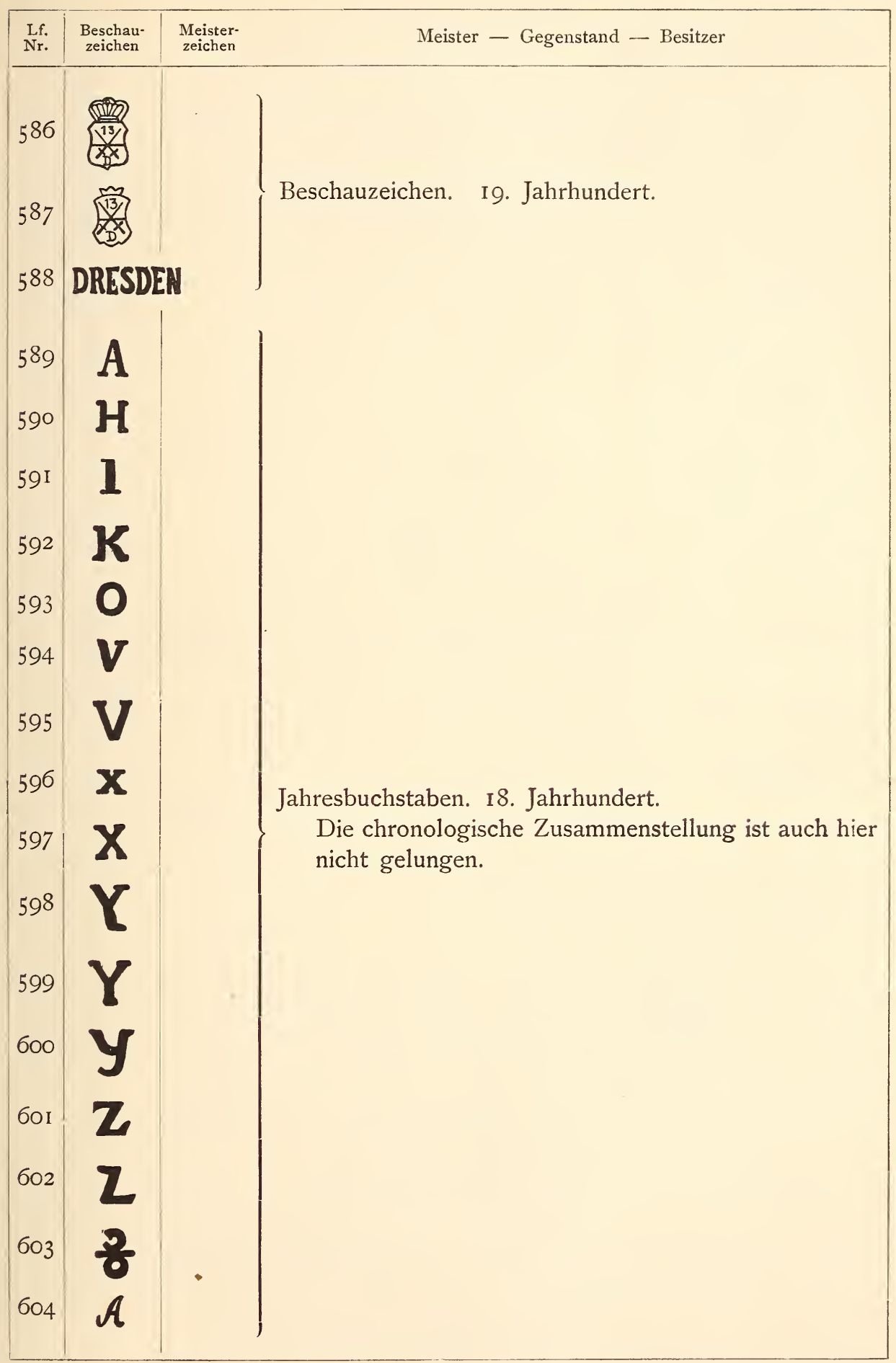




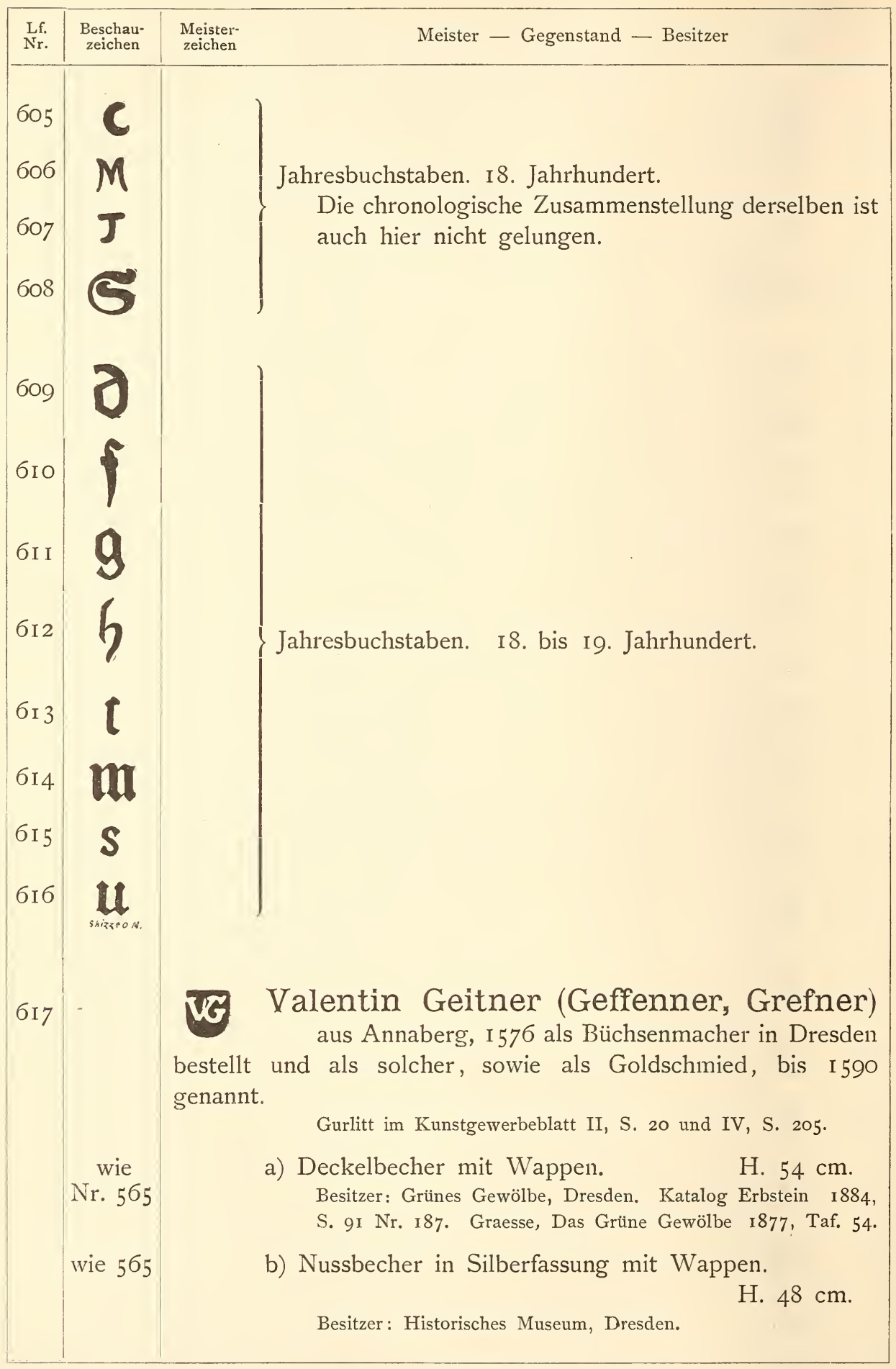




\begin{tabular}{|c|c|c|c|}
\hline$\underset{\text { Nr. }}{\text { Lf. }}$ & $\begin{array}{l}\text { Beschau- } \\
\text { zeichen }\end{array}$ & $\begin{array}{l}\text { eister- } \\
\text { ichen }\end{array}$ & Meister - Gegenstand - Desitzer \\
\hline 618 & $\begin{array}{c}\text { wie } \\
\text { Nr. } 565\end{array}$ & & $\begin{array}{l}\text { Urban Schneeweis, geb. I536, † I600. } \\
\text { Angabe von Erbstein, Grünes Gewölbe Dresden I } 884 \text {, S. } 87 \text {. } \\
\text { a) Doppelpokal. } \\
\text { Besitzer: Grünes Gewölbe, Dresden. Katalog Erbstein I } 884 \text {, } \\
\text { S. } 87 \text { Nr. I29 und I30. } \\
\text { b) Serpentinstein-Gefässe in vergoldeter Fassung. } \\
\text { Besitzer: Grünes Gewölbe, Dresden. Katalog Erbstein I884, } \\
\text { S. } 133-\text { I34. }\end{array}$ \\
\hline 6 I9 & $\begin{array}{c}\text { wie } \\
\text { Nr. } 565\end{array}$ & GM & 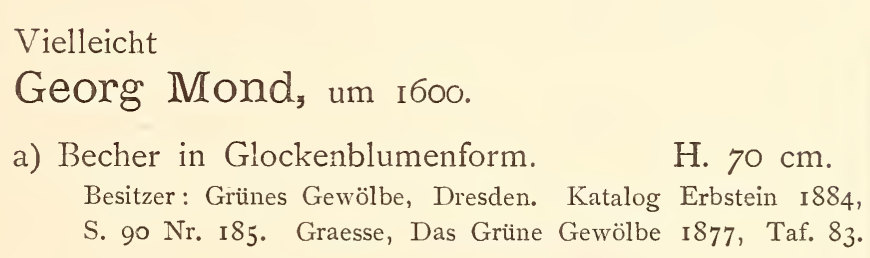 \\
\hline 620 & $\begin{array}{c}\text { wie } \\
\text { Nr. } 5 \sigma_{5} \\
\text { wie } 5 \sigma_{5}\end{array}$ & & $\begin{array}{l}\text { b) Trinkgefäss in Gestalt eines Thurmes. H. } 66 \mathrm{~cm} \text {. } \\
\text { Besitzer: Historisches Museum, Dresden. } \\
\begin{array}{ll}\text { c) Kelch in gothischem Stile. } & \text { H. } 20,5 \mathrm{~cm} . \\
\text { Besitzer: Evangelische Hof kirche, Dresden. } & \end{array}\end{array}$ \\
\hline $62 \mathrm{I}$ & $\begin{array}{c}\text { wie } \\
\text { Nr. } 565\end{array}$ & TP & $\begin{array}{l}\text { Joachim Puttlost, um r607. } \\
\text { Drei Jagdbestecke. } \\
\text { Besitzer: Historisches Museum, Dresden. }\end{array}$ \\
\hline 622 & $\begin{array}{c}\text { wie } \\
\text { Nr. } 56_{5}\end{array}$ & (8) & $\begin{array}{l}\text { (Hans) Johann Kellerthaler, thätig i6o8. } \\
\text { a u. b) Zwei Paar vergoldete Steigbügel. } \\
\text { Besitzer: Historisches Museum, Dresden. }\end{array}$ \\
\hline 623 & & $\mathbb{S B}_{\text {Shize om }}$ & $\begin{array}{l}\text { c) Altar von schwarzem Holze mit Silberplatten. Be- } \\
\text { zeichnet } 1608 \text {. } \\
\text { Besitzer: Grünes Gewölbe, Dresden. Katalog Erbstein I884, } \\
\text { S. } 77 \text { Nr. ro6. }\end{array}$ \\
\hline 624 & $\begin{array}{c}\text { wie } \\
\text { Nr. } 565\end{array}$ & Int & $\begin{array}{l}\text { Vergoldete Abendmahlskanne mit Wappen und r6r6. } \\
\text { H. } 24 \mathrm{~cm} \text {. } \\
\text { Besitzer: Evangelische Hofkirche, Dresden. }\end{array}$ \\
\hline
\end{tabular}




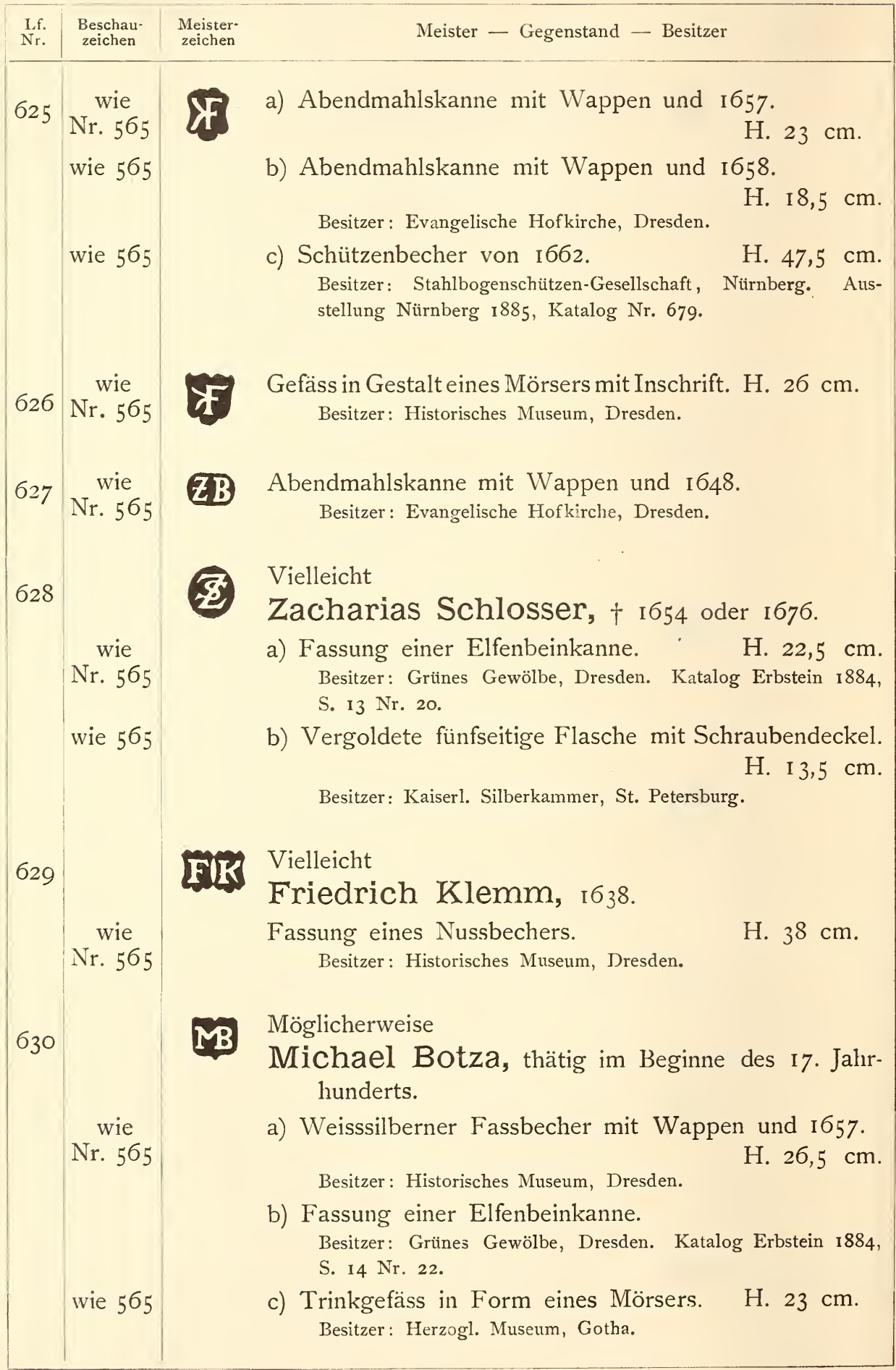




\begin{tabular}{|c|c|c|c|}
\hline $\begin{array}{l}\text { Lf. } \\
\text { Nr. }\end{array}$ & $\begin{array}{c}\text { Beschau• } \\
\text { zeichen }\end{array}$ & $\begin{array}{l}\text { Meister- } \\
\text { zeichen }\end{array}$ & Meister - Gegenstand - Besitzer \\
\hline $63 \mathrm{I}$ & $\begin{array}{c}\text { wie } \\
\text { Nr. } 565\end{array}$ & & $\begin{array}{l}\text { Trinkgefäss in Form eines Ziehbrunnens. } \\
\text { Besitzer: Historisches Museum, Dresden. }\end{array}$ \\
\hline 632 & $\begin{array}{c}\text { wie } \\
\text { Nr. } 565\end{array}$ & E & $\begin{array}{l}\text { Fassung eines Strausseneies. } \\
\text { Besitzer: Grünes Gewölbe, Dresden. }\end{array}$ \\
\hline 633 & $\begin{array}{c}\text { wie } \\
\text { Nr. } 5 \sigma_{5}\end{array}$ & & $\begin{array}{l}\text { Vergoldete Deckelkanne. } \\
\text { Besitzer (1883): Gebrüder Heilbronner, München. } 13 \mathrm{~cm} \text {. }\end{array}$ \\
\hline 634 & & & $\left\{\begin{array}{l}\text { Paul Ingermann, thätig um I7I8-I747. In } \\
\text { den Jahren I742-I743 Zeichenmeister und I739 } \\
\text { Aeltester. } \\
\text {,Die Hofsilberkammer" Dresden I880. }\end{array}\right.$ \\
\hline & $\begin{array}{l}\text { wie } \\
\mathrm{Nr} .567 \\
57 \mathrm{I} \mathrm{u} \\
572\end{array}$ & & $\begin{array}{l}\text { Verschiedenes Besteck und Leuchter. } \\
\text { Besitzer: Königl. Silberkammer, Dresden. }\end{array}$ \\
\hline 636 & & & $\begin{array}{l}\text { Chr. H. Ingermann, thätig um I745-I766. } \\
\text { „Die Hofsilberkammer" Dresden I88o. }\end{array}$ \\
\hline & $\begin{array}{c}\text { wie } \\
\text { Nr. } 567\end{array}$ & & $\begin{array}{l}\text { a-f) Sechs Trompeten, bezeichnet „Riedel fecit“. Am } \\
\text { Schallrande mit getriebenem Ornamente, in welchem } \\
\text { die Stempel. } \\
\text { Besitzer: Königl. Silberkammer, Dresden. }\end{array}$ \\
\hline & wie 566 & & $\begin{array}{l}\text { g) } 36 \text { Stück weisssilberne Rococo-Leuchter. } \\
\text { Besitzer: Königl. Silberkammer, Dresden. }\end{array}$ \\
\hline & wie 566 & & $\begin{array}{l}\text { h) Vergoldetes Besteck mit Porzellangriffen. } \\
\text { Besitzer: Königl. Silberkammer, Dresden. }\end{array}$ \\
\hline & wie 568 & & $\begin{array}{l}\text { i) Weisssilberner Tafelaufsatz. } \\
\text { Besitzer: Königl. Silberkammer, Dresden. }\end{array}$ \\
\hline 637 & $\begin{array}{c}\text { wie } \\
\text { Nr. } 572\end{array}$ & 7 & $\begin{array}{l}\text { Samuel Gaudig, I } 75(4 \text { ?) Aeltester. } \\
\text { a) Mit dem Jahresbuchstaben A Nr. } 604 \text { und dem } \\
\text { Feingehaltsstempel I3. }\end{array}$ \\
\hline & wie 572 & & 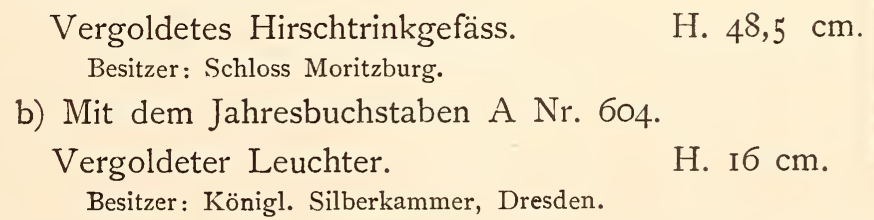 \\
\hline
\end{tabular}




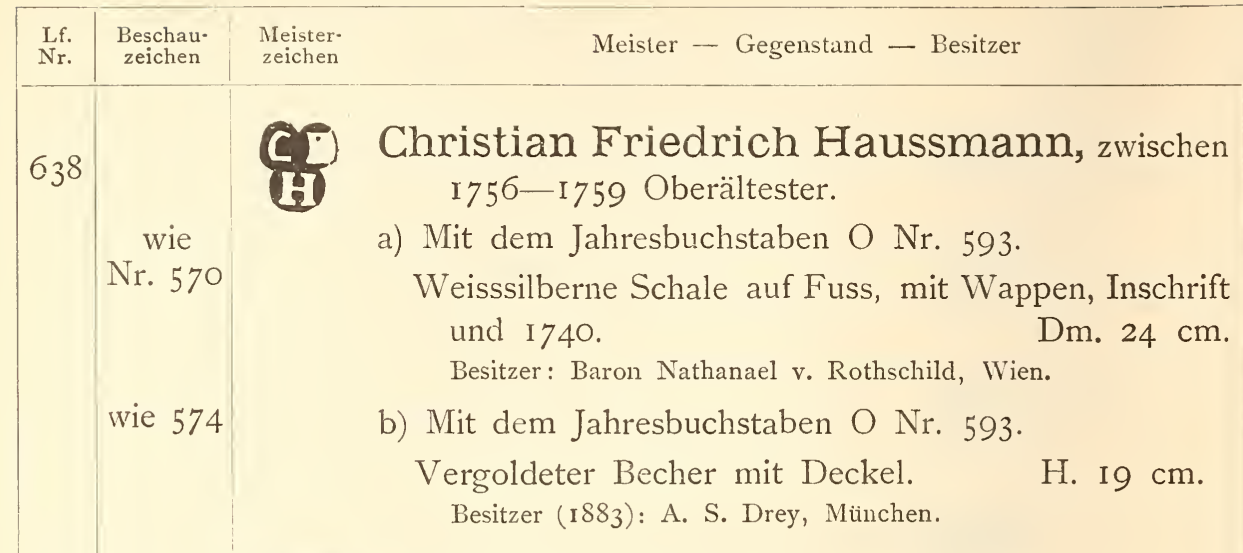

CDS Carl David Schrödel, um i 762.

wie

Nr. 584

wie

640 Nr. 583

wie 584

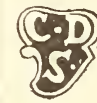
a) Vergoldeter Theelöffel mit Initialen. Lg. I3,5 cm. Besitzer: Königl. Silberkammer, Dresden.

b) Mit dem Jahresbuchstaben I. Nr. 59I.

Weisssilbernes terrinenförmiges Zuckergefäss.

Besitzer: Kunstgewerbe-Museum, Berlin.

H. $\mathrm{I} 7,5 \mathrm{~cm}$.

c) Mit dem Jahresbuchstaben H Nr. 590.

Weisssilbernes Besteck mit Initialen.

Besitzer : Königl. Silberkammer, Dresden.

d) Mit dem Jahresbuchstaben Y Nr. 599.

Weisssilbernes Salzfass mit Initialen.

Besitzer: Königl. Silberkammer, Dresden.

e) Weisssilberner Streuzuckerlöffel.

Besitzer: Königl. Silberkammer, Dresden.

f) Vergoldete Gabeln mit Initialen.

Besitzer: Königl. Silberkammer, Dresden.

64I Nr.584 $\begin{gathered}\text { wie } \\ ?\end{gathered}$

$\mathrm{g}-\mathrm{k})$ Vier vergoldete Leuchter mit Initialen.

Besitzer: Königl. Silberkammer, Dresden.

1-w) Zwölf ovale Glocken.

Besitzer: Königl. Silberkammer, Dresden.

x) Mit dem Jahresbuchstaben Y Nr. 598.

Weisssilberner Leuchter mit Initialen.

Besitzer : Königl. Silberkammer, Dresden.

wie 556

y u. z) Mit dem Jahresbuchstaben Z Nr. 603.

Zwei weisssilberne Leuchter mit Initialen.

Besitzer: Königl. Silberkammer, Dresden. 


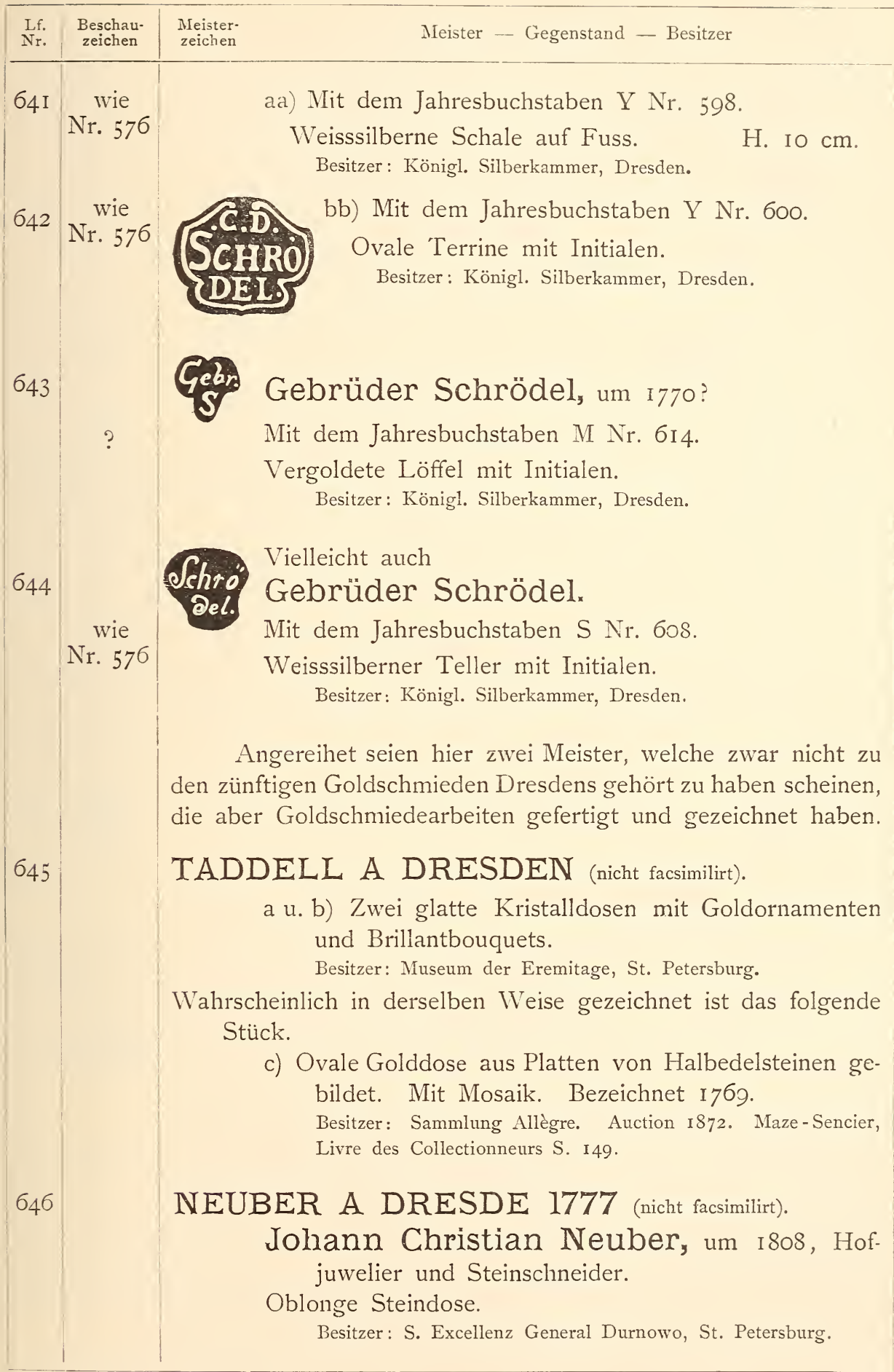




\section{ELBERFELD.}

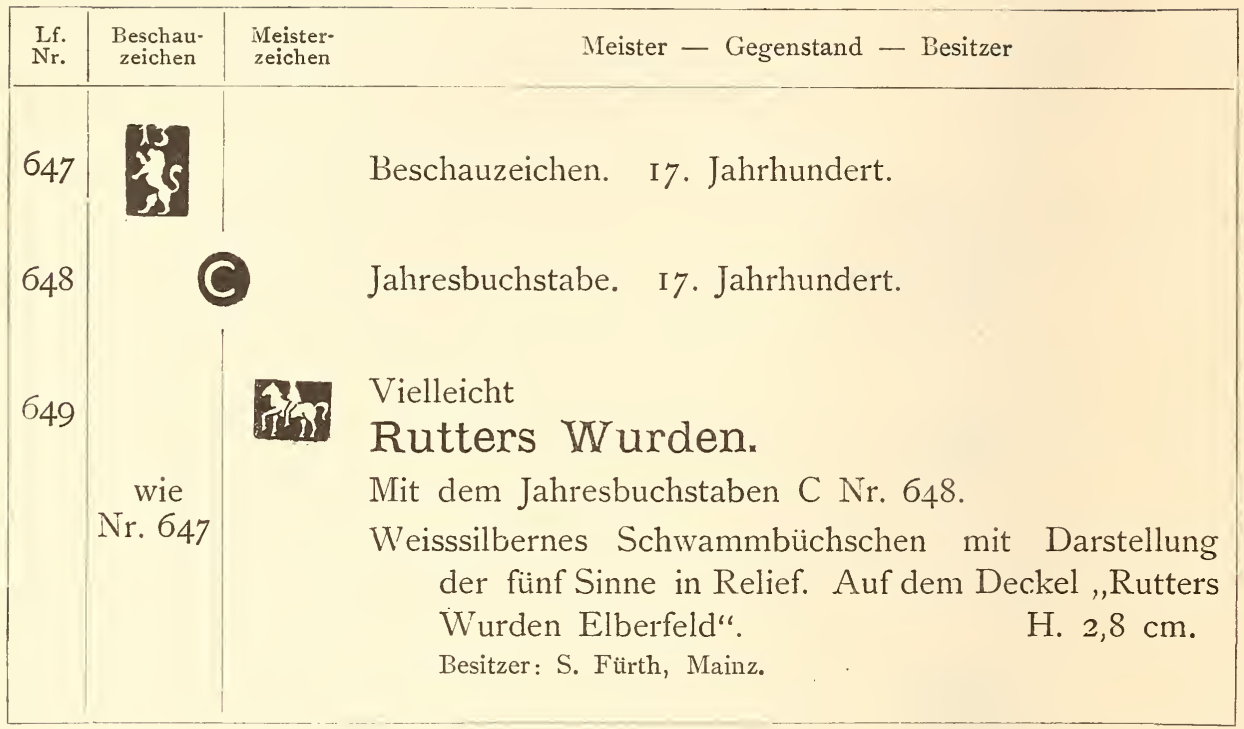

\section{ELBING.}

\begin{tabular}{|c|c|c|c|}
\hline $\begin{array}{l}\text { Lf. } \\
\text { Nr. }\end{array}$ & $\begin{array}{l}\text { Beschau- } \\
\text { zeichen }\end{array}$ & $\begin{array}{l}\text { Meister- } \\
\text { zeichen }\end{array}$ & Meister - Gegenstand - Besitzer \\
\hline$\sigma_{50}$ & 53 & & Beschauzeichen. I8. Jahrhundert. \\
\hline $6_{5} \mathrm{I}$ & & DS & Daniel Stahlenbrecher, I705. \\
\hline & $\begin{array}{c}\text { wie } \\
\text { Nr. 650 }\end{array}$ & & $\begin{array}{l}\text { Kanne mit eingelassenen Münzen und Inschriften, von } \\
\text { welchen eine den Verfertiger nennt: Daniel Stahlen- } \\
\text { brecher, Golt-Schmidt vnd Eltermann I 705. } \\
\text { Besitzer: Wilh. Metzler, Frankfurt a. M. Ausstellung Frank- } \\
\text { furt a. M. I } 875 \text { Taf. } 59 \text {. }\end{array}$ \\
\hline 652 & $\begin{array}{c}\text { Stadt- } \\
\text { wappen }\end{array}$ & ${ }_{35} \mathrm{NHI}^{\mathrm{s}}$ & $\begin{array}{l}\text { Kelch der Cramerzunft, bezeichnet I } 576 \text {. } \\
\text { Besitzer: Conventsammlung, Elbing. Gütige Mittheilung des } \\
\text { Löbl. Magistrats, Elbing. }\end{array}$ \\
\hline 653 & $\begin{array}{c}\text { Stadt- } \\
\text { wappen }\end{array}$ & ${ }_{35} \mathrm{DH}^{64}$ & $\begin{array}{l}\text { Rundlicher Schild, getrieben und mit Inschriften ver- } \\
\text { sehen. } \\
\text { Besitzer: St. Georgs Bruderschaft, Elbing. Gütige Mittheilung } \\
\text { des Löbl. Magistrats, Elbing. }\end{array}$ \\
\hline
\end{tabular}




\section{EMDEN.}

\begin{tabular}{|c|c|c|}
\hline $\begin{array}{l}\text { Lf. } \\
\text { Nr. }\end{array}$ & $\begin{array}{l}\text { Beschau- } \\
\text { zeichen }\end{array}$ & Meister - Gegenstand - Besitzer \\
\hline 654 & 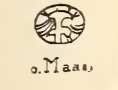 & Vielleicht Beschauzeichen um I60I. \\
\hline & & $\begin{array}{l}\text { Starcke \& Kohlmann, Der Emder Silberschatz, Emden } \\
\text { I } 880 \text { fol. sagen wörtlich: „Seit dem Jahre I } 508 \text { trugen auch } \\
\text { die von Emder Goldschmieden aus dem feinern »Rycksdaler- } \\
\text { Silber" angefertigten Stücke zum Unterschied einen Doppel- } \\
\text { adler." } \\
\text { Obgleich die obige Marke auf dem Originale sehr undeut- } \\
\text { lich ist, möchte ich sie doch versuchsweise mit dieser den } \\
\text { Akten entnommenen Stelle in Verbindung bringen. }\end{array}$ \\
\hline 655 & GC & $\begin{array}{l}\text { Beschauzeichen } 1603 \text {, verbunden mit dem Jahresbuch- } \\
\text { staben C fur } 1603 \text {. }\end{array}$ \\
\hline & & $\begin{array}{l}\text { „Ein E (ist das) Emder Goldschmiede(beschau)zeichen, } \\
\text { welches bis zum heutigen Tage noch gebraucht wird." } \\
\text { Starcke \& Kohlmann, Emder wilberschatz I8So, S. } 4 \text {. }\end{array}$ \\
\hline \multirow[t]{2}{*}{656} & 484 & $\begin{array}{l}\text { Beschauzeichen } 1645 \text {, verbunden mit der Zahl } 44 \text { für } \\
\text { das Jahr } 1645 \text {. }\end{array}$ \\
\hline & & $\begin{array}{l}\text { Pabst, Besteck-Sammlung Zschille, Nr. } 256 \text { spricht dieses } \\
\text { Zeichen für Emden an, und es fügt sich sehr wohl in die von } \\
\text { Starcke \& Kohlmann aufgestellte, weiter unten folgende Liste } \\
\text { der Jahresbuchstaben. Die Jahre I624-I65 I führen nämlich } \\
\text { ausnahmsweise nicht einen Jahresbuchstaben, sondern sie wer- } \\
\text { den in der Beschau dadurch gekennzeichnet, dass das Stadt- } \\
\text { zeichen E abwechselnd zwischen Einer und Zehner der Zahlen } \\
\text { 23-50 gestellt wird. }\end{array}$ \\
\hline
\end{tabular}




\begin{tabular}{|c|c|c|}
\hline $\begin{array}{l}\text { Lf. } \\
\text { Nr. }\end{array}$ & $\begin{array}{l}\text { Beschaul- } \\
\text { zeichen }\end{array}$ & Meister - Gegenstand - Besitzer \\
\hline 656 & & 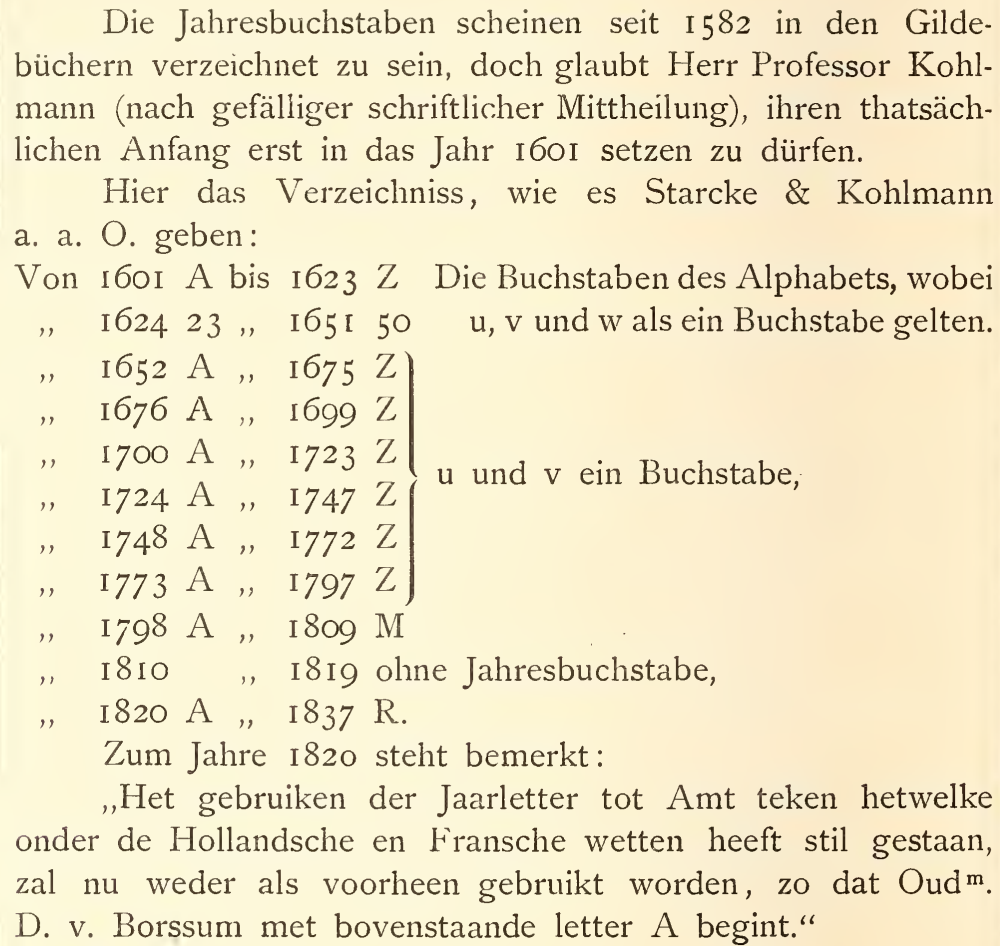 \\
\hline 657 & $\begin{array}{c}\text { wie } \\
\text { Nr. } 654\end{array}$ & $\begin{array}{l}\text { Vergoldeter Deckelpokal mit Figuren und Thieren } \\
\text { getrieben. } \\
\begin{array}{l}\text { H. } 60 \mathrm{~cm} . \\
\text { 0.Maas } \\
\text { (der Buch- } \\
\text { stabe H } \\
\text { erhaben) }\end{array} \\
\text { Besitzer: Magistrat, Emden. Abgebildet und beschrieben in } \\
\text { Starcke \& Kohlmann, Emder Silberschatz S. 2/3. Vergleiche } \\
\text { die Notiz oben zu Nr. 654. }\end{array}$ \\
\hline 658 & $\begin{array}{c}\text { wie } \\
\mathrm{Nr} .6_{55}\end{array}$ & $\begin{array}{l}\text { (1) Aufzulösen in I. D. V. Wahrscheinlich } \\
\text { Isaac de Voghelaer, I } 585 \text { Meister, von I } 590 \\
\text { bis I6I7 acht Mal Aeltermann. } \\
\text { Silbervergoldete Fruchtschale mit Deckel. Bezeichnet } \\
\text { I603. } \\
\text { Besitzer: Magistrat, Emden. Abgebildet und beschrieben bei } \\
\text { Starcke \& Kohlmann a. a. O. S. } 3 .\end{array}$ \\
\hline 659 & $\begin{array}{c}\text { wie } \\
\text { Nr. } 656\end{array}$ & $\begin{array}{l}\text { Löffel, Stiel mit Knopf. } \\
\text { Besitzer: Richard Zschille, Grossenhain. } 16 \mathrm{~cm} \text {. } \\
\text { Sammlung Zschille Nr. } 256 \text { Taf. } 37 .\end{array}$ \\
\hline
\end{tabular}




\section{ERFURT.}

Briefliche Mittheilungen und urkundliches Material über die Erfurter Goldschmiedekunst verdanke ich Herrn Franz Apell daselbst, der auch die Güte hatte, nach seinen eigenen Aufnahmen, die folgende Liste der Beschauzeichen zusammen zu stellen.

\begin{tabular}{|c|c|c|c|}
\hline $\begin{array}{l}\mathrm{Lff} \\
\mathrm{Nr} .\end{array}$ & $\begin{array}{l}\text { Beschau- } \\
\text { zeichen }\end{array}$ & $\begin{array}{l}\text { Meister- } \\
\text { zeichen }\end{array}$ & Meister - Gegenstand - Besitzer \\
\hline 660 & $\begin{array}{l}{ }_{\text {, }} \mathrm{E}^{\mathbf{6}} \\
\text { in } \\
\text { rundem } \\
\text { Schilde }\end{array}$ & & Beschauzeichen. Ende des I6. Jahrhunderts. \\
\hline 66 I & & & Beschauzeichen. Іб 8. \\
\hline 662 & & & Beschauzeichen. I653. \\
\hline 663 & & & Beschauzeichen. I659. \\
\hline 664 & & & Beschauzeichen. $\quad 1675$. \\
\hline 665 & & & Beschauzeichen. I 692. \\
\hline 666 & & & Beschauzeichen. I733. \\
\hline 667 & & & Beschauzeichen. I 760. \\
\hline 668 & & & Beschauzeichen. I 780. \\
\hline
\end{tabular}




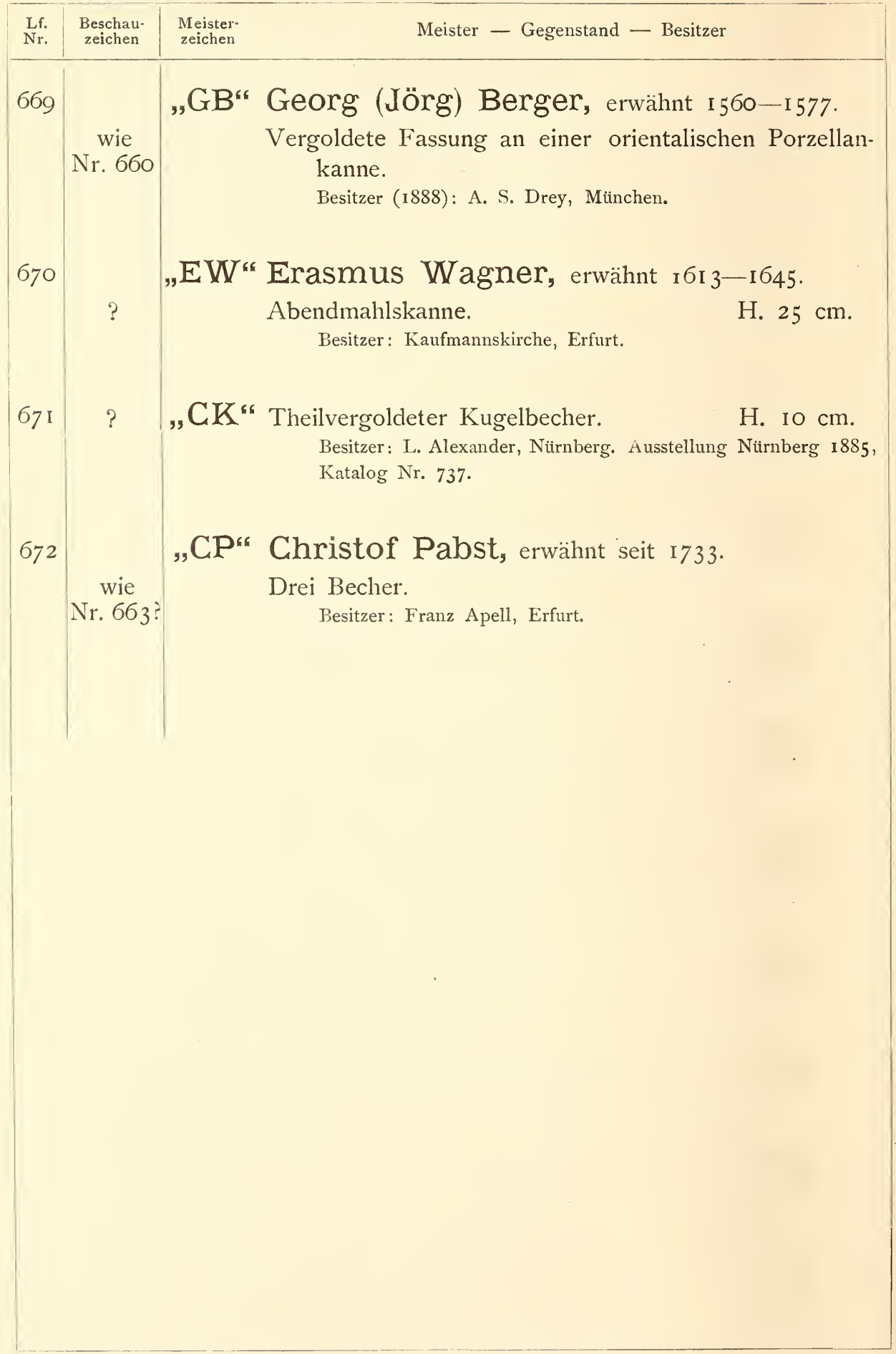




\section{FRANKFURT A. M.}

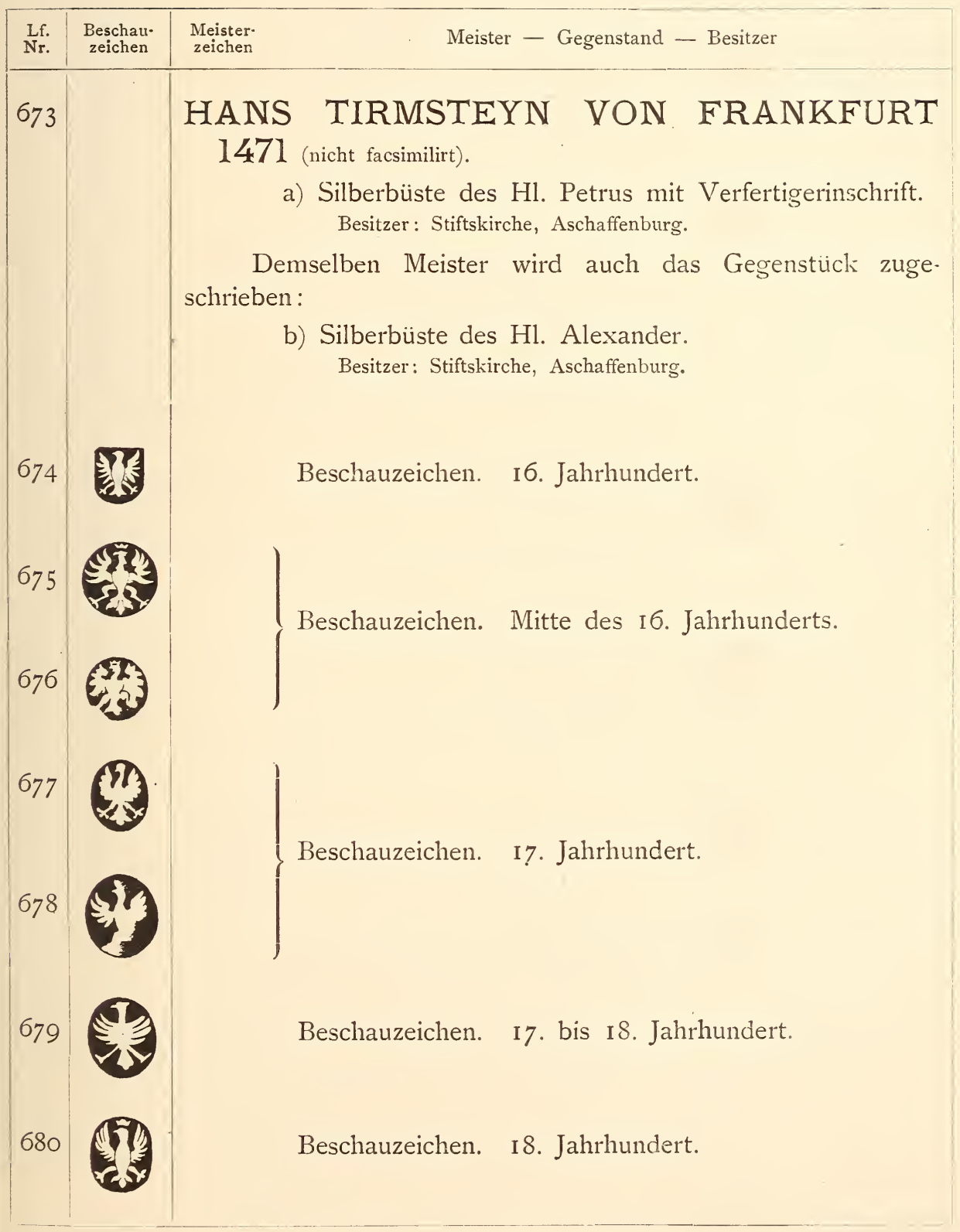




\begin{tabular}{|c|c|c|c|}
\hline $\begin{array}{l}\text { Lf. } \\
\text { Nr. }\end{array}$ & $\begin{array}{l}\text { Beschau- } \\
\text { zeichen }\end{array}$ & $\begin{array}{l}\text { Meister- } \\
\text { zeichen }\end{array}$ & Meister - Gegenstand - Besitzer \\
\hline 68I I & $\begin{array}{c}\text { wie } \\
\text { Nr. 674 }\end{array}$ & & $\begin{array}{l}\text { Pokal mit gravirten Renaissance-Ornamenten am Lippen- } \\
\text { rande. } \\
\text { Besitzer: Grossherzogl. Museum, Darmstadt. Kunstschätze des } \\
\text { Grossherzogl. Museums Taf. 20. }\end{array}$ \\
\hline 682 & $\begin{array}{c}\text { wie } \\
\mathrm{Nr} .674\end{array}$ & & $\begin{array}{l}\text { Kristallcuppa in vergoldeter Fassung mit Inschrift. } \\
\text { H. } 48,5 \mathrm{~cm} . \\
\text { Besitzer: S. K. H. d. Grossherzog von Hessen, Neues Palais } \\
\text { Darmstadt. }\end{array}$ \\
\hline 683 & $\begin{array}{c}\text { wie } \\
\text { Nr. } 674\end{array}$ & & $\begin{array}{l}\text { a) Spitzbecher, mit Lederwerkornament getrieben. } \\
\text { H. } 25,5 \mathrm{~cm} .\end{array}$ \\
\hline & wie 674 & & $\begin{array}{l}\text { b) Vergold. Buckelpokal der Frankfurter Goldschmiede- } \\
\text { innung mit Inschrift, Siegelabdruck und I } 592 \text {. } \\
\text { Besitzer: Baron v. Erlanger, Frankfurt a. M. Ausstellung } \\
\text { Frankfurt a. M. I875, Katalog Nr. 1683. Guitige Mittheilung } \\
\text { des Herrn Conservator O. Cornill, Frankfurt a. M. }\end{array}$ \\
\hline 684 & $\begin{array}{c}\text { wie } \\
\text { Nr. } 675\end{array}$ & & $\begin{array}{l}\text { Theilvergoldete Deckelkanne mit Schweissdecor am } \\
\text { Corpus. } \\
\text { H. I5 cm. } \\
\text { Besitzer: Johannes Paul, Hamburg. Auctionskatalog } 1882 \\
\text { Nr. 73I. }\end{array}$ \\
\hline 685 & $\begin{array}{c}\text { wie } \\
\text { Nr. } 676\end{array}$ & & $\begin{array}{l}\text { Vergoldete, nach oben verjüngte sechsseitige Kanne } \\
\text { mit den Planetengöttern in Relief, eingelassener } \\
\text { Medaille und gravirter Inschrift von I 564. } \\
\text { Besitzer: } \dagger \text { Baron Carl v. Rothschild, Frankfurt a. M. }\end{array}$ \\
\hline 686 & $\begin{array}{c}\text { wie } \\
\text { Nr. } 678\end{array}$ & & $\begin{array}{l}\text { Pokal der Frankfurter Fassbinderzunft mit Namen und } \\
\text { I677. H. } 4 \mathrm{I} \mathrm{cm} \text {. } \\
\text { Besitzer: Historisches Museum, Frankfurt a. M. }\end{array}$ \\
\hline 687 & $\begin{array}{c}\text { wie } \\
\text { Nr. } 677\end{array}$ & & $\begin{array}{l}\text { Paul Birckenholtz, um I627. } \\
\text { Zwei cylindrische Pokale mit aufgenietetem Decor von } \\
\text { Medaillen, Füllhörnern etc. (Marburger Jubiläums- } \\
\text { becher). Bezeichnet I627. } \\
\text { Besitzer: Kunstgewerbe-Museum, Berlin und Königl. Museum, } \\
\text { Cassel. Drach, Silberarbeiten Cassel I888, Tar. 20. Ein drittes } \\
\text { Exemplar in der Königl. Silberkammer, München hat kein Be- } \\
\text { schauzeichen, sondern nur einen Meisterstempel. }\end{array}$ \\
\hline
\end{tabular}




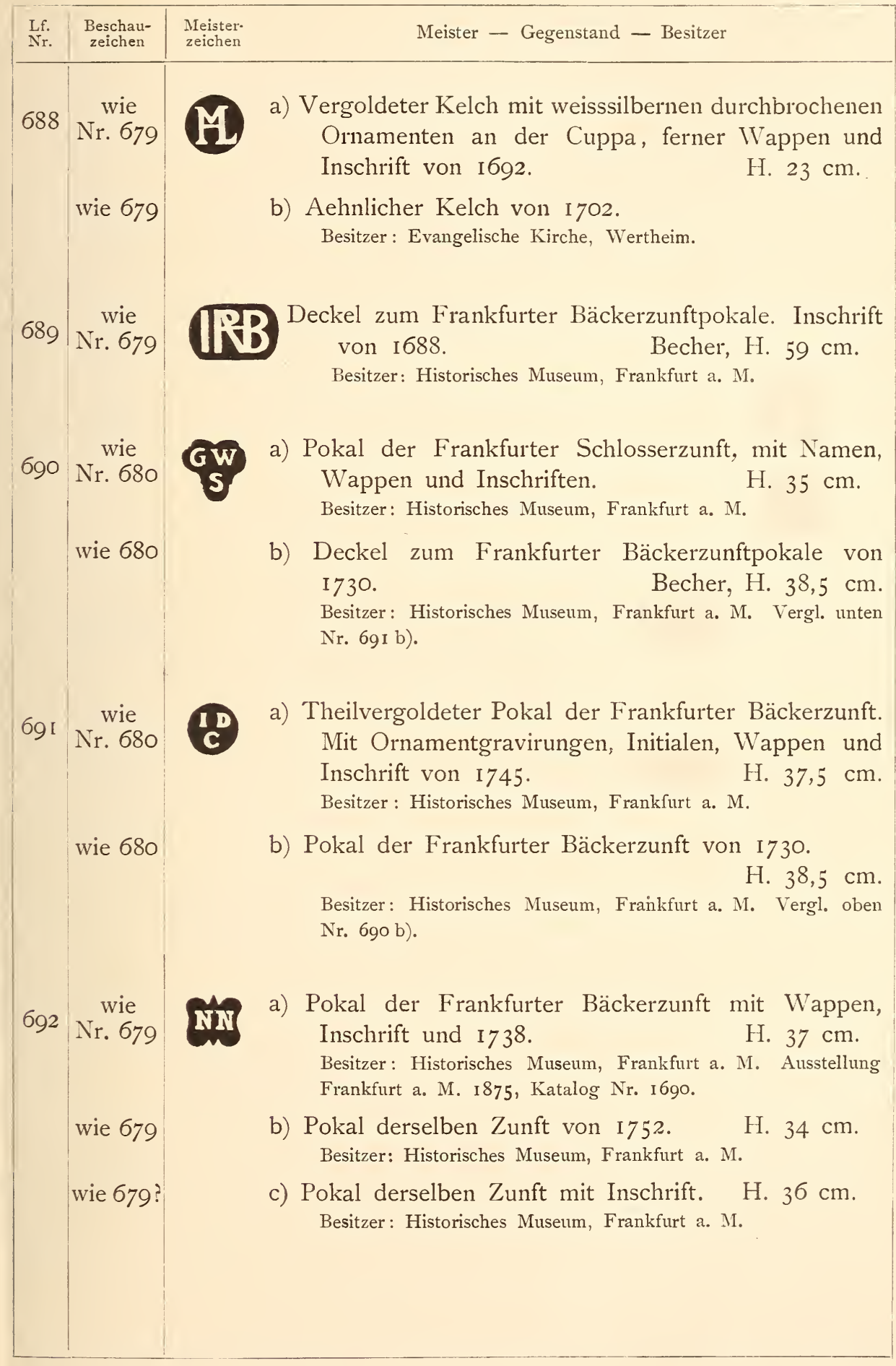




\section{FRANKFURT A. D. O.}

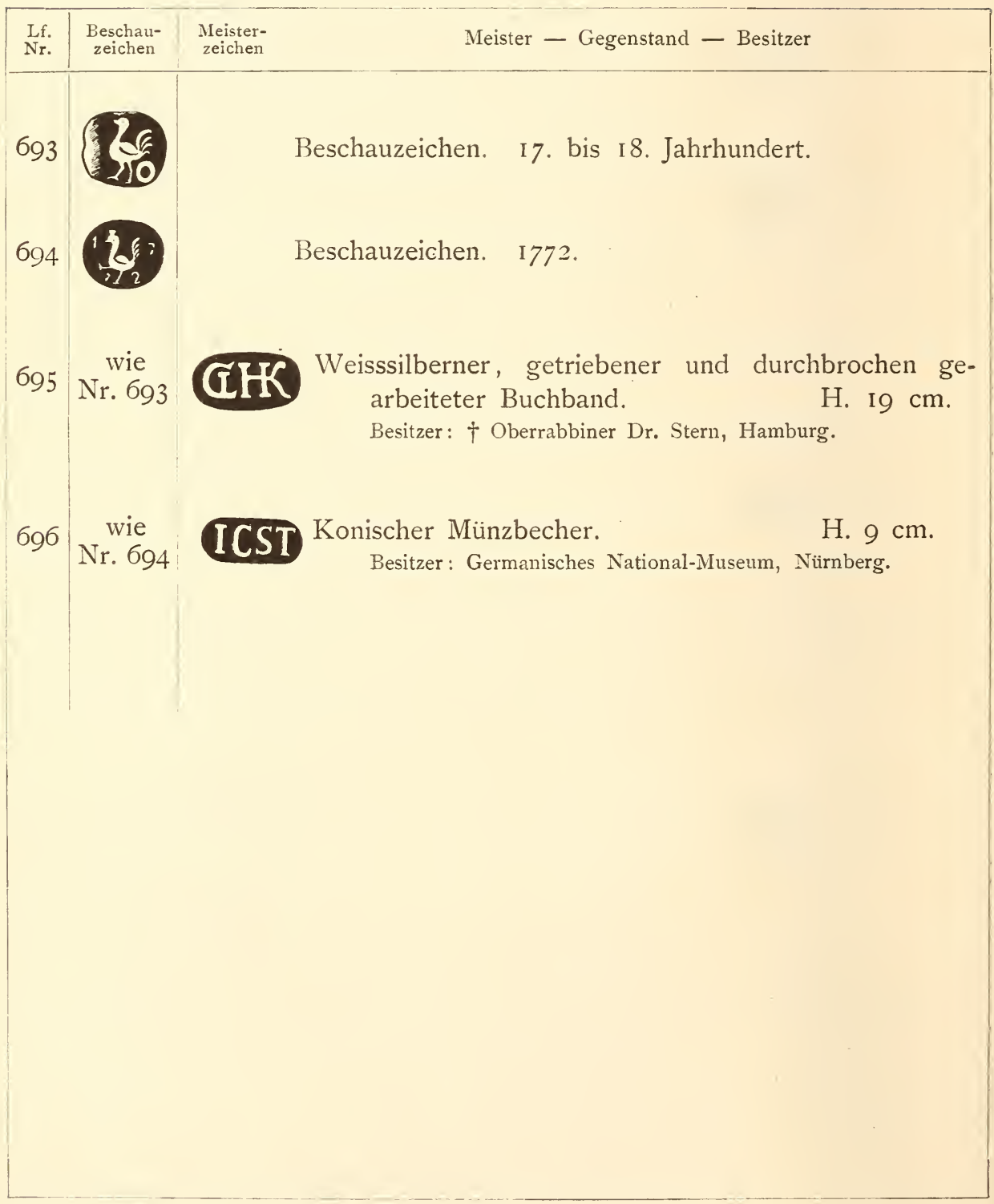




\section{FREIBERG I. S.}

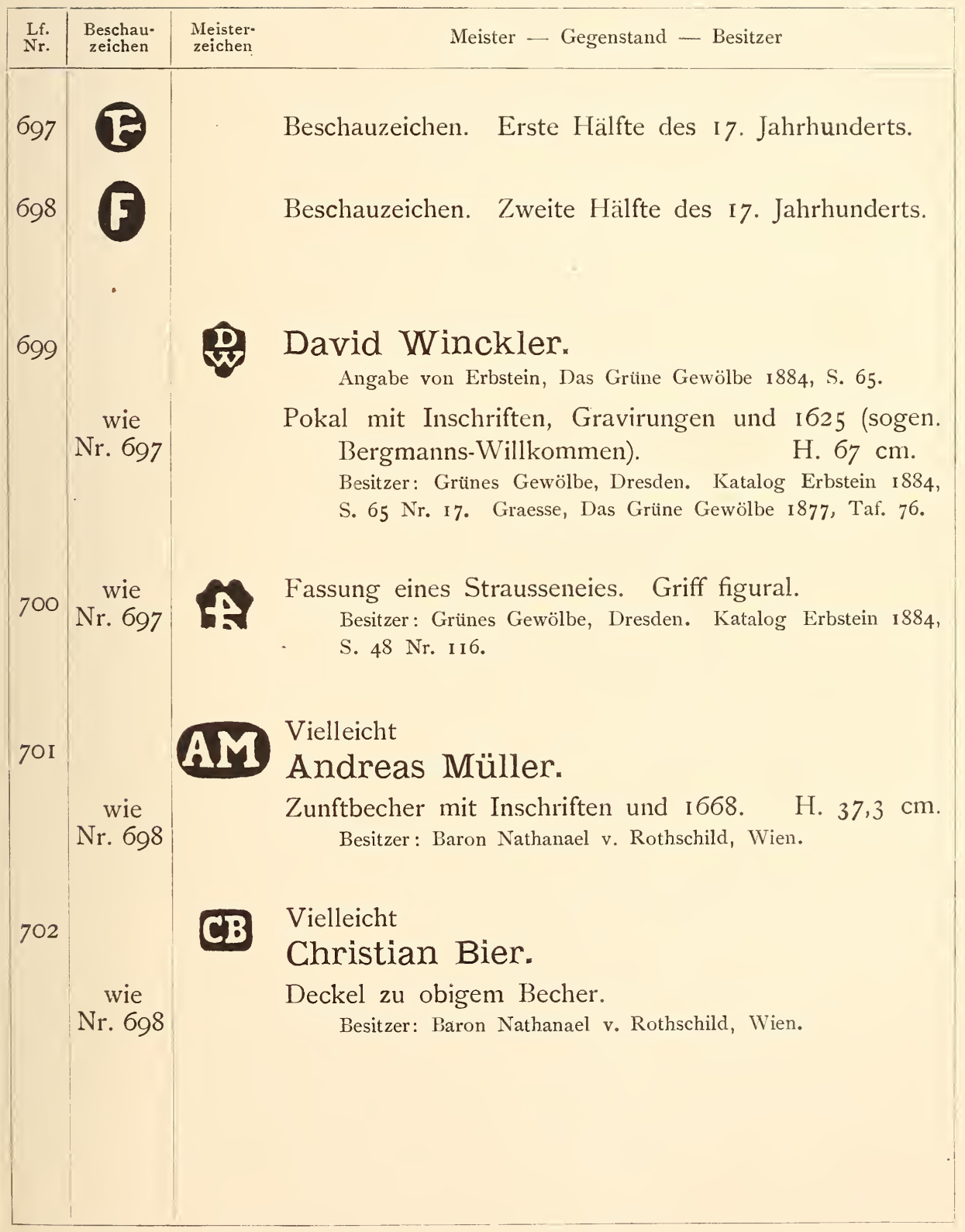




\section{FREIBURG I. B.}

Mittheilungen aus dem Archiv in Freiburg und collationirte Abschriften der Goldschniedeordnungen verdanke ich der Güte des Herrn Stadtarchivars Poinsignon, Hauptmann a. D. in Freiburg.

Stempelung scheint schon vor dem I6. Jahrhundert üblich gewesen zu sein, denn in der Freiburger Goldschmiedeordnung von 1523 wird derselben als einer bekannten Institution Erwähnung gethan:

„Das zeichen soll hinder dem handtwerckh ligen unnd under inen umbgon und nichts gezeichnet werden, es sig dann dess wïrdig."

I 532 wird diese Bestimmung gleichlautend wiederholt.

Erst in der Ordnung von 1575 wird das Zeichen beschrieben:

„Es sollen auch der Meisterschaft dieses Handtwerkhs, ietz, so die ordnung angehet, ein new handwerkhszeichen - Namblichen einen Rappenkopf stechen und machen lassen."

Es ist bekannt, dass unter diesem „Rappenkopf“ (für Rabenkopf) ein Adlerkopf $\mathrm{zu}$ verstehen ist. Um das Wort nicht ohne Bild zu lassen, und obgleich die Möglichkeit einer Verwechslung mit Stettin oder einem anderen Orte nahe liegt, setze ich doch versuchsweise das weiter unten folgende Zeichen Nr. 703 hierher. Zuvörderst seien aber noch einige Sätze aus derselben Ordnung von I 575 angeführt, welche auf das Meisterzeichen und auf die Stempelung älterer oder eingeführter Waare Bezug haben:

"Und auch dass man wiissen möge, welcher Goldtschmidt ein jede arbeith gemacht hab, soll fïter ein jeder Maister, der das Goldtschmidthandtwerkh in der Statt Freyburg treiben und brauchen will, ein besonder werkhzeichen, undt auf denselben Punkten (Punzen?) seinen Namen gestochen haben, das selbig, so offt er sein arbeith will lassen zaichnen, mit ihme tragen, undt durch die verordneten Beschawer neben das Handwerkhszeichen schlagen lasssen. Doch soll kein Silberarbeit, so vor langem gemacht ist, mit einem newen Zeichen veraeichnet werden, ess habe dan den gehalt nach besag dieser Ordnung bei der Pönn einer Markh Silbers, die ein jeder der solches verbricht, besseren solle."

"Verner so soll auch niemand khein goldtschmidtarbeith, so nit allhie gemacht ist, weder durch sich sells noch jemants anderst verkhauffen, sie seyen dan zuvor durch die geschworen schawer nothïrfftiglich besichtiget, undt so sie der allhiesigen prob allerdings gemäss und just erfunden wirdt, mit dem sonderlich da zue geordneten Puntzen gezeichnet. Undt sollen die schawer solche främbde arbeith, die ihnen zu probiren fïrgebracht wïrdt, ahn den verdächtigsten orthen, es sey am Corpus oder der kleidung, doch mit wenigstem schaden sie immer könden, undt bey ihren ayden niemant zu lieb noch zue leidt versuchen undt probieren; was sie nit der allhiesigen prob 
gemäss befänden, darmit vermög ihrer alten ordnung handlen. Wass aber Freyburger prob haltet, mit dem zeichen, wie von altem här gezeichnet worden, damit man sehe, dass es Freyburger prob seye, undt der sie verkhaufft, auch für solche verschafft hingeben, undt liffren möge."

„Damit aber die Freyburgische arbeith von der frembden unterscheiden undt desto besser erkhant, so soll dieselb hiefüro mit der stattschilt darauff also gezeichnet werden."

Ich vermuthe nach diesem Wortlaute, dass der vorhin genannte Adlerkopf eben dieses neuerdings für die Stempelung obligatorisch gemachte Stadtschild, und nicht etwa das Architekturbild (Thor mit zwei Thürmen) ist. Die fremde Waare dagegen wurde mit dem früheren Beschauzeichen, wahrscheinlich dem Kreuze, gestempelt.

\begin{tabular}{|c|c|c|c|}
\hline $\begin{array}{l}\text { Lf. } \\
\text { Nr. }\end{array}$ & $\begin{array}{l}\text { Beschau- } \\
\text { zeichen }\end{array}$ & $\begin{array}{l}\text { Meister- } \\
\text { zeichen }\end{array}$ & Mreister - Gegenstand - Besitzer \\
\hline 703 & & & Beschauzeichen (‡). I6. bis I7. Jahrhundert. \\
\hline 704 & $\begin{array}{l}\text { wie } \\
\text { Nr. } 703\end{array}$ & & $\begin{array}{l}\text { Vergoldete Fassung eines Kristallbechers. H. } 27,7 \mathrm{~cm} \text {. } \\
\text { Besitzer: National-Museum, München. }\end{array}$ \\
\hline 705 & $\begin{array}{l}\text { Adler- } \\
\text { kopf }\end{array}$ & ${ }_{33} \mathrm{BF}^{46}$ & $\begin{array}{l}\text { Erbstein nimmt für Freiburg in Anspruch: } \\
\text { Vergoldete und ornamentirte Fassung an einem Kristall- } \\
\text { kelch. } \\
\text { Besitzer: Grïnes Gewölbe, Dresden. Katalog Erbstein 1884, } \\
\text { S. } 126 \text { Nr. } 187 \text {. }\end{array}$ \\
\hline
\end{tabular}

In neuerer Zeit führt Freiburg gar kein Beschauzeichen mehr, wie die folgende Stempelung ausweist:

706 Feingehaltszeichen. 19. Jahrhundert.

WF Wilhelm Feuerstein, thätig i 883.

Mit dem Feingehaltszeichen ,I 3“" Nr. 706.

Verschiedene kirchliche Geräthe.

Privatbesitz, Freiburg. 


\section{FREISING.}

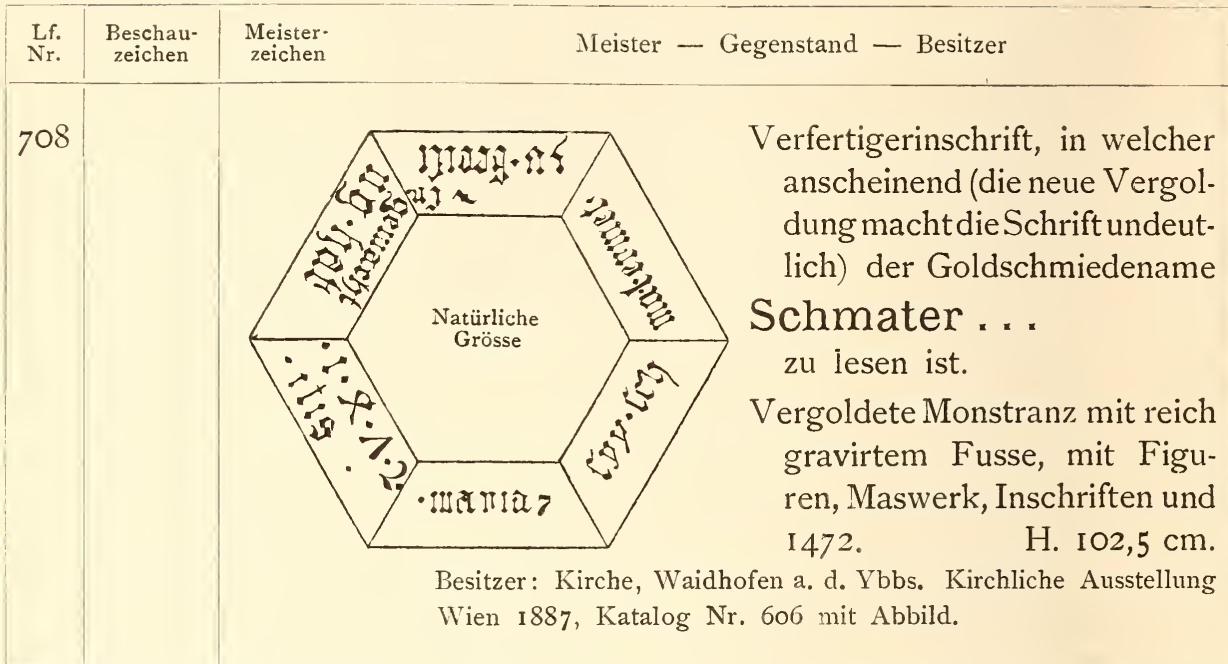

\section{GEISLINGEN.}

\begin{tabular}{|c|c|c|c|}
\hline $\begin{array}{l}\text { Lf. } \\
\text { Nr. }\end{array}$ & $\begin{array}{l}\text { Beschau- } \\
\text { zeichen }\end{array}$ & $\begin{array}{l}\text { Meister- } \\
\text { zeichen }\end{array}$ & Meister - Gegenstand - Besitzer \\
\hline 709 & 8 & & $\begin{array}{l}\text { Beschauzeichen. I7. bis I8. Jahrhundert. } \\
\text { Gefällige Mittheilung von Herrn Professor Seyffer in Stuttgart. }\end{array}$ \\
\hline 710 & $\begin{array}{c}\text { wie } \\
\text { Nr. } 709\end{array}$ & W & $\begin{array}{l}\text { a) Silberne Schuhschnalle mit gegossenen Ornamenten } \\
\text { (sogen. Ulmer Schnalle). } \\
\text { Besitzer: Prof. Seyffer, Stuttyart (1882). }\end{array}$ \\
\hline & wie 709 & & $\begin{array}{l}\text { b) Aehnliches Stück. } \\
\text { Besitzer (1882): A. Duss, Stuttgart. }\end{array}$ \\
\hline
\end{tabular}

\section{GENGENBACH.}

\begin{tabular}{|c|c|c|c|}
\hline $\begin{array}{l}\text { Lf. } \\
\text { Nr. }\end{array}$ & $\begin{array}{l}\text { Beschau- } \\
\text { zeichen }\end{array}$ & $\begin{array}{l}\text { Meister- } \\
\text { zeichen }\end{array}$ & Meister - Gegenstand - Besitzer \\
\hline $7 \mathrm{II}$ & $\begin{array}{l}\text { Sprin- } \\
\text { gender } \\
\text { Salm }\end{array}$ & & Beschauzeichen. Früh I6. Jahrhundert. \\
\hline 712 & $\begin{array}{c}\text { wie } \\
\text { Nr. 7 II }\end{array}$ & $\begin{array}{l}\text { Eine } \\
\text { kleine } \\
\text { Frucht }\end{array}$ & $\begin{array}{l}\text { Theilvergoldetes Amtsschild mit Wappen, Krone und } \\
\text { Ketten zum Anhängen. Bezeichnet I618. } \\
\text { Besitzer: Gemeinde Gengenbach. Ausstellung Karlsruhe 188I, } \\
\text { Katalog Nr. II } 8 \text {. Abgebildet in Aeltere kunstgewerbliche Ar- } \\
\text { beiten auf der Ausstellung Karlsruhe i88I. }\end{array}$ \\
\hline
\end{tabular}




\section{(SCHW ÄB.-)GMÜND.}

. Vergleiche Rosenberg in Kunst und Gewerbe I885.

\begin{tabular}{|c|c|c|c|}
\hline Lff. & $\begin{array}{l}\text { Beschau- } \\
\text { zeichen }\end{array}$ & $\begin{array}{l}\text { Meister- } \\
\text { zeichen }\end{array}$ & Meister - Gegenstand - Besitzer \\
\hline 713 & & & Beschauzeichen. I7. Jahrhundert. \\
\hline 714 & & & Beschauzeichen. I7. bis 18 . Jahrhundert. \\
\hline 715 & & & $\begin{array}{l}\text { Beschauzeichen. Mitte I8. Jahrhundert. } \\
\text { (Vielleicht Stuttgart.) }\end{array}$ \\
\hline 716 & & & Beschauzeichen. I8. Jahrhundert. \\
\hline 717 & 3 & & \\
\hline 718 & $\boldsymbol{D}$ & & Beschauzeichen. I8. bis I9. Jahrhundert. \\
\hline 719 & (2) & & \\
\hline 720 & (13) & & \\
\hline 721 & 18 & & \\
\hline 722 & 13 & & Feingehaltszeichen. IS. bis i9. Jahrhundert. \\
\hline 723 & 12 & & \\
\hline 724 & $\begin{array}{c}\text { wie } \\
\text { Nr. } 7 \text { I } 3\end{array}$ & $\mathbf{Q}$ & $\begin{array}{l}\text { Dose in Gestalt eines Hundes. } \\
\text { Besitzer: H. Boskowitz, Wien. }\end{array}$ \\
\hline 725 & $\begin{array}{c}\text { wie } \\
\text { Nr. 7 I 3 }\end{array}$ & MS & $\begin{array}{l}\text { Weisssilbernes Gefäss aus zwei dosenartigen Stücken } \\
\text { bestehend. } \\
\text { Besitzer: H. Boskowitz, Wien. }\end{array}$ \\
\hline 726 & $\begin{array}{c}\text { wie } \\
\text { Nr. 7 I4 }\end{array}$ & H2 & $\begin{array}{l}\text { Weisssilbernes Etui in Fischform. Lg. I 5,5 cm. } \\
\text { Besitzer: Baron Nathanael v. Rothschild, Wien. }\end{array}$ \\
\hline
\end{tabular}




\begin{tabular}{|c|c|c|c|}
\hline $\begin{array}{l}\text { Lf. } \\
\text { Nr. }\end{array}$ & $\begin{array}{l}\text { Beschau• } \\
\text { zeichen }\end{array}$ & $\begin{array}{l}\text { Meister- } \\
\text { zeichen }\end{array}$ & Meister - Gegenstand - Besitzer \\
\hline 727 & $\begin{array}{l}\text { wie } \\
\text { Nr. } 7 \text { I } 4\end{array}$ & & $\begin{array}{l}\text { Weisssilbernes Etui in Fischform. } \\
\text { Besitzer (1883): J. J. Boasberg, Amsterdam. }\end{array}$ \\
\hline 728 & $\begin{array}{l}\text { wie } \\
\text { Nr. 7 I4 }\end{array}$ & & $\begin{array}{l}\text { Weisssilbernes Etui in Fischform. } \\
\text { Besitzer: Excellenz Due, St. Petersburg. }\end{array}$ \\
\hline 729 & $\begin{array}{l}\text { wie } \\
\text { Nr. } 7 \text { I4 }\end{array}$ & & $\begin{array}{l}\text { Tabaksdose in Gestalt eines Löwen. } \\
\text { Besitzer: J. \& H. Jeidels, Frankfurt a. M. }\end{array}$ \\
\hline 730 & $\begin{array}{c}\text { wie } \\
\text { Nr. 7 I } 5\end{array}$ & & $\begin{array}{l}\text { Vergoldeter Pokal der Küferzunft in Stuttgart. Stiftungs- } \\
\text { inschrift von I } 745 \text {. } \\
\text { Besitzer: Küfferzunft, Stuttgart. Im Rathhause daselbst deponirt. } \\
\text { Bürgerzeitung I859 Nr. 22. Vielieicht Stuttgarter Arbeit. }\end{array}$ \\
\hline $73 \mathrm{I}$ & $\begin{array}{c}\text { wie } \\
\text { Nr. } 7 \text { I } 6\end{array}$ & & $\begin{array}{l}\mathrm{J}_{*} \text { Fischer, i } 8 \text {. Jahrhundert. Gefällige Mittheilung } \\
\text { des Herrn Commerzien-Rath Erhard, Gmünd. } \\
\text { Vergoldeter Kelch. } \\
\text { Besitzer: Kirche, Bargau. }\end{array}$ \\
\hline 732 & $\begin{array}{c}\text { wie } \\
\text { Nr. } 7 \text { I9 }\end{array}$ & IG & $\begin{array}{l}\text { Mit dem Feingehaltszeichen „I2" Nr. } 723 . \\
\text { Zwei Uhrketten. } \\
\quad \text { Besitzer (1882): G. van Aaken, Baden-Baden. }\end{array}$ \\
\hline 733 & Einhorn & ? & $\begin{array}{l}\text { Zwei Kelche. } \\
\text { Besitzer: Dorfkirchen in der Nähe von Gmünd. Gefällige Mit- } \\
\text { theilung des Herrn Professor G. Bauer, Gmünd. }\end{array}$ \\
\hline 734 & $\begin{array}{l}\text { Ein- } \\
\text { horn- } \\
\text { kopf }\end{array}$ & ? & $\begin{array}{l}\text { Beschlag eines Gebetbuches. } \\
\text { Besitzer: Dorf kirche in der Nähe von Gmünd. Gefällige Mit- } \\
\text { theilung des Herrn Professor G. Bauer, Gmünd. }\end{array}$ \\
\hline 735 & $\begin{array}{c}\text { wie } \\
\text { Nr. } 7 \text { I } 7\end{array}$ & $?$ & $\begin{array}{l}\text { Mit dem Feingehaltszeichen „I } 3^{\prime \prime ~ N r . ~} 720 . \\
\text { Weisssilberner Stricknadelhalter. } \\
\text { Besitzer: J. Dreyfus-Jeidels, Frankfurt a. M. }\end{array}$ \\
\hline 736 & $\begin{array}{l}\text { wie } \\
\text { Nr. } 7 \text { I } 8\end{array}$ & ? & 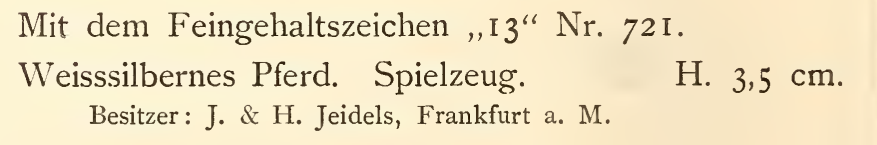 \\
\hline 737 & $\begin{array}{c}\text { wie } \\
\text { Nr. } 7 \text { I9 }\end{array}$ & ? & $\begin{array}{l}\text { Mit dem Feingehaltszeichen „I3“ Nr. } 722 . \\
\text { Petschaft. } \\
\quad \text { Besitzer (1882): G. van Aaken, Baden-Baden. }\end{array}$ \\
\hline
\end{tabular}




\section{GOTHA.}

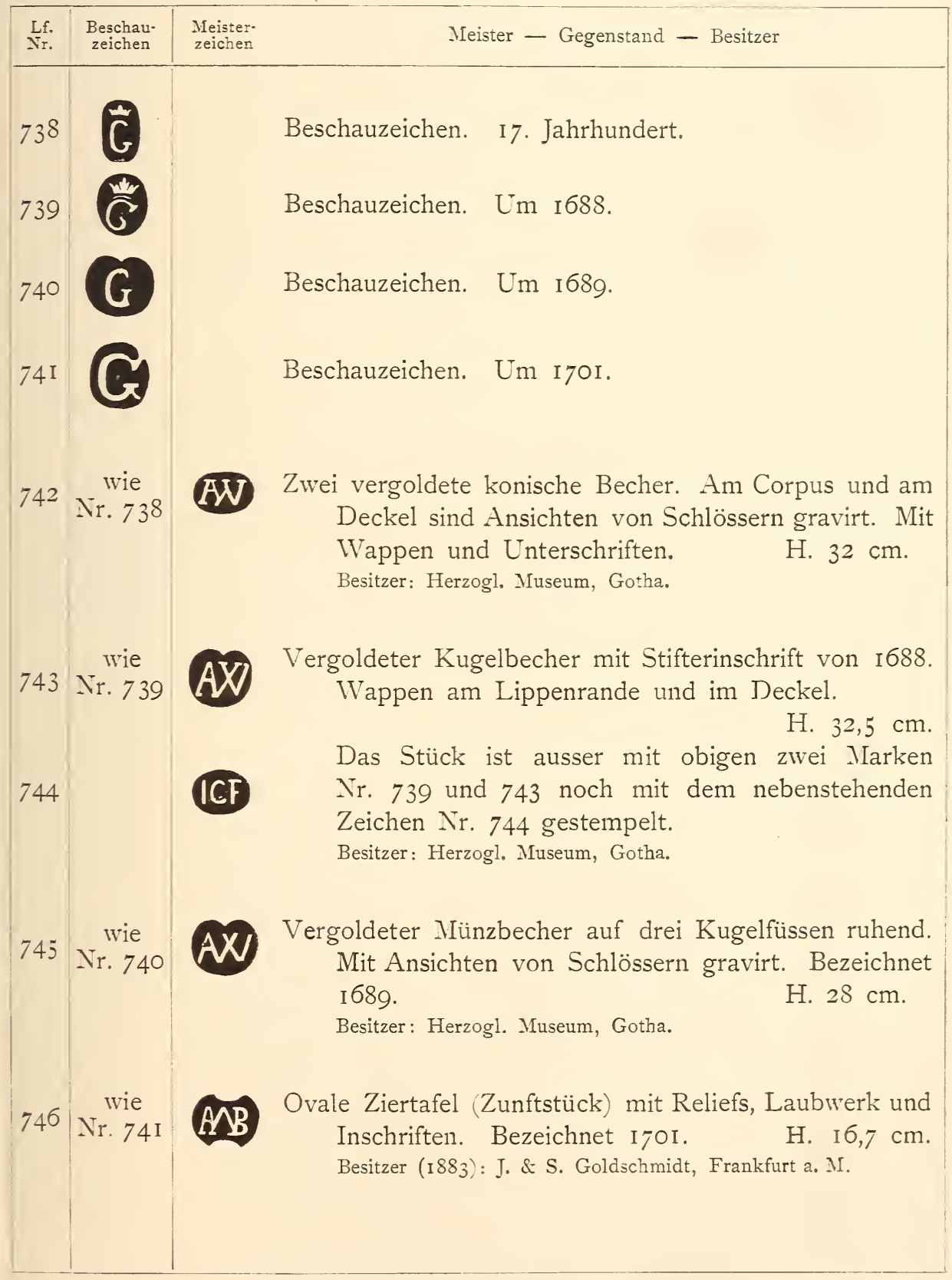




\section{HALBERSTADT.}

\begin{tabular}{|c|c|c|c|}
\hline $\begin{array}{l}\text { Lf. } \\
\text { Nr. }\end{array}$ & $\begin{array}{l}\text { Beschau- } \\
\text { zeichen }\end{array}$ & $\begin{array}{l}\text { Meister- } \\
\text { zeichen }\end{array}$ & Meister - Gegenstand - Besitzer \\
\hline 747 & & & Beschauzeichen. I8. Jahrhundert. \\
\hline 748 & $\begin{array}{c}\text { wie } \\
\mathrm{Nr} .747\end{array}$ & $\begin{array}{l}\text { SIE } \\
\text { BERT }\end{array}$ & $\begin{array}{l}\text { Silbernes Dejeuner, bestehend aus sechs Gefässen und } \\
\text { zwölf Kaffeelöffeln. Rococo. } \\
\text { Besitzer: Frau General v. Canstein, Cassel. }\end{array}$ \\
\hline
\end{tabular}

\section{(SCHW ÄB.-)HALL.}

Wegen älterer, anscheinend Haller, Arbeiten verweise ich auf den Limburgschen Schenkbecher, auf eine Elfenbeinkanne im Alterthümerkabinet Stuttgart (Ausstellung München I876, Katalog Nr. 249), sowie auf eine Elfenbeinkanne, bezeichnet I684, im Herzoglichen Museum Gotha, lauter Stuicke, von deren Stempel ich leider kein Facsimile vorlegen kann.

\begin{tabular}{|c|c|c|c|}
\hline $\begin{array}{l}\text { Lf. } \\
\text { Nr. }\end{array}$ & $\begin{array}{l}\text { Beschau- } \\
\text { zeichen }\end{array}$ & $\begin{array}{l}\text { Meister- } \\
\text { zeichen }\end{array}$ & Meister - Gegenstand - Besitzer \\
\hline 749 & & & \\
\hline 750 & & & \\
\hline $75 \mathrm{I}$ & & & Beschauzeichen. I7. bis I8. Jahrhundert. \\
\hline 753 & & & \\
\hline 754 & & & \\
\hline
\end{tabular}




\begin{tabular}{|c|c|c|c|}
\hline $\begin{array}{l}\text { Lf. } \\
\text { Nr. }\end{array}$ & $\begin{array}{l}\text { Beschau. } \\
\text { zeichen }\end{array}$ & $\begin{array}{l}\text { Meister- } \\
\text { zeichen }\end{array}$ & Meister - Gegenstand - Besitzer \\
\hline 755 & 13 & & Feingehaltszeichen. Früh I9. Jahrhundert. \\
\hline 756 & $\begin{array}{l}\text { wie } \\
\text { Nr. } 749\end{array}$ & & $\begin{array}{l}\text { Weisssilberner Apostellöffel. } \\
\text { Besitzer: Professor Seyffer, Stuttgart (1882). }\end{array}$ \\
\hline 757 & $\begin{array}{c}\text { wie } \\
\text { Nr. } 749\end{array}$ & & $\begin{array}{l}\text { Theilvergoldete bauchige Weinkanne. } \\
\text { Besitzer: Katharinenkirche, (Schwäb.-)Hall. }\end{array}$ \\
\hline 758 & $\begin{array}{c}\text { wie } \\
\mathrm{Nr} .750\end{array}$ & & $\begin{array}{l}\text { Weisssilberne Hostienbuichse und Patene, zu einem Reise } \\
\text { kelch gehörig. Mit Initialen und (I6)78. } \\
\text { Besitzer: Katharinenkirche, (Schwäb.-)Hall. }\end{array}$ \\
\hline 759 & $\begin{array}{c}\text { wie } \\
\mathrm{Nr} .750\end{array}$ & & $\begin{array}{l}\text { Vergoldete Deckelkanne. } \\
\text { Besitzer: Evangelische Kirche, Wertheim. }\end{array}$ \\
\hline 760 & $\begin{array}{c}\text { wie } \\
\text { Nr. } 75 \mathrm{I}\end{array}$ & & 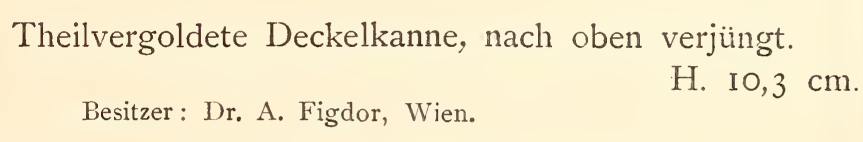 \\
\hline $76 \mathrm{I}$ & $\begin{array}{c}\text { wie } \\
\text { Nr. } 752\end{array}$ & LFB & $\begin{array}{l}\text { L. H. Beltz, um i } 769 \text {. } \\
\text { Vergoldete Hostienbüchse, bezeichnet I } 769 . \\
\quad \text { Besitzer: Michaelskirche, (Schwäb.-)Hall. }\end{array}$ \\
\hline 762 & $\begin{array}{c}\text { wie } \\
\text { Nr. } 753\end{array}$ & & $\begin{array}{l}\text { Drei vergoldete und gravirte Weinkannen. } \\
\text { Besitzer: Michaelskirche, (Schwäh.-)Hall. }\end{array}$ \\
\hline 763 & & & $\begin{array}{l}\text { Vielleicht } \\
\text { C. Ruprecht. }\end{array}$ \\
\hline & $\begin{array}{l}\text { wie } \\
\text { Nr. } 754\end{array}$ & 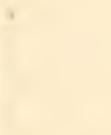 & $\begin{array}{l}\text { Theilvergoldete Weinkanne mit leicht gravirten grossen } \\
\text { Blättern und Inschriften von I } 779 . \\
\text { Besitzer: Michaelskirche, (Schwäb.-)Hall. }\end{array}$ \\
\hline 764 & $\begin{array}{l}\text { wie } \\
\text { Nr. } 75^{2}\end{array}$ & FLR & 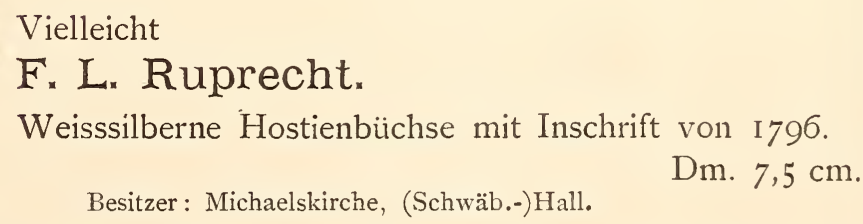 \\
\hline
\end{tabular}




\begin{tabular}{|c|c|c|c|}
\hline $\begin{array}{l}\text { Lf. } \\
\text { Nr. }\end{array}$ & $\begin{array}{l}\text { Beschau- } \\
\text { zeichen }\end{array}$ & $\begin{array}{l}\text { Meister- } \\
\text { zeichen }\end{array}$ & Meister - Gegenstand - Besitzer \\
\hline 765 & ? & $F B$ a) & $\begin{array}{l}\text { Weisssilberne Buchschliesse. } \\
\text { Besitzer: Museum vaterländischer Alterthumer, Stuttgart. }\end{array}$ \\
\hline & ? & b) & $\begin{array}{l}\text { Weisssilberne durchbrochene Buchschliesse. } \\
\text { Besitzer: Pfälz. Gewerbe-Museum, Kaiserslautern. Katalog } \\
\text { Nr. 37. } \\
\text { Löffel, Rococo. } \\
\text { Besitzer: Professor Seyffer, Stuttgart (1882). }\end{array}$ \\
\hline 766 & & E. Ylock & $\begin{array}{l}\text { E. Glock, † I88I oder I882. } \\
\text { Mit dem Feingehaltszeichen „, } 3 \text { “ Nr. } 755 . \\
\text { Weisssilberne viereckige Hostienbüchse mit Stifter- } \\
\begin{array}{l}\text { inschrift von I826. } \\
\text { Besitzer: Katharinenkirche, (Schwäb.-)Hall. } 8 \mathrm{~cm} \text {. }\end{array}\end{array}$ \\
\hline
\end{tabular}

\section{HALLE A. D. S.}

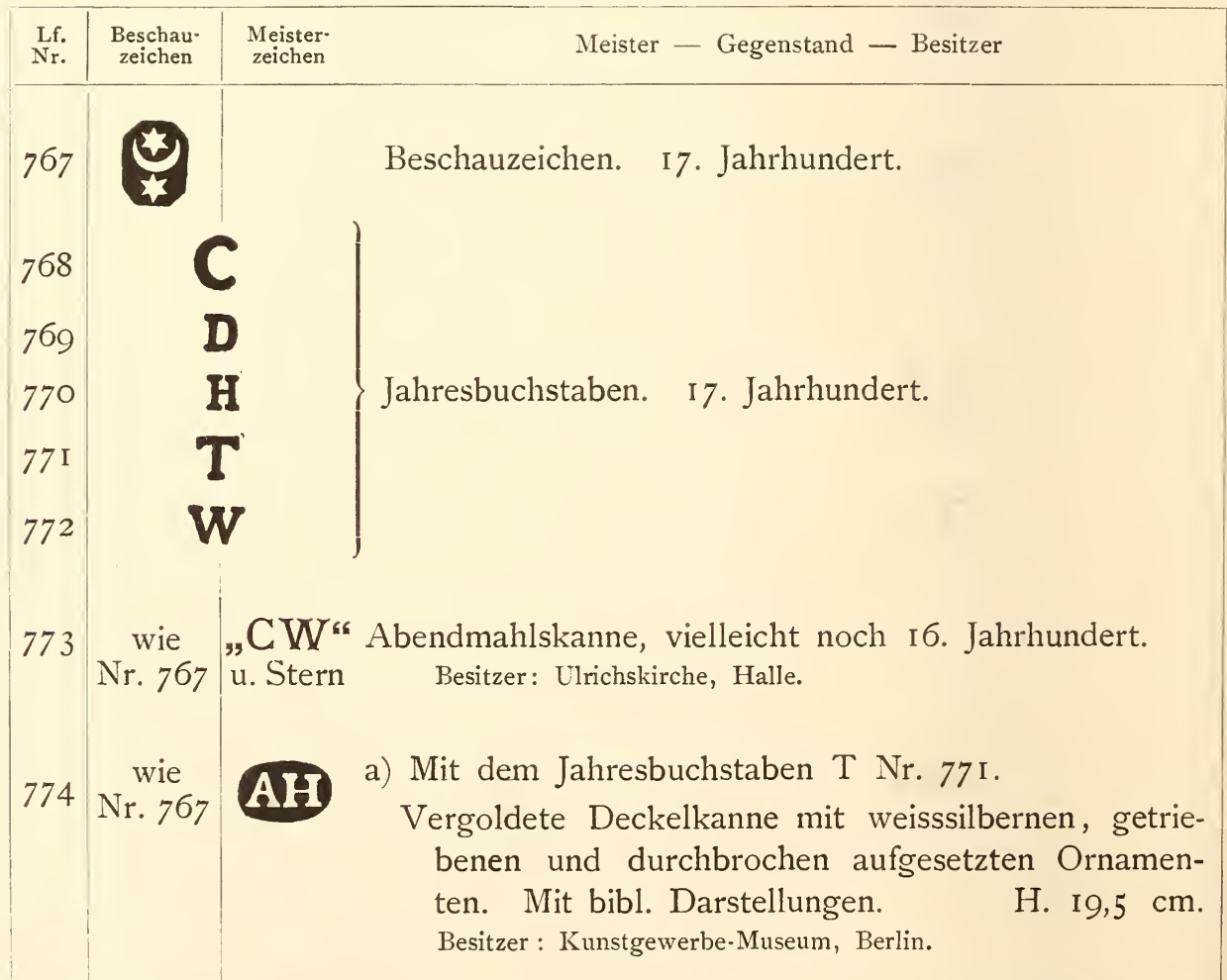




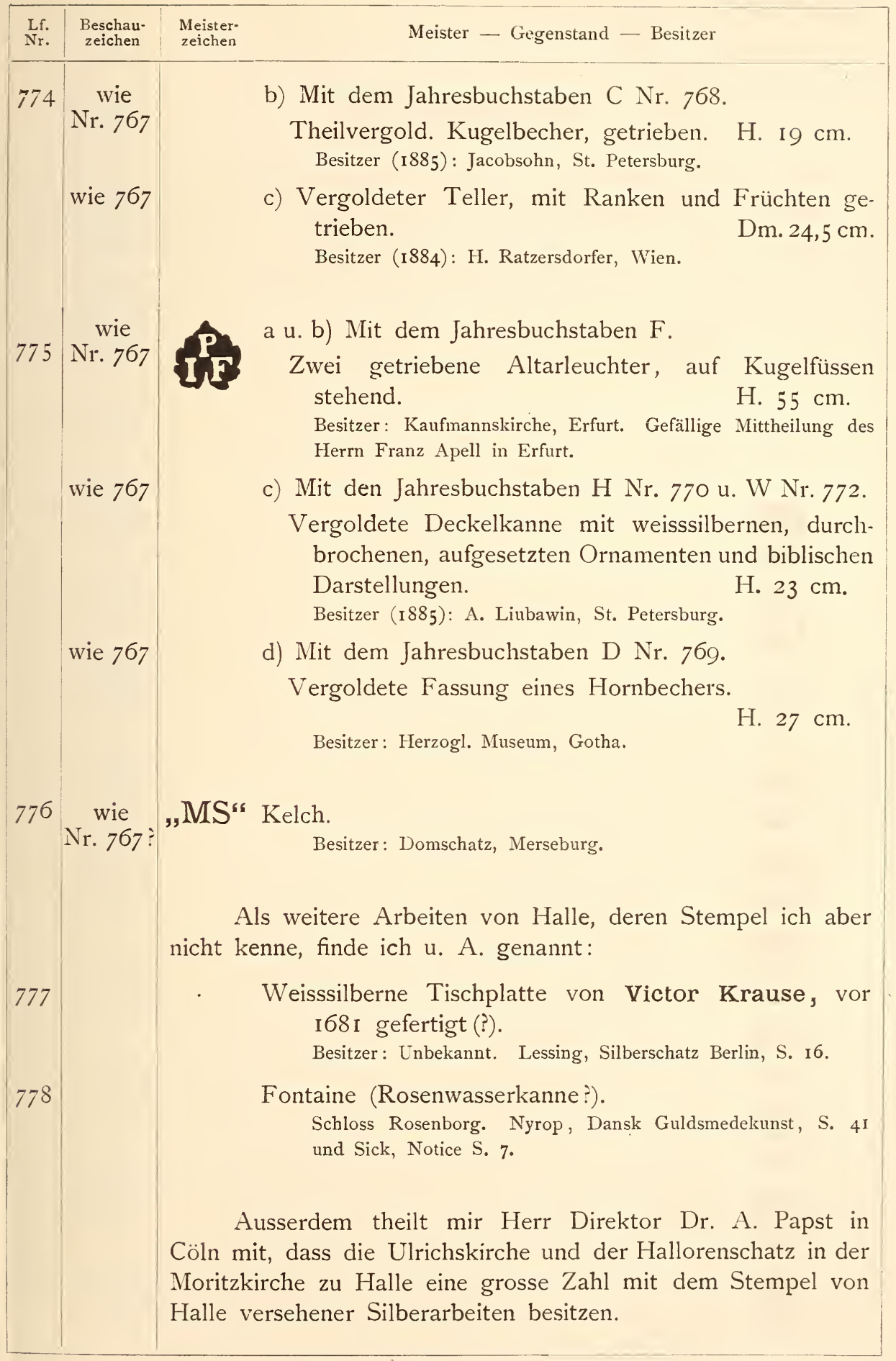




\section{HAMBURG.}

Wie Nyrop, Meddelelser om Dansk Guldsmedekunst, Kopenhagen I885, S. I 3 mittheilt, wird schon I 375 von dem Hamburger Stadtstempel gesprochen. Da Hamburg Mauer und Thürme im Wappen führt, ist die Feststellung seines Beschauzeichens, wegen der vielen gleichartigen Marken, sehr erschwert. Es ist nur als ein Versuch, der vielleicht missglückt ist, zu betrachten, wenn wir in folgendem einige Architekturmarken zusammenstellen, welche mit grösserer oder geringerer Wahrscheinlichkeit auf Hamburg zu weisen scheinen.

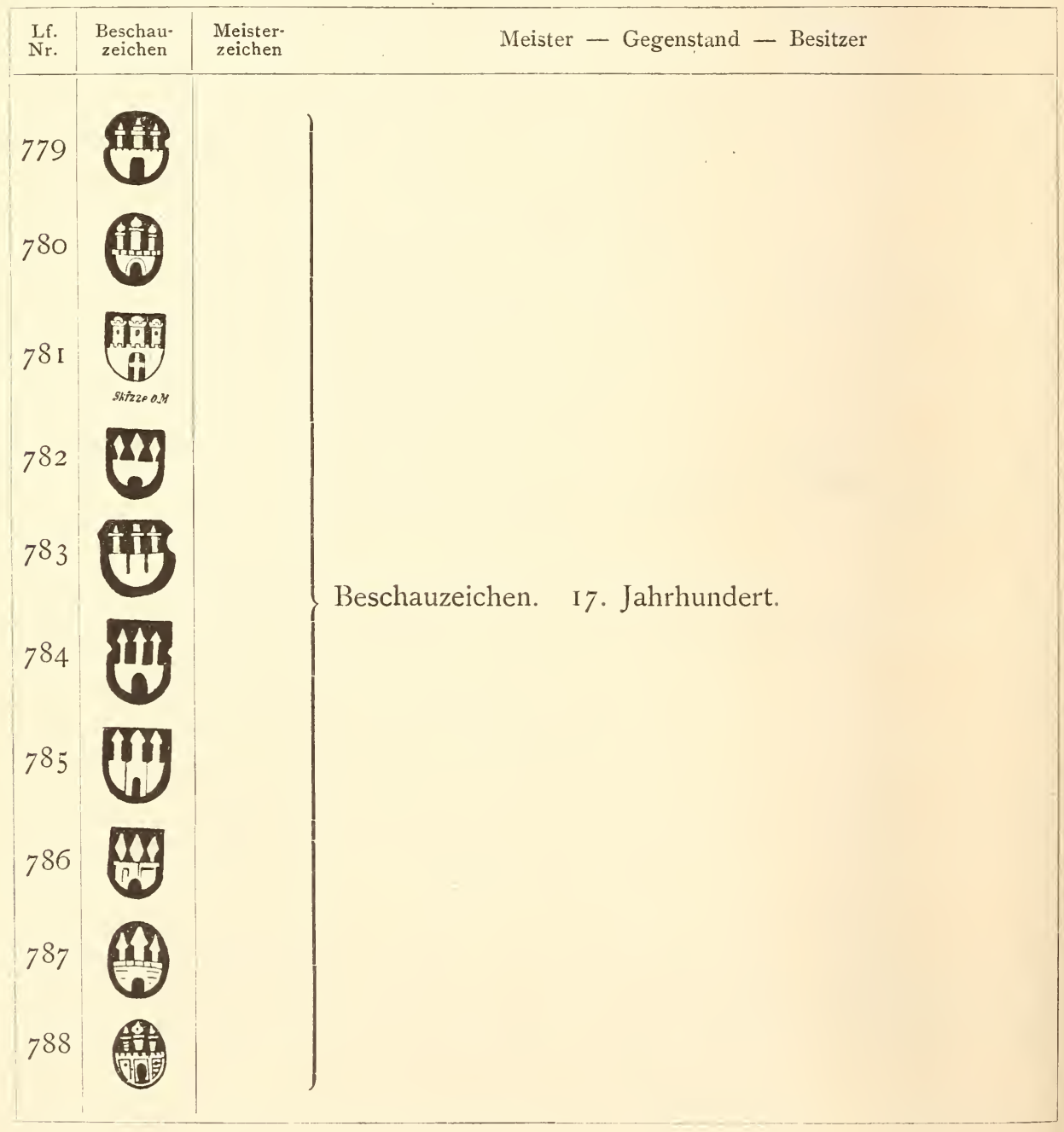




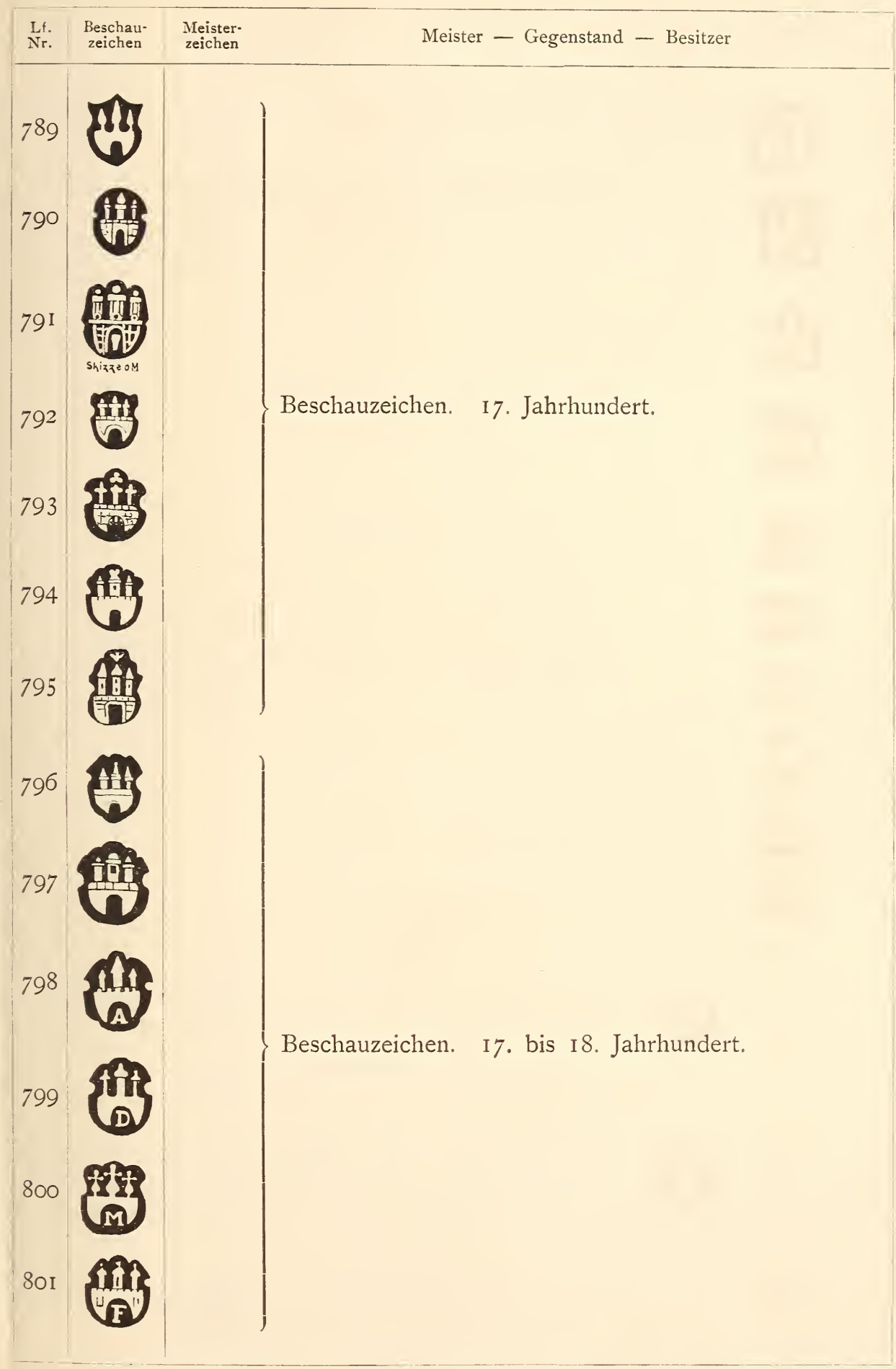




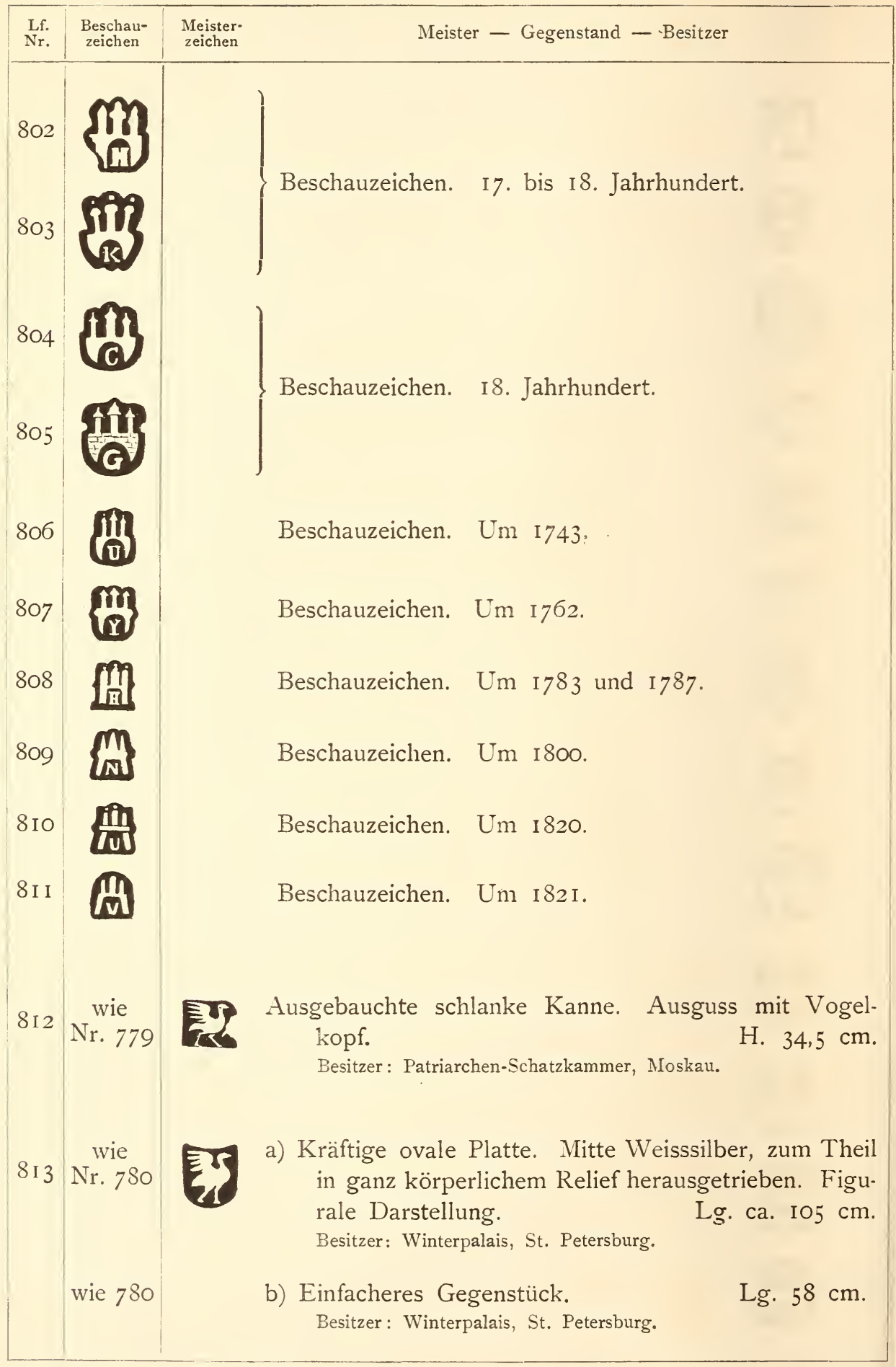




\begin{tabular}{|c|c|c|c|}
\hline $\begin{array}{l}\text { Lf. } \\
\text { Nr. }\end{array}$ & $\begin{array}{l}\text { Beschau- } \\
\text { zeichen }\end{array}$ & zeich & Meister - Gegenstand - Besitzer \\
\hline 814 & $\begin{array}{l}\text { wie } \\
\text { Nr. } 78 \text { I }\end{array}$ & & $\begin{array}{l}\text { Vergoldetes niederes, bauchiges Gefäss. H. } 8 \mathrm{~cm} \text {. } \\
\text { Besitzer (1 } 8_{3} \text { ): Gebr. Heilbronner, München. }\end{array}$ \\
\hline $8 I_{5}$ & $\begin{array}{l}\text { wie } \\
\text { Nr. } 782\end{array}$ & & $\begin{array}{l}\text { a) Vergoldete Bratina (niederes bauchiges Gefäss, } \\
\text { russische Form), mit Ornamenten am Corpus ge- } \\
\text { trieben. } \\
\text { H. I I } 7 \mathrm{~cm} .\end{array}$ \\
\hline & wie 782 & & $\begin{array}{l}\text { b) Aehnliches Stück. } \\
\text { Besitzer: Patriarchen-Schatzkammer, Moskau. }\end{array}$ \\
\hline & wie 782 & & $\begin{array}{l}\text { c) Vergoldete Bratina, mit Lederwerk-Ornamentik ge- } \\
\text { trieben und mit Inschrift versehen. } \\
\text { Besitzer: Patriarchen-Schatzkammer, Moskau. }\end{array}$ \\
\hline & wie 782 & & $\begin{array}{l}\text { d u. e) Zwei bauchige Gefässe mit Lederwerk-Orna- } \\
\text { mentik. } \\
\text { Besitzer: P. A. Kotschubey, St. Petersburg. }\end{array}$ \\
\hline 816 & $\begin{array}{l}\text { wie } \\
\operatorname{Nr} .783\end{array}$ & & $\begin{array}{l}\text { a) Vergoldeter Buckelpokal mit Lederwerk-Ornamentik. } \\
\text { Laut Inschrift um I656. H. } 69,5 \mathrm{~cm} \text {. } \\
\text { Besitzer: Patriarchen-Schatzkammer, Moskau. }\end{array}$ \\
\hline & wie 783 & & $\begin{array}{l}\text { b) Vergoldeter Buckelpokal. Ohne Deckel, H. } 44 \mathrm{~cm} \text {. } \\
\text { Besitzer: Patriarchen-Schatzkammer, Moskau. }\end{array}$ \\
\hline & wie 783 & & $\begin{array}{l}\text { c) Vergoldete Schüssel mit acht Mal eingezogenem } \\
\text { Rande. Griffe mit Gravirungen. H. } 22 \mathrm{~cm} \text {. } \\
\text { Besitzer: Patriarchen-Schatzkammer, Moskat. }\end{array}$ \\
\hline 817 & $\begin{array}{c}\text { wie } \\
\text { Nr. } 784\end{array}$ & & $\begin{array}{l}\text { Buckelpokal. H. } 56 \mathrm{~cm} \text {. } \\
\text { Besitzer: Sammlung Stroganoff, St. Petersburg. }\end{array}$ \\
\hline 818 & $\begin{array}{c}\text { wie } \\
\text { Nr. } 784\end{array}$ & & $\begin{array}{l}\text { Buckelpokal. } \\
\text { Besitzer: Patriarchen-Schatzkammer, Moskau. }\end{array}$ \\
\hline 819 & $\begin{array}{c}\text { wie } \\
\operatorname{Nr} .785\end{array}$ & & $\begin{array}{l}\text { Vergoldeter Buckelpokal. } \\
\begin{array}{l}\text { Besitzer: Patriarchen-Schatzkammer, Moskau. } \\
\text { H. 24,5 cm. }\end{array}\end{array}$ \\
\hline 820 & $\begin{array}{l}\text { wie } \\
\mathrm{Nr} .786\end{array}$ & & $\begin{array}{l}\text { Vergoldeter Buckelpokal. } \\
\text { Besitzer: Patriarchen-Schatzkammer, Moskau. }\end{array}$ \\
\hline
\end{tabular}




\begin{tabular}{|c|c|c|c|}
\hline $\begin{array}{l}\text { Lf. } \\
\text { Nr. }\end{array}$ & $\begin{array}{l}\text { Beschau- } \\
\text { zeichen }\end{array}$ & & Meister - Gegenstand - Besitzer \\
\hline $82 \mathrm{I}$ & $\begin{array}{c}\text { wie } \\
\text { Nr. } 787\end{array}$ & & $\begin{array}{l}\text { Vergoldeter Becher, auf Kugelfüssen ruhend, mit } \\
\text { Blumen getrieben. } \\
\text { Besitzer: Patriarchen-Schatzkammer, Moskau. }\end{array}$ \\
\hline 822 & $\begin{array}{l}\text { wie } \\
\operatorname{Nr} .789\end{array}$ & & $\begin{array}{l}\text { Weisssilberner Löffel. Am Griffe eine Hand mit Trauben. } \\
\text { Besitzer: Museum für Kunst und Gewerbe, Hamburg. }\end{array}$ \\
\hline 823 & $\begin{array}{c}\text { wie } \\
\text { Nr. } 790\end{array}$ & & $\begin{array}{l}\text { a) Konischer Becher mit grossen Blumen getrieben. } \\
\text { Inschrift von I667. } \\
\text { Besitzer: Excellenz Due, St. Petersburg. }\end{array}$ \\
\hline & wie 790 & & $\begin{array}{l}\text { b) Weisssilberner konischer Becher, mit grossen Blu- } \\
\text { men getrieben. } \\
\text { Hesitzer: S. Excellenz General Durnowo, St. Petersburg. }\end{array}$ \\
\hline 824 & $\begin{array}{c}\text { wie } \\
\text { Nr. } 788\end{array}$ & & $\begin{array}{l}\text { Hohe schlanke Kanne. Am Corpus getriebene Orna- } \\
\text { mente. } \\
\text { Besitzer (1883): J. \& S. Goldschmidt, Frankfurt a. M. }\end{array}$ \\
\hline 825 & $\begin{array}{c}\text { wie } \\
\text { Nr. } 792\end{array}$ & & $\begin{array}{l}\text { Hohes weisssilbernes Salzfass, mit Ranken getrieben. } \\
\text { Besitzer: Patriarchen-Schatzkammer, Moskau. }\end{array}$ \\
\hline 826 & $\begin{array}{c}\text { wie } \\
\text { Nr. } 794\end{array}$ & & $\begin{array}{l}\text { Drei glatte konische Becher mit vergoldetem Boden } \\
\text { und Lippenrande. Mit Wappen, Inschrift und I694. } \\
\text { Besitzer: Patriarchen-Schatzkammer, Moskau. }\end{array}$ \\
\hline 827 & $\begin{array}{c}\text { wie } \\
\text { Nr. } 793\end{array}$ & & $\begin{array}{l}\text { Theilvergoldete Kanne, auf Kugelfüssen ruhend, mit ge- } \\
\text { triebenen Ovalmedaillons. } \\
\begin{array}{ll}\text { Besitzer: } † \text { Haron Carl v. Rothschild, Frankfurt a. M. } & \mathrm{cm} .\end{array}\end{array}$ \\
\hline 828 & $\begin{array}{c}\text { wie } \\
\text { Nr. } 79 \text { I }\end{array}$ & & $\begin{array}{l}\text { Vergoldete Platte mit eingesetzten Münzen. Nach I694. } \\
\text { Lg. } 30 \mathrm{~cm} . \\
\text { Dazu die Kanne. } \\
\text { Hesitzer: Freih. v. Tucher, Nürnberg. Ausstellung Nürnberg } \\
\text { I885, Katalog Nr. } 798 .\end{array}$ \\
\hline 829 & $\begin{array}{c}\text { wie } \\
\text { Nr. } 795\end{array}$ & & $\begin{array}{l}\text { Kanne mit weisssilbernem Cylinder. Hirtenscenen in } \\
\text { Treibarbeit. } \\
\text { H. } 23 \mathrm{~cm} \text {. } \\
\text { Besitzer: } \dagger \text { Baron Carl v. Rothschild, Frankfurt a. M. }\end{array}$ \\
\hline
\end{tabular}




\begin{tabular}{|c|c|c|c|}
\hline $\begin{array}{l}\text { Lf. } \\
\text { Nr. }\end{array}$ & $\begin{array}{l}\text { Beschau- } \\
\text { zeichen }\end{array}$ & $\begin{array}{l}\text { Meister- } \\
\text { zeichen }\end{array}$ & Meister - Gegenstand - Besitzer \\
\hline 830 & $\begin{array}{c}\text { wie } \\
\text { Nr. } 796\end{array}$ & & $\begin{array}{l}\text { a u. b) Zwei weisssilberne Leuchter mit Blumen ge- } \\
\text { trieben. Den Schaft bildet eine gewundene Säule. } \\
\text { H. } 27,5 \mathrm{~cm} .\end{array}$ \\
\hline & wie 796 & & $\begin{array}{cc}\text { c) Weisssilkernes Salzfass. } & \text { H. IO, } 5 \mathrm{~cm} \text {. } \\
\text { Besitzer: Patriarchen-Schatzkammer, Moskau. } & \end{array}$ \\
\hline & wie 794 & & $\begin{array}{l}\text { d) Theilvergoldete Deckelkanne mit Rococo-Orna- } \\
\text { menten. } \\
\text { Besitzer (1885): Jacobsohn, St. Petersburg. }\end{array}$ \\
\hline $83 \mathrm{I}$ & $\begin{array}{l}\text { wie } \\
\text { Nr. } 797\end{array}$ & & $\begin{array}{l}\text { a) Ovale Reisebüchse für Speisen. Auf vier Kugel- } \\
\text { füssen ruhend. Rankengravirung. } \\
\text { Besitzer: Patriarchen-Schatzkammer, Noskau. } \\
\text { b u. c) Zwei nach oben erweiterte Becher mit Gra- } \\
\text { virungen. } \\
\text { Besitzer: H. Boskowitz, Wien. }\end{array}$ \\
\hline & wie 799 & & $\begin{array}{l}\text { d) Schlanker nach oben erweiterter Becher. } \\
\text { H. } 27 \mathrm{~cm} \text {. } \\
\text { Besitzer: Sammlung Stroganoff, St. Petersburg. }\end{array}$ \\
\hline & wie 799 & & $\begin{array}{l}\text { e) Theilvergoldete Deckelkanne mit gravirten Frucht- } \\
\text { gehängen. } \\
\text { H. } 22,3 \mathrm{~cm} \text {. } \\
\text { Besitzer: S. Excellenz General Durnowo, St. Petersburg. }\end{array}$ \\
\hline 832 & $\begin{array}{c}\text { wie } \\
\text { Nr. } 799\end{array}$ & & $\begin{array}{l}\text { Römer, Glasbecher mit silbernem Fusse und Deckel. } \\
\text { An letzterem Inschrift von I692. } \quad \text { H. } 4 \mathrm{I} \mathrm{cm} \text {. } \\
\text { Besitzer: J. Campe, Hamburg. }\end{array}$ \\
\hline 833 & $\begin{array}{c}\text { wie } \\
\text { Nr. 800 }\end{array}$ & & $\begin{array}{l}\text { Theilvergoldete Deckelkanne, auf drei Klauenfüssen } \\
\text { ruhend, mit Wappen. } \\
\text { Besitzer (1885): A. Liubawin, St. Petersburg. }\end{array}$ \\
\hline 834 & $\begin{array}{c}\text { wie } \\
\text { Nr. 80 I }\end{array}$ & & $\begin{array}{l}\text { Weisssilberne Deckelkanne auf Kugelfüssen. Am Kör- } \\
\text { per getriebene Putten und Ranken. H. I9,5 cm. } \\
\text { Besitzer (1885): Jacobsohn, St. Petersburg. }\end{array}$ \\
\hline 835 & $\begin{array}{c}\text { wie } \\
\text { Nr. 802 }\end{array}$ & & $\begin{array}{l}\text { Getriebene Tafel. Jüdisches Cultusgeräthe. H. } 4 \mathrm{I} \mathrm{cm} \text {. } \\
\text { Besitzer: Synagoge, Hamburg. }\end{array}$ \\
\hline
\end{tabular}




\begin{tabular}{|c|c|c|c|}
\hline $\begin{array}{l}\text { Lf. } \\
\text { Nr. }\end{array}$ & $\begin{array}{l}\text { Beschau- } \\
\text { zeichen }\end{array}$ & $\begin{array}{l}\text { Meister. } \\
\text { zeichen }\end{array}$ & Meister - Gegenstand - Besitzer \\
\hline 836 & $\begin{array}{l}\text { wie } \\
\text { Nr. } 803\end{array}$ & & $\begin{array}{l}\text { Taschenbügel mit biblischen Darstellungen. } \mathrm{Lg} \text {. I7 cm. } \\
\text { Besitzer: National-Museum, München. }\end{array}$ \\
\hline 837 & $\begin{array}{l}\text { wie } \\
\text { Nr. } 804\end{array}$ & & $\begin{array}{l}\text { Trinkgefäss in Form eines Schlüssels. Mit Inschriften, } \\
\text { Namen und I } 7 \text { I I. } \\
\text { Besitzer: Museum für Kunst und Gewerbe, Hamburg. }\end{array}$ \\
\hline 838 & $\begin{array}{l}\text { wie } \\
\text { Nr. } 805\end{array}$ & & $\begin{array}{l}\text { Vergoldete Deckelkanne, auf drei Kugelfüssen ruhend. } \\
\text { Mit gravirten Ranken. } \quad \text { H. } 23,5 \mathrm{~cm} . \\
\text { Besitzer (I885): A. Liubawin, St. Petersburg. }\end{array}$ \\
\hline
\end{tabular}

\section{HANAU.}

\begin{tabular}{|c|c|c|c|}
\hline $\begin{array}{l}\text { Lf. } \\
\mathrm{Nr} .\end{array}$ & $\begin{array}{l}\text { Beschau- } \\
\text { zeichen }\end{array}$ & $\begin{array}{l}\text { Meister- } \\
\text { zeichen }\end{array}$ & Meister - Gegenstand - Besitzer. \\
\hline 839 & & & Beschauzeichen (Alt-Hanau). I7. Jahrhundert. \\
\hline 840 & & & Beschauzeichen (Neu-Hanau). I8. Jahrhundert. \\
\hline $84 \mathrm{I}$ & $\overbrace{\mathrm{NH}}^{\mathrm{I} 3}$ & & Beschauzeichen (Neu-Hanau). I9. Jahrhundert. \\
\hline 842 & $\mathbf{I}$ & & Wardeinzeichen? I9. Jahrhundert. \\
\hline 843 & & & $\begin{array}{l}\text { Feingehaltszeichen auf modernen Silberarbeiten im alten } \\
\text { Stile. }\end{array}$ \\
\hline 844 & $\begin{array}{l}\text { wie } \\
\text { Nr. } 839\end{array}$ & & $\begin{array}{l}\text { Rathsbecher der Stadt Hanau. Am Griffe drei weib- } \\
\text { liche Figuren. Cuppa mit figuraler Treibarbeit. } \\
\text { H. } 64 \mathrm{~cm} . \\
\text { Besitzer: } \dagger \text { Baron Carl v. Rothschild, Frankfurt a. M. Luthmer, } \\
\text { Schatz Rothschild II, Taí. } \text { r }_{3} .\end{array}$ \\
\hline
\end{tabular}




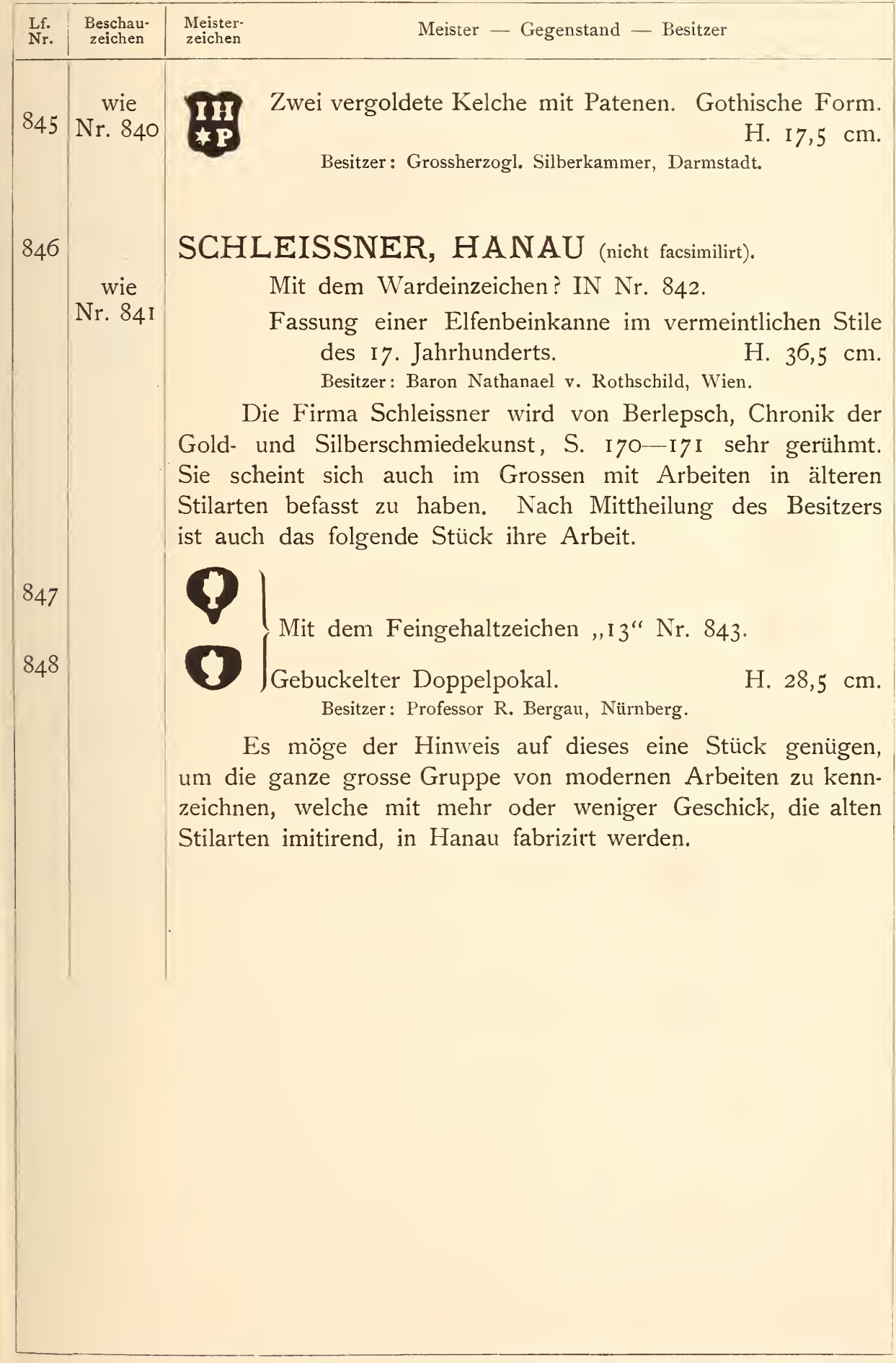




\section{HEIDELBERG.}

Die Heidelberger Goldschmiede-Ordnung von I 563, abgedruckt in Wirth, Archiv für die Geschichte der Stadt Heidelberg, Jahrgang II, S. 53 ff., spricht von einer Stempelung durch die Aeltesten der Innung.

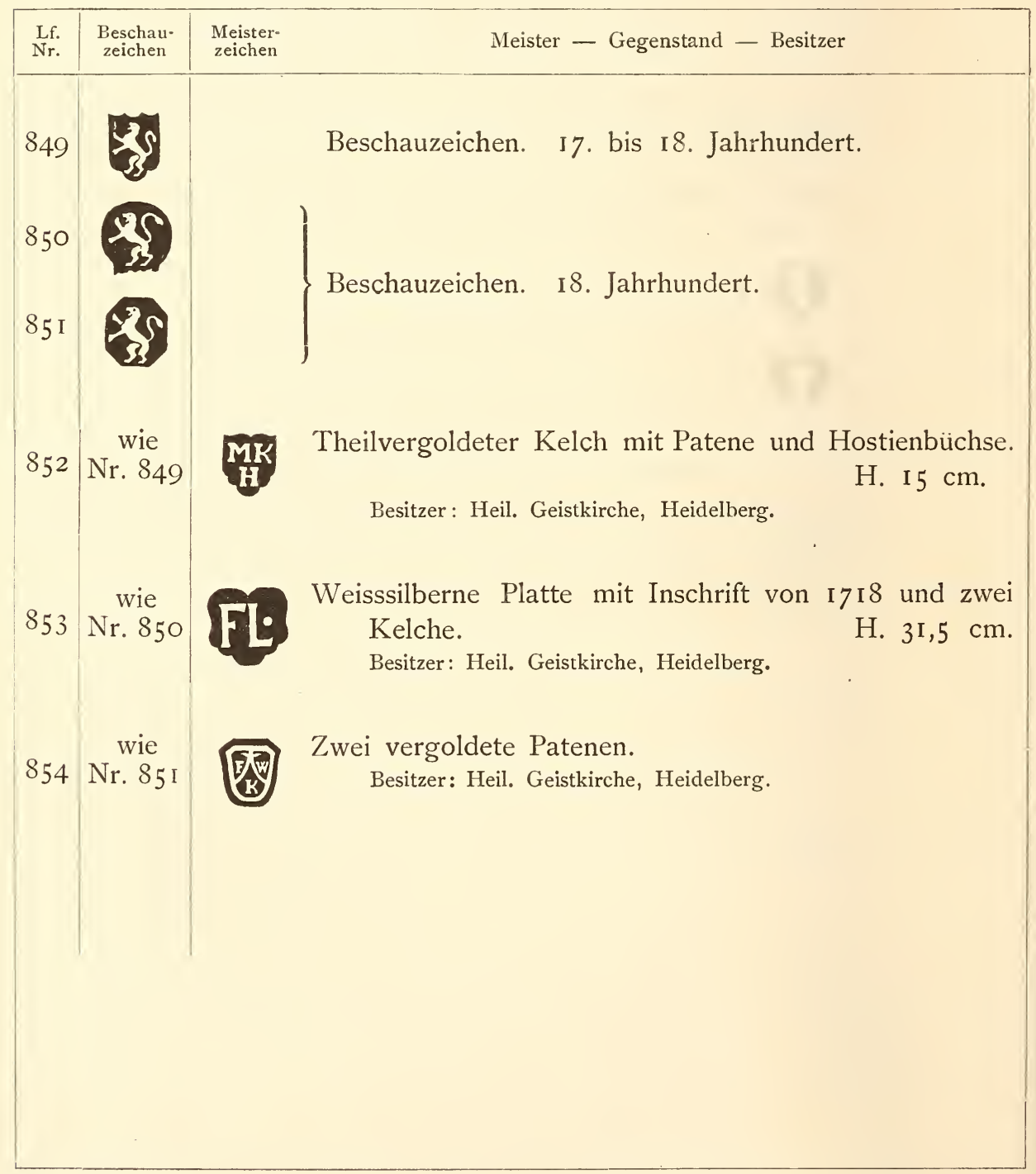




\section{HEILBRONN.}

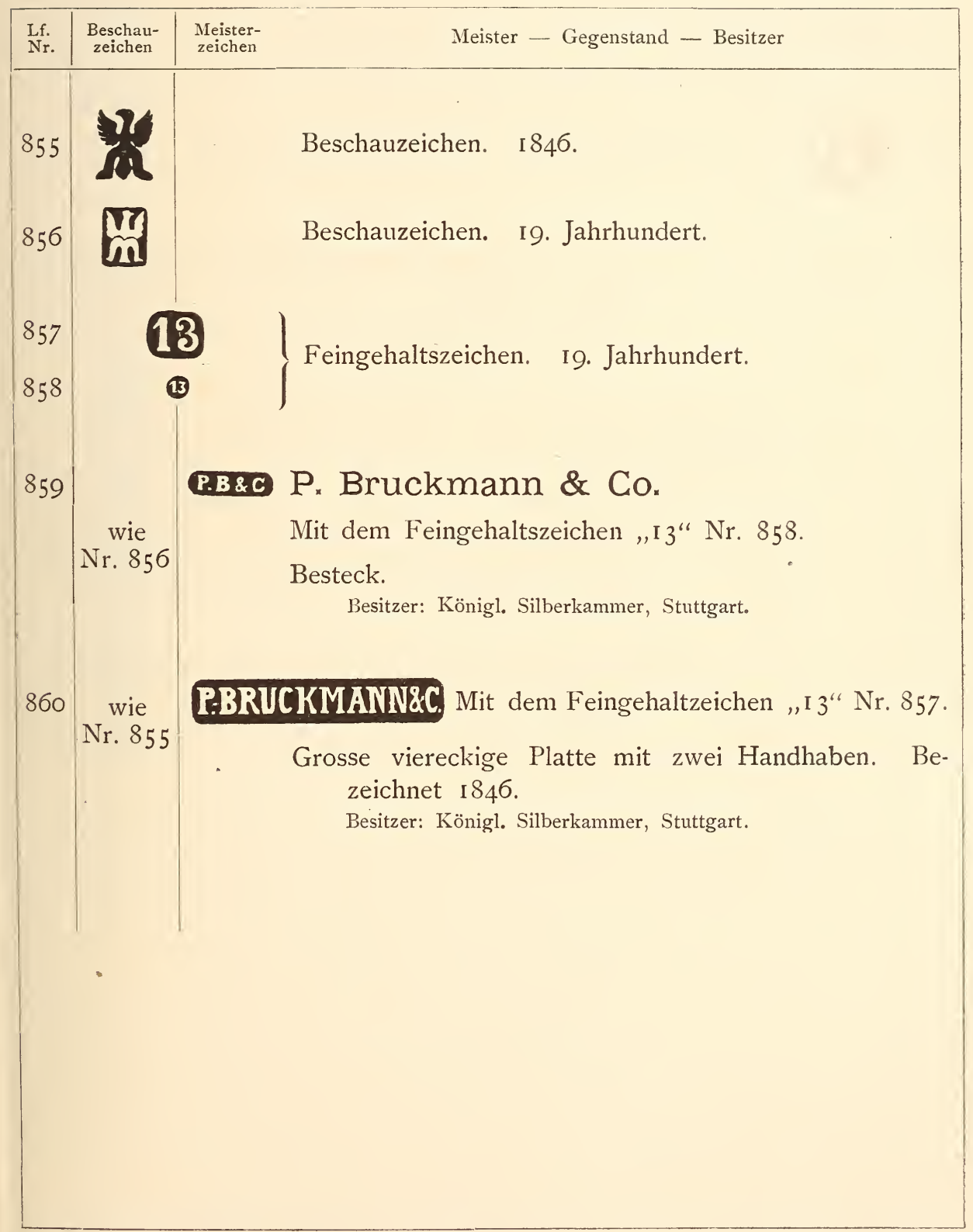




\section{INGOLSTADT.}

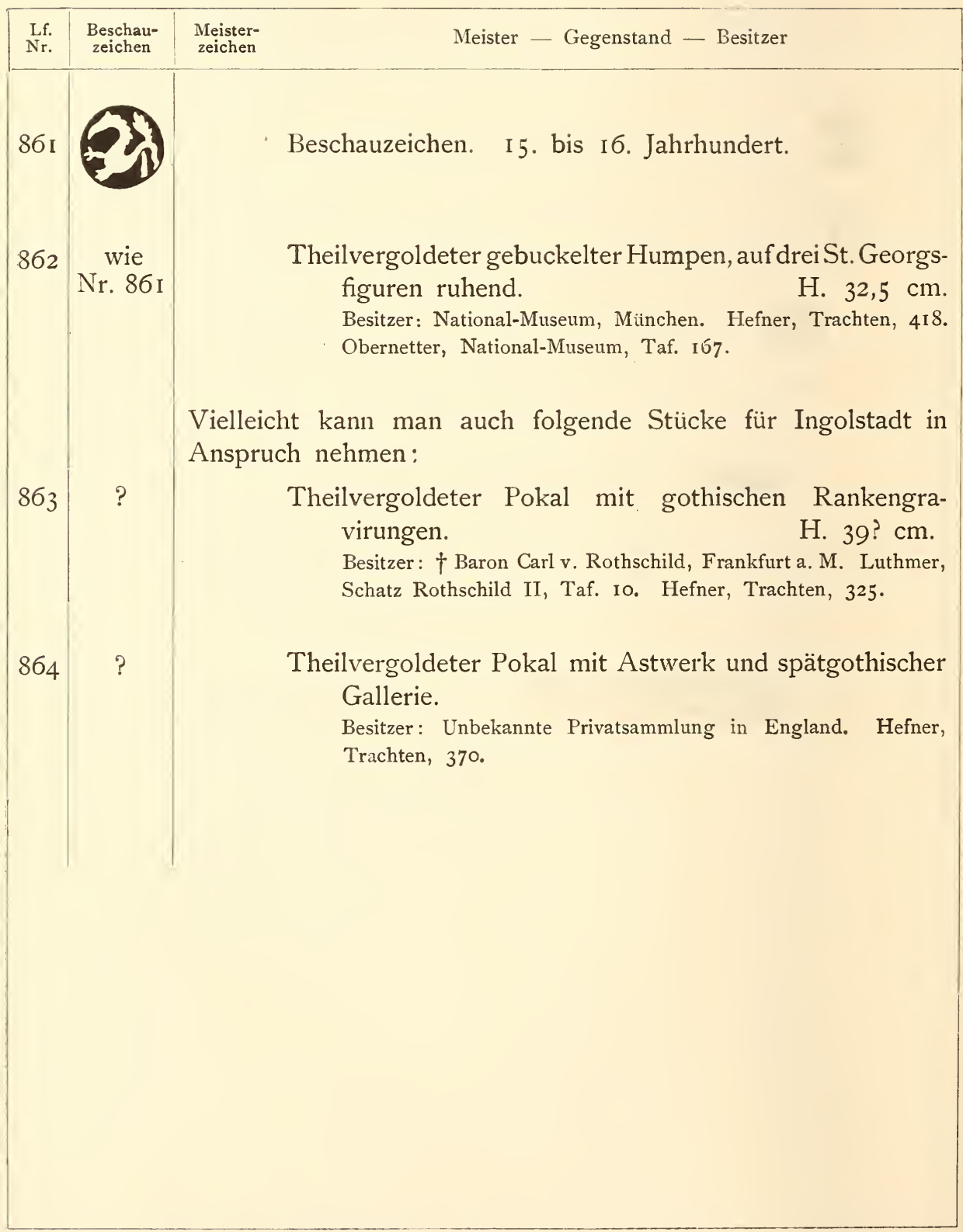




\section{KARLSRUHE.}

Ueber das ältere Beschauzeichen bin ich leider nicht unterrichtet. Es wird in einem Schrägbalken bestanden haben. Ich wage aber keine bestimmte Marke als Beispiel hierher zu setzen, weil eine Verwechslung mit anderen Orten, u. A. auch mit Baden-Baden, zu leicht möglich ist. Mit der Erhebung des Badischen Landes zum Grossherzogthum gewinnt das Wappen der Hauptstadt, durch die über demselben schwebende Krone, ein wichtiges Unterscheidungsmal. Von diesem Zeitpunkte $a b$ ist das Beschauzeichen leicht $z u$ bestimmen.

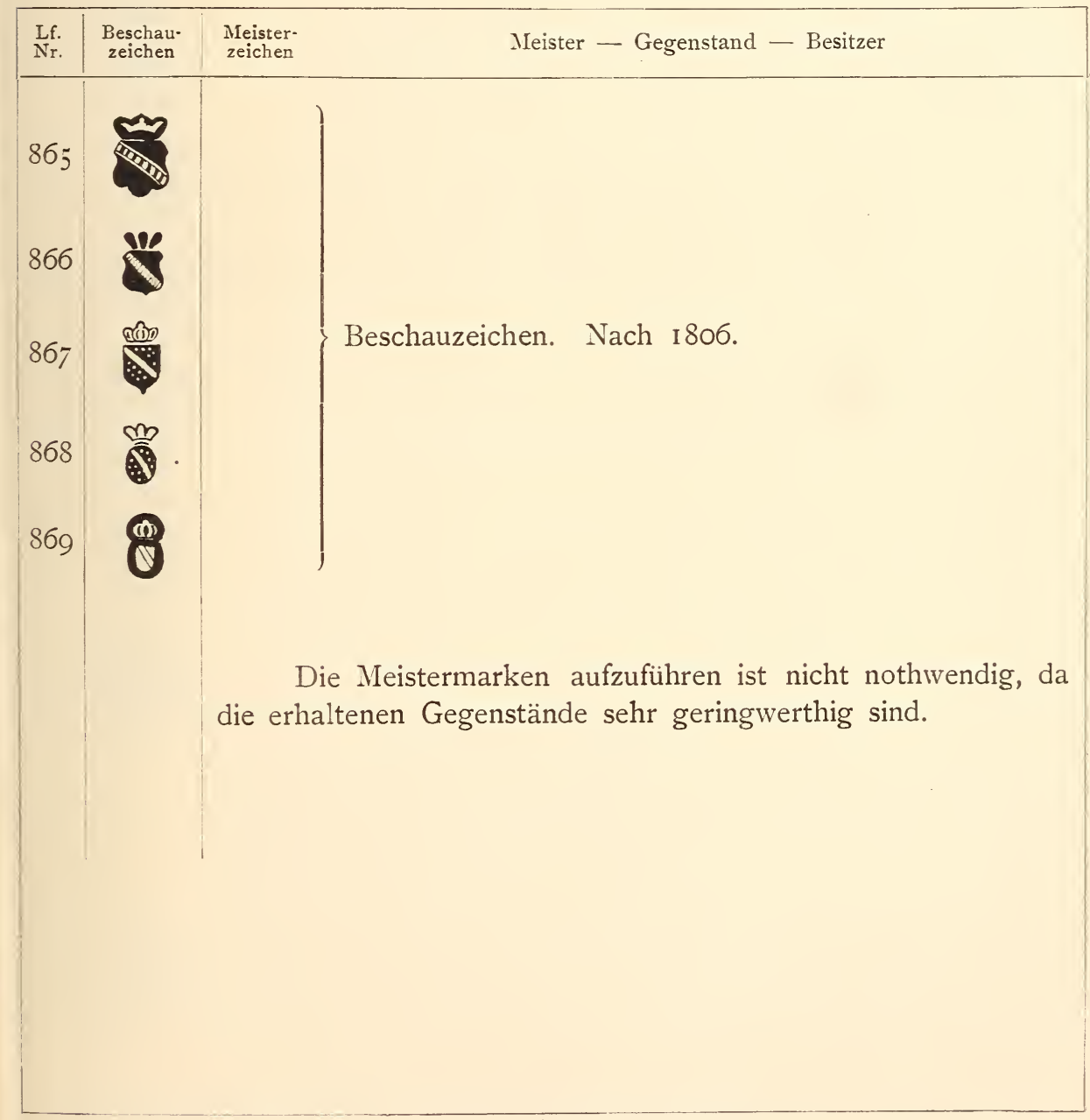




\section{KAUFBEUERN.}

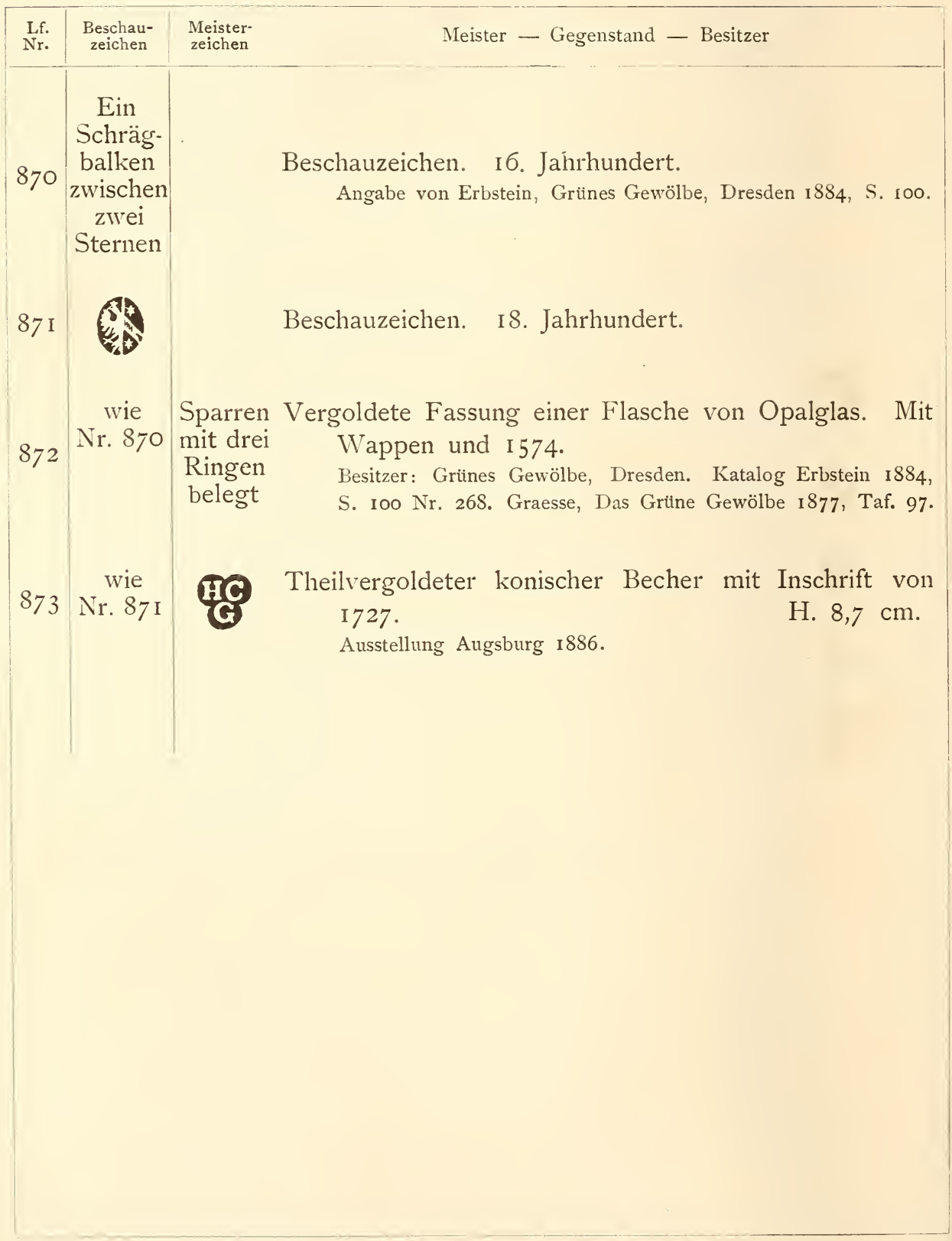




\section{KÖNIGSBERG I. P.}

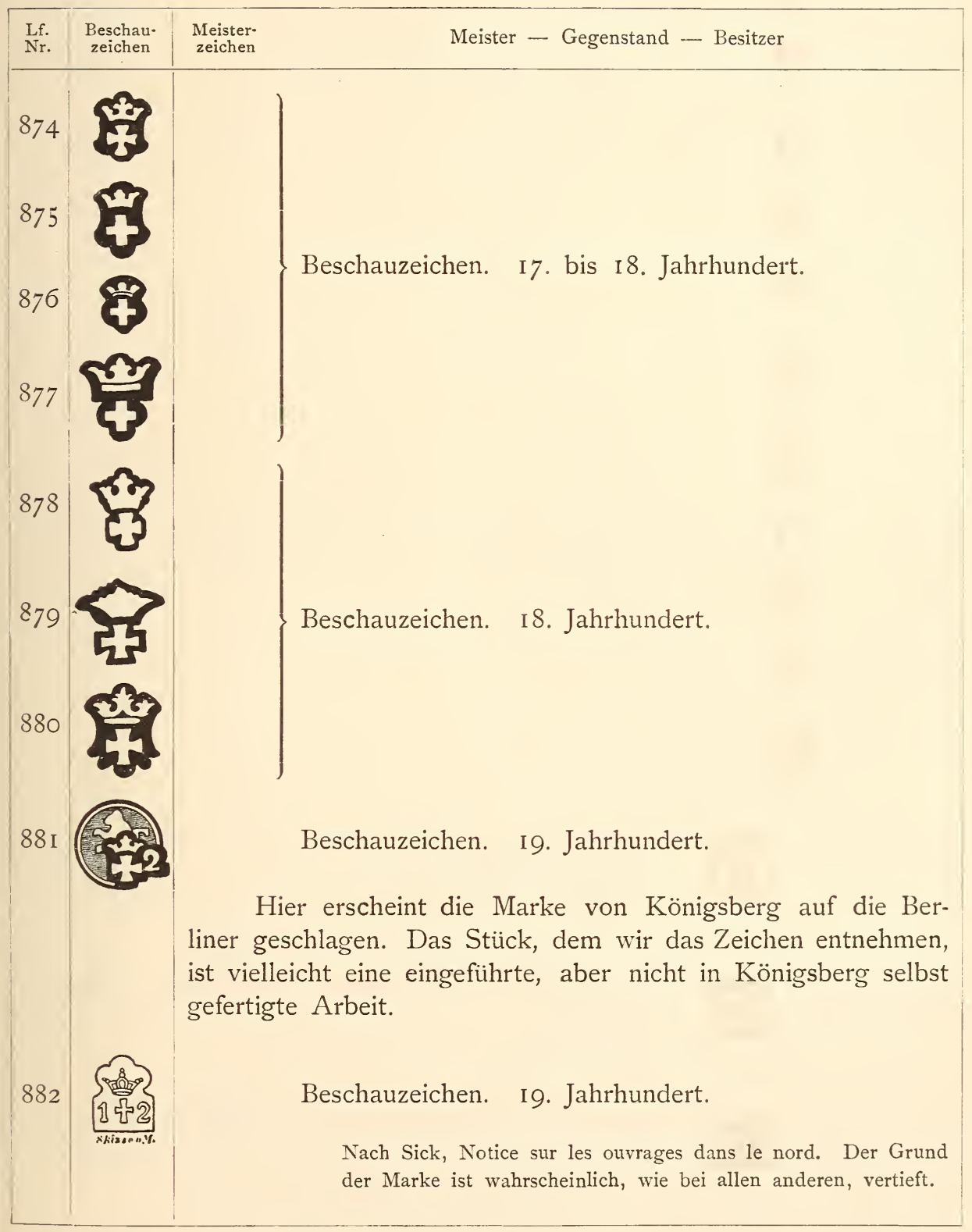




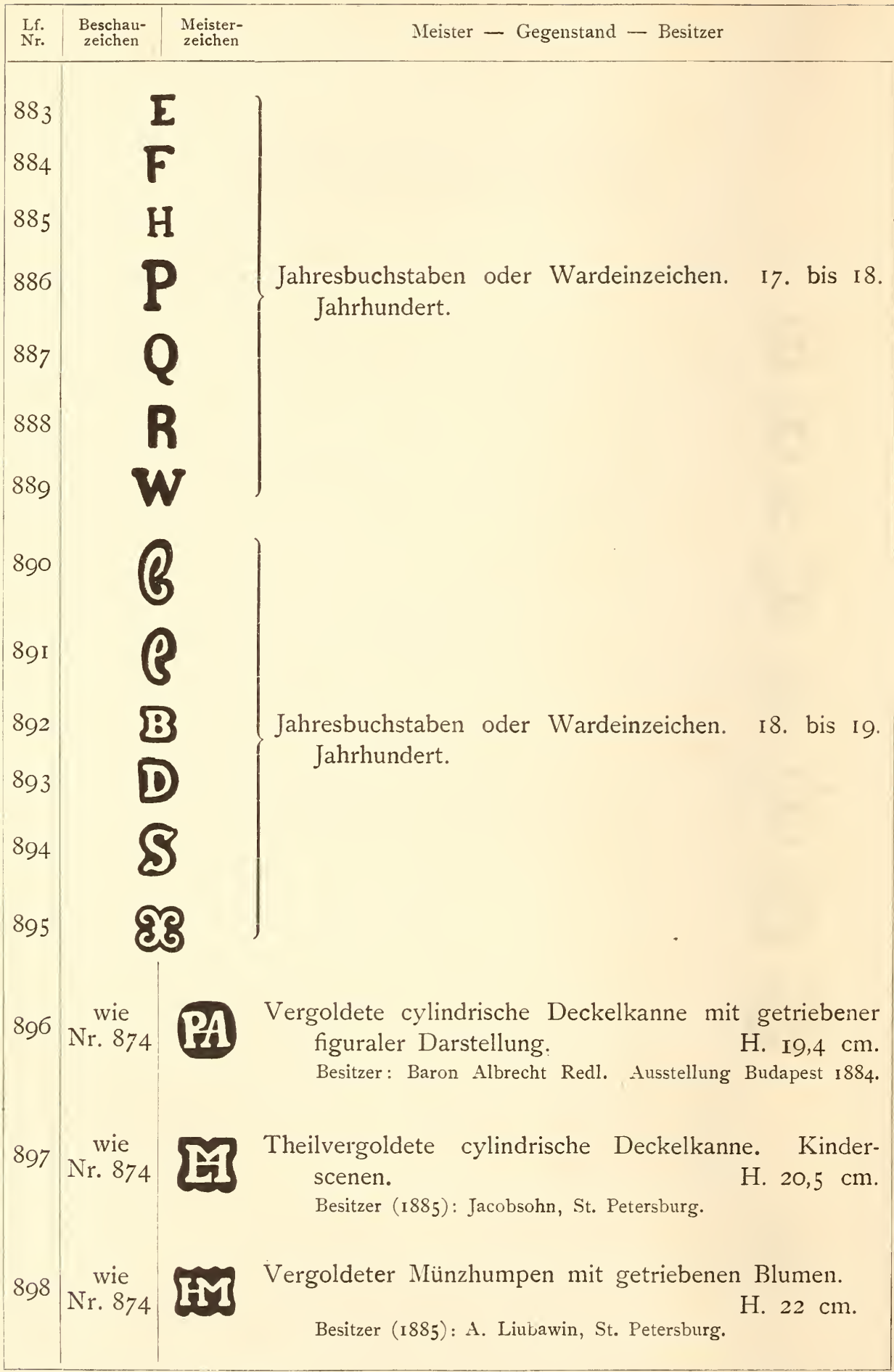




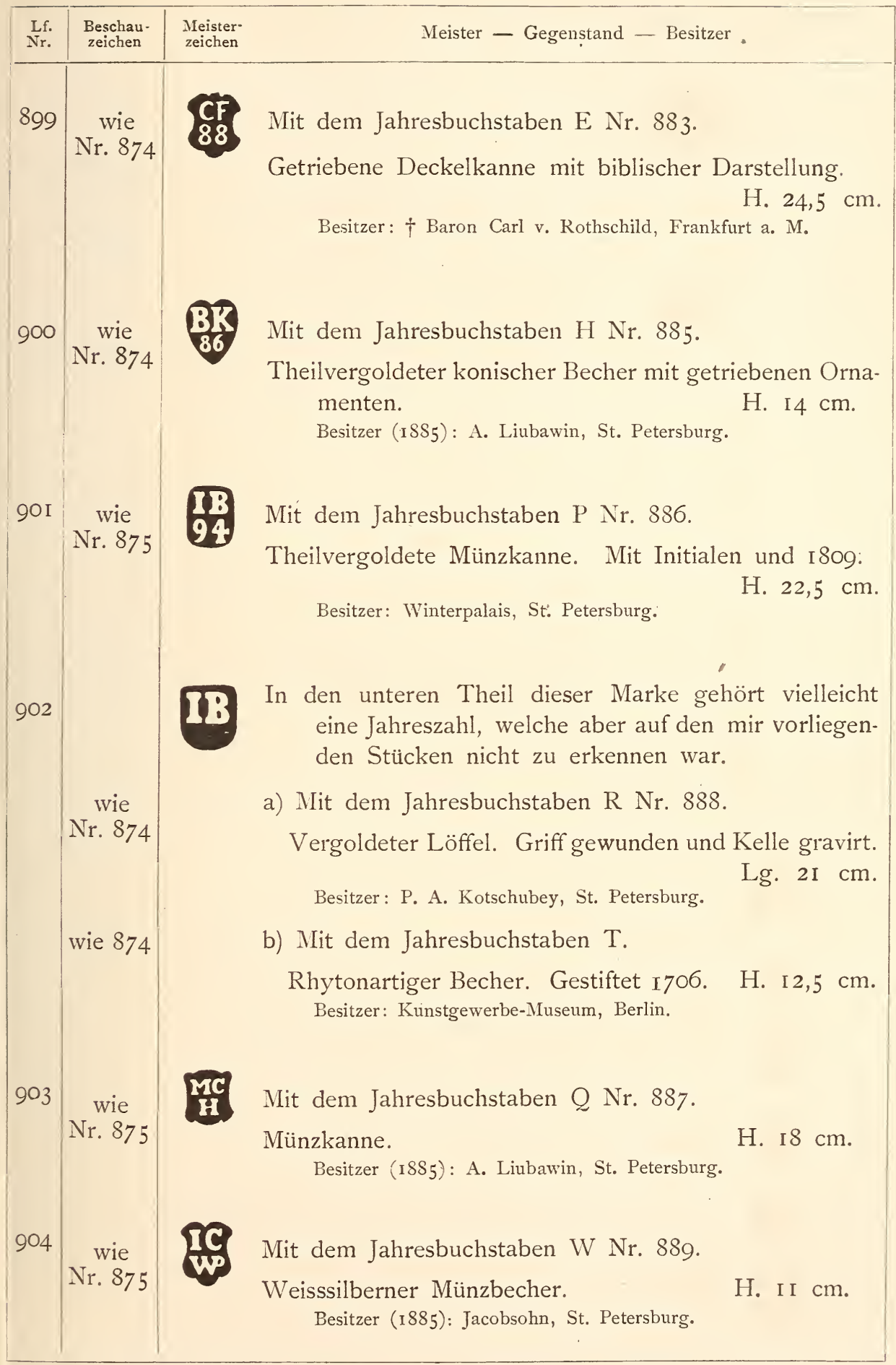




\begin{tabular}{|c|c|c|c|}
\hline $\begin{array}{l}\text { Lf. } \\
\text { Nr. }\end{array}$ & $\begin{array}{l}\text { Beschau. } \\
\text { zeichen }\end{array}$ & $\begin{array}{l}\text { Meister- } \\
\text { zeichen }\end{array}$ & Meister - Gegenstand - Besitzer \\
\hline 905 & $\begin{array}{c}\text { wie } \\
\text { Nr. } 876\end{array}$ & & $\begin{array}{l}\text { Mit dem Jahresbuchstaben B Nr. } 890 . \\
\text { Konischer Becher mit getriebenen Putten und Ranken. } \\
\begin{array}{ll}\text { H. } 7,5 \mathrm{~cm} .\end{array}\end{array}$ \\
\hline 906 & $\begin{array}{c}\text { wie } \\
\text { Nr. } 880\end{array}$ & AI & $\begin{array}{l}\text { Mit dem Jahresbuchstaben S Nr. } 894 . \\
\text { Konischer Münzbecher mit einer Medaille im Boden. } \\
\qquad \text { H. I I,6 cm. }\end{array}$ \\
\hline
\end{tabular}

\section{KONSTANZ.}

\begin{tabular}{|c|c|c|c|}
\hline $\begin{array}{l}\text { Lf. } \\
\text { Nr. }\end{array}$ & $\begin{array}{l}\text { Beschau- } \\
\text { zeichen }\end{array}$ & $\begin{array}{l}\text { Meister- } \\
\text { zeichen }\end{array}$ & Meister - Gegenstand - Besitzer \\
\hline 907 & & & Beschauzeichen. Um I 557. \\
\hline 908 & & & Beschauzeichen. I 6 . Jahrhundert. \\
\hline 910 & & & \\
\hline 9II & & & Beschauzeichen. 16 , bis 17 . Jahrhundert. \\
\hline 912 & & & \\
\hline
\end{tabular}




\begin{tabular}{|c|c|c|c|}
\hline $\begin{array}{l}\text { Lf. } \\
\text { Nr. }\end{array}$ & $\begin{array}{l}\text { Beschau- } \\
\text { zeichen }\end{array}$ & $\begin{array}{l}\text { Meister- } \\
\text { zeichen }\end{array}$ & Meister - Gegenstand - Besitzer \\
\hline 9 I 3 & & & Beschauzeichen. Um $\mathrm{I} 623$. \\
\hline 9 I 4 & 里电 & & Beschauzeichen. I8. Jahrhundert. \\
\hline 915 & 8 & & Beschauzeichen. Um I 846. \\
\hline 916 & $\begin{array}{c}\text { wie } \\
\text { Nr. } 907\end{array}$ & SKizze & $\begin{array}{l}\text { Theilvergoldetes Vortragekreuz. Gravirt und mit Me- } \\
\text { daillons in den Kreuzesarmen versehen. Mit } \\
\text { Wappen, Inschrift und I } 557 . \\
\text { Besitzer: Christliches Museum im Vatican, Rom. }\end{array}$ \\
\hline
\end{tabular}

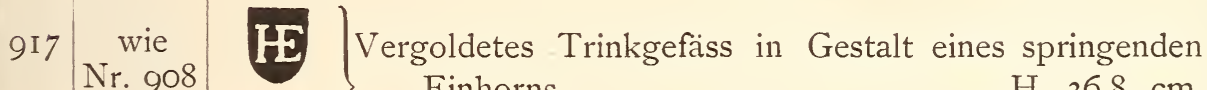 Einhorns. H. $36,8 \mathrm{~cm}$.
Besitzer: $†$ Baron Carl v. Rothschild, Frankfurt a. M.

919 $\begin{gathered}\text { wie } \\ \text { Nr. } 909\end{gathered}$ wie
Nr.9ro

92 I \begin{tabular}{c|c} 
wie & $\mathbf{I T}$ \\
Nr. 9I I & $\mathbf{4}$
\end{tabular}

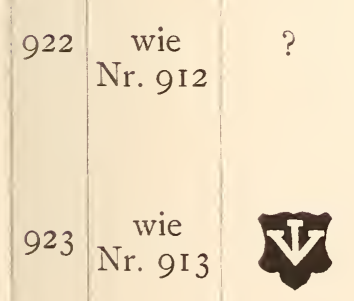

Theilvergoldeter cylindrischer Becher. Der untere Theil mit Buckeln getrieben.

Besitzer: Vereinigte Sammlungen, Karlsruhe.

H. $18,5 \mathrm{~cm}$. 
Deutschland - Konstanz (Arbeiten des 17. bis 19. Jahrh.)

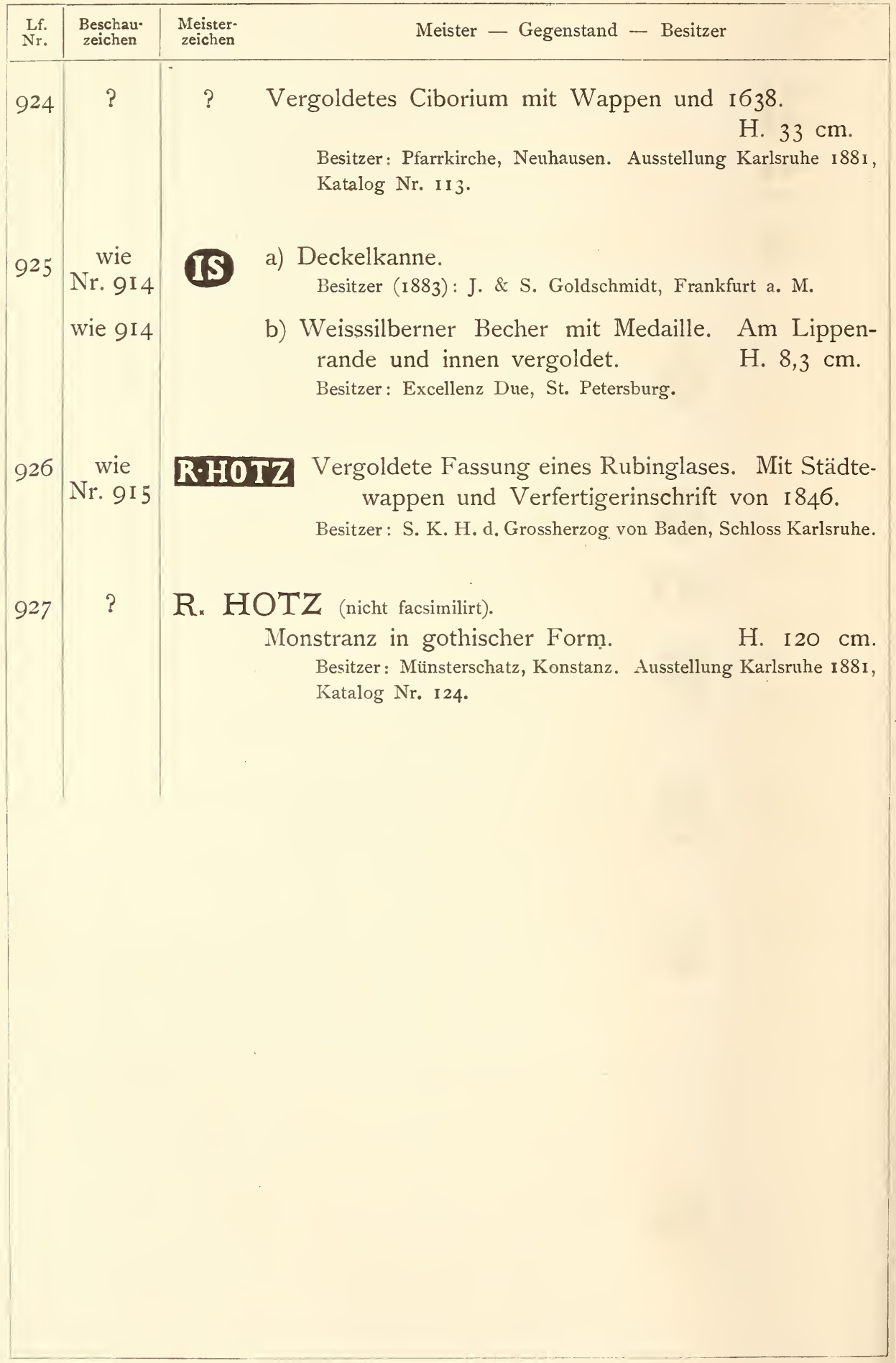




\section{LEIPZIG.}

Wustmann macht im Kunstgewerbeblatt I S. IбI ff. Mittheilungen über die Leipziger Goldschmiedezunft.

I584 wird zuerst urkundlich von dem $\mathrm{L}$ als Stadtzeichen mit einem zweiten Buchstaben für den Beschaumeister gesprochen.

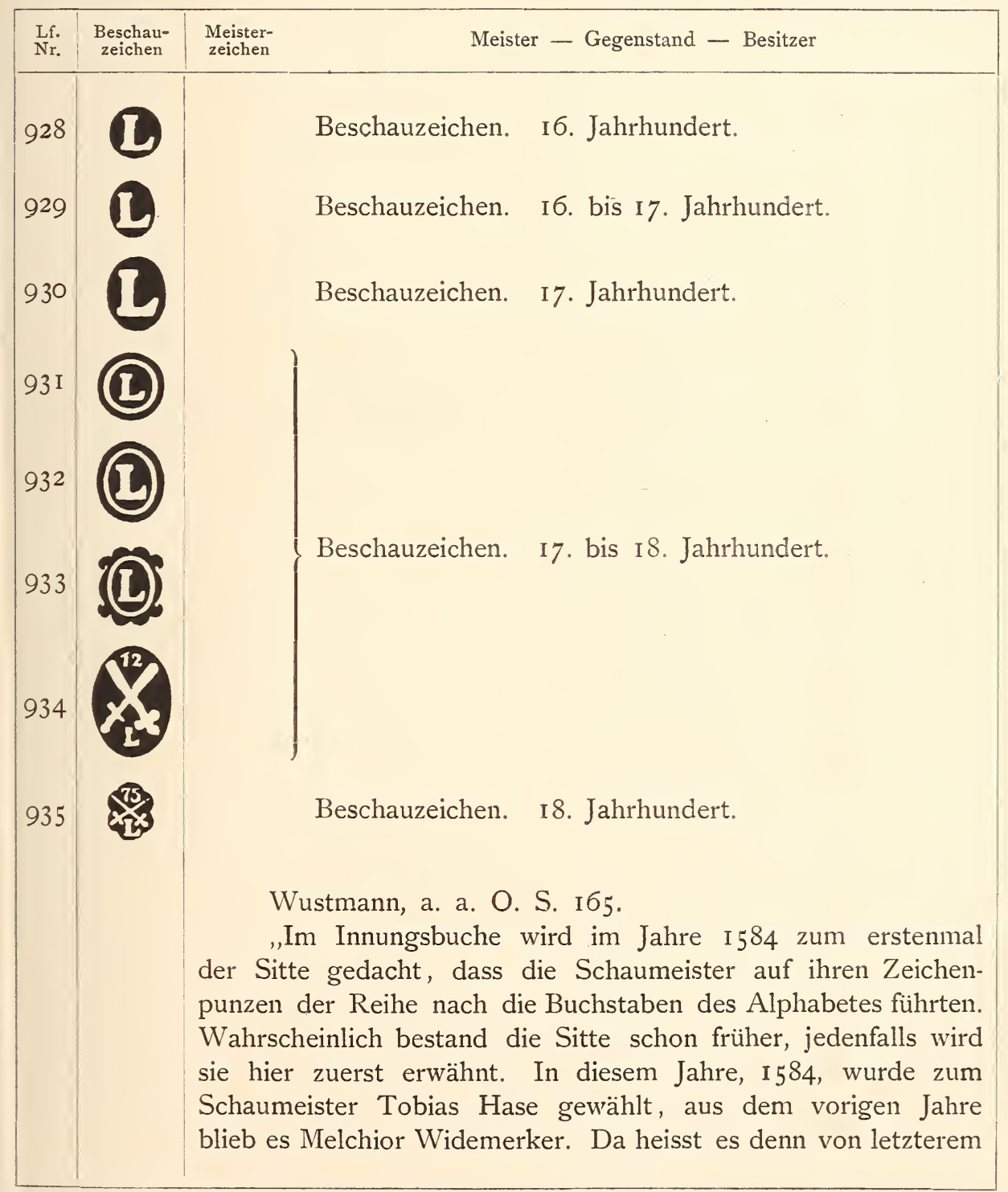




\begin{tabular}{|c|c|c|c|}
\hline $\begin{array}{l}\text { Lf. } \\
\text { Nr. }\end{array}$ & $\begin{array}{l}\text { Beschau- } \\
\text { zeichen }\end{array}$ & Meister - Gegenstand - & Besitzer \\
\hline 935 & & $\begin{array}{l}\text { im Innungsbuche: Und ist ihm zugestal } \\
\text { Stadtzeichen } L \text { der Buchstaben A und } \\
\text { Buchstab B." } \\
\text { Die Datirung der in folgendem zusam } \\
\text { buchstaben versuche ich mit den von } \\
\text { gemachten Angaben, sowie mit einem mir } \\
\text { guitigst mitgetheilten Aktenauszuge über de } \\
\text { der Jahresbuchstaben. }\end{array}$ & $\begin{array}{l}\text { worden neben dem } \\
\text { Tobias Hasen der } \\
\text { mengestellten Jahres- } \\
\text { Wustmann a. a. O. } \\
\text { on genanntem Herrn } \\
\text { n jeweiligen Wechsel }\end{array}$ \\
\hline 936 & & I 588 bis I 590 & \multirow{16}{*}{$\begin{array}{l}\text { Jahresbuchstaben } \\
\text { resp. Zeichen der } \\
\text { Beschaumeister. }\end{array}$} \\
\hline 937 & & I 59 I bis I 593 & \\
\hline 938 & & 1604 bis 1606 & \\
\hline 939 & & i608 bis I610 & \\
\hline 940 & & І6 44 bis ІбІ6 (oder 1635 bis I637) & \\
\hline $94 \mathrm{I}$ & & $\begin{array}{l}\text { I624 bis I626 (oder I646 bis I648) } \\
\text { (oder I695 bis } 1697 \text { ) }\end{array}$ & \\
\hline 942 & & $\begin{array}{l}\text { I625 bis I627 (oder I6 } 47 \text { bis I649) } \\
\text { (oder I669 bis I67I) }\end{array}$ & \\
\hline 943 & & I63I bis $16_{32}$ & \\
\hline 944 & & I632 bis I 634 (oder 1655 bis 1657 ) & \\
\hline 945 & & I $\sigma_{3} 6$ bis $1 \sigma_{3} 8$ (oder $1 \sigma_{59}$ bis 1662 ) & \\
\hline 946 & & 1638 bis 1640 & \\
\hline 947 & & I 640 bis I 642 (oder $166_{3}$ bis I $66_{5}$ ) & \\
\hline 948 & & $\begin{array}{l}\text { I } 642 \text { bis I } 645 \text { (oder } 1665 \text { bis I } 668 \text { ) } \\
\text { (oder I692 bis I694) }\end{array}$ & \\
\hline 949 & & 1648 bis 1650 & \\
\hline 950 & & $16_{5} \mathrm{I}$ bis $16_{53}$ & \\
\hline $95 \mathrm{I}$ & & І66 I bis 1663 & \\
\hline
\end{tabular}




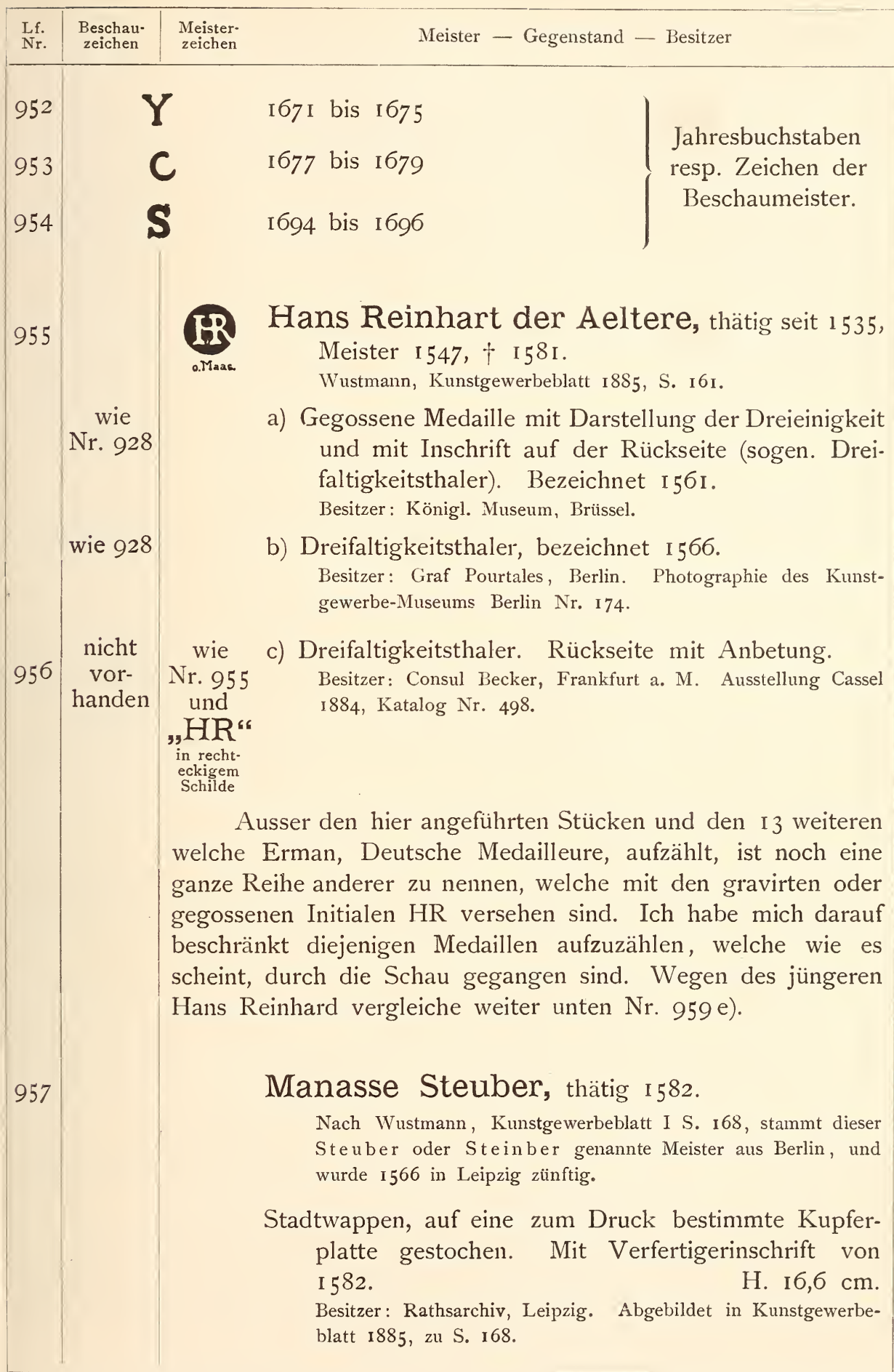




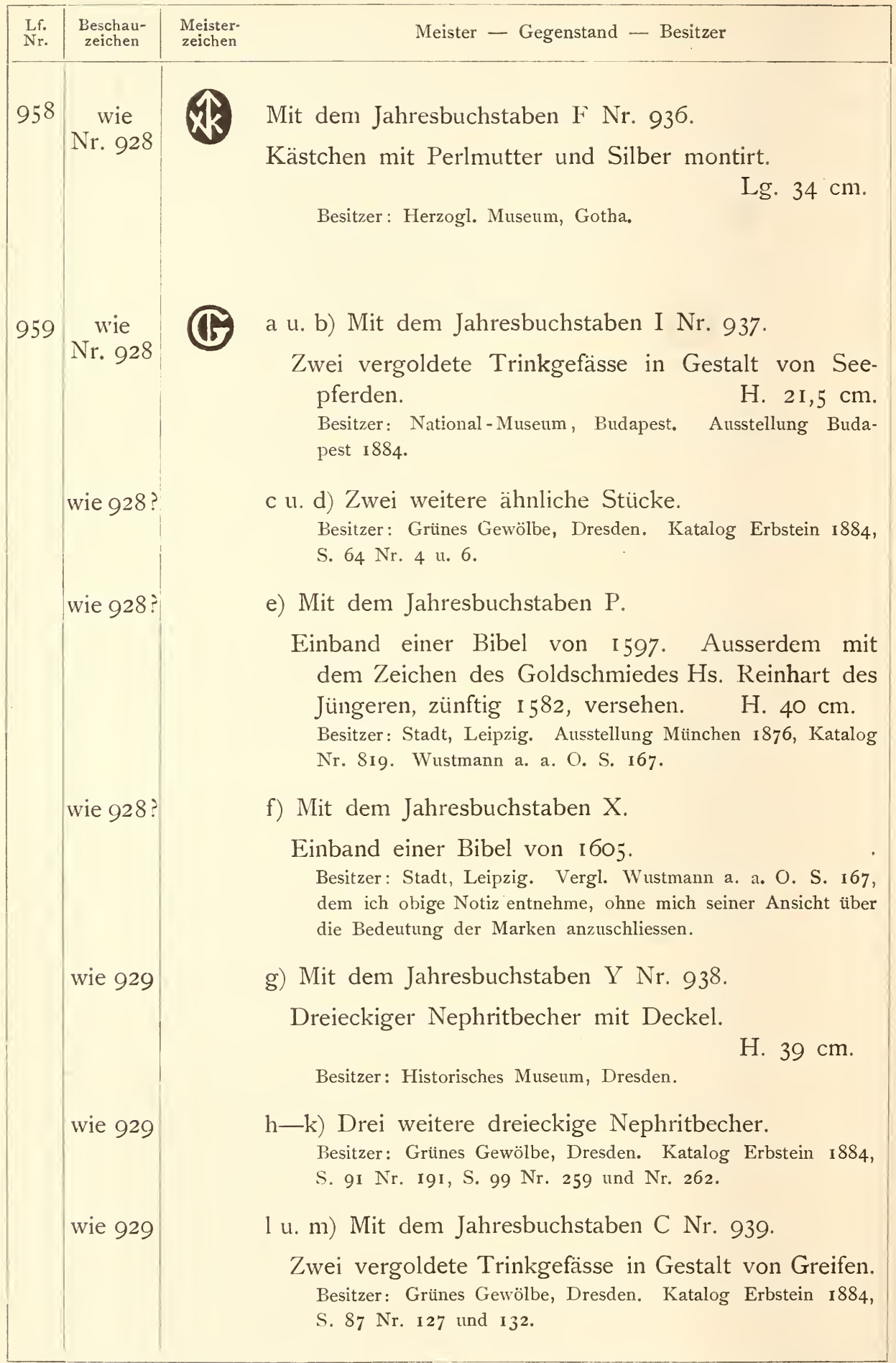




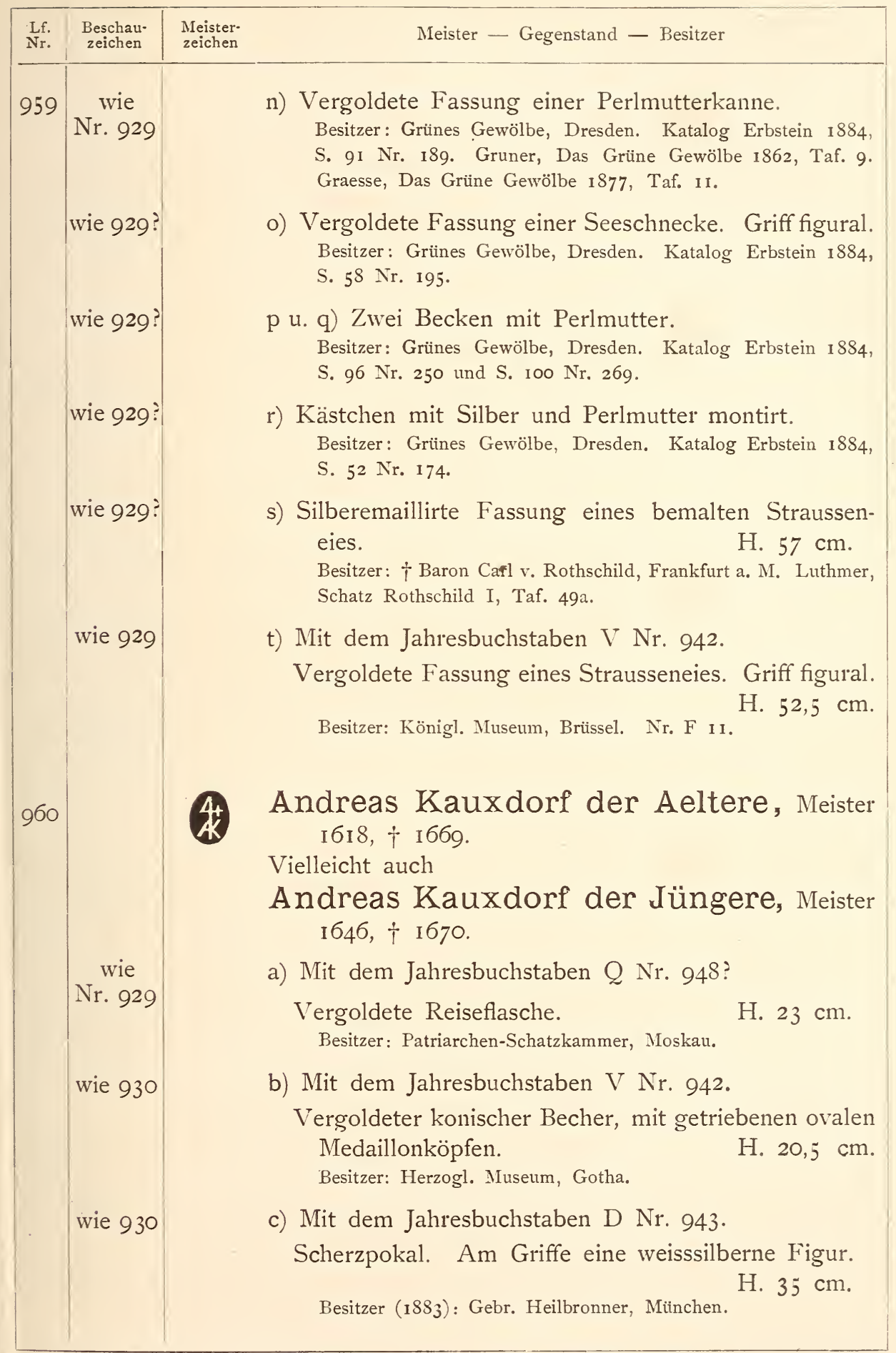




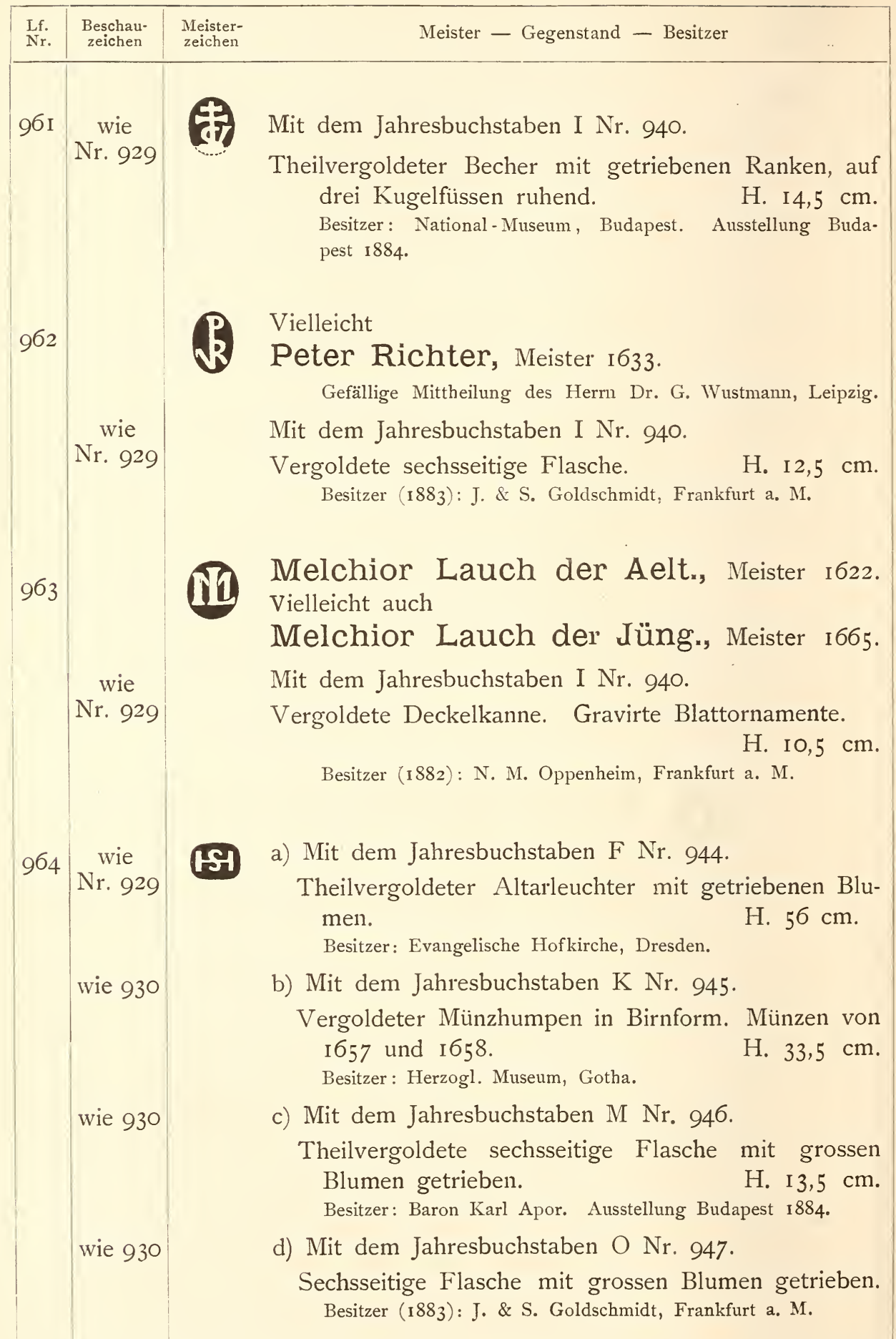




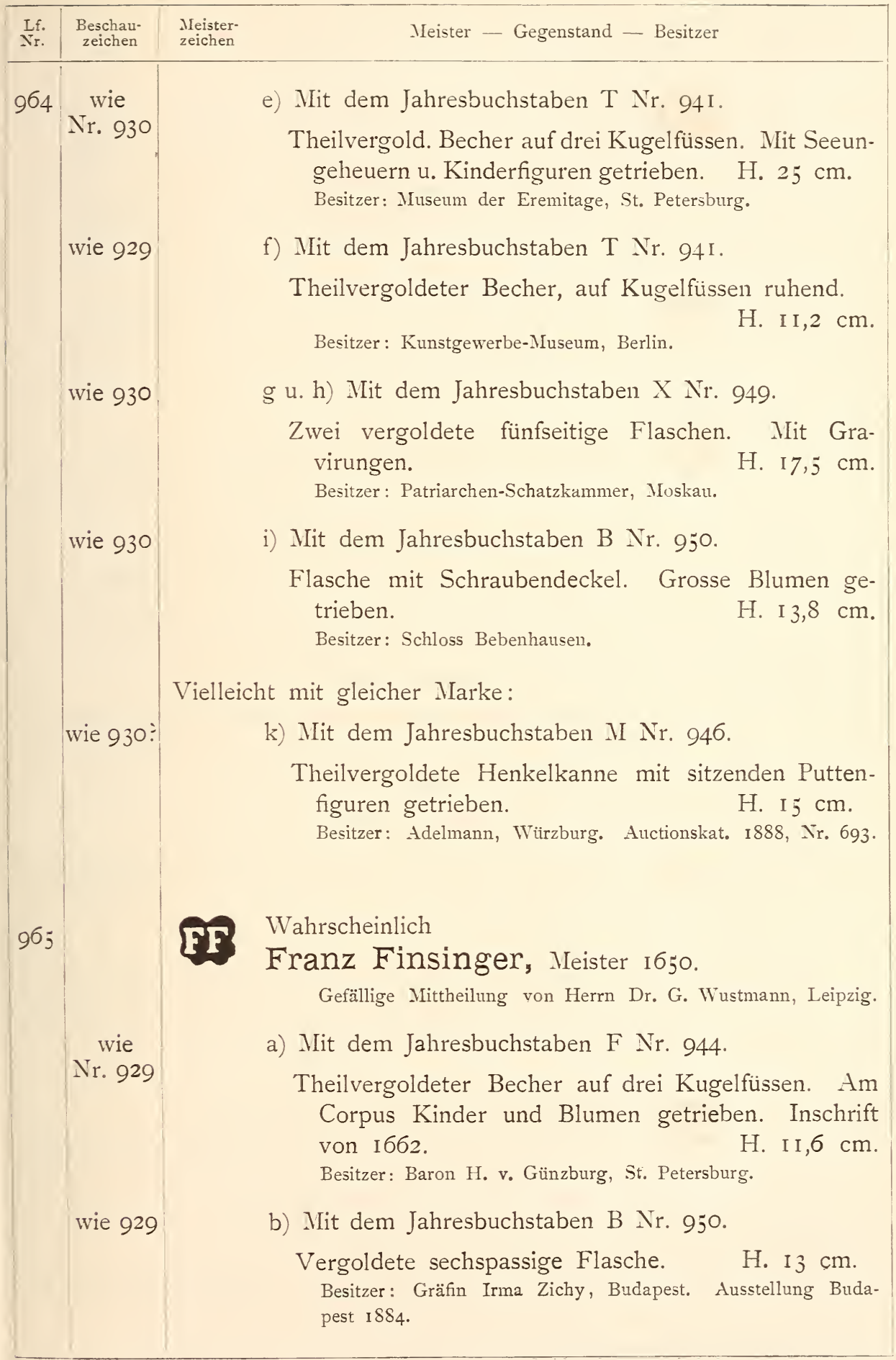




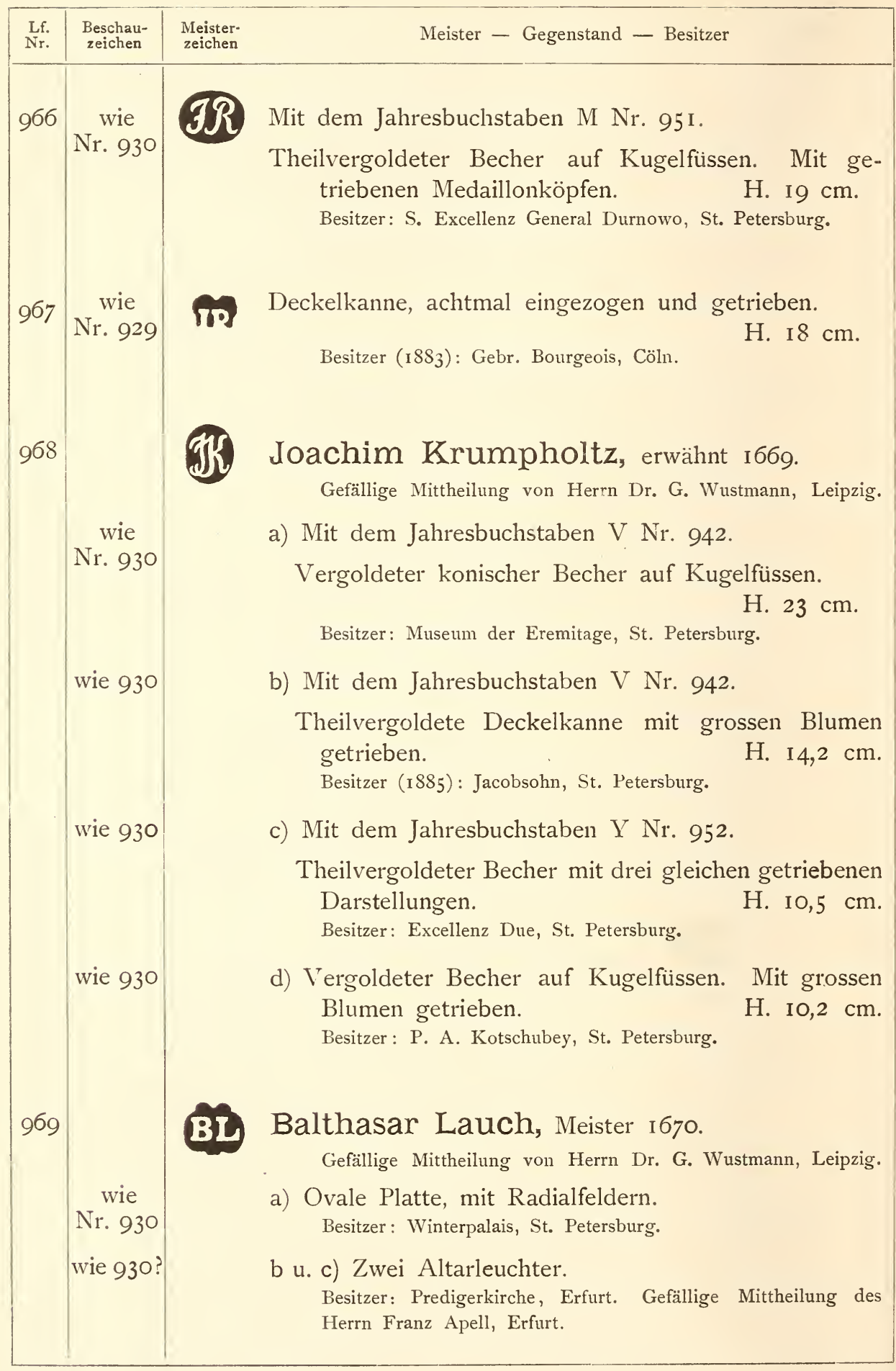




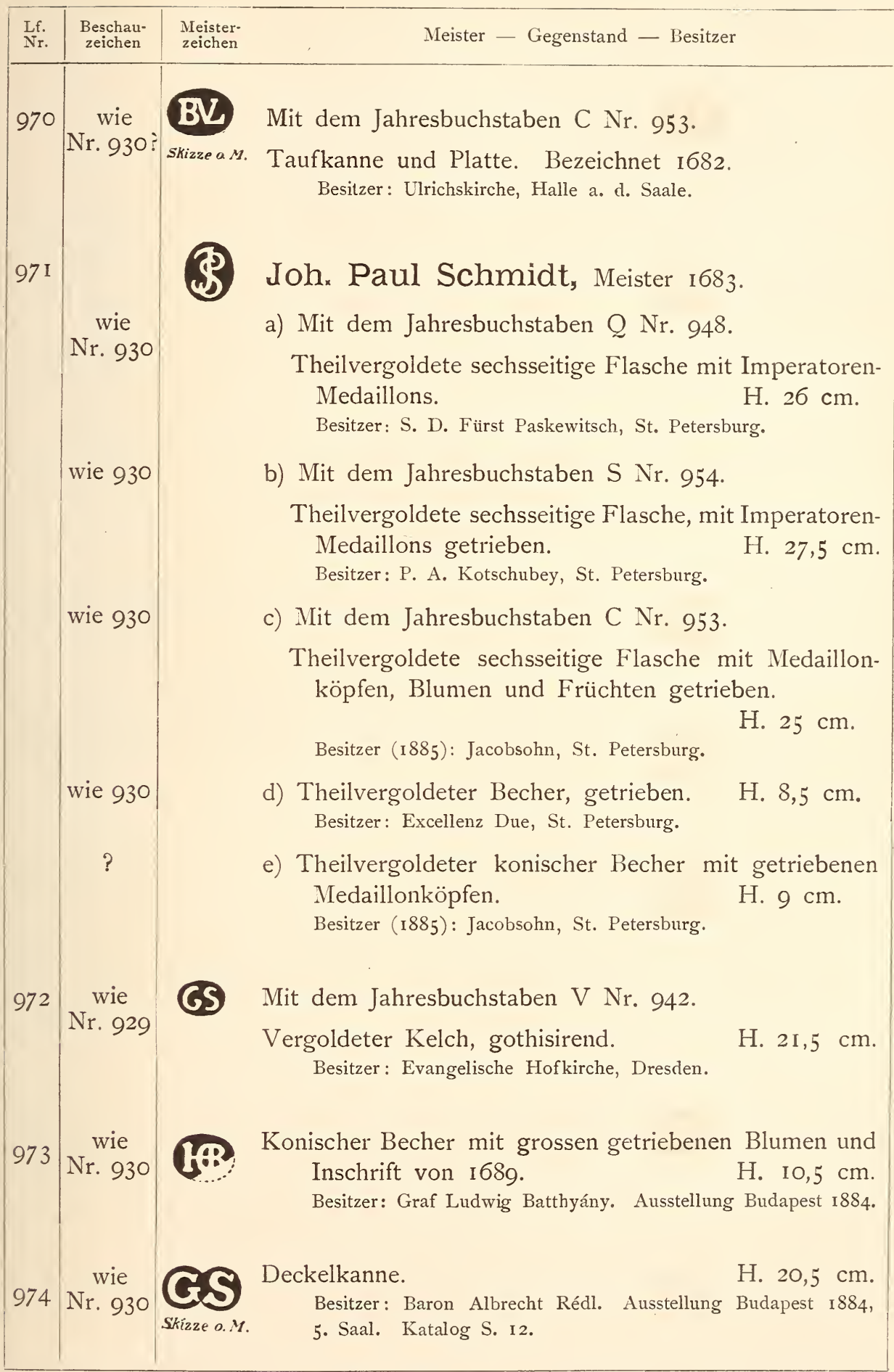




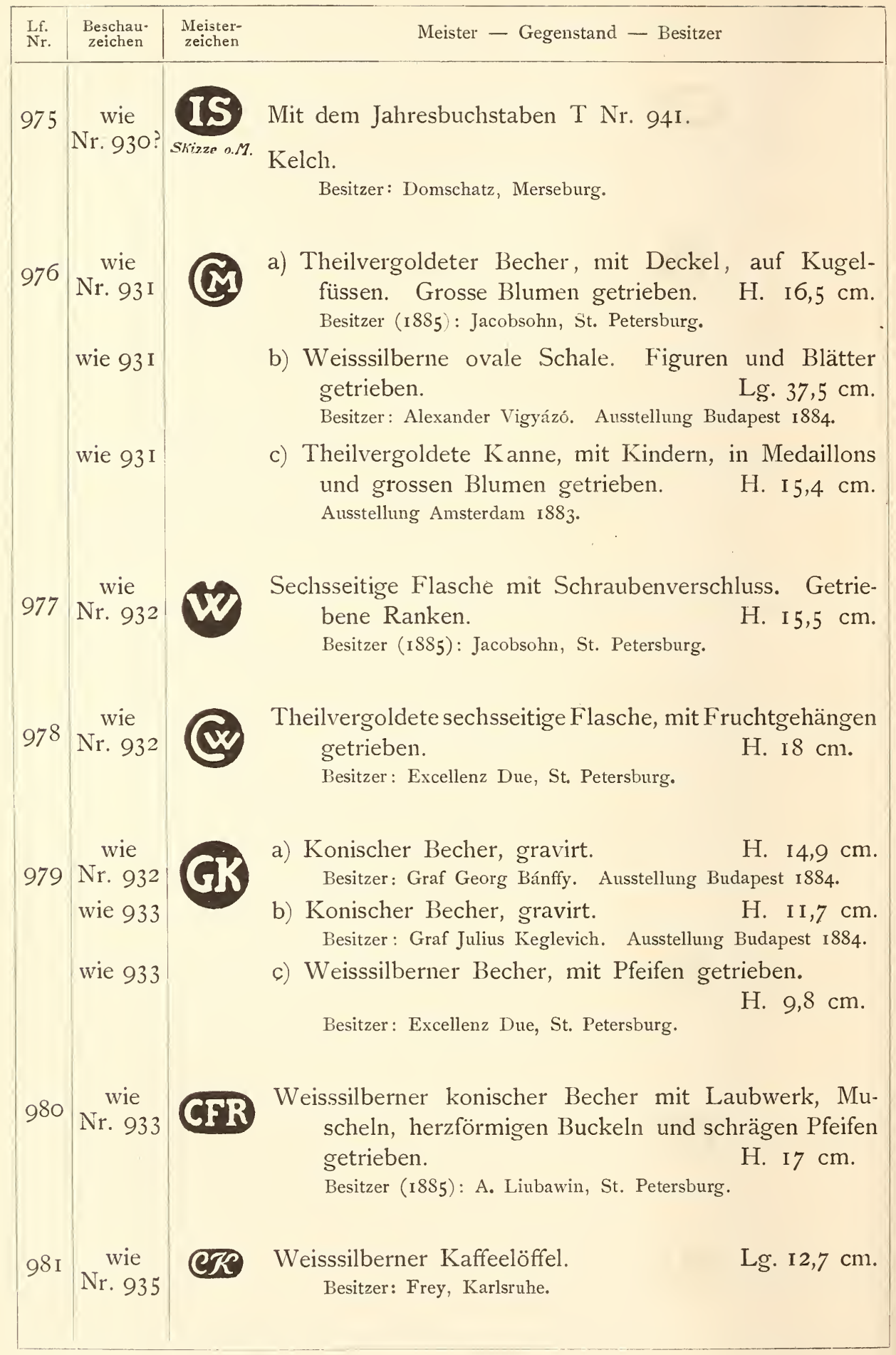




\section{LUDWIGSBURG.}

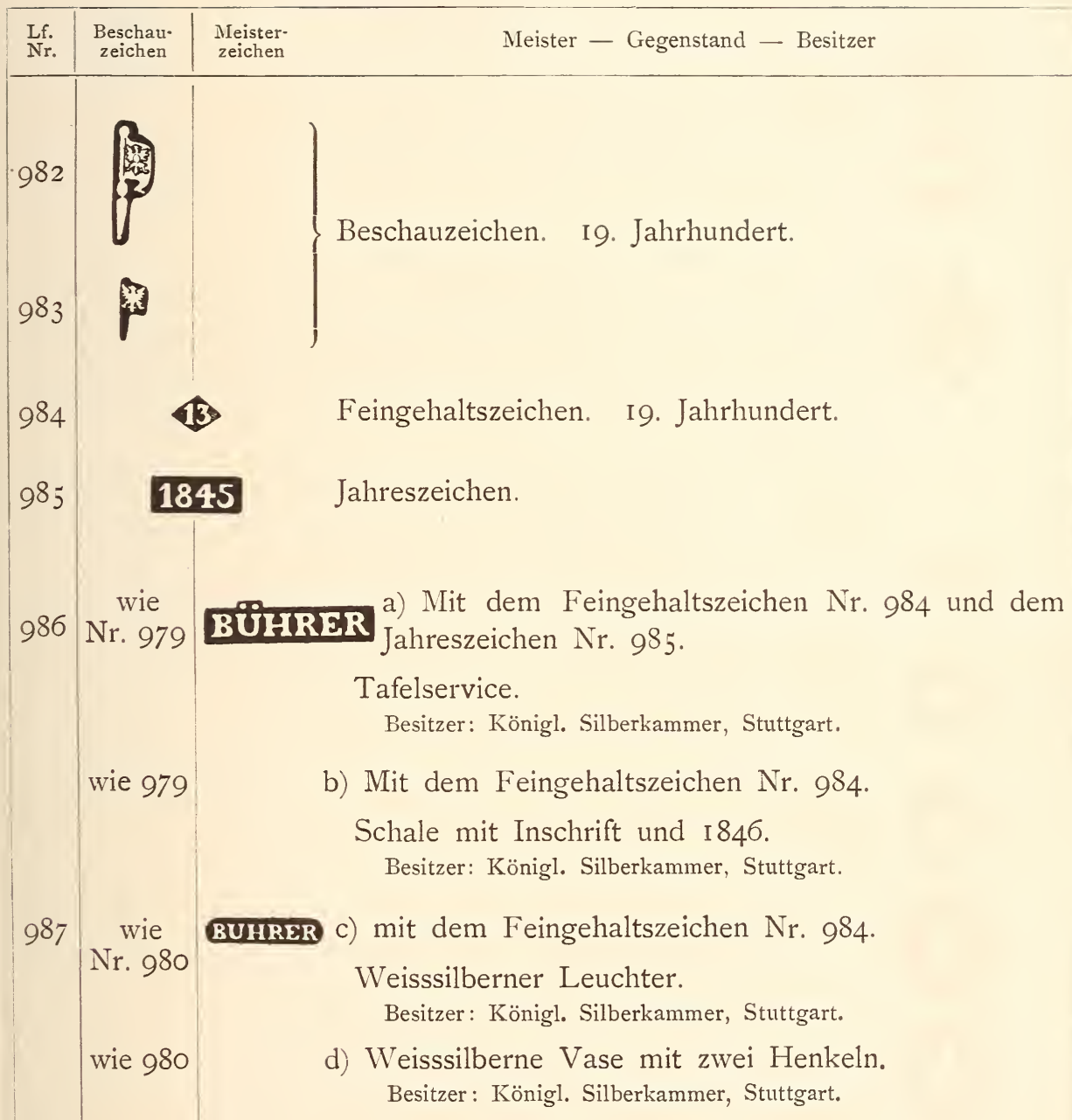




\section{LÜBECK.}

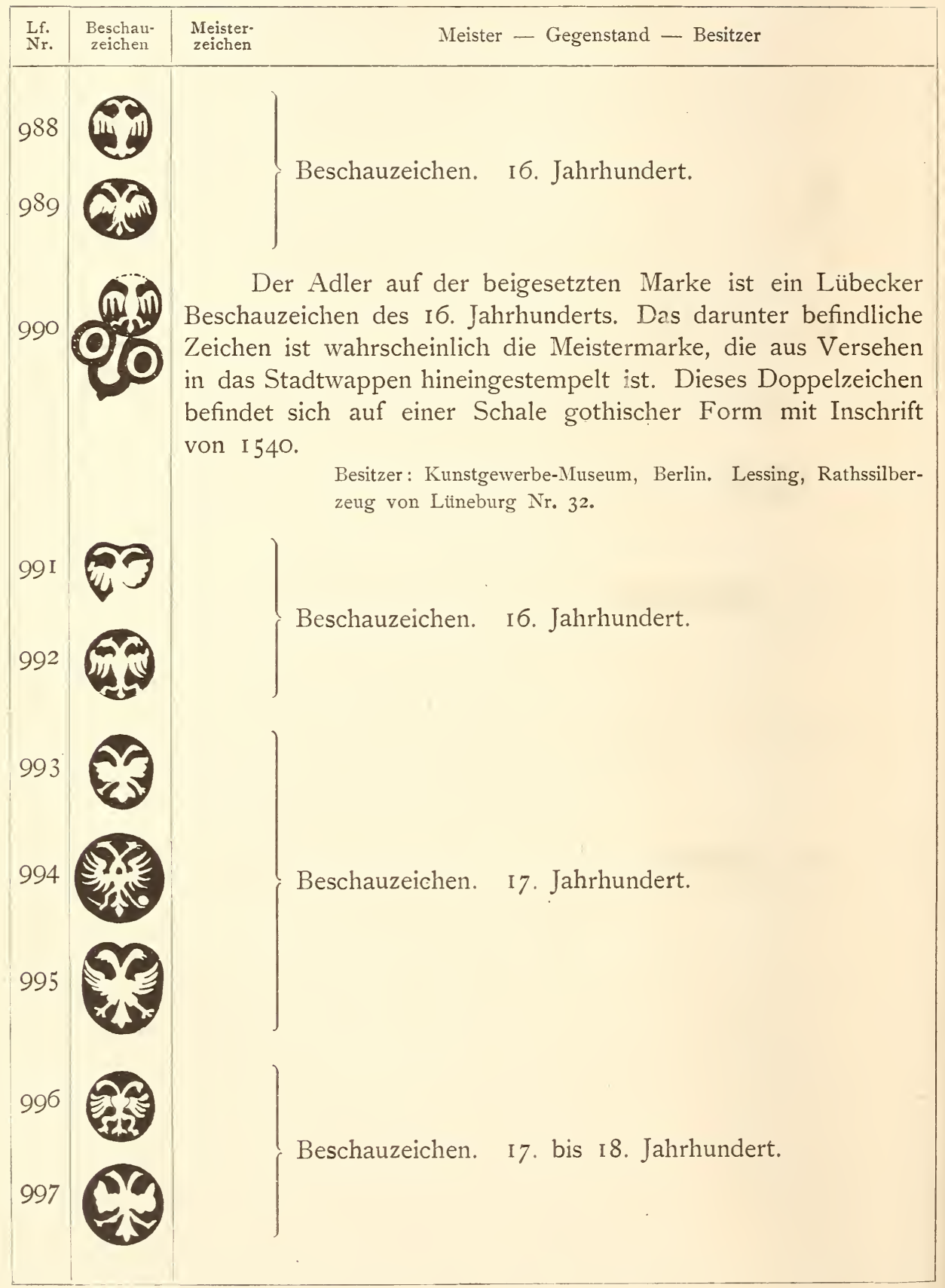




\begin{tabular}{|c|c|c|c|}
\hline $\begin{array}{c}\text { Lf. } \\
\text { Nr. }\end{array}$ & $\begin{array}{c}\text { Beschau } \\
\text { zeichen }\end{array}$ & $\begin{array}{c}\text { Meister- } \\
\text { zeichen }\end{array}$ \\
\hline & Beister - Gegenstand - Besitzer \\
\hline
\end{tabular}

I000 Feingehaltszeichen. I8. Jahrhundert.

wie Pokal in gothischer Form, mit Landsknecht. Inschrift von I $50 \mathrm{I}$.

Besitzer: Kunstgewerbe-Museum, Berlin. Lessing, Rathssilberzeug von Lüneburg Nr. 5.
1002 wie St. Georgsfigur. Bezeichnet I507.
Besitzer: Compagnie der Schwarzen Häupter, Riga. Katalog der Ausstellung Riga I883 Nr. I589, mit Abbildung Taf. 5 . Diesem Kataloge ist auch die Zeichnung der beistehenden Marken entnommen.

wie Schale mit Granatäpfeln.

Besitzer: Kunstgewerbe-Museum, Berlin. Lessing, Rathssilberzeug von Lïneburg Nr. $3 \mathrm{I}$.

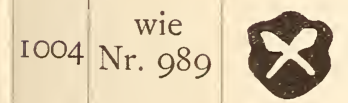

Vergoldeter Pokal mit Deckel. Auf demselben eine Figur in römischer Kriegertracht. H. $46 \mathrm{~cm}$.

Besitzer : † Baron Carl v. Rothschild, Frankfurt a. M.

wie Schlanke Kanne mit Griff. Formen der Frührenaissance. 1005 Nr. 989 Mit späterer Inschrift von 1798 . H. $26,5 \mathrm{~cm}$. Unsicher in Besitzer: $\uparrow$ Baron Carl v. Rothschild, Frankfurt a. M.

wie
1006 Nr. $992 \quad$ Theilvergoldete Abendmahlskanne. Am Fusse Engels-
köpfe. Inschrift von I63I. Besitzer: Lübeckische Gewerbekammer. Ausstellung Nürnberg 1885, Katalog Nr. 666. 
Deutschland — Lübeck - Lüchow

\begin{tabular}{|c|c|c|c|}
\hline $\begin{array}{l}\text { Lf. } \\
\text { Nr. }\end{array}$ & $\begin{array}{l}\text { Beschau- } \\
\text { zeichen }\end{array}$ & $\begin{array}{l}\text { Meister- } \\
\text { zeichen }\end{array}$ & Meister — Gegenstand — Besitzer \\
\hline 1007 & $\begin{array}{c}\text { wie } \\
\text { Nr. 99I }\end{array}$ & & $\begin{array}{l}\text { Vergoldeter Deckelpokal auf drei Thierklauen ruhend. } \\
\text { Mit Namen, Wappen und Inschrift von I65I. } \\
\text { Sogenannter Lübischer Willkomm. } \\
\text { Besitzer: Compagnie der Schwarzen Häupter, Riga. Katalog der } \\
\text { Ausstellung Riga } 188_{3} \text {, Nr. I591. Diesem Kataloge ist auch } \\
\text { die Zeichnung der beistehenden Marken entnommen. }\end{array}$ \\
\hline 1008 & $\begin{array}{c}\text { wie } \\
\text { Nr. } 993\end{array}$ & & $\begin{array}{l}\text { Weisssilberner Scherzbecher mit Ablauf. H. 23,5 cm. } \\
\text { Besitzer: } † \text { Baron Carl v. Rothschild, Frankfurt a. M. }\end{array}$ \\
\hline 1009 & $\begin{array}{l}\text { wie } \\
\text { Nr. } 994\end{array}$ & & $\begin{array}{l}\text { Apostellöffel. } \\
\text { Besitzer: Lübeckische Gewerbekammer. Ausstellung Nürnberg } \\
\text { 1885, Katalog Nr. } 668 \text {. }\end{array}$ \\
\hline IOIO & $\begin{array}{c}\text { wie } \\
\text { Nr. } 996\end{array}$ & & $\begin{array}{l}\text { Mit dem Feingehaltszeichen I2 L Nr. Iooo. } \\
\text { Gravirter Münzbecher. } \\
\text { Besitzer: Baron H. v. Günzburg, St. Petersburg. }\end{array}$ \\
\hline IOI I & $\begin{array}{c}\text { wie } \\
\mathrm{Nr} .995\end{array}$ & & $\begin{array}{l}\text { Weisssilbernes getriebenes Schild. Jüdisches Kultus- } \\
\text { geräth. } \\
\text { Besitzer: Baron H. v. Günzburg, St. Petersburg. }\end{array}$ \\
\hline
\end{tabular}

\section{LÜCHOW.}

\begin{tabular}{|c|c|c|c|}
\hline $\begin{array}{l}\text { Lf. } \\
\text { Nr. }\end{array}$ & $\begin{array}{l}\text { Beschau- } \\
\text { zeichen }\end{array}$ & $\begin{array}{l}\text { Meister- } \\
\text { zeichen }\end{array}$ & Meister - Gegenstand - Besitzer \\
\hline IOI 2 & Löwe & & $\begin{array}{l}\text { Stempelt betrügerischer Weise mit dem Lüneburger } \\
\text { Löwen. Siehe Lüneburg. }\end{array}$ \\
\hline
\end{tabular}




\section{LÜNEBURG.}

\begin{tabular}{|c|c|c|}
\hline $\begin{array}{l}\text { Lf. } \\
\text { Nr. }\end{array}$ & $\begin{array}{l}\text { Beschau- } \\
\text { zeichen }\end{array}$ & Meister - Gegenstand - Besitzer \\
\hline IOI 3 & & $\begin{array}{l}\text { Unbekanntes Zeichen. Wahrscheinlich weder Beschau- } \\
\text { zeichen noch Verfertigermarke, sondern ein Weihe- } \\
\text { kreuz. } \\
\text { Rundes Becken auf den vier Evangelistensym- } \\
\text { bolen ruhend. } \\
\begin{array}{l}\text { Besitzer: Kunstgewerbe-Museum, Berlin. Lessing, Rathssilber- } \\
\text { zeug von Luineburg Nr. } 25 .\end{array}\end{array}$ \\
\hline IOI4 & & $\begin{array}{l}\text { Wie oben. } \\
\text { Rundes Becken auf den Figuren der vier lateini- } \\
\text { schen Kirchenväter ruhend. Gestiftet } 1476 . \\
\text { H. I } 6,5 \mathrm{~cm} . \\
\text { Besitzer: Kunstgewerbe-Museum, Berlin. Lessing, Rathssilber- } \\
\text { zeug von Lüneburg Nr. } 24 .\end{array}$ \\
\hline
\end{tabular}

Bodmann, Lüneburger Zunfturkunden, Hannover I883 S. 95, Ordnung der Goldschmiede um I400, spricht von einer Beschau, ohne eines Beschauzeichens zu gedenken.

Aus dem Beginne des I6. Jahrhunderts sind die Beschauzeichen bekannt. Ein früher Beleg dafür, dass das Zeichen in einem Löwen bestand, liegt in folgender Stelle:

Archiv Lüneburg. Acta generalia. Goldschmiede I.

I 569 beklagten sich die Lüneburger Goldschmiede, dass einige umliegende Ortschaften wie Celle, Uelzen, Lüchow, Dannenberg, Scharmbeck und Winsen an der Lühe betrügerischer Weise mit dem Lüneburger Wappen stempeln. Es wird ihnen empfohlen, ihr eigenes Stadtzeichen ",und nicht den löwen uff yhr arbeit" zu schlagen.

Die grosse Verschiedenheit der in Folgendem zusammengestellten Lüneburger (Löwen-) Beschauzeichen erklärt sich aus der Selbststempelung:

Archiv Lüneburg. Acta generalia. Goldschmiede I.

I582. Der Münzmeister berichtet an den Rath über die Verhältnisse, die in der Lüneburger Schau herrschen. „Es seyndt mir auch etzlichemal silber zugekommen, welchs alhye ynn Luneburgk verarbeit, das ych wol so schlecht ond geringe ann Korn ge- 


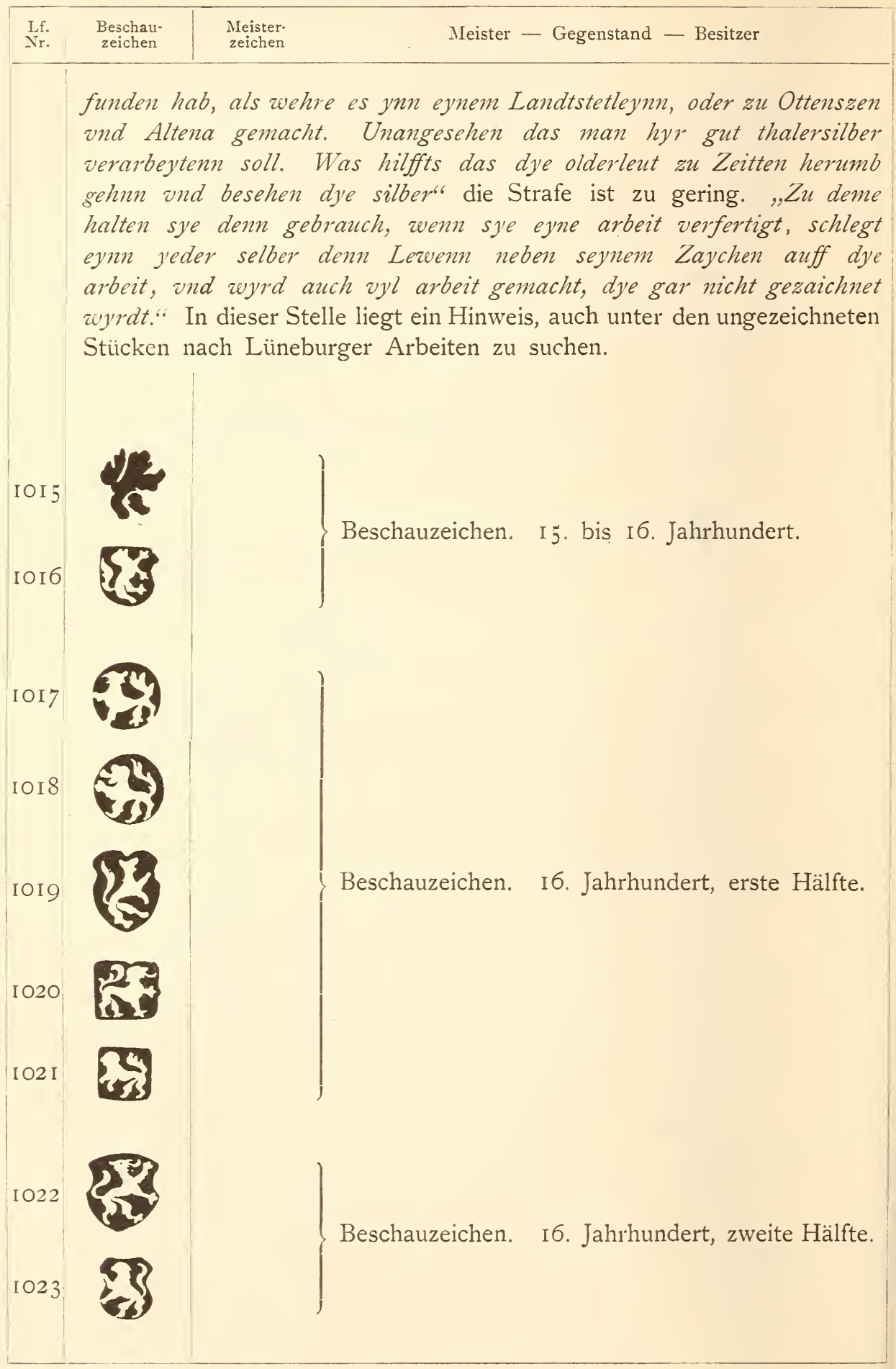




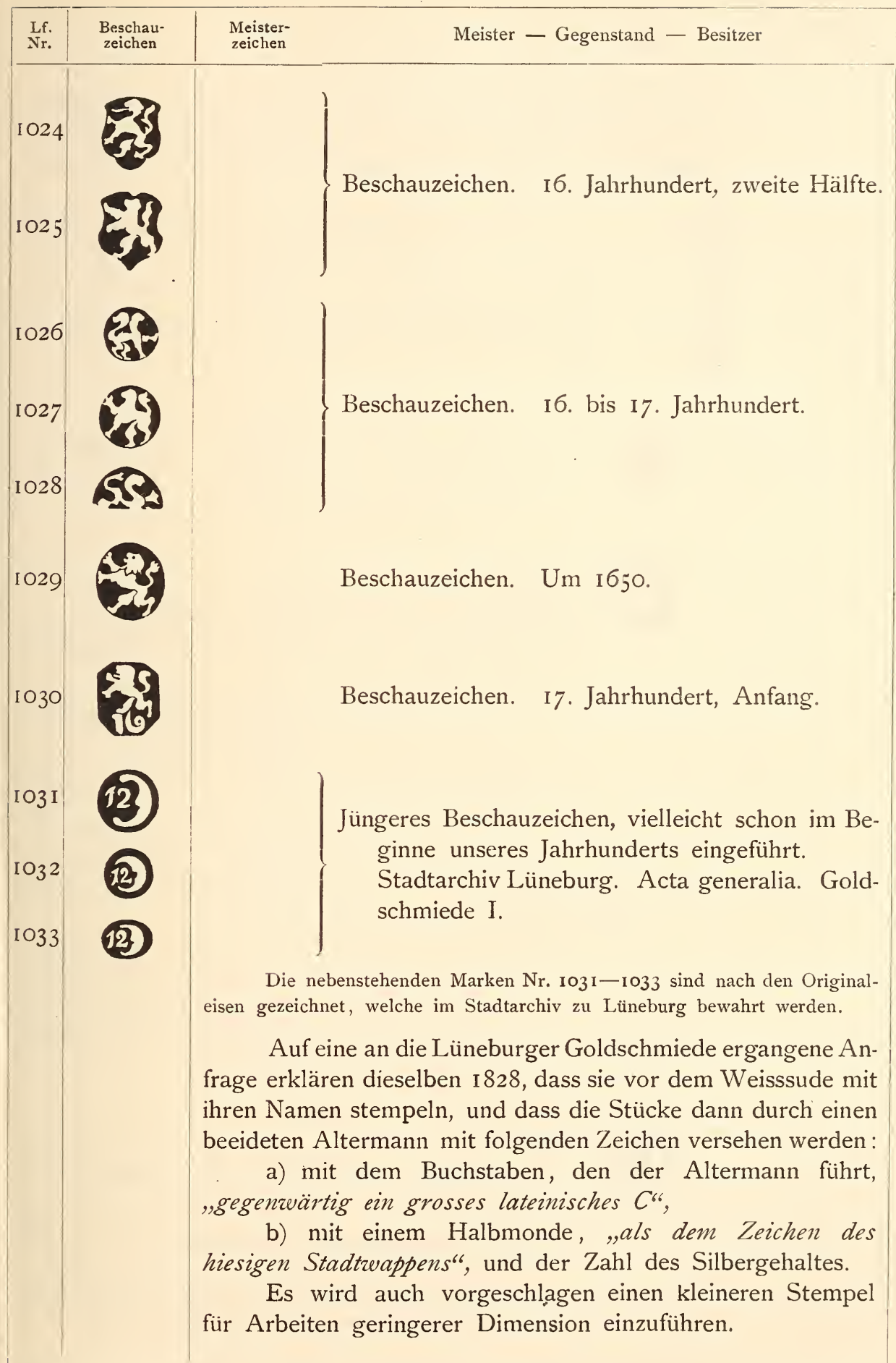




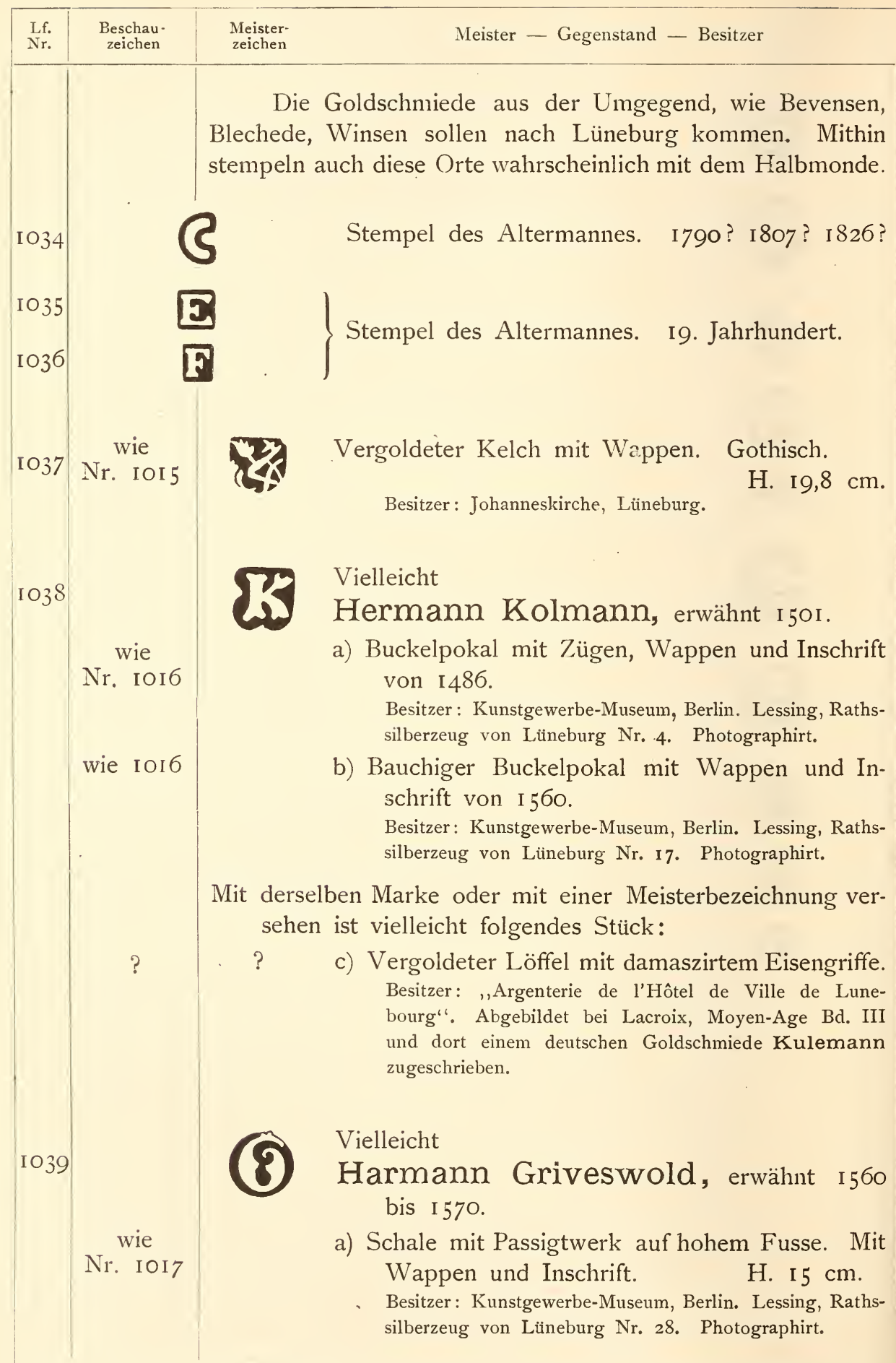




\begin{tabular}{|c|c|c|c|}
\hline $\begin{array}{l}\text { Lf. } \\
\text { Nr. }\end{array}$ & $\begin{array}{l}\text { Beschau- } \\
\text { zeichen }\end{array}$ & a & Meister - Gegenstand - Besitzer \\
\hline 1039 & $\begin{array}{l}\text { wie } \\
\text { Nr. IOI7 }\end{array}$ & & $\begin{array}{l}\text { b) Pokal mit drei Löwen. Mit Wappen. } \\
\text { H. } 43 \mathrm{~cm} \text {. } \\
\text { Besitzer: Kunstgewerbe-Museum, Berlin. Lessing, Raths- } \\
\text { silberzeug von Lüneburg Nr. 8. Photographirt. }\end{array}$ \\
\hline 1040 & $\begin{array}{l}\text { wie } \\
\text { Nr. IOI7 }\end{array}$ & & 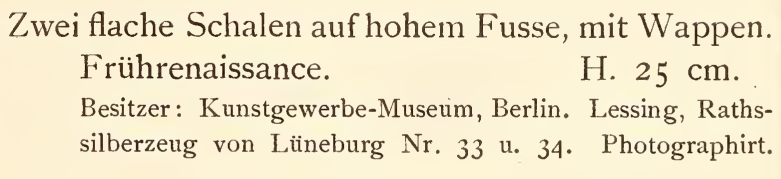 \\
\hline 104 I & $\begin{array}{l}\text { wie } \\
\text { Nr. } \text { IOI } 8\end{array}$ & & $\begin{array}{l}\text { a) Schale auf drei Granatäpfeln ruhend. Früh- } \\
\text { renaissance. } \\
\text { Besitzer: Kunstgewerbe-Museum, Berlin. Lessing, Raths- } \\
\text { silberzeug von Lüneburg Nr. 3o. Photographirt. }\end{array}$ \\
\hline & wie 1018 & & $\begin{array}{l}\text { b) Weisssilbernes Hostienkästchen mit gothischen } \\
\text { Ornamenten und Renaissancemotiven. } \\
\begin{array}{l}\text { Besitzer: Johanneskirche, Lüneburg. } \\
\text { H, } 5 \mathrm{~cm} .\end{array}\end{array}$ \\
\hline 1042 & $\begin{array}{l}\text { wie } \\
\text { Nr. Ior9 }\end{array}$ & & $\begin{array}{l}\text { Zwei vergoldete Abendmahlskelche. Gothisch. } \\
\text { H. } 28,5 \text { bezw. } 30,2 \mathrm{~cm} \text {. } \\
\text { Besitzer: Johanneskirche, Lüneburg. }\end{array}$ \\
\hline I043 & $\begin{array}{l}\text { wie } \\
\mathrm{Nr} \cdot \text { I } 1020\end{array}$ & & $\begin{array}{l}\text { Konischer Becher mit Untersatz und Deckel. In- } \\
\text { schrift von I } 566 . \\
\text { Besitzer: Kunstgewerbe-Museum, Berlin. Lessing, Raths- } \\
\text { silberzeug von Lüneburg Nr. 9. Photographirt. }\end{array}$ \\
\hline IO44 & & & $\begin{array}{l}\text { Die Lüneburger Familie } \\
\text { Martens führt ein ähnliches Wappen. Vergl. } \\
\quad \text { auch die folgende Marke. }\end{array}$ \\
\hline & $\begin{array}{l}\text { wie } \\
\text { Nr. IO2 I }\end{array}$ & & $\begin{array}{l}\text { a) Vergoldeter, bauchiger Buckelpokal mit Wap- } \\
\text { pen, Inschrift und I } 537 . \\
\text { H. } 55 \mathrm{~cm} \text {. }\end{array}$ \\
\hline & wie IO2I & & $\begin{array}{l}\text { b) Theilvergoldetes Giessgefäss in Gestalt eines } \\
\text { Löwen, mit Wappen, Inschrift und I } 540 . \\
\text { H. } 37 \mathrm{~cm} .\end{array}$ \\
\hline & wie IO2I & & $\begin{array}{c}\text { c) Theilvergoldete runde Schüssel mit Reliefs, } \\
\text { Wappen, Inschrift und } 1556 . \mathrm{Dm} \text {. } 6 \mathrm{I} \mathrm{cm} .\end{array}$ \\
\hline
\end{tabular}




\begin{tabular}{|c|c|c|c|}
\hline $\begin{array}{l}\text { Lf. } \\
\text { Nr. }\end{array}$ & $\begin{array}{l}\text { Beschau- } \\
\text { zeichen }\end{array}$ & $\begin{array}{l}\text { Meister- } \\
\text { zeichen }\end{array}$ & Meister - Gegenstand - Besitzer \\
\hline 1044 & $\begin{array}{c}\text { wie } \\
\mathrm{Nr} . \quad \text { IO2 I }\end{array}$ & & $\begin{array}{l}\text { d) Vergoldeter bauchiger (sogen. Interims-) Pokal } \\
\text { mit Wappen, Inschrift und I 574. H. 60 cm. } \\
\text { Besitzer: Kunstgewerbe-Museum, Berlin. Lessing, Raths- } \\
\text { silberzeug von Lüneburg Nr. 18, 21, } 23 \text { und I I. } \\
\text { Photographirt. }\end{array}$ \\
\hline IO45 & $\begin{array}{l}\text { wie } \\
\mathrm{Nr} . \quad \text { IO2 I }\end{array}$ & & $\begin{array}{l}\text { Vergleiche die vorhergehende Marke. } \\
\text { a) Theilvergoldeter bauchiger Buckelpokal mit } \\
\text { Münzen, Inschrift, Wappen und I } 536 . \\
\text { H. } 48 \mathrm{~cm} \text {. } \\
\text { Besitzer: Kunstgewerbe-Museum, Berlin. Lessing, Raths- } \\
\text { silberzeug von Lüneburg Nr. 15. Photographirt. }\end{array}$ \\
\hline 1046 & $\begin{array}{c}\text { wie } \\
\text { Nr. I } 022\end{array}$ & & $\begin{array}{l}\text { Theilvergoldeter bauchiger Pokal als Wurzel } \\
\text { Jesse gebildet. Mit Inschrift, Wappen und } \\
\text { I562. H. } 55 \mathrm{~cm} \text {. } \\
\text { Besitzer: Kunstgewerbe-Museum, Berlin. Lessing, Raths- } \\
\text { silberzeug von Lüneburg Nr. I2. Photographirt. }\end{array}$ \\
\hline 1047 & $\begin{array}{l}\text { wie } \\
\text { Nr. IO23 }\end{array}$ & & $\begin{array}{l}\text { Vergoldeter Pokal mit den sieben Kurfürsten in } \\
\text { Bogenstellungen. Mit Wappen und Inschrift. } \\
\text { H. } 60 \mathrm{~cm} \text {. } \\
\text { Besitzer: Kunstgewerbe-Museum, Berlin. Lessing, Raths- } \\
\text { silberzeug von Liuneburg Nr. 10. Photographirt. }\end{array}$ \\
\hline 1048 & $\begin{array}{c}\text { wie } \\
\text { Nr. } \quad \text { IO24 }\end{array}$ & & $\begin{array}{l}\text { Weisssilbernes Hostienkästchen. Mit Renaissance- } \\
\text { Gravirungen. } \\
\begin{array}{l}\text { Besitzer: Johanneskirche, Lüneburg. } 2,6 \mathrm{~cm} .\end{array}\end{array}$ \\
\hline 1049 & $\begin{array}{c}\text { wie } \\
\text { Nr. I025 }\end{array}$ & & $\begin{array}{l}\text { Vergoldeter Doppelpokal mit Wappen, Inschrift } \\
\text { und I } 585 . \\
\text { Besitzer: Kunstgewerbe-Museum, Berlin. Lessing, Raths- } \\
\text { silberzeug von Lïneburg Nr. 16. Photographirt. }\end{array}$ \\
\hline 1050 & $\begin{array}{c}\text { wie } \\
\text { Nr. I026 }\end{array}$ & & $\begin{array}{l}\text { Vergoldeter Pokal mit Thierlein. H. } 39 \mathrm{~cm} \text {. } \\
\text { Besitzer: Kunstgewerbe-Museum, Berlin. Lessing, Raths- } \\
\text { silberzeng von Lüneburg Nr. 14. Photographirt. }\end{array}$ \\
\hline
\end{tabular}




\section{MAGDEBURG.}

Ohne einen sicheren Nachweis führen zu können, vermuthe ich in folgenden Stempeln die älteren Beschauzeichen von Magdeburg.

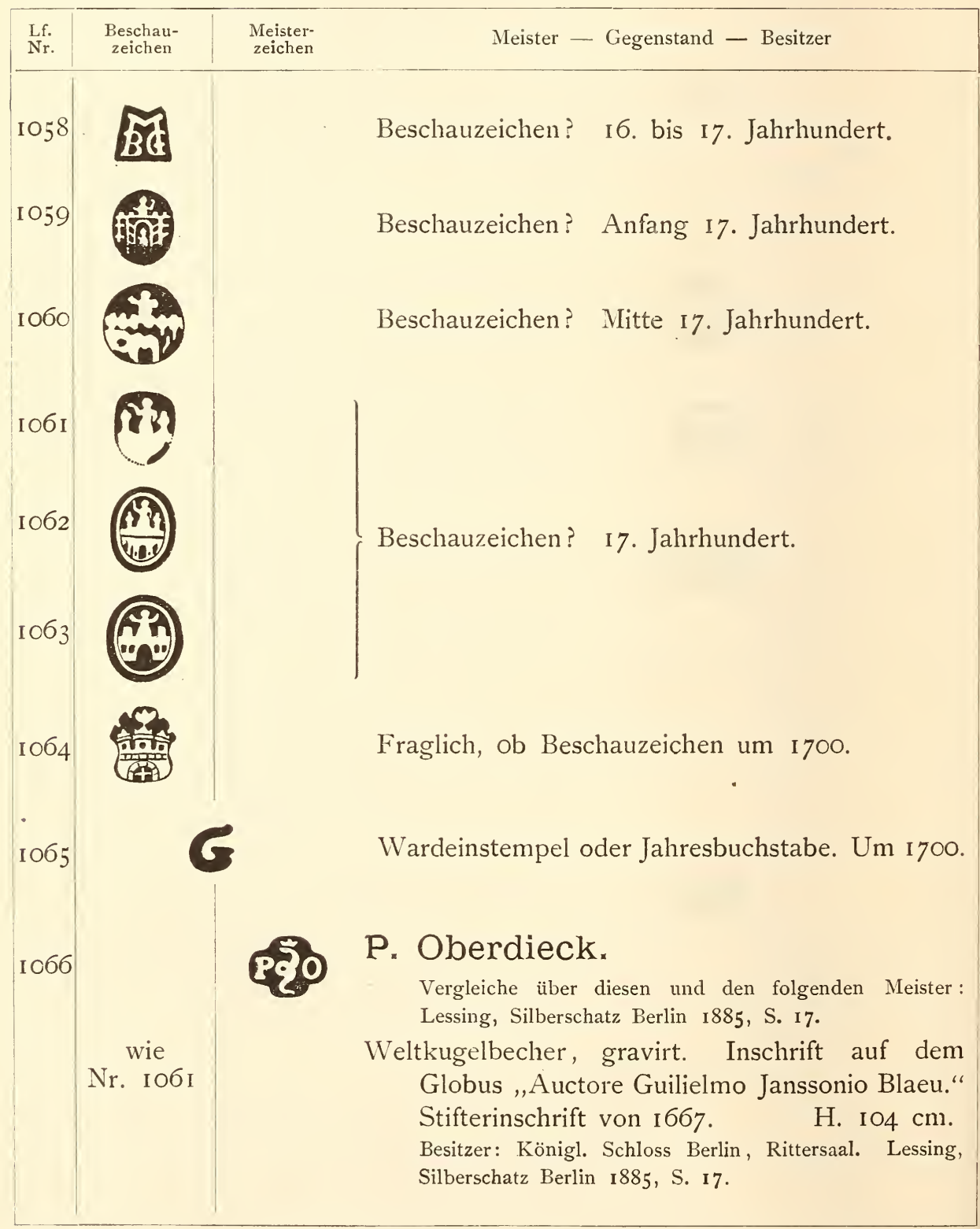




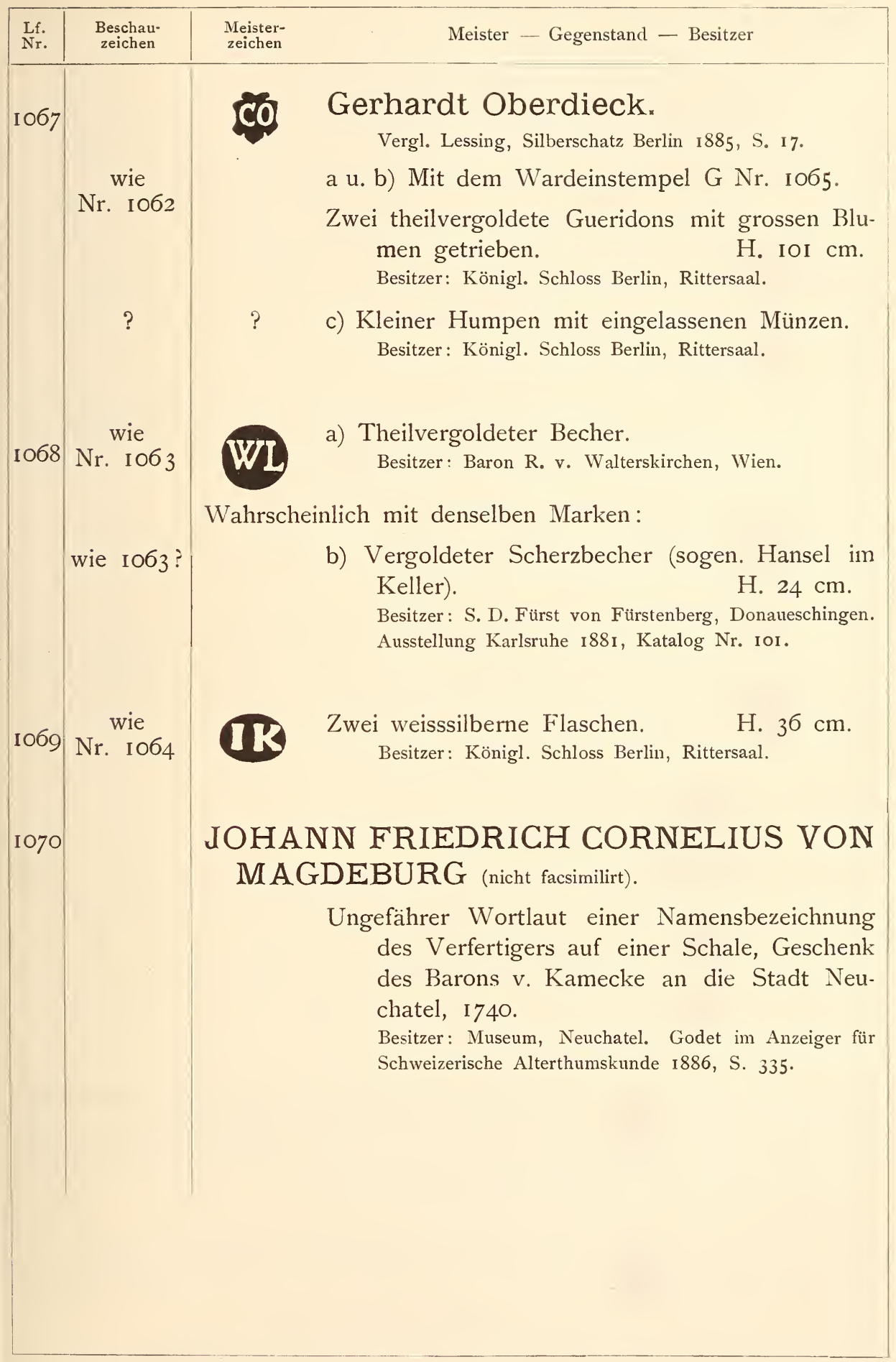




\section{MAINZ.}

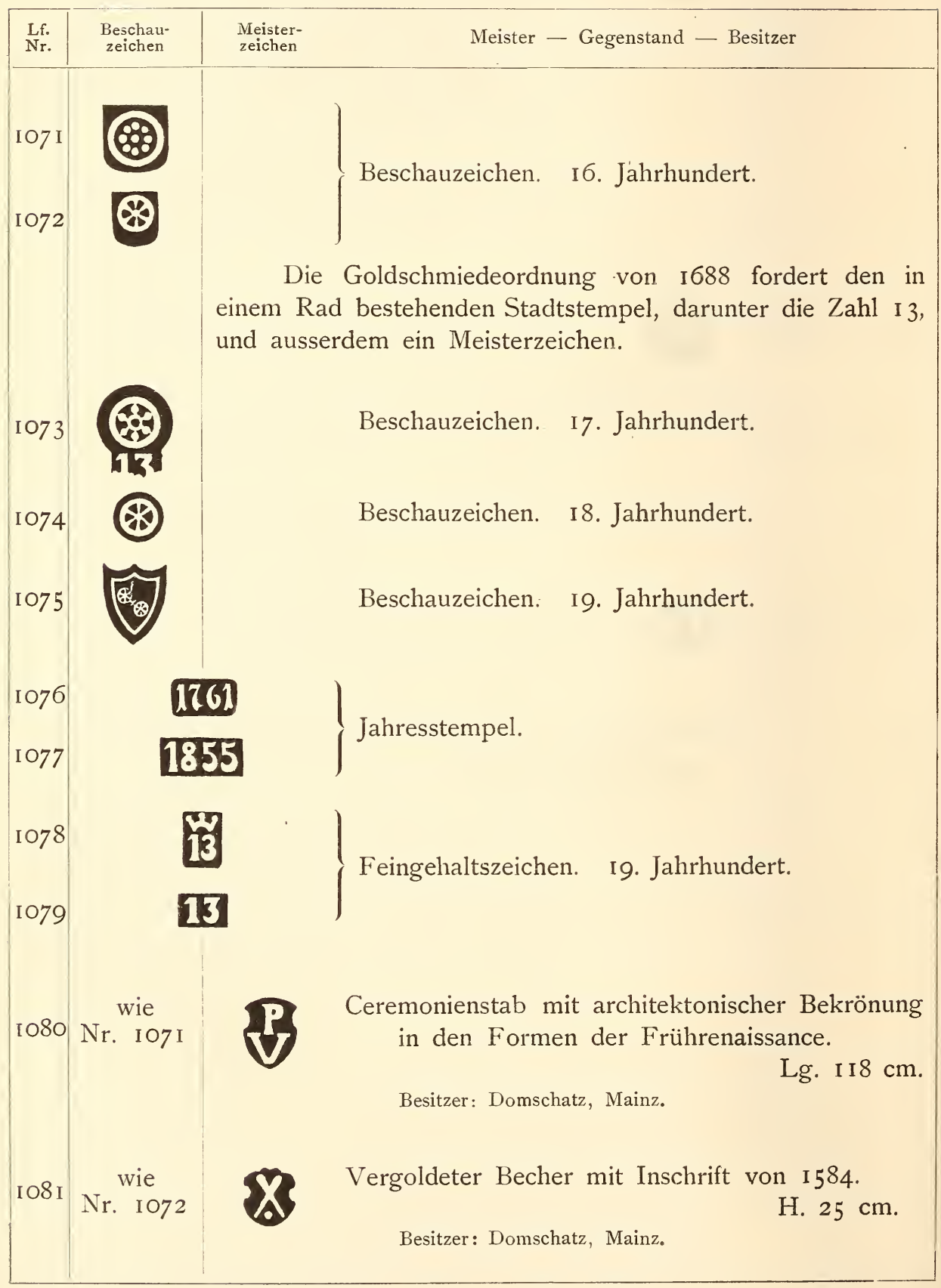




\begin{tabular}{|c|c|c|c|}
\hline $\begin{array}{l}\text { Lf. } \\
\text { Nr. }\end{array}$ & $\begin{array}{l}\text { Beschau- } \\
\text { zeichen }\end{array}$ & $\begin{array}{l}\text { Meister- } \\
\text { zeichen }\end{array}$ & Meister - Gegenstand - Besitzer \\
\hline 1082 & $\begin{array}{c}\text { wie } \\
\mathrm{Nr} . \quad \text { I072 }\end{array}$ & & $\begin{array}{l}\text { Vergoldeter Kelch. Gothische Form mit Re- } \\
\text { naissancemotiven. } \\
\begin{array}{l}\text { Besitzer: Domschatz, Mainz. } \\
\text { H. } 23 \mathrm{~cm} \text {. }\end{array}\end{array}$ \\
\hline 1083 & $\begin{array}{l}\text { wie } \\
\text { Nr. } \quad \text { I073 }\end{array}$ & & $\begin{array}{l}\text { Quirinus Rotenberg, I690 bis I } 7 \text { I7. } \\
\text { Vergoldeter nach oben erweiterter Becher. Sogen. } \\
\text { Bernhardsbecher. Mit Initialen und I } 697 . \\
\text { H. } 8,5 \mathrm{~cm} . \\
\text { Besitzer: Geistl. Rath Dr. Fr. Schneider, Mainz. }\end{array}$ \\
\hline 1084 & $\begin{array}{l}\text { wie } \\
\text { Nr. } \quad \text { I073 }\end{array}$ & & $\begin{array}{l}\text { Vielleicht } \\
\text { Johann Ledent, I70I, † I735. } \\
\text { Vergoldete Monstranz mit Inschrift und I 7OI. } \\
\quad \text { Besitzer: Kirche, Bodenheim. Gefällige Mittheilung } \\
\quad \text { des Herrn Geistl. Rath Dr. Fr. Schneider, Mainz. }\end{array}$ \\
\hline 1085 & $\begin{array}{l}\text { wie } \\
\text { Nr. }{ }^{\text {I }} 74\end{array}$ & & $\begin{array}{l}\text { Mit dem Jahresstempel I76I Nr. Iо76. } \\
\text { Wappenschildchen mit Inschrift von I 76г. An- } \\
\text { hängend an dem Holzfutteral eines ver- } \\
\text { lorenen Bechers. } \\
\text { Besitzer: Domschatz, Mainz. }\end{array}$ \\
\hline 1086 & $\begin{array}{c}\text { wie } \\
\text { Nr. }{ }^{2075}\end{array}$ & ITZ & $\begin{array}{l}\text { EDN a) Mit dem Feingehaltszeichen I } 3 \text { Nr. I078. } \\
\text { Theilvergoldeter Becher mit Inschrift von I } 838 . \\
\text { Besitzer: Domschatz, Mainz. } \\
\begin{array}{ll}\text { b) Weihwasserkessel von I } 847.4 \mathrm{~cm} . \\
\text { Besitzer: Domschatz, Mainz. }\end{array}\end{array}$ \\
\hline 1087 & $\begin{array}{c}\text { wie } \\
\mathrm{Nr} . \text { I075 }\end{array}$ & FORSC & $\begin{array}{l}\text { NIGER Mit dem Jahresstempel I } 855 \mathrm{Nr} \text {. I077 und } \\
\text { dem Feingehaltsszeichen I3 Nr. IO79. } \\
\begin{array}{ll}\text { Vergoldeter Kelch von I } 855 . & \text { H. } 20,5 \mathrm{~cm} . \\
\text { Besitzer: Domschatz, Mainz. } & \end{array}\end{array}$ \\
\hline
\end{tabular}




\section{MANNHEIM.}

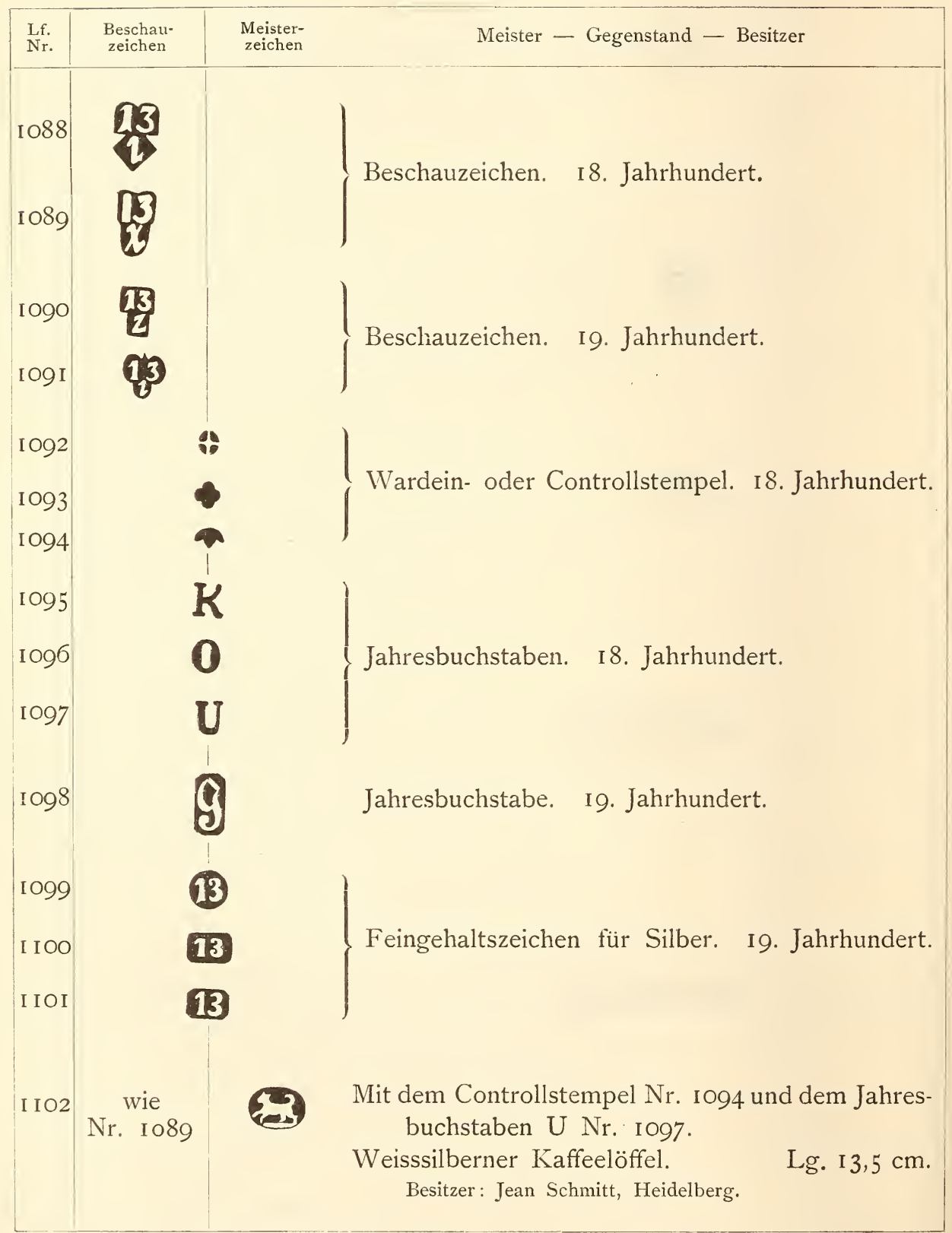




\begin{tabular}{|c|c|c|}
\hline $\begin{array}{l}\text { Lf. } \\
\text { Nr. }\end{array}$ & $\begin{array}{l}\text { Beschau- } \\
\text { zeichen }\end{array}$ & Meister — Gegenstand - Besitzer \\
\hline I IO3 & $\begin{array}{c}\text { wie } \\
\text { Nr. Iogo }\end{array}$ & $\begin{array}{l}\text { Gebhard Mit dem Jahresbuchstaben G Nr. Iog8. } \\
\text { Weisssilb. Essbesteck mit Initialen und I } 823 . \\
\text { Besitzer: F. Heckel, Neustadt a. d. Haardt. }\end{array}$ \\
\hline I 104 & fehlt & $\begin{array}{l}\text { Gebhard a) Weisssilberne Zuckerzange mit gravirten } \\
\text { Initialen. } \\
\text { Besitzer: S. K. H. d. Grossherzog von Baden, Schloss } \\
\text { Karlsruhe. } \\
\text { b u. c) Weisssilberne Platte und Löffel. } \\
\text { Besitzer: Königl. Silberkammer, München. }\end{array}$ \\
\hline
\end{tabular}

\section{MEMMINGEN.}

\begin{tabular}{|c|c|c|c|}
\hline $\begin{array}{l}\text { Lff. } \\
\text { Nr. }\end{array}$ & $\begin{array}{l}\text { Beschau- } \\
\text { zeichen }\end{array}$ & $\begin{array}{l}\text { Meister- } \\
\text { zeichen }\end{array}$ & Meister - Gegenstand - Besitzer \\
\hline $\mathrm{IIO}_{5}$ & 政 & & Beschauzeichen. Früh I6. Jahrhundert. \\
\hline I I06 & 2 & & $\begin{array}{l}\text { Beschauzeichen. Spät I6. Jahrhundert (wenn } \\
\text { nicht älter). }\end{array}$ \\
\hline I 107 & th & & Beschauzeichen. I7. Jahrhundert. \\
\hline I 108 & $\begin{array}{l}\text { wie } \\
\mathrm{Nr} . \\
\text { I IO5 }\end{array}$ & iv & $\begin{array}{c}\text { Konische gravirte Deckelkanne. Mit Wappen. } \\
\text { Besitzer: Unbekannt. Ausstellung Augsburg I886. }\end{array}$ \\
\hline I I IO & $\begin{array}{l}\text { wie } \\
\text { Nr. I I } 06\end{array}$ & ,IWV & $\begin{array}{l}\text { Die beistehende Marke sowohl als die Initialen } \\
\text { IW des Memminger Goldschmiedes } \\
\text { Johann Georg WVerner, thätig I } 578 \text { bis } \\
\text { I 579, finden sich auf dem folgenden Stücke. Es } \\
\text { bleibe dahingestellt, ob obiges Zeichen das Hand- } \\
\text { gemal des Johann Werner ist oder desjenigen } \\
\text { Goldschmiedes, welcher die älteren Theile des in } \\
\text { Rede stehenden Reliquiars gemacht hat. }\end{array}$ \\
\hline
\end{tabular}


Deutschland — Memmingen — Minden

\begin{tabular}{|c|c|c|c|}
\hline $\begin{array}{l}\text { Lf. } \\
\text { Nr. }\end{array}$ & $\begin{array}{l}\text { Beschau- } \\
\text { zeichen }\end{array}$ & $\begin{array}{l}\text { Meister- } \\
\text { zeichen }\end{array}$ & Meister — Gegenstand — Besitzer \\
\hline $\begin{array}{l}\text { I IO9 } \\
\text { I I IO }\end{array}$ & $\begin{array}{l}\text { wie } \\
\text { Nr. I I06 }\end{array}$ & & $\begin{array}{l}\text { Reliquienschrein, sogen. Alexanderschrein. } \\
\text { H. } 47 \mathrm{~cm} . \\
\text { Besitzer: Kloster Ottobeuern. Ausstellung Augsburg } \\
\text { ז886. Meisterwerke Schwäbischer Kunst, Taf. I9. }\end{array}$ \\
\hline I I I I & $\begin{array}{l}\text { wie } \\
\text { Nr. I IO7 } \\
\text { wie I } 107\end{array}$ & & $\begin{array}{l}\text { a) Vergoldeter Pokal mit zugespitzten Buckeln. } \\
\text { Hesitzer: Unbekannt. Ausstellung Zürich } 1883 \mathrm{~cm} \text {. } \\
\text { b) Schälchen mit Inschrift von I } 643 . \\
\text { Besitzer: National-Museum, Budapest. Ausstellung Buda- } \\
\text { pest } 1884 .\end{array}$ \\
\hline
\end{tabular}

MINDEN.

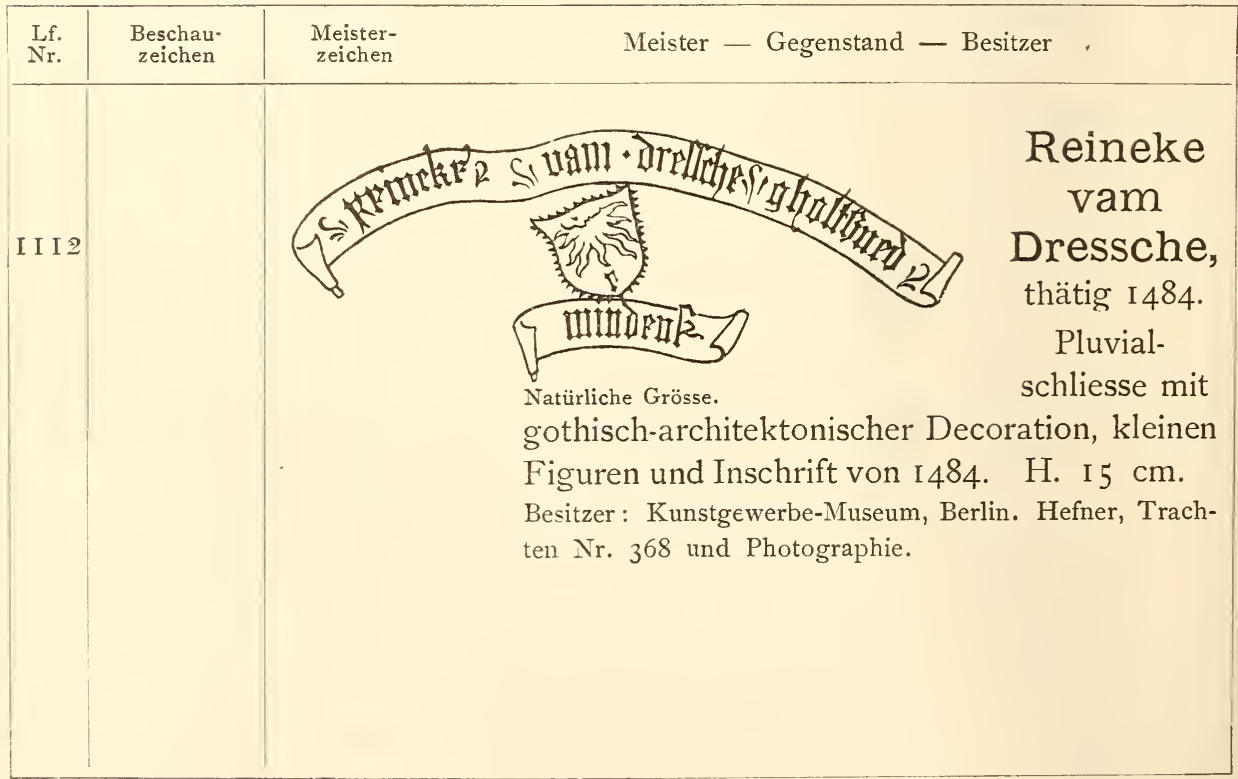




\section{MÜLHAUSEN I. E.}

Um aus den vielen, noch ungedeuteten, in einem Rade bestehenden Stadtzeichen wenigstens einige herauszuheben, sei der Versuch gemacht die folgenden drei für Mülhausen i. E. in Anspruch zu nehmen.

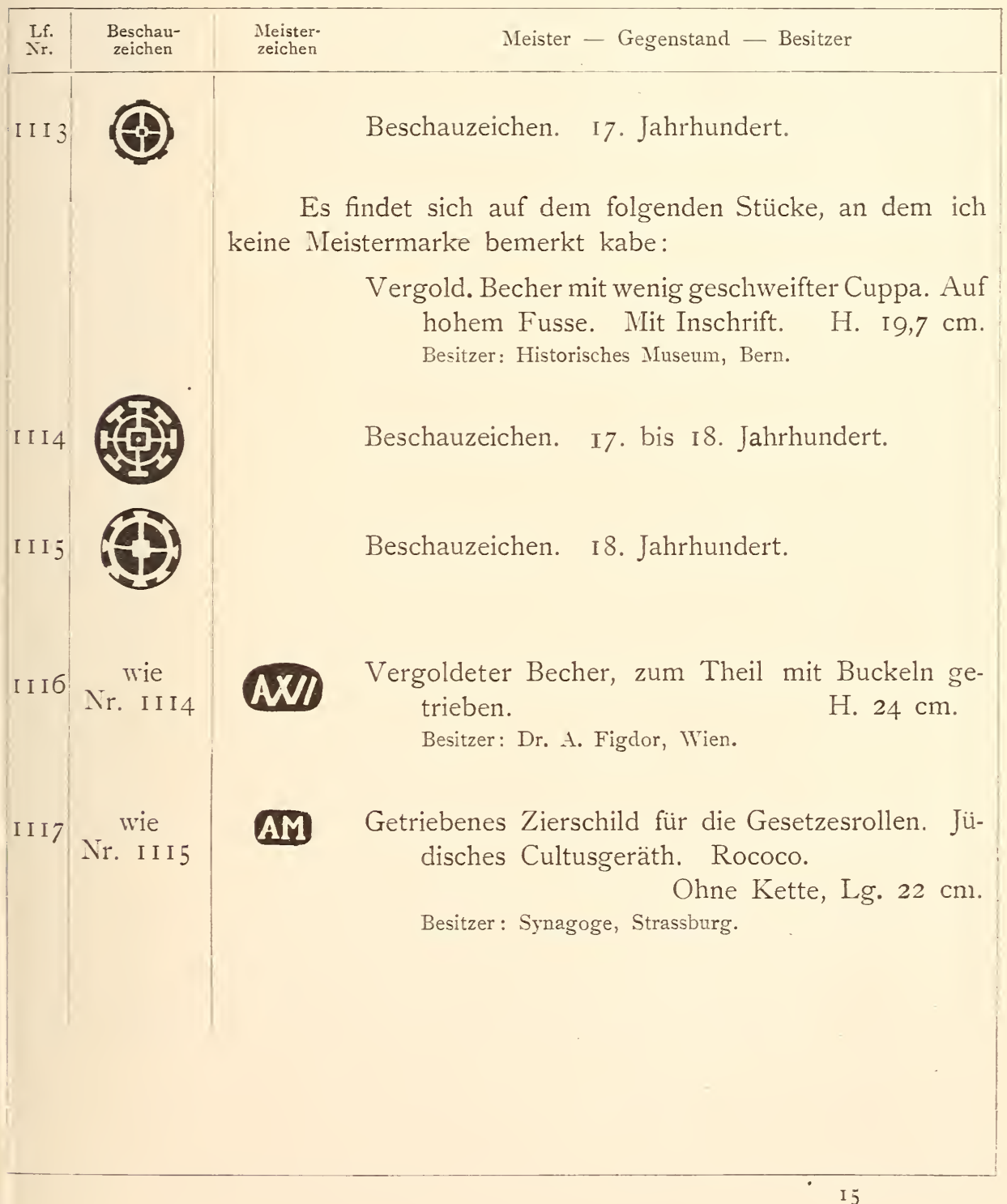




\section{MÜNSTER I. W.}

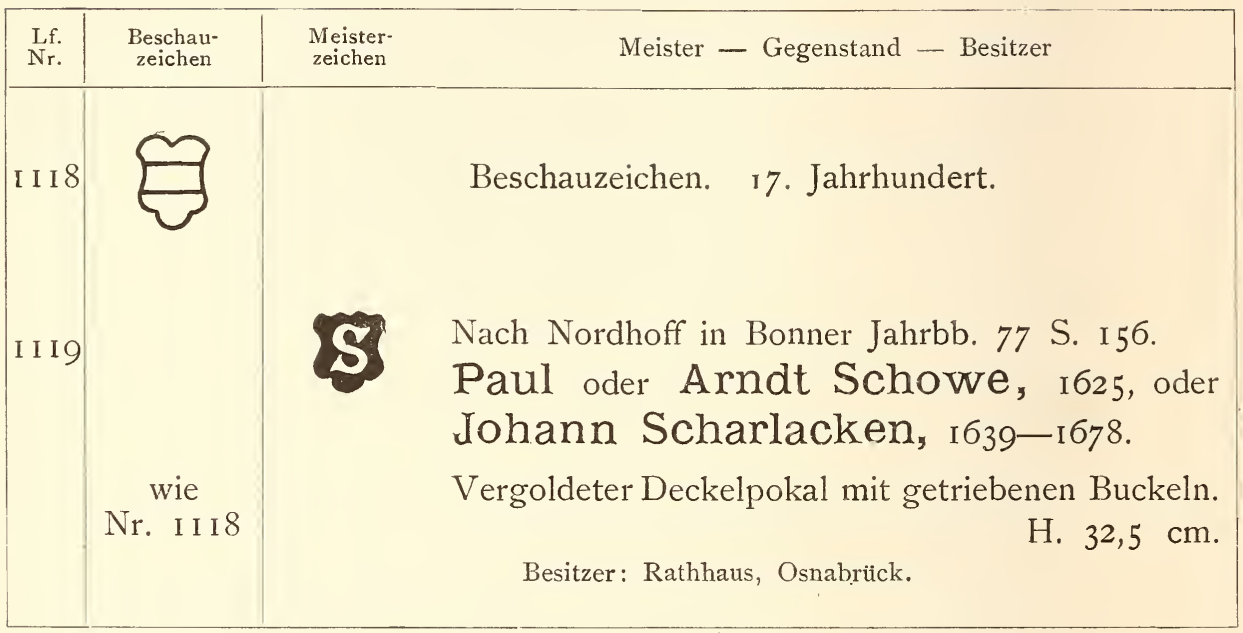

\section{MÜNCHEN.}

\begin{tabular}{|c|c|c|}
\hline $\begin{array}{l}\text { Lf. } \\
\text { Nr. }\end{array}$ & $\begin{array}{l}\text { Beschau- } \\
\text { zeichen }\end{array}$ & Meister — Gegenstand - Besitzer \\
\hline I 120 & & $\begin{array}{l}\text { Beschauzeichen. I6. Jahrhundert. } \\
\text { Ich datire diesen Stempel: I6. Jahrhundert, da mir } \\
\text { mit demselben versehene Arbeiten nur aus dieser Zeit be- } \\
\text { kannt geworden sind. Es scheint aber, dass er sowohl } \\
\text { schon im 15. Jahrhundert vorkommt, als auch im I7. noch } \\
\text { gebraucht worden ist. }\end{array}$ \\
\hline I I 2 I & & Beschauzeichen, 2. Hälfte I7. Jahrhundert. \\
\hline I I 23 & & \\
\hline
\end{tabular}




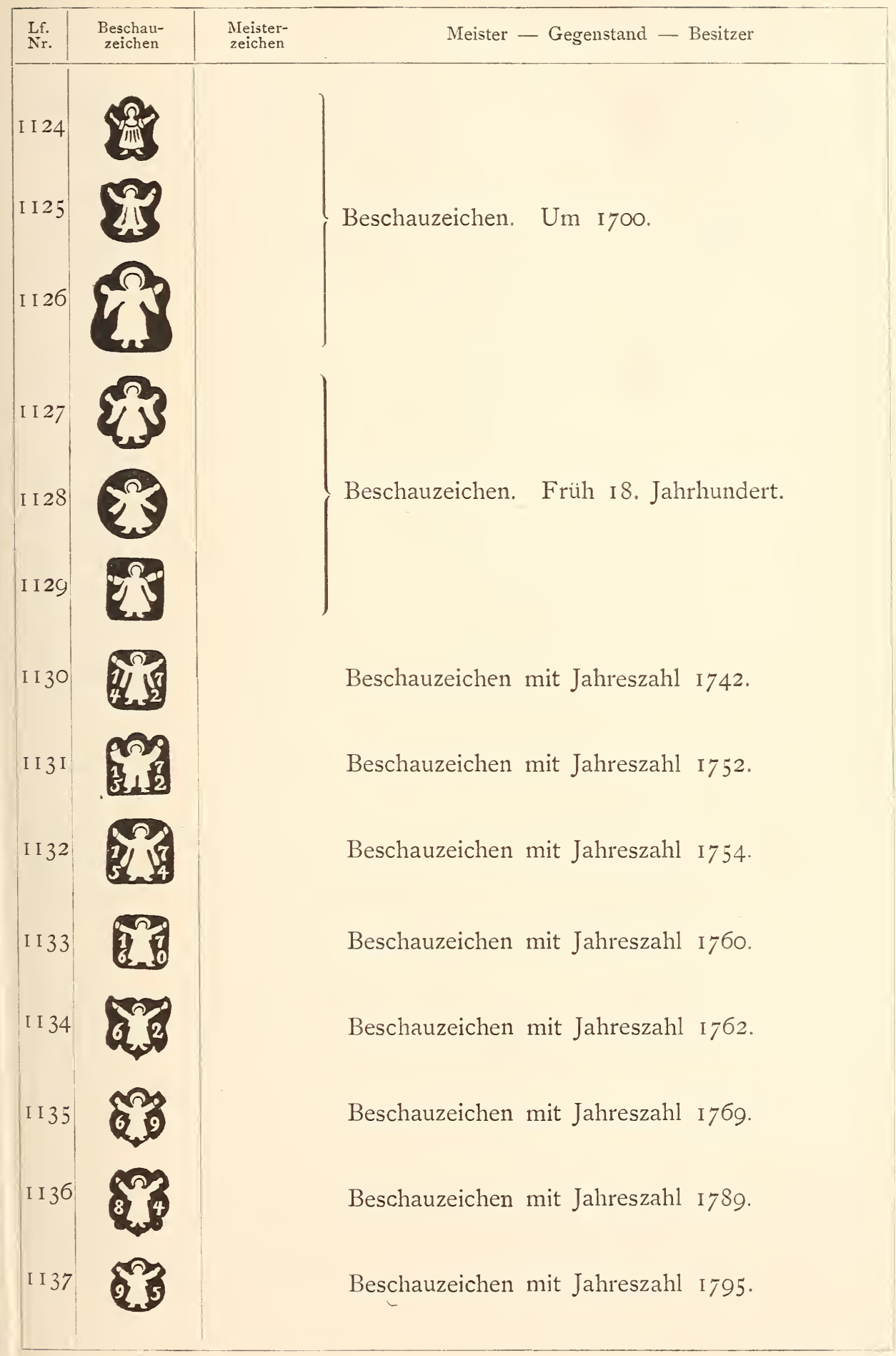




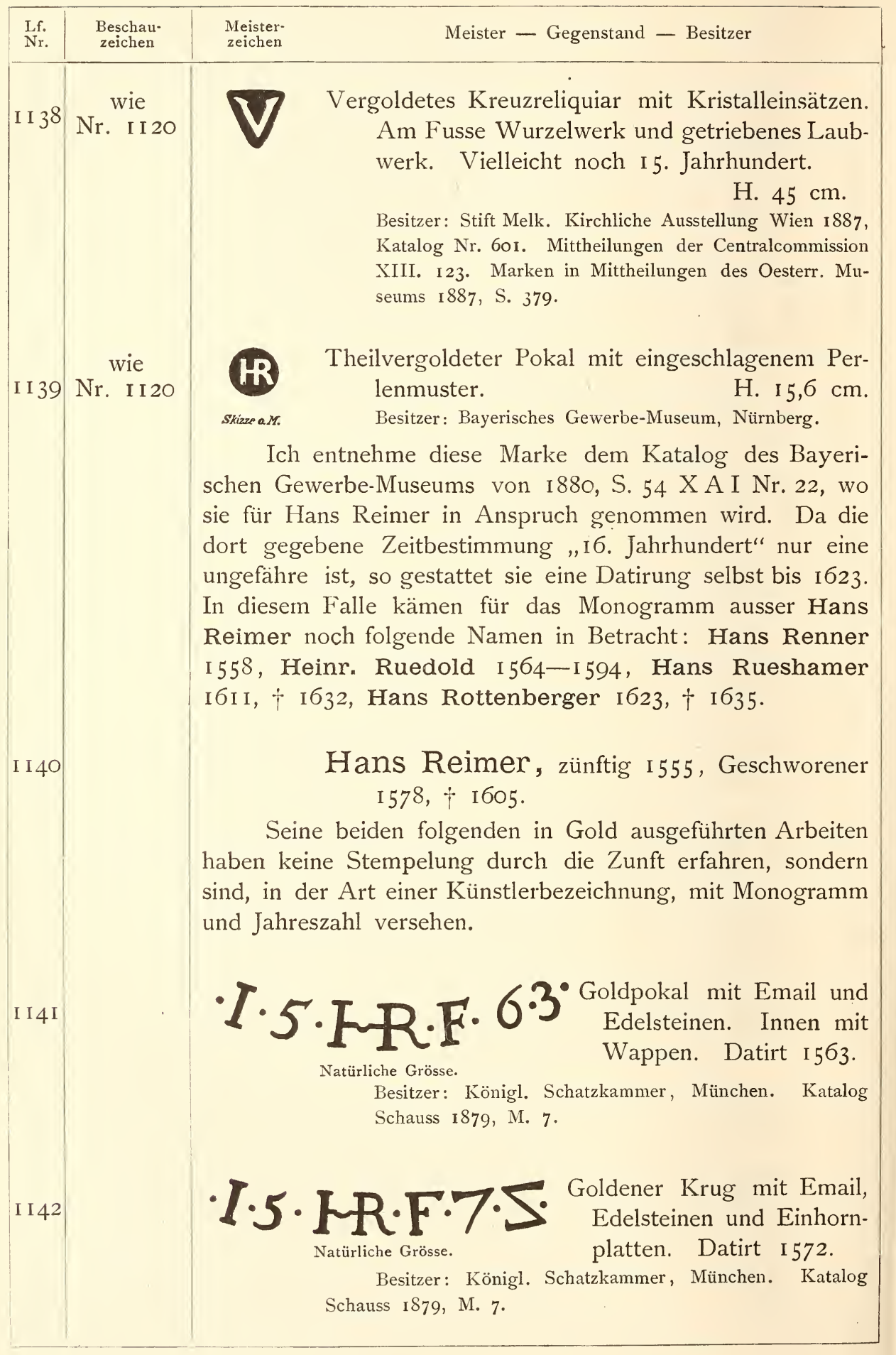




\begin{tabular}{|c|c|c|c|}
\hline Lf. & $\begin{array}{l}\text { Beschau- } \\
\text { zeichen }\end{array}$ & $\begin{array}{l}\text { Meister- } \\
\text { zeichen }\end{array}$ & Meister - Gegenstand - Besitzer \\
\hline I I 43 & $\begin{array}{l}\text { wie } \\
\text { Nr. I I } 20\end{array}$ & 建 & $\begin{array}{l}\text { Pax mit Email, Cameen und Miniaturen. Be- } \\
\text { zeichnet I } 592 . \\
\text { Besitzer: Reiche Kapelle, München. Stockbauer, Reiche } \\
\text { Kapelle i876, Taf. } 5 \text { u. } 6 \text {. }\end{array}$ \\
\hline I I 44 & & & $\begin{array}{l}\text { Wappen mit Lilie führen um die hier in Betracht } \\
\text { kommende Zeit folgende Münchener Gold- } \\
\text { schmiede: }\end{array}$ \\
\hline & & & $\begin{array}{l}\text { Hans Schleich, I582, } \dagger \text { г6 } 6 \text {, } \\
\text { Jacob Wilhelm, I593, † г639, } \\
\text { Heinr. Albertin, I599. }\end{array}$ \\
\hline & $\begin{array}{l}\text { wie } \\
\text { Nr. I I } 20\end{array}$ & & $\begin{array}{l}\text { a) Weisssilberner Apostellöffel. } \\
\text { Besitzer (I883): A. S. Drey, München. }\end{array}$ \\
\hline & wie I I 20 & & $\begin{array}{l}\text { b) Salzfass auf drei Füssen. } \\
\text { Besitzer: Dr. Niemeyer, Baden-Baden. }\end{array}$ \\
\hline I I 45 & & & Ferd. Zschokke, пбго bis I6з8. \\
\hline & $\begin{array}{l}\text { wie } \\
\mathrm{Nr} . \quad \text { I } 20\end{array}$ & & $\begin{array}{l}\text { Kelch mit Patene und Löffelchen. Inschrift von } \\
\text { I } 620 . \\
\text { Besitzer: Stiftskirche, Aschaffenburg. }\end{array}$ \\
\hline I I 46 & & $B P$ & $\begin{array}{l}\text { Bernhard Peter (Petri) von Husum, } \\
\text { zünftig i6i } 4, \dagger \mathrm{i} 648 \text {. }\end{array}$ \\
\hline & $\begin{array}{l}\text { wie } \\
\text { Nr. I I } 20\end{array}$ & & $\begin{array}{l}\text { a u. b) Zwei Monstranzen mit Email und Edel- } \\
\text { steinen, Wappen und Initialen. H. } 54,5 \mathrm{~cm} \text {. } \\
\text { Besitzer: Reiche Kapelle, München. Stockbauer, Reiche } \\
\text { Kapelle } 1876 \text {, Taf. } 38 \text {. }\end{array}$ \\
\hline & wie I I 20 & & $\begin{array}{l}\text { c) Weisssilberne Engel am Altar ( } 6 \text { I } 5 \text { ?). } \\
\text { Besitzer: Reiche Kapelle, München. Stockbauer, Reiche } \\
\text { Kapelle } 1876 \text {, Taf. } 19 .\end{array}$ \\
\hline & wie I I 20 & & $\begin{array}{l}\text { d) Vergoldete Figur, St. Sebastian, an einem } \\
\text { Altärchen von schwarzem Holze mit Email } \\
\text { und Wappen. } \\
\text { Besitzer: Königl. Museum, Brïssel. }\end{array}$ \\
\hline
\end{tabular}




\begin{tabular}{|c|c|c|c|}
\hline $\begin{array}{l}\text { Lf. } \\
\text { Nr. }\end{array}$ & $\begin{array}{l}\text { Beschau- } \\
\text { zeichen }\end{array}$ & $\begin{array}{l}\text { Meister- } \\
\text { zeichen }\end{array}$ & Meister - Gegenstand - Besitzer \\
\hline I I 47 & $\begin{array}{l}\text { wie } \\
\text { Nr. I I } 20\end{array}$ & & 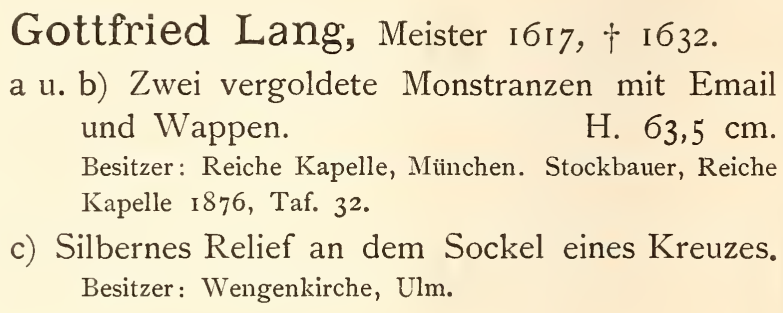 \\
\hline I I 48 & $\begin{array}{l}\text { wie } \\
\text { Nr. I I } 20\end{array}$ & & $\begin{array}{l}\text { a) Theilvergoldetes Etui mit Wappen und In- } \\
\text { schrift von I604. } \\
\text { Besitzer: Königl. Schatzkammer, München. Katalog } \\
\text { Schauss I879, S. } 436 . \\
\begin{array}{ll}\text { b) Deckelkanne mit Gravirung. } & \text { H. } 25,2 \mathrm{~cm} \text {. } \\
\text { Besitzer: } \dagger \text { Baron Carl v. Rothschild, Frankfurt a. M. }\end{array}\end{array}$ \\
\hline I I 49 & $\begin{array}{c}\text { wie } \\
\text { Nr. I I } 20\end{array}$ & & $\begin{array}{l}\text { Jagdbesteck. Scheide des Waidblattes getrieben } \\
\text { und auf der Rückseite gravirt. } \\
\text { Besitzer: Historisches Museum, Dresden. }\end{array}$ \\
\hline I I 50 & $\begin{array}{c}\text { wie } \\
\mathrm{Nr} \text {. I I } 20\end{array}$ & & $\begin{array}{l}\text { a-d) Vier kleine theilverg. Altäre. H. 58,5 cm. } \\
\text { e) Monstranz mit Halbedelsteinen. } \\
\text { Besitzer: Reiche Kapelle, München. }\end{array}$ \\
\hline I I 5 I & $\begin{array}{c}\text { wie } \\
\text { Nr. I I } 2 \text { I }\end{array}$ & & $\begin{array}{l}\text { Franz Oxner, zünftig i } 647 . \\
\text { Vergoldeter konischer Becher. Schweissarbeit. } \\
\text { H. S,5 cm. } \\
\quad \text { Besitzer (1885): L. Alexander, Nürnberg. Ausstellung } \\
\quad \text { Nürnberg 1885, Katalog Nr. 732. }\end{array}$ \\
\hline I I 52 & $\begin{array}{c}\text { wie } \\
\text { Nr. I I } 22\end{array}$ & & $\begin{array}{l}\text { Sebastian Wendl, I662- - } 688 . \\
\text { Vergoldete Schliesse, mit Laubwerk getrieben. } \\
\text { Lg. I7 cm. } \\
\text { Besitzer: Gg. Gimbel, Baden-Baden. Ausstellung Karls- } \\
\text { ruhe } 188 \text { I, Katalog Nr. I4I. }\end{array}$ \\
\hline I I 53 & $\begin{array}{c}\text { wie } \\
\text { Nr. I I } 24\end{array}$ & & $\begin{array}{l}\text { Franz Kessler, zünftig I664, † I7I7. } \\
\text { a) Fassung einer Elfenbeinkanne. Deckel und } \\
\text { Fuss mit getriebenen Blättern. } \\
\text { Besitzer (I882): J. \& S. Goldschmidt, Frankfurt a. M. }\end{array}$ \\
\hline
\end{tabular}




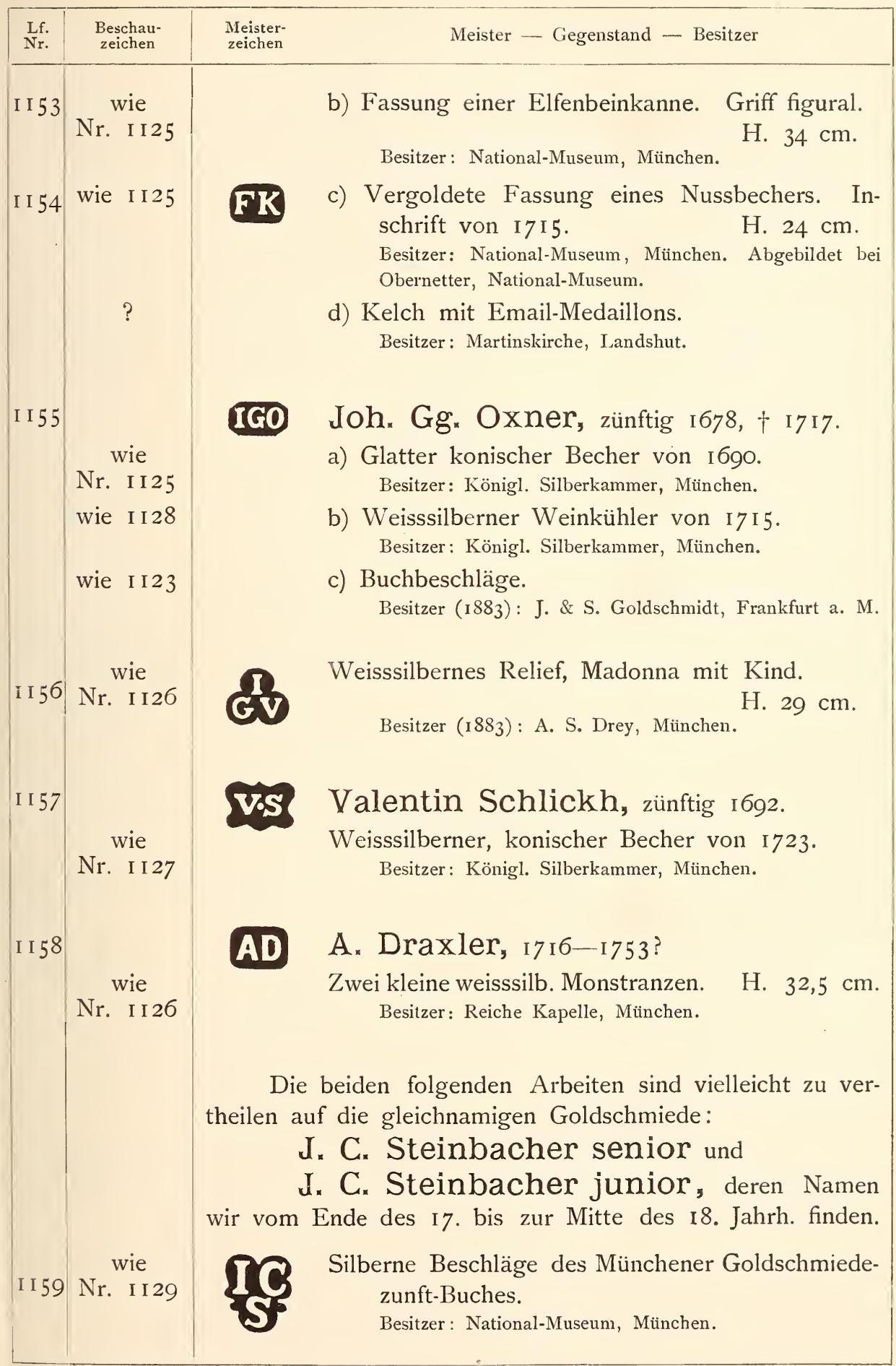




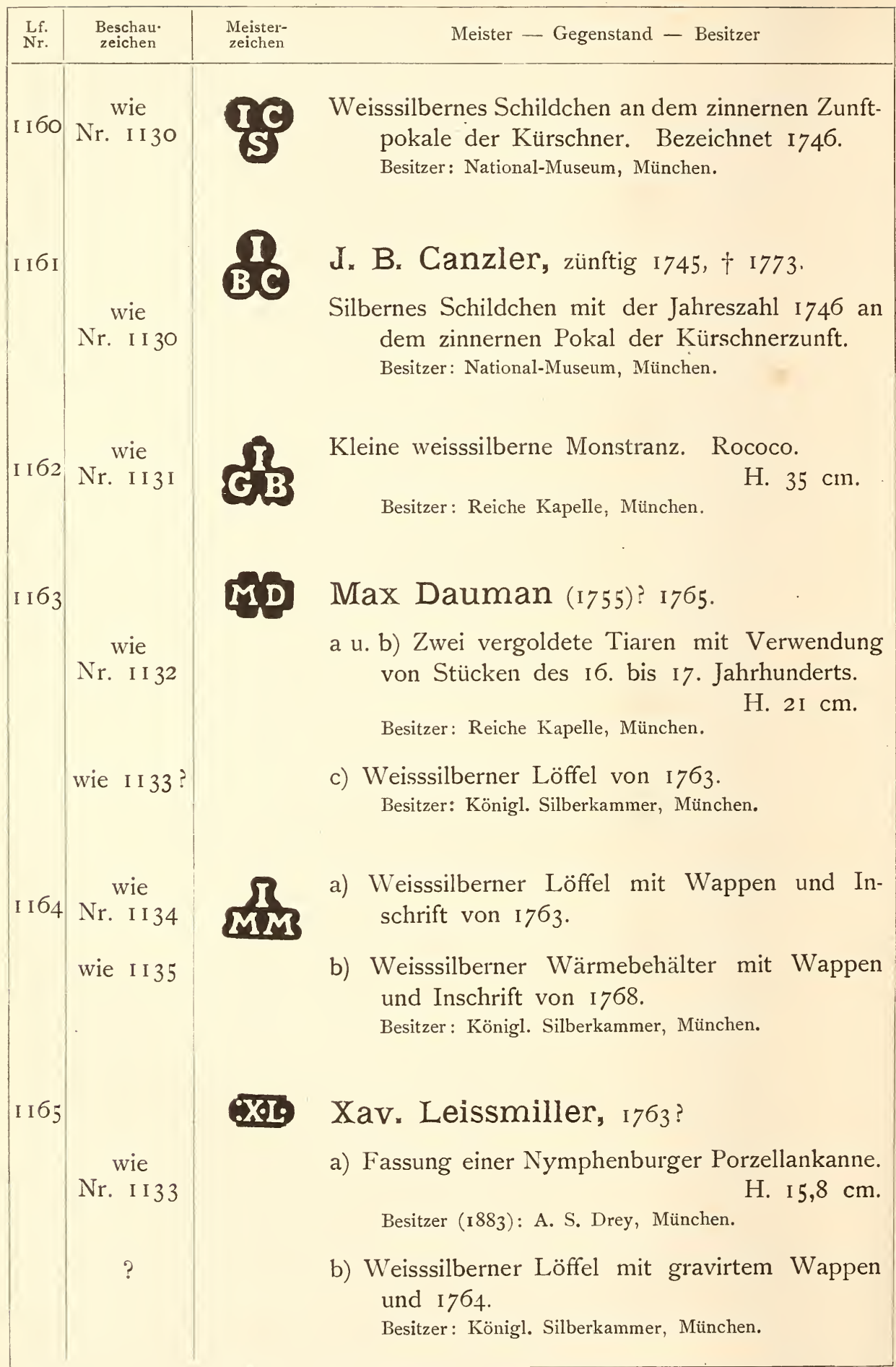




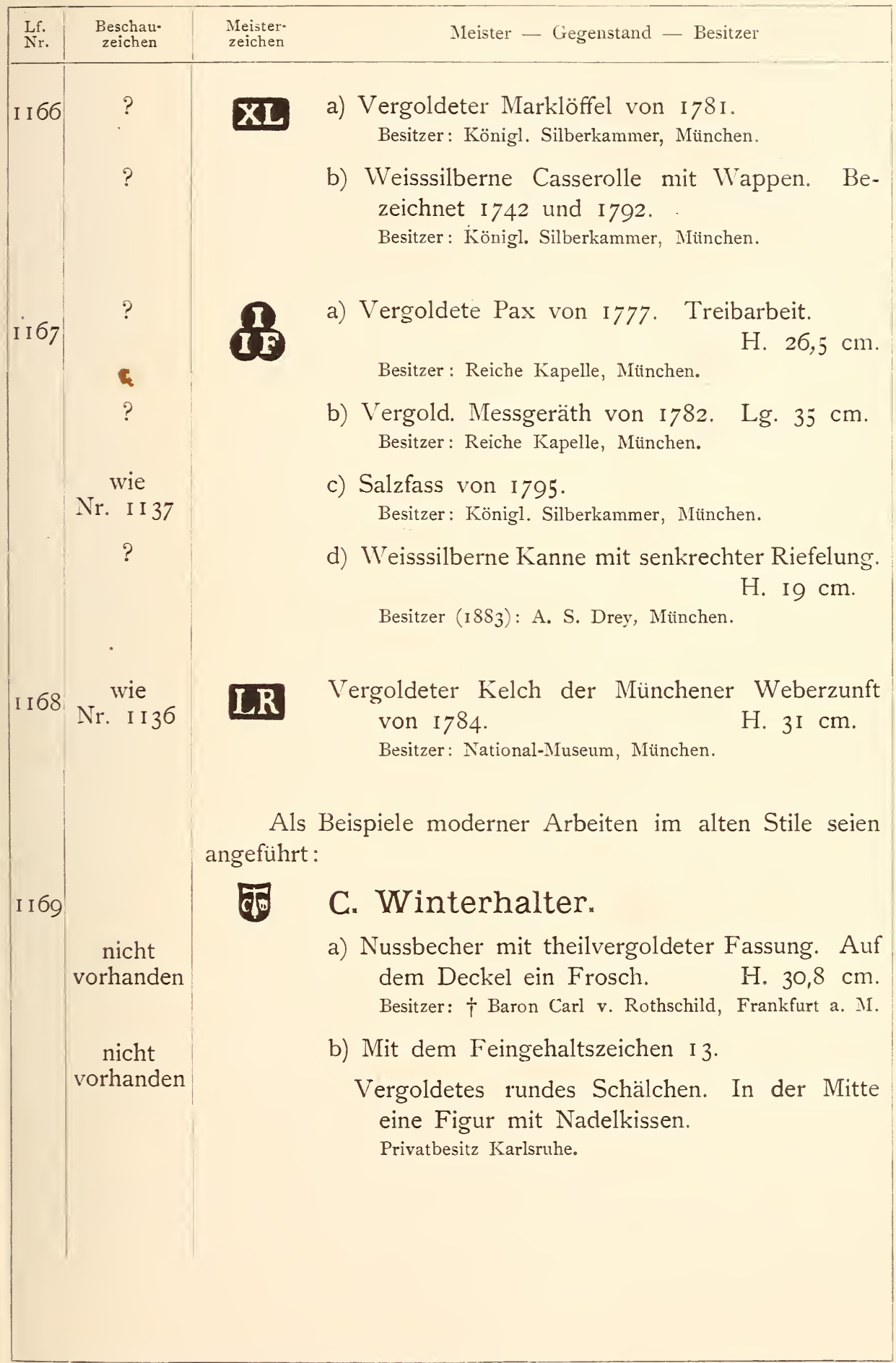




\section{NEUSTADT A. D. H.}

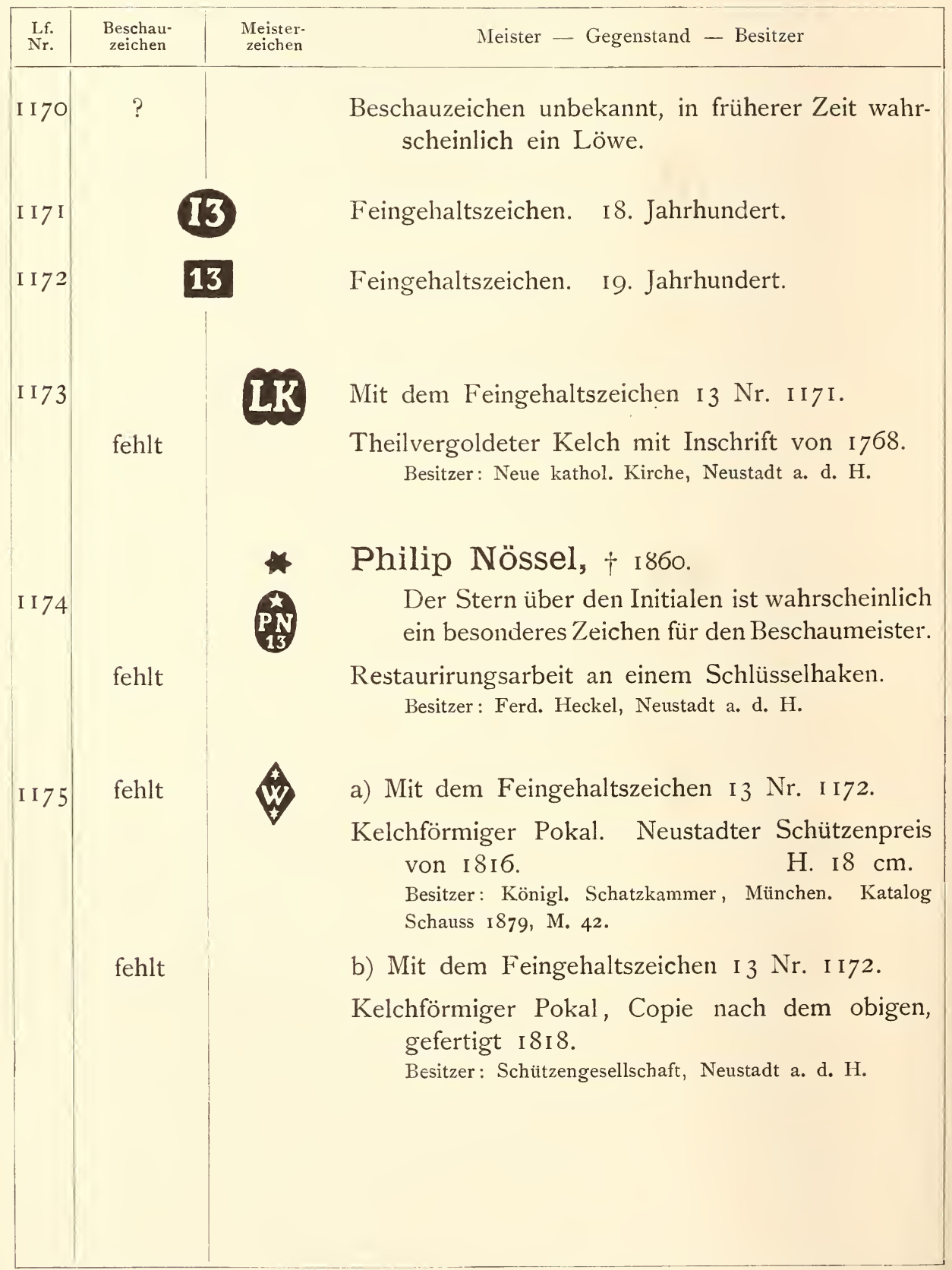




\section{NÖRDLINGEN.}

\begin{tabular}{|c|c|c|c|}
\hline $\begin{array}{c}\text { Lf. } \\
\text { Nr. }\end{array}$ & $\begin{array}{l}\text { Beschau- } \\
\text { zeichen }\end{array}$ & $\begin{array}{l}\text { Meister- } \\
\text { ze:chen }\end{array}$ & Meister - Gegenstand - Besitzer \\
\hline I 176 & & & Beschauzeichen. I7. Jahrhundert. \\
\hline I I 77 & $\begin{array}{l}\text { wie } \\
\text { Nr. I I } 76\end{array}$ & 77 & $\begin{array}{l}\text { Hostienbüchse mit Wappen, Inschrift und I639. } \\
\begin{array}{l}\text { Besitzer: Kirche, Nördlingen. } \\
\text { I } 3,5 \mathrm{~cm} .\end{array}\end{array}$ \\
\hline
\end{tabular}

\section{NORDEN (PROY. HANNOVER).}

\begin{tabular}{|l|c|c|}
\hline $\begin{array}{c}\text { Lff. } \\
\text { Nr. }\end{array}$ & $\begin{array}{c}\text { Beschau } \\
\text { zeichen }\end{array}$ & $\begin{array}{c}\text { Meister. } \\
\text { zeichen }\end{array}$ \\
\hline II78 & Beister - Gegenstand - Besitzer \\
II79 & Beschauzeichen. I8. bis I9. Jahrhundert. \\
II8C & Beschauzeichen mit Meisternamen. I9. Jahrh. \\
\hline
\end{tabular}




\section{NÜRNBERG.}

\begin{tabular}{|c|c|c|}
\hline $\begin{array}{l}\text { Lf. } \\
\text { Nr. }\end{array}$ & $\begin{array}{l}\text { Beschau- } \\
\text { zeichen }\end{array}$ & Meister - Gegenstand - Besitzer \\
\hline I I 83 & (1) & $\begin{array}{l}\left\{\begin{array}{l}\text { Beschauzeichen. Früh I6. Jahrhundert. An- } \\
\text { scheinend schon am Schlusse des I 5. Jahr- } \\
\text { hunderts, vielleicht um I480, eingeführt, bleibt } \\
\text { dieses Zeichen bis etwa I } 536 \text { oder I 54I in }\end{array}\right. \\
\text { Gebrauch. Es erscheint immer allein, d. h. ohne Meister- } \\
\text { zeichen, denn in der Zeit, da es als Beschauzeichen Ver- } \\
\text { wendung fand, war das Meisterzeichen in Nürnberg noch } \\
\text { nicht üblich. Es seien daher zunächst diejenigen Stücke } \\
\text { angeführt, welche mir mit diesem Beschauzeichen bekannt } \\
\text { geworden sind }\end{array}$ \\
\hline & ? & $\begin{array}{l}\text { a) Silberaltar. } \\
\text { Besitzer: Domschatz, Krakau. Gefällige Mittheilung des } \\
\text { Herrn Professor Dr. Julius Lessing in Berlin. Wenn } \\
\text { dieses Stück, das ich aus eigener Anschauung nicht } \\
\text { kenne, für den gleich zu nennenden Meister nicht zu } \\
\text { jung ist, so könnte es möglicherweise identisch sein mit } \\
\text { dem von Neudörfer und von Doppelmayr erwähnten } \\
\text { Altar, für den König von Polen (Doppelmayr sagt } \\
\text { Sigismund II.) gefertigt von } \\
\text { Melchior Bayer, Meister 1525, Geschworener 1534, } \\
\dagger \text { I577. (Vergl. unten Nr. I249.) Bergau, Zeitschrift } \\
\text { für bild. Kunst I88o S. I8, gibt etwas andere Daten, } \\
\text { auf Grund deren Ilg im Allgemeinen Künstlerlexikon } \\
\text { zwei verschiedene Altäre annimmt. }\end{array}$ \\
\hline & wie II 82 & $\begin{array}{l}\text { b) Vergoldete, theilweise emaillirte Fassung eines } \\
\text { Kristall-Doppelbechers. Mit offenem Henkel. } \\
\text { Gothische Form. } \\
\text { Besitzer: Kaiserl. Schatzkammer, Wien. Katalog Leitner } \\
\text { 1882, S. } 54 \text { Nr. } 32 \text {. }\end{array}$ \\
\hline & wie 1 I 82 & $\begin{array}{l}\text { c) Vergoldete Fassung eines Nussbechers mit } \\
\text { Wappen und I536. } \\
\text { Besitzer: Deutschordensschatz, Wien. }\end{array}$ \\
\hline & wie I $_{3} 8$ & $\begin{array}{l}\text { d) Vergoldete Fassung eines aus Hornplatten ge- } \\
\text { bildeten Bechers. Mit anscheinend nicht dazu } \\
\text { gehörigem Deckel. } \\
\text { Besitzer: Königl. Silberkammer, München. } 29 \mathrm{~cm} \text {. }\end{array}$ \\
\hline
\end{tabular}




\begin{tabular}{|c|c|c|c|}
\hline $\begin{array}{l}\text { Lf. } \\
\text { Nr. }\end{array}$ & $\begin{array}{l}\text { Beschau- } \\
\text { zeichen }\end{array}$ & $\begin{array}{l}\text { Meister- } \\
\text { zeichen }\end{array}$ & Meister - Gegenstand - Besitzer \\
\hline 83 & $\begin{array}{l}\text { wie } \\
\text { Nr. II } 82\end{array}$ & fehlt & $\begin{array}{c}\text { e) Doppelbecher mit Passigtwerk. H. I2,2 cm. } \\
\text { Besitzer: Max B. H. Goldschmidt, Frankfurt a. MI. }\end{array}$ \\
\hline & wie I $_{8} 3$ & , & $\begin{array}{l}\text { f) Doppelbecher mit getriebenen Buckeln. } \\
\text { H. } 40 \mathrm{~cm} \text {. } \\
\text { Besitzer: } \uparrow \text { Baron Carl v. Rothschild, Frankfurt a. M. }\end{array}$ \\
\hline & wie I I 82 &, & $\begin{array}{l}\text { g) Vergoldeter Kelch. Gothisch. H. I9 cm. } \\
\text { Besitzer (1883): A. S. Drey, München. }\end{array}$ \\
\hline & wie I 83 & ", & $\begin{array}{l}\text { h) Vergoldeter Kelch mit Inschrift. Gothisch. } \\
\text { H. I } 8 \mathrm{~cm} \text {. }\end{array}$ \\
\hline & wie $\mathrm{II}_{3}$ & , & $\begin{array}{l}\mathrm{i}-\mathrm{m}) \text { Vier vergoldete Kelche; darunter einer mit } \\
\text { Wappen und I 5 } 5 \text {, und zwei mit Inschriften. } \\
\text { Gothisch. } \\
\text { Besitzer: Lorenzkirche, Nürnberg. }\end{array}$ \\
\hline & wie I $_{3} 8_{3}$ & , & $\begin{array}{l}\text { n) Vergoldeter Kelch mit Inschrift. H. I8,5 cm. } \\
\text { Besitzer: Johanneskirche, Nürnberg. }\end{array}$ \\
\hline & wie II 83 & $"$ & $\begin{array}{l}\text { o) Vergoldeter Kelch mit gothischen Ornament- } \\
\text { gravirungen. } \\
\text { Besitzer: Leonhardskirche, Nürnberg. }\end{array}$ \\
\hline & wie $\mathrm{II}_{3}$ & ," & $\begin{array}{l}\text { p) Vergoldeter Kelch. } \\
\text { Besitzer: Sebalduskirche, Nürnberg. }\end{array}$ \\
\hline & wie I $_{3} 3$ & $"$ & $\begin{array}{r}\text { q) Vergoldeter Pokal mit getriebenen Buckeln } \\
\text { und Ornamentgravirungen am Lippenrande. } \\
\text { H. } 20 \mathrm{~cm} . \\
\text { Besitzer: Germanisches National-Museum, Nürnberg. }\end{array}$ \\
\hline & wie I 183 & $"$ & $\begin{array}{l}\text { r) Vergoldeter Becher mit getriebenen Buckeln } \\
\text { und Blumen. Auf dem Deckel ein Schwan. } \\
\text { H. I7 cm. } \\
\text { Besitzer: Baron Karl Apor. Ausstellung Budapest I } 88_{4} \text {, } \\
\text { 5. Saal, Katalog S. I3. }\end{array}$ \\
\hline & wie II $83_{3}$ & $"$ & $\begin{array}{l}\text { s) Hoher vergoldeter Pokal, sogen. Kurfürsten- } \\
\text { becher. Mit späterer Inschrift von I } 586 \text {. } \\
\text { Besitzer: Kunstgewerbe-Museum, Berlin. Lessing, Raths. } \\
\text { silberzeug von Lüneburg Nr. 19. }\end{array}$ \\
\hline & wie I I $_{3}$ & ", & $\begin{array}{l}\text { t) Vergoldete flache Schale mit Passigtwerk und } \\
\text { eingelassener Medaille. } \mathrm{Lg} .20,5 \mathrm{~cm} \text {. } \\
\text { Besitzer: Baron Nathanael v. Rothschild, Wien. }\end{array}$ \\
\hline
\end{tabular}




\begin{tabular}{|c|c|c|}
\hline $\begin{array}{l}\text { Lf. } \\
\text { Nr. }\end{array}$ & $\begin{array}{l}\text { Beschau- } \\
\text { zeichen }\end{array}$ & Meister - Gegenstand - Besitzer \\
\hline \multirow{3}{*}{ I I 84} & & $\begin{array}{l}\text { Ohne in den Zeitraum herüberzutreten, in welchem das } \\
\text { Meisterzeichen schon obligatorisch ist, haben wir hier zwei } \\
\text { Stücke anzuschliessen, von welchen das eine ausser dem } \\
\text { Beschauzeichen noch einen Meisterstempel trägt, und das } \\
\text { andere anscheinend nur diesen hat. }\end{array}$ \\
\hline & $\begin{array}{l}\text { wie } \\
\mathrm{Nr} . \quad \text { I } 83\end{array}$ & $\begin{array}{l}\text { a) Vergoldeter gebuckelter Doppelbecher. Mit } \\
\text { Medaille, Wappen von I593 und Inschrift } \\
\text { von I 5 I9: } \\
\text { Besitzer: } \dagger \text { Baron Carl v. Rothschild, Frankfurt a. M. }\end{array}$ \\
\hline & fehlt & $\begin{array}{l}\text { b) Vergoldeter, niederer bauchiger Becher mit ge- } \\
\text { triebenen Buckeln. } \quad \text { H. } 6 \mathrm{~cm} \text {. } \\
\text { Besitzer (1883): J. \& S. Goldschmidt, Frankfurt a. M. }\end{array}$ \\
\hline
\end{tabular}

Eine regelrechte Stempelung mit Beschauzeichen, Meisterstempel und Controllstich wird erst durch die Ordnung von 154I eingeführt. Stockbauer hat in „Kunst und Gewerbe“ I876, S. II 3 ff. die wichtigsten Daten über diesen Gegenstand beigebracht. Wir citiren seine Auseinandersetzungen sowie die von ihm angezogenen Stellen, soweit sie für unseren Zweck wichtig sind.

„Darnach war es von 154I an Gesetz, dass jeder Gold- und Silberschmied sein eigenes Zeichen habe, und damit musste er Alles, was in seiner Werkstätte aus Silber gearbeitet wurde, bezeichnen. Hierauf musste das so bezeichnete Objekt den Geschwornen vorgezeigt werden, welche es prüften, $\mathrm{ob}$ es an Silbergehalt den Verordnungen entspreche, und war diess der Fall, so bestachen sie es, d. h. sie bezeichneten es mit jenen Zickzacklinien, die man jetzt Controllzeichen nennt, und versahen dieselben mit ihrem in Wachs gedruckten Stempel, dem wächsernen oder Wüchsenzeichen, als sichtlichem Beleg dafür, dass keine unberechtigte Hand das Controllzeichen eingegraben hatte. Mit diesen drei Zeichen, dem Goldschmied-, Controllund Wüchsenzeichen versehen, kam der silberne Gegenstand dann in die Schau und wurde vom Wardein mit dem Stadtzeichen $\mathrm{N}$ als Nürnberger Arbeit amtlich beglaubigt."

Die einschlägigen Verordnungen lauten: „Verner hat ain Erbar Rat auss beweglichen guten vrsachen gesetzt vnnd verordnet, das muhn fürohin ain yeder geschworner onnd alle andern maister die von silber arbeiten sein aigens vntterschiedliche sichtliche onnd erkenntliche zaichen haben vnnd auf alle silberne onnd vergultte arbeit, die er durch sich selber onnd seine gepröte erhalten, machen vnnd den geschwornen zu der schaw haimschickhen wiirdet vor onnd che er die den geschwornen neu zu beschauen zubringt, stempffen wnnd also damit bezaichnen soll, dass die alle Zeit erkhannt onnd ungepürlicher Betrug. . . dadurch verhüet werde." 


\begin{tabular}{|l|c|c|c|}
\hline $\begin{array}{c}\text { Lf. } \\
\text { Nr. }\end{array}$ & $\begin{array}{c}\text { Beschau- } \\
\text { zeichen }\end{array}$ & $\begin{array}{c}\text { Meister- } \\
\text { zeichen }\end{array}$ & Meister - Gegenstand - Besitzer \\
\hline
\end{tabular}

„Vnnd soll ain yeder maister der yetzo ist onnd fiurohin zu maister gemacht wnnd angesagt wiirdet, der von silber arbeiten will, sollich sein zaichen, aufs geschmeidigst es sein khan, Inn ain puntzel schneiden onnd dermass onnterschiedlich fürnemen onnd machen lassen, dass kainss dem andern gleich, sondern wol onnd aigentlich voneinander zu erkhennen sey, annd volgendts derselbig puntal durch die geschwornen maister onnd den Gwardin in der Schaw Inn zwo darzu verordnet gleichförmige pleyerne platten gestempfft oder geschlagen, auch desselben maisters Tauf onnd Zunamen sambt seinem zaichen inn zway puechlein onnd In yedes sonderlich geschrieben vnnd veraaichnet, vnnd alweg dass ain pley vnnd puechlein durch die geschwornen maister wnd das andere durch den Gwardin In der Schaw behalten vnnd bewart werden."

Die Variationen in der Form des Beschauzeichens sind verhältnissmässig gering, und bei der häufigen Undeutlichkeit der Stempel schwer zu beobachten. Dennoch glaube ich folgende Haupttypen erkannt zu haben, welche aber wie es scheint oft nebeneinander in Gebrauch gewesen sind.

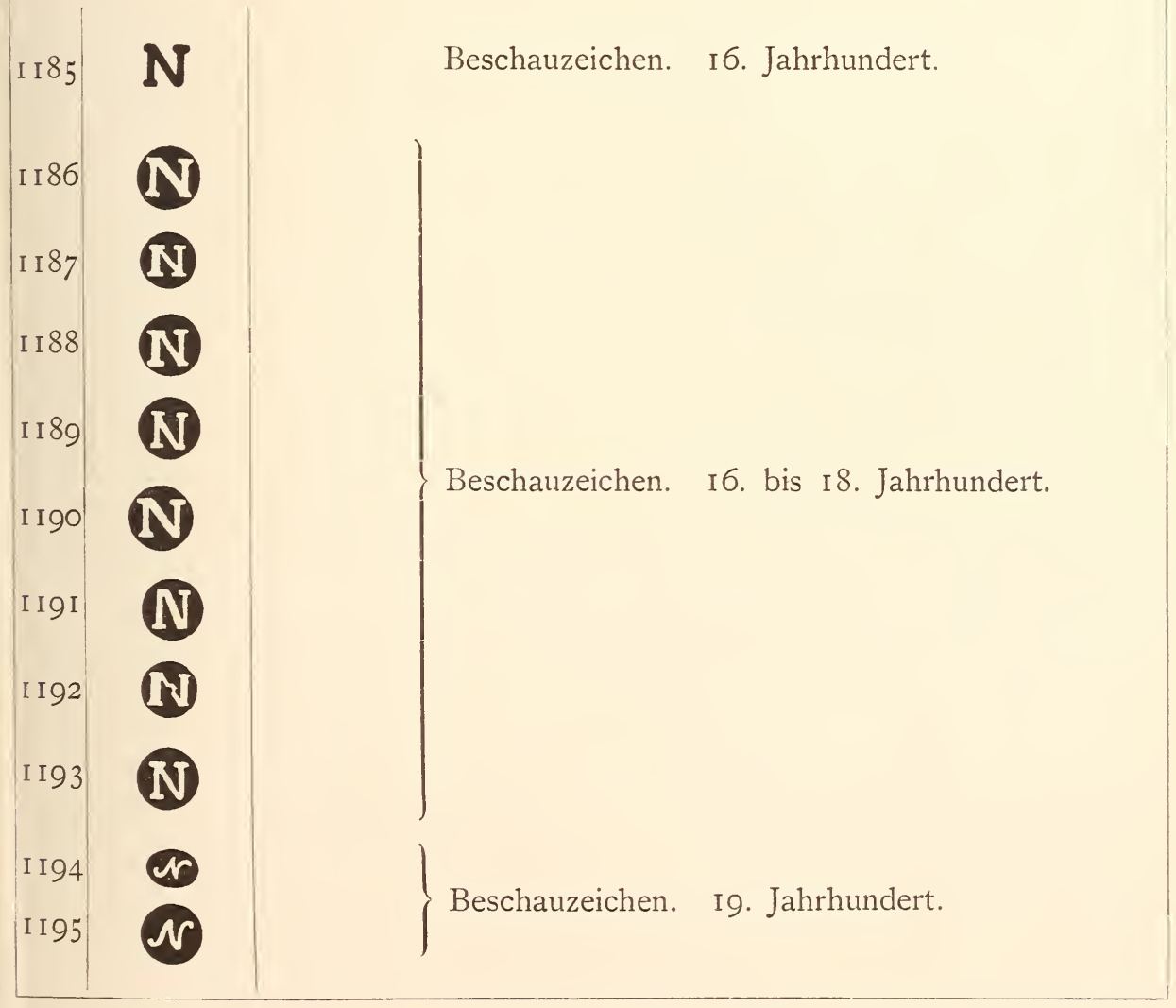




\begin{tabular}{|c|c|c|}
\hline $\begin{array}{l}\text { Lf. } \\
\text { Nr. }\end{array}$ & $\begin{array}{l}\text { Beschau- } \\
\text { zeichen }\end{array}$ & $\begin{array}{l}\text { Meister- } \\
\text { zeichen }\end{array}$ \\
\hline
\end{tabular}

Wardeinmarken, die auf das Stück eingeschlagen wurden, waren früher in Nürnberg nicht üblich. Die Ordnung von I 562 bei Stockbauer in ,Kunst und Gewerbe“ 1878, S. 289 spricht sich darüber ganz deutlich aus: „Was nun ein geschworner Meister der Goldschmide beschaut und bestochen und an Gehalt recht befunden hat, darauf soll er sein eigenes Zeichen in Wachs gedruckt setzen, ehe er es in die Schau schicke, wo es mit dem Stadtzeichen $N$ bezeichnet wird."

Noch klarer wird die Sache aus dem Wortlaut von I697: „Was ein jeder Geschworner Meister der Goldschmid bestochen und an Halt recht hefunden hat, da soll er auf einen jeden Stich sein eigenes Zeichen in ein Wachs driucken, ehe er es dem Quardein der Schau mit dem $N$ zu bezeichnen zuschickt, und von jedem solchen Stich soll man ihm zum Lohn einen Pfennig geben."

Später dagegen, in der Ordnung von 1766 wird ein Wardeinstempel statt des Wachszeichens verlangt. Er besteht in einem Buchstaben, den der Vorgeher führt. Hier der Wortlaut der betreffenden Verordnung: "Der Vorgeher soll, anstatt wie bisher gewöhnlich gezvesen, seinen Namen oder Zeichen auf ein Wachs zu driicken, den ihm während seines Vorgeheramts anvertrauten auf einem Bunzen befindlichen alphabetischen Buchstaben darauf schlagen und in die Schau schicken, dass solches mit dem $N$ bezeichnet werde."

Im Jahre 1808 war Goldschmied Joh. Fr. Ehe Vorgeher, einige Tage vor seinem Tode wurde ihm der Jahresstempel $\mathrm{M}$ abgenommen und seinem Nachfolger der Stempel $\mathrm{N}$ übergeben; da aber dieses $\mathrm{N}$ mit dem Beschauzeichen übereinstimmte, wurde ihm nach einigen Tagen der Jahresbuchstabe O ausgefolgt.

Daraus ist zu ersehen, dass von I 766 bis I 808 , also während 42 Jahren, I 2 Buchstaben verwandt wurden. Da jeder Vorgeher gewöhnlich 4 Jahre im Amt blieb, so sollte man eigentlich erst nach 48 Jahren bei $\mathrm{N}$ angekommen sein. Es haben demnach während dieser 42 Jahre einige Unregelmässigkeiten Platz gegriffen, die zum Theil in der durch Tod verkürzten Amtsdauer der Vorgeher zu suchen sind.

Die folgende Zusammenstellung nimmt vermuthungsweise auf diese Verhältnisse Rücksicht.

$\left.\begin{array}{llll}\text { II96 } & \mathbf{A} & \text { 1766 bis } & \text { I769 } \\ \text { I I97 } & \mathbf{B} & \text { I769 bis } & \text { I773 } \\ \text { I198 } & \mathbf{C} & \text { I773 bis } & \text { I776 }\end{array}\right\} \begin{array}{r}\text { Jahresbuchstaben resp. Zeichen } \\ \text { der Vorgeher. }\end{array}$




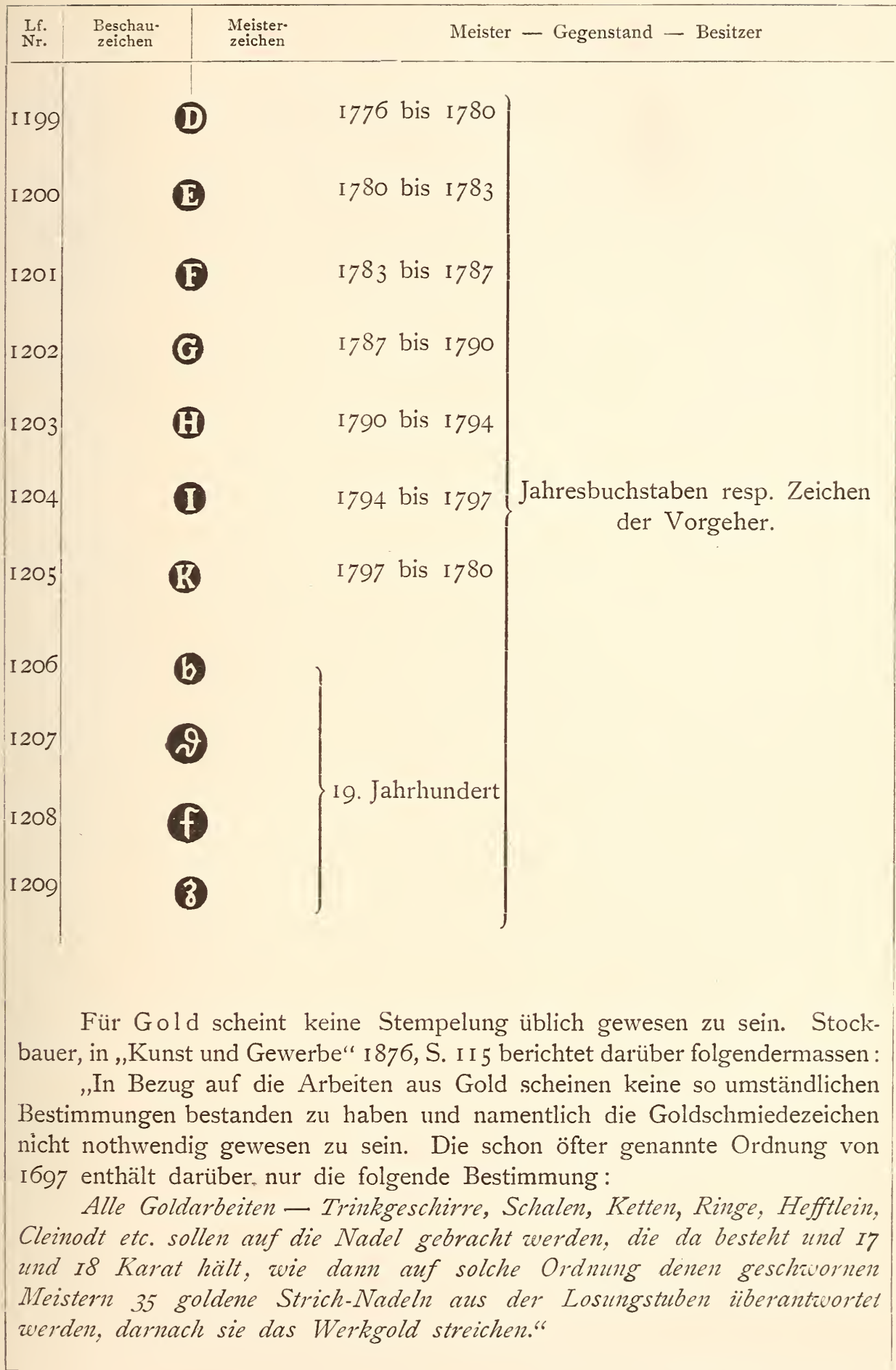




\begin{tabular}{|c|c|c|c|}
\hline $\begin{array}{ll}\text { Lf. } \\
\text { Nr. }\end{array}$ & $\begin{array}{l}\text { Beschau- } \\
\text { zeichen }\end{array}$ & $\begin{array}{l}\text { Meister- } \\
\text { zeichen }\end{array}$ & Meister - Gegenstand - Besitzer \\
\hline 1210 & & W & $\begin{array}{l}\text { Wentzel Jamnitzer, geboren in Wien } \\
\text { I 508, zünftig in Nürnberg I 534, } \dagger \text { I } 585 .\end{array}$ \\
\hline & $?$ & & $\begin{array}{l}\text { a) Vergoldeter Vierbecher, bestehend aus vier } \\
\text { aufeinander gestellten Gefässen in Gestalt von } \\
\text { Maserbowlen. Mit vielen Wappen und einer } \\
\begin{array}{ll}\text { eingelassenen Medaille. } & \text { H. } 54 \mathrm{~cm} \text {. } \\
\text { Besitzer: Herzogl. Museum, Gotha. } & \end{array}\end{array}$ \\
\hline & ? & & $\begin{array}{l}\text { b) Tafelaufsatz mit Email und Theilvergoldung. } \\
\text { Griff figural. Mit Inschriften. Sogen. Mer- } \\
\text { kelscher Tafelaufsatz. } \\
\text { Besitzer: } † \text { H. IOo cm. } \\
\text { Bergau in ,Zeitschrift für bildende Kunst" I878. Luth- } \\
\text { mer, Schatz Rothschild II, Taf. I-3. }\end{array}$ \\
\hline & wie I I 86 & & $\begin{array}{l}\text { c) Vergoldete Schmuckcassette mit vier Hermen } \\
\text { und den Thaten des Herkules, Reliefs auf } \\
\text { Steingrund. Mit Inschriften. H. } 22 \mathrm{~cm} \text {. } \\
\text { Besitzer: Königl. Schatzkammer, München. Katalog } \\
\text { Schauss 1879, C. 90. Abg. bei Schauss, Schatzkammer. }\end{array}$ \\
\hline & Ivie I I 86 & & $\begin{array}{l}\text { d) Theilvergoldete Schreibzeugcassette mit Her- } \\
\text { men, Emailfüllungen und Triglyphenfries. } \\
\text { Auf dem Deckel eine weibliche Figur mit } \\
\text { Inschrift von I } 557 \text {. } \\
\text { Besitzer: Grünes Gewölbe, Dresden. Katalog Erbstein } \\
\text { I884, S. II } 7 \text { Nr. 163. Graesse, Das Grüne Gewölbe } \\
\text { I877, Taf. I3. }\end{array}$ \\
\hline & wie II89 & & 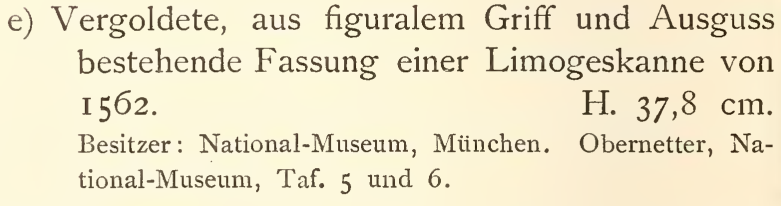 \\
\hline & ? & & $\begin{array}{l}\text { f) Vergoldete, aus figuralem Griff und Ausguss } \\
\text { bestehende Fassung einer Limogeskanne. Wie- } \\
\text { derholung des vorhergehenden Stückes. } \\
\text { Besitzer: Königl. Schatzkammer, München. Katalog } \\
\text { Schauss I879, K. I4. Abg. bei Schauss, Schatzkammer. }\end{array}$ \\
\hline & wie I 86 & & $\begin{array}{l}\text { g) Vergoldeter Pokal mit Horizontalprofilirungen. } \\
\text { Corpus reich getrieben, am Griffe allegorische } \\
\text { Figuren, auf dem Deckel Fürstengestalten. }\end{array}$ \\
\hline
\end{tabular}




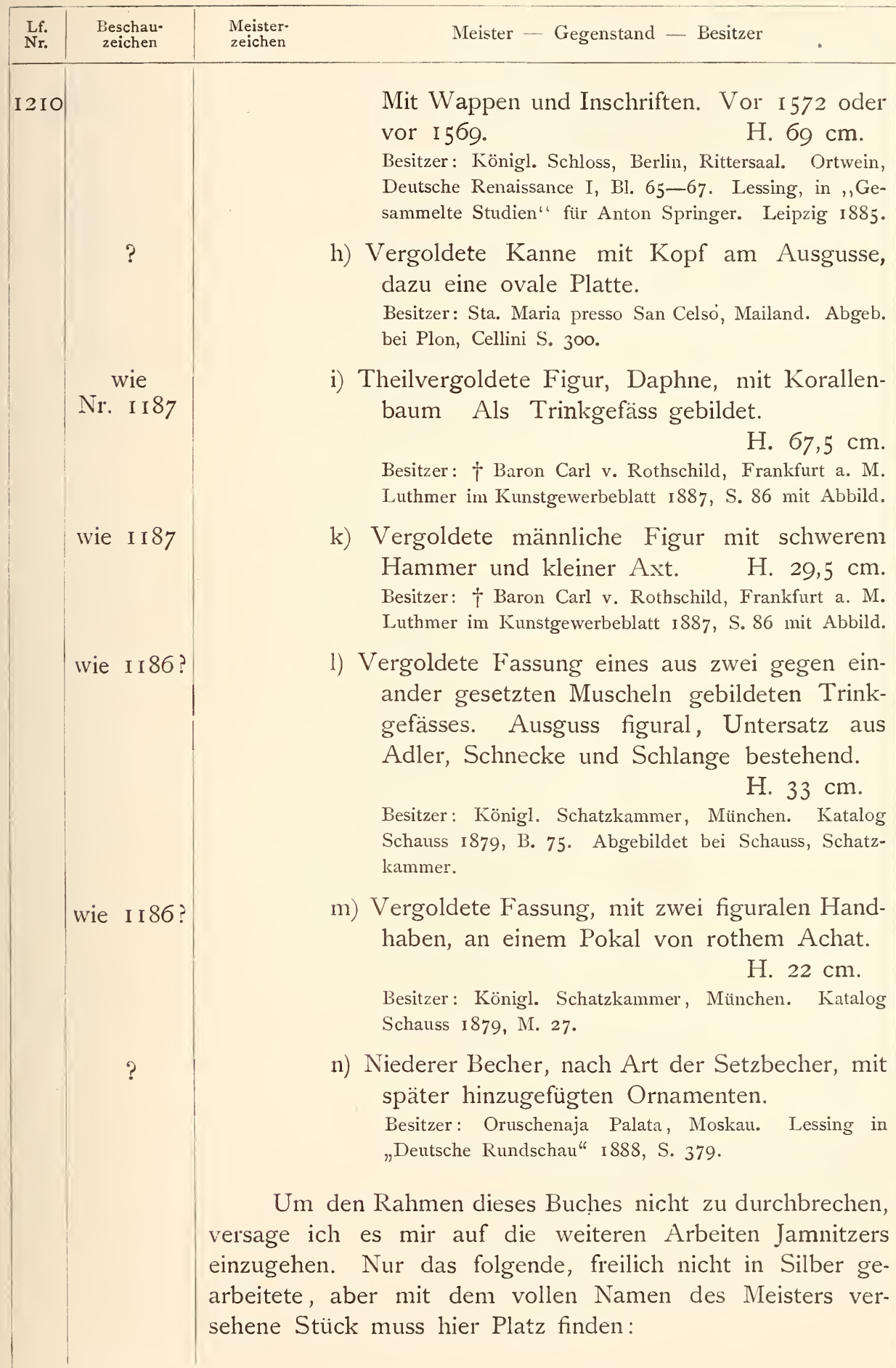




\begin{tabular}{|c|c|c|}
\hline $\begin{array}{l}\text { Lf. } \\
\text { Nr. }\end{array}$ & $\begin{array}{l}\text { Beschau- } \\
\text { zeichen }\end{array}$ & Meister - Gegenstand - Besitzer \\
\hline 1210 & & $\begin{array}{l}\text { DURCH WENTZEL JAMNITZER VER- } \\
\text { FERTIGT MDLXXVIII (nicht facsimilirt). } \\
\text { o) Astrolabium von vergoldeter Bronce. } \\
\text { Besitzer: Königl. mathem. physikal. Salon, Dresden. } \\
\text { Gurlitt im Kunstgewerbeblatt } 1885 \text {, S. 52, mit Detail- } \\
\text { abbildung. Vergl. auch Steche im Anzeiger für Kunde } \\
\text { der deutschen Vorzeit } 1877 \text {, Sp. } 55 \text {. }\end{array}$ \\
\hline
\end{tabular}

Ich glaube der Bequemlichkeit der Benutzer dieses Buches entgegenzukommen, wenn ich hier von der sonst immer angestrebten chronologischen Ordnung abweiche, und sämmtliche Mitglieder der Familie Jamnitzer nach einander anführe.

Albrecht Jamnitzer, Meister I 550, † I 590.

Trinkgefäss in Gestalt eines springenden Hirsches. Am Untersatz Thierlein und Blumenwerk. Besitzer (1884): Gebr. Egger, Budapest. Ausstellung Budapest 1884. 3. Saal, I4. Schrank, Nr. I. Katalog S. 145. Hunfalvy in Ungar. Revue 1884, S. 5 10. Bucher in Mitth. k. k. österr. Mus. 1884, S. 128. Abgeb. in Chefs d'œuvre d'orfèvrerie à l'exposition de Budapest.

Hans Jamnitzer, Meister i 561, Genannter I $596,+1603$.

Vergoldete Schmuckcassette mit Perlmutter, Email und Halbedelsteinen. Mit Inschrift.

H. I9 $\mathrm{cm}$.

Besitzer: Schloss Bebenhausen. Ausstellung München 1876, Katalog Nr. 2004. Biermann, Ausstellung Gmünd Tafel 6,7 und 8 .

Bartl Jamnitzer, Meister I 575, Geschworener 1595.

wie

Nr. I 187

a) Vergoldetes Trinkgefäss in Gestalt einer Amorfigur. Auf Postament mit Uhrwerk.

H. $30 \mathrm{~cm}$.

Besitzer: † Baron Carl v. Rothschild, Frankfurt a. M. Luthmer, Schatz Rothschild II, Taf. 6. 


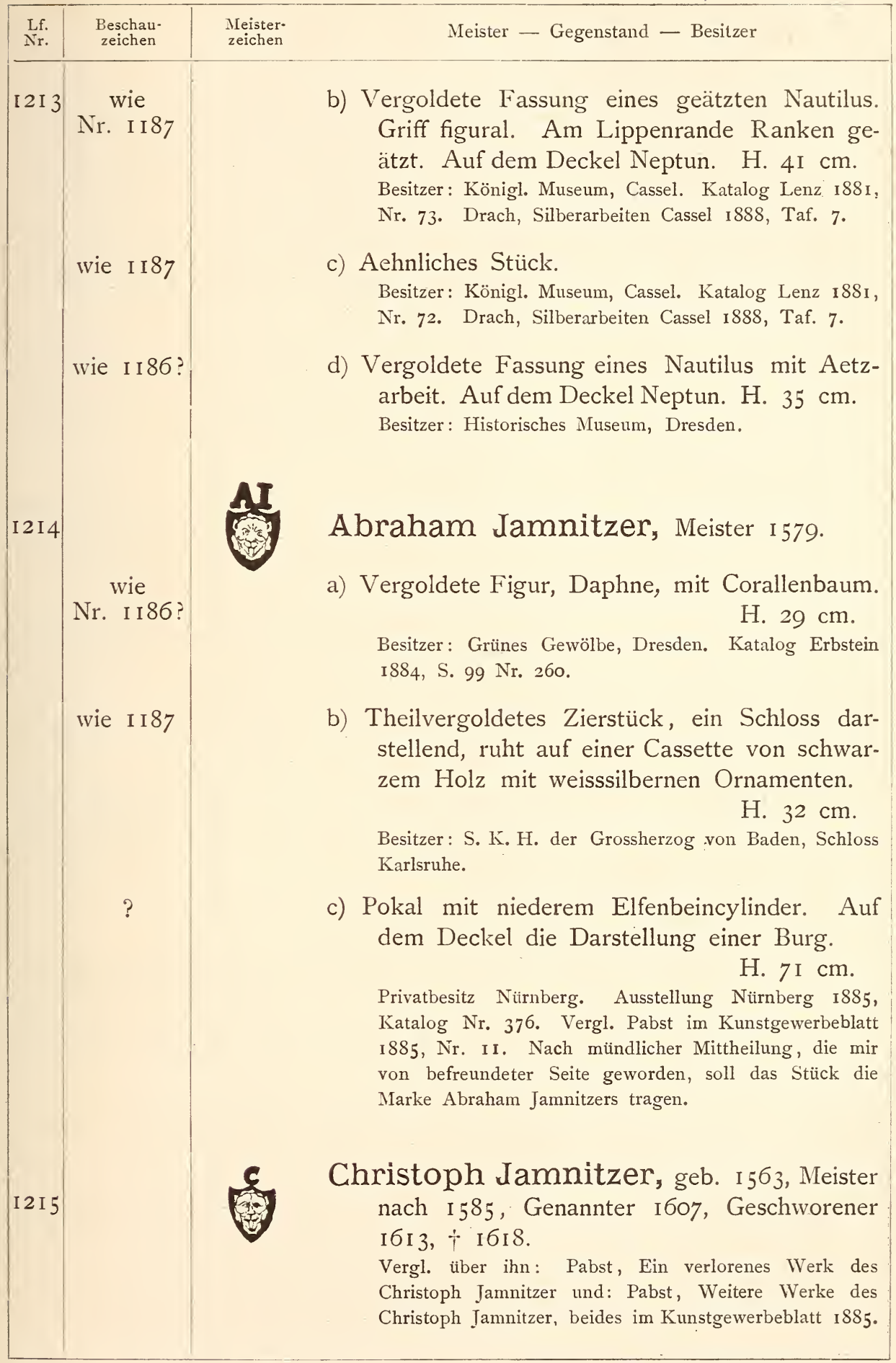




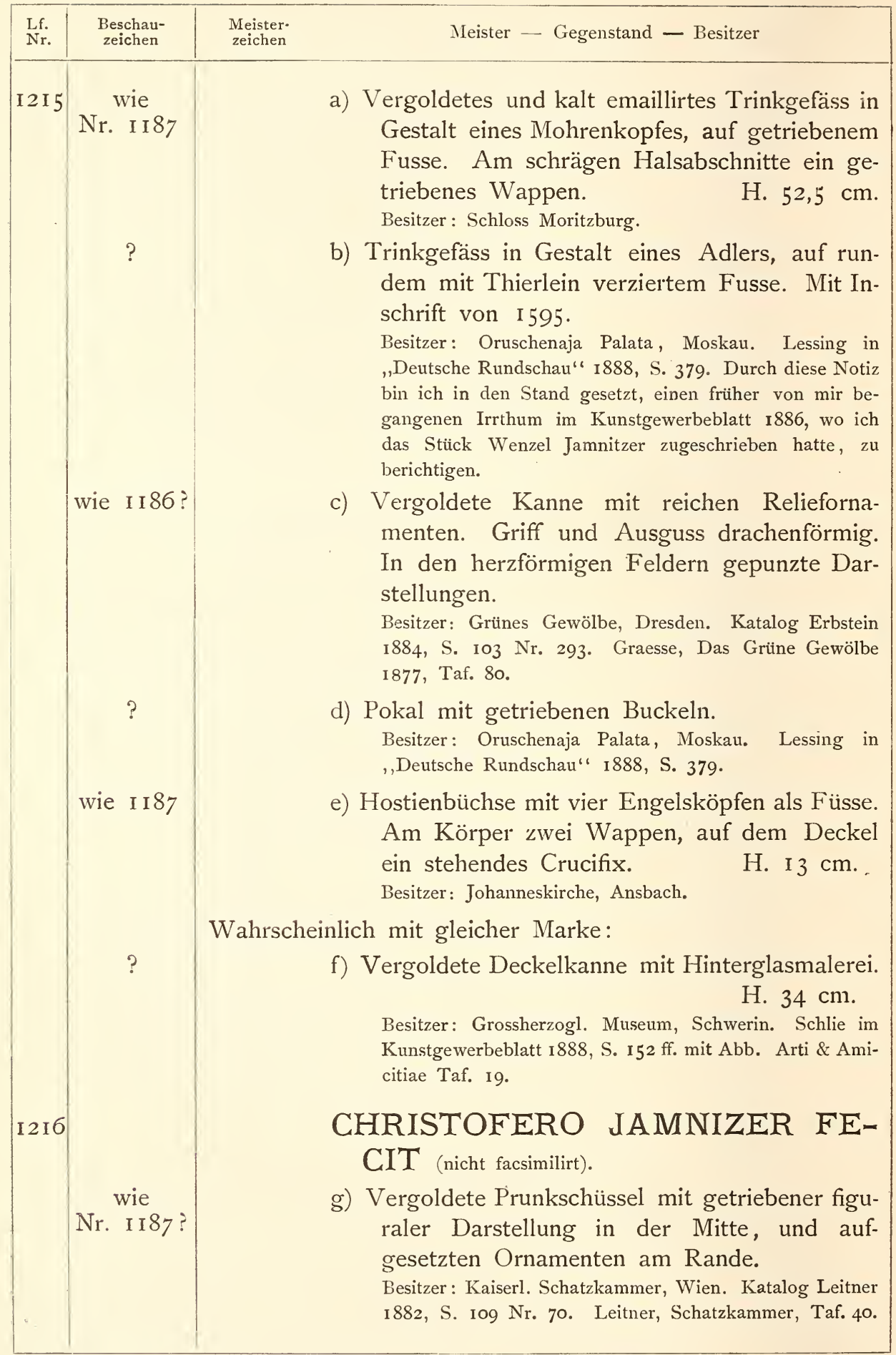




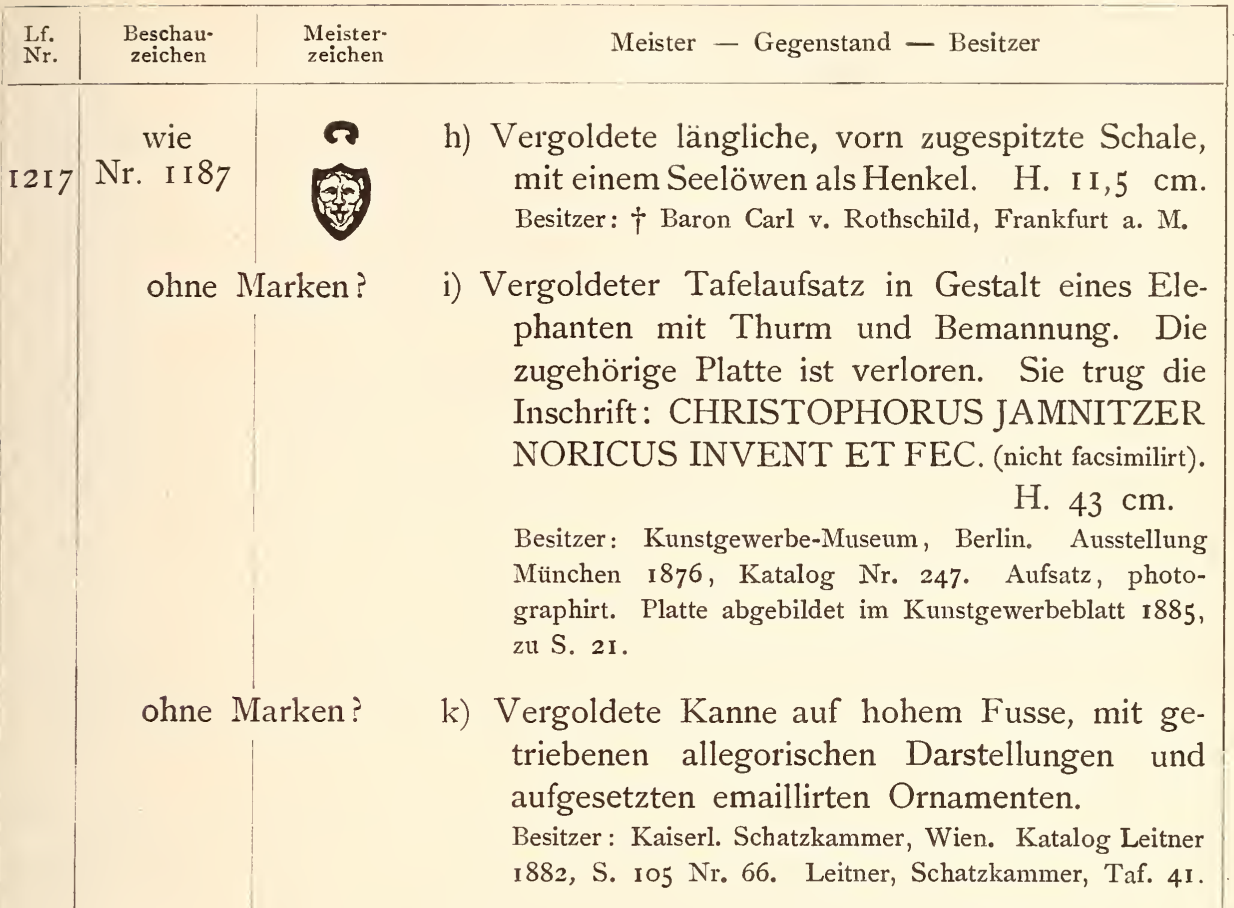

RB Kaspar Bauch, Meister I54I, Geschworener ${ }_{5} 567, \dagger$ I 583 .

wie

Nr. I I 87

wie I I 87

a) Theilvergoldeter Becher auf drei Schellenfüssen.

H. I $3,5 \mathrm{~cm}$.

Besitzer: Pfälzisches Gewerbe-Museum, Kaiserslautern. Katalog Nr. 18. Ausstellung Nürnberg 1885, Katalog Nr. 657.

b) Vergoldeter Pokal, in Kelchform, mit Inschriften.

H. I $5 \mathrm{~cm}$.

Besitzer: Grïnes Gewölbe, Dresden.

Wahrscheinlich mit gleichem Stempel:

c) Deckel auf einem Pokale, Augsburger Arbeit. Besitzer: Grünes Gewölbe, Dresden. Katalog Erbstein 1884, S. 98 Nr. 254. Graesșe, Das Grüne Gewölbe I 877 , Taf. 46.

d) Deckelkanne, mit Maskarons, Vögeln und Fruchtgehängen getrieben.

Besitzer: A. v. Sallet, Berlin. 


\begin{tabular}{|c|c|c|c|}
\hline $\begin{array}{l}\text { Lf. } \\
\text { Nr. }\end{array}$ & & $\begin{array}{l}\text { Meister- } \\
\text { zeichen }\end{array}$ & Meister - Gegenstand - Besitzer \\
\hline \multirow[t]{2}{*}{1219} & & KB & $\begin{array}{l}\text { Wahrscheinlich etwas verschobener Abschlag des } \\
\text { obigen Stempels Nr. I2 I } 8 \text {. }\end{array}$ \\
\hline & $\begin{array}{l}\text { wie } \\
\text { Nr. } \quad \text { I } 189\end{array}$ & & $\begin{array}{l}\text { Pokal mit halbkugelförmiger Cuppa. H. I } 4 \mathrm{~cm} \text {. } \\
\text { Besitzer: Grünes Gewölbe, Dresden. }\end{array}$ \\
\hline \multirow[t]{3}{*}{1220} & $\begin{array}{l}\text { wie } \\
\text { Nr. } \\
\text { I } 187\end{array}$ & (ג) & $\begin{array}{l}\text { Hannss Braband, Meister I } 535, \dagger \text { I } 569 \text {. } \\
\text { a) Vergoldeter Pokal mit niederer geschweifter } \\
\text { Cuppa und geätzten Ornamenten. H. I6 cm. } \\
\text { Besitzer: P. A. Kotschubey, St. Petersburg. }\end{array}$ \\
\hline & ? & \multicolumn{2}{|c|}{$\begin{array}{l}\text { Vermuthlich mit gleicher Marke: } \\
\text { b) Schüssel mit Perlmutterplatten. } \\
\text { Besitzer: Oruschenaja Palata, Moskau. Gefällige Mit- } \\
\text { theilung des Herm Prof. Dr. Julius Lessing, Berlin. }\end{array}$} \\
\hline & & \multicolumn{2}{|c|}{$\begin{array}{l}\text { Die beiden hier folgenden Lilienstempel } \mathrm{Nr} \text {. I22 I und } \\
\text { I222 gehören möglicherweise einem und demselben Meister } \\
\text { an. Jedenfalls ist aber einer davon zu deuten auf: } \\
\text { Christoph Lindenberger, Meister I } 546 \text {, } \\
\text { Geschworener I } 557 \text {, † nach I } 573 \text {. }\end{array}$} \\
\hline $122 \mathrm{I}$ & $\begin{array}{l}\text { wie } \\
\text { Nr. } \quad \text { I } 87\end{array}$ & है? & $\begin{array}{l}\text { a) Zwei vergoldete Setzbecher mit ciselirten Orna- } \\
\text { menten. } \quad \text { Zusammen, H. IO, } 5 \mathrm{~cm} \text {. } \\
\text { Besitzer: } \dagger \text { Baron Carl v. Rothschild, Frankfurt a. M. }\end{array}$ \\
\hline \multirow{3}{*}{ I 222} & wie II 87 & & $\begin{array}{l}\text { b) Einzelner vergoldeter Setzbecher mit ciselirten } \\
\text { Ornamenten. H. } 8 \mathrm{~cm} \text {. } \\
\text { Besitzer: Schongauer-Minseum, Colmar. Ausstellung } \\
\text { Nürnberg I } 885 \text {, Katalog Nr. 639. }\end{array}$ \\
\hline & $\begin{array}{l}\text { wie } \\
\mathrm{Nr} . \quad 1287\end{array}$ & ध & $\begin{array}{l}\text { c) Vergoldetes Scherztrinkgefäss in Gestalt eines } \\
\text { als Fass gebildeten Mannes mit Karre. In- } \\
\text { schrift. } \\
\text { Besitzer: Historisches Museum, Dresden. }\end{array}$ \\
\hline & ? & \multicolumn{2}{|c|}{ 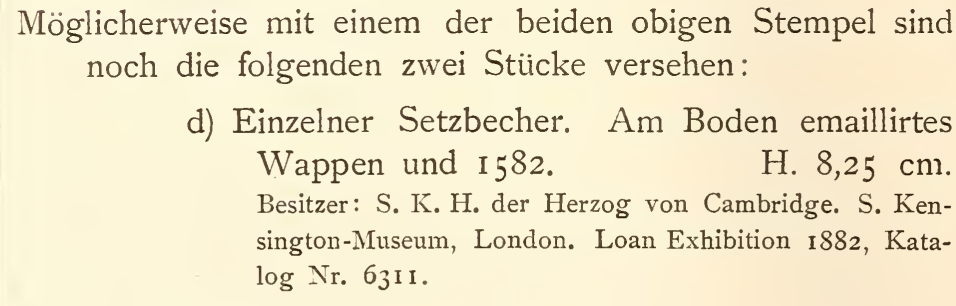 } \\
\hline
\end{tabular}




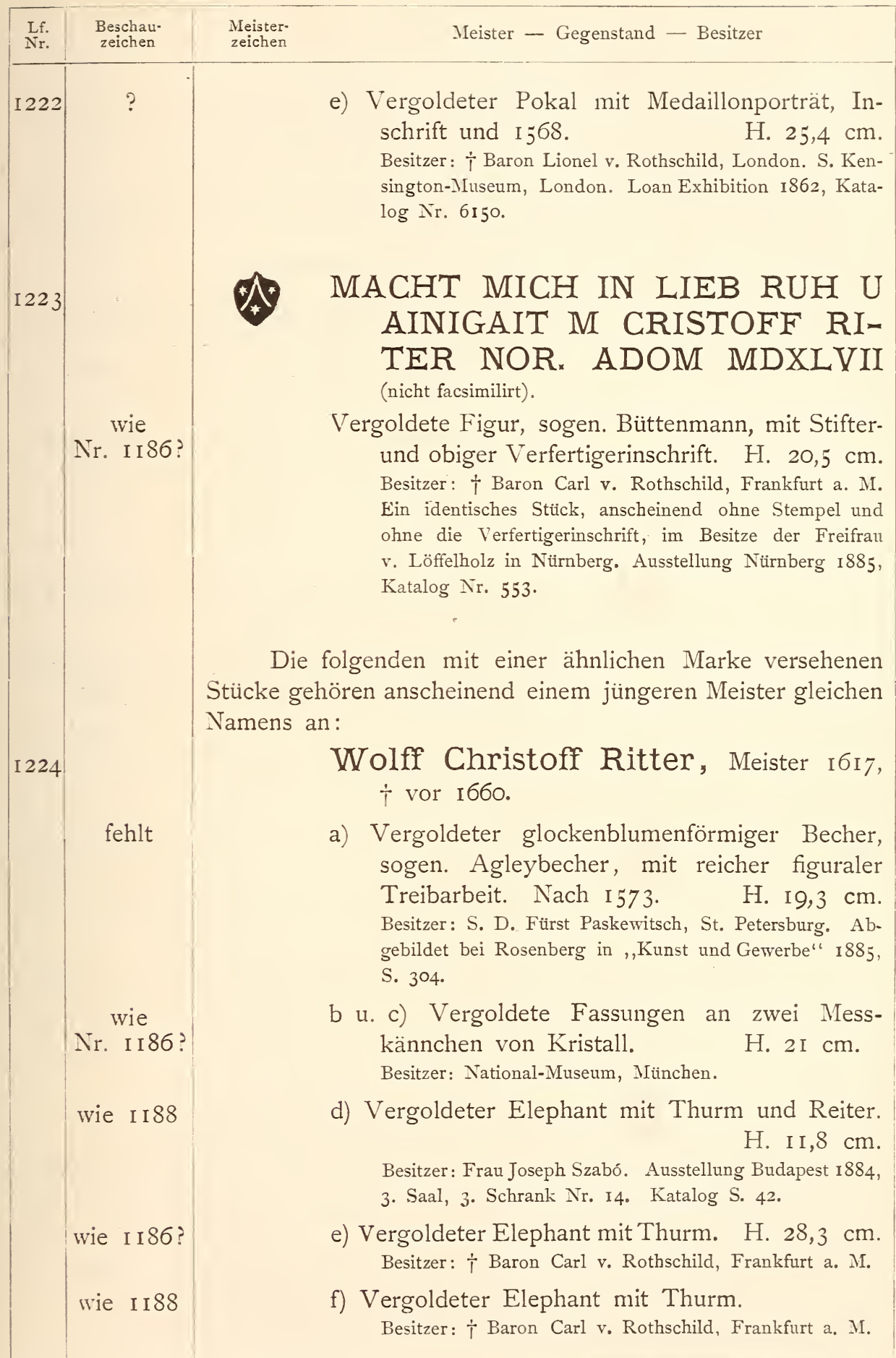




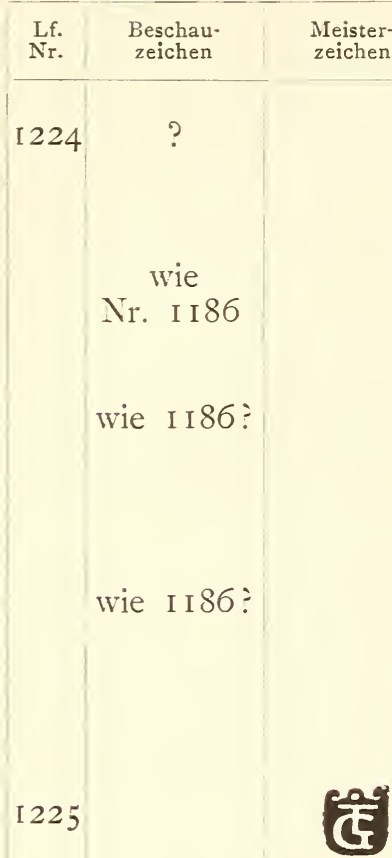

wie

Nr. II 87 g) Vergoldetes Trinkgefäss in Gestalt eines Bockes. Auf Untersatz mit Rädern. H. $23 \mathrm{~cm}$. Besitzer (I 885): Jacobsohn, St. Petersburg.

h) Vergoldetes Trinkgefäss in Gestalt eines Wildschweines. H. $15 \mathrm{~cm}$. Besitzer: Schloss Moritzburg.

i u. k) Kanne in Gestalt eines Vogels, mit Steinen besetzt, und zugehöriger Platte.

Kanne, H. $32 \mathrm{~cm}$., Platte Lg. $\sigma_{3} \mathrm{~cm}$. Besitzer : Königl. Silberkammer, München.

1) Laterne mit figuraler Gravirung und Inschrift. Besitzer: Graf Aladar Andrássy. Ausstellung Budapest I884.

Gregorius Türck, Meister I547, Geschworener I $56 \mathrm{I}$, † 1569 .

Vergoldete Fassung eines Nussbechers. Im Deckel Porträtmedaille und Inschrift von I 566 .

H. $24,5 \mathrm{~cm}$.

Besitzer: National-Museum, München.

a) Vergoldete Deckelkanne mit Darstellung der Planeten.

H. $17 \mathrm{~cm}$.

Besitzer: $\uparrow$ Baron Carl v. Rothschild, Frankfurt a. M. Luthmer, Schatz Rothschild I, Taf. 45 b.

wie I I 86

I 227

wie

Nr. II 87

wie I 87

\section{Hannss Koppel, Meister I 549.}

a) Vergoldeter Pokal mit Horizontalprofilirungen. H. $19,5 \mathrm{~cm}$. Besitzer: Patriarchen-Schatzkammer, Moskau.

b) Vergoldeter Deckel zu einem von Hans auf der Burg verfertigten Pokale.

Besitzer: Patriarchen-Schatzkammer, Moskau. 


\begin{tabular}{|c|c|c|c|}
\hline $\begin{array}{l}\mathrm{Lff} \\
\mathrm{Nr} .\end{array}$ & $\begin{array}{l}\text { Beschau- } \\
\text { zeichen }\end{array}$ & $\begin{array}{l}\text { Meister- } \\
\text { zeichen }\end{array}$ & Meister - Gegenstand - Resitzer \\
\hline I 228 & $\begin{array}{l}\text { wie } \\
\mathrm{Nr} . \quad \text { I I } 86\end{array}$ & & $\begin{array}{l}\text { a) Vergoldetes Trinkgefäss in Gestalt einer Gemse, } \\
\text { auf einer Bergspitze stehend. } \\
\text { Besitzer: Baron Nathanael v. Rothschild, Wien. Photo- } \\
\text { graphirt. }\end{array}$ \\
\hline & wie I I 86 & & $\begin{array}{l}\text { b) Vergoldete Fassung einer orientalischen Por- } \\
\text { zellanflasche. } \\
\text { Besitzer: } \uparrow \text { Haron Carl v. Rothschild, Frankfurt a. M. }\end{array}$ \\
\hline & ? & & $\begin{array}{l}\text { c) Vergoldete Fassung und Deckel eines Glases. } \\
\text { Besitzer: Johanneskirche, Hamburg. ,Von den Arbeiten } \\
\text { der Kunstgewerke zu Hamburg"“. Herausgegeben vom } \\
\text { Verein für Hamburgische Geschichte } 1885 \text {. }\end{array}$ \\
\hline & ? & & $\begin{array}{l}\text { d) Becher auf hohem Fusse mit wenig geschweif- } \\
\text { ter Cuppa. Mit späteren Besitzerinitialen und } \\
\text { I66I. H. I6,5 cm. } \\
\text { Besitzer: Kirche, Bretzenheim (bei Mainz). Gefällige } \\
\text { Mittheilung des Herrn Geistl. Rath Dr. Fr. Schneider, } \\
\text { Mainz. }\end{array}$ \\
\hline
\end{tabular}

Hans Lencker der Aeltere, Meister I 550, Geschworener I559, Genannter I 575 , $\dagger \mathrm{r} 585$.

wie

Nr. I 185

wie II 85 ?

a u. b) Zwei runde Tassen von emaillirtem Silber. Vergoldete Delphine als Füsse. H. $8 \mathrm{~cm}$.

Besitzer: Königl. Schatzkammer, München. Katalog Schauss I879, E I.

\section{HANS LENKER * NÜRNBERG 1554 M. FECIT (nicht facsimilirt).}

c) Emaillirte Beschläge an einem Gebetbuche. Besitzer: Königl. Hofbibliothek, München. Schauss, Katalog der Schatzkammer München I879, E I.

wie

Nr. I I 88

wie I I 88

Paulus Dulner, Meister I552, Geschworener I 563 , Genannter I 584, Rathsfreund I 586 , $\dagger \mathrm{I} 596$.

a) Vergoldetes Trinkgefäss in Gestalt eines Hundes. Mit Wappen. (Um i 566.) H. $34 \mathrm{~cm}$.

Besitzer: Deutschordensschatz, Wien.

b) Vergold. Trinkgefäss in Gestalt eines Fuchses, der eine Ente fortträgt. (Um I 572.) H. $28,5 \mathrm{~cm}$. Besitzer: Deutschordensschatz, Wien. 


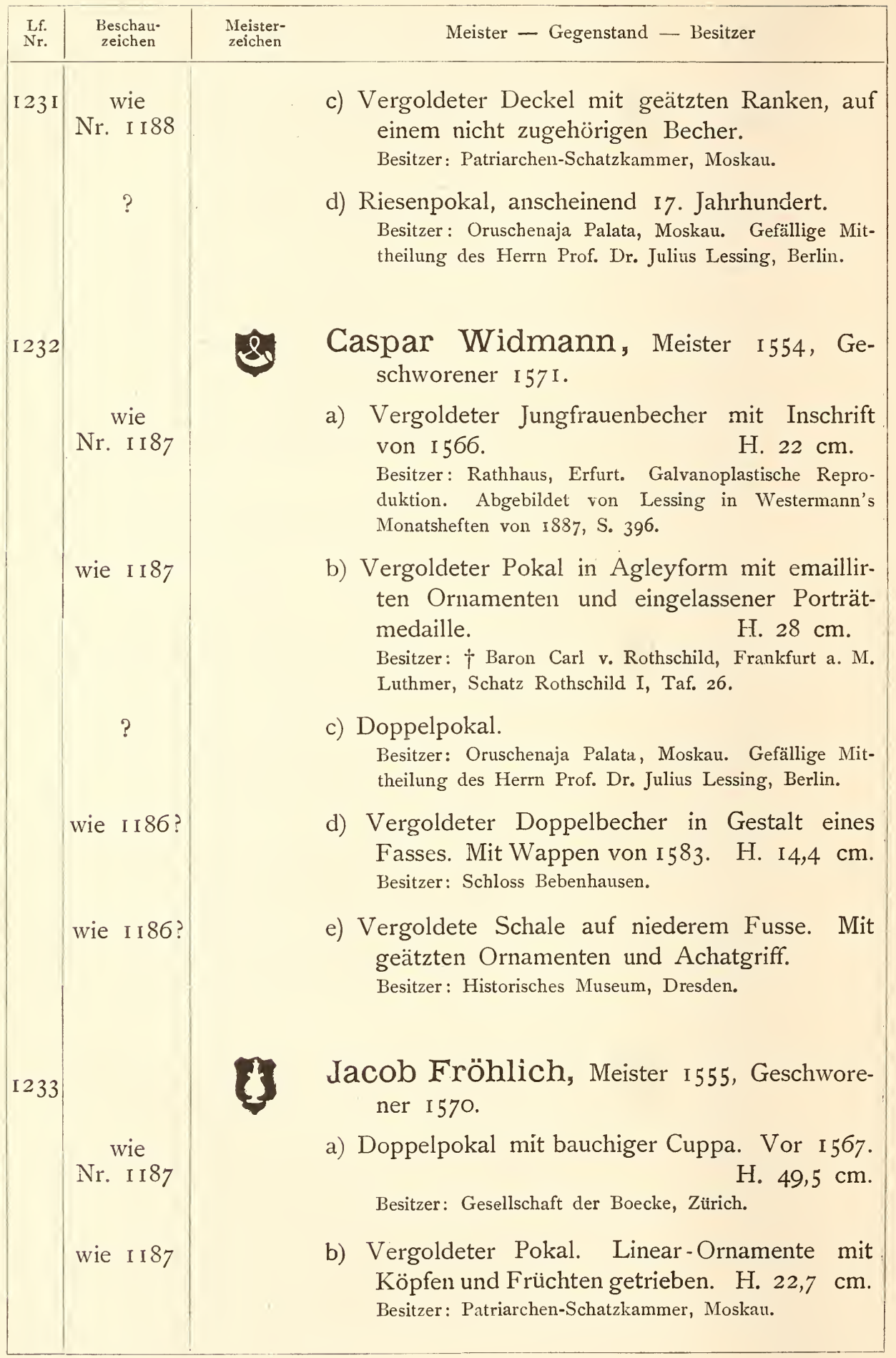




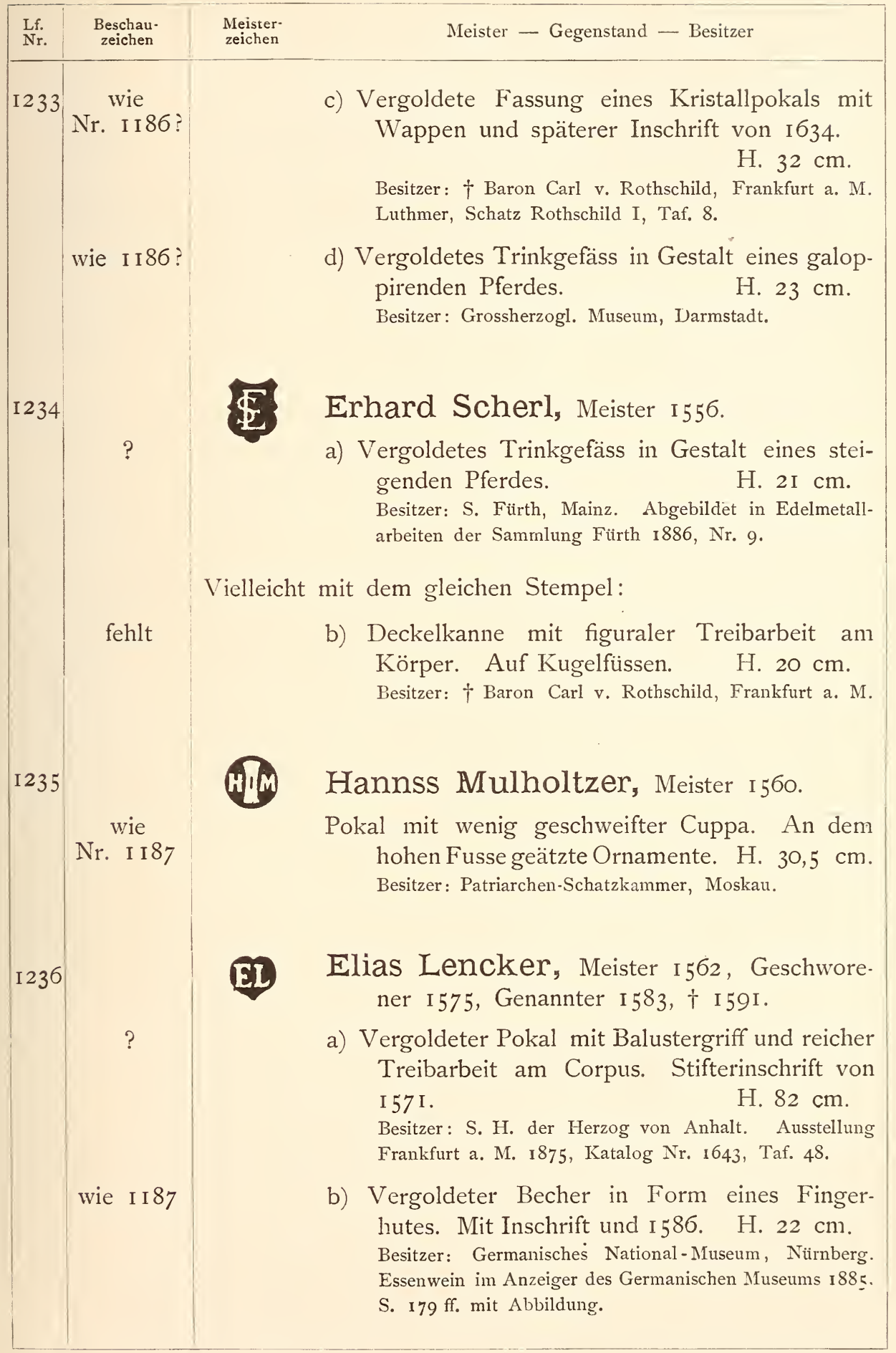




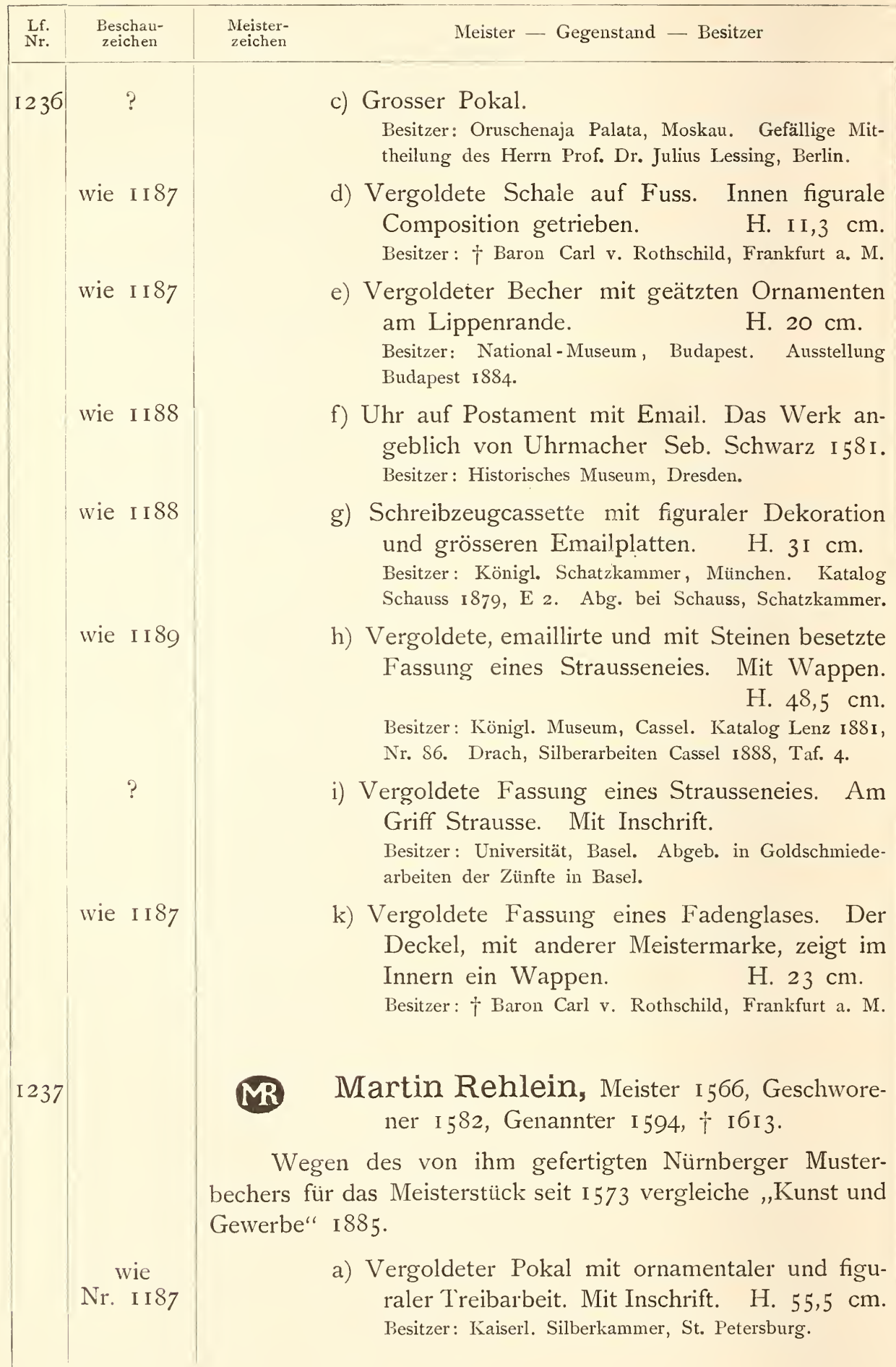




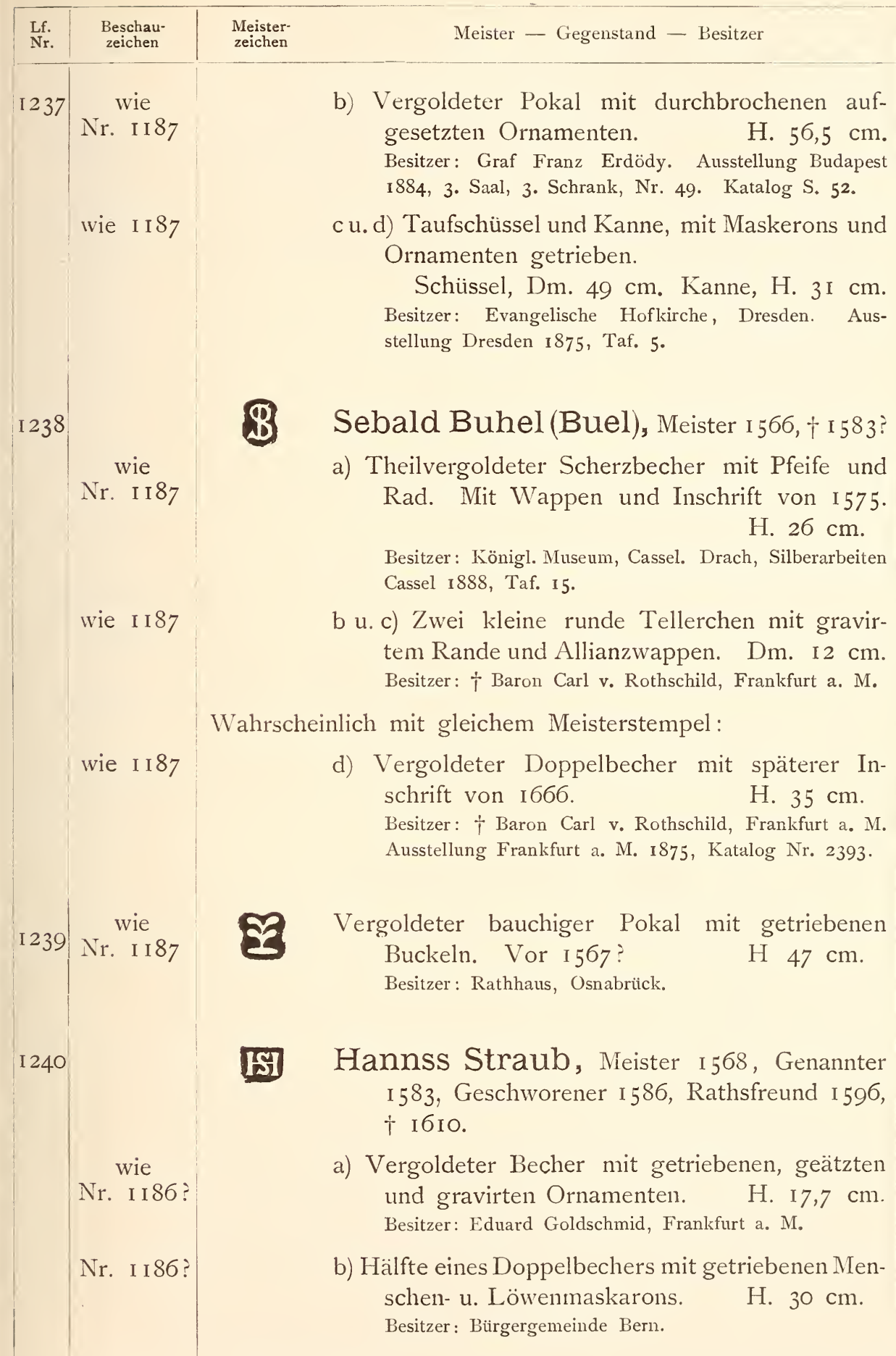




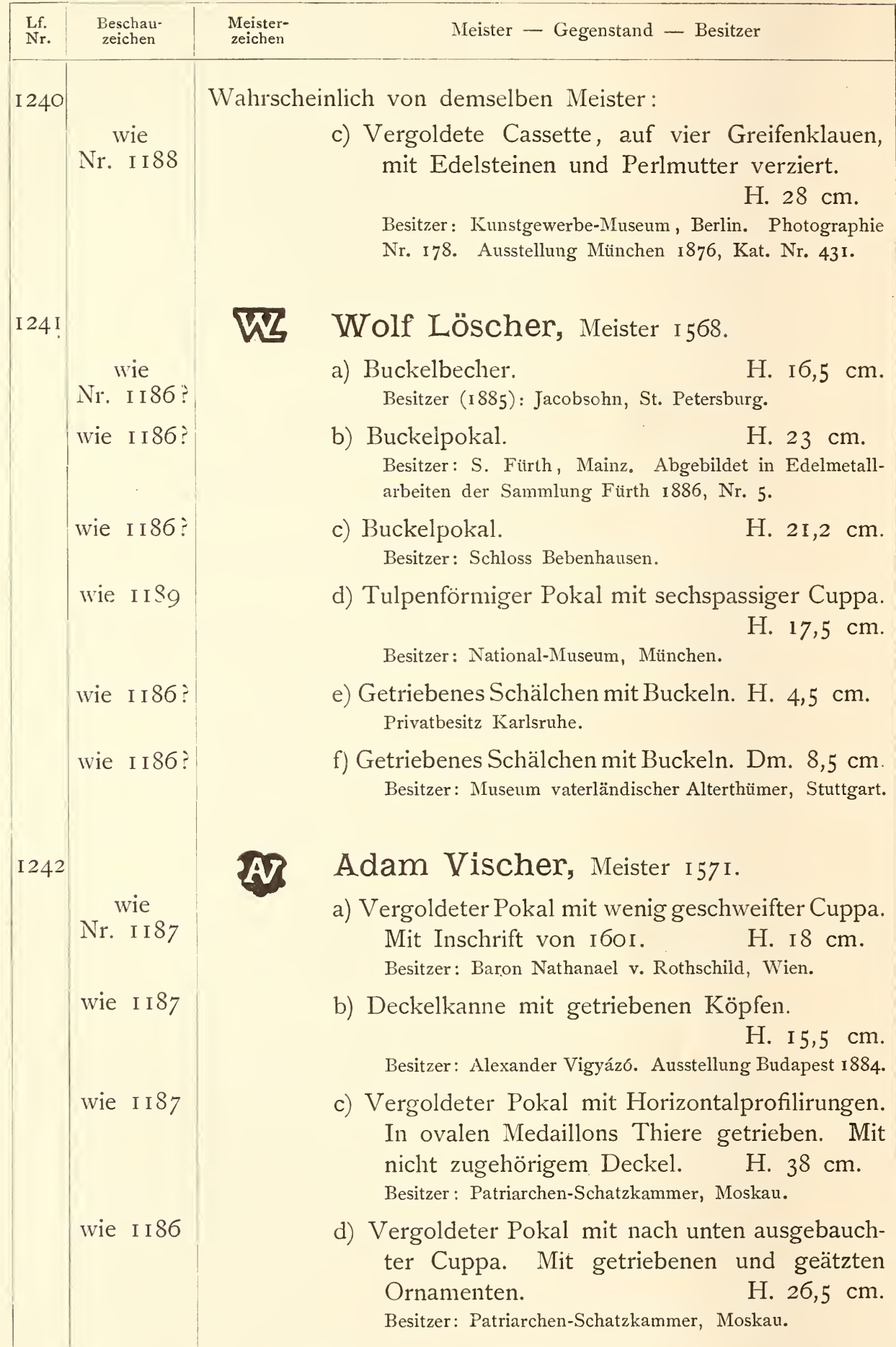




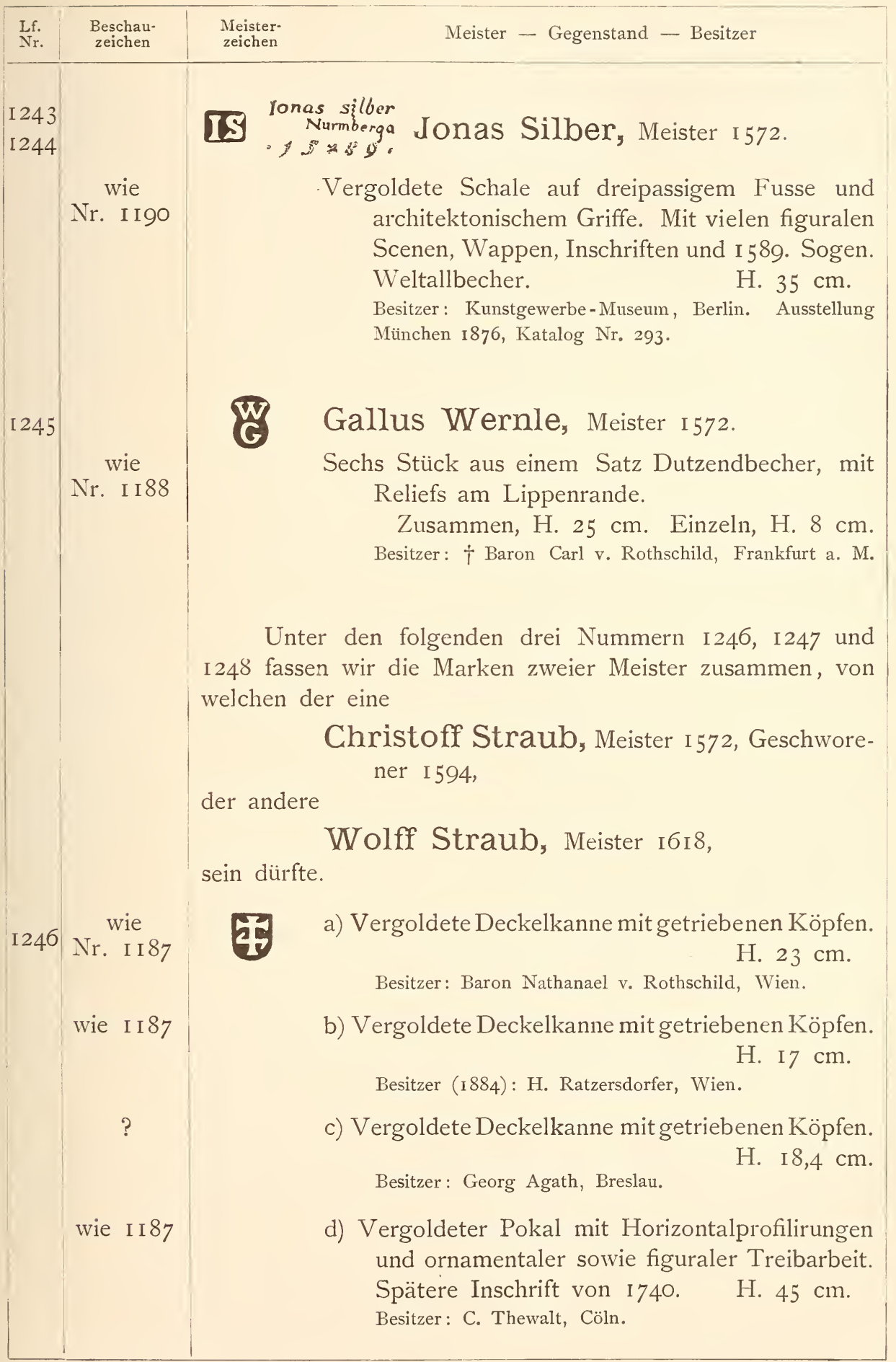




\begin{tabular}{|c|c|cc}
\hline $\begin{array}{c}\text { Lf. } \\
\text { Nr. }\end{array}$ & $\begin{array}{c}\text { Beschau- } \\
\text { zeichen }\end{array}$ & $\begin{array}{c}\text { Meister- } \\
\text { zeichen }\end{array} \quad$ Meister - Gegenstand - Besitzer \\
\hline
\end{tabular}

wie I 87 wie I 187

g) Stengelpokal mit sechsmal eingezogener Cuppa. H. I7 $\mathrm{cm}$.

Besitzer: J. Beck, Nürnberg. Ausstellung Nürnberg I885, Katalog Nr. $75^{\circ}$.

h) Stengelpokal mit sechsmal eingezogener Cuppa. H. $20,5 \mathrm{~cm}$. Besitzer: Pfälzisches Gewerbe-Museum, Kaiserslautern. Ausstellung Nürnberg 1885, Katalog Nr. 658 .

wie I 87

i) Stengelpokal mit sechsmal eingezogener Cuppa.

H. $20,5 \mathrm{~cm}$.

Ausstellung Augsburg I 886 . Möglicherweise identisch mit dem vorhergehenden Stiicke.

wie I I86? k) Vergoldeter Becher mit Buckeln und Zügen.

Besitzer: H. Boskowitz, Wien.

H. $16,5 \mathrm{~cm}$.

wie I I92

1) Vergoldetes Schmuckkofferchen, auf vier Kugelfüssen ruhend.

Lg. $6,5 \mathrm{~cm}$.

Besitzer: Frhr. v. Rehlingen, Hainhofen? Ausstellung Augsburg 1886, Katalog Nr. I899?

Mit einer der drei vorhergehenden Marken ist auch das folgende Stück gestempelt:

m) Doppelpokal.

Besitzer: Oruschenaja Palata, Moskau. Gefällige Mittheilung des Herrn Prof. Dr. Julius Lessing, Berlin.

(M) Möglicherweise gehört diese Marke demselben Melchior Bayer, Meister I525, Geschworener $\mathrm{I}_{534}$, $\uparrow \mathrm{I} 577$ an, welcher oben S. $236 \mathrm{Nr}$. II83 bereits erwähnt ist.

Ich kann diesen Meister leider erst an dieser Stelle, etwas zu spät, einreihen, weil sich die Erklärung der Marke erst während der Correctur ergeben hat. 


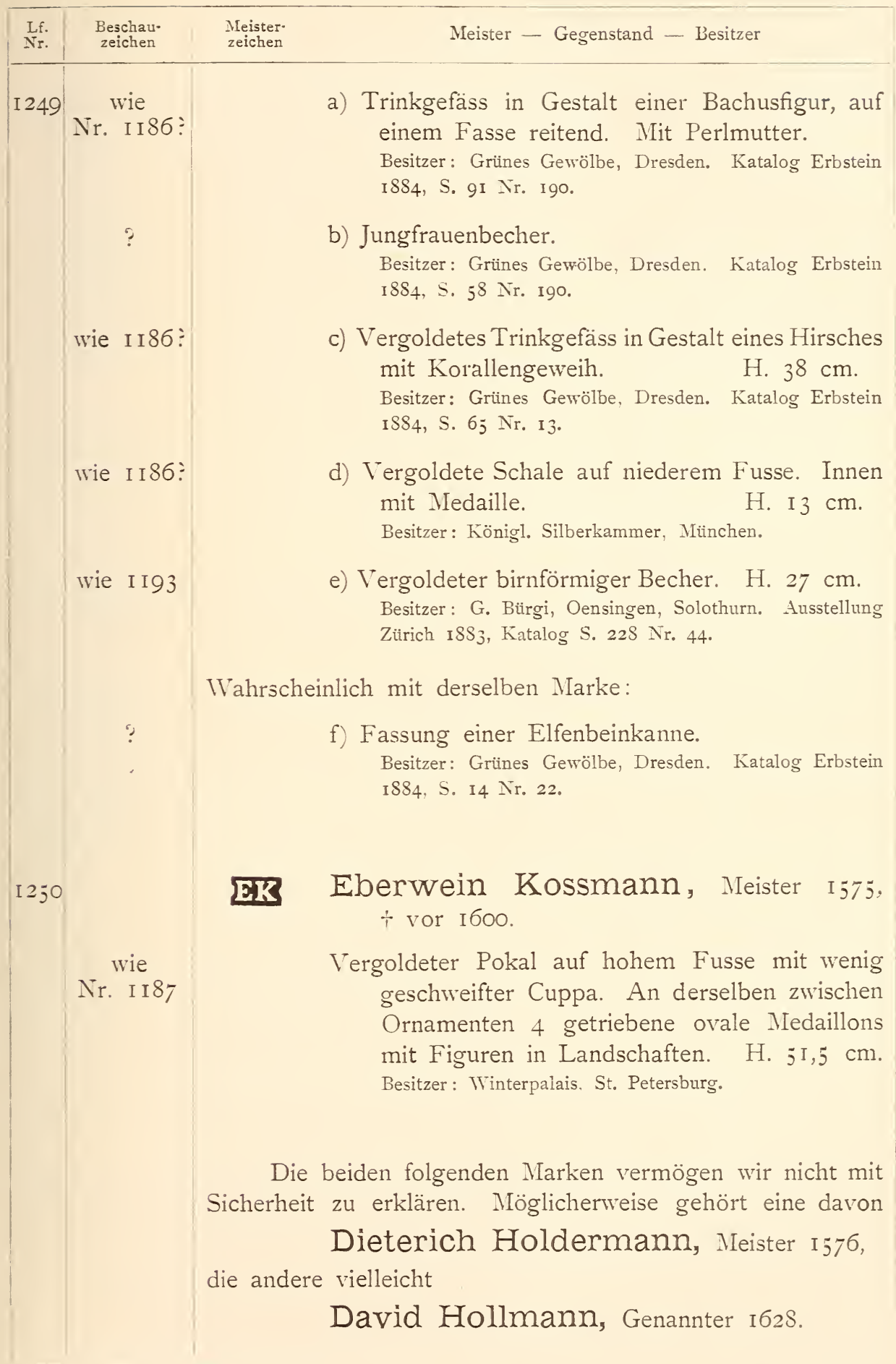




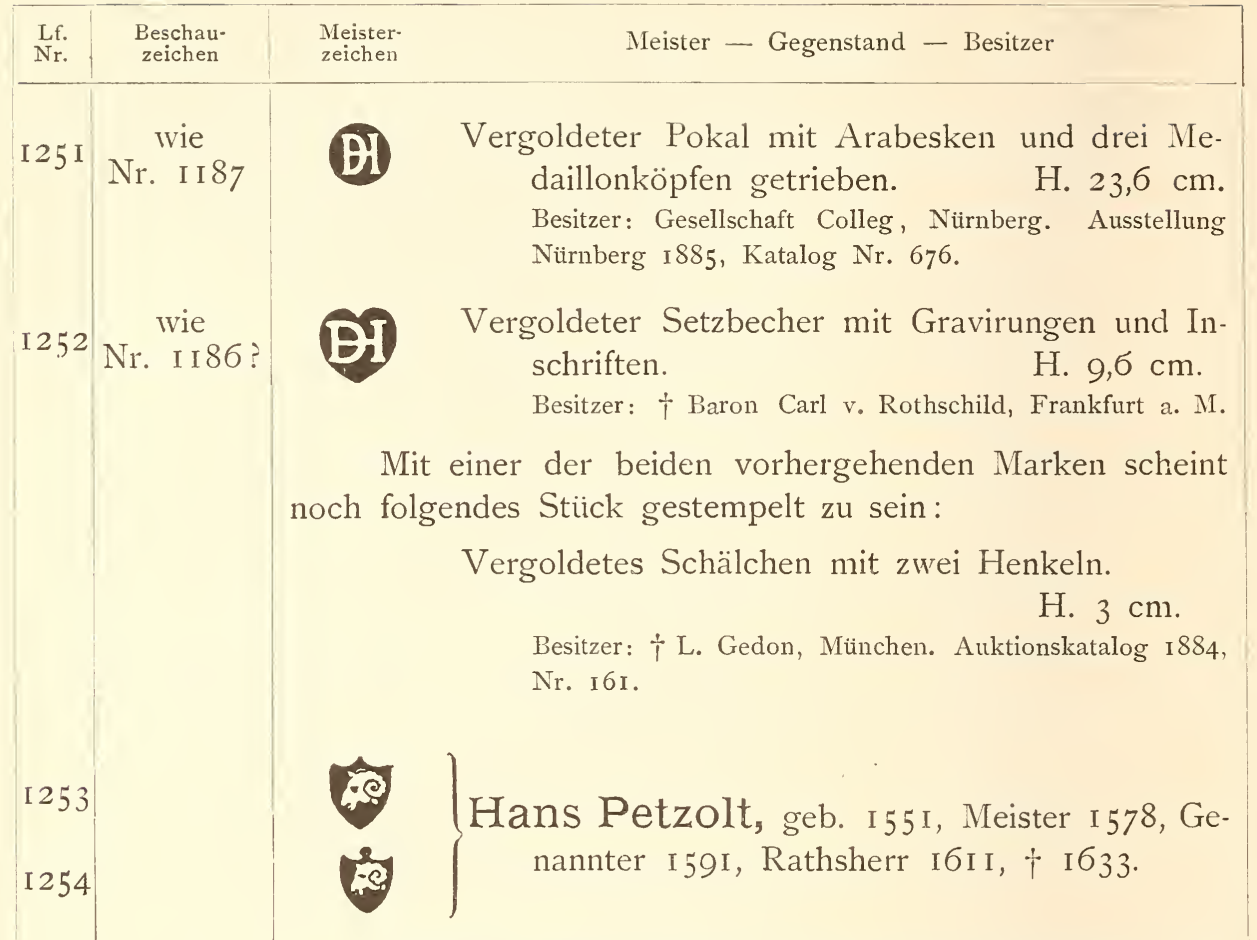

Obgleich beide Marken, wie sie hier gezeichnet sind, auf den Arbeiten vorkommen, glaube ich doch, dass sie nur auf einen einzigen Punzen zurückzuführen sind, der sich der zweiten Figur genähert haben wird. Abnützung und undeutliches Ausschlagen werden die Ursachen der Differenz sein, so dass meistens der Stempel wie in der ersten Figur erscheint.

wie

Nr. I I 86

a) Vergoldeter Pokal mit getriebenen Buckeln und aufgesetzten Ornamenten. Am Fuss- und Lippenrande geätzt. Am Griffe Karyatiden weiblicher Bildung, am Fusse Laubwerk und Engelsköpfe und auf dem Deckel eine Diana.

H. $79,5 \mathrm{~cm}$.

Besitzer: Königl. Schloss Berlin, Rittersaal. Ausstellung Frankfurt a. M. I 875, Katalog Nr. 1613. Abb. Taf. 47 .

b) Vergoldeter Pokal mit getriebenen Buckeln und gegossenen, aufgesetzten Ornamenten. An der Cuppa ein Triglyphenfries. Deckelbekrönung Amor mit Schild und Pfeil.

Besitzer: † Baron Carl v. Rothschild, Frankfurt a. M. Luthmer, Schatz Rothschild II, Taf. 23. 


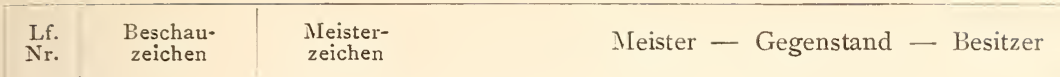

I 253 wie

I $254 \mathrm{Nr}$. I I 86

wie I 87

?

?

?

ohne Marken c) Vergoldeter Pokal mit getriebenen, ornamentirten Buckeln und aufgesetzten, gegossenen Ornamenten. Auf dem Deckel weibliche Figur mit Segel. H. $62 \mathrm{~cm}$.

Besitzer: $\uparrow$ Baron Carl v. Rothschild, Frankfurt a. M. Luthmer, Schatz Rothschild II, Taf. 8.

d) Pokal mit getriebenen figuralen Darstellungen und aufgesetzten, gegossenen Ornamenten.

H. ca. $100 \mathrm{~cm}$.

Besitzer: Oruschenaja Palata, Moskau. Lessing in „,Deutsche Rundschau“" I888, S. 379.

e) Vergoldeter Ananaspokal. Griff figural.

Besitzer: Kunstgewerbe-Museum, Berlin.

f) Vergoldeter Doppelpokal mit getriebenen Bukkeln und aufgesetzten Ornamenten. Lippenrand gravirt, Medaille von I 596 eingelassen.

H. $54 \mathrm{~cm}$.

Besitzer: $†$ Baron Carl v. Rothschild, Frankfurt a. M.

g) Doppelpokal mit getriebenen Buckeln und gravirtem Lippenrande.

Besitzer: Oruschenaja Palata, Moskau. Lessing in „,Deutsche Rundschau“ I888, S. 379.

h) Vergoldeter Pokal mit eiförmiger Cuppa, an welcher allegorische Figuren getrieben sind.

H. 3 I $\mathrm{cm}$.

Besitzer: Baron Nathanael v. Rothschild, Wien.

i) Aehnliches Stück.

Besitzer: Graf Eltz, Eltville. Ausstellung Frankfurt a. M. I875, Katalog Nr. 1634. Abbildung Taf. 4.

k) Aehnliches Stück mit eingelassener Medaille von I 580 .

H. $33,5 \mathrm{~cm}$. Besitzer: Gräfin Livia Zichy, Budapest. Austellung Budapest 1884, 3. Saal, 14. Schrank, Nr. 4. Katalog S. I49. Vergl. ïber diese drei Stiicke Kunstgewerbeblatt I 885, S. 60. 


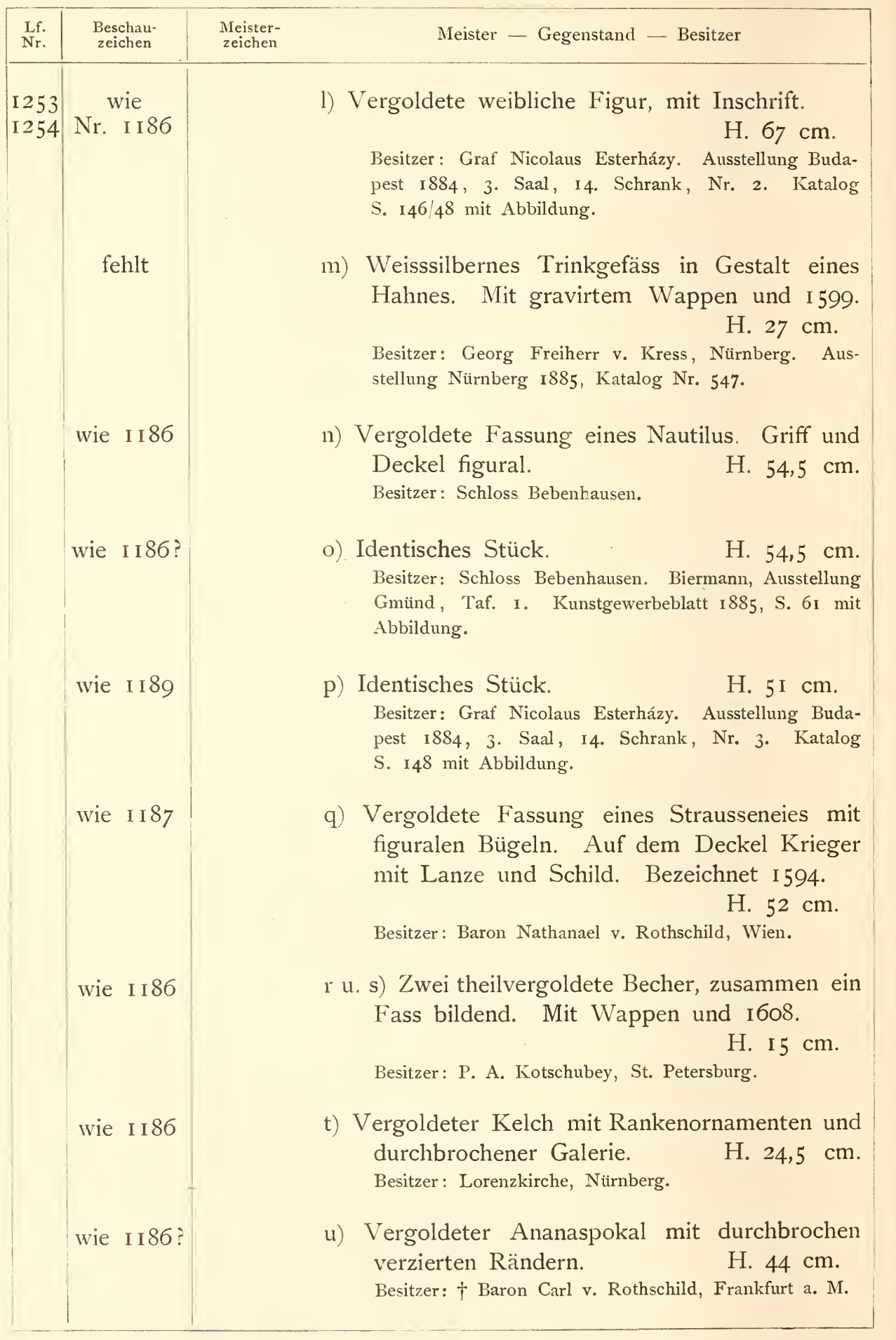




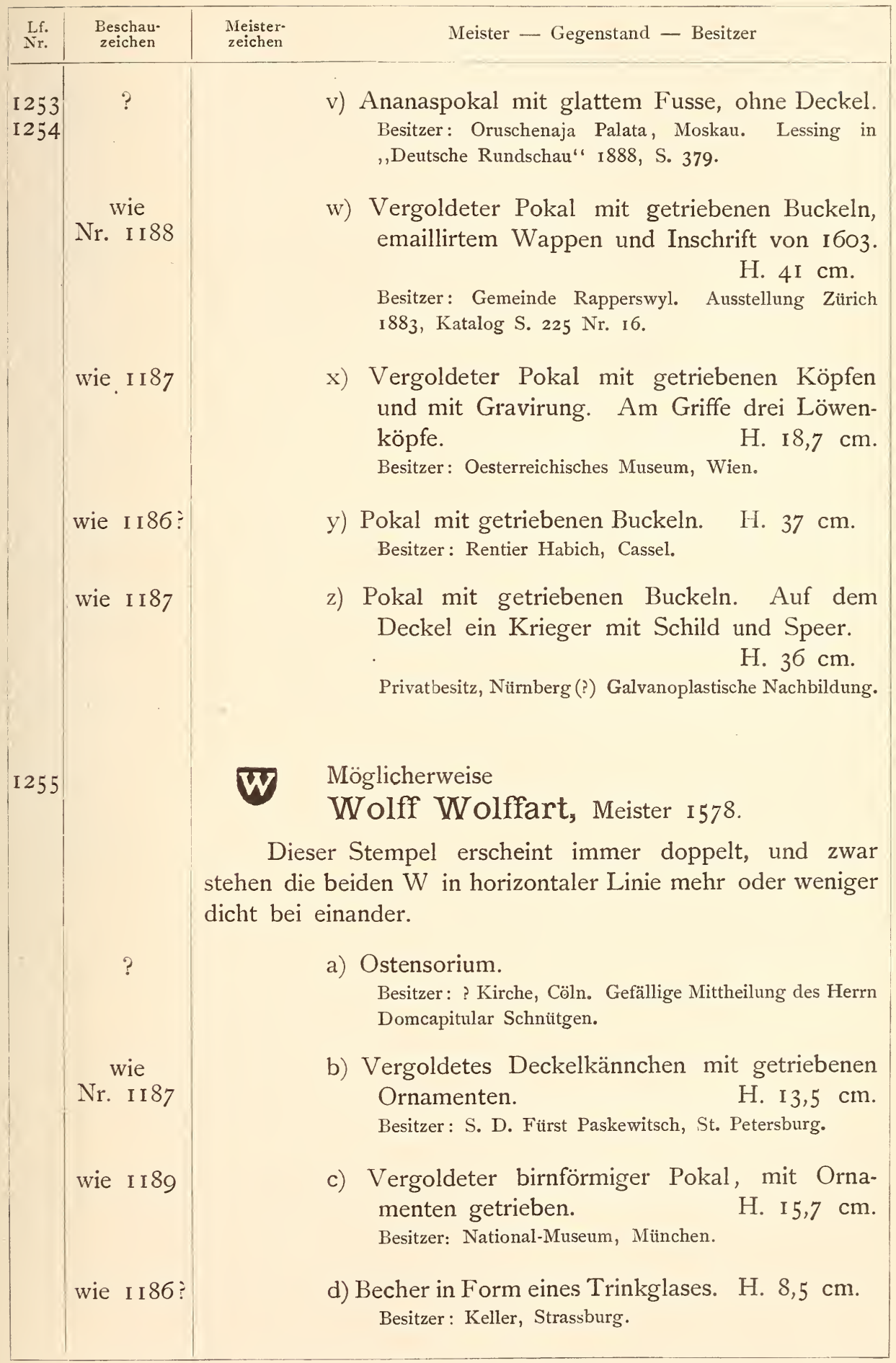




\begin{tabular}{|c|c|c|c|}
\hline $\begin{array}{l}\text { Lf. } \\
\text { Nr. }\end{array}$ & $\begin{array}{l}\text { Beschau- } \\
\text { zeichen }\end{array}$ & $\begin{array}{l}\text { Meister- } \\
\text { zeichen }\end{array}$ & Meister - Gegenstand - Besitzer \\
\hline 255 & $\begin{array}{l}\text { wie } \\
\text { Nr. I I } 86 ?\end{array}$ & & $\begin{array}{l}\text { e) Vergoldeter geschweifter Becher mit aufgesetzten } \\
\text { getriebenen Imperatorenköpfen. H. I4,5 cm. } \\
\text { Besitzer: Keller, Strassburg. }\end{array}$ \\
\hline $\begin{array}{l}\text { I } 256 \\
\text { I } 257\end{array}$ & & $\begin{array}{l}\text { FH } \\
\text { FH } \\
\text { FH }\end{array}$ & $\begin{array}{l}\text { FriedrichHillebrand(t)(Hildebrand } \\
\text { oder Hilleprand), Meister I 580, Ge- } \\
\text { nannter I 593, Geschworener I597, † I608. } \\
\text { Vergl. uber diesen Meister Kunst und Gewerbe 1885, } \\
\text { S. I10/13. }\end{array}$ \\
\hline & $\begin{array}{l}\text { wie } \\
\text { Nr. I I } 86 ?\end{array}$ & & $\begin{array}{l}\text { a) Jungfrauenbecher mit Muschel. H. } 44,5 \mathrm{~cm} \text {. } \\
\text { Besitzer: Grünes Gewölbe, Dresden. Katalog Erbstein } \\
\text { 1884, S. } 54 \mathrm{Nr} \text {. 184. Graesse, Das Grüne Gewölbe } \\
\text { 1877, Taf. } 6 \text {. }\end{array}$ \\
\hline & wie I 187 & & $\begin{array}{l}\text { b) Vergoldete Fassung eines Muschelbechers mit } \\
\text { geätztem Rande und figuralem Griffe, Wappen } \\
\text { und Initialen. } \\
\text { Besitzer: } † \text { Haron Carl v. Rothschild, Frankfurt a. M. } \\
\text { Luthmer, Schatz Rothschild I, Taf. 4 b. }\end{array}$ \\
\hline & wie I I86? & & $\begin{array}{l}\text { c) Pokal aus einer Muschel gebildet, mit figuralem } \\
\text { Griffe. } \\
\text { Besitzer: Grünes Gewölbe, Dresden. Katalog Erbstein } \\
\text { ı884, S. } 50 \text { Nr. 147. }\end{array}$ \\
\hline & wie I I 86 & & $\begin{array}{l}\text { d) Fassung eines Muschelbechers mit geätztem } \\
\text { Rande und figuralem Griffe. H. } 47 \mathrm{~cm} \text {. } \\
\text { Besitzer: Grossherzogl. Museum, Darmstadt. Schäfer, } \\
\text { Kunstschätze des Museums, Taf. 16. }\end{array}$ \\
\hline & wie I I 86 & & $\begin{array}{l}\text { e) Vergoldete Fassung eines Muschelbechers mit } \\
\text { figuralem Griffe. } \\
\begin{array}{ll}\text { Besitzer: Herzogl. Museum, Gotha. } & \text { H6,5 cm. }\end{array}\end{array}$ \\
\hline & ? & & $\begin{array}{l}\text { f) Fassung eines Muschelbechers mit geätztem } \\
\text { Rande und figuralem Griffe. H. } 37 \mathrm{~cm} \text {. } \\
\text { Besitzer: P. Ehrenheim. Ausstellung Stockholm } \mathbf{1 8 8 7} \text {, } \\
\text { Taf. 3. }\end{array}$ \\
\hline & wie I 87 & & $\begin{array}{l}\text { g) Fassung eines Muschelbechers mit getriebenen } \\
\text { und gravirten Ornamenten. Im Deckel Wap- } \\
\text { pen von I } 595 . \\
\text { Besitzer: Germanisches National-Museum, Nürnberg. } \\
\text { Essenwein im Anzeiger des Germanischen Museums I887, } \\
\text { S. } 33 \text { ff. mit Abbildung. }\end{array}$ \\
\hline
\end{tabular}




\begin{tabular}{c|cc} 
Lf. & $\begin{array}{c}\text { Beschau- } \\
\text { zeichen }\end{array}$ & $\begin{array}{c}\text { Meister- } \\
\text { zeichen }\end{array}$ \\
Nr. & Meister - Gegenstand - Besitzer
\end{tabular}

I 258 wie

$\mathrm{Nr} . \mathrm{I}$ I 86 ?

wie I I 86?

wie I I 86

wie I I 86:

wie I I 87

wie I I 88

wie I I9I

wie I I 86 h) Trinkgefäss in Gestalt eines Schwanes, der Leib aus einer Muschel gebildet.

Besitzer: Grünes Gewölbe, Dresden. Katalog Erbstein I884, S. 49 Nr. I 44.

i) Gefäss in Gestalt eines Rebhuhns mit Perlmutter und Edelsteinen.

Besitzer: Griines Gewölbe, Dresden. Katalog Erbstein I884, S. 50 Nr. I50. Gruner, Das Grüne Gewölbe I862, Taf. Iо.

k) Vergold. Rebhuhn mit Federn von Perlmutter und mit Edelsteinen besetzt. H. $28,5 \mathrm{~cm}$. Besitzer: Herzogl. Museum, Gotha." Katalog Bube 1869 , S. 55 Nr. 13.

1) Henne, aus einer geschnittenen Muschel gebildet.

Besitzer: Grünes Gewölbe, Dresden. Katalog Erbstein I884, S. 58 Nr. 193.

m) Vergold. Trinkgefäss in Gestalt eines Hahnes. Auf ornamentirtem Untersatze. H. $42,5 \mathrm{~cm}$. Besitzer: Museum der Eremitage, St. Petersburg.

n) Hahn von vergoldetem Silber. Der Leib aus einer Muschel gebildet.

Besitzer: Grünes Gewölbe, Dresden. Katalog Errbstein I884, S. 5 I Nr. 156.

o) Vergoldeter Spitzbecher mit Perlmutterplättchen an der Cuppa.

H. $4 \mathrm{I} \mathrm{cm}$.

Besitzer: Königl. Museum, Cassel. Katalog Lenz I88I, Nr. 70. Drach, Silberarbeiten Cassel 1888, Taf. 14.

p-w) Acht Doppelbecher mit Perlmutter, Smaragden und Rubinen besetzt.

Besitzer: Kaiserl. Schatzkammer, Wien. Katalog Leitner 1882, S. 98 Nr. $31-38$.

x u. y) Zwei Deckelbecher, eiförmig, mit Perlmutter belegt.

Besitzer: Kaiserl. Schatzkammer, Wien. Katalog Leitner I 882 , S. 97 Nr. 29 und 30.

z) Einzelner Setzbecher mit gegossenem Relief am Lippenrande.

H. $8,2 \mathrm{~cm}$.

Besitzer (I883): J. J. Boasberg, Amsterdam.

aa) Vergoldete Lichtputzscheere. Lg. $25 \mathrm{~cm}$. Besitzer: Reiche Kapelle, München. 


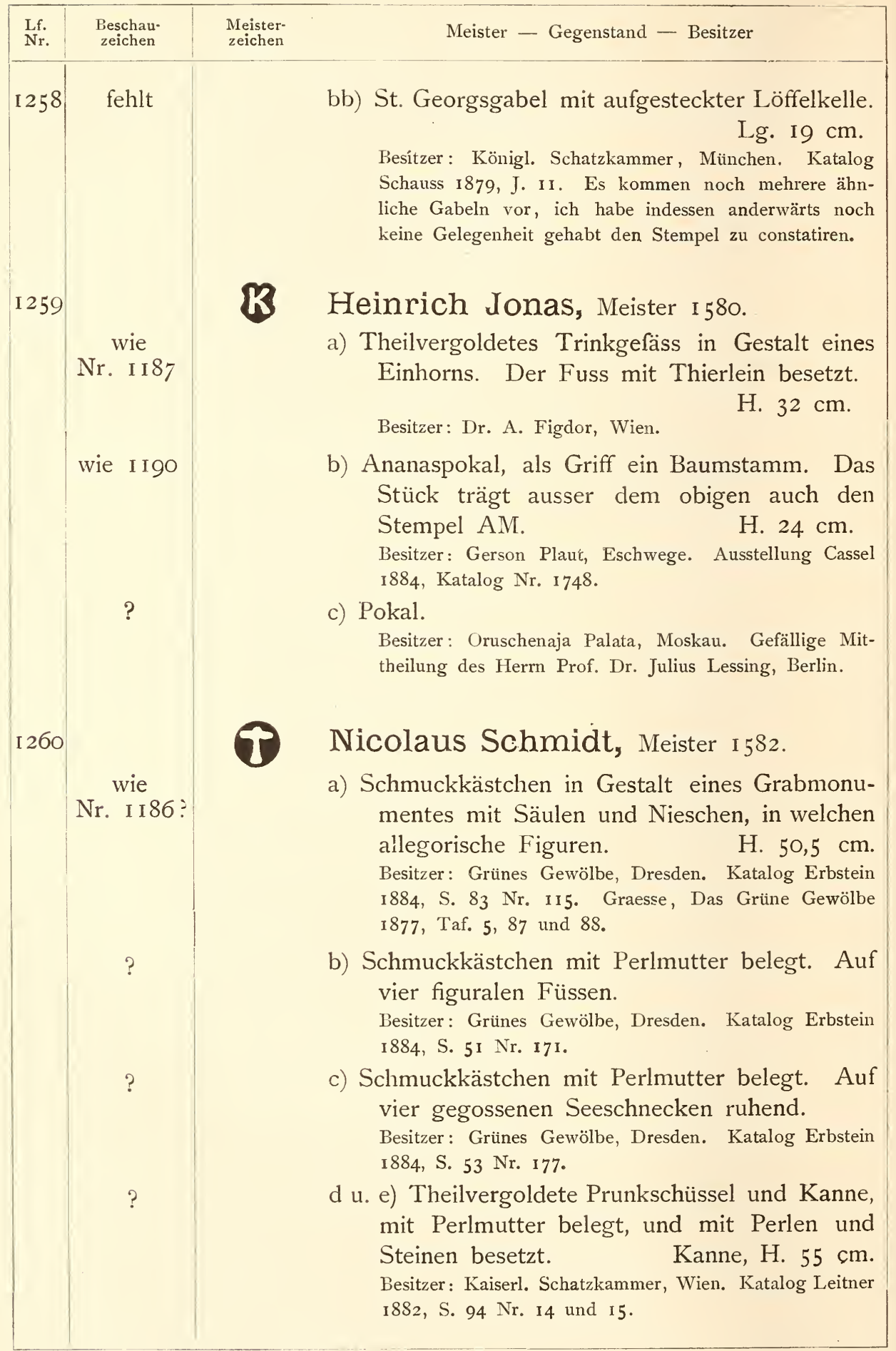




\begin{tabular}{c|c|c|c} 
Lf. & $\begin{array}{c}\text { Beschau- } \\
\text { zeichen }\end{array}$ & $\begin{array}{c}\text { Meister- } \\
\text { zeichen }\end{array}$ & Meister - Gegenstand - Besitzer \\
Nr. &
\end{tabular}

I 260

Nr. I I 86

wie I I 86

wie I 187

wie I 187

f u. g) Vergoldetes rundes Becken, mit Perlmutter und figuraler Treibarbeit geziert. Dazu die Kanne in Gestalt eines Fabelthieres. Flügel und Schwanz aus Seeschnecken gebildet. Besitzer: Grünes Gewölbe, Dresden. Katalog Erbstein I884, S. 96 Nr. 248 und S. 98 Nr. 256. Graesse, Das Grüne Gewölbe I877, Taf. 6I und Taf. II.

h) Vergoldeter Pokal mit getriebenen Renaissanceornamenten.

H. $48 \mathrm{~cm}$.

Besitzer: † Eugen Felix, Leipzig. Auctionskatalog I 886, Nr. 420 mit kleiner Abbildung. Ausstellung Dresden I875, Taf. 24.

i) Vergoldete Fassung eines Strausseneies.

Besitzer: Grünes Gewölbe, Dresden. Katalog Erbstein I884, S. 6o Nr. 226. Graesse, Das Grüne Gewölbe IS 77 , Taf. $7 \mathrm{I} \mathrm{b.}$

Hans Keller (Kelner?), Meister i 582 , Geschworener I60I.

a) Dreifaches Trinkgefäss in Gestalt des hl. Georg mit dem Drachen. Mit Wappen. Vor I6 Iо. Besitzer: Grünes Gewölbe, Dresden. Katalog Erbstein I884, S. 86 Nr. I 24.

b) Tafelaufsatz mit Adam und Eva an einem Korallenbaume. H. $35 \mathrm{~cm}$.

Besitzer: National-Museum, München.

c) Vergoldeter und theilweise kalt emaillirter Jungfrauenbecher. Das Gewand mit linearen und vegetabilen Ornamenten getrieben.

H. $25 \mathrm{~cm}$.

Besitzer: Pfälzisches Gewerbemuseum, Kaiserslautern. Ausstellung Augsburg 1886, Katalog Nr. 1475. Meisterwerke Schwäbischer Kunst Taf. 27 Nr. 2.

d) Vergoldetes Trinkgefäss in Gestalt eines Hirsches.

Das Gehörn weisssilbern. Am Postamente Thierlein.

H. $42 \mathrm{~cm}$.

Besitzer: Schloss Moritzburg. 


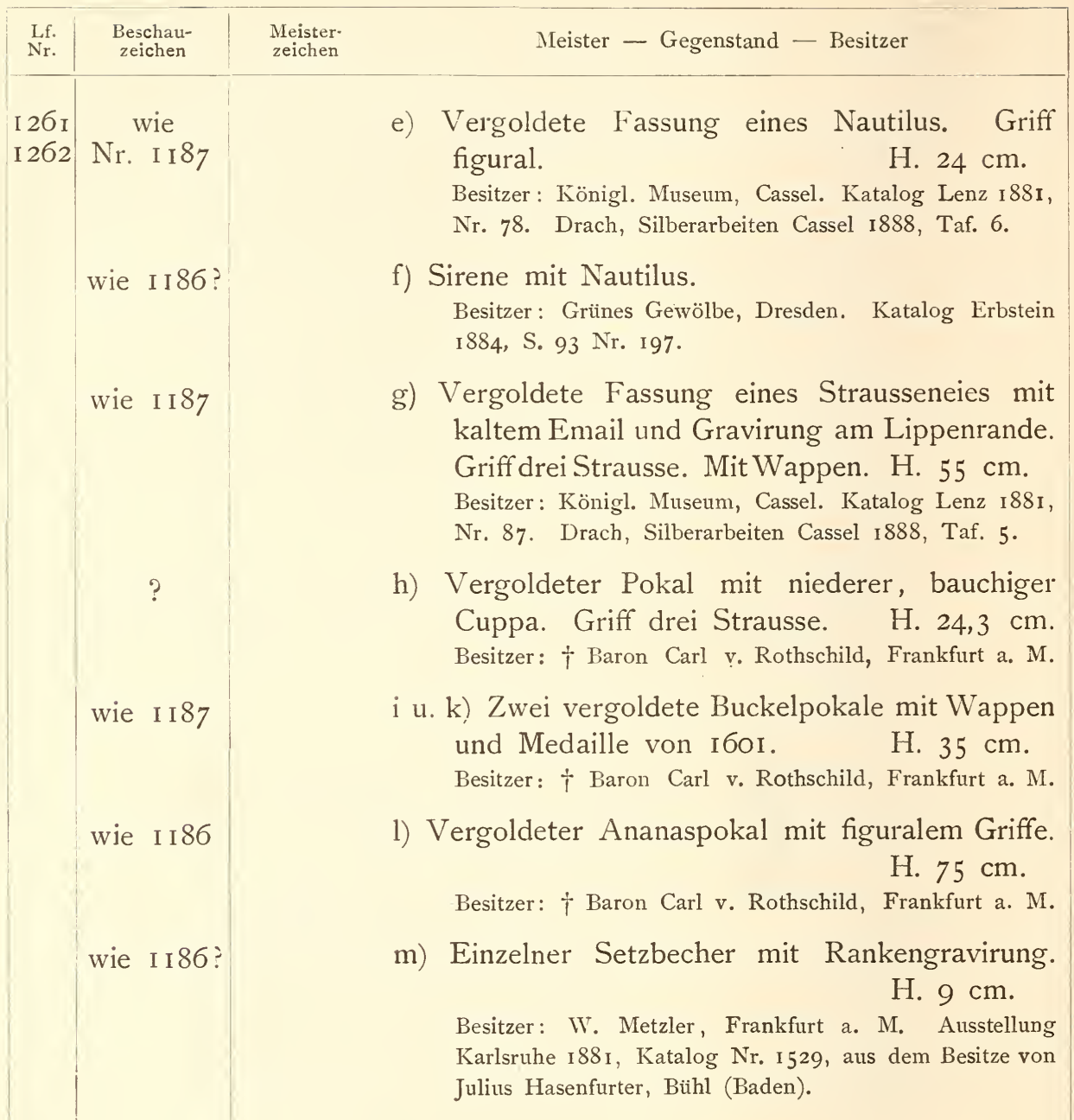

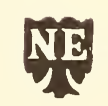

Nicolaus Emmerling, Meister I 582 oder 1587 , $†$ zwischen 1600 und 1660 .

Die Stücke, welche ich hier zusammenfasse, tragen nur zum Theil die obige Marke in deutlichem Abschlage. An mehreren Stellen erscheint sie bei gleicher Schildform als NI. Ich hoffe aber, durch diese Zusammenstellung eine genaue Prüfung der einschlägigen Arbeiten anzuregen.

wie II 87

a) Jungfrauenbecher mit halb gegengetriebener Gravirung. Der kleine Becher mit Schuppen. H. $20,3 \mathrm{~cm}$. Besitzer: C. Thewalt, Cöln. 


\begin{tabular}{|c|c|c|c|}
\hline $\begin{array}{l}\text { Lf. } \\
\text { Nr. }\end{array}$ & $\begin{array}{l}\text { Beschau- } \\
\text { zeichen }\end{array}$ & $\begin{array}{l}\text { Meister- } \\
\text { zeichen }\end{array}$ & Meister - Gegenstand - Desitzer \\
\hline $12 \sigma_{3}$ & $\begin{array}{c}\text { wie } \\
\text { Nr. I I } 87\end{array}$ & & $\begin{array}{l}\text { b) Vergoldeter Pokal mit getriebenen Ornamenten } \\
\text { und Horizontalprofilirungen. Inschrift von } \\
\text { I6I 3. H. } 21,5 \mathrm{~cm} \text {. } \\
\text { Besitzer: J. Paul, Hamburg. Auctionskatalog I882, } \\
\text { Nr. 725. }\end{array}$ \\
\hline & wie I I 87 & & $\begin{array}{l}\text { c) Vergoldeter Pokal mit getriebenen Ornamenten } \\
\text { und Horizontalprofilirungen. H. I8, I cm. } \\
\text { Besitzer: P. A. Kotschubey, St. Petersburg. }\end{array}$ \\
\hline & wie I I 89 & & $\begin{array}{l}\text { d) Vergoldeter Ananaspokal auf gebuckelten } \\
\text { Fusse. } \\
\text { Besitzer: Königl. Museum, Cassel. Katalog Lenz I88I, } \\
\text { Nr. I9. }\end{array}$ \\
\hline & wie I I 86: & & $\begin{array}{l}\text { e) Vergoldeter Pokal mit ovalen Buckeln zwischen } \\
\text { Ornamenten. } \\
\text { Besitzer: S. D. Fürst Paskewitsch, St. Petersburg. }\end{array}$ \\
\hline & wie I I90 & & $\begin{array}{l}\text { fu. g) Zivei niedere Leuchter mit Dorn für Wachs- } \\
\text { kerzen. Mit Wappen. H. I } 5 \mathrm{~cm} \text {. } \\
\text { Besitzer: Reiche Kapelle, München. Stockbauer, Reiche } \\
\text { Kapelle II, Bl. } 24 \text { Nr. 2. }\end{array}$ \\
\hline & wie I I9o & & $\begin{array}{l}\text { h) Vergoldete Hostienbüchse mit Wappen. } \\
\text { H. I } 7 \mathrm{~cm} . \\
\text { Besitzer: Reiche Kapelle, München. }\end{array}$ \\
\hline
\end{tabular}

David Lau(e)r, Meister I583, Geschworener 1606 .

a) Vergoldeter Pokal auf hohem Fusse. Cuppa mit Diamantbuckeln.

H. $32,3 \mathrm{~cm}$. Besitzer: P. A. Kotschubey, St. Petersburg.

b) Vergoldetes, konisches, gravirtes Becherchen. Mit Wappen. H. $5 \mathrm{~cm}$. Besitzer: Ludwig Kahn-Speyer, Wien.

Lucas Hillebrand, Meister i 582 oder i 586.

wie

Nr. I I 87 a) Vergoldeter Pokal mit Perlmutterplättchen bedeckt. Mit gravirtem Lippenrande und figuralem Griffe. H. $4.2 \mathrm{~cm}$. Besitzer: Herzogl. Museum, Gotha. Katalog Bube IS60, S. 56 Nr. I5. Kunsthandwerk I876, Taf. I. 


\begin{tabular}{|c|c|c|c|}
\hline $\begin{array}{l}\text { Lf. } \\
\text { Nr. }\end{array}$ & $\begin{array}{l}\text { Beschau- } \\
\text { zeichen }\end{array}$ & $\begin{array}{l}\text { Ieister- } \\
\text { reichen }\end{array}$ & Meister - Gegenstand - Besitzer \\
\hline 1265 & $\begin{array}{c}\text { wie } \\
\text { Nr. I I } 86\end{array}$ & & $\begin{array}{l}\text { b) Vergoldeter Pokal mit Perlmutterplättchen be- } \\
\text { legt. Griff figural. } \quad \text { H. } 54 \mathrm{~cm} \text {. } \\
\text { Besitzer: Königl. Museum, Cassel. Katalog Lenz 1881, } \\
\text { Nr. 69. Drach, Silberarbeiten Cassel 1888, Taf. Io. }\end{array}$ \\
\hline I 266 & $\begin{array}{c}\text { wie } \\
\text { Nr. I I } 86\end{array}$ & & $\begin{array}{l}\text { Wahrscheinlich } \\
\text { Hannss Zeier (Zeiher), Meister i } 583 \text {. } \\
\begin{array}{ll}\text { a u. b) Vergoldeter Kelch nebst Patene. Mit } \\
\text { Wappen und Initialen. } & \text { H. } 22,5 \mathrm{~cm} . \\
\text { Besitzer: Johanneskirche, Nürnberg. } & \end{array}\end{array}$ \\
\hline & wie I I90 & & $\begin{array}{l}\mathrm{c}-\mathrm{m}) \text { Zehn Setzbecher mit Gravirung. Ausser } \\
\text { mit dem obigen noch mit dem Meister- } \\
\text { stempel A B M uiber einer Figur Nr. I } 355 \text { und } \\
\text { I } 356 \text { versehen. Einzeln, H. } 7,7 \mathrm{~cm} \text {. } \\
\text { Besitzer: † Baron Carl'v. Rothschild, Frankfurt a. M. }\end{array}$ \\
\hline I 267 & & & $\begin{array}{l}\text { Jobst Hamman (Hammon), Meister } \\
\text { I585. }\end{array}$ \\
\hline & $\begin{array}{c}\text { wie } \\
\text { Nr. I I } 86\end{array}$ & & $\begin{array}{l}\text { Vergold. Deckelpokal mit Horizontalprofilirungen. } \\
\text { Corpus getrieben. } \\
\begin{array}{ll}\text { Besitzer: Patriarchen-Schatzkammer, Moskau. } 28,5 \mathrm{~cm} \text {. }\end{array}\end{array}$ \\
\hline I 268 & & $\theta$ & $\begin{array}{l}\text { Caspar Beutmüller d. Aeltere, Meister } \\
\text { I 585, Genannter I596, Geschworener I6 I , } \\
\quad \nmid \text { I618. }\end{array}$ \\
\hline & $\begin{array}{c}\text { wie } \\
\text { Nr. I I 86? }\end{array}$ & & $\begin{array}{l}\text { a) Vergoldeter Doppelbecher mit getriebenen } \\
\text { Buckeln und Gravirungen am Lippenrande. } \\
\text { H. } 45,5 \mathrm{~cm} . \\
\text { Besitzer: } † \text { Baron Carl v. Rothschild, Frankfurt a. M. }\end{array}$ \\
\hline & wie I I 86? & & $\begin{array}{l}\text { b) Buckelpokal mit Wappen. H. } 33,5 \mathrm{~cm} \text {. } \\
\text { Besitzer: Eduard Goldschmid, Frankfurt a. M. }\end{array}$ \\
\hline & wie I I 86 & & $\begin{array}{l}\text { c) Einzelner vergoldeter Setzbecher. H. } 9,5 \mathrm{~cm} \text {. } \\
\text { Besitzer: National-Museum, Budapest. Ausstellung Buda- } \\
\text { pest } 1884 \text {, 3. Saal, 2. Schrank. }\end{array}$ \\
\hline & wie I I86? & & $\begin{array}{l}\text { d) Trinkgefäss in Gestalt eines Fasses. Mit Wap- } \\
\text { pen, Inschrift und I } 596 . \quad \text { H. I } 5,2 \mathrm{~cm} \text {. } \\
\text { Besitzer: Max B. H. Goldschmidt, Frankfurt a. M. }\end{array}$ \\
\hline
\end{tabular}




\begin{tabular}{|c|c|c|c|}
\hline $\begin{array}{l}\text { Lf. } \\
\text { Nr. }\end{array}$ & $\begin{array}{l}\text { Beschau- } \\
\text { zeichen }\end{array}$ & $\begin{array}{l}\text { Meister- } \\
\text { zeichen }\end{array}$ & Meister - Gegenstand - Besitzer \\
\hline 1269 & & W & Urban Wolff, Meister I 585. \\
\hline & $\begin{array}{c}\text { wie } \\
\text { Nr. I I } 8_{7}\end{array}$ & & 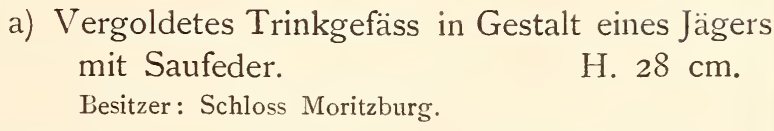 \\
\hline & wie I I86: & & $\begin{array}{l}\text { b) Trinkgefäss in Gestalt eines Löwen mit Krone, } \\
\text { Schild und Wappen. } \\
\text { Besitzer: Grünes Gewölbe, Dresden. Katalog Erbstein } \\
\text { ı } 884 \text {, S. } 65 \text { Nr. ı. }\end{array}$ \\
\hline & wie I I 86 & & $\begin{array}{l}\text { c) Elephant als Trinkgefäss gebildet, mit bemann- } \\
\text { tem abnehmbarem Thurme. } \\
\text { Besitzer: Grünes Gewölbe, Dresden. Katalog Erbstein } \\
\text { r } 884 \text {, S. } 85 \text { Nr. 120. }\end{array}$ \\
\hline & wie I I 87 & & $\begin{array}{l}\text { d) Vergoldetes Trinkgefäss in Gestalt eines Bären } \\
\text { mit Wappenschild. Bezeichnet I } 620 \text {. } \\
\text { Besitzer: Schloss Moritzburg. }\end{array}$ \\
\hline & ? & & $\begin{array}{l}\text { e) Vergoldete Fassung eines Pokals mit Perl- } \\
\text { mutter-Cuppa. } \\
\text { Besitzer: Grünes Gewölbe, Dresden. Katalog Erbstein } \\
\text { I884, S. 50 Nr. 154. }\end{array}$ \\
\hline & wie 1187 & & $\begin{array}{l}\text { f) Vergoldeter Pokal mit Perlmutterschuppen. } \\
\text { H. } 59 \mathrm{~cm} \text {. } \\
\text { Besitzer: S. D. Fürst Nicolaus Esterházy. Ausstellung } \\
\text { Budapest i } 884 \text {, 3. Saal, i4. Schrank, Nr. 8. Katalog } \\
\text { S. I55. }\end{array}$ \\
\hline
\end{tabular}

Eustachius Hohman, Meister I587, Geschworener 1605 .

wie

Nr. I I 86

wie I I 86

wie I I 86:

wie I I 90 a) Vergoldeter Buckelpokal mit Inschrift.

H. $20 \mathrm{~cm}$.

Besitzer: Patriarchen-Schatzkammer, Moskau.

b) Vergoldeter Buckelpokal. H. $30 \mathrm{~cm}$.

Besitzer (I 885): Jacobsohn, St. Petersburg.

c) Vergoldeter, kelchförmiger Pokal mit Ornamenten getrieben.

H. I $5,5 \mathrm{~cm}$.

Besitzer: Museum für Kunst und Gewerbe, Hamburg.

d) Vergoldeter Ananaspokal mit figuralem Griffe.

H. $53 \mathrm{~cm}$.

Besitzer: Baron Nathanael v. Rothschild, Wien. 


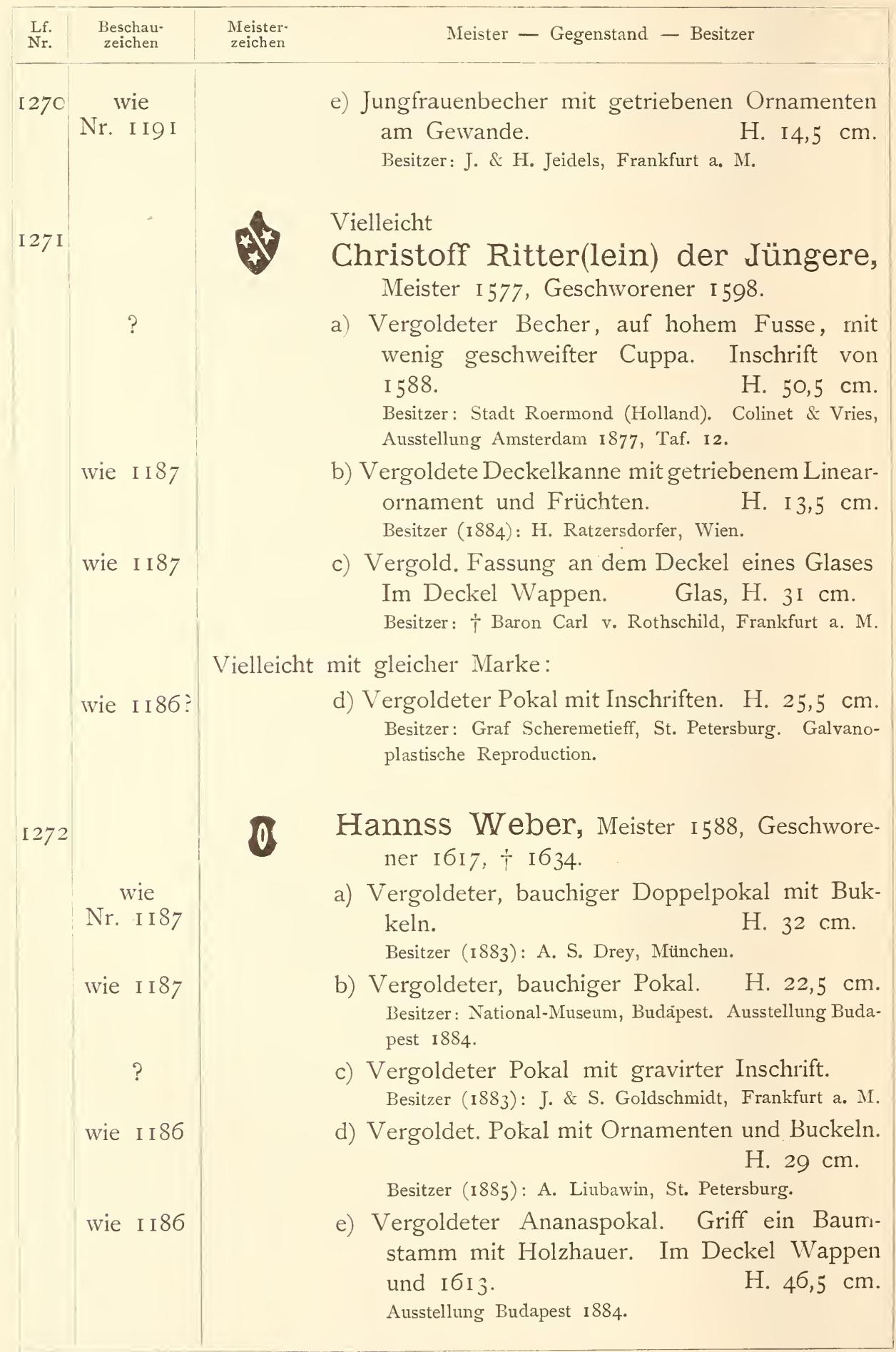




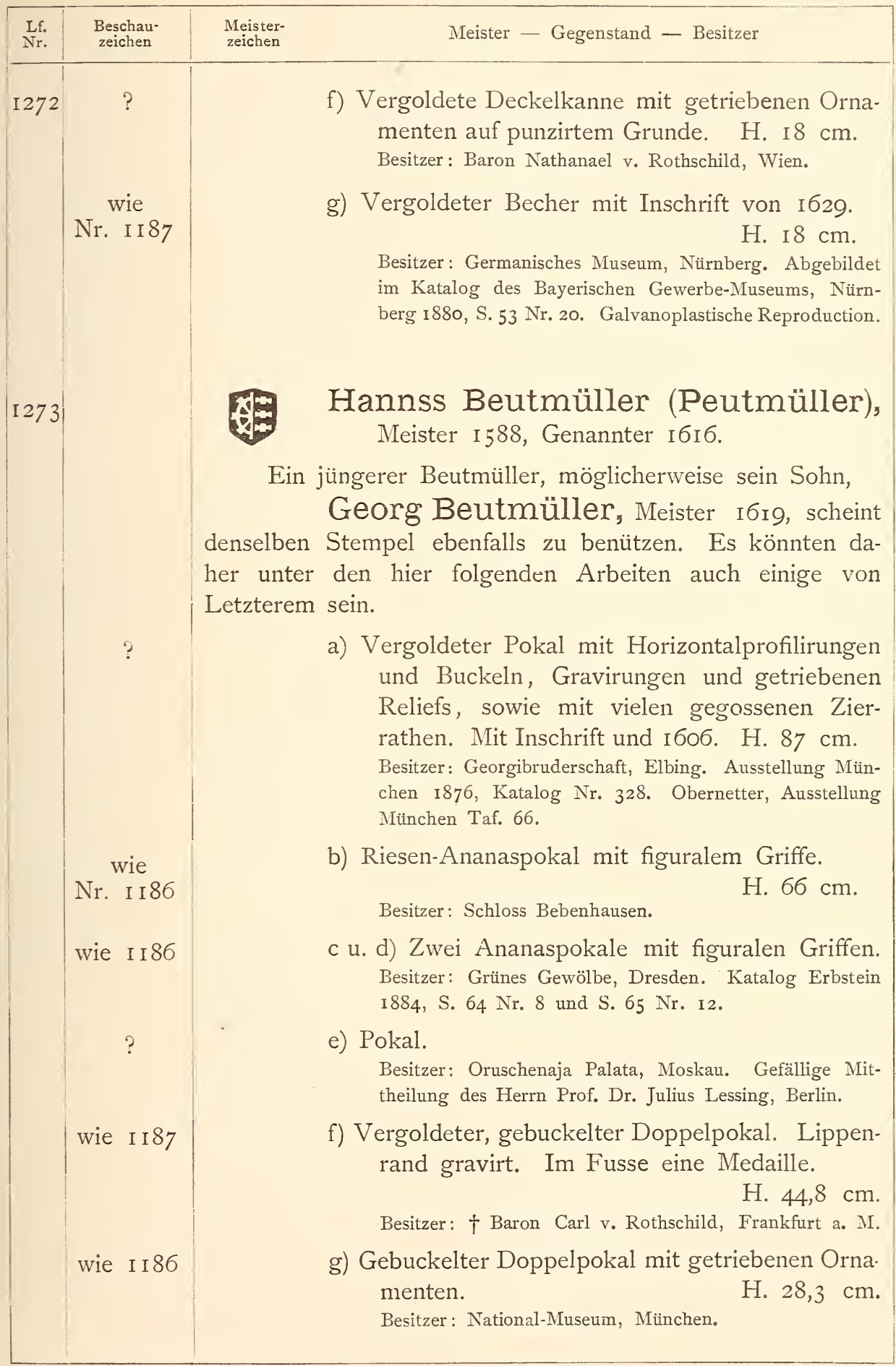




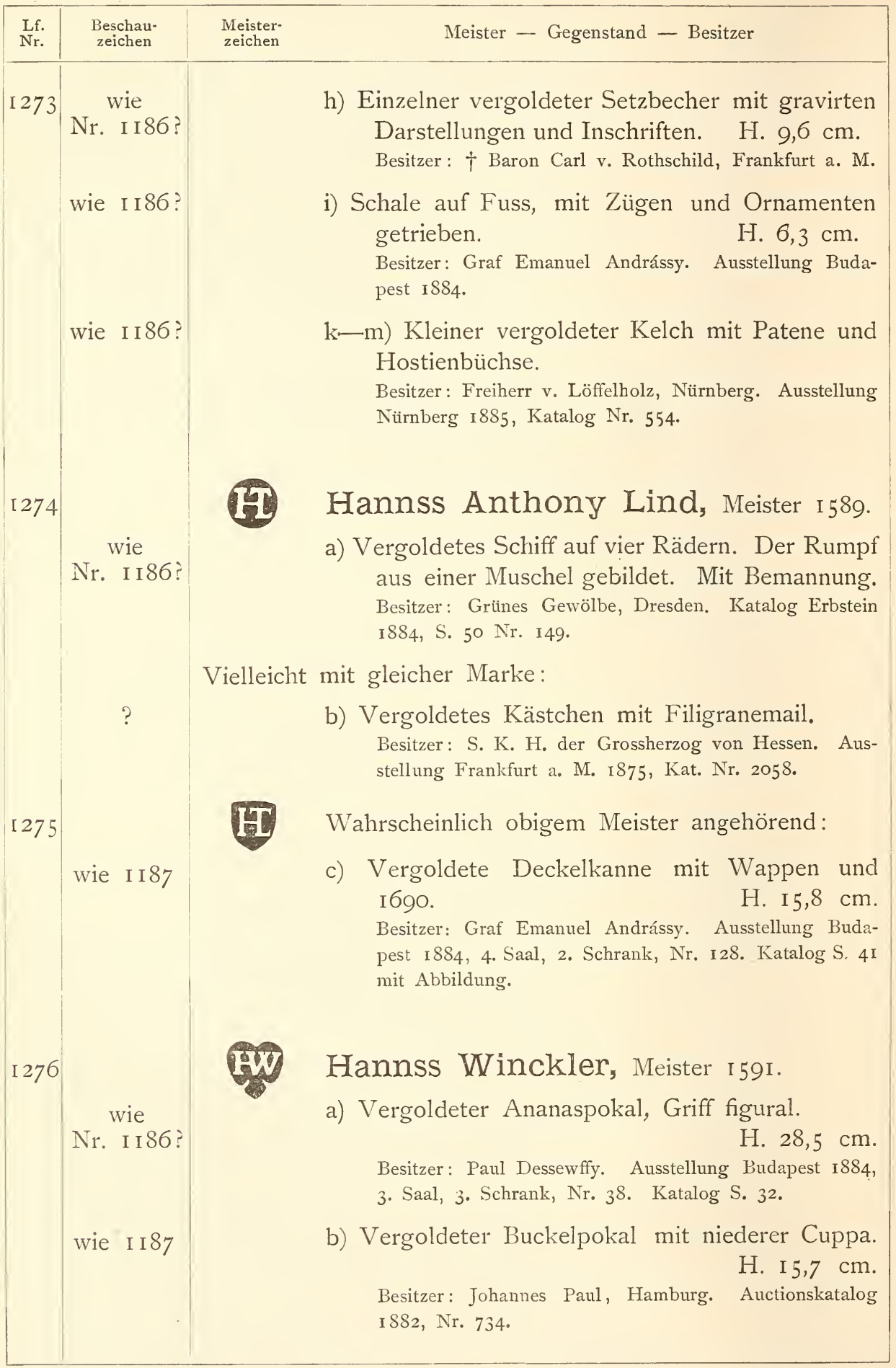




\begin{tabular}{|c|c|c|c|}
\hline$\underset{\mathrm{N}}{\mathrm{Lff} .}$ & $\begin{array}{l}\text { Beschau- } \\
\text { zeichen }\end{array}$ & $\begin{array}{l}\text { Meister- } \\
\text { zeichen }\end{array}$ & Meister - Gegenstand - Besitzer \\
\hline I 277 & & AP & 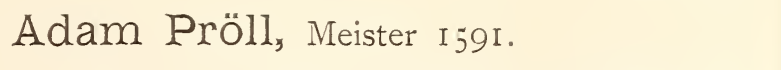 \\
\hline & $\begin{array}{c}\text { wie } \\
\text { Nr. I I } 87\end{array}$ & & $\begin{array}{l}\text { a) Vergoldetes Schifftrinkgefäss mit Bemannung. } \\
\text { Theilweise bemalt und mit Wappen am } \\
\text { Rumpfe. H. } 33,5 \mathrm{~cm} . \\
\text { Besitzer: Prof. Dr. A. Freiherr v. Scheurl, Nürnberg. } \\
\text { Ausstellung Nürnberg I885, Katalog Nr. } 796 .\end{array}$ \\
\hline & wie 1187 & & $\begin{array}{l}\text { b) Theilvergoldetes Trinkgefäss in Form einer } \\
\text { Laterne. }\end{array}$ \\
\hline
\end{tabular}

I 278

wie

Nr. II 86:

I 279

I 230

wie

Nr. II 87

wie II86:

?

I 281

wie II 86
过

Wahrscheinlich derselbe Meister:

b) Einzelner vergoldeter Setzbecher mit Gravirungen.

H. $9,8 \mathrm{~cm}$.

Besitzer: National-Museum Budapest. Ausstellung Budapest 1884, 3. Saal, 2. Schrank.

Jeronymus Behaim, Meister I 593.

a) Vergoldeter Deckelpokal.

H. $20 \mathrm{~cm}$.

Besitzer: HI. Geistkirche, Heidelberg.

b) Vergoldeter Pokal mit Buckeln und Ornamenten getrieben.

H. $26,5 \mathrm{~cm}$.

Besitzer: H. Boskowitz, Wien.

c-e) Vergoldeter Buckelpokal, sowie zwei weitere Stücke.

Besitzer: Oruschenaja Palata, Moskau. Gefällige Mittheilung von Herrn Prof. Dr. Julius Lessing, Berlin.

Vielleicht

Peter Schutzing; Meister I 593, oder Peter Sïgmund, Meister i6o8.

wie

Nr. II 86: a) Vergold.Buckelpokal mit Inschrift. H. 5 I $\mathrm{cm}$.

Besitzer: Stadt Witzenhausen. Ausstellung Cassel I 884 , Katalog Nr. II 4 . 


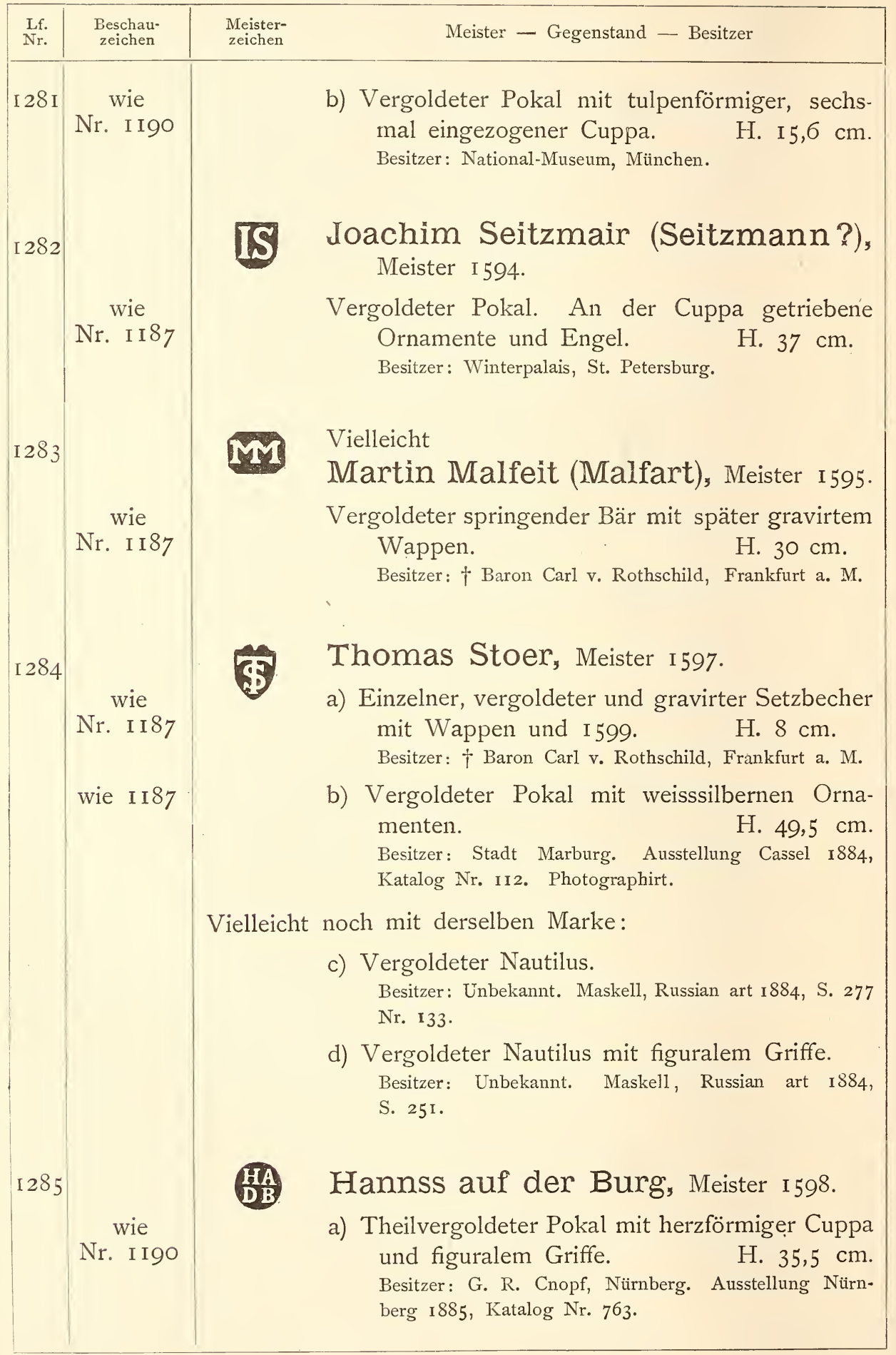




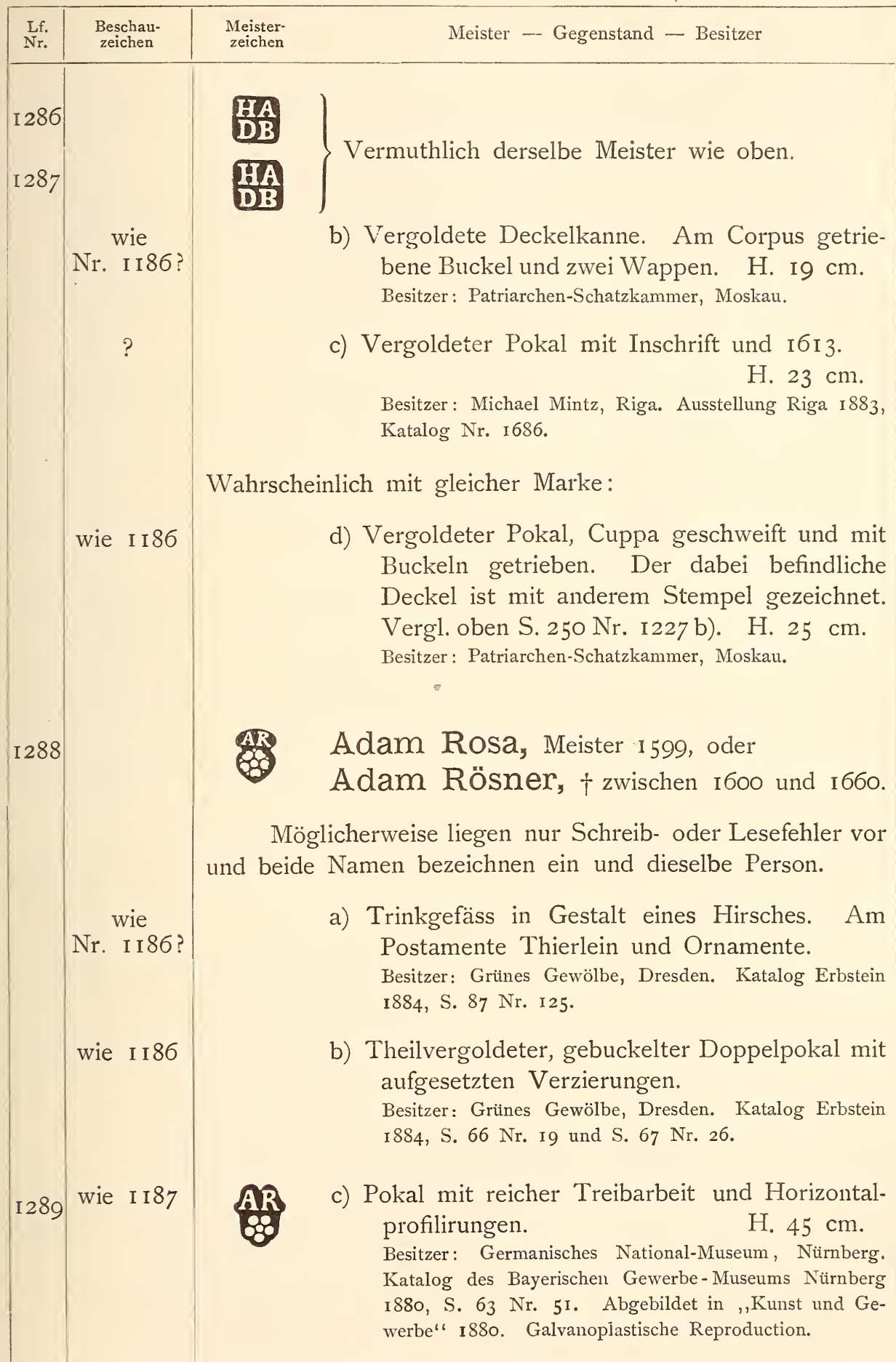




\begin{tabular}{|c|c|c|}
\hline ifr. & 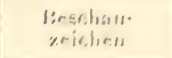 & Meister - Gerrenstand $=$ Begitzer \\
\hline 1284 & ? & 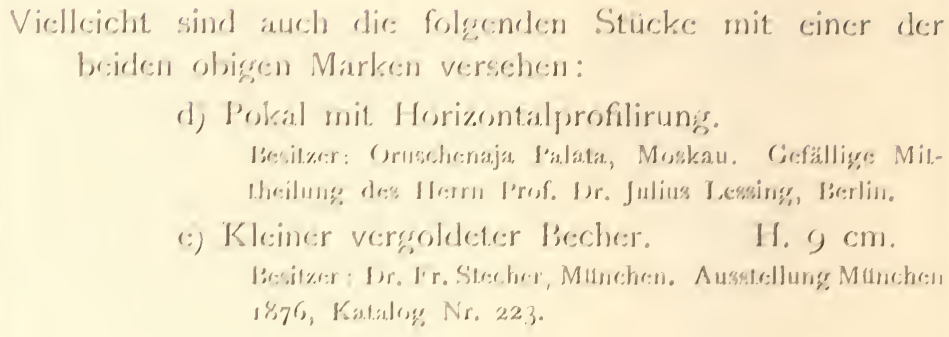 \\
\hline$\left.(2,)^{\prime}\right)$ & $\begin{array}{l}\text { wic } \\
\text { Ni. I I's6? }\end{array}$ & 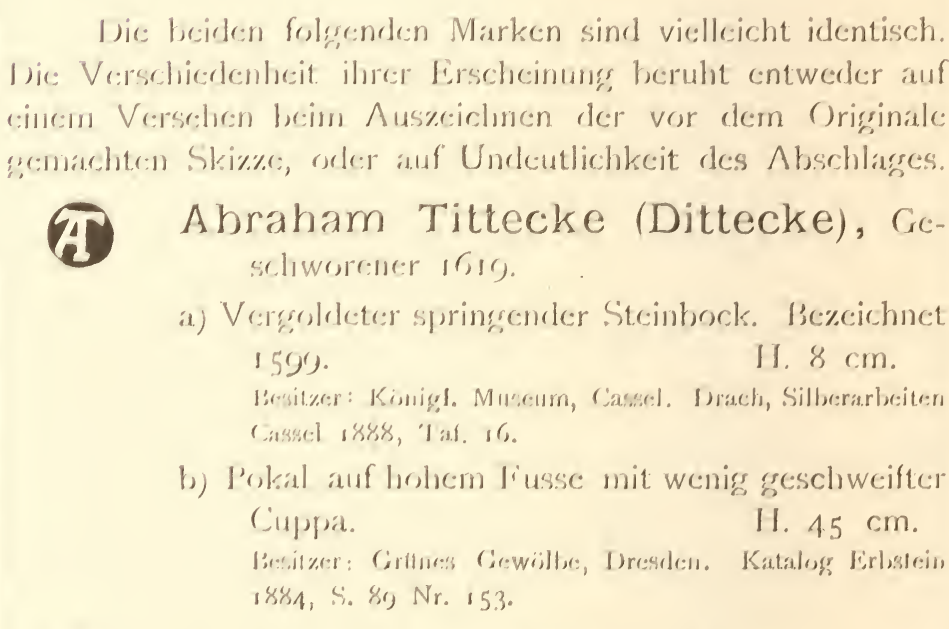 \\
\hline 120,1 & ? & 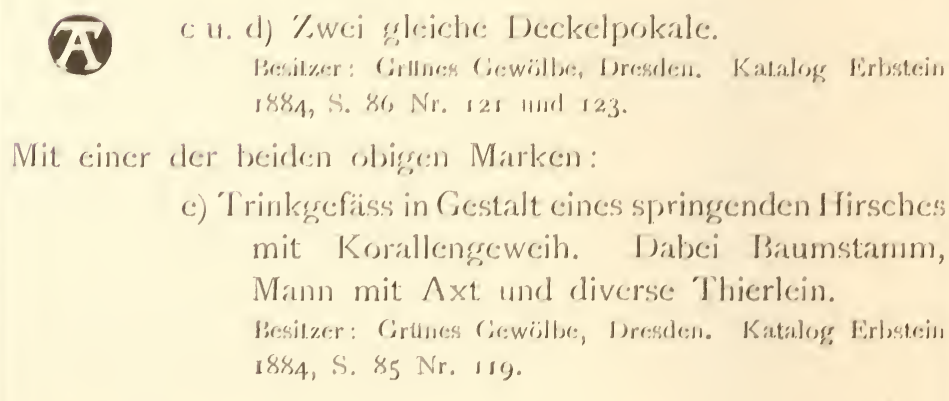 \\
\hline 120,2 & $\begin{array}{c}\text { wic: } \\
\mathrm{Nr} .1186 ?\end{array}$ & 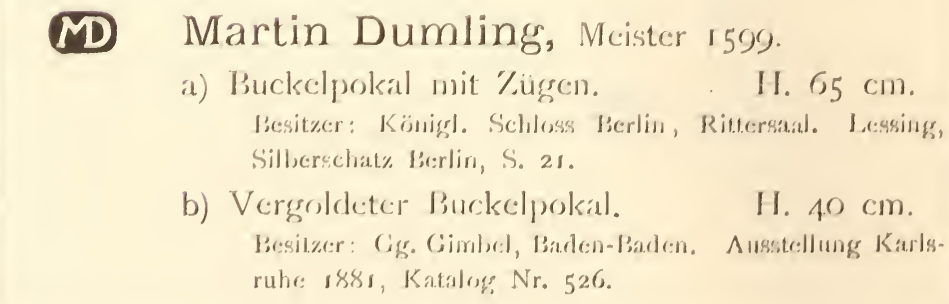 \\
\hline
\end{tabular}




\begin{tabular}{|c|c|c|c|}
\hline $\begin{array}{l}\text { Lff. } \\
\text { Nr. }\end{array}$ & $\begin{array}{l}\text { Beschau- } \\
\text { zeichen }\end{array}$ & $\begin{array}{l}\text { Meister- } \\
\text { zeichen }\end{array}$ & Meister — Gegenstand - Besitzer \\
\hline 1293 & $\begin{array}{l}\text { wie } \\
\text { Nr. I I } 90\end{array}$ & 6 & $\begin{array}{l}\text { a) Becherschraube in Gestalt eines Mannes in } \\
\text { langem Gewande. } \\
\text { Besitzer: J. \& H. Jeidels, Frankfurt a. M. }\end{array}$ \\
\hline & wie I I 86 & - & $\begin{array}{l}\text { b) Becherschraube in Gestalt eines Mannes in } \\
\text { langem Gewande. H. I6 cm. } \\
\text { Besitzer: Dr. J. P. Six, Amsterdam. Ausstellung Amster- } \\
\text { dam I883. Silberausstellung I881, Katalog Nr. } 83 \text {. } \\
\text { c) Jungfrauenbecher. } \\
\text { Ausstellung Budapest I } 884 .\end{array}$ \\
\hline- & wie I I 86 & & $\begin{array}{l}\text { d) Vergoldeter Doppeladler mit abnehmbarem } \\
\text { Kopfe. Als Trinkgefäss gebildet. Mit In- } \\
\text { schrift. } \\
\text { Besitzer: Winterpalais, St. Petersburg. } 69 \mathrm{~cm} \text {. }\end{array}$ \\
\hline & wie I I 86: & & $\begin{array}{l}\text { e) Trinkgefäss in Gestalt eines Schwanes. Durch } \\
\text { Abnehmen der Flügel öffnet man das Ge- } \\
\text { fäss. H. } 28,5 \mathrm{~cm} \text {. } \\
\text { Besitzer: † Baron Carl v. Rothschild, Frankfurt a. M. }\end{array}$ \\
\hline & wie I I 86 & & $\begin{array}{l}\text { f) Vergoldete Fassung eines Strausseneies. Griff } \\
\text { figural. } \\
\text { Besitzer: Prof. Dr. A. Freih. v. Scheurl, Nürnberg. Aus- } \\
\text { stellung Nürnberg 1885, Kat. Nr. } 795 \text { mit Abbildung. }\end{array}$ \\
\hline & wie I I9o? & & $\begin{array}{l}\text { g) Fassung eines Nautilus. Griff figural. Am } \\
\text { Lippenrande Gravirung. } \\
\text { Besitzer: C. H. Baker, Amsterdam. Ausstellung Amster- } \\
\text { dam I883. Silberausstellung I881, Katalog Nr. I02. }\end{array}$ \\
\hline & wie I I90 & & $\begin{array}{l}\text { h) Schifftrinkgefäss mit Muschel. } \\
\text { Besitzer: Grünes Gewölbe, Dresden. Katalog Erbstein } \\
\text { 1 } 884, \text { S. } 50 \text { Nr. 152. }\end{array}$ \\
\hline & wie I I 86 & & $\begin{array}{l}\text { i) Vergoldeter Ananaspokal. Griff ein Baum mit } \\
\text { Adam und Eva. Am Fusse vier Wappen. } \\
\text { Bezeichnet I6०3. } \\
\text { Besitzer: } † \text { Haron Carl v. Rothschild, Frankfurt a. M. }\end{array}$ \\
\hline & wie I I86? & & $\begin{array}{l}\text { k) Ananaspokal. H. } 32 \mathrm{~cm} \text {. } \\
\text { Besitzer: v. Vultée, Cassel. Ausstellung Cassel I } 884 \text {, } \\
\text { Katalog Nr. } 1723 .\end{array}$ \\
\hline I 294 & $\begin{array}{c}\text { wie } \\
\text { Nr. I I } 87\end{array}$ & FE & $\begin{array}{l}\text { a) Vergoldeter Becher auf niederem Fusse. Am } \\
\text { Lippenrande gravirte Ornamente. } \\
\text { H. IO, } 5 \mathrm{~cm} . \\
\text { Besitzer (I884): G. van Aaken, Baden-Baden. }\end{array}$ \\
\hline
\end{tabular}




\begin{tabular}{|c|c|c|c|}
\hline $\begin{array}{l}\text { Lff. } \\
\text { Nr. }\end{array}$ & $\begin{array}{l}\text { Beschau- } \\
\text { zeichen }\end{array}$ & $\begin{array}{l}\text { Meister- } \\
\text { zeichen }\end{array}$ & Meister - Gegenstand - Besitzer \\
\hline I 294 & $\begin{array}{l}\text { wie } \\
\text { Nr. I I } 87\end{array}$ & & $\begin{array}{l}\text { b) Vergoldeter Becher auf niederem Fusse. Am } \\
\text { Lippenrande gravirte Ornamente. H. I } 8 \mathrm{~cm} \text {. } \\
\text { Besitzer (I884): Gebr. Bourgeois, Cöln. Ich vermuthe, } \\
\text { dass"trotz der Verschiedenheit in den Massen, die viel- } \\
\text { leicht nur auf einem Irrthume beruht, diese beiden Stiicke } \\
\text { identisch sind. }\end{array}$ \\
\hline I 295 & & & $\begin{array}{l}\text { Franz Vischer (Fischer), Meister I600, } \\
\text { Geschworener I62 I, Genannter I624, Raths- } \\
\text { freund } 1646, \dagger \text { vor I66o. }\end{array}$ \\
\hline & $\begin{array}{l}\text { wie } \\
\text { Nr. I I } 86 ?\end{array}$ & & $\begin{array}{l}\text { a) Vergoldete Schale, gravirt mit Namen, Wappen } \\
\text { und I620. Dm. I } 3,2 \mathrm{~cm} \text {. } \\
\text { Besitzer: G. Gimbel, Baden-Baden. Ausstellung Karls- } \\
\text { ruhe I88I, Katalog 1Nr. 548. }\end{array}$ \\
\hline & ? & & $\begin{array}{l}\text { b) Vergoldeter Pokal mit Buckeln und Orna- } \\
\text { menten. } \\
\text { Hesitzer: } † \text {. } 59 \mathrm{~cm} \text {. } \\
\text { Baron Carl v. Rothschild, Frankfurt a. M. }\end{array}$ \\
\hline & wie I I90 & & $\begin{array}{l}\text { c) Vergoldeter Ananaspokal. H. } 33,5 \mathrm{~cm} \text {. } \\
\text { Besitzer: Dr. Krauss, Augsburg. Ausstellung Augsburg } \\
\text { 1886, Katalog Nr. 1470. }\end{array}$ \\
\hline & wie II86 & & $\begin{array}{l}\text { d) Vergoldeter Ananaspokal. Griff ein weiss- } \\
\text { silberner Baumstamm mit Holzhauer. } \\
\text { H. } 34,5 \mathrm{~cm} \text {. } \\
\text { Besitzer: Excellenz Due, St. Petersburg. }\end{array}$ \\
\hline & wie II86 & & $\begin{array}{l}\text { e) Vergoldeter Ananaspokal mit figuralem Griffe. } \\
\text { H. } 63 \mathrm{~cm} \text {. } \\
\text { Besitzer: Kaiserl. Silberkammer, St. Petersburg. }\end{array}$ \\
\hline & ? & & $\begin{array}{l}\text { f) Pokal mit spärlichen Buckeln. H. } 3 \text { I cm. } \\
\text { Besitzer: Patriarchen-Schatzkammer, Moskau. }\end{array}$ \\
\hline & ? & & $\begin{array}{l}\text { g) Vergoldeter Becherdeckel mit der Figur eines } \\
\text { Kriegers. Der Becher von einem anderen } \\
\text { Meister. } \\
\text { Besitzer: Patriarchen-Schatzkammer, Moskau. }\end{array}$ \\
\hline & ? & & $\begin{array}{l}\text { h) Vergoldeter Pokal mit Buckeln und Orna- } \\
\text { menten getrieben. Mit Inschrift und I646. } \\
\text { H. } 42,5 \mathrm{~cm} \text {. } \\
\text { Besitzer: Patriarchen-Schatzkammer, Moskau. }\end{array}$ \\
\hline & wie IIgo & & $\begin{array}{l}\text { i) Vergoldeter Pokal mit Buckeln und Ornamenten } \\
\text { getrieben. } \\
\text { Besitzer (1883): J. \& S. Goldschmidt, Frankfurt a. M. }\end{array}$ \\
\hline
\end{tabular}




\begin{tabular}{|c|c|c|c|}
\hline $\begin{array}{l}\text { Lf. } \\
\text { Nr. }\end{array}$ & $\begin{array}{l}\text { Beschau- } \\
\text { zeichen }\end{array}$ & $\begin{array}{l}\text { Meister- } \\
\text { zeichen }\end{array}$ & Meister - Gegenstand - Besitzer \\
\hline \multirow[t]{4}{*}{ I 295} & $\begin{array}{c}\text { wie } \\
\text { Nr. I I } 89\end{array}$ & & $\begin{array}{l}\text { k) Vergoldeter Pokal mit Buckeln und Zügen. } \\
\text { H. } 3 \text { I, } 8 \mathrm{~cm} \text {. } \\
\text { Besitzer: Patriarchen-Schatzkammer, Moskau. }\end{array}$ \\
\hline & ? & & $\begin{array}{l}\text { 1) Becher in Gestalt einer Birne, mit getriebenen } \\
\text { Ornamenten. } \\
\text { Besitzer: Baron R. v. Walterskirchen, Wien. }\end{array}$ \\
\hline & wie I I 86 & & $\begin{array}{l}\text { m u. n) Zwei vergold. Becher mit gravirten bibli- } \\
\text { schen Darstellungen und getriebenen Pfeifen. } \\
\text { Besitzer: Kunstgewerbe-Museum, Berlin. }\end{array}$ \\
\hline & wie I I 86 & & $\begin{array}{l}\text { o) Vergoldeter Buckelpokal mit getriebenen Orna- } \\
\text { menten. Das Stück hat ausserdem noch } \\
\text { andere Meistermarken. } \\
\text { Besitzer: Winterpalais, St. Petersburg. }\end{array}$ \\
\hline \multirow[t]{4}{*}{1296} & $\begin{array}{c}\text { wie } \\
\text { Nr. I I } 86\end{array}$ & & $\begin{array}{l}\text { a u. b) Vergoldete Taufkanne nebst Becken, mit } \\
\text { aufgelötheten Relieftheilen und Perlmutter ver- } \\
\text { ziert. Mit Wappen und Inschrift. } \\
\text { Becken, Dm. } 63 \mathrm{~cm} \text {., Kanne, H. } 35 \mathrm{~cm} \text {. } \\
\text { Besitzer: Evangelische Hofkirche, Dresden. }\end{array}$ \\
\hline & wie I 86 & & $\begin{array}{l}\text { c) Vergoldeter, konischer Becher mit Emblem- } \\
\text { Gravirungen. } \\
\text { Besitzer: Professor Seyffer, Stuttgart (1882). }\end{array}$ \\
\hline & wie I 86 & & 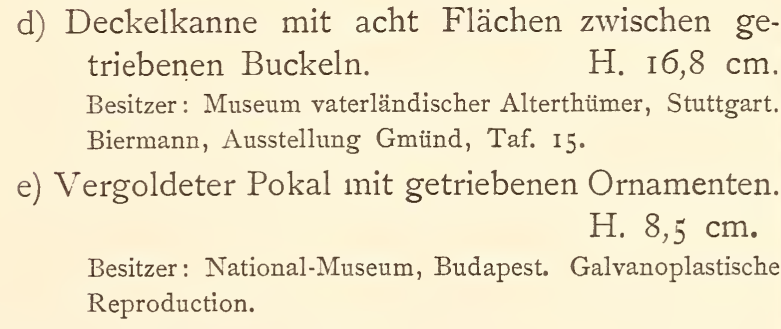 \\
\hline & ? & Wahrsc & $\begin{array}{l}\text { inlich mit gleicher Marke: } \\
\text { f) Riesenpokal. Mitte I7. Jahrh. } \\
\text { Besitzer: Oruschenaja Palata, Moskau. Gefällige Mit- } \\
\text { theilung des Herrn Prof. Dr. Julius Lessing, Berlin. }\end{array}$ \\
\hline \multirow[t]{2}{*}{ I 297} & & & Jannss Bertolt, Meister ıбог. \\
\hline & $\begin{array}{l}\text { wie } \\
\text { Nr. I I } 86\end{array}$ & & $\begin{array}{l}\text { Vergoldeter Pokal mit Horizontalprofilirungen. } \\
\text { Mit Inschrift von vor I645. H. } 20 \mathrm{~cm} \text {. } \\
\text { Besitzer: Patriarchen-Schatzkammer, Moskau. }\end{array}$ \\
\hline
\end{tabular}




\begin{tabular}{|c|c|c|c|}
\hline $\begin{array}{l}\text { Lf. } \\
\text { Nr. }\end{array}$ & $\begin{array}{l}\text { Beschau- } \\
\text { zeichen }\end{array}$ & $\begin{array}{l}\text { Meister- } \\
\text { zeichen }\end{array}$ & Meister — Gegenstand - Besitzer \\
\hline I 298 & $\begin{array}{l}\text { wie } \\
\mathrm{Nr} . \quad \text { I I } 86\end{array}$ & $M$ & 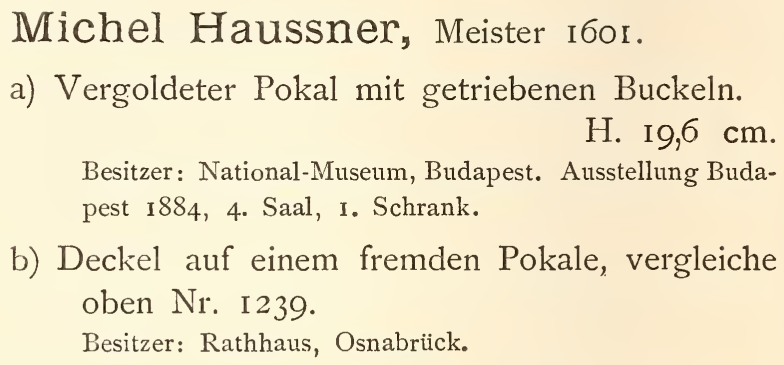 \\
\hline I 299 & $\begin{array}{c}\text { wie } \\
\mathrm{Nr} . \\
\text { I I } 86\end{array}$ & & $\begin{array}{l}\text { Paulus Flind der Jüngere, Meister } \\
\text { I6oı. } \\
\text { Vergoldete, ovale Platte mit getriebener figuraler } \\
\text { Darstellung. Mit Inschrift. Bezeichnet I6o6. } \\
\text { Lg. } 58 \mathrm{~cm} \text {. } \\
\text { Besitzer: Patriarchen-Schatzkammer, Moskau. }\end{array}$ \\
\hline I 300 & $\begin{array}{l}\text { wr. I I } 86 \\
\text { wie I I } 9 \text { I? }\end{array}$ & Mitg & 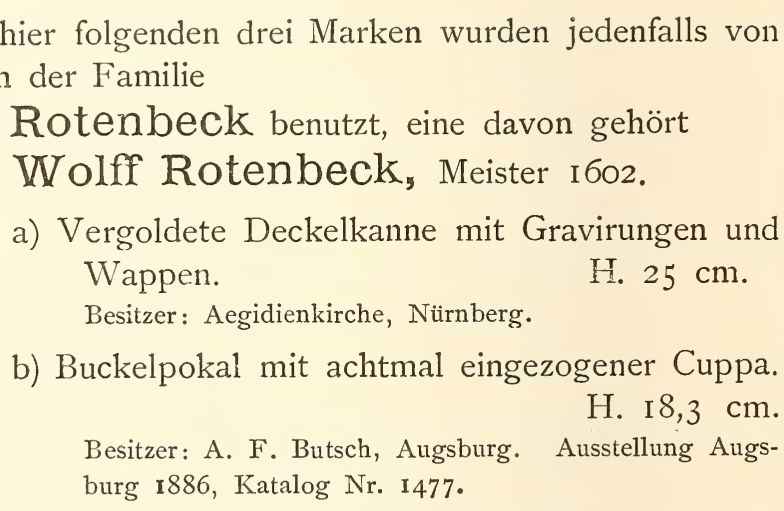 \\
\hline I 301 & wie I I 86 & & 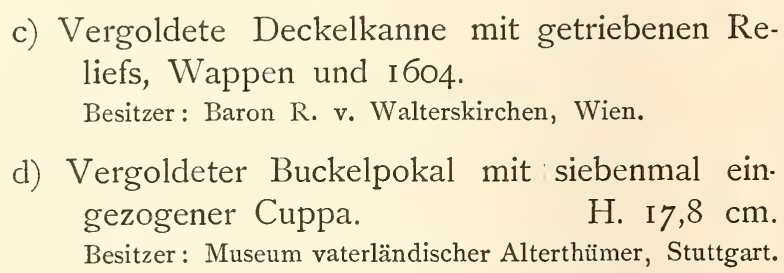 \\
\hline & $\begin{array}{l}\text { wie I I } 86 \\
\text { wie I I9o }\end{array}$ & & 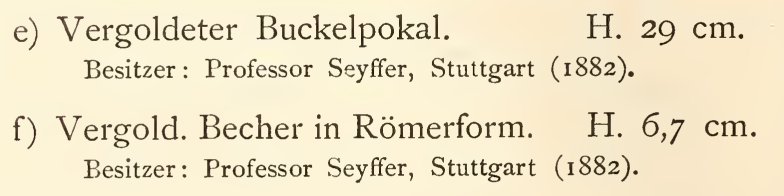 \\
\hline
\end{tabular}




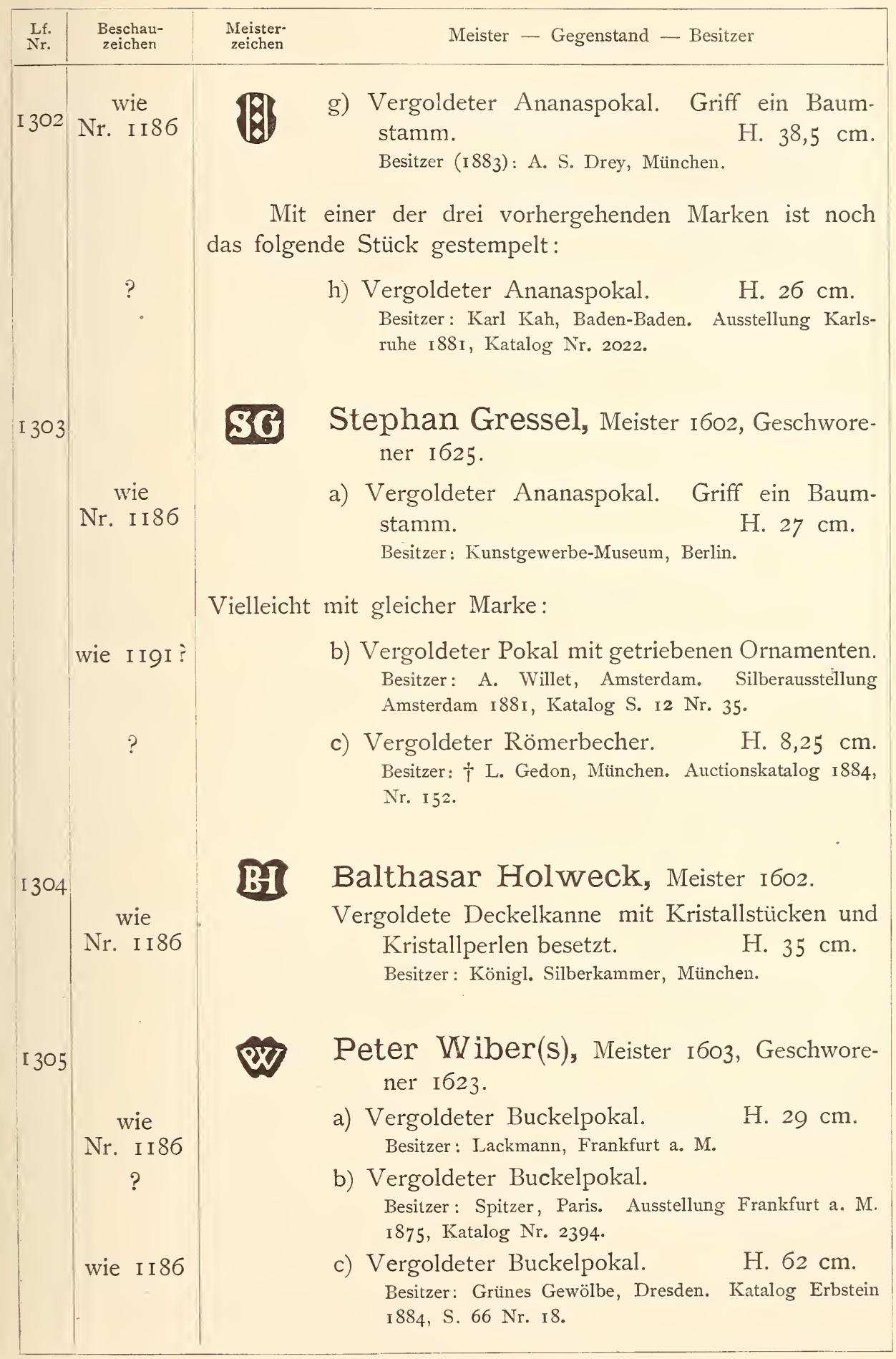




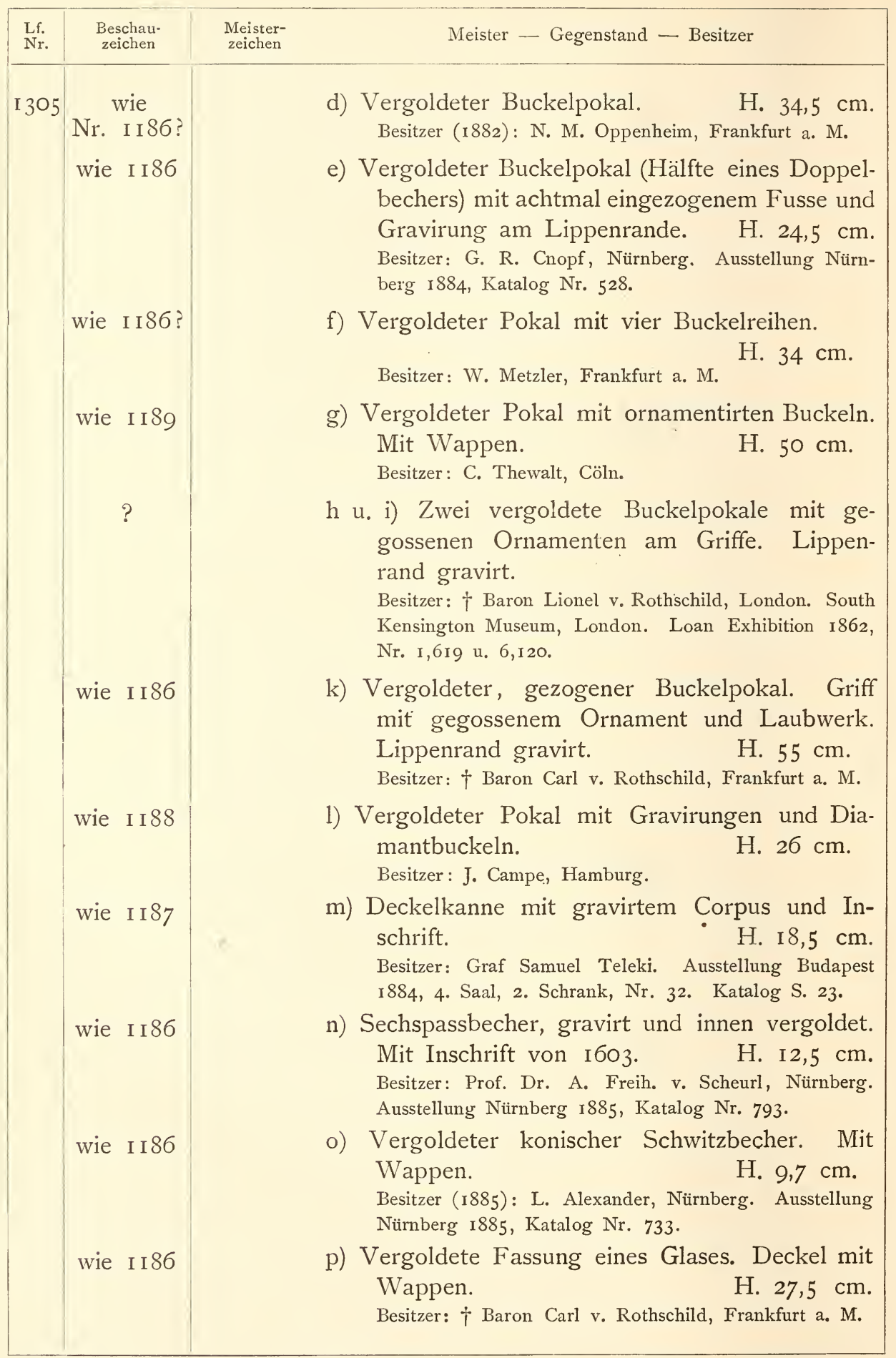




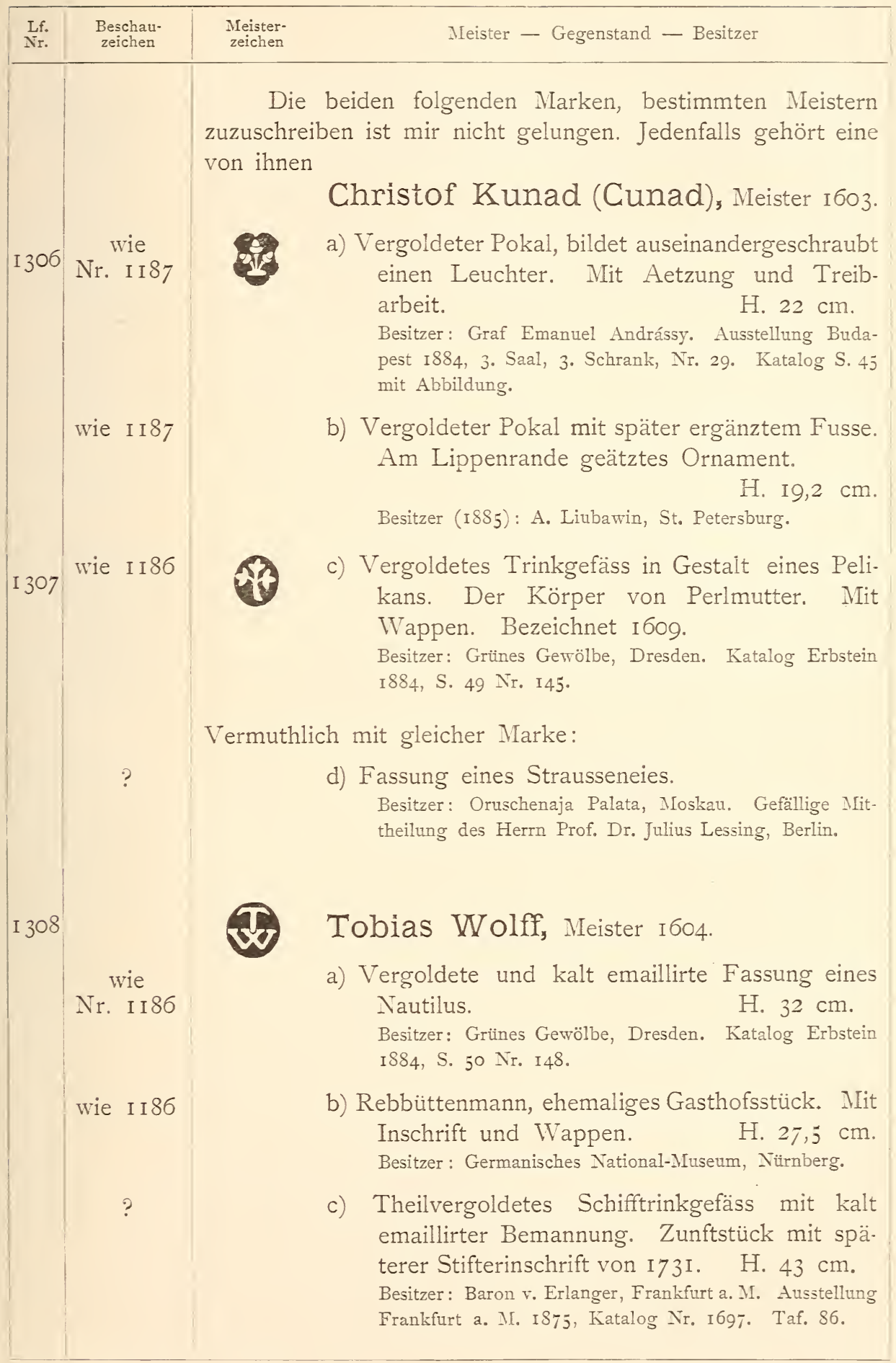




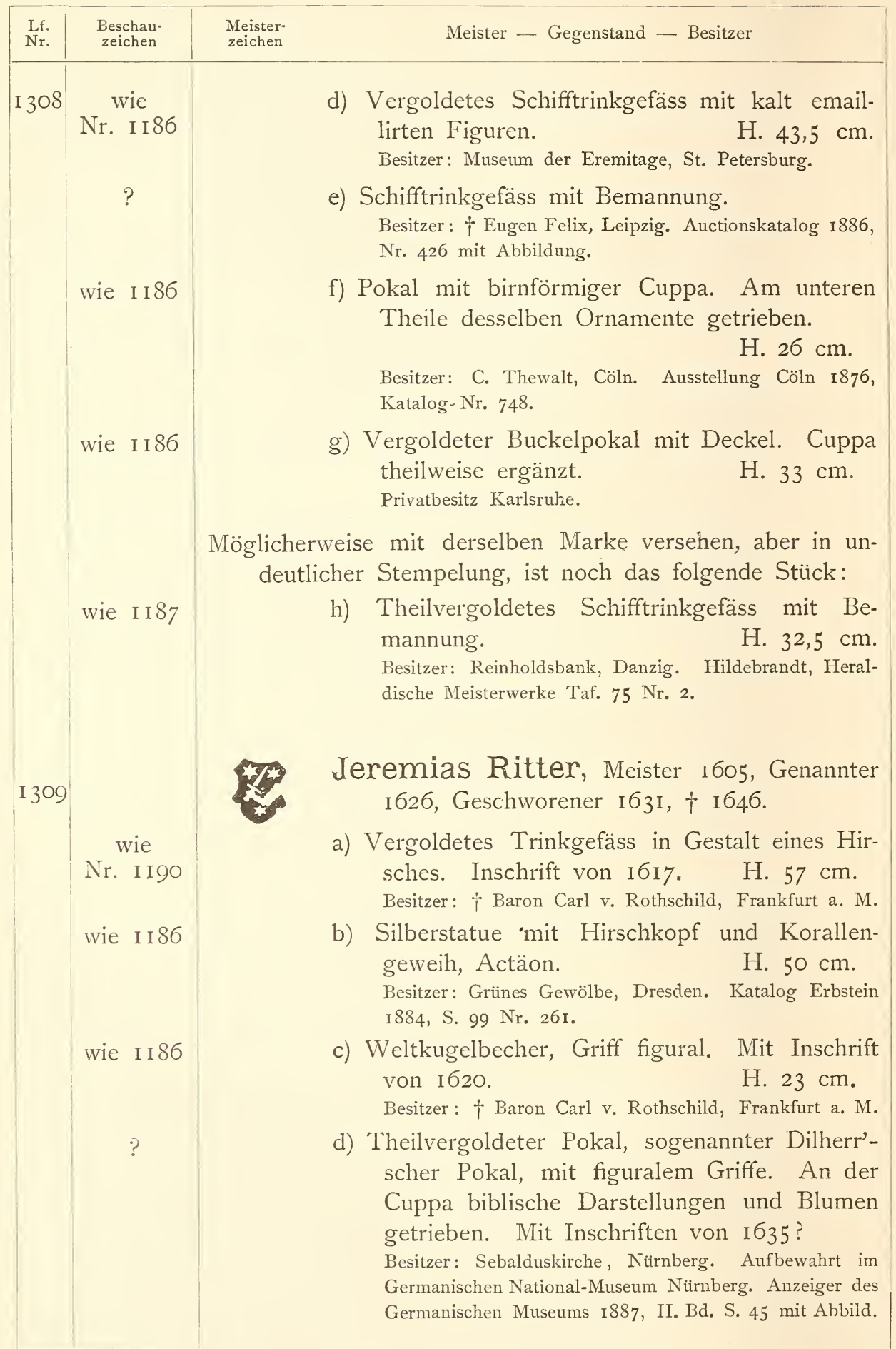




\begin{tabular}{|c|c|c|c|}
\hline $\begin{array}{l}\text { Lf. } \\
\text { Nr. }\end{array}$ & $\begin{array}{l}\text { Beschau- } \\
\text { zeichen }\end{array}$ & $\begin{array}{l}\text { Meister- } \\
\text { zeichen }\end{array}$ & Meister - Gegenstand - Besitzer \\
\hline 1309 & $\begin{array}{l}\text { wie } \\
\text { Nr. I I } 86\end{array}$ & & $\begin{array}{l}\text { e) Vergoldeter Pokal mit zugespitzten verzierten } \\
\text { Buckeln. H. } 69 \mathrm{~cm} \text {. } \\
\text { Besitzer: Patriarchen-Schatzkammer, Moskau. }\end{array}$ \\
\hline & ? & & $\begin{array}{l}\text { f) Aehnliches Stück. H. } 3 \text { I cm. } \\
\text { Besitzer: Patriarchen-Schatzkammer, Moskau. }\end{array}$ \\
\hline & wie I I 86 & & $\begin{array}{l}\text { g) Vergoldeter Pokal mit Buckeln und Orna- } \\
\text { menten. } \\
\text { Besitzer: Patriarchen-Schatzkammer, Moskau. } 33 \mathrm{~cm} \text {. }\end{array}$ \\
\hline & wie I I 89 & & $\begin{array}{l}\text { h) Vergoldeter Pokal. } \\
\text { Besitzer: Graf Samuel Teleki. Ausstellung Budapest } \\
\text { I884, 3. Saal, 3. Schrank, Nr. 28. Katalog S. 29. }\end{array}$ \\
\hline & wie I I90 & & $\begin{array}{l}\text { i) Vergoldeter Ananaspokal mit weisssilbernem } \\
\text { Baumstamme als Griff. } \\
\text { Besitzer: Kunstgewerbe-Museum, Berlin. }\end{array}$ \\
\hline & wie I I 86 & & $\begin{array}{l}\text { k) Ananaspokal. Griff Baumstamm mit Holz- } \\
\text { hauer. } \\
\text { Besitzer: Schloss Bebenhausen. }\end{array}$ \\
\hline & wie I I 86 & & $\begin{array}{l}\text { 1) Vergoldete Fassung einer Elfenbeinkanne. } \\
\text { H. } 38,8 \mathrm{~cm} . \\
\text { Besitzer: S. K. H. d. Grossherzog von Baden. Schloss } \\
\text { Karlsruhe. }\end{array}$ \\
\hline & ? & & $\begin{array}{l}\text { m) Vergoldete, ovale Platte mit getriebenen Orna- } \\
\text { menten und allegorischen Darstellungen. } \\
\text { Lg. } 60 \mathrm{~cm} . \\
\text { Besitzer: } \uparrow \text { Baron Carl v. Rothschild, Frankfurt a. M. }\end{array}$ \\
\hline & wie I I86 & & $\begin{array}{l}\text { n) Einzelner Setzbecher mit Aetzarbeit und Re- } \\
\text { liefs. } \\
\text { Hesitzer: } \$ \text { : Baron Carl v. Rothschild, Frankfurt a. M. }\end{array}$ \\
\hline & wie I I 86 & & $\begin{array}{l}\text { o) Vergoldetes Trinkgefäss in Gestalt einer } \\
\text { Kanone. } \\
\text { Besitzer: Historisches Museum, Dresden. }\end{array}$ \\
\hline & wie I I9I? & & $\begin{array}{l}\text { p) Theilvergoldete Schale mit Blumen getrieben. } \\
\text { Besitzer (I883): J. J. Boasberg, Amsterdam. }\end{array}$ \\
\hline & ? & & $\begin{array}{l}\text { q-t) Vier runde Zunftschilder mit Gürtleremblemen } \\
\text { und Inschrift von } 1656 \text {. Dm. je } 26 \mathrm{~cm} \text {. } \\
\text { Besitzer: } \dagger \text { Baron Carl v. Rothschild, Frankfurt a. M. }\end{array}$ \\
\hline
\end{tabular}




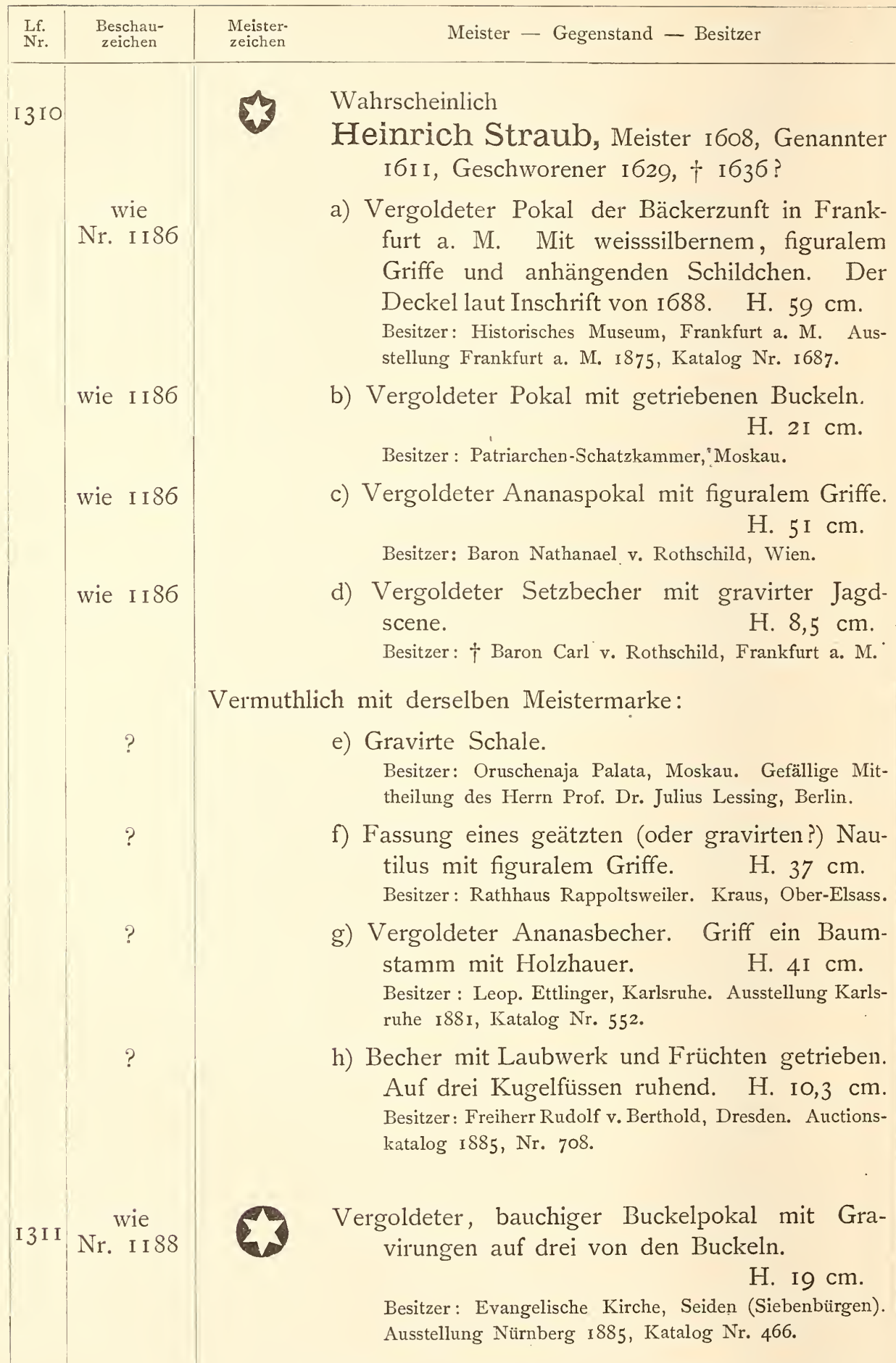




\begin{tabular}{|c|c|c|c|}
\hline$\underset{\text { Lff. }}{\text { Lf. }}$ & $\begin{array}{l}\text { Beschau- } \\
\text { zeichen }\end{array}$ & $\begin{array}{l}\text { Meister- } \\
\text { zeichen }\end{array}$ & Meister — Gegenstand - Besitzer \\
\hline I 3 I 2 & & 6 & $\begin{array}{l}\text { Wahrscheinlich } \\
\text { Esaias Zur Linden, Meister I609. }\end{array}$ \\
\hline & $\begin{array}{l}\text { wie } \\
\text { Nr. I I } 86\end{array}$ & & $\begin{array}{l}\text { a) Schiffpokal mit Inschrift von I628. H. } 43 \mathrm{~cm} \text {. } \\
\text { Besitzer: Friedr. Hiller, Augsburg. Ausstellung Augs- } \\
\text { burg I886, Katalog Nr. I } 474 .\end{array}$ \\
\hline & wie I I 86 & & $\begin{array}{l}\text { b) Vergoldetes Schifftrinkgefäss auf vier Rädern. } \\
\text { Mit gegossenen reliefirten Fahnen. } \\
\text { H. } 39,3 \mathrm{~cm} . \\
\text { Besitzer: † Baron Carl v. Rothschild, Frankfurt a. M. } \\
\text { Luthmer, Schatz Rothschild I, Taf. I7. }\end{array}$ \\
\hline & wie I I 86 & & $\begin{array}{ll}\text { c) Vergoldetes Schifftrinkgefäss auf vier Rädern. } & \text { H. 2I,2 cm. } \\
\begin{array}{ll}\text { Bemannung emaillirt. } & \text {. } \\
\text { Besitzer: } \dagger \text { Baron Carl v. Rothschild, Frankfurt a. M. }\end{array}\end{array}$ \\
\hline & $?$ & & $\begin{array}{r}\text { d) Vergoldetes Schifftrinkgefäss auf vier Rädern. } \\
\text { H. I9 cm. } \\
\text { Besitzer: Saly Fürth, Mainz. Abgebildet in Edelmetall- } \\
\text { arbeiten der Sammlung Fürth I886, Nr. } 28 .\end{array}$ \\
\hline & wie I I 86 & & $\begin{array}{l}\text { e) Schifftrinkgefäss auf vier Rädern. Am Kiel } \\
\text { Thierkopf mit Röhre. } \\
\text { Besitzer: Eduard Goldschmit, Frankfurt a. } 23,5 \mathrm{~cm} \text {. }\end{array}$ \\
\hline & wie I I 89 & & $\begin{array}{l}\text { fu. g) Zwei Schiffpokale. } \\
\text { H. } 37 \mathrm{~cm} . \text { resp. H. } 35 \mathrm{~cm} \text {. } \\
\text { Besitzer: Museum der Eremitage, St. Petersburg. }\end{array}$ \\
\hline & wie I I 86 & & $\begin{array}{l}\text { h-1) Vier Schiffpokale. } \\
\text { H. 48, 43,5, 30,2 und I7 cm. } \\
\text { Besitzer: J. \& H. Jeidels, Frankfurt a. M. }\end{array}$ \\
\hline & wie I I86 & & $\begin{array}{l}\text { m) Schiffpokal, theilweise kalt emaillirt. } \\
\begin{array}{ll}\text { Besitzer: Königl. Museum, Cassel. } & \text { H2,5 cm. }\end{array}\end{array}$ \\
\hline & wie I I 86 & & $\begin{array}{l}\text { n) Schiffpokal. H. } 37 \mathrm{~cm} \text {. } \\
\text { Besitzer: Freih. v. Löffelholz, Nürnberg. Ausstellung } \\
\text { Nürnberg I885, Katalog Nr. 530. }\end{array}$ \\
\hline & wie II 89 & & $\begin{array}{l}\text { o u. p) Zwei theilvergoldete Schiffe auf Rädern. } \\
\text { Mit Röhren zum Trinken. } \\
\text { H. } 25,5 \text { resp. H. I } 8,5 \mathrm{~cm} . \\
\text { Besitzer: Museum der Eremitage, St. Petersburg. }\end{array}$ \\
\hline & wie I I90 & & $\begin{array}{l}\text { q) Fassung eines „Trinkbechers“. } \\
\text { Besitzer: Kaiserl. Schatzkammer, Wien. Katalog Leitner } \\
\text { I882, S. } 69 \text { Nr. 202. }\end{array}$ \\
\hline
\end{tabular}




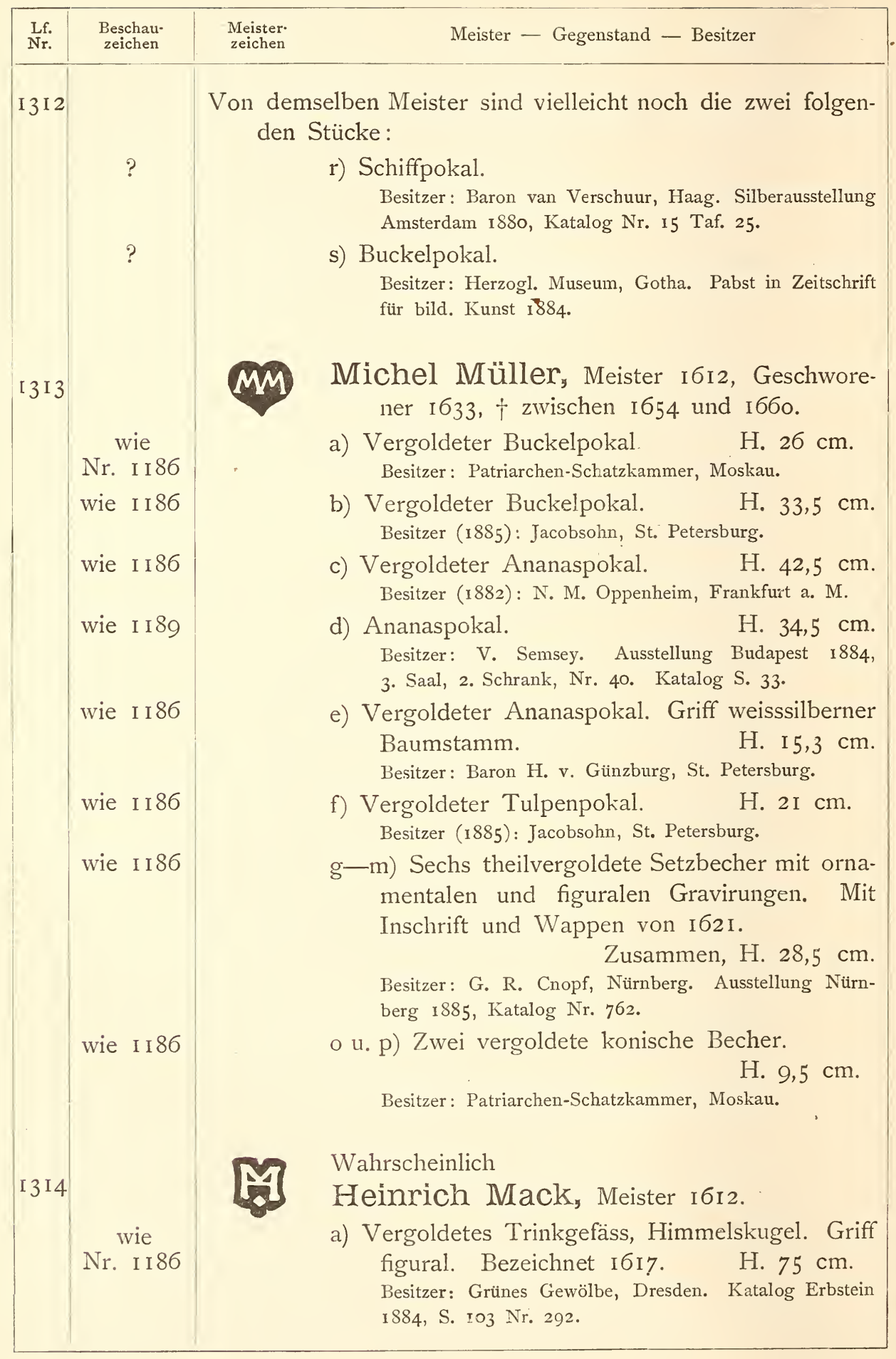




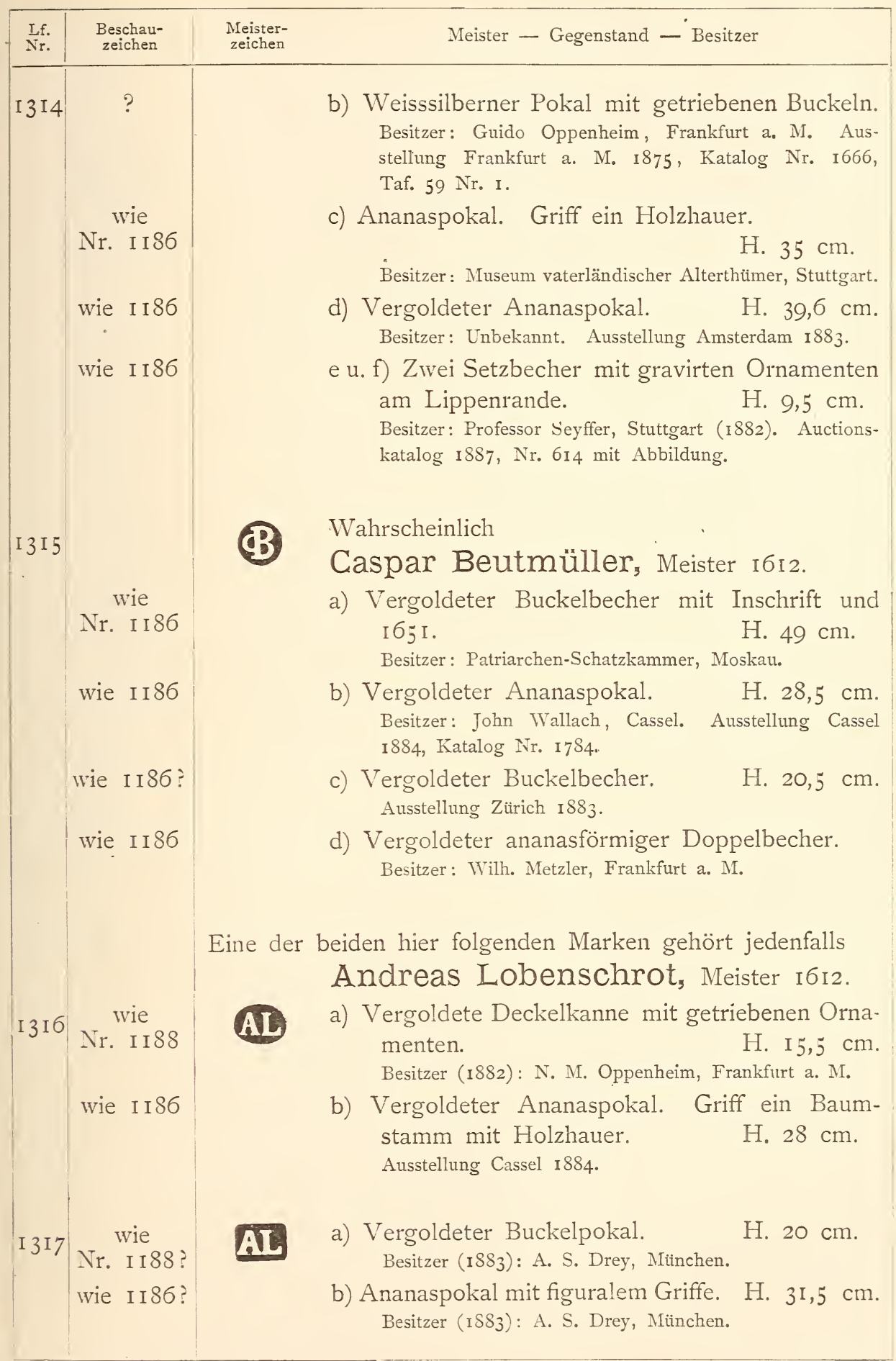




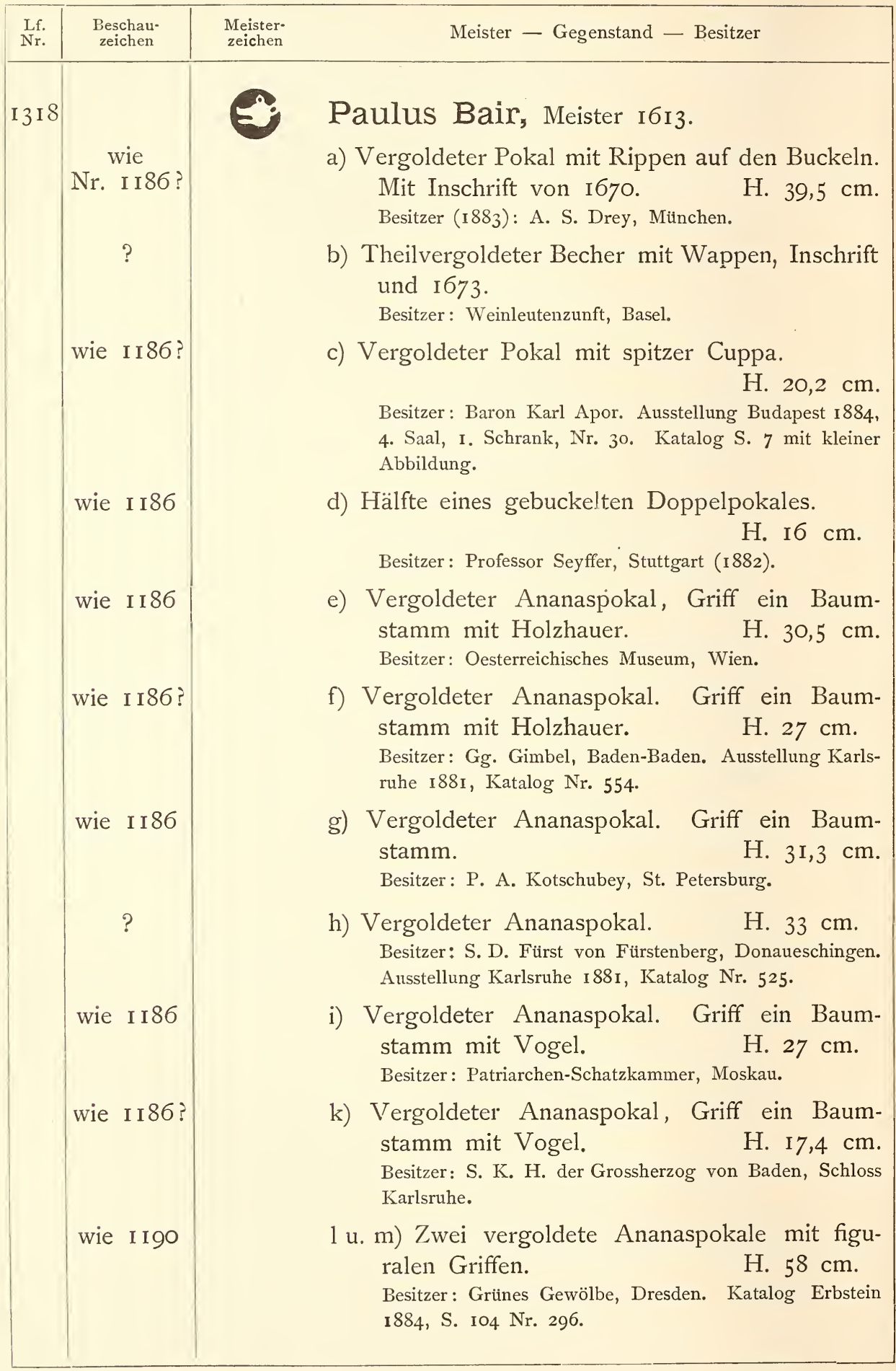




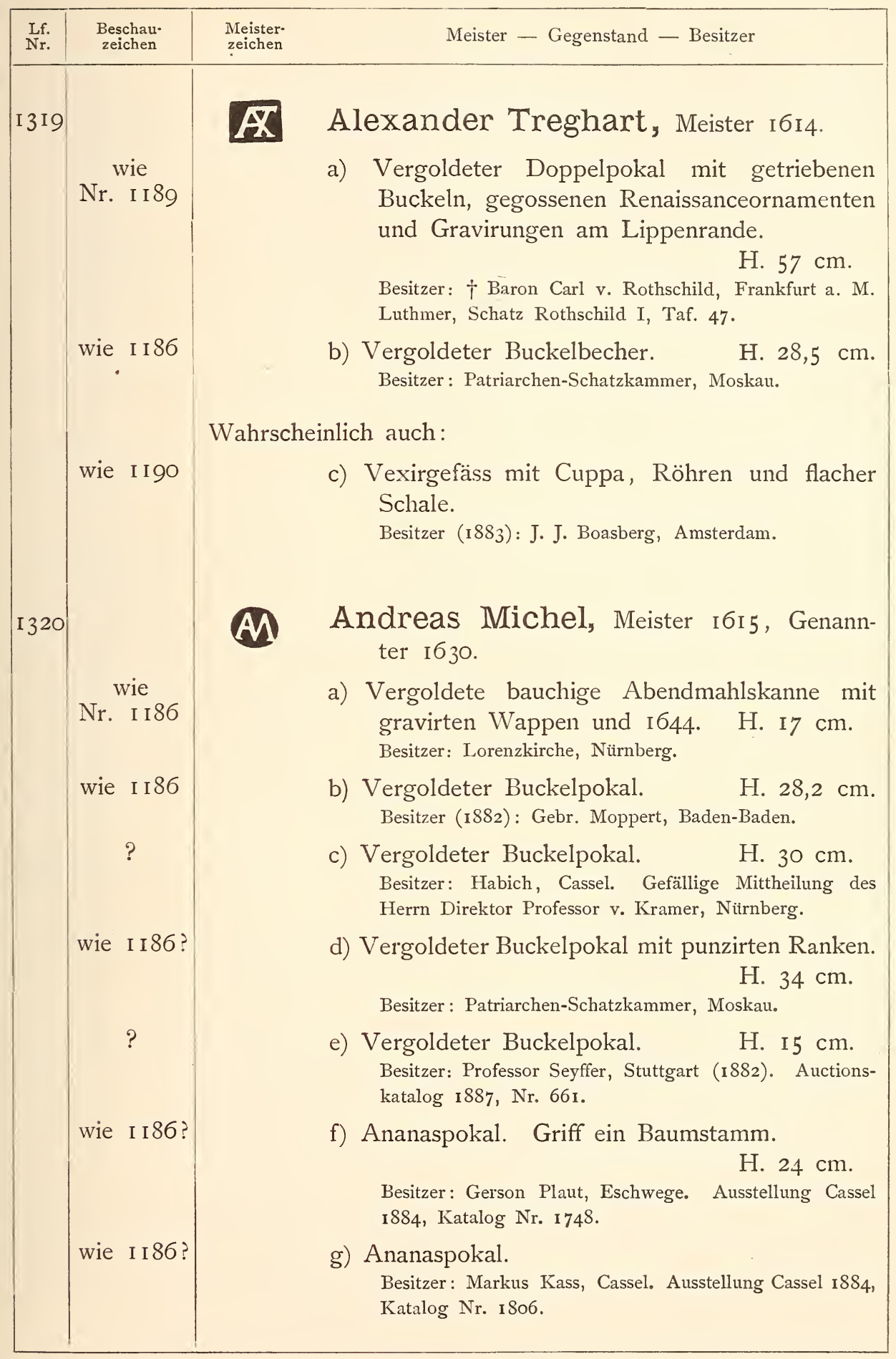




\begin{tabular}{|c|c|c|c|}
\hline $\begin{array}{l}\text { Lf. } \\
\text { Nr. }\end{array}$ & $\begin{array}{l}\text { Beschau- } \\
\text { zeichen }\end{array}$ & & Meister - Gegenstand - Besitzer \\
\hline 1320 & $\begin{array}{c}\text { wie } \\
\mathrm{Nr} . \text { I I } 86 ?\end{array}$ & Wahrsc & $\begin{array}{l}\text { h) Pokal. } \\
\text { Besitzer: Paul Andaházi. Ausstellung Budapest I884, } \\
\text { 3. Saal, 2. Schrank, Nr. 20. Katalog S. 27. } \\
\text { inlich von demselben Meister: } \\
\text { i) Silberfassung eines Beckens von Bernstein. } \\
\text { Besitzer: Grünes Gewölbe, Dresden. Katalog Erbstein } \\
\text { 1884, S. } 44 \text { Nr. } 76 \text {. }\end{array}$ \\
\hline I 32 I & $\begin{array}{c}\text { wie } \\
\text { Nr. I I } 86\end{array}$ & & $\begin{array}{l}\text { Georg Koler, Meister I6I7, Genannter I633, } \\
\text { Geschworener I635, † um I660? } \\
\begin{array}{ll}\text { a) Vergoldeter Ananaspokal. Griff Baumstamm } \\
\text { mit Holzhauer. } & \text { H. } 34 \mathrm{~cm} \text {. } \\
\text { Besitzer (1883): A. S. Drey, München. }\end{array}\end{array}$ \\
\hline & wie $\quad$ I 192 & & 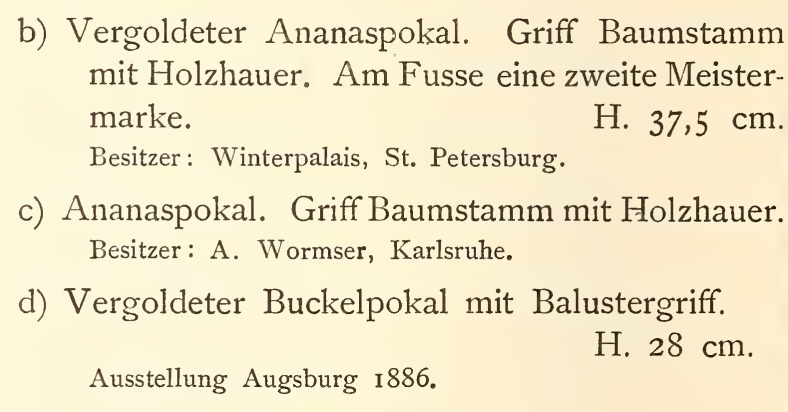 \\
\hline I 322 & $\begin{array}{c}\text { wie } \\
\mathrm{Nr} . \quad \text { I } 87\end{array}$ & & $\begin{array}{l}\text { Weisssilbernes Taufbecken. Die dabei befindliche } \\
\text { Kanne mit Zügen. } \\
\text { Becken, Lg. } 47 \mathrm{~cm} \text {. Kanne, H. } 2 \text { I cm. } \\
\text { Besitzer: Sebalduskirche, Nürnberg. }\end{array}$ \\
\hline 1323 & $\begin{array}{c}\text { wie } \\
\text { Nr. I I } 87\end{array}$ & & $\begin{array}{c}\text { Vergoldeter Pokal mit Horizontalprofilirungen. } \\
\text { Corpus mit Ornamenten getrieben, Fuss } \\
\text { geätzt. } \\
\text { Besitzer: Patriarchen-Schatzkammer, Moskau. }\end{array}$ \\
\hline I 324 & $\begin{array}{c}\text { wie } \\
\text { Nr. I I } 86\end{array}$ & F & 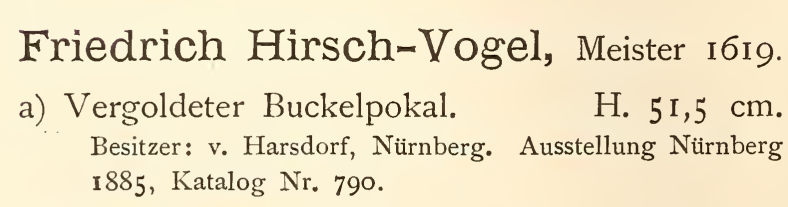 \\
\hline
\end{tabular}




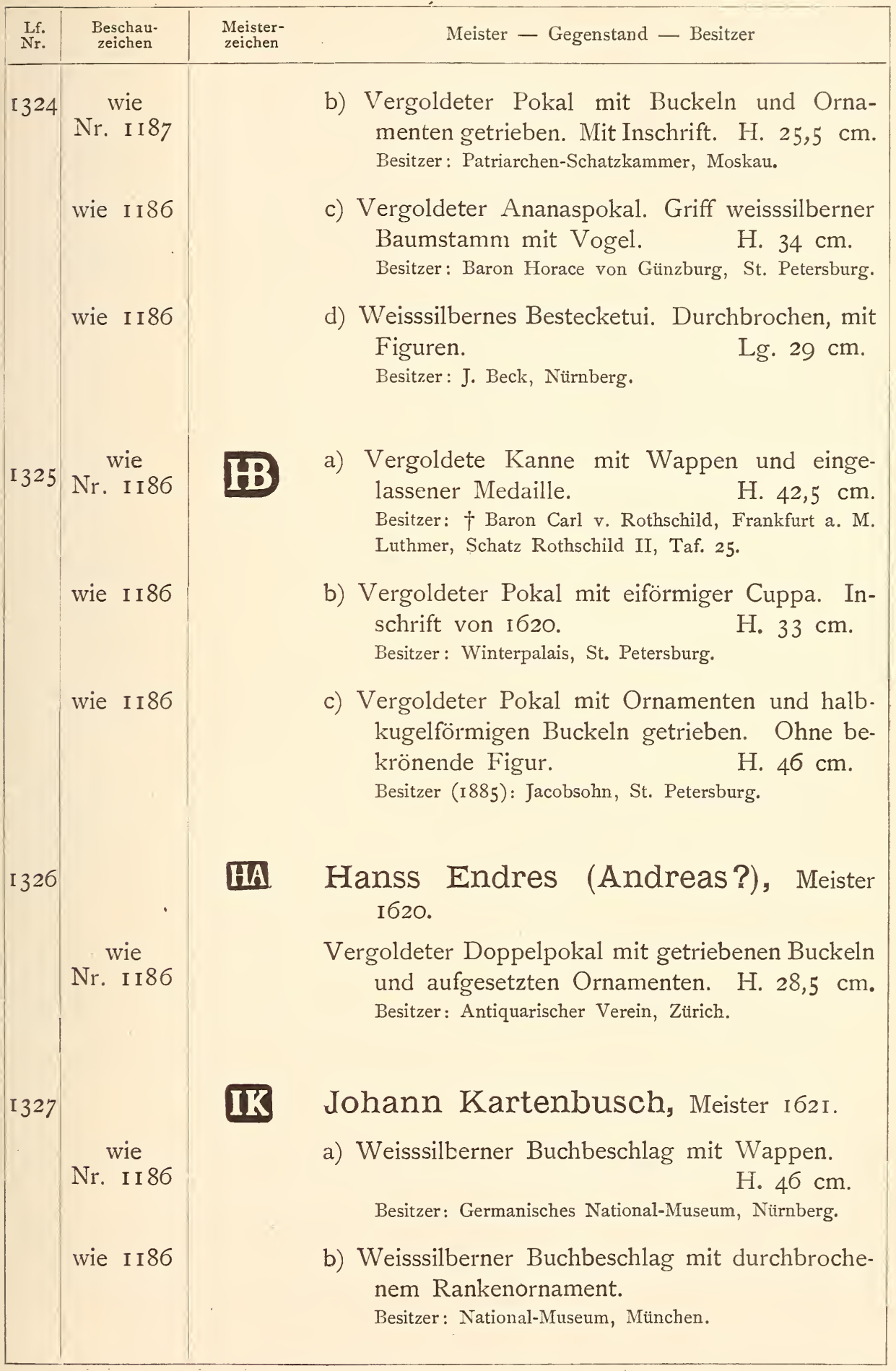




\begin{tabular}{|c|c|c|c|}
\hline $\begin{array}{l}\text { Lf. } \\
\text { Nr. }\end{array}$ & $\begin{array}{l}\text { Beschau- } \\
\text { zeichen }\end{array}$ & $\begin{array}{l}\text { Meister- } \\
\text { zeichen }\end{array}$ & Meister - Gegenstand - Besitzer \\
\hline I 328 & $\begin{array}{l}\text { wie } \\
\text { Nr. I I } 87 \\
\text { wie I } 86\end{array}$ & (TD) & $\begin{array}{l}\text { Thomas Danner, Meister I62I. } \\
\text { a) Vergoldete Tasse mit gravirten Ornamenten } \\
\text { und zwei gegossenen Henkeln. H. 5, I cm. } \\
\text { Besitzer: Ludwig Kahn-Speyer, Wien. } \\
\text { b) Deckel zu einem Buckelpokal, welcher mit } \\
\text { anderem Stempel gezeichnet ist. Vergl. } \\
\text { oben Nr. I295. } \\
\text { Besitzer: Patriarchen-Schatzkammer, Moskau. }\end{array}$ \\
\hline
\end{tabular}

wie

Nr. I I9I

wie I I 88

wie

Nr. I 87

wie II9I

wie I I 86

wie I 86

I33 I

wie

Nr. I 187 a) Vergoldeter Buckelpokal mit Wappen und Initialen.

H. $27 \mathrm{~cm}$.

Besitzer: Saly Fïrth, Mainz. Abgebildet in Edelmetallarbeiten der Sammlung Fürth 1886, Nr. 21.

b) Vergoldeter Ananaspokal mit figuralem Griffe. H. $55 \mathrm{~cm}$.

Besitzer: Ludwig Kahn-Speyer, Wien.

(IV) Leonhard Vorch(h)amer, Meister I623, $\dagger$ zwischen 1640 und 1660 .

Vergoldete Deckelkanne mit Inschrift von I634. H. $14 \mathrm{~cm}$.

Besitzer: Baron Horace von Günzburg, St. Petersburg.

b) Vergoldete Deckelkanne, sechsseitig mit Buckeln. Besitzer (1883): J. J. Boasberg, Amsterdam.

c) Vergoldeter gebuckelter Doppelpokal.

H. $45 \mathrm{~cm}$.

Besitzer: † Baron Carl v. Rothschild, Frankfurt a. M.

d) Vergoldeter Ananaspokal.

H. $44,5 \mathrm{~cm}$. Besitzer: Stadt Marburg. Ausstellung Cassel 1884, Katalog Nr. I13.

Georg Müller, Meister ı624, Geschworener I643.

a) Vergoldeter Dreibecher. Die einzelnen Pokale herzförmig mit Diamantbuckeln. Griff figural. H. $43 \mathrm{~cm}$.

Besitzer: Königl. Museum, Cassel. Katalog Lenz I881, Nr. I4. 


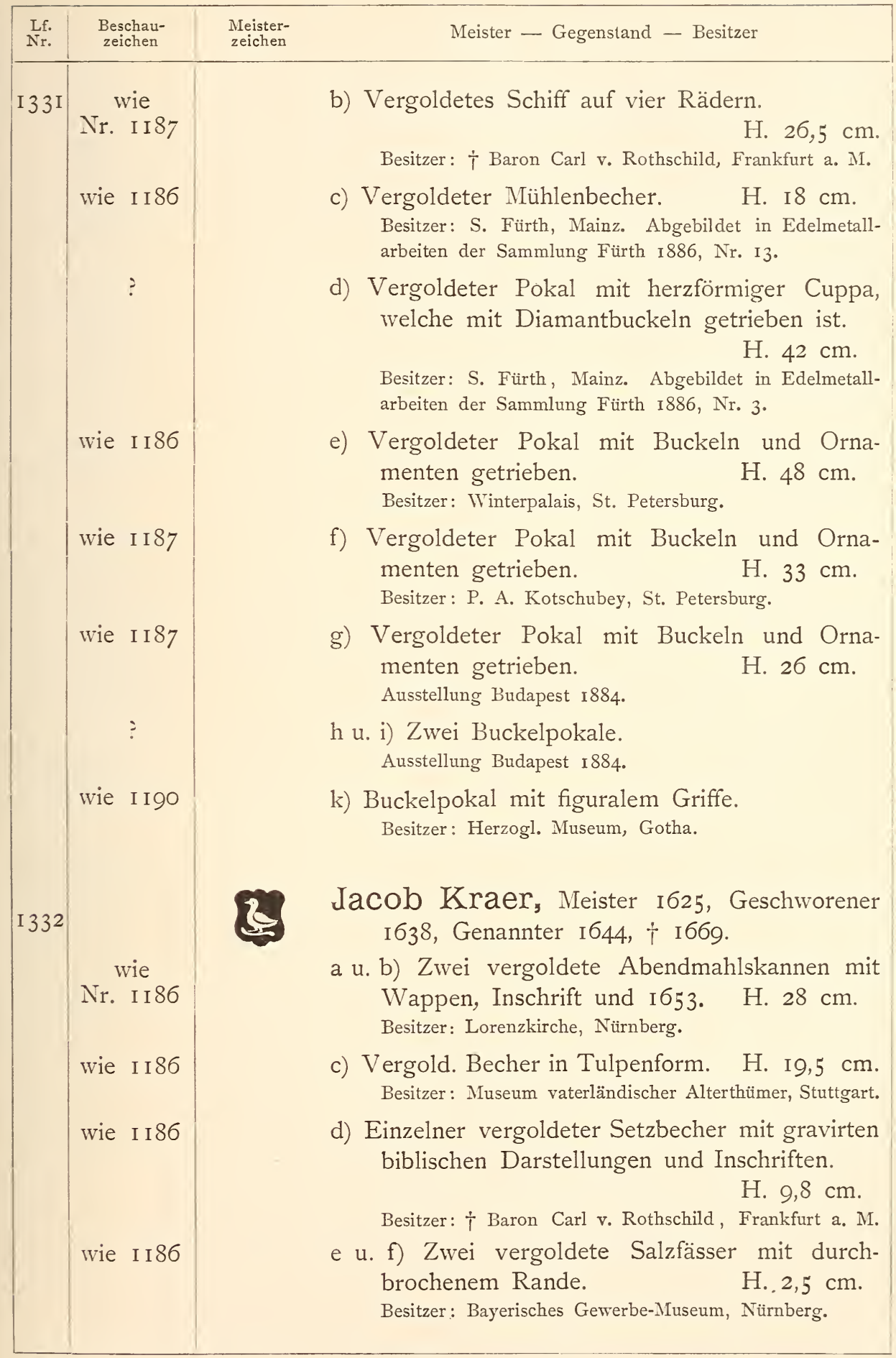




\begin{tabular}{|c|c|c|c|}
\hline $\begin{array}{l}\text { Lf. } \\
\text { Nr. }\end{array}$ & $\begin{array}{l}\text { Beschau- } \\
\text { zeichen }\end{array}$ & & Meister - Gegenstand - Besitzer \\
\hline I 333 & $\begin{array}{c}\text { wie } \\
\text { Nr. I I } 86\end{array}$ & & $\begin{array}{l}\text { Gg. Pfeilstricker, Meister I626. } \\
\text { Fassung eines Nautilus mit gravirtem Rande. } \\
\text { Griff figural. } \\
\begin{array}{ll}\text { Besitzer: National-Museum, Budapest. A } 1,5 \mathrm{~cm} \text {. Ausstellung } \\
\text { Budapest i884. }\end{array}\end{array}$ \\
\hline I 334 & $\begin{array}{l}\text { wie } \\
\text { Nr. I } 87 \\
\text { wie I } 193 \text { ? }\end{array}$ & & $\begin{array}{l}\text { a) Buckelpokal. } 20,5 \mathrm{~cm} \text {. } \\
\text { Besitzer: S. D. Fürst Paskewitsch, St. Petersburg. } \\
\text { b) Theilvergoldeter Becher mit getriebenen Tulpen- } \\
\text { ornamenten, auf Kugelfüssen ruhend. } \\
\text { H. } 8,3 \mathrm{~cm} \text {. } \\
\text { Besitzer (1885): L. Alexander, Nürnberg. Ausstellung } \\
\text { Nürnberg 1885, Katalog Nr. } 738 .\end{array}$ \\
\hline & wie I I93? & & $\begin{array}{l}\text { c) Theilvergoldeter Becher auf Kugelfüssen. } \\
\text { H. I 3,5 cm. } \\
\text { Besitzer: J. Beck, Nürnberg. Ausstellung Nürnberg } \\
\text { 1885, Katalog Nr. } 749 .\end{array}$ \\
\hline & wie II 86 & & $\begin{array}{l}\text { d) Becher mit getriebenen Schuppen, auf Kugel- } \\
\text { füssen ruhend. } \\
\text { Besitzer: Professor Seyffer, Stuttgart (I882). }\end{array}$ \\
\hline & wie I I86 & & $\begin{array}{l}\text { e) Vergoldeter, konischer Becher mit getriebenen } \\
\text { Blumen und Vögeln. } \\
\text { Besitzer (1883): J. Drey, München. }\end{array}$ \\
\hline & wie 1189 & & $\begin{array}{l}\text { f) Theilvergoldete Henkelschale mit getriebenen } \\
\text { Tulpenornamenten. } \quad \text { Lg. I3 cm. } \\
\text { Besitzer: Pfälzisches Gewerbe-Museum, Kaiserslautern. } \\
\text { Ausstellung Nürnberg i } 885 \text {, Katalog Nr. } 662 .\end{array}$ \\
\hline & wie II 86 & & $\begin{array}{l}\text { g) Vergoldete Henkelschale mit getriebenen Blu- } \\
\text { men. Rand stark ausgebogen. Lg. I7, } 6 \mathrm{~cm} \text {. } \\
\text { Besitzer: Geistl. Rath Dr. Fr. Schneider, Mainz. }\end{array}$ \\
\hline & wie 1189 & & $\begin{array}{l}\text { h) Vergoldetes Schälchen mit getriebenen und } \\
\text { gravirten Tulpen. } \\
\text { Ausstellung Augsburg i } 886 .\end{array}$ \\
\hline I 335 & $\begin{array}{l}\text { wie } \\
\text { Nr. I I } 86\end{array}$ & & $\begin{array}{l}\text { Johannes Clauss, Meister I627. } \\
\begin{array}{ll}\text { a) Gebuckelter Dreibecher. } & \text { H. } 5 \mathrm{I} \mathrm{cm} \text {. } \\
\text { Besitzer: Königl. Museum, Cassel. Photographirt. }\end{array}\end{array}$ \\
\hline
\end{tabular}




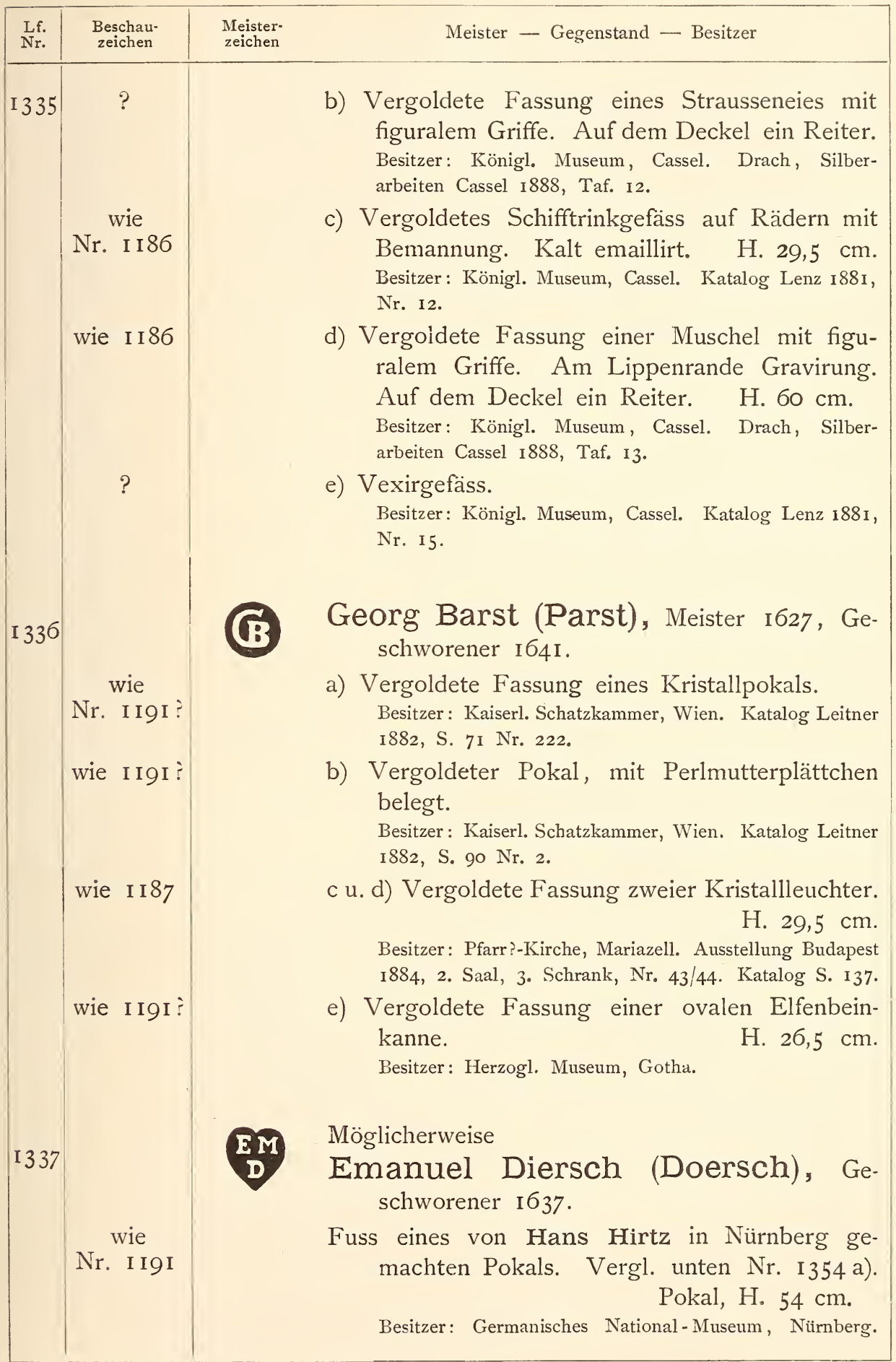




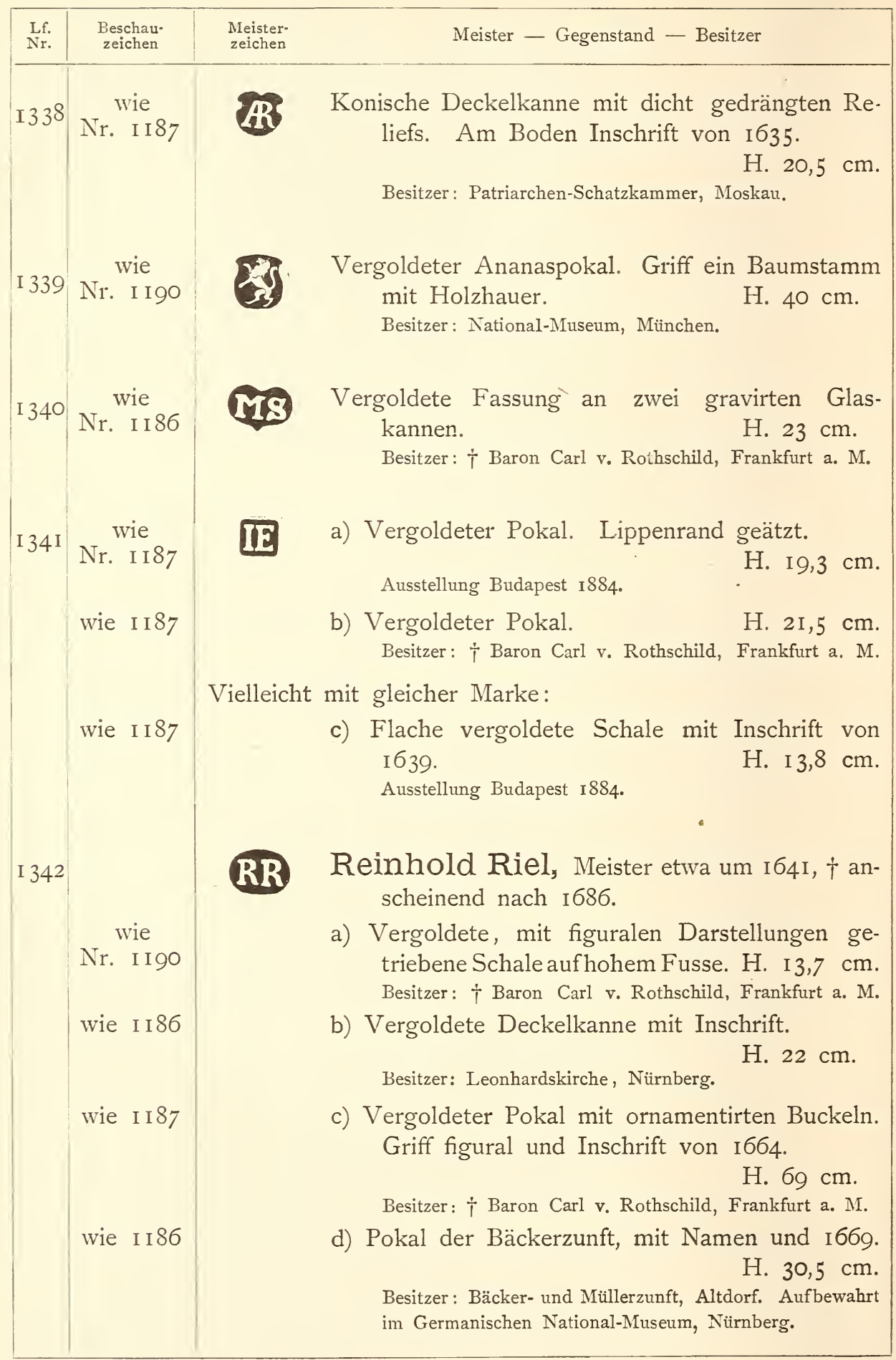




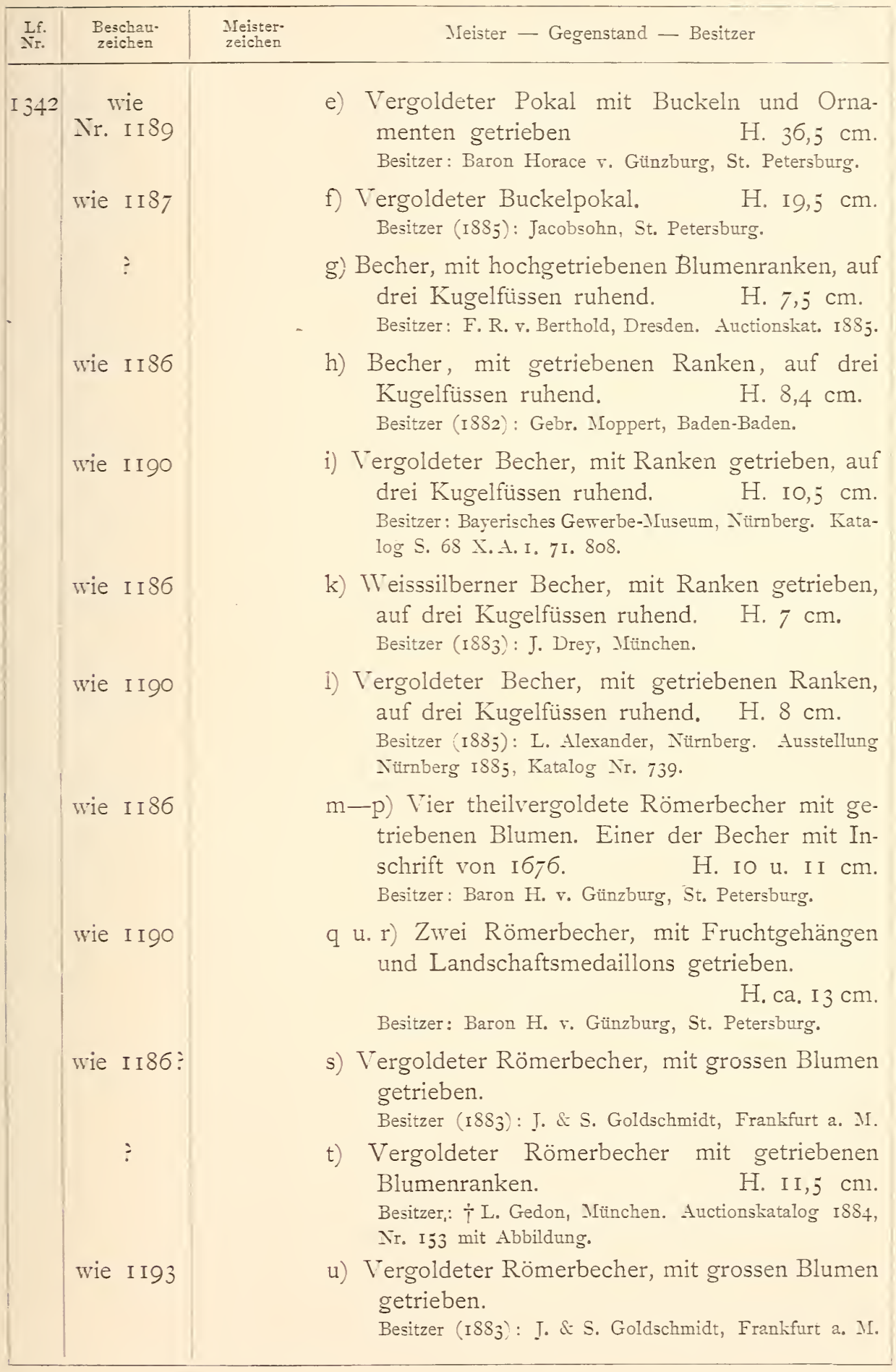


Deutschland - Nürnberg (Meister des I 7. Jahrh.)

\begin{tabular}{|c|c|c|c|}
\hline $\begin{array}{l}\text { Lf. } \\
\text { Nr. }\end{array}$ & $\begin{array}{l}\text { Beschau- } \\
\text { zeichen }\end{array}$ & $\begin{array}{l}\text { Meister- } \\
\text { zeichen }\end{array}$ & Meister - Gegenstand - Besitzer \\
\hline \multirow[t]{5}{*}{342} & ? & & $\begin{array}{l}\text { v) Vergoldeter Römerbecher mit hochgetriebenen } \\
\text { Ranken. H. 9,5 cm. } \\
\text { Besitzer: Saly Fürth, Mainz. Abgebildet in Edelmetall- } \\
\text { arbeiten der Sammlung Fürth I886, Nr. } 33 .\end{array}$ \\
\hline & $\begin{array}{l}\text { wie } \\
\text { Nr. I I } 86\end{array}$ & & $\begin{array}{l}\text { w) Bauchiger Römerbecher. } \\
\text { Ausstellung Budapest I } 884 \text {. }\end{array}$ \\
\hline & ? & & $\begin{array}{l}\text { x u. y) Zwei vergoldete Römerbecher. } \\
\text { H. IO und I I, } 5 \mathrm{~cm} \text {. } \\
\text { Besitzer: O. v. Essen, Baden-Baden. Ausstellung Karls- } \\
\text { ruhe 1881, Katalog Nr. I } 672 .\end{array}$ \\
\hline & ? & & $\begin{array}{l}\text { z) Tummelchen, mit grossen Blumen getrieben. } \\
\text { H. } 5,5 \mathrm{~cm} . \\
\text { Besitzer: Professor Seyffer, Stuttgart (1882). }\end{array}$ \\
\hline & wie IIgo & & $\begin{array}{l}\text { aa) Vergoldetes Besteck. Griff gegossen, mit } \\
\text { gewundenen Ranken. } \\
\text { Besitzer: Zschille, Grossenheim. Pabst. Bestecksamm- } \\
\text { lung Zschille 1886, Nr. } 77 \text { Taf. 9. }\end{array}$ \\
\hline \multirow[t]{3}{*}{ I 343} & $\begin{array}{l}\text { wie } \\
\text { Nr. I I } 86\end{array}$ & & $\begin{array}{l}\text { a) Konischer Becher mit Emblemen und In- } \\
\text { schriften von I642. H. } 6 \mathrm{~cm} \text {. } \\
\text { Besitzer: Antiquarischer Verein, Zürich. }\end{array}$ \\
\hline & wie II 86 & & $\begin{array}{l}\text { b) Vergoldetes Vexirgefäss, aus Becher und } \\
\text { Schale gebildet. Mit gravirten Ornamenten. } \\
\text { H. } 34,5 \text { cm. } \\
\text { Besitzer: S. K. H. der Grossherzog von Baden, Schloss } \\
\text { Karlsruhe. }\end{array}$ \\
\hline & wie II 86 & & $\begin{array}{l}\text { c) Weisssilberner Löffel mit Gravirung. } \\
\text { Besitzer: Professor Seyffer, Stuttgart (1882). Auctions- } \\
\text { katalog I888, Nr. 541. Mit Abbildung. }\end{array}$ \\
\hline \multirow[t]{3}{*}{ I 344} & $\begin{array}{l}\text { wie } \\
\text { Nr. I I } 87\end{array}$ & $(8)$ & $\begin{array}{l}\text { a u. b) Zwei vergoldete Abendmahlskannen mit } \\
\text { gravirten Wappen und I643. H. I7 cm. } \\
\text { Besitzer: Sebalduskirche, Nürnberg. }\end{array}$ \\
\hline & wie II 86 & & $\begin{array}{l}\text { c) Vergoldeter Kelch mit Treibarbeit. Inschrift } \\
\text { von I } 647 \text {. } \\
\text { Besitzer: Johanneskirche, Ansbach. }\end{array}$ \\
\hline & wie I I86 & & $\begin{array}{l}\text { d) Gravirte Patene mit Inschrift von i65 I. } \\
\text { Besitzer: Johanneskirche, Ansbach. }\end{array}$ \\
\hline
\end{tabular}




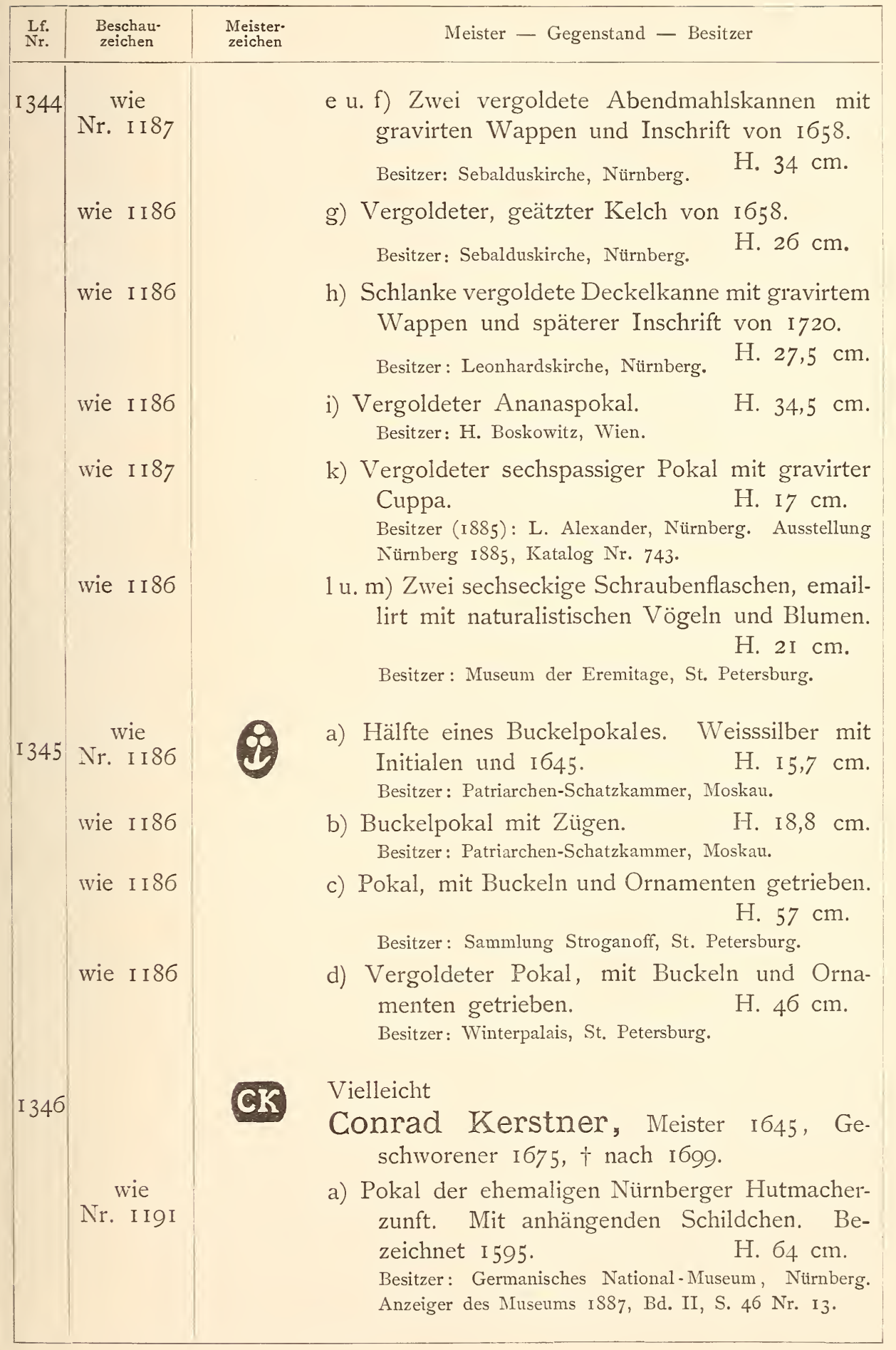




\begin{tabular}{|c|c|c|c|}
\hline $\begin{array}{l}\text { Lf. } \\
\text { Nr. }\end{array}$ & $\begin{array}{l}\text { Beschau- } \\
\text { zeichen }\end{array}$ & $\begin{array}{l}\text { Meister- } \\
\text { zeichen }\end{array}$ & Meister - Gegenstand — Besitzer \\
\hline I 346 & ? & & $\begin{array}{l}\text { b) Gebuckelter Pokal. Deckelbekrönung Blumen- } \\
\text { bouquet und Crucifix. Inschrift von I699. } \\
\text { H. } 27,6 \mathrm{~cm} . \\
\text { Besitzer: Baron van Reynegom de Buzet, Herenthout. } \\
\text { Ausstellung Mecheln i864, Katalog Nr. 615. }\end{array}$ \\
\hline & $\begin{array}{l}\text { wie } \\
\text { Nr. I I } 86\end{array}$ & & $\begin{array}{l}\text { c) Vergoldeter Ananaspokal. Griff Baumstamm } \\
\text { mit Holzhauer. } \\
\text { Besitzer: Patriarchen-Schatzkammer, Moskau. } 27,5 \mathrm{~cm}\end{array}$ \\
\hline & wie I I86 & & $\begin{array}{l}\text { d) Vergoldeter Buckelpokal mit sechseckigen } \\
\text { Feldern. } \\
\text { Besitzer: Graf Altenkirchen, Cassel. Ausstellung Cassel } \\
\text { I884, Katalog Nr. 1707. }\end{array}$ \\
\hline I 347 & $\begin{array}{l}\text { wie } \\
\text { Nr. I I } 88\end{array}$ & & $\begin{array}{l}\text { a) Vergoldeter Buckelpokal mit Inschrift von r648. } \\
\text { Der Deckel von einem anderen Meister. } \\
\text { Ohne Deckel, H. } 35 \mathrm{~cm} . \\
\text { Besitzer: Patriarchen-Schatzkammer, Moskau. }\end{array}$ \\
\hline & wie 1 I 87 & & $\begin{array}{l}\text { b) Hoher vergoldeter Pokal mit zweimal aus- } \\
\text { gebauchter Cuppa. } \\
\text { Besitzer: Patriarchen-Schatzkammer, Moskau. }\end{array}$ \\
\hline & wie I I86 & & $\begin{array}{l}\text { c) Deckel auf einem vergoldeten Buckelpokale, } \\
\text { dessen Griff mit Köpfen und Voluten ver- } \\
\text { ziert ist. Pokal, H. } 46 \mathrm{~cm} \text {. } \\
\text { Besitzer (1885) : Jacobsohn, St. Petersburg. }\end{array}$ \\
\hline & wie 1 I 87 & & $\begin{array}{l}\text { d) Deckel eines Pokals mit Ovalmedaillons in } \\
\text { Treibarbeit. Pokal, H. } 38 \mathrm{~cm} \text {. } \\
\text { Besitzer: Patriarchen-Schatzkammer, Moskau. }\end{array}$ \\
\hline I 348 & $\begin{array}{l}\text { wie } \\
\text { Nr. I I } 87\end{array}$ & & $\begin{array}{l}\text { Vergoldeter Pokal auf hohem Fusse mit wenig } \\
\text { geschweifter Cuppa. Inschrift von I648. } \\
\text { H. } 49 \mathrm{~cm} . \\
\text { Besitzer: Patriarchen-Schatzkammer, Moskau. }\end{array}$ \\
\hline I 349 & $\begin{array}{l}\text { wie } \\
\text { Nr. I Igc }\end{array}$ & (i) & $\begin{array}{l}\text { a) Pokal mit getriebenen Buckeln und figuralem } \\
\text { Griffe. } \\
\text { Besitzer: Herzogl. Museum, Gotha. Katalog Bube } 1869 \text {, } \\
\text { Nr. } 27 . \\
\text { b) Pokal mit figuralem Griffe. Bäckerzunftstück. } \\
\text { H. } 31,5 \mathrm{~cm} . \\
\text { Besitzer: J. \& H. Jeidels, Frankfurt a. M. }\end{array}$ \\
\hline
\end{tabular}




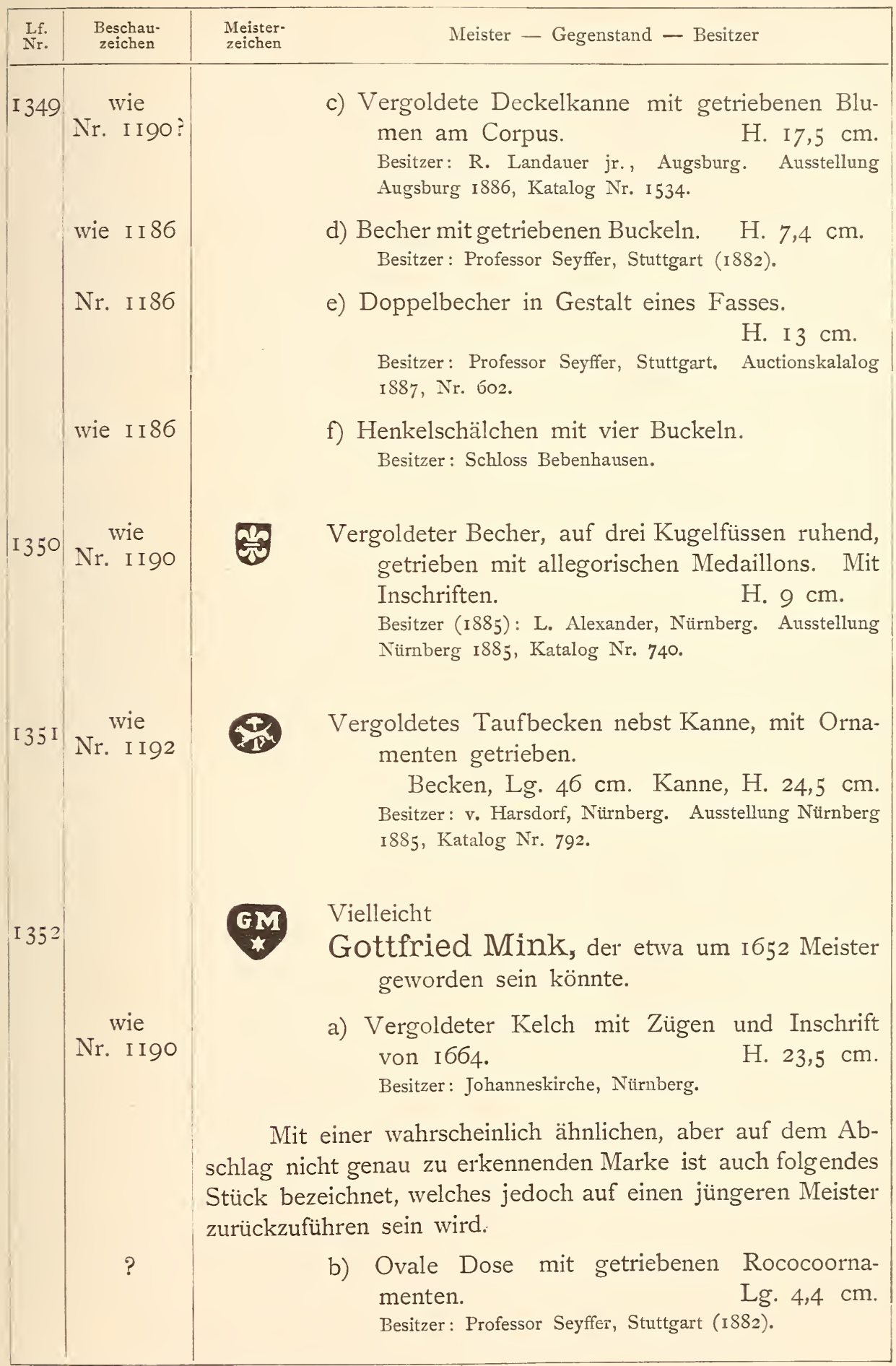




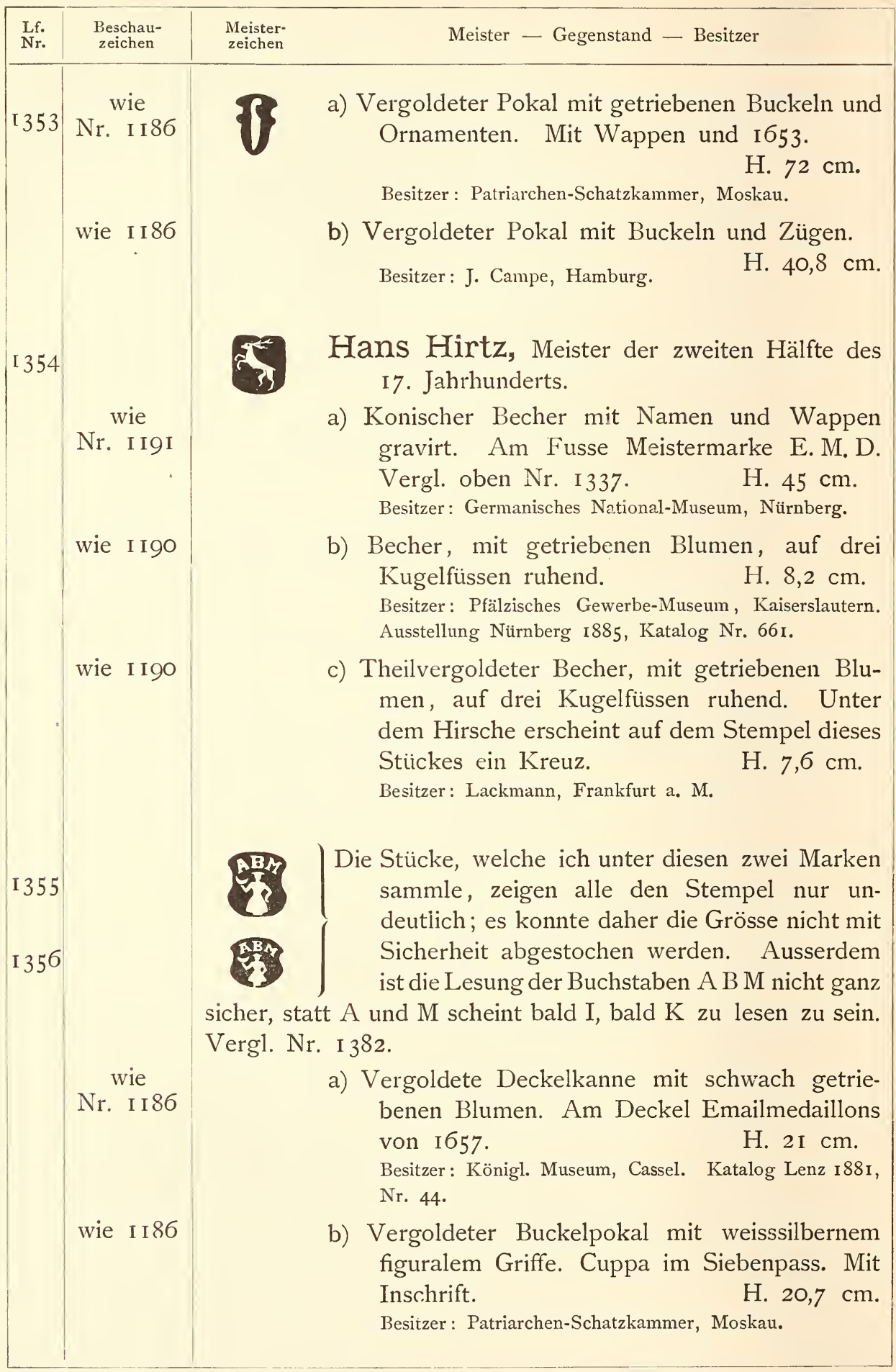




\begin{tabular}{|c|c|c|c|}
\hline $\begin{array}{l}\text { Lf. } \\
\text { Nr. }\end{array}$ & $\begin{array}{l}\text { Beschau- } \\
\text { zeichen }\end{array}$ & $\begin{array}{l}\text { Meister- } \\
\text { zeichen }\end{array}$ & Meister - Gegenstand - Besitzer. \\
\hline \multirow[t]{9}{*}{$\begin{array}{l}\text { I } 35 \\
\text { I } 35\end{array}$} & $\begin{array}{c}\text { wie } \\
\text { Nr. I I } 90\end{array}$ & & $\begin{array}{l}\text { c) Pokal mit Blumenranken getrieben. Mit spä- } \\
\text { terer Inschrift von I722. } \\
\text { Besitzer: Germanisches National-Museum, Nürnberg. }\end{array}$ \\
\hline & wie I I 86 & & $\begin{array}{l}\text { d) Becher mit gravirten und schwach getriebenen } \\
\text { Blumen. H. } 6 \mathrm{~cm} \text {. } \\
\text { Besitzer: J. \& H. Jeidels, Frankfurt a. M. }\end{array}$ \\
\hline & ? & & $\begin{array}{l}\text { e) Becher mit grossen Blumen getrieben. } \\
\text { Besitzer: Herzogl. Museum, Gotha. } 6,4 \mathrm{~cm} \text {. }\end{array}$ \\
\hline & wie I I 86 & & $\begin{array}{l}\text { f) Theilvergoldeter Pokal mit flacher Schale. } \\
\text { H. } 26,5 \mathrm{~cm} . \\
\text { Besitzer: Museum der Eremitage, St. Petersburg. }\end{array}$ \\
\hline & wie I I9o & & $\begin{array}{l}\text { g-q) Zehn Setzbecher mit Gravirungen und In- } \\
\text { schriften. Vgl. oben Nr. I } 266 \text {. H. } 7,7 \mathrm{~cm} \text {. } \\
\text { Besitzer: } \dagger \text { Baron Carl v. Rothschild, Frankfurt a. M. }\end{array}$ \\
\hline & wie I I90 & & $\begin{array}{l}\text { r) Fassung eines Elfenbeincylinders. H. I } 5,5 \mathrm{~cm} \text {. } \\
\text { Besitzer: Herzogl. Museum, Gotha. Katalog Bube I } 869 \text {, } \\
\text { Nr. 148 a. }\end{array}$ \\
\hline & wie I I90 & & $\begin{array}{l}\text { s) Weisssilberner Teller mit getriebenen Blumen } \\
\text { und Ranken. } \\
\text { Besitzer: Siegmund Warburg, Hamburg. } 22 \mathrm{~cm} \text {. }\end{array}$ \\
\hline & & & $\begin{array}{l}\text { t) Schälchen mit flachen Handhaben. Aussen mit } \\
\text { Amoretten und Ranken gravirt. } \\
\text { Besitzer: Professor Seyffer, Stuttgart (1882). }\end{array}$ \\
\hline & wie I I 86 & & $\begin{array}{r}\text { u) Vergoldetes Salzfass auf hohen Volutenfüssen. } \\
\text { H. I I } 3 \mathrm{~cm} \text {. } \\
\text { Besitzer: Museum vaterländischer Alterthümer, Stuttgart. }\end{array}$ \\
\hline \multirow[t]{3}{*}{ I 357} & & $\frac{23}{5}$ & $\begin{array}{l}\text { Johann Jacob Wolrab, geboren } 1633 \\
\text { in Regensburg, Meister in Nürnberg } 1662 \text {, } \\
\text { ener } 1673 \text { und } 1687, \dagger 1690 \text {. }\end{array}$ \\
\hline & $\begin{array}{l}\text { wie } \\
\text { Nr. I I } 90\end{array}$ & & $\begin{array}{l}\text { a) Fassung einer muschelförmigen Kristallschale } \\
\text { mit figuralem Griffe. } \\
\begin{array}{ll}\text { Besitzer: National-Museum, München. } & \text { H. } 28 \mathrm{~cm} \text {. }\end{array}\end{array}$ \\
\hline & wie II 89 ? & & $\begin{array}{l}\text { b) Vergoldetes Trinkgefäss in Gestalt einer Eule. } \\
\text { H. I } 3 \mathrm{~cm} \text {. } \\
\text { Besitzer: J. \& H. Jeidels, Frankfurt a. M. }\end{array}$ \\
\hline
\end{tabular}




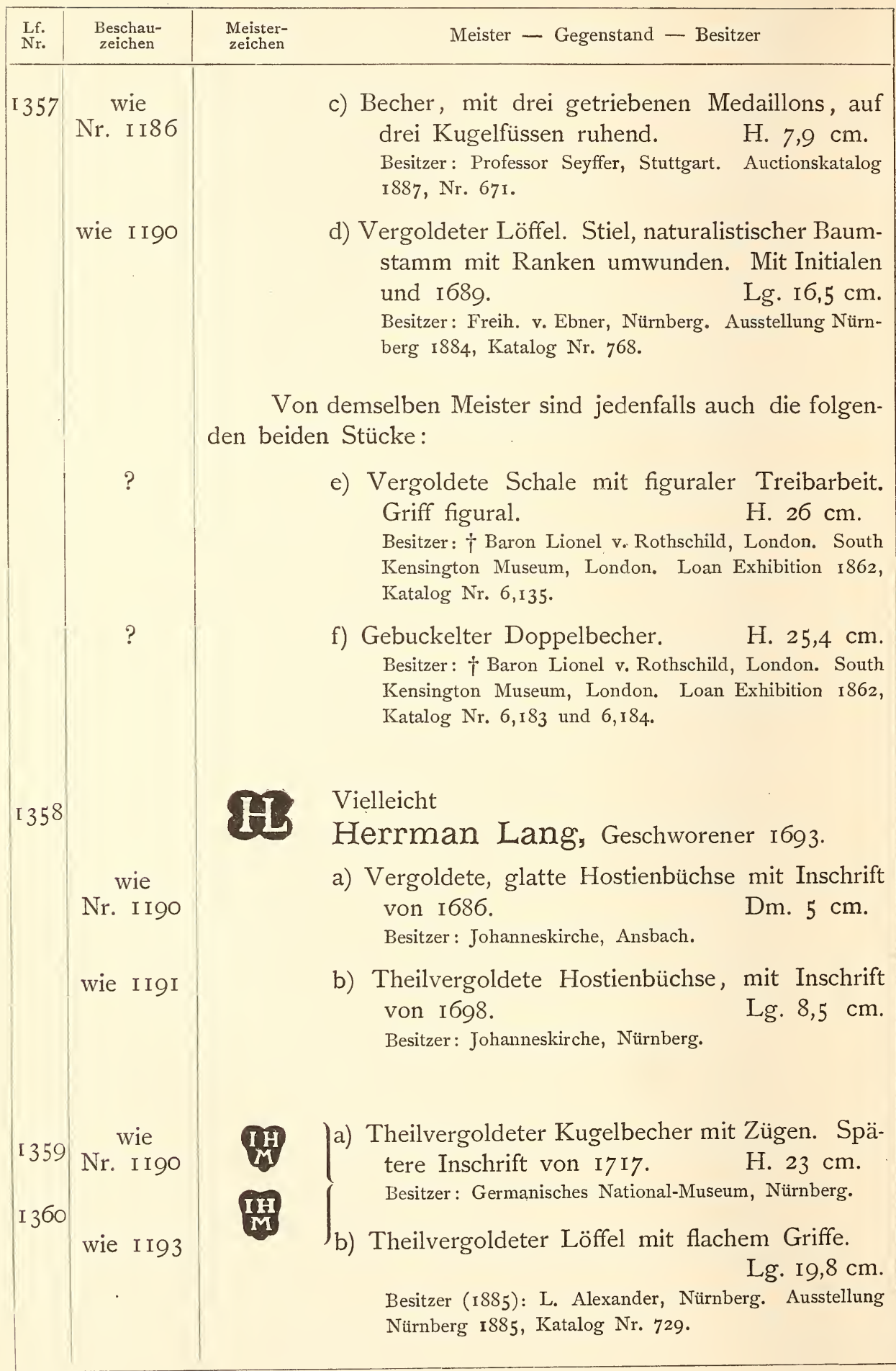




\begin{tabular}{|c|c|c|c|}
\hline $\begin{array}{l}\text { Lf. } \\
\text { Nr. }\end{array}$ & $\begin{array}{l}\text { Beschau- } \\
\text { zeichen }\end{array}$ & $\begin{array}{l}\text { Meister- } \\
\text { zeichen }\end{array}$ & Meister - Gegenstand - Besitzer \\
\hline $\begin{array}{l}1359 \\
1360\end{array}$ & $\begin{array}{l}\text { wie } \\
\mathrm{Nr} . \quad \text { I I93 }\end{array}$ & & $\begin{array}{l}\text { c) Weisssilberner Wachsstockhalter, getrieben und } \\
\text { gravirt. H. } 8,2 \mathrm{~cm} \text {. } \\
\text { Besitzer: Freih. v. Löffelholz, Nürnberg. Ausstellung } \\
\text { Nürnberg i885, Katalog Nr. } 788 .\end{array}$ \\
\hline & wie I I 87 & & $\begin{array}{l}\text { d u. e) Weisssilbernes Taufbecken nebst Kanne. } \\
\begin{array}{ll}\text { Besitzer: Lorenzkirche, Nürnberg. } & \text { H. } 24,5 \mathrm{~cm} .\end{array}\end{array}$ \\
\hline & wie I I90 & & $\begin{array}{l}\text { f) Vergoldeter glatter Kelch. } \\
\text { Besitzer: Johanneskirche, Nürnberg. }\end{array}$ \\
\hline I 36 I & $\begin{array}{l}\text { wie } \\
\text { Nr. } 1 \text { I } 87\end{array}$ & \&N & $\begin{array}{l}\text { Vergoldete Deckelkanne mit grossen Blumenran- } \\
\text { ken getrieben. } \\
\text { Besitzer (1885): A. Liubawin, St. Petersburg. }\end{array}$ \\
\hline I 362 & & $5 B$ & $\begin{array}{l}\text { Anscheinend ein Mitglied der Goldschmiedefamilie } \\
\text { Ferrn, aus der zweiten Hälfte des I7. Jahrh. }\end{array}$ \\
\hline & $\begin{array}{l}\text { wie } \\
\text { Nr. I I } 90\end{array}$ & & $\begin{array}{l}\text { a) Theilvergoldeter Pokal, mit figuralem Griffe. } \\
\text { Cuppa in Tulpenform mit getriebenem Tulpen- } \\
\text { ornament. Mit Inschrift von } 1673 . \mathrm{H} .38,5 \mathrm{~cm} \text {. } \\
\text { Besitzer: Pegnesischer Blumenorden, Nürnberg. Aus- } \\
\text { stellung Nürnberg } 1885 \text {, Katalog Nr. } 677 \text {. }\end{array}$ \\
\hline & wie 1187 & & $\begin{array}{l}\text { b) Vergoldeter Pokal mit tulpenförmiger Cuppa. } \\
\text { Griff figural. } \\
\text { Besitzer: P. A. Kotschubey, St. Petersburg. } 30,7 \mathrm{~cm} \text {. }\end{array}$ \\
\hline & wie I I 86 & & $\begin{array}{l}\text { c) Pokal mit tulpenähnlicher Cuppa und emaillir- } \\
\text { tem figuralem Griffe. } \\
\text { Besitzer: Museum der Eremitage, St. Petersburg. }\end{array}$ \\
\hline & wie I I86 & & $\begin{array}{l}\text { d) Vergold. Pokal mit Tulpencuppa. H. I8,5 cm. } \\
\text { Besitzer: Patriarchen-Schatzkammer, Moskau. }\end{array}$ \\
\hline & ? & & $\begin{array}{l}\text { e) Vergoldeter tulpenförmiger Pokal mit Deckel. } \\
\text { H. } 38 \mathrm{~cm} \text {. } \\
\text { Besitzer: J. D. Fürstin Menschikof, Baden-Baden. Aus- } \\
\text { stellung Karlsruhe I88I, Katalog Nr. 559. }\end{array}$ \\
\hline & wie II86? & & $\begin{array}{l}\text { f) Theilvergold. Kugelbecher mit drei getriebenen } \\
\text { Landschaftsmedaillons zwischen Blumenorna- } \\
\text { menten. Bezeichnet I692. H. } 7,5 \mathrm{~cm} \text {. } \\
\text { Besitzer (1882): Gebr. Moppert, Baden-Baden. }\end{array}$ \\
\hline
\end{tabular}




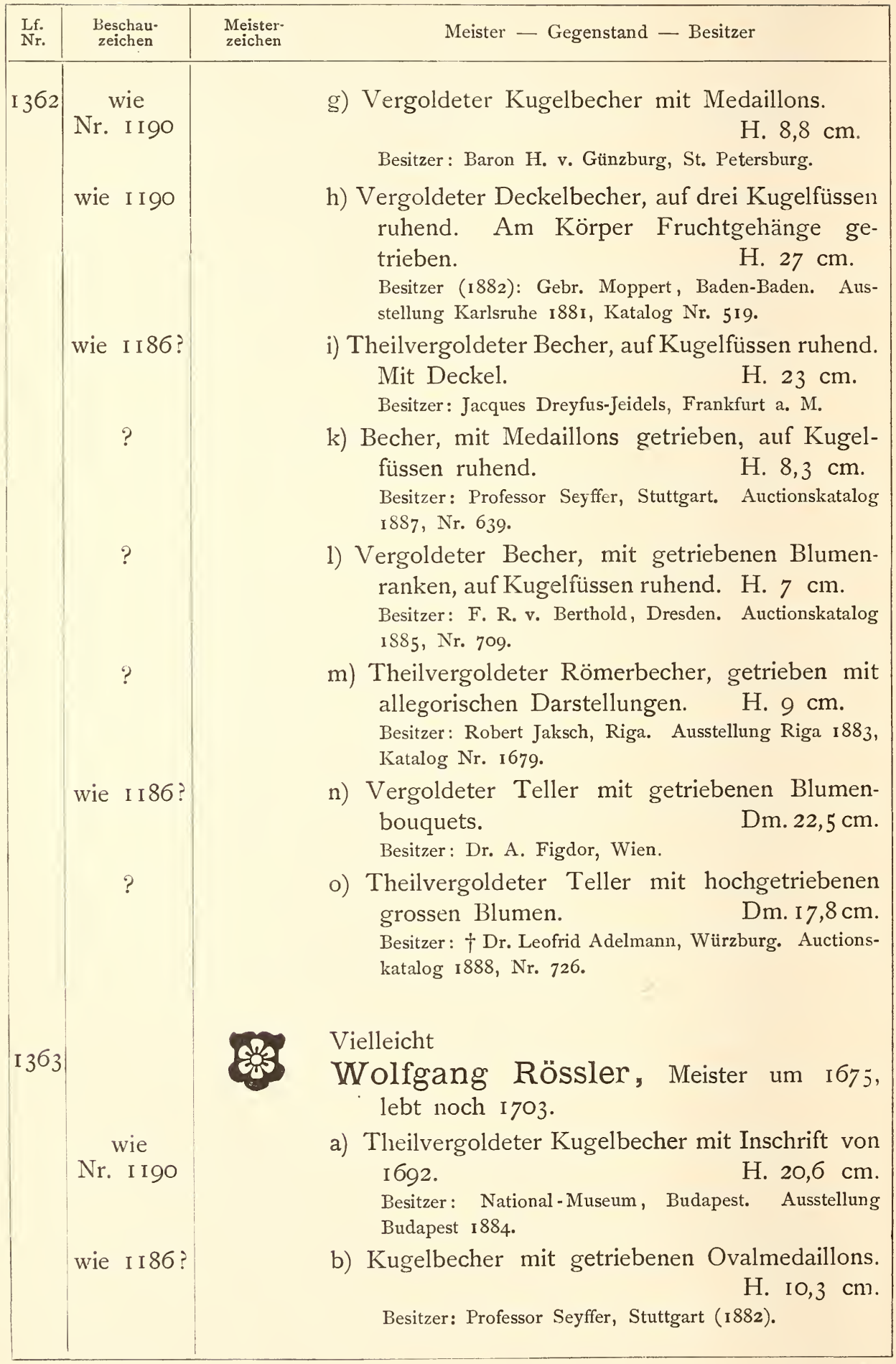




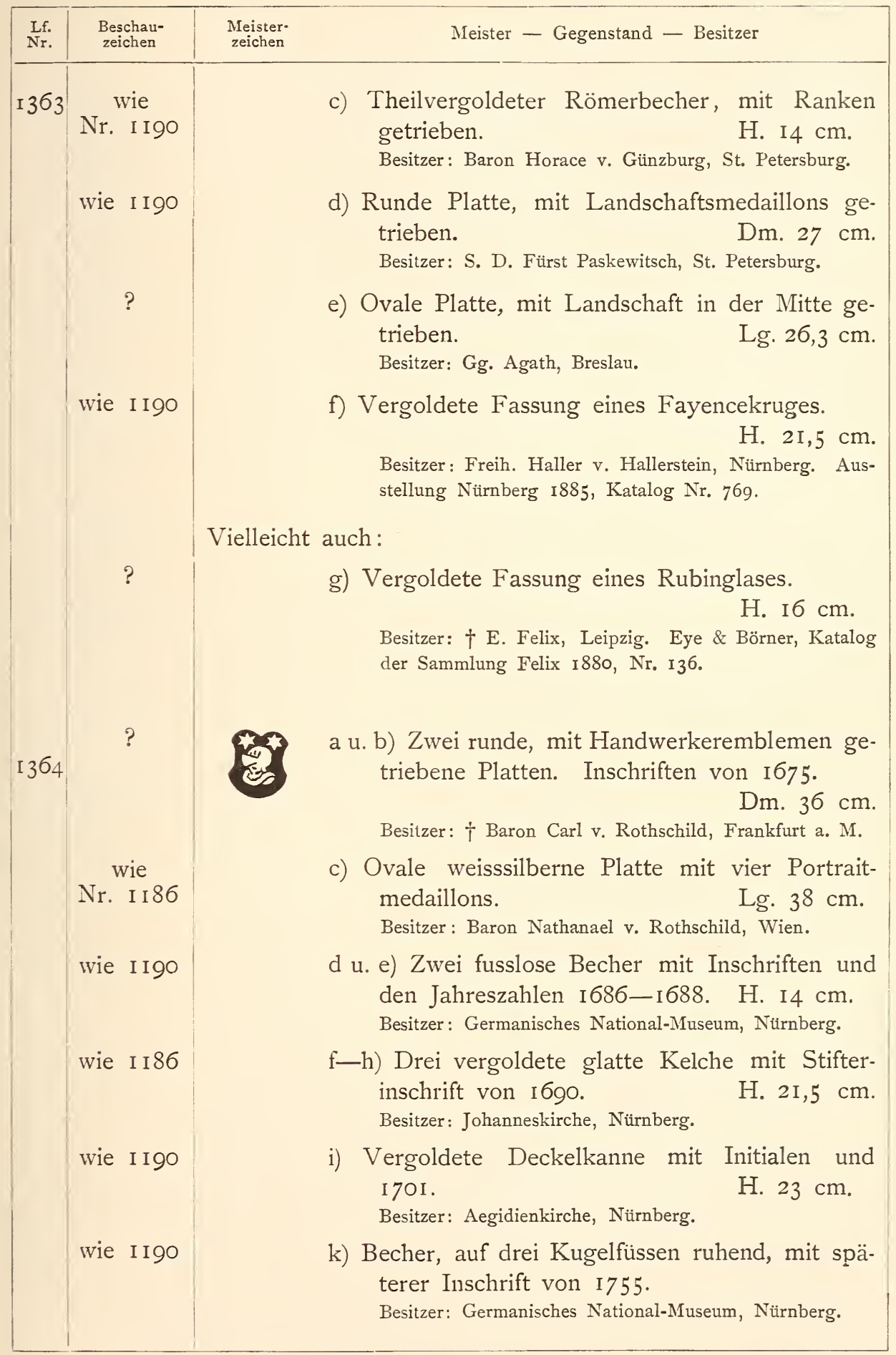




\begin{tabular}{|c|c|c|c|}
\hline $\begin{array}{l}\text { Lf. } \\
\text { Nr. }\end{array}$ & $\begin{array}{l}\text { Beschau- } \\
\text { zeichen }\end{array}$ & & Meister — Gegenstand - Besitzer \\
\hline \multirow[t]{8}{*}{ I364 } & $\begin{array}{l}\text { wie } \\
\mathrm{Nr}, \quad \text { I I } 86\end{array}$ & & $\begin{array}{l}\text { 1) Theilvergoldeter Becher, auf drei Kugelfüssen } \\
\text { ruhend. Als Deckelbekrönung eine emaillirte } \\
\text { Blume. H. I9,5 cm. } \\
\text { Besitzer: Pegnesischer Blumenorden, Nürnberg. Aus- } \\
\text { stellung Nürnberg I885, Katalog Nr. } 678 \text {. }\end{array}$ \\
\hline & wie II9I? & & $\begin{array}{l}\text { m) Fassung einer muschelförmigen Schale von } \\
\text { Blutjaspis. } \\
\text { Besitzer: Königl. Schatzkammer, München. Katalog } \\
\text { Schauss } 1879, \text { D. 24. }\end{array}$ \\
\hline & wie II9I? & & $\begin{array}{l}\text { n) Fassung einer Kanne aus Rhinoceroshorn. } \\
\text { Besitzer: Königl. Schatzkammer, München. Katalog } \\
\text { Schauss, I879, E. I7. Abgebildet bei Schauss, Schatz- } \\
\text { kammer. }\end{array}$ \\
\hline & wie I I 86 & & $\begin{array}{l}\text { o) Vergoldete Fassung einer Elfenbeinkanne. } \\
\text { H. } 30 \mathrm{~cm} \text {. } \\
\text { Besitzer: S. K. H. der Grossherzog von Baden, Schloss } \\
\text { Karlsruhe. Ausstellung Karlsruhe I88I, Kat. Nr. 63ז. } \\
\text { Abgebildet in Aeltere Kunstgewerbliche Arbeiten auf der } \\
\text { Ausstellung Karlsruhe I88I. }\end{array}$ \\
\hline & wie I I 86 & & $\begin{array}{l}\text { p) Fassung einer Elfenbeinkanne. } \\
\text { Besitzer: Grünes Gewölbe, Dresden. Katalog Erbstein } \\
\text { I884, S. I4 Nr. 2I. }\end{array}$ \\
\hline & ? & & $\begin{array}{l}\text { q) Vergoldete Fassung einer Elfenbeinkanne. } \\
\text { Besitzer: Grünes Gewölbe, Dresden. Katalog Erbstein } \\
\text { I884, S. 3I Nr. } 388 \text {. }\end{array}$ \\
\hline & ? & & $\begin{array}{l}\text { r) Fassung eines Elfenbeinbechers. H. } 25 \mathrm{~cm} \text {. } \\
\text { Besitzer: Gg. Agath, Breslau. }\end{array}$ \\
\hline & wie II 86 & & $\begin{array}{l}\text { s) Weisssilberne getriebene Kalenderdecke mit } \\
\text { Elfenbeineinlagen. } \\
\text { Besitzer (1883): Salomon, Dresden. }\end{array}$ \\
\hline \multirow[t]{3}{*}{1365} & $\begin{array}{l}\text { wie } \\
\text { Nr. I I } 86\end{array}$ & & $\begin{array}{l}\text { a) Vergoldeter Pokal, die Cuppa in Herzform, mit } \\
\text { getriebenen Diamantbuckeln. H. } 30 \mathrm{~cm} \text {. } \\
\text { Besitzer: H. Boskowitz, Wien. }\end{array}$ \\
\hline & wie I I 86 & & $\begin{array}{l}\text { b) Pokal mit tulpenförmiger Cuppa. H. I6 cm. } \\
\text { Besitzer: H. Boskowitz, Wien. }\end{array}$ \\
\hline & wie I I93 & & $\begin{array}{l}\text { c) Vergoldeter Pokal, mit Buckeln und Orna- } \\
\text { menten getrieben. } \\
\text { Besitzer: P. A. Kotschubey, St. Petersburg. } 25,5 \mathrm{~cm} \text {. }\end{array}$ \\
\hline
\end{tabular}




\begin{tabular}{|c|c|c|c|}
\hline $\begin{array}{l}\text { Lf. } \\
\text { Nr. }\end{array}$ & $\begin{array}{l}\text { Beschau- } \\
\text { zeichen }\end{array}$ & & Meister - Gegenstand - Besitzer \\
\hline \multirow[t]{6}{*}{1365} & $\begin{array}{l}\text { wie } \\
\text { Nr. I I } 86\end{array}$ & & $\begin{array}{l}\text { d) Vergoldeter Pokal, mit Buckeln und Orna- } \\
\text { menten getrieben. Griff figural. H. } 26,3 \mathrm{~cm} \text {. } \\
\text { Besitzer: Patriarchen-Schatzkammer, Moskau. }\end{array}$ \\
\hline & wie II 86 & & $\begin{array}{l}\text { e) Vergoldeter Pokal, mit Buckeln und Orna- } \\
\text { menten getrieben. Mit Wappen, Namen und } \\
\text { I } 675 . \\
\text { Besitzer: Alexander Vigyázó. Ausstellung Budapest i } 884 .\end{array}$ \\
\hline & wie I I86? & & $\begin{array}{l}\text { f) Vergoldeter Pokal, mit Buckeln und Orna- } \\
\text { menten getrieben. } \quad \text { H. I9 cm. } \\
\text { Besitzer: S. Fürth, Mainz. Abgebildet in Edelmetall- } \\
\text { arbeiten der Sammlung Fürth I886, Nr. } 25 .\end{array}$ \\
\hline & wie II86? & & $\begin{array}{l}\text { g) Vergoldeter Pokal. H. I6 cm. } \\
\text { Besitzer: S. Fürth, Mainz. Abgebildet in Edelmetall- } \\
\text { arbeiten der Sammlung Fürth 1886, Nr. } 30 .\end{array}$ \\
\hline & wie II86? & & 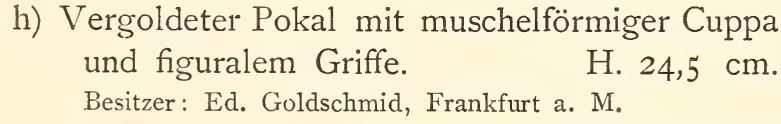 \\
\hline & wie I I86 & & $\begin{array}{l}\text { i) Vergoldetes Taufgefäss mit figuralem Griffe und } \\
\text { späterer Inschrift von I73I. H. } 25,7 \mathrm{~cm} \text {. } \\
\text { Besitzer: National-Museum, Budapest. Ausstellung Buda- } \\
\text { pest } 1884 \text {. }\end{array}$ \\
\hline \multirow[t]{6}{*}{ I 366} & $\begin{array}{l}\text { wie } \\
\text { Nr. I I } 86 ?\end{array}$ & & $\begin{array}{l}\text { a) Vergoldeter Römerbecher mit getriebenen } \\
\text { Landschaften. } \\
\text { H. IO } \mathrm{cm} \text {. }\end{array}$ \\
\hline & wie I I86? & & $\begin{array}{l}\text { b) Theilvergoldeter Römerbecher mit getriebenen } \\
\text { Landschaften. } \\
\text { Besitzer (1883): J. Drey, München. } 8,5 \mathrm{~cm} .\end{array}$ \\
\hline & wie II86? & & $\begin{array}{l}\text { c) Vergoldeter Römerbecher, mit grossen Blumen } \\
\text { getrieben. } \\
\text { Besitzer (I883): J. \& S. Goldschmidt, Frankfurt a. M. }\end{array}$ \\
\hline & wie I I90 & & $\begin{array}{l}\text { d) Vergoldeter Becher mit getriebenen Tulpen- } \\
\text { ornamenten. Auf drei Kugelfüssen ruhend. } \\
\text { H. } 9 \mathrm{~cm} \text {. } \\
\text { Besitzer: Freih. Haller v. Hallerstein, Nürnberg. Aus- } \\
\text { stellung Nürnberg } 1885 \text {, Katalog Nr. } 772 \text {. }\end{array}$ \\
\hline & wie I I9o & & $\begin{array}{l}\text { e) Vergoldeter Löffel. Der Griff mit naturalisti- } \\
\text { schem Baumstamm und Laubwerk. }\end{array}$ \\
\hline & & & $\begin{array}{l}\text { Lg. I } 7,3 \mathrm{~cm} \text {. } \\
\text { Besitzer: J. Beck, Nürnberg. } \\
\text { I } 885 \text {, Katalogstellung Nürnberg } \\
\text { Nr. } 746 .\end{array}$ \\
\hline
\end{tabular}




\begin{tabular}{|c|c|c|c|}
\hline $\begin{array}{l}\text { Lf. } \\
\text { Nr. }\end{array}$ & $\begin{array}{l}\text { Beschau- } \\
\text { zeichen }\end{array}$ & $\begin{array}{l}\text { Meister- } \\
\text { zeichen }\end{array}$ & Meister - Gegenstand - Besitzer \\
\hline I366 & $\begin{array}{l}\text { wie } \\
\text { Nr. I I } 90\end{array}$ & & $\begin{array}{l}\text { f) Weisssilberner Löffel, bezeichnet I } 676 \text {. } \\
\text { Besitzer: National-Museum, München. }\end{array}$ \\
\hline I 367 & ? & & $\begin{array}{c}\text { a) Theilvergoldeter Tulpenbecher. H. } 36,5 \mathrm{~cm} \text {. } \\
\text { Besitzer: Museum der Eremitage, St. Petersburg. }\end{array}$ \\
\hline & $\begin{array}{l}\text { wie } \\
\text { Nr. I I } 86\end{array}$ & & $\begin{array}{l}\text { b) Theilvergoldete bauchige Weinkanne mit Gra- } \\
\text { virung, Wappen, Inschrift und } 1678 . \\
\begin{array}{l}\text { H. } 33 \mathrm{~cm} \text {. } \\
\text { Besitzer: Gumbertuskirche, Ansbach. }\end{array}\end{array}$ \\
\hline & wie 1187 & & $\begin{array}{l}\text { c) Vergoldeter Ananaspokal. Griff Baumstamm } \\
\text { mit Holzhauer. Am Lippenrande die Meister- } \\
\text { marke Nr. I } 32 \mathrm{I} \text {. } \\
\begin{array}{ll}\text { Besitzer: Winterpalais, St. Petersburg. } & 37,5 \mathrm{~cm} \text {. }\end{array}\end{array}$ \\
\hline & ? & \multicolumn{2}{|c|}{$\begin{array}{l}\text { Vielleicht von demselben Meister: } \\
\begin{array}{l}\text { d) Deckelkanne mit getriebener Landschaft und } \\
\text { Kindern. } \\
\text { Besitzer: Pickert, Nürnberg. Auctionskatalog } \mathbf{c m} \text {. } 88 \mathbf{1} \text {, } \\
\text { Nr. } 378 .\end{array}\end{array}$} \\
\hline
\end{tabular}

Die folgenden zwei aus IR gebildeten Marken gehen vielleicht nur auf einen einzigen runden Punzen zurück, dessen Abschlag bei der letzten Ausarbeitung des Gefässes etwas in die Breite getrieben worden sein mag.

I $368 \underset{\mathrm{Nr} \text {. I I } 86}{\text { wie }}$

wie I 186

I369 Nr. II 86

wie I I86 a) Vergoldeter Pokal, mit Buckeln und Ornamenten getrieben. Inschrift von 1679 .

Besitzer: P. A. Kotschubey, St. Petersburg.

H. $49,5 \mathrm{~cm}$.

b) Vergoldeter Römerbecher, mit Blumenwerk getrieben.

H. $9,8 \mathrm{~cm}$.

Besitzer: Graf Johann Csekonics. Ausstellung Budapest 1884, 4. Saal, 1. Schrank, Nr. 35. Katalog S. 7.

c) Pokal einer Schützengesellschaft mit Inschrift. H. $38 \mathrm{~cm}$. Besitzer: Germanisches National-Museum, Nürnberg.

d) Becherschraube in Gestalt einer knieenden männlichen Figur.

H. $5,5 \mathrm{~cm}$. 


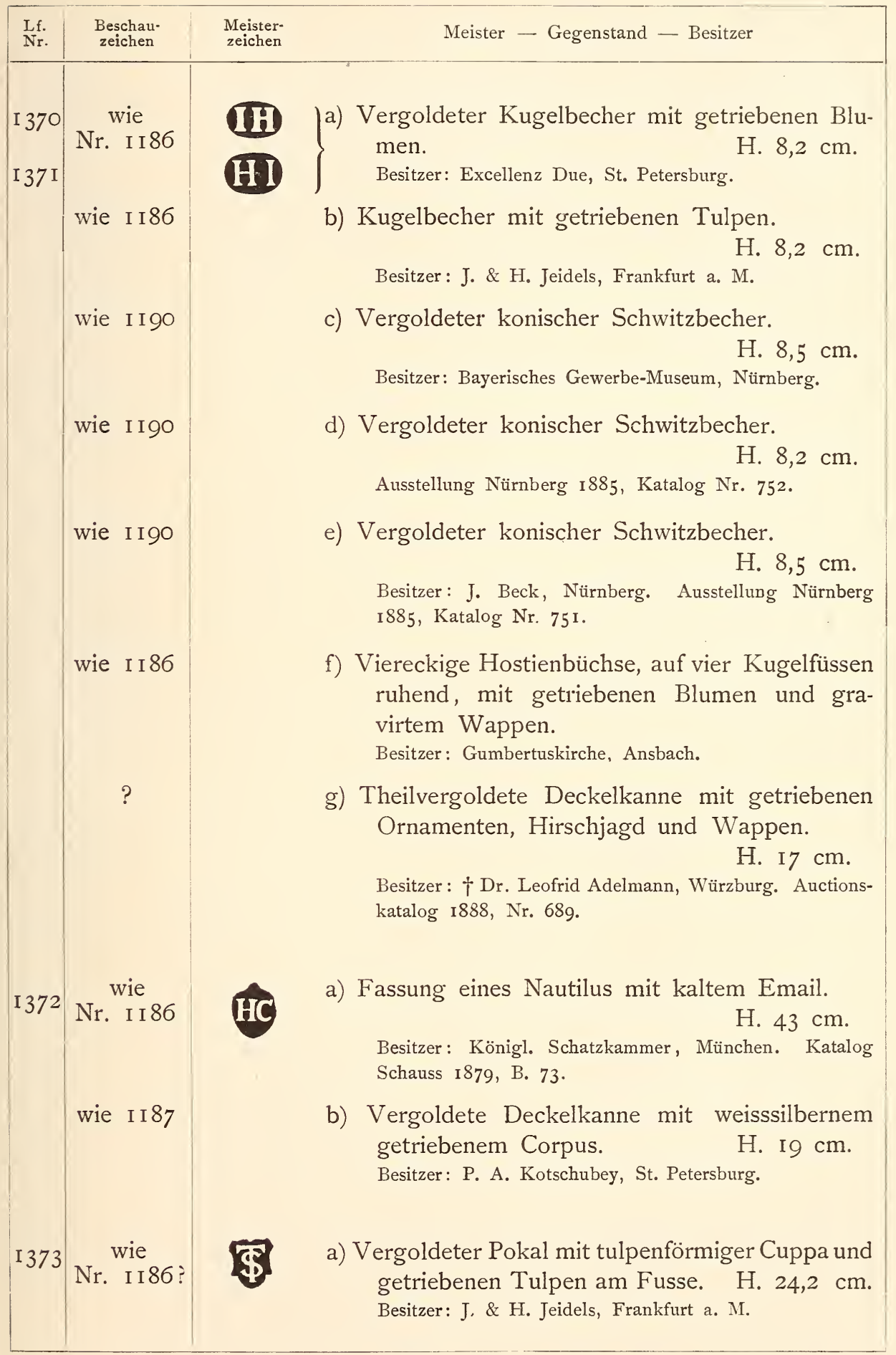




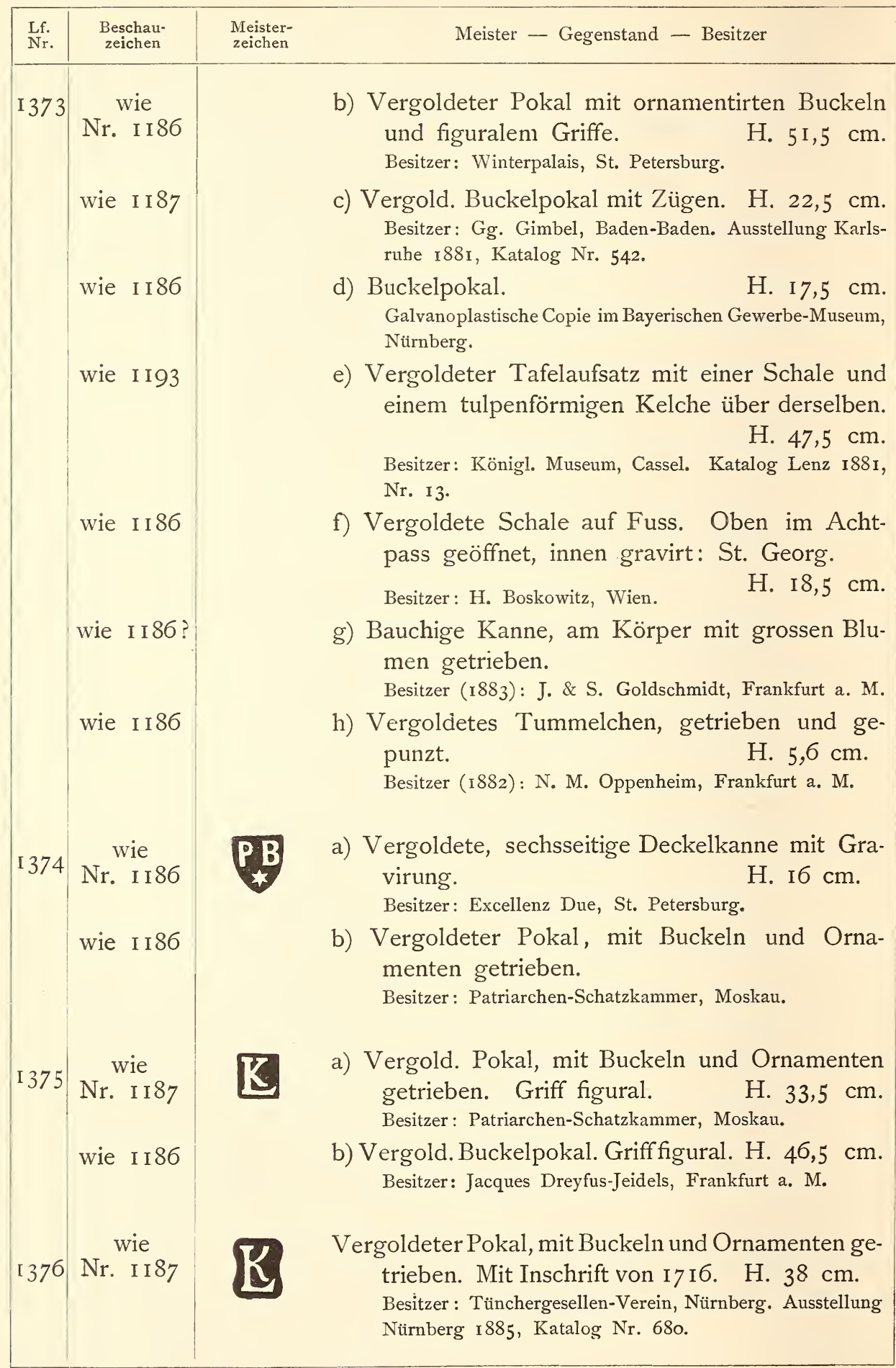




\begin{tabular}{|c|c|c|c|}
\hline $\begin{array}{l}\text { Lf. } \\
\text { Nr. }\end{array}$ & $\begin{array}{l}\text { Seschau. } \\
\text { zeichen }\end{array}$ & $\begin{array}{l}\text { Meister- } \\
\text { zeichen }\end{array}$ & Meister - Gegenstand - Besitzer \\
\hline I 377 & $\begin{array}{l}\text { wie } \\
\text { Nr. II } 86\end{array}$ & EA & $\begin{array}{l}\text { Vergoldetes Salzfass mit muschelförmiger Schale. } \\
\text { Besitzer: Dr. A. Figdor, Wien. }\end{array}$ \\
\hline I 378 & $\begin{array}{l}\text { wie } \\
\text { Nr. I I } 85\end{array}$ & & $\begin{array}{l}\text { a) Pokal mit getriebener biblischer Darstellung } \\
\text { und figuralem Griffe. Gravirte Wappen, Na- } \\
\text { men und I68I. } \\
\text { Besitzer: Germanisches National-Nuseum, Nïrnberg. }\end{array}$ \\
\hline & wie II86 & & $\begin{array}{l}\text { b) Theilvergoldeter konischer Becher mit getrie- } \\
\text { benen Tulpenornamenten. H. 8,5 cm. } \\
\text { Besitzer: Pfälzisches Gewerbe-Museum, Kaiserslautern. } \\
\text { Ausstellung Nürnberg i885, Katalog Nr. } 660 \text {. }\end{array}$ \\
\hline I 379 & $\begin{array}{c}\text { wie } \\
\text { Nr. I I } 86\end{array}$ & IP & $\begin{array}{l}\text { Vielleicht } \\
\text { Jacob Pfaff, Geschworener } 1685 \text { und } 1695 \text {. } \\
\text { a) Theilvergoldeter Römerbecher, getrieben mit } \\
\text { Medaillons. } \\
\text { Besitzer (1882): N. M. Oppenheim, Frankfurt a. M. }\end{array}$ \\
\hline & wie II 86? & & $\begin{array}{ll}\text { b u. c) Henkelbecher } & \text { H. I8, } 5 \mathrm{~cm} . \\
\begin{array}{l}\text { und Kugelbecher. } \\
\text { Ausstellung Amsterdam I883. }\end{array} & \text { H. I3,9 cm. }\end{array}$ \\
\hline & wie I I90 & & $\begin{array}{l}\text { d) Theilvergoldeter Kelch mit getriebenen Engels- } \\
\text { köpfen und Blumen. Inschrift von I684. } \\
\text { H. } 26 \mathrm{~cm} . \\
\text { Besitzer: Deutschordensschatz, Wien. }\end{array}$ \\
\hline & wie I I93 & & $\begin{array}{ll}\text { e) Vergoldeter Kelch. } & \text { H. } 25 \mathrm{~cm} . \\
\text { Besitzer: Aegidienkirche, Nürnberg. } & \end{array}$ \\
\hline & wie IIgI & & $\begin{array}{l}\text { f) Vergoldete schlanke Abendmahlskanne. } \\
\text { Besitzer: Johanneskirche, Nürnberg. }\end{array}$ \\
\hline & wie I I90 & & $\begin{array}{l}\text { g) Theilvergoldete Deckelkanne, mit Landschaften } \\
\text { u. Blumenornamenten getrieben. H. I } 5,7 \mathrm{~cm} \text {. } \\
\text { Ausstellung Nürnberg I } 885 \text {. }\end{array}$ \\
\hline & wie I I90 & & $\begin{array}{l}\text { h) Vergoldete runde Platte mit hochgetriebenen } \\
\text { weisssilbernen Portraits und Früchten. } \\
\text { Dm. } 25 \mathrm{~cm} \text {. } \\
\text { Besitzer (1883): Gebr. Heilbronner, München. }\end{array}$ \\
\hline
\end{tabular}


Deutschland - Nürnberg (Meister des 17. bis 18. Jahrh.)

\begin{tabular}{|c|c|c|c|}
\hline $\begin{array}{l}\text { Lf. } \\
\text { Nr. }\end{array}$ & $\begin{array}{l}\text { Beschau- } \\
\text { zeichen }\end{array}$ & sichen & Meister - Gegenstand - Besitzer \\
\hline I 380 & $\begin{array}{l}\text { wie } \\
\text { Nr. I I } 86 \\
\text { wie I I } 86\end{array}$ & & $\begin{array}{l}\text { a) Pokal, mit Buckeln und Ornamenten getrieben. } \\
\text { H. } 37,5 \mathrm{~cm} \text {. } \\
\text { Besitzer: Alexander Vigyázó. Ausstellung Budapest I } 884 . \\
\text { b) Vergoldete Deckelkanne. In den sechs Feldern } \\
\text { Vögel gravirt. } \\
\text { Besitzer: H. Boskowitz, Wien. }\end{array}$ \\
\hline I $38 \mathrm{I}$ & $\begin{array}{c}\text { wie } \\
\text { Nr. I I } 86\end{array}$ & IB & $\begin{array}{l}\text { Joh. Berckmann, Meister um I688, Ge- } \\
\text { schworener I7II. } \\
\text { Becher einer Schützengesellschaft mit gravirtem } \\
\text { Wappen, Inschrift und I693. H. } 47 \mathrm{~cm} \text {. } \\
\text { Besitzer: Germanisches National-Museum, Nürnberg. }\end{array}$ \\
\hline I 382 & $\begin{array}{l}\text { wie } \\
\text { Nr. I I go }\end{array}$ & & 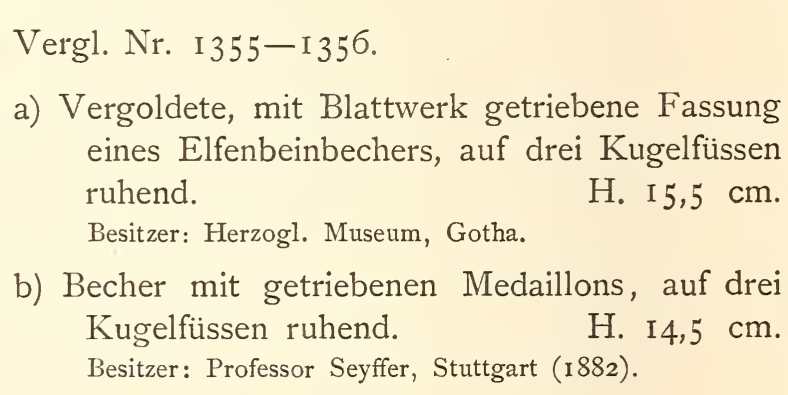 \\
\hline 1383 & $\begin{array}{c}\text { wie } \\
\text { Nr. I I } 86 ?\end{array}$ & & $\begin{array}{l}\text { Vielleicht } \\
\text { Johann Samuel Spörl, Genanntèr I697, } \\
\text { Geschworener I704 und I720, † I748 (?). } \\
\text { Theilvergoldete Fassung einer Elfenbeinkanne. } \\
\text { H. } 30,4 \mathrm{~cm} . \\
\text { Besitzer: S. K. H. der Grossherzog von Baden, Schloss } \\
\text { Karlsruhe. }\end{array}$ \\
\hline I 384 & $\begin{array}{l}\text { wie } \\
\text { Nr. I I } 90\end{array}$ & 97 & $\begin{array}{l}\text { a) Pokal, Schützenstück, mit vielen Wappen. Griff } \\
\text { figural. H. } 58 \mathrm{~cm} \text {. } \\
\text { Besitzer: Germanisches National-Museum, Nürnberg. } \\
\text { b) Vergoldeter konischer Becher, aussen ge- } \\
\text { schweisst. } \mathrm{H} .9 \mathrm{~cm} \text {. } \\
\text { Besitzer (I882): Gebr. Moppert, Baden-Baden. } \\
\text { c) Flach getriebene Fassung einer Elfenbeinkanne. } \\
\text { Besitzer: Museum der Eremitage, St. Petersburg. }\end{array}$ \\
\hline
\end{tabular}




\begin{tabular}{|c|c|c|c|}
\hline $\begin{array}{l}\text { Lf. } \\
\text { Nr. }\end{array}$ & $\begin{array}{l}\text { Beschau- } \\
\text { zeichen }\end{array}$ & $\begin{array}{l}\text { Meist, } \\
\text { zeiche }\end{array}$ & Meister - Gegenstand - Besitzer \\
\hline I 385 & $\begin{array}{c}\text { wie } \\
\text { Nr. I I9I }\end{array}$ & & $\begin{array}{l}\text { Vergoldeter glatter Löffel, bezeichnet I } 698 . \\
\text { Lg. I } 8,5 \mathrm{~cm} \text {. } \\
\text { Besitzer: Johanneskirche, Nürnberg. }\end{array}$ \\
\hline I 386 & $\begin{array}{l}\text { wie } \\
\text { Nr. I I } 86\end{array}$ & & $\begin{array}{l}\text { a) Becher mit getriebenen Buckeln, auf drei Kugel- } \\
\text { füssen ruhend. Bezeichnet I698. H. I } 8,5 \mathrm{~cm} \text {. } \\
\text { Besitzer: Germanisches National-Museum, Nürnberg. }\end{array}$ \\
\hline & wie I I90 & & $\begin{array}{l}\text { b) Becher mit getriebenen Fruchtbouquets, auf drei } \\
\text { Kugelfüssen ruhend. } \quad \text { H. I4 cm. } \\
\text { Besitzer: Patriarchen-Schatzkammer, Moskau. }\end{array}$ \\
\hline & wie II 86 & & $\begin{array}{l}\text { c) Kleiner Becher, auf drei Kugelfüssen ruhend. } \\
\text { H. } 5 \mathrm{~cm} \text {. } \\
\text { Besitzer: Professor Seyffer, Stuttgart (I882). }\end{array}$ \\
\hline I 387 & $\begin{array}{l}\text { wie } \\
\text { Nr. I I93 }\end{array}$ & & $\begin{array}{l}\text { a) Vergoldete schlanke Abendmahlskanne. } \\
\text { Besitzer: Johanneskirche, Nürnberg. }\end{array}$ \\
\hline & wie I I93 & & $\begin{array}{l}\text { b) Vergoldeter Kelch mit Patene. Inschrift von } \\
\text { I709. } \\
\text { Besitzer: Johanneskirche, Nürnberg. }\end{array}$ \\
\hline & wie I I90 & & $\begin{array}{l}\text { c) Vergoldeter Kelch. H. I } 3 \mathrm{~cm} \text {. } \\
\text { Besitzer (1885): L. Alexander, Nürnberg. Ausstellung } \\
\text { Nürnberg I } 885 \text {, Katalog Nr. 74I. }\end{array}$ \\
\hline & wie I I93 & & $\begin{array}{l}\text { d) Vergoldete Hostienbüchse mit Inschrift von } \\
\text { I698. } \\
\text { Besitzer: Johanneskirche, Nürnberg. }\end{array}$ \\
\hline & wie II93 & & $\begin{array}{l}\text { e u. f) Zwei weisssilberne Altarleuchter mit getrie- } \\
\text { benen stilisirten Ornamenten. } \quad \text { H. } 64 \mathrm{~cm} \text {. } \\
\text { Besitzer: Aegidienkirche, Nürnberg. }\end{array}$ \\
\hline & wie I I 90 & & $\begin{array}{l}\text { g) Theilvergoldete Deckelkanne, getrieben mit } \\
\text { drei Landschaftsmedaillons. H. I8,7 cm. } \\
\text { Besitzer (1885): Jacobsohn, St. Petersburg. }\end{array}$ \\
\hline & wie I I90 & & $\begin{array}{l}\text { h) Theilvergoldeter Becher, mit Medaillons getrie- } \\
\text { ben, auf Kugelfuissen ruhend. H. I } 5,5 \mathrm{~cm} \text {. } \\
\text { Besitzer (I885): Jacobsohn, St. Petersburg. }\end{array}$ \\
\hline & wie I I93 & & $\begin{array}{l}\text { i) Becher, mit Zügen getrieben, auf Kugelfüssen } \\
\text { ruhend. } \\
\text { Besitzer: H. Boskowitz, Wien. }\end{array}$ \\
\hline
\end{tabular}




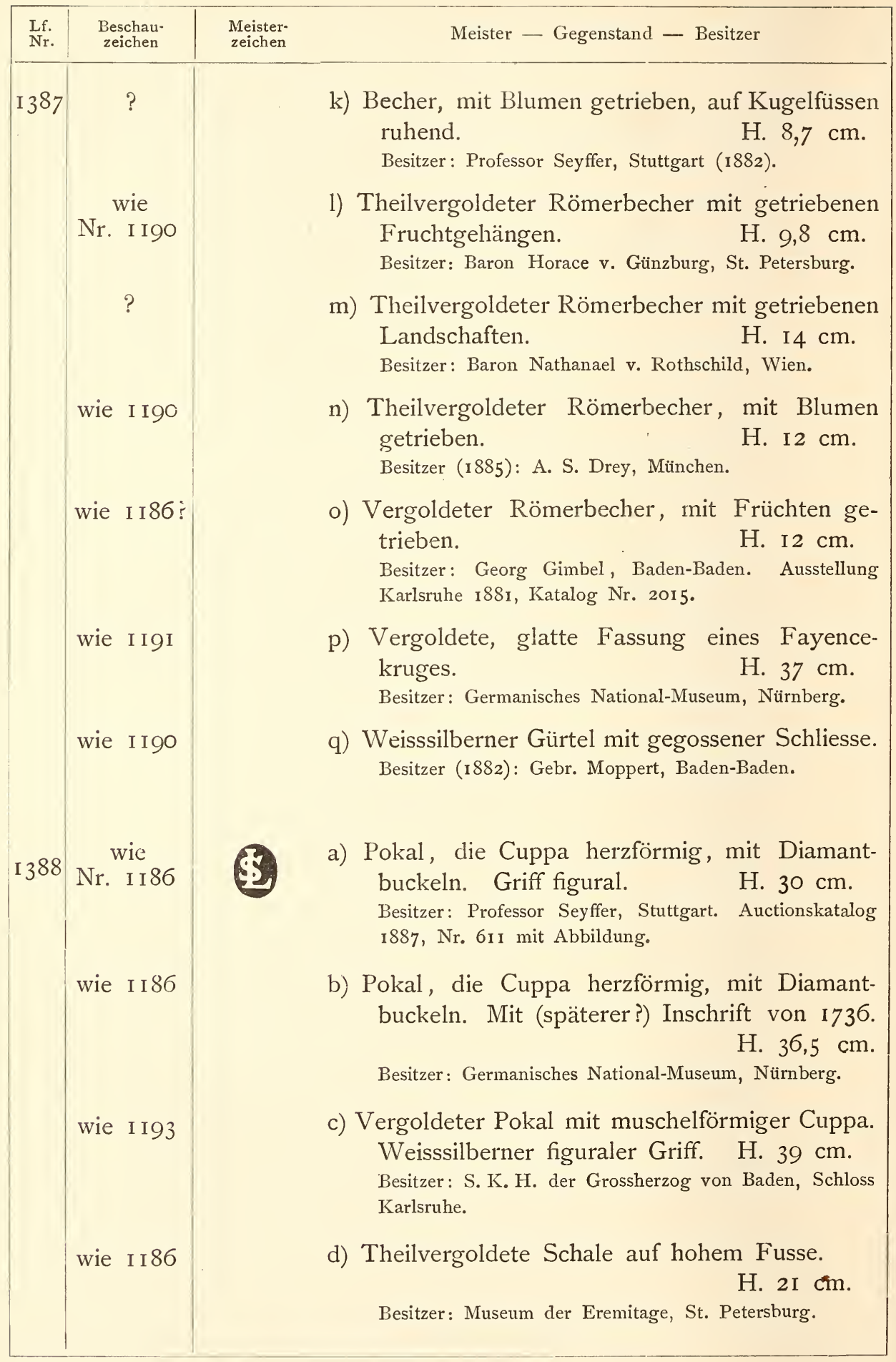




\begin{tabular}{|c|c|c|c|}
\hline $\begin{array}{l}\text { Lff. } \\
\text { sir. }\end{array}$ & $\begin{array}{l}\text { Beschau- } \\
\text { zeichen }\end{array}$ & $\begin{array}{l}\text { Meister- } \\
\text { zeichen }\end{array}$ & Meister - Gegenstand - Besitzer \\
\hline 89 & & & $\begin{array}{l}\text { Johann Philipp Höfler, Geschworener } \\
\text { I703, } \dagger \text { I } 722 \text {. }\end{array}$ \\
\hline & $\begin{array}{l}\text { wie } \\
\text { Nr. I I } 90\end{array}$ & & $\begin{array}{l}\text { a) Vergoldeter Kugelbecher mit getriebenen Ve- } \\
\text { duten. H. I4, } 5 \mathrm{~cm} \text {. } \\
\text { Besitzer: Excellenz Due, St. Petersburg. }\end{array}$ \\
\hline & wie I I9o & & $\begin{array}{l}\text { b u. c) Zwei vergoldete konische Schwitzbecher. } \\
\text { H. } 9 \mathrm{~cm} \text {. } \\
\text { Besitzer (1885): L. Alexander, Nürnberg. Ausstellung } \\
\text { Nürnberg 1885, Katalog Nr. 734. }\end{array}$ \\
\hline & wie I I99 & & $\begin{array}{l}\text { d) Weisssilb. Gestell einer Sanduhr. H. } 2 \text { I,5 cm. } \\
\text { Besitzer: Aegidienkirche, Nürnberg. }\end{array}$ \\
\hline I 390 & & & $\begin{array}{l}\text { Johann Leonhard Eyssler, Geschwore- } \\
\text { ner } 1723 \text {. }\end{array}$ \\
\hline & $\begin{array}{l}\text { wie } \\
\text { Nr. I I } 90\end{array}$ & & $\begin{array}{r}\text { a) Deckelpokal, Schützenstiuck, mit Inschriften } \\
\text { und den Jahreszahlen I605, I637 und I709. } \\
\text { H. } 62 \mathrm{~cm} . \\
\text { Besitzer: Germanisches National-Museum, Nürnberg. }\end{array}$ \\
\hline & wie I Igo & & $\begin{array}{l}\text { b) Weisssilbernes Gestell einer Sanduhr. In- } \\
\text { schrift von I } 726 . \\
\text { Besitzer: Lorenzkirche, Nürnberg. }\end{array}$ \\
\hline & wie II 86: & & $\begin{array}{l}\text { c) Glatte vergoldete Fassung eines Steinge- } \\
\text { fässes. } \\
\text { Besitzer: Neues Palais, Darmstadt. }\end{array}$ \\
\hline I39I & $\begin{array}{l}\text { wie } \\
\text { Nr. I I } 93\end{array}$ & & $\begin{array}{l}\text { Johann Jacob Fern, Geschworener I729. } \\
\text { a) Löffel mit vergoldeter Kelle, am Griffe Fili- } \\
\text { granornamente. Lg. I } 9,7 \mathrm{~cm} \text {. } \\
\text { Besitzer: Freih. v. Pölnitz, Augsburg. Ausstellung } \\
\text { Augsburg 1886, Katalog Nr. I84r. }\end{array}$ \\
\hline & wie I Igo & & $\begin{array}{l}\text { b u. c) Vergoldeter Löffel mit Wappen von I7 I9. } \\
\text { Dazu ein silbernes Etui mit der gleichen } \\
\text { Marke. } \\
\text { Besitzer: Aegidienkirche, Nürnberg. }\end{array}$ \\
\hline & wie I I93 & & $\begin{array}{l}\text { d) Weisssilbernes Crucifix, auf Sockel, mit auf- } \\
\text { gesetzten durchbrochenen Ornamenten. } \\
\text { Besitzer: Aegidienkirche, Nürnberg. }\end{array}$ \\
\hline
\end{tabular}




\begin{tabular}{|c|c|c|c|}
\hline $\begin{array}{l}\text { Lf. } \\
\text { Nr. }\end{array}$ & $\begin{array}{l}\text { Beschau• } \\
\text { zeichen }\end{array}$ & $\begin{array}{l}\text { Meister- } \\
\text { zeichen }\end{array}$ & Meister - Gegenstand - Besitzer \\
\hline \multirow[t]{6}{*}{ I 392} & & & Kann als $\mathrm{HN}$ oder $\mathrm{NH}$ gelesen werden. \\
\hline & $\begin{array}{l}\text { wie } \\
\text { Nr. I I } 1 \text { I }\end{array}$ & & $\begin{array}{l}\text { a) Weisssilberne ovale Platte. In der Mitte figür- } \\
\text { liche Darstellung, am Rande Früchte und } \\
\text { Ranken getrieben. } \\
\text { Besitzer: Kunstgewerbe-Museum, Berlin. } 30,5 \mathrm{~cm} \text {. }\end{array}$ \\
\hline & wie I I93 & & $\begin{array}{l}\text { b-d) Vergoldeter Kelch mit Inschrift von I723. } \\
\text { Dazu Patene und Hostienbüchse. H. } 28 \mathrm{~cm} \text {. } \\
\text { Besitzer: Aegidienkirche, Nürnberg. }\end{array}$ \\
\hline & wie I I93 & & $\begin{array}{l}\text { e) Vergoldeter Kelch mit Inschrift von I } 724 . \\
\text { Besitzer: Aegidienkirche, Nürnberg. } \\
\text { H. } 26 \mathrm{~cm} .\end{array}$ \\
\hline & wie I I93 & & $\begin{array}{l}\text { f) Vergoldete glatte Deckelkanne mit Inschrift } \\
\begin{array}{ll}\text { von I } 724 . & \text { H. } 34 \mathrm{~cm} . \\
\text { Besitzer: Aegidienkirche, Nürnberg. } & \end{array}\end{array}$ \\
\hline & wie I I90 & & $\begin{array}{l}\text { g u. h) Theilvergoldete bauchige Kanne nebst } \\
\text { Platte mit ornamentaler Treibarbeit. } \\
\text { Platte, Lg. } 64 \mathrm{~cm} \text {. Kanne, H. } 28 \mathrm{~cm} \text {. } \\
\text { Besitzer: Protestantische Kirchenverwaltung, Hersbruck. } \\
\text { Ausstellung Nürnberg i } 885 \text {, Katalog Nr. } 674 .\end{array}$ \\
\hline \multirow[t]{6}{*}{ I 393} & $\begin{array}{l}\text { wie } \\
\text { Nr. I I } 93\end{array}$ & & $\begin{array}{l}\text { a) Vergoldete Deckelkanne, Corpus mit Orna- } \\
\text { menten und figuralen Medaillons getrieben. } \\
\text { H. I } 9 \mathrm{~cm} \text {. } \\
\text { Besitzer: Freih. v. Pölnitz, Augsburg. Ausstellung } \\
\text { Augsburg 1886, Katalog Nr. } 1533 .\end{array}$ \\
\hline & wie I I86 & & $\begin{array}{l}\text { b) Vergoldete Deckelkanne mit gravirtem Wappen } \\
\begin{array}{ll}\text { von I } 727 . & \text { H. } 26,5 \mathrm{~cm} . \\
\text { Besitzer: Leonhardskirche, Nürnberg. }\end{array}\end{array}$ \\
\hline & wie I I 86 & & $\begin{array}{l}\text { c) Vergoldete Deckelkanne mit Inschrift von } \\
\text { I740. } \\
\text { Besitzer: Leonhardskirche, Nürnberg. }\end{array}$ \\
\hline & wie I I93 & & $\begin{array}{l}\text { d) Theilvergoldete bauchige Abendmahlskanne } \\
\text { mit Inschrift von I74I. } \\
\text { Besitzer: Katharinenkirche, Schwäb.-Hall. } 33 \mathrm{~cm} \text {. }\end{array}$ \\
\hline & wie I I93 & & $\begin{array}{l}\text { e) Theilvergoldete bauchige Abendmahlskanne } \\
\text { mit Inschrift von I } 742 . \\
\text { Besitzer: Katharinenkirche, Schwäb.-Hall. } 27,5 \mathrm{~cm} \text {. }\end{array}$ \\
\hline & wie I I 86 & & $\begin{array}{l}\text { f) Vergoldeter Kelch. } \\
\text { Besitzer: Leonhardskirche, Nïrnberg. }\end{array}$ \\
\hline
\end{tabular}




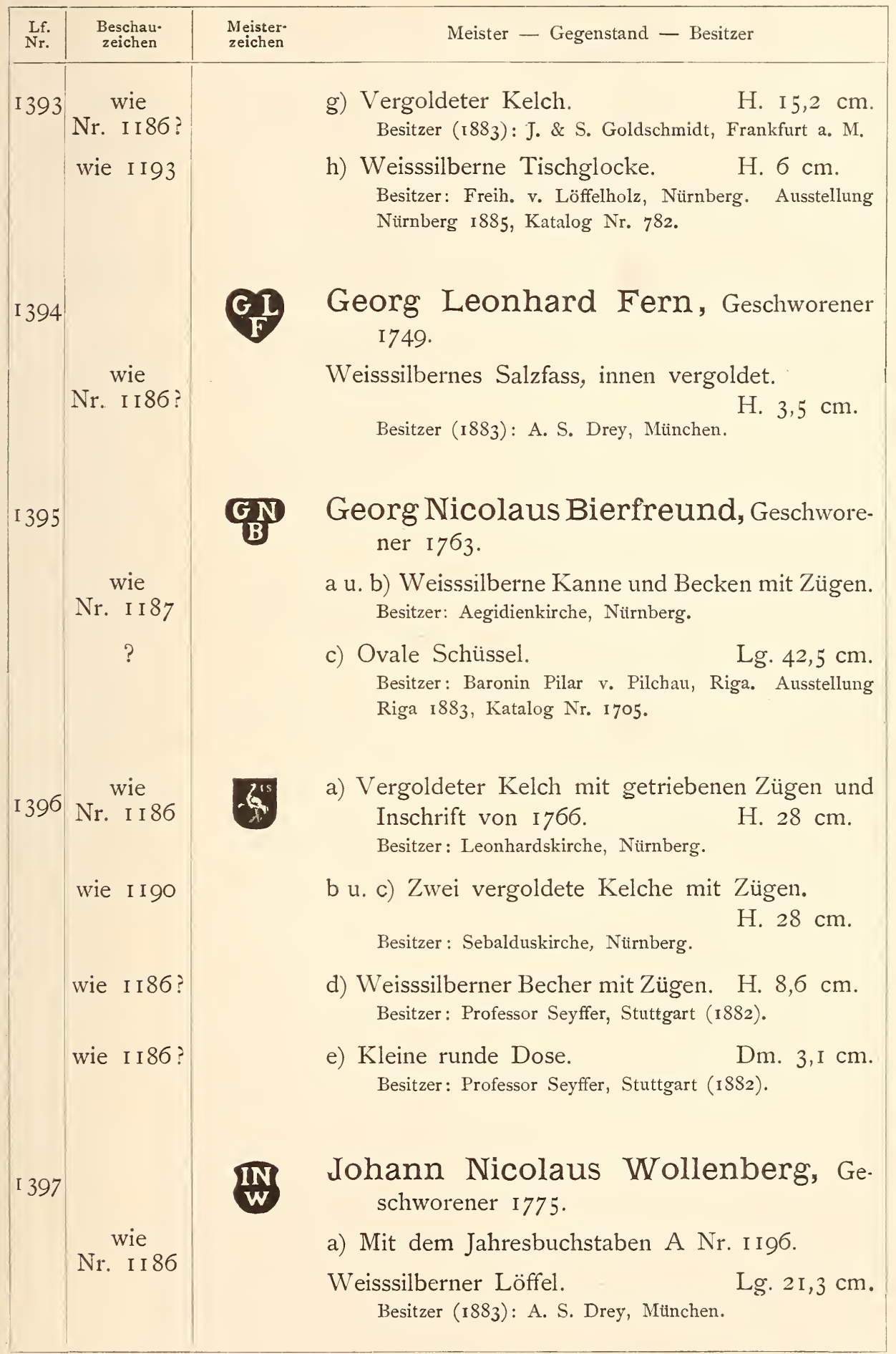




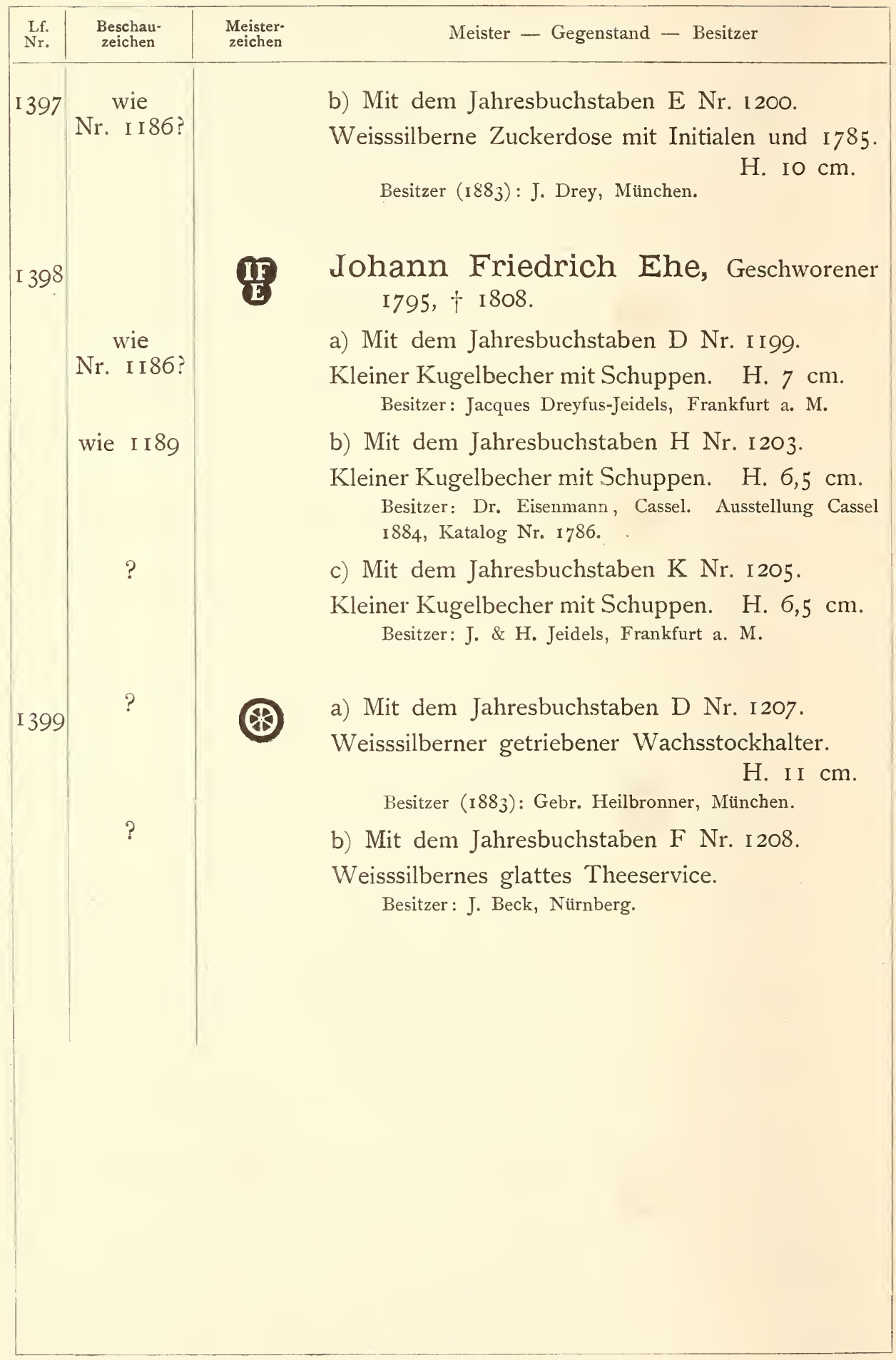




\section{OETTINGEN.}

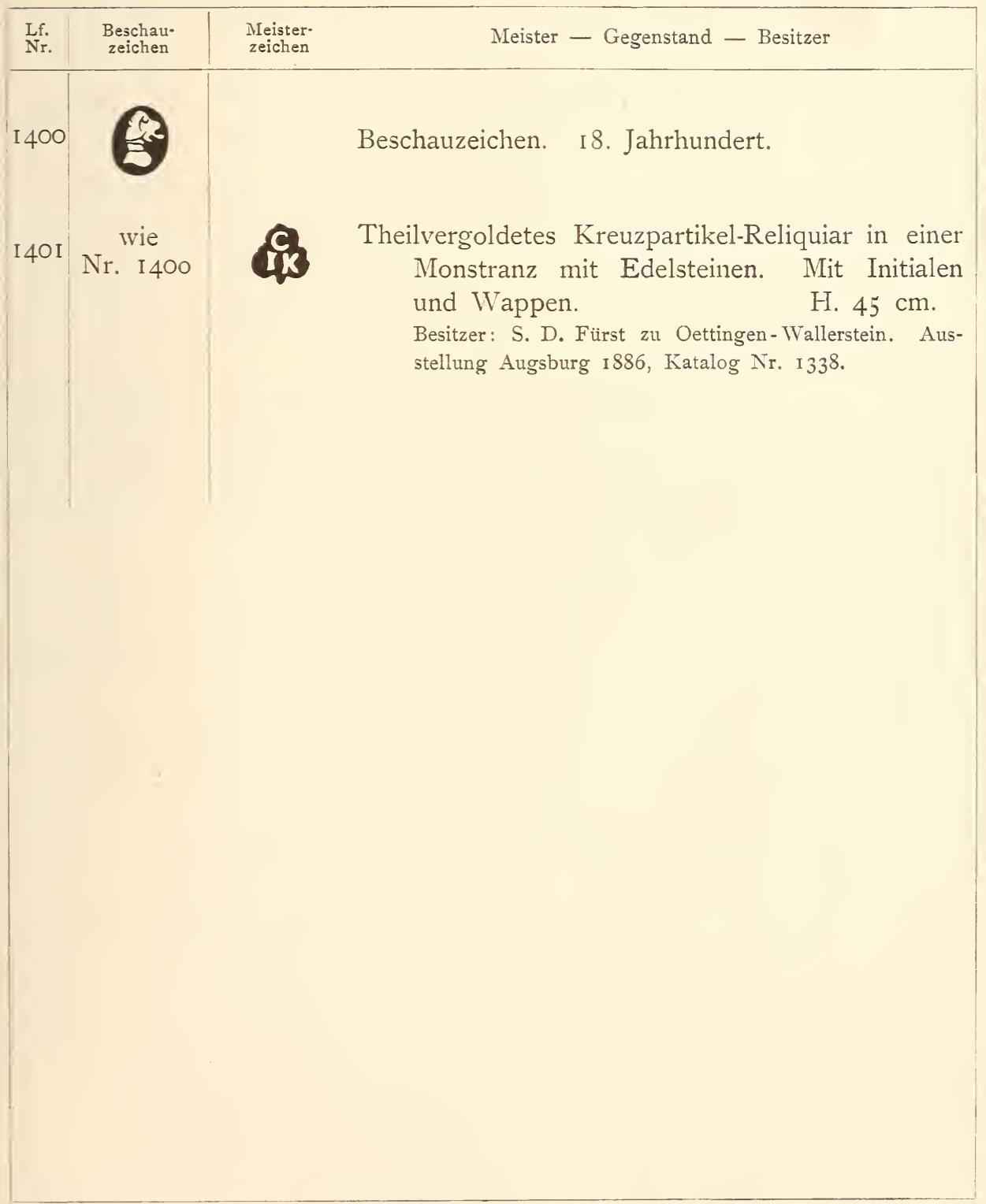




\section{PASSAU.}

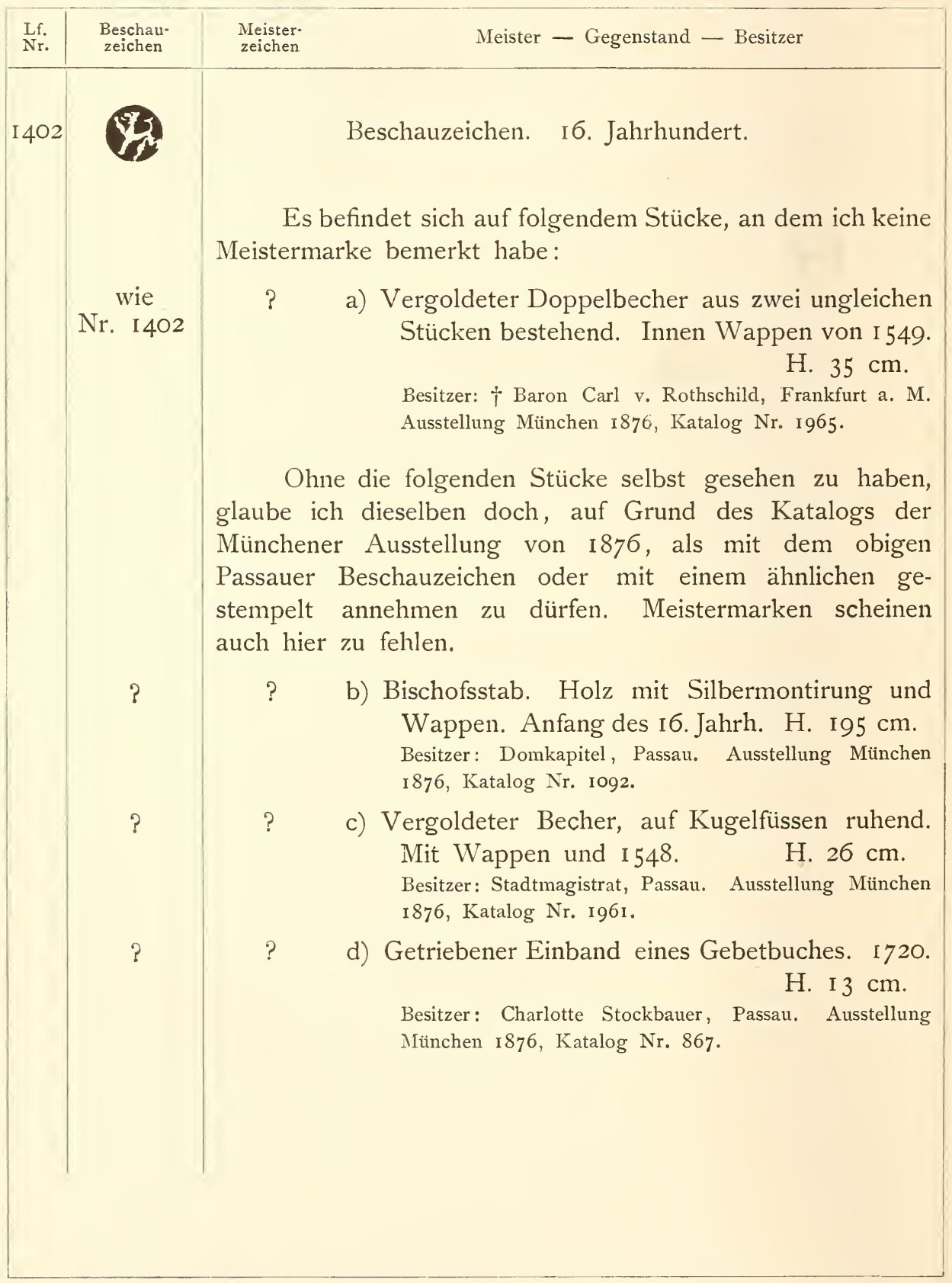




\section{PFORZHEIM.}

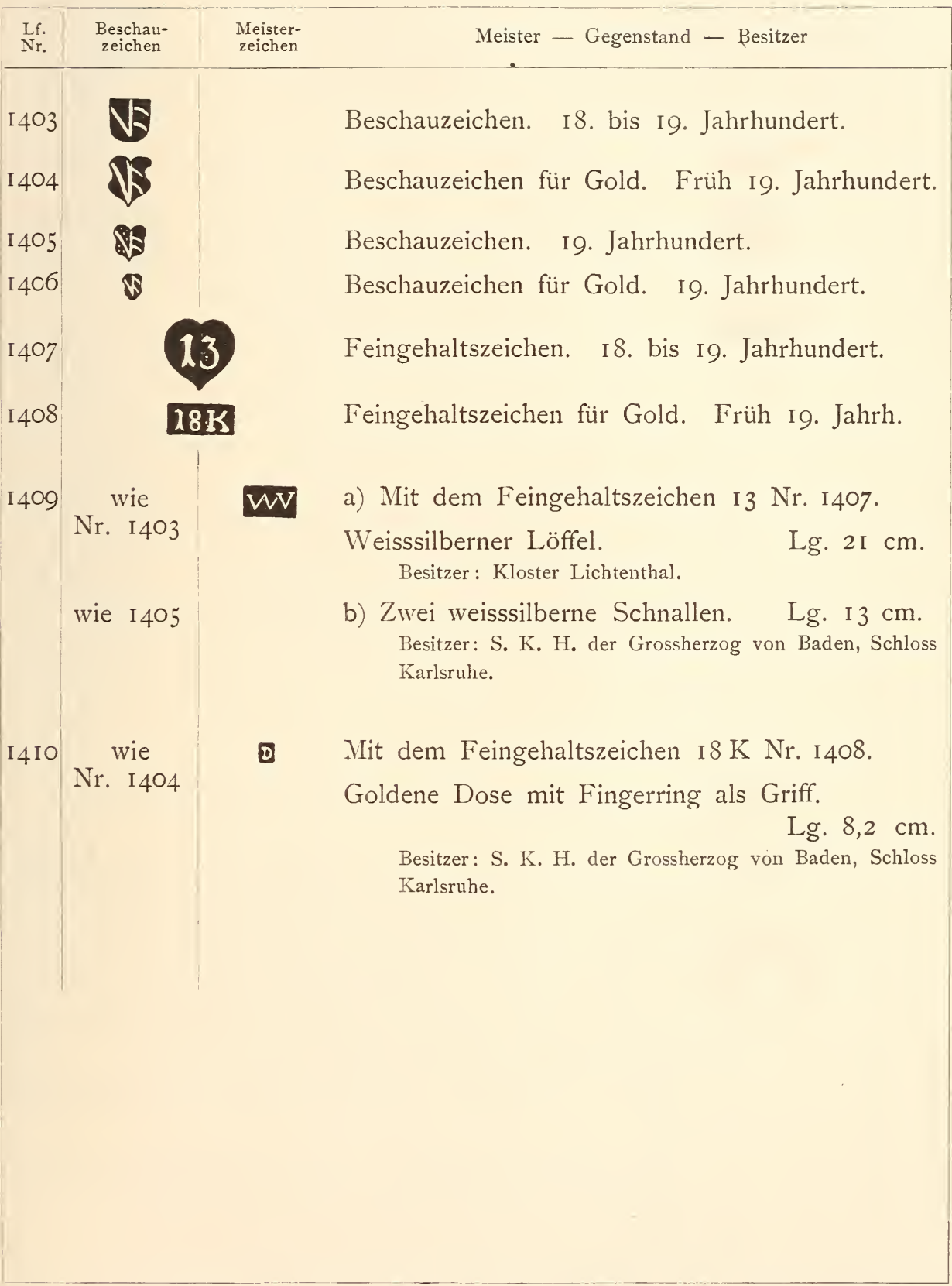




\section{PREUSSEN.}

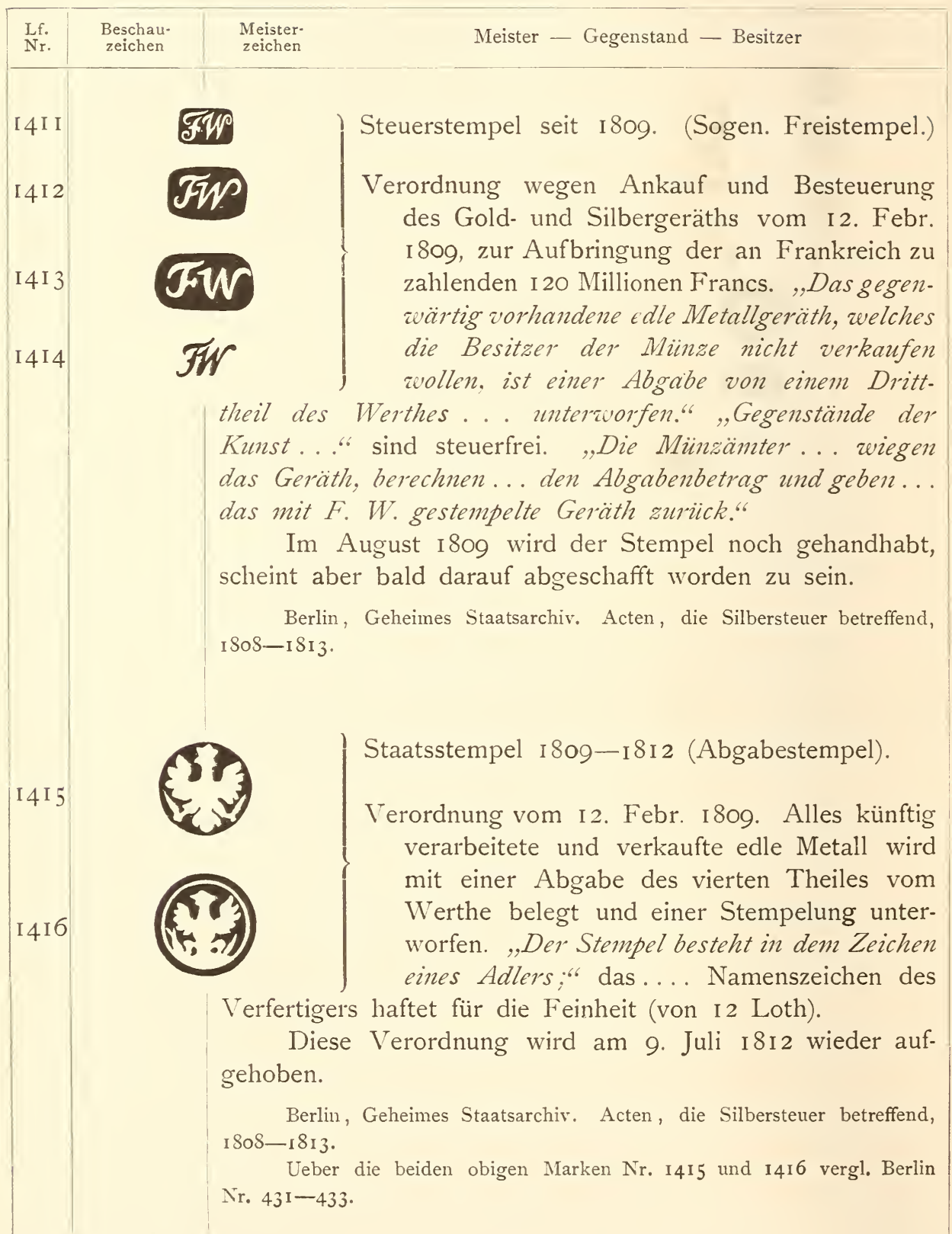




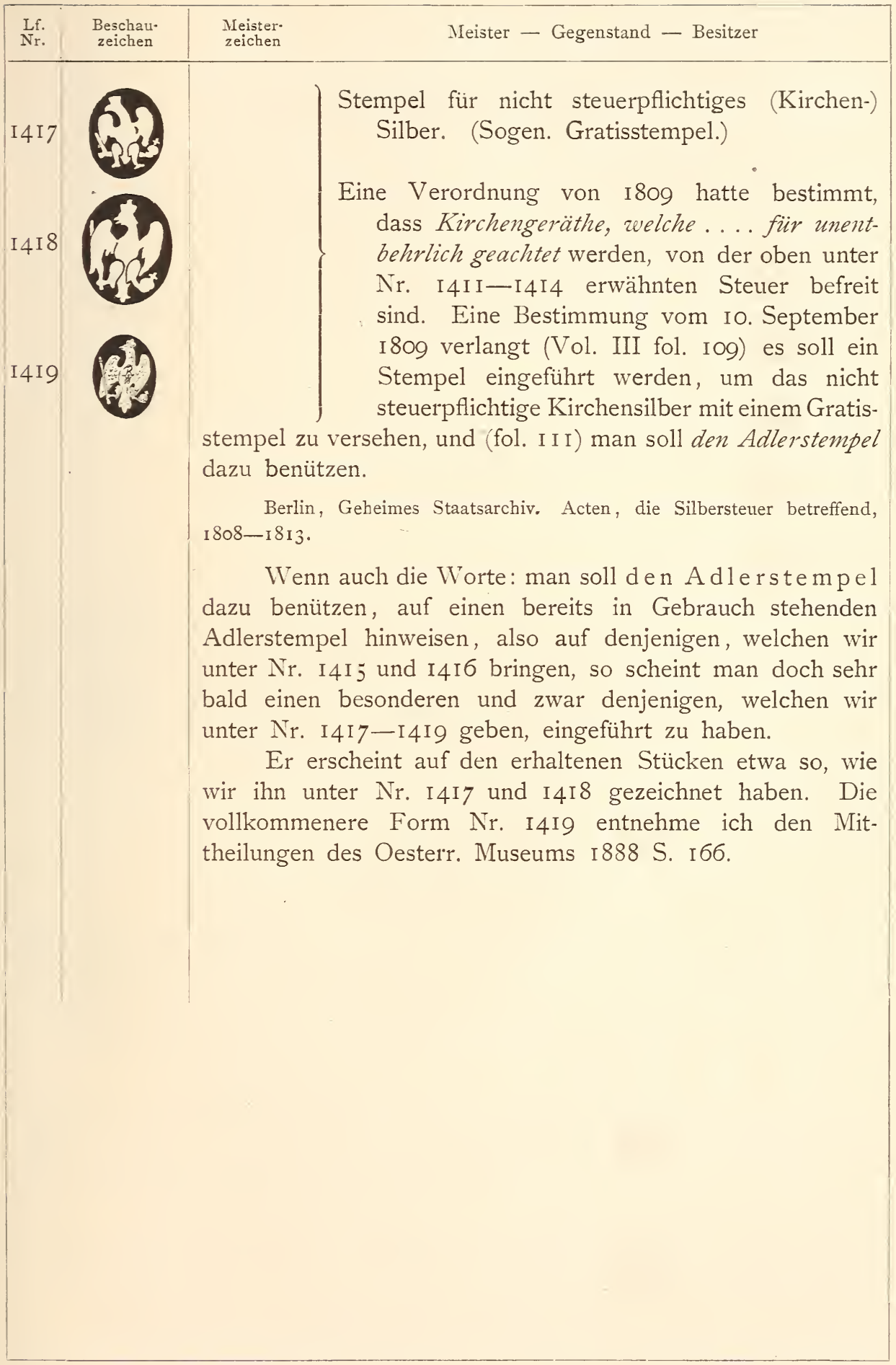




\section{REGENSBURG *}

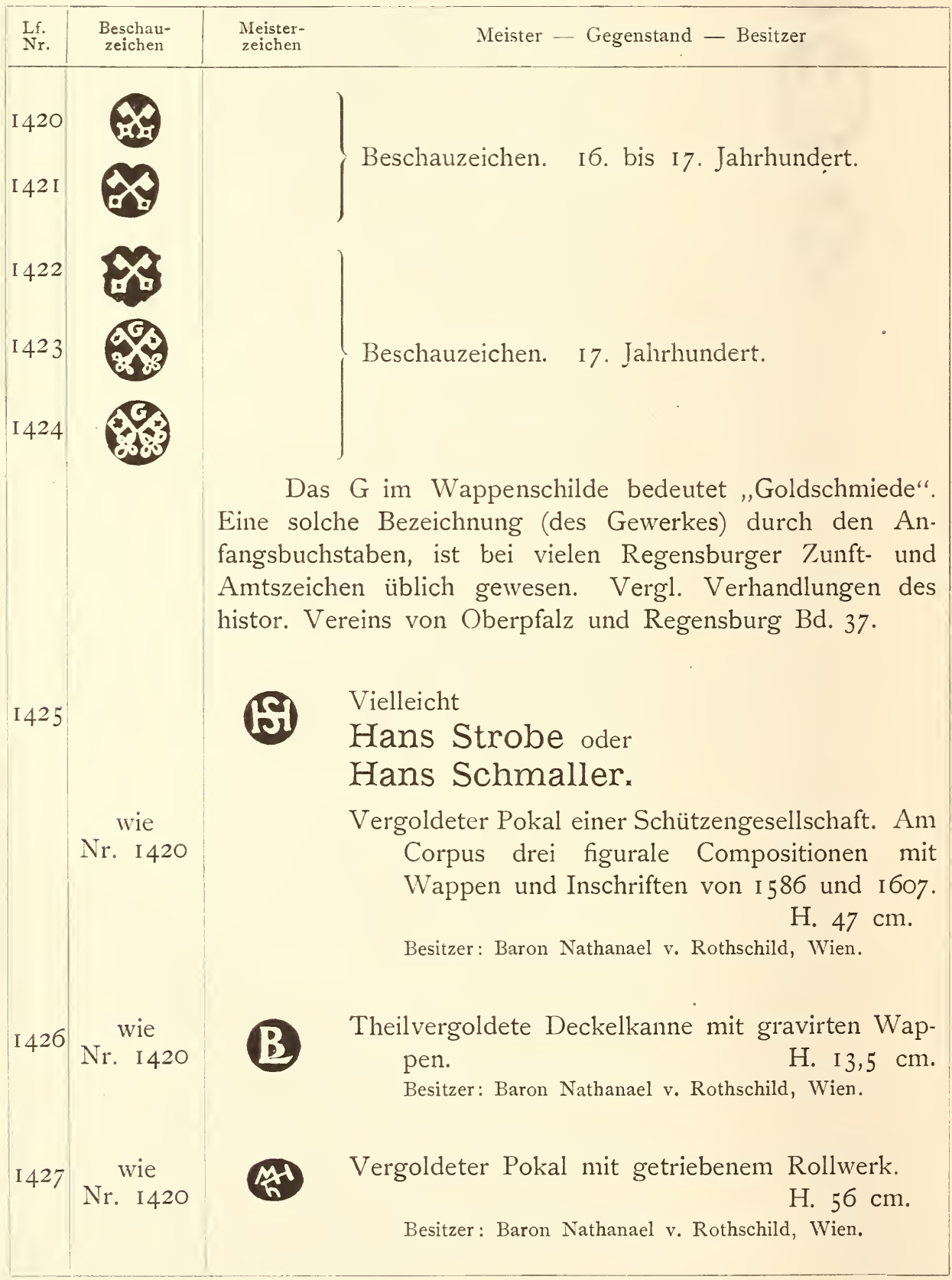




\begin{tabular}{|c|c|c|c|}
\hline$\underset{\text { Lff. }}{\text { Lr. }}$ & $\begin{array}{l}\text { Beschau- } \\
\text { zeichen }\end{array}$ & $\begin{array}{l}\text { Meister- } \\
\text { zeichen }\end{array}$ & Meister — Gegenstand - Besitzer \\
\hline I4 428 & ? & & $\begin{array}{l}\text { Vergoldeter Pokal in Agleyform, mit getrie- } \\
\text { benen Buckeln. } \\
\text { Besitzer: } \dagger \text {. } 22 \mathrm{~cm} \text {. } \\
\text { Katalog der Sammlung Felix, Leipzig. Eye \& } 1880 \text {, Nr. } 43 .\end{array}$ \\
\hline 1429 & $\begin{array}{c}\text { wie } \\
\text { Nr. I420 }\end{array}$ & & $\begin{array}{l}\text { Weisssilberne achtseitige Deckelkanne, mit Buckeln, } \\
\text { Früchten und Putten ornamentirt. } \\
\text { Besitzer: G. Oppenheim, Frankfurt a. M. Ausstellung } \\
\text { Frankfurt a. M. I875, Kat. Nr. I734. }\end{array}$ \\
\hline 1430 & $\begin{array}{c}\text { wie } \\
\text { Nr. I420 }\end{array}$ & & $\begin{array}{l}\text { Löffel, der Stiel glatt mit profilirtem Knopfe. } \\
\text { Mit Initialen und I607. } \\
\text { Besitzer: Richard Zschille, Grossenhain. Pabst, Besteck- } \\
\text { Sammlung Zschille, Taf. } 38 \text {. }\end{array}$ \\
\hline I $43 \mathrm{I}$ & $\begin{array}{l}\text { wie } \\
\text { Nr. } \text { I }^{2} 20\end{array}$ & & $\begin{array}{l}\text { Vergoldeter Pokal, mit Buckeln, Blattwerk und } \\
\text { Ornamenten getrieben. Inschrift von } 1657 \text {. } \\
\text { H. } 40 \mathrm{~cm} \text {. }\end{array}$ \\
\hline 1432 & & & Hans Federer? \\
\hline & $\begin{array}{l}\text { wie } \\
\text { Nr. I420 }\end{array}$ & & $\begin{array}{l}\text { Vergoldete Henkelschale mit weisssilbernen ge- } \\
\text { triebenen Blumen. } \\
\text { Besitzer: Bayr. Gewerbe-Museum, Nürnberg. }\end{array}$ \\
\hline I 433 & $\begin{array}{l}\text { wie } \\
\text { Nr. I420 }\end{array}$ & & 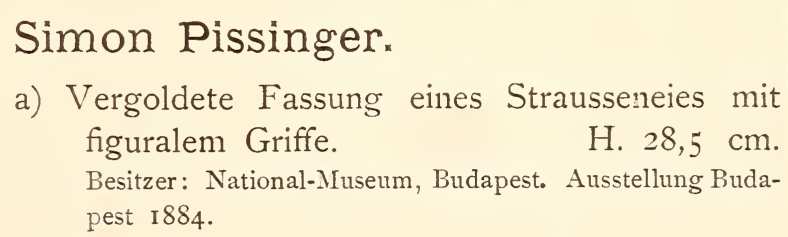 \\
\hline • & wie I42I & & $\begin{array}{l}\text { b) Vergoldete Fassung eines Nussbechers. Deckel- } \\
\text { krönung, Mannm. Wappenschild. H. } 30 \mathrm{~cm} \text {. } \\
\text { Besitzer: Königl. Museum, Cassel. Katalog Lenz I88I, } \\
\text { Nr. } 88 .\end{array}$ \\
\hline & ? & & $\begin{array}{l}\text { c) Vergoldeter Doppelpokal, mit Porträtköpfen } \\
\text { auf Buckeln getrieben. } \\
\begin{array}{ll}\text { Besitzer: } \dagger \text { Eugen Felix. Leipzig. Auctionskatalog } \\
\text { 1886, Nr. 417 mit Abbildung. }\end{array}\end{array}$ \\
\hline
\end{tabular}




\begin{tabular}{|c|c|c|c|}
\hline $\begin{array}{l}\text { Lf. } \\
\text { Nr. }\end{array}$ & $\begin{array}{l}\text { Beschau- } \\
\text { zeichen }\end{array}$ & $\begin{array}{l}\text { Meister- } \\
\text { zeichen }\end{array}$ & Meister - Gegenstand - Besitzer \\
\hline I 433 & ? & & $\begin{array}{l}\text { d) Löffel mit eiförmiger Kelle. Am Stielende } \\
\text { ein Schild mit Initialen. } \\
\text { Besitzer: } \dagger \text { Eugen Felix, Leipzig. Eye \& } 6 \text { cm. } \\
\text { Katalog der Sammlung Felix ı } 880 \text {, Nr. I54. }\end{array}$ \\
\hline I 434 & $\begin{array}{c}\text { wie } \\
\text { Nr. I42 I }\end{array}$ & & $\begin{array}{l}\text { Vergoldeter Pokal mit getriebenen Renaissance- } \\
\text { Ornamenten. Die Cuppa in Form einer See- } \\
\text { schnecke. } \\
\text { H. } 36,5 \mathrm{~cm} . \\
\text { Besitzer: } \dagger \text { Baron Carl v. Rothschild, Frankfurt a. M. } \\
\text { Luthmer, Schatz Rothschild I, Taf. 24. }\end{array}$ \\
\hline I 435 & $\begin{array}{c}\text { wie } \\
\mathrm{Nr} . \quad \text { I42 I }\end{array}$ & & $\begin{array}{l}\text { Löffel mit gravirtem Stiel, der in eine weibliche } \\
\text { Herme ausläuft. } \\
\text { Besitzer: } \dagger \text { Lg. I } 6 \mathrm{~cm} \text {. } \\
\text { 1886, Nr. } 854 \text {. }\end{array}$ \\
\hline 1436 & $\begin{array}{c}\text { wie } \\
\text { Nr. I422 }\end{array}$ & & $\begin{array}{l}\text { Vergoldete sechsseitige Deckelkanne mit getrie- } \\
\text { benen Tulpenornamenten. Inschrift und } 1673 . \\
\text { H. } 22 \mathrm{~cm} . \\
\text { Besitzer: Kunstgewerbe-Museum, Dresden. Ausstellung } \\
\text { Nürnberg } 1885 \text {, Katalog Nr. } 647 .\end{array}$ \\
\hline 1437 & $\begin{array}{c}\text { wie } \\
\text { Nr. I422 }\end{array}$ & & $\begin{array}{l}\text { Löffel mit Renaissance-Ornamenten und Inschrift. } \\
\text { Besitzer: Gg. Agath, Breslau. }\end{array}$ \\
\hline 1438 & $\begin{array}{c}\text { wie } \\
\text { Nr. } \quad \text { I } 423\end{array}$ & & $\begin{array}{l}\text { Weihwasserkessel mit Email und getriebenem } \\
\text { Laubwerk. } \\
\text { Besitzer (1883): J. \& S. Goldschmidt, Frankfurt a. M. }\end{array}$ \\
\hline I 439 & $\begin{array}{l}\text { wie } \\
\text { Nr. I } 424\end{array}$ & & $\begin{array}{l}\text { Vergoldeter Kelch mit figuralen Darstellungen. } \\
\text { Besitzer: Deutschordensschatz, Wien. } 25 \mathrm{~cm} \text {. }\end{array}$ \\
\hline I 440 & ? & & $\begin{array}{l}\text { Zwei weisssilberne Leuchter mit getriebenen Zügen. } \\
\text { H. } 24 \mathrm{~cm} . \\
\text { Besitzer: Oesterreichisches Museum, Wien. }\end{array}$ \\
\hline
\end{tabular}




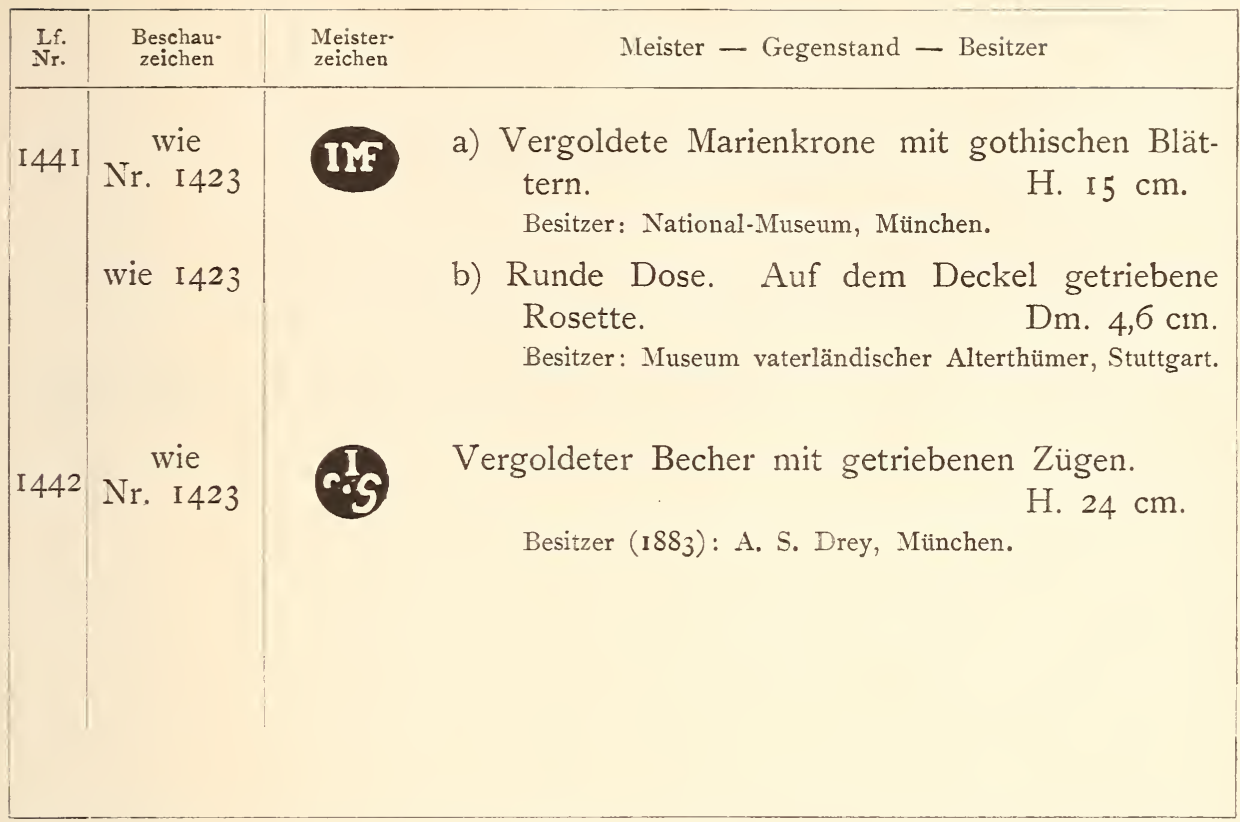

\section{REUTLINGEN.}

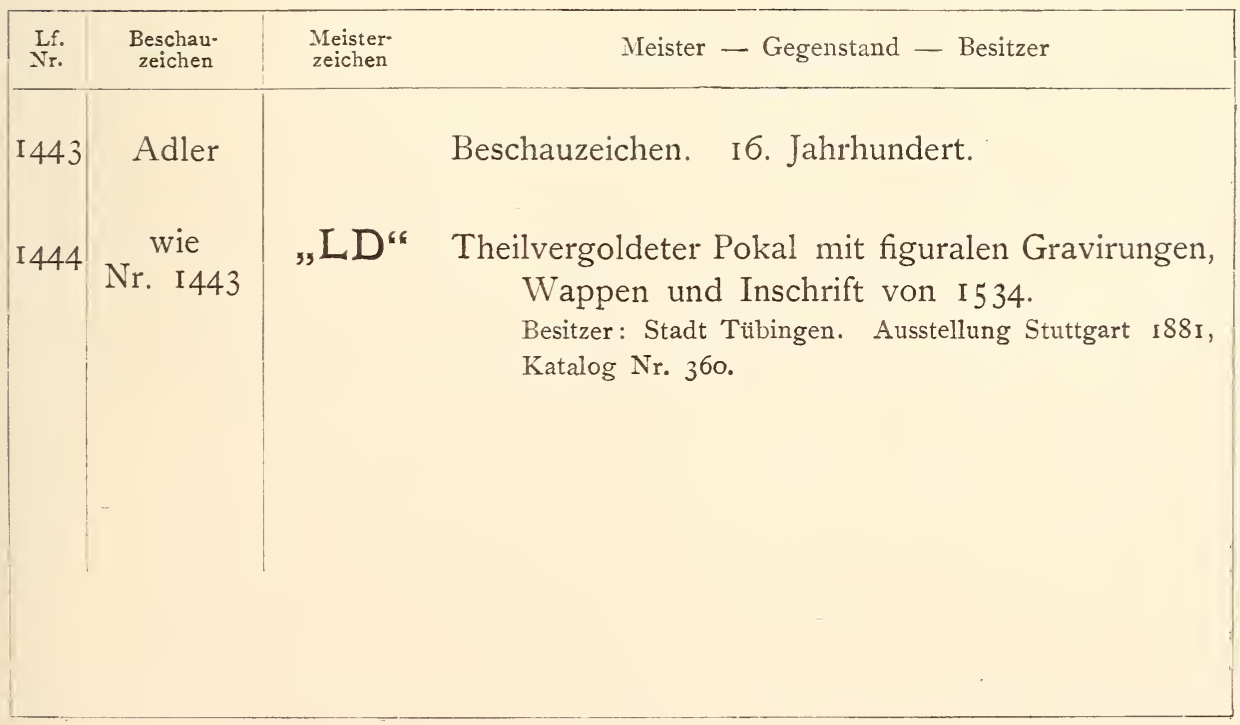




\section{SCHARMBECK.}

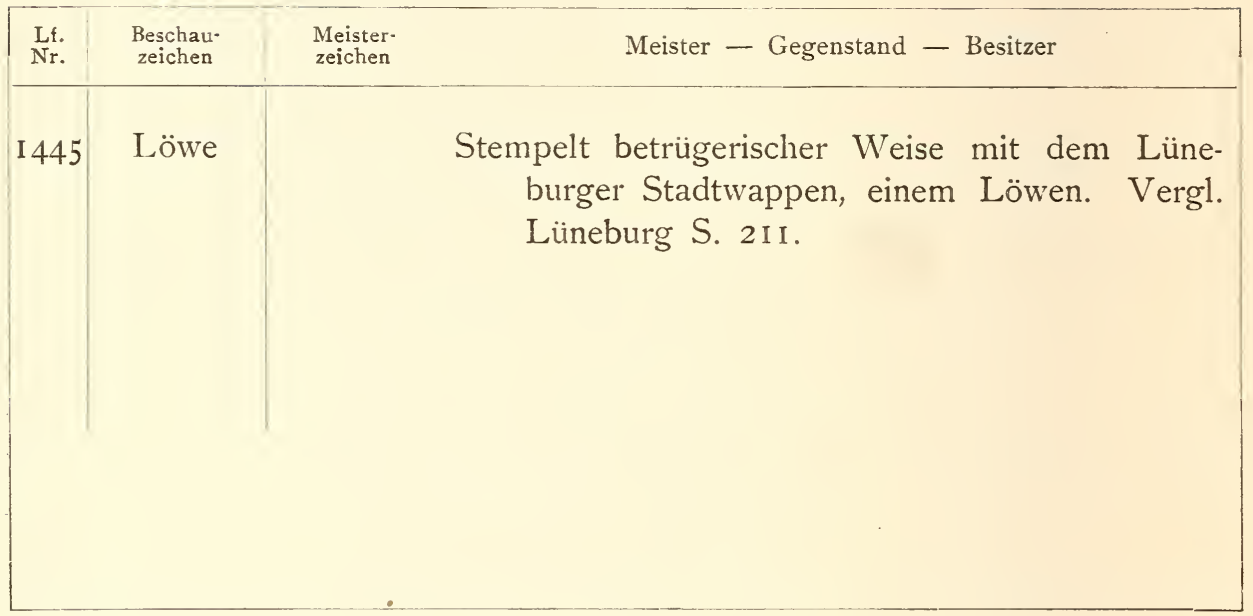

\section{SCHWABACH.}

\begin{tabular}{|c|c|c|}
\hline $\begin{array}{c}\text { Lf. } \\
\text { Nr. }\end{array}$ & $\begin{array}{c}\text { Beschau- } \\
\text { zeichen }\end{array}$ & $\begin{array}{c}\text { Meister- } \\
\text { zeichen }\end{array}$ \\
\hline I446 & ? & $\begin{array}{c}\text { Es scheint, dass eine Stempelung in dieser Stadt be- } \\
\text { standen hat. } \\
\text { Schwabach schreibt I6I 5 nach Dresden und bittet um } \\
\text { die dortige Ordnung (welche Stempelung vorschreibt), weil } \\
\text { das Goldschmiedehandwerk in ihrer Stadt lebhafter erblühe. } \\
\text { Dresden, Rathsarchiv. Zunft-Acten. Goldschmiede I, 23. } \\
\text { Es ist merkwürdig, dass man sich in Schwabach nicht } \\
\text { damit begnügt hat, dem Beispiele Nürnbergs zu folgen. }\end{array}$ \\
& \\
\hline
\end{tabular}




\section{SCHWEINFURT.}

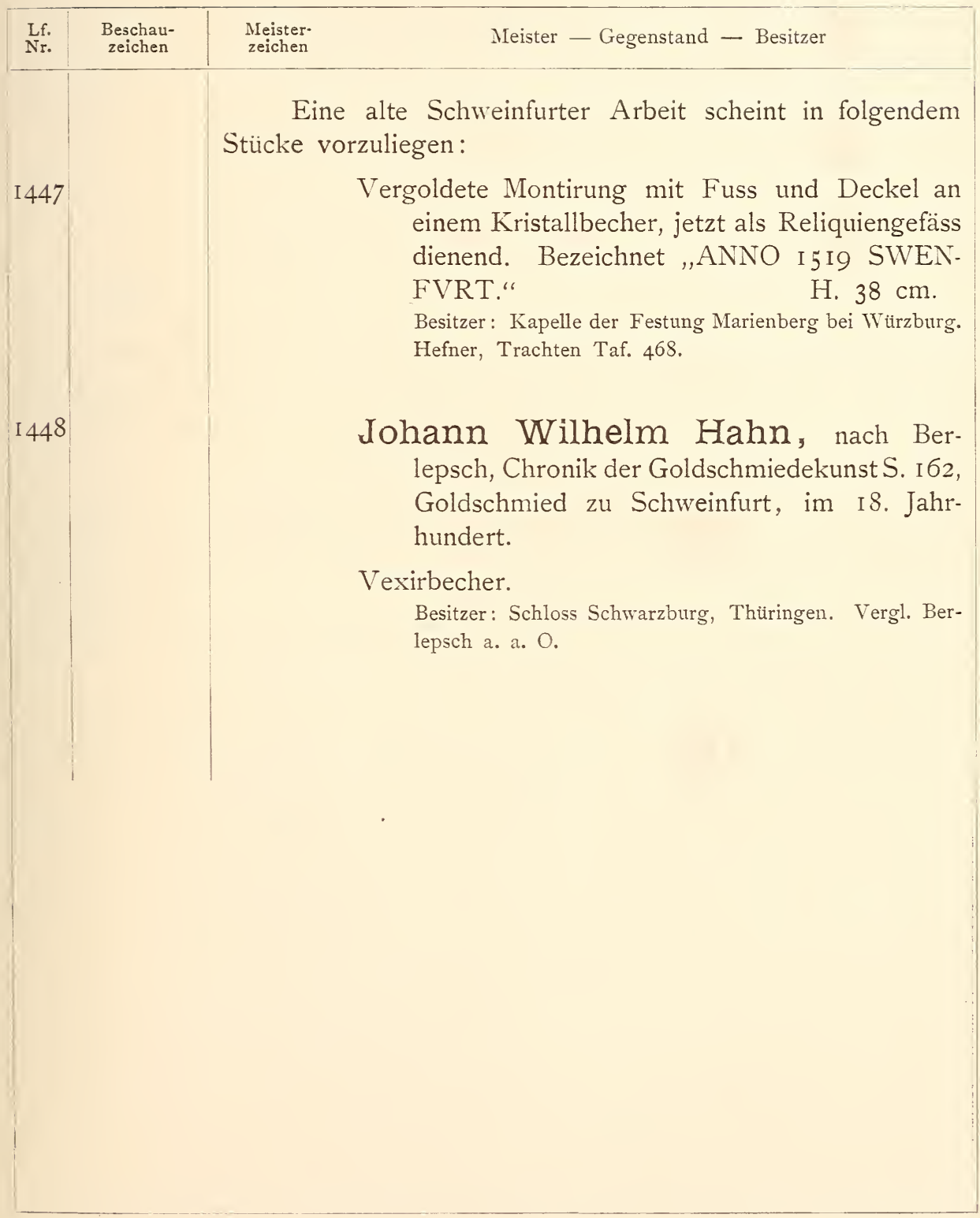




\section{SPEIER.}

\begin{tabular}{|c|c|c|c|}
\hline $\begin{array}{l}\text { Lff. } \\
\mathrm{Nr}_{\mathrm{r}}\end{array}$ & $\begin{array}{l}\text { Beschau- } \\
\text { zeichen }\end{array}$ & $\begin{array}{l}\text { Meister- } \\
\text { zeichen }\end{array}$ & Meister - Gegenstand - Besitzer \\
\hline I 449 & 舟角 & & Beschauzeichen. I6. Jahrhundert. \\
\hline 1450 & 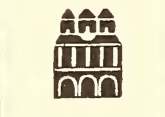 & & Beschauzeichen. I7. Jahrhundert. \\
\hline I $45 \mathrm{I}$ & mintin & & Beschauzeichen. Spät I7. Jahrhundert. \\
\hline 1452 & $\begin{array}{l}\text { wie } \\
\text { Nr. } \quad \text { I } 449\end{array}$ & $\begin{array}{l}\text { nicht } \\
\text { vorhanden }\end{array}$ & $\begin{array}{l}\text { Serie von acht Setzbechern mit Inschriften, Wap- } \\
\text { pen und I } 519 . \\
\text { Besitzer: Königl. Museum, Cassel. Drach, Silberarbeiten } \\
\text { Cassel 1888, Taf. 3. }\end{array}$ \\
\hline I 453 & $\begin{array}{c}\text { wie } \\
\text { Nr. I } 450\end{array}$ & & $\begin{array}{l}\text { Theilvergoldeter Pokal, Gildebecher der Maurer- } \\
\text { zunft (zu Speier?). Mit Inschrift, Wappen } \\
\text { und I624. } \\
\text { Besitzer: Consul Becker, Frankfurt a. M. Ausstellung } \\
\text { Cassel I } 884 \text {, Katalog Nr. } 523 .\end{array}$ \\
\hline 1454 & $\begin{array}{l}\text { wie } \\
\text { Nr. I45 I }\end{array}$ & & $\begin{array}{l}\text { Patene von vor } \mathrm{I}_{8} \mathrm{O}_{3} \text {, beigelegt einem Kelche des } \\
\text { I } 5 \text {. Jahrhunderts. } \\
\text { Besitzer: Deutschordensschatz, Wien. }\end{array}$ \\
\hline
\end{tabular}




\section{STETTIN.}

Eine regelrechte Stempelung scheint I 549 noch nicht üblich gewesen zu sein; wenigstens erwähnt es Blümcke: Die Handwerkerzünfte im mittelalterlichen Stettin, Stettin I884, nicht, obgleich er reichliche Excerpte aus einer Ordnung von I 549 macht.

Das Beschauzeichen, das wir in Folgendem anführen, wird demnach nicht über dieses Jahr I 549 hinaus zurückzudatiren sein, wenn wir überhaupt keinen Irrthum begehen, indem wir es für Stettin in Anspruch nehmen.

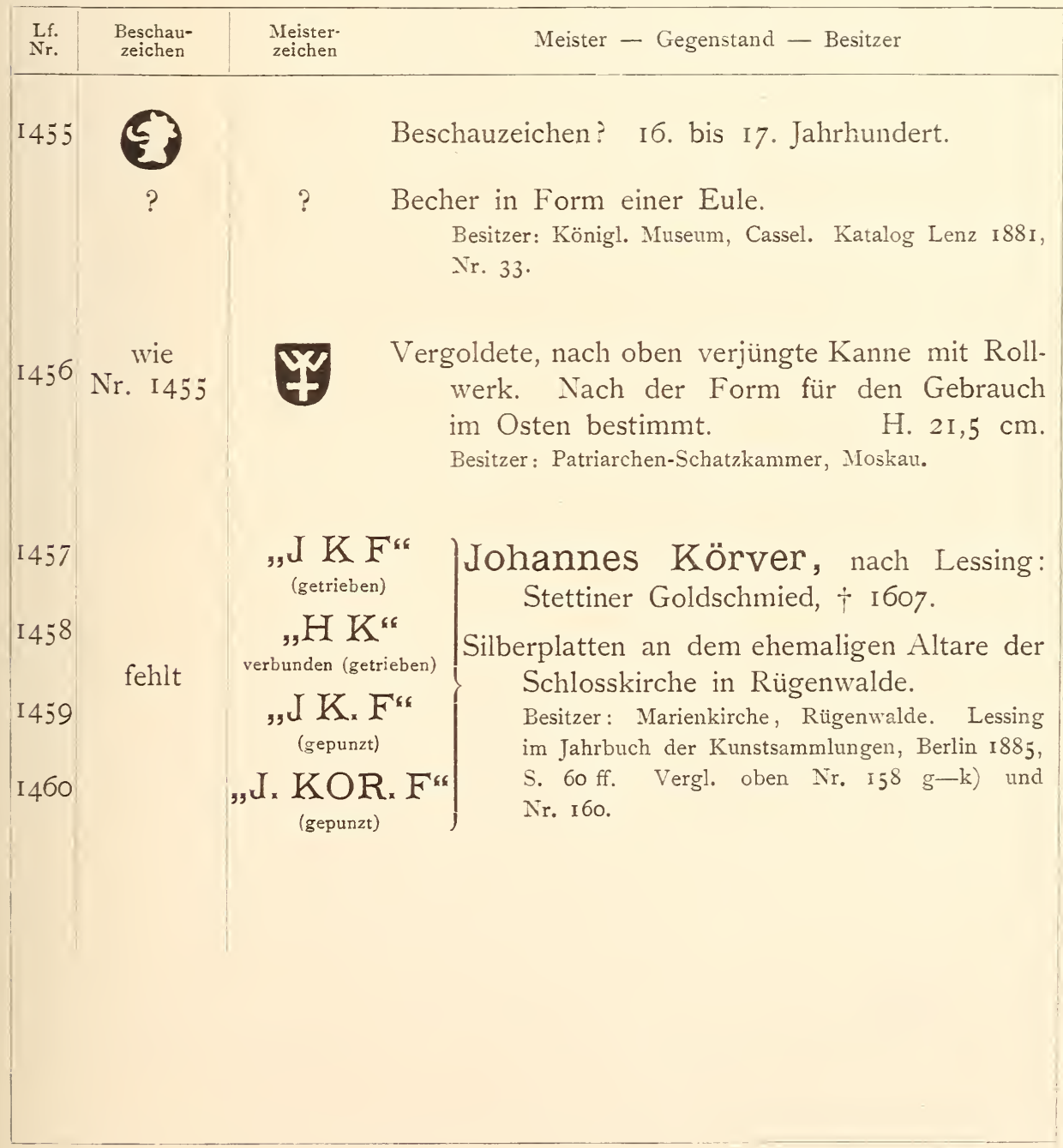




\section{STRASSBURG.}

Vergl. Hans Meyer, Die Strassburger Goldschmiedezunft von ihrem Entstehen bis I68I. Urkunden und Darstellung. Ein Beitrag zur Gewerbegeschichte des Mittelalters. Leipzig i88 I. 8॰. Dazu Marc Rosenberg, Eine vergessene Goldschmiedestadt im Kunstgewerbeblatt II S. 4I ff.

Die erste Bestimmung über einen Stempel findet sich in der grossen Besserung zur Ordnung von circa I 363 , und beweist, dass ein Stadtzeichen schon vorher üblich war, während ein Meisterzeichen erst jetzt eingeführt wird.

Art. 2I. Die goltsmide söllent och haben ein gemein zeichen, daz sie die vorgenanten geschirre domitte zeichent.

Art. 22. Und umb des willen, daz niemann betrogen werde, möge ouch sich kein heymscher oder ein heymscher mit eim frömden entschuldigen. und daz menglich wissen möge, was ein jeglicher gemacht hab, und dazselbe ein wissen sin möge, was wercks ein jeglicher mache, ouch des in künftiger zit werschafft tragen sölle, so ist bedocht, das ein jeglich goltschmydt sin wercke mit eime besondern eignen zeichen zeichnen soll zu der statt zeichen. und sol ein jeglich goltschmydt yetzt ein zeichenysen machen und das hinder die goltschmydtmeisterschafft in ein stück silber stempfen, uff daz man es kennen möge. und ob einem goldschmydt ein zeichenysen von herte abspringe und untöuglich wiirde, daz er ein nüwes haben müst, so sol er solich sin ysen aber hinder die goldschmydtmeisterschafft bringen und stempfen, domit man sin zeichen allewegen kennen möge. und was wercks er macht, daz man zeichen mag, sol er by sinem eyde mit sinem zeichen zeichnen, ee denn er es verguldet. und was ïber vier lot wigt, daz sol man ouch mit der statt zeichen zeichnen.

$$
\text { Meyer a. a. O. S. } 5 \text {. }
$$

$\mathrm{Ob}$ das hier erwähnte gemein zeichen schon damals wie später in einem Felde mit drei leeren Schilden bestand, bleibe dahingestellt, da noch keine Strassburger Arbeit aus dieser Zeit nachgewiesen werden konnte. Sehr bemerkenswerth ist es, dass hier, I363, allgemeines und persönliches Zeichen gefordert wird, während die Ordnung von I 472 von keinem Meisterzeichen spricht und ein aus dieser Zeit erhaltener Kelch auch keines aufweist.

\begin{tabular}{|c|c|c|}
\hline $\begin{array}{l}\text { Lf. } \\
\text { Nr. }\end{array}$ & $\begin{array}{c}\text { Beschau- } \\
\text { zeichen }\end{array}$ & Meister — Gegenstand - Besitzer \\
\hline I 46 I & & $\begin{array}{l}\text { Beschauzeichen von } 1472 \text { circa, in ähnlicher Form } \\
\text { giltig bis I } 534 \text {. } \\
\text { Wie die goltsmyde ir wergk zeichenen und eyn ge- } \\
\text { meyn zeichen haben söllent. }\end{array}$ \\
\hline
\end{tabular}




\begin{tabular}{|c|c|c|}
\hline $\begin{array}{l}\text { Lf. } \\
\text { Nr. }\end{array}$ & $\begin{array}{l}\text { Beschau- } \\
\text { zeichen }\end{array}$ & Meister - Gegenstand - Besitzer \\
\hline I 46 I & $\begin{array}{c}\text { wie } \\
\mathrm{Nr} . \quad \text { I 46 I }\end{array}$ & $\begin{array}{l}\text { Die goldsmyde söllent haben ein gemeyn zeichen, } \\
\text { und was sie werckes machent, das man zeichenen sol oder } \\
\text { mag, sol ein yeglicher dem meister und sinen geswornen } \\
\text { zeigen oder dem merenteil under inen und das zeichen in } \\
\text { eines geswornen gadem. es sol ouch der meister und sin } \\
\text { gesworne deheinen kein zeichenysen heym geben, sonder er } \\
\text { by inen behaben. sie söllent ouch das cleyn gesmyde, das } \\
\text { man nit gezeichenen mag, behiuten und bewaren, wie dicke } \\
\text { in das fïget. by iren eiden, on alle geferde, also das von } \\
\text { alter harkommen ist. } \\
\text { Drittes Buch der Goldschmiede. I472 Art. 4. Meyer S. } 54 \mathrm{ff} . \\
\text { Vergoldeter Kelch mit Wappen und Inschrift. } \\
\text { nicht H. } 22 \text { cm. } \\
\text { vorhanden } \\
\quad \text { gesitzer: Katholische Pfarrkirche, Baden-Baden. Kunst- } \\
\text { Im Jahre I } 534 \text { wird dieser Stempel resp. dieses Be- } \\
\text { schauzeichen in seiner Grundform beibehalten, aber mit der } \\
\text { Strassburger Lilie in Verbindung gebracht. } \\
\text { Keiner soll on den andern zeichen. } \\
\text { Art. I2. Dasz gemein hantwerckszeichen soll } \\
\text { ouch in ein besonder lade gelegt, und dieselbig lad mit } \\
\text { zweyen schlossen verwart werden, dartzu die zwen ver- } \\
\text { ordenten goldtschmidt yeder ein besondern schlïssel haben } \\
\text { sollen. und soll dieselbig lad in ein kensterlin (?) uff der } \\
\text { zunftstuben gestelt und verschlossen werden, und der dritt } \\
\text { verordent beschawer, so durch meyster und rathe yeder zeit } \\
\text { verordent wïrt, allein ein schlüssel zu dem kensterlin haben, } \\
\text { domit keiner on den andern über das zeichen komen möge. } \\
\text { Art. I3. Es sollen ouch die meysterschaft zur Steltzen } \\
\text { yetzt, so disse ordenungen angadt, ein nuw hantwercks- } \\
\text { zeichen machen und obwendig der dreyer schiltlin } \\
\text { uff das zeichen ein gilg (Lilie) stechen lossen, domit man } \\
\text { sehen möge, das sollich getzeichente arbeit in der stat } \\
\text { Straszburg gemacht sey. }\end{array}$ \\
\hline 1462 & & $\begin{array}{l}\text { Beschauzeichen, I } 534 \text { bis } 1567 \text {. } \\
\text { Goldschmiedeartikel von I } 534 \text {, Art. I2 bis 2I. Meyer } \\
\text { S. } 85 \text {. }\end{array}$ \\
\hline
\end{tabular}




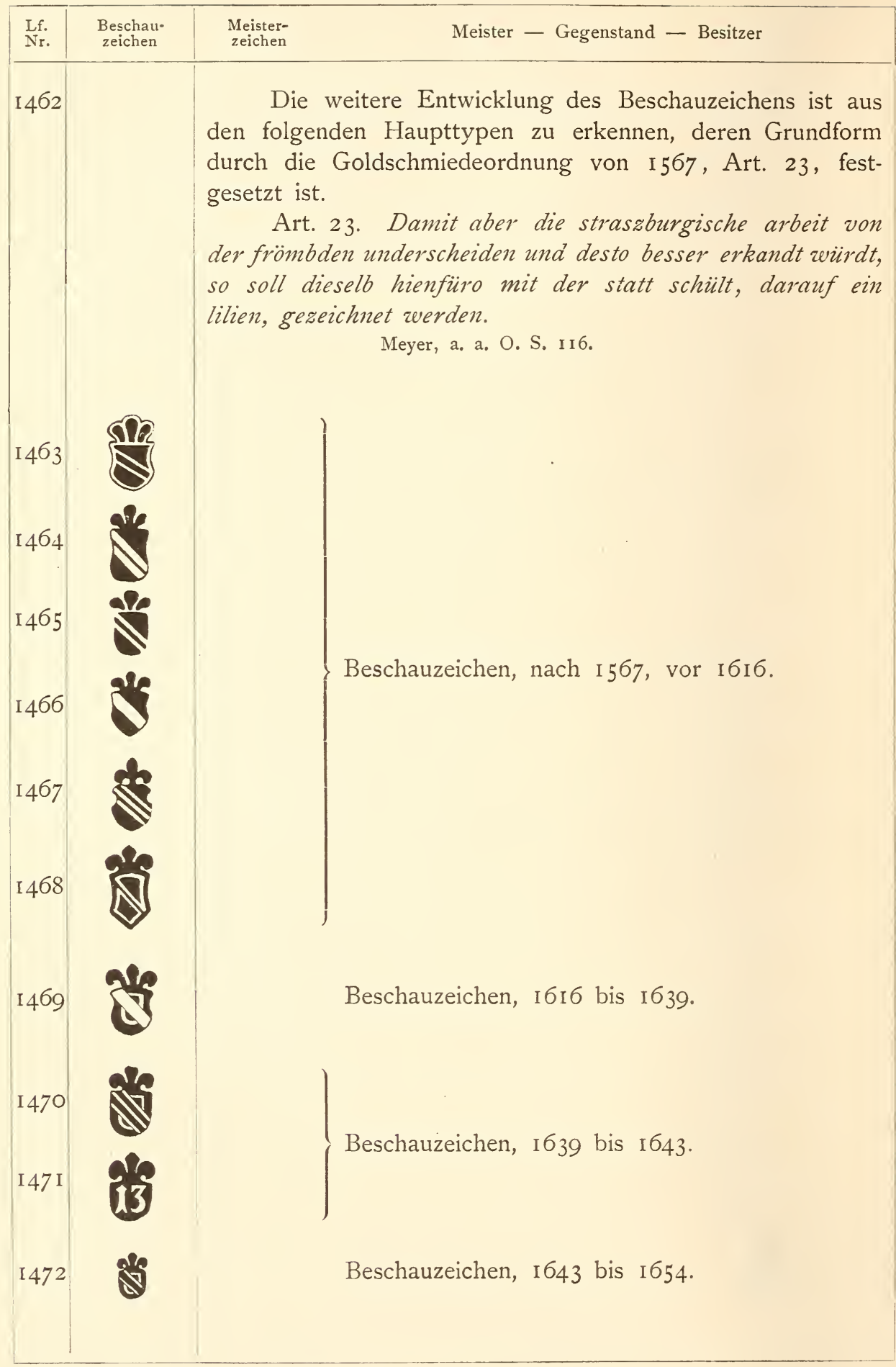




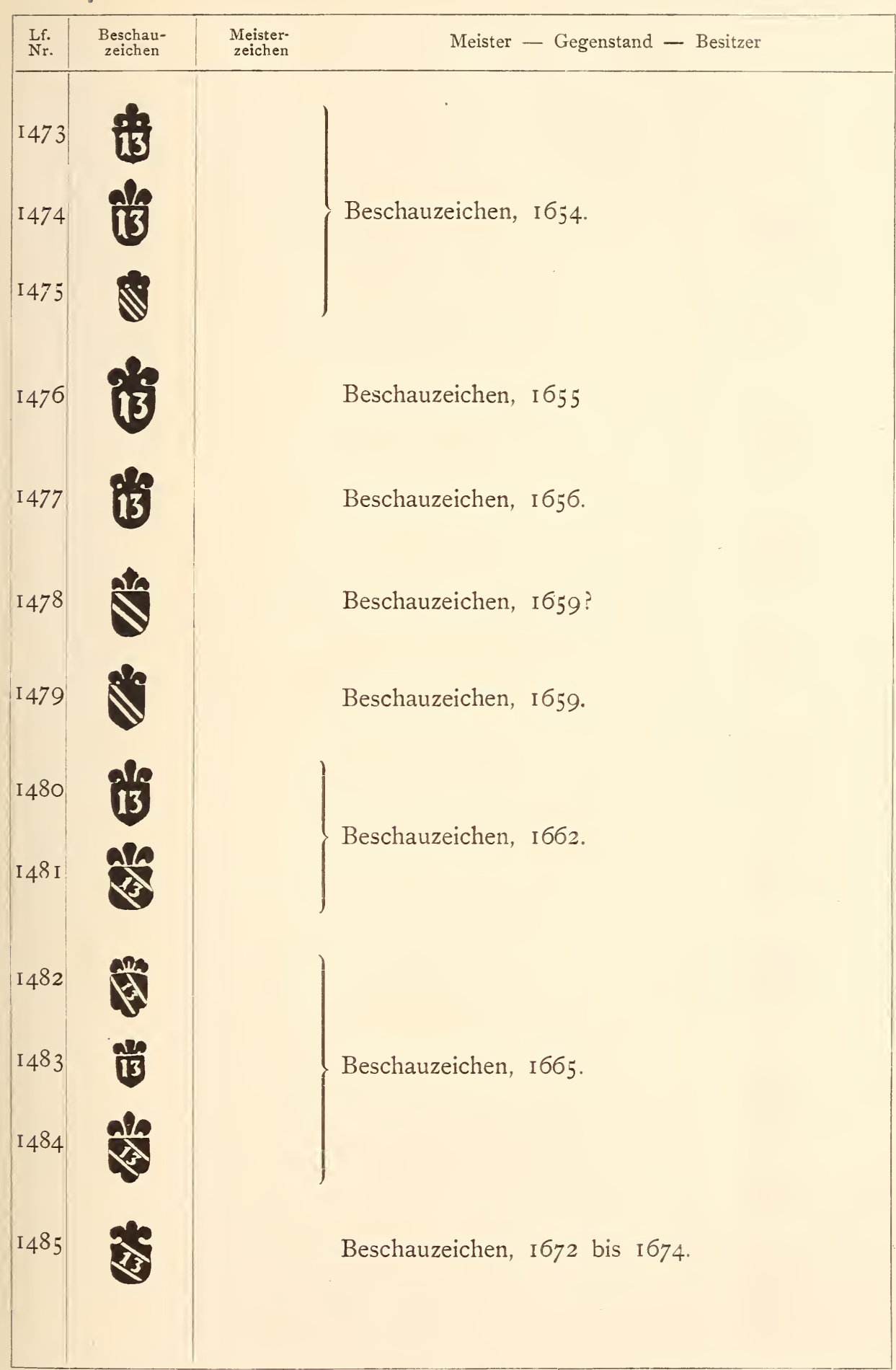




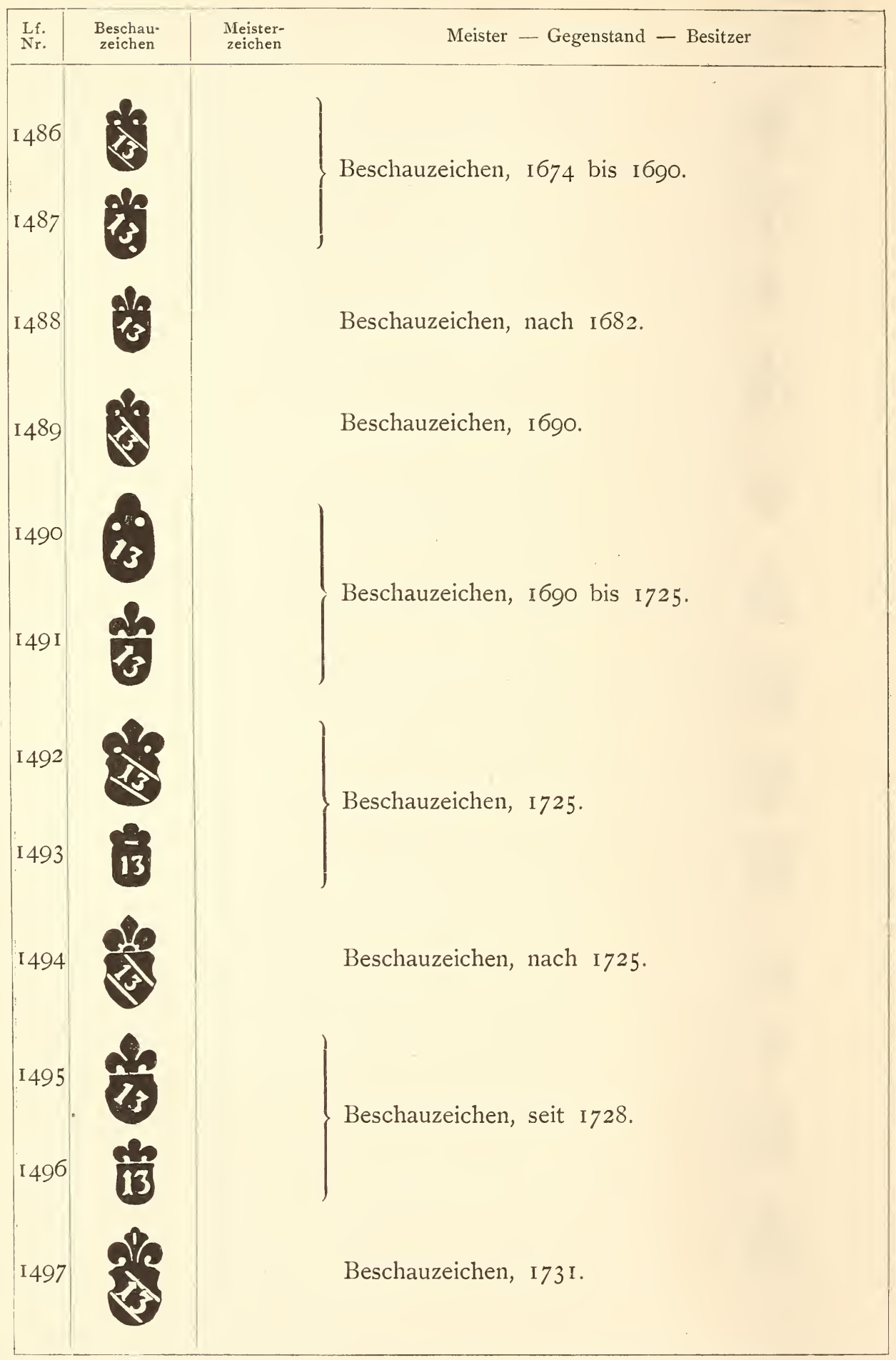




\begin{tabular}{|c|c|c|c|}
\hline $\begin{array}{l}\text { Lf. } \\
\text { Nr. }\end{array}$ & $\begin{array}{l}\text { Beschau- } \\
\text { zeichen }\end{array}$ & $\begin{array}{l}\text { Neister- } \\
\text { zeichen }\end{array}$ & Meister - Gegenstand - Besitzer \\
\hline 1498 & & & Beschauzeichen, I 736. \\
\hline I 499 & & & Beschauzeichen, I 739. \\
\hline I $50 \mathrm{I}$ & & & Beschauzeichen, I749 bis I75I. \\
\hline I 502. & ( & & \\
\hline 1503 & & & \\
\hline I 504 & & & \\
\hline I 505 & & & Feingehaltszeichen, von I 750 bis I 796 ? \\
\hline I 506 & & & \\
\hline I 507 & & & \\
\hline 1508 & & & \\
\hline I 509 & & & Feingehaltszeichen, um 1690. \\
\hline 1510 & & & \\
\hline
\end{tabular}




Ir.




\begin{tabular}{|c|c|c|}
\hline $\begin{array}{l}\text { Lf. } \\
\text { Nr. }\end{array}$ & $\begin{array}{l}\text { Beschau- } \\
\text { zeichen }\end{array}$ & Meister - Gegenstand - Besitzer \\
\hline I 522 & $\begin{array}{l}\text { De } \\
\text { von aus } \\
\text { in der } \\
\text { fremden } \\
\text { Stempel }\end{array}$ & $\begin{array}{l}\text { Kampf, den die Goldschmiede fast aller Städte gegen die } \\
\text { rts eingeführte geringhaltige Waare zu führen haben, findet } \\
\text { gel seinen Abschluss durch Einführung einer Beschau der } \\
\text { aare. In Strassburg wird zu diesem Zwecke ein besonder } \\
\text { gefertigt. }\end{array}$ \\
\hline
\end{tabular}

Frembde arbeit soll von den schauern an den verdächtigsten orten probirt werden.

Art. 22. Und sollen die schanwer solche frembde arbeit, die inen zu probieren fürbracht wiirdt, an den verdechtigsten orten, es sey am corpus oder der cleidung, doch mit wenigstem schaden sie immer können, und bey iren eiden niemandt zu lieb noch zu leidt ersuchen und probieren, was sie nit der allhiesigen prob gemesz befünden, damit vermög irer alten ordnung handeln, was aber straszburger prob haltet, mit einer halben lilien und einem $\mathrm{P}$ zeichnen, damit man sehe, das es strasaburger prob seihe, und der sie verkaufft, auch für soliche werschafft hingeben und lïffern mege.

Goldschmiedeordnung von 1567. Meyer S. I16.

Das $\mathrm{P}$ in dem obigen Stempel ist offenbar die Abkürzung für Probe (probehaltig). Man hat in späterer Zeit entweder diesen Stempel ganz weggelassen oder nur die Lilie aus demselben beibehalten, um die eingeführte Waare zu zeichnen.

Die theoretisch vorgeschriebene Form erleidet natürlich bei der Uebertragung auf den Stempel, bei seiner Abnützung und ferner durch die häufige Undeutlichkeit des Abschlages eine gewisse Veränderung, aus welcher das Modellzeichen etwa in dieser Form hervorgeht:

I 524

Einfuhrstempel, um 1567 .

Vielleicht sehen wir dieses Zeichen in der obigen Gestalt nur durch eine Verstempelung und es ist als identisch mit dem folgenden $\mathrm{zu}$ betrachten: 


\begin{tabular}{|c|c|c|}
\hline $\begin{array}{c}\text { Lf. } \\
\text { Nr. }\end{array}$ & $\begin{array}{c}\text { Beschau. } \\
\text { zeichen }\end{array}$ & $\begin{array}{c}\text { Meister. } \\
\text { zeichen }\end{array}$ \\
\hline
\end{tabular}

Einfuhrstempel, I739.

Einfuhrstempel, nach I739.

Feder goldtschmid sol sin eygen zeichen hahen.

Art. I8. Und uff das man wissen möge, welcher goldtschmidt ein yede arbeit gemacht habe, sol fürtter ein yegklicher goldschmidt, der das hantwerck in der stat Straszburg treyben and bruchen will, ein besonder merckzeichen und uff demselben puntzen synen namen gestochen haben, dasselbig, so offt er sin arbeit will lossen zeichen, mit yme tragen und durch die verordenten beschauwer neben des hantwercks zeichen schlagen lossen. doch soll kein silberarbeit, so vor langem gemacht ist, mit einem nuwen zeichen getzeichent werden, es hab dann den gehalt nach besag diser ordenung, bei der pen 10 lib is, die cin yeder, der solichs verbricht, bessern soll.

Art. I9. Es soll auch ein yeder goldtschmidt von demselbigen synem mergkzeichen uff die stub zur Steltzen ein abtrugk und synen namen dobey gerchriben geben, domit man allwegen wissen mege, was mergkzeichens ein yeder habe.

Art. 20. Und domit rich und arme goldischmid beyeinander pleiben und sich neren mögen, ist verordent, welcher goldtschmidt eim andern arbeit zu machen verdingt und demselben zu solicher arbeit diser ordenungen nach 


\begin{tabular}{|c|c|c|}
\hline $\begin{array}{l}\text { Lf. } \\
\text { Nr. }\end{array}$ & $\begin{array}{l}\text { Beschau- } \\
\text { zeichen }\end{array}$ & Meister - Gegenstand - Besitzer \\
\hline I 528 & & $\begin{array}{l}\text { silber zustelt, soll der goltschmidt, des die arbeit ist, gut } \\
\text { fug und macht haben, syn mergkzeichen, glich als ob die } \\
\text { arbeit in synem husz gemacht were, darauf schlagen ze } \\
\text { lassen. welcher aber dasselbig nit thun wolt, soll dieselbig } \\
\text { arbeit mit des meisters zeichen, der sie gemacht hat, ge- } \\
\text { zeichent werden. was arbeyt aber einer usz synem eigenen } \\
\text { silber fremden oder heimschen umb lon oder fiir sich selbst } \\
\text { in synem husz macht und dieselbig darnach eym goldtschmidt } \\
\text { oder eym andern zu kauffen gibt, der soll sich sins eigenen } \\
\text { und keins andern mergkzeichens oder byschlags neben des } \\
\text { hantwercks zeichen gebruchen by vorgeschribner peen. } \\
\text { Goldschmiedeordnung von }{ }_{1534} \text {, Art. I8 bis } 2 \mathrm{I} \text {. Meyer } \\
\text { S. } 86 \text {. }\end{array}$ \\
\hline I 529 & ? & $\begin{array}{l}\text { Abraham Berner, Meister I } 547 \text {. } \\
\text { Pokal. } \\
\text { Besitzer: Ehemalige Sammlung Demidoff, San Donato } \\
\text { bei Florenz. Gefällige Mittheilung des geistlichen Raths } \\
\text { Hern Dr. Fr. Schneider, Mainz. }\end{array}$ \\
\hline I 530 & \begin{tabular}{ll}
\multicolumn{2}{c}{ wie } \\
$\mathrm{Nr}$. & $\mathrm{I} 46_{2}$ \\
wie & $\mathrm{I} 46_{3}$
\end{tabular} & 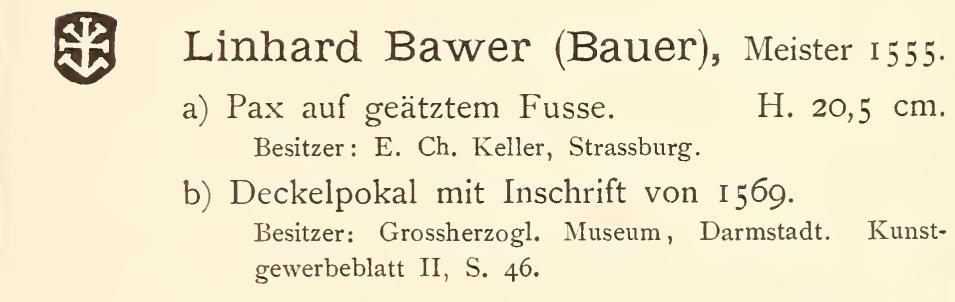 \\
\hline I $53 \mathrm{I}$ & $\begin{array}{c}\text { wie } \\
\text { Nr. } 1463\end{array}$ & $\begin{array}{l}\text { Georg Kobenhaupt, Meister I } 540 \text {. } \\
\text { a) Becher, in Gestalt einer Bacchusfigur, mit } \\
\text { Wappen und Inschrift von I 567. H. } 35,5 \mathrm{~cm} \text {. } \\
\text { Besitzer: Neues Palais, Darmstadt. Luthmer, Gross- } \\
\text { herzogl. Hessische Silberkammer, Taf. 24. }\end{array}$ \\
\hline & wie I464 & 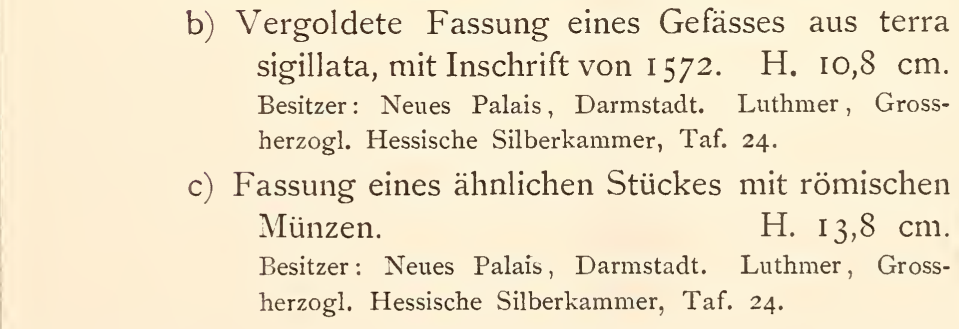 \\
\hline
\end{tabular}




\begin{tabular}{|c|c|c|c|}
\hline $\begin{array}{l}\text { Lf. } \\
\text { Nr. }\end{array}$ & $\begin{array}{l}\text { Beschau- } \\
\text { zeichen }\end{array}$ & $\begin{array}{l}\text { Meister- } \\
\text { zeichen }\end{array}$ & Meister - Gegenstand - Besitzer \\
\hline I 532 & $\begin{array}{c}\text { wie } \\
\text { Nr. I } 464\end{array}$ & & $\begin{array}{l}\text { Paulus Graseck, Meister I } 559 . \\
\text { Theilvergoldeter Pokal. } \\
\begin{array}{l}\text { Besitzer: Schongauer Nuseum, Colmar. } 25,5 \mathrm{~cm} \text {. Ausstellung } \\
\text { Nürnberg 1885, Katalog Nr. } 642 .\end{array}\end{array}$ \\
\hline 1533 & $\begin{array}{c}\text { wie } \\
\text { Nr. I } 46_{5}\end{array}$ & & 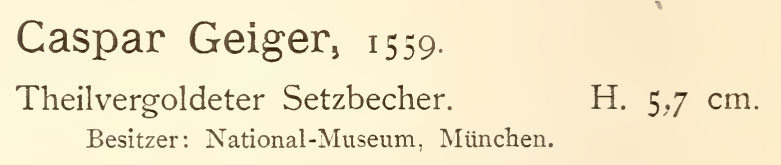 \\
\hline I 534 & $\begin{array}{c}\text { wie } \\
\text { Nr. } 1466\end{array}$ & & $\begin{array}{l}\text { Vergoldeter Pokal mit getriebenen Ornamenten, } \\
\text { Wappen und I60I. } \\
\begin{array}{l}\text { Besitzer: J. Ricard-Abenheimer, Frankfurt a. M. Kunst- } \\
\text { gewerbeblatt II, S. } 63 \text { mit Abbildung. }\end{array}\end{array}$ \\
\hline I 536 & & & $\left\{\begin{array}{l}\text { Reinhard Dietmar, Meister i } 582 \text {. } \\
\text { Das zweite Zeichen Nr. I } 536 \text { entnehme ich der Stempel- } \\
\text { tafel, habe es aber auf einer ausgeführten Arbeit noch } \\
\text { nicht gesehen. }\end{array}\right.$ \\
\hline & $\begin{array}{l}\text { wie } \\
\text { Nr. I467 }\end{array}$ & $\begin{array}{l}\text { wie } \\
\text { Nr. I } 535\end{array}$ & $\begin{array}{l}\text { Kanne und Platte mit Wappen. } \\
\text { Platte, Dm. } 46 \mathrm{~cm} \text {. Kanne, H. } 24 \mathrm{~cm} \text {. } \\
\text { Besitzer: Stadt Emden. Starcke, Emdner Silber, mit } \\
\text { Abbildung. }\end{array}$ \\
\hline I 537 & $\begin{array}{c}\text { wie } \\
\text { Nr. I46弓? }\end{array}$ & & $\begin{array}{l}\text { Hans Diebolt Vogell, Meister 1605. } \\
\text { Silberne Fassung eines Kännchens von Berg- } \\
\text { kristall. Wappen von I617. } \\
\text { Besitzer: J. Sichel, Paris. Ausstellung iFrankfurt a. M. } \\
\text { I875, Katalog Nr. 6o8. Gefällige Mittheilung von Hern } \\
\text { Otto Cornill, Frankfurt a. M. }\end{array}$ \\
\hline I 538 & & & \\
\hline I 540 & & & $\begin{array}{l}\text { Nicolaus Riedinger, Meister I609. } \\
\mathrm{Da} \text { die Marken auf den mir bekannten Stïcken undeut- } \\
\text { lich sind, habe ich vorgezogen, sie nach der Stempel- } \\
\text { tafel widerzugeben. }\end{array}$ \\
\hline I 54 I & & & \\
\hline
\end{tabular}




\begin{tabular}{|c|c|c|c|}
\hline$\underset{\text { Lff. }}{\text { Lf. }}$ & $\begin{array}{l}\text { Beschau. } \\
\text { zeichen }\end{array}$ & $\begin{array}{l}\text { Meister- } \\
\text { zeichen }\end{array}$ & Meister - Gegenstand - Besitzer \\
\hline I $54 \mathrm{I}$ & $\begin{array}{c}\text { wie } \\
\text { Nr. I } 468\end{array}$ & Nr. I 540 ? & $\begin{array}{l}\text { a) Weisssilberne Fassung eines geschnitzten Cocos- } \\
\text { nussbechers. Bezeichnet I6II. H. } 32,3 \mathrm{~cm} \text {. } \\
\text { Besitzer: V. Gontard, Frankfurt a. M. Vergl. Kunst- } \\
\text { gewerbeblatt II, S. } 65 \text { mit Abbildung. }\end{array}$ \\
\hline & wie 1469 & wie I 54 I & $\begin{array}{l}\text { b) Büchschen mit Email. H. 4,6 cm. } \\
\text { Besitzer: Joh. Paul, Hamburg. Auctionskatalog I } 882 \text {, } \\
\text { Nr. 704a. Vergl. Kunstgewerbeblatt II, S. } 66 \text { mit Ab- } \\
\text { bildung. }\end{array}$ \\
\hline I 542 & ? & & $\begin{array}{l}\text { Paul Oelinger, Neister ıбг } 2 \text {. } \\
\text { Montirung eines geschnitzten Büttenträgers. } \\
\text { Besitzer: Grünes Gewölbe, Dresden. Katalog Erbstein } \\
\text { г884, S. 165 Nr. } 4 \text {. }\end{array}$ \\
\hline I 543 & $\begin{array}{l}\text { wie } \\
\text { Nr. I47 I ? }\end{array}$ & & $\begin{array}{l}\text { Hans Jacob Erhart, Meister I } 634 . \\
\text { Vergoldeter konischer Becher mit getriebenen } \\
\text { Blumen. } \\
\begin{array}{l}\text { Besitzer (1883): J. Drey, München. } 9,5 \mathrm{~cm} .\end{array}\end{array}$ \\
\hline I 545 & & & Daniel Harnischter, Meister I65 I. \\
\hline & $\begin{array}{l}\text { wie } \\
\text { Nr. } 1478\end{array}$ & $\begin{array}{l}\text { wie } \\
\text { Nr. I } 545\end{array}$ & $\begin{array}{l}\text { Fassung eines Elfenbeinkruges. } \\
\text { Besitzer: Grünes Gewölbe, Dresden. Katalog Erbstein } \\
\text { I884, S. } 33 \text { Nr. 395. Ausstellung Dresden I875, Taf. 7I. }\end{array}$ \\
\hline I 546 & $\begin{array}{l}\text { wie } \\
\text { Nr. I } 478\end{array}$ & (1) & $\begin{array}{l}\text { Theilvergoldeter Becher mit Treibarbeit. } \\
\text { H. } 20 \mathrm{~cm} \text {. } \\
\text { Besitzer: Schongauer-Museum, Colmar. Ausstellung } \\
\text { Nürnberg i } 885 \text {, Katalog Nr. 64r. }\end{array}$ \\
\hline I 547 & $?$ & & $\begin{array}{l}\text { Cornelius Linck, Meister I656. } \\
\text { Apostellöffel. } \\
\text { Besitzer: S. Fürth, Mainz. }\end{array}$ \\
\hline
\end{tabular}




\begin{tabular}{|c|c|c|c|}
\hline $\begin{array}{l}\text { Lf. } \\
\text { Nr. }\end{array}$ & $\begin{array}{l}\text { Beschau- } \\
\text { zeichen }\end{array}$ & $\begin{array}{l}\text { Meister- } \\
\text { zeichen }\end{array}$ & Meister - Gegenstand - Besitzer \\
\hline I 549 & & & $\left\{\begin{array}{l}\text { Daniel Hammerer, Meister } 1659 . \\
\text { Ausser den beiden Stempeln Nr. } 1548 \text { und } 1549 \text { sind } \\
\text { auf der Stempeltafel bei den Namen dieses Meisters } \\
\text { noch drei angegeben, deren kleinster der beistehende } \\
\text { Nr. } 1550 \text { ist. }\end{array}\right.$ \\
\hline & $\begin{array}{c}\text { wie } \\
\text { Nr. I4866 }\end{array}$ & $\begin{array}{l}\text { wie } \\
\text { Nr. } \quad \text { I } 548\end{array}$ & 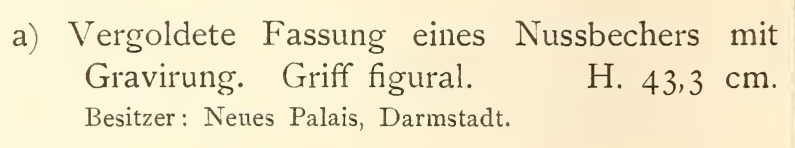 \\
\hline & ? & wie I 549 & $\begin{array}{l}\text { b) Vergoldete Fassung einer Elfenbeinkanne. } \\
\text { Besitzer (1883): J. \& S. Goldschmidt, Frankfurt a. M. }\end{array}$ \\
\hline I $55 \mathrm{I}$ & & & $\left\{\begin{array}{l}\text { Jacob Oberlin, Meister } 166_{5} . \\
\text { Das zweite Zeichen Nr. } 155^{2} \text { entnehme ich der Stempel- } \\
\text { tafel, habe es aber auf einer ausgeführten Arbeit noch } \\
\text { nicht gesehen. }\end{array}\right.$ \\
\hline & $\begin{array}{c}\text { wie } \\
\mathrm{Nr} . \quad 1486\end{array}$ & $\begin{array}{l}\text { wie } \\
\text { Nr. I } 55 \text { I }\end{array}$ & $\begin{array}{l}\text { Weisssilberner konischer Becher, mit Jagdscenen } \\
\text { getrieben. } \\
\text { Hesitzer: } \dagger \text { Haron Carl v. Rothschild, Frankfurt a. M. }\end{array}$ \\
\hline I553 & $\begin{array}{c}\text { wie } \\
\text { Nr. I488 }\end{array}$ & & $\begin{array}{l}\text { Johann Georg Burger, Meister I682. } \\
\text { Vergoldeter konischer Schwitzbecher, mit Deckel } \\
\begin{array}{ll}\text { und Inschrift. } & \text { H. I7,5 cm. } \\
\text { Besitzer: Neues Yalais, Darmstadt. } & \end{array}\end{array}$ \\
\hline I 554 & Nr. I 49 I & & $\begin{array}{l}\text { Johann Ludwig Imlin, Meister I } 689 . \\
\text { Zwei silberne Vasen. } \\
\quad \text { Besitzer: Grossherzogl. Silberkammer, Darmstadt. }\end{array}$ \\
\hline 1555 & $\begin{array}{l}\text { wie } \\
\text { Nr. I49 I }\end{array}$ & & $\begin{array}{l}\text { Johann Christoph Roth, Meister I694. } \\
\text { Weisssilberne gravirte Decken und Beschläge } \\
\text { eines Gebetbuches. } \\
\text { Besitzer: Museum für Kunst und Gewerbe, Hamburg. }\end{array}$ \\
\hline
\end{tabular}




\begin{tabular}{|c|c|c|c|}
\hline $\begin{array}{l}\text { Lf. } \\
\text { Nr. }\end{array}$ & $\begin{array}{l}\text { Beschau- } \\
\text { zeichen }\end{array}$ & $\begin{array}{l}\text { Meister- } \\
\text { zeichen }\end{array}$ & Meister - Gegenstand - Besitzer \\
\hline 1556 & $\begin{array}{l}\text { wie } \\
\mathrm{Nr} . \quad \text { I 49I }\end{array}$ & & $\begin{array}{l}\text { Johan Peter Strehle, Meister I694. } \\
\text { Weisssilberne ovale Schale. } \quad \text { Lg. I } 5 \mathrm{~cm} \text {. } \\
\text { Besitzer (1883): Gebr. Heilbronner, München. }\end{array}$ \\
\hline $\begin{array}{l}\text { I } 558 \\
\text { I } 559\end{array}$ & W & & $\begin{array}{l}\text { Daniel Würtz, Meister I708. } \\
\text { Während die erste dieser Marken Nr. 1557 auf dem } \\
\text { gleich zu beschreibenden Stuicke vorkommt, finde ich } \\
\text { auf der Stempeltafel nur die beiden Zeichen Nr. } 1558 \\
\text { und } 1559 .\end{array}$ \\
\hline & $\begin{array}{c}\text { wie } \\
\text { Nr. I498 }\end{array}$ & $\begin{array}{c}\text { wie } \\
\mathrm{Nr} . \quad \text { I } 557\end{array}$ & $\begin{array}{l}\text { Weibliche Figur aus Barokperlen, mit Steinen } \\
\text { besetzt. Das Gegenstück dazu ist Augs- } \\
\text { burger Arbeit. Vgl. oben S. I05 Nr. } 353 \text { b). } \\
\text { Besitzer: Königl. Schatzkammer, München. Katalog } \\
\text { Schauss 1879, S. } 142 \text { B. } 72 \text {. }\end{array}$ \\
\hline 1560 & $\begin{array}{c}\text { wie } \\
\text { Nr. } \quad \text { I } 503\end{array}$ & STAHL & $\begin{array}{l}\text { Johann Stahl, Meister I7I8. } \\
\text { Mit dem Jahresbuchstaben A von I75I. } \\
\text { Weisssilberner Leuchter. } \\
\begin{array}{l}\text { Besitzer: Kath. Pfarrkirche, Baden-Baden. }\end{array}\end{array}$ \\
\hline I $56 \mathrm{I}$ & $\begin{array}{l}\text { wie } \\
\text { Nr. I495 }\end{array}$ & & $\begin{array}{l}\text { Johann Ludwig Imlin, Meister I } 720 . \\
\text { a) Schüsseln, Platten, Teller u. s. w. } \\
\text { Besitzer: Grossherzogl. Silberkammer, Darmstadt. Ab- } \\
\text { gebildet bei Luthmer, Grossherzogl. Silberkammer. }\end{array}$ \\
\hline 1562 & fehlt & & $\begin{array}{l}\text { b) Mit dem Feingehaltszeichen Nr. I } 5 \text { I I. } \\
\text { Weisssilberne Terrine. } \\
\text { Besitzer: Königl. Silberkammer, München. }\end{array}$ \\
\hline $15 \sigma_{3}$ & $\begin{array}{c}\text { wie } \\
\mathrm{Nr} . \quad \text { I496? }\end{array}$ & & $\begin{array}{l}\text { Ludwig Zentel, Meister I } 732 \text {. } \\
\text { Vergoldeter Kelch, getrieben und gravirt. } \\
\text { H. } 25,5 \mathrm{~cm} \text {. } \\
\text { Besitzer: Pfarrkirche, Neuhausen bei Pforzheim. Aus- } \\
\text { stellung Karlsruhe I88I, Katalog Nr. } 89 .\end{array}$ \\
\hline
\end{tabular}




\begin{tabular}{|c|c|c|c|}
\hline $\begin{array}{l}\text { Lf. } \\
\text { Nr. }\end{array}$ & $\begin{array}{l}\text { Beschau. } \\
\text { zeichen }\end{array}$ & $\begin{array}{l}\text { Meister- } \\
\text { zeichen }\end{array}$ & Meister - Gegenstand - Besitzer \\
\hline I 564 & $\begin{array}{l}\text { wie } \\
\text { Nr. I } 498\end{array}$ & STRAVS & $\begin{array}{l}\text { Johann Ludwig Strauss, Meister I737. } \\
\text { a) Vergoldete Jagdbecher, zu einer Serie von } 36 \\
\text { Stück gehörend. } \\
\text { Besitzer: Grossherzogl. Silberkammer, Darmstadt. }\end{array}$ \\
\hline & wie I 498 & & $\begin{array}{l}\text { b) Kelch mit Patene. H. } 26 \mathrm{~cm} \text {. } \\
\text { Besitzer: Grossherzogl. Silberkammer, Darmstadt. }\end{array}$ \\
\hline 1565 & fehlt & KRUC & $\begin{array}{l}\text { Tobias Ludwig Krug, Meister I738. } \\
\text { Mit dem Feingehaltszeichen I } 3 \text { Nr. I503 und } \\
\text { dem Jahresbuchstaben K Nr. I5I4 von } \\
\text { I } 66 \text { I. } \\
\text { Fassung einer Elfenbeinkanne. } \\
\begin{array}{ll}\text { Besitzer: Königl. Schatzkammer, München. Katalog } \\
\text { Schauss I879, S. 260 F. } 4 .\end{array}\end{array}$ \\
\hline 1567 & & & $\left\{\begin{array}{l}\text { Joh. Friedr. Krug, Meister I } 739 . \\
\text { Von beiden nebenstehenden, auf der Stempeltafel neben } \\
\text { dem Namen des Meisters eingeschlagenen Marken finde } \\
\text { ich nur die erstere Nr. I } 566 \text { auf erhaltenen Arbeiten. }\end{array}\right.$ \\
\hline & fehlt & $\begin{array}{l}\text { wie } \\
\text { Nr. } \quad \text { I } 566\end{array}$ & $\begin{array}{l}\text { a u. b) Mit dem Feingehaltszeichen I I/I } 2 \text { und } \\
\text { dem Jahresbuchstaben B von I } 753 \text {. } \\
\text { Zwei Milchkännchen. } \\
\text { Besitzer: Königl. Silberkammer, Stuttgart. }\end{array}$ \\
\hline & fehlt & wie I 566 & $\begin{array}{l}\text { c) Mit dem Feingehaltszeichen I } 3 \mathrm{Nr} \text {. I404 und } \\
\text { dem Jahresbuchstaben B von I753. } \\
\text { Vergoldeter gravirter Becher mit Deckel. } \\
\text { H. I } 2,5 \mathrm{~cm} \text {. } \\
\text { Besitzer: Professor Seyffer, Stuttgart (I882). }\end{array}$ \\
\hline 1568 & fehlt & & $\begin{array}{l}\text { Joh. Georg Pik, Meister I } 739 . \\
\text { Mit dem Feingehaltszeichen i } 3 \text { Nr. I } 507 \text { und } \\
\text { dem Jahresbuchstaben Y von I774. } \\
\text { Weisssilb. Rauchfass. Mit Kette. H. I Io cm. } \\
\text { Besitzer: Katholische Pfarrkirche, Baden-Baden. }\end{array}$ \\
\hline
\end{tabular}




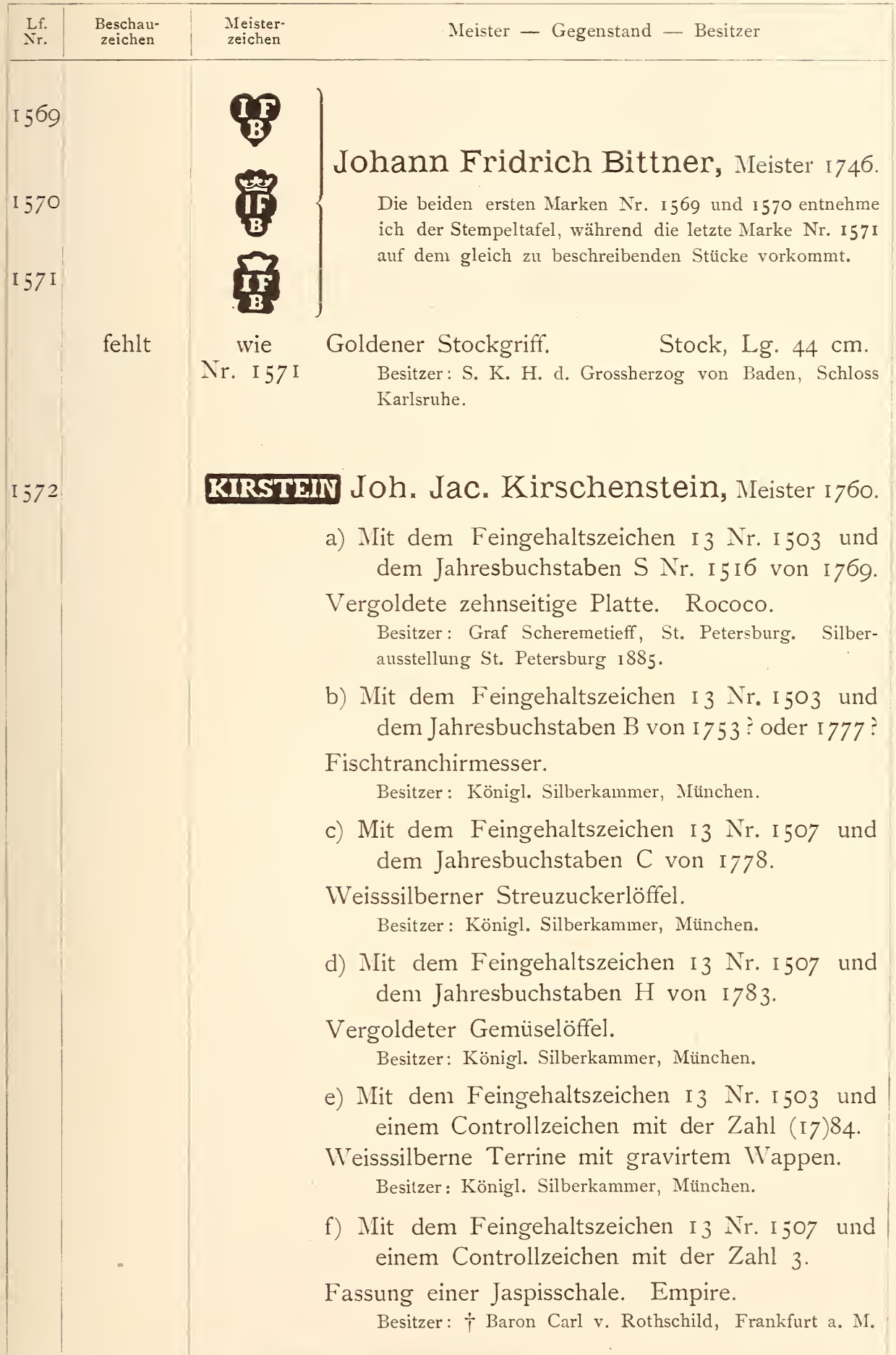




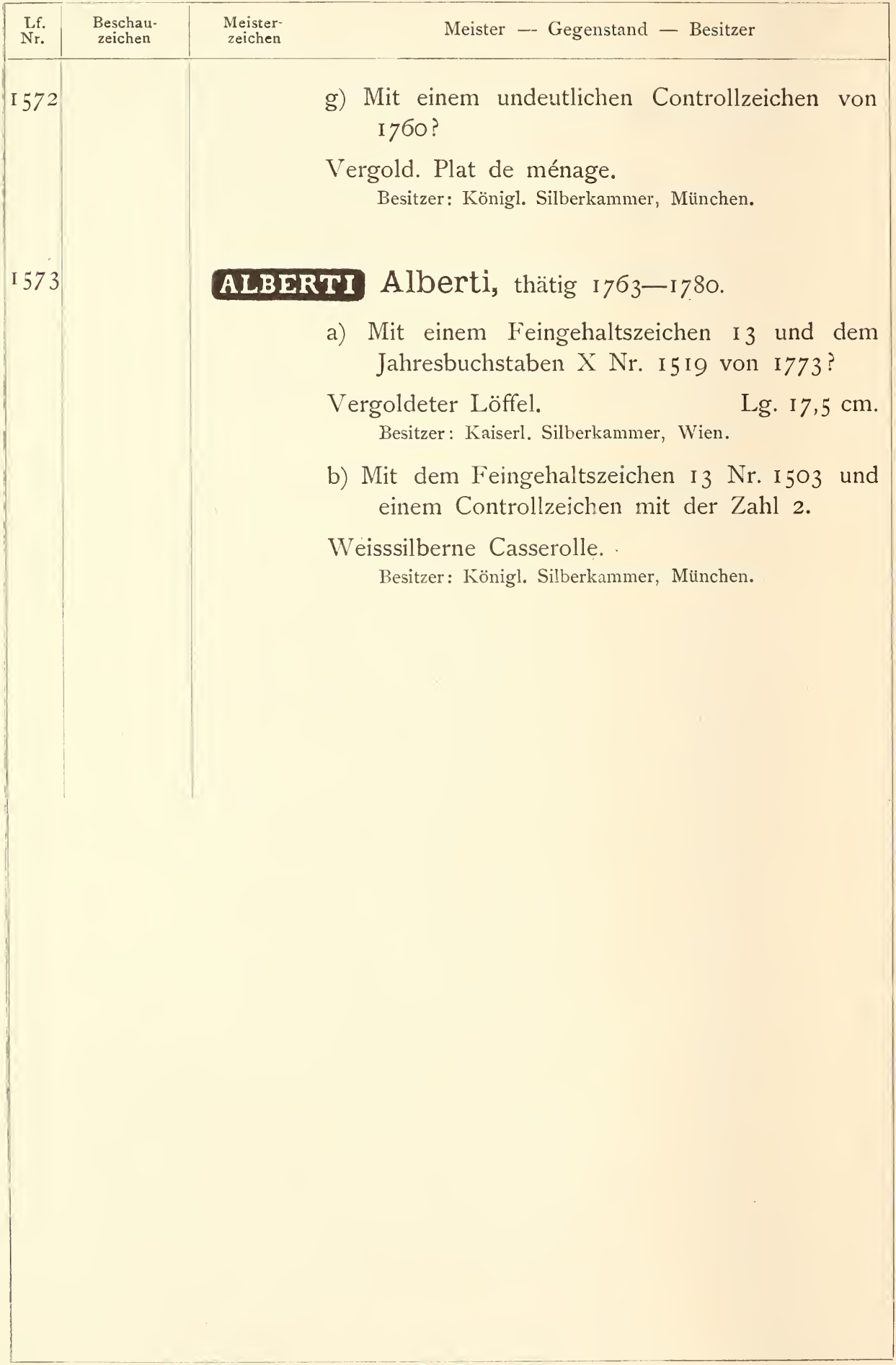




\section{STRAUBING.}

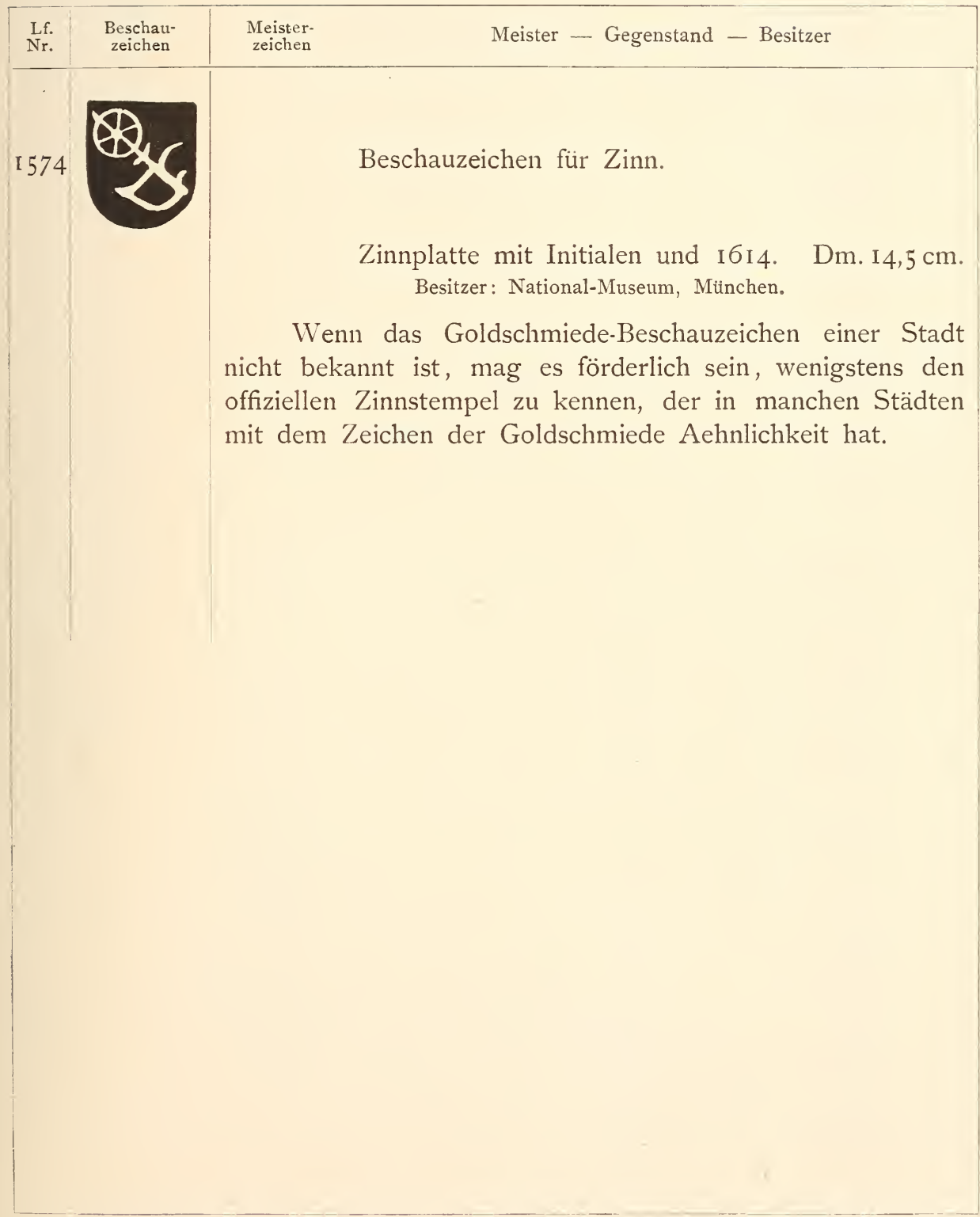




\section{STUTTGART.}

\begin{tabular}{|c|c|c|c|}
\hline Lff. & $\begin{array}{l}\text { Beschau- } \\
\text { zeichen }\end{array}$ & $\begin{array}{l}\text { Meister- } \\
\text { zeichen }\end{array}$ & Meister - Gegenstand - Besitzer \\
\hline 1575 & & & Beschauzeichen, Ende I 6. Jahrhundert. \\
\hline 1576 & & & Beschauzeichen, um I600. \\
\hline I 577 & & & Beschauzeichen, Mitte I7. Jahrhundert. \\
\hline I 578 & & & Beschauzeichen, um I680. \\
\hline I 579 & & & Beschauzeichen, Ende I7. Jahrhundert. \\
\hline I 580 & & & Beschauzeichen, um I 700. \\
\hline $\begin{array}{l}1581 \\
1582\end{array}$ & & & Beschauzeichen, um I700 bis I760. \\
\hline 1583 & & & \\
\hline $\begin{array}{l}1584 \\
1585 \\
1586\end{array}$ & & & Beschauzeichen, I8. bis 19. Jahrhundert. \\
\hline I 587 & & & \\
\hline 1588 & & & \\
\hline
\end{tabular}




\begin{tabular}{|c|c|c|c|}
\hline $\begin{array}{c}\text { Lf. } \\
\text { Nr. }\end{array}$ & $\begin{array}{c}\text { Beschau- } \\
\text { zeichen }\end{array}$ & $\begin{array}{c}\text { Meister- } \\
\text { zeichen }\end{array}$ & Meister - Gegenstand - Besitzer \\
Beschauzeichen, I8. bis I9. Jahrhundert.
\end{tabular}




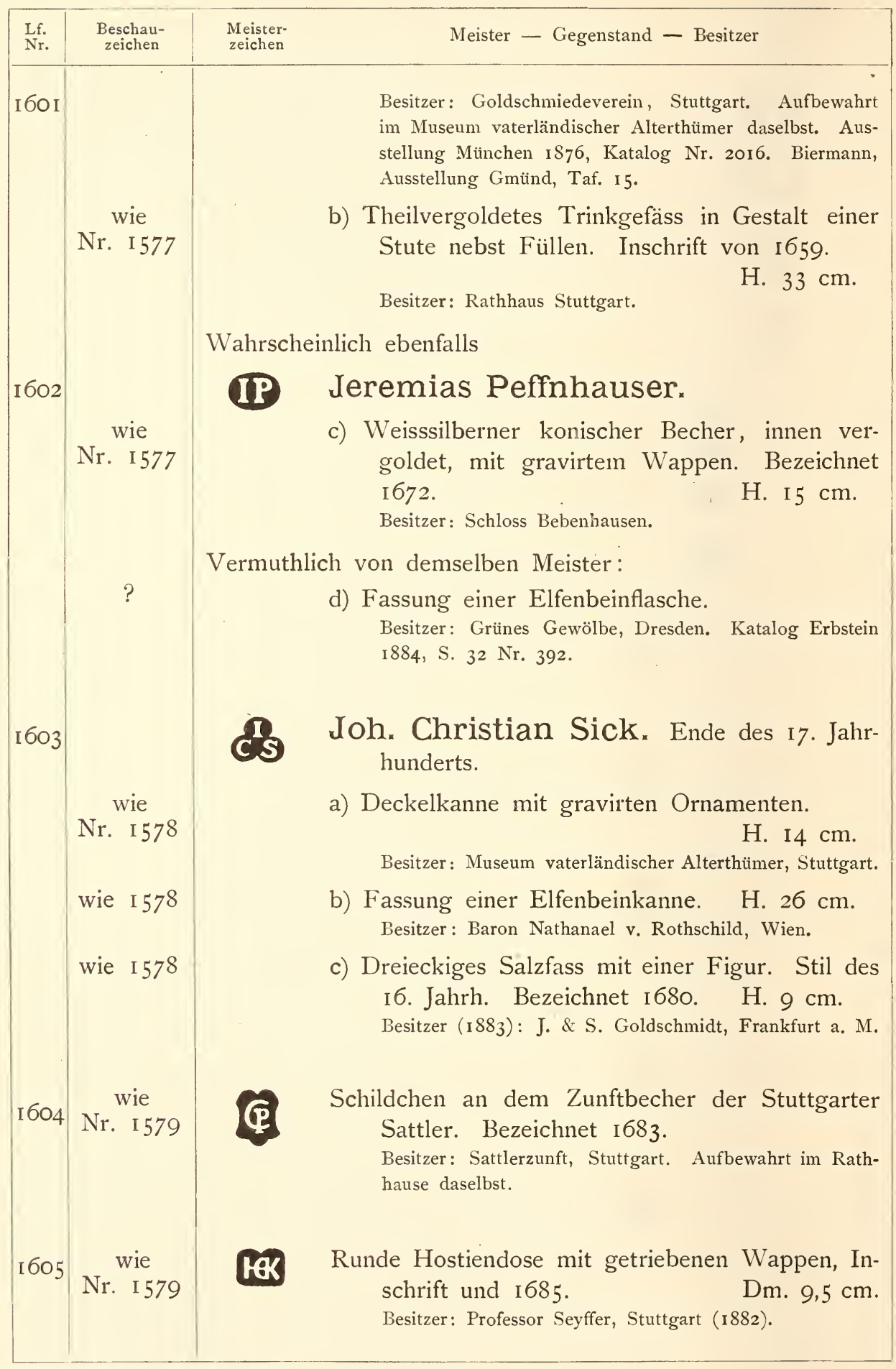




\begin{tabular}{|c|c|c|c|}
\hline $\begin{array}{l}\text { Lf. } \\
\text { Nr. }\end{array}$ & $\begin{array}{l}\text { Beschaul- } \\
\text { zeichen }\end{array}$ & $\begin{array}{l}\text { Meister- } \\
\text { zeichen }\end{array}$ & Meister - Gegenstand - Besitzer \\
\hline 1606 & $\begin{array}{l}\text { wie } \\
\text { Nr. } \quad \text { I } 580\end{array}$ & CW: & $\begin{array}{l}\text { Konischer Becher mit vielen gravirten Wappen und } \\
\text { Inschriften von I697 und I7 IO. H. I } 5 \mathrm{~cm} \text {. } \\
\text { Besitzer: Schloss Bebenhansen. }\end{array}$ \\
\hline 1607 & & JOH & $\begin{array}{l}\text { DAN. BAUER (nicht facsimilirt), † I72 I. } \\
\text { Deckelpokal mit Ciselirarbeit von I699. } \\
\text { H. } 30 \mathrm{~cm} . \\
\text { Besitzer: Goldschmiedeverein, Stuttgart. Aufbewahrt im } \\
\text { Museum vaterländischer Alterthümer, Stuttgart. Meyer, } \\
\text { Künstlerlexikon III, S. I55. }\end{array}$ \\
\hline 1608 & $\begin{array}{c}\text { wie } \\
\mathrm{Nr} . \\
\text { I } 58 \mathrm{I}\end{array}$ & & $\begin{array}{l}\text { a) Weisssilberner konischer Becher mit gravirtem } \\
\text { Wappen, Inschrift und I729. H. I4,5 cm. } \\
\text { Besitzer: Schloss Bebenhausen. }\end{array}$ \\
\hline & wie I 581 ? & & $\begin{array}{l}\text { b) Pokal der Nagelschmiede mit anhängenden } \\
\text { Schildchen von I } 779 \text { bis I } 820 \text {. H. } 26,7 \mathrm{~cm} \text {. } \\
\text { Besitzer: Nagelschmiedezunft, Stuttgart. Aufbewahrt im } \\
\text { Rathhause daselbst. }\end{array}$ \\
\hline 1609 & $\begin{array}{l}\text { wie } \\
\text { Nr. I } 58 \text { I }\end{array}$ & & $\begin{array}{l}\text { Weisssilberne durchbrochene Buchschliesse. } \\
\text { Lg. I I cm. } \\
\text { Besitzer: Museum vaterländischer Alterthümer, Stuttgart. }\end{array}$ \\
\hline I6 IO & $\begin{array}{l}\text { wie } \\
\text { Nr. I } 58 \text { I } \\
\text { mit dem Buch- } \\
\text { staben "K" } \\
\text { wie I } 584\end{array}$ & TP & $\begin{array}{l}\text { a) Vergoldeter Löffel mit gravirten Ornamenten. } \\
\text { Lg. I6,4 cm. } \\
\text { Besitzer: Prof. Seyffer, Stuttgart (I882). } \\
\begin{array}{ll}\text { b) Weisssilbernes Salzfass. } & \text { H. } 3,4 \mathrm{~cm} .\end{array} \\
\begin{array}{l}\text { Besitzer (1882): G. van Aaken, Baden-Baden. }\end{array}\end{array}$ \\
\hline I6 I I & $\begin{array}{c}\text { wie } \\
\text { Nr. I } 582\end{array}$ & ID & 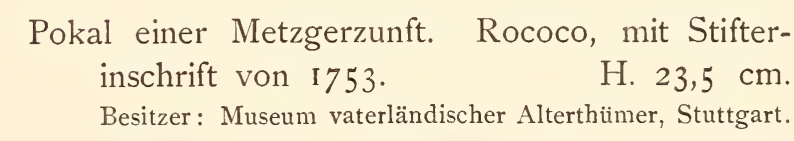 \\
\hline I6 I 2 & $\begin{array}{c}\text { wie } \\
\text { Nr. I } 587\end{array}$ & ES & $\begin{array}{l}\text { Eberhard Sick, I8. Jahrhundert. } \\
\text { a) Vergold. Zunftschildchen mit Verfertigerinschrift } \\
\text { von I } 7 \sigma_{3} \text {, an einem Zunftpokale hängend. } \\
\text { Besitzer: Küferzunft, Stuttgart. Aufbewahrt im Rath- } \\
\text { hause daselbst. }\end{array}$ \\
\hline
\end{tabular}




\begin{tabular}{|c|c|c|c|}
\hline $\begin{array}{l}\text { Lf. } \\
\text { Nr. }\end{array}$ & $\begin{array}{l}\text { Beschau- } \\
\text { zeichen }\end{array}$ & $\begin{array}{l}\text { Meister- } \\
\text { zeichen }\end{array}$ & Meister — Gegenstand - Besitzer \\
\hline І6І 2 & $\begin{array}{l}\text { wie } \\
\text { Nr. I } 579 \\
\text { mit dem Buch- } \\
\text { staben "O" }\end{array}$ & & $\begin{array}{l}\text { b u. c) Zwei ovale Platten mit durchbrochenem } \\
\text { Rande. } \\
\text { Besitzer: Königl. Silberkammer, Stuttgart. }\end{array}$ \\
\hline I6I 3 & $\begin{array}{l}\text { wie } \\
\text { Nr. } \quad \text { I } 586\end{array}$ & $\mathcal{J G v l}$ & $\begin{array}{l}\text { a) Vergoldete Fassung einer Elfenbeinkanne. } \\
\text { H. } 23 \mathrm{~cm} . \\
\text { Besitzer: Baron Nathanael v. Rothschild, Wien. }\end{array}$ \\
\hline & wie I 588 & & $\begin{array}{l}\text { b u. c) Zwei weisssilberne Leuchter. } \\
\text { Besitzer: Königl. Silberkammer, Stuttgart. }\end{array}$ \\
\hline & wie 1588 & & $\begin{array}{l}\text { d) Weisssilberne Theekanne in Empireform mit } \\
\text { Ornatnenten des I6. Jahrhunderts. } \\
\text { Besitzer (1882): M. Reutlinger, Karlsruhe. }\end{array}$ \\
\hline & fehlt & & $\begin{array}{l}\text { e) Mit dem Feingehaltszeichen I } 3 \text { Nr. I } 595 . \\
\text { Kaffelöffel. I9. Jahrhundert. } \\
\text { Besitzer: Ferd. Heckel, Neustadt a. d. Haardt. }\end{array}$ \\
\hline
\end{tabular}




\section{TORGAU.}

\begin{tabular}{|c|c|c|c|}
\hline Lf. & $\begin{array}{l}\text { Beschau- } \\
\text { zeichen }\end{array}$ & $\begin{array}{l}\text { Meister- } \\
\text { zeichen }\end{array}$ & Meister - Gegenstand - Besitzer \\
\hline 1615 & & & Beschauzeichen, I6. bis I7. Jahrhundert. \\
\hline І6І 7 & $\begin{array}{c}\text { wie } \\
\text { Nr. I6I4 } 4\end{array}$ & & $\begin{array}{l}\text { a) Vergoldeter und kalt emaillirter Pokal, Stiftung } \\
\text { von I } 559 . \\
\text { Besitzer: Stadt Torgau. Gefällige Mittheilung des Herrn } \\
\text { Senator Knibbe in Torgau. }\end{array}$ \\
\hline & & & $\begin{array}{l}\text { b) Trinkgefäss in Gestalt eines Falken. } \\
\text { Besitzer: Kunstgewerbe-Museum, Berlin. Abgebildet im } \\
\text { Kunstgewerbeblatt } \mathrm{I} 889 \text {, S. } 56 \text {. }\end{array}$ \\
\hline 1618 & & $\underset{\text { Skizzeo }}{\stackrel{\text { EB }}{*}}$ & $\begin{array}{l}\text { Dieses Zeichen entnehme ich dem Kataloge des } \\
\text { Grünen Gewölbes von Erbstein, nach dessen } \\
\text { Angaben es an folgenden zwei Stücken vor- } \\
\text { kommt: }\end{array}$ \\
\hline \multirow{4}{*}{1619} & ? & \multirow{4}{*}{ 乘 } & $\begin{array}{l}\text { a) Kästchen mit Perlmutter belegt. } \\
\text { Besitzer: Grünes Gewölbe, Dresden. Katalog Erbstein } \\
\text { 1 } 884, \text { S. } 52 \text { Nr. } 173 \text {. }\end{array}$ \\
\hline & ? & & $\begin{array}{l}\text { b) Kästchen mit Perlmutterschuppen, getragen } \\
\text { von vier Schnecken. } \\
\text { Besitzer: Grünes Gewölbe, Dresden. Katalog Erbstein } \\
\text { 1884, S. } 5^{2} \text { Nr. 176. Vergl. Gurlitt im Kunstgewerbe- } \\
\text { blatt II, S. 19. }\end{array}$ \\
\hline & $\begin{array}{c}\text { wie } \\
\mathrm{Nr} . \quad \text { I6I } 4\end{array}$ & & $\begin{array}{l}\text { a u. b) Zwei Schiffe, Perlmutter mit vergoldeter } \\
\text { Montirung. } \\
\text { Besitzer: Grünes Gewölbe, Dresden. Katalog Erbstein } \\
\text { I } 884 \text {, S. } 58 \text { Nr. 19I und 194. }\end{array}$ \\
\hline & wie I6I4 & & 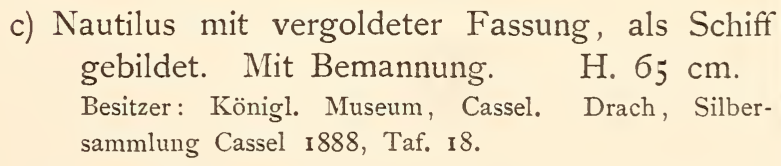 \\
\hline
\end{tabular}




\begin{tabular}{|c|c|c|c|}
\hline $\begin{array}{l}\text { Lff. } \\
\mathrm{N}_{\mathrm{r}}\end{array}$ & $\begin{array}{l}\text { Beschau- } \\
\text { zeichen }\end{array}$ & $\begin{array}{l}\text { Meister- } \\
\text { zeichen }\end{array}$ & Meister - Gegenstand - Besitzer \\
\hline I619 & $\begin{array}{l}\text { wie } \\
\text { Nr. I6 I } 5\end{array}$ & & $\begin{array}{l}\text { d) Nautilus, als Schiff gebildet, mit Bemannung. } \\
\text { H. 59,5 cm. } \\
\text { Besitzer: Herzogl. Museum, Gotha. Katalog Bube i } 869 \text {, } \\
\text { Nr. I3. }\end{array}$ \\
\hline 1620 & $\begin{array}{l}\text { wie } \\
\text { Nr. I6I4 }\end{array}$ & & $\begin{array}{l}\text { Vergoldeter kelchförmiger Becher, getrieben mit } \\
\text { Putten. } \\
\text { Hesitzer: Graf Stephan Szápáry. Ausstellung Budapest } \\
\text { 1884, 4. Saal, I. Schrank, Nr. 22. Katalog S. } 6 \text {. }\end{array}$ \\
\hline $\mathrm{I} 62 \mathrm{I}$ & $?$ & $\underset{\text { IKizzou: }}{\text { IHS }}$ & $\begin{array}{l}\text { Zwei Hostienteller und zwei getriebene Altar- } \\
\text { leuchter. } \\
\text { Besitzer: Stadtkirche, Torgaul. Gefällige Mittheilung des } \\
\text { Herrn Senator Knibbe in Torgau. }\end{array}$ \\
\hline I 622 & $\begin{array}{l}\text { wie } \\
\text { Nr. I6I } 4\end{array}$ & $E B$ & $\begin{array}{l}\text { Theilvergold. Deckelkanne, gravirt. H. I } 3,5 \mathrm{~cm} \text {. } \\
\text { Besitzer: H. Boskowitz, Wien. }\end{array}$ \\
\hline 1623 & & $A K$ & $\begin{array}{l}\text { Andr. Klette, um i } 600 . \\
\text { Angabe von Erbstein im Katalog des Grünen Gewölbes } \\
\text { I } 884, \text { S. } 47 .\end{array}$ \\
\hline & $\begin{array}{l}\text { wie } \\
\text { Nr. I6 I4 }\end{array}$ & & $\begin{array}{l}\text { Straussenei, als Pelikan montirt. } \\
\text { Besitzer: Grünes Gewölbe, Dresden. Katalog Erbstein } \\
\text { 1884, S. } 47 \text { Nr. 106. }\end{array}$ \\
\hline 1624 & $\begin{array}{l}\text { wie } \\
\text { Nr. I6 } 64\end{array}$ & 2 & $\begin{array}{r}\text { Trinkgefäss in Gestalt einer sitzenden Frau in } \\
\text { modischer Tracht. Auf dem Kopfe Korallen. } \\
\text { H. } 33 \mathrm{~cm} \text {. } \\
\text { Besitzer: Grünes Gewölbe, Dresden. Katalog Erbstein } \\
\text { 1884, S. } 85 \text { Nr. 116. Daselbst ist auch eine männliche } \\
\text { Figur als Gegenstück zu obigem Stücke angeführt. }\end{array}$ \\
\hline 1625 & $\begin{array}{l}\text { wie } \\
\text { Nr. I6I } 5\end{array}$ & EE & $\begin{array}{l}\text { Fussloser Becher mit Gravirung, Landschaft. } \\
\text { H. I9,5 cm. } \\
\text { Besitzer: Stadt Fulda. Ausstellung Cassel I } 884 \text {, Kata- } \\
\log \text { Nr. } 86 .\end{array}$ \\
\hline 1626 & $\begin{array}{l}\text { wie } \\
\text { Nr. I6I } 5\end{array}$ & CH & $\begin{array}{l}\text { Theilvergoldete schlanke Kanne mit Gravirung. } \\
\text { H. 3I,5 cm. } \\
\text { Besitzer: } † \text { Baron Carl v. Rothschild, Frankfurt a. M. }\end{array}$ \\
\hline
\end{tabular}




\begin{tabular}{|c|c|c|c|}
\hline $\begin{array}{l}\text { Lf. } \\
\text { Nr. }\end{array}$ & $\begin{array}{l}\text { Beschau- } \\
\text { zeichen }\end{array}$ & $\begin{array}{l}\text { Meister- } \\
\text { zeichen }\end{array}$ & Meister - Gegenstand - Besitzer \\
\hline 1627 & $\begin{array}{c}\text { wie } \\
\text { Nr. I6I5 }\end{array}$ & CL & $\begin{array}{l}\text { Vergoldeter Pokal, reich mit Ornamenten und } \\
\text { ineinander laufenden Buckeln getrieben. } \\
\text { H. } 62 \mathrm{~cm} \text {. } \\
\text { Besitzer: † Baron Carl v. Rothschild, Frankfurt a. II. }\end{array}$ \\
\hline 1628 & $\begin{array}{c}\text { wie } \\
\text { Nr. I6I6 }\end{array}$ & [F] & $\begin{array}{l}\text { Theilvergoldete cylindrische Deckelkanne, gravirt } \\
\text { mit Inschrift und I } 72 \mathrm{I} . \\
\text { Besitzer: S. D. Fürst Paskewitsch, St. Petersburg. }\end{array}$ \\
\hline 1629 & $\begin{array}{c}\text { wie } \\
\text { Nr. I6I6 }\end{array}$ & $\stackrel{C}{\mathbf{I B}}$ & $\begin{array}{r}\text { Kleine vergoldete Kanne. Im Deckel Medaille } \\
\text { von I624. Am Corpus moderne Treibarbeit. } \\
\text { H. I } 3 \mathrm{~cm} . \\
\text { Besitzer: Joseph Csoma. Ausstellung Budapest I } 884 .\end{array}$ \\
\hline
\end{tabular}

\section{TÜBINGEN.}

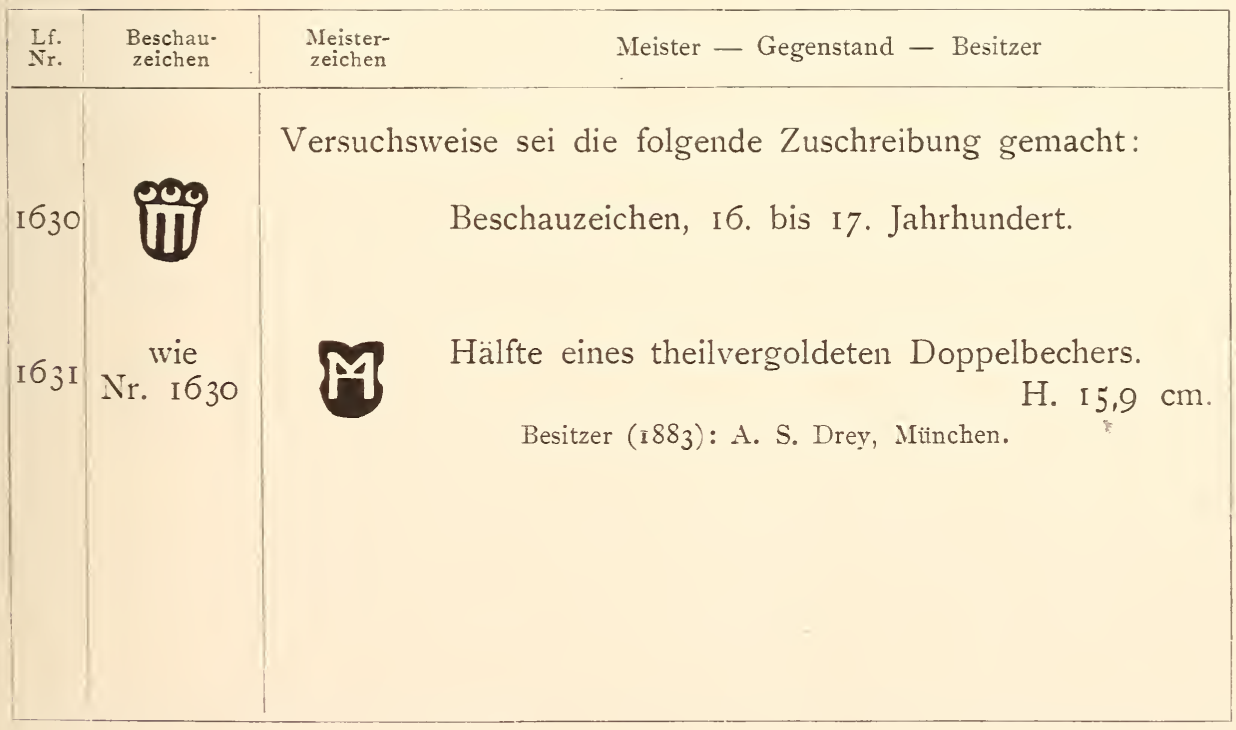




\section{TUTTLINGEN.}

Chaffers, Hall Marks S. 220-225 führt das unten verzeichnete Stück mit den beigesetzten drei Marken als Württemberg an. Ich glaube, man könnte es speziell für Tuttlingen in Anspruch nehmen.

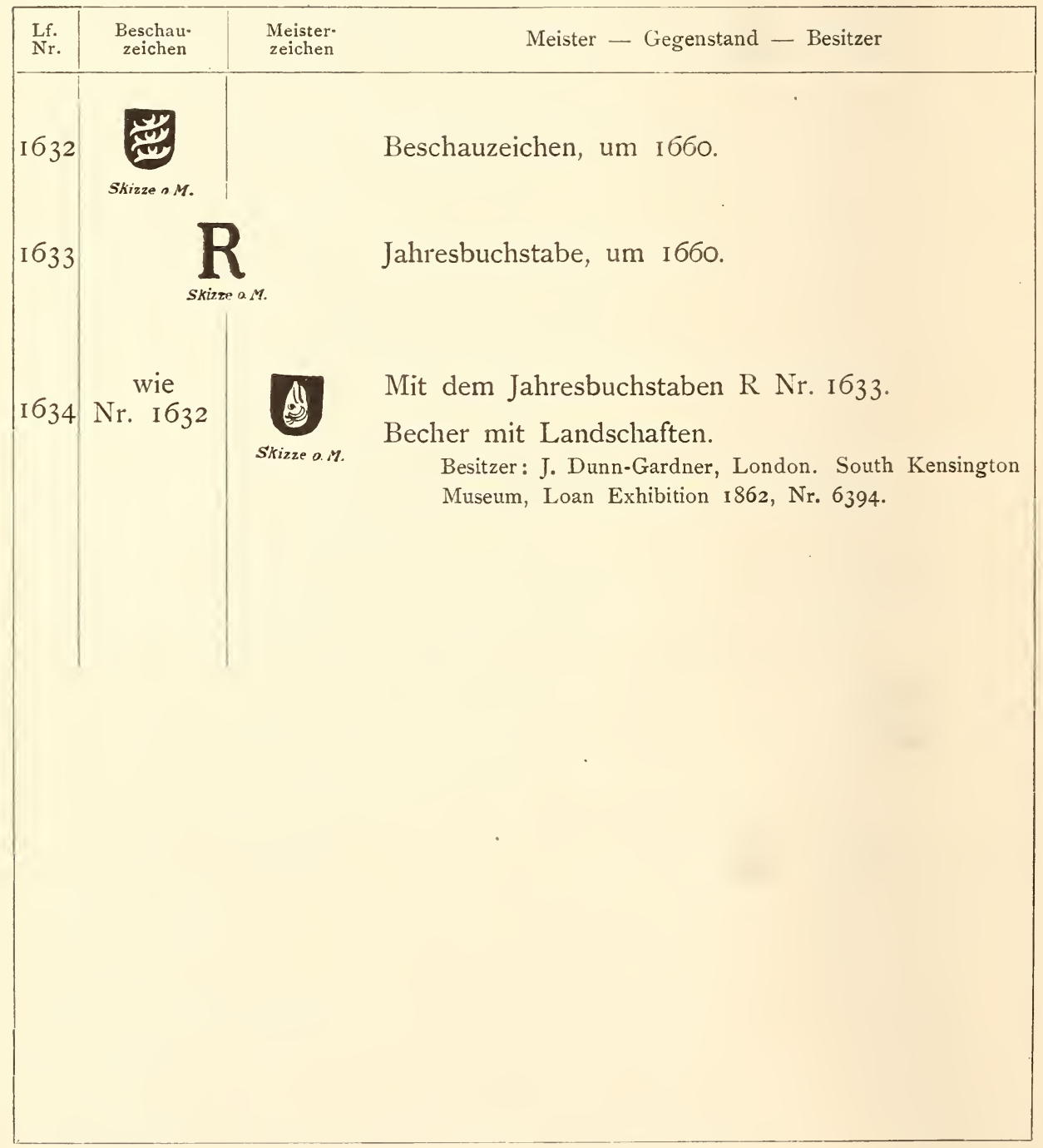




\section{UEBERLINGEN.}

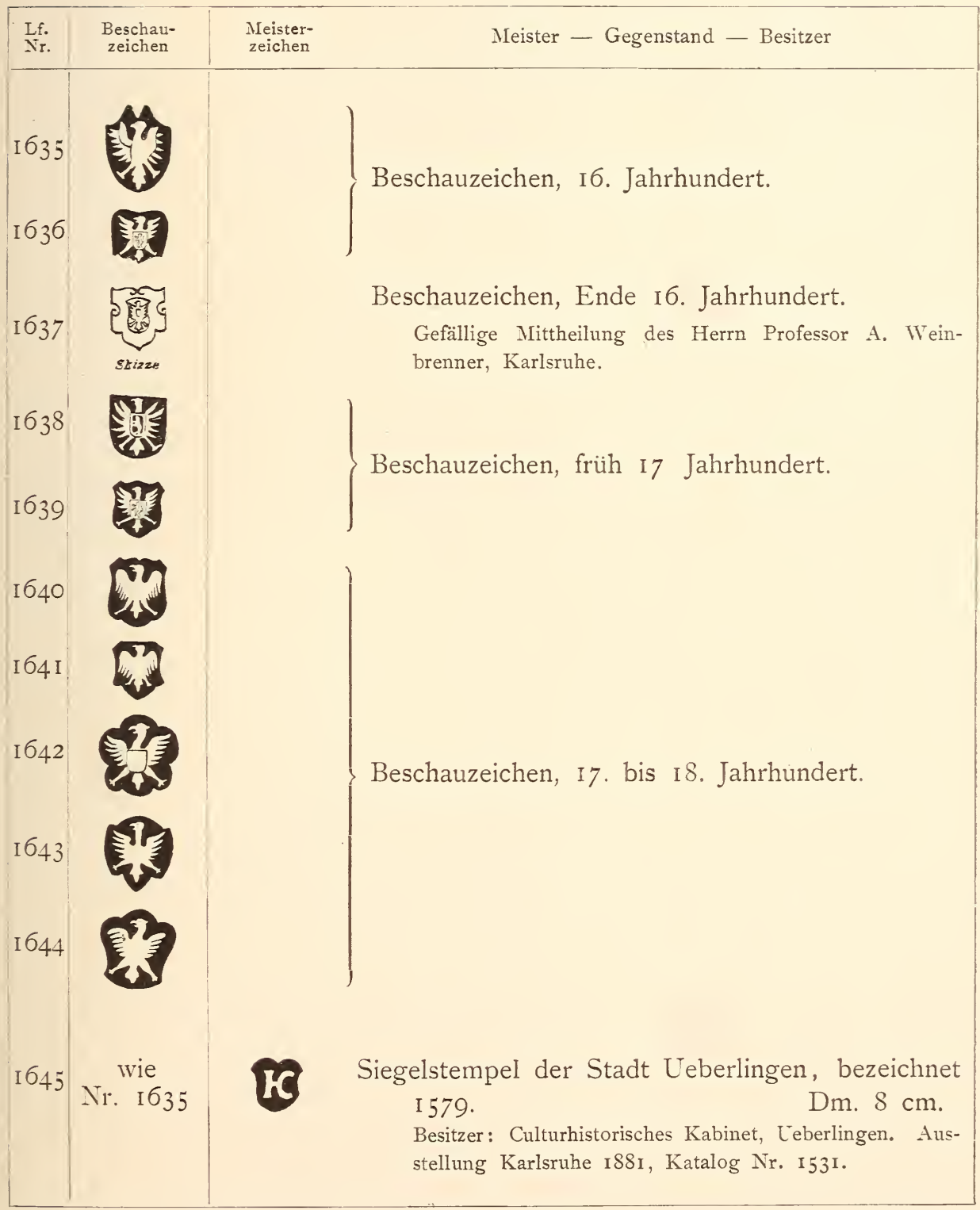




\begin{tabular}{|c|c|c|c|}
\hline $\begin{array}{l}\text { Lf. } \\
\text { Nr. }\end{array}$ & $\begin{array}{l}\text { Beschau- } \\
\text { zeichen }\end{array}$ & $\begin{array}{l}\text { Meister- } \\
\text { zeichen }\end{array}$ & Meister - Gegenstand - Besitzer \\
\hline I 646 & $\begin{array}{c}\text { wie } \\
\text { Nr. I636 }\end{array}$ & & 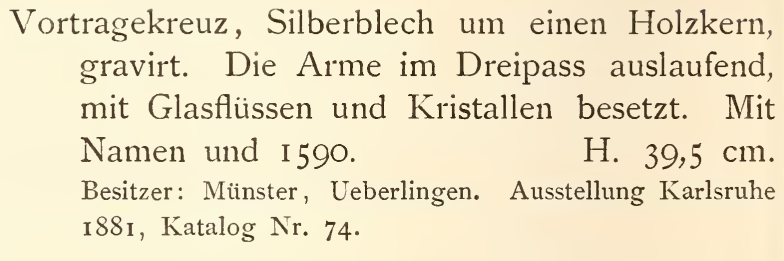 \\
\hline 1647 & $\begin{array}{c}\text { wie } \\
\text { Nr. } 1637\end{array}$ & & $\begin{array}{l}\text { Vortragekreuz von Silberplatten um einen Holz- } \\
\text { kern in Lilienarme auslaufend; an denselben } \\
\text { Wappen. Vielleicht I 594. H. } 52 \mathrm{~cm} \text {. } \\
\text { Besitzer: Kirche in Niederzell, Reichenau. Gefälige } \\
\text { Mittheilung des Herrn Prof. A. Weinbrenner, Karlsruhe. }\end{array}$ \\
\hline I 648 & $\begin{array}{c}\text { wie } \\
\text { Nr. }{ }^{1638}\end{array}$ & $\begin{array}{l}\text { Schild dorm } \\
\text { unsicher }\end{array}$ & $\begin{array}{l}\text { a) Getriebene Halbfigur. St. Sebastian von Pfeilen } \\
\text { getroffen darstellend. Am Postamente In- } \\
\text { schrift von 16I5. H. } 85 \mathrm{~cm} \text {. } \\
\text { Besitzer: Münster, Ueberlingen. Ausstellung Karlsruhe } \\
\text { 188I, Katalog Nr. 1312. Abgebildet in Aeltere Kunst- } \\
\text { gewerbliche Arbeiten auf der Ausstellung Karlsruhe. }\end{array}$ \\
\hline & wie 1638 & & $\begin{array}{l}\text { b) Gruppe aus getriebenen Halbfiguren bestehend; } \\
\text { Anna selbdritt. Am Postamente Wappen } \\
\text { und Inschrift. } \\
\text { Besitzer: Münster, Ueberlingen. Ausstellung Karlsruhe } \\
\text { I88:, Katalog Nr. I3II. }\end{array}$ \\
\hline & wie $1 \sigma_{3} 8$ & & $\begin{array}{l}\text { c) Vergoldetes Weihrauchschiff mit Wappen. } \\
\text { H. } 20 \mathrm{~cm} . \\
\text { Besitzer: Münster, Ueberlingen. Ausstellung Karlsruhe } \\
\text { 1881, Katalog Nr. 1527. }\end{array}$ \\
\hline & wie 1639 & & $\begin{array}{l}\text { d) Theilvergoldetes Messgeräth, Platte und zwei } \\
\text { Kännchen, mit Wappen und I6I I. } \\
\text { Platte, Lg. } 36 \mathrm{~cm} \text {. Kännchen, H. I } 4 \mathrm{~cm} \text {. } \\
\text { Besitzer: Münster, Ueberlingen. Ausstellung Karlsruhe } \\
\text { I88I, Katalog Nr. ıo8. }\end{array}$ \\
\hline 1649 & $\begin{array}{l}\text { wie } \\
\text { Nr. } 1640\end{array}$ & 15 & $\begin{array}{l}\text { a u. b) Zwei sich ähnliche vergoldete Kelche. I7. } \\
\begin{array}{ll}\text { bis I } 8 \text {. Jahrhundert. } & \text { H. } 25 \mathrm{~cm} . \\
\text { Besitzer: Münster, Ueberlingen. } & \end{array}\end{array}$ \\
\hline & wie I64I & & $\begin{array}{l}\text { c) Kelch mit farbigen Steinen besetzt. Rococo. } \\
\text { Besitzer: Münster, Ueberlingen. } \\
\text { H. } 25,4 \mathrm{~cm} \text {. }\end{array}$ \\
\hline
\end{tabular}


a) Silbervergoldeter Kelch mit sechs Emailmedaillons, darunter eines mit Wappen.

H. $27,5 \mathrm{~cm}$.

Besitzer: Münster, Ueberlingen. Ausstellung Karlsruhe I881, Katalog Nr. I Io.

b u. c) Zwei silberne Messkännchen, getrieben mit Blumen u. Fruchtornamenten. H. $16,2 \mathrm{~cm}$. Besitzer: Münster, Ueberlingen.

d) Vergoldeter Kelch mit je drei ovalen Medaillons an Fuss und Knauf. Mit Stifterinschrift von I7I 3 oder I 723 . H. $27,5 \mathrm{~cm}$. Besitzer: Münster, Ueberlingen. 


\section{UELZEN.}

\begin{tabular}{|c|c|cc|}
\hline $\begin{array}{c}\text { Lf. } \\
\text { Nr. }\end{array}$ & $\begin{array}{c}\text { Beschau- } \\
\text { zeichen }\end{array}$ & $\begin{array}{c}\text { Meister- } \\
\text { zeichen }\end{array}$ & Meister - Gegenstand - Besitzer \\
\hline 1652 & Löwe & $\begin{array}{c}\text { Stempelt um I 569 betrügerischer Weise mit dem } \\
\text { Lüneburger Stadtwappen, dem Löwen. Siehe } \\
\end{array}$ & Lüneburg S. 2 I I.. \\
\hline
\end{tabular}

\section{ULM.}

\begin{tabular}{|c|c|c|c|}
\hline $\begin{array}{l}\text { Lf. } \\
\mathrm{N}_{\mathrm{r}}\end{array}$ & $\begin{array}{l}\text { Beschau- } \\
\text { zeichen }\end{array}$ & $\begin{array}{l}\text { Meister- } \\
\text { zeichen }\end{array}$ & Meister - Gegenstand - Besitzer \\
\hline I653 & & - & Beschauzeichen, I6. Jahrhundert. \\
\hline I 655 & & & Beschauzeichen, I6. bis I7. Jahrhundert. \\
\hline 658 & 5 & & Beschauzeichen, I7. Jahrhundert. \\
\hline & $\infty$ & & \\
\hline
\end{tabular}




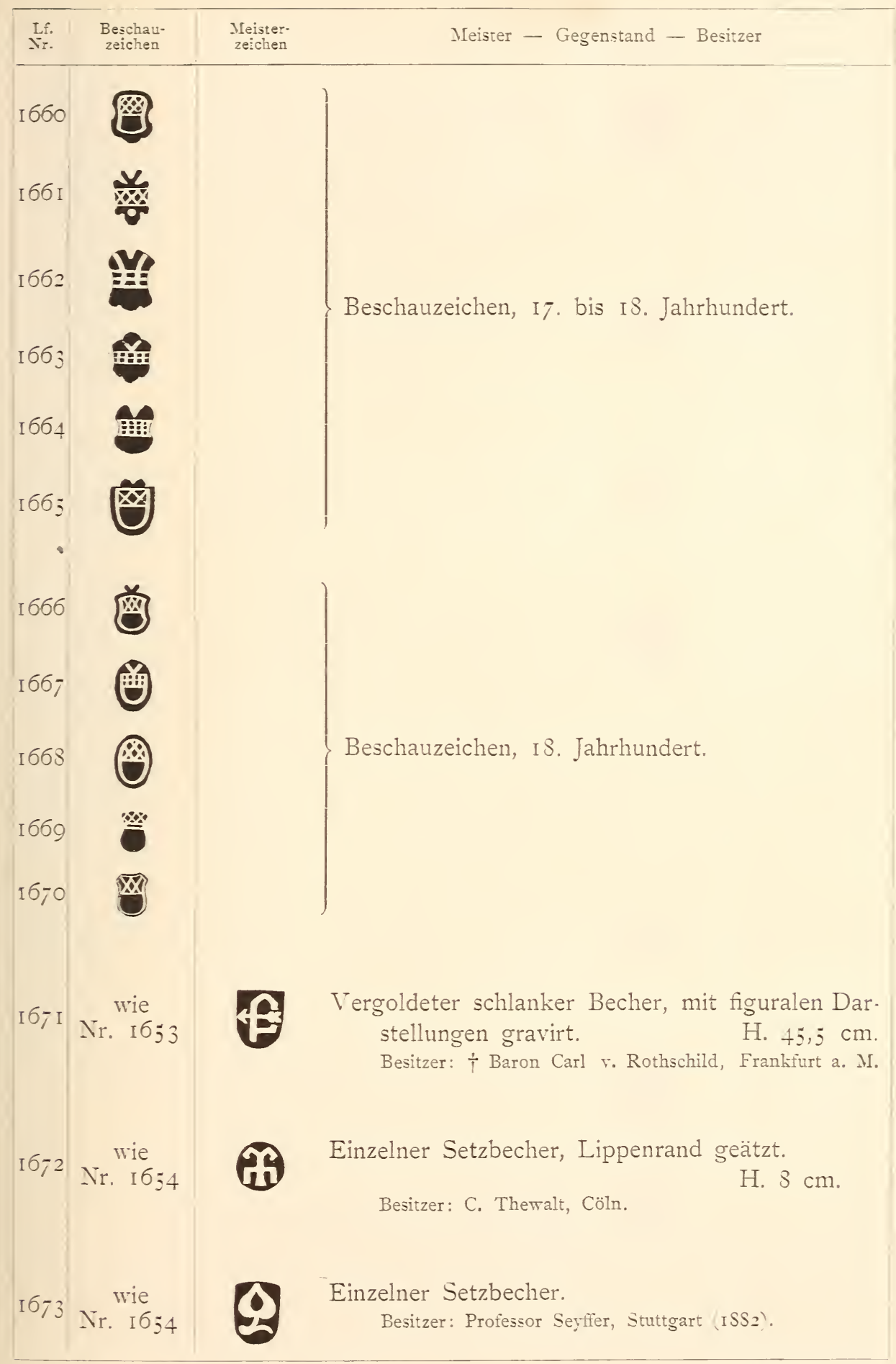




\begin{tabular}{|c|c|c|c|}
\hline $\begin{array}{l}\text { Lf. } \\
\text { Nr. }\end{array}$ & $\begin{array}{l}\text { Beschau- } \\
\text { zeichen }\end{array}$ & $\begin{array}{l}\text { Meister- } \\
\text { zeichen }\end{array}$ & Meister - Gegenstand - Besitzer \\
\hline 1674 & $\begin{array}{c}\text { wie } \\
\text { Nr. I654 }\end{array}$ & & $\begin{array}{l}\text { Complete Serie von I2 Setzbechern. Am Rande } \\
\text { oben figurale Friescompositionen. } \\
\text { H. einzeln, 9, I cm. Zusammen, H. } 45 \mathrm{~cm} \text {. } \\
\text { Besitzer: Reiche Kapelle, München. Stockbauer, Reiche } \\
\text { Kapelle, Taf. 24. }\end{array}$ \\
\hline 1675 & $\begin{array}{c}\text { wie } \\
\text { Nr. } \quad \text { I654 }\end{array}$ & & $\begin{array}{l}\text { Theilvergoldetes Trinkgefäss in Gestalt einer Eule. } \\
\text { Mit Inschrift und Wappen. H. } 29,5 \mathrm{~cm} \text {. } \\
\text { Besitzer: National-Museum, Budapest. Ausstellung } \\
\text { Budapest i } 884 \text {. }\end{array}$ \\
\hline 1676 & $\begin{array}{c}\text { wie } \\
\text { Nr. }{ }^{1} 6_{54}\end{array}$ & & $\begin{array}{l}\text { Hälfte eines Doppelbechers mit halbkugelförmiger } \\
\text { Cuppa. Ornamentik flach eingeschlagen. } \\
\text { Besitzer (1883): A. S. Drey, München. }\end{array}$ \\
\hline 1677 & $\begin{array}{c}\text { wie } \\
\text { Nr. I654 }\end{array}$ & & $\begin{array}{l}\text { a) Vergoldeter Doppelbecher, Cuppa halbkugel- } \\
\text { förmig, mit Ornamenten getrieben. } \\
\text { H. } 27 \mathrm{~cm} \text {. } \\
\text { Besitzer: S. Fürth, Mainz. Edelmetallarbeiten der } \\
\text { Sammlung Fürth I886, Nr. 2. }\end{array}$ \\
\hline & wie 1654 & & $\begin{array}{l}\text { b) Schiff auf Rädern. Am Rumpfe Seethiere ge- } \\
\text { trieben. } \\
\text { Hesitzer: J. \& H. Jeidels, Frankfurt a. M. }\end{array}$ \\
\hline 1678 & $\begin{array}{c}\text { wie } \\
\text { Nr. } 1654\end{array}$ & & $\begin{array}{l}\text { Beschläge an einem in Holz geschnitzten Reb- } \\
\text { büttenmanne. } \\
\text { Besitzer (1884): H. Ratzersdorfer, Wien. } 22,8 \mathrm{~cm} \text {. }\end{array}$ \\
\hline I679 & $\begin{array}{c}\text { wie } \\
\mathrm{Nr} . \quad \text { I654? }\end{array}$ & & $\begin{array}{l}\text { Deckelkanne, mit figuralen Scenen getrieben. } \\
\text { Besitzer: Baron Alfred v. Rothschild, London. }\end{array}$ \\
\hline I680 & $\begin{array}{c}\text { wie } \\
\text { Nr. I654 }\end{array}$ & & $\begin{array}{l}\text { Vielleicht } \\
\text { Mathäus Hof herr, geb. I 524, † 1600. } \\
\text { Vergoldeter Becher mit cylindrischer Cuppa, auf } \\
\text { hohem Fusse. } \\
\begin{array}{l}\text { Besitzer (1883): J. J. Boasberg, Amsterdam. } 29 \mathrm{~cm} .\end{array}\end{array}$ \\
\hline
\end{tabular}




\begin{tabular}{|c|c|c|c|}
\hline $\begin{array}{l}\text { Lf. } \\
\text { Nr. }\end{array}$ & $\begin{array}{l}\text { eschau- } \\
\text { eichen }\end{array}$ & $\begin{array}{l}\text { Meister- } \\
\text { zeichen }\end{array}$ & Meister - Gegenstand - Besitzer \\
\hline $168 \mathrm{I}$ & $\begin{array}{c}\text { wie } \\
\text { Nr. }{ }^{2} 6_{54}\end{array}$ & & $\begin{array}{l}\text { Vergoldeter Becher. Die Cuppa nach oben sich } \\
\text { ausbiegend. Auf dem Deckel Greif mit } \\
\text { Wappen. } \\
\text { Hesitzer: Gemeinde, Rappersweil. Ausstellung Zürich } \\
\text { 1883, Katalog Nr. 38 S. 228. }\end{array}$ \\
\hline I682 & $\begin{array}{c}\text { wie } \\
\text { Nr. }{ }^{2} 6_{53}\end{array}$ & & $\begin{array}{l}\text { Vergoldeter Buckelbecher auf Kugelfüssen. } \\
\text { H. } 9 \mathrm{~cm} . \\
\text { Besitzer: Germanisches National-Museum, Nürnberg. }\end{array}$ \\
\hline 1683 & $\begin{array}{c}\text { wie } \\
\text { Nr. }{ }^{1654}\end{array}$ & & $\begin{array}{l}\text { Vergoldeter Pokal mit wenig ausgeschweifter } \\
\text { Cuppa, auf hohem Fusse. Stifterinschrift } \\
\text { von I607. } \\
\text { Besitzer: Gewerbe-Museum, Ulm. Ausstellung Augsburg } \\
\text { 1886, Katalog Nr. 1486. Meisterwerke Schwäb. Kunst } \\
\text { Taf. I3. }\end{array}$ \\
\hline & & $\begin{array}{l}\text { Hie } \\
\text { scheinlich } \\
\text { wie die } \\
\text { nicht aus }\end{array}$ & $\begin{array}{l}\text { seien drei Stücke angeschlossen, die höchst wahr- } \\
\text { Ulmer Arbeit sind, und in dieselbe Zeit gehören } \\
\text { orhergehenden. Ueber die Marken bin ich leider } \\
\text { eigener Anschauung unterrichtet. }\end{array}$ \\
\hline I 684 & $\begin{array}{c}\text { wie } \\
\text { Nr. }{ }^{6} 6_{54}\end{array}$ & & $\begin{array}{l}\text { Theilvergoldete Monstranz. } \\
\text { Besitzer: Kirchenschatz, (Schwäb.-)Gmïnd. Biermann, } \\
\text { Ausstellung Gmünd, Taf. } 19 .\end{array}$ \\
\hline 1685 & $\begin{array}{c}\text { wie } \\
\text { Nr. I654 }\end{array}$ & $\underset{\text { Skizze }}{0 . M .}$ & $\begin{array}{l}\text { Salzfass. I6. Jahrhundert. } \\
\text { Besitzer: Ehemalige Sammlung Bernal, London. Chaffers, } \\
\text { Hall Marks I } 883, \text { S. 221. }\end{array}$ \\
\hline I 686 & $\begin{array}{c}\text { wie } \\
\text { Nr. }{ }^{2} 5_{54}\end{array}$ & ? & $\begin{array}{l}\text { Vergoldetes Trinkgefäss in Gestalt eines Peli- } \\
\text { kans. Theilweise bemalt. Mit Wappen und } \\
\mathrm{I}_{5} \AA_{3} \text {. } \\
\text { Besitzer: Kaiserl. Schatzkammer, Wien. Katalog Leitner } \\
\text { 1882. S. } 98 \text { Nr. } 39 \text {. }\end{array}$ \\
\hline 1687 & $\begin{array}{c}\text { wie } \\
\text { Nr. I655 }\end{array}$ & HaR & $\begin{array}{l}\text { Hans Ludw. Kienlen, geb. I } 572, \uparrow \text { I6 } 635 . \\
\text { a) Vergoldete Schale mit Elfenbeintheilen. } \\
\text { H. } 29 \mathrm{~cm} . \\
\text { Besitzer: Baron Nathanael v. Rothschild, Wien. }\end{array}$ \\
\hline
\end{tabular}




\begin{tabular}{|c|c|c|c|}
\hline $\begin{array}{l}\text { Lf. } \\
\text { Nr. }\end{array}$ & $\begin{array}{l}\text { Beschau- } \\
\text { zeichen }\end{array}$ & $\begin{array}{l}\text { Meister- } \\
\text { zeichen }\end{array}$ & Meister - Gegenstand - Besitzer \\
\hline I 687 & $\begin{array}{l}\text { wie } \\
\mathrm{Nr} . \\
\text { I658 }\end{array}$ & & $\begin{array}{l}\text { b) Vergoldetes Schiff, bemannt, auf vier Rädern. } \\
\text { Mit gravirtem Wappen. } \\
\text { Besitzer: Neues Palais, Darmstadt. }\end{array}$ \\
\hline I688 & & & $\begin{array}{l}\text { In dieser Weise auf dern Stücke gesehen, ist die } \\
\text { Marke vielleicht dennoch mit der obigen des } \\
\text { Hans Ludwig Kienlen identisch. Ich fand } \\
\text { sie auf folgendem Stücke: }\end{array}$ \\
\hline & $\begin{array}{l}\text { wie } \\
\mathrm{Nr} . \mathrm{I} 656\end{array}$ & & $\begin{array}{l}\text { c) Montirung eines Bechers aus Rhinoceroshorn. } \\
\text { Besitzer: Königl. Schatzkammer, München. Katalog } \\
\text { Schauss } 1879 \text {, E. ı. }\end{array}$ \\
\hline I 689 & $\begin{array}{l}\text { wie } \\
\text { Nr. } \quad 1657\end{array}$ & & $\begin{array}{l}\text { Vergoldeter Ananaspokal. Griff figural. } \\
\begin{array}{l}\text { Besitzer: Gg. Agath, Breslau. } \\
\text { H. } 30,5 \mathrm{~cm} \text {. }\end{array}\end{array}$ \\
\hline 1690 & $\begin{array}{l}\text { wie } \\
\text { Nr. } \quad \text { I657 }\end{array}$ & & $\begin{array}{l}\text { Fassung eines Nautilus. Fuss glatt. Bezeichnet } \\
\begin{array}{l}\text { I669. } \\
\text { Besitzer: Herzogl. Museum, Gotha. } 9,5 \mathrm{~cm} .\end{array}\end{array}$ \\
\hline I69 I & & & $\begin{array}{l}\text { Johann Bartholome Müller, ı67 } \\
\text { Münzmeister. }\end{array}$ \\
\hline & $\begin{array}{l}\text { wie } \\
\mathrm{Nr} . \\
\text { I658 }\end{array}$ & & $\begin{array}{l}\text { Vergoldete Fassung einer Elfenbeinkanne. } \\
\text { H. } 23 \mathrm{~cm} \text {. } \\
\text { Besitzer: Consul Becker, Frankfurt a. M. Ausstellung } \\
\text { Cassel I } 884 \text {, Katalog Nr. } 456 .\end{array}$ \\
\hline I 692 & $\begin{array}{l}\text { wie } \\
\text { Nr. }{ }^{2} 657\end{array}$ & & $\begin{array}{l}\text { Scherzbecher (Hansel im Keller). H. } 2 \mathrm{I}, 8 \mathrm{~cm} \text {. } \\
\text { Besitzer: Baron R. v. Walterskirchen, Wien. }\end{array}$ \\
\hline I 693 & $\begin{array}{l}\text { wie } \\
\text { Nr. }{ }^{1} 658\end{array}$ & & $\begin{array}{l}\text { Vergoldete Fassung einer Elfenbeinkanne. } \\
\text { H. } 28 \mathrm{~cm} \text {. } \\
\text { Besitzer: Kunstgewerbe-Museum, Berlin. }\end{array}$ \\
\hline I 694 & $\begin{array}{l}\text { wie } \\
\text { Nr. } 1658\end{array}$ & PI & $\begin{array}{l}\text { Weisssilberner Buchdeckel mit grossen Blumen } \\
\text { getrieben. } \\
\text { Besitzer: Unbekannt. A } 2 \mathrm{~cm} \text {. }\end{array}$ \\
\hline
\end{tabular}




\begin{tabular}{|c|c|c|c|}
\hline $\begin{array}{l}\text { Lf. } \\
\text { Nr. }\end{array}$ & $\begin{array}{l}\text { Beschau- } \\
\text { zeichen }\end{array}$ & $\begin{array}{l}\text { Meister- } \\
\text { zeichen }\end{array}$ & Meister - Gegenstand - Besitzer \\
\hline I 695 & $\begin{array}{l}\text { wie } \\
\text { Nr. } 16 ; 8\end{array}$ & & $\begin{array}{l}\text { Vergoldetes Schiff, auf vier Rädern, mit Be- } \\
\text { mannung. Ornamentale Treibarbeit. } \\
\text { H. } 25,5 \mathrm{~cm} . \\
\text { Besitzer: S. U. Fürst Paskewitsch, St. Petersburg. }\end{array}$ \\
\hline 1696 & $\begin{array}{l}\text { wie } \\
\text { Nr. } 1659\end{array}$ & & $\begin{array}{l}\text { Bäckerzunft-Pokal mit anhängenden Schildchen } \\
\text { und Inschrift von I68 I-I7I } 2 . \text { H. } 32 \mathrm{~cm} \text {. } \\
\text { Besitzer: Verein für Kunst und Alterthum, Ulm. Aus- } \\
\text { stellung Augsburg i } 886 \text {, Katalog Nr. I490. }\end{array}$ \\
\hline I 697 & wr. 1660 & Fin & $\begin{array}{l}\text { Vergoldeter Scherzbecher (Hansel im Keller). } \\
\text { H. } 24,5 \mathrm{~cm} . \\
\text { Besitzer: Baron H. v. Günzburg, St. Petersburg. }\end{array}$ \\
\hline 1698 & 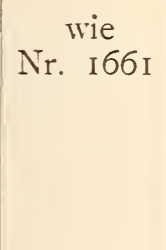 & & $\begin{array}{l}\text { Trinkgefäss in Gestalt eines Schiffes, gestiftet } \\
\text { I627, renovirt I } 757 \text {. Mit vielen anhängenden } \\
\text { Schildchen. } \\
\text { Besitzer: Verein für Kunst und Alterthum, Ulm. Aus- } \\
\text { stellung Augsburg } 1886 \text {, Katalog Nr. I489. Vergl. Ling, } \\
\text { Pokal der Schifferinnung Ulm I856. }\end{array}$ \\
\hline I 699 & $\begin{array}{l}\text { wie } \\
\text { Nr. } 1658\end{array}$ & & $\begin{array}{l}\text { a) Theilvergoldeter Pokal mit muschelförmiger } \\
\text { Cuppa. Griff figural. Mit Wappen und In- } \\
\text { schrift von I68I. } \\
\text { Besitzer: Gemeinde Bischofszell. Ausstellung Zürich } \\
\text { 1883, Katalog S. } 224 \text { Nr. 4. }\end{array}$ \\
\hline & wie 1658 & & $\begin{array}{l}\text { b) Theilvergoldeter Pokal mit muschelförmiger } \\
\text { Cuppa. Griff figural. Wappen und Inschrift } \\
\text { von I68I. } \\
\text { Hesitzer: } \dagger \text { H Baron Carl v. Rothschild, Frankfurt a. M. } \\
\text { Ausstellung Zürich 1883, Katalog S. } 224 \text { Nr. } 3 .\end{array}$ \\
\hline & wie $16 ; 8$ & & $\begin{array}{l}\text { c) Vergoldeter Muschelpokal mit Inschrift. } \\
\text { H. } 25 \mathrm{~cm} . \\
\left.\text { Besitzer ( } 188_{3}\right) \text { : Gebr. Heilbronner, München. }\end{array}$ \\
\hline & wie 1656 & & $\begin{array}{l}\text { d) Deckelkanne mit grossen Blumen getrieben. } \\
\text { Dieses Stück trägt ausserdem noch das Strass- } \\
\text { burger Beschauzeichen Nr. I 474. H. I } 7,5 \mathrm{~cm} \text {. } \\
\text { Besitzer: H. Boskowitz, Wien. }\end{array}$ \\
\hline & wie 1662 & & $\begin{array}{l}\text { e) Weisssilberner Buchbeschlag, bezeichnet I } 700 . \\
\text { Besitzer: Wengenkirche, Ulm. }\end{array}$ \\
\hline
\end{tabular}




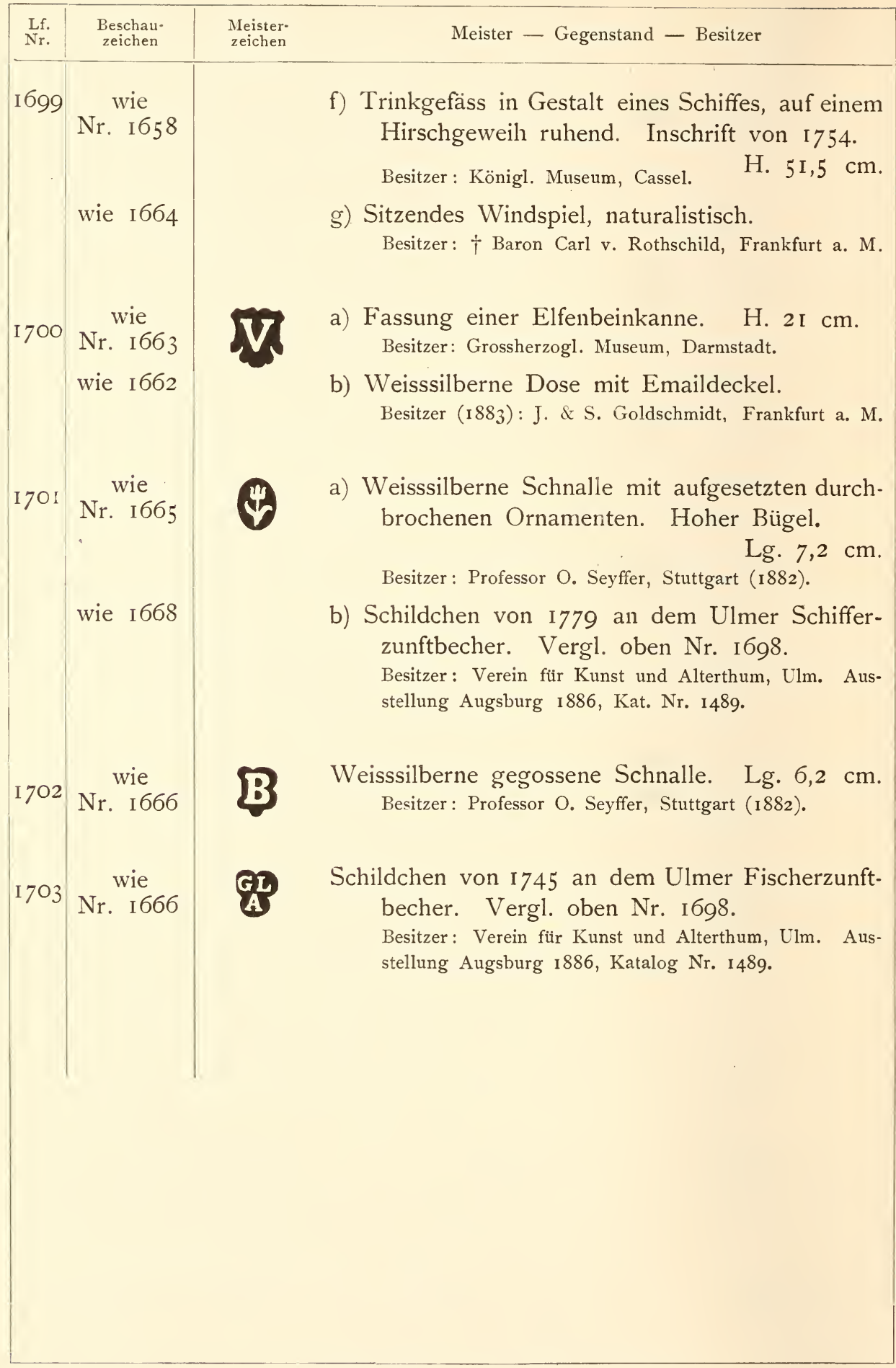




\section{VILLINGEN.}

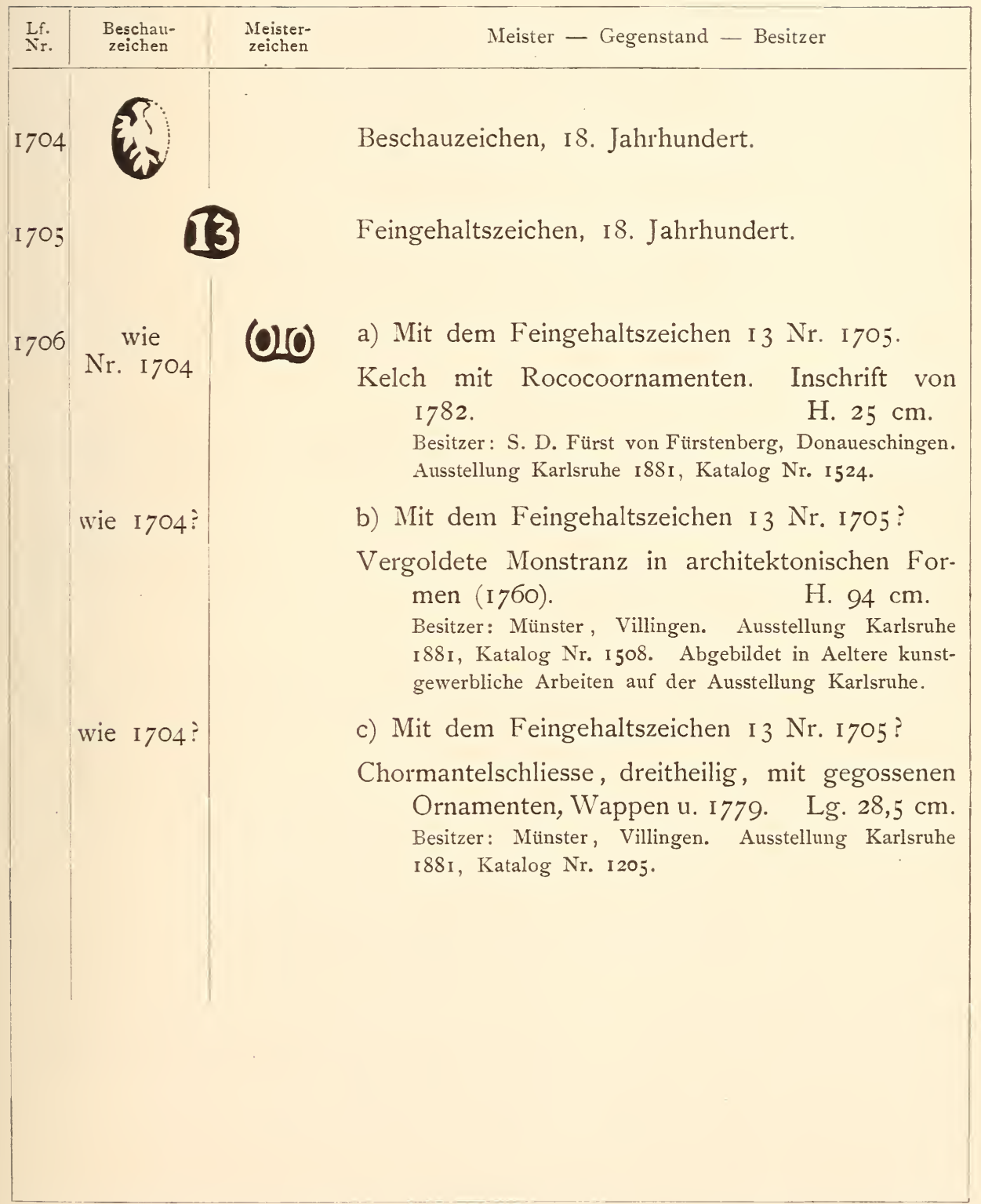




\section{WARBURG.}

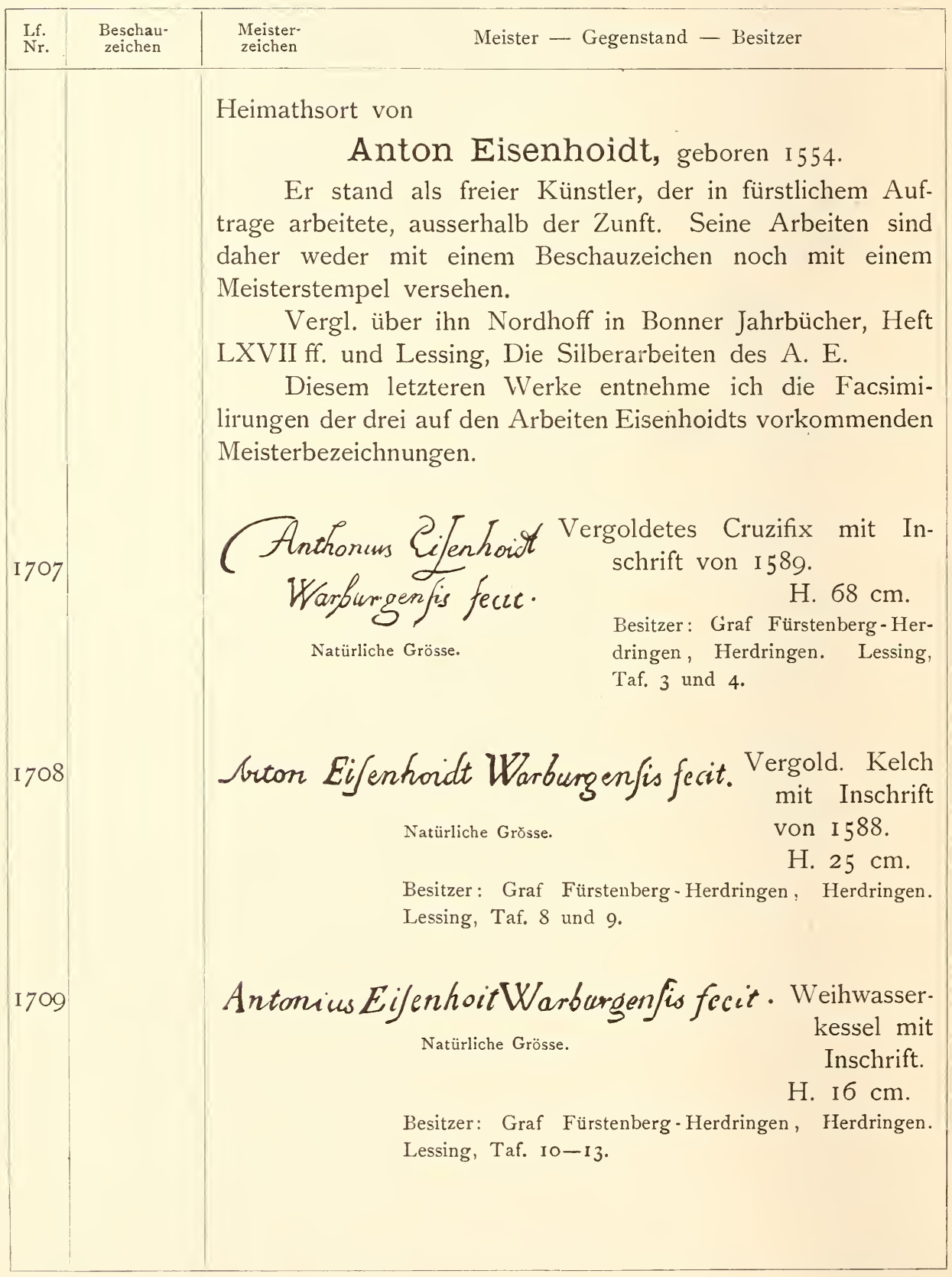




\section{WARENDORF.}

Den Nachweis der folgenden Stücke, sowie deren Zuschreibung an bestimmte Meister, entnehme ich den Notizen Nordhoffs in seinen Studien über Eisenhoidt, Bonner Jahrbücher, Heft LXVII ff.

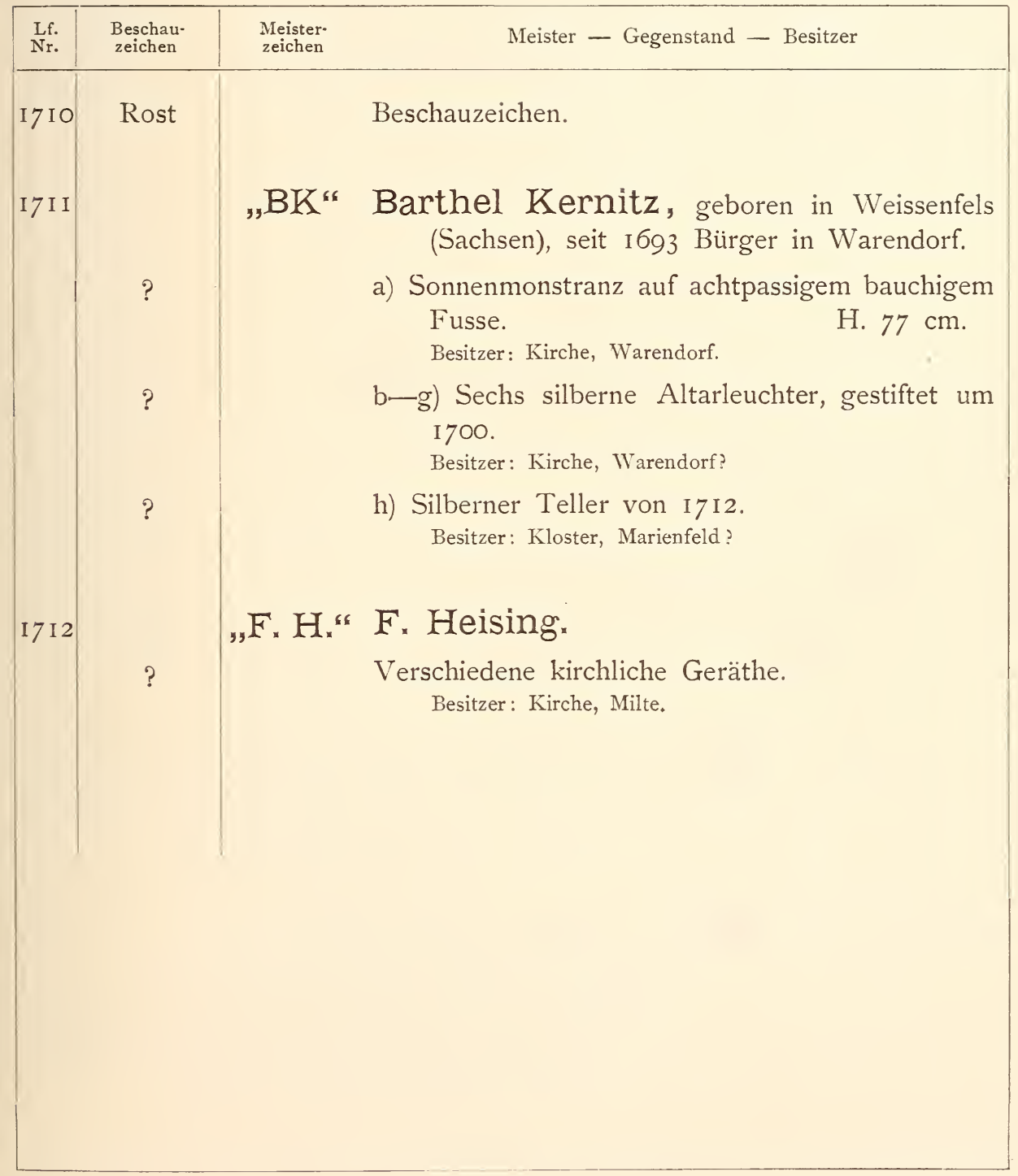




\section{WEIMAR.}

\begin{tabular}{|c|c|c|}
\hline $\begin{array}{l}\text { Lf. } \\
\text { Nr. }\end{array}$ & $\begin{array}{l}\text { Beschau- } \\
\text { zeichen }\end{array}$ & Meister - Gegenstand - Besitzer \\
\hline I 7 I 3 & & $\begin{array}{l}\text { GEBR } \text { STRAUBE IN WEIMAR (nicht facsimilirt). } \\
\text { Vergoldete Altarglocke mit ciselirten Reliefdeco- } \\
\text { rationen und Inschrift. Früh I9. Jahrhundert. } \\
\text { H. I2 cm. } \\
\text { Besitzer: Katholische Stadtkirche, Karlsruhe. Ausstellung } \\
\text { Karlsruhe } 188 \mathrm{I}, \text { Katalog Nr. } 83 \text {. }\end{array}$ \\
\hline
\end{tabular}

\section{WERTHEIM.}

\begin{tabular}{|c|c|c|c|}
\hline $\begin{array}{l}\text { Lf. } \\
\text { Nr. }\end{array}$ & $\begin{array}{l}\text { Beschau- } \\
\text { zeichen }\end{array}$ & $\begin{array}{l}\text { Meister- } \\
\text { zeichen }\end{array}$ & Meister - Gegenstand - Besitzer \\
\hline I 7 I 4 & $\frac{37}{8.60}$ & & Beschauzeichen, um 1660. \\
\hline I 7 I 5 & & & Feingehaltszeichen, I9. Jahrhundert. \\
\hline I 7 I 6 & $\begin{array}{l}\text { wie } \\
\text { Nr. I } 7 \text { I4 }\end{array}$ & $\mathbf{B}$ & $\begin{array}{l}\text { Weisssilbernes Taufbecken und vergoldete Kanne } \\
\text { mit Stifterinschrift von I66I. } \\
\text { Besitzer: Evangelische Kirche, Wertheim. Ausstellung } \\
\text { Karlsruhe I88I, Katalog Nr. } 77 \text { und } 95 .\end{array}$ \\
\hline I 7 I 7 & fehlt & L] & $\begin{array}{l}\text { L. Jan, I9. Jahrhundert. } \\
\text { Mit dem Feingehaltszeichen I } 3 \text { Nr. I7 I } 5 \text {. } \\
\text { Weisssilbernes durchbrochenes Gefäss mit Deckel. } \\
\text { Oben ein Agnus Dei. Mit Inschrift von I } 822 . \\
\text { Besitzer: Evangelische Kirche, Wertheim. }\end{array}$ \\
\hline
\end{tabular}




\section{WINSEN A. L.}

\begin{tabular}{|c|c|c|c|}
\hline Lf. & $\begin{array}{l}\text { Beschau- } \\
\text { zeichen }\end{array}$ & $\begin{array}{l}\text { Meister- } \\
\text { zeichen }\end{array}$ & Meister - Gegenstand - Besitzer \\
\hline 1718 & Löwe & & $\begin{array}{l}\text { Stempelt I } 569 \text { betrügerischer Weise mit dem } \\
\text { Stadtwappen von Lüneburg, dem Löwen. } \\
\text { Vergl. oben S. 2I I. }\end{array}$ \\
\hline 1719 & Halbmond & & $\begin{array}{l}\text { I } 826 \text { muss dieser Ort seine Arbeiten nach Lüne- } \\
\text { burg zur Stempelung mit dem Halbmonde } \\
\text { bringen. Vergl. oben S. 2I4. }\end{array}$ \\
\hline
\end{tabular}

\section{WISMAR.}

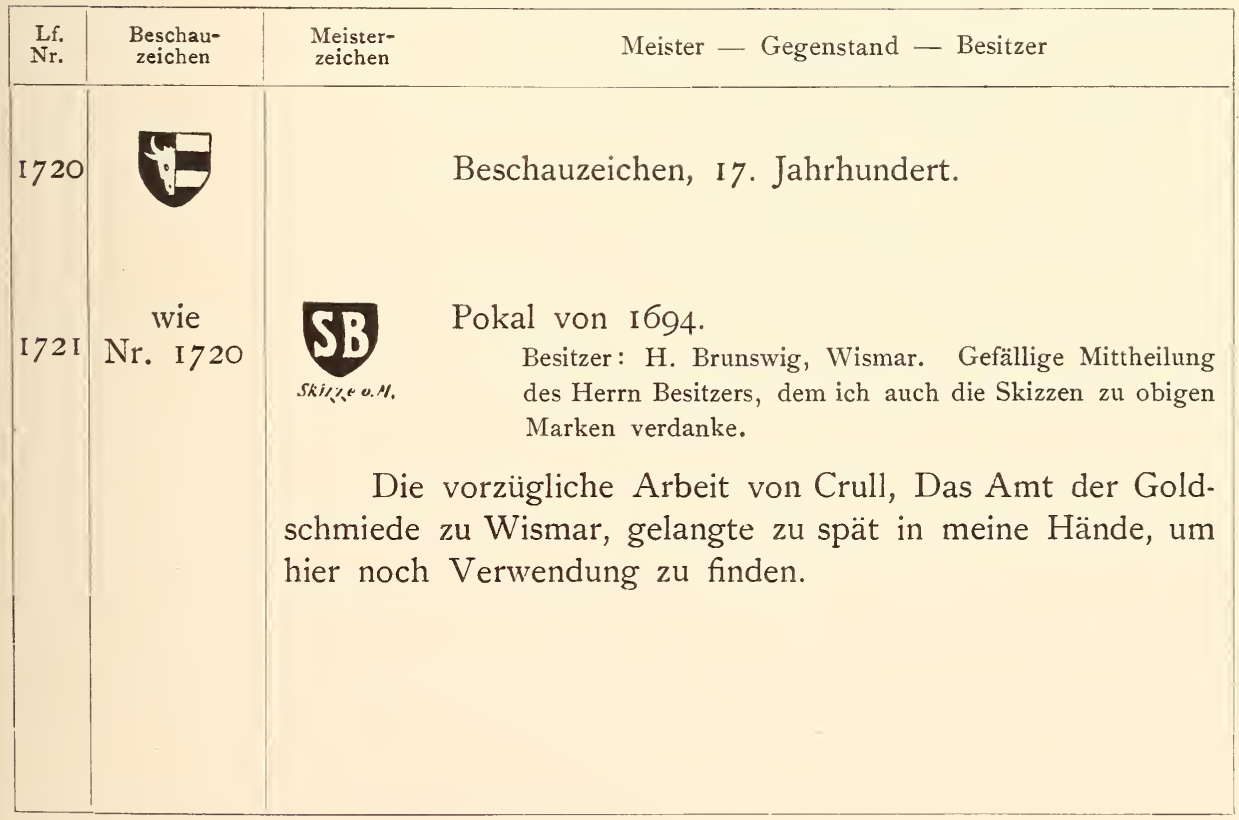




\section{WITTENBERG.}

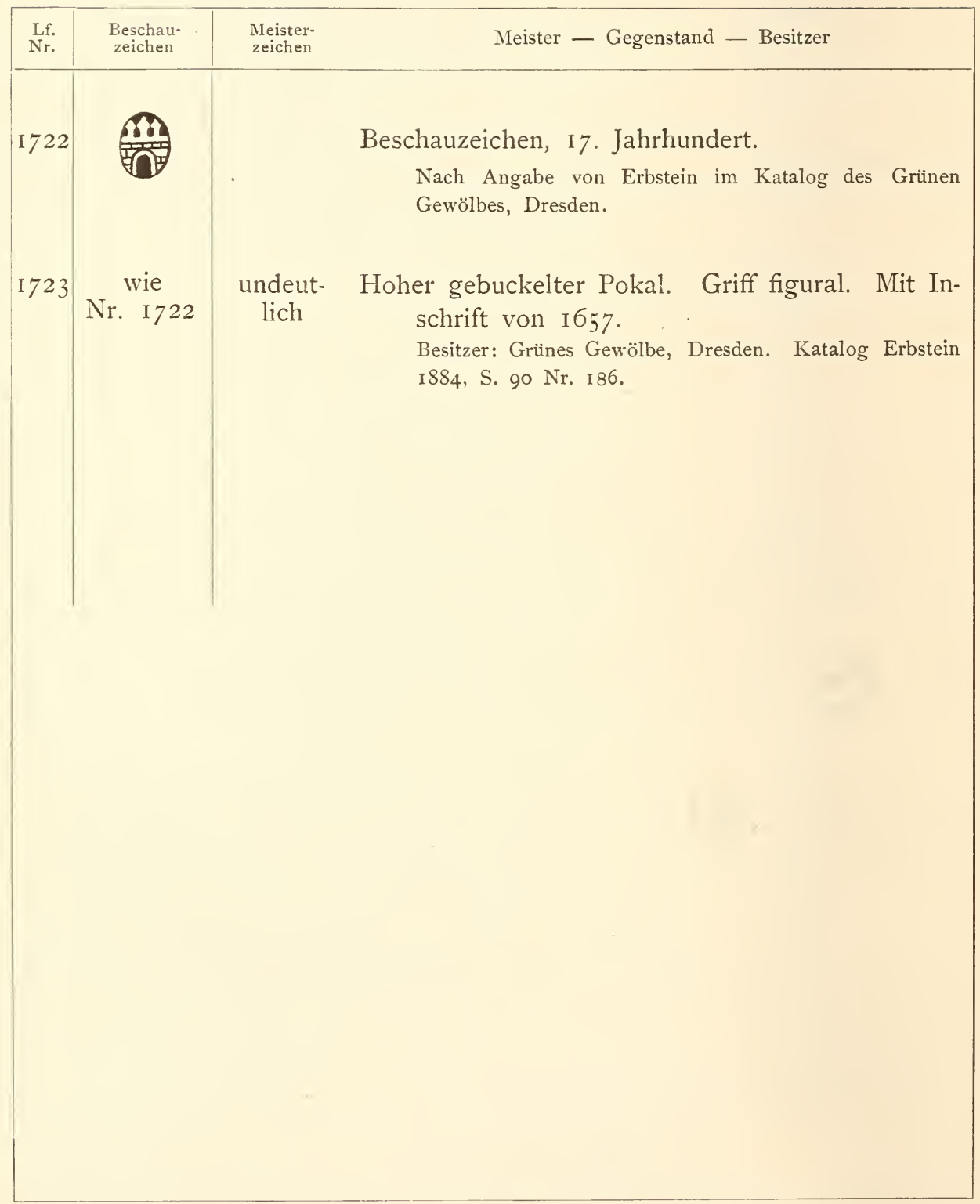




\section{WORMS.}

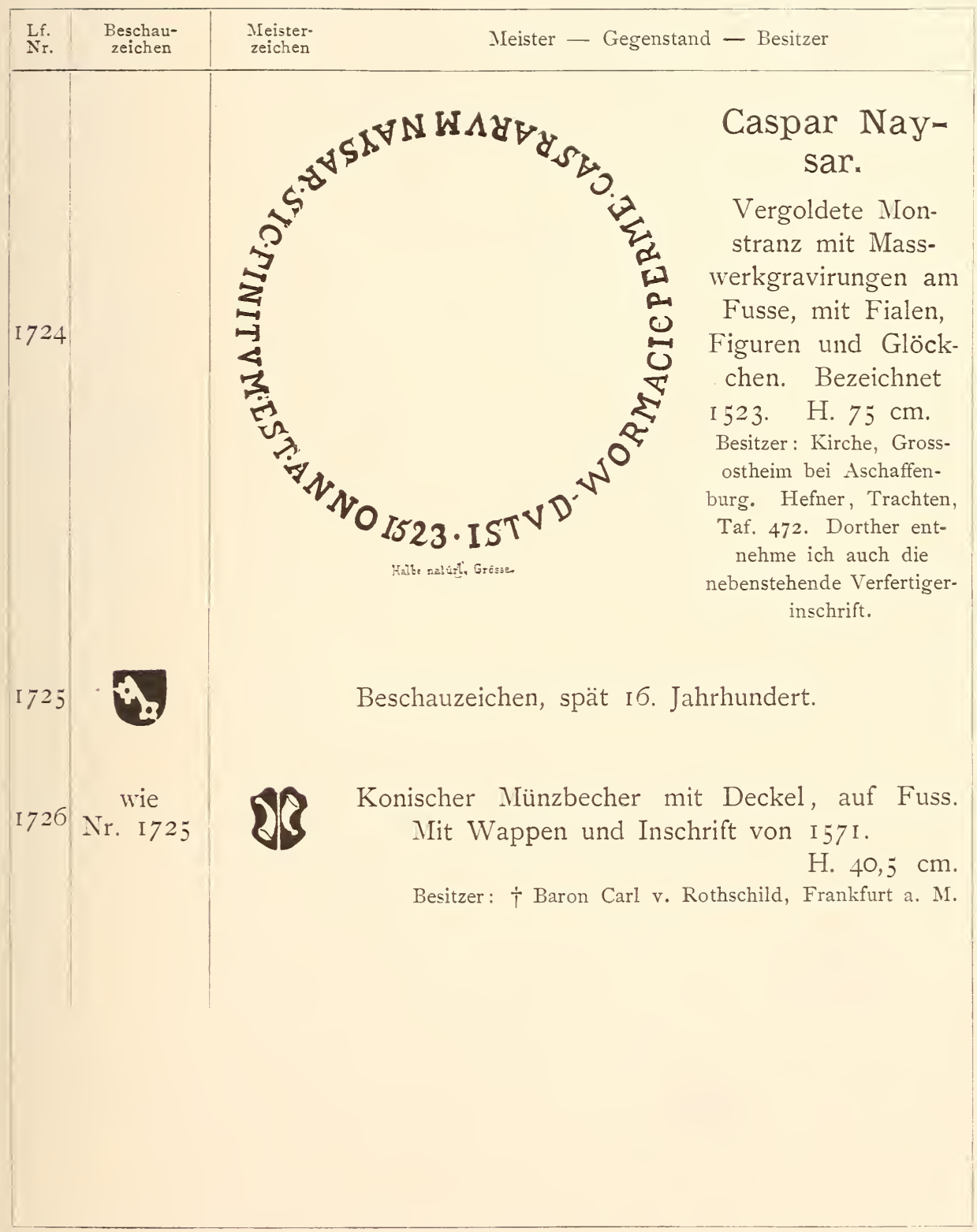




\section{WÜRZBURG.}

\begin{tabular}{|c|c|cc|}
\hline $\begin{array}{c}\text { Lf. } \\
\text { Nr. }\end{array}$ & $\begin{array}{c}\text { Beschau } \\
\text { zeichen }\end{array}$ & $\begin{array}{c}\text { Meister- } \\
\text { zeichen }\end{array}$ & Meister - Gegenstand - Besitzer \\
\hline & & Beschauzeichen, früh I9. Jahrhundert. \\
\hline
\end{tabular}

\section{ZEITZ.}

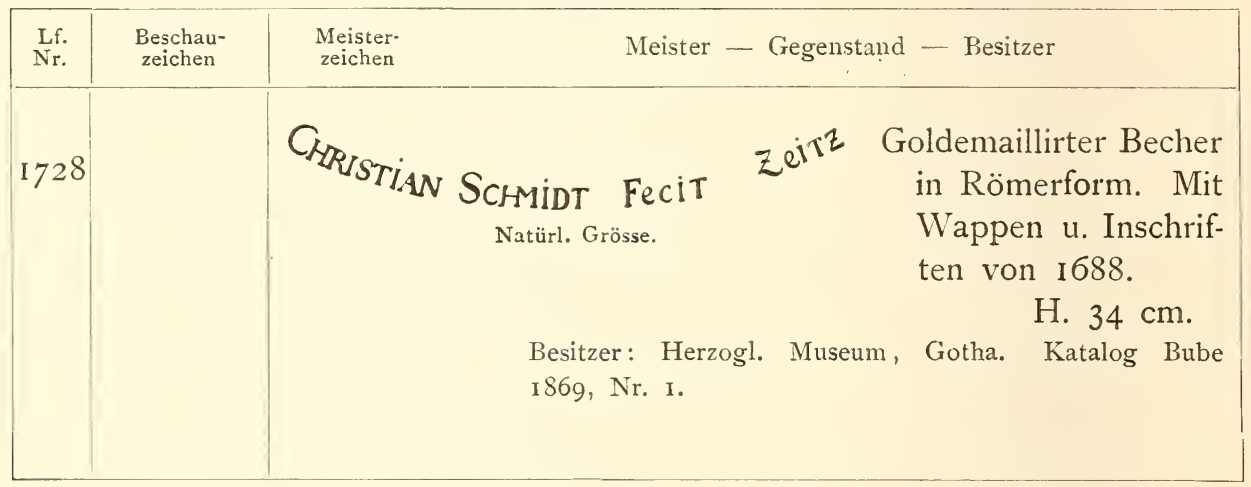

\section{ZWEIBRÜCKEN.}

\begin{tabular}{|c|c|c|c|}
\hline $\begin{array}{l}\text { Lf. } \\
\text { Nr. }\end{array}$ & $\begin{array}{l}\text { Beschau- } \\
\text { zeichen }\end{array}$ & $\begin{array}{l}\text { Meister- } \\
\text { zeichen }\end{array}$ & Meister - Gegenstand - Besitzer \\
\hline I 729 & $E$ & & ichen, I8. Jahrhundert. \\
\hline 1730 & $\begin{array}{l}\text { wie } \\
\text { Nr. I } 729\end{array}$ & & $\begin{array}{l}\text { Tafelsilber mit Wappen. I8. Jahrh. } \\
\text { r: Königl. Silberkammer, München. }\end{array}$ \\
\hline
\end{tabular}




\section{ZWICKAU.}

Ich verdanke Herrn Professor Dr. A. v. Drach in Marburg die Mittheilung, dass das Beschauzeichen von Zwickau in einem Schwan besteht. Ohne die Form dieser Marke zu kennen, lasse ich hier zwei Stücke folgen, welche einen Schwan als Beschauzeichen haben. Es bleibt natürlich fraglich, ob sie für Zwickau in Anspruch zu nehmen sind.

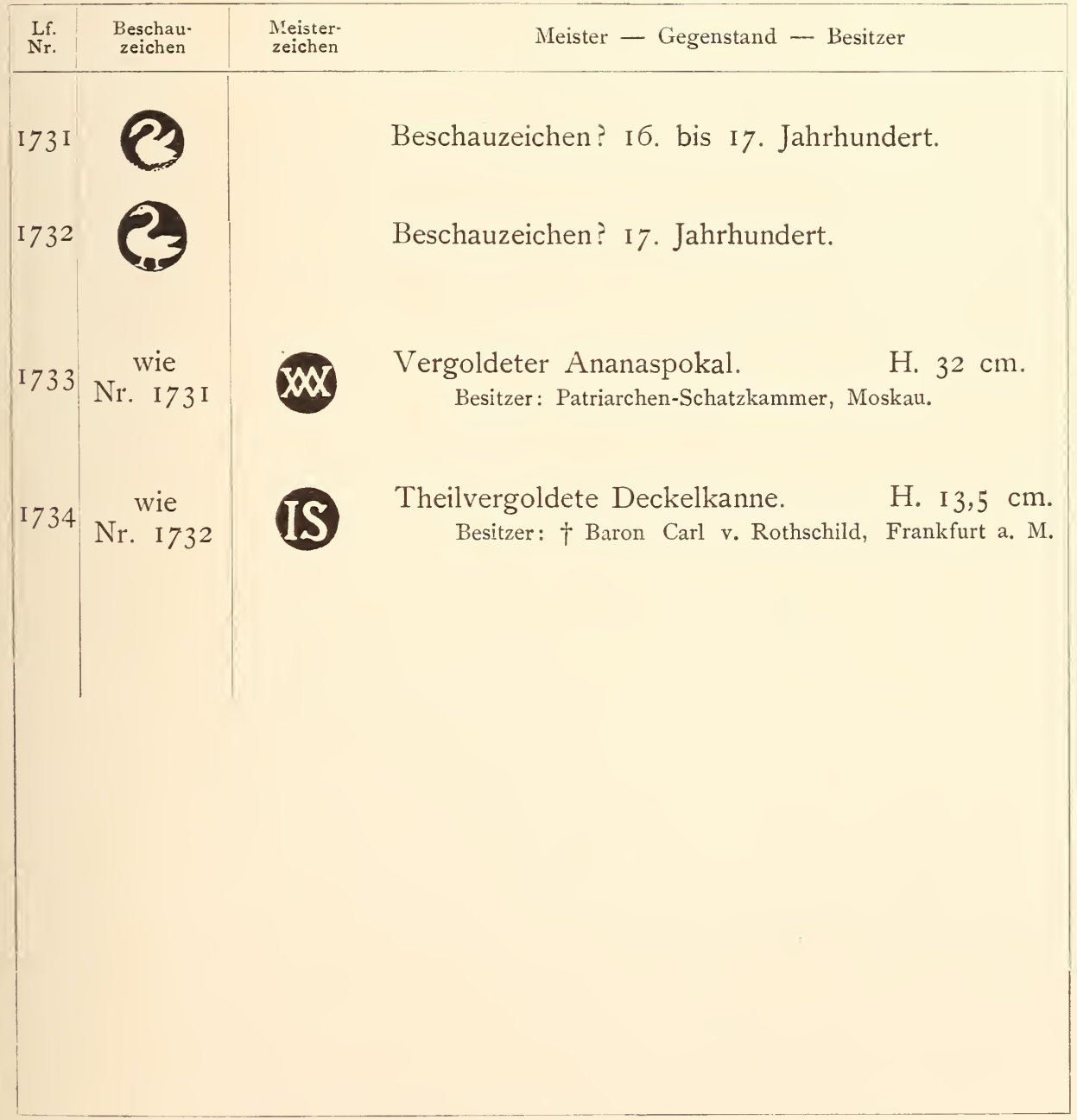





\section{A USLA N D.}

Die Staaten folgen einander nach dem Alphabet, doch sind diejenigen, welche sich in Personalunion befinden, sowie die Länder der englischen Krone, beisammen gelassen. So folgt Ungarn unmittelbar nach Oesterreich, Norwegen nach Schweden, England, Schottland und Irland nach Grossbritannien. Innerhalb der einzelnen Staaten sind die Städte alphabetisch geordnet. 


\section{BELGIEN.}

Ueber die das ganze Königreich umfassende moderne Stempelung liegen ausführliche Verordnungen im Druck vor. Es genügt für unsere Zwecke, wenn wir nach einer amtlichen Veröffentlichung von I868 die Stempel für den Gold- und Silberfeingehalt reproduciren.

I735 Staatsstempel für Silber. Grössere Stücke. 900 fein.

I736

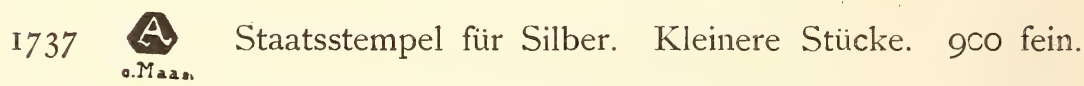

I738 A Staatsstempel für Silber. Kleinere Stücke. Soo fein.

I739 Staatsstempel für Gold. Grössere Stücke. Soo fein.

I740 Staatsstempel für Gold. Grössere Stücke. 750 fein.

I74I Statsstempel für Gold. Kleinere Stücke. 800 fein.

I742 


\section{ANTWERPEN.}

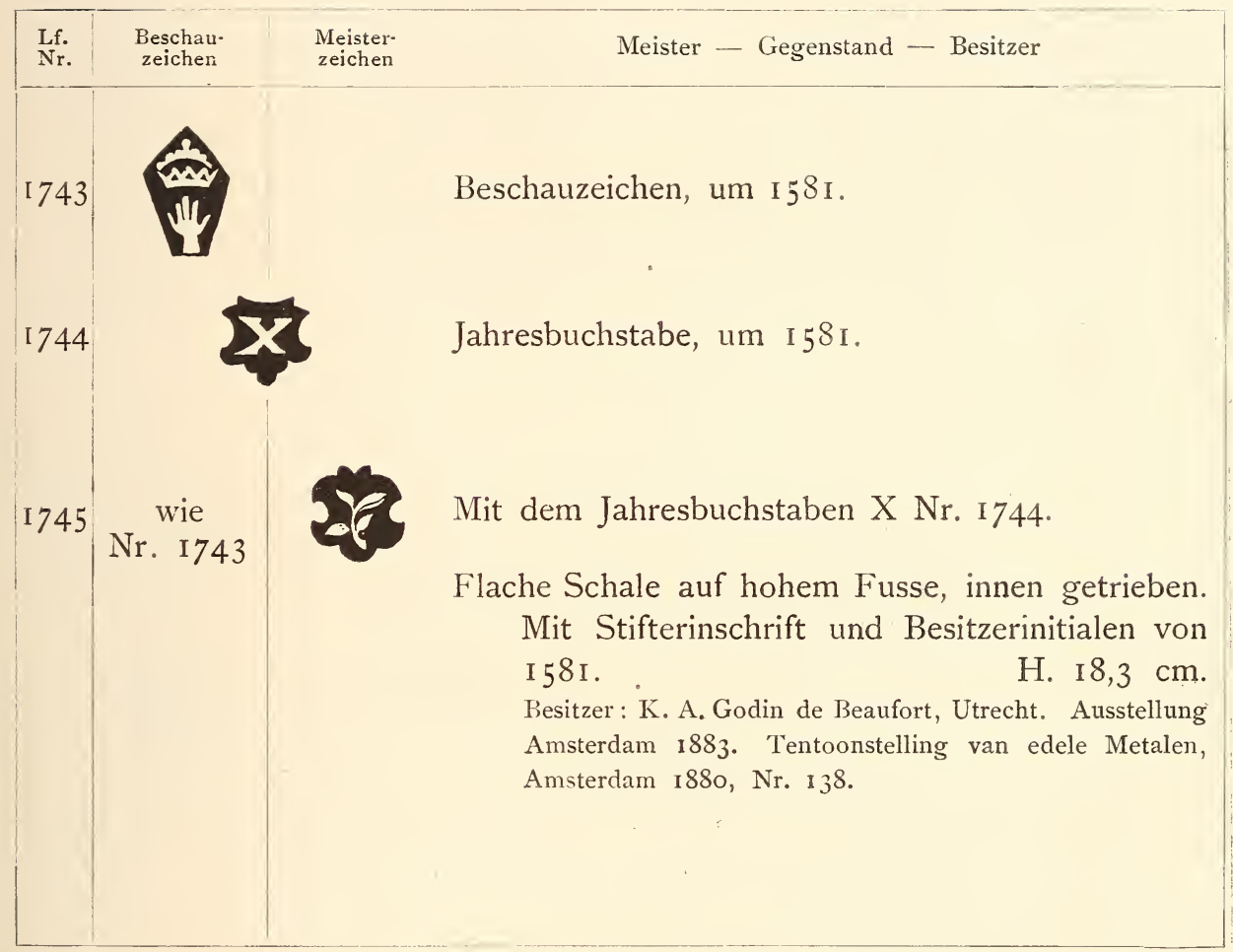

\section{AUDENARDE.}

Eine Goldschmiede-Stempeltafel von 1502 ist erhalten und befindet sich im Musée communal d'archéologie, Gent.

Gefällige Mittheilung des Herrn Direktor Hermann van Duyse, Gent. Vergl. auch den Katalog der Ausstellung Brüssel I 880, IV. Sect. A Nr. 2557. 


\section{BRÜGGE.}

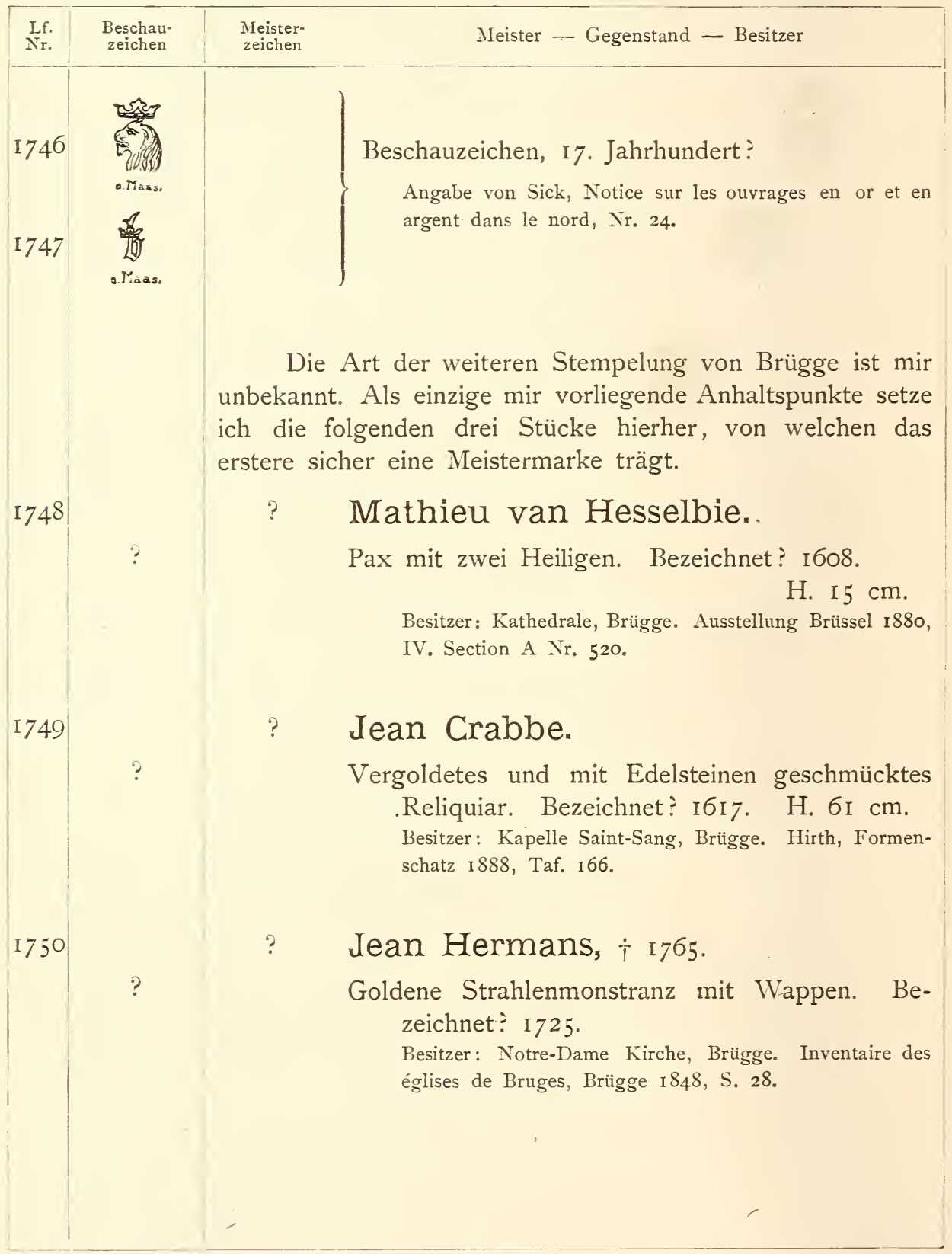




\section{BRÜSSEL.}

Schon 1372 besteht in Brüssel eine ordnungsmässige Stempelung mit Stadt- (aurifabri habent unum certum et commune signum) und Meisterstempel (quilibet aurifaber ipsius ville habet sum proprium signum).

Der Rath von Brïssel beantwortet eine Anfrage des Breslauer Rathes, I7. Juli 1372. Breslau, Stadtarchiv.

In einer Goldschmiedeordnung aus dem Schlusse des I5. Jahrhunderts wird vorgeschrieben, dass zwei Wardeine mit einem vom Magistrat und vom Fürsten festzustellenden Stempel die löthige Arbeit bezeichnen sollen.

Henne und Vauters, Histoire de la ville de Bruxelles i 845 .

Mit dieser Verordnung lässt sich sehr gut die Stempelung auf dem einzigen Brüsseler Stücke, das wir beizubringen vermögen, erklären.

\begin{tabular}{|c|c|c|c|}
\hline $\begin{array}{l}\text { Lf. } \\
\text { Nr. }\end{array}$ & $\begin{array}{l}\text { Beschau. } \\
\text { zeichen }\end{array}$ & $\begin{array}{l}\text { Meister- } \\
\text { zeichen }\end{array}$ & Meister - Gegenstand - Besitzer \\
\hline
\end{tabular}

Beschauzeichen, um I6I8.

Staatscontrollzeichen, um iб 8.

Jahresbuchstabe, um Iб 8 .

wie

I754 Nr. I75 I

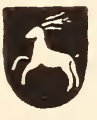

Mit dem Zeichen der Staatscontrolle Nr. I752 und dem Jahresbuchstaben O Nr. 1753.

Weisssilberner Etalonlöffel (Normalmass) für die Brüsseler Getreidesteuer. Kelle als Kugel segment, am Griffe das Stadtwappen. Mit gravirtem Wappen und Inschrift von 16 I 8.

Lg. $36,5 \mathrm{~cm}$.

Besitzer: Stadt Brüssel. Wauters in ,La Belgique communale" I 847 , Nr. 4, mit Abbildung, nach welcher die obigen Marken gezeichnet sind. 


\section{DENDERMONDE.}

Eine Goldschmiede-Stempeltafel aus dem 17. Jahrhundert befindet sich im Musée communal d'archéologie, Gent.

Gefällige Mittheilung des Herrn Direktor Hermann van Duyse, Gent.

\section{GENT.}

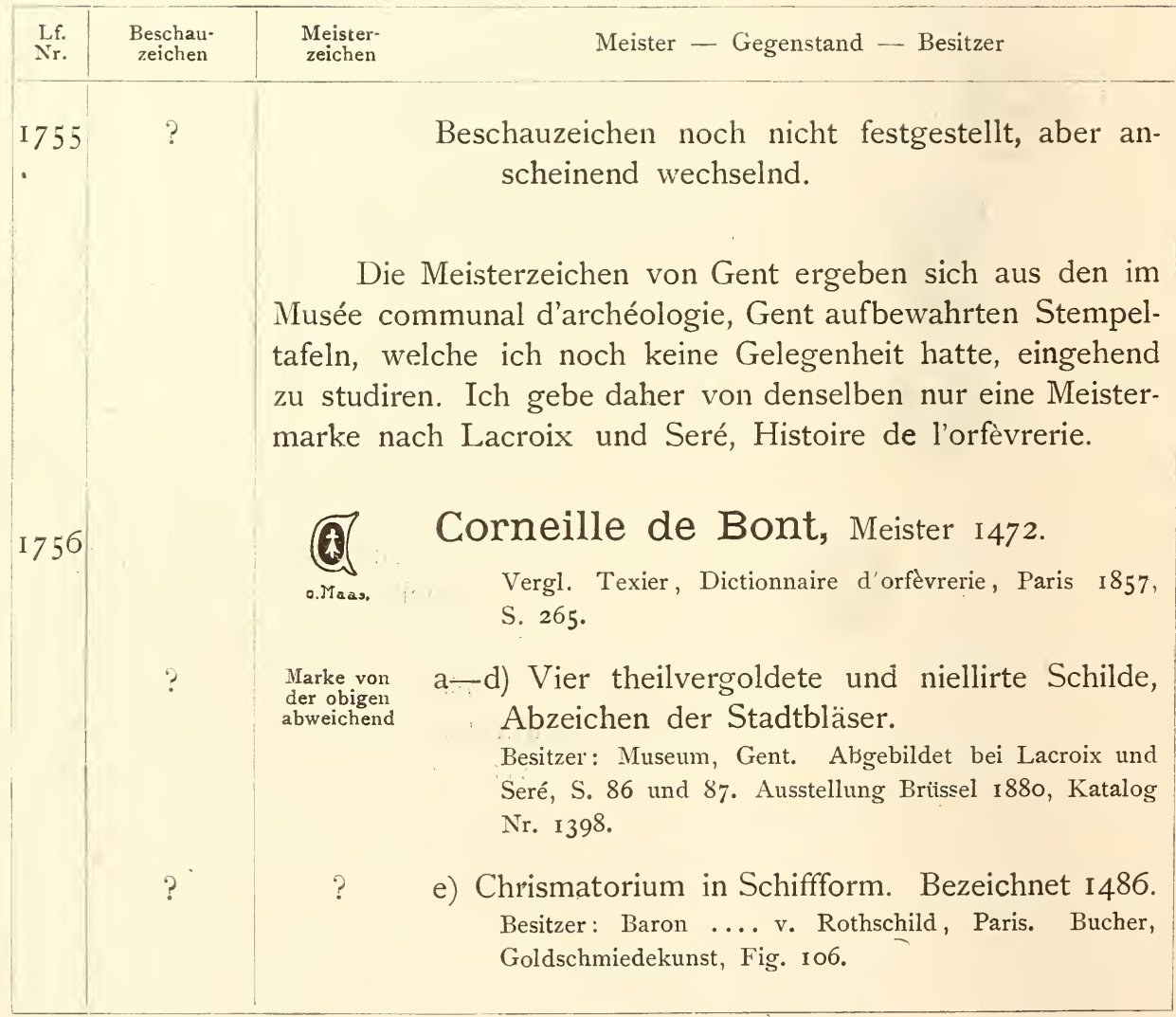




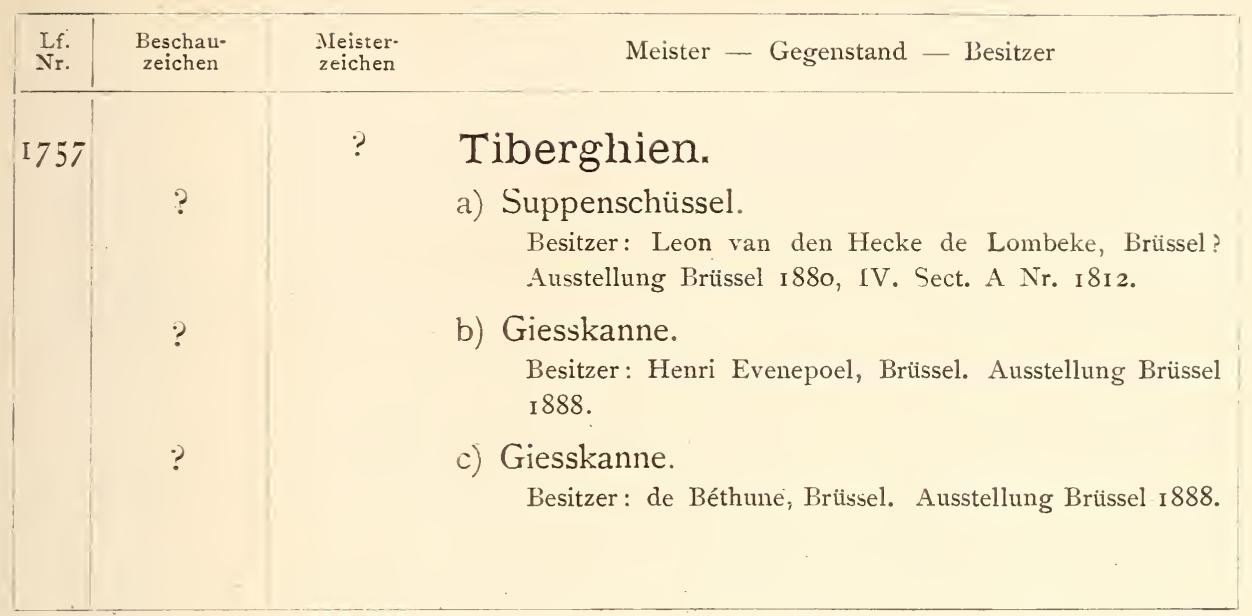

\section{LOKEREN.}

Eine Goldschmiede-Stempeltafel aus dem I7. Jahrhundert befindet sich im Musée communal d'archéologie, Gent.

Gefällige Mittheilung des Herrn Direktor Hermann van Duyse, Gent.

\section{MONS.}

Das Material über Beschauzeichen und Meisterstempel ist mir erst während des Druckes zugekommen und konnte keine Aufnahme mehr finden. Ich muss mich daher mit den folgenden aus der Literatur geschöpften Angaben begnügen.

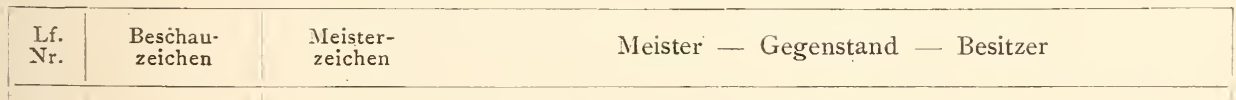

\section{HUGUES DE LA VIGNE (nicht facsimilirt).}

Schrein des Heiligen Makarius in Form einer Kirche, auf vier Löwen ruhend. Mit Reliefs, Wappen, Inschrift und г $616 . \quad$ H. $76 \mathrm{~cm}$. Besitzer: Kathedrale, Gent. Ausstellung Mecheln I864, Katalog Nr. 5 I9. 


\begin{tabular}{|c|c|c|}
\hline $\begin{array}{l}\text { Lf. } \\
\text { Nr. }\end{array}$ & $\begin{array}{l}\text { Beschau- } \\
\text { zeichen }\end{array}$ & Meister - Gegenstand - Besitzer \\
\hline I759 & & $\begin{array}{l}\text { Lambert Gérard. } \\
\text { Gruppe mit der heil. Elisabeth an einem Amts- } \\
\text { stabe von I6I6. } \\
\text { Besitzer: Elisabethenkirche, Mons. Ausstellung Brüsse } \\
\text { 1880, IV. Sect. A, Nr. 526. Vergl. unten Nr. 1760. }\end{array}$ \\
\hline 1760 & & $\begin{array}{l}\text { A. } C_{x} J_{x} \text { de Bettignies. } \\
\text { Amtsstab von I6ı mit der Gruppe der heil. } \\
\text { Elisabeth. } \\
\text { Besitzer: Elisabethenkirche, Mons. Ausstellung Brüssel } \\
\text { 1880, IV. Sect. A Nr. 526. Vergl. oben Nr. 1759. }\end{array}$ \\
\hline I $76 \mathrm{I}$ & & $\begin{array}{l}\text { Henri Beghin. } \\
\text { a u. b) Zwei Terrinen mit. Wappen. I } 766 \text {. } \\
\text { Besitzer: Baron v. Joigny de Pamele, Brüssel. Aus- } \\
\text { stellung Brüssel I880, IV. Sect. A Nr. 1494. } \\
\text { c u. d) Zwei? Terrinen? } \\
\text { Besitzer: de Lichtervelde, Brüssel. Ausstellung Brüssel } \\
\text { ı888, IV. Sect. A Nr. 359. } \\
\text { e u f) Zwei Terrinen mit Wappen. I } 766 \text {. } \\
\text { Besitzer: Gräfin L. v. Nédonchel. Ausstellung Brüssel } \\
\text { ı88, IV. Sect. A Nr. I507. } \\
\text { g) Kaffekanne mit Portraitmedaillons. } \\
\text { Besitzer: Fräulein Clémence Stevens. Ausstellung Brissel } \\
\text { ı880, IV. Sect. A Nr. I796. }\end{array}$ \\
\hline I 762 & & $\begin{array}{l}\text { F. } J_{*} \text { BEGHIN FECIT (nicht facsimilirt). } \\
\text { François Joseph Beghin, }+ \text { I } 787 \text {. } \\
\text { Silberportrait. } \\
\text { Besitzer: Henri Delmotte, Brïssel. Ausstellung Brïssel } \\
\text { I880, IV. Sect. A Nr. I50I. }\end{array}$ \\
\hline 1763 & & 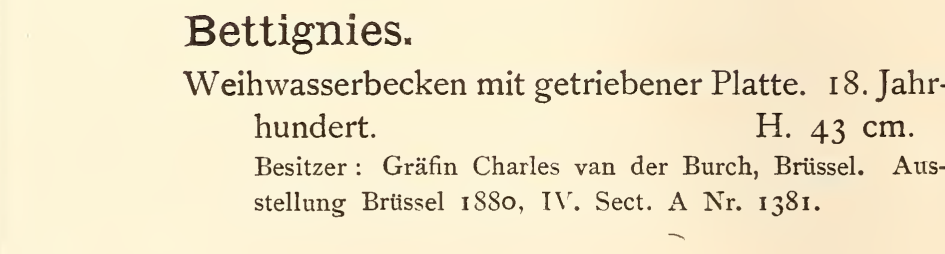 \\
\hline
\end{tabular}




\section{OIGNIES (BEI NAMUR).}

\begin{tabular}{|c|c|c|}
\hline $\begin{array}{l}\text { Lf. } \\
\text { Nr. }\end{array}$ & $\begin{array}{l}\text { Beschau- } \\
\text { zeichen }\end{array}$ & Meister - Gegenstand - Besitzer \\
\hline I 764 & & $\begin{array}{l}\text { HugO, Mönch von Oignies. Um I } 228 \text {. } \\
\text { In Folgendem gebe ich die seinen Namen enthaltenden } \\
\text { Theile von Inschriften, die sich auf den von ihm aus- } \\
\text { geführten Arbeiten befinden. } \\
\text { Man glaubt ihm im Ganzen bis I8 Stück zuschreiben } \\
\text { zu können. Labarte, Arts industriels II, S. 29I sagt sogar } \\
\text {,seize ou dix-huit pièces sont signé es de lui“. } \\
\text { HUGO ME FECIT (nicht facsimilirt). } \\
\text { a) Vergoldeter Kelch mit Niellen und Ciselirungen. } \\
\text { Besitzer: Soeurs de Notre-Dame, Namur. Ausstellung } \\
\text { Brïssel I888, IV. Sect. A Nr. I53. } \\
\text { ORE CANUNT ALII CRISTUM, CANIT } \\
\text { ARTE FABRILI HUGO (nicht facsimilirt). } \\
\text { b) Evangelienbuch mit Treibarbeit, Niellen und } \\
\text { Edelsteinen. } \\
\text { Besitzer: Soeurs de Notre-Dame, Namur. Exposition de } \\
\text { I'art ancien au pays de Liège i88I, Pl. 24. Ausstellung } \\
\text { Brissel I88o, IV. Sect. A Nr. I43. }\end{array}$ \\
\hline
\end{tabular}

\section{TAMISE.}

Eine Goldschmiede-Stempeltafel aus dem 17. Jahrhundert befindet sich im Musée communal d'archéologie, Gent. 


\section{DÄNEMARK.}

I490 wird bestimmt, dass jede Goldschmiedearbeit sowohl Stadt-als Meisterzeichen tragen soll. Aus einer Verordnung von I496 citirt Sick Notice sur les ouvrages en or et en argent dans le nord, wörtlich: „oc oer tegnet met byes moerckoe, som gjort oer, oc met hans moerckoe som henne giort haffuer". Dieses wird I539 mit folgenden Worten aufs neue bestätigt: "at the schulle sette bode byens och thieris egett thegen oc stemp paa same soeff". 


\section{KOPENHAGEN.}

Nach Nyrop, Meddelelser om Dansk Guldsmedekunst, S. I3 findet sich I49I eine Verordnung über die Stempelung, aus welcher hervorgeht, dass ein Stadtstempel schon vorher üblich war. In diesem Jahre aber wird ein Meisterstempel neben dem Stadtstempel verlangt. Es scheint zunächst Selbststempelung bestanden $\mathrm{zu}$ haben, welche erst $\mathrm{r} 540$ aufgehoben worden ist. Nur der Altmeister hat von da ab das Recht den Stadtstempel auf die Arbeit zu setzen.

Da die älteste, uns bis jetzt bekannt gewordene, Kopenhagener Stempelung von I639 datirt, so fehlen uns die Beispiele für die Periode der Selbststempelung sowie für das erste Jahrhundert der Stempelung durch Wardeine (Altmeister).

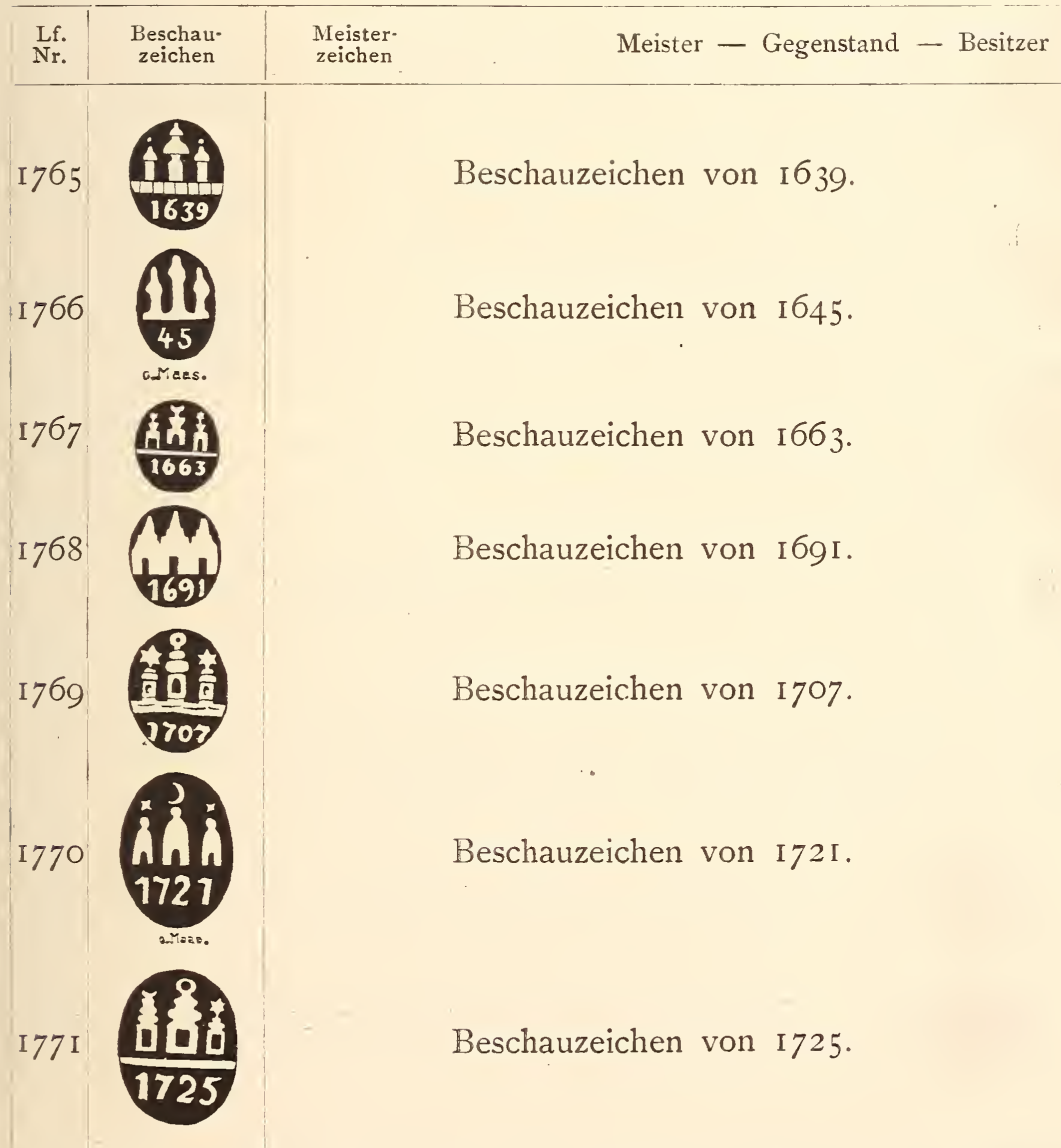




\begin{tabular}{|l|c|c|}
\hline Lf. & $\begin{array}{c}\text { Beschau. } \\
\text { zeichen }\end{array}$ & $\begin{array}{c}\text { Meister- } \\
\text { zeichen }\end{array}$ \\
\hline Nr. & Meister - Gegenstand - Besitzer \\
\hline
\end{tabular}

\section{周}

1772

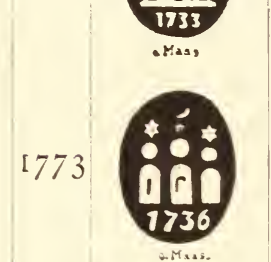

1774

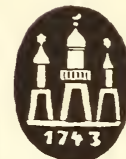

I $775 \frac{i \frac{1}{10}}{1747}$

1776 विक

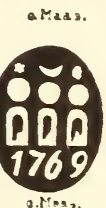

1778

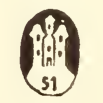

Beschauzeichen von 1733 .

Beschauzeichen ron 1736 .

Beschauzeichen von 1743 .

Beschauzeichen von 1747 .

Beschauzeichen von 1758 .

Beschauzeichen von 1769.

Beschauzeichen? von 1751 oder 1851 ?

Nach Nyrop S. I44 geben wir hier eine kleine Liste von Beschaumeistern mit den Marken, welche sie amtlich führten.

Conrad Ludolf, Münzwardein 1679-1729. bis 1749 . 


Christoffer Fabritius, Wardein I749
bis I787.




\begin{tabular}{|c|c|c|}
\hline $\begin{array}{c}\text { Lf. } \\
\text { Nr. }\end{array}$ & $\begin{array}{c}\text { Beschau- } \\
\text { zeichen }\end{array}$ & $\begin{array}{c}\text { Meister- } \\
\text { zeichen }\end{array}$ \\
\hline
\end{tabular}

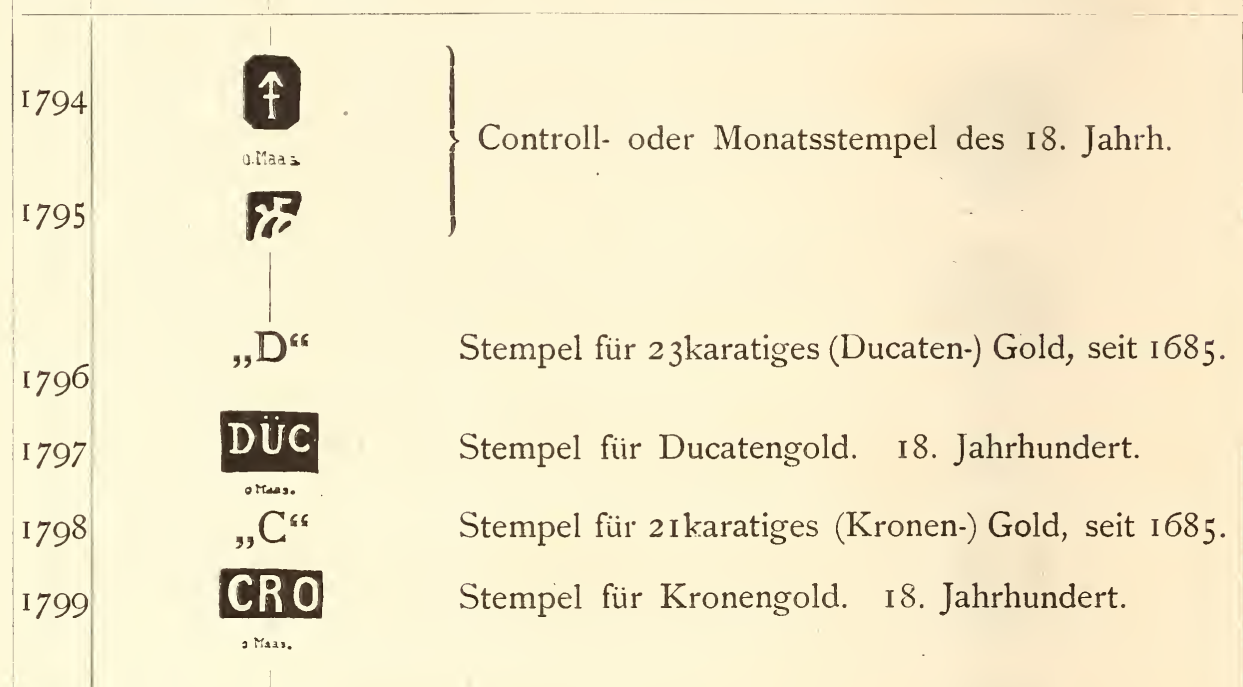

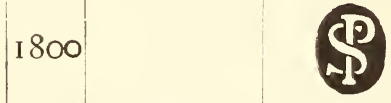

wie

Nr. 1765

wie 1766

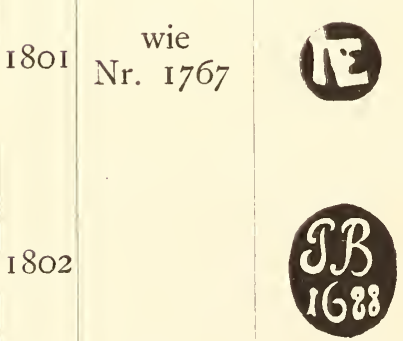

wie

Nr. 1768
Steen Petersen, zünftig ı620, Aeltermann I 623 bis I 627 .

a) Weisssilberne achteckige Weinkanne von 1639 . H. $18 \mathrm{~cm}$.

Besitzer: Patriarchen-Schatzkammer, Moskau. Katalog S. $4 \mathrm{I}$, Taf. 8 Nr. 73 .

b) Löffel von I645 mit fruchtartiger Endigung am Stiele.

Besitzer: Alterthums-Museum, Kopenhagen. Nr. 22,350. Nyrop, S. 45 gibt J. Stickmann I65I oder J. Stilcke 1651 als Verfertiger an.

Vergoldete Henkelkanne von $166_{3}$ mit Inschrift. H. $19,5 \mathrm{~cm}$.

Besitzer: Winterpalais, St. Petersburg.

Pet. Borreby, urkundlich genannt um 1700 oder

Peter Burraeus, Wardein 1677 bis 1679 .

Mit dem Zeichen des Beschaumeisters Conr. Ludolf Nr. 1779 und dem Controllstempel Nr. 1792. Silberner Löffel von I69I.

Besitzer: Museum für Kunst und Gewerbe, Hamburg. 


\begin{tabular}{|c|c|c|c|}
\hline Lf. & $\begin{array}{l}\text { Beschau- } \\
\text { zeichen }\end{array}$ & $\begin{array}{l}\text { Meister- } \\
\text { zeichen }\end{array}$ & Meister - Gegenstand - Besitzer \\
\hline 1803 & $\begin{array}{c}\text { wie } \\
\text { Nr. } 1769\end{array}$ & $\begin{array}{l}\text { DSR } \\
\text { teori }\end{array}$ & $\begin{array}{l}\text { Dietrich Skillings, I7co. } \\
\text { Mit dem Zeichen des Beschaumeisters Ludolf } \\
\text { Nr. I779 und dem Controllstempel Nr. I795. } \\
\text { Weisssilberne runde Platte mit Ornamenten ge- } \\
\text { trieben. Gestempelt I 707. Dm. } 3,6 \mathrm{~cm} \text {. } \\
\text { Besitzer: Excellenz Graf Paar, Rom. }\end{array}$ \\
\hline
\end{tabular}

I 804

wie

Nr. 1770

1805

wie

Nr. I77I

1806

wie

Nr. 1772

I 807

wie

Nr. I 774 und 1775

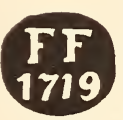

Friedrich Fabritius, Altmeister I 729 und I 735 bis I74I.

Mit dem Zeichen des Beschaumeisters Pet. Nicolai von Haven Nr. 1780 und dem Goldstempel DÜC Nr. I797.

Goldener Becher von I $72 \mathrm{I}$.

Besitzer: Schloss Rosenborg, bei Kopenhagen. Nyrop, S. 74 .

J. Hoe, i682, oder

Jacob Hoffmann, I69o.

Mit dem Zeichen des Beschaumeisters Ludolf Nr. I779 und dem Controllstempel Nr. I790. Weisssilberner Becher, gravirt mit Initialen und I 725. H. I $2,7 \mathrm{~cm}$. Besitzer: Excellenz Graf Paar, Rom.

INR $J_{\text {1733. }}$ N. Randers, I733?, I742.

Mit dem Zeichen des Beschaumeisters Pet. Nicolai von Haven Nr. I780 und dem Controllstempel Nr. I794.

Sick theilt diese Marken mit, ohne den Gegenstand zu nennen, dem er sie entnommen hat.

\section{Dietrich Hoff? I699.}

Mit den Zeichen der Beschaumeister Pet. Nicolai von Haven Nr. I780 und Christoffer Fabritius 


\begin{tabular}{|c|c|c|c|}
\hline $\begin{array}{l}\text { Lf. } \\
\text { Nr. }\end{array}$ & $\begin{array}{l}\text { Beschau- } \\
\text { zeichen }\end{array}$ & $\begin{array}{l}\text { Meister- } \\
\text { zeichen }\end{array}$ & Meister - Gegenstand - Besitzer \\
\hline I 807 & \multirow{5}{*}{$\begin{array}{l}\text { wie } \\
\text { Nr. } \quad \text { I } 776\end{array}$} & \multirow{5}{*}{$\underset{\text { c.mass. }}{\mathbf{N F}}$} & $\begin{array}{l}\text { Nr. I78 I sowie den Controllstempeln Nr. I789 } \\
\text { und Nr. I 79I. }\end{array}$ \\
\hline & & & $\begin{array}{l}\text { Sick theilt diese Marken mit, ohne die Gegenstände } \\
\text { zu nennen, welchen er sie entnommen hat. }\end{array}$ \\
\hline I 808 & & & $\begin{array}{l}\text { Niels Fuchs, oder } \\
\text { Nicolaj Fux, I742. }\end{array}$ \\
\hline & & & $\begin{array}{l}\text { Mit dem Zeichen des Beschaumeisters Christoffer } \\
\text { Fabritius Nr. I78 I und dem Goldstempel } \\
\text { CRO Nr. I799. }\end{array}$ \\
\hline & & & $\begin{array}{l}\text { Goldenes Gefäss in Gestalt einer sitzenden Frau } \\
\text { mit Hund (Guldlugtedaase). I } 758 \text {. } \\
\text { Besitzer: Schloss Rosenborg, bei Kopenhagen. Nyrop, } \\
\text { S. } 83 \text {. }\end{array}$ \\
\hline
\end{tabular}

\section{ODENSE.}

\begin{tabular}{|c|c|c|c|}
\hline $\begin{array}{l}\text { Lf. } \\
\text { Nr. }\end{array}$ & $\begin{array}{l}\text { Beschau- } \\
\text { zeichen }\end{array}$ & $\begin{array}{l}\text { Meister- } \\
\text { zeichen }\end{array}$ & Meister - Gegenstand - Besitzer \\
\hline
\end{tabular}

1809

Beschauzeichen 1763 .

I 8 IO

\section{3}

Jahresstempel von 1763 .

Mit dem Jahresstempel i763 Nr. I8Io.

wie 


\section{FRANKREICH.}

Ueber die alten französischen Goldschmiedemarken liegen vier beachtenswerthe Spezialstudien vor:

I) (Pichon), Représentation de quelques pièces d'orfèvrerie ancienne faisant partie de la collection de M. le Bon J. P. Paris I878.

2) Eudel, 60 planches d'orfèvrerie de la collection de P. E. Paris I884.

3) Cripps, Old french plate. London 1880.

4) Chaffers, L'orfèvrerie française. II. Theil von desselben Verfassers Hall marks on gold and silver plate. VI. Auflage. London I883.

Durch diese Arbeiten ist das Prinzip der französischen Stempelung vollkommen aufgeklärt, von der grossen Zahl der existirenden Controllmarken sind die 'meisten richtig gedeutet, und es fehlt hauptsächlich nur noch eine ausgedehntere Erklärung der Meistermarken.

Unter diesen Umständen beschränke ich mich darauf, von den verschiedenartigen Controllmarken, zum Theil nach den oben citirten Werken, eine Auswahl zu geben, und Meistermarken nur soweit anzuführen, als ich im Stande bin, sie mit einiger Sicherheit zu deuten.

Wer das Verhältniss kennt, in welchem Paris zur Provinz steht, wird es nicht auffallend finden, dass in dieser auf das Allgemeine gehenden Uebersicht nur diese eine Stadt beriicksichtigt worden ist. 


\section{PARIS.}

\begin{tabular}{|c|c|c|c|}
\hline $\begin{array}{l}\text { Lf. } \\
\text { Nr. }\end{array}$ & $\begin{array}{l}\text { Beschau- } \\
\text { zeichen }\end{array}$ & $\begin{array}{l}\text { Meister- } \\
\text { zeichen }\end{array}$ & - Gegenstand - Besitzer \\
\hline I 812 & ${ }_{\text {mit Krone }} \mathrm{P}^{\kappa i}$ & \multicolumn{2}{|c|}{$\begin{array}{l}\text { Stadtzeichen von I } 260 . \\
\text { Chaffers, Hall marks S. } 278 \text {. }\end{array}$} \\
\hline I8I3 & ? & \multicolumn{2}{|c|}{$\begin{array}{l}\text { I275 wird urkundlich zum ersten Male ein Stadt } \\
\text { zeichen verlangt. }\end{array}$} \\
\hline I8I4 & $\begin{array}{l}\text { Lilie } \\
\text { in rhombische } \\
\text { Felde }\end{array}$ & \multicolumn{2}{|c|}{$\begin{array}{l}\text { Stadtzeichen in I4. und I 5. Jahrhundert. } \\
\text { Cripps, French plate S. } 37 .\end{array}$} \\
\hline I 8 I 5 & $\begin{array}{c}\text { Lilie } \\
\text { mit einem } \\
\text { Buchstaben }\end{array}$ & \multicolumn{2}{|c|}{$\begin{array}{l}\text { Das Stadtzeichen erscheint mit dem Jahresbuch } \\
\text { staben verbunden etwa von 1461 bis 1650. }\end{array}$} \\
\hline & \multicolumn{3}{|c|}{$\begin{array}{l}\text { Um diese Zeit werden die Marken der Pächter (Pächter der } \\
\text { Stempelsteuer) eingeführt, und da deren Zeichen in den verschiedenen } \\
\text { Städten aus verschiedenen Buchstaben bestehen, bieten sie der For- } \\
\text { schung dieselbe Handhabe wie die Beschauzeichen. . Wir setzten aus } \\
\text { diesem Grunde die folgenden Zeichen in die Rubrik der Beschauzeichen. } \\
\text { Ich fusse dabei vornehmlich auf die mir vorliegende Literatur } \\
\text { und bemerke ausdrücklich, dass ich manche offenbar ungenaue Angabe } \\
\text { mit aufnehmen musste, weil es mich zu weit geführt haben würde, das } \\
\text { Richtige aus den Quellen selbst zu schöpfen. }\end{array}$} \\
\hline 1816 & & \multirow[t]{2}{*}{ I 672 bis I 680} & \multirow{3}{*}{ Stadtzeıchen der Pächter. } \\
\hline I 8 I 7 & & & \\
\hline I8 8 I & & I 680 bis 1684 & \\
\hline
\end{tabular}




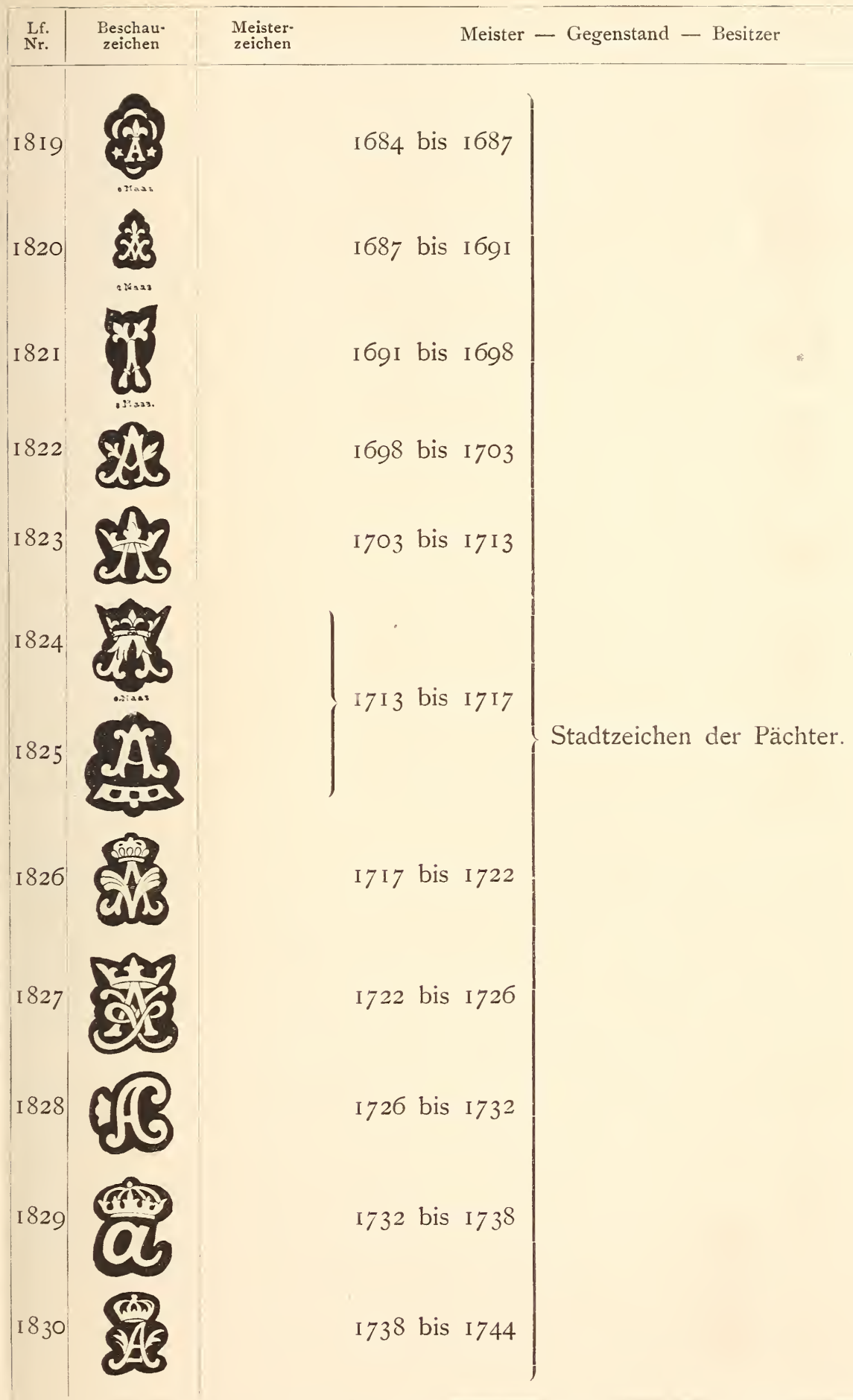




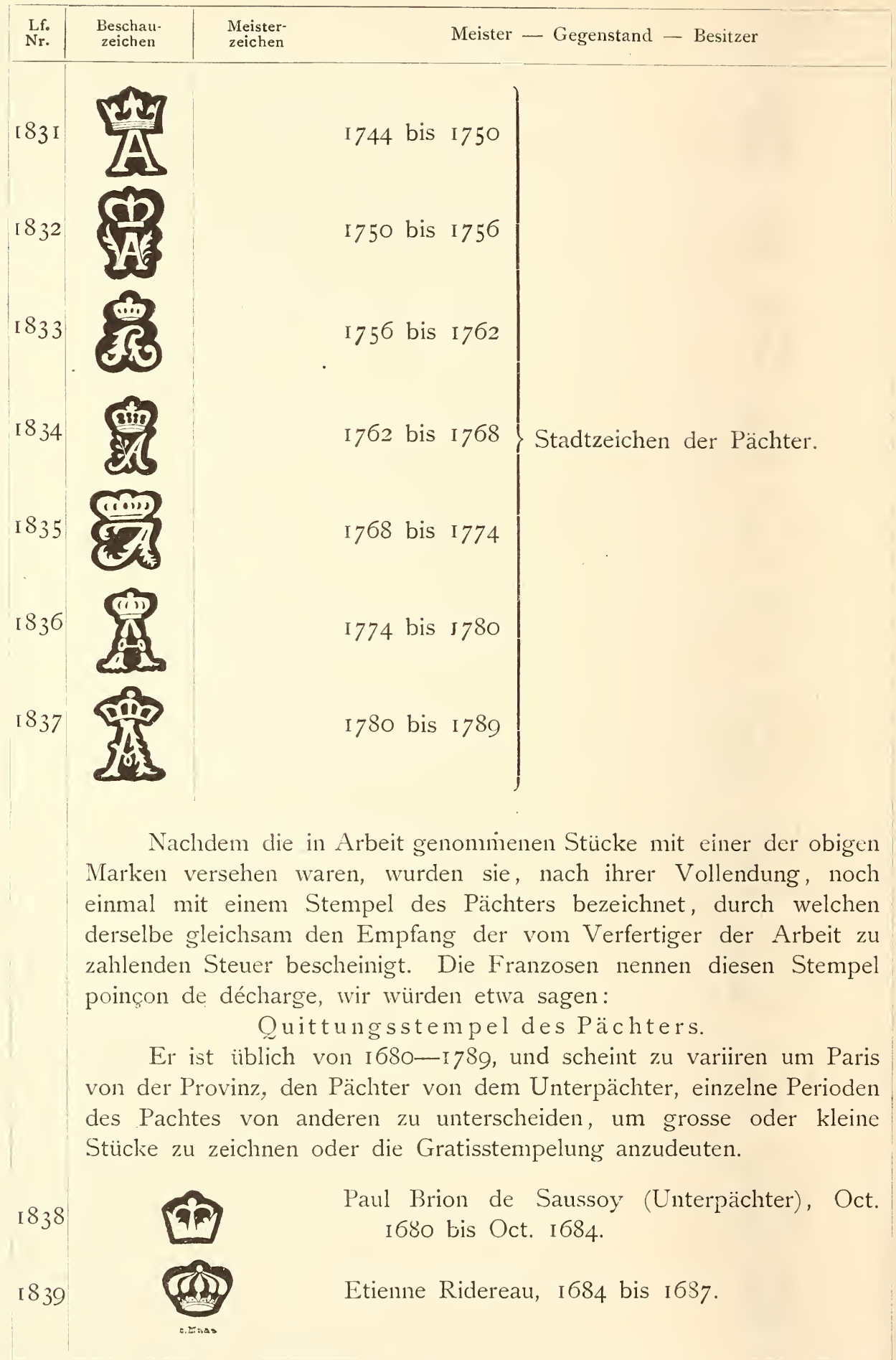




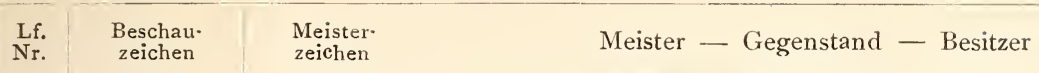

Jacques Leger, Oct. I687 bis Dez. I69 I.

I 84 I

Pierre Pointeau, Dez. I69 I bis I698.

I 842

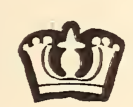

Perrine, 1698 bis I 703.

I 843

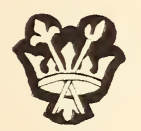

I 844

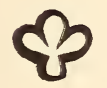

Etienne Baligny, I7O3 bis Dez. I7 I3.

Die zweite Marke sollte eine Fliege sein.

I 845

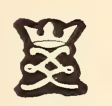

I 846

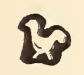

Florent Sollier, Dez. I7 3 bis Oct. I7 I7.

I 847

I 848

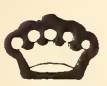

'Etienne de Bouges, Oct. I7I7 bis I722.

I 849

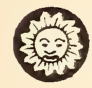

I 850

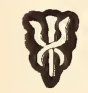

Charles Cordier, I 722 bis Nov. I 726.

I 85 I

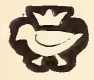

I 852

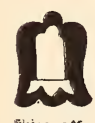

Jacques Cottin, Dez. I726 bis Oct. I732.

Die zweite Marke ist in dieser auffallenden Art bei Cripps angegeben. 


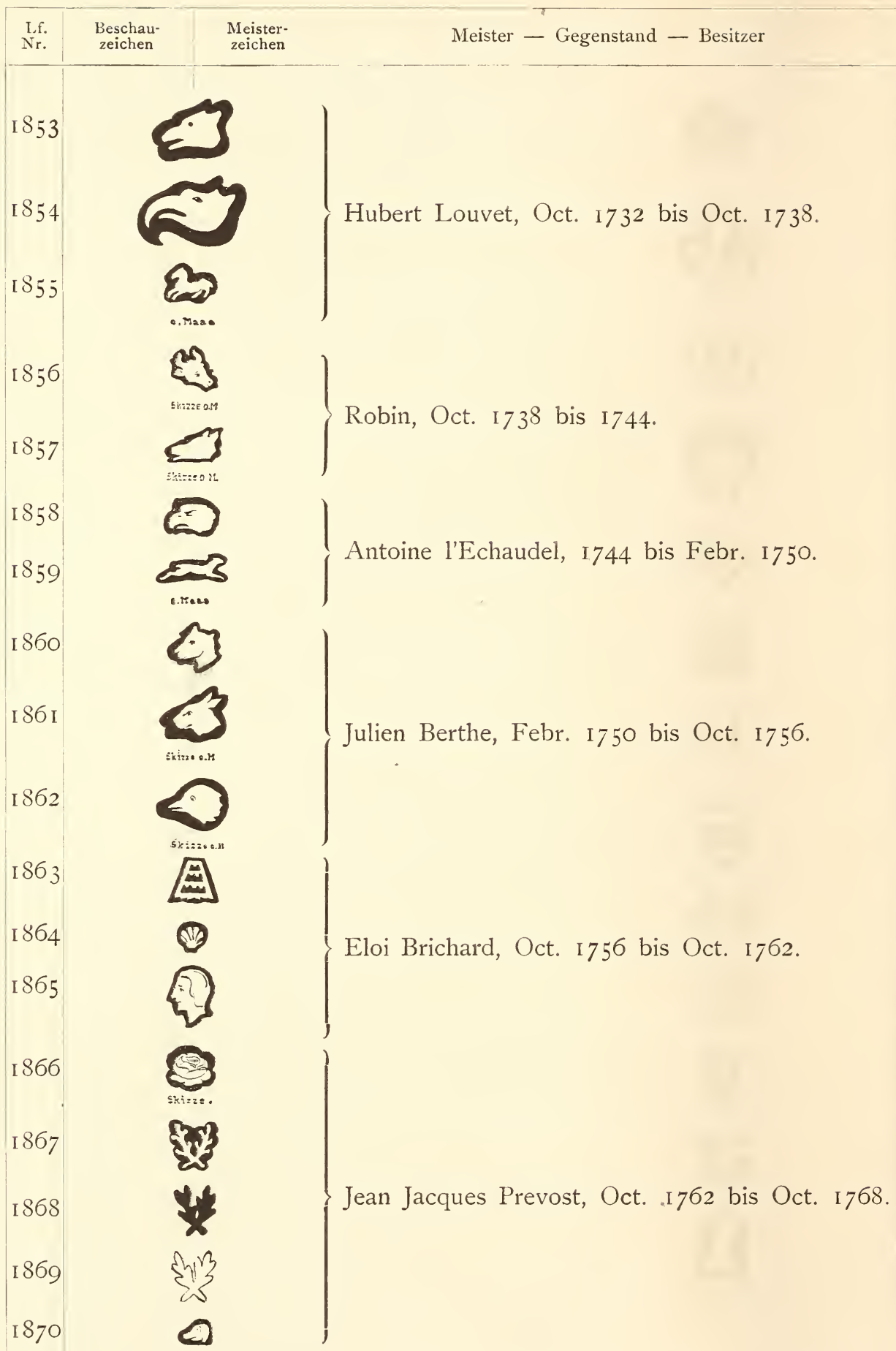




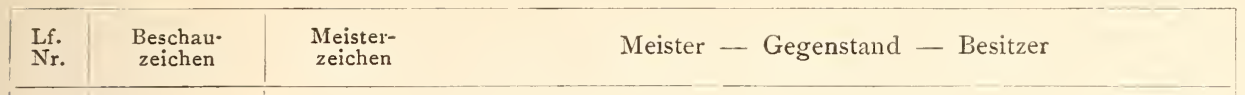

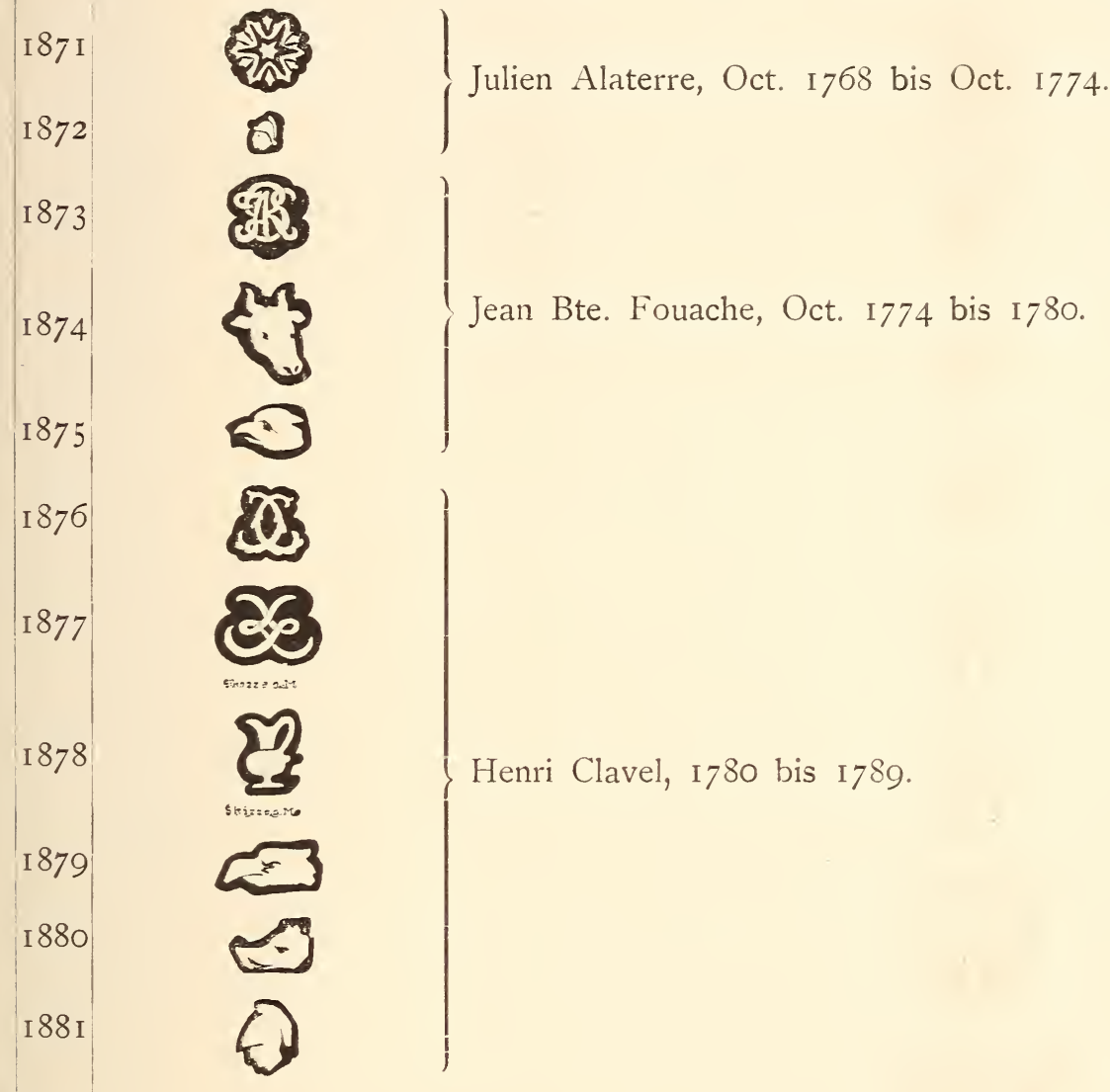

Während des Ueberganges vom I5. zum I6. Jahrhundert, etwa seit I46I, kommt zu dem Stadtzeichen noch ein Jahresbuchstabe.

Eine urkundliche Erwähnung desselben kommt erst I506 vor. Auf erhaltenen Arbeiten nachweisbar ist er nicht früher als 1649.

I 882

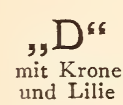
I649 bis 1650
Cripps, French
plate S. 39 . 


I68 I bis I682


\begin{tabular}{l|l|l} 
Lf. & $\begin{array}{c}\text { Beschau. } \\
\text { zeichen }\end{array}$ & Meister. \\
zeichen
\end{tabular} zeichen

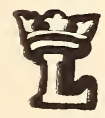

1727 bis 1728

1900

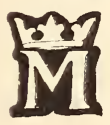

I728 bis 1729

I9O I

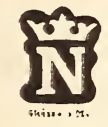

1902

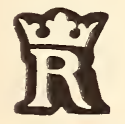

1903

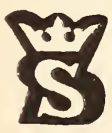

1734 bis 1735

I729 bis I730

Jahresbuchstaben für Silber.

1904

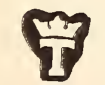

I735 bis 1736

1905

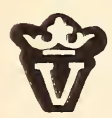

I733 bis I734

I736 bis 1737

1906

1738 bis 1739

1907

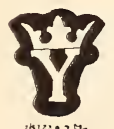




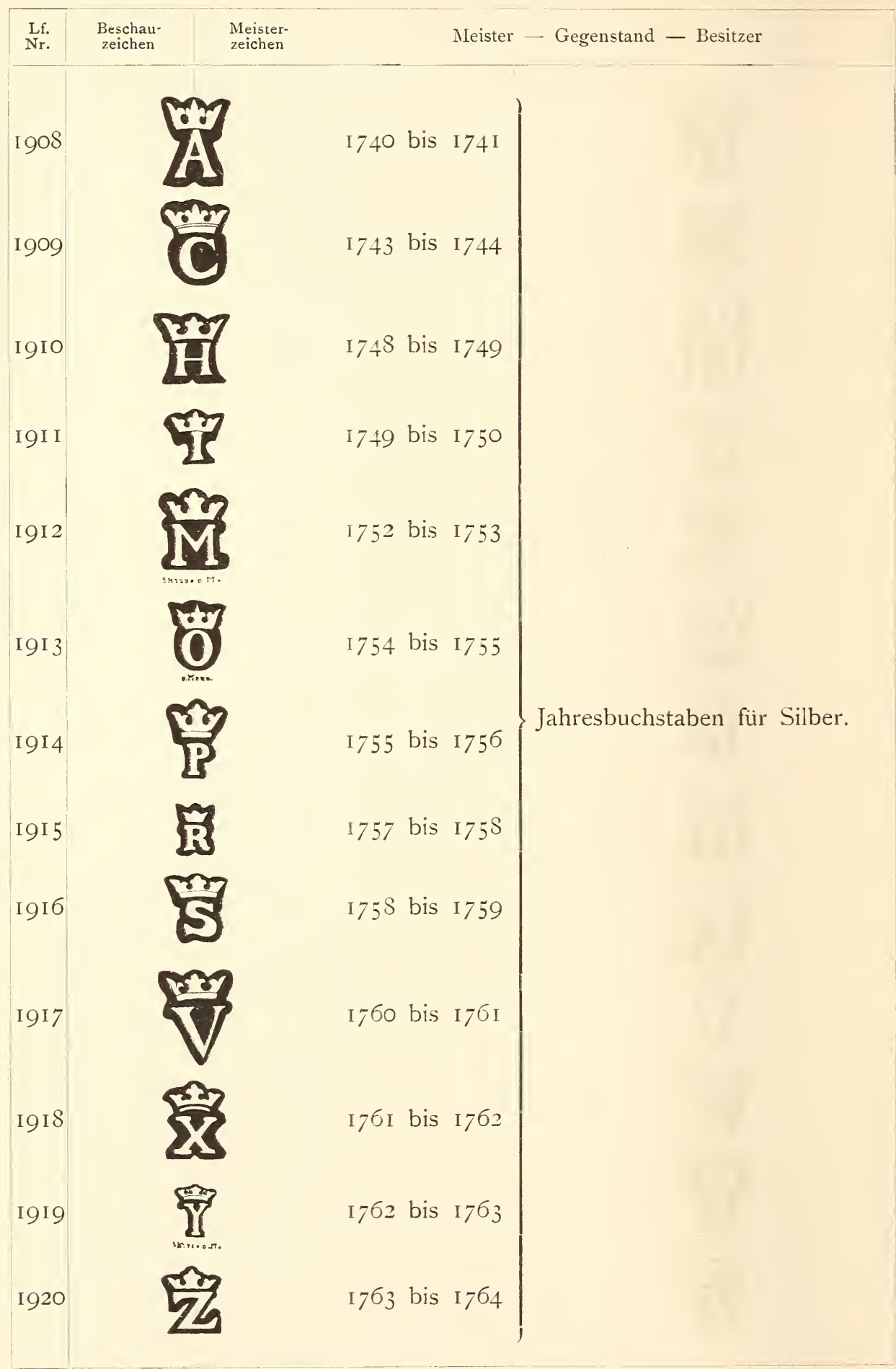




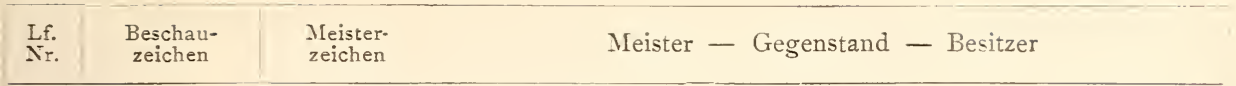

I92I

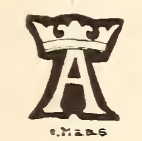

I764 bis 1765
I765 bis 1766

192.2

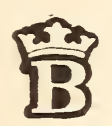

I 766 bis 1767

I923

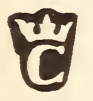

1

I924

Eี

I 67 bis I 768

I925

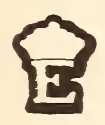

I 768 bis 1769

I926

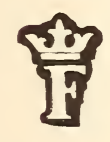

I769 bis 1770

I927

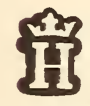

I928

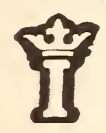

I $77 \mathrm{I}$ bis $\mathrm{I} 772$

1772 bis 1773

Jahresbuchstaben für Silber.

I929

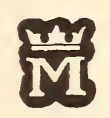

I775 bis 1776

I930

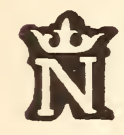

I 776 bis 1777

I93 I

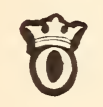

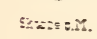

1777 bis 1778

1932

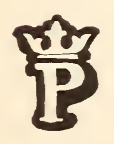

I933

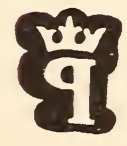

I778 bis I779

I779 bis I780 


I7780 bis I78 I




\begin{tabular}{|c|c|c|c|}
\hline $\begin{array}{l}\text { Lf. } \\
\text { Nr. }\end{array}$ & $\begin{array}{l}\text { Meister- } \\
\text { zeichen }\end{array}$ & Meister & — Gegenstand - Besitzer \\
\hline 1946 & है & 1761 bis 1762 & \\
\hline 1947 & 보 & I 762 bis 1763 & \\
\hline I948 & 2 & 1763 bis I764 & \\
\hline I949 & 2 & I 764 bis 1765 & \\
\hline 1950 & 8 & I765 bis 1766 & \\
\hline I95 I & 9 & I 767 bis 1768 & \\
\hline 1952 & $\mathcal{E}$ & I768 bis 1769 & \\
\hline 1953 & g & $\mathrm{I} 770$ bis $177 \mathrm{I}$ & \\
\hline 1954 & 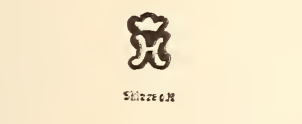 & I $77 \mathrm{I}$ bis 1772 & Jahresbuchstaben für Gold. \\
\hline I955 & 8 & I 772 bis 1773 & \\
\hline 1956 & $\frac{\pi}{6}$ & 1773 bis 1774 & \\
\hline 1957 & $\mathbb{E}$ & I 774 bis 1775 & \\
\hline 1958 & $\underset{8}{20}$ & I 775 bis 1776 & \\
\hline 1959 & $\mathcal{J}$ & $\mathrm{I} 778$ bis 1779 & \\
\hline 1960 & $\widehat{R}$ & I 780 bis I $78 \mathrm{I}$ & \\
\hline 1961 & 8 & I781 bis 1782 & \\
\hline
\end{tabular}




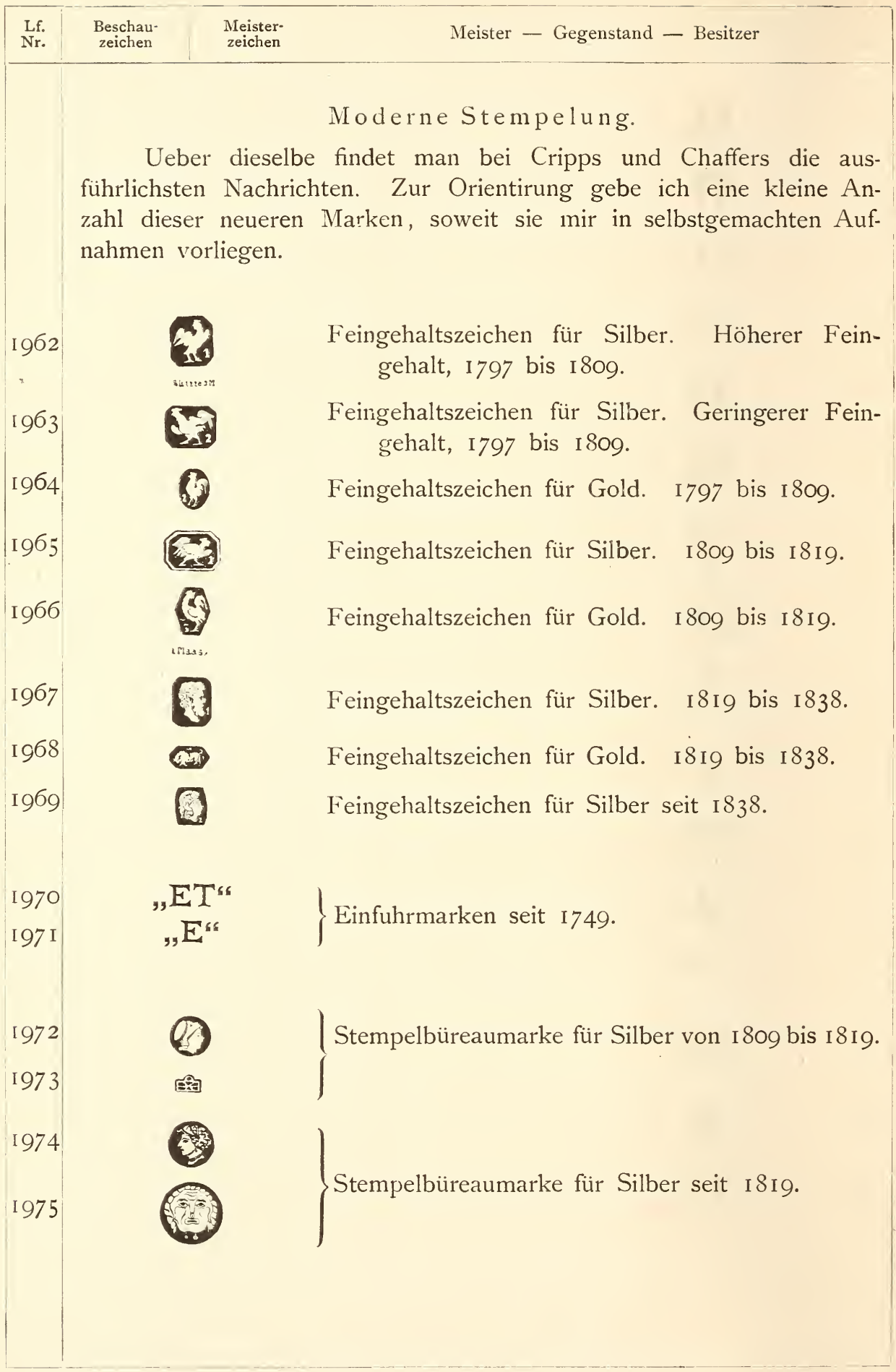


Lf. Beschau.
Nr.
Meisterzeichen

\author{
Meister - Gegenstand - Besitzer
}

\section{Meisterstempel.}

In Etienne Boileau, livre des métiers, um I 268 ist noch von keinerlei Stempelung die Rede. In einer Bestimmung von I 275 wird, wie es scheint, das Meisterzeichen als üblich vorausgesetzt, aber erst in der Verordnung von I 355 ist eine Bestimmung enthalten, nach welcher man unter gewissen Bedingungen berechtigt ist, sich in Paris als Goldschmied niederzulassen und ein eigenes Meisterzeichen $z$ u führen: d'avoir poinçon à contreseign.

Seit I493 ist dieser contreseign für a lle Goldschmiede gleichmässig eine Lilie mit zwei Punkten neben den Initialen, somit als eigentliches Unterscheidungsmal wieder aufgehoben.

I 5 c6 bekommen alle Goldschmiede neue Stempel.

In der Deutung der Meistermarken folge ich zum allergrössten Theile dem Vorgange von Eudel, der oft auf Pichon zurückgeht, obgleich mir seine Angaben nicht immer frei von Irrthümern zu sein scheinen. Es fehlt mir aber das Material, um dieselben zu berichtigen.

Nach Pichon

Louis Loir, Zunftvorsteher I692 bis I693.

Claude Ballin der Jüngere, Meister I688, † 1754 .

J. B. Loir, thätig I 70 I bis I 7 IS.

A.M Grégoire Massé, um izos.

Nach Eudel

Antoine Jossey, um izi4.

Nach Eudel

Antoine de Saint-Nicolas, thätig izı6 bis 1727 .

Nach Eudel 


\begin{tabular}{l|l}
\hline $\begin{array}{c}\text { Leschau- } \\
\text { zeichen }\end{array}$ \\
Nr.
\end{tabular}




\begin{tabular}{|c|c|c|c|}
\hline $\begin{array}{l}\text { Lf. } \\
\text { Nr. }\end{array}$ & $\begin{array}{l}\text { Beschau- } \\
\text { zeichen }\end{array}$ & $\begin{array}{l}\text { Meister- } \\
\text { zeichen }\end{array}$ & Meister - Gegenstand - Besitzer \\
\hline I995 & & & $J_{x}$ Formey, thätig I756 bis I 768 . \\
\hline I996 & & & $\begin{array}{l}\text { Robert-Jacques (Joseph) Auguste, } \\
\text { Ciseleur, dann I } 757 \text { Meister bei den Gold- } \\
\text { schmieden. }\end{array}$ \\
\hline I997 & & & $\begin{array}{l}\text { Nach Pichon } \\
\text { Henri Allain, um I } 758 .\end{array}$ \\
\hline I998 & & & $\begin{array}{l}\text { Jean-Charles Ducrollay, Meister } 1737 \\
\text { bis } 176 \mathrm{r} .\end{array}$ \\
\hline I999 & - & & $\begin{array}{l}\text { Nach Eudel } \\
\text { Alexander de Roussy, thätig } 17 \sigma_{5} \text { bis } \\
\text { I777. }\end{array}$ \\
\hline 2000 & - & & $\begin{array}{l}\text { Nach Pichon } \\
\text { Jean Baptiste Cheret, um I } 766 \text { bis i } 786 .\end{array}$ \\
\hline $200 \mathrm{I}$ & & & P. Drais (Draise?), thätig I772 bis I774. \\
\hline 2002 & & & $\begin{array}{l}\text { Nach Pichon } \\
\text { Claude Nicolas Delanoy, thätig } 1772 \\
\text { bis } 1775 .\end{array}$ \\
\hline 2003 & & & $\begin{array}{l}\text { Nach Eudel } \\
J_{*} \text { T. Vanconverberghen, thätig I } 775 \\
\text { bis I } 784 .\end{array}$ \\
\hline 2004 & & & $\begin{array}{l}\text { Vielleicht } \\
\text { Charles Sprimann, um } 1776 \text { bis } 1778 .\end{array}$ \\
\hline 2005 & & & $\begin{array}{l}\text { Nach Eudel } \\
\text { Marc Etienne Janety, thätig I } 777 \text { bis } \\
\quad \text { I } 784 \text {. }\end{array}$ \\
\hline 2006 & & & J* B. C. Odiot, um I797. \\
\hline 2007 & & & Biennais, um isig. \\
\hline
\end{tabular}




\section{GROSSBRITANNIEN.}

Besser noch als über Frankreich sind wir über die Stempelung in England, Schottland und Irland unterrichtet.

Den besten Aufschluss geben folgende Bücher:

I) The book of hall marks. London bei Hotten 1872. Bespricht die praktische Handhabung der modernen Stempelung.

2) Chaffers, Hall marks on plate. London bei Bickers \& Son. 6. Auflage I 883 .

3) Cripps, Old English plate. London bei Murray i 878 .

Die beiden letzteren Schriftsteller behandeln den Gegenstand unter ähnlichen Gesichtspunkten, und man wird bei eingehenderen Studien beide Werke zu Rathe ziehen müssen.

4) Chaffers, Gilda aurifabrorum. London bei Allen \& Co. I883. Beschäftigt sich hauptsächlich mit den Londoner Meistermarken.

Aus diesen vier Schriften habe ich, um wenigstens eine Uebersicht über die Stempelung in Grossbritannien zu geben, eine Reihe von Marken mit ihren Erklärungen herausgezogen und da und dort, was mir an eigenen Aufnahmen vorlag, angereiht.

Angesichts des bereits vorliegenden umfangreichen gedruckten Materials beschränke ich mich auf die drei Hauptstädte London, Edinburgh und Dublin. 


\section{LONDON.}

Manche der hier folgenden Angaben gehören eigentlich unter die Rubrik Grossbritannien, doch setze ich sie der Einfachheit halber hierher. Aus demselben Grunde habe ich noch andere Abweichungen eintreten lassen. So steht z. B. der Leopardenkopf in der Rubrik Beschauzeichen, obgleich er eigentlich das nicht ist, was man in den Deutschen Städten unter Beschauzeichen versteht.

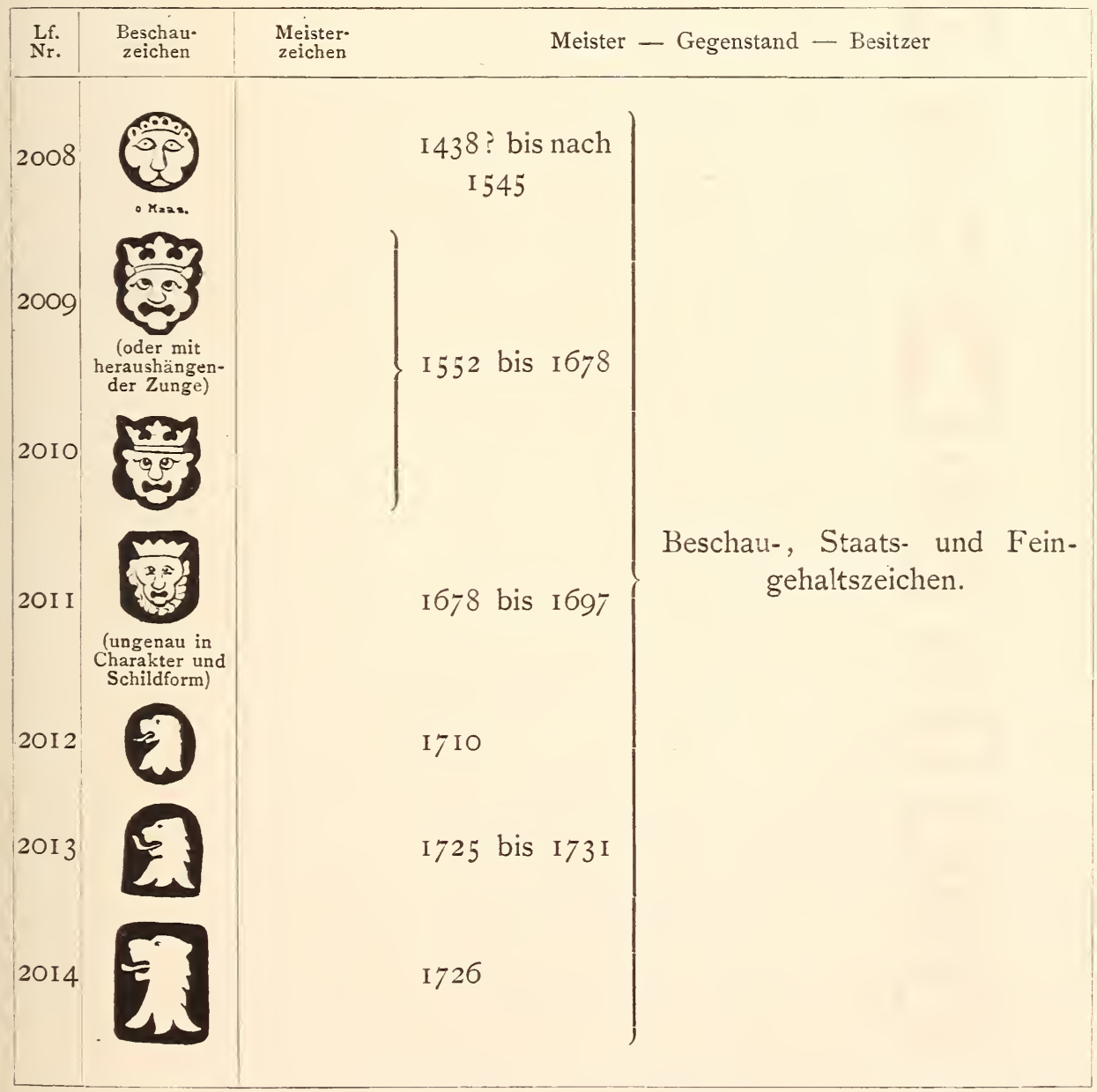




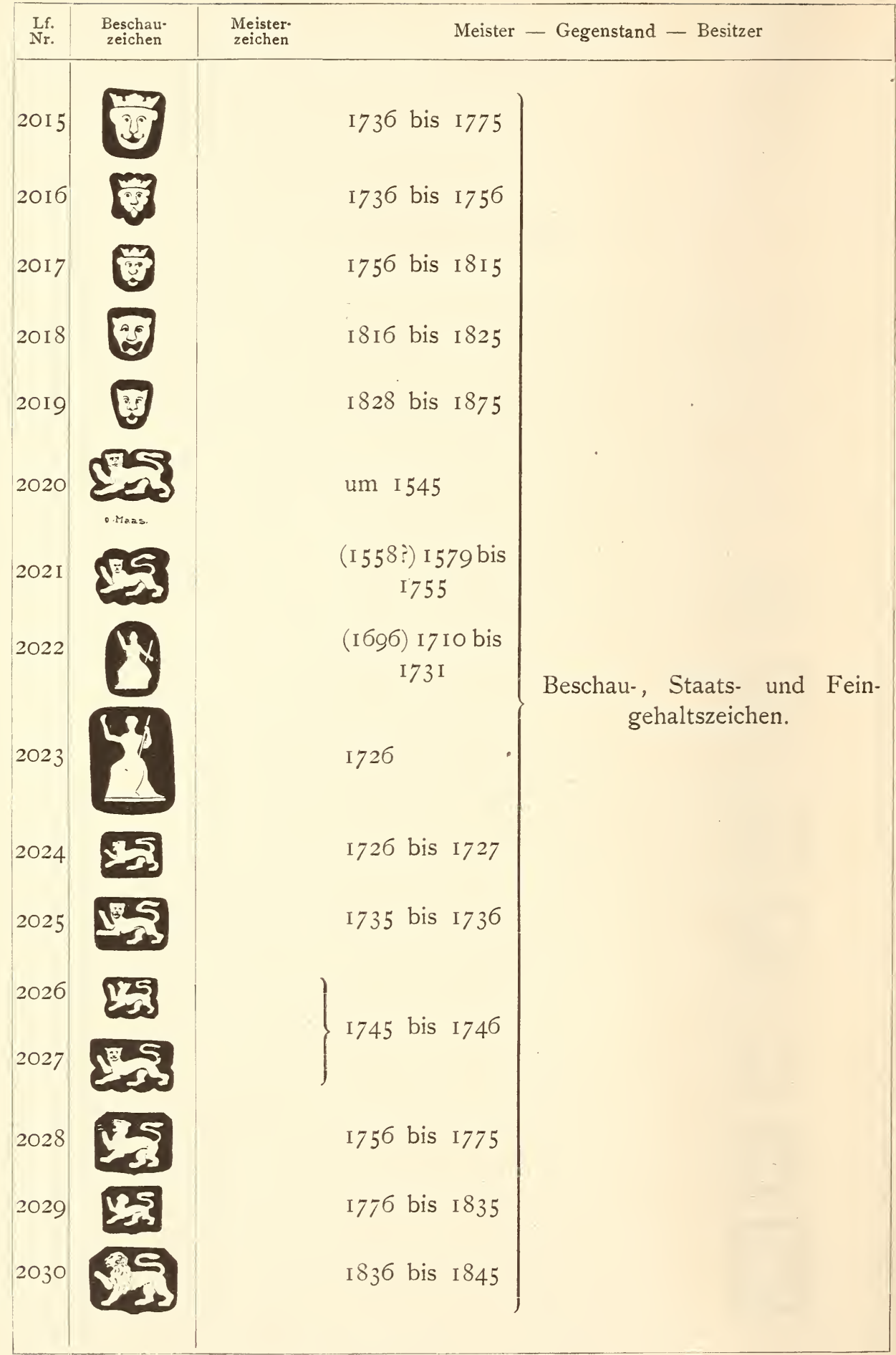




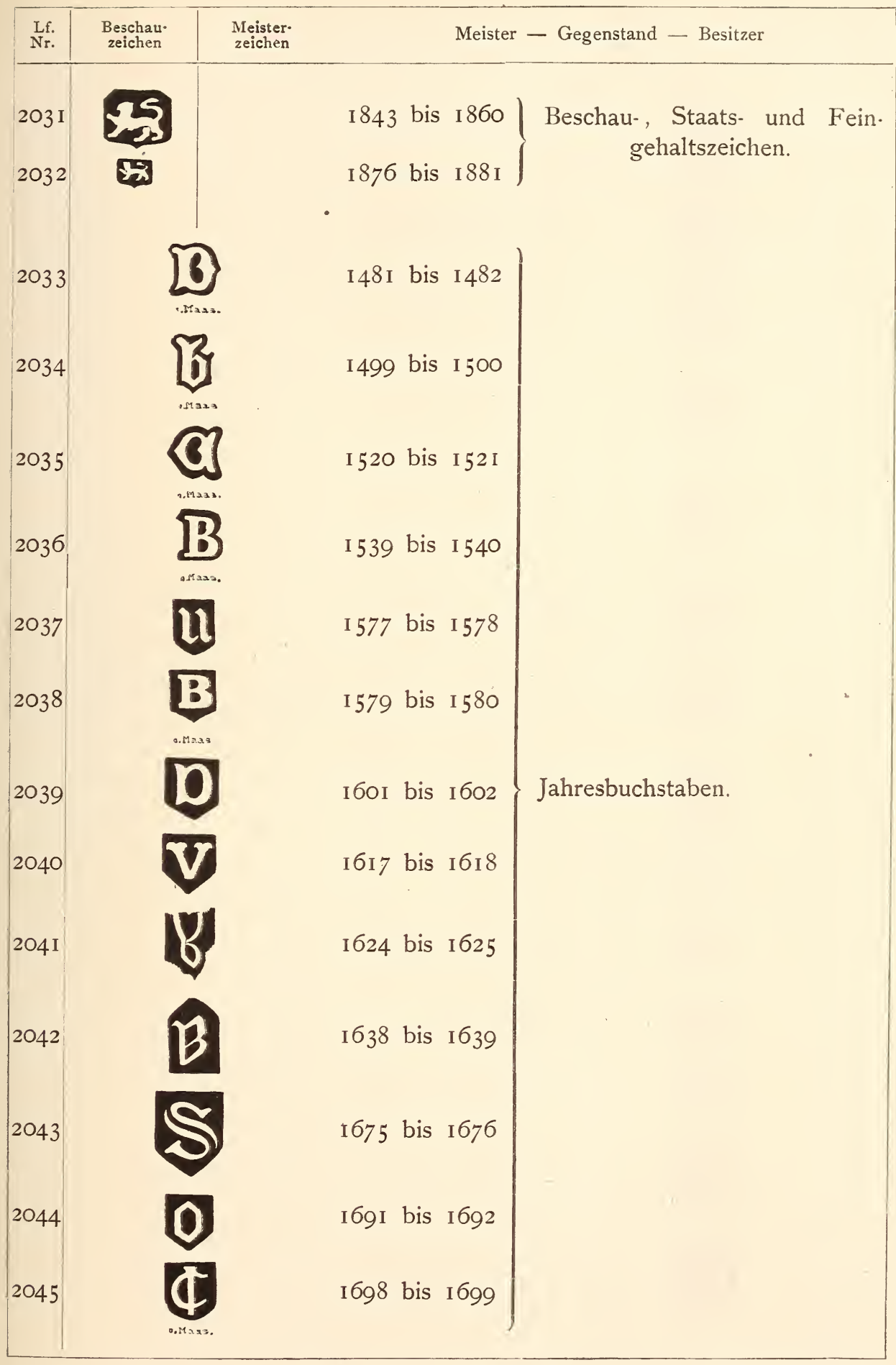




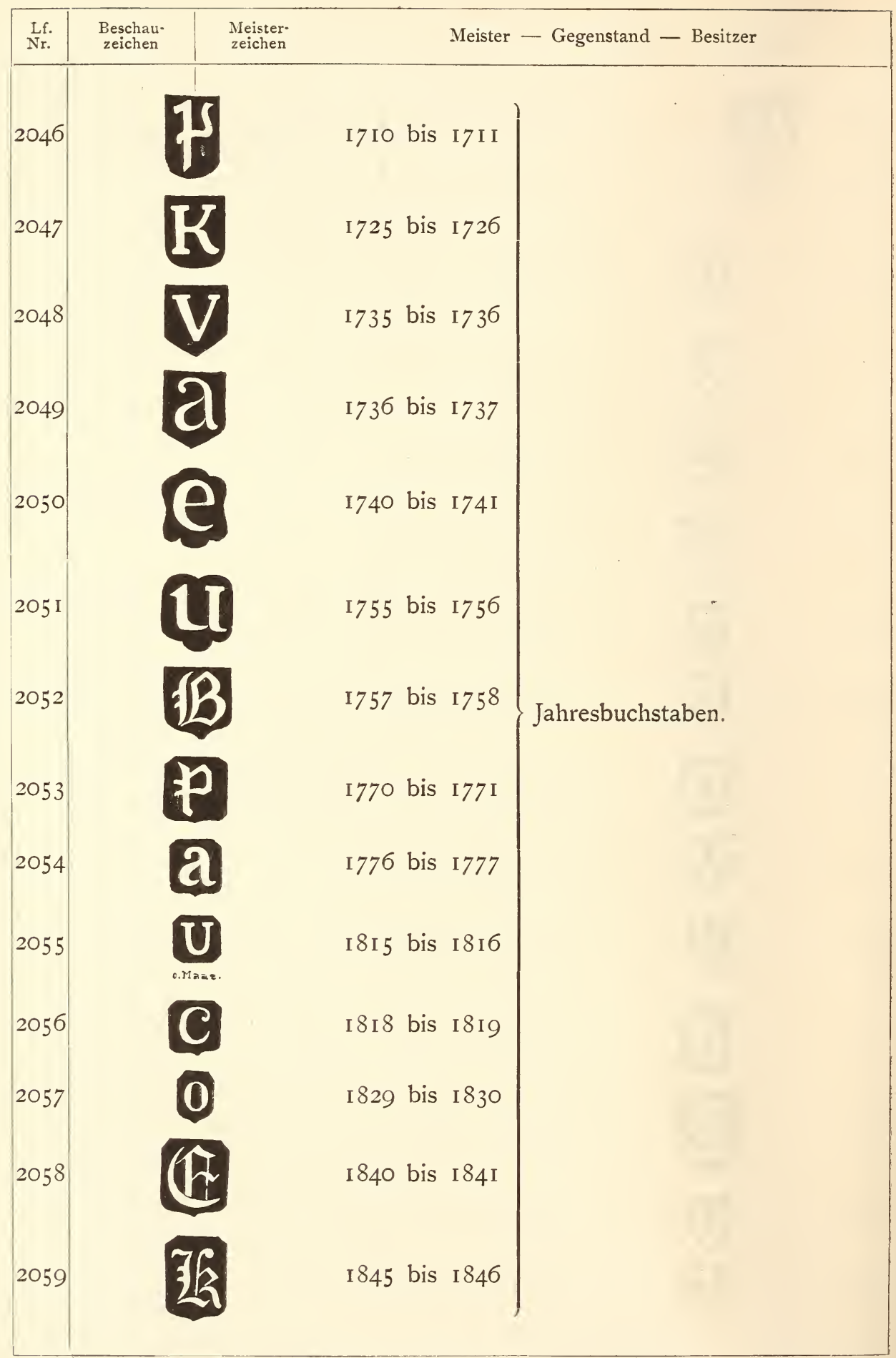




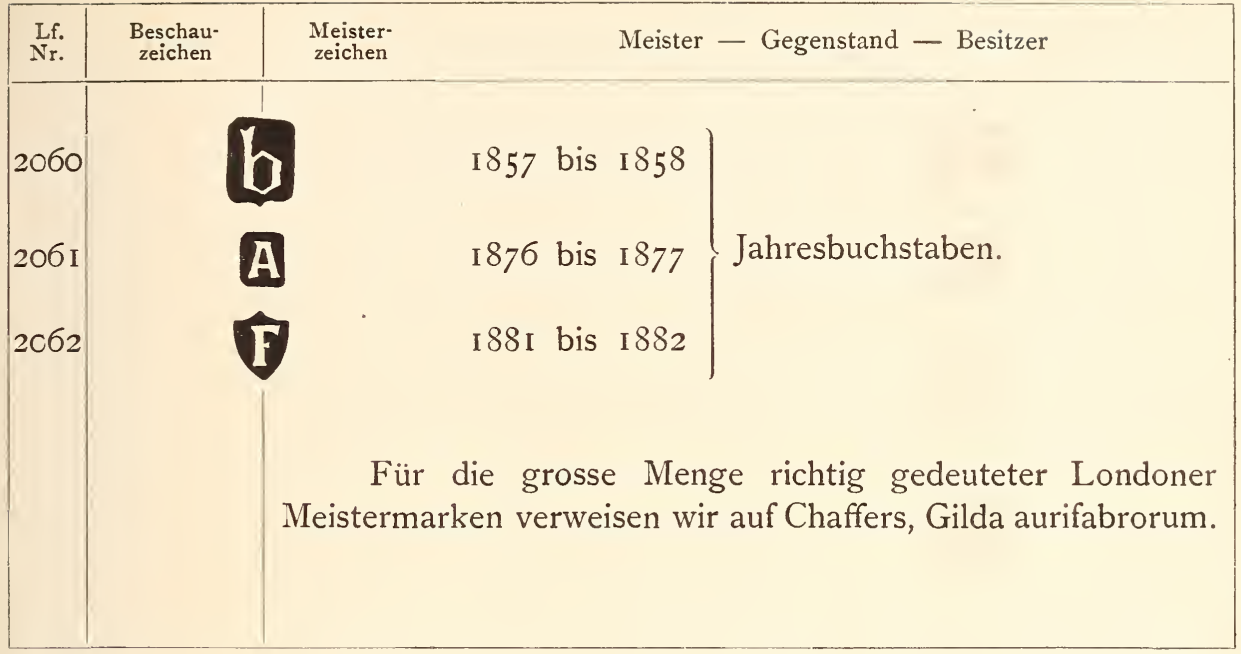

\section{EDINBURGH.}

\begin{tabular}{|c|c|c|c|}
\hline $\begin{array}{l}\text { Lf. } \\
\text { Nr. }\end{array}$ & $\begin{array}{l}\text { Beschau- } \\
\text { zeichen }\end{array}$ & $\begin{array}{l}\text { Meister- } \\
\text { zeichen }\end{array}$ & Meister - Gegenstand - Besitzer \\
\hline 2063 & 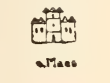 & & Beschauzeichen, um I628? \\
\hline 2064 & - & & Beschauzeichen, um I642. \\
\hline 2065 & 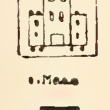 & & Beschauzeichen, um I7I3. \\
\hline 2066 & . & & Beschauzeichen, um I749. \\
\hline 2067 & שיח & & Beschauzeichen, um 1757. \\
\hline $2 c 68$ & 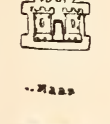 & & Beschauzeichen, um I766. \\
\hline 2069 & Difion & & Beschauzeichen, I9. Jahrhundert. \\
\hline
\end{tabular}




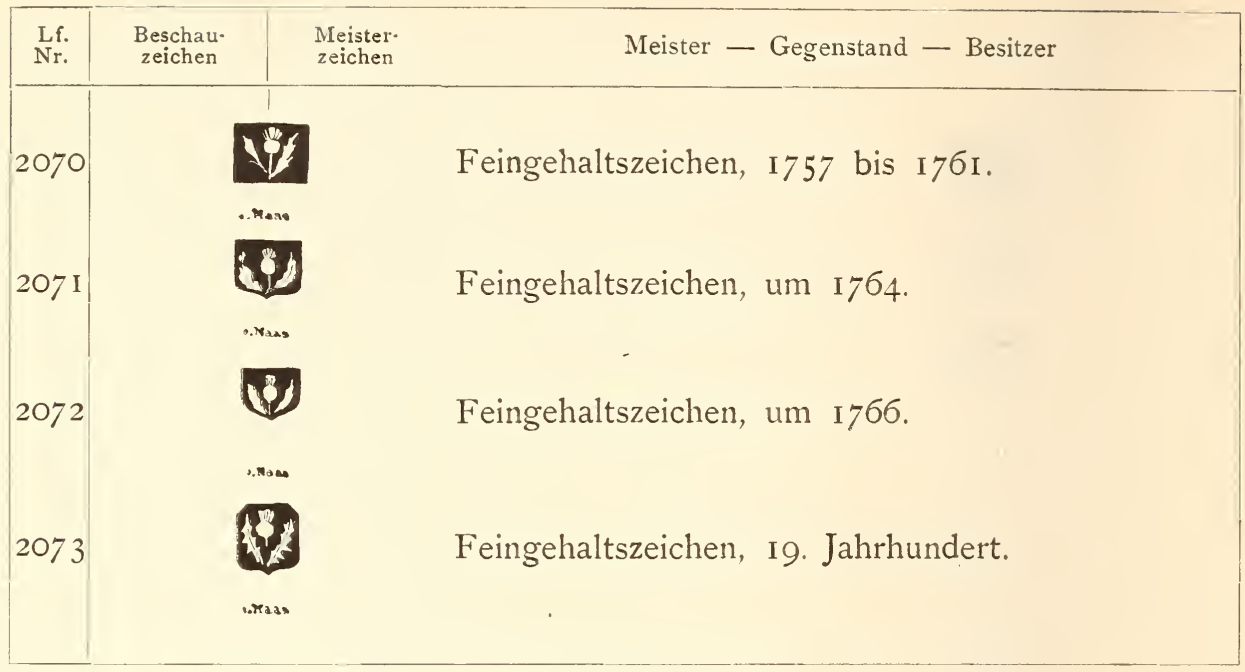

\section{DUBLIN.}

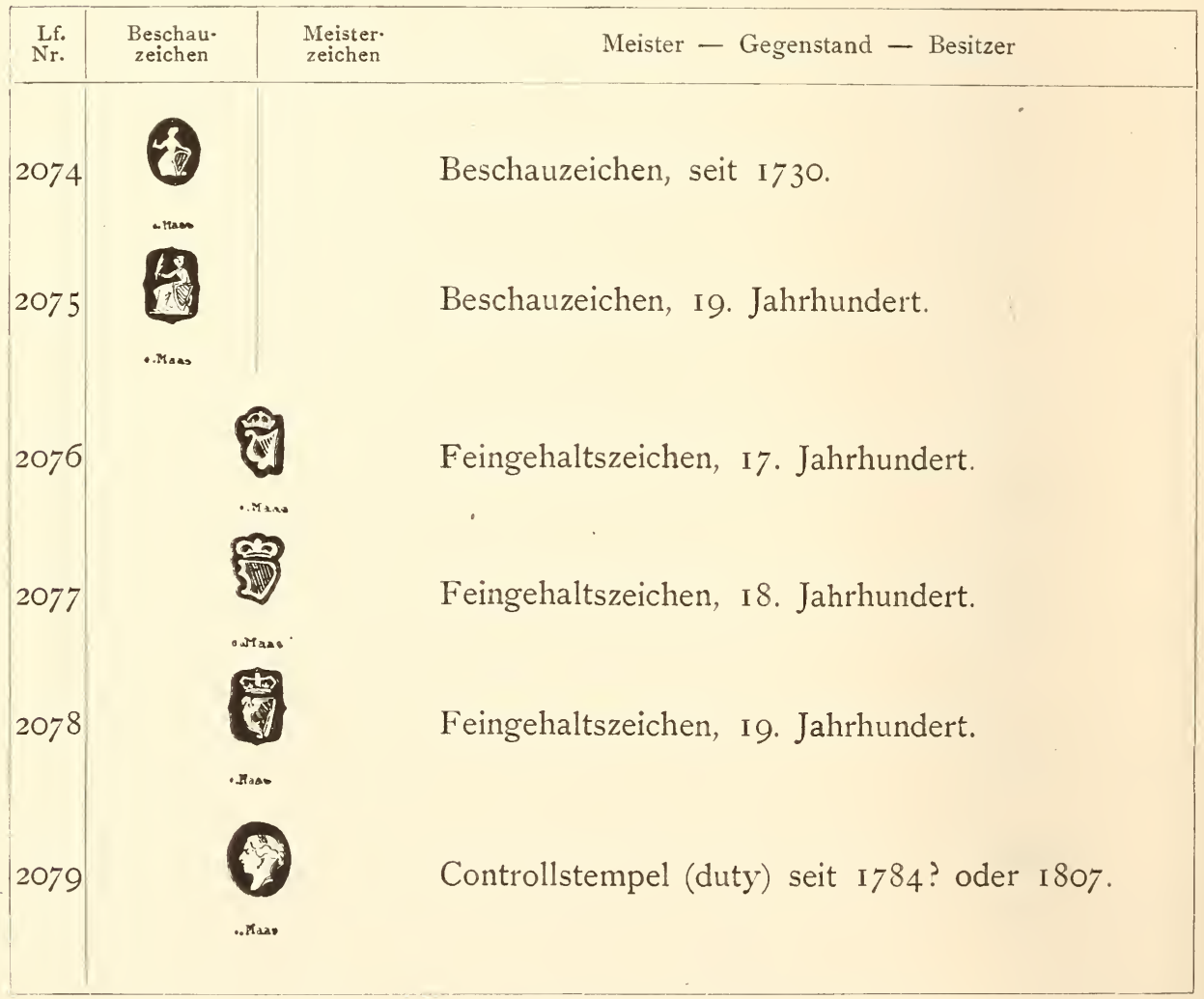




\section{ITALIEN.}

Die folgenden mehr zufällig gefundenen, als systematisch gesammelten Nachrichten über die neuere Stempelung in Italien vermögen natürlich kein Bild von dem Reichthum dieses Landes an guten alten, mit dem vollen Namen des Verfertigers bezeichneten, oder mit Stempeln versehenen Arbeiten zu geben. Ich hoffe dieselben an anderer Stelle später zu bringen, da meine eigenen Aufnahmen vorderhand im Verhältniss zu dem Vorhandenen noch sehr gering sind. 


\section{NEAPEL.}

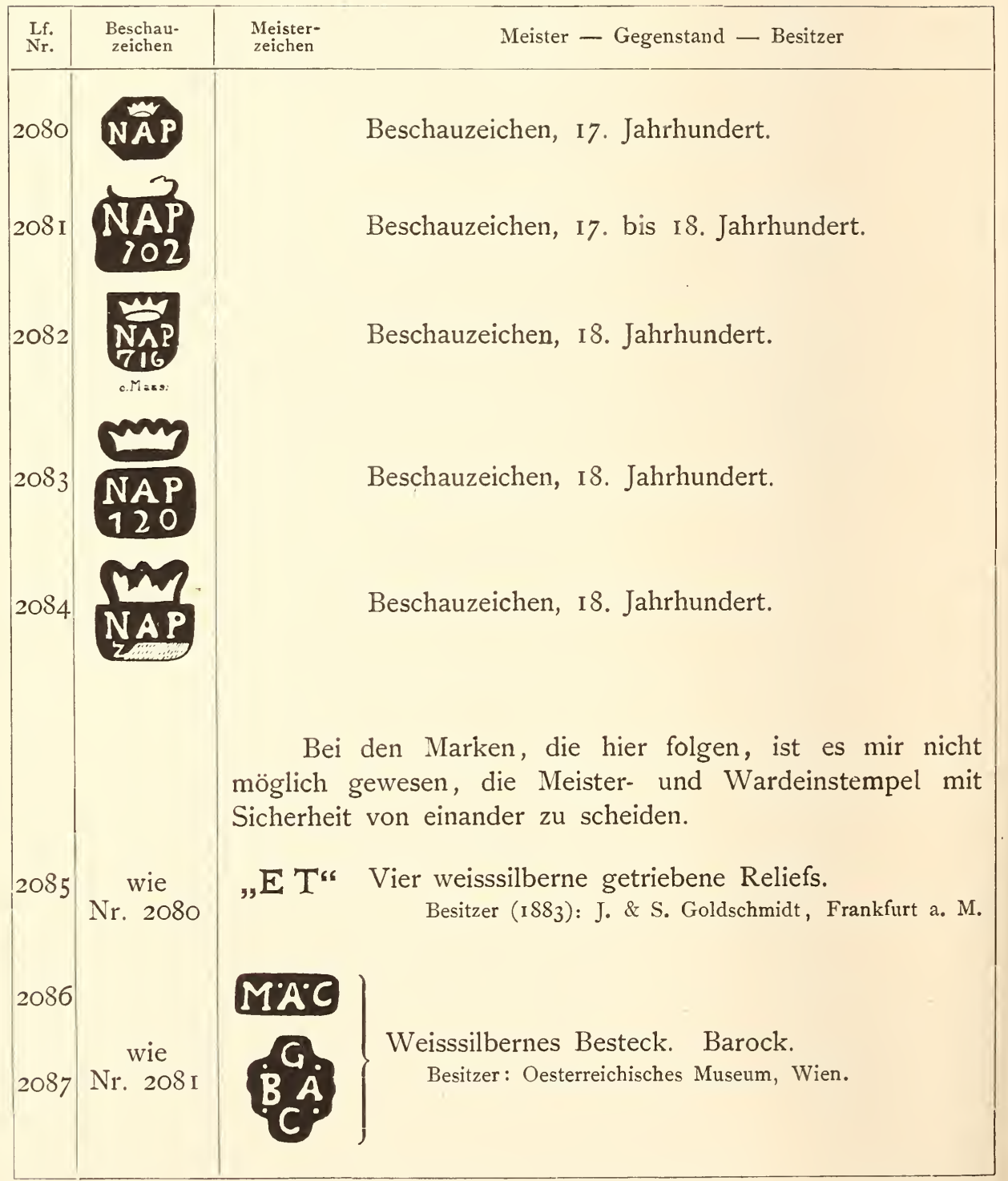




\begin{tabular}{|c|c|c|c|}
\hline $\begin{array}{l}\text { Lff. } \\
\text { Nr. }\end{array}$ & $\begin{array}{l}\text { Beschau- } \\
\text { zeichen }\end{array}$ & $\begin{array}{l}\text { Meister- } \\
\text { zeichen }\end{array}$ & Meister - Gegenstand - Besitzer \\
\hline 2089 & $\begin{array}{l}\text { wie } \\
\text { Nr. } 2082\end{array}$ & & $\begin{array}{l}\text { Besteck. } \\
\text { Besitzer: Professor Church, London. Chaffers, Hall } \\
\text { marks on plate, S. } 220 \text { und } \mathbf{2 2 5} \text {. }\end{array}$ \\
\hline 2090 & Nr. 2083 & & $\begin{array}{l}\text { Weisssilbernes Besteck mit figuralen Griffen. } \\
\text { Besitzer (1883): A. S. Drey, München. }\end{array}$ \\
\hline $2 \mathrm{cg} 2$ & $\begin{array}{l}\text { wie } \\
\text { Nr. } 2084\end{array}$ & & $\begin{array}{l}\text { Grosse getriebene Vase. } \\
\text { Besitzer (1883): A. S. Drey, München. }\end{array}$ \\
\hline
\end{tabular}

\section{PADUA.}

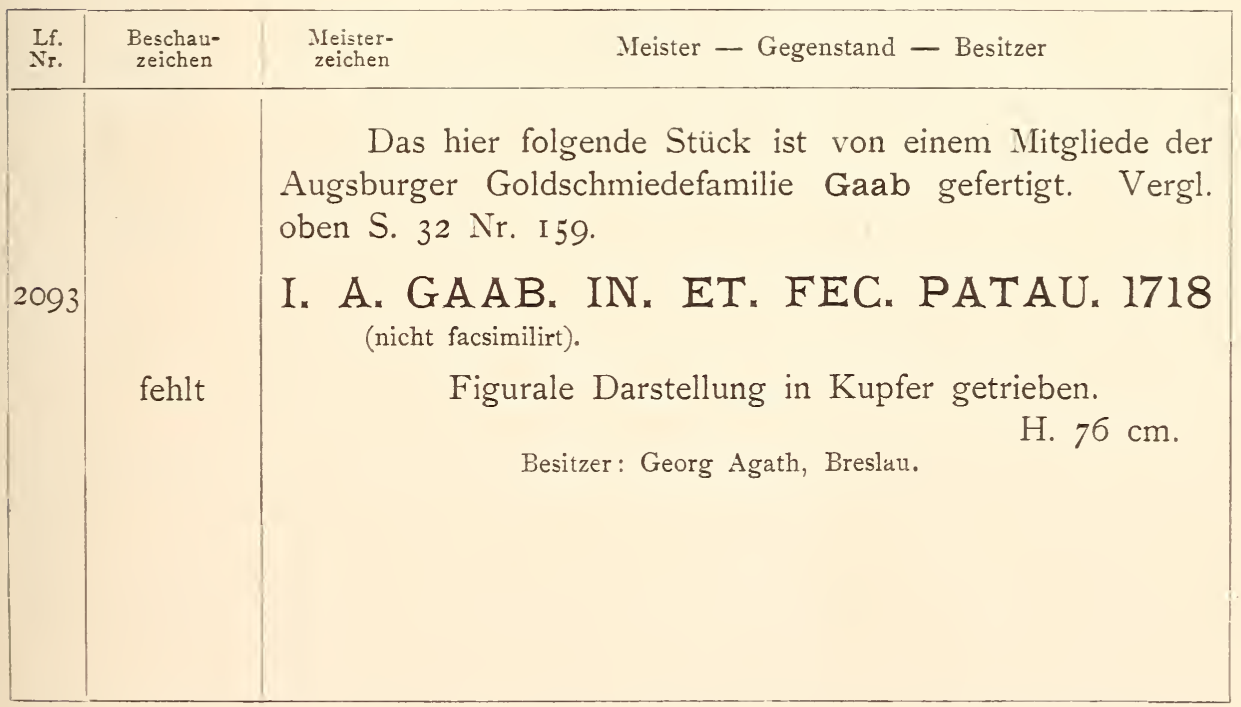




\section{ROM.}

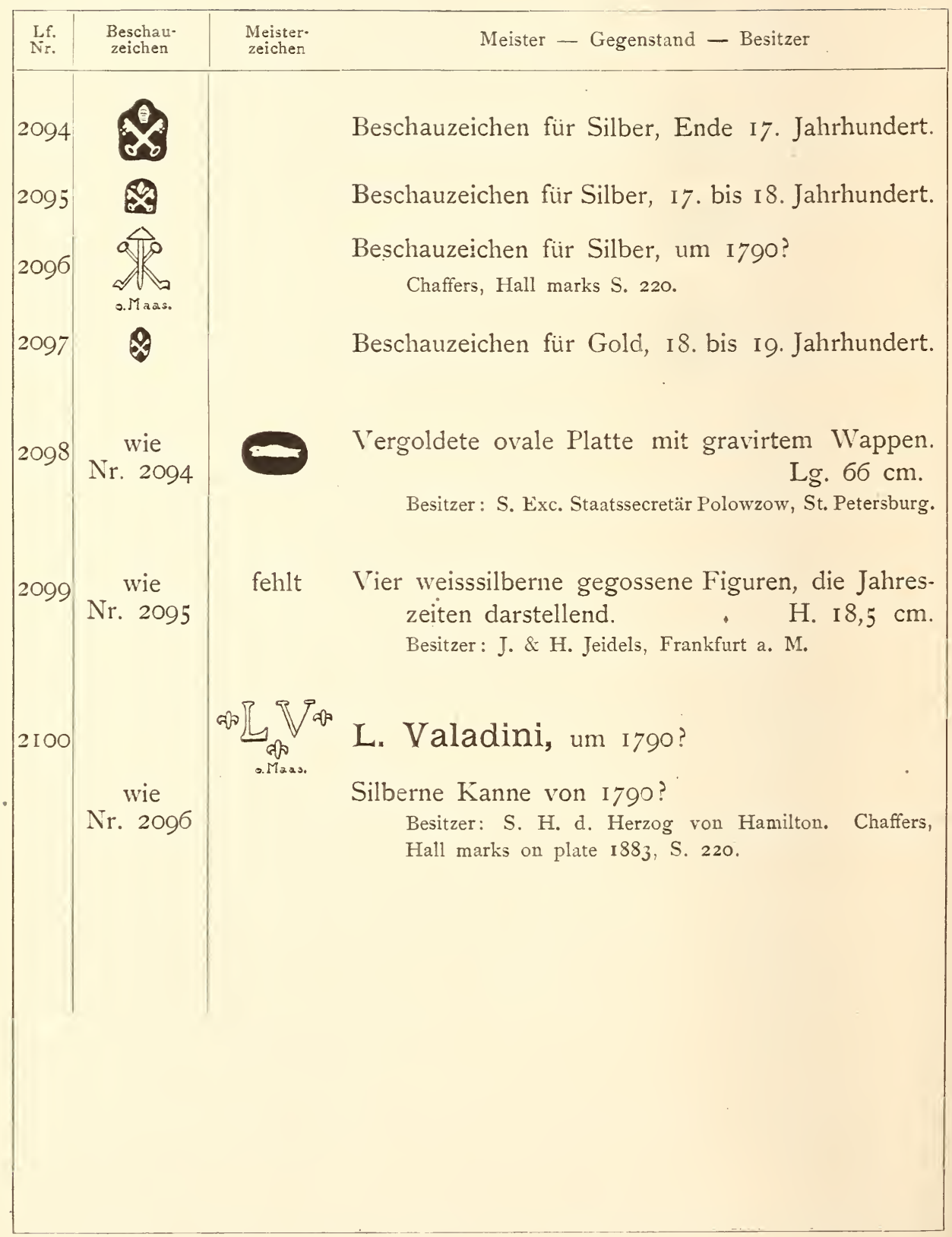




\section{NIEDERLANDE.}

Die Verordnungen, auf Grund deren die gegenwärtige Stempelung gehandhabt wird, sind niedergelegt in:

Wet omtrent den waarborg en de belasting der gouden en zilveren werken. Met aantekeningen door Schuurman. Zwolle bei Tjeenk Willink.

Kürzer und mit Abbildung der Marken versehen ist:

Uittreksel der wet van I8 September 1852 (Staatsblad no. I78) omtrent den waarborg etc., in verband met de wet van 7 Mei 1859 (Staats-. blad no. 3r). Im Haag bei Gebr. Giunta D'albani.

Dieser letzteren Veröffentlichung entnehme ich die folgenden Marken.

$2 \mathrm{IOI}$

2102

$2 \mathrm{IO}$

2104

2105 तु

2106

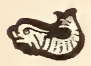

0.Mอละว
Stempelbüreaumarke für Silber.

Der beigefügte Buchstabe wechselt nach den verschiedenen Städten.

Stempelbüreaumarke für Gold.

Der beigefügte Buchstabe wechselt nach den verschiedenen Städten.

Feingehaltszeichen für Silber. Grössere Stücke. 934 fein.

Feingehaltszeichen für Silber. Grössere Stücke. 833 fein.

Feingehaltszeichen für Silber. Kleine Stücke. 934 bis 833 fein.

Feingehaltszeichen für Silber unter 833 fein oder für Gold unter $5^{8} 3$ fein.

Feingehaltszeichen für Gold. Grössere Stücke. 916 fein. 
2108 Feingehaltszeichen für Gold. Grössere Stücke. 833 fein.

2109 Feingehaltszeichen für Gold. Grössere Stücke. 750 fein.

2 I IO

2 I I I Feingehaltszeichen für Gold. Grössere Stuicke. 583 fein.

2II2 Feingehaltszeichen für Gold. Kleinere Stücke. 583 fein.

2II3 Stückcontrolle für Gold mit wechselnder Zahl für die Summe der ein Stück bildenden Einzeltheile.

2I I4

Stempel für im Inland befindliche alte, in den Handel kommende Arbeiten von Silber und Gold.

2II 5

Einfuhrstempel für Silber (und Gold?).

21 I6 E Einfuhrstempel? für Gold?

2 I 7 Einfuhrstempel für Silber (und Gold?). Kleinere Stücke.

2II8 


\section{AMSTERDAM.}

\begin{tabular}{|c|c|c|c|}
\hline $\begin{array}{l}\text { Lf. } \\
\text { Nr. }\end{array}$ & $\begin{array}{l}\text { Beschau- } \\
\text { zeichen }\end{array}$ & $\begin{array}{l}\text { Meister- } \\
\text { zeichen }\end{array}$ & Meister - Gegenstand - Besitzer \\
\hline 2119 & & & Beschauzeichen, um I 566. \\
\hline $2 \mathrm{I} 2 \mathrm{O}$ & & & Beschauzeichen, 16 . bis I7. Jahrhundert. \\
\hline $2 \mathrm{I} 2 \mathrm{I}$ & & & Beschauzeichen, um I606. \\
\hline $2 \mathrm{I} 22$ & & & Beschauzeichen, um 1608. \\
\hline 2 I 23 & & & Beschauzeichen, um 1655. \\
\hline $2 \mathrm{I} 24$ & & & Beschauzeichen, um I694. \\
\hline 2125 & & & \\
\hline 2126 & & & Beschauzeichen, I8. Jahrhundert. \\
\hline 2127 & & & \\
\hline
\end{tabular}




2I 28 I 30 If




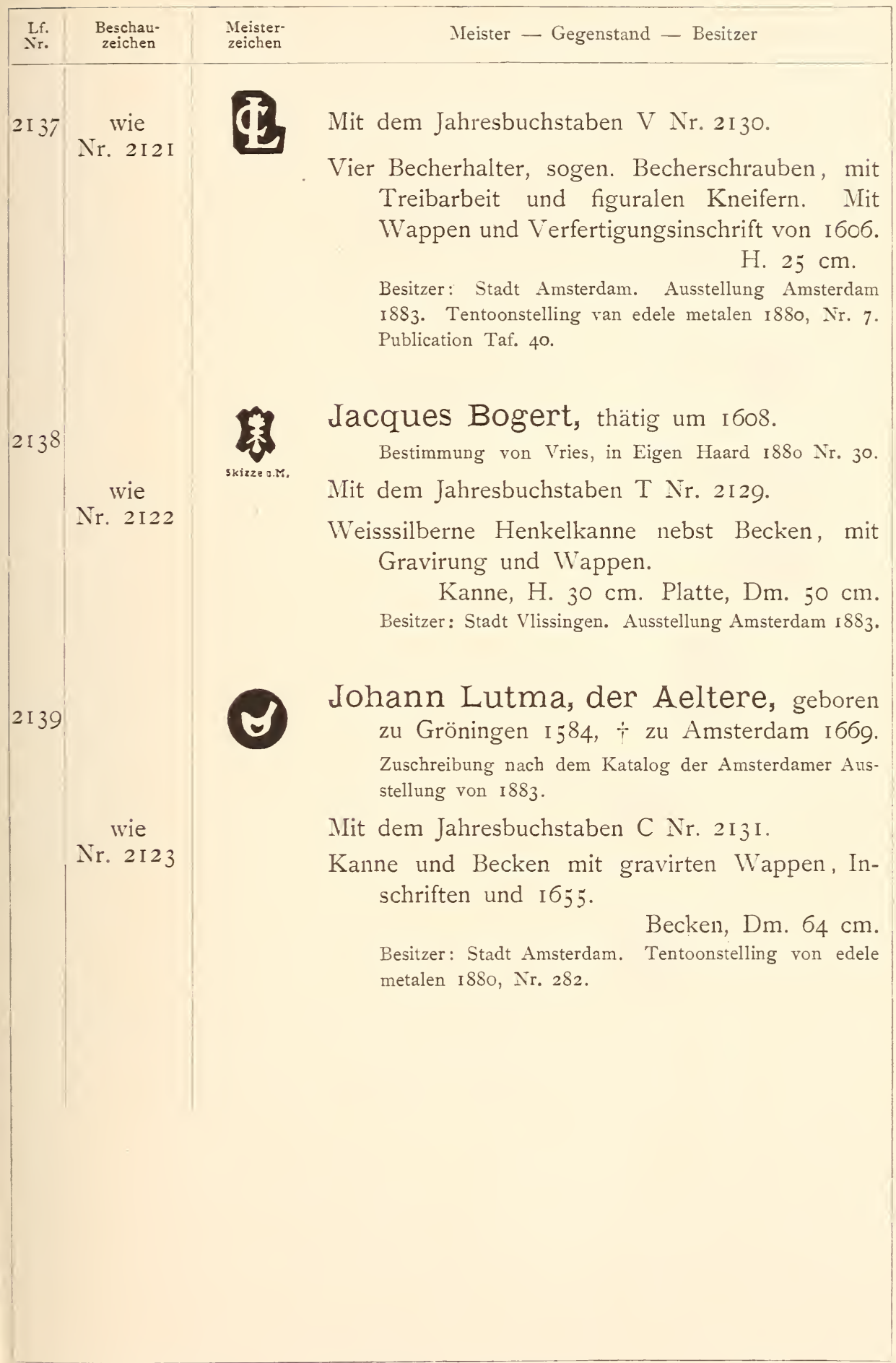




\section{BREDA.}

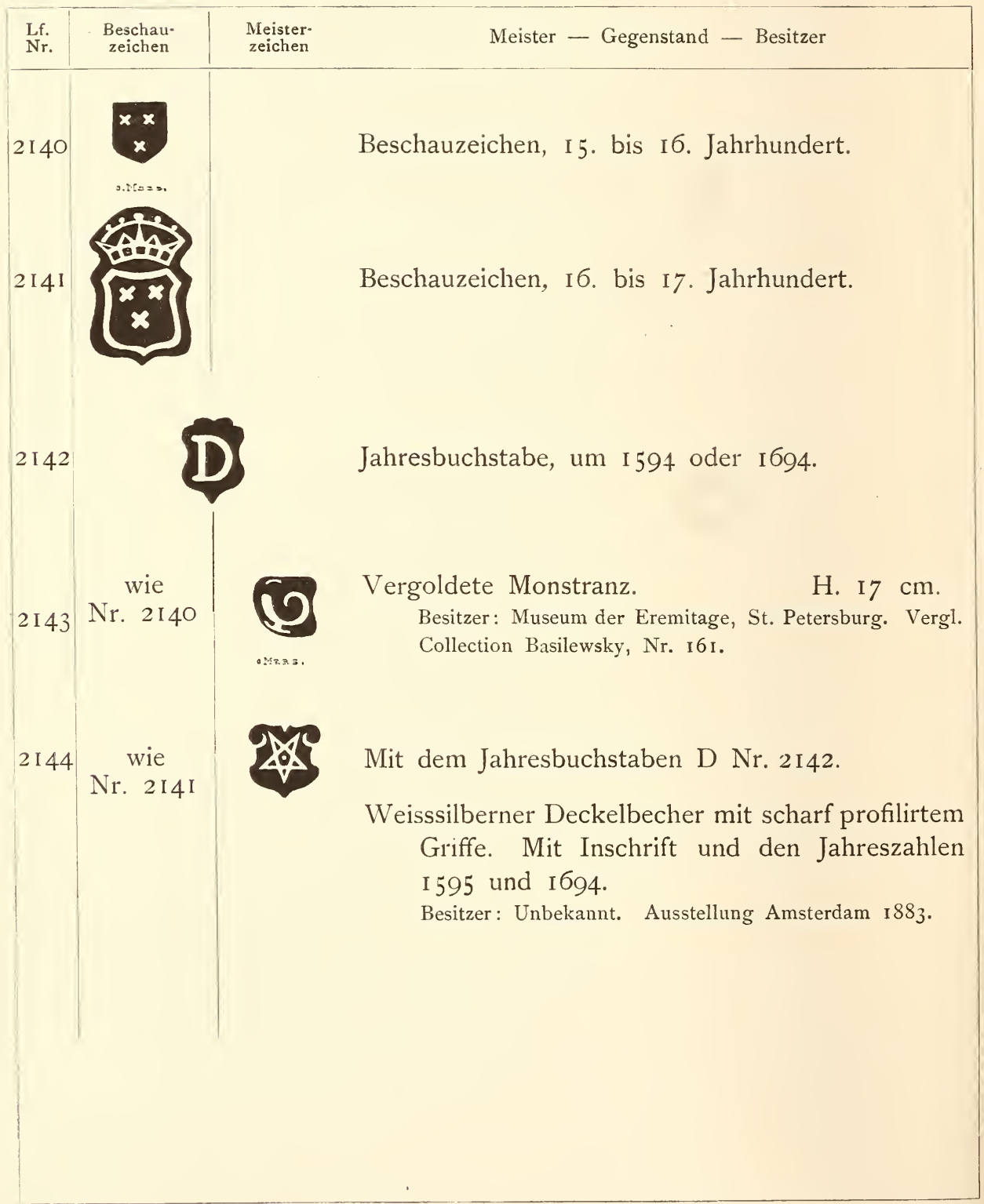




\section{DOKKUM.}

\begin{tabular}{|c|c|c|}
\hline$\underset{\mathrm{N}}{\mathrm{Lf} .}$ & $\begin{array}{l}\text { Beschau- } \\
\text { zeichen }\end{array}$ & Meister - Gegenstand - Besitzer \\
\hline 2145 & * & $\begin{array}{l}\text { Die folgenden drei Marken, offenbar nicht genau } \\
\text { facsimilirt, giebt Chaffers, Hall marks on plate, London I } 883 \text {, } \\
\text { S. 221, mit der Zuschreibung für Dokkum. } \\
\text { Beschauzeichen, um I648. }\end{array}$ \\
\hline 2146 & & Jahresbuchstabe ron 1648 . \\
\hline $2 \mathrm{I} 47$ & $\begin{array}{c}\text { wie } \\
\text { Nr. } 2 \text { I } 45\end{array}$ & $\begin{array}{l}\text { Mit dem Jahresbuchstaben R Nr. } 2 \text { I } 46 . \\
\text { Becher mit gravirten Figuren von I } 648 . \\
\text { Besitzer: South Kensington Museum, London. Nr. } 3636 .\end{array}$ \\
\hline
\end{tabular}




\section{DER HAAG.}

2I I I50




\section{HAARLEM.}

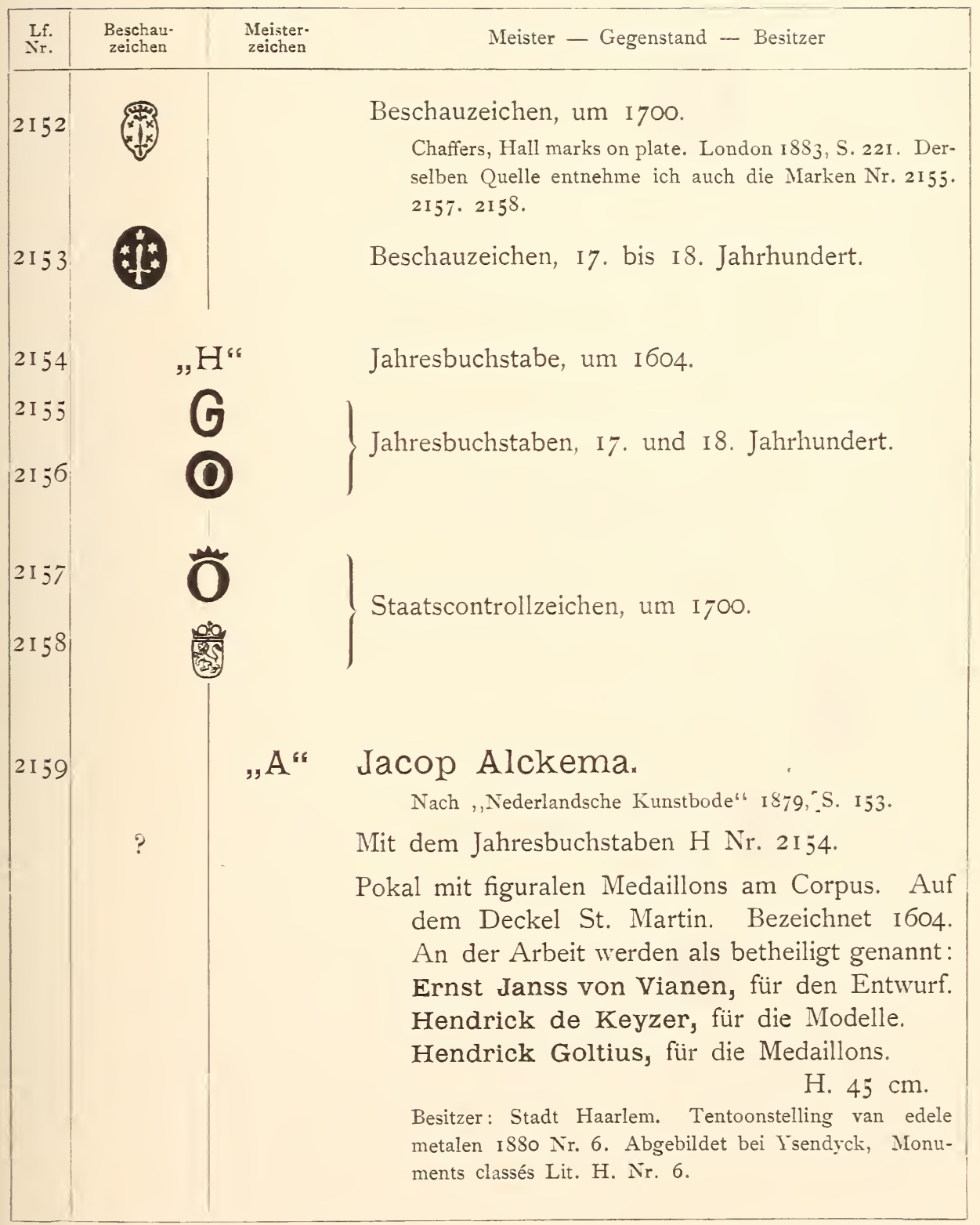




\begin{tabular}{|c|c|c|c|}
\hline $\begin{array}{l}\text { Lf. } \\
\text { Nr. }\end{array}$ & $\begin{array}{l}\text { Beschau- } \\
\text { zeichen }\end{array}$ & $\begin{array}{l}\text { Meister- } \\
\text { zeichen }\end{array}$ & Meister - Gegenstand - Besitzer \\
\hline 2160 & $\begin{array}{c}\text { wie } \\
\text { Nr. } 2 \text { I } 52\end{array}$ & fehlt? & $\begin{array}{l}\text { Mit dem Jahresbuchstaben G Nr. 21 } 55 \text { und den } \\
\text { Staatscontrollzeichen Nr. 21 } 57 \text { und 21 } 58 \text {. } \\
\text { Ovale Theebüchse. } \\
\text { Besitzer: South Kensington Museum, London. Chaffers, } \\
\text { Hall marks, S. 221. }\end{array}$ \\
\hline $216 I$ & $\begin{array}{c}\text { wie } \\
\text { Nr. } 2 \text { I } 53\end{array}$ & & $\begin{array}{l}\text { Mit dem Jahresbuchstaben O Nr. 21 } 56 . \\
\text { Weisssilberner Streuzuckerlöffel. Am Griffe eine } \\
\text { Figur mit Zimmermannswerkzeugen. } \\
\text { Besitzer (1883): J. J. Boasberg, Amsterdam. }\end{array}$ \\
\hline
\end{tabular}

\section{HERZOGENBUSCH.}

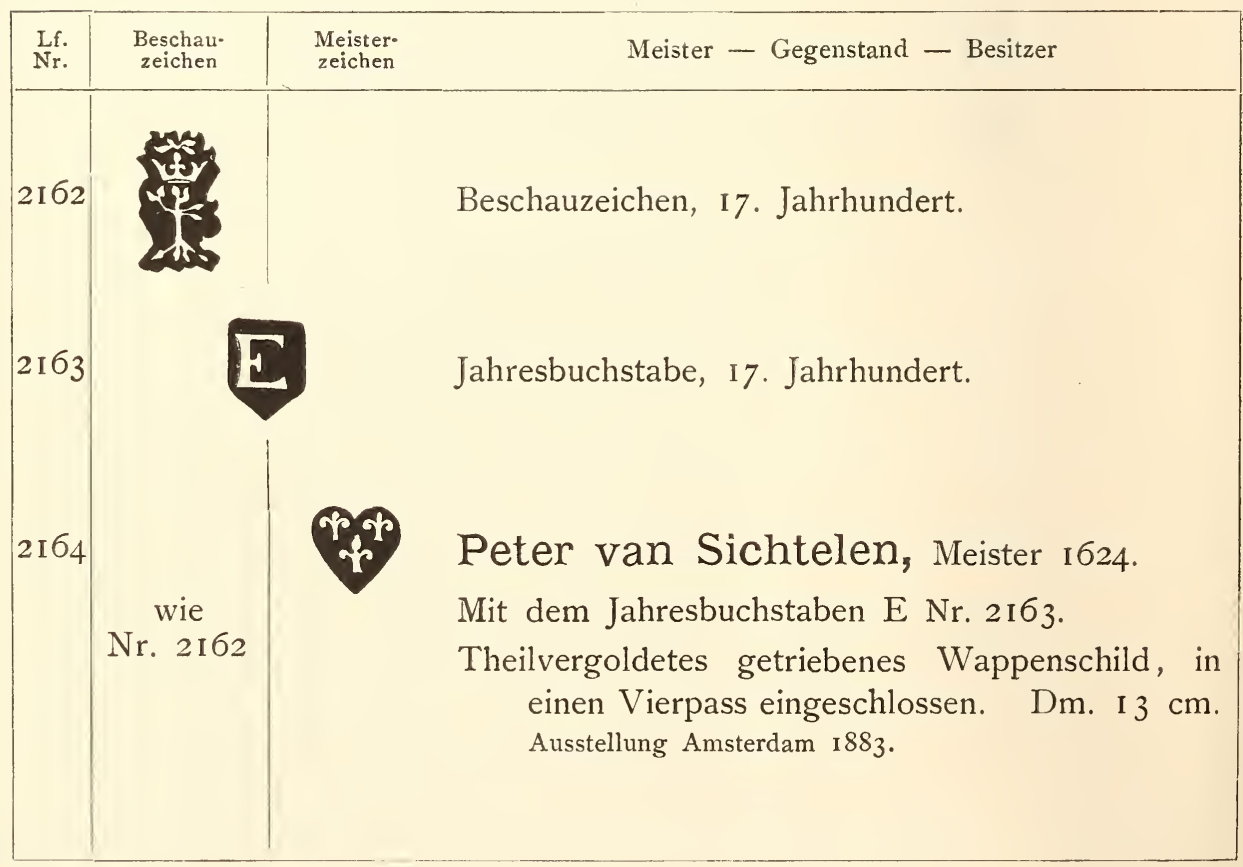




\section{LEEUW ARDEN.}

\begin{tabular}{|l|l|l|}
\hline $\begin{array}{c}\text { Lf. } \\
\text { Nr. }\end{array}$ & $\begin{array}{c}\text { Beschau- } \\
\text { zeichen }\end{array}$ \\
2 zeicher-
\end{tabular}




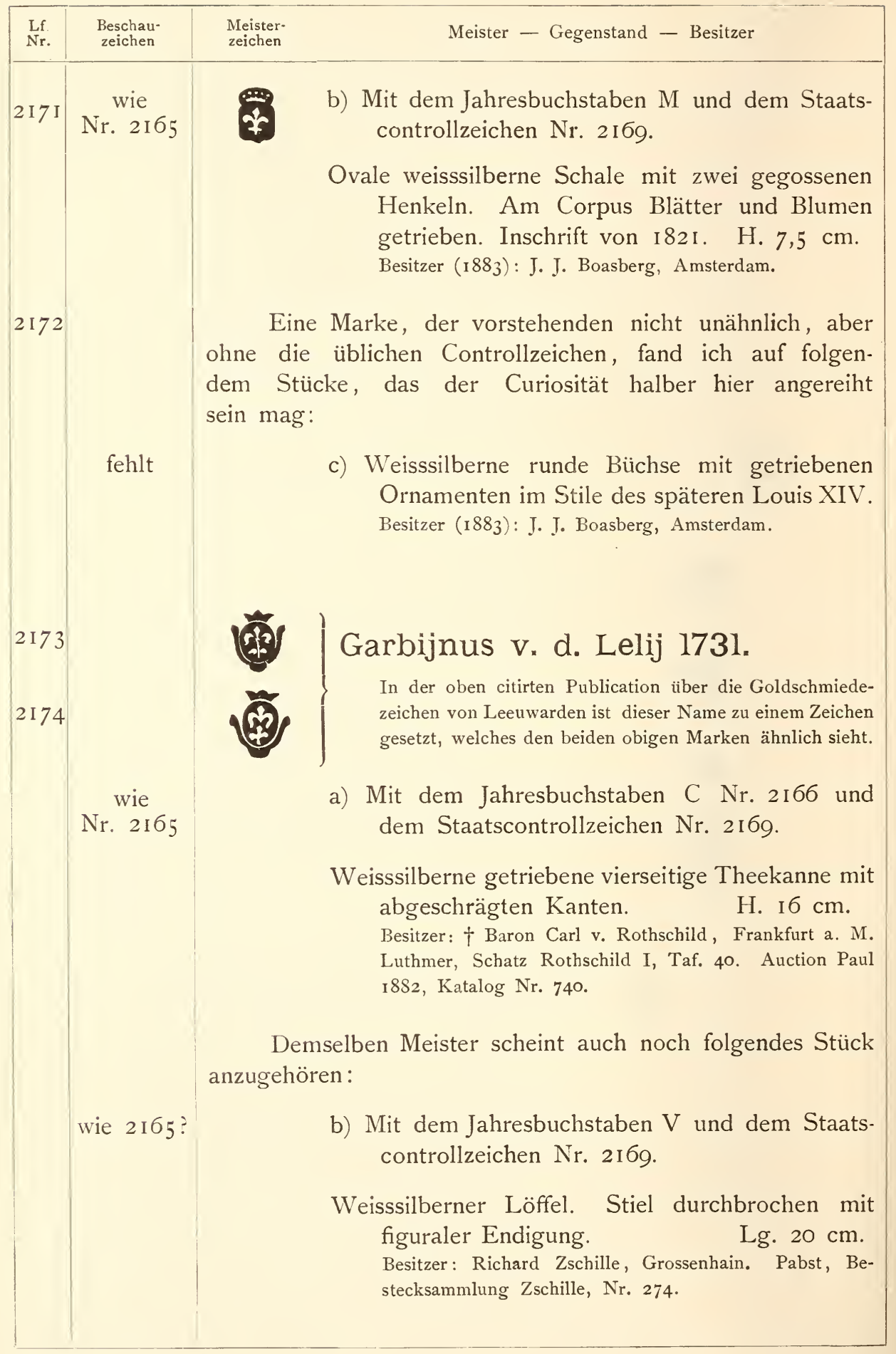




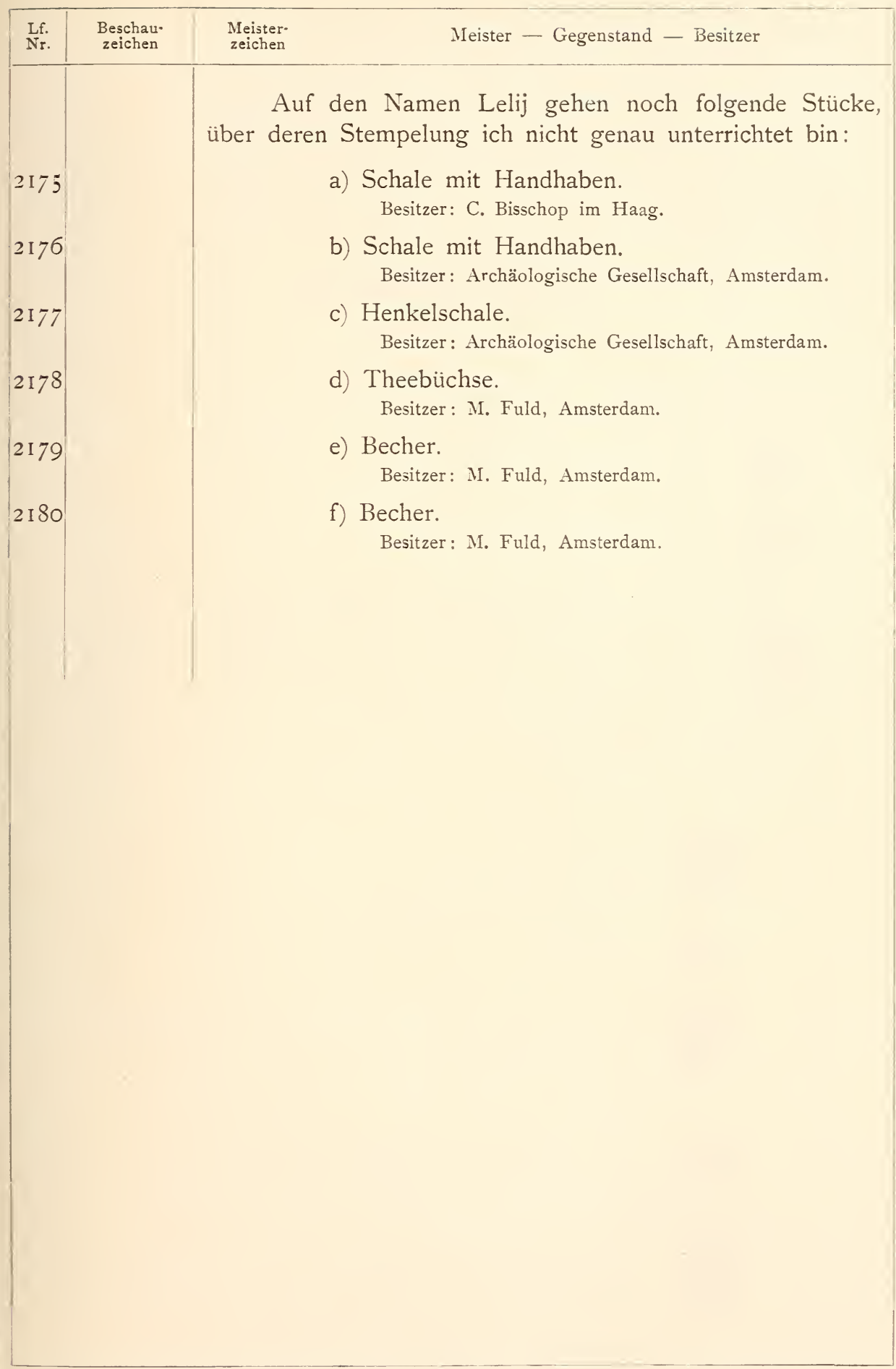




\section{ROTTERDAM.}

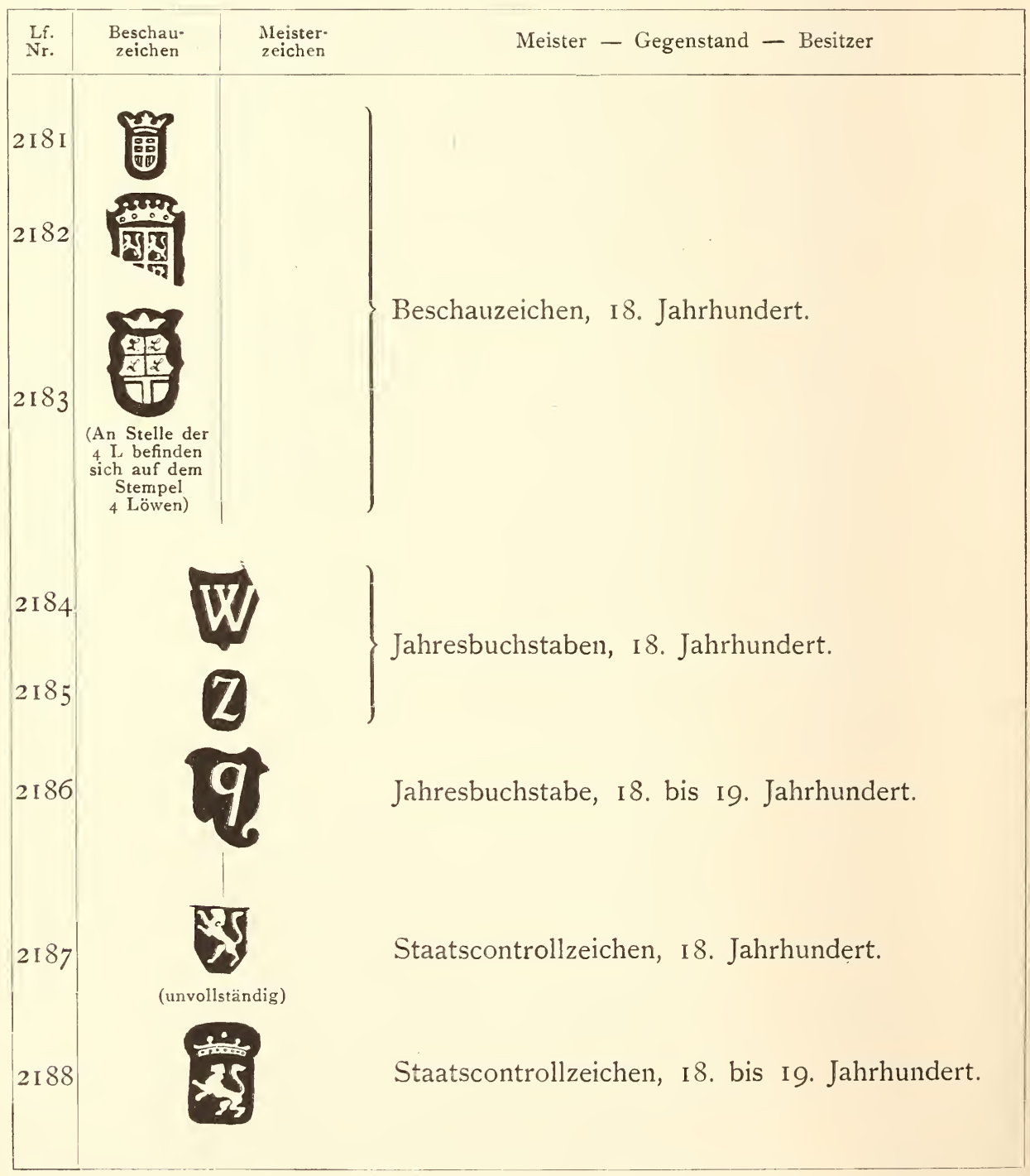




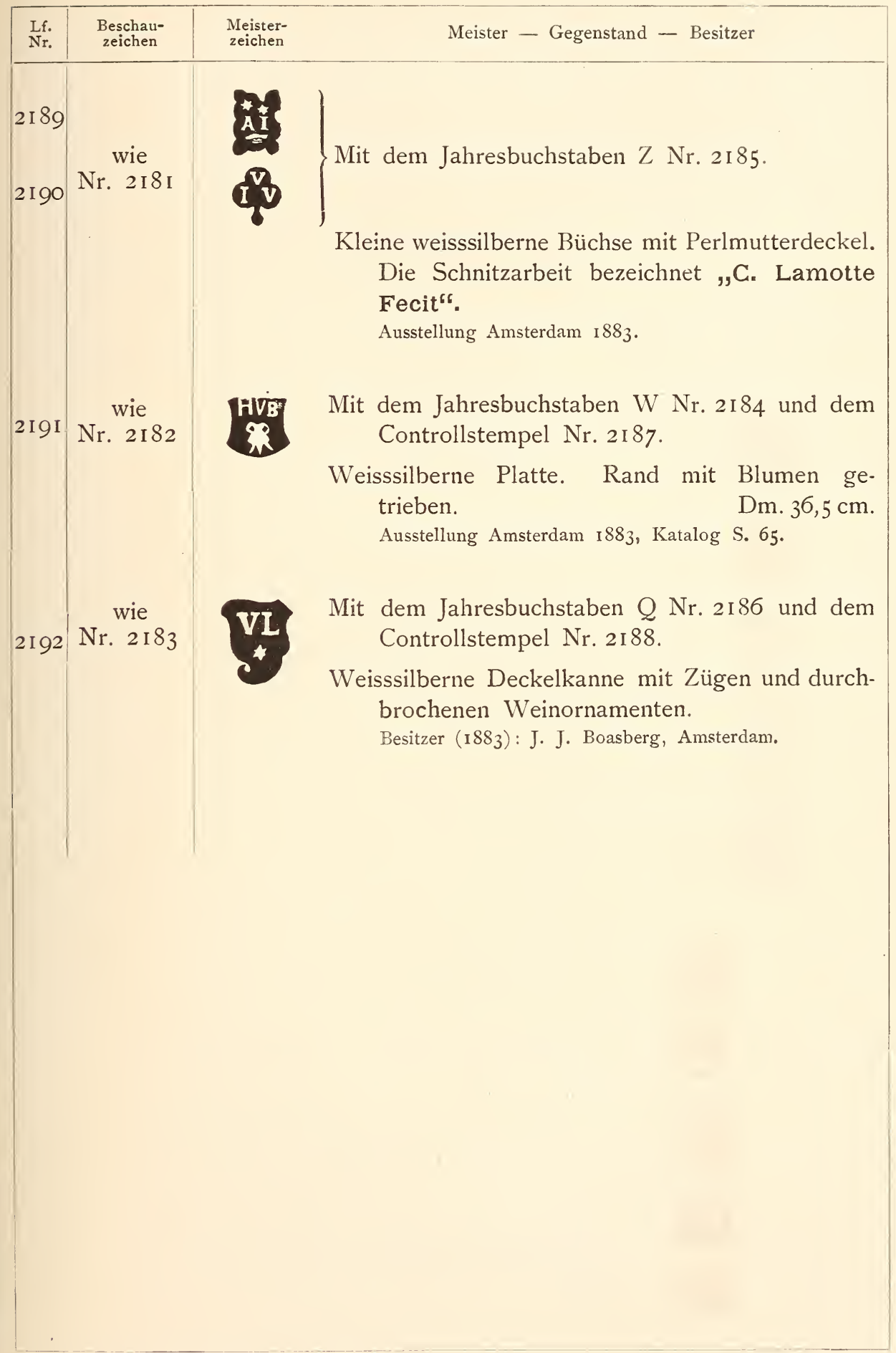




\section{UTRECHT.}

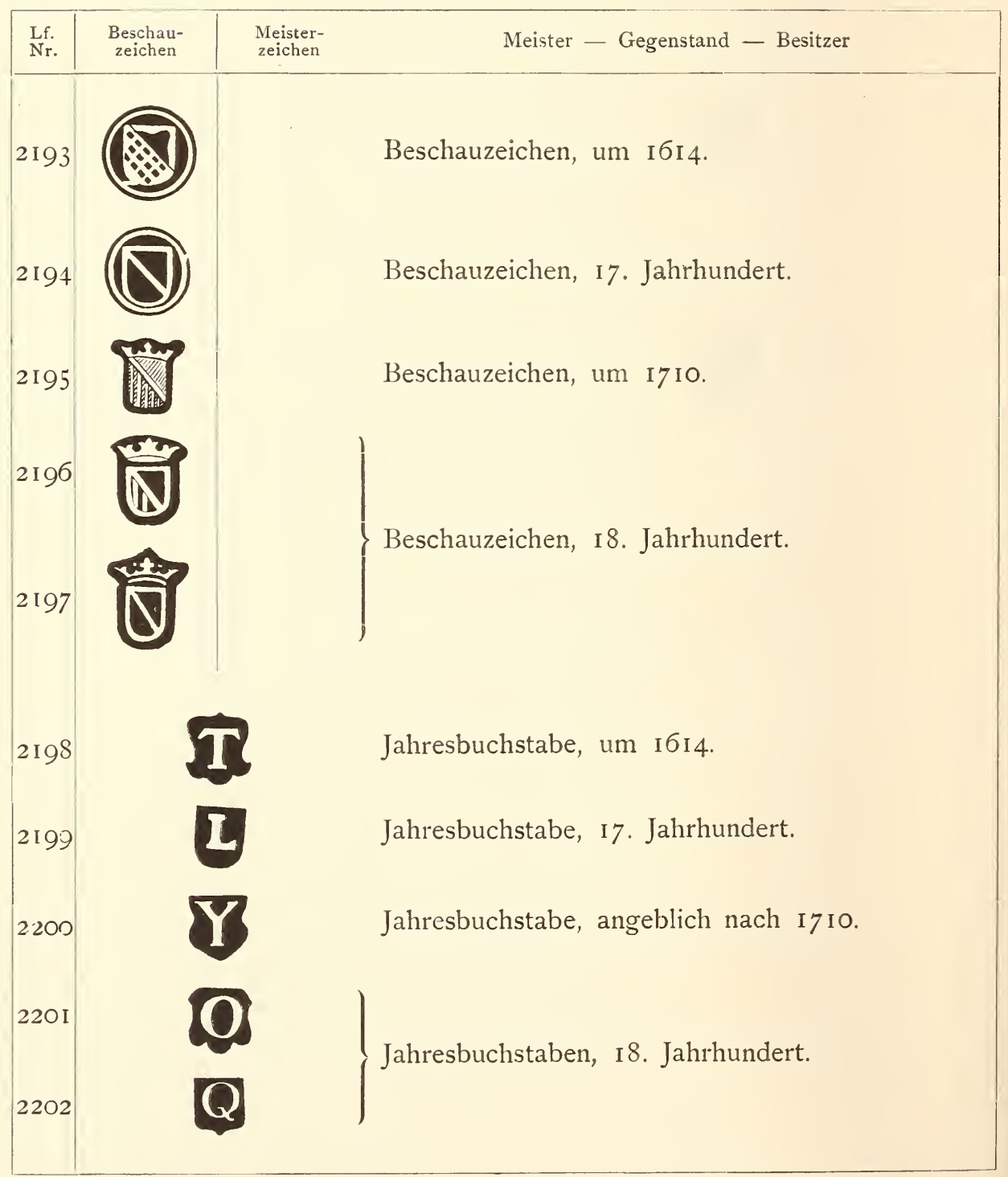




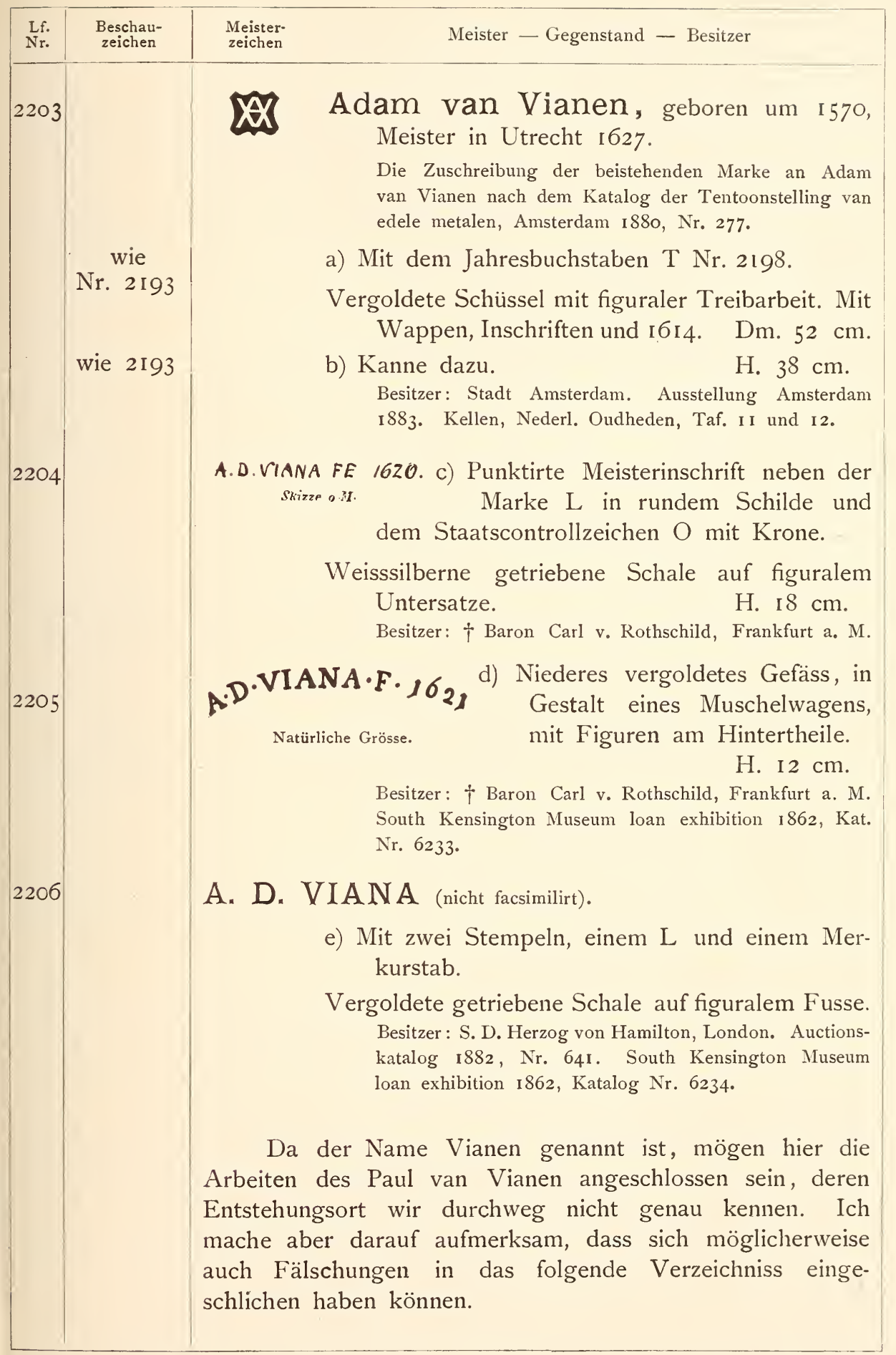




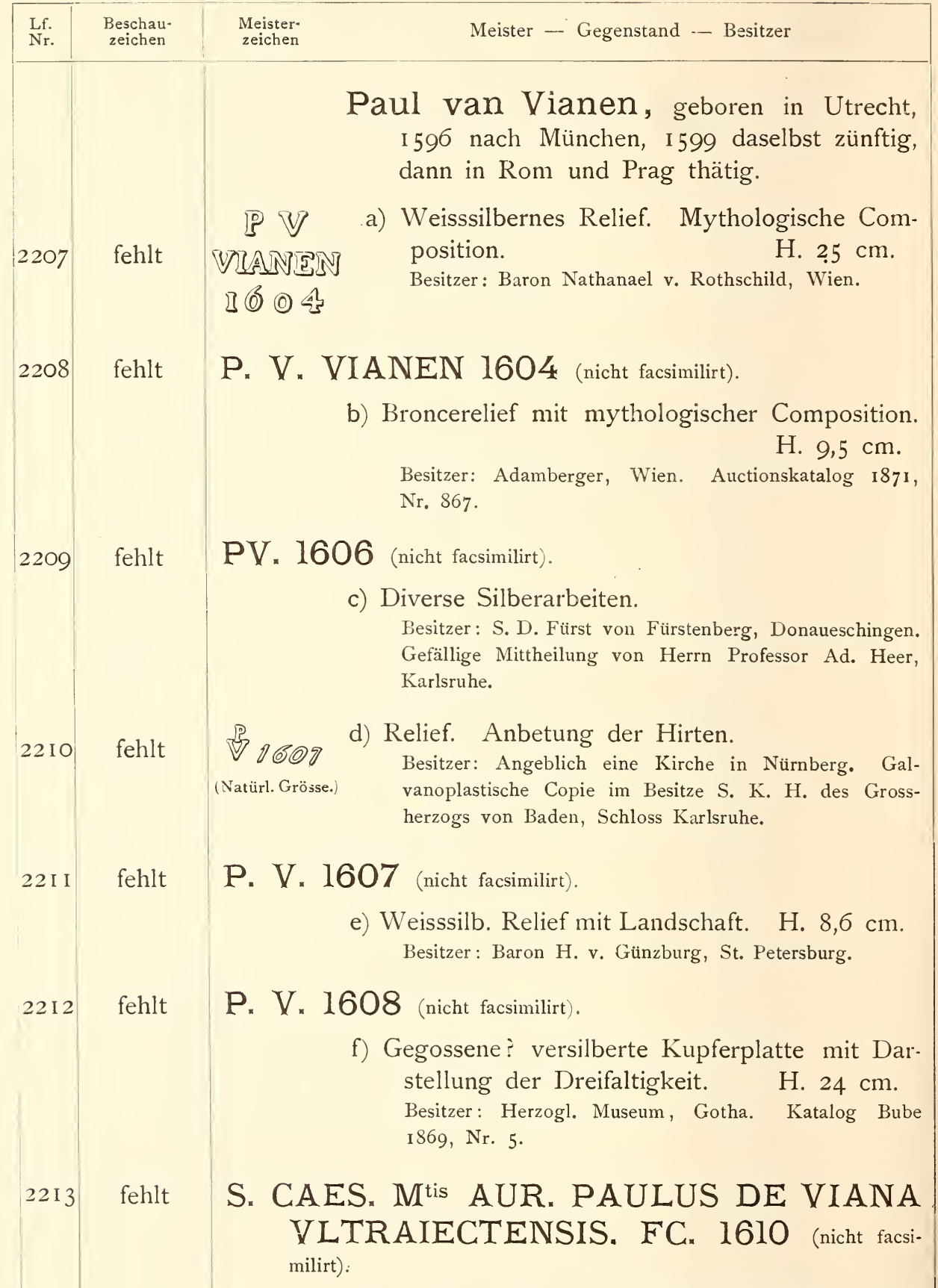

g) Goldene Deckelschale, auf Fuss, mit mythologischen Darstellungen.

Besitzer: Weiland S. K. H. Prinz Friedrich der Niederlande. 


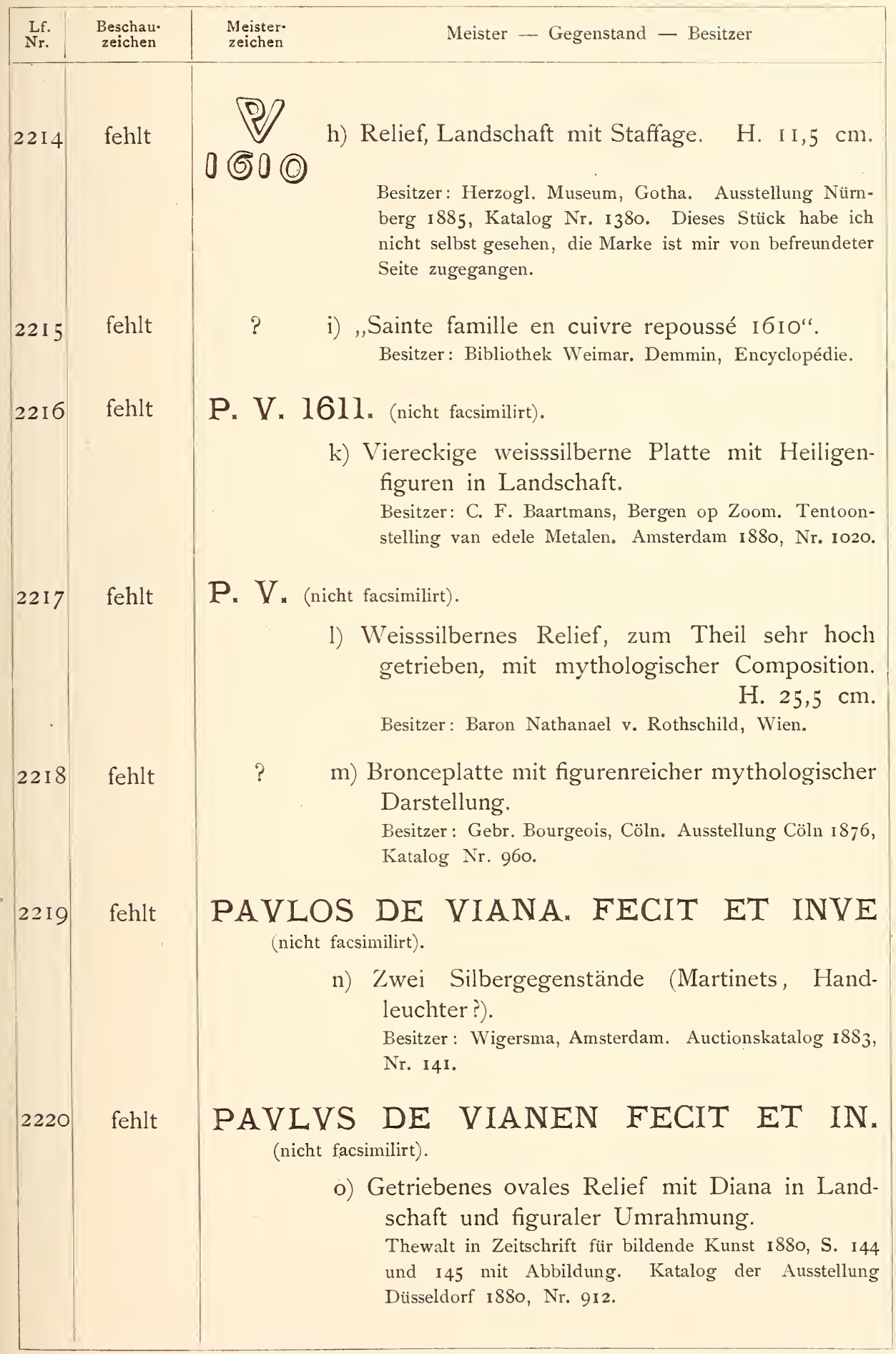




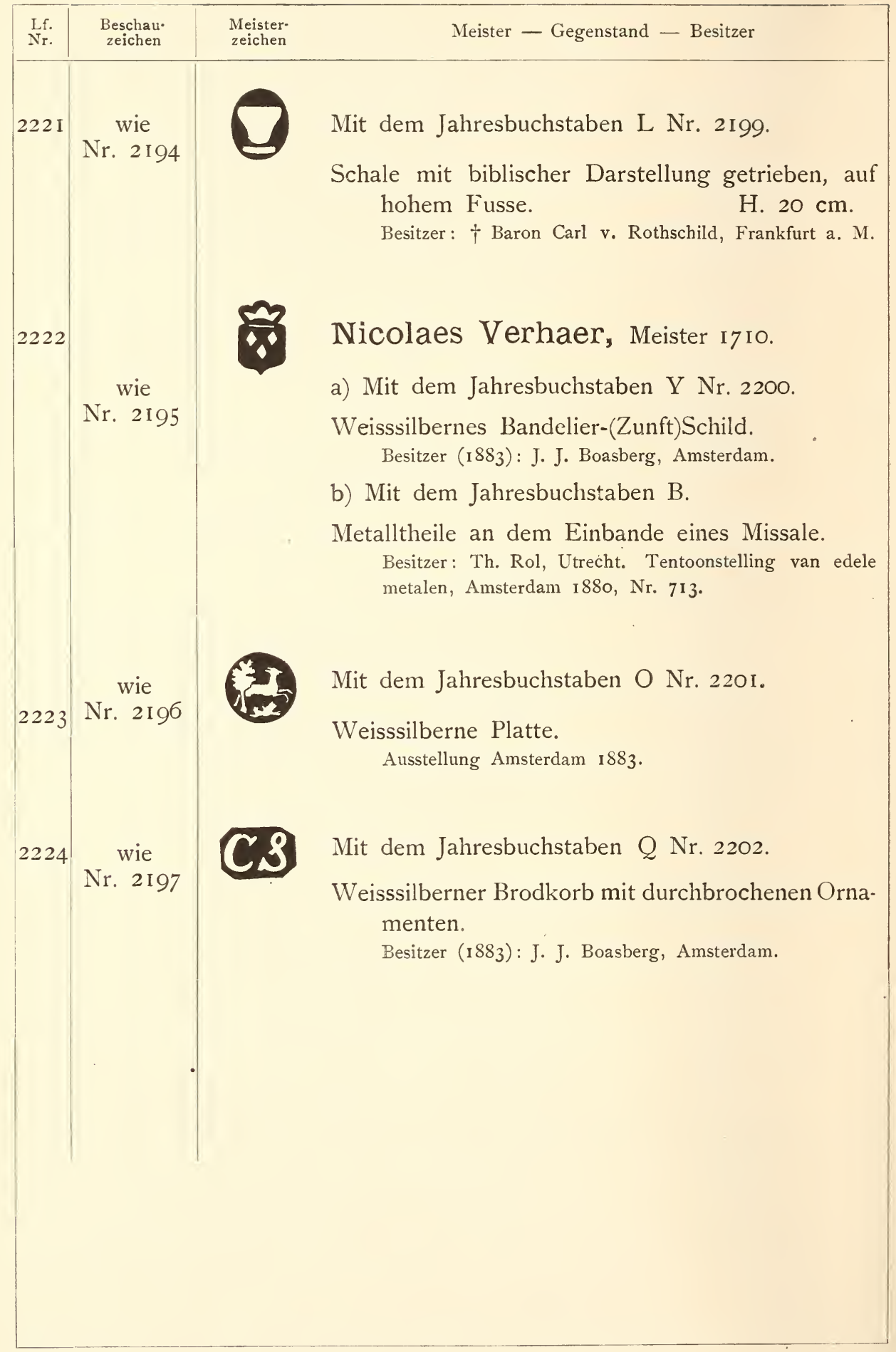




\section{VLISSINGEN.}

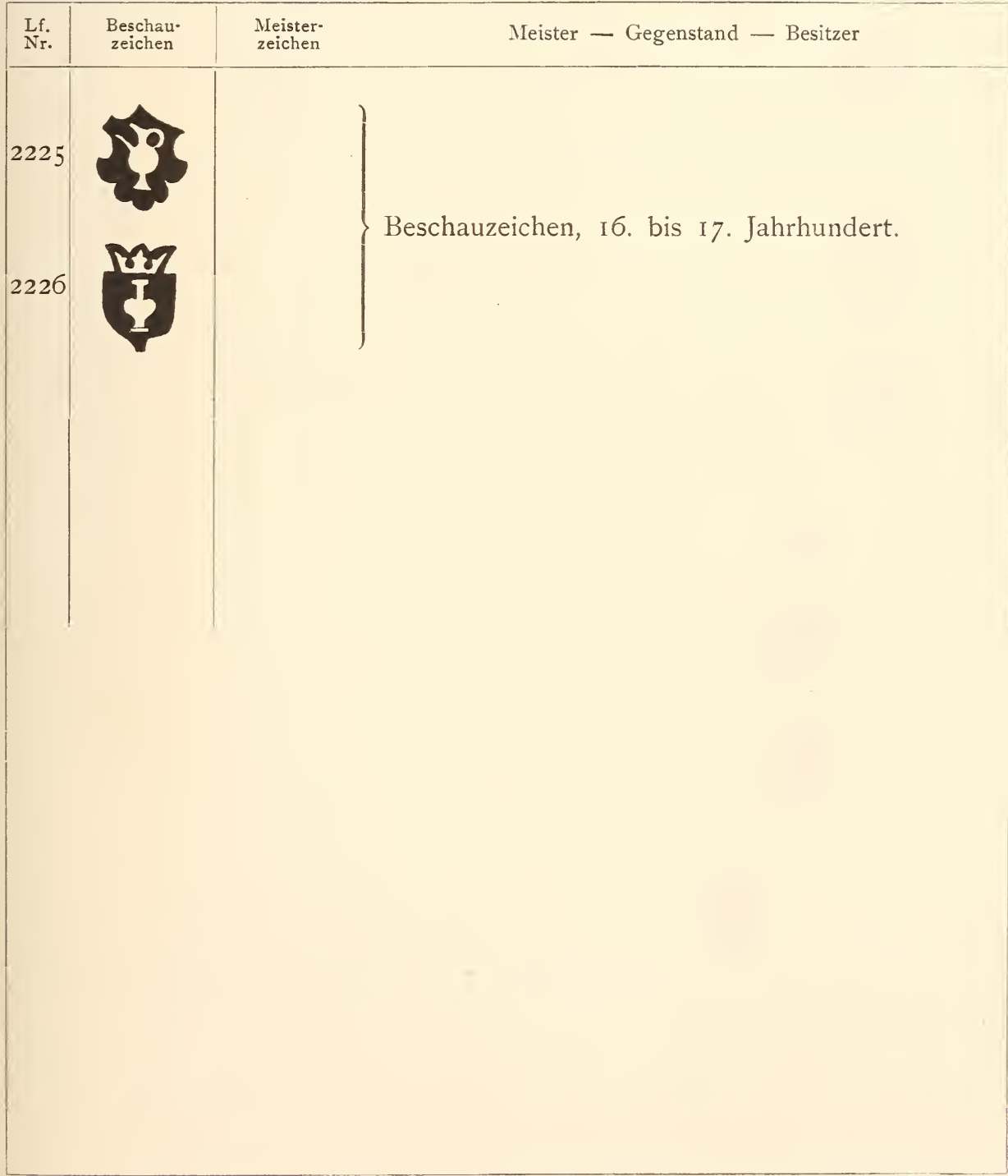




\section{ZWOLLE.}

\begin{tabular}{|c|c|c|c|}
\hline $\begin{array}{l}\text { Lf. } \\
\text { Nr. }\end{array}$ & $\begin{array}{l}\text { Beschau } \\
\text { zeichen }\end{array}$ & $\begin{array}{l}\text { Meister- } \\
\text { zeichen }\end{array}$ & Meister - Gegenstand - Besitzer \\
\hline 2227 & 물 & & Beschauzeichen, 17. Jahrhundert. \\
\hline 2228 & 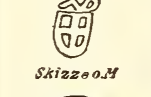 & & Beschauzeichen, um 1678. \\
\hline 2229 & & & Beschauzeichen, um I72I. \\
\hline 2230 & & & Beschauzeichen, um 1726. \\
\hline 2231 & & & Jahresbuchstabe, I7. Jahrhundert. \\
\hline 2232 & & & Jahresbuchstabe?, um I $72 \mathrm{I}$. \\
\hline 2233 & & & Jahresbuchstabe, um I 726. \\
\hline 2234 & $\begin{array}{l}\text { wie } \\
\text { Nr. } 2227\end{array}$ & & $\begin{array}{l}\text { Mit dem Jahresbuchstaben C Nr. 223I. } \\
\text { Weisssilberne, mehrfach ausgezackte Platte mit } \\
\text { Vögeln, Ranken und Wappen gravirt. } \\
\text { Dm. } 32,5 \mathrm{~cm} . \\
\text { Besitzer: v. d. Aa, Deventer. Diese Meistermarke ist schon } \\
\text { im Katalog der Tentoonstelling van edele metalen, Amster- } \\
\text { dam I880, Nr. } 293 \text { für Zwolle in Anspruch genommen. }\end{array}$ \\
\hline
\end{tabular}




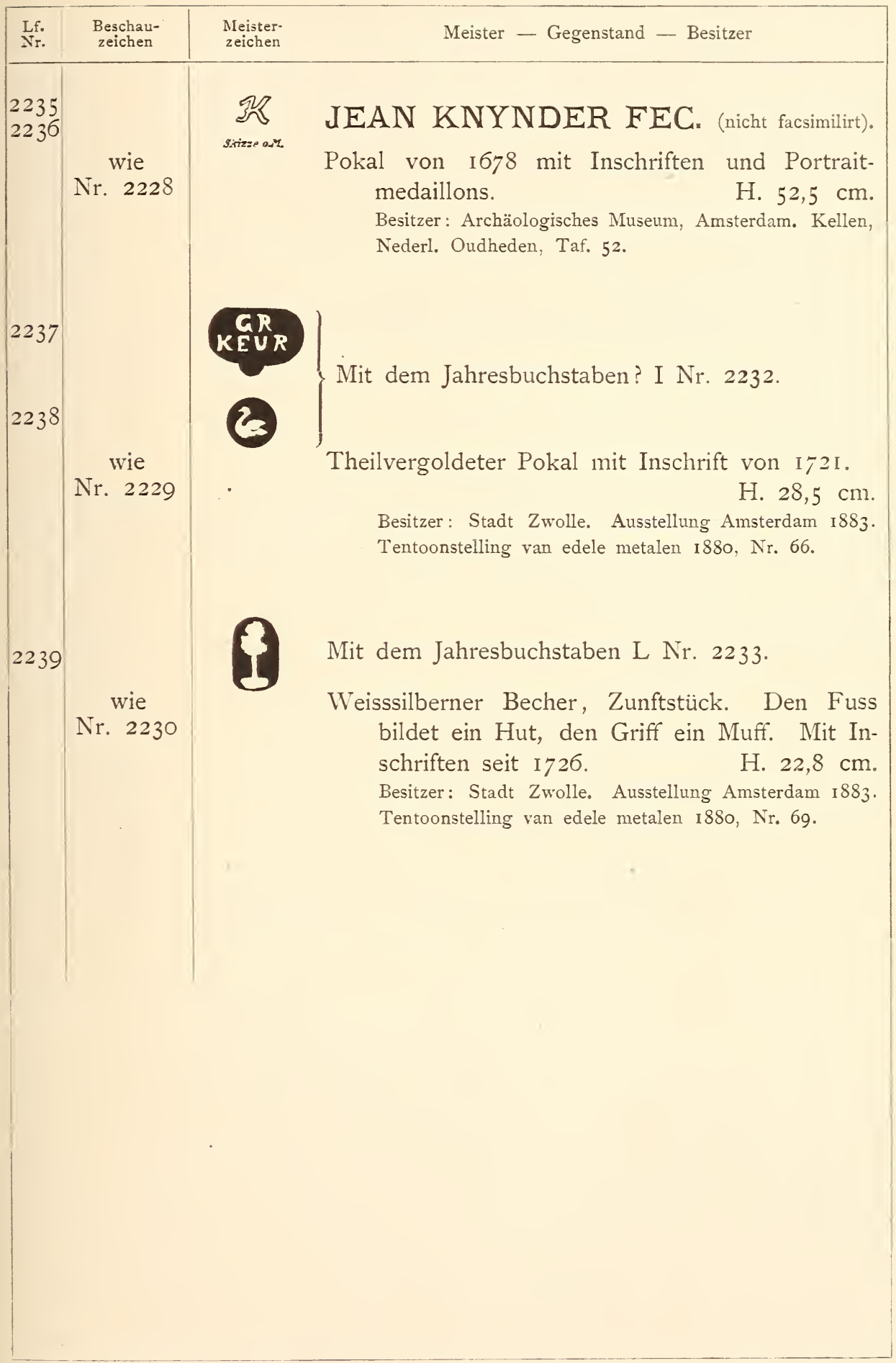




\section{OESTERREICH-UNGARN.}

Wir bringen zunächst die moderne Stempelung und die Stempel der Silbersteuer von I806 und I809. Dann folgen die Städte Oesterreichs nach dem Alphabet und darauf die Städte Ungarns in derselben Reihenfolge.

\section{Moderne Stempelung.}

Seit dem Jahre (I786) I788 wird im Kaiserthum Oesterreich eine einheitliche Art der Stempelung angestrebt. Wie aus der von Lepszy in den Mitth. d. österr. Museums I 888 S. I90 mitgetheilten Liste ersichtlich, gelangt man erst (I824) I826 zu einer Bezeichnung der einzelnen Punzirungs-Aemter und Stätten durch Buchstaben und Zahlen, die wir z. Th. weiter unten bei den Städten als „Beschauzeichen (I824)" angeführt haben. Eine weiter ins Detail gehende Durchführung erhält dieses Prinzip durch zwei Erlasse von I866 und I872. Es werden neue Zeichen für die verschiedenen Feingehaltsgrade, für ältere und ausländische Arbeiten eingeführt, und zur Unterscheidung der einzelnen Städte mit Buchstaben, oder Buchstaben und Zahlen, versehen. 
Wir geben in Folgendem die Normaltypen und verweisen für das Ganze der Unterscheidungsmerkmale auf die amtlichen Veröffentlichungen im Reichsgesetzblatt I 866 Nr. 423 und I872 Nr. 51. Bei denjenigen Städten, welche wir wegen der älteren Stempelung in Folgendem anführen, sind die Buchstaben und Zahlen, welche die betreffende Stadt bezeichnen nach den Erlassen von I866 und I872 in der Rubrik Beschauzeichen als "Amtszeichen“ angeführt.

$\left.\begin{array}{l}\begin{array}{l}950 \text { fein } \\ 2240 \text { fein } \\ 2241\end{array} \\ 200 \text { fein } \\ 2240 \text { fein }\end{array}\right\} \begin{gathered}\text { Silber. } \\ \text { Grössere Stücke. } \\ 2243 \\ 2245\end{gathered}$




\section{Repunzirung. Gesetz von 1806.}

Vergl. Lepszy in den Mittheilungen des Oesterr. Mus. I888 S. I65 ff.

2256 Steuerstempel von I806 bis I824 für älteres I2löthiges Silbergeräth.

2257 Steuerstempel von I806 bis I 824 für älteres, nicht I2löthiges Silbergeräth.

2258 Steuerstempel von I806 bis I824 für ältere Arbeiten kleineren Umfanges in Silber und Gold.

\section{Steuerstempel. \\ Gesetz von I809. \\ Vergl. Lepszy a. a. O. S. 197. 188.}

2259 T Steuerstempel für neuere Arbeiten, von I809 (I810) bis I824.

Das A in den Marken Nr. 2256 bis 2259 bezeichnet das Hauptpunzirungsamt Wien. Die anderen Filialpunzirungsämter sind von 1806 bis I 824? durch folgende Buchstaben unterschieden:

$\begin{array}{llll}\text { Prag } & \text { B } & \text { Graz } & \text { G } \\ \text { Brünn } & \text { C } & \text { Laibach } & \text { H } \\ \text { Lemberg } & \text { D } & \text { Klagenfurt } & \text { I } \\ \text { Krakau } & \text { E (1806-1809) } & \text { Triest } & \text { K } \\ \text { Linz } & \text { F } & \text { Salzburg } & \text { L. }\end{array}$

\section{Freistempel. \\ Gesetz von I809? \\ Vergl. Lepszy a. a. O. S. 187.}

2260 NRs Freistempel für ältere grössere Silberarbeiten, welche FRei von der Einlieferung resp. Einschmelzung sind.

2261 Th Freistempel für kleinere Stücke. 


\section{O E S T E R R E I C H.}

\section{BRÜNN.}

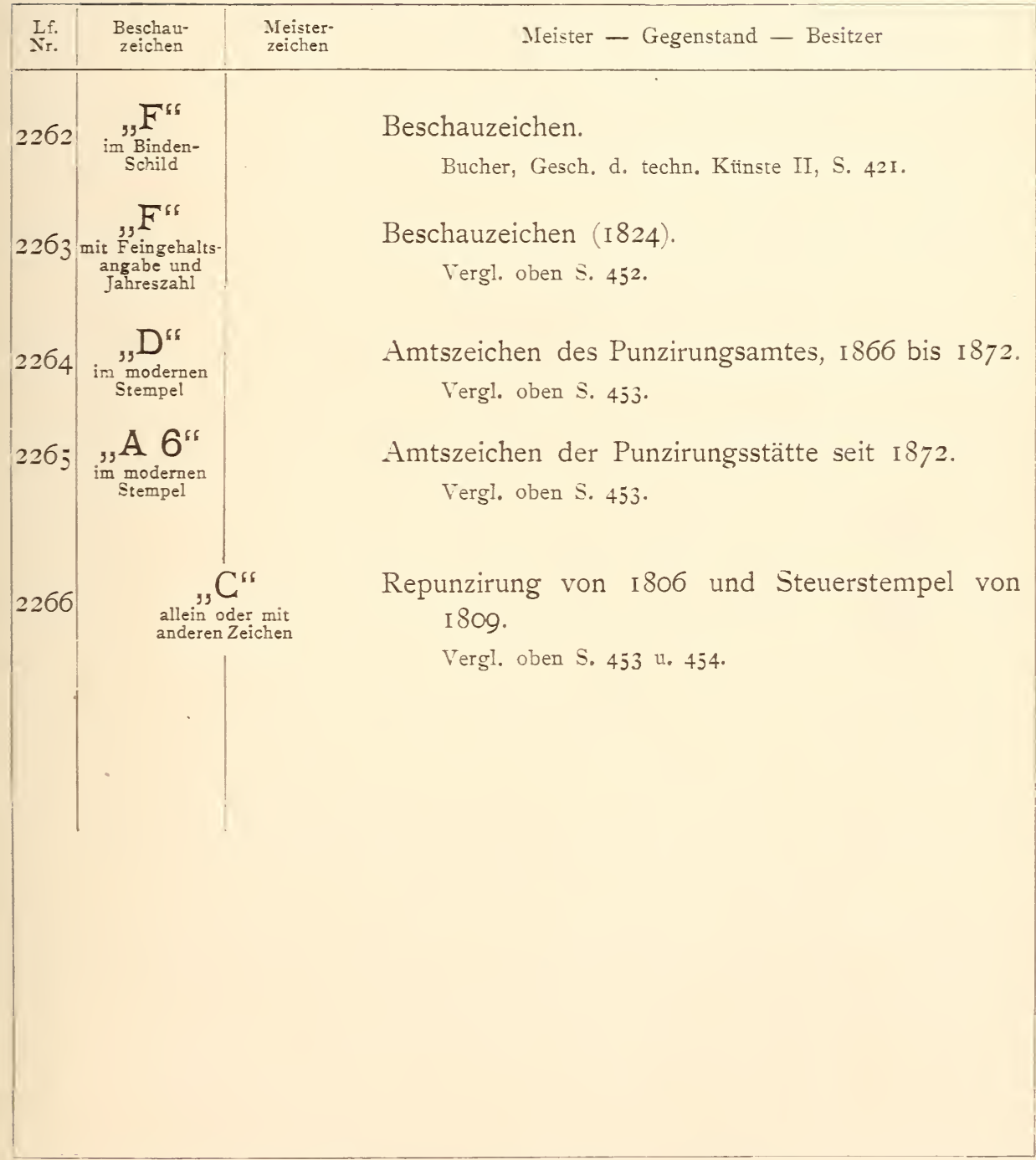




\section{EGER.}

\begin{tabular}{|c|c|c|c|}
\hline $\begin{array}{l}\text { Lf. } \\
\text { Nr. }\end{array}$ & $\begin{array}{l}\text { Beschau- } \\
\text { zeichen }\end{array}$ & $\begin{array}{l}\text { Meister. } \\
\text { zeichen }\end{array}$ & Meister - Gegenstand - Besitzer \\
\hline 2267 & $\frac{17}{x \times x}$ & & ichen, 17 . bis 18 . Jahrh. \\
\hline 2268 & $\underset{\text { im modernen }}{\text { Stempel }}$ & & $\begin{array}{l}\text { en der Punzirungsstätte seit } 1872 \text {. } \\
\text { oben S. } 453 \text {. }\end{array}$ \\
\hline
\end{tabular}

\section{GRAZ.}

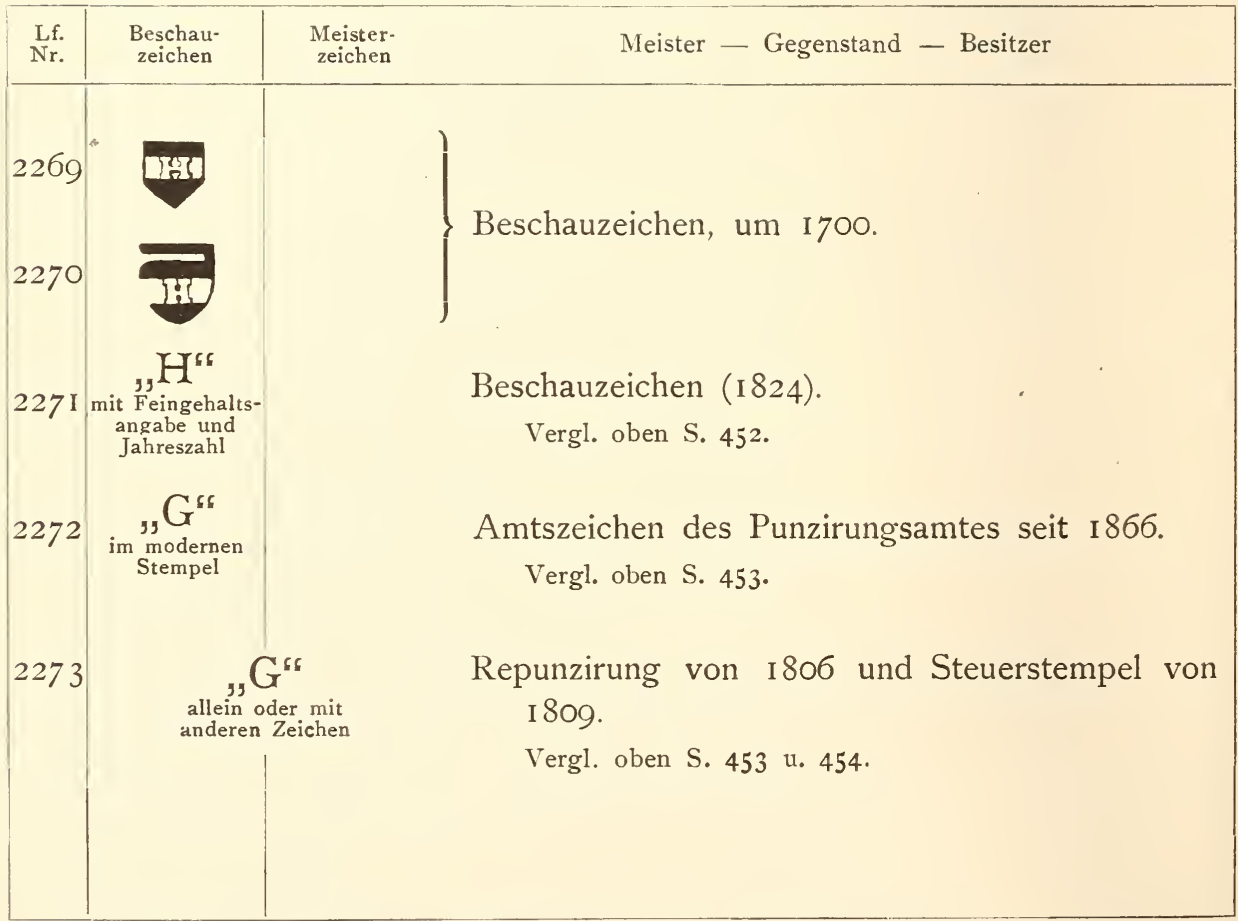




\section{KLAGENFURT.}

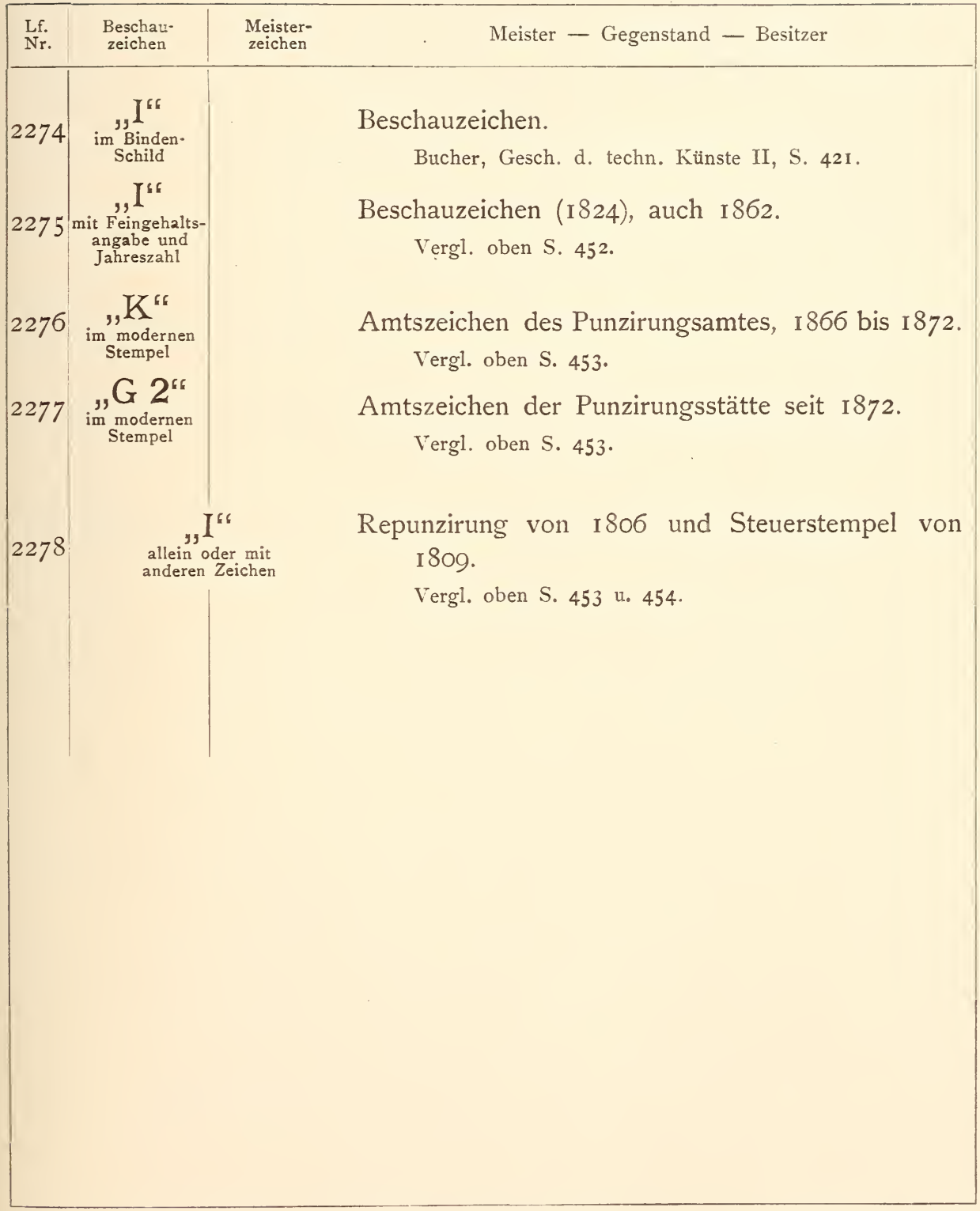




\section{LAIBACH.}

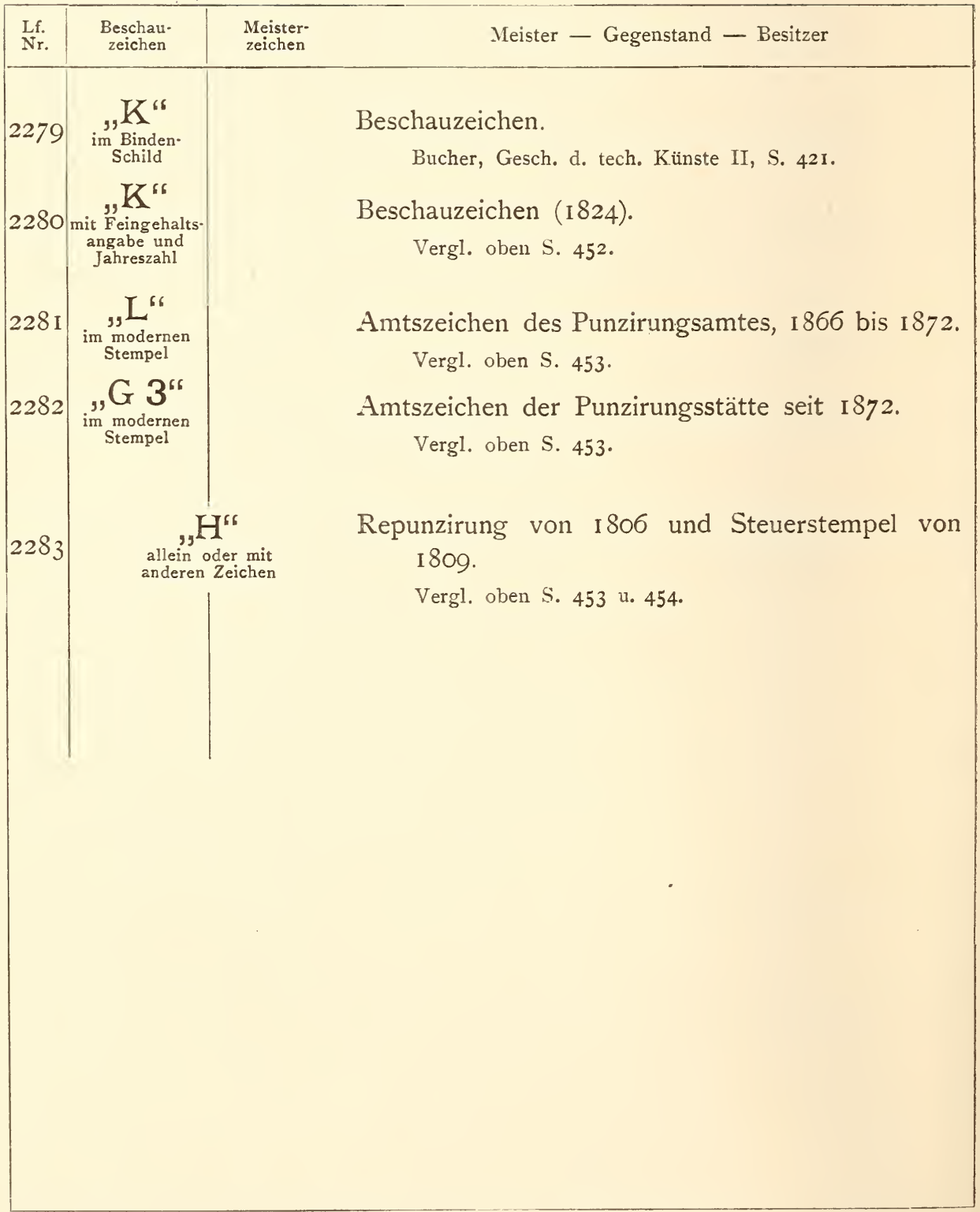




\section{LEMBERG.}

\begin{tabular}{|c|c|c|c|}
\hline $\begin{array}{l}\text { Lf. } \\
\text { Nr. }\end{array}$ & $\begin{array}{l}\text { Beschau- } \\
\text { zeichen }\end{array}$ & $\begin{array}{l}\text { Meister- } \\
\text { zeichen }\end{array}$ & Meister - Gegenstand - Besitzer \\
\hline 2285 & $\begin{array}{l}\text { "D } \mathrm{D}^{66} \\
\text { im Binden- } \\
\text { Schild } \\
\mathrm{D}^{66} \\
\text { mit Feingehalts- } \\
\text { angabe und } \\
\text { Jahreszahl }\end{array}$ & & $\begin{array}{l}\text { Beschauzeichen. } \\
\text { Bucher, Gesch. d. techn. Künste II, S. } 42 \text { I, } \\
\text { Beschauzeichen (I } 824 \text { ) schon I } 8 \text { I6. } \\
\text { Vergl. oben S. } 452 \text {. }\end{array}$ \\
\hline 2286 & 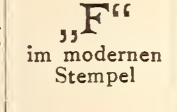 & & $\begin{array}{l}\text { Amtszeichen des Punzirungsamtes seit I } 866 . \\
\text { Vergl. oben S. } 453 .\end{array}$ \\
\hline 2287 & $\begin{array}{l}\text { gg } \\
\text { allein } \\
\text { anderen }\end{array}$ & & $\begin{array}{l}\text { Repunzirung von I } 806 \text { und Steuerstempel von } \\
\text { I } 809 \text {. } \\
\text { Vergl. oben S. } 453 \text { u. } 454 \text {. }\end{array}$ \\
\hline
\end{tabular}

\section{LINZ.}

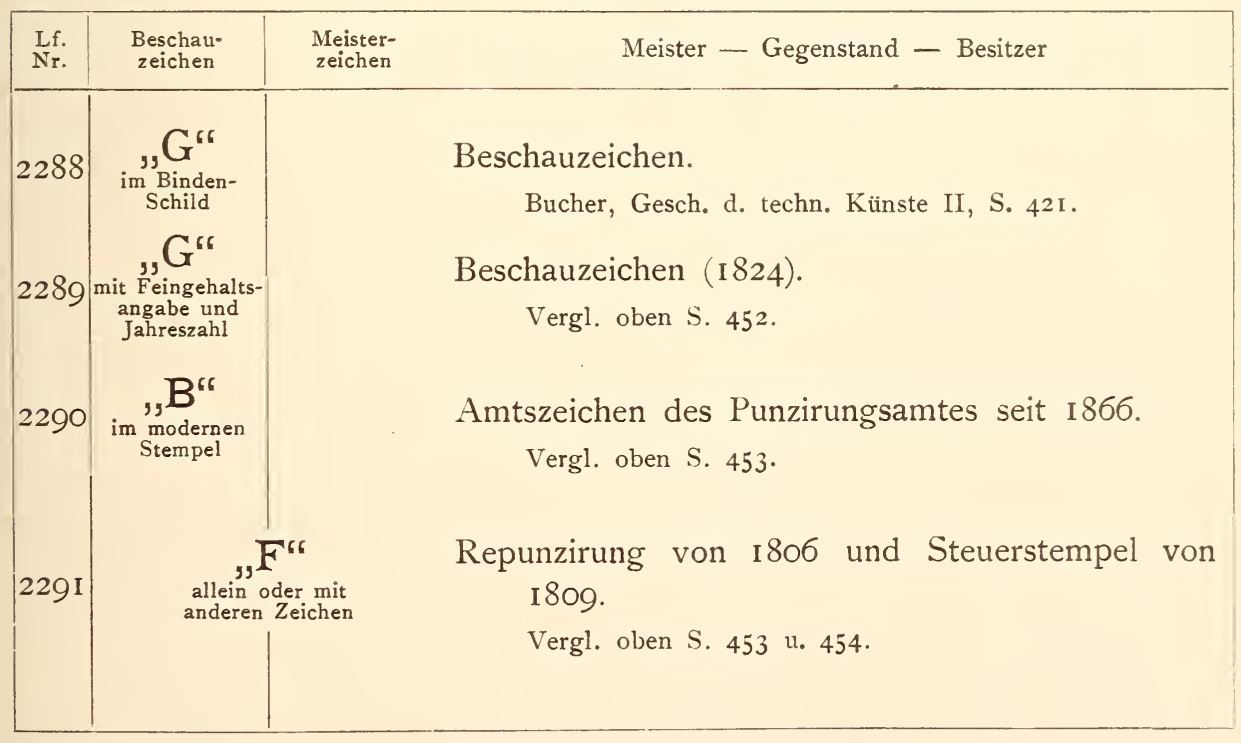




\section{PRAG.}

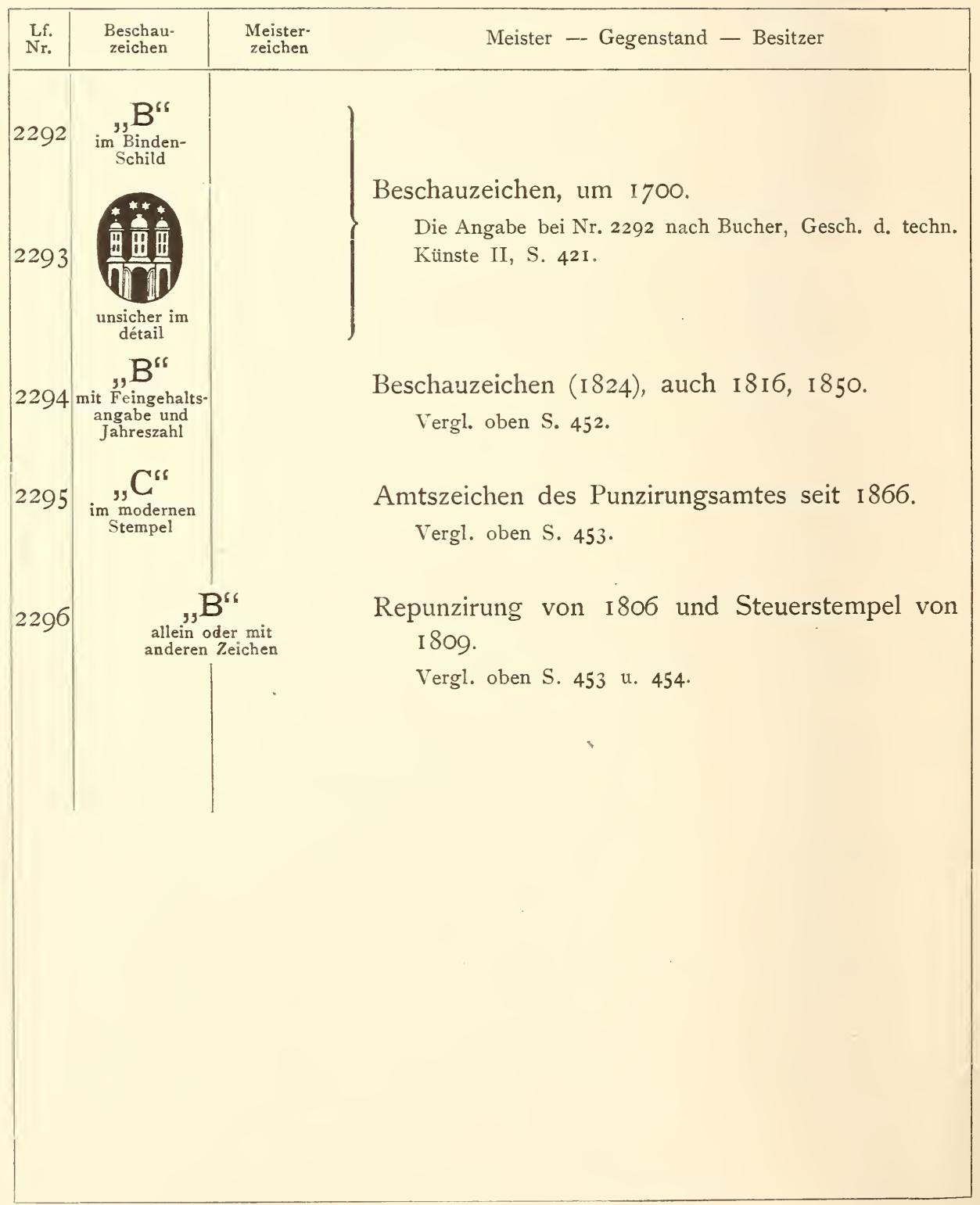




\section{SALZBURG.}

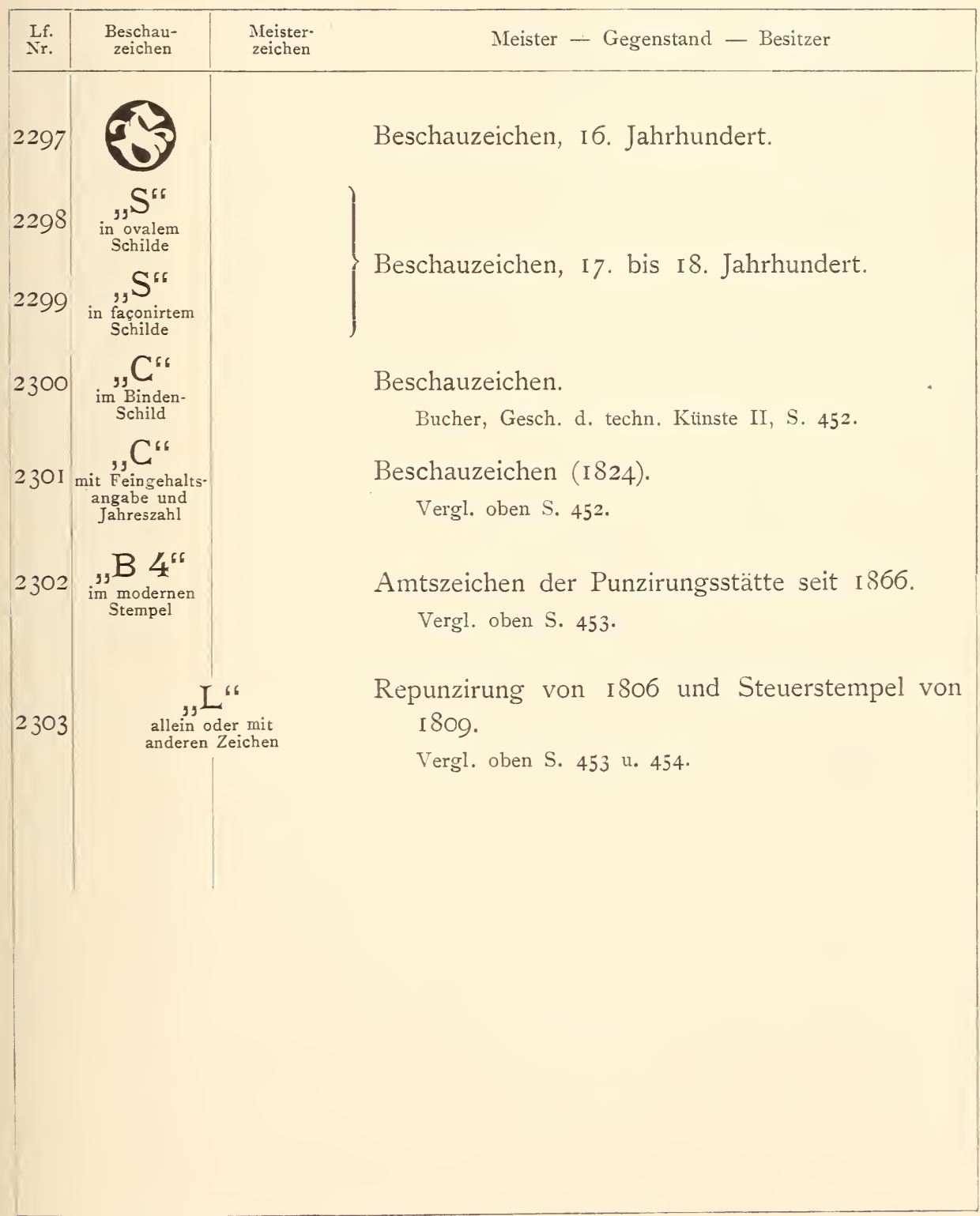




\section{TRIEST.}

\begin{tabular}{|c|c|c|c|}
\hline $\begin{array}{l}\text { Lf. } \\
\text { Nr. }\end{array}$ & $\begin{array}{l}\text { Beschau- } \\
\text { zeichen }\end{array}$ & $\begin{array}{l}\text { Meister- } \\
\text { zeichen }\end{array}$ & Meister - Gegenstand - Besitzer. \\
\hline 2305 & $\begin{array}{l}\text { ", "L6 } \\
\text { im Binden- } \\
\text { Schild } \\
\text { mit Feingehalts- } \\
\text { angabe und } \\
\text { Jahreszahl } \\
\text { "M."W6 } \\
\text { im modernen } \\
\text { Stempel }\end{array}$ & & $\begin{array}{l}\text { Beschauzeichen. } \\
\quad \text { Bucher, Gesch. d. techn. Künste II, S. } 42 \text { I. } \\
\text { Beschauzeichen (I } 824) \text {. } \\
\quad \text { Vergl. oben S. } 45^{2} \text {. } \\
\text { Amtszeichen des Punzirungsamtes seit I } 866 . \\
\quad \text { Vergl. oben S. } 453 .\end{array}$ \\
\hline 2307 & $\begin{array}{l}\text { allein } \\
\text { anderen }\end{array}$ & & $\begin{array}{l}\text { Repunzirung von I } 806 \text { und Steuerstempel von } \\
\text { I } 809 \text {. } \\
\text { Vergl. oben S. } 453 \text { u. } 454 \text {. }\end{array}$ \\
\hline
\end{tabular}

\section{TROPPAU.}

\begin{tabular}{|c|c|c|c|}
\hline $\begin{array}{l}\text { Lf. } \\
\text { Nr. }\end{array}$ & $\begin{array}{l}\text { Beschau. } \\
\text { zeichen }\end{array}$ & $\begin{array}{l}\text { Meister- } \\
\text { zeichen }\end{array}$ & Meister - Gegenstand - Besitzer \\
\hline 2308 & & & Beschauzeichen, I6. bis I7. Jahrhundert. \\
\hline 2309 & $\begin{array}{c}\text { } \\
\text { mit Feingehalts- } \\
\text { angabe und } \\
\text { Jahreszahl }\end{array}$ & & $\begin{array}{c}\text { Beschauzeichen }(\mathrm{I} \$ 24) \text {. } \\
\text { Vergl. oben S. } 45^{2} \text {. }\end{array}$ \\
\hline 2310 & $\begin{array}{l}\text {, D } 4^{\text {sf }} \\
\text { im modernen } \\
\text { Stempel }\end{array}$ & & $\begin{array}{l}\text { Amtszeichen der Punzirungsstätte, I } 866 \text { bis I } 872 . \\
\text { Vergl. oben S. } 453 \text {. }\end{array}$ \\
\hline 23 I I & $\begin{array}{l}\text {, A } 10^{5} \\
\text { im modernen } \\
\text { Stempel }\end{array}$ & & $\begin{array}{l}\text { Amtszeichen der Punzirungsstätte seit I } 872 . \\
\text { Vergl. oben S. } 453 \text {. }\end{array}$ \\
\hline
\end{tabular}




\section{WIEN.}

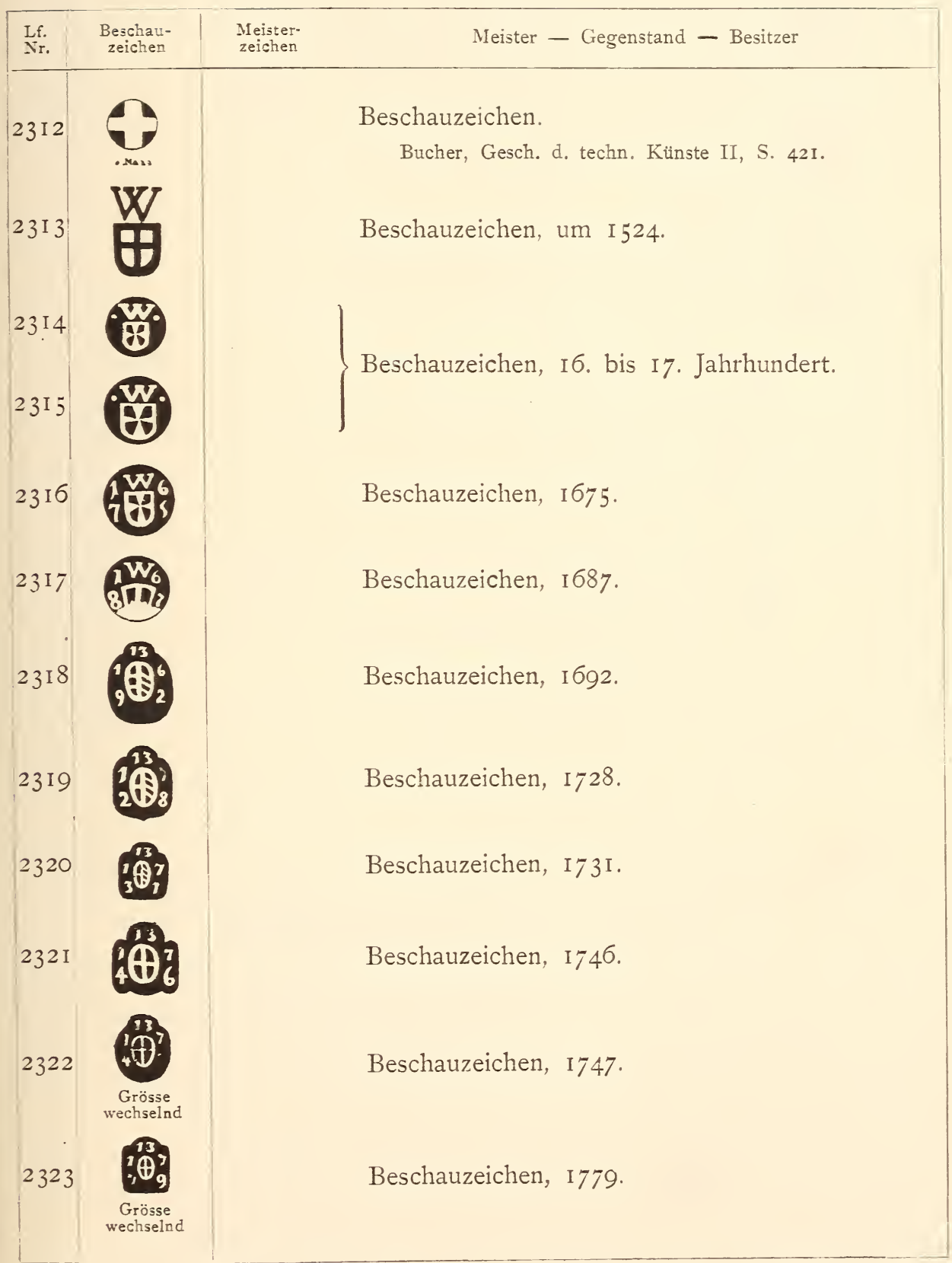




\begin{tabular}{|c|c|c|c|}
\hline Lf. & $\begin{array}{l}\text { Beschau• } \\
\text { zeichen }\end{array}$ & $\begin{array}{l}\text { Meister- } \\
\text { zeichen }\end{array}$ & Meister - Gegenstand - Besitzer \\
\hline 2324 & & & Beschauzeichen, I798. \\
\hline 2325 & $\begin{array}{c}{ }_{1}^{1} \mathrm{PO}_{4}^{3} \\
\text { Grösse } \\
\text { wechselnd }\end{array}$ & & Beschauzeichen, i8I4. \\
\hline 2326 & & & Beschauzeichen, 1838. \\
\hline 2327 & 1866 & & Beschauzeichen, I 866. \\
\hline 2329 & & & Staatszeichen für Silber, 800 fein, seit I 866. \\
\hline 2330 & & & Einfuhrstempel für Silber seit I 872. \\
\hline $\begin{array}{l}2331 \\
2332\end{array}$ & & & Goldfeingehalt, I8. bis I9. Jahrhundert. \\
\hline 2333 & $\begin{array}{l}\text { allein } \\
\text { andere }\end{array}$ & & $\begin{array}{l}\text { Repunzirung von I } 806 \text { und Steuerstempel von } \\
\text { I } 809 \text {. } \\
\text { Vergl. oben S. } 453 \text { u. } 454 \text {. Nr. } 2256 \text { bis } 2259 \text {. }\end{array}$ \\
\hline 2334 & $\begin{array}{l}\text { wie } \\
\text { Nr. } 23 \text { I } 3\end{array}$ & & 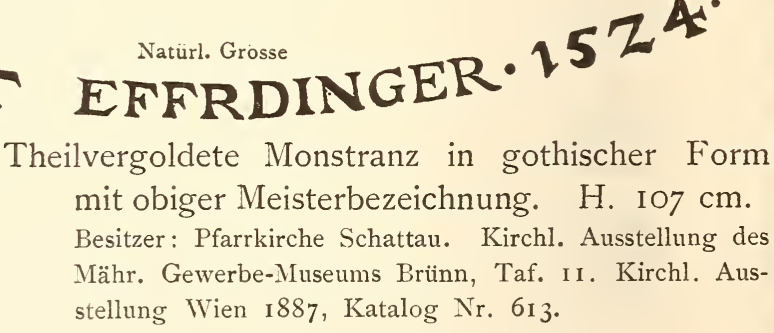 \\
\hline 2335 & $\begin{array}{c}\text { wie } \\
\text { Nr. } 23 \text { I4 }\end{array}$ & & $\begin{array}{l}\text { Vergoldeter Kelch mit Frührenaissanceorna- } \\
\text { menten. } \\
\text { Ausstellung Budapest 1884. }\end{array}$ \\
\hline
\end{tabular}




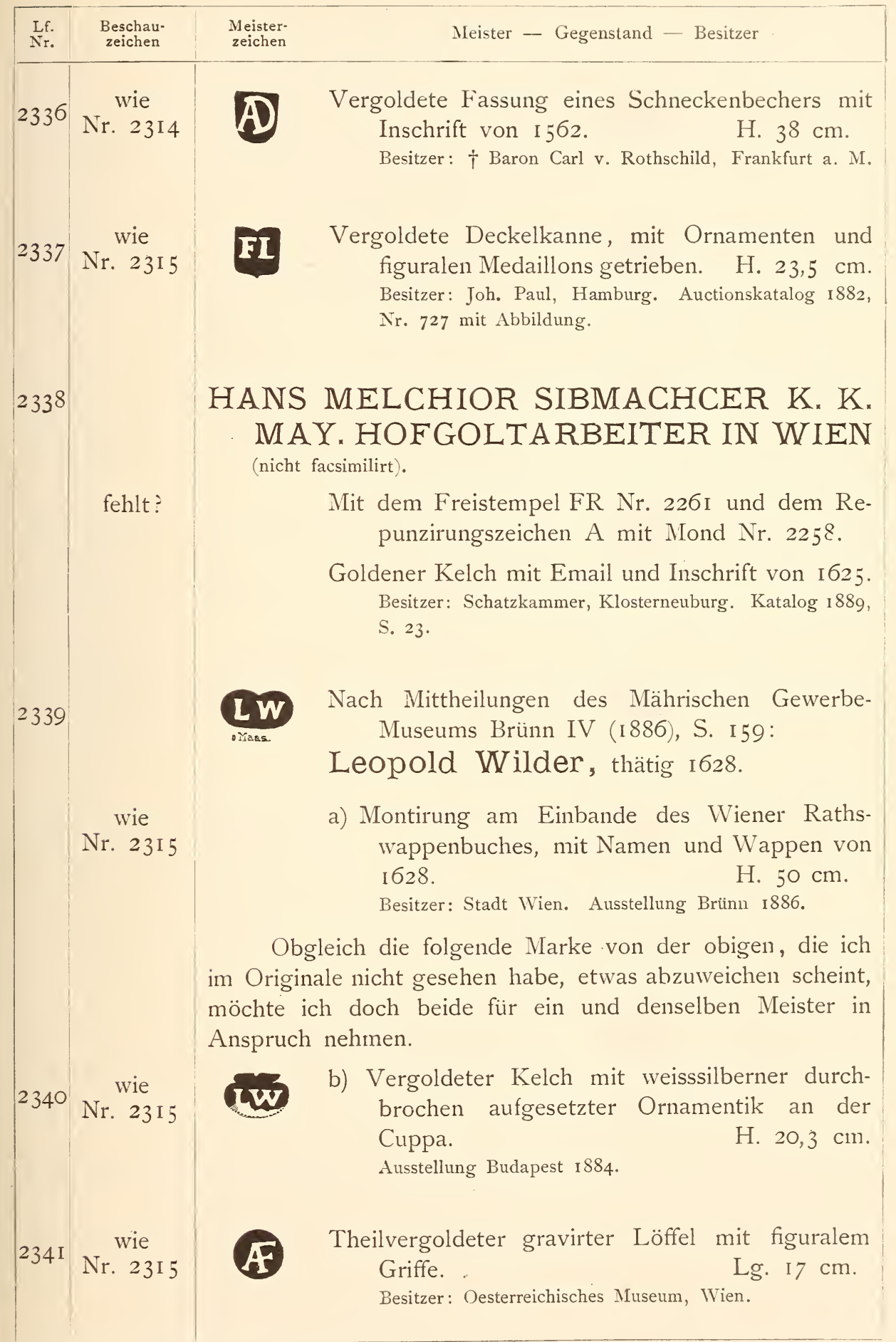




\begin{tabular}{|c|c|c|c|}
\hline $\begin{array}{l}\text { Lf. } \\
\text { Nr. }\end{array}$ & $\begin{array}{l}\text { Beschau- } \\
\text { zeichen }\end{array}$ & zeichen & Meister - Gegenstand - Besitzer \\
\hline 2342 & $\begin{array}{c}\text { wie } \\
\text { Nr. } 23 \text { I } 5\end{array}$ & & $\begin{array}{l}\text { Vergoldete ovale Platte mit Treibarbeit. } \\
\text { Lg. } 54,5 \mathrm{~cm} \text {. } \\
\text { Besitzer: Graf Erdödy. Ausstellung Budapest } \mathrm{I} 884 .\end{array}$ \\
\hline 2343 & $\begin{array}{c}\text { wie } \\
\text { Nr. } 2315\end{array}$ & & $\begin{array}{l}\text { a) Vergoldete getriebene Fassung einer Schale } \\
\text { mit Hinterglasmalerei. } \\
\text { Besitzer: Herzogl. Museum, Gotha. }\end{array}$ \\
\hline 2344 & $\begin{array}{c}\text { wie } \\
\text { Nr. } 23 \text { I } 5\end{array}$ & Mit & $\begin{array}{l}\text { Marke ist die folgende vielleicht identisch: } \\
\text { b) Hälfte eines Doppelbechers, Corpus getrieben } \\
\text { und mit Inschrift versehen. H. I } 5,4 \mathrm{~cm} \text {. } \\
\text { Besitzer: Baron H. v. Günzburg, St. Petersburg. }\end{array}$ \\
\hline 2345 & $\begin{array}{c}\text { wie } \\
\text { Nr. } 2316\end{array}$ & & $\begin{array}{l}\text { Vergoldetes Scherztrinkgefäss mit Mühlrad. In- } \\
\text { schrift. } \\
\text { Besitzer: National-Museum, Budapest. Ausstellung Buda- } \\
\text { pest I } 884 .\end{array}$ \\
\hline 2346 & $\begin{array}{c}\text { wie } \\
\text { Nr. } 2316 \\
\text { mit } 1679\end{array}$ & & $\begin{array}{l}\text { Vergoldete Deckelkanne mit eingelassenen Mün- } \\
\text { zen. } \\
\text { Ausstellung Budapest I } 884 .\end{array}$ \\
\hline 2347 & $\begin{array}{l}\text { wie } \\
\text { Nr. } 23 \text { I6 } \\
\text { mit } 1690 \\
\text { wie } 23 \text { I } 8 \\
\text { mit } 17 \text { I }\end{array}$ & & $\begin{array}{l}\text { a) Vergoldeter Kelch, getrieben. H. } 27,5 \mathrm{~cm} \text {. } \\
\text { Besitzer: Graf Georg Bánffy. Ausstellung Budapest } \\
\text { I } 884, \text { 2. Saal, I2. Schrank, Nr. 29 B. Katalog S. I35. } \\
\text { b) Vergold. Crucifix mit Glasflüssen. H. } 29 \mathrm{~cm} \text {. } \\
\text { Ausstellung Budapest I } 884 .\end{array}$ \\
\hline 2348 & $\begin{array}{c}\text { wie } \\
\text { Nr. } 2318 \\
\text { mit } 1692\end{array}$ & FO & $\begin{array}{l}\text { a) Mit dem Repunzirungszeichen I2 A Nr. } 2256 \text {. } \\
\text { Theilvergoldetes Kännchen, mit Ranken getrieben. } \\
\text { Besitzer: H. Boskowitz, Wien. } \\
\begin{array}{l}\text { b) Mit dem Repunzirungszeichen I2 F und dem } \\
\text { Freistempel FR Nr. 226I. }\end{array}\end{array}$ \\
\hline & & & $\begin{array}{l}\text { Theilvergoldetes Schälchen. Innen figural ge- } \\
\text { trieben. } \\
\text { Besitzer: Baron R. v. Walterskirchen, Wien. }\end{array}$ \\
\hline
\end{tabular}




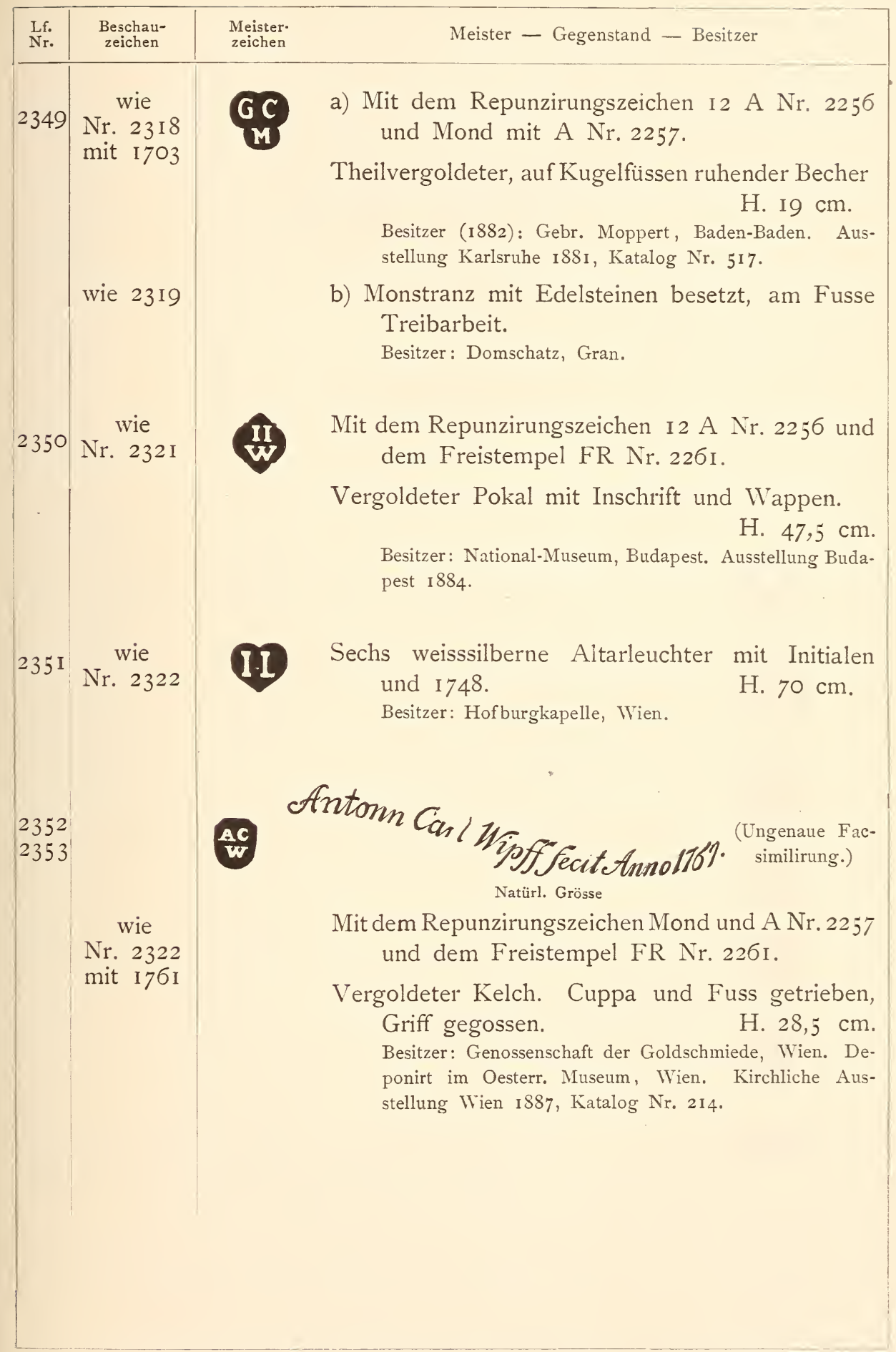




\section{U N G A R N.}

\section{BUDAPEST.}

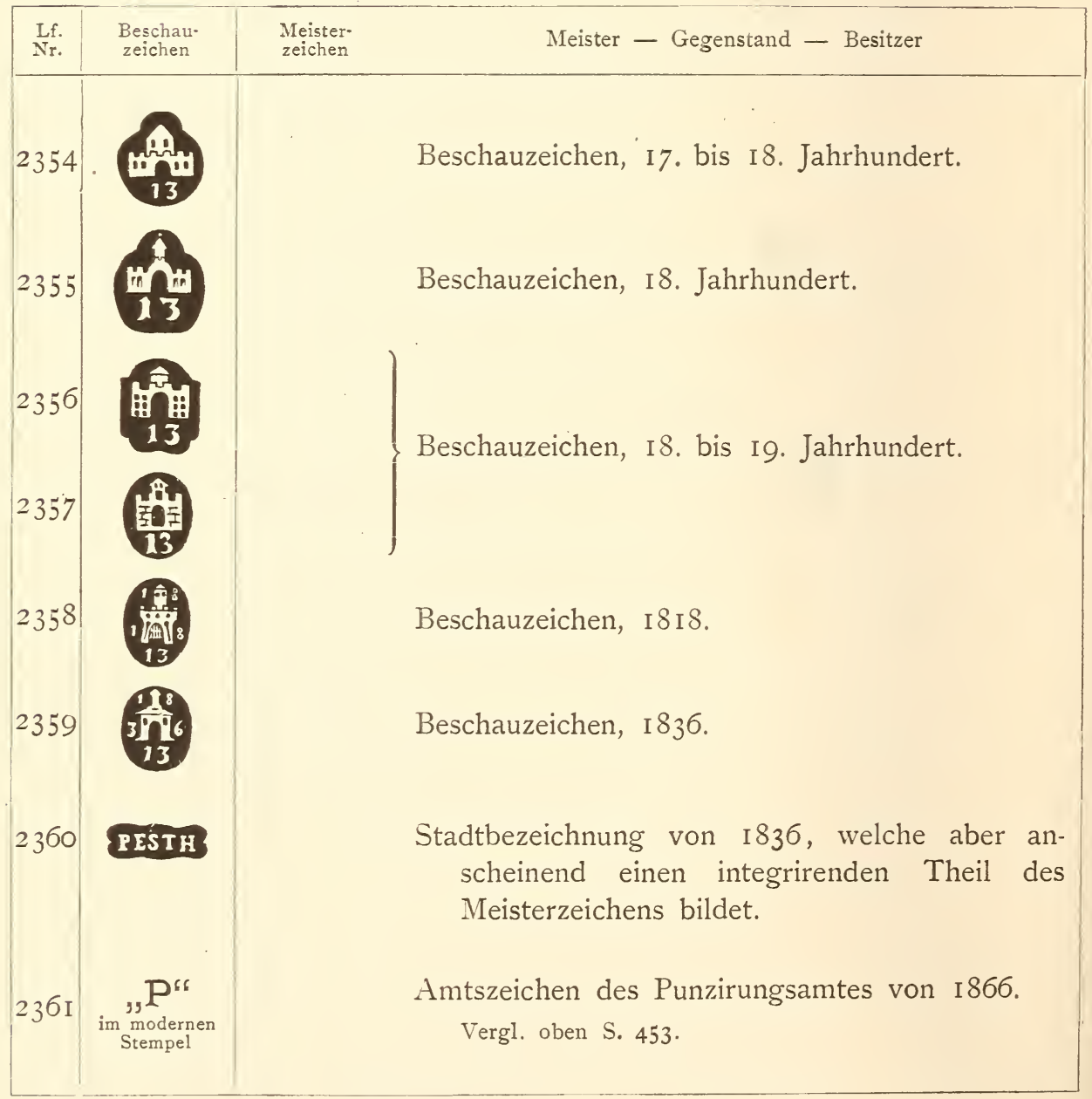




\begin{tabular}{|c|c|c|c|}
\hline Lff. & $\begin{array}{l}\text { Beschau- } \\
\text { zeichen }\end{array}$ & $\begin{array}{l}\text { Meister- } \\
\text { zeichen }\end{array}$ & Meister - Gegenstand - Besitzer \\
\hline 2362 & & & $\begin{array}{l}\text { Jahresbuchstaben oder Beschaumeisterzeichen, } \\
\text { I } 7 \text {. bis } 18 \text {. Jahrhundert. }\end{array}$ \\
\hline 2363 & & & $\begin{array}{l}\text { Jahresbuchstaben oder Beschaumeisterzeichen, } \\
\text { I } 8 \text {. Jahrhundert. }\end{array}$ \\
\hline $\begin{array}{l}2364 \\
2365\end{array}$ & & & $\begin{array}{l}\text { Jahresbuchstaben oder Beschaumeisterzeichen, } \\
\text { I8. bis I9. Jahrhundert. }\end{array}$ \\
\hline 2366 & $\begin{array}{l}\text { wie } \\
\text { Nr. } 2354\end{array}$ & & $\begin{array}{l}\text { Mit dem Jahresbuchstaben E Nr. } 2362 . \\
\begin{array}{l}\text { Vergoldete Monstranz. } \\
\text { Besitzer: ? Kirche, Budapest. }\end{array}\end{array}$ \\
\hline 2367 & $\begin{array}{l}\text { wie } \\
\text { Nr. } 2355\end{array}$ & & $\begin{array}{l}\text { Mit dem Jahresbuchstaben C Nr. } 2363 . \\
\text { a) Pfeffer- und Senfgefäss. Rococo. H. I } 8,5 \mathrm{~cm} \text {. } \\
\text { Besitzer: S. D. Prinz Heinr. Reuss, Wien. }\end{array}$ \\
\hline 2368 & $\begin{array}{l}\text { wie } \\
\text { Nr. } 2356\end{array}$ & & $\begin{array}{l}\text { Mit dem Jahresbuchstaben I Nr. } 2364 . \\
\begin{array}{ll}\text { b) Vergoldete Strahlenmonstranz mit Empire- } \\
\text { Ornamenten. } & \text { H. } 59,5 \mathrm{~cm} . \\
\text { Ausstellung Budapest } 1884 . & \end{array}\end{array}$ \\
\hline 2369 & $\begin{array}{l}\text { wie } \\
\text { Nr. } 2557\end{array}$ & & $\begin{array}{l}\text { Mit dem Jahresbuchstaben N Nr. } 2365 \text {. } \\
\text { Silbernes Beschläge einer Meerschaumpfeife. } \\
\text { Besitzer: S. K. H. d. Grossherzog von Baden, Schloss } \\
\text { Karlsruhe. }\end{array}$ \\
\hline
\end{tabular}




\section{HERMANNSTADT.}

Eine Ordnung aus dem Beginne des I6. Jahrhunderts bestimmt, dass kein Meister irgend eine Arbeit verkaufen dürfe, ohne dass dieselbe mit seinem Privatzeichen und, von Seiten der Zunft, durch den Zunftmeister und zwei Mitmeister, nach vorhergegangener Prüfung, mit der Zunftmarke gestempelt worden wäre.

Friedrich Müller im Sächsischen Hausfreund von 1864 bis 1865 .

Aus dieser relativ frühen Hermannstädter Stempelperiode, in welcher neben dem Meisterzeichen das Stadtwappen oder ein Wardeinstempel erscheinen müsste, weiss ich keine Arbeiten nachzuweisen.

Die Goldschmiedeordnung von I539 sagt: jeder Meister hat seinen Stempel in der Zukunft abmalen zu lassen und an jeder Arbeit anzubringen. Müller a. a. O.

Es scheint also, dass 1539 kein Stadt- oder Wardeinzeichen mehr verlangt wurde.

\begin{tabular}{|c|c|c|c|}
\hline $\begin{array}{l}\text { Lf. } \\
\text { Nr. }\end{array}$ & $\begin{array}{l}\text { Beschau- } \\
\text { zeichen }\end{array}$ & $\begin{array}{l}\text { Meister- } \\
\text { zeichen }\end{array}$ & Meister - Gegenstand - Besitzer \\
\hline 2370 & $\begin{array}{l}\text {,yg } 4^{k r} \\
\text { im modernen } \\
\text { Stempel }\end{array}$ & & $\begin{array}{l}\text { Amtszeichen des Punzirungsamtes von I } 866 . \\
\text { Vergl. oben S. } 453 \text {. }\end{array}$ \\
\hline $237 \mathrm{I}$ & fehlt & & $\begin{array}{l}\text { Nach dem Katalog der Internationalen Ausstellung } \\
\text { Nürnberg I } 885 \mathrm{Nr} .455 \text { : } \\
\text { Daniel Bulkesch. } \\
\begin{array}{ll}\text { Vergoldete Deckelkanne, getrieben, mit Mono- } \\
\text { gramm und I } 589 . & \text { H. } 20,8 \mathrm{~cm} \text {. } \\
\text { Besitzer:? Kirche, Mediasch. } & \end{array}\end{array}$ \\
\hline 2372 & fehlt & & $\begin{array}{l}\text { Nach dem Katalog der Internationalen Ausstellung } \\
\text { Nürnberg I } 885 \text { Nr. } 475 \text { : } \\
\text { Hans Friedrich Benedikt. } \\
\text { Vergoldete Weinkanne, gravirt und mit Münzen } \\
\text { eingelegt. Inschrift von I680. H. } 23,5 \mathrm{~cm} \text {. } \\
\quad \text { Besitzer: Evang. Kirche, Lechnic. }\end{array}$ \\
\hline
\end{tabular}




\begin{tabular}{|c|c|c|c|}
\hline$\underset{\text { Iff. }}{\text { Lff. }}$ & $\begin{array}{l}\text { Beschau. } \\
\text { zeichen }\end{array}$ & $\begin{array}{l}\text { Meister- } \\
\text { zeichen }\end{array}$ & Meister - Gegenstand - Besitzer \\
\hline 2373 & & SH & $\begin{array}{l}\text { Sebastian Hann der Aeltere, geb. } \\
\text { I644, Meister I675, Zunftvorsteher I689, } \\
\quad+\text { I7 } 3 \text {. }\end{array}$ \\
\hline & fehlt & & $\begin{array}{l}\text { a) Theilvergoldete Deckelkanne mit antiker Dar- } \\
\text { stellung in Treibarbeit. Im Deckel Wappen } \\
\text { mit Initialen vor I680. } \\
\text { Besitzer: Freih. Ludwig v. Rosenfeldt. Arbeiten des } \\
\text { Hermannstädter Goldschmiedes Sebastian Hann, Wien } \\
\text { I887, Taf. I und 2. }\end{array}$ \\
\hline & fehlt & & 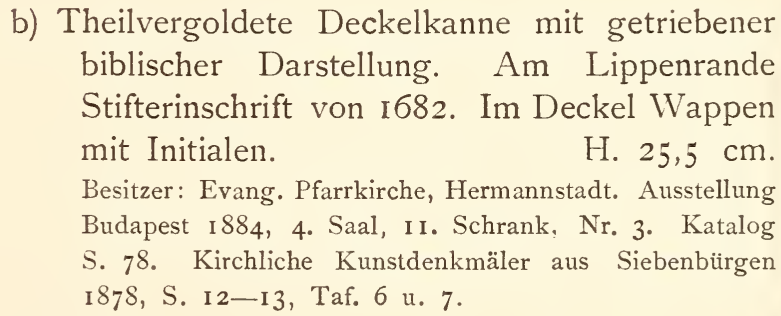 \\
\hline & fehlt & & 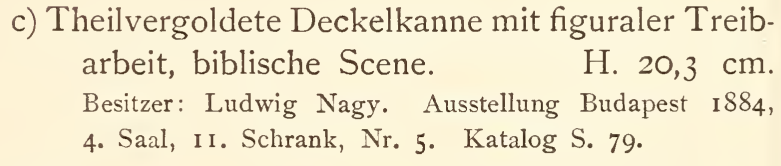 \\
\hline & fehlt & & $\begin{array}{l}\text { d) Vergoldete Deckelkanne mit antiken Dar- } \\
\text { stellungen in Treibarbeit. Mit Wappen und } \\
\text { Inschriften von I697. } \\
\text { Besitzer: National-Museum, Budapest. Ausstellung Buda- } \\
\text { pest 1884, 4. Saal, II. Schrank, Nr. } 6 \text {. Kat. S. 79. } \\
\text { Galvanoplastische Reproduction. Arbeiten des Seb. } \\
\text { Hann, Taf. 5, } 6 \text { und } 7 .\end{array}$ \\
\hline & fehlt & & $\begin{array}{l}\text { e) Theilvergoldete Deckelkanne mit figuraler Treib- } \\
\text { arbeit. Antike Scenen. Inschriften von } 1697 . \\
\text { H. } 27 \mathrm{~cm} . \\
\text { Besitzer: Ernst Lüdecke (Lindecke)?, Hermannstadt. } \\
\text { Ausstellung Budapest I } 884 \text {, 4. Saal, Ir. Schrank, Nr. } 4 \\
\text { Katalog S. 78. J. Szendrei, Erinnerung der hist. Aus- } \\
\text { stellung ungar. Goldschmiedearbeiten I884 (Ungarisch), } \\
\text { S. 3I, Taf. I I. }\end{array}$ \\
\hline & fehlt & & $\begin{array}{l}\text { f) Theilvergoldete Deckelkanne mit figuraler Treib- } \\
\text { arbeit, biblische Scenen und Inschriften von } \\
\text { I(6)99? Im Deckel ein Wappen. H. } 3 \mathrm{I}, 5 \mathrm{~cm} \text {. } \\
\text { Besitzer: † Baron Carl v. Rothschild, Frankfurt a. M. }\end{array}$ \\
\hline
\end{tabular}




\begin{tabular}{|c|c|c|c|}
\hline $\begin{array}{l}\text { Lf. } \\
\text { Nr. }\end{array}$ & $\begin{array}{l}\text { Beschau- } \\
\text { zeichen }\end{array}$ & $\begin{array}{l}\text { Meister- } \\
\text { zeichen }\end{array}$ & Meister - Gegenstand - Besitzer \\
\hline $\begin{array}{l}2373 \\
2374\end{array}$ & fehlt & & $\begin{array}{l}\text { g) Vergoldeter Pokal mit Volutengriff, Cuppa } \\
\text { und Deckel gravirt. Im Deckel ein Wappen } \\
\text { mit Initialen getrieben (I680-I684). } \\
\text { H. } 34 \mathrm{~cm} \text {. } \\
\text { Besitzer: Freih. Ludwig v. Rosenfeld. Arbeiten des } \\
\text { Seb. Hann, Taf. 3. }\end{array}$ \\
\hline & fehlt & & $\begin{array}{l}\text { h) Vergoldeter Leuchter mit dreitheiligem Fusse, } \\
\text { Schaft mit Blumen decorirt. Inschrift von } \\
\text { I69I. } \\
\text { Besitzer: Evang. } 67 \mathrm{~cm} \text {. } \\
\text { Budapest 1884, 4. Saal, 11. Schrank, Nr. I. Katalog } \\
\text { S. } 77 .\end{array}$ \\
\hline & fehlt & & $\begin{array}{l}\text { i) Vergoldete Flasche mit Schraubendeckel. } \\
\text { H. 23,4 cm. } \\
\text { Besitzer: } † \text { Baron Carl v. Rothschild, Frankfurt a. M. } \\
\text { k) Vergoldetes Ciborium mit getriebenem Me- } \\
\text { daillon im Innern. } \\
\text { Besitzer: Evang. Pfarrkirche, Hermannstadt. Ausstellung } \\
\text { Budapest I884, 4. Saal, II. Schrank, Nr. Io. Katalog } \\
\text { S. 80. Kirchliche Kunstdenkmäler aus Siebenbuirgen } \\
\text { 1879, S. 25-26, Taf. I5-16. }\end{array}$ \\
\hline & fehlt & & $\begin{array}{l}\text { 1) Vergoldete ovale Henkelschale, in der Mitte } \\
\text { Treibarbeit. } \\
\text { Besitzer: Freih. Ludwig v. Rosenfeld. Arbeiten des } \\
\text { Seb. Hann, Taf. } 4 .\end{array}$ \\
\hline & fehlt & & $\begin{array}{l}\text { m) Vergoldete rundliche Henkelschale auf drei } \\
\text { Füssen ruhend. Am Boden Medaillon mit } \\
\text { antiker Darstellung getrieben. Inschrift von } \\
\text { I } 06 . \\
\text { Besitzer: Freiherr Sam. v. Bruckenthal, Hermannstadt. } \\
\text { Ausstellung Budapest I884, 4. Saal, II. Schrank, Nr. 9. } \\
\text { Katalog S. 8o. Arbeiten des Seb. Hann, Taf. 8. }\end{array}$ \\
\hline & fehlt & & $\begin{array}{l}\text { n) Ovale Henkelschale, innen mit figuraler Treib- } \\
\text { arbeit. } \\
\text { Bes. I 5,5 cm. Pfïlzisches Gewerbe-Museum, Kaiserslautern. } \\
\text { Katalog Nr. 23. }\end{array}$ \\
\hline & fehlt & & $\begin{array}{l}\text { o) Schale auf Fuss. } \\
\text { Besitzer: Freih. Fr. v. Mylius, Klagenfurt. Ausstellung } \\
\text { Klagenfurt I } 885 \text {. Arbeiten des Seb. Hann, S. } 4 \text {. }\end{array}$ \\
\hline
\end{tabular}




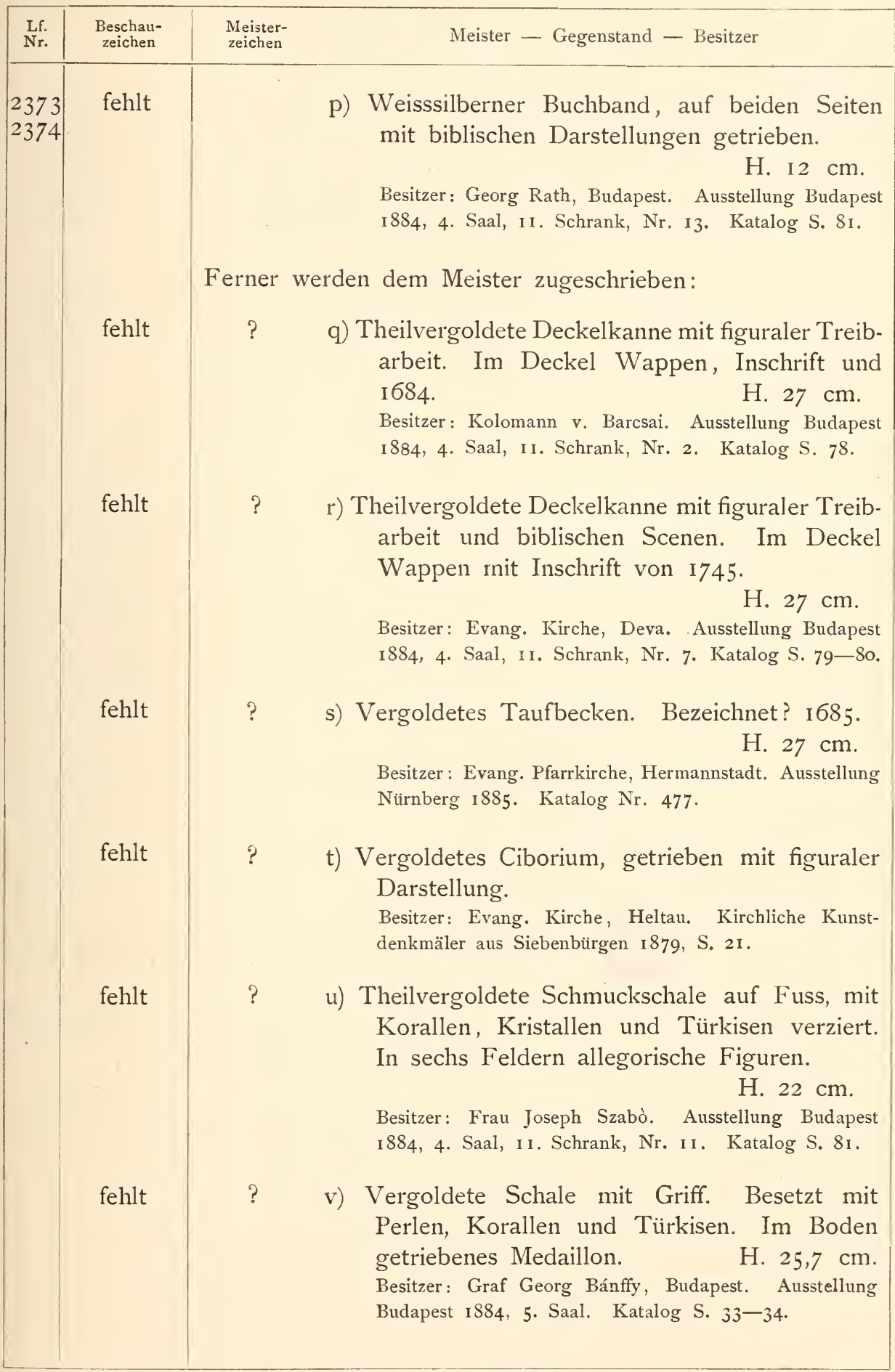




\begin{tabular}{|c|c|c|c|}
\hline $\begin{array}{l}\text { Lf. } \\
\text { Nr. }\end{array}$ & $\begin{array}{l}\text { Beschau• } \\
\text { zeichen }\end{array}$ & $\begin{array}{l}\text { Meister- } \\
\text { zeichen }\end{array}$ & Meister - Gegenstand - Besitzer \\
\hline $\begin{array}{l}2373 \\
2374\end{array}$ & fehlt & ? & $\begin{array}{l}\text { Theilvergoldete Schale mit achtmal einge- } \\
\text { zogenem Rande, innen figurale Treibarbeit. } \\
\text { Dm. I4 cm. } \\
\text { Besitzer: Graf Georg Bánffy, Budapest. Ausstellung } \\
\text { Budapest I884, 4. Saal, I I. Schrank, Nr. 8. Katalog } \\
\text { S. 8o. }\end{array}$ \\
\hline & fehlt & ? & $\begin{array}{l}\text { x) Getriebenes Silberrelief, biblische Darstellung. } \\
\text { Besitzer: Graf Franz Zichy, Budapest. Ausstellung } \\
\text { Budapest I } 884 \text {, 4. Saal, II. Schrank, Nr. I2. Katalog } \\
\text { S. 8I. }\end{array}$ \\
\hline & - & & \\
\hline
\end{tabular}

\section{MEDIASCH.}

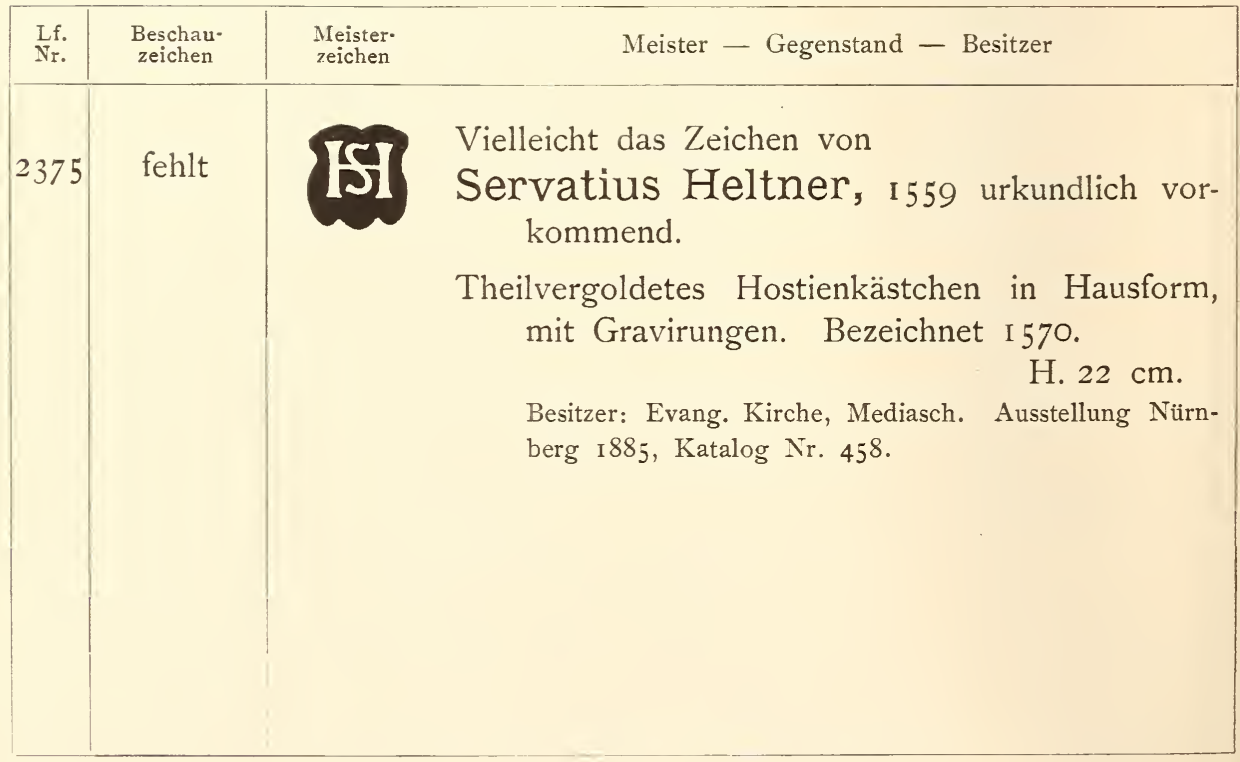




\section{SCHEMNITZ.}

\begin{tabular}{|c|c|c|c|}
\hline Lff. & $\begin{array}{l}\text { Beschau- } \\
\text { zeichen }\end{array}$ & $\begin{array}{l}\text { Meister- } \\
\text { zeichen }\end{array}$ & Meister - Gegenstand - Besitzer \\
\hline 36 & & & Beschauzeichen, I7. Jahrhundert. \\
\hline 2378 & & & Beschauzeichen, I7. bis I8. Jahrhundert. \\
\hline 2379 & & & Beschauzeichen, I8. Jahrhundert. \\
\hline 2380 & $\begin{array}{l}\text { gy } 2 \text { is } \\
\text { im modernen } \\
\text { Stempel }\end{array}$ & & $\begin{array}{l}\text { Amtszeichen des Punzirungsamtes von } 1866 . \\
\text { Vergl. oben S. } 453 \text {. }\end{array}$ \\
\hline $238 \mathrm{I}$ & $\begin{array}{c}\text { wie } \\
\text { Nr. } 2376\end{array}$ & $R$ & $\begin{array}{l}\text { a) Theilvergoldeter Becher mit gravirtem Wappen } \\
\text { und Namen. } \\
\text { Hesitzer: Kathol. Kirche, Schemnitz. Ausstellung Buda- } \\
\text { pest } 1884 \text {. }\end{array}$ \\
\hline & wie 2376 & & $\begin{array}{l}\text { b) Theilvergoldete Schraubenflasche mit ornamen- } \\
\text { tirten Buckeln. } \quad \text { H. I } 7,5 \mathrm{~cm} \text {. } \\
\text { Besitzer: Kath. Kirche, Schemnitz. Ausstellung Buda- } \\
\text { pest i } 884 \text {. }\end{array}$ \\
\hline & wie 2376 & & $\begin{array}{l}\text { c) Weisssilberner Löffel. } \quad \text { Lg. I } 7 \mathrm{~cm} \text {. } \\
\text { Besitzer: National-Museum, Budapest. Ausstellung Buda- } \\
\text { pest I884. }\end{array}$ \\
\hline & wie 2376 & & $\begin{array}{l}\text { d) Vergoldeter Buckelpokal mit Inschrift und } \\
\text { I690. } \\
\text { Besitzer: National-Museum, Budapest. Ausstellung Buda- } \\
\text { pest i } 884 \text {. }\end{array}$ \\
\hline
\end{tabular}




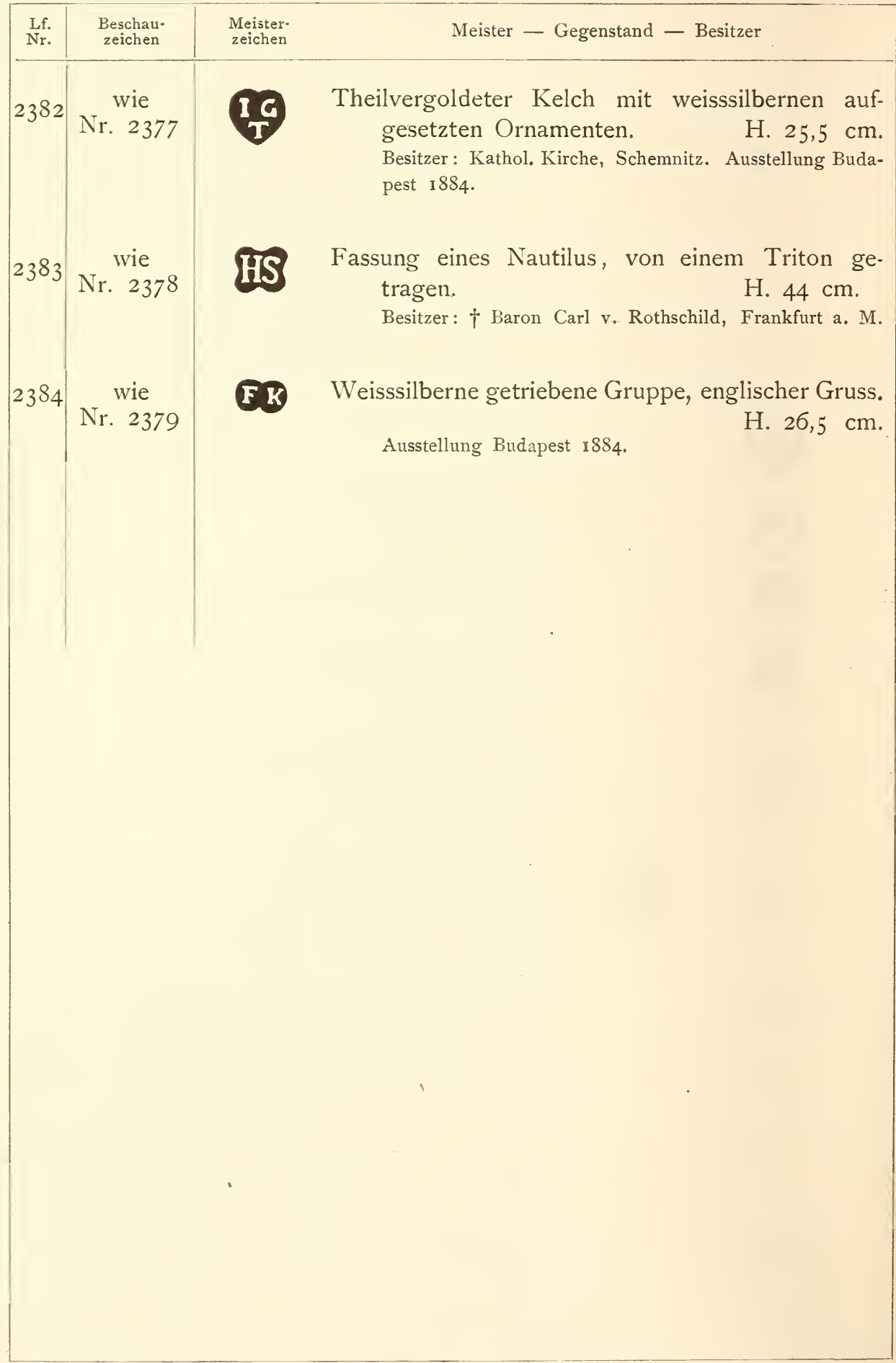




\section{R U S S L A N D.}

Da mir für Russland, mit Ausnahme von Riga, die Deutung der Meistermarken nur in sehr geringem Grade gelungen ist, und ich nur verhältnissmässig junge und geringwerthige Arbeiten kennen gelernt habe, mag es genügen die Beschauzeichen allein anzuführen.

Jarosslawl.

2385 Beschauzeichen, I767.

\section{Kaluga.}

$2386 \rightleftharpoons$ Beschauzeichen, Ende I8. Jahrhundert.

\section{Kaminetz - Podolski.}

2387 Beschauzeichen, 1858.

2388 Beschauzeichen, I797.

\section{Kasan.}

\section{Kiew.}

2389 Beschauzeichen, um I794.

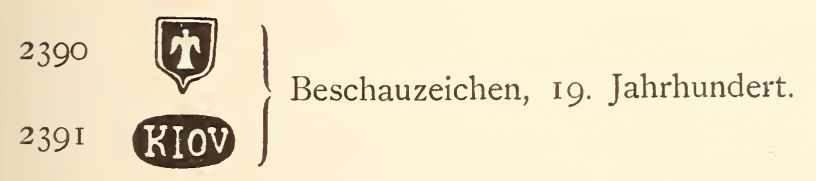

Kostroma oder Lomsha.

2392 Beschauzeichen, I78I.

\section{Moskau.}


Beschauzeichen, I 747 .

2395 Bर्जि

2396 Beschauzeichen, I780.

\section{Nowgorod.}

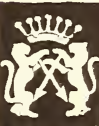

Beschauzeichen, I774.

St. Petersburg.

2398

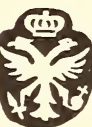

2399

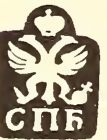

Beschauzeichen, um 1736.

2400

ơ

1746

240 I

2402 of

2403 of 18 Beschauzeichen, I801.

2404 B⿺辶一

2405 ôt Beschauzeichen, 1829 bis I 880. In verschie-
denen Grössen

\section{Reval.}




\section{RIGA.}

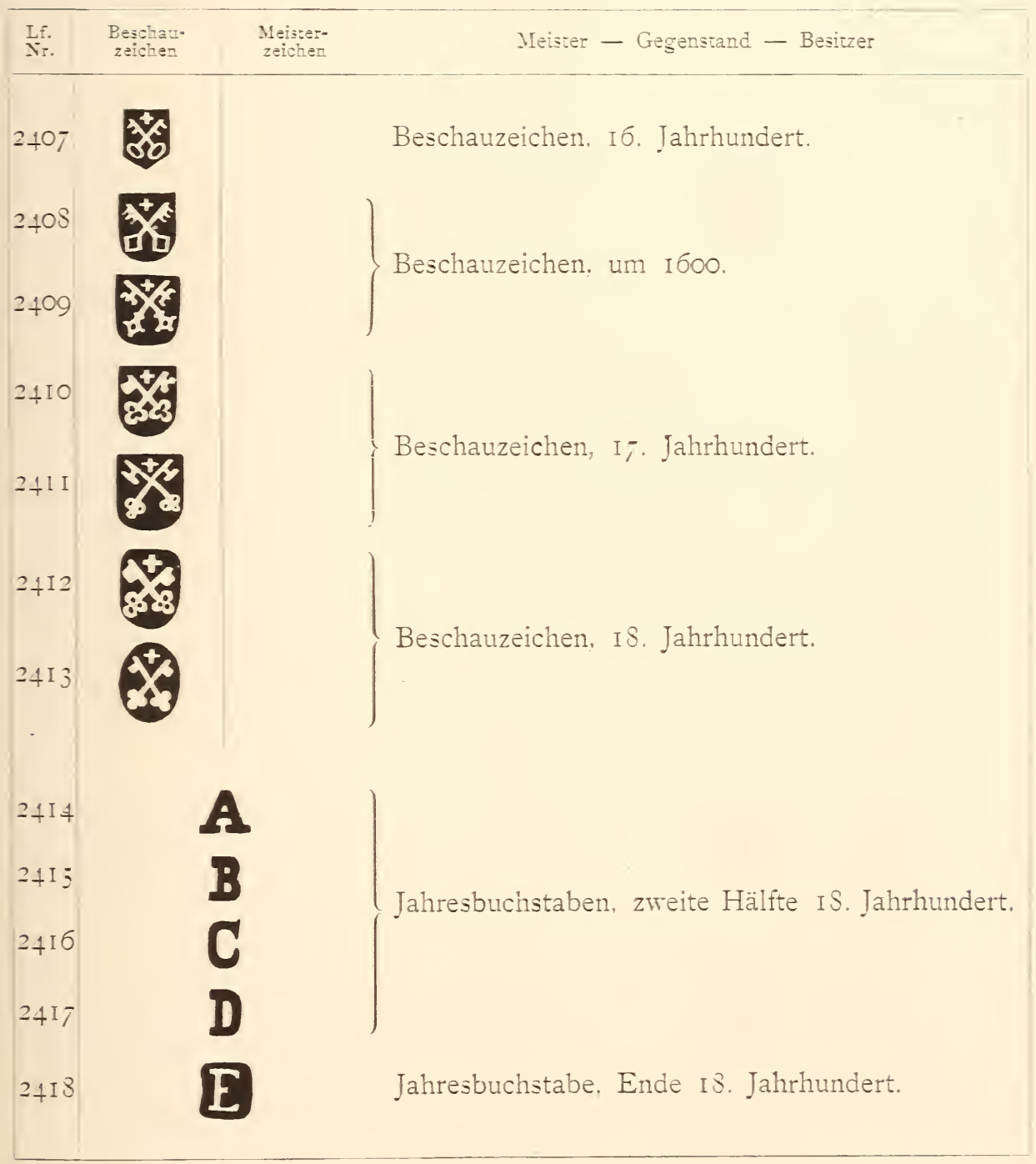




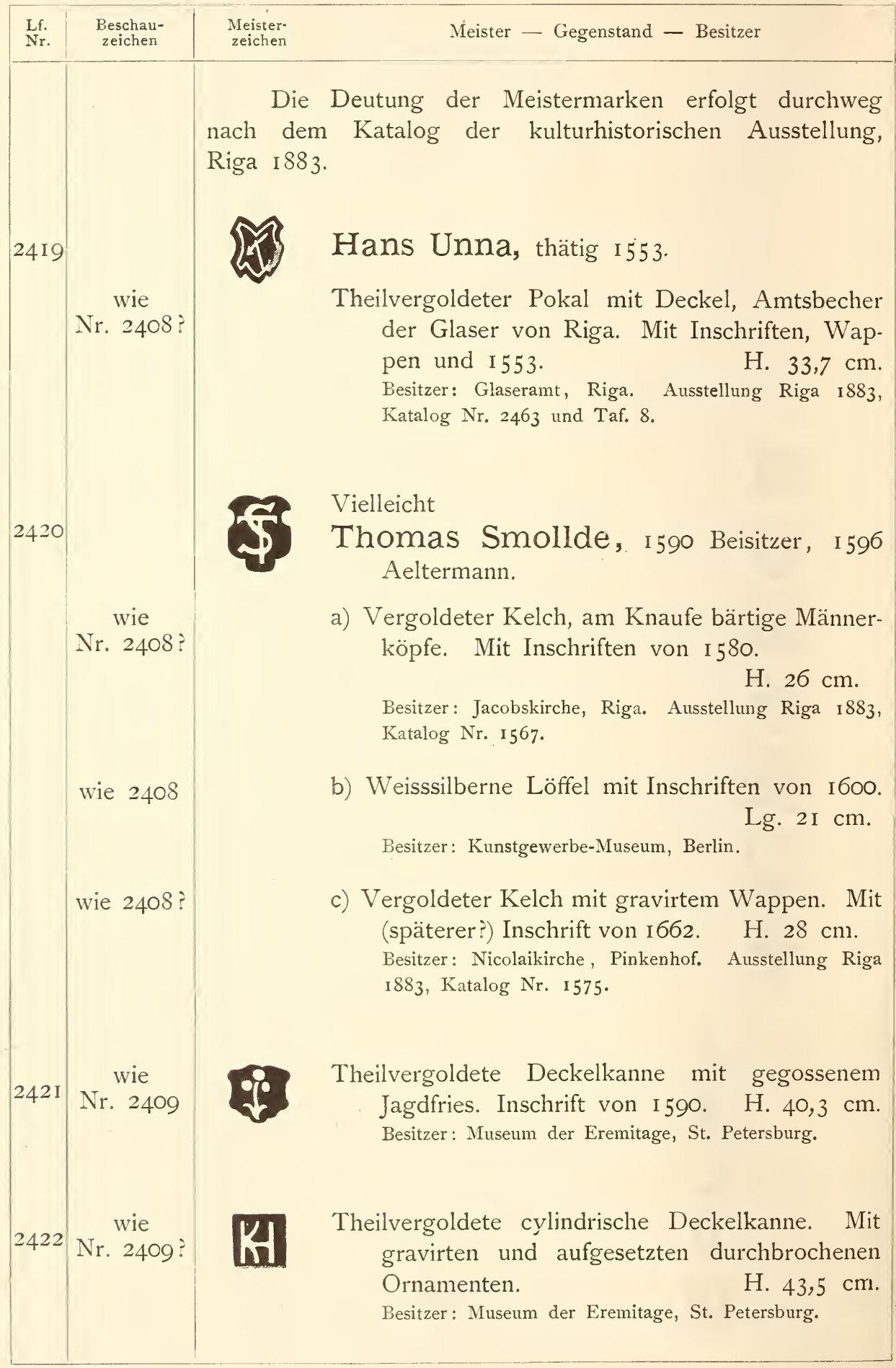




\begin{tabular}{|c|c|c|c|}
\hline $\begin{array}{l}\text { Lf. } \\
\text { Nr. }\end{array}$ & $\begin{array}{l}\text { Beschau- } \\
\text { zeichen }\end{array}$ & $\begin{array}{l}\text { Meister- } \\
\text { zeichen }\end{array}$ & Meister - Gegenstand - Besitzer \\
\hline 2423 & $\begin{array}{c}\text { wie } \\
\text { Nr. 24IO? }\end{array}$ & & $\begin{array}{l}\text { Vergoldeter Deckelpokal auf drei Löwen ruhend, } \\
\text { der „,Riga'sche Willkommen“" genannt. Mit } \\
\text { Wappen, Initialen und vielen Inschriften von } \\
\text { I6I6. H. } 62 \mathrm{~cm} \text {. } \\
\text { Besitzer: Compagnie der Schwarzen Häupter, Riga. } \\
\text { Ausstellung Riga I883, Katalog Nr. I590 und Taf. } 6 . \\
\text { Neumann, Kunstgewerbe in Liv-, Est- und Kurland, } \\
\text { S. I74 mit Abbildung. }\end{array}$ \\
\hline 2424 & $\begin{array}{c}\text { wie } \\
\mathrm{Nr} .24 \mathrm{IO}\end{array}$ & & 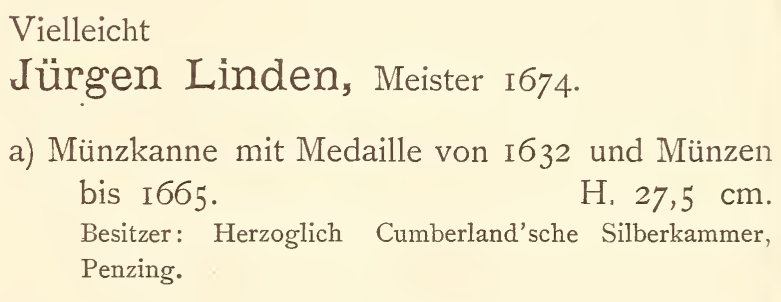 \\
\hline & wie $2410 ?$ & & $\begin{array}{l}\text { b u. c) Zwei ovale getriebene Schüsseln mit bibli- } \\
\text { schen Darstellungen. Wappen und Inschrift } \\
\text { von I67I. } \mathrm{Lg.} 40 \mathrm{~cm} \text {. } \\
\text { Besitzer: Compagnie der Schwarzen Häupter, Riga. } \\
\text { Ausstellung Riga 1883, Katalog Nr. } 597 \text { und 1598. } \\
\text { d u. e) Zwei ovale getriebene Schüsseln mit bibli- } \\
\text { schen Darstellungen, Wappen und Inschrift } \\
\text { von I672. } \\
\text { Besitzer: Compagnie der Schwarzen Häupter, Riga. } \\
\text { Ausstellung Riga 1883, Katalog Nr. } 1599 \text { und 1600. }\end{array}$ \\
\hline & wie 2410 ? & & $\begin{array}{l}\text { f) "Armbrust". } \\
\text { Lg. I6 cm. } \\
\text { Besitzer: Compagnie der Schwarzen Häupter, Riga. } \\
\text { Ausstellung Riga 1883, Katalog Nr. 1605. }\end{array}$ \\
\hline & wie 2410 ? & & $\begin{array}{l}\text { g) Vergoldete Thalerkanne, auf drei Löwen } \\
\text { ruhend. Mit Wappen, Inschrift und I676. } \\
\text { H. } 26 \mathrm{~cm} \text {. } \\
\text { Besitzer: Compagnie der Schwarzen Häupter, Riga. } \\
\text { Ausstellung Riga 1883, Katalog Nr. 1606. }\end{array}$ \\
\hline & wie $24 \mathrm{I} 2$ & & $\begin{array}{l}\text { h) Theilvergoldete Schüssel auf drei Kugelfüssen } \\
\text { ruhend. Mit Deckel und Handhaben. } \\
\text { H. } 20 \mathrm{~cm} \text {. } \\
\text { Besitzer: S. D. Fürst Paskewitsch, St. Petersburg. }\end{array}$ \\
\hline
\end{tabular}




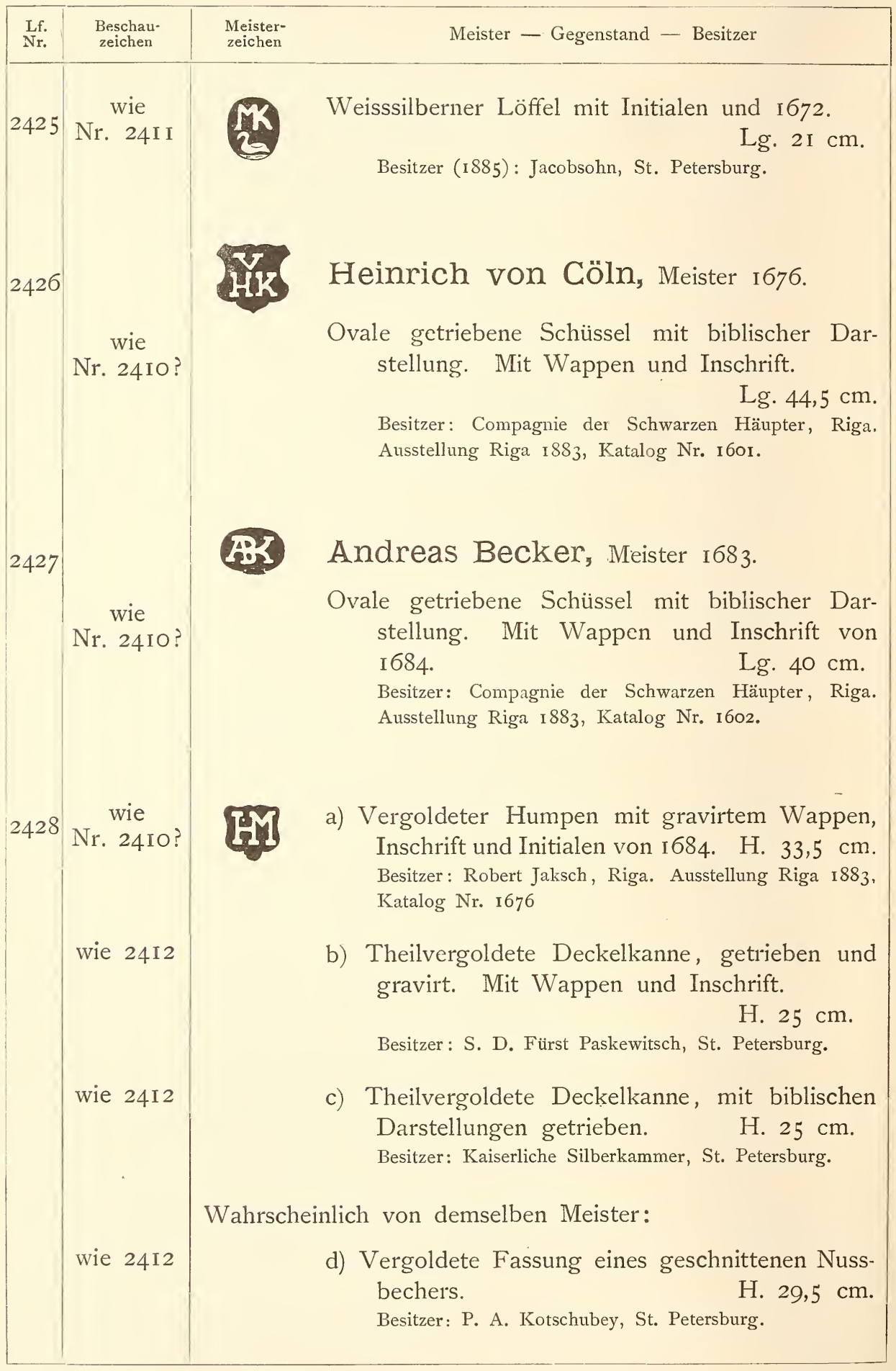




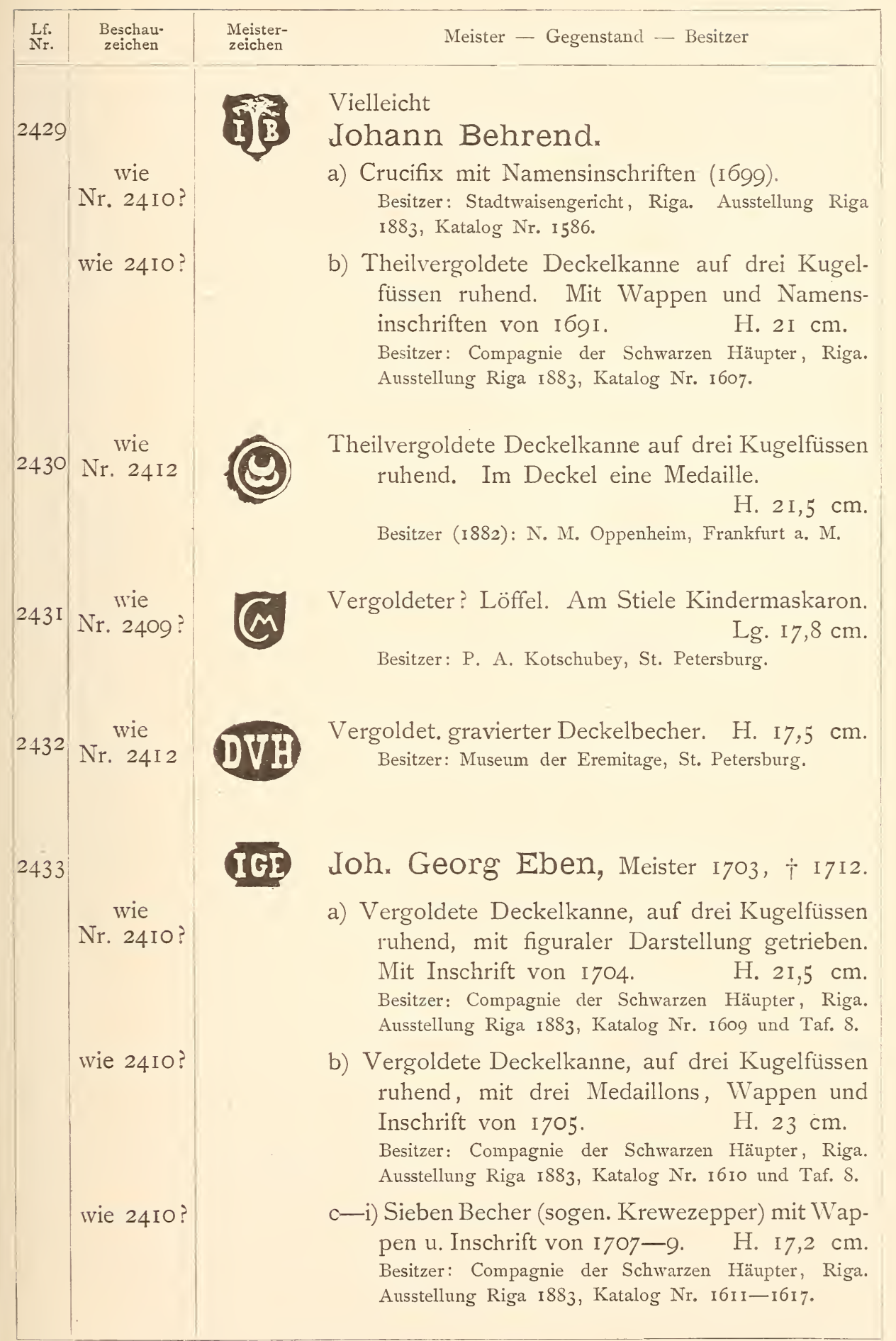




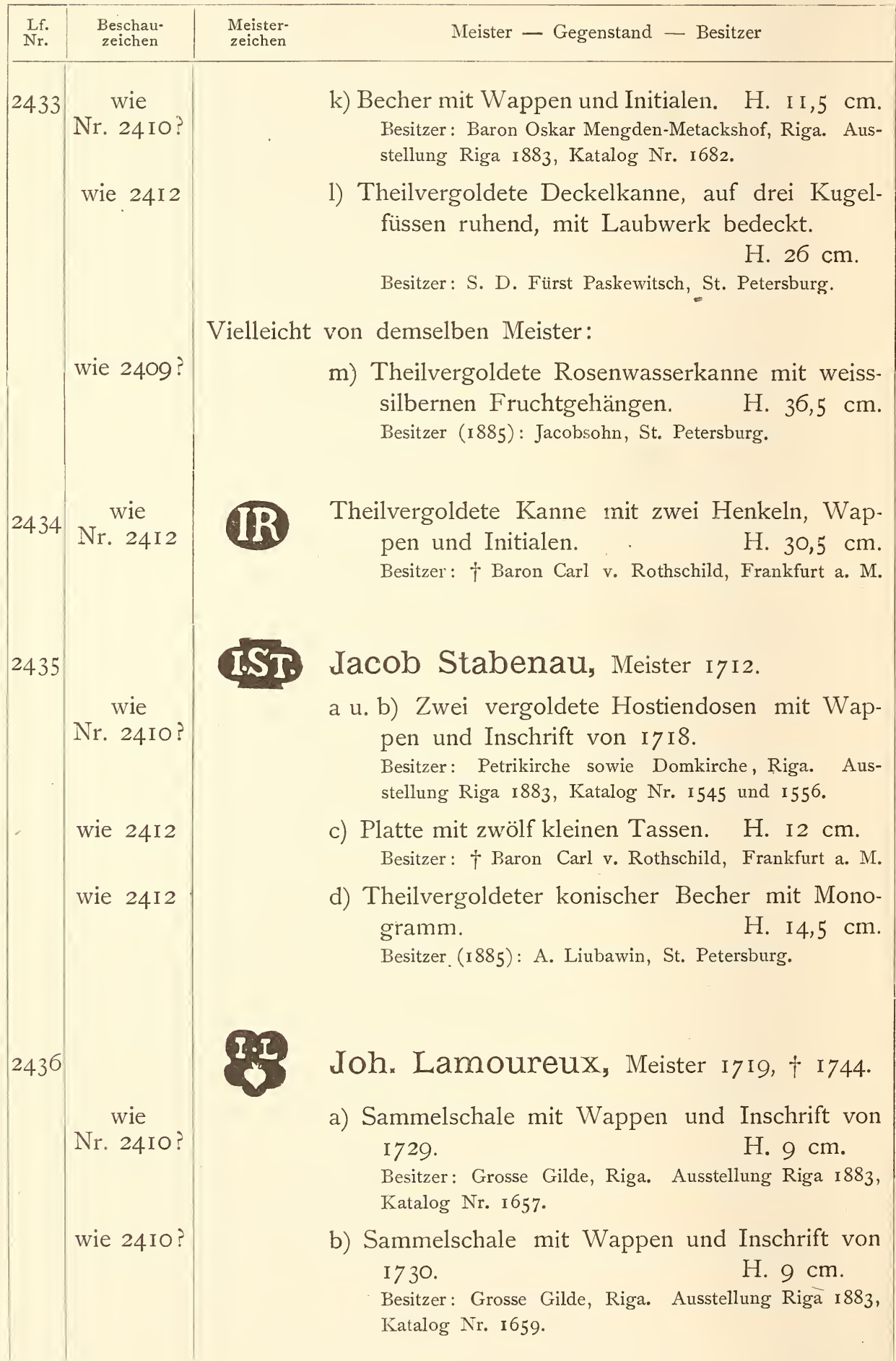




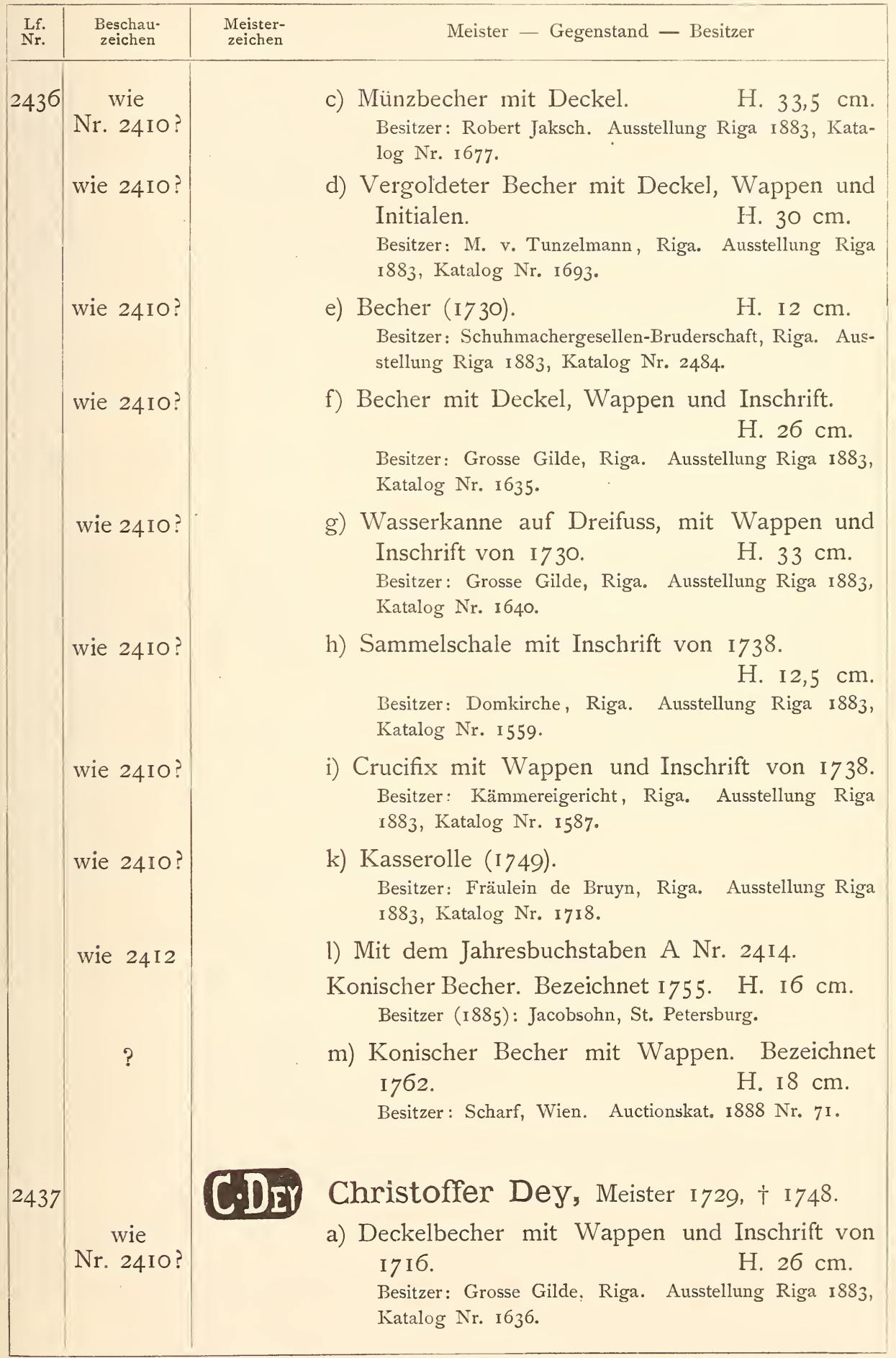




\begin{tabular}{|c|c|c|c|}
\hline $\begin{array}{l}\text { Lff. } \\
\text { Nr. }\end{array}$ & $\begin{array}{l}\text { Beschau- } \\
\text { zeichen }\end{array}$ & $\begin{array}{l}\text { Meister- } \\
\text { zeichen }\end{array}$ & Meister - Gegenstand - Besitzer \\
\hline 2437 & $\begin{array}{c}\text { wie } \\
\mathrm{Nr} .2410 ?\end{array}$ & & $\begin{array}{l}\text { b) Münzbecher mit Inschrift von I739. } \\
\text { H. I8,5 cm. } \\
\text { Besitzer: Stadtdienerbruderschaft, Riga. Ausstellung } \\
\text { Riga I883, Katalog Nr. 1672. }\end{array}$ \\
\hline & wie 24IO? & & $\begin{array}{l}\text { c) Münzbecher mit Inschrift. H. } 27,5 \mathrm{~cm} \text {. } \\
\text { Besitzer: Frau H. Grimm, Riga. Ausstellung Riga I883, } \\
\text { Katalog Nr. 169o. }\end{array}$ \\
\hline & wie $2410 ?$ & & $\begin{array}{l}\text { d) Terrine mit Deckel. Inschrift von I } 739 . \\
\text { Besitzer: J. C. Schwartz, Riga. Ausstellung Riga } 1883 . \\
\text { Katalog Nr. } 1702 \text {. }\end{array}$ \\
\hline & wie $24 \mathrm{I} 3$ & & $\begin{array}{l}\text { e) Vergoldete Suppenschale mit flachen Hand- } \\
\text { haben. } \\
\text { Besitzer: Kaiserl. Silberkammer, St. Petersburg. }\end{array}$ \\
\hline & wie $2410 ?$ & & $\begin{array}{l}\text { f) Vergoldeter Willkommen mit anhängenden } \\
\text { Schildchen von I740. } \\
\text { Besitzer: Stadtdienerbruderschaft, Riga. Ausstellung } \\
\text { Riga } 188_{3} \text {, Katalog Nr. 167ı. }\end{array}$ \\
\hline & wie 24 IO? & & $\begin{array}{l}\text { g) Becher von I740. H. I8,5 cm. } \\
\text { Besitzer: Stadtdienerbruderschaft, Riga. Ausstellung } \\
\text { Riga 1883, Katalog Nr. 1673. }\end{array}$ \\
\hline & wie 24IO? & & $\begin{array}{l}\text { h u. i) Zwei Sammelschalen mit Wappen und } \\
\text { Inschrift von I752. } \\
\text { Besitzer: Grosse Gilde, Riga. Ausstellung Riga I } 883 \text {, } \\
\text { Katalog Nr. 1660 und 166r. }\end{array}$ \\
\hline & wie $2410 ?$ & & $\begin{array}{l}\text { k) Zuckerdose mit Wappen und Inschrift von I754. } \\
\text { Besitzer: N. Bockslaff, Riga. Ausstellung Riga I883, } \\
\text { Katalog Nr. I726. }\end{array}$ \\
\hline & wie 2410 ? & & 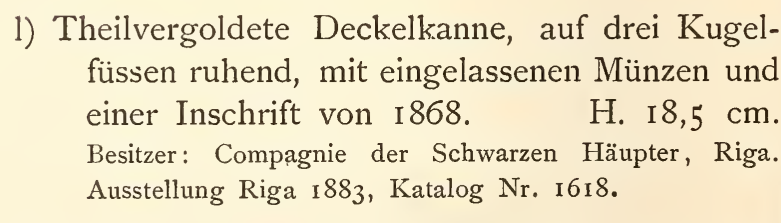 \\
\hline & wie 24 IO? & & $\begin{array}{c}\text { m) Becher mit Wappen und Inschrift von I756. } \\
\text { H. I6,2 cm. } \\
\text { Besitzer: Compagnie der Schwarzen Häupter, Riga. } \\
\text { Ausstellung Riga 1883, Katalog Nr. 1620. }\end{array}$ \\
\hline
\end{tabular}




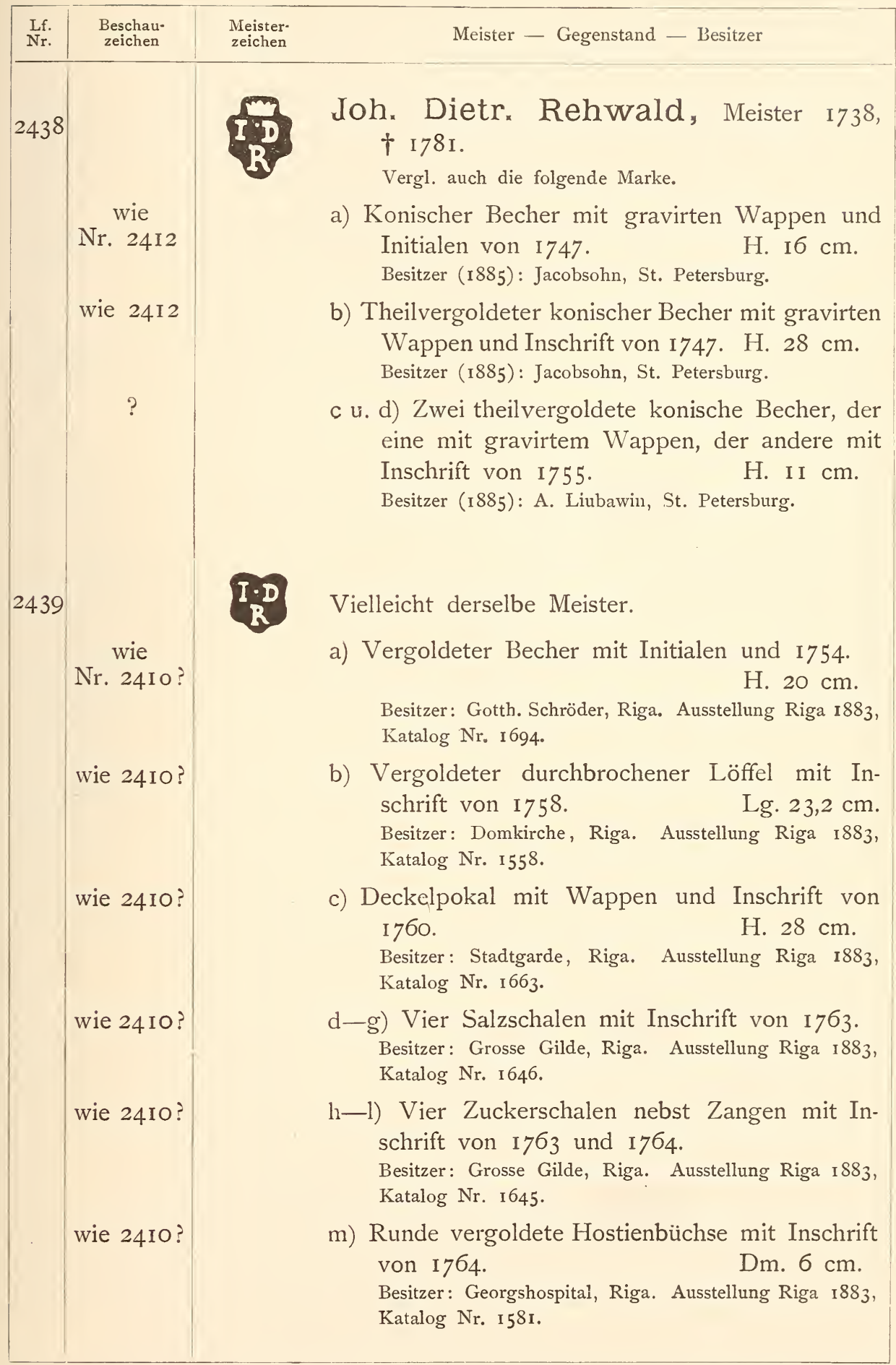




\begin{tabular}{|c|c|c|c|}
\hline $\begin{array}{l}\text { Lf. } \\
\text { Nr. }\end{array}$ & $\begin{array}{l}\text { Beschau- } \\
\text { zeichen }\end{array}$ & & Meister - Gegenstand - Besitzer \\
\hline 2439 & $\begin{array}{c}\text { wie } \\
\mathrm{Nr} .24 \mathrm{IO} ?\end{array}$ & & $\begin{array}{l}\text { n u. o) Zwei Deckelpokale mit Wappen und In- } \\
\text { schriften von I } 766 \text { und I779. H. } 28 \mathrm{~cm} \text {. } \\
\text { Besitzer: Stadtgarde, Riga. Ausstellung Riga I883, } \\
\text { Katalog Nr. 1665 und r666. }\end{array}$ \\
\hline & wie 24I0? & & $\begin{array}{l}\text { p) Zuckerschale mit Inschrift von I } 774 \text {. } \\
\text { Besitzer: Julius Koch, Riga. Ausstellung Riga } 1883 \text {, } \\
\text { Katalog Nr. } 1728 \text {. }\end{array}$ \\
\hline & wie $24 \mathrm{I} 2$ & & $\begin{array}{l}\text { q) Mit dem Jahresbuchstaben E Nr. 24I } 8 \text {. } \\
\text { Vergoldeter konischer Becher, mit Medaillons- } \\
\text { köpfen getrieben. } \\
\text { Besitzer: Excellenz Due, St. Petersburg. }\end{array}$ \\
\hline 2440 & & & $\begin{array}{l}\text { Joh. Christian Henck, Meister I750. } \\
\text { a) Mit dem Tahresbuchstaben B Nr. 24I } 5 \text {. }\end{array}$ \\
\hline & $\begin{array}{l}\text { W1e } \\
\text { Nr. } 24 \text { I } 2\end{array}$ & & $\begin{array}{l}\text { a) Mit dem Jahresbuchstaben B Nr. 24I5. } \\
\text { Theilvergoldeter Vorlegelöffel mit Holzstiel. Mit } \\
\text { eingelassener Münze und Inschrift von I759. } \\
\text { Besitzer (1885): Jacobsohn, St. Petersburg. }\end{array}$ \\
\hline & wie $2410 ?$ & & $\begin{array}{l}\text { b) Deckelpokal mit Wappen und Inschrift von } \\
\text { I } 764 \text {. } \\
\text { Besitzer: Stadtgarde, Riga. Ausstellung Riga i } 288_{3} \text {, } \\
\text { Katalog Nr. 1664. }\end{array}$ \\
\hline & wie 24IO? & & $\begin{array}{l}\text { c) Platte mit eingelegten Münzen. Dm. } 28,5 \mathrm{~cm} \text {. } \\
\text { Besitzer: Frau Ida Helmsing, Riga. Ausstellung Riga } \\
\text { 1883, Katalog Nr. I } 7 \text { r. }\end{array}$ \\
\hline & wie 24 IO? & & $\begin{array}{l}\text { d u. e) Zwei Salzfässer mit Initialen. } \\
\text { Besitzer: Frau Wilhelmine v. Löwenberg, Riga. Aus- } \\
\text { stellung Riga 1883, Katalog Nr. } 1738 \text {. }\end{array}$ \\
\hline $244 \mathrm{I}$ & & & Mit dem Jahresbuchstaben C Nr. 24I6. \\
\hline & $\begin{array}{c}\text { wie } \\
\text { Nr. } 24 \text { I } 2\end{array}$ & & $\begin{array}{l}\text { Weisssilberner konischer Becher, mit Hirschjagd } \\
\text { getrieben. } \\
\text { H. I6,7 cm. } \\
\text { Besitzer (1885): A. Liubawin, St. Petersburg. }\end{array}$ \\
\hline 2442 & $\begin{array}{l}\text { wie } \\
\text { Nr. 24IO? }\end{array}$ & $M$ & 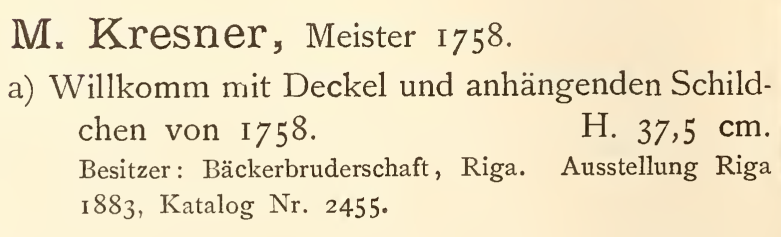 \\
\hline
\end{tabular}




\begin{tabular}{|c|c|c|c|}
\hline$\underset{\mathrm{Lr}}{\mathrm{Lr} .}$ & $\begin{array}{l}\text { Beschau- } \\
\text { zeichen }\end{array}$ & $\begin{array}{l}\text { Meister- } \\
\text { zeichen }\end{array}$ & Meister - Gegenstand - Besitzer \\
\hline 2442 & $\begin{array}{c}\text { wie } \\
\mathrm{Nr} .2410 ?\end{array}$ & & $\begin{array}{l}\text { b) Willkomm mit anhängenden Schildchen. } \\
\text { H. } 45 \mathrm{~cm} \text {. } \\
\text { Besitzer: Schneideramt, Riga. Ausstellung Riga 1883, } \\
\text { Katalog Nr. } 2479 .\end{array}$ \\
\hline & wie $2410 ?$ & & $\begin{array}{l}\text { c u. d) Zwei Rahmkannen mit Wappen und In- } \\
\text { schrift von I762. } \\
\text { Besitzer: Grosse Gilde, Riga. Ausstellung Riga } 1883 \text {, } \\
\text { Katalog Nr. 1644. }\end{array}$ \\
\hline & wie 2410? & & $\begin{array}{l}\text { e) Chocoladenkanne mit Initialen und I } 764 \text {. } \\
\text { Besitzer: Fräulein Elise Pfab, Riga. Ausstellung Riga } \\
\text { I883, Katalog Nr. I721. }\end{array}$ \\
\hline & wie $2410 ?$ & & $\begin{array}{l}\text { f) Theekanne mit Inschrift. } \\
\text { Besitzer: Frau Wilhelmine v. Löwenberg, Riga. Aus- } \\
\text { stellung Riga I883, Katalog Nr. I722. }\end{array}$ \\
\hline & wie 24I0? & & $\begin{array}{l}\text { g) Kaffekanne mit Initialen und I } 767 \text {. } \\
\text { Besitzer: Gotth. Schröder, Riga. Ausstellung Riga } \\
\text { I883, Katalog Nr. I719. }\end{array}$ \\
\hline & wie $2410 ?$ & & $\begin{array}{l}\text { h u. i) Zwei Altarleuchter mit Wappen und In- } \\
\text { schrift von I } 767 . \\
\text { Besitzer: Petrikirche, Riga. Ausstellung Riga } 188_{3} \text {, } \\
\text { Katalog Nr. I549. }\end{array}$ \\
\hline & wie 24 I 2 & & k) Mit dem Jahresbuchstaben D Nr. 24I7. \\
\hline & & & $\begin{array}{l}\text { Theilvergoldeter konischer Becher mit Deckel. } \\
\text { Inschrift von I764? und I795. H. } 24,7 \mathrm{~cm} \text {. } \\
\text { Besitzer (1885): A. Liubawin, St. Petersburg. }\end{array}$ \\
\hline & wie 24 IO? & & $\begin{array}{l}\text { 1) Vergoldeter Becher von I772. H. } 2 \text { I cm. } \\
\text { Besitzer: Schuhmachergesellen-Bruderschaft, Riga. Aus- } \\
\text { stellung Riga I883, Katalog Nr. } 2485 .\end{array}$ \\
\hline & wie 24 I 2 & & m) Mit dem Jahresbuchstaben E Nr. 24I8. \\
\hline & & & $\begin{array}{l}\text { Zuckerdose mit Inschrift von I776. H. I4 } \mathrm{cm} \text {. } \\
\text { Besitzer: Museum der Eremitage, St. Petersburg. }\end{array}$ \\
\hline & wie $24 \mathrm{I} 2$ & & n) Mit dem Jahresbuchstaben E Nr. 2418. \\
\hline & & & $\begin{array}{l}\text { Runde weisssilberne Platte. In der Mitte Doppel- } \\
\text { adler mit Wappen. } \\
\text { Besitzer: Winterpalais, St. Petersburg. }\end{array}$ \\
\hline & wie 2410 ? & & $\begin{array}{l}\text { o) Zuckerdose mit Inschrift von I } 782 \text {. } \\
\text { Besitzer: N. Bockslaff, Riga. Ausstellung Riga I883, } \\
\text { Katalog Nr. I7jo. }\end{array}$ \\
\hline
\end{tabular}




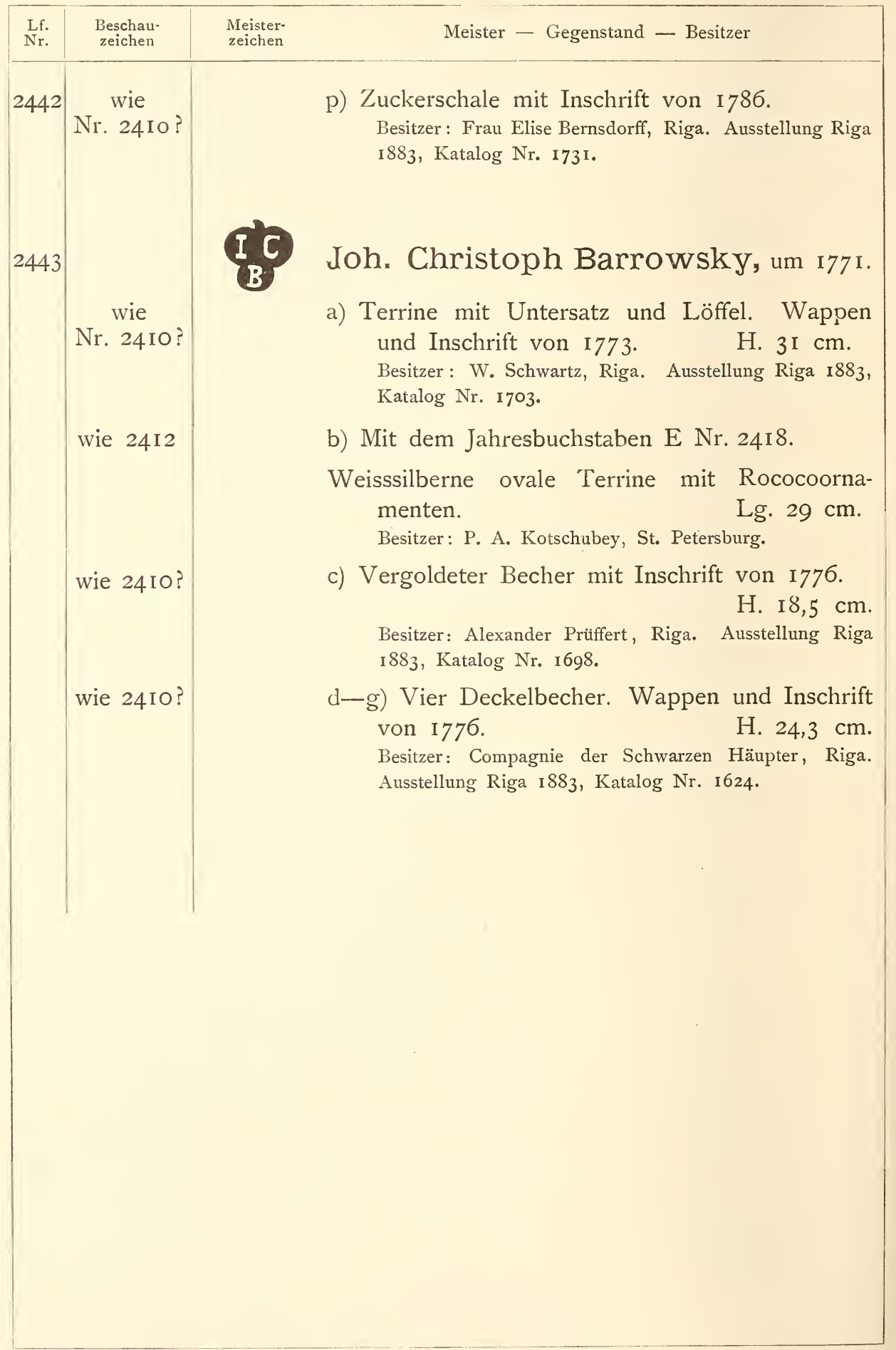




\section{SCHWEDEN UND NORWEGEN.}

Die allgemeinen Bestimmungen, Schweden und Norwegen bis I523 betreffend, siehe bei Dänemark.

Ebendort auch die Verordnung von 1539, welche sich mit auf Norwegen, nicht mehr aber auf Schweden erstreckt. 


\section{SCHWEDEN.}

Für Schweden legt Sick, Notice sur les ouvrages en or et en argent dans le Nord, die Verhältnisse seit I754 dar. Es werden die drei Kronen des Schwedischen Wappens als Staatscontrollmarke für das ganze Land eingeführt, daneben das Beschauzeichen der Stadt und das Meisterzeichen, seit I759 auch ein gemeinsamer Jahresbuchstabe für alle Städte des Landes:

$$
\begin{aligned}
& \mathrm{A}=\mathrm{I} 759 \quad \mathrm{~A}_{2}=\mathrm{I} 783 \quad \mathrm{~A}_{3}=\mathrm{I} 807 \\
& \mathrm{~B}=\mathrm{I} 760 \quad \mathrm{~B} 2=\mathrm{I} 784 \quad \mathrm{~B} 3=\mathrm{I} 808 \\
& \mathrm{Z}=\mathrm{I}_{782} \quad \mathrm{Z}_{2}=\mathrm{I} 806 \quad \mathrm{Z}_{3}=\mathrm{I} 830 \text {. }
\end{aligned}
$$

Seit I860 steht statt des Stadtwappens eine Initiale als Beschauzeichen. $\mathrm{Da}$, wie es scheint, in Schweden die Anfertigung der Staatscontrollmarke nicht wie in Preussen und Oesterreich einer Centralstelle reservirt blieb, sondern den einzelnen Städten selbst oblag, konnte es nicht fehlen, dass trotz der einheitlichen Vorschrift die Stempel etwas verschiedenartig ausfielen. Beispiele sowohl für die drei Kronen, als für die Jahresbuchstaben sind daher bei den einzelnen Städten zu suchen. 


\section{KRISTIANSTAD.}

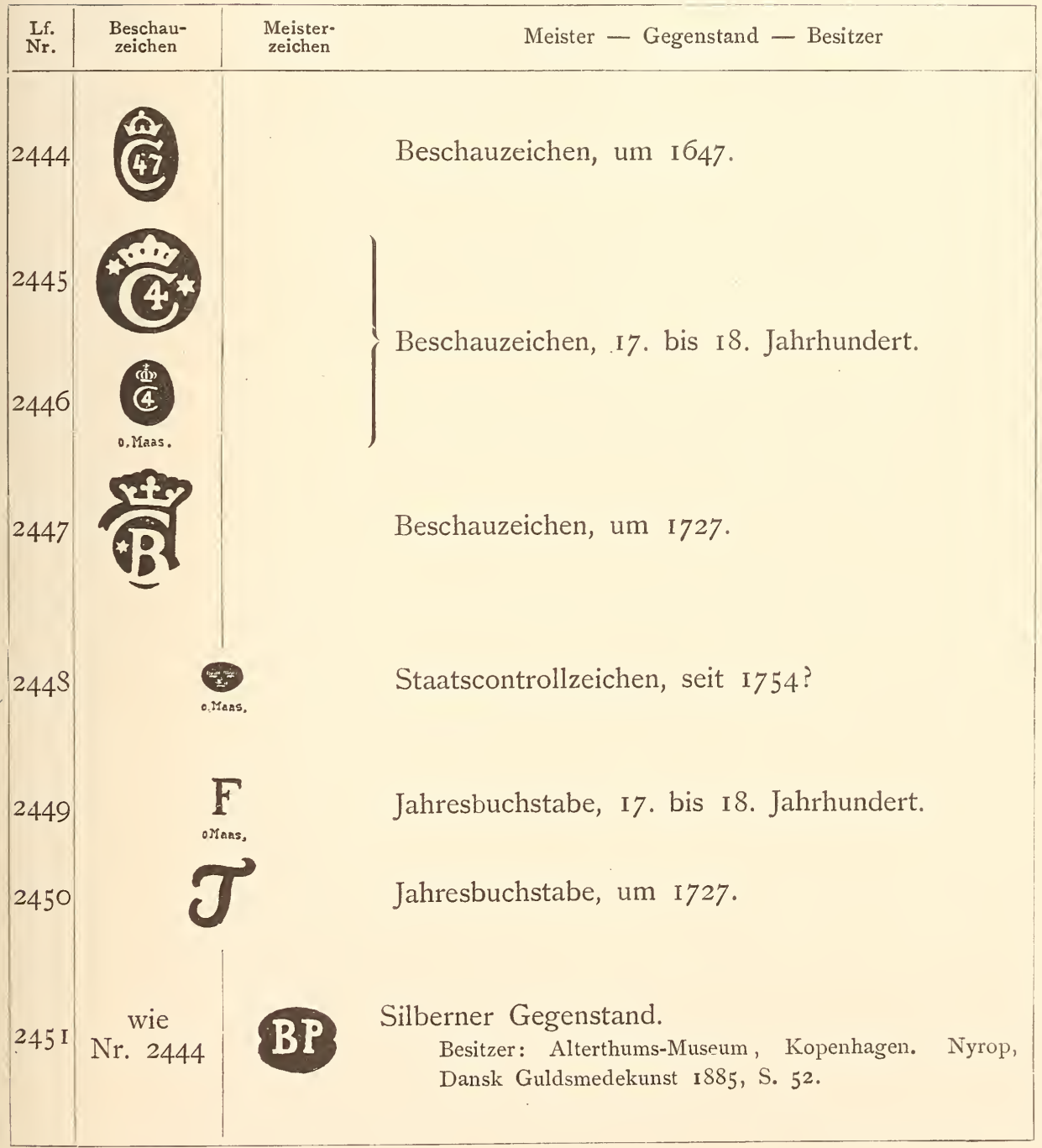




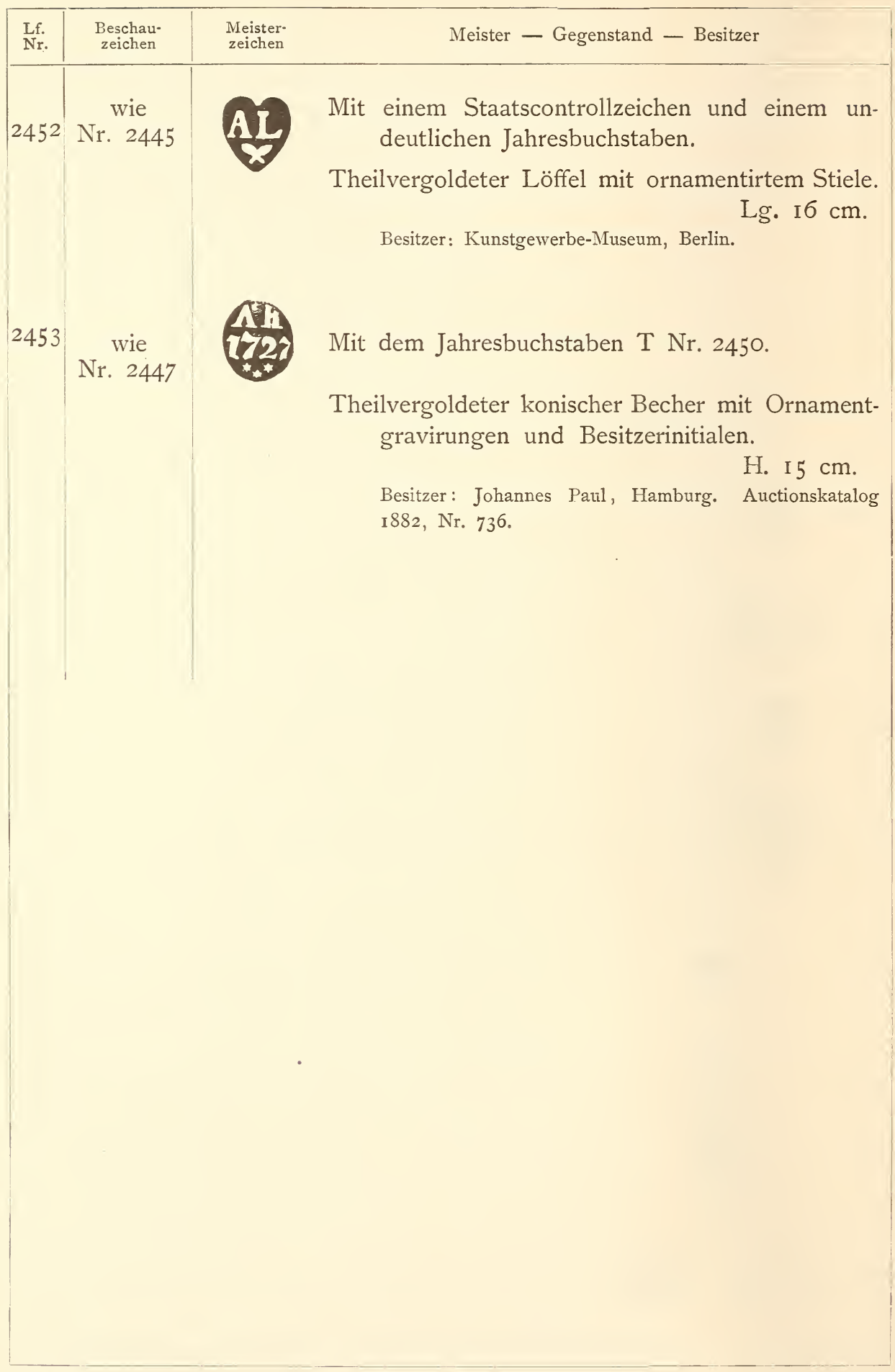




\section{STOCKHOLM.}

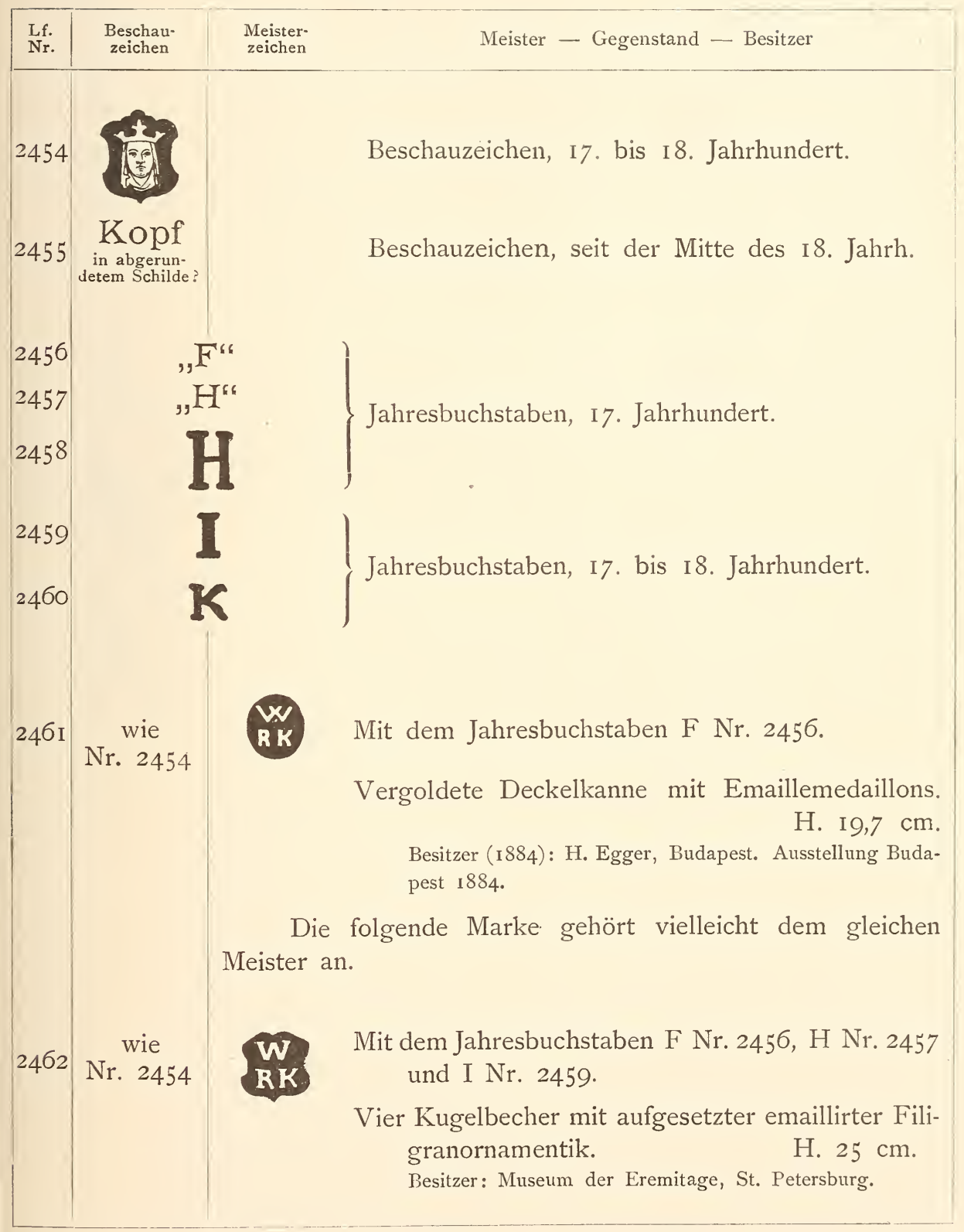




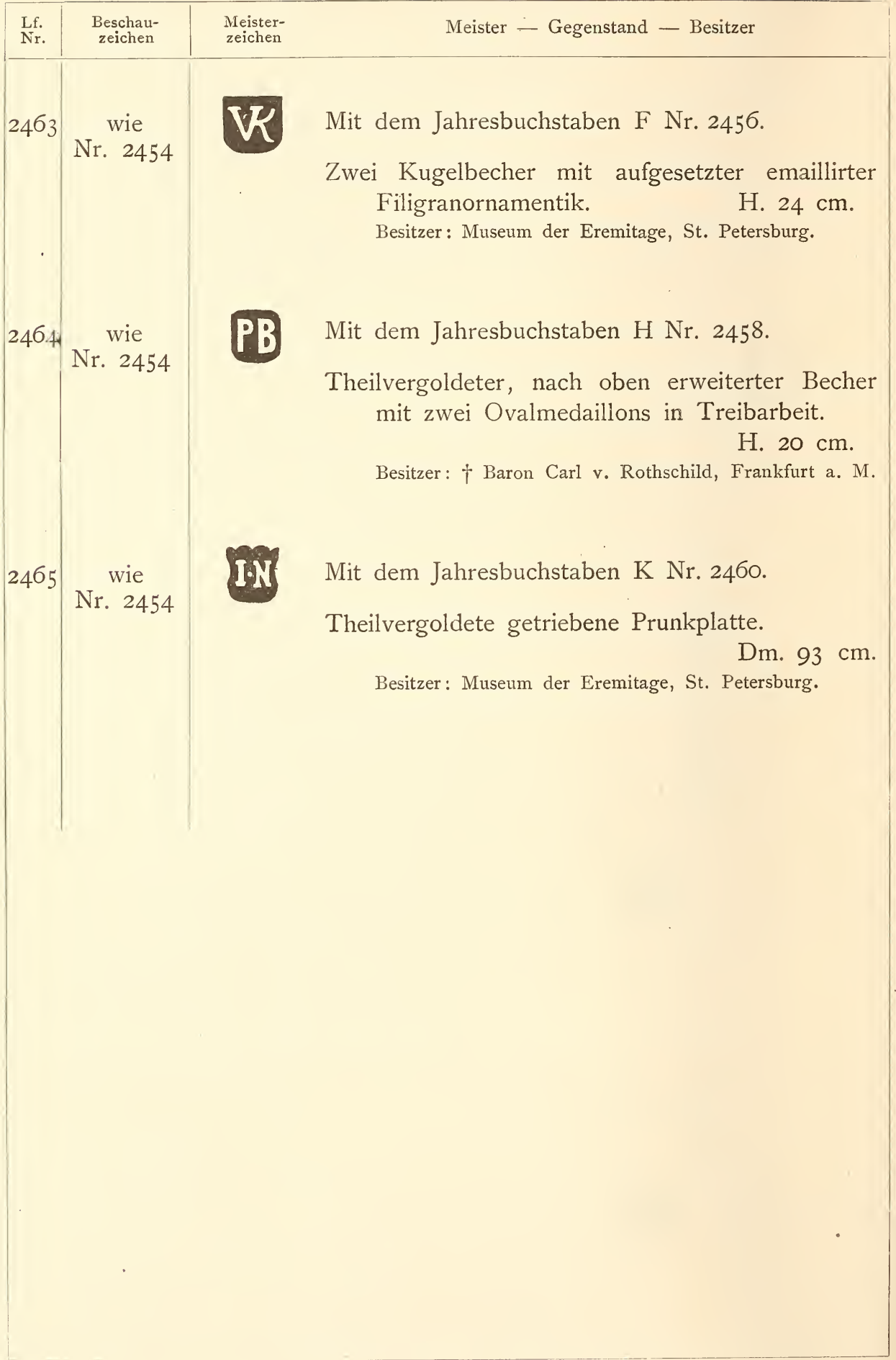




\section{N O R W E G EN.}

\section{BERGEN.}

Aus einer Verordnung von 1535 ersieht man, dass damals in Bergen Selbststempelung üblich war. Nyrop, Dansk Guldsmedekunst, S. 30. Später folgt die Stadt den allgemeinen Landesbestimmungen.

\begin{tabular}{|c|c|c|c|}
\hline$\frac{\mathrm{Lf}}{\mathrm{N}}$ & $\begin{array}{l}\text { Beschau- } \\
\text { zeichen }\end{array}$ & $\begin{array}{l}\text { Meister- } \\
\text { zeichen }\end{array}$ & Meister - Gegenstand - Besitzer \\
\hline 2466 & & & Beschauzeichen, I699. \\
\hline 2467 & & & Beschauzeichen, I 787. \\
\hline 2468 & & & Beschauzeichen, I8I 2. \\
\hline 2469 & & & Beschauzeichen, I 820. \\
\hline 2470 & & & Jahresstempel für 1699. \\
\hline $247 \mathrm{I}$ & & & Jahresstempel für 1787 . \\
\hline 2472 & & & Jahresstempel für I $8 \mathrm{I} 2$. \\
\hline 2473 & & & Jahresstempel für I 820. \\
\hline 2474 & & & Monatszeichen, r 699. \\
\hline 2475 & & & Monatszeichen, I 787. \\
\hline
\end{tabular}




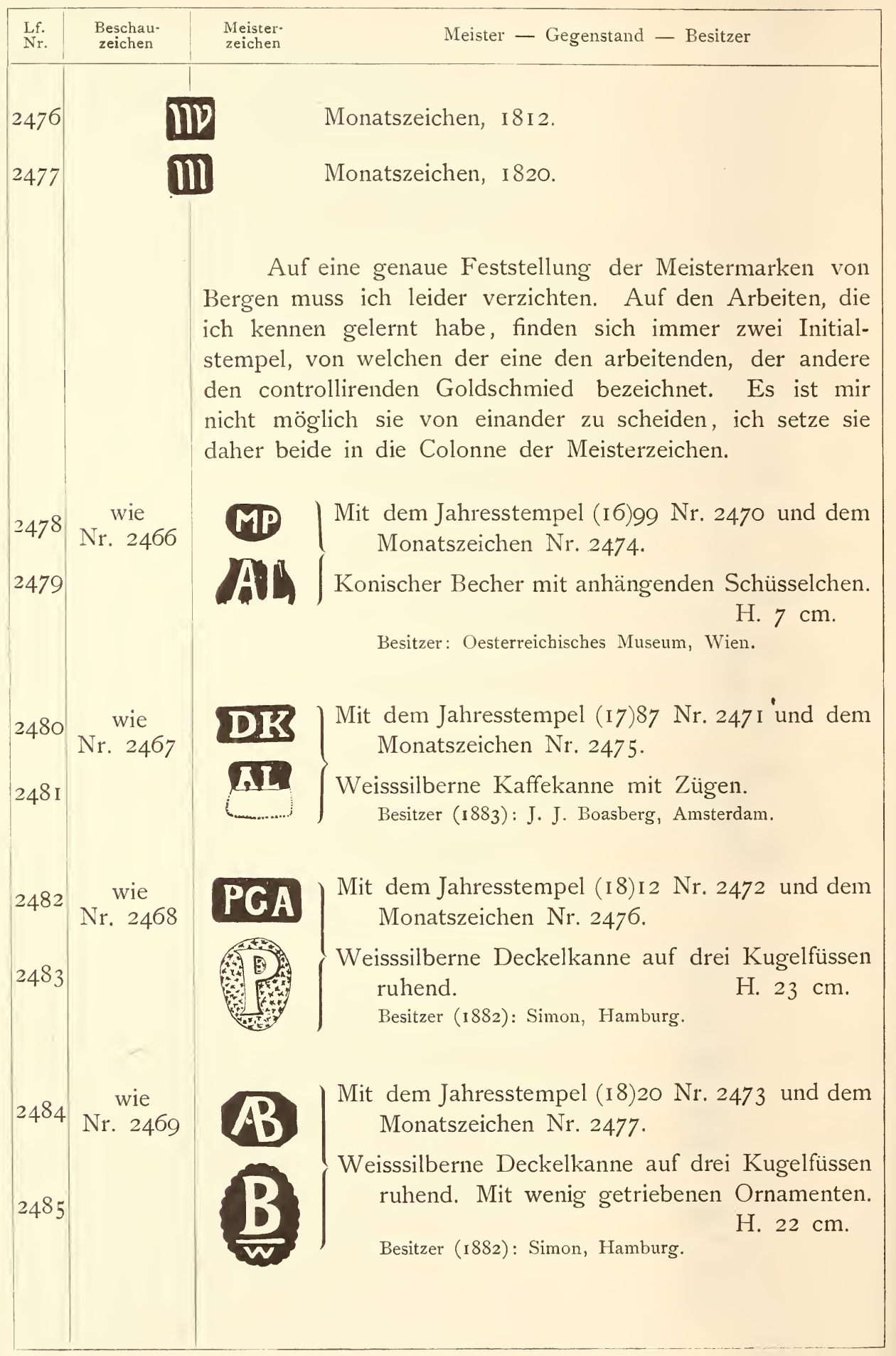




\section{SCHWEIZ.}

\section{Moderne Stempelung.}

Die Bestimmungen über die neuere, die ganze Schweiz umfassende Goldund Silberstempelung sind niedergelegt in:

I) Loi fédérale concernant le contrôle et la garantie du titre des ouvrages d'or et d'argent du 23 décembre r88o. Voir feuille fédérale de i88i tome I. p. I.

2) Règlement d'exécution concernant le contrôle et la garantie du titre des ouvrages d'or et d'argent du I7 mai I88I.

Diesen Bestimmungen zufolge gelten in der Schweiz die folgenden Stempel, welche in verschiedenen Grössen angefertigt und mit Unterscheidungszeichen für die verschiedenen Stempelämter versehen werden.

Staatscontrolle für Silber. 875 fein.

Auskunft über die ältere Stempelung in den einzelnen Städten verdanke ich Herrn Professor Dr. Rud. Rahn und Herrn Zeller-Werthmüller in Zürich, sowie den ungenannten Verfassern des Katalogs der Schweizerischen Landesausstellung, Zürich I883. Spezialkatalog der Gruppe XXXVIII. „Alte Kunst". 


\section{BADEN.}

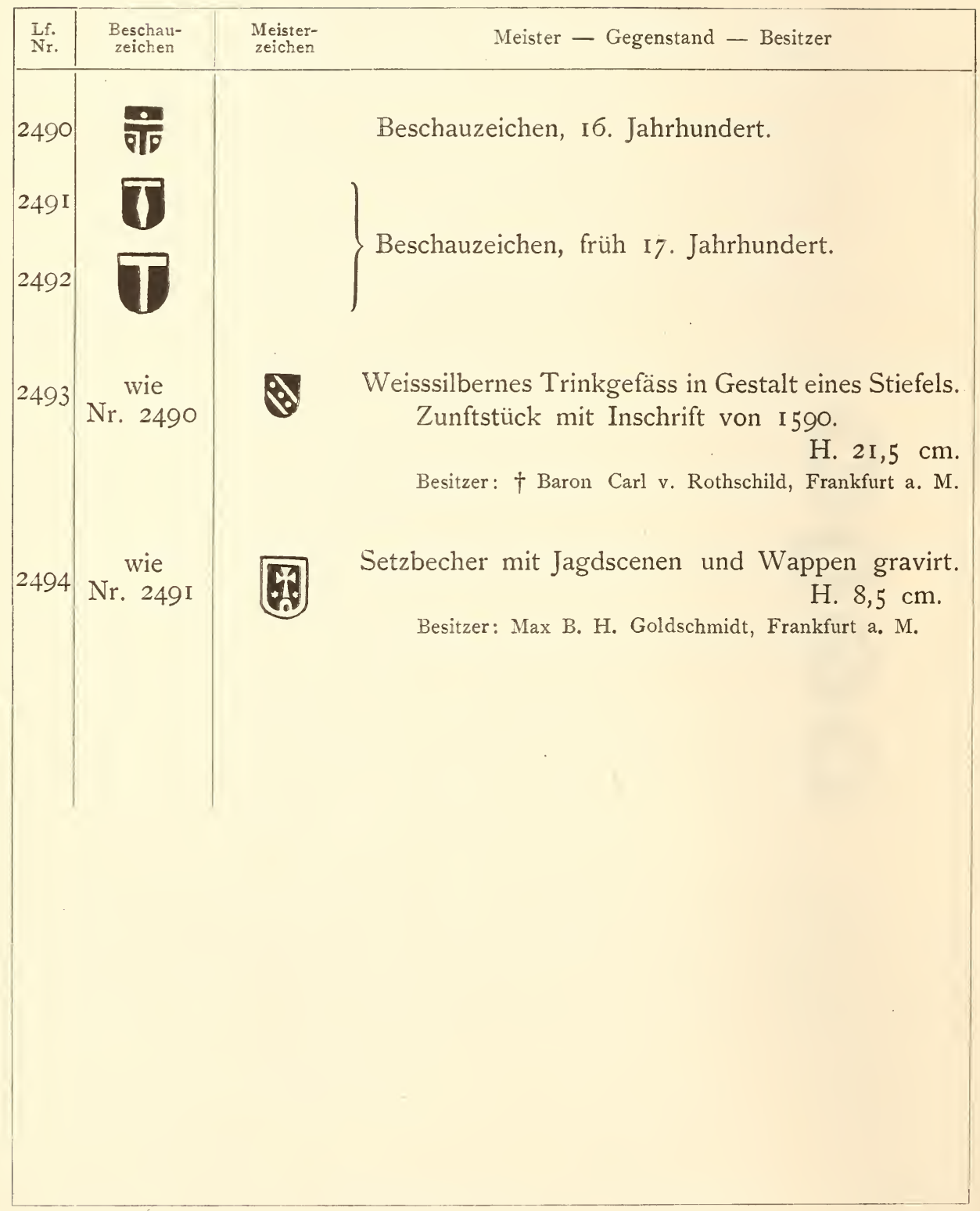




\section{BASEL.}

\begin{tabular}{|c|c|c|}
\hline $\begin{array}{l}\text { Lf. } \\
\text { Nr. }\end{array}$ & & Meister - Gegenstand - Besitzer \\
\hline 2496 & $\begin{array}{l}\text { Baselstab ge- } \\
\text { treckt, in einem } \\
\text { Schilde des } \\
\text { I5. Jahrh. } \\
\text { Thurzers } \\
\begin{array}{c}\text { Gezeicheret nach } \\
\text { schriftlicher } \\
\text { Angabe }\end{array}\end{array}$ & $\begin{array}{l}\text { M. Heyne, Ueber Basler Goldschmiedezeichen im } \\
\text { Anzeiger für Kunde der deutschen Vorzeit } \\
\text { I } 883 \text { Sp. } 209 \text { constatirt als } \\
\text { Beschauzeichen, früh I6. Jahrhundert, den Basel- } \\
\text { stab wie nebenstehend beschrieben, und als } \\
\text { Beschauzeichen, seit dem I6. Jahrhundert, den } \\
\text { Baselstab in rundem Schilde. } \\
\text { Ich habe noch keine Gelegenheit gehabt diese Marken } \\
\text { auf Originalarbeiten zu sehen, setze aber dennoch die auf } \\
\text { sorgfältige Beobachtungen gegründeten Bemerkungen von } \\
\text { Heyne über die Basler Beschauzeichen, sowie über die ihm } \\
\text { bekannt gewordenen ältesten gezeichneten Basler Arbeiten } \\
\text { hierher: } \\
\text { „Das Basler Beschauzeichen, wie es seit dem I6. Jahr- } \\
\text { hundert erscheint, ist der Baselstab, d. h. die heraldische } \\
\text { Veränderung eines Bischofsstabes. Seit dem I4. Jahrhundert } \\
\text { braucht der Bischof von Basel als Marke für das Eigen- } \\
\text { thum seines Hofhaltes diesen Stab, und die Stadt nimmt } \\
\text { ihn bereits im frühen I 5. Jahrhundert dergestalt als Wappen } \\
\text { an, dass sie ihn verkürzt und gedrungen geschweift dar- } \\
\text { stellt, ihm im oberen Theile, vor Aufsetzung der Krümmung, } \\
\text { ein dreifach gegliedertes Beschläge giebt und den Stachel } \\
\text { in einen breiten Dreispitz auslaufen lässt. Die Krümmung } \\
\text { selbst geht bald nach links, bald nach rechts." } \\
\text { „Dieser Baselstab erscheint als Beschauzeichen allein, } \\
\text { im runden oder ovalen Feld, häufig im I6. und I7. Jahr- } \\
\text { hundert; häufig aber im I7. und I8. auch mit Zusätzen } \\
\text { versehen. Die zwei, seit nachweislich dem I } \text {. Jahrhundert } \\
\text { gleichzeitig angestellten „Bunzenmeister“ führten kleine } \\
\text { Unterscheidungszeichen, die wieder zu ihrer Controlle dienten, } \\
\text { und jedem neu ernannten solchen Beschauer wurde von der } \\
\text { Zunft ein eigener derartiger Stempel bestellt. Zunftauf- } \\
\text { zeichnungen darüber sind bis jetzt nicht ans Licht getreten; } \\
\text { einiges ergiebt sich aus datirten Arbeiten." }\end{array}$ \\
\hline
\end{tabular}




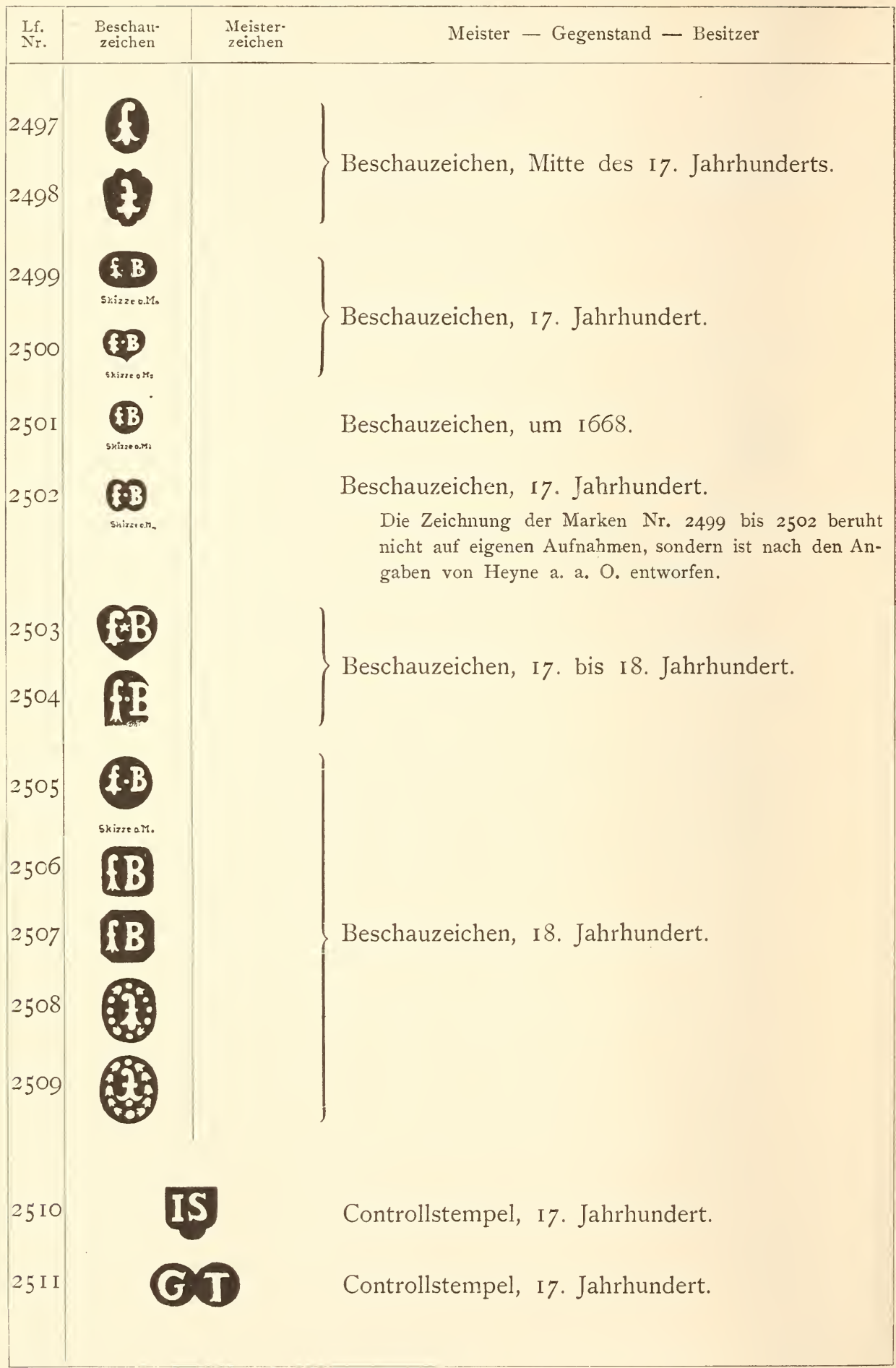




\begin{tabular}{|c|c|c|c|}
\hline $\begin{array}{l}\text { Lf. } \\
\text { Nr. }\end{array}$ & $\begin{array}{l}\text { Beschaur } \\
\text { zeichen }\end{array}$ & $\begin{array}{l}\text { Meister- } \\
\text { zeichen }\end{array}$ & Meister - Gegenstand - Besitzer \\
\hline 25 I 2 & $\begin{array}{c}\text { wie } \\
\mathrm{Nr} .2495\end{array}$ & $\begin{array}{l}\text { Die } \\
\text { die einzeln } \\
\text { Daten entr } \\
{ }_{, 5} \mathrm{~F}(\mathrm{~B}) \text { ? }\end{array}$ & $\begin{array}{l}\text { Deutung der hier folgenden Meistermarken auf } \\
\text { en Goldschmiede, sowie die den Namen beigefügten } \\
\text { hehme ich der genannten Arbeit von Heyne. } \\
\text { Vielleicht } \\
\text { Friedrich Bildtschnitzer, Meister I } 526 . \\
\text { Kelch. } \\
\quad \text { Besitzer : Kirche, Baden (Schweiz). }\end{array}$ \\
\hline 2513 & $\begin{array}{c}\text { wie } \\
\text { Nr. } 2496\end{array}$ & $\begin{array}{l}\text { Lamms- oder } \\
\text { Schweinskopf }\end{array}$ & $\begin{array}{l}\text { Becher mit Inschrift von I5I3 (Erasmusbecher). } \\
\text { Besitzer: Mittelalterliche Sammlung, Basel. Heyne, } \\
\text { Kunst im Hause, Heft II, Taf. I4. }\end{array}$ \\
\hline \multirow[t]{4}{*}{25 I 4} & & 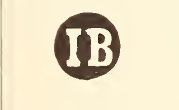 & $\begin{array}{l}\text { Jacob Birmann der Aeltere, Meister } \\
\text { I625, } \uparrow 1672 \text {. Vergl. auch die folgende Marke. }\end{array}$ \\
\hline & $\begin{array}{c}\text { wie } \\
\text { Nr. } 2497\end{array}$ & & $\begin{array}{l}\text { a) Trinkgeschirr in Gestalt eines Löwen mit Rebe } \\
\text { und Rebmesser. Mit Wappen und Inschrift } \\
\text { von I } 637 \text {. } \\
\text { Besitzer: Gesellschaft zum Rebhaus, Basel. Abgebildet } \\
\text { in Goldschmiedearbeiten der Zünfte und Gesellschaften } \\
\text { in Basel, XIII. 30. }\end{array}$ \\
\hline & wie 2497 & & $\begin{array}{l}\text { b) Vergoldeter Deckelpokal mit Inschriften und } \\
\text { Wappen, bezeichnet }{ }_{1} 638 \text {. H. } 40 \mathrm{~cm} \text {. } \\
\text { Besitzer: S. K. H. d. Grossherzog von Baden, Schloss } \\
\text { Karlsruhe. Ausstellung Karlsruhe i88I, Kat. Nr. } 545 .\end{array}$ \\
\hline & wie 2497 & & $\begin{array}{l}\text { c) Vergoldete Deckelkanne, sechsseitig und ge- } \\
\text { buckelt. } \\
\text { Besitzer: Georg Agath, Breslau. }\end{array}$ \\
\hline 25 I 5 & wie 2497 & & $\begin{array}{l}\text { d) Theilvergoldetes Bouillongefäss mit Deckel, } \\
\text { auf drei Kugelfüssen ruhend. H. ca. } 10 \mathrm{~cm} \text {. } \\
\text { Besitzer: Dr. A. Figdor, Wien. }\end{array}$ \\
\hline 2516 & & & $\begin{array}{l}\text { Sebastian Fechter der Aeltere, } \\
\text { Meister } 1633, \dagger \text { i692. Arbeitet nach Heyne } \\
\text { mit seinem Sohne } \\
\text { Sebastian Fechter dem Jüngeren, } \\
\text { Meister } 1673, \dagger 1687 \text {. }\end{array}$ \\
\hline
\end{tabular}




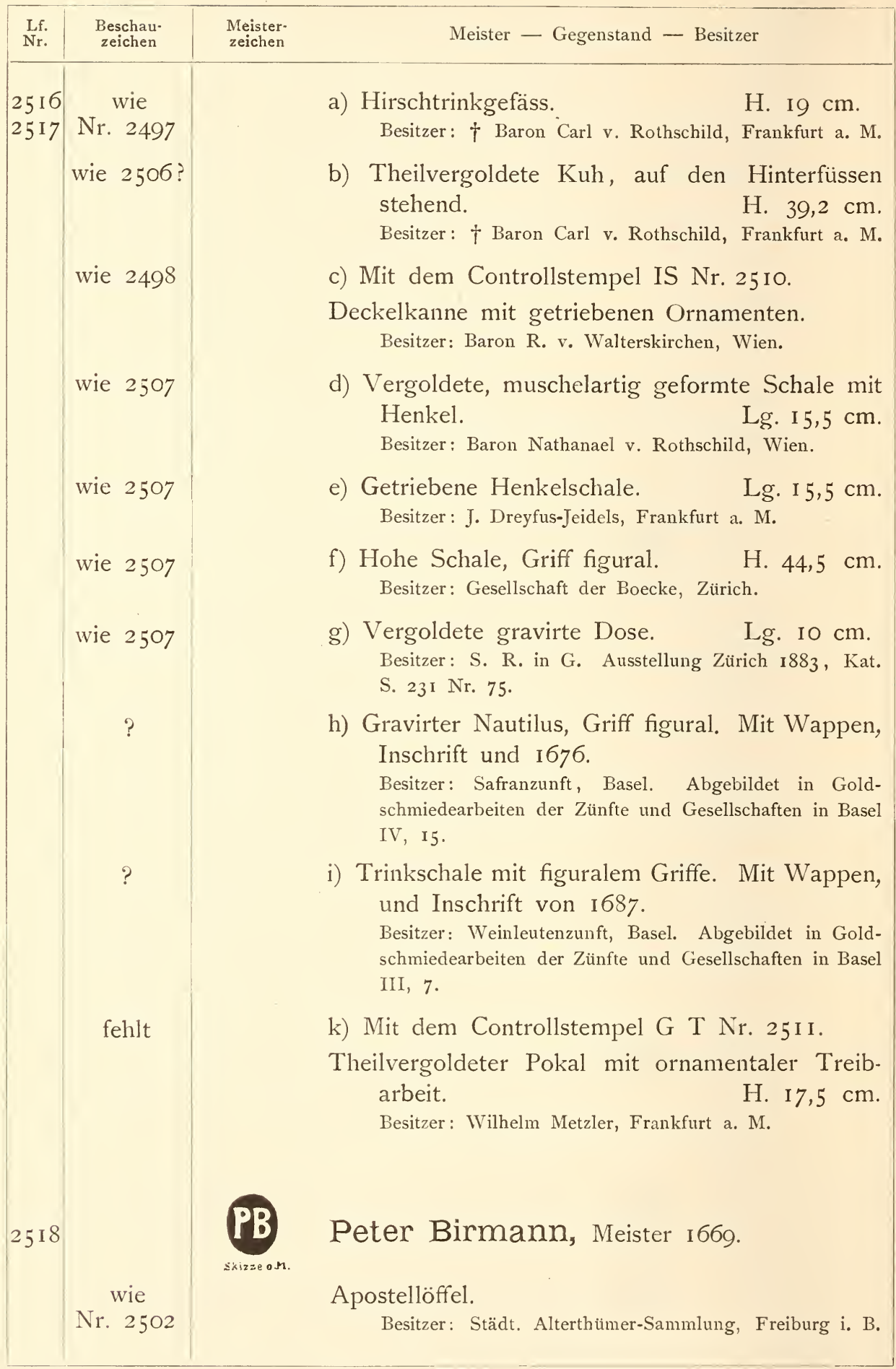




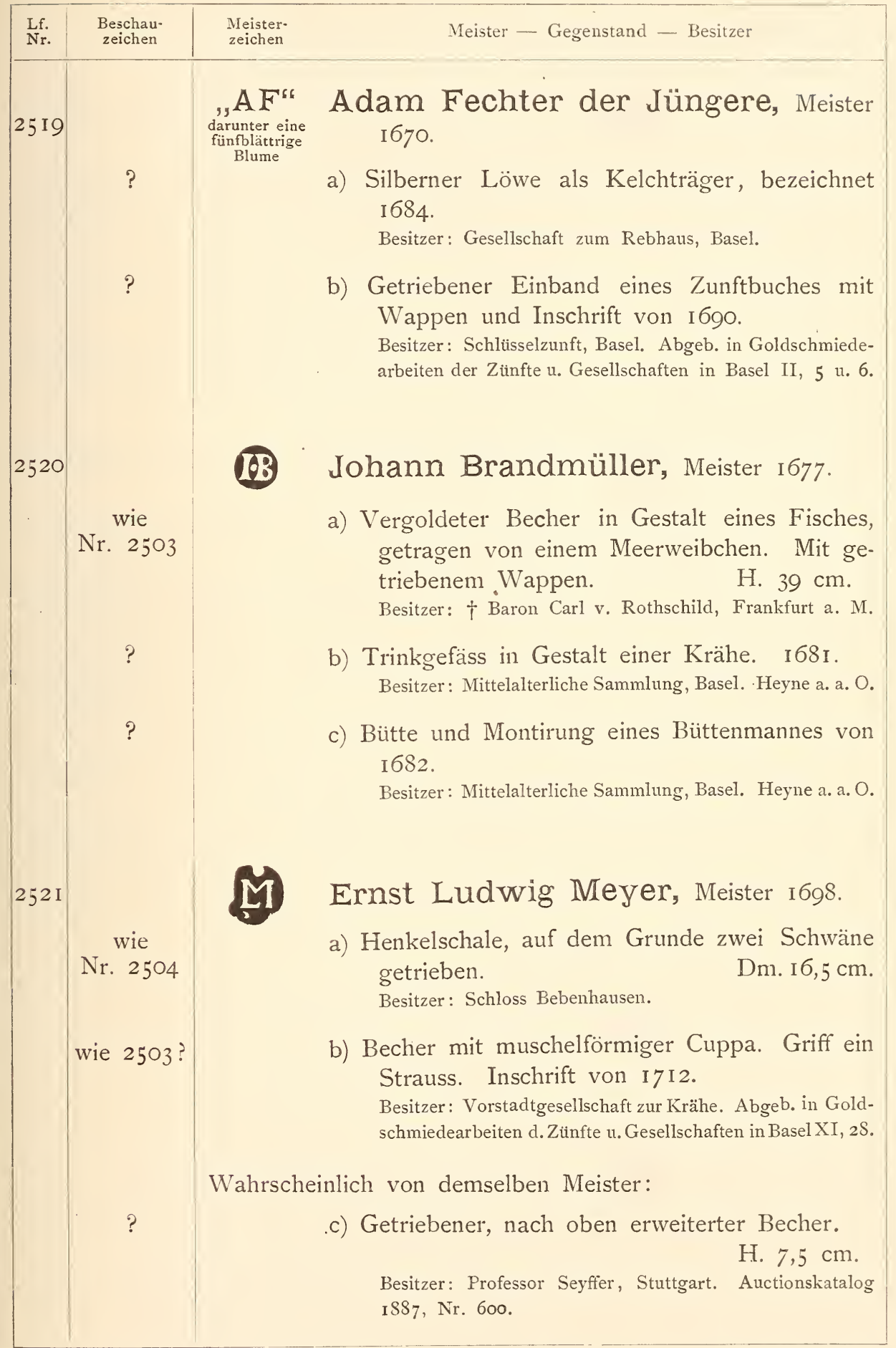




\begin{tabular}{|c|c|c|c|}
\hline $\begin{array}{l}\text { Lf. } \\
\text { Nr. }\end{array}$ & $\begin{array}{l}\text { Beschau- } \\
\text { zeichen }\end{array}$ & $\begin{array}{l}\text { Meist } \\
\text { zeich }\end{array}$ & Meister - Gegenstand - Besitzer \\
\hline 2522 & & & $\begin{array}{l}\text { Hans Heinrich Schrotberger, Meister } \\
\text { I698. }\end{array}$ \\
\hline & $\begin{array}{c}\text { wie } \\
\text { Nr. } 2503\end{array}$ & & $\begin{array}{l}\text { a) Vergoldeter Becher mit Inschrift und gravirten } \\
\text { Wappen. H. I } 8,7 \mathrm{~cm} \text {. } \\
\text { Besitzer: Imhof-R iisch, Basel. Ausstellung Zürich I } 883 \text {, } \\
\text { Katalog S. } 229 \text { Nr. 46. }\end{array}$ \\
\hline & wie 2503 & & $\begin{array}{l}\text { b) Trinkschale mit figuralem Griffe, mit Wappen } \\
\text { und Inschrift von I 709. } \\
\text { Besitzer: Weinleutenzunft, Basel. Abgeb.in Goldschmiede- } \\
\text { arbeiten der Zünfte u. Gesellschaften in Basel V, I I. }\end{array}$ \\
\hline 2523 & & & $\begin{array}{l}\text { Johann Ulrich Fecinter der Aeltere, } \\
\text { Meister } \mathrm{I} 702, \dagger \mathrm{i} 747 \text {. }\end{array}$ \\
\hline & ? & & $\begin{array}{l}\text { a) Pokal, theilweise mit Ornamenten getrieben. } \\
\text { Griff figural. } \\
\text { Besitzer: Schlosserzunft, Basel. Abgeb. in Goldschmiede- } \\
\text { arbeiten der Zünfte u. Gesellschaften in Basel VIII, } 24\end{array}$ \\
\hline & $\begin{array}{l}\text { wie } \\
\text { Nr. } 2507\end{array}$ & & $\begin{array}{l}\text { b) Pokal in Gestalt einer Jungfrau mit Inschrift } \\
\text { von I } 722 . \\
\text { Besitzer: Gesellschaft zur Mägd, Basel. Abgebildet in } \\
\text { Goldschmiedearbeiten der Zünfte in Basel. }\end{array}$ \\
\hline & wie 2508 & & $\begin{array}{l}\text { c) Löwe als Kelchträger mit Rebmesser. Wappen } \\
\text { und Inschrift von I } 728 \text {. } \\
\text { Besitzer: Gesellschaft zum Rebhaus, Basel. Abgeb. in } \\
\text { Goldschmiedearbeiten der Zünfte u. Gesellschaften in Basel. }\end{array}$ \\
\hline & fehlt & & $\begin{array}{l}\text { d) Ovale getriebene Dose. } \\
\text { Besitzer: S. B. Goldschmidt, Mainz. } 4 \mathrm{~cm} \text {. }\end{array}$ \\
\hline
\end{tabular}

Hans Jacob Fäsch, Meister I732.

Deckelpokal, Griff ein Löwe.

Privatbesitz, Freiburg i. B.

wie

Nr. 2508

\section{Johannes Fechter, Meister I735.}

a) Pokal, Griff figural, mit Wappen, Inschrift und I 748 (I 749?).

Besitzer: Vorstadtgesellschaft zum Rupf, Basel. Abgeb. in Goldschmiedearbeiten der Zünfte u. Gesellschaften in Basel. 


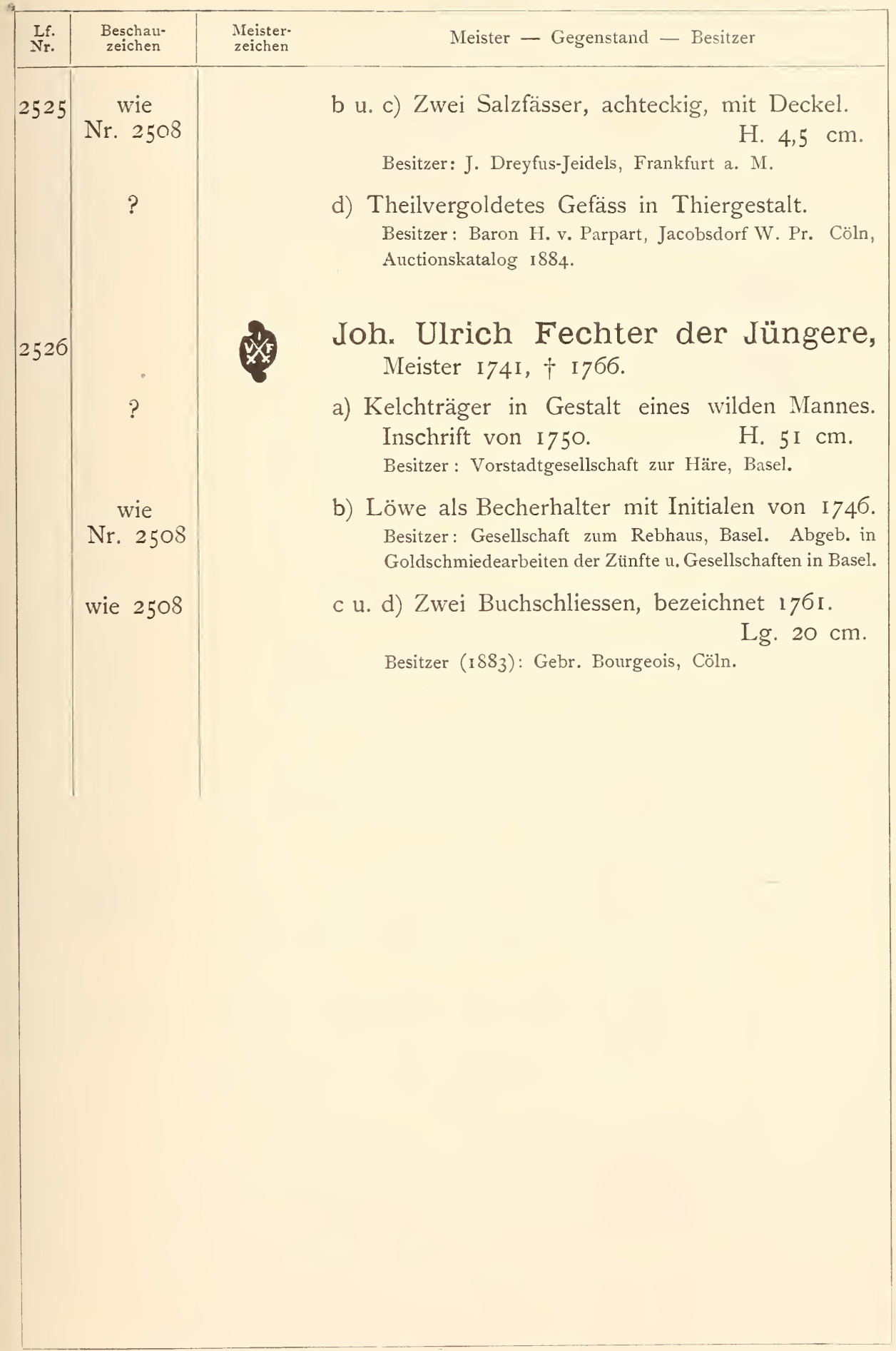




\section{BERN.}

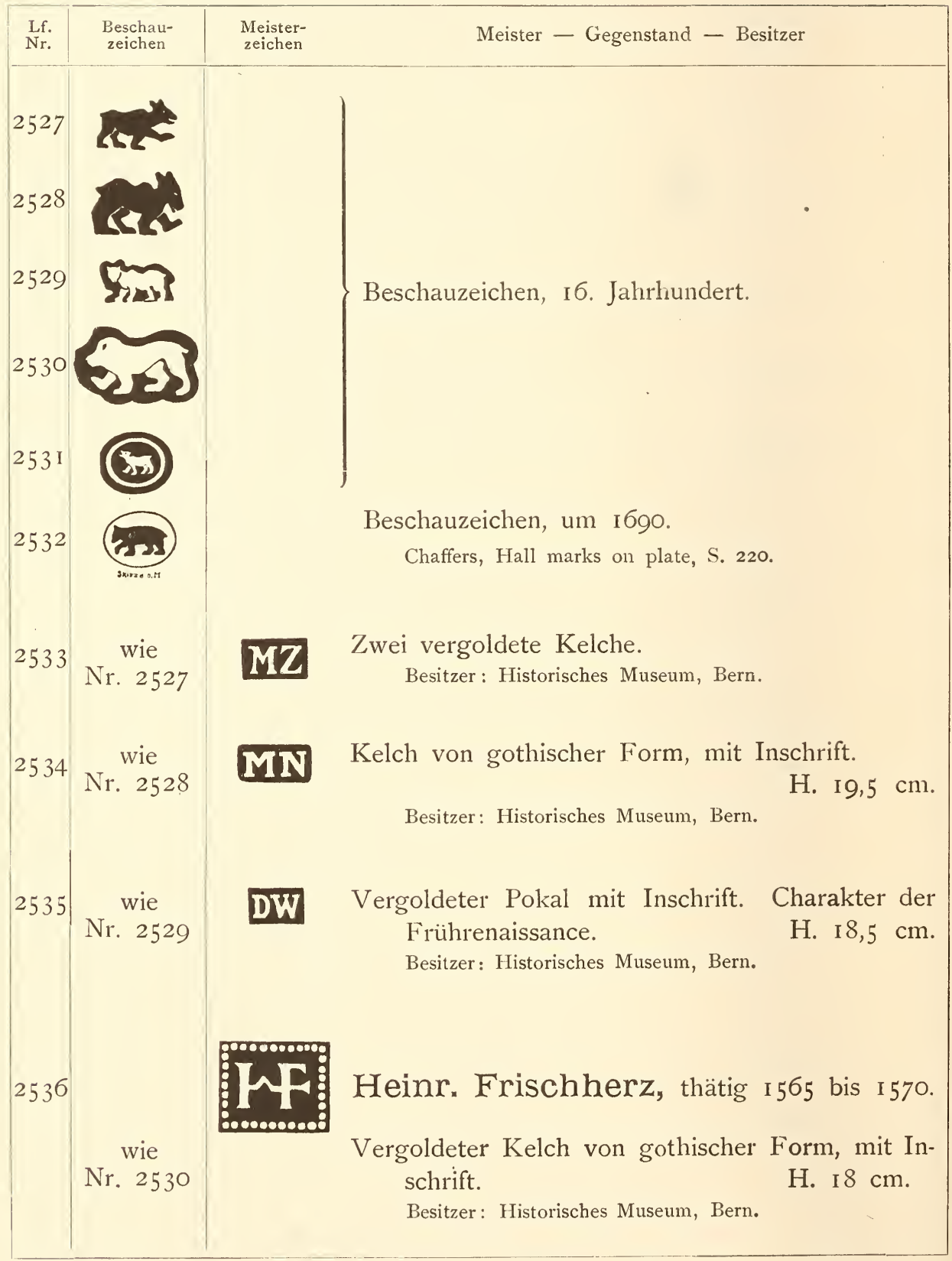




\begin{tabular}{|c|c|c|c|}
\hline $\begin{array}{l}\text { Lf. } \\
\text { Nr. }\end{array}$ & $\begin{array}{l}\text { Beschau• } \\
\text { zeichen }\end{array}$ & $\begin{array}{l}\text { Meister- } \\
\text { zeichen }\end{array}$ & Meister - Gegenstand - Besitzer \\
\hline 2537 & $\begin{array}{c}\text { wie } \\
\text { Nr. } 2531\end{array}$ & & $\begin{array}{l}\text { Vergoldeter Kelch in gothischer Form. } \\
\text { H. } 18,5 \mathrm{~cm} \text {. } \\
\text { Besitzer: Historisches Museum, Bern. }\end{array}$ \\
\hline 2538 & $\begin{array}{c}\text { wie } \\
\text { Nr. } 2532\end{array}$ & E I I & $\begin{array}{l}\text { Löwentrinkgefäss mit Inschrift, Wappen und I690. } \\
\text { Besitzer: Baron M. v. Rothschild, London. South } \\
\text { Kensington Museum, London. Loan Exhibition I862, } \\
\text { Katalog Nr. 6363. Die Marke nach Chaffers S. 220. }\end{array}$ \\
\hline
\end{tabular}

\section{BIEL.}

\begin{tabular}{|c|c|c|c|}
\hline $\begin{array}{l}\text { Lf. } \\
\text { Nr. }\end{array}$ & $\begin{array}{c}\text { Beschau- } \\
\text { zeichen }\end{array}$ & $\begin{array}{l}\text { Meister- } \\
\text { zeichen }\end{array}$ & Meister - Gegenstand - Besitzer \\
\hline 2539 & & & Beschauzeichen, i8. Jahrhundert. \\
\hline 2540 & $\begin{array}{c}\text { wie } \\
\text { Nr. } 2539\end{array}$ & $A^{+M}$ & $\begin{array}{l}\text { Plat de ménage, durchbrochen gearbeitet und mit } \\
\text { Rococoornamenten getrieben. H. 22,5 cm. } \\
\text { Besitzer: Techtermann, Freiburg (Schweiz). Ausstellung } \\
\text { Zürich } 1883 \text {, Katalog S. } 229 \text { Nr. } 52 \text {. }\end{array}$ \\
\hline
\end{tabular}




\section{CHUR.}

Obgleich die Möglichkeit einer Verwechslung mit Schaffhausen sehr nahe liegt, glaube ich doch das folgende Stück für obige Stadt in Anspruch nehmen zu dürfen.

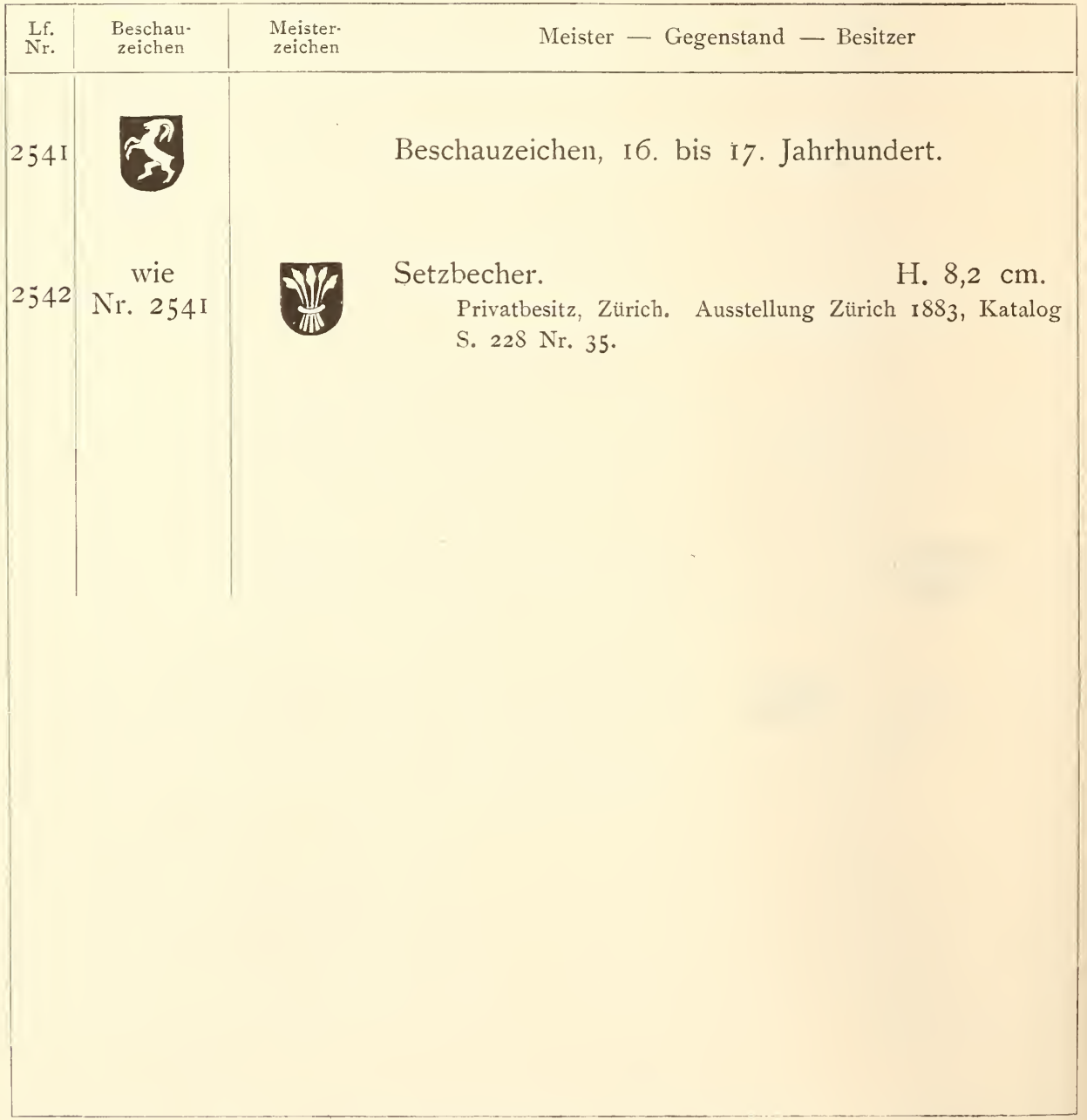




\section{EINSIEDELN.}

\begin{tabular}{|c|c|c|c|}
\hline $\begin{array}{l}\text { Lf. } \\
\text { Nr. }\end{array}$ & $\begin{array}{l}\text { Beschau- } \\
\text { zeichen }\end{array}$ & $\begin{array}{l}\text { Meister- } \\
\text { zeichen }\end{array}$ & Meister - Gegenstand - Besitzer \\
\hline 2543 & CW & & Beschauzeichen, I8. Jahrhundert. \\
\hline 2544 & $\begin{array}{l}\text { wie } \\
\mathrm{Nr}: 2543\end{array}$ & & $\begin{array}{l}\text { Joseph Anton Curiger, geboren I750. } \\
\text { Berlepsch, Chronik der Gold- und Silber- } \\
\text { schmiedekunst, S. I I7. }\end{array}$ \\
\hline & & & $\begin{array}{l}\text { Deckelpokal mit Wappen. } \quad \text { H. } 29 \mathrm{~cm} \text {. } \\
\text { Besitzer: Gesellschaft der Boecke, Zürich. }\end{array}$ \\
\hline 2545 & $\begin{array}{c}\text { wie } \\
\text { Nr. } 2543\end{array}$ & IBC & $\begin{array}{l}\text { Vergoldeter Untersatz einer Elfenbeinfigur. } \\
\text { Besitzer: S. K. H. d. Grossherzog von Baden, Schloss } \\
\text { Karlsruhe. }\end{array}$ \\
\hline
\end{tabular}

\section{LUZERN.}

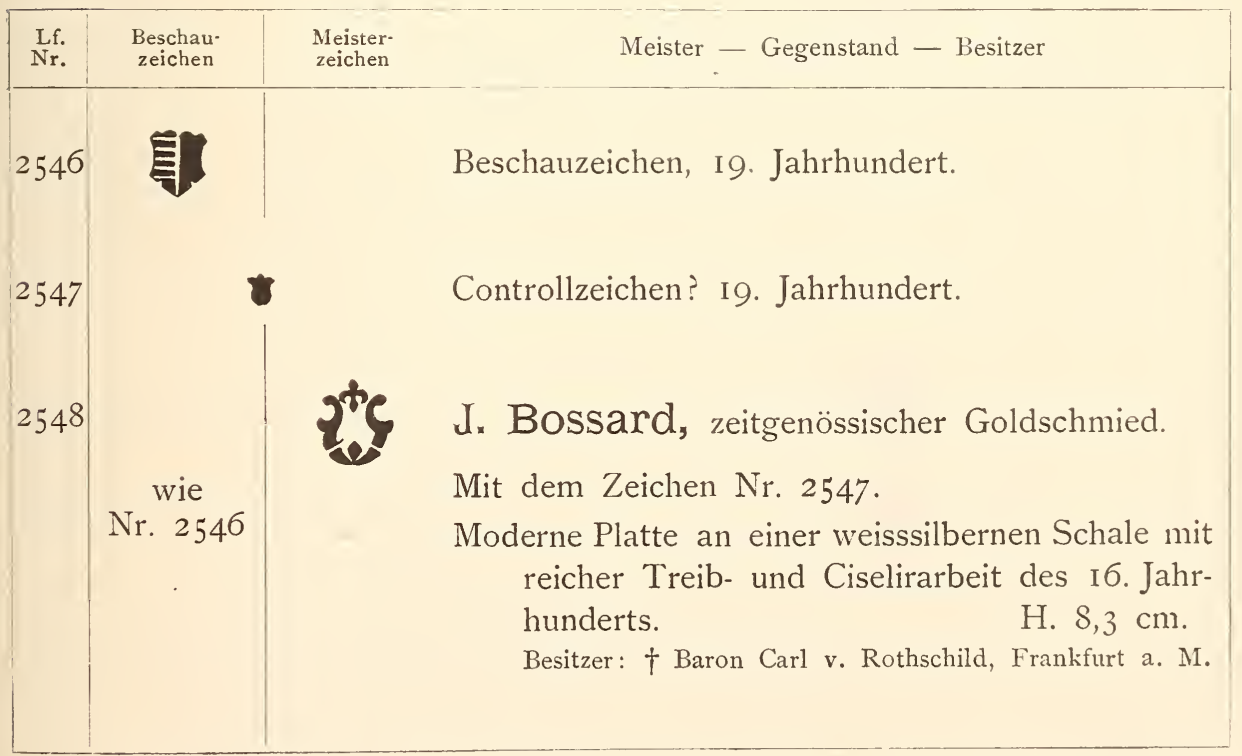




\section{NEUCHATEL.}

Einen Theil der folgenden Marken und ihre Deutung entnehme ich Godet, Poinçons Neuchâtelois in Anzeiger für Schweizerische Alterthumskunde I886, S. $335 \mathrm{ff}$.

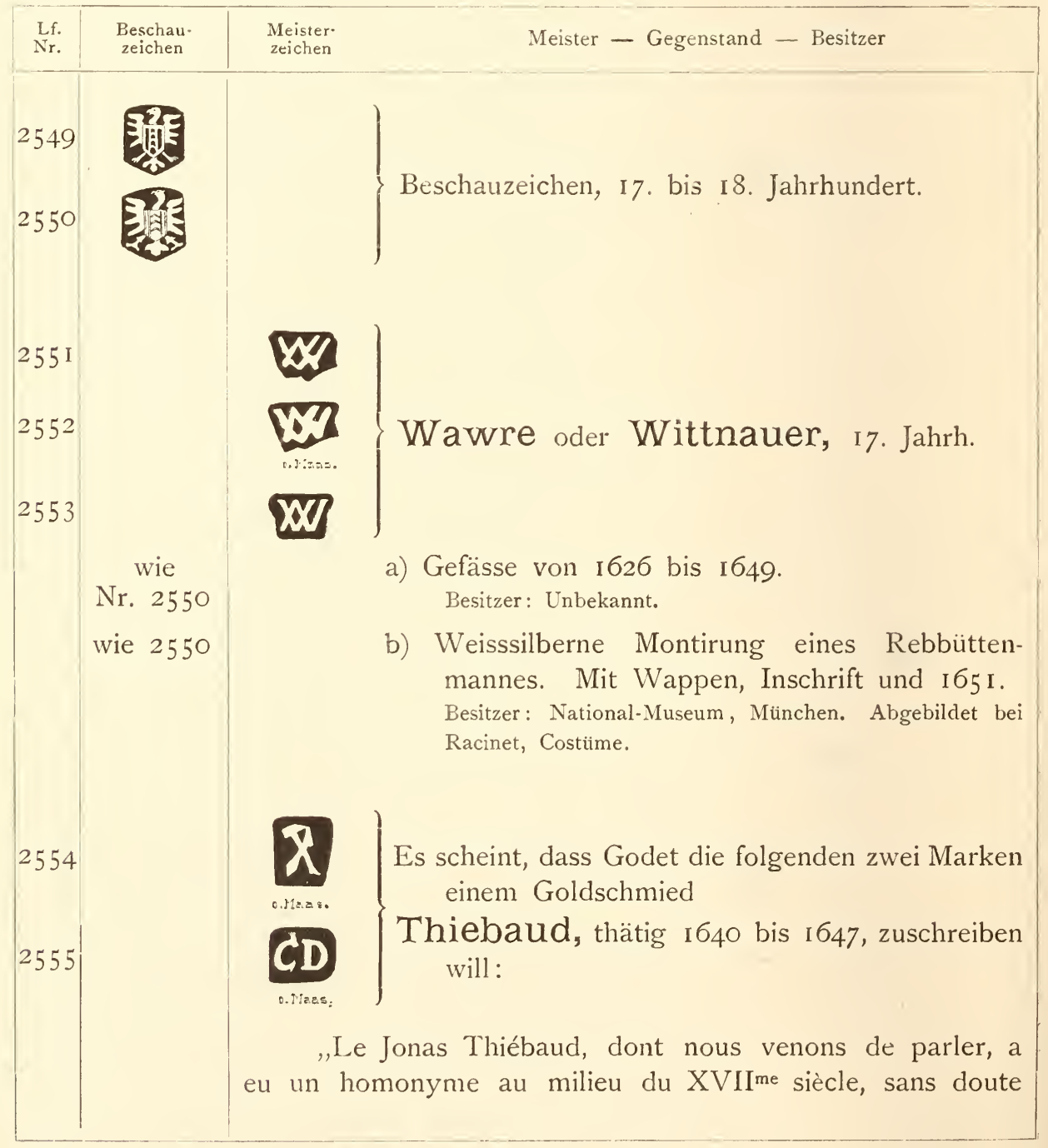




\begin{tabular}{|c|c|c|}
\hline $\begin{array}{l}\text { Lf. } \\
\text { Nr. }\end{array}$ & $\begin{array}{l}\text { Beschau- } \\
\text { zeichen }\end{array}$ & Meister - Gegenstand - Pesitzer \\
\hline 2555 & & $\begin{array}{l}\text { un ancêtre. Il signe 》Thiébaud le fils « (évidement fils } \\
\text { d'un Thiébaud plus ancien). Ce nom est écrit en toutes } \\
\text { lettres sur une coupe de la compagnie de fusiliers, de } 1647 \text {. } \\
\text { Son poinçon associé à celui de Neuchâtel n'est pas très- } \\
\text { claire. Ce poinçon se trouve sur des coupes de i640 à } \\
\text { I647." }\end{array}$ \\
\hline 2556 & $\begin{array}{c}\text { wie } \\
\text { Nr. } 255^{\circ}\end{array}$ & $\begin{array}{l}\text { N. Matthey, thätig I } 663 \text { bis I } 679 . \\
\text { Mehrere Becher, darunter ein Ananaspokal. } \\
\text { Besitzer: Historisches Museum, Neuchâtel. }\end{array}$ \\
\hline 2557 & $\begin{array}{l}\text { wie } \\
\text { Nr. } 2550\end{array}$ & $\begin{array}{l}\text { G* Tavargier } \\
\text { Trinkgefäss mit Inschrift von I } 699 . \\
\text { Besitzer: Stadt Neuchâtel. }\end{array}$ \\
\hline 2558 & & $\begin{array}{l}\text { J.M. Matthey, I8. Jahrh. } \\
\text { Wegen der etwas complizirten Verhältnisse, die bei } \\
\text { diesem Goldschmiede vorzuliegen scheinen, ziehe ich vor, } \\
\text { den Wortlaut von Godet herzusetzen: } \\
\text { "Ensuite vient I. I. (Jean-Jacques?) Matthey. Sans } \\
\text { doute un descendant de N. Matthey. Il vécut dans la } \\
\text { première moitié du XVIII siècle. Son poinçon est toujours } \\
\text { associé à celui de Neuchâtel. Le nom de cet artiste se } \\
\text { trouve gravé en toutes lettres sur une coupe de la compagnie } \\
\text { des fusiliers, de I730. 》J. J. Mathey fabricavit: Jonas } \\
\text { Thiébaud sculpsit. Je suppose que J. J. Matthey étudia } \\
\text { en Allemagne l'art du ciseleur, car son poinçon se trouve } \\
\text { associé à celui d'un ciseleur allemand. "Jean Friderich } \\
\text { Cornelius de la ville de Magdebourg en Prusse, " dans } \\
\text { la belle coupe que le baron de Kameke donna en I740 à } \\
\text { la ville de Neuchâtel. - J. J. Mathey a aussi fabriqué une } \\
\text { de nos belles plaques d'huissier. }\end{array}$ \\
\hline
\end{tabular}




\section{RAPPERSWEIL.}

\begin{tabular}{|c|c|c|c|}
\hline $\begin{array}{l}\text { Lf. } \\
\text { Nr. }\end{array}$ & $\begin{array}{l}\text { Beschau- } \\
\text { zeichen }\end{array}$ & $\begin{array}{l}\text { Meister- } \\
\text { zeichen }\end{array}$ & Meister - Gegenstand - Besitzer \\
\hline 2560 & ) & & Beschauzeichen, I6. und I7. Jahrhundert. \\
\hline $256 \mathrm{I}$ & & & Beschauzeichen, I8. Jahrhundert. \\
\hline 2562 & $\begin{array}{c}\text { wie } \\
\text { Nr. } 2559\end{array}$ & & $\begin{array}{l}\text { a) Birnbecher mit getriebenen Ornamenten. } \\
\text { H. } 33 \mathrm{~cm} \text {. } \\
\text { Besitzer: Gemeinde Rappersweil. Ausstellung Zürich } \\
\text { I883, Katalog S. } 226 \text { Nr. 19. }\end{array}$ \\
\hline & wie 2559 & & $\begin{array}{l}\text { b u. c) Zwei Reliquiarbüsten (St. Blasius und } \\
\text { St. Mauritius) mit Inschrift von I668. } \\
\text { Besitzer: Kirchenpflege, Rheinau. Ausstellung Zürich } \\
\text { I883, Katalog S. 218 Nr. I und 2. }\end{array}$ \\
\hline 2563 & $\begin{array}{c}\text { wie } \\
\text { Nr. } 2560\end{array}$ & & $\begin{array}{l}\text { Vergoldeter Becher mit Deckel. Wappen und } \\
\text { Inschrift von I6I9. } \\
\text { Besitzer: Gemeinde Rappersweil. Ausstellung Zürich } \\
\text { I } 88_{3} \text {, Katalog S. } 225 \text { Nr. 8. }\end{array}$ \\
\hline 2564 & $\begin{array}{c}\text { wie } \\
\text { Nr. } 2560\end{array}$ & & $\begin{array}{l}\text { Theilvergoldete Messkännchen und Platte. Mit } \\
\text { Laubwerk getrieben. I7. Jahrhundert. } \\
\text { Platte, Lg. } 29 \mathrm{~cm} \text {. Kännch. H. I } 3,3 \mathrm{~cm} \text {. } \\
\text { Besitzer: Kirche, Bischofszell. Ausstellung Zürich I883, } \\
\text { Katalog S. 221 Nr. 29. }\end{array}$ \\
\hline 2565 & $\begin{array}{l}\text { wie } \\
\text { Nr. } 256 \mathrm{I}\end{array}$ & & $\begin{array}{l}\text { Löffel, mit Initialen gravirt. } \\
\text { Besitzer (I882): A. Duss, Stuttgart. }\end{array}$ \\
\hline
\end{tabular}




\section{SCHAFFHAUSEN.}

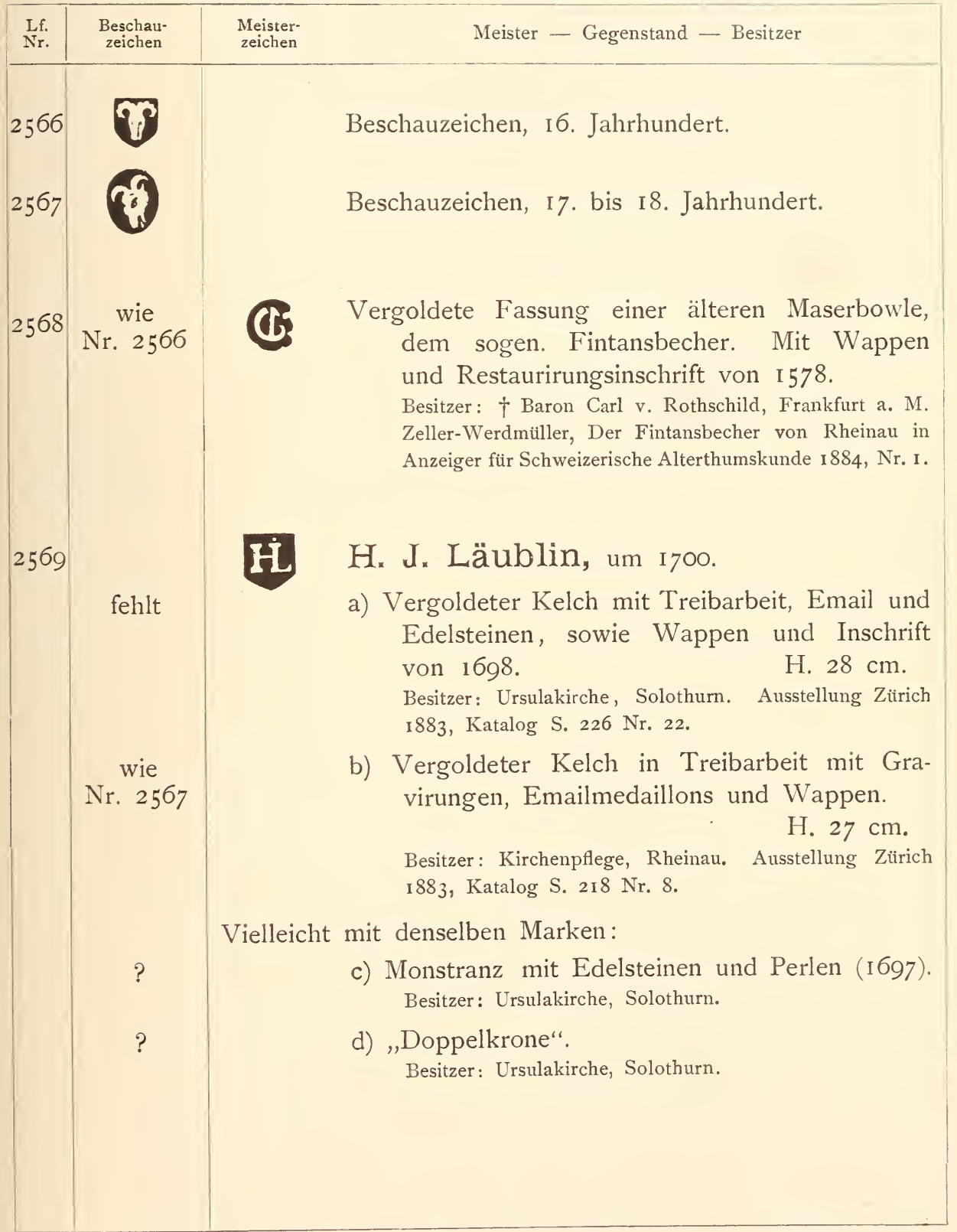




\section{WINTERTHUR.}

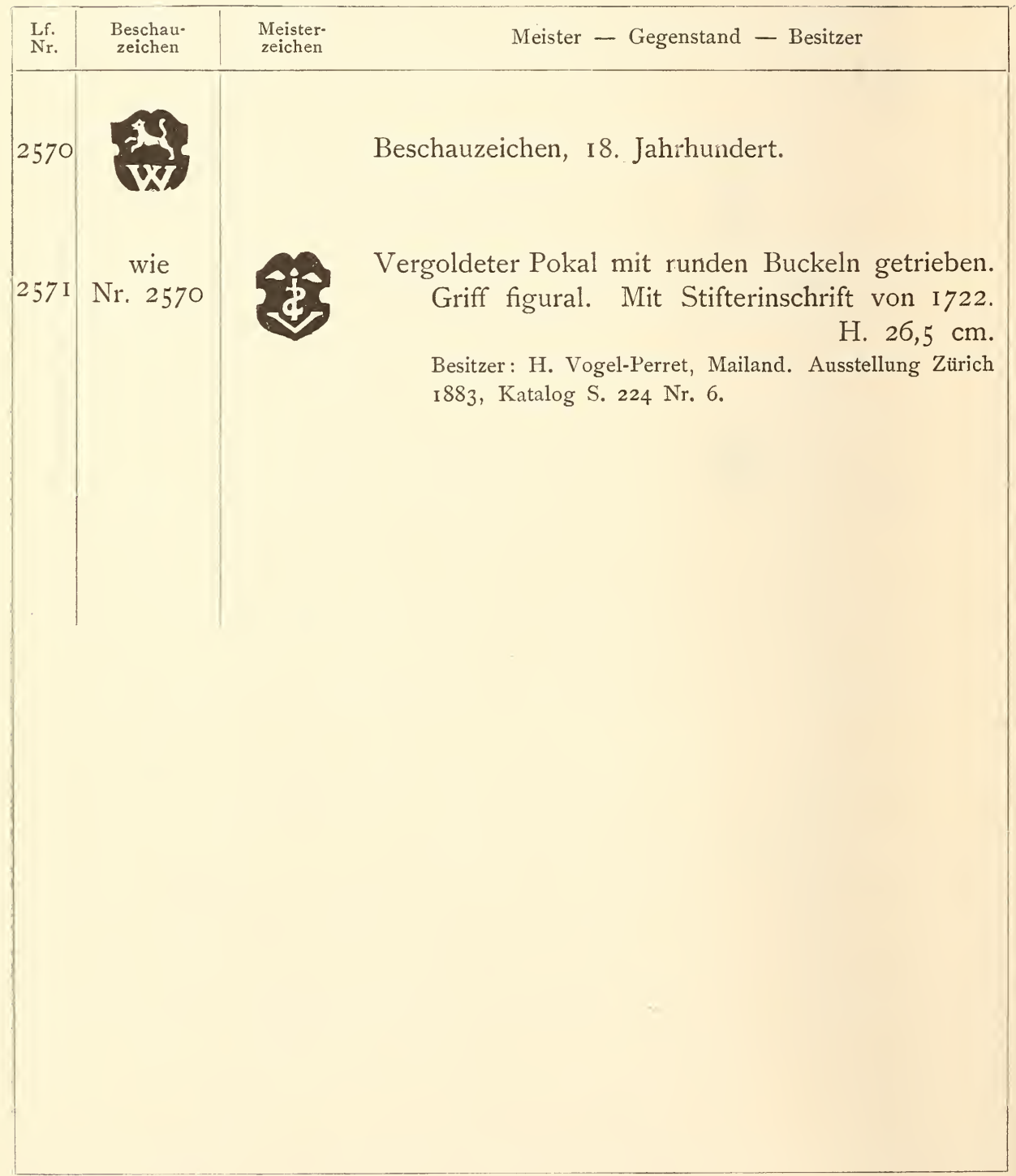




\section{ZÜRICH.}

Wie in Lüneburg und Bern scheint auch hier Selbststempelung bestanden zu haben, d. h. das Beschauzeichen wurde (wie auch das Meisterzeichen) von den Meistern, welche die zu zeichnende Arbeit gemacht hatten, nicht aber von den dazu bestellten Wardeinen eingeschlagen.

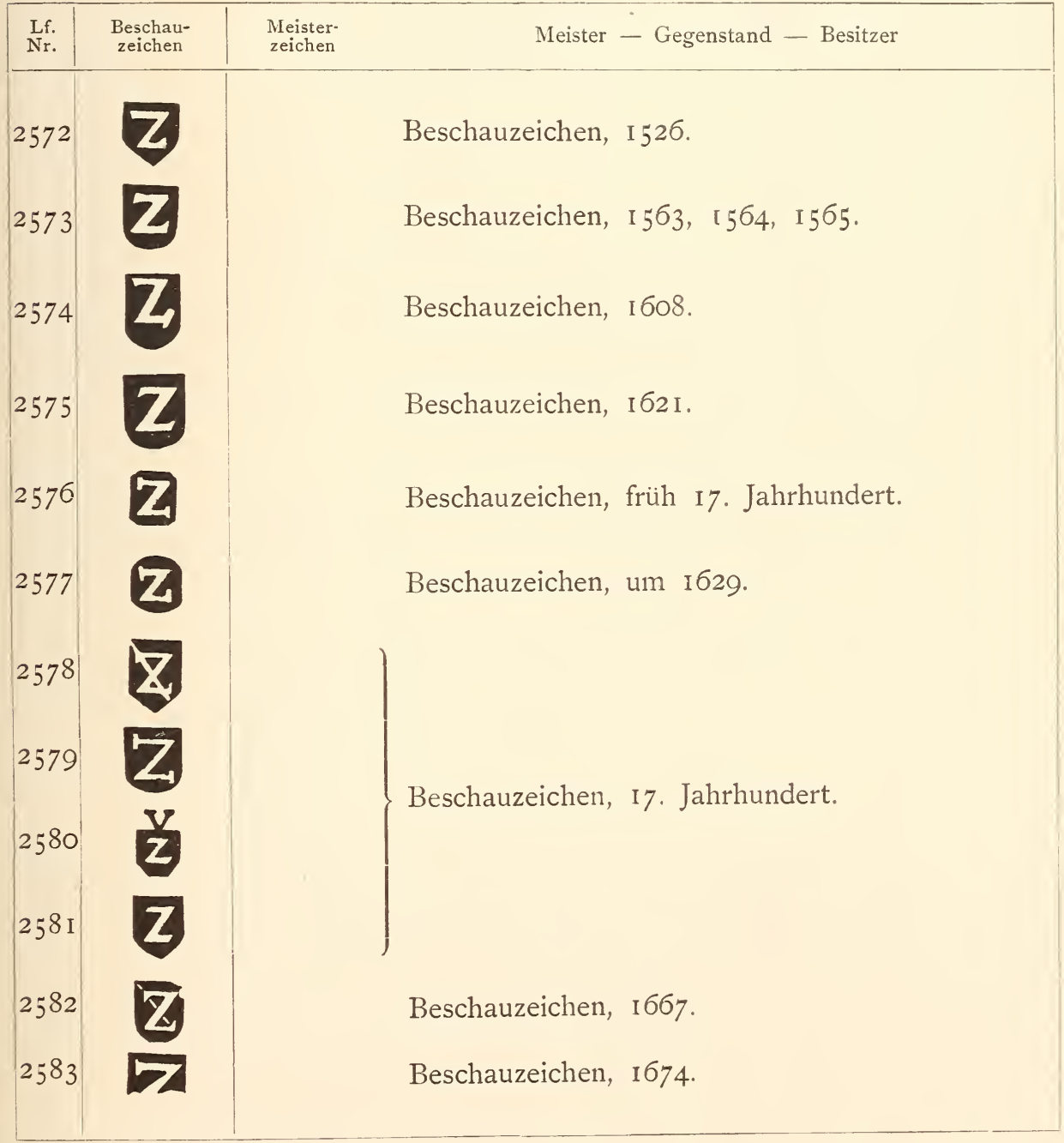




\begin{tabular}{|c|c|c|c|}
\hline Lf. & $\begin{array}{l}\text { Beschau- } \\
\text { zeichen }\end{array}$ & $\begin{array}{l}\text { Meister- } \\
\text { zeichen }\end{array}$ & Meister - Gegenstand - Besitzer \\
\hline 84 & & & $\begin{array}{l}\text { Nach Mittheilung von Herrn H. Zeller - Werd- } \\
\text { müller in Zürich: } \\
\text { Hans Gg } \text { Müller, Meister I 524, } † \text { I 567, oder } \\
\text { Hans Müller aus Ulm, Bürger in Zürich } \\
\text { I } 526 \text {. }\end{array}$ \\
\hline & $\begin{array}{l}\text { wie } \\
\text { Nr. } 2572\end{array}$ & & 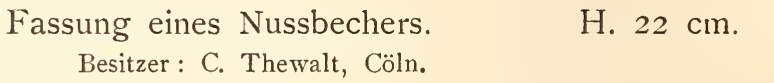 \\
\hline 85 & $\begin{array}{c}\text { wie } \\
\text { Nr. } 2573\end{array}$ & & $\begin{array}{l}\text { a) Schlanker konischer Becher, auf Kugelfüssen } \\
\text { ruhend, mit Stifterinschrift von I } 563 . \\
\begin{array}{l}\text { H. } 22 \mathrm{~cm} . \\
\text { Besitzer: Stadtbibliothek, Zürich. }\end{array}\end{array}$ \\
\hline & wie 2573 & & $\begin{array}{l}\text { b) Schlanker konischer Becher, auf Kugelfüssen } \\
\text { ruhend, mit Stifterinschrift von I } 564 . \\
\text { H. } 22 \mathrm{~cm} . \\
\text { Besitzer: Stadtbibliothek, Zürich. }\end{array}$ \\
\hline & wie 2573 & & $\begin{array}{l}\text { c) Schlanker konischer Becher mit Stifterinschrift } \\
\text { von I } 565 . \\
\text { Besitzer: Stadtbibliothek, Zürich. Abgebildet im Neu- } \\
\text { jahrsblatt der Stadtbibliothek Zürich, r } 860 \text {. }\end{array}$ \\
\hline
\end{tabular}

VLRICH ORI FIGVRAVIT DIETHELM HOLZHALB FECIT (nicht facsimilirt).

Diethelm Holzhalb, г608.

Gefäss in Gestalt eines Löwen mit Meister-, Entwerfer- und Stifterinschrift von 1608.

H. $3 \mathrm{I} \mathrm{cm}$.

Besitzer: Gesellschaft der Boecke, Zürich.

wie

Nr. 2575

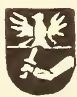

Nach Mittheilung von Herrn H. Zeller-Werdmüller in Zürich

Hans Heinrich Riva, i6rı.

a) Vergoldete Fassung eines Nautilus mit Stiftungsinschrift von I62I.

H. $32,5 \mathrm{~cm}$. 


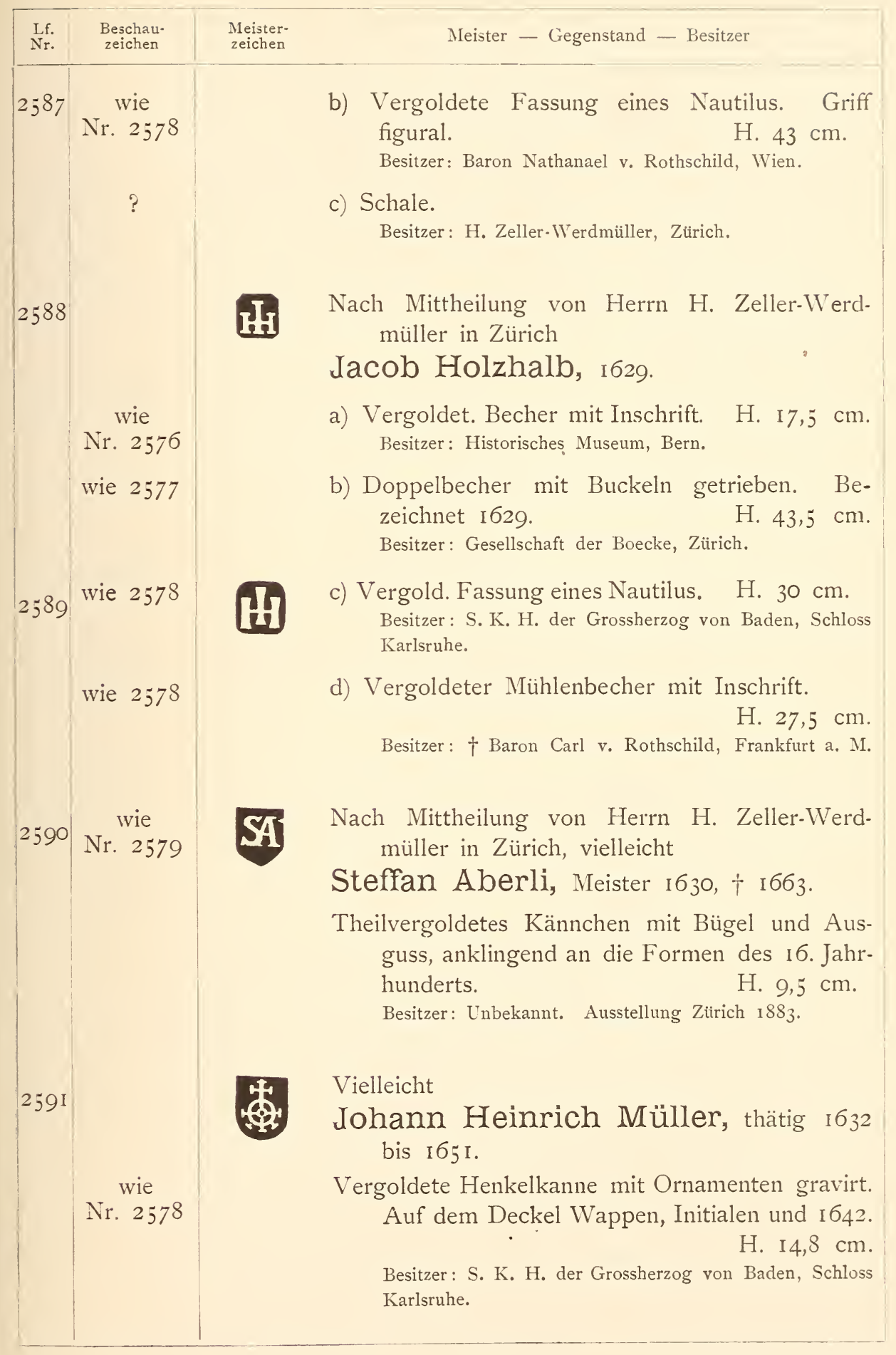




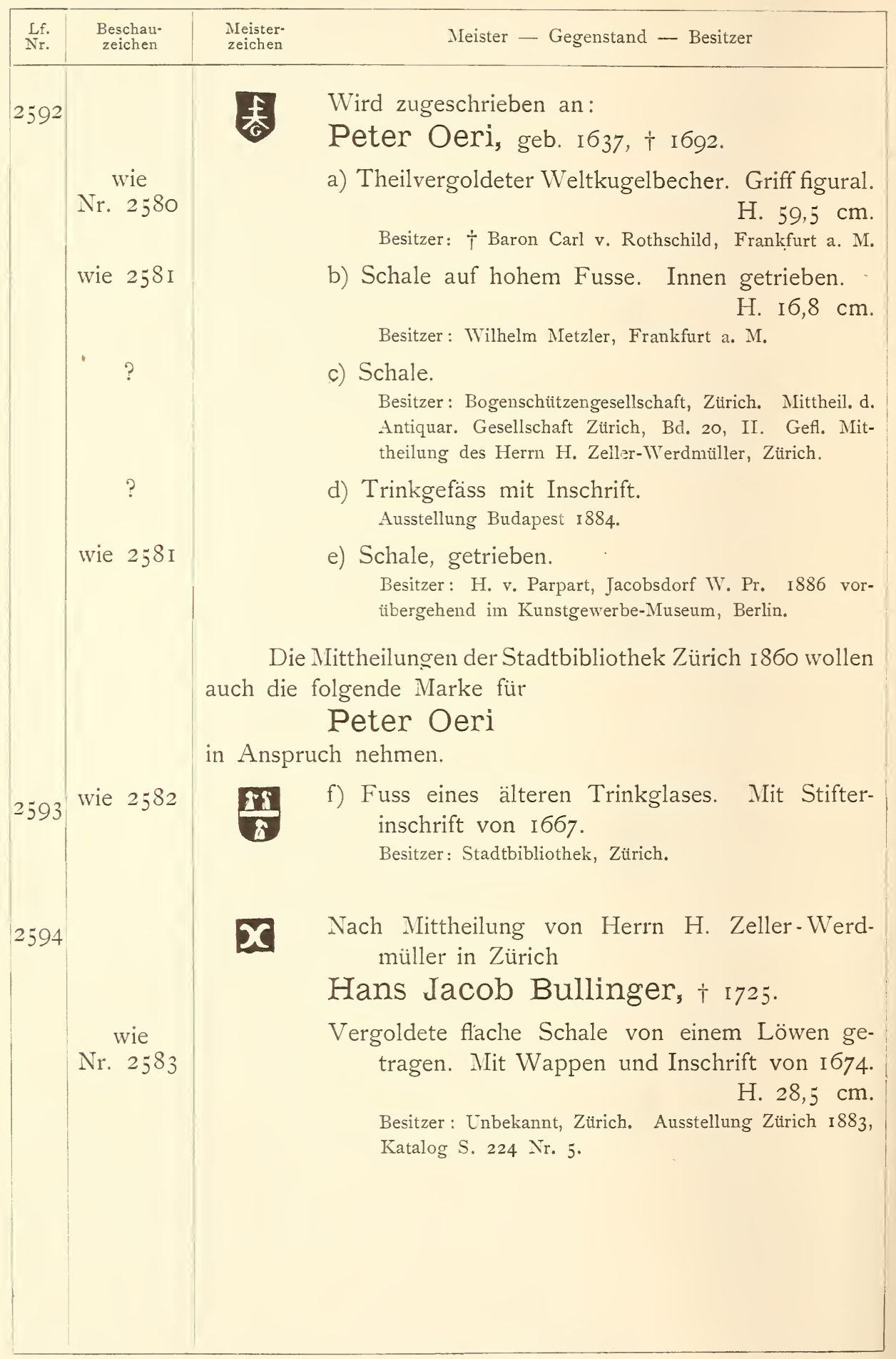




\section{ZUG.}

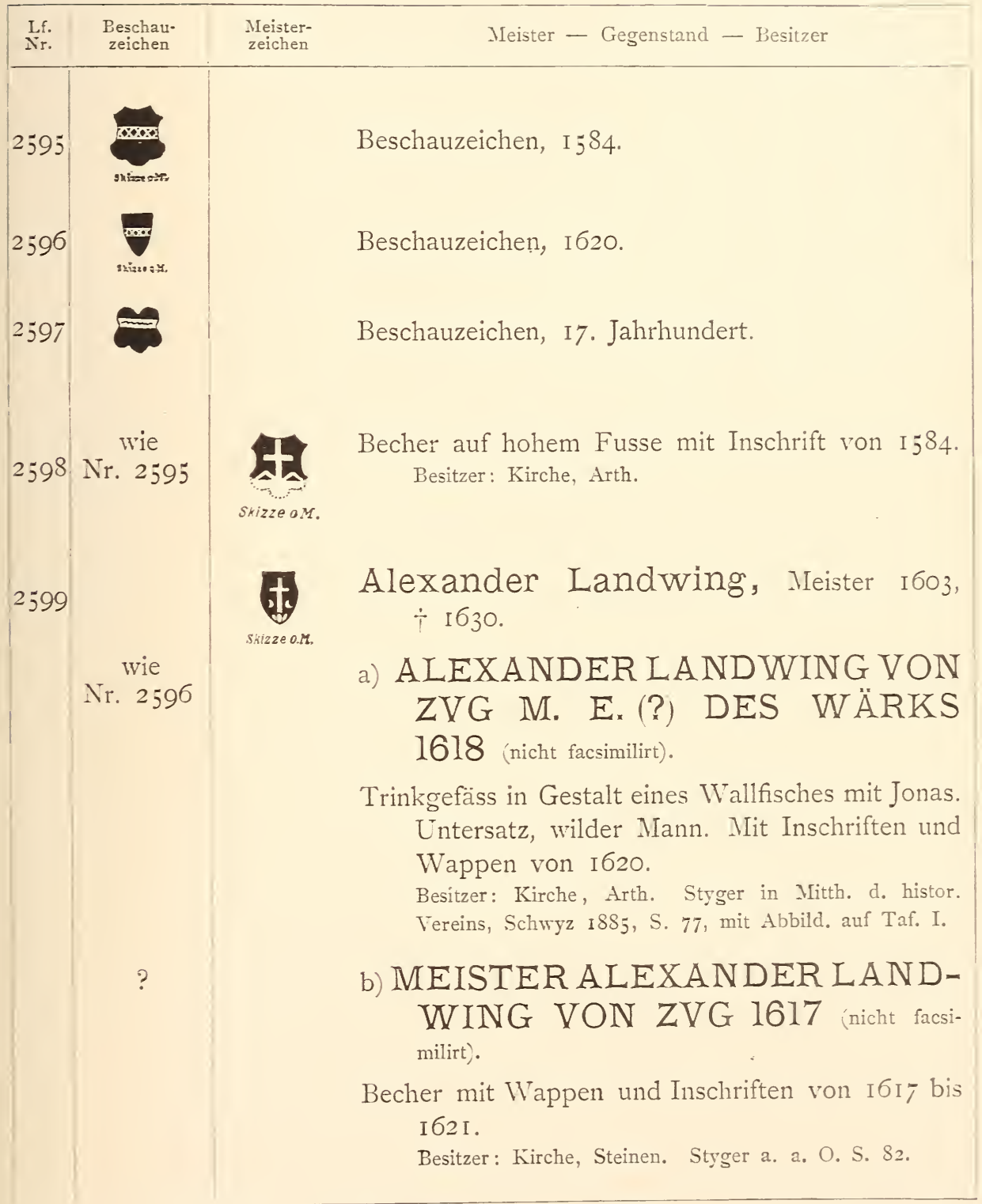




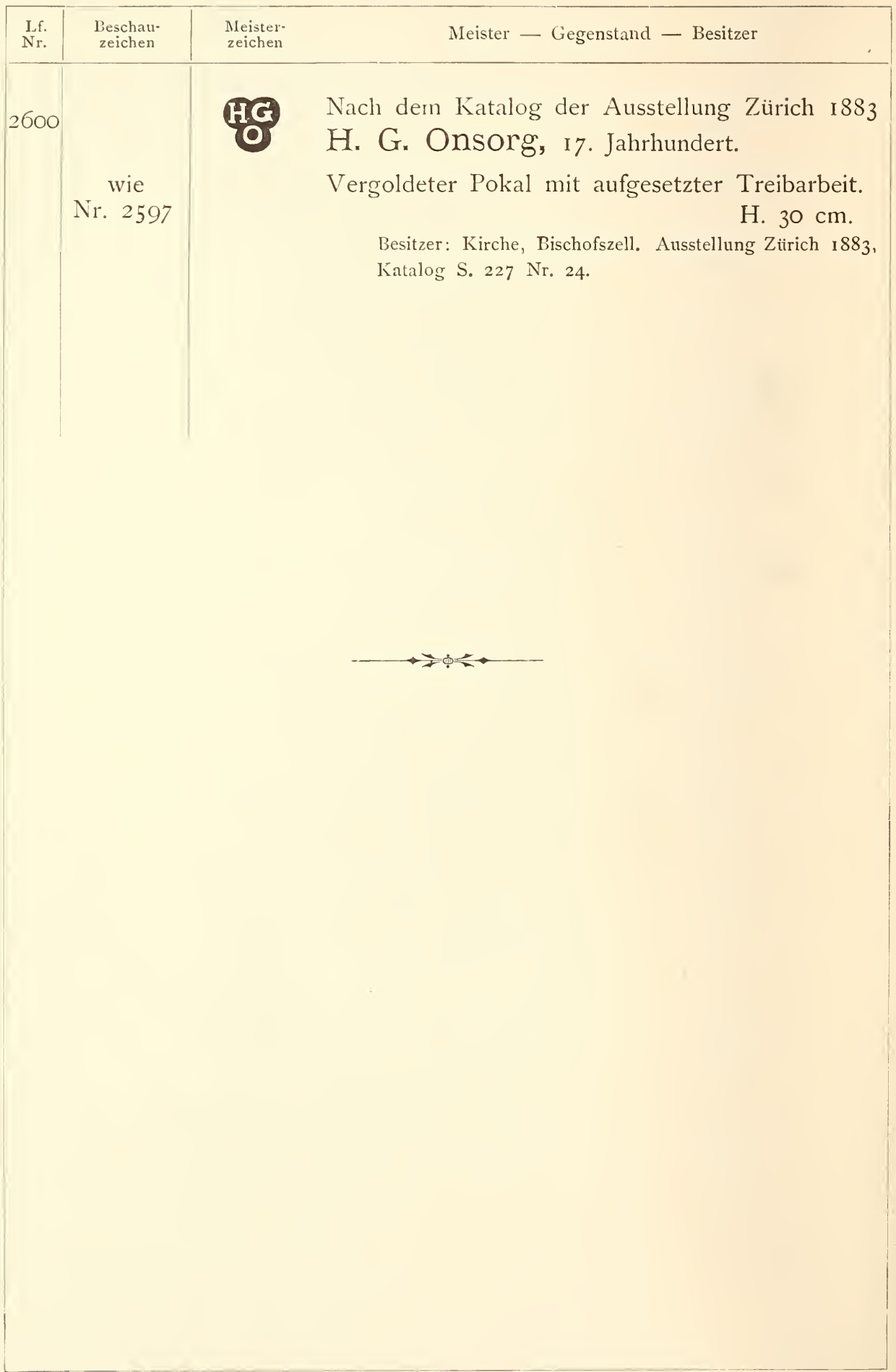




\section{Register.}

I. Markenregister:

a) Register der Monogramme.

b) Register der figürlichen Marken.

c) Zahlen.

II. Verzeichniss der Goldschmiedenamen.

III. Verzeichniss der Besitzer. 
Die Markenregister I.a), I. b) und I.c) sind in der Weise mit einander verbunden, dass die Zeichen, welche man in mehreren derselben suchen könnte, möglichst in dem voranstehenden Register untergebracht sind.

Demnach sind die Marken folgendermassen aufzusuchen: figürliche Zeichen mit Buchstaben bei Buchstaben I. a) Buchstaben mit Zahlen bei Buchstaben I. a) figürliche Zeichen mit Zahlen bei figürlichen Zeichen I.b) Zahlen allein I. c). 


\section{Markenregister.}

a) Register der Monogramme.

Alle Stempel, welche aus Buchstaben bestehen, oder aus Buchstaben und anderen Zeichen, finden hier ihren Platz.

Die Reihenfolge ist eine alphabetische; die Buchstaben des russischen Alphabets sind, soweit sie den Formen des lateinischen entsprechen, bei diesem eingereiht, demnach ist das russische $\mathrm{C}$ nicht bei $\mathrm{S}$, sondern bei $\mathrm{C}$ $\mathrm{zu}$ suchen.

Die als Stempel vorkommenden voll ausgeschriebenen Goldschmiedenamen sind nach dem Verzeichnisse der letzteren aufzusuchen.

Bei der Anordnung innerhalb des Alphabets habe ich mich sehr oft nach den in Naglers Monogrammisten Band I niedergelegten Principien gerichtet. Ein strenges System wäre ohne grosse Härten nicht durchführbar gewesen. Im Allgemeinen imag etwa Folgendes zu bemerken sein:

Bei verbundenen oder verschlungenen Buchstaben entscheidet derjenige, welcher am meisten nach links vortritt, in zweifelhaften Fällen derjenige, welcher im Alphabet früher vorkommt. Wo die Buchstaben eines Stempels in mehreren Linien angeordnet sind, richtet sich die Einreihung nach dem ersten Buchstaben derjenigen Zeile, welche die meisten Buchstaben enthält, die weitere Einfügung wird bedingt durch die Buchstaben der unteren Linie, $\mathrm{AB}$

welcher endlich die der oberen folgen; demnach ist CFD bei CFDHAAB HA

zu suchen.

Die Schriftgattungen sind getrennt, die gothische geht voran, dann folgen Antiqua und Cursiv. Die Kleinbuchstaben stehen erst nach allen Grossbuchstaben.

Die Einzelbuchstaben machen den Anfang und die vertieften gehen den erhabenen voran.

Die Schildform geht vom Rund und Oval zum Quadratischen und Vielseitigen über.

Die Anordnung der Beizeichen ist die gleiche, wie die der figürlichen Marken im folgenden Register I. b). 


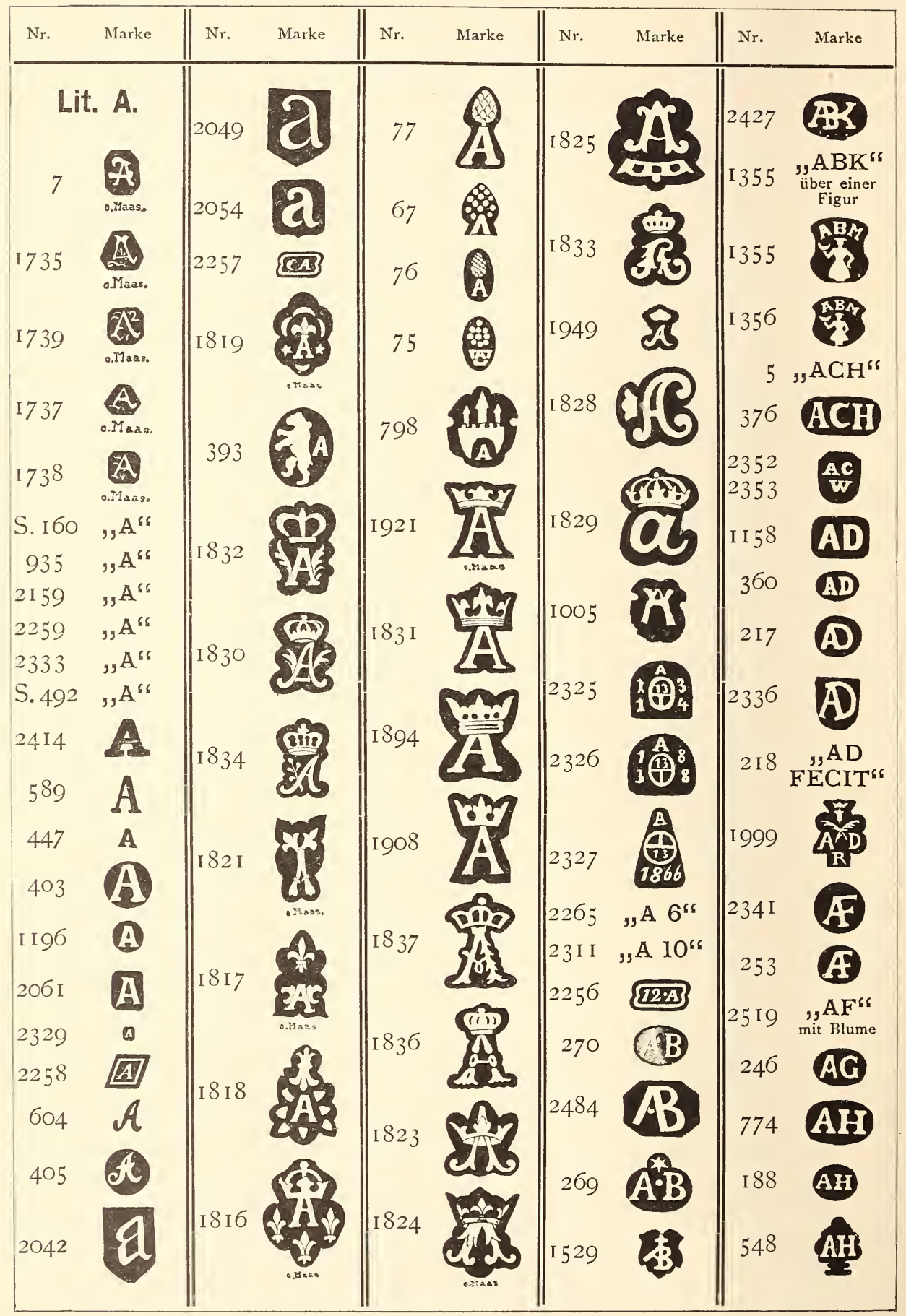




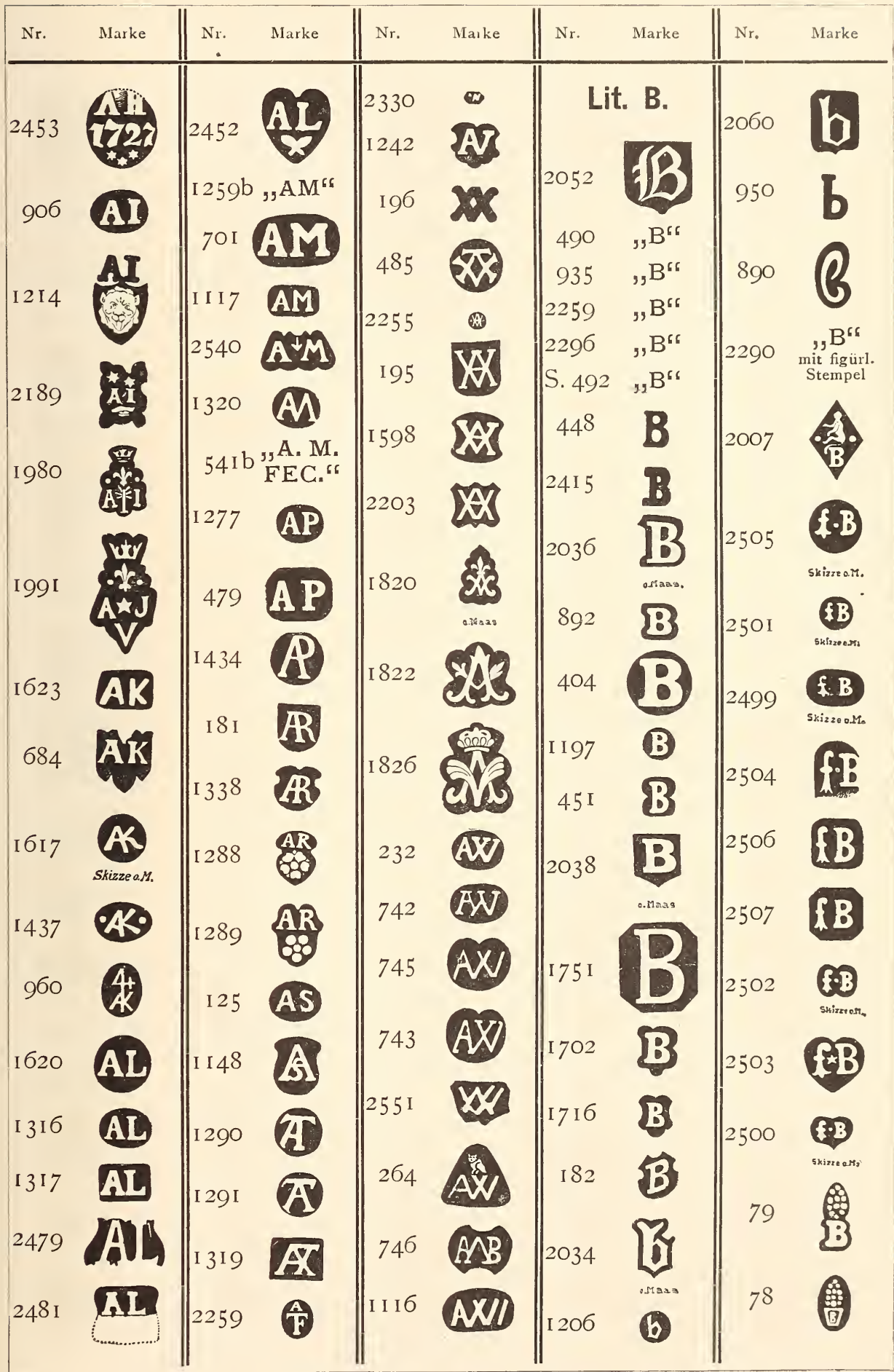




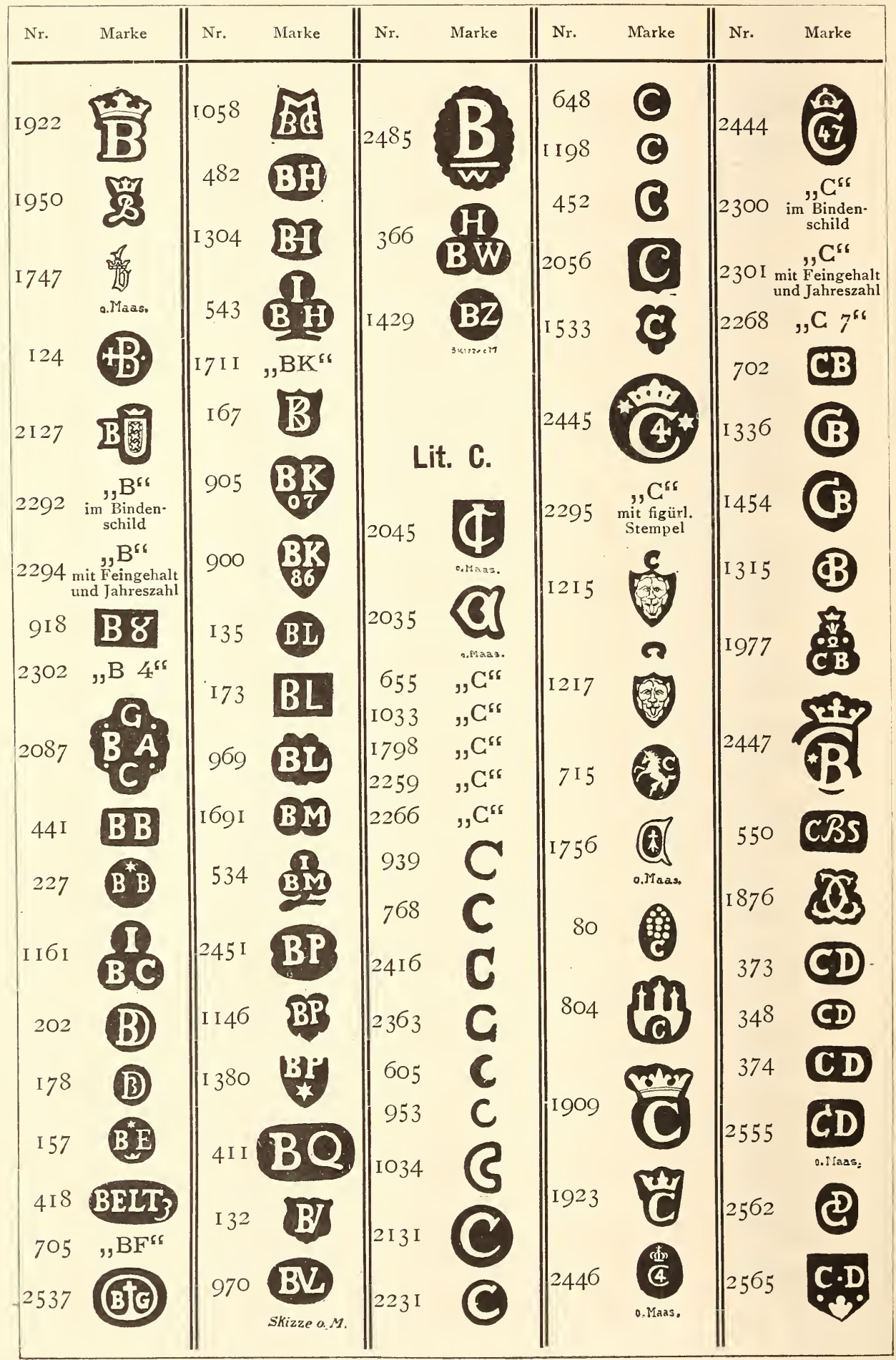




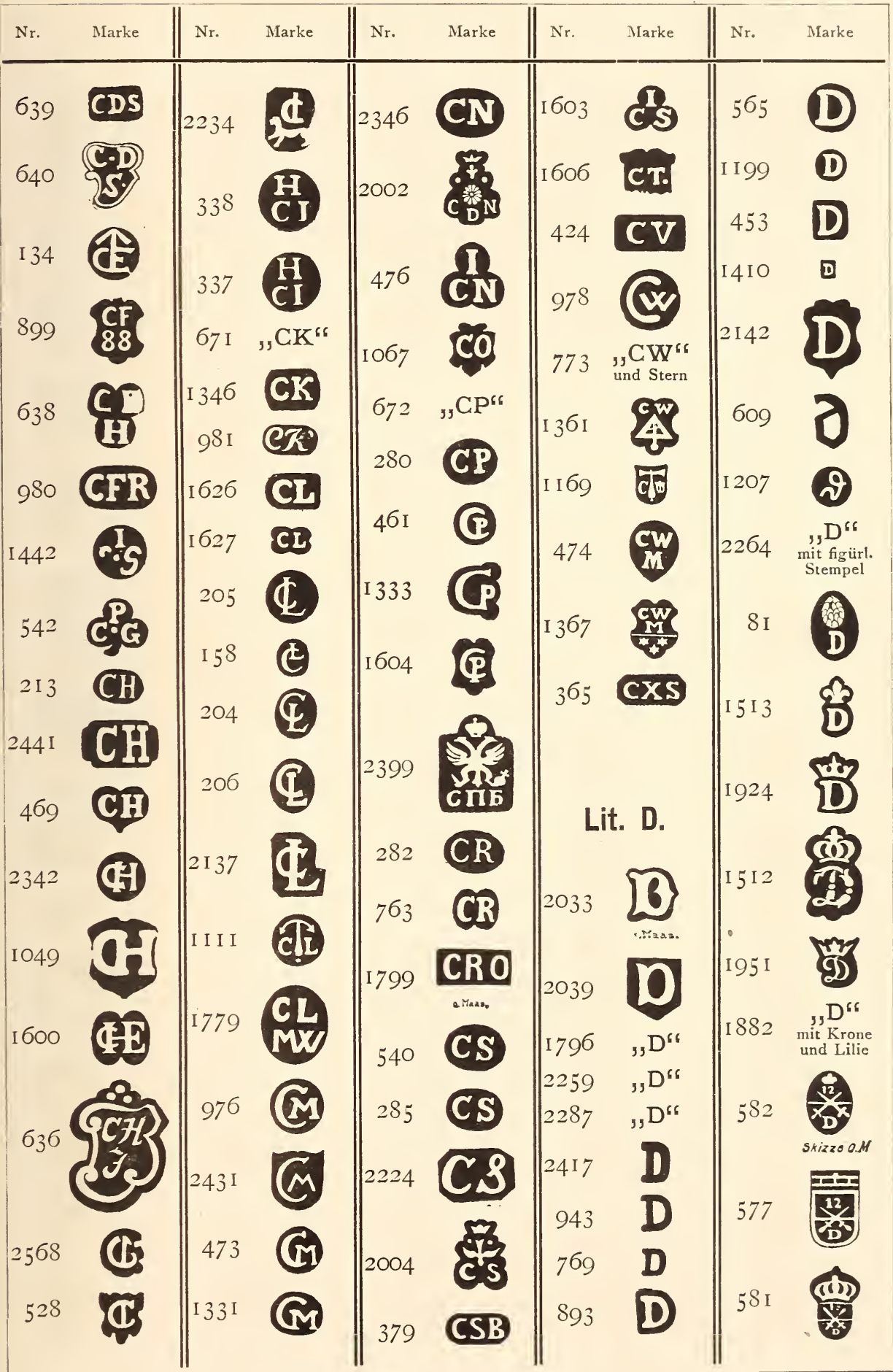




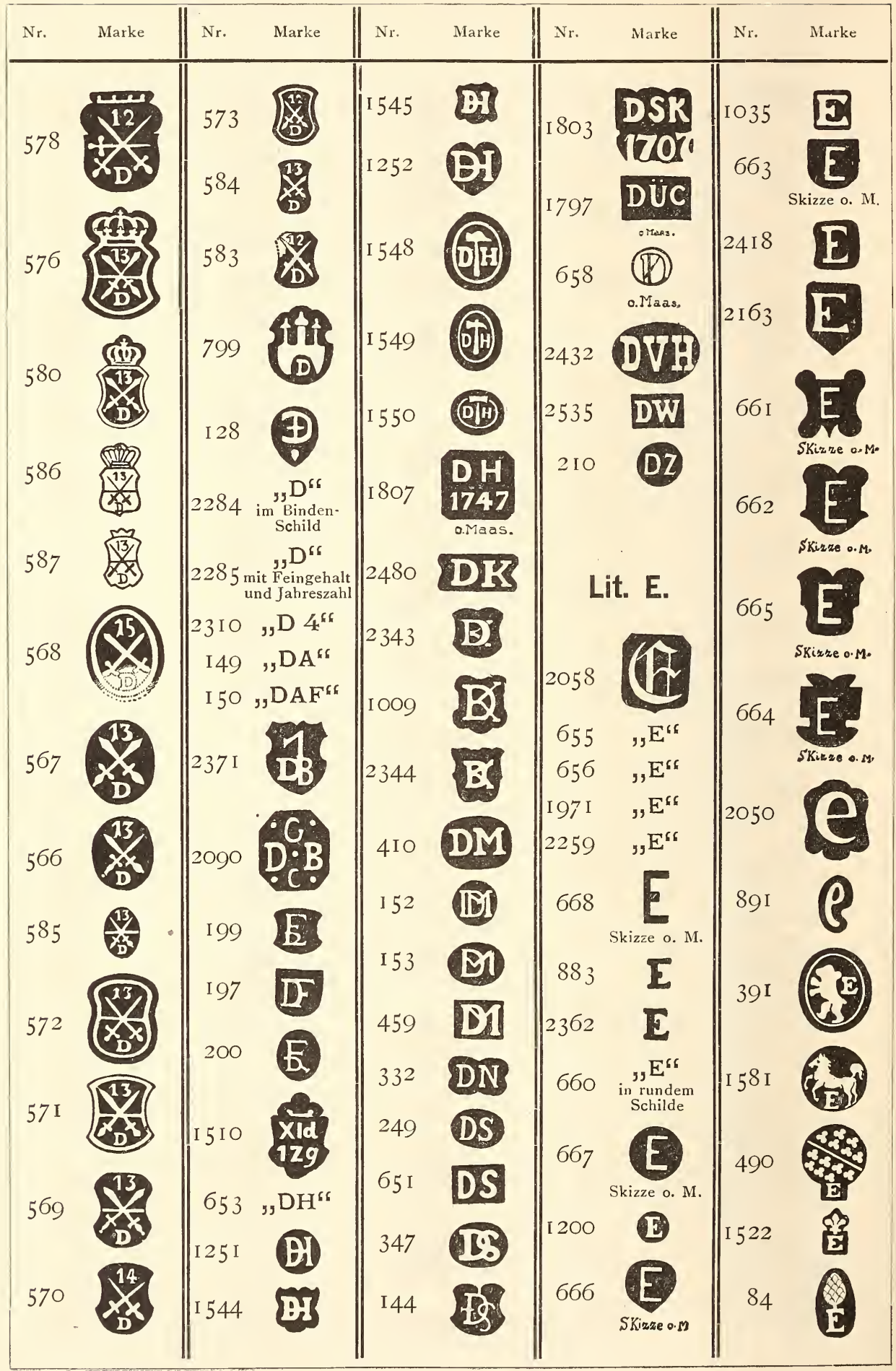




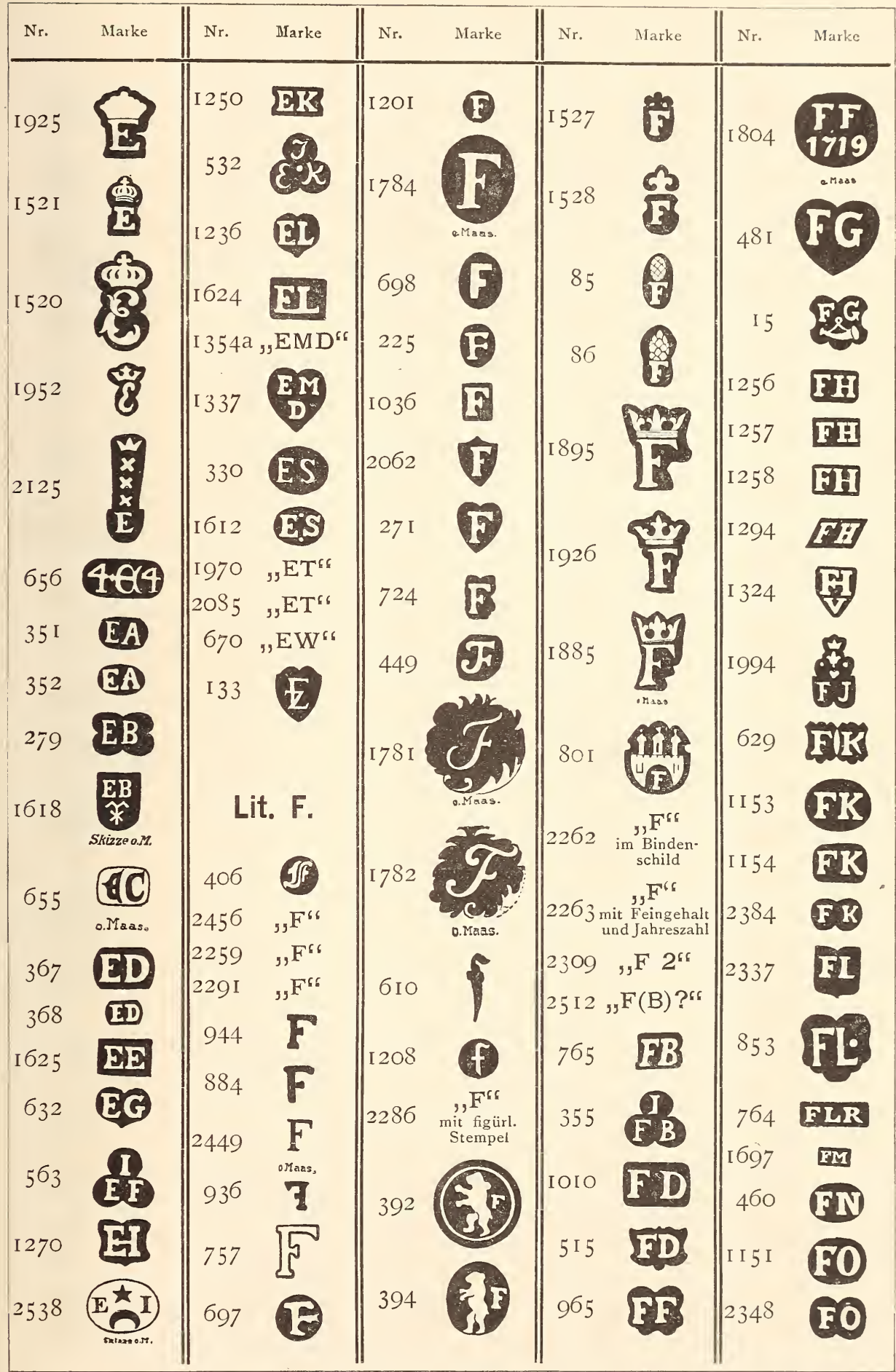




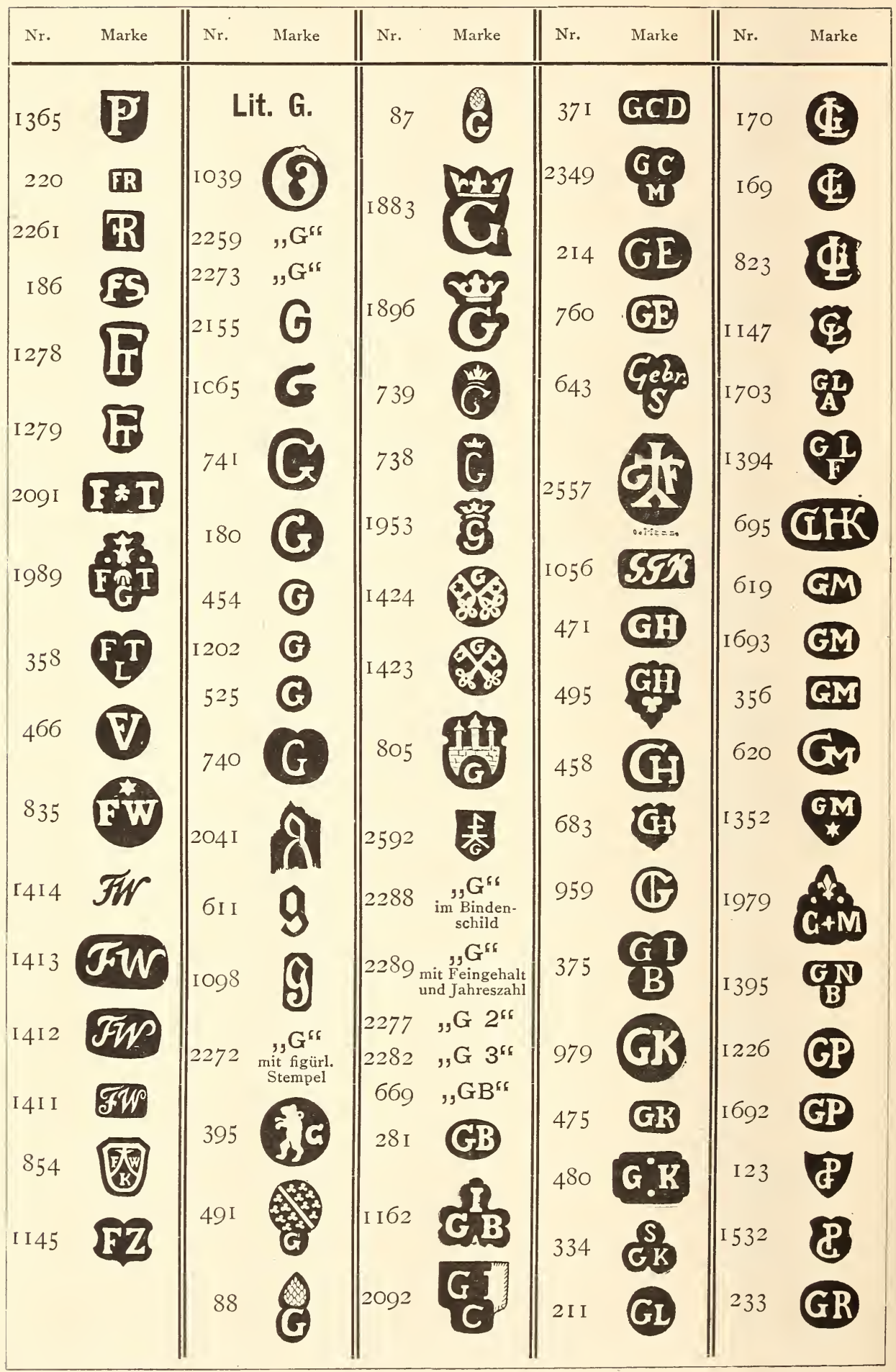




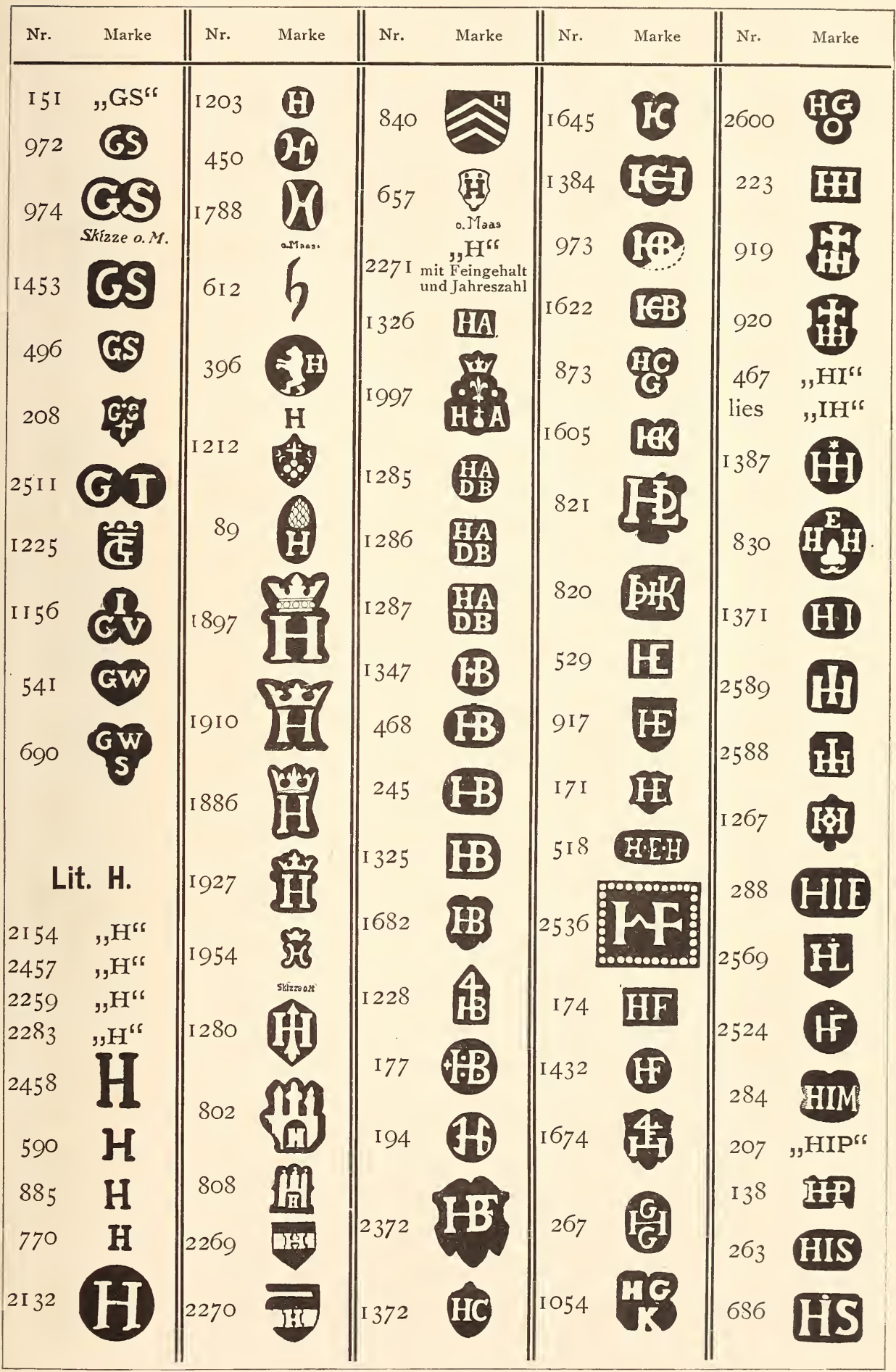




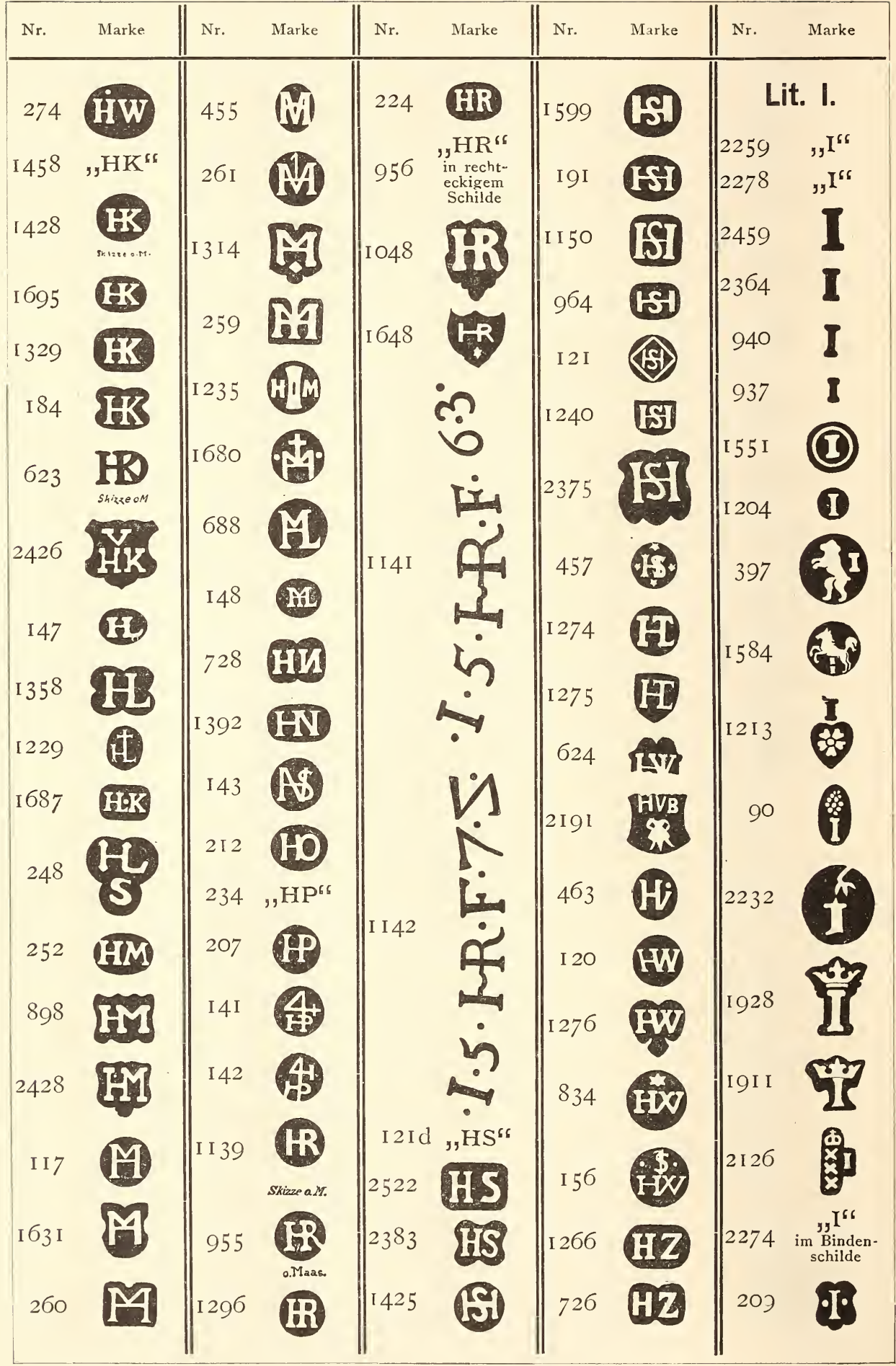




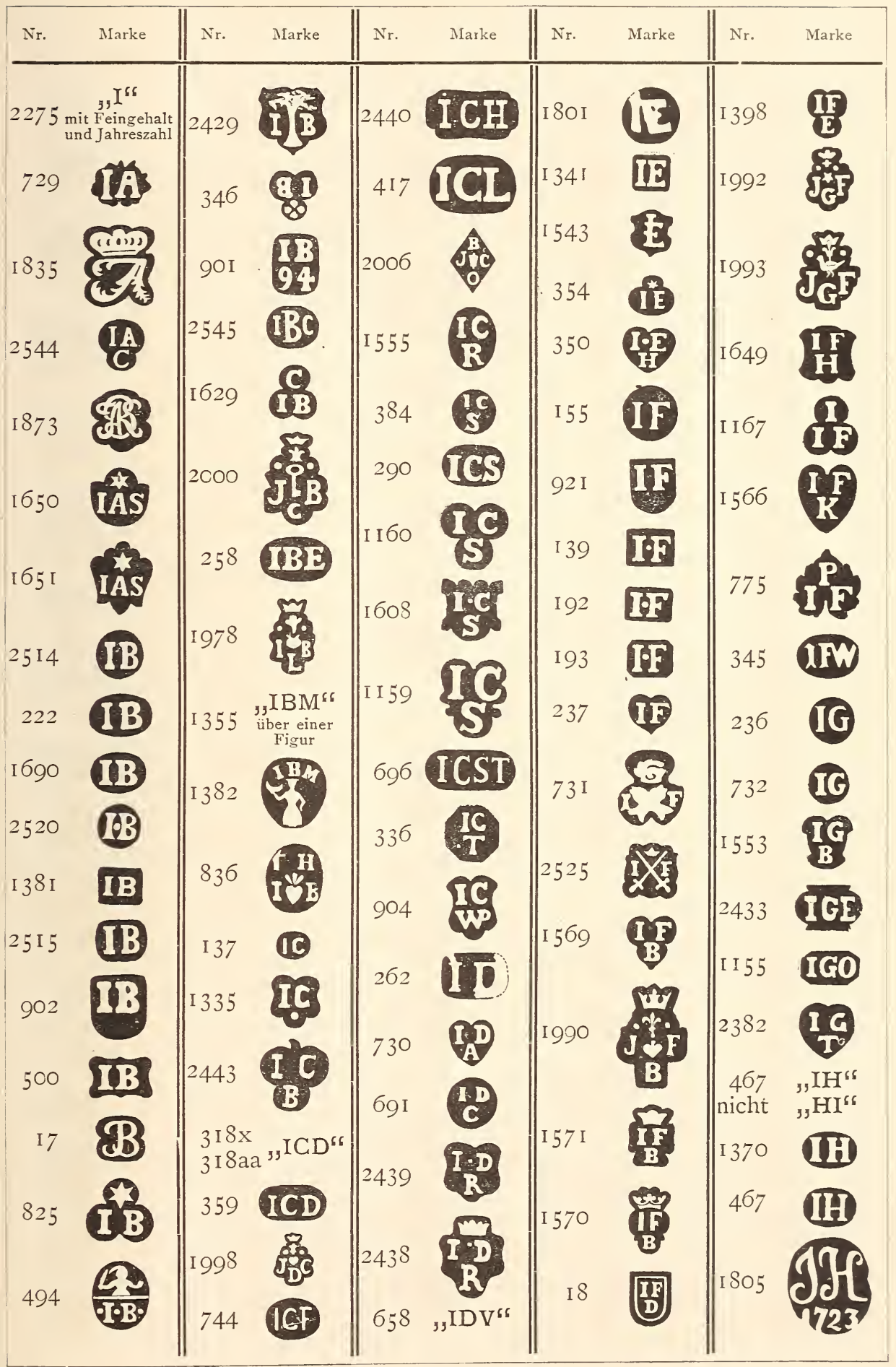




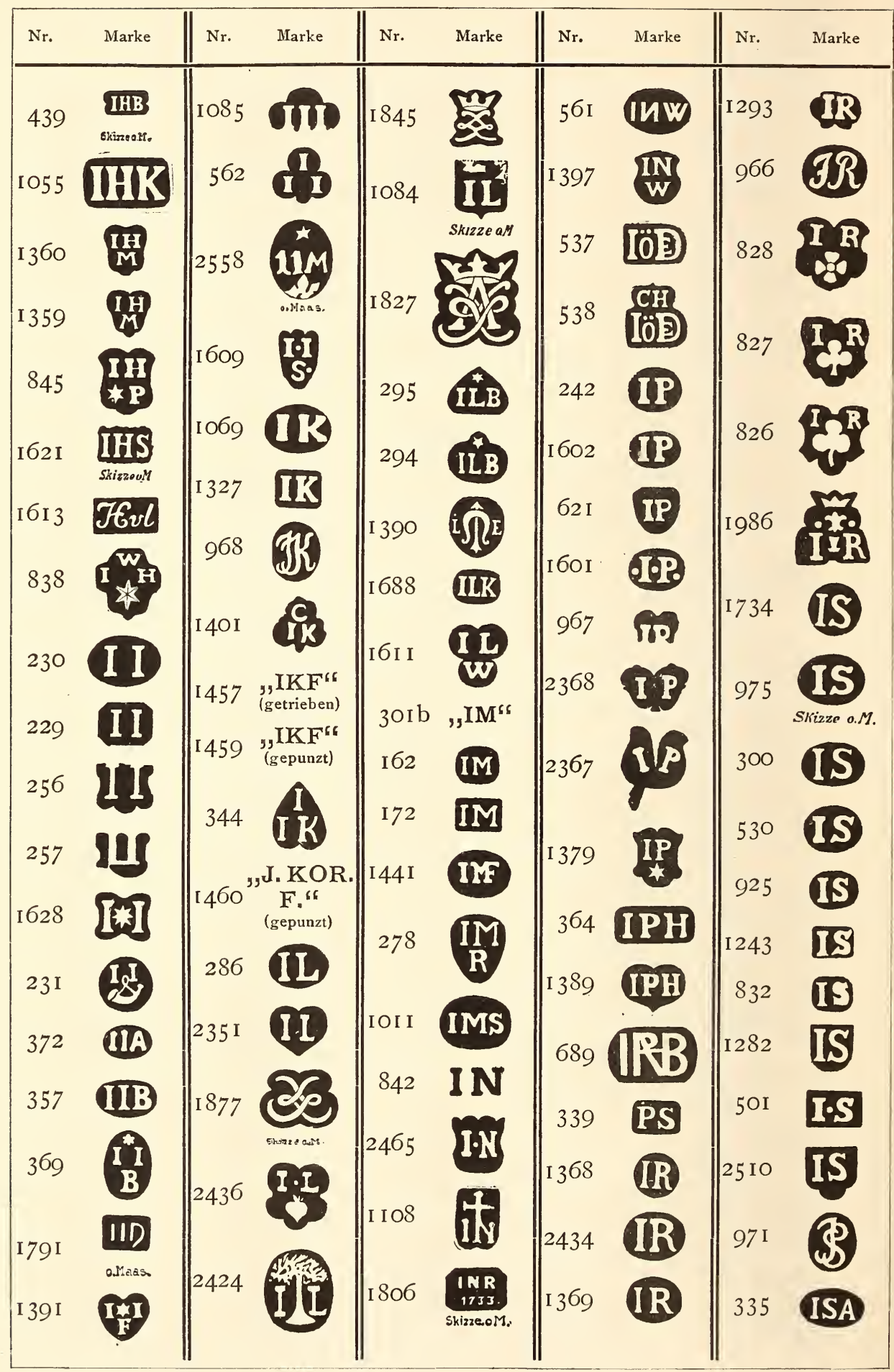




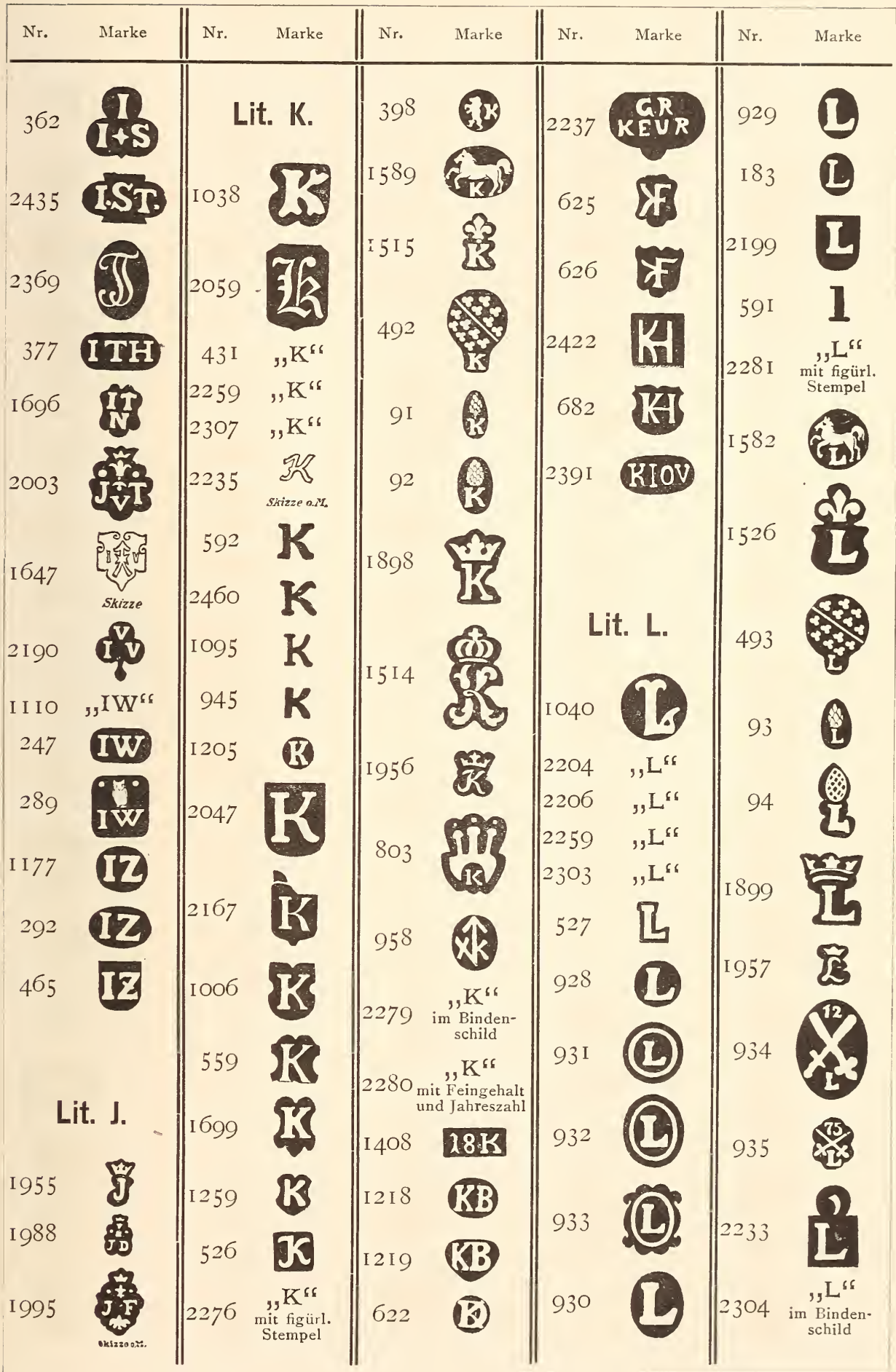




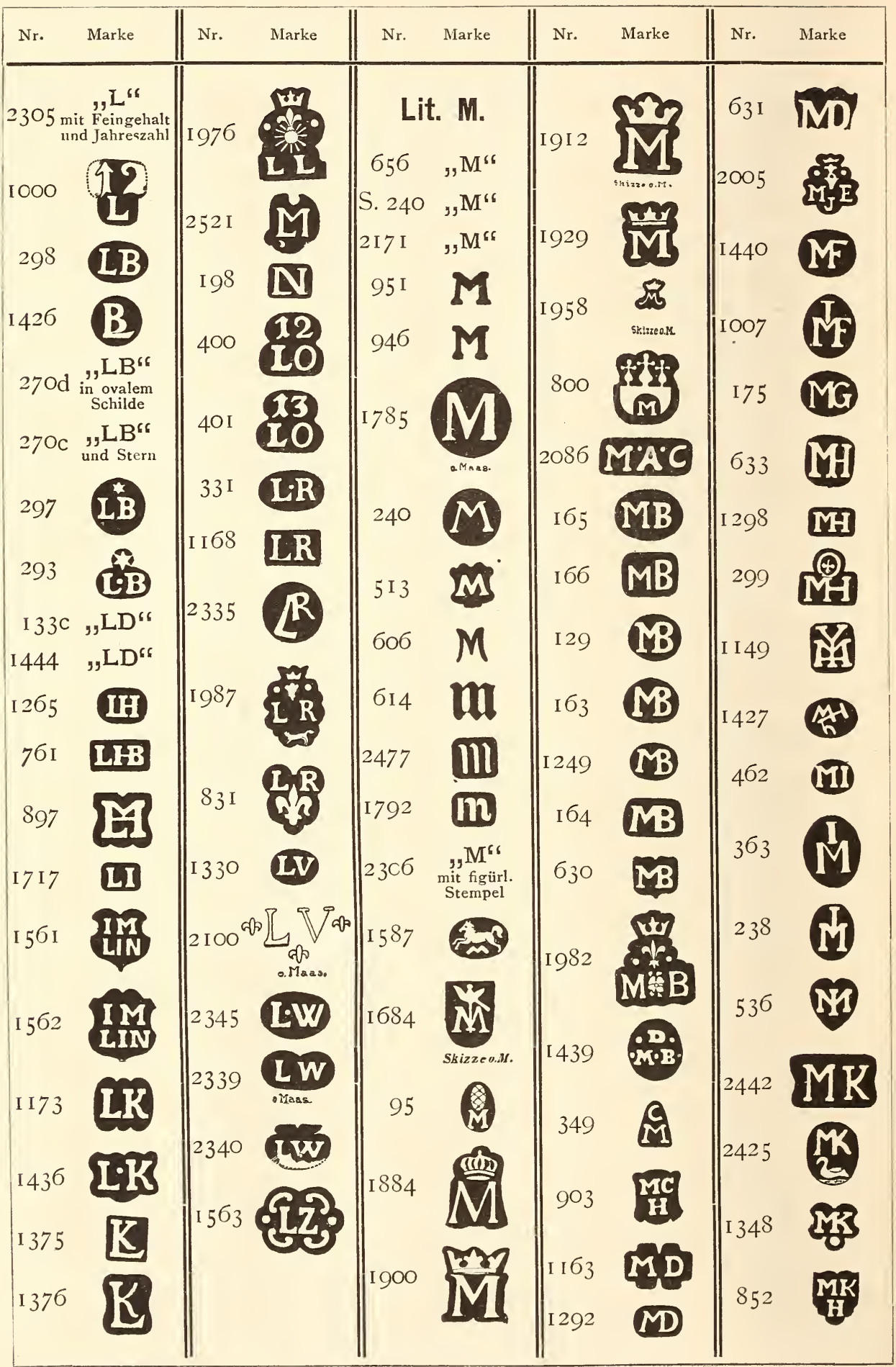




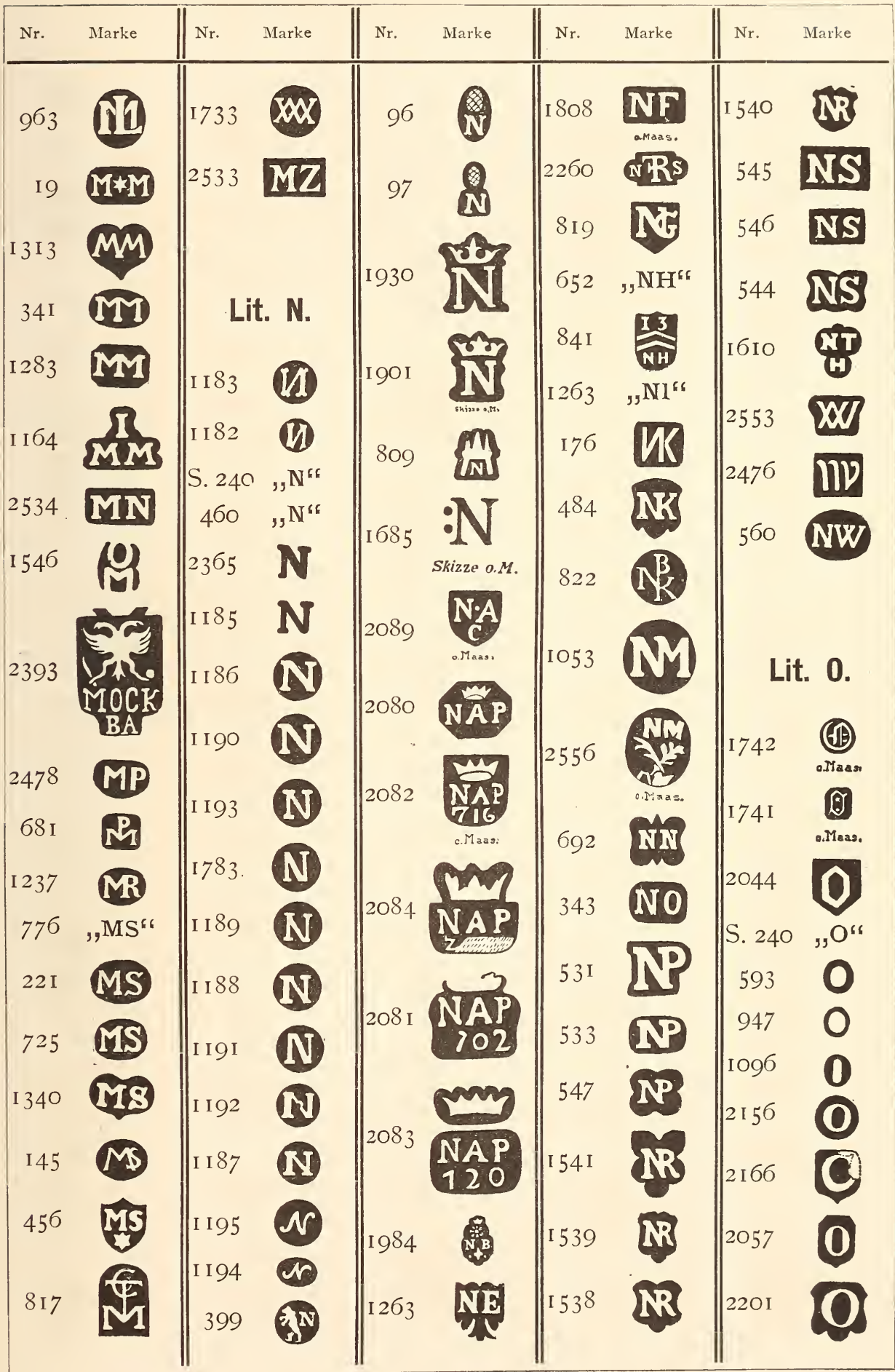




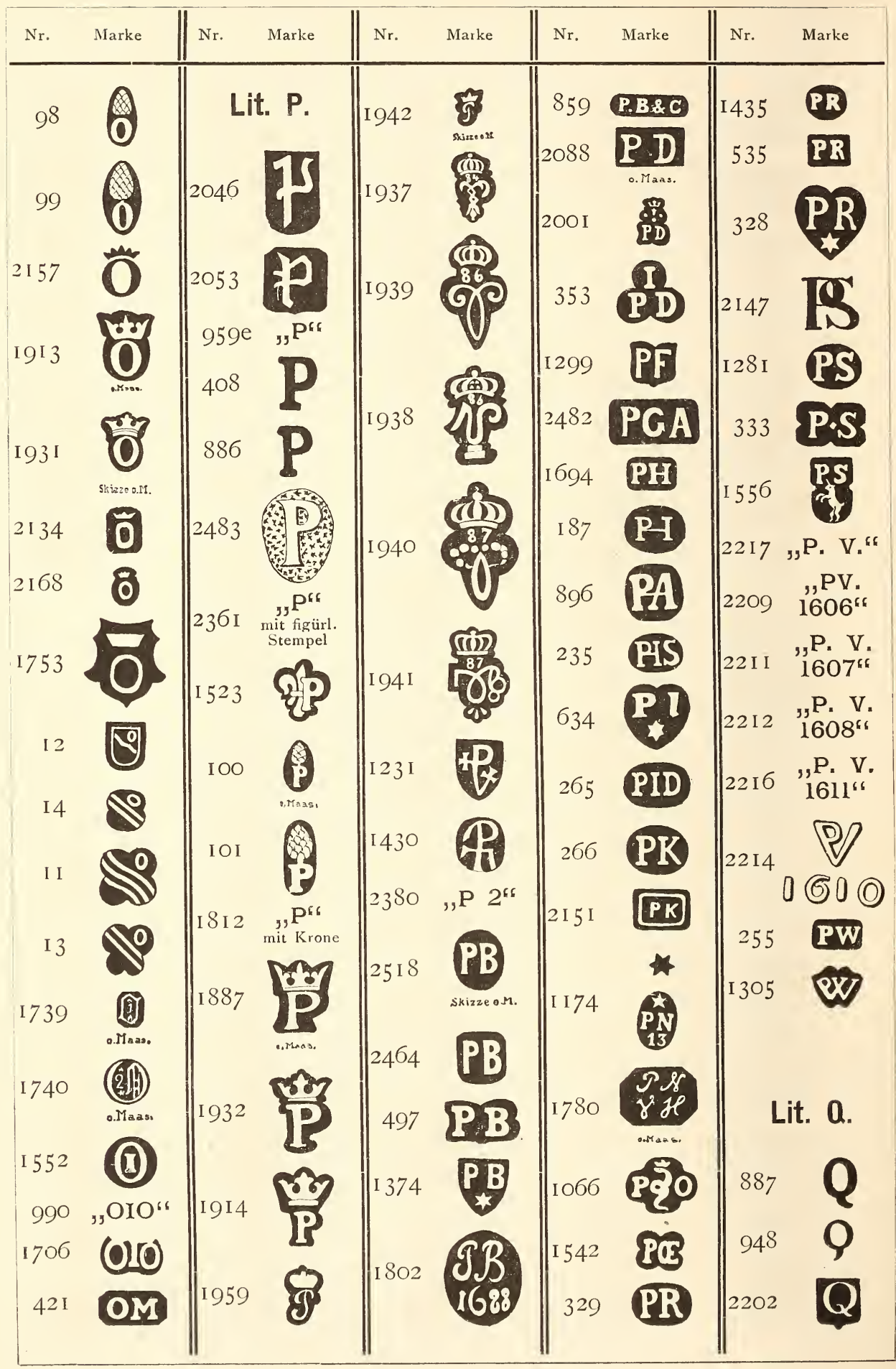




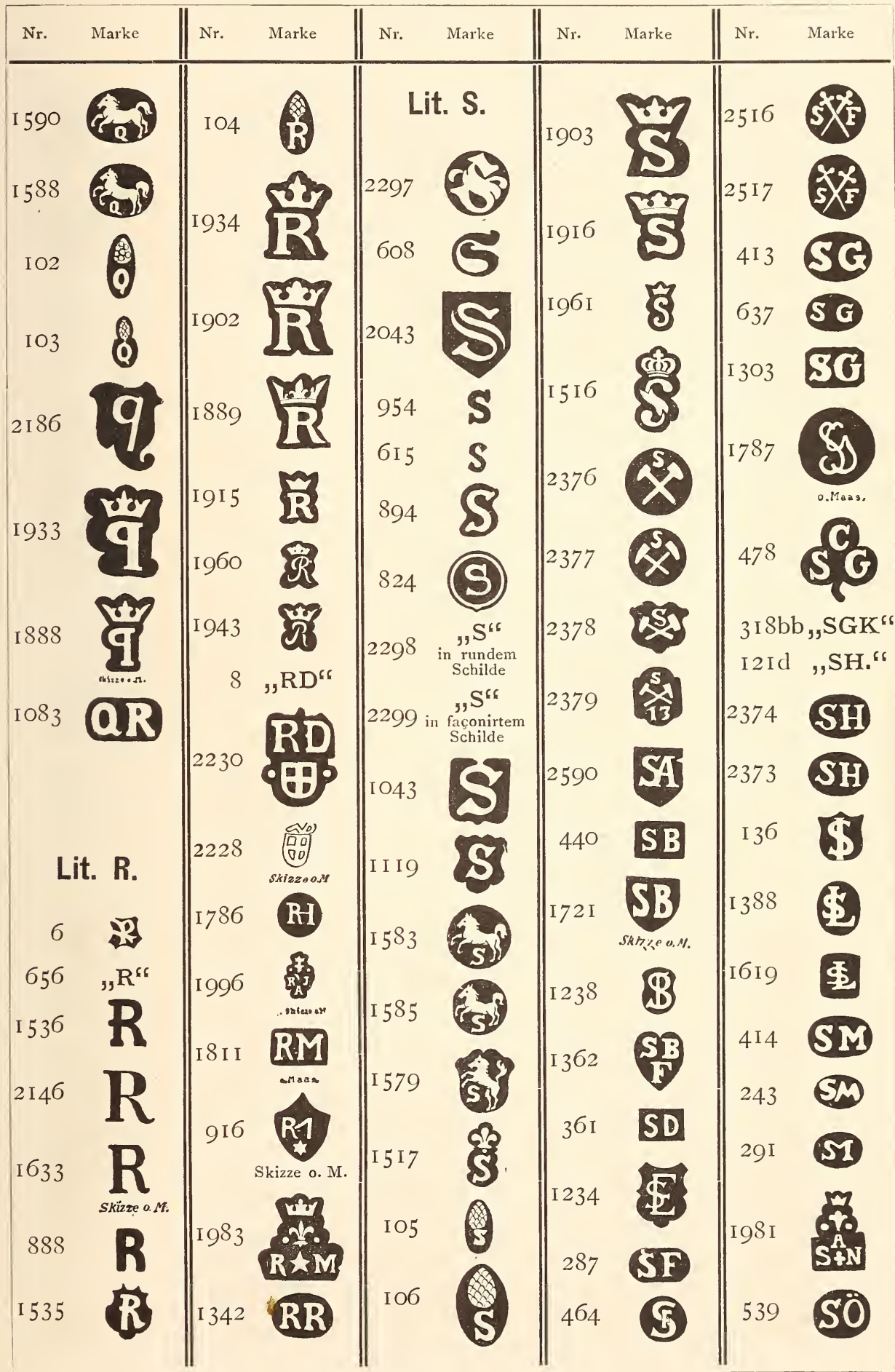




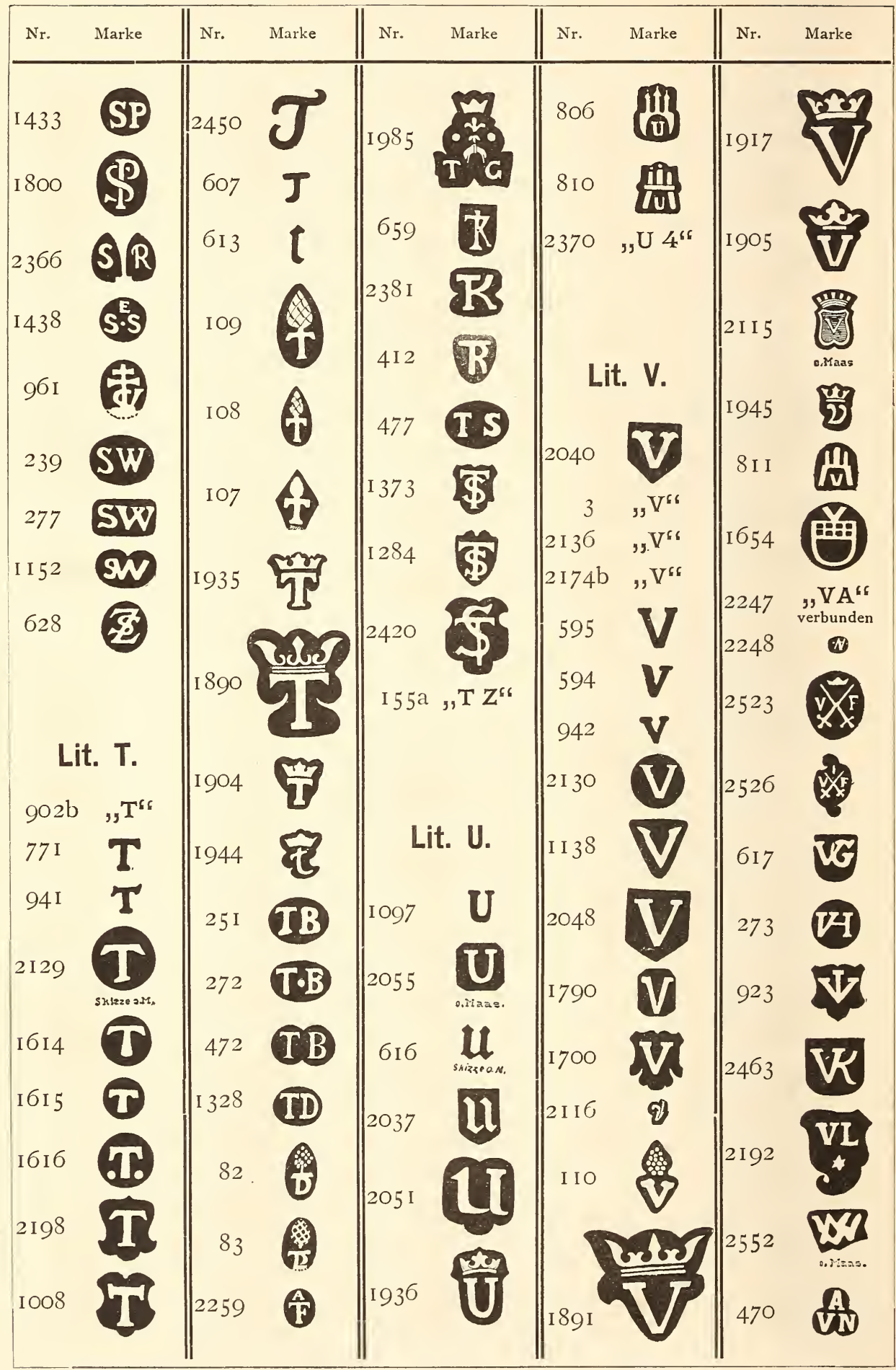




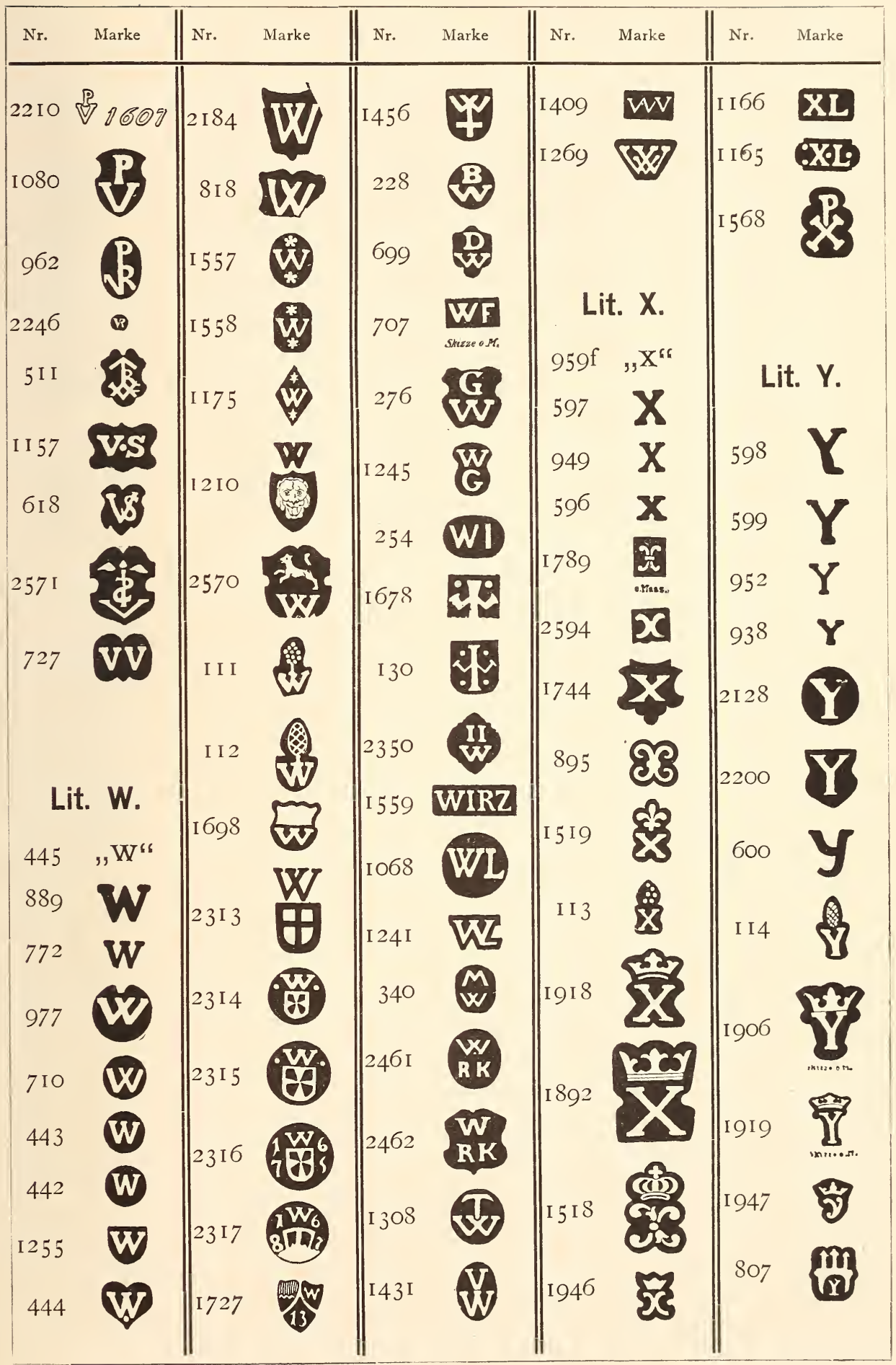




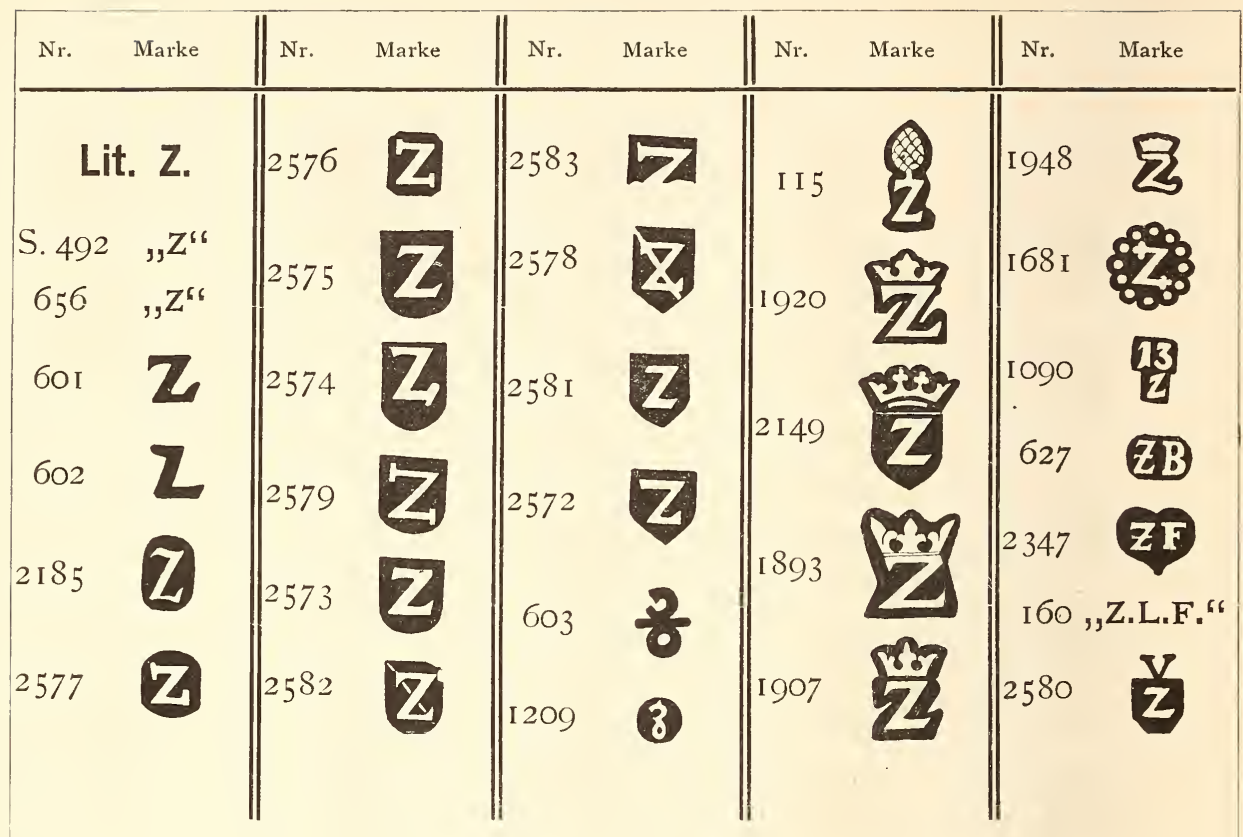


b) Verzeichniss der figürlichen Marken.

Die Marken sind in folgende Gruppen zusammengefasst: Sonne, Mond, Sterne. - Mensch. - Löwe. - Diverse Säugethiere. - Adler, Greif, Diverse Vögel. - Niedere Thiere, Wasser. - Vegetabilien. - Krone, Scepter, Waffen. - Geräthe. - Architektur. - Kreuze. - Hausmarken. - Heroldstücke, Punkte.

\begin{tabular}{ll||lll|llll||ll} 
Nr. Marke & Nr. & Marke & Nr. & Marke & Nr. & Marke & Nr. & Marke \\
\hline
\end{tabular}

Sonne, Mond, Sterne.

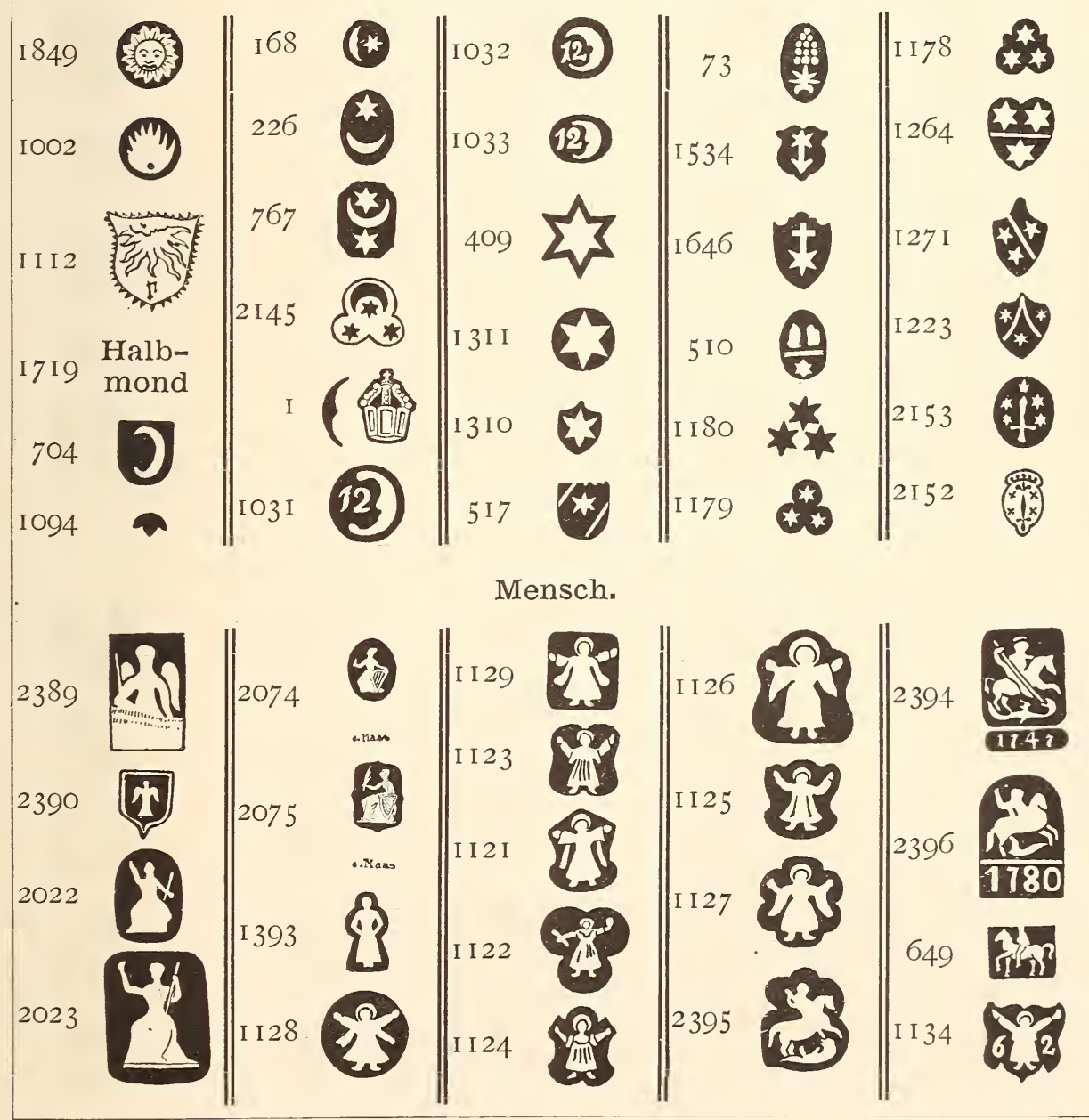




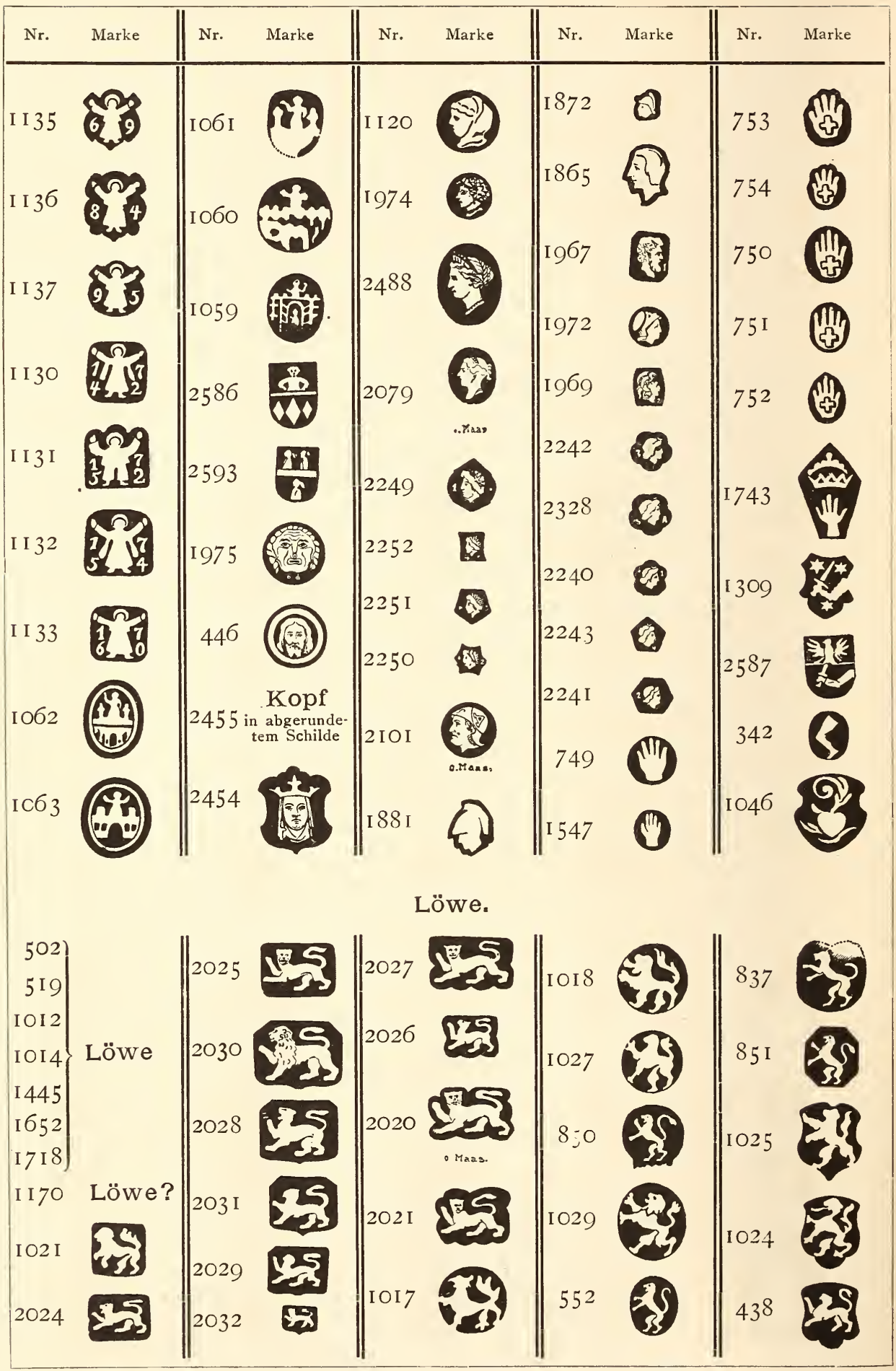


1. Markenregister - b) Verzeichniss der figürlichen Marken (Löwe - Säugethiere) 547

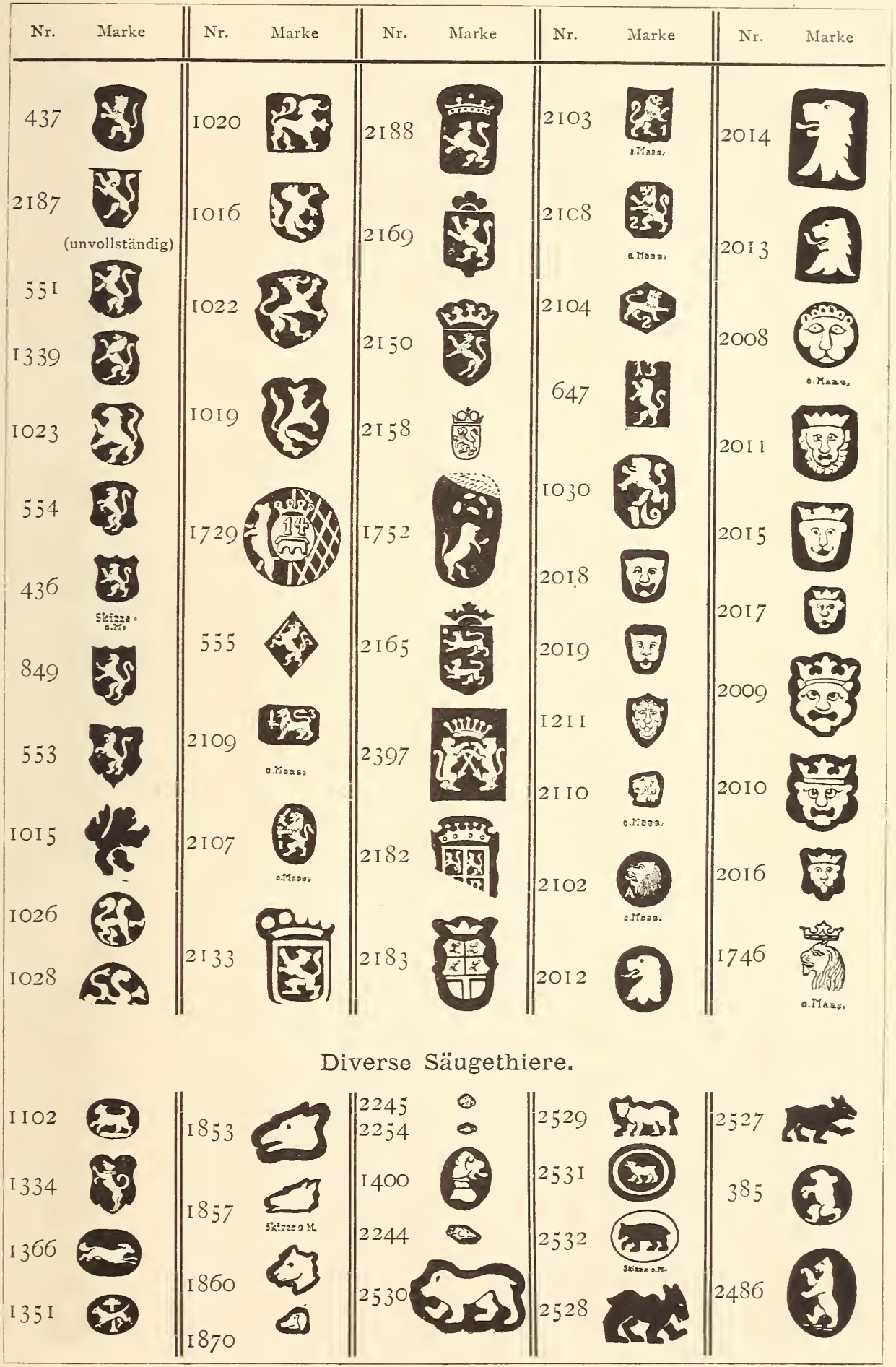


548 I. Markenregister - b) Verzeichniss der figürlichen Marken (Div. Säugeth. - Adler)

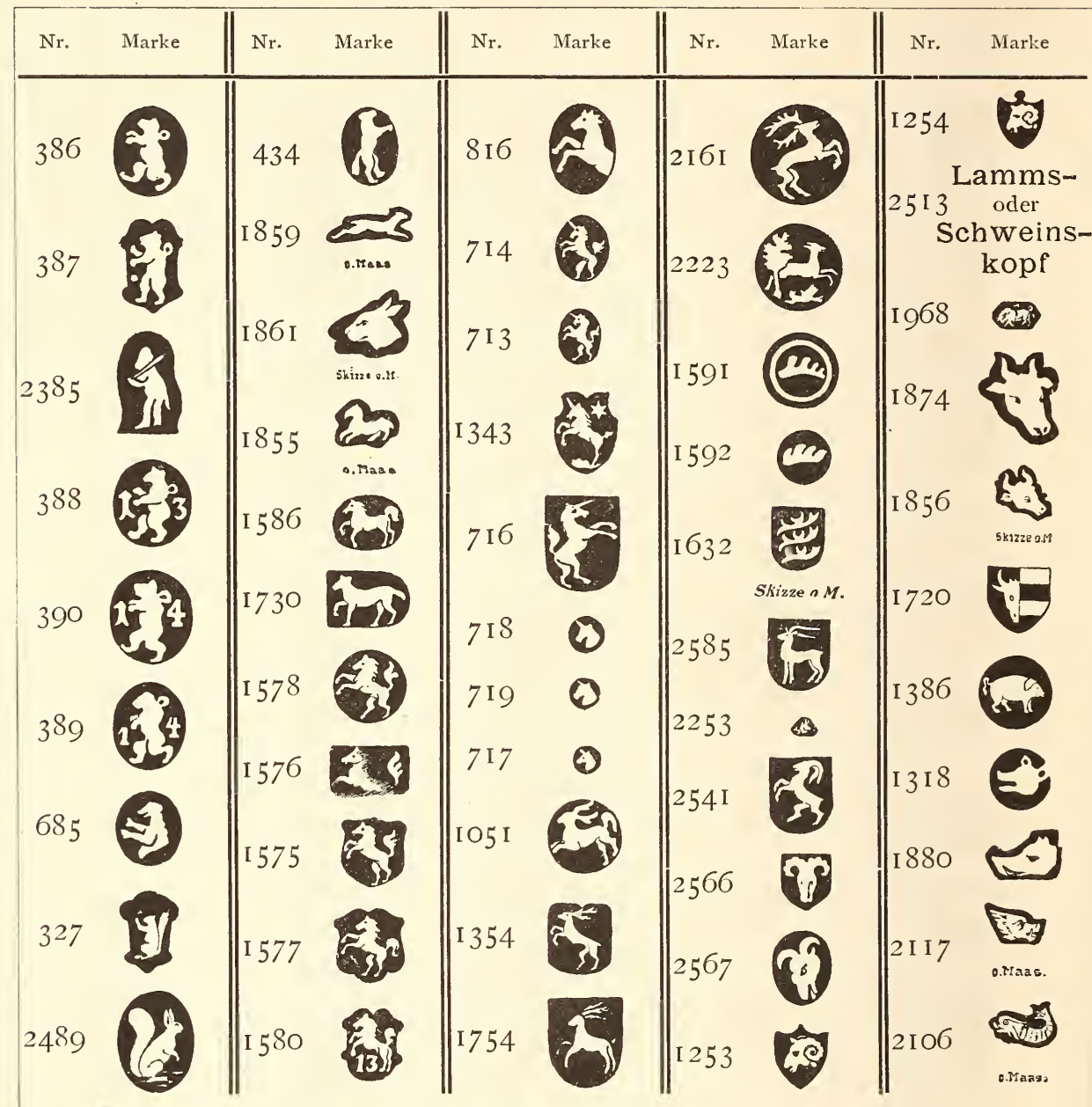

Adler, Greif, Diverse Vögel.

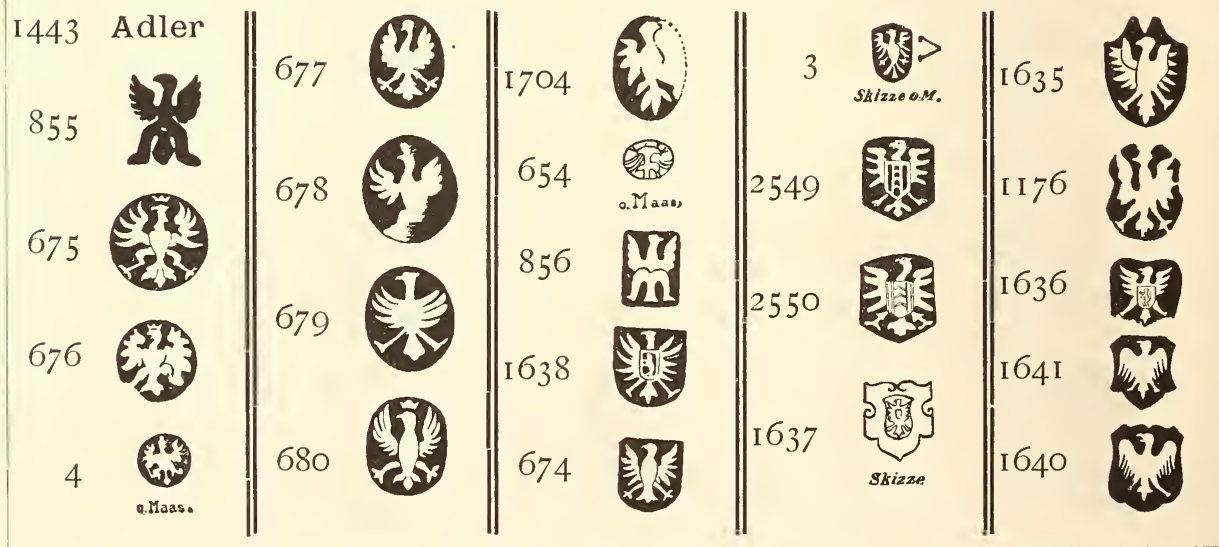


I. Markenregister - b) Verzeichniss der figürlichen Marken (Adler - Diverse Vögel) 549

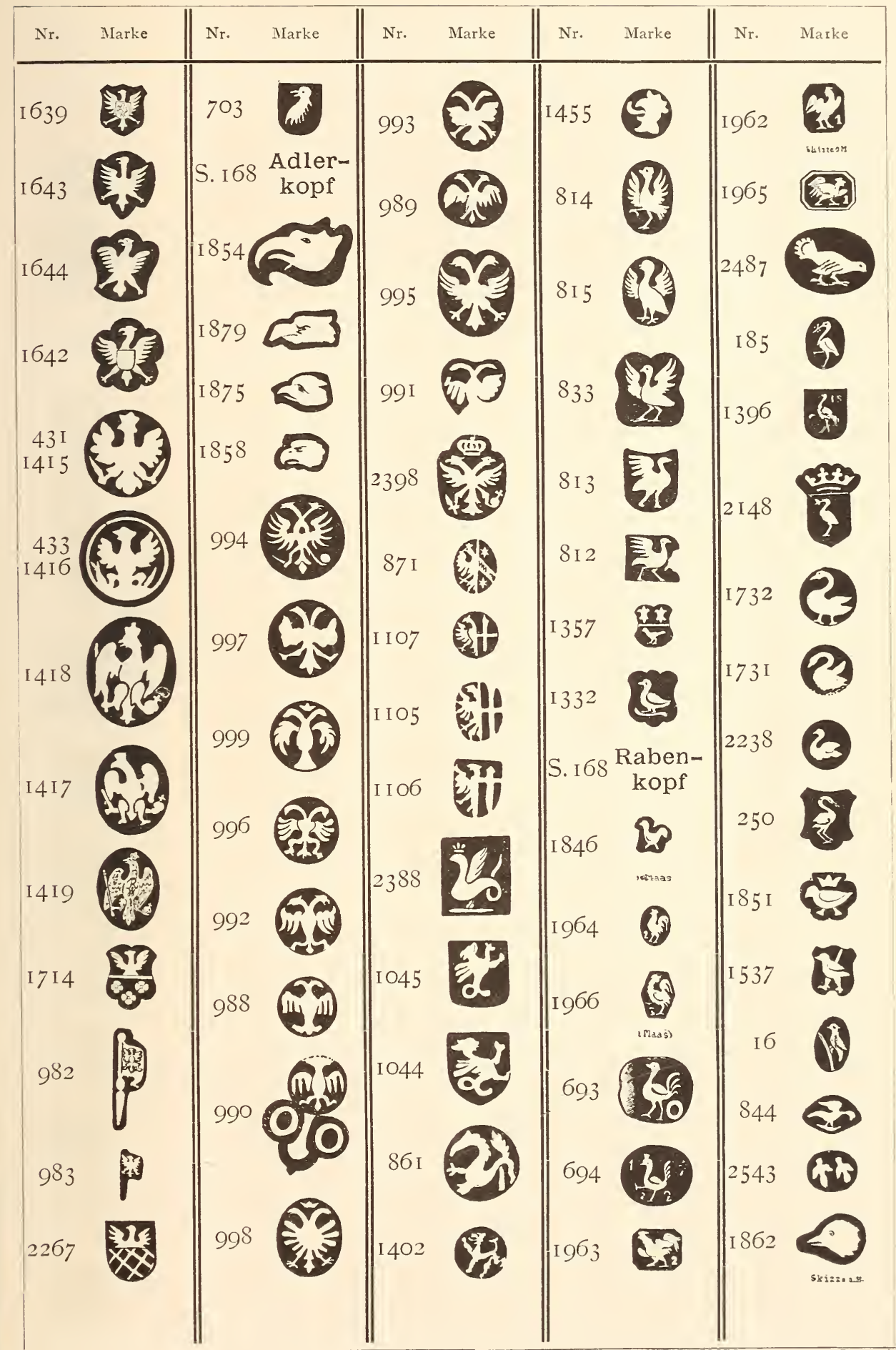


550 I. Markenregister - b) Verzeichniss der figürlichen Marken (Nied. Thiere - Pflanzen)

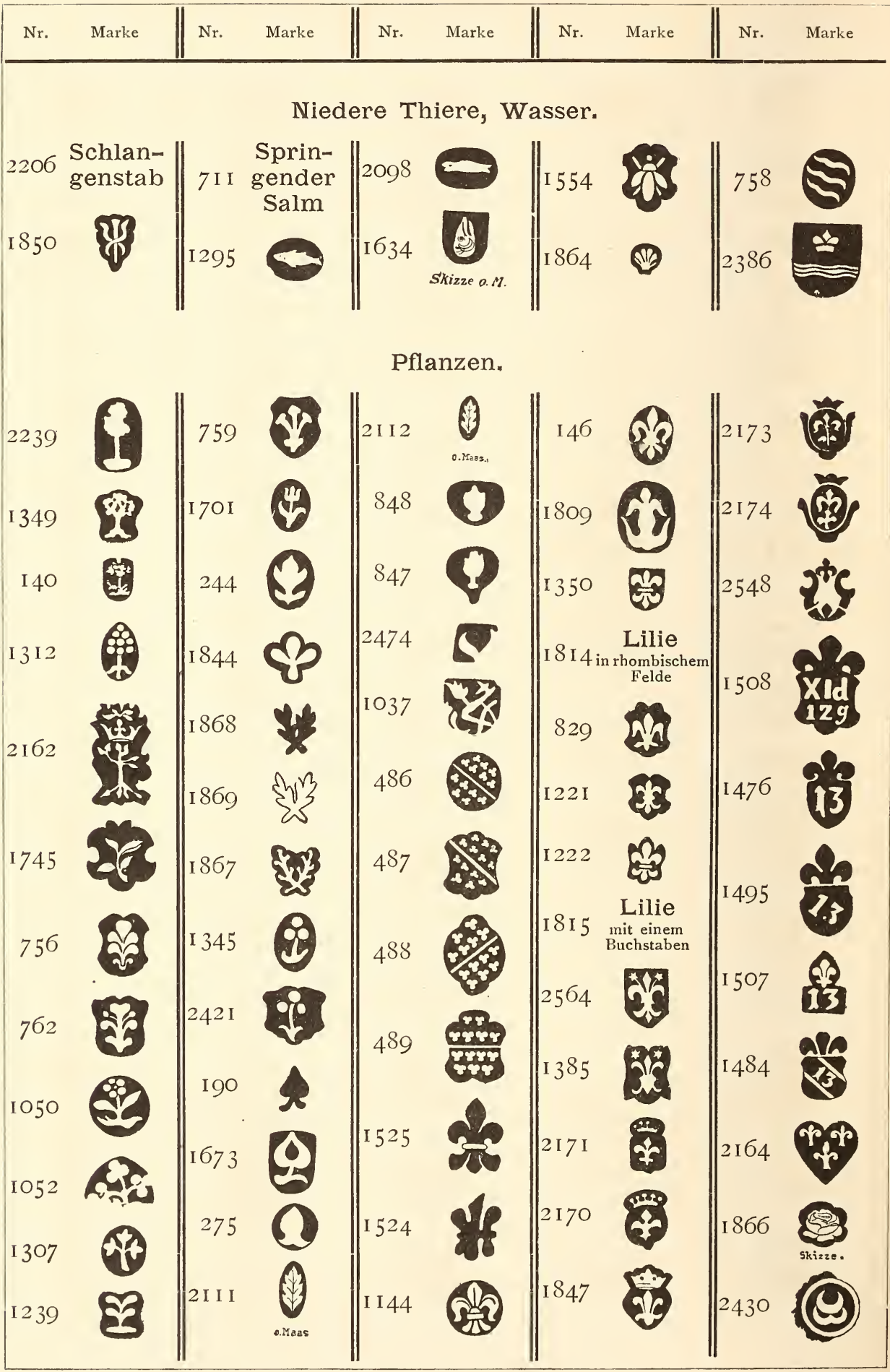


1. Markenregister - b) Verzeichniss der figürlichen Marken (Pflanzen - Scepter) 55 I

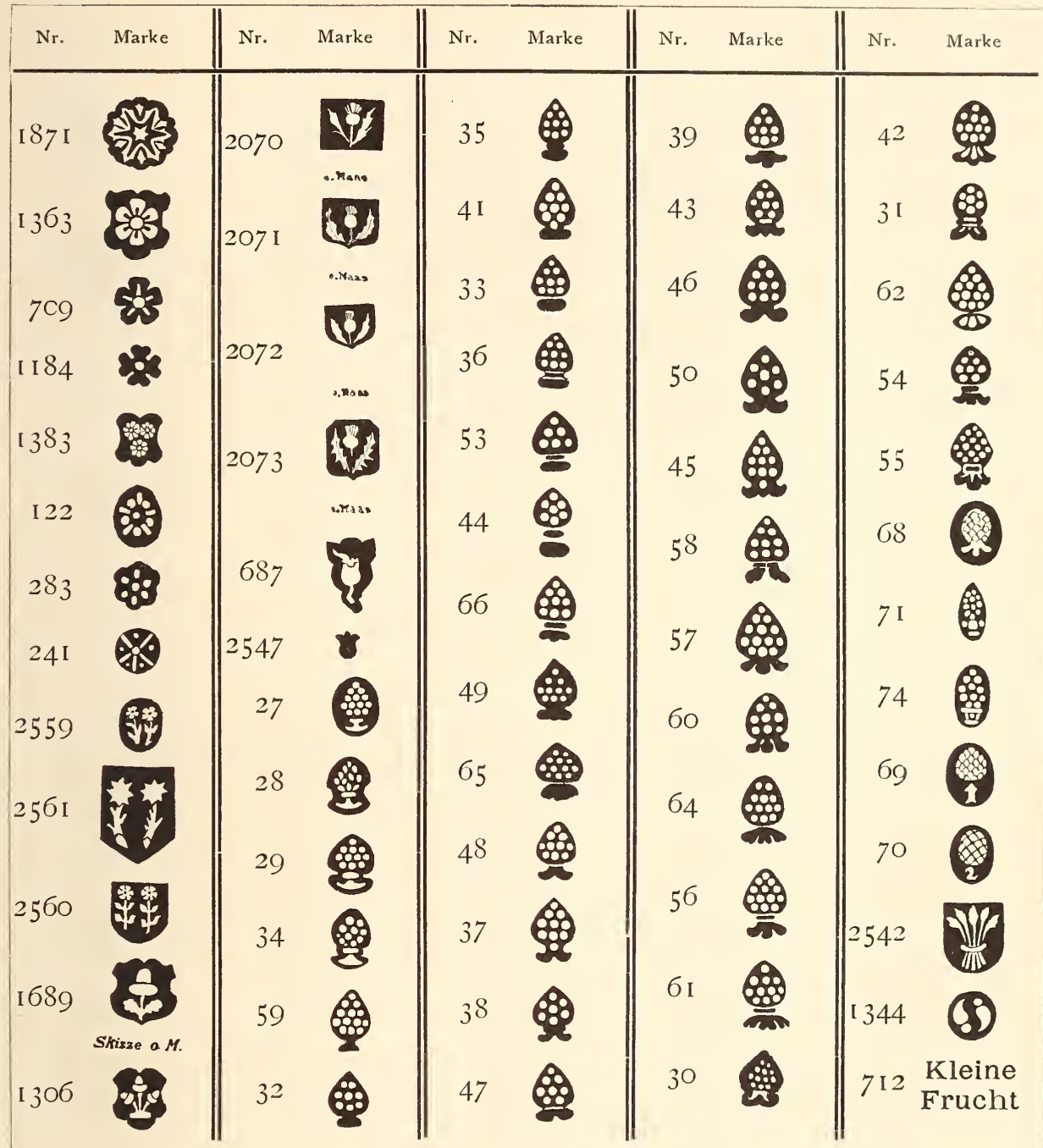

Krone (vergl. Kreuz), Scepter, Waffen.

I 84 I


552 I. Markenregister - b) Verzeichniss der figürlichen Marken (Scepter — Geräthe)

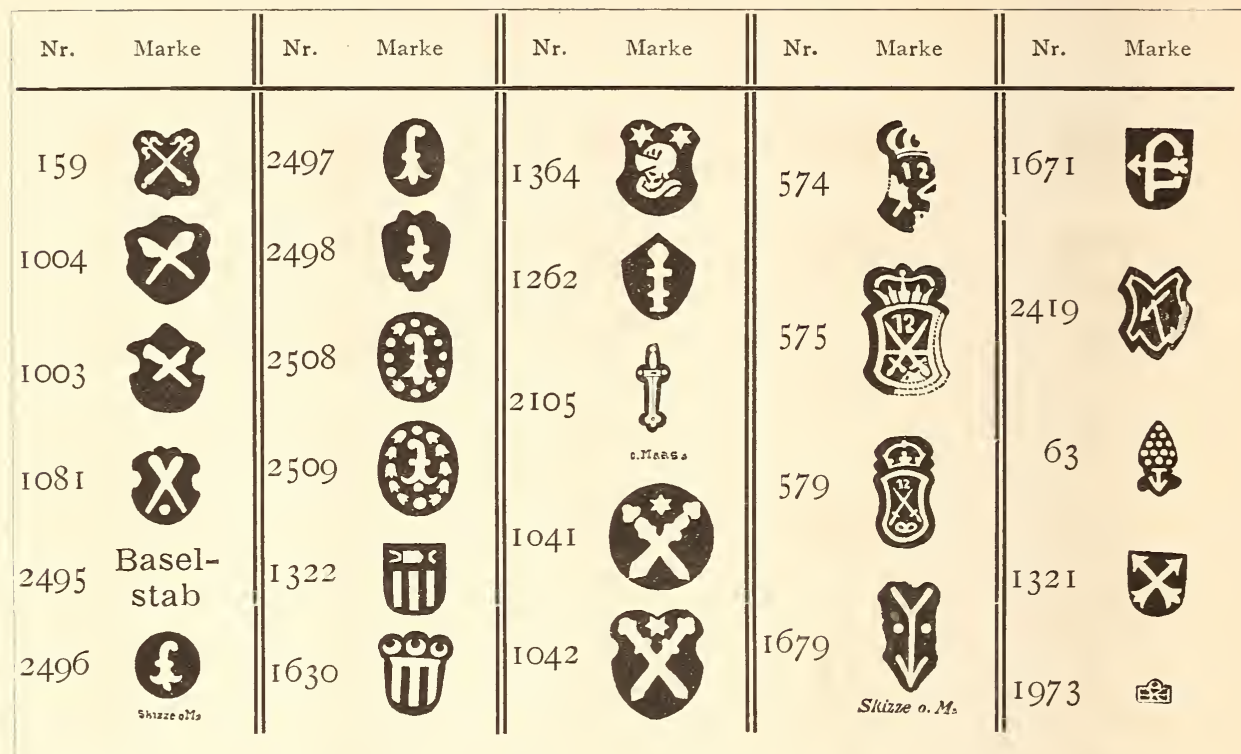

Geräthe.

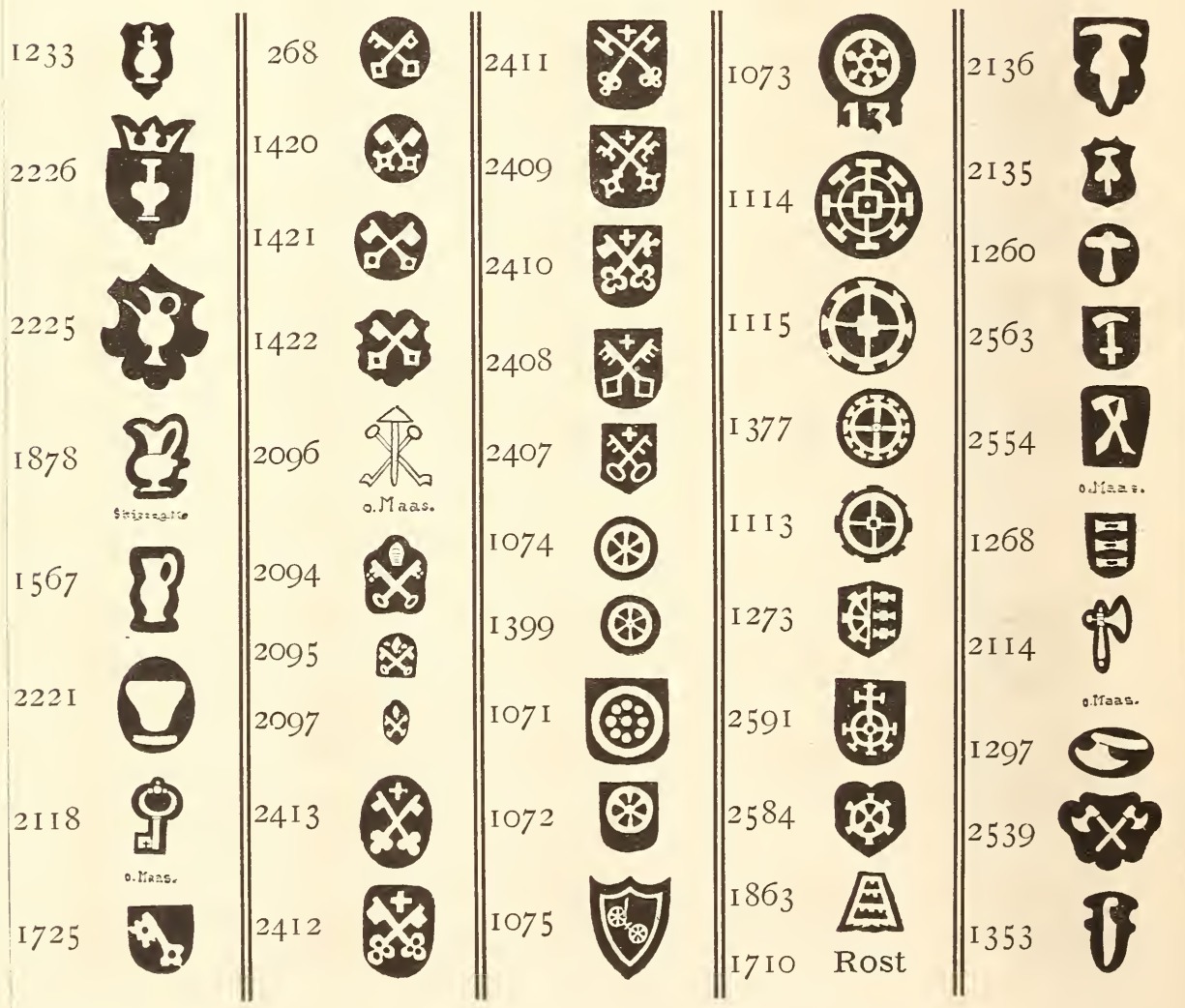


I. Markenregister - b) Verzeichniss der figürlichen Marken (Geräthe - Architektur) 553

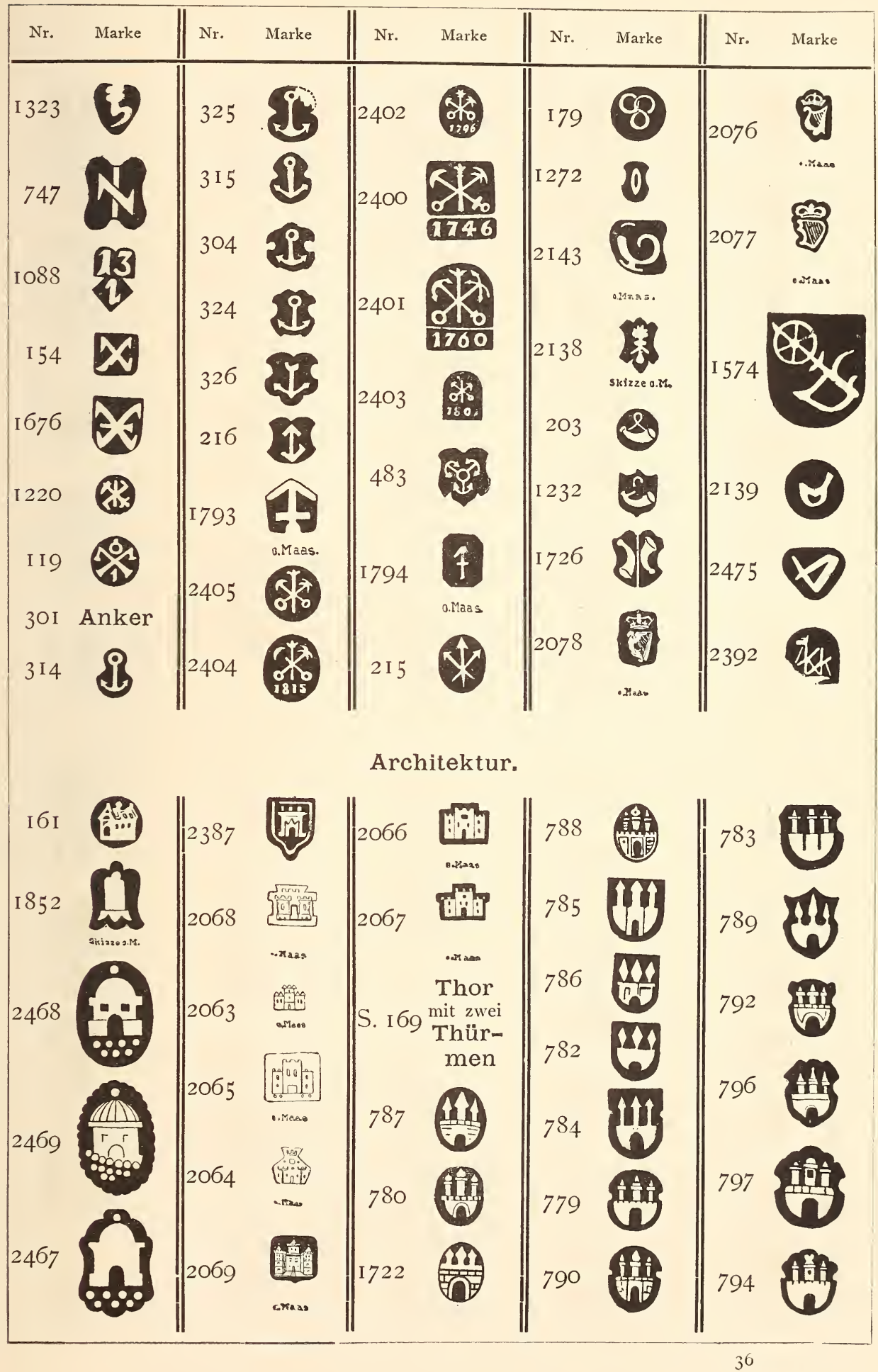


554 I. Markenregister - b) Verzeichniss der figürlichen Marken (Architektur - Kreuze)

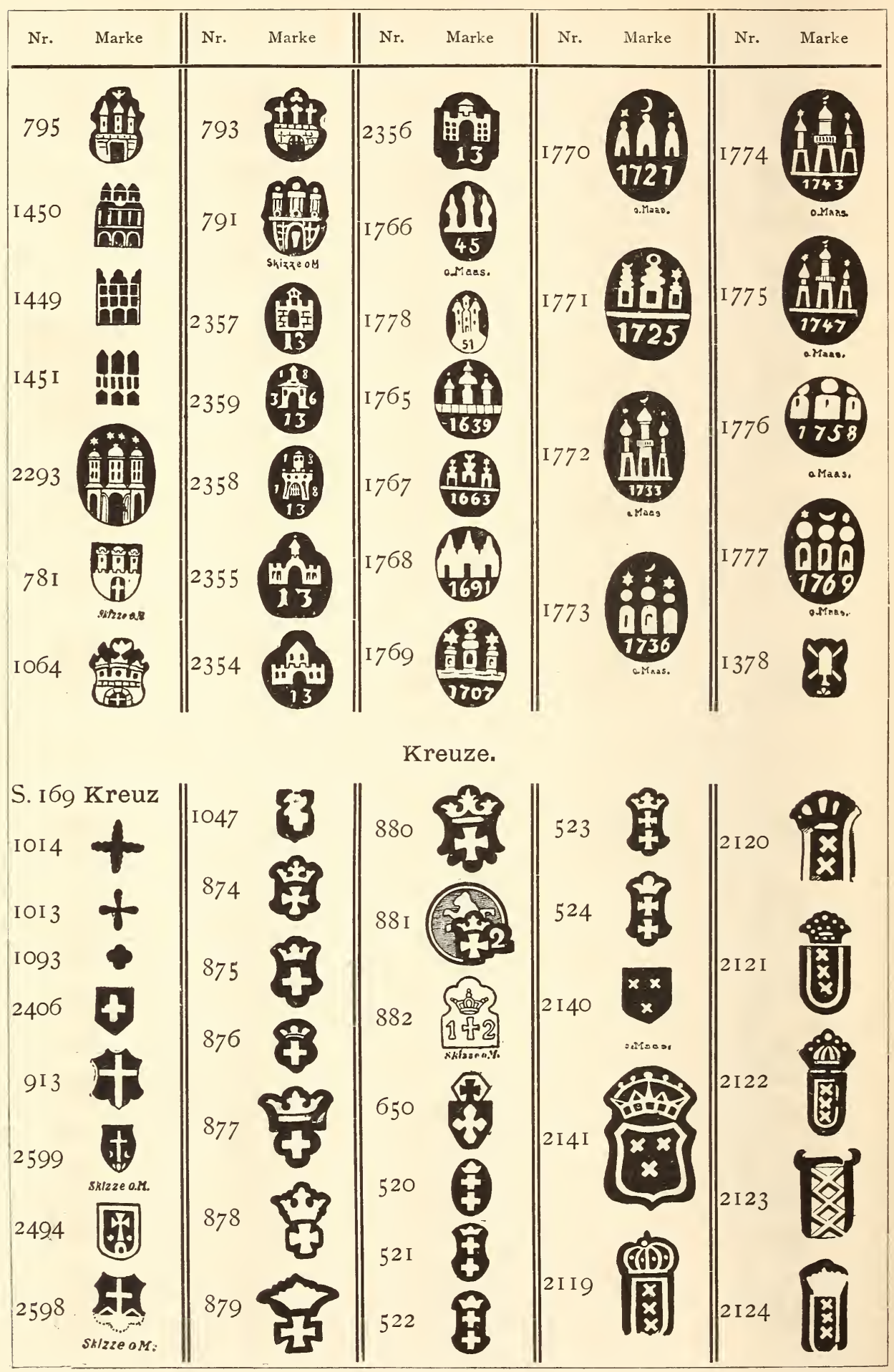


I. Markenregister - b) Verzeichniss der figürlichen Marken (Hausmarken - Heroldstiicke) 555

Nr. Marke || Nr. Marke $\|$ Nr. Marke $\|$ Nr. $\quad$ Marke $\|$ Nr. $\quad$ Marke

Hausmarken.

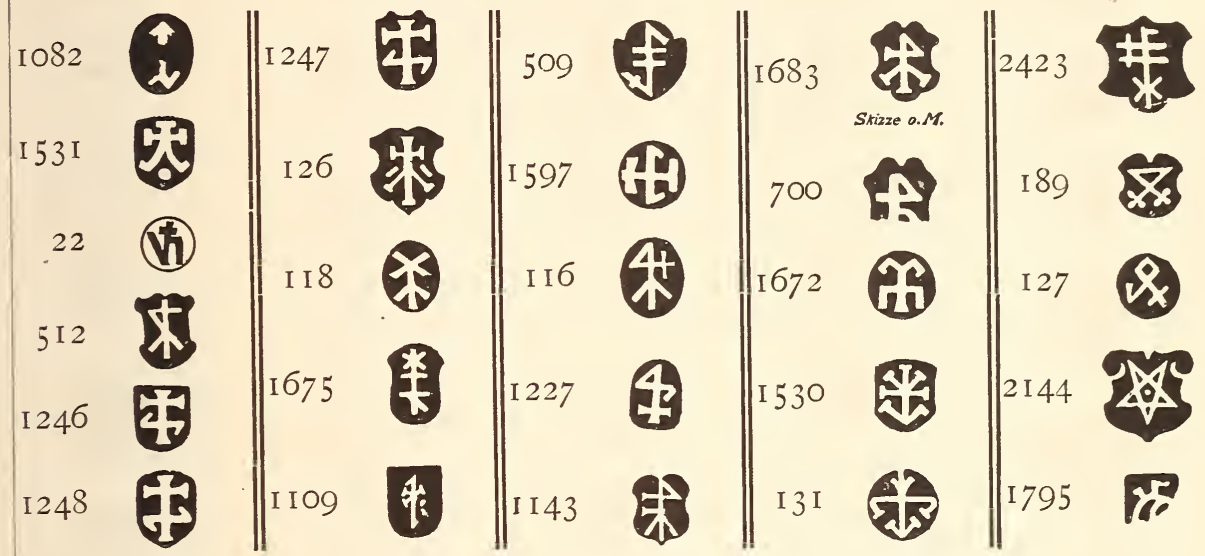

Heroldstücke, Punkte.

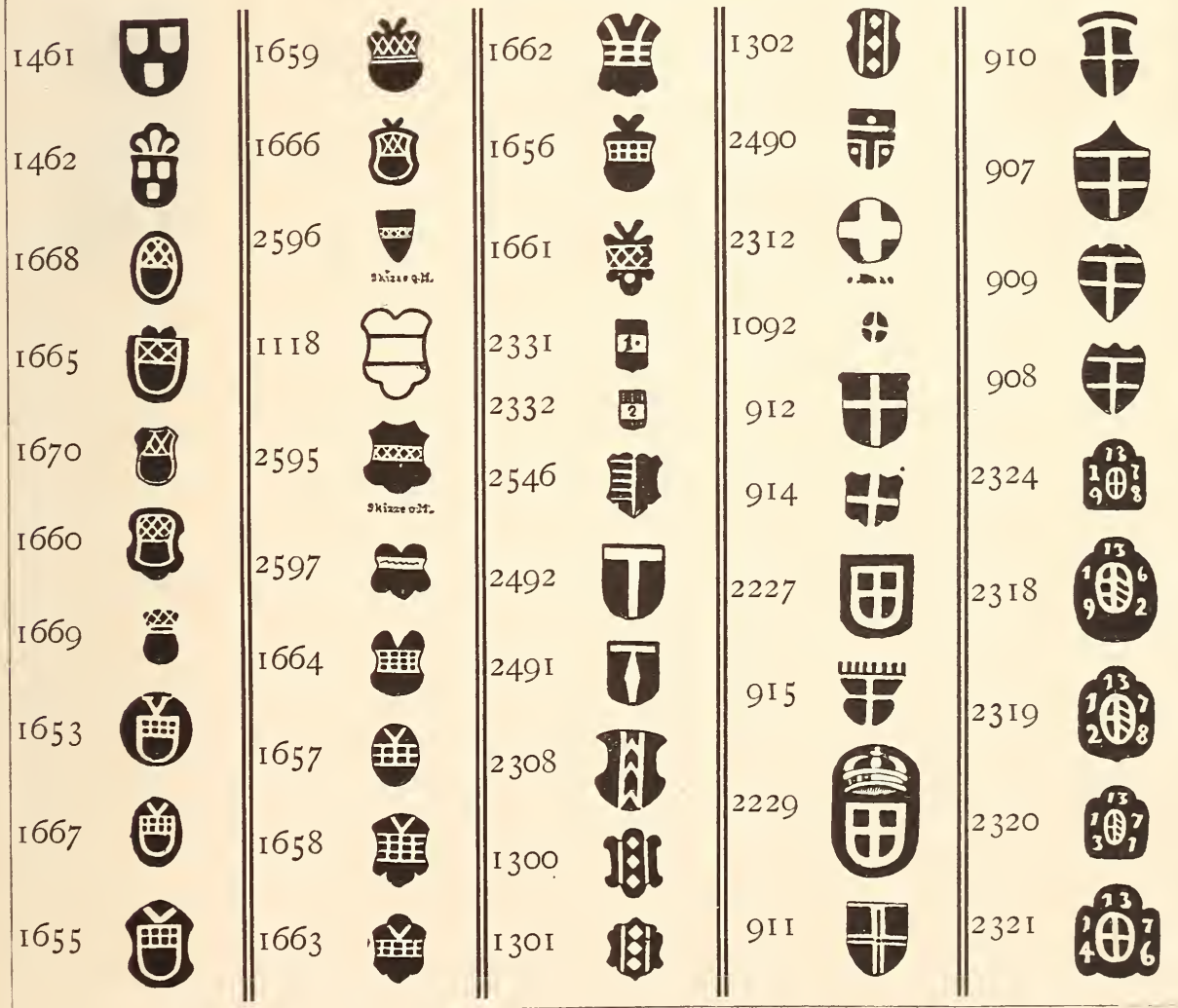


556 I. Markenregister - b) Verzeichniss der figürlichen Marken (Heroldstücke — Punkte)

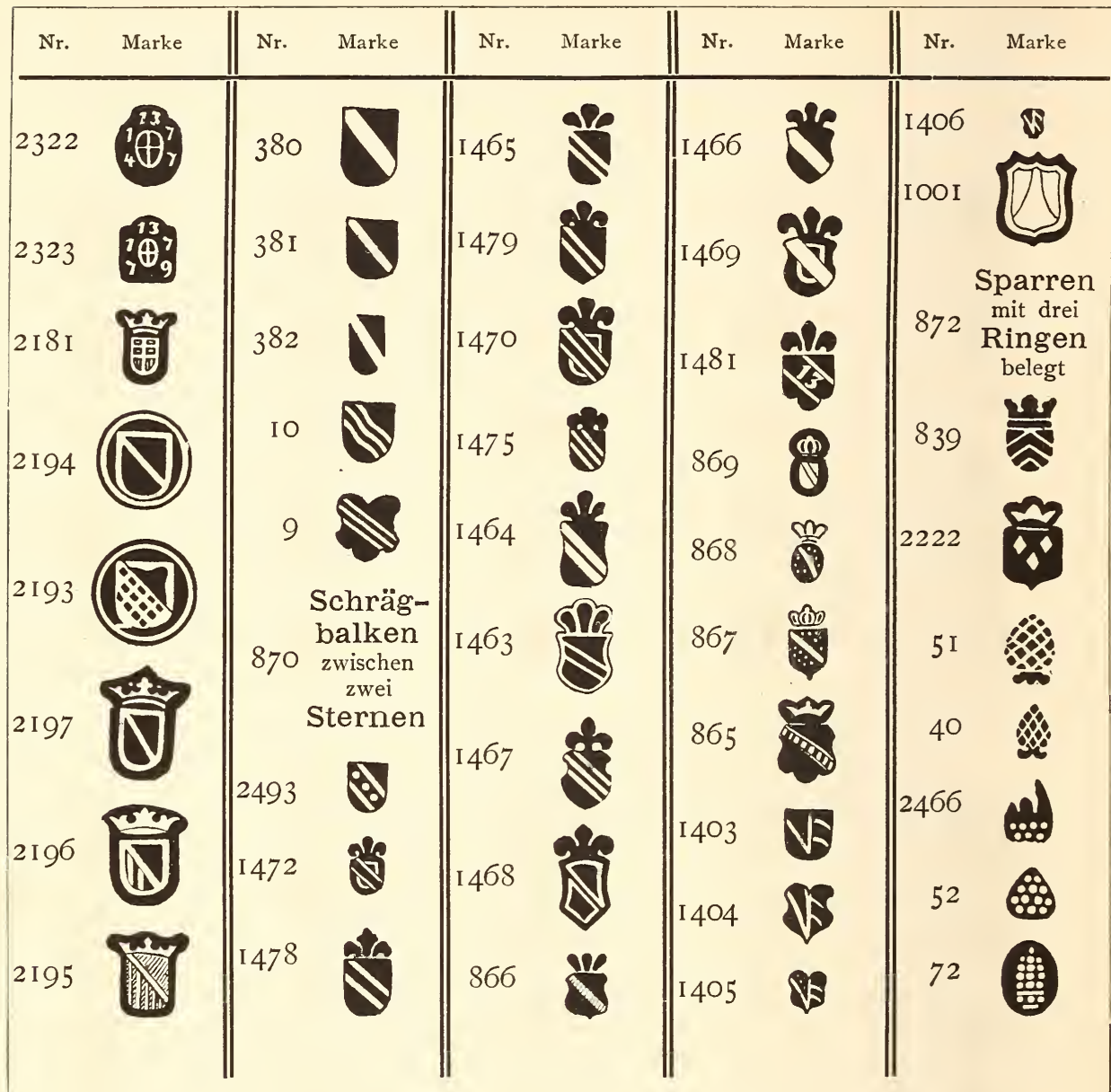


c) Zahlen.

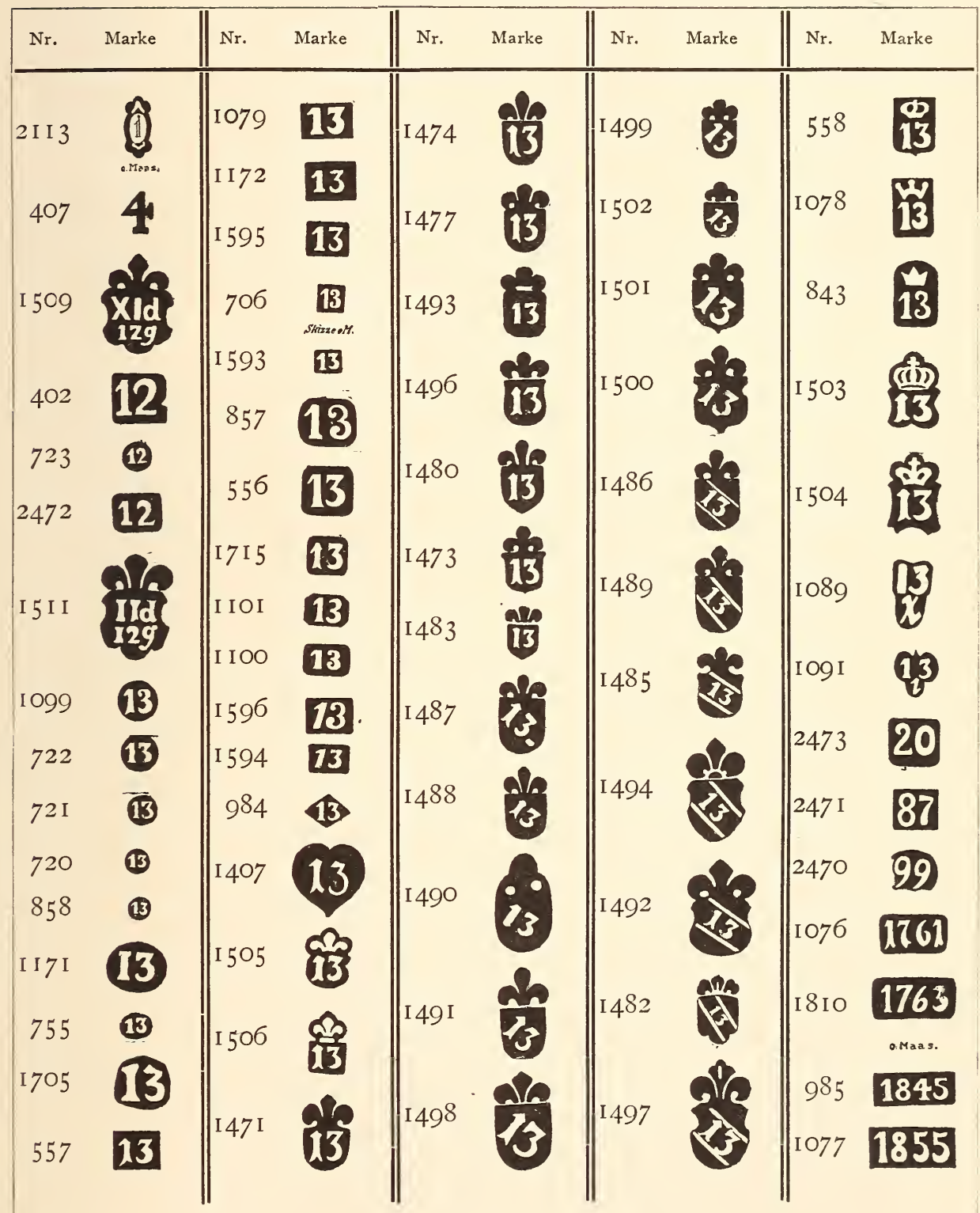




\section{Verzeichniss der Goldschmiedenamen.}

Die hier folgenden Meister sind nach dem Zunamen alphabetisch geordnet. Selbst dann, wenn ein Meister allgemein bei seinem Taufnamen genannt worden $\mathrm{zu}$ sein scheint, habe ich mich bemüht, ihn der Gleichförmigkeit halber mit seinem zweiten Namen einzureihen.

\begin{tabular}{|c|c|c|c|}
\hline $\mathrm{Nr}$. & Familien- und Vornamen & $\mathrm{Nr}$. & Familien- und Vornamen. \\
\hline 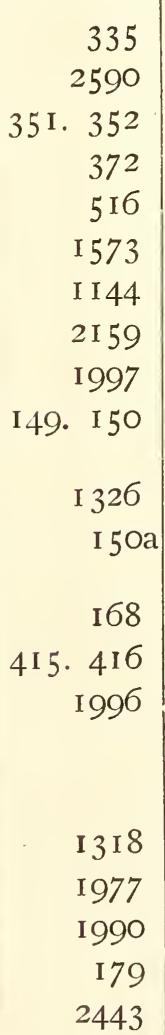 & $\begin{array}{l}\text { Aberell, Joh. Siegmund } \\
\text { Aberli, Steffan } \\
\text { Adam, Elias } \\
\text { Adam, Joh. Jacob } \\
\text { Adelkirchen, J. J. } \\
\text { Alberti } \\
\text { Albertin, Heinr. } \\
\text { Alckema, Jacop } \\
\text { Allain, Henri } \\
\text { Altenstetter, David, vgl. auch } \\
\text { Nr. Ir6c } \\
\text { Andreas, Hanss } \\
\text { Angermaier, Christof, Elfen- } \\
\text { beinarbeiter } \\
\text { Anthoni, Hans Andreas } \\
\text { Ast, J. } \\
\text { Auguste, Robert - Jacques } \\
\text { (Joseph) } \\
\text { Bair, Paulus } \\
\text { Ballin, Claude, d. Jüng. } \\
\text { Balzac, Jean François } \\
\text { Bantzer, Christof } \\
\text { Barrowsky, Joh. Christoph }\end{array}$ & $\begin{array}{r}\mathrm{I} 336 \\
500 \\
\mathrm{I} 2 \mathrm{I} 8 \\
375 \\
28 \mathrm{I} \\
\mathrm{I} 607 \\
\mathrm{I} 530 \\
\mathrm{I} 6 \mathrm{I} \\
375 \\
\mathrm{I} 24 \\
\mathrm{I} \mathrm{I} 83 . \mathrm{I} 249 \\
\mathrm{I} 77 \\
\mathrm{I} 63 \\
\mathrm{I} 530 \\
500 \\
490 \\
2427 \\
\mathrm{I} 762 \\
\mathrm{I} 76 \mathrm{I} \\
\mathrm{I} 280 \\
2429 \\
4 \mathrm{I} 8 \\
76 \mathrm{I} \\
2372\end{array}$ & $\begin{array}{l}\text { Barst, Georg } \\
\text { Baucair, J. } \\
\text { Bauch, Kaspar } \\
\text { Bauer, Georg Ignatius } \\
\text { Bauer, Gottlieb } \\
\text { Bauer, Joh. Dan. } \\
\text { Bauer, Linhard } \\
\text { Baumann, Peter } \\
\text { Baur } \\
\text { Bayer } \\
\text { Bayer, Melchior } \\
\text { Bayr } \\
\text { Bayr, Melchior } \\
\text { Bawer, Linhard } \\
\text { Beauclair, J. } \\
\text { Beck } \\
\text { Becker, Andreas } \\
\text { Beghin, François Joseph } \\
\text { Beghin, Henri } \\
\text { Behaim, Ieronymus } \\
\text { Behrend, Johann } \\
\text { Beltz } \\
\text { Beltz, L. H. } \\
\text { Benedikt, Hans Friedrich }\end{array}$ \\
\hline
\end{tabular}




\begin{tabular}{|c|c|c|c|}
\hline $\mathrm{Nr}$. & Familien- und Vornamen & Nr. & Familien- und Vornamen \\
\hline $\begin{array}{r}\mathrm{I} 38 \mathrm{I} \\
669 \\
\mathrm{I} 529 \\
\mathrm{I} 982 \\
28 \mathrm{I} \\
\mathrm{I} 297 \\
28 \mathrm{I} \\
\mathrm{I} 984 \\
379 \\
\mathrm{I} 763 \\
\mathrm{I} 760 \\
439 \\
\mathrm{I} 268 \\
\mathrm{I} 3 \mathrm{I} 5 \\
\mathrm{I} 273 \\
\mathrm{I} 273 \\
472 \\
2007 \\
702 \\
\mathrm{I} 395 \\
25 \mathrm{I} 2 \\
269 \\
269.270 \\
346 \\
227 \\
369 \\
293.294\end{array}$ & $\begin{array}{l}\text { Berckmann, Joh. } \\
\text { Berger, Georg (Jörg) } \\
\text { Berner, Abraham } \\
\text { Berthe, Martin } \\
\text { Berthold, Georg } \\
\text { Bertolt, Hannss } \\
\text { Besmann, Gabriel } \\
\text { Besnier, Nicolas } \\
\text { Betkober, Carl Samuel } \\
\text { Bettignies } \\
\text { de Bettignies, A. C. J. } \\
\text { Beust, Heinr. } \\
\text { Beutmüller, Caspar, d. Aelt. } \\
\text { Beutmüller, Caspar, d. Jüng. } \\
\text { Beutmüller, Georg } \\
\text { Beutmüller, H. } \\
\text { Beyl, Thomas } \\
\text { Biennais } \\
\text { Bier, Christian } \\
\text { Bierfreund, Georg Nicolaus } \\
\text { Bildtschnitzer, Friedrich } \\
\text { Biller, Albrecht, d. Aelt. } \\
\text { Biller, Albrecht, d. J., vgl. } \\
\text { auch Nr. 297e u. 298b u. c } \\
\text { Biller, Johannes } \\
\text { Biller, Johann Baptist } \\
\text { Biller, Joh. Jac. } \\
\text { Biller (Johann Ludwig ?), d. } \\
\text { Aelt. } \\
\text { Biller, Johann Ludwig } \\
\text { Biller, Johann Ludwig, d. J. } \\
\text { Biller, Laurentius } \\
\text { Biller, Lorenz, vergl. auch } \\
\text { Nr. 293d } \\
\text { Biller, Ludwig, d. Aelt. } \\
\text { Birckenholtz, Paul } \\
\text { Birmann, Jacob, d. Aelt. } \\
\text { Birmann, Peter } \\
\text { Bittner, Johann Fridrich } \\
\text { Bogert, Jaques } \\
\text { de Bont, Corneille }\end{array}$ & $\begin{array}{r}\mathrm{I} 802 \\
\mathrm{~S} . \quad 160 \\
2548 \\
630 \\
468 \\
468 \\
\mathrm{I} 220 \\
355 \\
2520 \\
\mathrm{I} 63 \\
859 . \quad 860 \\
357 \\
986 \\
1238 \\
\mathrm{I} 238 \\
987 \\
237 \mathrm{I} \\
2594 \\
\mathrm{I} 553 \\
\mathrm{I} 802 \\
279 \\
227\end{array}$ & $\begin{array}{l}\text { Borreby, Pet. } \\
\text { von Borssum, D. } \\
\text { Bossard, J. } \\
\text { Botza, Michael } \\
\text { Boxhammer, Hans } \\
\text { Boy, Hans } \\
\text { Braband, Hannss } \\
\text { Bräuer, Joh. Friedr. } \\
\text { Brandmüller, Johann } \\
\text { Bregel, Mathias } \\
\text { Bruckmann \& Co., P. } \\
\text { Bruglocher, Joh. Jac. } \\
\text { Bührer } \\
\text { Buel, Sebald } \\
\text { Buhel, Sebald } \\
\text { Buhrer } \\
\text { Bulkesch, Daniel } \\
\text { Bullinger, Hans Jacob } \\
\text { Burger, Johann Georg } \\
\text { Burraeus, Peter } \\
\text { Busch, Elias } \\
\text { Byler, Johann Baptist } \\
\text { Canzler, J. B. } \\
\text { Cheret, Jean Baptiste } \\
\text { Clauss, Johannes } \\
\text { von Cöln, Heinrich } \\
\text { Cornelius, Johann Friedrich } \\
\text { Cornelius, Jean Friderich } \\
\text { Crabbe, Jean } \\
\text { Cunad, Christof; } \\
\text { Curiger, Joseph Anton } \\
\text { Danner, Thomas } \\
\text { Daumann, Max } \\
\text { Delanoy, Claude Nicolas } \\
\text { Delot, J. A. } \\
\text { Deschler, Jac. } \\
\text { Dey, Christoffer } \\
\text { Diersch, Emanuel } \\
\text { Dision }\end{array}$ \\
\hline
\end{tabular}




\begin{tabular}{|c|c|c|c|}
\hline Nr. & Familien- und Vornamen & $\mathrm{Nr}$. & Familien- und Vornamen \\
\hline I 535. I 536 & Dietmar, Reinhard & O7-I 709 & Eisenhoidt, Anthon \\
\hline $\mathrm{I} 290$ & Dittecke, Abraham & I 263 & Emmerling, $\mathrm{Nic}$ \\
\hline I 337 & Doersch, Emanuel & I 326 & Endres, \\
\hline 515 & Dorn, $F$. & 354 & Engelbrecht, Joha1 \\
\hline I 278 & Dotte, Franz & I 543 & Erhart, Hans Jac \\
\hline $200 \mathrm{I}$ & Drais (Draise ?), $\mathrm{P}$. & $2 \mathrm{I} 4$ & Ernst, Gec \\
\hline I I 58 & Draxler, A. & 288 & Ernst, Hans Jacob \\
\hline I I I 2 & vam Dressche, Reineke & 258 & Ernst, Joh. Babtist \\
\hline 219 & $\begin{array}{l}\text { Drentwet, Abraham, der } \\
\text { Aeltere }\end{array}$ & I 390 & Eyssler, Johann Leonhard \\
\hline 360 & $\begin{array}{l}\text { Drentwet, Abraham, der } \\
\text { Jüng. }\end{array}$ & I $78 \mathrm{I}$ & Fabritius, Chri \\
\hline $373 \cdot 374$ & $\begin{array}{l}\text { Drentwet, Christianus, der } \\
\text { Jüngere }\end{array}$ & $\begin{array}{l}\text { I } 804 \\
\text { I } 782\end{array}$ & $\begin{array}{l}\text { Fabritius, Friedrich } \\
\text { Fabritius, Frederick }\end{array}$ \\
\hline $367 \cdot 368$ & Drentwet, Emanuel & I 784 & Fabritius, Jacob Greg. Graah \\
\hline $37 \mathrm{I}$ & Drentwet, Gottl. Christian & & \\
\hline 327 & Drentwett, A.? & 2524 & Fäsch, Hans Jacob \\
\hline $2 \mathrm{I} 7$ & $\begin{array}{l}\text { Drentwett, Abraham, der } \\
\text { Aeltere }\end{array}$ & $\begin{array}{l}2519 \\
2525\end{array}$ & $\begin{array}{l}\text { Fechter, Adam, d. Jüng. } \\
\text { Fechter, Johannes }\end{array}$ \\
\hline 2 I 8 & $\begin{array}{l}\text { Drentwett, Abraham, der } \\
\text { Jüngere }\end{array}$ & 2523 & $\begin{array}{l}\text { Fechter, Joh. Ulrich, der } \\
\text { Aeltere }\end{array}$ \\
\hline 348 & $\begin{array}{l}\text { Drentwett, Christianus, der } \\
\text { Aeltere }\end{array}$ & 2526 & $\begin{array}{l}\text { Fechter, Joh. Ulrich, der } \\
\text { Jüngere }\end{array}$ \\
\hline $\begin{array}{l}359 \\
265\end{array}$ & $\begin{array}{l}\text { Drentwett, Joh. Christoph } \\
\text { Drentwett, Philipp Jacob }\end{array}$ & 25 I6 & $\begin{array}{l}\text { Fechter, Sebastian, der } \\
\text { Aeltere. }\end{array}$ \\
\hline $\begin{array}{l}370 \\
361\end{array}$ & $\begin{array}{l}\text { Drexel, Michael } \\
\text { Dreyer, Salomon }\end{array}$ & $25 \mathrm{I} 7$ & $\begin{array}{l}\text { Fechter, Sebastian, der } \\
\text { Jüngere }\end{array}$ \\
\hline I988 & Ducrollay, J. & I 432 & Federer?, Hans \\
\hline 1998 & Jean & I74 & Fendl, Hans \\
\hline $5 \mathrm{I} 4$ & rgh, Conradt & I 394 & Fern, Georg Leonhard \\
\hline I23 I & Dulner, Paulus & I39I & Fern, Johann Jacob \\
\hline 262 & Dum, Joh. & I 362 & Ferrn \\
\hline I 292 & Dumling, Martin & $2 \mathrm{OI}$ & Fesenmair, Hans Christof \\
\hline & Ebe & $20 \mathrm{I}$ & $\begin{array}{l}\text { Fesen Meyr, Joan Christoph, } \\
\text { steht wahrscheinlich fälschlich } \\
\text { für Fesen Mayr }\end{array}$ \\
\hline I 7 & Eber & 707 & Feuerstein, Wilhelm \\
\hline 2334 & Effrdinger, Erha & 965 & Finsinger, Franz \\
\hline I 398 & $\begin{array}{l}\text { Ehe, Johann Friedrich, vgl. } \\
\text { auch S. } 240\end{array}$ & $\begin{array}{r}1295 \\
73 \mathrm{I}\end{array}$ & $\begin{array}{l}\text { Fischer, Franz } \\
\text { Fischer, J. }\end{array}$ \\
\hline I 7 I & Eichler, Heinr. & I 299 & Flind, Paulus, d. Jüng. \\
\hline
\end{tabular}




\begin{tabular}{|c|c|c|c|}
\hline Nr. & Familien- und Vo & Nr. & amilien- und Vornamen \\
\hline $\begin{array}{r}\mathrm{I} 59 \\
2093 \\
\mathrm{I} 992 \\
\mathrm{I} 75 \\
637 \\
\mathrm{I} 103 . \mathrm{I} 104 \\
6 \mathrm{I} 7 \\
\mathrm{I} 533 \\
6 \mathrm{I} 7 \\
\mathrm{I} 90.275 \\
\mathrm{I} 759 \\
1989 \\
\mathrm{I} 985 \\
\mathrm{I} 18 \\
766 \\
2 \mathrm{I} 59 \\
\mathrm{I} 993 \\
419 \\
\mathrm{I} 532 \\
6 \mathrm{I} 7 \\
\mathrm{I} 303 \\
250 \\
\\
48 \mathrm{I} \\
\mathrm{I} 85 \\
\mathrm{I} 039 \\
\mathrm{I} 16 \\
\mathrm{I} 16 \\
\mathrm{I} 787\end{array}$ & $\begin{array}{l}\text { Formey, J. } \\
\text { Forschinger } \\
\text { Forster, Adam } \\
\text { Freudenberger, Samuel } \\
\text { Frischherz, Heinr. } \\
\text { Fröhlich, Jacob } \\
\text { Fuchs, Niels } \\
\text { Funckler, Georg } \\
\text { Fux, Hans } \\
\text { Fux, Nicolay } \\
\text { Graab } \\
\text { Gaab, J. A. } \\
\text { Garand, J. F. } \\
\text { Gass, Michael } \\
\text { Gaudig, Samuel } \\
\text { Gebhard } \\
\text { Geffenner, Valentin } \\
\text { Geiger, Caspar } \\
\text { Geitner, Valentin } \\
\text { Gelb } \\
\text { Gérard, Lambert } \\
\text { Germain, François Thomas } \\
\text { Germain, Thomas } \\
\text { Glaudich, Teophil } \\
\text { Glock, E. } \\
\text { Goltius, Hendrick } \\
\text { Gorget, Jean François } \\
\text { Graf } \\
\text { Graseck, Paulus } \\
\text { Grefener, Valentin } \\
\text { Gressel, Stephan } \\
\text { Griel, steht irrthümlich für einen } \\
\text { unbekannten Meister } \\
\text { Griesche, Ferdinand } \\
\text { Grill } \\
\text { Griveswold, Harmann } \\
\text { Grosz, Cornelius } \\
\text { Grosz, Elias } \\
\text { Groth, Sim. Chr. Sch. } \\
\quad \text { Wardein }\end{array}$ & $\begin{array}{r}\mathrm{I} 448 \\
549 \\
548 \\
\mathrm{I} 88 \\
\mathrm{I} 267 \\
\mathrm{I} 548-\mathrm{I} 550 \\
\mathrm{I} 267 \\
2373.2374 \\
\mathrm{I} 285 \cdot \mathrm{I} 287 \\
\mathrm{I} \\
\mathrm{I} 544 . \mathrm{I} 545 \\
935 \\
638 \\
\mathrm{I} 298 \\
\mathrm{I} 780 \\
\\
24 \mathrm{I} .283 \\
299 \\
364 \\
\mathrm{I} 7 \mathrm{I} 2 \\
2375 \\
2440 \\
482 \\
\mathrm{I} 750 \\
23 \\
\mathrm{I} 748 \\
350 \\
377 \\
\mathrm{I} 18 \mathrm{I} \\
\mathrm{I} 256 \\
\mathrm{I} 265 \\
\mathrm{I} 256-\mathrm{I} 258 \\
\mathrm{I} 256 \\
467\end{array}$ & $\begin{array}{l}\text { Hahn, Johann Wilhelm } \\
\text { Haidt } \\
\text { Haidt, A. } \\
\text { Hamburger, Andreas } \\
\text { Hamman, Jobst } \\
\text { Hammerer, Daniel } \\
\text { Hammon, Jobst } \\
\text { Hann, Sebastian, d. Aelt. } \\
\text { Hannss auf der Burg vergl. } \\
\text { auch Nr. I227 b } \\
\text { Harnischter, Daniel } \\
\text { Hase, Tobias } \\
\text { Haussmann, Christ. Friedr. } \\
\text { Haussner, Michel } \\
\text { von Haven, Pet. Nicolai, } \\
\text { Wardein } \\
\text { Heckel } \\
\text { Heckel, Michael } \\
\text { Heckenauer, Joh. Ph. } \\
\text { Heising, F. } \\
\text { Heltner, Servatius } \\
\text { Henck, Joh. Christian } \\
\text { Hentschel, Benjamin } \\
\text { Hermans, Jean } \\
\text { Herwarth, Petrus } \\
\text { van Hesselbie, Mathieu } \\
\text { Heuglin, Joh. Ekhardt } \\
\text { Hezebik, Joseph Tobias } \\
\text { Hicken } \\
\text { Hildebrand Friedrich } \\
\text { Hillebrand, Lucas } \\
\text { Hillebrand(t), Friedrich } \\
\text { Hilleprand, Friedrich } \\
\text { Hiller, Jochen, und nicht Hans } \\
\text { Jachmann } \\
\text { Hinnerup, Peter Reimer, } \\
\text { wardein } \\
\text { Hirsch-Vogel, Friedrich } \\
\text { Hirtz, Hans } \\
\text { Hoe, J. } \\
\text { Höfler, Johann Philipp }\end{array}$ \\
\hline
\end{tabular}




\begin{tabular}{|c|c|c|c|}
\hline Nr. & Familien- und Vornamen & Nr. & Familien- und Vornamen \\
\hline 469 & Hönsch, Christof & 254 & John, Wolfgang \\
\hline I 807 & Hoff?, Dietrich & I 259 & Jonas, $\mathrm{He}$ \\
\hline $45^{8}$ & Hoffmann, Georg & I980 & Jossey, Antoine \\
\hline 1805 & Hoffmann, Jakob & I994 & Joubert, Fra \\
\hline I680 & Hofherr, Mathäus & 1086 & Itzstein \\
\hline I 270 & Hohmann, Eustachius & & \\
\hline I 25 I. I 252 & Holdermann, Diet & & \\
\hline 25 I. I 252 & Hollmann, David & I 327 & Kartenbusch, Johann \\
\hline 376 & Holm, & 960 & Kauxdorf, \\
\hline I3O4 & Ho & 960 & Kauxdorf, An \\
\hline 2586 & Ho & I26I. I 262 & Keller, Hans \\
\hline 2588 & lb, Jacob & 622 & Kellerthaler, (Hans) Johann \\
\hline 926.927 & Hot & I 26 I & Kelner, Hans \\
\hline 273 & $\mathrm{Hu}$ & I 7 I I & Kernitz, Barthel \\
\hline 22 & Hufnagel, Hainrich & I 346 & Kerstner, Conrad \\
\hline I764 & Hugo, Mönch & I I 53 & Kessler, F \\
\hline & & $\begin{array}{l}2237 \\
2159\end{array}$ & $\begin{array}{l}\text { Ket } \\
\text { de }\end{array}$ \\
\hline 467 & Jachmann, $\mathrm{H}$ & I687. I688 & Kienlen, Hans Ludw. \\
\hline & $\begin{array}{l}\text { steht hier irrthümlich für } \\
\text { Jochen Hiller }\end{array}$ & I 329 & $\begin{array}{l}\text { Kindsvater, Hans } \\
\text { Kirschenstein. Ioh. }\end{array}$ \\
\hline 462 & Jachmann, Matheus & $\begin{array}{l}1572 \\
1572\end{array}$ & Kirstein, Joh. Jac. \\
\hline 462 & Jach & 629 & Klemm, Friedrich \\
\hline 203 & Jae & 1055 & Kle \\
\hline $23 \mathrm{I}$ & Jäg & 1623 & $\mathrm{Kl}$ \\
\hline I 2 I 4 & Jan & 2235.2236 & $\mathrm{Kn}$ \\
\hline I 2 I I & Albrecht & I 53 I & Ko \\
\hline I 2 I 3 & Jamnitzer, Bartl & I67 & Ko \\
\hline $215-1217$ & , Christoph & $1457-1460$ & Körver, Johannes \\
\hline $\mathrm{I} 2 \mathrm{I} 2$ & Jamı & I 59 & Ko \\
\hline I 210 & , Wentzel & I 84 & Ko \\
\hline I7 17 & & 176 & Ko \\
\hline 2005 & Jan & I 32 I & Ko \\
\hline I 554 & $\begin{array}{l}\text { Imlin, Johann Ludwig, d. } \\
\text { Aelt. }\end{array}$ & $\begin{array}{l}1038 \\
\text { I } 227\end{array}$ & $\begin{array}{l}\text { Kolmann, Hermann } \\
\text { Koppel, Hannss }\end{array}$ \\
\hline I 56 I & $\begin{array}{l}\text { Imlin, Johann Ludwig, d. } \\
\text { Jüng. }\end{array}$ & $\begin{array}{l}\text { I } 250 \\
\text { I } 332\end{array}$ & $\begin{array}{l}\text { Kossmann, Eberwein } \\
\text { Kraer, Jacob }\end{array}$ \\
\hline 636 & Ingermann, Chr. $\mathrm{H}$. & 564 & Krako zum Dringenberge, \\
\hline 634 & Ingermann, Paul & & Hans \\
\hline 53 & Jöd(c & I 27 & Kra \\
\hline 538 & & 344 & Kraus, Joh. Jac. \\
\hline
\end{tabular}




\begin{tabular}{|c|c|c|c|}
\hline Nr. & Familien- und Vornamen & $\mathrm{N}_{\mathrm{r}}$ & Familien- und Vornamen \\
\hline 777 & Krause, Victor & 20 & von Lindau, Conrad, vgl. auch \\
\hline 2442 & Kresner, M. & & Nr. 25 und 378 \\
\hline I 566. I 567 & Krug, Joh. Friedr. & I 3 I 2 & Zur Linden, Esaias \\
\hline I 565 & Krug, Tobias Ludwig & 2424 & Linden, Jürgen \\
\hline 968 & Krumpholtz, Joachim & I 22 I. I 222 & Lindenberger, Christoph \\
\hline 1056 & Krumshoh, G. F. & 20 & de Lindovve, Conrad \\
\hline 266 & Küsel, Philip & I3 16 & Lobenschrot, Andreas \\
\hline $1038 c$ & Kulemann & I $24 \mathrm{I}$ & Löscher, Wolf \\
\hline I 306 & Kunad, Christof & 1978 & Loir, J. B. \\
\hline & & 1976 & Loir, Louis \\
\hline & & I 35 & Lotter, Bartolme \\
\hline & & I779 & Ludolf, Conrad, Wardein \\
\hline 2569 & Läublin, H. J. & 2139 & Lutma, Johann, d. Aelt. \\
\hline 2190 & Lamotte, C., Elfenbeinschnitzer & 286 & Luz, Jacob \\
\hline 2436 & Lamoureux, Joh. & & \\
\hline 2599 & Landwing, Alexander & & \\
\hline I I 47 & Lang, Gottfried & & \\
\hline I 358 & Lang, Herrman & I3 I 4 & Mack, Heinrich \\
\hline 358 & Lanz, Franz Thaddaeus & $42 \mathrm{I}$ & Männlich, Daniel \\
\hline 969 & Lauch, Balthasar & $42 \mathrm{I}$ & Männlich, Otto \\
\hline 963 & Lauch, Melchior, d. Aelt. & 363 & Mald, Jacob \\
\hline 963 & Lauch, Melchior, d. Jüng. & I 283 & Malfart, Martin; \\
\hline 1264 & Lau(e)r, David & I 283 & Malfeit Martin \\
\hline 286 & Lautterer, Jc & 259 & Manhart, Hans \\
\hline 1084 & Ledent, Johann & 410 & Manlich, Daniel \\
\hline I 165 & Leismiller, Xav. & 252 & Mannlich, Heinrich \\
\hline I73 & Leitenhoffer, B., d. Aelt. & 259 & Mannlich, Johann Heinrich \\
\hline I73 & Leitenhoffer, B., d. Jüng. & 1044 & Martens \\
\hline 2173 & v. d. Lelij, Garbijnus & 1979 & Massé, Grégoire \\
\hline 2170 & Lelij, Johannes & 2558 & Matthey, J. J. \\
\hline I 58. I 59 & Lencker, Christoph & 2556 & Matthey, N. \\
\hline 1236 & Lencker, Elias & $34 \mathrm{I}$ & Mayr, Michael \\
\hline I 229 & Lencker, Hans, d. Aelt. & $105 \mathrm{I}$ & Meding \\
\hline I 59 & Lencker, Johannes & 356 & Mentzel, Gottlieb \\
\hline 286 & Lenker, Johannes & 473 & Menzel, Christian \\
\hline 160 & Lenker, Zacharias & $252 \mathrm{I}$ & Meyer, Ernst Ludwig \\
\hline 422 & Lieberkühn, Christian & 284 & Michael, Hans Jerg \\
\hline 423 & Lieberkuhn & I 320 & Michel, Andreas \\
\hline I 547 & Linck, Cornelius & $29 I$ & Milius, Joh. Seb. \\
\hline 286 & Lincker, Johannes & I 352 & Mink, Gottfried \\
\hline I 274.1275 & Lind, Hannss Anthony & 349 & Mitnacht, Christianus \\
\hline
\end{tabular}




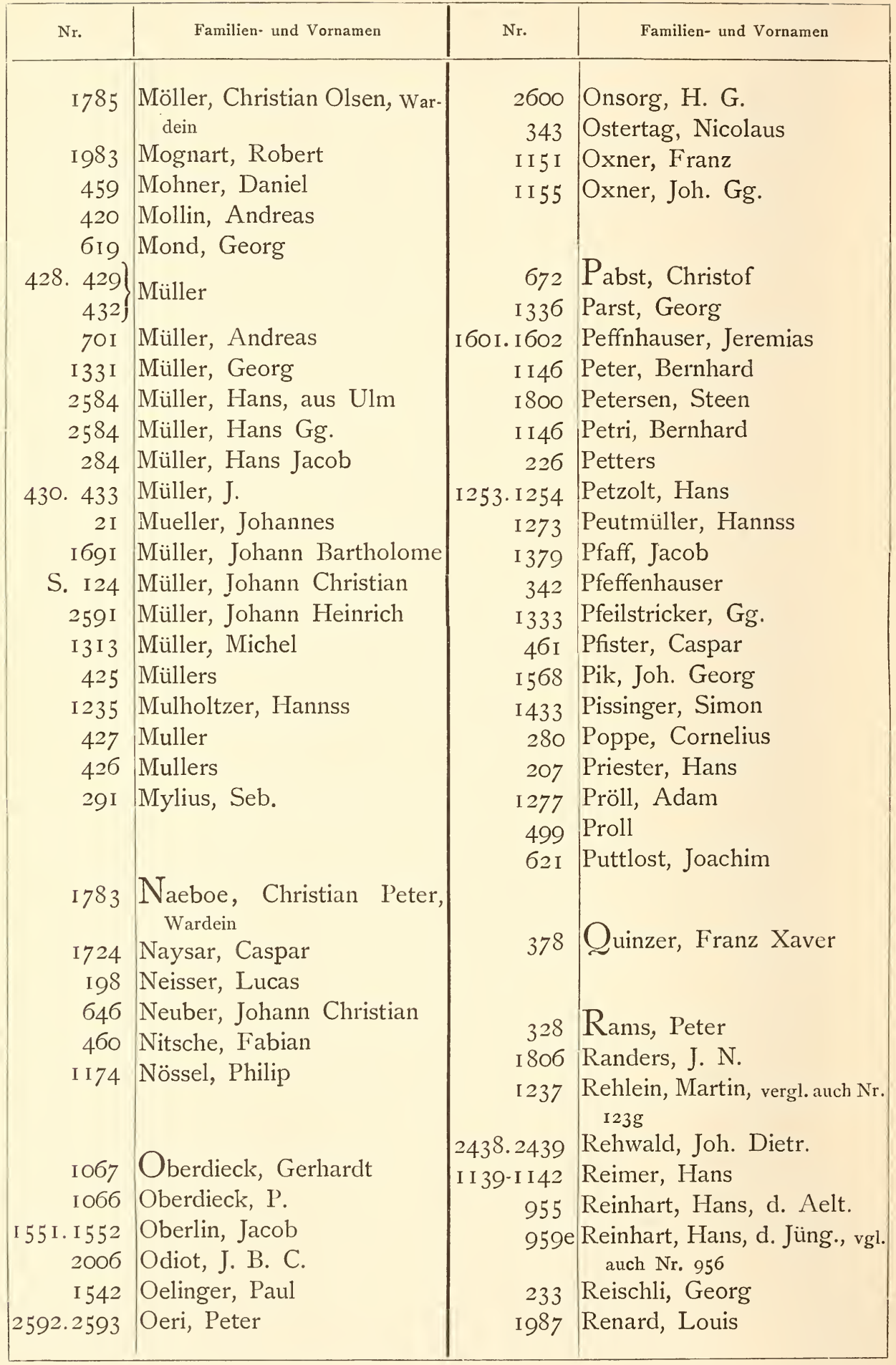




\begin{tabular}{|c|c|c|c|}
\hline $\mathrm{Nr}$. & Familien- und Vornamen & Nr. & Familien- und Vornamen \\
\hline I I 39 & Renner, Hans & 268 & Schliesser, Christian \\
\hline 6 & von Reutlingen, Hans (Jan) & 628 & Schlosser, Zacharias \\
\hline 962 & Richter, Peter & 1425 & Schmaller, Hans \\
\hline 636 & Riedel, Instrumentenmacher & 708 & Schmater \\
\hline I 8 I & Riederer, Abraham & 496 & Schmidt, Georg \\
\hline I $538-154 \mathrm{I}$ & Riedinger, Nicolaus & 1728 & Schmidt, Christian \\
\hline I 342 & Riel, Reinhold & $293 b$ & Schmidt, Christoph, Graveur \\
\hline 282 & Riss von Rissenfels, Caspar & $97 \mathrm{I}$ & Schmidt, Joh. Paul \\
\hline I 223 & Riter, Christoff & I 260 & Schmidt, Nicolaus \\
\hline I 309 & Ritter, Jeremias & 6 I 8 & Schneeweis, Urban \\
\hline I 224 & Ritter, Wolff Christoff & 290 & Schnell, Joh. Conrad \\
\hline I 27 I & Ritter(lein), Chri & 362 & Schoap, Joh. Jacob d. Aelt. \\
\hline 2587 & Riva, Hans Heir & 362 & Schoap, Joh. Jacob d. Jüng. \\
\hline I 288. I 289 & Rösner, Adam & 464 & Schönaw, Fridrich \\
\hline I 363 & Rössler, Wolfgang & I 26 & Schönmacher, Ulrich \\
\hline I986 & Roettiers, Jacques & 457 & Schonow, Hans \\
\hline I 288.1289 & Rosa, Adam & I I I9 & Schowe, Paul oder Arndt \\
\hline 300. I 302 & Rotenbeck, Wolff & $639 \cdot 642$ & Schrödel, Cari David \\
\hline 1083 & Rotenberg, Quirinus & $643 \cdot 644$ & Schröder, Gebrüder \\
\hline I 555 & Roth, Johann Christoph & 2522 & Schrotberger, Hans Heinrich \\
\hline 224 & Rott, $\mathrm{He}$ & 339 & $\mathrm{Scl}$ \\
\hline I I 39 & Rottenberger, Hans & I 36 & Sch(uhm)a(ch)er, Jakob \\
\hline I999 & De Roussy, Alexander & I $28 \mathrm{I}$ & Schutzing, Pet \\
\hline 328 & Rox, Peter & 125 & glin, Anthoni \\
\hline I I 39 & Ruedold, Heinr. & I 282 & Seitzmair, Joachim \\
\hline I I 39 & Rueshamer, Hans & I 282 & Seitzmann, Joachim \\
\hline 763 & Rupr & 24. 25 & Seld, Geo \\
\hline 764 & Ruprecht, F. L. & 26 & Seld, Nico \\
\hline & & $\begin{array}{r}2338 \\
508\end{array}$ & $\begin{array}{l}\text { Sibmacher, Hans Melchior } \\
\text { Sibricht, Gillis }\end{array}$ \\
\hline I98 I & de Saint-Nicolas, Antoine & 2164 & van Sichtelen, Peter \\
\hline 235 & Saller, Ph. & І6І 2 & Sick, Eberhard \\
\hline I I I 9 & Scharlacken, Johann & 1603 & Sick, Joh. Christian \\
\hline 263 & Schech, Hans Jacob & I 5 I & Siebenbürger, Georg \\
\hline I 234 & Scherl, Erhard & 748 & Siebe \\
\hline 263 & Schick, Hans Jacob & I $28 \mathrm{I}$ & Sigmund, Peter \\
\hline 330 & Schiflen, Eli & I 24 & Silb \\
\hline I I 44 & Schleich, Hans & I 803 & Skillings, Dietrich \\
\hline 347 & Schlesinger, Daniel & 2420 & Smollde, Thomas \\
\hline 846 & Schl & $\mathrm{I} 25$ & Sorg, Anthoni \\
\hline I I 57 & Schlickh, Valentin & 1383 & Spörl, Johann Samuel \\
\hline
\end{tabular}




\begin{tabular}{|c|c|c|c|}
\hline $\mathrm{Nr}$. & Familien- und Vornamen & Nr. & Familien- und Vornamen \\
\hline 2004 & Sprimann, Charles & 2100 & , L. \\
\hline 235 & Sproeckhoff, Paul. H. & 2003 & Vanconverberghen, J. T. \\
\hline 2435 & Stabenau, Jacob & 2222 & Verhaer, Nicolaes \\
\hline I 560 & Stahl, Johann & I 32 & Vesenmaier, Bernhard \\
\hline $65 \mathrm{I}$ & Stahlenbrecher, Daniel & 2204-2206 & Viana, A. D. \\
\hline I I 59 & Steinbacher, J. C., senior & 2213.2219 & de Viana, Paulus \\
\hline I I 59 & Steinbacher, J. C., junior & $2203-2206$ & van Vianen, Adam \\
\hline 957 & Steinber, Manasse & 2159 & von Vianen, Ernst Janss \\
\hline 333 & Stenglin, Philipp & 2220 & De Vianen, Paulus \\
\hline 957 & Mar & $2207-2220$ & van Vianen, Paul \\
\hline 330 & , Esaias & $2207-2208$ & Vianen, P. V. \\
\hline 365 & Stipeldey, Caspar Xaver & 466 & Viecke, Fridrich \\
\hline I 284 & Stoer, Thomas & 1758 & De la Vigne, Hugues \\
\hline 1052 & Stöterogg & I99I & de Villeclair, Antoine Jean \\
\hline I 246-1 248 & Straub, Christoff & 1242 & Vischer, Adam \\
\hline I 240 & Straub, Han & I 295 & Vischer, Franz \\
\hline I 310 & Straub, $\mathrm{He}$ & I 537 & Vogell, Hans Diebolt \\
\hline I $246-1248$ & Straub, Wolff & 658 & de Voghelaer, Isaac \\
\hline I7 I 3 & Stra & 463 & Volgnadt, \\
\hline 1564 & Johann Ludwig & 1330 & Vorch(h)amer, Leonhard \\
\hline 1556 & Strehle, Johan Peter & & \\
\hline 457 & Stric & & \\
\hline 1425 & Strobe, H & 670 & W agner, Erasmus \\
\hline & & 140 & Wallbaum, Mathaeus \\
\hline & & 264 & Waremberger, Abraham \\
\hline & & 289 & Warmberger, Jacob \\
\hline 645 & & $255 \mathrm{I} \cdot 2553$ & Wa \\
\hline 2557 & Tav & 1272 & Weber, Hannss \\
\hline 3 I 9 & , J. A. & 420 & Weidemann, Bernhard \\
\hline $301-326$ & Johann Andreas, vgl. & 498 & Weigel \\
\hline 2554.2 & $\begin{array}{r}\text { at } \\
\text { Thi }\end{array}$ & 228 & Weinedt, $\mathrm{B}$. \\
\hline 1757 & Tiberghien & I 28 & Weinodt, Hanss \\
\hline 673 & Tirmsteyn, Han & I I 52 & Wendl, Sebastian \\
\hline I 290 & Tittecke, Abraham & 228 & Wen \\
\hline 336 & Träffler, Joh. Christo & I I09. I I IO & Werner, Johann Georg \\
\hline I 319 & Treghart, Alexander & I 245 & Wernle, Gallus \\
\hline 1225 & Türck, Gregorius & 366 & Weye, Bernhard Heinricl \\
\hline & & & Weyse, Bernhard Heinrich \\
\hline & & I 305 & \\
\hline 2419 & Unna, Hans & 232 & $\begin{array}{l}\text { Wichhert, Andreas } \\
\text { Wickhart Simon }\end{array}$ \\
\hline & & & \\
\hline
\end{tabular}




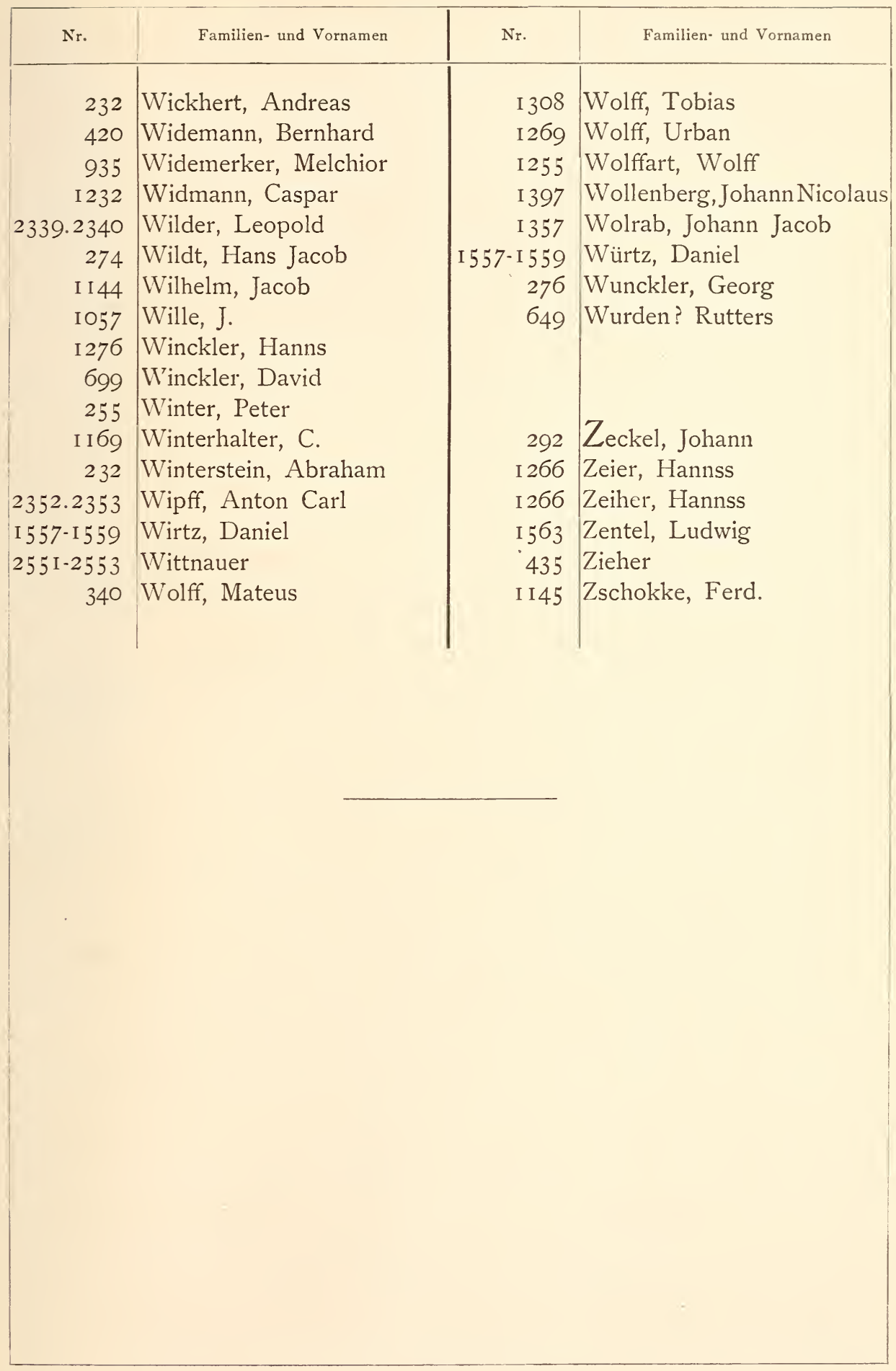




\section{Verzeichniss der Besitzer.}

Die Zahlen hinter den Besitzern und Sammlungen beziehen sich auf die laufenden Nummern.

Unter der Rubrik „Ausstellung" sind nur diejenigen Stücke angefiihrt, deren Besitzer ich nicht feststellen konnte.

Alle Besitzer, deren Wohnort mir nicht bekannt war, sind bei der Hauptstadt ihres Landes untergebracht.

\section{Aachen.}

Museumsverein $167 \mathrm{~d}$

$\dagger$ Suermondt, Barthold 8 .

\section{Altdorf.}

Bäcker- und Müllerzunft I $342 \mathrm{~d}$.

\section{Amsterdam.}

Weiland S. K. H. Prinz Friedrich der Niederlande $2213 \mathrm{~g}$.

Archäologische Gesellschaft 2176b - 2177c -

Archäologisches Museum $\int 2236$.

Ausstellung von 1883 I $46 \mathrm{c}-198 \mathrm{~d}-213-226 \mathrm{c}-$ $259 d-976 c-1314 d-1379 b$ und $c-2144-$ $2151-2164-2189-2190-2191-2223$.

Baker, C. H. I 293 g.

Becker, C. $223 \mathrm{c}$.

Boasberg, J. J. 243c - $252 \mathrm{~g}-295 \mathrm{~d}-528-727-$ $1258 \mathrm{z}-1309 \mathrm{p}-1319 \mathrm{c}-1330 \mathrm{~b}-1680-216 \mathrm{I}-$ 2 I 7 I b - 2I 7 I c - 2192-2222a - 2224 - 248o $248 \mathrm{I}$.

Bonebakker, J. C. R. 2 I9.

Fuld, M. 21 $78 \mathrm{~d}-2179 \mathrm{e}-2 \mathrm{I} 8 \circ \mathrm{f}$.

Jitta, J. 3I 9 ee.

Six, Dr. J. P. I 293 b.

Stadtverwaltung 2I $35-2$ I $37-2$ I $39-2203 \mathrm{~b}$.

Wigersma $2219 \mathrm{n}$.

Willet, A. 1 $303 \mathrm{~b}$.

\section{Ansbach.}

Gumbertuskirche I 7 - I $8-359 \mathrm{a}-$ I $367 \mathrm{~b}$.

Johanneskirche $16-19 \mathrm{a}$ und $\mathrm{b}-222 \mathrm{~d}-254 \mathrm{a}-$ $339 a-36$ I a-368c und d-I 15 c - I $344 c-$ I $344 \mathrm{~d}-\mathrm{I} 358 \mathrm{a}$.

\section{Arth.}

? Kirche 2598 - 2599a.

\section{Aschaffenburg.}

Stiftskirche $292 \mathrm{~d}-358 \mathrm{k}-368 \mathrm{a}-369 \mathrm{a}$ und $\mathrm{b}$ $673 \mathrm{a}$ und $\mathrm{b}-\mathrm{I}$ I 45 .

\section{Augsburg.}

S. D. Fürst Fugger-Babenhausen I $50 \mathrm{~d}-16$ I c 22 Id - 248b-253-275a-28oc-303-313q$326 \mathrm{tt}$ und uu $-349 \mathrm{k}-547 \mathrm{c}$.

Amann, Wendelin I $42 \mathrm{c}$.

Annakirche 2551-366d und e.

Ausstellung von I 886 I $84-214 d-225 b-227 a-$ $258 \mathrm{~b}-283 \mathrm{a}$ und $\mathrm{b}-286 \mathrm{a}-346 \mathrm{~g}-349 \mathrm{l}-$ $358 \mathrm{~g}-360 \mathrm{~g}$ und $\mathrm{h}-873-\mathrm{I} 108-\mathrm{I} 248 \mathrm{i}=$ I 32 I d - I 334 h.

Barfiisserkirche $353 \mathrm{~d}$ und $\mathrm{e}-366 \mathrm{a}$ und $\mathrm{b}$.

Bischöfliches Domkapitel $\}$ siehe Domschatz.

Brauerverein $372 \mathrm{~d}-3741-375 \mathrm{~d}$.

Butsch, A. F. 235a-I30ob.

Degmair, Rud. \& B. Bosch $333 \mathrm{~g}$.

Domschatz 23-26-225a-255 i-286d und e $377 \mathrm{~d}$.

v. Fröhlich, Fanny 3IIo-3I 7 v.

Georgskirche 28I e.

Handelsverein $374 \mathrm{~h}$, i und $\mathrm{k}$.

Hiller, Friedrich 1312a.

v. Hosslin, A. I50c.

Jacobskirche $222 \mathrm{~b}-244 \mathrm{a}-33 \mathrm{I}$ c.

Krauss, Dr. I 295 c.

Kreuzkirche $20-25-238$ e $-242 \mathrm{f}-245 \mathrm{a}-33 \mathrm{I}$ e und $f-292$ i. 
Landauer, Ed. 3 I 8 y und $z$.

Landauer, R. jr. I349 c.

Maximilianskirche $34 \mathrm{I}$ a.

Moritzkirche $2 \mathrm{I}$.

v. Pölnitz, Freiherr, Ludwig I391 a - I393a.

v. Rad, A. 247 f - 312p - 326 qq und rr.

Riedinger, A. I 55 a.

v. Schätzler, Baron 370 .

v. Stettensches Töchterinstitut I5oh.

Ulrichskirche $2 \mathrm{I} 7 \mathrm{~b}-222 \mathrm{c}-25 \mathrm{Ia}-26 \mathrm{c}$ und d $277 \mathrm{a}$ und $\mathrm{b}-315 \mathrm{~s}-327 \mathrm{c}-346 \mathrm{f}-359 \mathrm{f}$.

\section{Baden-Baden.}

I. D. Fürstin Menschikoff $246 \mathrm{~g}-$ I $362 \mathrm{e}$.

Aaken, G. van I68b-22I i - 239d - 24I d 285 d - 359e - $732-737-$ I $294 a-$ I 6 Iob.

v. Essen, Baron O. $258 \mathrm{~d}-1342 \mathrm{x}$ und $\mathrm{y}$.

Gimbel, G. I 7 I c - I 9 I c und d - 220 - 268 c $352 f-363 g-1152-1292 b-1295 a-1318 f-$ I $373 \mathrm{C}-$ I 3870 .

Kah, Karl I85b-1302 h.

Kath. Pfarrkirche $238 \mathrm{~b}-274-355$ e und $\mathrm{f}$ $360 d-362 c-365 c, d$ und $f-383-384-$ I 560 - I 568 .

Moppert, Gebr. 372h - 376a - 531 a - 535a I $320 b$ - I $342 \mathrm{~h}$ - I $362 \mathrm{f}$ und h - I 384b - $2349 \mathrm{a}$.

Niemeyer, Dr. G. I I 44 b.

Wolter, Emil 2221.

\section{Baden (Schweiz).}

Kath. Pfarrkirche 25I 2.

\section{Bargau.}

Kirche 731 .

\section{Basel.}

Gesellschaft zur Mägd 2523b.

Gesellschaft zum Rebhaus 2514a - 2519a $2523 \mathrm{c}-2526 \mathrm{~b}$.

Imhof-Riisch 2522 a.

Mittelalterliche Sammlung 25I3-2520 b und c. Safranzunft $25 \mathrm{r} 7 \mathrm{~h}$.

Schlosserzunft 2523 a.

Schlüsselzunft 25 I9b.

Universität $1236 \mathrm{i}$.

Vorstadtgesellschaft zur Häre 2526 a.

Vorstadtgesellschaft zur Krähe 252I b.

Vorstadtgesellschaft zum Rupf $2525 \mathrm{a}$.

Weberzunft $265 \mathrm{~b}$.

Weinleutzunft I3 I 8 b - 25 I $7 \mathrm{i}-2522 \mathrm{~b}$.

\section{Bebenhausen.}

Schloss I 64b - 207b - 228i . 265d und e - 280n und o - 28I d - $290-300 \mathrm{e}-964 \mathrm{i}-\mathrm{I} 2 \mathrm{I} 2$ $1232 \mathrm{~d}-\mathrm{I} 24 \mathrm{I} \mathrm{c}-\mathrm{I} 254 \mathrm{n}$ und o - I27.3 b I $309 \mathrm{k}$ - I349f - I600 - I602c - I606 - I608a $252 \mathrm{I}$ a.

\section{Bergen op Zoom.}

Baartmans, C. F. $22 \mathrm{I} 6 \mathrm{k}$.

\section{Berlin.}

Königl. Museum 22.

Königl. Schloss, Rittersaal 2 I 4 b und c $-252 \mathrm{k}$ $270 d$ bis i - 291 a, b und $n-293 b-294 r$ und s - $297 \mathrm{~g}$ und $\mathrm{h}-298 \mathrm{a}$ bis c $-354 \mathrm{k}$ und 1 - 357d-4Ioa bis c und e bis h 4 I 2 $4 \mathrm{I} 6 \mathrm{a}-4 \mathrm{I} 8 \mathrm{a}-4 \mathrm{I} 9-420-423 \mathrm{c}$ bis e - Io66 I 067 a bis c - I969 - I 2 I0 - I 254a - I 2$) 2$ a.

Königl. Silberkammer $368 \mathrm{~b}-422 \mathrm{a}$ und b $428 \mathrm{a}-429 \mathrm{a}$ bis c $-430-432-433$.

Kunstgewerbe-Museum I $16 \mathrm{~d}-140 \mathrm{u}$ bis $\mathrm{y}$ I 5 of - I 54b - I 75 - I $76-232 \mathrm{~g}-246 \mathrm{c}-255 \mathrm{~g}$ und h - 258a - 259l - 260-27I c - 291 i $293 \mathrm{a}-333 \mathrm{c}-345-372 \mathrm{k}-43 \mathrm{I}-456-532 \mathrm{c}-$ $640 b-687-774-902 b-964 f-990-1001-$ IOO3 - IOI 3 - IOI4 - IO38 a und b - IO39a und b - IO40 - IO4Ia - I043 - I044d - I045a 1046 - I047 - 1049 - I050 - I05I - III 2 II $83 \mathrm{~s}-1217 \mathrm{i}-\mathrm{I} 240 \mathrm{c}-1244-1254 \mathrm{e}$ $1295 \mathrm{~m}$ und $\mathrm{n}$ - I303a - I309i - I392a I 617 b - I693 - 2420 b - 2452 .

Graf Pourtales 955 b.

v. Sallet, A. I $218 \mathrm{~d}$.

\section{Bern.}

Bürgergemeinde I 23 a u. b-I 23 e - I 82 a - I 240 b. Historisches Museum I9I f - 2I6b - 5I 8 - I II 3 I $83 \mathrm{~h}-2533-2534-2535-2536-2537-$ 2588 a.

\section{Bischofszell.}

Gemeinde I699a.

? Kirche $2564-2600$.

\section{Bleiburg.}

Graf Thurn-Valsássina, I 4oe und f.

\section{Bodenheim.}

Albanskirche $36_{3} \mathrm{e}-\mathrm{I} 084$.

\section{Braunschweig.}

Herzogl. Museum 2590 und p. 


\section{Breslau.}

Agath, Georg I I $8 \mathrm{~h}$ bis n - I28d - I34e - I 79b $250 \mathrm{c}-27 \mathrm{Ie}-29 \mathrm{Il}-4 \mathrm{IOl}-463 \mathrm{~b}-544 \mathrm{c}-545 \mathrm{f}$ und $g-1246 c-1363 e-1364 r-1437-1689-$ $2093-2514 \mathrm{c}$.

\section{Bretzenheim.}

Georgskirche I228 d.

\section{Brixen.}

Domschatz $140 \mathrm{gg}$.

\section{Brügge.}

Kapelle Saint-Sang 1749 .

Kathedrale 1748 .

Notre-Dame Kirche I 750.

\section{Brünn.}

Domschatz $292 \mathrm{~g}$.

\section{Brüssel.}

de Béthune $1757 \mathrm{c}$.

van der Burch, Gräfin Charles 1763 .

Delmotte, Henri i 762 .

Evenepoel, Henri I 757 b.

van den Hecke de Lombeke, Léon I 757 a.

v. Joigny de Pamele, Baron i76r a und b.

Königl. Museum, siehe Musée royal d'antiquitées. de Lichtervelde $176 \mathrm{I} \mathrm{c}$ und $\mathrm{d}$.

Musée de la porte de Hal, siehe Musée royal d'antiquitées.

Musée royal antiquitées II $7 \mathrm{e}-955 \mathrm{a}-959 \mathrm{t}-$ I $146 \mathrm{~d}$.

Gräfin L. v. Nédonchel I 76I e und f.

Stadtverwaltung $\mathbf{I} 754$.

Stevens, Clémence I76I g.

\section{Budapest.}

Andaházi, Paul $1320 \mathrm{~h}$.

Andrássy, Graf Aladar 226a - 12241.

Andrássy, Graf Emanuel 178b - $202 \mathrm{a}-250 \mathrm{~b}$ $254 \mathrm{~b}$ und $\mathrm{c}-340 \mathrm{c}-\mathrm{II} 73 \mathrm{i}-\mathrm{I} 275 \mathrm{c}-1306 \mathrm{a}$. Andrássy, Graf Julius 339 c.

Apor, Baron Carl I27g - 202 c - 227c-238p $340 \mathrm{~h}-964 \mathrm{c}-\mathrm{II} 83 \mathrm{r}-\mathrm{I} 3 \mathrm{I} 8 \mathrm{c}$.

Ausstellung von I884 I $26 \mathrm{~d}-\mathrm{I} 27 \mathrm{c}$ und $\mathrm{d}$ I $50 \mathrm{k}-16 \mathrm{I} \mathrm{c}-\mathrm{I} 88 \mathrm{c}-\mathrm{I} 9 \mathrm{I} \mathrm{h}-\mathrm{I} 98 \mathrm{~b}$ und $\mathrm{c}-$ $201-202 \mathrm{k}-214 \mathrm{a}-222 \mathrm{k}-224 \mathrm{a}-236 \mathrm{~b}-$ $238 \mathrm{n}-245 \mathrm{~g}-249 \mathrm{~h}-263 \mathrm{a}-265 \mathrm{f}$ und $\mathrm{g}-$ $273 a-32500-340 f-473 b-1293 c-1331 g$ bis $\mathrm{i}-\mathrm{I} 34 \mathrm{I}$ a und $\mathrm{c}-1342 \mathrm{w}-\mathrm{I} 694-2335-$ $2340-2346-2347 b-2368 b-2384-2592 d$.
Bánffy, Graf Georg 202 b - 979a - 2347 a $2374 \mathrm{v}-2374 \mathrm{w}$.

Batthyány, Graf Ludwig 203b und c-973.

Császka, Bischof Georg 123 i.

Csekonics, Graf Johann I368b.

Csoma, Joseph i629.

Dessewffy, Paul 1276 a.

Egger, Gebrüder I2 II.

Egger, H. 246I.

Erdödy, Graf Franz I 23 g - I 45 a - 200 a, b und c - I 237 b - 2342 .

Keglevich, Graf Julius 979 b.

? Kirche 2366.

National-Museum I 8 b - I32d - I34c - I40a $155 d-157 b-159 e-163 c-179 a-187 b-$ $190 c-229-246 h-249 d-261-278 a-$ $283 \mathrm{c}-324 \mathrm{~mm}-328 \mathrm{a}$ bis c $-33 \mathrm{ob}$ und c $336 \mathrm{e}-44 \mathrm{I}-536 \mathrm{~b}-543 \mathrm{~b}-959 \mathrm{a}$ und $\mathrm{b}-96 \mathrm{I}-$ IIIIb - I236e - I268c - I272 b-I279b $1296 e-1298 a-1333-1363 a-1365 i$ I $433 \mathrm{a}-\mathrm{I} 675-2345-2350-2374 \mathrm{~d}-238 \mathrm{Ic}$ und $\mathrm{d}$.

Rath, Georg 2374p.

Redl, Baron Albrecht 252 f - 468 - 545 d - 896 974.

v. Rosenfeldt, Freiherr Ludwig 2374a, g und l. Semsey, V. I3I3 d.

Szabó, Frau Joseph 238 o- I224d - 2374 u.

Szápáry, Graf Stephan 1620.

Teleki, Graf Samuel 279b - 480 - I305m I $309 \mathrm{~h}$.

Vigyácó, Alexander 204b - 212b - 976b - 1 242b I 365 e - i 380 a.

Zichy, Graf Franz 2374x.

Zichy, Gräfin Irma 965 b.

Zichy, Gräfin Livia $1254 \mathrm{k}$.

\section{Bühl (Ortenau).}

Privatbesitz 363 a.

\section{Cappellen.}

Hoogendijk, O. 205 a.

\section{Cassel.}

Altenkirchen, Graf I346 d.

Ausstellung von I $884240 \mathrm{~b}-259 \mathrm{~b}-13 \mathrm{I} 6 \mathrm{~b}$. Bartels 424 .

von Canstein, Frau 748.

Eisenmann, Dr. 495 - I398b. 
Habich 1254 y - I $320 \mathrm{c}$.

Harnier, Dr. R. $500 \mathrm{c}$.

Hoffmeister, J. $496 \mathrm{c}$.

Kass, Markus I $320 \mathrm{~g}$.

Knetsch, Frau 498.

Königl. Museum 13 I b - 133b - 134 d - I35a $165 b-166 b-232 a-245 c$ und $d-249 a$ und b-25I b - 270k bis q-28oa-316327d und $\mathrm{f}-374 \mathrm{e}-4 \mathrm{Iod}-440 \mathrm{a}-497-499$ $500 \mathrm{a}$ und $\mathrm{b}-687-1213 \mathrm{~b}$ und $\mathrm{c}-1236 \mathrm{~h}-$ $1238 \mathrm{a}-1258 \mathrm{o}-1262 \mathrm{e}$ und $\mathrm{g}-\mathrm{I} 263 \mathrm{~d}-$ $1265 \mathrm{~b}-1290 \mathrm{a}-1312 \mathrm{~m}-1331 \mathrm{a}-1335 \mathrm{a}$ bis e - $1356 a-1373$ e - I $433 b-1452-1455-$ I6Igc - I699 f.

Schick, Fräulein 501.

Stadtverwaltung 494 .

v. Vultée $1293 \mathrm{k}$.

Wallach, John 1315 b.

Cöln.

Bourgeois, Gebr. 243g - 967 - I294b , 2218m $2526 \mathrm{c}$ und $\mathrm{d}$.

$\dagger$ Disch, Carl 218.

Domschatz 5 I 4.

? Kirche 1255 a.

Peterskirche 516.

Schnütgen, A. Domherr 330 a.

Thewalt, C. 167 a und b - 463a-1246d $1263 a-1305 g-1369 d-1672-2220-2584$.

\section{Colmar.}

Schongauer-Museum I 221 b- I 532 - 1546.

\section{Danzig.}

Reinholdsbank $1308 \mathrm{~h}$.

\section{Darmstadt.}

S. K. H. der Grossherzog von Hessen 1274 b. Vergl. Neues Palais und die andern Sammlungen in Darmstadt.

Grossherzogl. Museum I35c - 172 b - 193c $246 \mathrm{e}-269 \mathrm{~b}-355 \mathrm{c}$ und $d-68 \mathrm{I}-1233 \mathrm{~d}-$ I $258 \mathrm{~d}-1530 \mathrm{~b}-\mathrm{I} 700 \mathrm{a}$.

Grossherzogl. Silberkammer $215 \mathrm{c}-222 \mathrm{a}$ und e $23 \mathrm{Id}-247 \mathrm{c}$ und $\mathrm{d}-257-300 \mathrm{~g}$ bis $\mathrm{m}-335 \mathrm{c}-$ $342 \mathrm{a}-347 \mathrm{e}$ und $\mathrm{f}-355 \mathrm{a}-356 \mathrm{k}-363 \mathrm{~b}$ und $c-372 a-374 b$ bis $d-560-561-563-$ 845 - I 554 - I56 I a $1564 \mathrm{a}$ und b.

Neues Palais 215b - 231c - 247b - 269a - 559$562-682-1274 b-1390 c-1531$ a bis c $1550 \mathrm{a}-1553-\mathrm{I} 687 \mathrm{~b}$.

\section{Dessau.}

S. H. d. Herzog von Anhalt 272b-1236a.

\section{Deva.}

v. Barcsai, Kolomann 2374 q.

Evang. Kirche $2374 \mathrm{r}$.

\section{Deventer.}

v. d. Aa 2234 .

\section{Doboka (Siebenbürgen).}

Nagy, Ludwig $2374 \mathrm{c}$.

\section{Donaueschingen.}

S. D. Fürst von Fürstenberg $140 \mathrm{~h}, \mathrm{i}$ und dd $207 a-1068 b-1318 h-1706 a-2209 c$.

\section{Dresden.}

v. Berthold, F. R. 1310h - I342 g-13621.

Grünes Gewölbe I 21 a - I32b - I42a - I43c $154 \mathrm{a}-183 \mathrm{a}$ und $\mathrm{b}-185 \mathrm{~g}-193 \mathrm{a}-228 \mathrm{a}-$ $232 \mathrm{~d}-243 \mathrm{~b}-245 \mathrm{~b}-255 \mathrm{~b}-259 \mathrm{e}, \mathrm{f}, \mathrm{g}, \mathrm{k}$, $\mathrm{n}$ und $\mathrm{q}-285 \mathrm{a}-295 \mathrm{i}$ und $\mathrm{k}-307 \mathrm{k}-327 \mathrm{r}$ $347 \mathrm{a}$ bis $\mathrm{d}, \mathrm{q}$ und $\mathrm{r}-350 \mathrm{a}$ und $\mathrm{b}-35^{2} \mathrm{ee}-$ $356 \mathrm{~m}$ bis o-41 1 - 440 b-617a-618a und b-619a-623c-628a-63ob-632-699 $700-705-872-959 \mathrm{c}, \mathrm{d}, \mathrm{h}$ bis $\mathrm{r}-\mathrm{I} 210 \mathrm{~d}-$ $1214 \mathrm{a}-1215 \mathrm{c}-1218 \mathrm{~b}$ und $\mathrm{c}-1219-1249 \mathrm{a}$, b, c und f - I258a, c, h, i, l und n - I260a, b, c, f, g und i - I 262 a und f - I 269 b, c und $e-1273 c$ und $d-1274 a-1288 a$ und b $1290 \mathrm{~b}$ bis e $-1293 \mathrm{~h}-1305 \mathrm{C}-1307 \mathrm{c}-1308 \mathrm{a}$ I309 b - I $314 \mathrm{a}-13 \mathrm{I} 81$ und $\mathrm{m}-1320 \mathrm{i}-1364 \mathrm{p}$ und $q-1542-1545-1602 d-1618 a$ und $b$ I619a und b-1623-1624-1723.

Historisches Museum I $29 \mathrm{~b}-\mathrm{I} 40 \mathrm{p}$ und q - 147 $194 \mathrm{a}$ und $\mathrm{b}-259 \mathrm{a}-6 \mathrm{r} 7 \mathrm{~b}-620 \mathrm{~b}-62 \mathrm{I}$. $622 \mathrm{a}$ und $\mathrm{b}-626-629-630 \mathrm{a}-63 \mathrm{I}-9599$ I1 $49-1213 \mathrm{~d}-1222 \mathrm{c}-1232 \mathrm{e}-1236 \mathrm{f}$ 13090.

Hof kirche $232 \mathrm{~h}-620 \mathrm{c}-624-625 \mathrm{a}$ und $\mathrm{b}$ $627-964 a-972-1237 c$ und $d-1296 a$ und $b$.

Königl. mathem.-physikal. Salon I 2 Iоo.

Königl. Schloss 270 a bis c -294 b bis q -297 e $328 \mathrm{e}-332 \mathrm{a}$ und $\mathrm{b}-346 \mathrm{a}$ und $\mathrm{b}-354 \mathrm{~d}$ und e -356 a bis $d-357$ a.

Königl. Silberkammer 295 a bis c $-332 \mathrm{c}$ und $\mathrm{d}-339 \mathrm{f}-342 \mathrm{~b}$ und $\mathrm{c}-346 \mathrm{~d}$ und $\mathrm{e}-347 \mathrm{a}$ bis $d, g$ und $h-349 \mathrm{c}$ bis $\mathrm{f}-352 \mathrm{~s}$ und $\mathrm{t}$ $353 \mathrm{f}-354 \mathrm{a}$ bis $\mathrm{c}-3561, \mathrm{p}, \mathrm{t}$ und $\mathrm{u}-4 \mathrm{I} 7 \mathrm{~b}-$ 
42 Ia und $\mathrm{b}-635-636 \mathrm{a}$ bis $\mathrm{i}-637 \mathrm{~b}-639 \mathrm{a}-$

$640 \mathrm{c}$ bis 644 .

Kunstgewerbe-Museum 228 e - 1436.

Salomon, M. I364s.

\section{Eisenbach.}

Frhr. Riedesel, L. 27I a.

\section{Elbing.}

Conventsammlung 652 .

Georgs Bruderschaft $653-$ I $273 \mathrm{a}$.

\section{Eltville.}

Eltz, Graf I254i.

\section{Emden.}

Stadtverwaltung $657-658-1536$.

\section{Engen.}

? Kirche 923.

\section{Erding.}

Johanneskirche I86b-28If.

\section{Erfurt.}

Apell, Franz 672.

Kaufmannskirche $670-775 \mathrm{a}$ und $\mathrm{b}$.

Predigerkirche $969 \mathrm{~b}$ und $\mathrm{c}$.

Rathhaus I 232 a.

\section{Eschwege.}

Plaut, Gerson I259b - I320f.

\section{Forchtenstein.}

S. I. Fürst Nicolaus Esterházy, I 7oa-217e I 2541 und $p-2$ I $69 f$.

\section{Frankfurt a. M.}

Ricard-Abenheimer, J. I 534 .

Becker, Consul 244b - 956c - I379a - I453I69I.

Bondi, B. I 57 a - 221 e und g.

Dreyfus-Jeidels, Jacques I68c - I9I b - 22Il $33 \mathrm{I} g-735-1362 \mathrm{i}-1375 \mathrm{~b}-1398 \mathrm{a}-25 \mathrm{I} 7 \mathrm{e}-$ $2525 \mathrm{~b}$ und $\mathrm{c}$.

v. Erlanger, Baron 68 3 b - 1308c.

Goldschmid, Eduard I240a - I268b-I312 e I $365 \mathrm{~h}$.

Goldschmidt, J. \& S. I I $8 d$ bis g - I28c - I $57 \mathrm{c}$ $246 d-279 a-280 p-28 I c-283 d-293 f-$ $333 f-337-352 b-363 d$ und $f-470 d$ und $e-472 b-533-535 c-746-824-925 a-962-$ $964 d-I 153 a-I I 55 c-$ II $84 b-$ I $272 c$ -
I $295 \mathrm{i}-\mathrm{I} 342 \mathrm{~s}$ und u - I366c - I $373 \mathrm{~g}-\mathrm{I} 393 \mathrm{~g}-$ $1438-1550 \mathrm{~b}-1603 \mathrm{c}-1700 \mathrm{~b}-2085$.

Goldschmidt, Max B. H. I183e - I268d I 597 - 2494.

Gontard, M. I 54 I a.

Historisches Museum 686-689-690a und b 69I a und b- 692 a bis c - I 247 c - I 310 a.

Jeidels, J. \& H. I26b-136a-I56d-164a $212 \mathrm{c}-36 \mathrm{rb}-474-729-736-1248 \mathrm{f}-$ I 270 e - I 293 a I $312 \mathrm{~h}$ bis $1-$ I 349 b I $356 \mathrm{~d}$ $1357 b-1371 \mathrm{~b}-1373 \mathrm{a}-1398 \mathrm{c}-1677 \mathrm{~b}-$ 2099.

Kath. Kirche $360 \mathrm{c}$.

Lackmann, Robert 127k - I87d - 29Im - I305a. I $354 \mathrm{c}$.

Löwenstein, Gebr. I40z.

Metzler, Wilhelm I33e-I43b-65 I - I262 m $1305 \mathrm{f}-1315 \mathrm{~d}-2517 \mathrm{k}-2592 \mathrm{~b}$.

Oppenheim, E. 197b-1429.

Oppenheim, Guido I314b.

Oppenheim, N. M. 185d-963-1305d-1313cI3 $16 \mathrm{a}-1373 \mathrm{~h}-2430$.

$\dagger$ v. Rothschild, Baron Carl II 7 a und b II $8 \mathrm{a}$ und $\mathrm{c}-\mathrm{II} 9-\mathrm{I} 22-\mathrm{I} 23 \mathrm{c}$ und d - I24a I $27 \mathrm{f}$ und $\mathrm{i}-\mathrm{I} 28 \mathrm{~b}-\mathrm{I} 3 \mathrm{I} \mathrm{a}-\mathrm{I} 33 \mathrm{C}-\mathrm{I} 34 \mathrm{a}$ und $\mathrm{b}-\mathrm{I} 4 \mathrm{O}$ s und $\mathrm{t}-\mathrm{I} 42 \mathrm{~b}-\mathrm{I} 45 \mathrm{~b}-\mathrm{I} 53 \mathrm{a}$ bis c I $59 \mathrm{~d}-\mathrm{I} 62 \mathrm{~d}-\mathrm{I} 70 \mathrm{c}-\mathrm{I} 72 \mathrm{a}-\mathrm{I} 73 \mathrm{a}-\mathrm{I} 88 \mathrm{a}-$ $190 a-193 b-198 e-203 a-221 b-231 a-$ $232 \mathrm{i}-242 \mathrm{a}$ bis c $-243 \mathrm{a}-252 \mathrm{a}$ und $\mathrm{c}-$ $255 \mathrm{c}$ bis $\mathrm{f}-265 \mathrm{a}-269 \mathrm{f}-276-284-29 \mathrm{Ic}$ und $f$ bis $h-293 \mathrm{e}-3000-301 \mathrm{c}$ und $\mathrm{d}$ $304 \mathrm{~g}-305 \mathrm{~h}-306 \mathrm{i}-309 \mathrm{~m}-3 \mathrm{I} 8 \mathrm{cc}$ und dd $32 \mathrm{Igg}-322 \mathrm{hh}-323 \mathrm{ii}-324 \mathrm{nn}-326 \mathrm{ss}-$ $327 \mathrm{l}$ bis $q-336 \mathrm{a}-340 \mathrm{a}$ und $\mathrm{g}-34 \mathrm{Ib}-343-$ $346 \mathrm{~h}-372 \mathrm{~b}-375 \mathrm{~b}-416 \mathrm{~b}-457-459-$ $485-509-5$ IO - 5II - 5I3 - 535b-54I a $543 a-685-827-829-844-863-899-$ $918-959 \mathrm{~s}-1004-1005-1008-1148 \mathrm{~b}-$ II69a - I I83f - II $84 a-$ I $210 b$ und i - I2I3a I $217 \mathrm{~h}-\mathrm{I} 22 \mathrm{I}$ a $-I 223-\mathrm{I} 224 \mathrm{f}-\mathrm{I} 226 \mathrm{a}$ und b -1228 b - I 232 b - I $233 \mathrm{C}-\mathrm{I} 234 \mathrm{~b}-\mathrm{I} 236 \mathrm{~d}$ und $k-I 238 d-I 245-I 252-I 254 b, c, f$ und $\mathrm{u}-\mathrm{I} 258 \mathrm{~b}-\mathrm{I} 262 \mathrm{~h}$ bis $\mathrm{l}-\mathrm{I} 266 \mathrm{c}$ bis $\mathrm{m}$ I268a - I27Ic - I273f und h - I277b I 283 - I 284 a - I 293 e und i - I295 b - I 305k und $\mathrm{p}$ - I309a, c, m, n und q bis $\mathrm{t}$ - I3rod I3I $2 b$ und $c-1319 a-1325 a-1330 c-1331 b-$ I332d - I340 - I34Ib - I $342 \mathrm{a}$ und c - I356g bis q 1364 a und b - $1402 \mathrm{a}-\mathrm{I} 434-1552$ I $572 f-I 626-1627-$ I $671-I 699 b$ und $g$ - 
$1726-1734-2170 a-2174 a-2204 c-2205 d-$ $2221-2336-2374 \mathrm{f}$ und $\mathrm{i}-238_{j}-2434-$ $2435 \mathrm{c}-2464-2493-2516 \mathrm{a}-25 \mathrm{I} 7 \mathrm{~b}-2520 \mathrm{a}-$ $2548-2558-2589 \mathrm{~d}-2592 \mathrm{a}$.

\section{Freckenhorst.}

Stiftskirche $285 \mathrm{~g}$.

\section{Freiburg i. B.}

Privatbesitz $707 \cdot 2524$.

Städt. Alterthümer-Sammlung 2518.

Universität $358 \mathrm{f}$.

\section{Freiburg (Schweiz).}

Techtermann 2540 .

\section{Fulda.}

Stadtverwaltung 1625 .

\section{Genf.}

Pasteur, Mme. 339d.

\section{Gengenbach.}

Stadtverwaltung 7 I2.

\section{Gent.}

Kathedrale $\mathrm{I} 75^{8}$.

Museum 1756 a bis d.

\section{(Schwäb.-)Gmünd.}

Dorf kirchen in der Nähe von Gmünd $733-734$. Kirchenschatz 288b - I684.

Kirche und Schulpflege $34 \mathrm{I}$ c.

\section{Gotha.}

Herzogl. Hofkapelle I 2 I b und c.

Herzogl. Museum I40o- I50m und n- I63a I65c - I9I g - $222 \mathrm{f}$ bis i - 232c - 239a $244 \mathrm{c}$ und d $-272 \mathrm{a}-295 \mathrm{e}$ bis $\mathrm{h}-297 \mathrm{a}$ und b $-333 c-334 b-335 a-336 f-340 b-$ $347 \mathrm{~m}$ bis $\mathrm{p}-349 \mathrm{~h}-352 \mathrm{l}$ bis $\mathrm{r}$ und $\mathrm{z}$ bis dd $357 \mathrm{~b}, \mathrm{c}, \mathrm{g}$ und $\mathrm{h}-464 \mathrm{a}-532 \mathrm{a}-630 \mathrm{c}-742-$ $744-745-775 d-958-960 b-964 b-1210 a-$ $125^{8} \mathrm{e}$ und $\mathrm{k}-1265 \mathrm{a}-1312 \mathrm{~s}-1331 \mathrm{k}$ I3.36e - I349a - I356e und r - I382a - I6r $9 d$ I69o- I $728-22$ I $2 \mathrm{f}-22 \mathrm{I} 4 \mathrm{~h}-2343 \mathrm{a}$.

\section{Gran.}

Domschatz 34I d - 2349b.

Graz.

Landhaus 12 I d.

\section{Grossenhain.}

Zschille, Richard 659-1342 aa - 1430-2 174b.

\section{Gross-0stheim (bei Aschaffenburg).}

? Kirche I 724 .

\section{Gudensberg.}

Nagel, S. $265 \mathrm{c}$.

\section{Der Haag.}

Bisschop, C. 2175 a.

van Verschuur, Baron 1312r.

\section{Hainhofen.}

v. Rehlingen, Freiherr I 2481.

\section{Haldenwang.}

v. Freyberg, Freiherr 286 b.

Halle a. d. S.

Ulrichskirche $773-970$.

\section{Hamburg.}

Campe, J. 832 - I305 I- 1353b.

Johanneskirche I228c.

Museum für Kunst und Gewerbe 413-4I4$822-837$ - I270 c - I 555 - I802.

Paul, Johannes $352 \mathrm{~h}, \mathrm{v}$ und $\mathrm{w}-684-1263 \mathrm{~b}-$ I $276 \mathrm{~b}-$ I 54 I b - $2337-2453$.

Simon, J. B. $2482-2483-2484-2485$.

Stern, Dr. 695.

Synagoge 835 .

Warburg, Siegmund 1356s.

\section{Heidelberg.}

Heil. Geistkirche $329-852-853-854$ - I 280 a.

Schmitt, Jean I IO2.

\section{Heltau.}

Evang. Kirche 1374t.

\section{Herdringen.}

Fürstenberg-Herdringen, Graf I707 - I708 1709.

\section{Herenthout.}

Van Reynegom de Buzet, Baron 1346b.

\section{Hermannstadt.}

v. Bruckenthal, Freiherr Sam. $2374 \mathrm{~m}$.

Evang. Pfarrkirche $2374 \mathrm{~b}, \mathrm{~h}, \mathrm{k}$ und $\mathrm{s}$. Lüdecke (Lindecke), Ernst $2374 \mathrm{e}$.

\section{Hersbruck.}

Protestantische Kirchenverwaltung I392g und h. 
Stadtverwaltung $496 \mathrm{~b}$.

\section{(Schwäb.-)Hall.}

Katharinenkirche $344-364 a-757-758-766-$ I $393 \mathrm{~d}$ und $e$.

Michaelskirche $333 b-761-762-763-764$.

\section{Jacobsdorf W. $\operatorname{Pr}$.}

v. Parquart, Baron H. 2525 d-2592e.

\section{Jettingen.}

v. Stauffenberg, Graf $360 e$ und f.

\section{Ingolstadt.}

Frauenkirche 292 e.

\section{Kaiserslautern.}

Pfälz. Gewerbe-Museum 765b - I 2 I8a - I248h I $262 \mathrm{c}-\mathrm{I} 334 \mathrm{f}-\mathrm{I} 354 \mathrm{~b}-1378 \mathrm{~b}-2374 \mathrm{n}$.

\section{Kaisheim.}

Kath. Kirche $35^{8} \mathrm{e}$.

\section{Kandern.}

Grossherzogliche Bezirksfortei I35b.

\section{Karlsruhe.}

S. K. H. der Grossherzog von Baden 137 $174-216 \mathrm{a}-232 \mathrm{~b}-25 \mathrm{Ic}$ und $\mathrm{d}-252 \mathrm{~b}-$ $299 \mathrm{k}-347 \mathrm{k}-348-352 \mathrm{e}, \mathrm{i}, \mathrm{z}$ und $\mathrm{y}-$ $365 \mathrm{e}-372 \mathrm{f}-926-\mathrm{I} 104 \mathrm{a}-1214 \mathrm{~b}-13091-$ I3 I8k-1343 b - I364o-1383-I388c I 409b - I $410-1571-2369-2514 \mathrm{~b}-2545$; $2589 \mathrm{c}-259 \mathrm{I}$.

v. Chelius, Ph. $376 \mathrm{~d}$.

Ettlinger, Leop. 13IOog.

Evang. Kirchengemeinde $377 \mathrm{~g}$.

Frey 981 .

v. Freydorf, Freifrau Alberta, Excellenz 358 d. Kath. Stadtkirche 17I3.

Paar, L. 126c - 197a.

Privatbesitz $372 \mathrm{c}-1169 \mathrm{~b}-\mathrm{I} 308 \mathrm{~g}$.

Reutlinger, M. $1613 \mathrm{~d}$.

Verein. Sammlungen 162e - 919 - 920-921 - 922.

Wormser, A. I32I c.

\section{Klagenfurt.}

v. Mylius, Freiherr Fr. 23740.

\section{Klausenburg.}

? Kirche 34I e.

\section{Klosterneuburg.}

Schatzkammer 2338.

\section{Konstanz.}

Domschatz 286c - 927 .

\section{Kopenhagen.}

Alterthums-Museum I26f - I800 l - $245 \mathrm{I}$.

Schloss Rosenborg 439-778- I804- I808.

Verdier, Frau S. 1811.

\section{Krakau.}

Domschatz I $183 \mathrm{a}$.

\section{Landshut.}

Martinskirche 1 I $54 \mathrm{~d}$.

Lauda.

Stadtkirche $375 \mathrm{c}$.

\section{Lechnic.}

Evangelische Kirche 2372.

\section{Leipzig.}

$\dagger$ Felix, Eugen I8If - 126oh - 1308e - I363g $1428-1433 \mathrm{c}$ und $\mathrm{d}-\mathrm{I} 435$.

Rathsarchiv 957 .

Stadtverwaltung $959 \mathrm{e}$ und $\mathrm{f}$.

\section{Lichtenthal.}

Kloster 1409a.

\section{Linz.}

Kronberger, J. $280 \mathrm{f}$.

\section{Lissabon.}

Königl. Academie der Wissenschaften 3081 .

\section{London.}

S. K. H. der Herzog von Cambridge $1222 \mathrm{~d}$.

S. D. der Herzog von Hamilton 2100 $2206 \mathrm{e}$.

Bernal, ehemalige Sammlung 1685 .

Bischoffsheim $366 \mathrm{f}$.

Church, Professor 2088-2089.

Dunn-Gardner, J. 1634 .

v. Rothschild, Baron Alfred 1679 .

$\dagger$ v. Rothschild, Baron Lionel 1581 und $\mathrm{m}$ $467 \mathrm{~b}-1222 \mathrm{e}-\mathrm{I} 305 \mathrm{~h}$ und $\mathrm{i}-\mathrm{I} 357 \mathrm{e}$ und $\mathrm{f}$. v. Rothschild, Baron M. 2538 .

South Kensington Museum 2147-2160. 


\section{Lübeck.}

Gewerbekammer I006 - Ioog.

\section{Lüneburg.}

Johanneskirche 1037 - I04I b - 1042 - 1048 $1052-1054-1055 b-1056$.

Nicolaikirche $428 \mathrm{~b}$ - 1053 - 1057 .

Stadtverwaltung 1038 .

\section{Lüne.}

Kloster I055a.

\section{Mailand.}

Sta. Maria presso San Celso I $2 \mathbf{I o h}$.

Städtisches Museum 140 bb.

Vogel-Perret, H. 257 I.

\section{Mainz.}

Domschatz $292 \mathrm{f}-35^{8} \mathrm{i}-377 \mathrm{~b}-1080-108 \mathrm{I}-$ $1082-1085-1086 a_{1}$ und $b-1087$.

Englische Fräulein $197 \mathrm{c}$.

Fürth, Saly $136 \mathrm{~d}-143 \mathrm{a}-15^{6} \mathrm{a}$ und b- $161 \mathrm{a}-$ 245 e $-262-336 b$ bis $d-455-638 b-649-$ $1234 \mathrm{a}-\mathrm{I} 24 \mathrm{I}$ b - I312d - I329a - I331 c und $d-1342 v-1365 f$ und $g-1547-1677 a$. Goldschmidt, S. B. 2523 d.

Schneider, Geistlicher Rath Dr. Fr. I08 $_{3}$ I334 $\mathrm{g}$.

\section{Marburg.}

Stadtverwaltung I 284 b- I 330 d.

\section{Maria-Zell.}

Pfarrkirche $1336 \mathrm{c}$ und $\mathrm{d}$.

\section{Marienfeld.}

Kloster I 7 I I h.

\section{Mediasch.}

? Kirche 237 I - 2375.

\section{Melk.}

Stift 1138.

\section{Merseburg.}

Domschatz $776-975$.

\section{Milte.}

Kirche I7 I 2.

\section{Mons.}

Elisabethenkirche I 759 - I760.

\section{Moritzburg.}

Schloss 129a - 139 - 1 50 - 291e - 637a - 1215a$1224 \mathrm{~h}-\mathrm{I} 262 \mathrm{~d}-1269 \mathrm{a}$ und $\mathrm{d}$.

\section{Moskau.}

Grosses Palais im Kreml 217d-294a-327a und b - 353 c - 354m.

Oruschenaja Palata 193d - 296 - I210n - I215b und $d-1220 b-123 I d-1232 c-1236 c-$ $1248 \mathrm{~m}-\mathrm{I} 254 \mathrm{~d}, \mathrm{~g}$ und $\mathrm{v}-1259 \mathrm{c}-1273 \mathrm{e}-$ I 280 c bis e - I $289 \mathrm{~d}$ - I $296 \mathrm{f}$ - I $307 \mathrm{~d}$ - I $310 \mathrm{e}$. Patriarchen-Schatzkammer I 29 c - I46a-148 I $80 \mathrm{~b}$ und $\mathrm{c}-\mathrm{I} 8 \mathrm{I}$ a bis e $-\mathrm{I} 85 \mathrm{c}$, e und $\mathrm{f}$ I $89 \mathrm{~b}-206 \mathrm{a}-208-212 \mathrm{f}-223 \mathrm{a}-224 \mathrm{c}$ bis e -238 g und $h-273 b-280 q-281 a-484$ $812-815 b$ und $\mathrm{c}-8 \mathrm{I} 6 \mathrm{a}$ bis $\mathrm{c}-8 \mathrm{I} 8-8 \mathrm{I} 9$ $820-821-825-826-830$ a bis c -831 a $960 \mathrm{a}-964 \mathrm{~g}$ und $\mathrm{h}-1227 \mathrm{a}$ und b- I $231 \mathrm{c}-$ $1233 \mathrm{~b}-.1235$ - I $242 \mathrm{c}$ und $\mathrm{d}-\mathrm{I} 267-1270 \mathrm{a}-$ $1287 \mathrm{~b}$ und $\mathrm{d}-\mathrm{I} 295 \mathrm{f}, \mathrm{g}, \mathrm{h}$ und $\mathrm{k}-\mathrm{I} 297$ I 299 - I 309 e bis $\mathrm{g}-1$ 1310b - I3 $13 \mathrm{a}$, o und p - I315a-1318i - 1319b-1320d-1323$1324 b-1328 b-1338-1345 a$ und b - I346c $1347 \mathrm{a}, \mathrm{b}$ und $\mathrm{d}-1348-1353 \mathrm{a}-1356 \mathrm{~b}-$ $1362 d-1365 d-1374 b-1375 a-1386 b-$ $1456-1733-1800 a-2136$.

\section{München.}

Weiland Se. Majestät König Ludwig I. von Bayern 24.

Berchem, Graf $146 \mathrm{c}-317 \mathrm{w}$.

Drey, A. S. I3ob - I46b u. d - I 55c-I6rh $17 \mathrm{I} b-178 \mathrm{a}$ und $\mathrm{c}-187 \mathrm{a}-198 \mathrm{a}-221 \mathrm{~h}$ und $k-258 c-288 a-293 c-415-467 a-$ $482 a$ und b - 515-529-669- I I 44a - I I 56 $1165 a-1167 d-1183 g-1272 a-1302 g-$ I3 I 7a und b - I318a - I321a - I387n - I394 I397a - I43I-I442-I63I-I676-2090 2091 - 2092.

Drey, J. I24b - I77a - 377f - 46I - 48I I334 e - I342 k-1366b-1397b- I 543 .

$\dagger$ Gedon, L. 227d - 464c - 1252-1303c 1342 t.

Heilbronner, Gebr. I26e - I55e - I56c und e $161 \mathrm{~g}-177 \mathrm{~b}-205 \mathrm{~b}-233 \mathrm{a}-292 \mathrm{c}-379 \mathrm{~b}$ und $c-417 a-476 a$ und $b-633-814-960 c-$ I 379 h - I 399 a - I 556 - I 699 c.

Königl. Hof bibliothek I230c.

Königl. Schatzkammer I16a - I25a und b I $29 \mathrm{~d}$ und e - 132a - I33a-140r - I59a I66 a 217a 226d $228 \mathrm{f}$ und $\mathrm{g} \cdot 232 \mathrm{f}$. 
$238 d-243 d-250 a-25$ I e und f - 252 i $255 \mathrm{a}-256-259 \mathrm{~m}-299 \mathrm{a}-301 \mathrm{a}$ und b 3 IOn - 318x, aa und bb - 334a - 352a $353 b-359 b$ bis $d-366 c-465-816 a, b$ und c - I I 4 I - I142 - I I48a - I I 75a - I 2 I oc, $\mathrm{f}, 1$ und $\mathrm{m}$ - I229a und b - I236g - I $258 \mathrm{bb}$ I $364 \mathrm{~m}$ und $\mathrm{n}-\mathrm{I} 559-\mathrm{I} 565-\mathrm{I} 688 \mathrm{c}$.

Königl. Silberkammer I33d - I59b und c $228 \mathrm{~h}-231 \mathrm{~b}-240 \mathrm{a}-347 \mathrm{i}-350 \mathrm{~d}-354 \mathrm{i}-$ $356 \mathrm{~h}$ und $\mathrm{i}-357 \mathrm{i}-360 \mathrm{i}$ und $\mathrm{m}-36 \mathrm{ic}$ $364 c-366 g-371-372 g-374 g-376 b$ und $\mathrm{c}-379 \mathrm{a}-5 \mathrm{I2}-1104 \mathrm{~b}$ und $\mathrm{c}-$ I I $55 \mathrm{a}$ und b - I I 57 - I I63c-i i $64 a$ und b - I i 65 b I $66 \mathrm{a}$ und $\mathrm{b}-$ II67c - II83 $\mathrm{d}$ - I224 i und $\mathrm{k}-1249 \mathrm{~d}-\mathrm{I} 304-\mathrm{I} 562 \mathrm{~b}-\mathrm{I} 572 \mathrm{~b}$ bis e and g - I 573 b - I 730 .

National-Museum 15 - I26a - I27 e - I 50a und b - 202h - 292h - 320ff - 418b-704-836862 - I I 53 b - I I54 c - II 59 - I I60 - I I6I ; II 68 - I 2 IOe - I 224 b und c - I225 - I 241 d $1255 \mathrm{c}-\mathrm{I} 262 \mathrm{~b}-1273 \mathrm{~g}-\mathrm{I} 28 \mathrm{I}$ b - I327b 1339 - 1357a - 1366f - I441a - I533 - I574 $2553 \mathrm{~b}$.

Reiche Kapelle 123h - I36c - I40n, ii und $\mathrm{kk}-\mathrm{I} 54 \mathrm{c}$ und $\mathrm{d}-\mathrm{I} 58 \mathrm{a}-\mathrm{I} 59 \mathrm{f}-\mathrm{I} 62 \mathrm{~b}$ und $c-168 \mathrm{a}-196-234 \mathrm{~b}-327 \mathrm{~g}$ bis $\mathrm{k}-353 \mathrm{~g}$ und $\mathrm{h}-374-\mathrm{I} 143-\mathrm{I} 446 \mathrm{a}$ bis $\mathrm{c}-1147 \mathrm{a}$ und b - I I50a bis e - I I58 - II62 - II63a und b - I $167 \mathrm{a}$ und $\mathrm{b}-1258 \mathrm{aa}-1263 \mathrm{f}$ bis h - I674.

Stecher, Dr. Fr. I289e.

Törring-Jettenbach, Graf $202 \mathrm{~d}$ und e - 2 I $2 \mathrm{a}$ 3531 .

\section{Namur.}

Soeurs de Notre-Dame i 764 a und b.

\section{Neuburg a. d. D.}

Hof kirche I $86 \mathrm{a}-362 \mathrm{e}$.

\section{Neuchâtel.}

Museum 1070 - 2556 .

Stadtverwaltung 2557 .

\section{Neuhausen (bei Pforzheim).}

Pfarrkirche 924 - I563.

\section{Neustadt a. d. H.}

Heckel, Ferd. I I 74 - I6I3 e.

Neue kathol. Kirche I 173 .

Schützengesellschaft I 75 h.

\section{(Mähr.-)Neustadt.}

Böhm, Jul. $25^{2}$ h.

\section{Nördlingen.}

Kirche I 177.

\section{Nürnberg.}

Aeyidienkirche 158c-1300a - I364i - 1379e 1387 e und $\mathrm{f}$ - I389d - I39 I b bis d - I392 b bis $\mathrm{f}-\mathrm{I} 395 \mathrm{a}$ und $\mathrm{b}$.

Alexander, L. 223b - 67I - II5I - I3050 I 334 b - I342 l - I344 k - I350 - I36ob I $387 \mathrm{c}-1389 \mathrm{~b}$ und $\mathrm{c}$.

Ausstellung von I885 I37 I d - I379g,

Bayerisches Gewerbe-Museum 120 - I 82 b - 230 $255 \mathrm{~m}-300 \mathrm{f}-33 \mathrm{I} d-496 \mathrm{a}-\mathrm{I}$ I 39 - I $332 \mathrm{e}$ und $\mathrm{f}-\mathrm{I} 342 \mathrm{i}-\mathrm{I} 37 \mathrm{I} \mathrm{c}-\mathrm{I} 373 \mathrm{~d}-1432$.

Beck, J. I 248g - I324d - 1334c - 1366e - 1399b. Bergau, Prof. R. 848 .

Cnopf, G. R. 1285a - 1305e - I313g bis m. v. Ebner, Freiherr 1357d.

Germanisches National-Museum 268a - 696 I $18_{3} q-1236 b-1258 g-1272 g-1289 c-$ $1308 \mathrm{~b}-1327 \mathrm{a}-1337-1346 \mathrm{a}-1354 \mathrm{a}-$ I $356 \mathrm{c}$ - I359a - I364 d, e und k - 1369 c $1378 \mathrm{a}-138 \mathrm{I}-1384 \mathrm{a}-1386 \mathrm{a}-1387 \mathrm{p}-$ I 388 b - I390a - I682.

Gesellschaft Colleg 1251 .

Haller v. Hallerstein, Freiherr 1363f - I366 d. v. Harsdorf I 324 a - I 35 I.

Johanneskirche I $83 \mathrm{n}$ - I266a und b - I352a I $358 \mathrm{~b}-\mathrm{I}_{3} 6 \mathrm{of}-\mathrm{I}_{3} 64 \mathrm{f}$ bis h - I379f - I385 $1387 \mathrm{a}, \mathrm{b}$ und $\mathrm{d}$.

? Kirche 22 rod.

v. Kress, Georg Freiherr 1254m.

Leonhardskirche $1 \mathrm{I} 83$ o - I 342b - I 344h - I 393b, c und f - 1396a.

v. Löffelholz, Freih. $339 \mathrm{e}-1273 \mathrm{k}$ bis m I3I $2 \mathrm{n}$ - I360 - I393 h.

Lorenzkirche $1183 \mathrm{i}$ bis $\mathrm{m}-1254 \mathrm{t}-1320 \mathrm{a}$ I $332 \mathrm{a}$ und b - I $360 \mathrm{~d}$ und e - I $390 \mathrm{~b}$.

Pegnesischer Blumenorden 1362a- I364l.

Pickert, A. $1367 \mathrm{~d}$.

Privatbesitz I 2 I $4 \mathrm{C}-1254 \mathrm{z}$.

v. Scheurl, Prof. Dr. A., Freiherr $1277 \mathrm{a}$ - I $293 \mathrm{f}$ I $305 \mathrm{n}$.

Sebalduskirche I 83 p - I309d - I322 - I344a, b und e bis g - I396 b und c.

Stahlbogenschützen-Gesellschaft $625 \mathrm{c}$. v. Tucher, Freiherr 280 e -331 b $-469-828$. Tünchergesellen-Verein $\mathbf{1} 376$. 


\section{Oensingen (Solothurn).}

Bïrgi, G. I 249 e.

\section{Orterstein (Schloss bei Gera).}

S. D. Fürst Reuss j. I. 36Id - 366h.

\section{Osnabrück.}

Domschatz 292a - 297c und d - 299b und h $362 \mathrm{a}$ und $\mathrm{b}$.

Katharinenkirche $233 \mathrm{~b}$.

Rathhaus I I I9 - I 239 - I 298 b.

\section{Ottobeuern.}

Kloster I I IO.

\section{Paderborn.}

Domschatz 564

\section{Paris.}

Allègre, Sammlung $645 \mathrm{c}$.

v. Rothschild, Baron $1756 \mathrm{e}$.

Sichel, J. I 537 .

Spitzer I $305 \mathrm{~b}$.

\section{Passau.}

Domkapitel $1402 \mathrm{~b}$.

Stadtverwaltung $1402 \mathrm{c}$.

Stockhauer, Charlotte $1402 \mathrm{~d}$.

\section{St. Paul.}

Stift 237 a und b.

\section{Penzing.}

Herzogl. Cumberland'sche Silberkammer 2424a.

\section{St. Petersburg.}

S. D. Fürst Paskewitsch I 58 e - I65a- 18oa $24 I a-353 a-531 b-542 b-544 b-548 d-$ 97 I $a-1224 a-1255 b-1263 e-1334 a-1363 d-$ I $628-1695-2424 \mathrm{~h}-2428 \mathrm{~b}-24331$.

Balaschow, E. A. 425 .

Due, Excellenz 202f - 242d - 243f - 247a - 259c $272 c-277 c-350 c-472 a-532 b-540 c-$ $547 \mathrm{a}$ und $\mathrm{b}-548 \mathrm{a}$ bis $\mathrm{c}-549 \mathrm{f}$ und $\mathrm{g}-728$ $823 a-925 b-968 c-971 d-978-979 c-$ I $295 \mathrm{~d}-1370 \mathrm{a}-1374 \mathrm{a}-1389 \mathrm{a}-2439 \mathrm{q}$.

Durnowo, General, Excell. 246f - 249c - 478 $646-823$ b - 831 e - 966 .

v. Günzburg, Baron Alexander $278 \mathrm{c}$.

v. Giinzburg, Baron Horace, Excellenz $25 \mathrm{I} g$ $263 b-273 c-280 b$ und $1-287-477-965 a-$
IOIO - IOII - I3I3e - I3240 - I330 - I342e und $\mathrm{m}$ bis $\mathrm{r}-1362 \mathrm{~g}-1363 \mathrm{c}-13871-1697$. 22 I I e - 2344 b.

Jacobson, J. I 3 I C - I6Id - 236a - 239e - $249 \mathrm{~g}-$ $265 \mathrm{~h}-278 \mathrm{~b}-299 \mathrm{i}-353 \mathrm{k}-356 \mathrm{~s}-360 \mathrm{a}-$ $372 \mathrm{e}-4 \mathrm{IO}-418 \mathrm{c}-426 \mathrm{a}$ und $\mathrm{b}-45^{8}-$ $473 a-774-834-897-904-905-906-$ $968 \mathrm{~b}-97$ I c und e - 976a - 977 - I224g I 24 I a - I $270 b-13$ I 3 b und f - I325c - I342f $1347 \mathrm{c}-1387 \mathrm{~g}$ und $\mathrm{h}-2425-2433 \mathrm{~m}$ $24361-2438 a$ und b - 2440a.

Kaiserl. Silberkammer 224b - 266d - 330a $3531-357 \mathrm{e}-360 \mathrm{~b}-628 \mathrm{~b}-1237 \mathrm{a}-1295 \mathrm{e}-$ $2428 \mathrm{c}-2437 \mathrm{e}$.

Kotschubey, P. A. I 27 h - I9I a - 2I I - 24I b$264 \mathrm{c}$ und $\mathrm{d}-28 \mathrm{2}-354 \mathrm{~h}-466-47 \mathrm{Ib}-475-$ $476 c-479-534 a-537-538-539 a-540 a-$ $542 \mathrm{c}$ und d - 8I5d und e - 902a - 968d $97 \mathrm{Ib}-1220 \mathrm{a}-1254 \mathrm{r}$ und s - I263c- I $264 \mathrm{a}-$ $1318 g-1331 f-1362 b-1365 c-1368 a-$ I 372 b - 2428d - 243I - 2443 b.

Kunstgewerbe-Museum 267.

Liubawin, A. I9I e $-239 \mathrm{~b}-280 \mathrm{~g}$ bis i $-28 \mathrm{I}$ b $300 n-353 \mathrm{i}-410 \mathrm{i}-550-775 \mathrm{c}-833-838-$ $898-900-903-980-1272 d-1306 b$. I36 I - 2435 d - $2438 \mathrm{c}$ und d - 244I - $2442 \mathrm{k}$. Museum der Eremitage I28a - I7ob - I87c $199 \mathrm{c}-202 \mathrm{~g}-210-228 \mathrm{~b}$ bis d $-232 \mathrm{e}-$ $238 \mathrm{i}$ bis $\mathrm{m}-243 \mathrm{c}-245 \mathrm{f}-266 \mathrm{~b}$ und $\mathrm{c}$ $280 \mathrm{~m}-289-293 \mathrm{~d}-328 \mathrm{~d}-333 \mathrm{~d}-33^{8}-$ $339 b-352 c$ und $d-464 b-470 b$ und $c$ $541 \mathrm{~b}-544 \mathrm{a}-545 \mathrm{c}-546 \mathrm{a}$ und $\mathrm{b}-645$ $964 \mathrm{e}-968 \mathrm{a}-\mathrm{I} 258 \mathrm{~m}-\mathrm{I} 308 \mathrm{~d}-\mathrm{I} 3 \mathrm{I} 2 \mathrm{f}, \mathrm{g}, \mathrm{o}$ und $p-1344 \mathrm{l}$ und $\mathrm{m}-\mathrm{I} 356 \mathrm{f}-\mathrm{I} 362 \mathrm{c}$ $1367 \mathrm{a}-1384 \mathrm{c}-1388 \mathrm{~d}-2143-2421-2422$ $2432-2442 \mathrm{~m}-2462-246_{3}-2465$.

Polowzow, Excellenz 342d - 427- 2098.

Scheremetieff, Graf I27 Id - I572a.

Stroganoff, Sammlung 239c - 252d und e 285 e und $f-817-83 I d-2345 c$.

Winterpalais $202 \mathrm{i}-212 \mathrm{e}-238 \mathrm{f}-240 \mathrm{c}$ bis e 242 e -249 e $-264 a$ und b - 269e - $297 f$ $300 \mathrm{a}$ und $\mathrm{b}-340 \mathrm{~d}$ und $\mathrm{e}-346 \mathrm{c}-352 \mathrm{~g}-$ $356 \mathrm{e}$ bis $g$ - $470 \mathrm{a}-530-534 \mathrm{~b}-536 \mathrm{a}$ $542 \mathrm{a}-545 \mathrm{a}$ und $\mathrm{b}-546 \mathrm{c}-8 \mathrm{I} 3 \mathrm{a}$ und $\mathrm{b}$ $901-969 a-1250-1278 a-1282-1293 d-$ $12950-1321 b-1325 b-133 I c-1345 d-$ $1367 \mathrm{c}-1373 \mathrm{~b}-18 \mathrm{I}-2442 \mathrm{n}$.

\section{Pinkenhof.}

Nicolaikirche $2420 \mathrm{c}$ 


\section{Porto.}

v. Retzende, Gräfin 302 e.

\section{Raigern.}

Stift $292 \mathrm{~b}$.

\section{Rappersweil.}

Gemeinde I254w - I68I-2562a-2563.

\section{Rappoltsweiler.}

Rathhaus I3IOf.

\section{Reichenau.}

Peter- und Paulskirche in Nieder-Zell I647.

\section{Rheinau (Schweiz).}

Kirchenpflege $300 \mathrm{c}-2562 \mathrm{~b}$ und c $-2569 \mathrm{~b}$.

\section{Riga.}

Bäckerbruderschaft $2442 \mathrm{a}$.

Bernsdorf, Frau Elise $2442 \mathrm{p}$.

Bockslaff, N. $2437 \mathrm{k}-2442 \mathrm{o}$.

de Bruyn, Fräulein $2436 \mathrm{k}$.

Compagnie der Schwarzen Häupter 29I d $1002-1007-2423-2424$ b bis $\mathrm{g}-2426-$ $2427-2429 \mathrm{~b}-2433$ a bis $\mathrm{i}-24371$ und $\mathrm{m}$ $2443 \mathrm{~d}$ bis $\mathrm{g}$.

Domkirche 2435 b -2436 h -2439 b.

Georgshospital $2439 \mathrm{~m}$.

Glaseramt 24I9.

Grimm, Frau H. 2437 c.

Grosse Gilde $2436 \mathrm{a}$, b, f und $\mathrm{g}-2437 \mathrm{a}$, h und $\mathrm{i}-2439 \mathrm{~d}$ bis $1-2442 \mathrm{c}$ und d.

Helmsing, Frau Ida $2440 \mathrm{c}$.

Jacobskirche 2420 a.

Jaksch, Robert 239f - 1362m-2428a-2436c. Kämmereigericht $2436 \mathrm{i}$.

Koch, Julius 2439p.

v. Löwenberg, Frau Wilhelmine $2440 \mathrm{~d}$ und e $2442 \mathrm{f}$.

Mengden-Metackshof, Baron Oskar $2433 \mathrm{k}$.

Mintz, Michael I287 c.

Petrikirche $2435 \mathrm{a}-2442 \mathrm{~h}$ und i.

Pfab, Fräulein Elise 2442 e.

Pilar v. Pilchau, Baronin I395c.

Prüffert, Alexander $2443 \mathrm{c}$.

Schneideramt 2442 b.

Schröder, Gotth. 2439a - 2442 g.

Schuhmachergesellen-Bruderschaft 2436e-2442l.

Schwartz, J. C. 2437 d.

Schwartz, W. 2443 a.
Stadtdienerbruderchaft $2437 \mathrm{~b}$, f und $\mathrm{g}$.

Stadtgarde $2439 \mathrm{c}, \mathrm{n}$ und $\mathrm{o}-244 \mathrm{ob}$.

Stadtwaisengericht 2429 a.

Tunzelmann, M. v. $2436 \mathrm{~d}$.

\section{Roermond (Holland).}

Stadtverwaltung r27 I a.

\section{Rom.}

Christliches Museum im Vatican 9I6.

Paar, Graf, Excellenz 1803 - I805.

\section{Rosenborg.}

Siehe Kopenhagen, Schloss Rosenborg.

\section{Rügenwalde.}

Marienkirche $158 \mathrm{~g}$ bis k - $160-1457-1458$. 1459 - 1460.

\section{Salem.}

Kath. Pfarrkirche $358 \mathrm{~b}$ und $\mathrm{h}$.

\section{San Donato (bei Florenz).}

Ehemalige Sammlung Demidoff 1529.

\section{Schattau.}

Pfarrkirche 2334 .

\section{Schemnitz.}

Kath. Kirche 2381 a und b-2382.

\section{Schwerin.}

Grossherzogl. Museum I21 5 f.

\section{Schwarzburg (Thüringen).}

Schloss 1448 .

\section{Seiden (Siebenbürgen).}

Evangelische Kirche I3II.

\section{Sigmaringen.}

S. H. Fürst von Hohenzollern I25c - $237 \mathrm{c}-$ $266 \mathrm{~d}-28 \mathrm{od}-324 \mathrm{kk}-363 \mathrm{~h}-365 \mathrm{a}$ und b $377 \mathrm{c}$ und $\mathrm{e}$.

\section{Sneek (Holland).}

Gemeinde $2.80 \mathrm{k}$.

\section{Solothurn.}

Ursulakirche $167 \mathrm{c}-2569 \mathrm{a}$, c und d.

\section{Spital am Pyrhn.}

Pfarrei 140 aa. 


\section{Steinen.}

? Kirche 2599b.

\section{Stockholm.}

Ehrenheim, P. I $258 \mathrm{f}$.

\section{Strassburg.}

Keller, E. Ch. I255 d und e - I530a.

Synagoge I I I 7 .

\section{Stuttgart.}

Duss, A. 7 Iob -2565 .

Eberhardskirche $225 \mathrm{c}-353 \mathrm{~m}-358 \mathrm{c}$ und 1 .

Goldschmiedeverein I60I - I607.

Gutekunst, G. H. I4011.

Küferzunft $730-$ I6I 2 a.

Museum vaterländischer Alterthümer 221 c $246 a-248 a-268 b-275 b-300 p-333 a-$ $539 b-765 a-I 24 I f-I 296 d-I 30 I d-$ I $314 c-1332 e-1356 u-I 44 I b-I 603 a-$ I609 - I6II, vergl. Goldschmiedeverein.

Nagelschmiedezunft I608 b.

Rathhaus I60I b, vergl. die Zünfte.

Sattlerzunft I 599 - I604.

Seyffer, Prof. Otto $164 \mathrm{c}$ und d $-212 \mathrm{~d}-215 \mathrm{a}-$ $235 \mathrm{~b}-352 \mathrm{k}-363 \mathrm{l}-364 \mathrm{~b}-372 \mathrm{i}-379 \mathrm{~d}-$ 7 roa $-756-765 c-$ I $296 c-$ I 301 e und $f-$ I3I4e und $f-1318 d-1320 e-1334 d-$ I $342 z-r 343 c-1349 d$ und e - I352b $1356 t-1357 c-1362 k-1363 b-1366 a-$ $1382 b-I_{3} 86 c-I_{3} 87 k-I_{3} 88 a-1396 d$ und e - I $567 \mathrm{c}-1605-16$ Iоa - I673- I701a I $702-$ I 52 I c.

Königl. Silberkammer $354 \mathrm{f}$ und $\mathrm{g}-356 \mathrm{v}-36 \mathrm{ol}$. $374 f-859-860-986 a$ und $b-987 c$ und $d-$ $1567 a$ und $b-1612 b$ und $c-1613 b$ und $c$.

Stadtverwaltung I6 I 7 a.

\section{Torgau.}

Stadtkirche 1621 .

\section{Tübingen.}

Stadtverwaltung 1444 .

\section{Ueberlingen.}

Culturhistorisches Cabinet 2645 .

Münsterschatz I $40 \mathrm{~g}-\mathrm{I} 646-1648$ a bis d - I 649 a bis c- 1650 a bis c $-1651 \mathrm{~d}$.

\section{UIm.}

Gewerbe-Museum I5I - I683.
Verein für Kunst und Alterthum in Llm und Oberschwaben I53d - 314r - I696- I698I 701 b - I 703 .

Wengenkirche $238 \mathrm{a}$ and $\mathrm{c}-355 \mathrm{~b}-434-435-$ I 147 c - I699e.

\section{Utrecht.}

Godin de Beaufort, K. A. I 745 .

Rol, Th. 2222 b.

\section{Villingen.}

Münsterschatz $\mathrm{I} 706 \mathrm{~b}$ und $\mathrm{c}$.

\section{Wallerstein.}

S. D. Fürst zu Oettingen-Wallerstein I40I.

\section{Waidhofen a. d. Ybbs.}

? Kirche 708 .

\section{Wandsbeck.}

Rederburg, Dr. I59g.

\section{Warendorf.}

? Kirche I $7 \mathrm{I} \mathrm{b}$ bis $\mathrm{g}$.

\section{Weimar.}

Bibliothek 221 5 i.

\section{Weinheim.}

Katharinenkirche 375 a.

\section{Weitnau.}

Widmann, J. 138 .

\section{Wertheim.}

Evang. Kirche $362 d-688-759-1716-1717$.

\section{Wesel.}

Stadtverwaltung 508 .

\section{Wien.}

S. D. Fürst Johann von und zu Liechtenstein 7 - I I $7 \mathrm{c}$.

S. D. Prinz Heinrich Reuss $259 \mathrm{i}-545 \mathrm{e}$ 2367 a.

Adamberger, ehemalige Sammlung 2208b.

Ambraser Sammlung 123f - 266e.

Boskowitz, H. I 44 - I $85 \mathrm{a}-204 \mathrm{a}-209 \mathrm{a}-240 \mathrm{of}$ $724-725-83 \mathrm{I} b$ und $\mathrm{c}-\mathrm{I} 248 \mathrm{k}-\mathrm{I} 28 \mathrm{Ob}-$ I344 $\mathrm{i}-\mathrm{I} 365 \mathrm{a}$ und $\mathrm{b}-\mathrm{I} 373 \mathrm{f}-\mathrm{I} 380 \mathrm{~b}$ $1387 \mathrm{i}-1622-1699 \mathrm{~d}-2348 \mathrm{a}$. 
Deutschordensschatz I63b - I 89a - 327s - I I 82c I 23 I a und b - I379d - I439 - 1454 .

Figdor, Dr. A. I6If - 22If - 249f - $460-760$ III6-1259a- I362n - I $377-2514 \mathrm{~d}$.

Genossenschaft der Goldschmiede 2352 - 2353 .

Hof burgkapelle I $40 \mathrm{c}, \mathrm{d}, \mathrm{k}, \mathrm{l}, \mathrm{m}$, ee und ff 235 I.

Kahn-Speyer, Ludwig I6I b - 24I c - I264 b I $328 \mathrm{a}-\mathrm{I} 329 \mathrm{~b}$.

Kaiserl. Schatzkammer $6-116 \mathrm{~b}$ und $\mathrm{c}-\mathrm{I} 50 \mathrm{e}$ und i - $158 \mathrm{f}-\mathrm{I} 8 \mathrm{od}-1182 \mathrm{~b}-\mathrm{I} 2 \mathrm{I} 6 \mathrm{~g}-\mathrm{I} 2 \mathrm{I} 7 \mathrm{k}$ I $25^{8} \mathrm{p}$ bis y - I312q-1336a und b- I686.

Kaiserl. Silberkammer $356 \mathrm{q}$ und $\mathrm{r}-369 \mathrm{c}$ und d - I $260 \mathrm{~d}$ und e - I $573 \mathrm{a}$.

Kapuzinerkloster $\mathbf{1} 4 \mathrm{O} \mathrm{hh}$.

Oesterreichisches Museum I $40 \mathrm{Om}$ - 158b - 462 $\mathrm{I} 254 \mathrm{X}-\mathrm{I} 3 \mathrm{I} 8 \mathrm{e}-\mathrm{I} 440-2086-2087-234 \mathrm{I}-$ $2478-2479$.

Ratzersdorfer, H. I95 - 27I d - 300 - 540 $774 \mathrm{c}-1246 \mathrm{~b}-\mathrm{I} 27 \mathrm{I}$ b - I 678 .

v. Rothschild, Baron Nathaniel $127 \mathrm{a}$ und b $132 c-136 b-140 b-155 b-162 a-171 a-$ $173 \mathrm{~b}-188 \mathrm{~b}-190 \mathrm{~b}-199 \mathrm{a}$ und $\mathrm{b}-22 \mathrm{I} a-$ $246 \mathrm{~b}-250 \mathrm{~d}-259 \mathrm{~h}-264 \mathrm{e}-27 \mathrm{I} b-285 \mathrm{c}-$ $291 \mathrm{k}-324 \mathrm{ll}-326 \mathrm{pp}-349 \mathrm{a}$ und b - 47 I a $548 \mathrm{e}-638 \mathrm{a}-701-702-726-846-$ I I $83 \mathrm{t}$ $\mathrm{I} 228 \mathrm{a}-\mathrm{I} 242 \mathrm{a}-\mathrm{I} 246 \mathrm{a}-\mathrm{I} 254 \mathrm{~h}$ und $\mathrm{q}$ $1270 \mathrm{~d}-1272 \mathrm{f}-1310 \mathrm{c}-1364 \mathrm{c}-1387 \mathrm{~m}-$ $1425-1426-1427-1598-1603 b-1613 a-$ $1687 \mathrm{a}-2217 \mathrm{l}-2517 \mathrm{~d}-2587 \mathrm{~b}$.
Scharf $2436 \mathrm{~m}$.

Stadtverwaltung 2339a.

v. Walterskirchen, Baron R. I $30 \mathrm{a}-\mathrm{I} 66 \mathrm{c}$ $206 \mathrm{~b}-209 \mathrm{~b}-226 \mathrm{~b}-227 \mathrm{~b}-255 \mathrm{k}-285 \mathrm{a}-$ $335 \mathrm{~b}-363 \mathrm{i}$ und $\mathrm{k}-482-683 \mathrm{a}-1068 \mathrm{a}-$ 1295 l - I $300 c-1692-2348$ b - 2517 c.

\section{Wismar.}

Brunswig, H. I 721 .

\section{Witzenhausen.}

Stadtverwaltung I 28I a.

\section{Würzburg.}

$\dagger$ Adelmann, Dr. Leofrid 964k - I3620. Kapelle der Festung Marienberg I447.

\section{Schloss Zleb (Böhmen).}

S. D. Fürst Auersberg I I $7 \mathrm{~d}-26 \mathrm{I}$.

\section{Zürich.}

Antiquarischer Verein I326- I343a.

Ausstellung von I883 IIIIa - I3I5c - S. R. in G. $2517 \mathrm{~g}-2542-2590-2594$.

Bogenschützengesellschaft $2592 \mathrm{c}$.

Stadtbibliothek 2585 a bis c - $2593 \mathrm{f}$.

Zeller-Werdmüller, H. $2587 \mathrm{c}$.

\section{Zwolle.}

Stadtverwaltung $2238-2239$.

Besitzer unbekannt $358 \mathrm{a}-362 \mathrm{f}-377 \mathrm{a}-777$ -

$864-1284 \mathrm{c}$ und $d-2553 a$. 


\section{Druckfehler und Berichtigungen.}

S. 2 Nr. I und 2. Diese Marken werden meistentheils vertieft gestempelt.

S. 6 Nr. 22. Die Höhe dieses Stiickes ist im citirten Kataloge mit $54 \mathrm{~cm}$ angegeben. Es steht dort unter Nr. 588.

S. I 5 Nr. II 7 e statt ,Musée de la Porte de Hal", lies ,Musée royal d'antiquitées".

S. I 7 Nr. I25 statt, ,Sorgt" lies, ,Sorg".

S. 23 Nr. I 40 e und f statt ,Valesarmia" lies „Valsássina".

S. 25 Nr. I40aa statt "Pyhrn" lies „Pyrhn".

S. 27 Nr. 145 a ist hinzuzufügen "Besitzer Graf Franz Erdödy, Budapest".

S. $30 \mathrm{Nr}$. I 54 a statt , 1867 "lies , , I 877 ".

S. $32 \mathrm{Nr}$. $158 \mathrm{~g}-\mathrm{k}$. Am Schlusse ist hinzuzufügen ,, sowie S. 337, Nr. 1457-60".

S. 33 Nr. I60. Am Schlusse ist hinzuzufügen, ,und unten S. 337, Nr. 1457-60".

S. 34 Nr. 163 b. Die Höhe wird an anderer Stelle mit $47,5 \mathrm{~cm}$ angegeben.

S. 36 Nr. 167 a und b statt ,E. Thewalt" lies ,C. Thewalt".

S. $4 \mathrm{I}$ Nr. I $85 \mathrm{~g}$ statt, ,I 887 "lies, ,I 884 ".

S. 45 Nr. 201 statt ,FESEN MEYR" lies ,FESEN MAYR“.

S. 53 Nr. 223c statt ",Silberausstellung“ - ,Nr. 260" lies ,Ausstellung r887. Colinet \& de Vries, Tentoonstelling 1877 , Taf. 42. Tentoonstelling van edele Metalen, Amsterdam r880, Nr. 260".

S. 62 Nr. $243 \mathrm{~g}$ statt ,,Bourgois" lies ,Bourgeois".

S. 64 Nr. 249 c statt "Durnawo" lies ,Durnowo".

S. 64 Nr. 250 statt "Meister aus der Goldschmiedefamilie Griel" lies ,Unbekannter Meister".

S. 68 Nr. 258 d statt ,O. Esser" lies ,Baron O. v. Essen".

S. 69 Nr. $259 \mathrm{~g}$ statt ,Taf. 26 " lies ,Taf. 16".

S. 89 Nr. 301 a ,Arbeit des Augsburger Meisters Grill" ist zu streichen.

S. I00 Nr. 34I a statt "Stadtpfarrei" lies "Maximilianskirche".

S. I03 Nr. 348 ist nach dem Namen , der Aeltere" hinzuzufügen.

S. Io9 statt ,Kirche Niederbühl" lies ,,unbekannt".

S. II I Nr. 362. Die Marke steht verkehrt und ist nicht, ,SII" sondern „IS "zu lesen.

S. I1 2 Nr. $362 \mathrm{f}$ statt , Kirche Niederbuihl" lies, ,unbekannt".

S. II 2 Nr. 363 e statt ,Kirche" lies ,Albanskirche".

S. I 14 Nr. $367 / 8$ a. In die Rubrik ,Meisterzeichen" ist zu setzen , wie Nr. 367 und 368 ".

S. I 6 Nr. $373 / 4$ ist hinzuzufigen , der Jüngere".

S. I $26 \mathrm{Nr}$. 432 statt "Nr. 433" lies "Nr. 43I"; statt ,Schatzkammer" lies ,Silberkammer". Die Worte im Texte nach: Vorlegelöffel ,,wie Nr. 433" sind zu streichen.

S. I $26 \mathrm{Nr}$. 433. Die Worte im Texte nach: Gravirung, ,wie Nr. 433" sind zu streichen. 
S. I 28 Nr. $442 / 3$ und 445 statt ,Stadtbibliothek" lies ,Stadtarchiv".

S. I 29 Nr. 446 statt "Stadtbibliothek" lies ,Stadtarchiv".

S. I3 I Nr. 467. Die Marke ist umgekehrt zu stellen und als , $\mathrm{IH}^{\prime}$ zu lesen. Statt „Hans Jachmann erwähnt 1617 und I640" lies ,Jochen Hiller, I602".

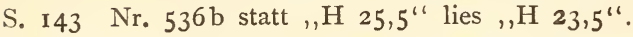

S. 148 Dringenberg sollte nach Dresden stehen.

S. I84 Nr. 839 statt ,(Alt-Hanau)“ lies ,(Neu-Hanau)". Ich verdanke diese Berichtigung Herrn Dr. Sponsel-Dresden.

S. 2 II Nr. IOI 3 sind die Worte, ,sondern ein Weihekreuz" zu streichen.

S. 22 I Nr. 1084 statt ,Kirche" lies ,Albanskirche".

S. 226 Münster i. W. sollte nach München stehen.

S. 227 Nr. II 36 statt, , I 789 " lies, ,I 784 ".

S. 25 I Nr. I228d statt ,Kirche" lies ,Georgskirche".

S. 283 Nr. 1303b statt, ,I 88 I" lies, 1880 ".

S. 288 Nr. I310h statt ,Freiherr Rudolf von" lies ,F. R. von".

S. 302 Nr. $1342 \mathrm{x}$ und y statt ,O. von Essen" lies „Baron O. von Essen".

S. 302 Nr. I342 aa statt "Grossenheim" lies ,Grossenhain".

S. 33I Nr. 1429 statt ,G. Oppenheim" lies ,E. Oppenheim".

S. 350 Nr. I55 I und 1552. Diese beiden Marken stehen irrthümlich in der Rubrik der Beschaulzeichen, sie gehören in die Rubrik der Meisterzeichen.

S. 35I Nr. I557-59. Diese drei Marken stehen irrthümlich in der Rubrik der Beschauzeichen, sie gehören in die Rubrik der Meisterzeichen.

S. 42 I Nr. 204I und 42. Diese beiden Marken stehen verkehrt. Sie sind als , g" resp. ,a " zu lesen.

S. 432 Nr. 2130 statt "I609" lies ,I606".

S. 447 Nr. 2220 ist hinzuzufügen ,,Besitzer C. Thewalt, Cöln".

S. $47 \mathrm{I}$ Nr. 2374c nach "Nagy" ist einzuschalten ,,in Doboka" (Siebenbürgen).

S. 473 Nr. 2374 q nach ,Barcsai" ist einzuschalten ,,in Deva".

S. 479 Nr. 24IO/I I statt ,I7. Jahrhundert" lies ,, I7. bis I8. Jahrhundert". 



